\title{
1.1.3 Jour
}

.

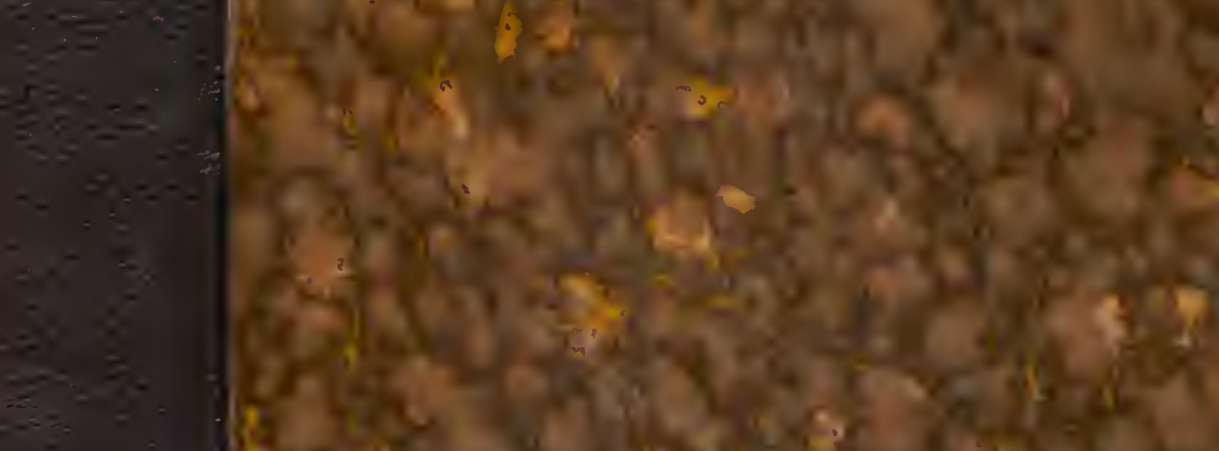

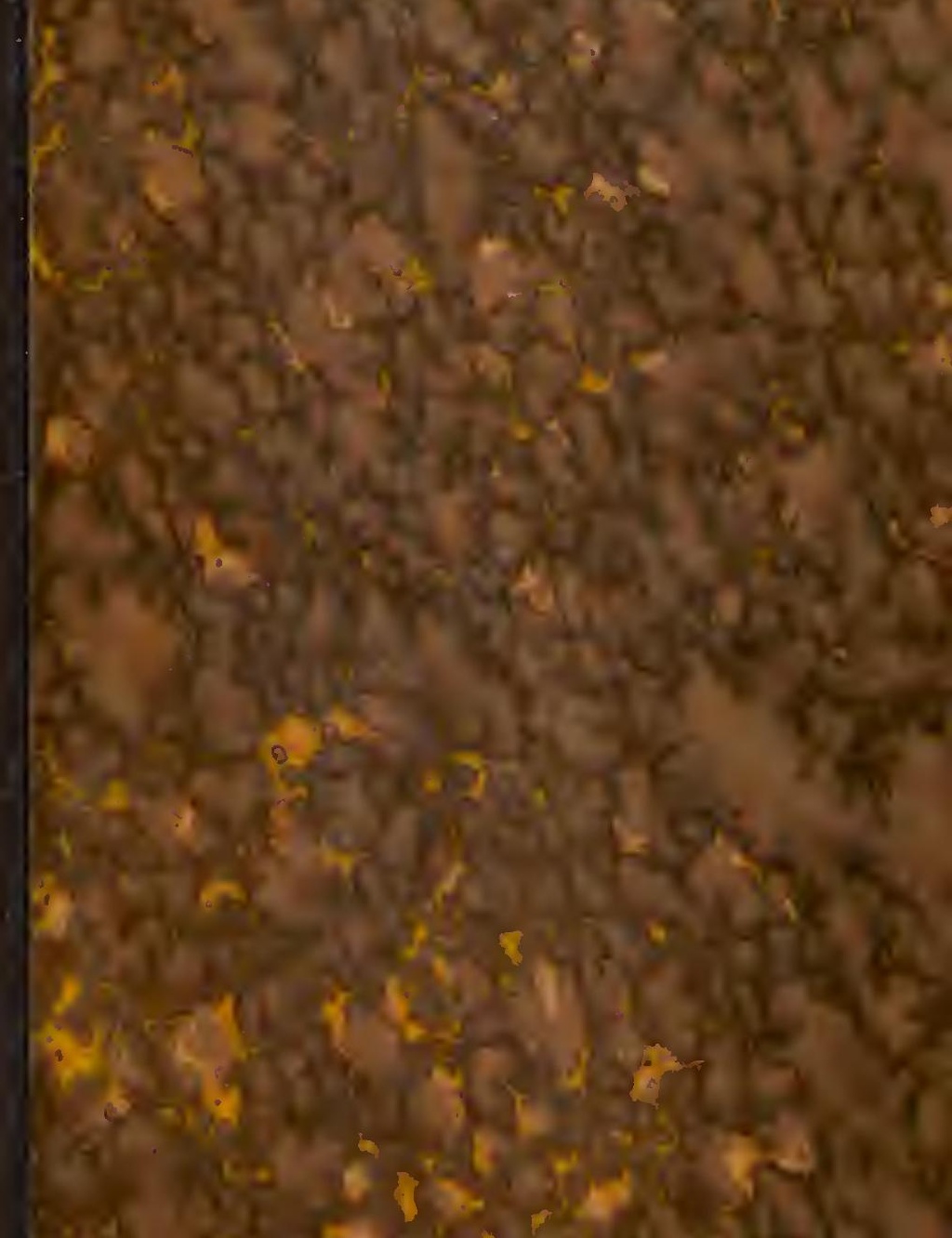




\section{LEGAAT VAN}

MEdUFFROUW C. A. VAN WICKEVOORT CROMMELIN

WILDHOEF

BLOEMENDAAL

1936

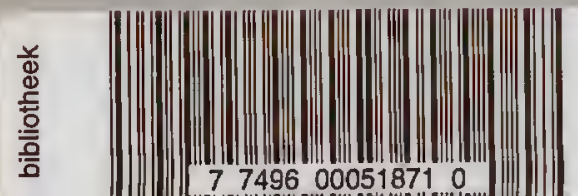

naturalls

natlonaal natuurhistorisch

museum

postbus 9517

2300 RA lalden 


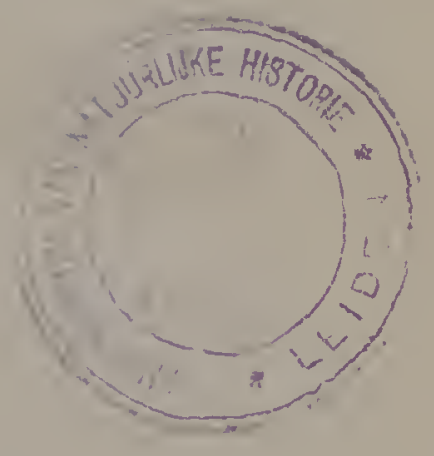





\section{DICTIONNAIRE}

\section{DES TERMES USITÉS}

DANS

\section{LES SCIENCES NATURELLES.}




\section{CHEZ IE METIE IIBRAIRI.}

SOUS PRESSE.

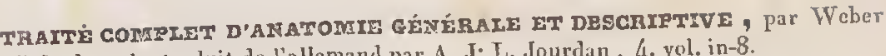
et Ifildenbraud, traduit de l'allemand par A. J. L. Jourdan, 4. vol. in-8.

ICOKOGRAPHIS DU REGTE ATIMAI, DE M. IE EARON CUVTER, ou Représcntation d'après nature de l'une des Espéces les plus remarquables, et souvent non eneorc fgurées, de chaque genre d'Animaux, Ouvrage pouvant servir d'Allas a tous les Traités de Zoologie; par F.-E. Guérin, Membre des Sociétés d'Histoire Naturelle et Entomologique de France, ete. Cet Ourrage sera publié en 45 livraisons, clacune de Io planches, nravées prar les meilleurs artistes, et qui paraisseut de mois en mois. Prix le chaque livraison in- 8 , figures noires:

- Le mêne in-8, ligures coloriées:

- Le même in-4, figures coloriées :

$15 \mathrm{fr}$.

34 Livraisons sont en vente.

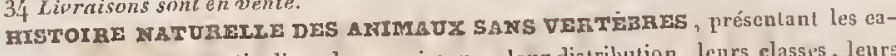
ractères gẻnéraux el particuliers de ces auimaux, leur distribution, leurs classı's, leurs familles, leurs genres, et la cilation des prineipales especes qui s'y rapportent. Par J.-B. I.A мансK, inembie de l'Institut, professcur at Muséum d'Ilistoire naturelle. 7 vol. in-8.

$56 \mathrm{fr}$.

PHrxosorntz zoozogrque, ou Exposition des cousinlérations relatives à l'Histoire naturelle des animaux, à la diversilé de leur organisation et des facultés qu'ils en obtiennent, aux ciuses physiques qui mainticnnent en eux la vie el donnent lieu aux mouvemens 'pu'ils exćculent, entin à celles qui produisent, les unes le sentiment, et les iutres l'intelligence de ceux qui en sont doués. Par J.-B. Ta MaRCK, $2^{2}$ édil. Paris, 1830, 2 vol. in -8 .

SESTHMY ANALYTEQVE DES CORMAISSATCES FOSTTVES DE I'HOMME, restreintes à celles qui provienueut dircelement ou indirectement de l'observation. Par MÉMOIR工 SUR LES FOSGIJS DES ENVIRONS DE FARIS, conprenant la défermination des espleces qui apparlicnuent aux a uimaux marins sans vertèbres, et dont. la plupart sout figure's dans la colleclion du Muséum. Par J.-B. Lamanck, in-4. Io fr.

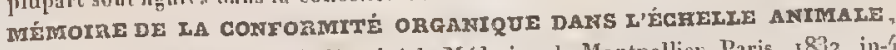
par Asт. Decìs, professeur à la Faculle de Médecine de Montpellier. Paris, 1832 , in-1 avee 6 plauches :

FARALLES NATLRLLIES DU RigNE ANIFAX, exposecs succinetement et dans

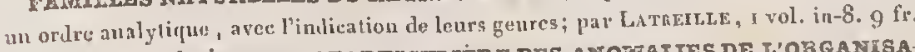

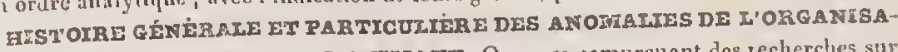
TION CREX I'HOMME ET IES ANIAA UX. Ouvrage compreuant des recherches sur les caractères, la classıficalion, l'influence physiologique et pathologique, les rapports yénéraux, les lois el les sauses des morsmrosrzis, des variétés et viees de conformation; on Trailé de Tératelogie, par Isid. Geoferot-Salvt-Hitanre, D. M. P. menbre de l'I ustitut, aide naturaliste de 7.00 logie a Musćum d'Ilistoire naturelle, ele. Paris, 1832, un fort vol, in-8 et atlas de $12 \mathrm{pl}$. $12 \mathrm{fr}$,

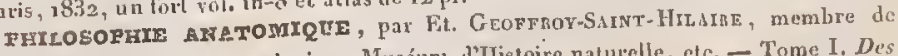
l'Instilut, professeur de zovlogie a Musćun d'Ilistoire naturdle, etc. - Tome I. Des Organes respüratoires. - Tone II. Monstruosités humaines. Paris, $1818 \cdot 1823,2$ vol. in-8, et 2 atlas in -4 . $22 \mathrm{fr}$. RAPRORT HISTORIOUUS SUR IES PIOGRË DES SCIENCES สATURELIES depuis 1789 et sur leur état aetuel; présenté au gouveruement en 1808 , par 1'Institut; xiJigó par M. le laron G. Cuvier, membre de l'Institul, professeur administrateur du Musṕum d'Ilistoire naturelle. Nouv. édil. Paris, 1827 , in-8.

$6 \mathrm{fr} .50 \mathrm{c}$. 


\section{DICTIONNAIRE}

RAISONNE, ÍTYMOLOGIQUE, SYNONYMIQUE ET POLYGLOTTE,

\section{DES TERMES}

TSITÉS DANS LES

\section{SGIENGES NATUELLES,}

COMPAENANT

L'ANaTOMIE, L'TIISTOIRE NATURELLE ET LA PIIYSIOLOGIE GÉNlRALES, L'ASTRONONE, LA BOTANIQUE, LA GIIIME, LA GÉGRAPIIIE PIIYSIQUE,

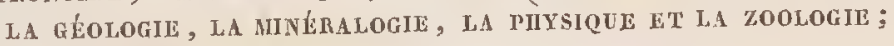

\section{PAR A.J.L. JOURDAN,}

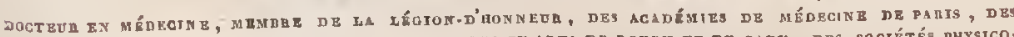
SCIRNCES DE TUIX,

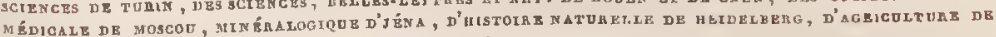
CAMLONS ET D'ORLÉANS, DES REAUK-ARTS DE GAND, eto.

Pofectò physiographiam qu colit, wllo pacto metam perfectioris cognitionis felicius non altinget, quàn st aliquot dies termunts perduscendis tribueril.

LINNÉ.

TOME PREMIER.

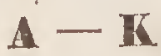

\section{PARIS,}

J.- B. BAILLIE்E,

LUDRAIRE DE T'ACADÉMIE ROYALE DE MÉDECINE, RUE DE L'ÉCOLE DE MÉDECINE, $\mathbb{N}^{0} \mathbf{1} 3$ bis;

LONDRE, MÊME MALSON, 219, REGENT-STREET ;

1834 . 

A

\section{C OUR T I N,}

ANGIFN MAGISTRAT.

IOMMAGE D'AMITIE.

A.-J.-L. JOURDAN. 



\section{PRÉFACE.}

Qu'ic soit impossibleaujourd'hui d'étudier les sciences physiques avec fruit, sans une connaissance approfondie de la terminologie, c'est une vérité devenue triviale et désormais à l'abri de toute contestation. A ceux qui, pour justifier le dédain qu'elle leur inspire, citeraient encore l'autorité de Buffon et de Bonnet, on opposerait celle non moins imposante de J.J. Rousseau, qui a si éloquemment proclamé la nécessité d'un langage spécial dans une branche du savoir humain à laquelle on ne donne le caractère de l'exactitude et de la précision qu'en exprimant une foule de nuances délicates dont la peinture ne trouve aucune ressource dans la langue usuelle. C'est dans les sciences physiques surtout qu'on peut dire, avec Voltaire, que si les hommes définissaient les mots dont ils se servent, il y aurait moins de disputes; car ce n'est pas assez d'être entendu, il faut encore qu'on ne puisse pas être mal interprété. 
Depuis trente ans, l'histoire naturelle a fait de si grands progrès, elle s'est enrichie d'une telle masse de découvertes spéciales, et, par une conséquence nécessaire, l'art des classifications a été si laborieusement travaillé, que le nombre des termes techniques s'est accru à un point vraiment prodigieux. Présenter un tableau complet de ces termes pouvait donc être considéré comme un des besoins de l'époque. J'ai osé entreprendre ce travail pénible, qui nécessitait d'immenses recherches; car il fallait lire tous les dictionnaires, tous les traités élémentaires, tous les ouvrages généraux et spéciaux, toutes les monographies, tous les recueils périodiques, toutes les collections académiques, qui ont paru, tant en France qu'en Allemagne, en Angleterre, aux États-Unis d'Amérique et en Italie. Mais les difficultés et les fatigues s'évanouissent devant les puissans attraits de l'histoire naturelle, cette science.aimable, qui fut la passion de mes plus jeunes ans, et à laquelle je croyais consacrer ma vie entière dans l'âge heureux d'illusions, où l'homme se berce du chimérique espoir de maîtriser les événemens et de fixer sa destinée.

N'ayant pas, comme Illiger, le projet d'écrire une terminologie systématique, et de présenter un certain nombre de termes choisis, mais voulant développer sur une plus grande échelle, et d'après un autre 
plan, l'idée qui domine clans le savant glossaire de Théis, c'est-à-dire réunir tous les termes dont les auteurs se sont servis, ceux mème qui n'ont point reçu la sanction générale, l'ordre alphabétique était celui que je devais adopter, comme étant lc plus commode. J'ai admis sans distinction tous les mots que j'ai rencontrés, bien que, dans le nombre, il s'en trouve beaucoup qui méritaient peu les honneurs de l'exhumation.' Mais il m'a semblé qu'un dictionnaire devait être complet, du moins autant que possible, sans quoi il perdait une grande partie de sa valeur, et rentrait, malgré sa forme, dans la classe des ouvrages didactiques, qui ne sauraient guère être plus mal présentés que sons un pareil mode de rédaction. Je n'en demeure pas moins convaincu que; si l'orateur latin était fondé à dire: Imponenda nova novis rebus nomina, un de nos contemporains, dont le talent et le caractère commandent également l'estimc (Raspail), l'était peut-être davantage encore à poser ce principe : « La science ne marche que par la nouveauté des faits; ct la nouveauté des mots, ou la rend stationnaire, ou bien la fait rétrograder. "

Quant au mode d'exécution que j'ai suivi dans ce Dictionnaire, le titre l'annonce d'une manière explicite. J'ai voulu donner la lexicographie des sciences qui ont pour objet les productions et les phénomènes de la na- 
ture, en indiquant à chaque mot les écrivains qui s'en sont servis, les particularités de conformation, de structure ou d'action qui l'ont fait créer, les nuances d'acception que souvent il présente, et selon les auteurs, et selon la science dans laquelle on l'employe, enfin les synonymes et équivalens plus ou moins parfaits qu'il peut avoir. En un mot, mon but ne dépassait pas les limites d'une exposition purement orismologique. Aussi ai-je dû, dans les articles consacrés aux ordres, familles et tribus, c'est-à-dire dans ceux qui concernent la classification, me borner aux énoncés qui rentraient rigoureusement dans mon plan, et m'abstenir d'énumérer les séries souvent si variées de genres. qu'un même groupe nominal renferme dans des auteurs différens. Ce sera là l'objet d'un autre ouvrage dont je m'occupe depuis nombre d'années, qui offrira en outre un synopsis complet des genres créés depuis Linné, et dont celui-ci peut être considéré en quelque sorte comme l'introduction. Je n'ajouterai plus qu'une seule remarque, qui me paraît nécessaire pour faire. apprécier le point de vue sous lequel je me suis placé : jai cru devoir multiplier les exemples, et partout j'ai choisi ceux qui semblaient être le plus proprcs à l'éclaircissement du texte. Je les ai d'ailleurs vérifiés pour la plupart sur la nature, sur de bonnes figures, ou au moins sur des descriptions bien faites. Si je me 
suis attaché à ce que la plupart de ceux qui concernent les mots adjectifs offrissent plusieurs désinences génériques, ce n'est pas par une ridicule affectation de pédantisme, mais parce que j’ai cru voir en cela un moyen d'indiquer avec plus ou moins de probabilité la fréquence de l'emploi qu'on a pu faire de chaque terme. Quelque jugement que le public porte sur un travail qui a exigé de si longues veilles, j’aurai du moins la consolation de penser quion ne pourra pas mappliquer ces paroles de saint Paul : Quos oportet redargui, qui universos domos subvertunt, docentes qua non oportet, turpis lucri gratiâ. 



\title{
DICTIONNAIRE
}

\author{
DES TERMES USITÉS
}

DANS

\section{LES SCIENCES NATURELLES.}

A.

ABAISSÉ, adj., demissus; herabgesetzt (all.); lowercul (angl.); abbassato (it.). Se dit, en hotanique, de la lèvre inférieurc d'une corolle labiée, quand clle forme un anglc presque droit avec le tube. Ex. Siachys germanica.

ABAJOUE, s. f., saceulus buccalis, ventrieulus buccalis, bucca saccata, thesautrus; Balilicntasche (all.); scrbatojo del eibo (it.). Les zoochesistes dounent ce nom ì deux poches qu'un assez grand nombre de mammifères portcnt sur les côtés de la bouche, soit à l'extérieur des joues, comme dans quelques rongenrs (ex. saccomys anthophiluss), soit à l'intéres, entre les joues et les mâchoi(ex. Cercopins heaucoup de singes rongeurs (exithecus auratus), certains quelques ch. Crieetus vilgaris), et Geoffroyi) choptères (cx. Nyctcris tôt, ce qui Ges poches servent tarmet.tre qui est le plus ordinaire, à animaux réserre les alimens que les lonté de cont pas le loisir ou la votantôt, consommer sur-le-champ ; I. procurcr le gonflement du corps, en permettant le passage de l'air extéricur dans un grand sac sous-cutané, avec lequel elles communiquent.

ABAMÍ́ES, adj. et s. f. pl. , $A b a-$ mea. Nom donné par Reichenbach à un groupe de la famille des Liliacées, qui a pour type le genre Abamea.

ABATARDISSEMENT, s. m. , degenteratio, depravatio; Ausartuns (all.); degeneracy (angl.); abbastardimento (it.). Altération en mal, sous le point de vie physique ou noral, d'un corps organisé, qui ainsi déclieoit de son état naturel ou le plus ordinaire.

ABDITOLARVES, adj. et s. m. pl. , Abditolarvati (abdo, cacher, larva, larve). Nom imposé par Duméril à une famille d'insectes liymćnoptères, dont les larres se développent dans le tissu des plantes vivantes, où les mères ont déposé leurs oufs. Voy. Núottocryptes.

ABDOMEN, s. m., abdomen, abdumen, venter, venter imus s, infi-

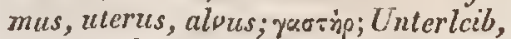
IInterleib (all.); abdomine (it.) (ab- 
do, cacher ). Terme emprunté à l'anatomic humaine, et qui, étendu par analogie à diverses classes du règne animal, n'cst plus dès lors suseeptible d'unc définition gćnérule, tant la région du corps qu'il scrt à désigner, varie rclativement aux parties qui la constituent et aux organes qu'elle renferme. On appelle ainsi ${ }^{a}$ ehez les mamnuifères, tantôt sculement, ce qui a lieu surlout ehez l'homme, la partie antérieure et inféricure du trone, tantôt aussi, ec qui rend le mot synouyme de cavile abdominale, la portion du trone comprise cntre le diaphragme, qui la sépare de la poitrine, l'épine du dos, le bassin el les museles du bus-ventre, et qui renferme les organes digestifs, urinaires et génitaux; $2^{\circ}$ ebez les oiseaux, la partie inférieurc et inolle du corps, située entre la pointe du sternum et l'anus; $3^{\circ}$ ehez les reptiles, la portion molle du dessous du corps, qui préeède l'anus ; $4^{\circ}$ chez les poissons, la parlie inférieure et molle du corps, qui loge les organes de la digestion et de la génération; $5^{\circ}$ chez Jes animaux articulés, la portion du tronc qui fait suite au thorax, et qui ne porte pas d'organes locomoteurs, ou n'en offre au plus que des rudimens; $6^{\circ}$ cliez les trilobites, la région moyenne du corps. Wicdemann. n'appelle abdomen, dans les insectes diptères, que la face supérieure de cette partie du corps, et il donne le nom de ventre à l'inférieure.

ABDOMINAL, adj., abrlominalis. Épithète donnée $1^{\circ}$ à des organes qui font parlie de l'abdomen, ou qui ont des connexions avec cette scetion du corps); cổé abdominal (gastroum d'Illiger), celui qui, ehez la plupart des animaux, est tourné vers le sol ou repose dessus; membres abdominaux, chez les animanx vertébrés, ceux qui ticnnent au bassin; nageoires abdominales, dans les poissons, eclles qui, par leur connexion avec le squelette, plutôt que par leur posilion extérieure, représeulent les menbres abdominaux des autres vertébrés; plumes abdominales, celles qui garnissent le ventre des oiscaux; segmens abdominaux, dans les animaux arlieulés, eeuxqui forment l'abdomen. par leur réuxion; $2^{\circ}$ à des animaux dont l'abdomen se fait remarquer d'une manière quelconque, soit par son volume (cx. Hippocampus abdominalis), soit par une couleur différente de cclle du corps ( ex. Melyris abdominalis).

Asponirive, adj. et s. m. pl., Abdoninales. Nom imposé, 10 en iehthyologie, ì un ordre dans la classificalion de Linné, à cinq sous-ordres dans eelle de Lacćpède, à un ordre dans celles de Cuvier, de Blainville et de Latreille, paree que les poissons que ees divers groupes renferment ont leurs nageoires abdominales situées sous le ventre, en arrière des pectorales; $2^{\circ}$ en entomologie, ì une seetion de la tribu des carabiques, dans les classifieations de Latreille et d'Eiehwald, paree que les colćoptères qui composent ces groupes ont l'abdomen très-grand, relativement aus prothorax.

ABDCCTION, s. f., abductio; й̈rqux; Abzichen (all.) ( abduco, écarler). Action par latquelle une partic du corps vicnt à être portće en dehors de la ligne perpendieulaire qu'on suppose partager en deux segmens égaux le membre dont elle fait partie ou lc eorps cutier.

ABERhATOX, s. f., aberratio; Abirrung (all.); aberrazione (it.) (abcrro, s'écarler). Ce terme est cmployé, 10 en astronomie; aberration de la lumière ou des étoiles fixes, illusion d'optique qui fait voir les étoiles où elles ne sont pas réellement, et dont la cause, découverte par Bradley, tient à l'inégalité de vitesse du 


\section{ABIÉ}

mouvement annuel de la terre dans son orbe et à la progression en sens inverse de la lumière; $2^{\circ}$ en physique; $a b c r$ ration de réfrangibitité, diffusion du foyer des rayous lumineux concentrés par un verre biconvexe, qui dépend de ec que, les rayons diversemeral colorés n'ayant pas la même réfrangibilité, la lentille ne peut point les concentrer tous dans le prolongement de son nxe; aberration de sphéricité, antre genre de diffusion du foyer des rayons lumineux eoucentrés par un verre biconvexe, qui tient à ce que la figourc des lentilles le permet qu'aux rayous très-roisins de I'axe de concourir sensiblement en un point commun, lous Ics autres, qui ćprouvent une réfraction plus furle, coupant l'axe en-deç̀ de ce point, d'où il suit que le foyer, au lieu de représenter un point, est réelduent un espacc d'uncertaine ćtendue, et que l'image prineipale, cellc qui se produit à l'endroit où seréunissent le plus de rayons, est comme offusquéc par une multiturle d'autres inages, qui rendent la vision confuse; déran plysiologie ; pour exprimer un rable, une plus ou moius eonsidcbituel, une irrégularitédans l'état hation d'uspect, la strueture, l'acficulté.

\section{ABI'́}

sapin). EIN, adj., abictinus (abies, dont les Eithète donnée à des corps manière laciniures sont disposées de une feuille imiter cn quelque sorte abictina) de sapin (ex. Corallina croissent, et ì des cryplogames qui Bacomyces ab des arbres verts (ex. tinum). Apri

sapin). Caill, s. โ. abictina (abies, stanec résinot appelle ainsi une sub. la térébenthise qu'il a extraite de Berzelius nine de Strasbourg, et que eette térćbenthine. résine gamma de
ABOR

ABY CTTNÉES, adj. ets. f. pl., Abietinea, Abietina (abics, sapin). Nom donné par A. Riehard, Bartling et Kunth à une section de la famillc des Conifìres, ayant pour type le genre Abies.

ABIÍTIQUE, adj., abieticus (abics, sipin). Baup applique eetic épithètc a un acide partieulier qu'il dit avoir trouvé dans la rérine du Pinus Abies. Lc môme nom d'acide abićtique est donnć par Caillot à une matière résineuse qu'il a reneontrée dans la térébenthine de Strasbourg, et que Berzelins regarda comme un mélange des résines alpla et bêta de cette térćben thine.

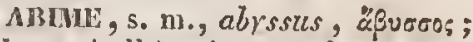
Abgrund (all.); alysss (angl.); abisso (it.) (a priv., putos, fond). Lues géognostes désigncnt sous ce nom des cavités naturclies qui sont presque perpendieulaires, dont on suppose la profondeur incommensurable, et qui ne renferment aucun liquide.

ABOI. $V$ oy. A BOIEMENT.

ABOHEMLNT, s. in., latratio, latratus ; Bellen (all.); barking, baying (angl. ); abbajumento (it.); cri le plus ordinaire dn ehien, qui en outre clabaude, hurle et jappe.

ABOHGENE, s. nı. , aborigenis ; Eingebohren, Urbewohner (all.) (ab, de, orior, nilître). Fípithètc donnée aux hommes, aux animaux et quelquefois aussi aux végétaux qu'on supposc origninaires du pays même qu'ils habitent, soit qu'ils y aient réellement existé de toute antiquité, soit que l'époque de leur transplantation se perde dans la nuit des temps.

ABONTT, adj., abortisnes, abor-

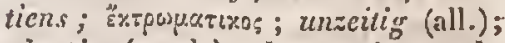
abortive (angl.); abortito (it.) ( $a b$, avant, ortus, naissance). Sc dit d'un corps organisé enticr ou d'un organe queleonque, qui n'a point acquis son dévcloppement complet, ou qui manque de eertaines conditions essen- 


\section{ABRI}

tielles à l'exercicc de la vie. Etamino abortive, celle qui n'a point d'anthère, ou qui n'en a qu'une ébanchée ou indéhisccutc. - Fleur aborlive, celle qui, bien que munie des deux sexes, tombe sans laiss cr aucune trace de fécondation.-Foclus abortif, celui qui se détache de l'organe materncl avant d'êtrc eu état de suffire par lui-mème aux exigenees de la vic. - Graine aborlive, celle qui n'cst point apte à germer et à reproduire l'espèec. L'épithète d'aborlivc a été donnce par les botanistes à quelques plantes, soit parce que, lcurs fleurs étunt très-pctites, on les regardait comme avortées (ex. Ranunculus abortivuss), soit parce que leurs fleurs représentent une figure manquée ou avortéc (cx. Orchis abortiva).

ABOVEur, adj., latrans; bcllend (all.); Zarker (angl.); abbajatorc (it.). On donne l'ćpithète d'aboycusc à unc barge (Scolopax glollis), à cause du cri qu'elle fait entendre et qui ressemble un peu'à celui du chicu.

ABRACHE, s. f., abrachia; Armlosigkeit (all.) ( $\alpha$ priv. , Ppaxiws, bras). Nom donné par Breschet à un genre de déviation organique, ou d'agénesie partielle, qui a pour caractc̀re I'absence des bras.

ABRANCIIES, adj. ct s. m. pl.,

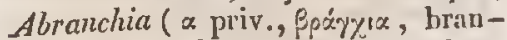
chies). Nom d'un ordre de la classe des Annelides, dans la méthode de Cuvier et de Straus, renfermant les espèces sans branchics apparcntes, qui semblent respirer par la surface du corps.

abri. Voy. HiberNacle.

ABIHTAX'T, adj., muniens; schülzend (all.). Se dit, en botanique, des feuilles, lorsque, pendant le sommeil de la plante, ellessont abaisséesvers la terre, et semblent former une sorte d'abri aux flcurs situées au-dessons d'elles ( ex. Impations noti me tangerc).

\section{ABSO}

ABRUPTI-RENNË, adj., abruptcpinnatus; abgebrochen-gefiedert(all.); pennato mozio (it.). Se dit, en botanique, des feuilles pennées (voy. ce mot ), quand le pétiolc commuu se terminc brusquement, sans foliole impaire, ni vrille. Ex. : Orobus tuberosus.

ABSINTHATE, s. m., absinthas. Nom donnć à un genre de sels (wermuthsaure Salze, all.) qui sont formés par la combinaison de l'acide absinthique avec les bases salifiables.

ABSLNTHIE, s. f., absinthina; Wermuthstoff, Wermulhbitter (all.). Principe amer de l'absinthe, que Caventou a isolć.

ABSINTHIQUE, adj. , absinthicus, Épithète donnée par Braconnot à un acide particulier (Wermuthsaüre, all.), dont il admet l'existence dans l'absinthe.

ABSOLU, adj. et s. m., absolutus. absoluitum; undebingt (all.); absolute (angl.): assoluto (it.) (ab, de, solvo, détacber); qui subsiste par soi-même, dégagé de tout lien, de tout rapport, de toute connexion. Se dit : $\mathrm{I}^{\circ} \mathrm{en}$ idéologie, des connaissances, lorsque, indépendarnment des circonstances dans lesquelles nous nous trouvons placés, elles restent invariables au milieu des changemens que notre existence ćprouve ; $2^{\circ}$ en philosophic, d'un principe suprême et unique, que l'ćcole de Schelling assigne à l'existcnce et à la pensée, considérées par elle comme de simples modilications de ce principe; $3^{\circ}$ en physique, d'une propriété d'un corps, quand elle est le résultat immédiat de l'observation; $4^{\circ}$ en chimie, de certaines substances, lorsqu'elles sont parfaite' ment pures et exemptes de tout mé lange étranger; alcool absolu, celu? qui ne eontient pas d'eau; suif abssolil la stéarine purc; huilc absolue, l'o' léinc pure.

ABSORBANT, adj. et s. m., absor 


\section{ABST}

bans ( $a b$, de, sorbeo, boire). Cette épithète , donnéc d'une nanière générale à toute substance qui possède la propriété d'introdnire en soi un fluide quelconque, liquide ou même gazeux, est appliquée, dans les eorps organisés, notaument dans les animaux, à ceux des vaisseanx qui recoivent du dehors des fluides sur lesquels on suppose qu'ils agissent en les pompant ou aspirant.

ABSORPTION, s. f., alsorptio, resorptio, inhalatio; Verschluckung, Einsaugung (all, ); assorbimcnto (it.) $(a b$, de, sorbeo, boire). On donne ce nom: I" en physique, à uu phénomène qui consiste daus l'attraction et la condensation d'uı fluide élastique ou d'un liquide par un corpssolide ou liquide; $2^{a}$ en physiologie, à une fonetion, dévoluc aux ĉtres organisés, par laquelle ils font pénćtrer daus la unasse de leur fluide nourricier des molćeules exlćrieures destinécs ì lentretenir ou à l'augmenter.

ABSTRACTIF, adj. abstractivines, abstractitius (ab, de, traho, tirel'). $\mathrm{O}_{\mathrm{n}}$ a quelquefois donné le non de $f a-$ culté abstractive ì eelle dont nous jouissons de tirer des abstraetions. Les ancients appelaient esprits abstractifs ceux qu'ils relimient des plantes par la distillation.

ABSTRACTION, s. f. , abstractio; astrazione (it.). Les idéologistes donavont ce nom, $1^{\circ}$ au pouvoir que nous des autroler les idées simples les unes mens qui con séparer les divers élémune, qui composent une pensée comidées pour d'exclmre une ou plusieurs d'une our plus occuper spécialement nir celles plusieurs autres, et de réudans plusir se rotrouvent les mêmes générnlusieurs objets sous une idée répond à laquelle nul objet réel ne de celtc fans la nature; $2^{\circ}$ à l'exereice l'éliminate faculté; $3^{\circ}$ ì son produit, rapprochement des idées similaires ; $4^{\circ}$ entin à toute conception d'un esprit. qui, au lieu de s'appuyer sur l'obscrvation, ne travaille que sur des idées.

ABSTLAIT, adj. , ahsuactus ; abstract (all. angl.); astratto (it.). Se dit d'une idéc qui a ćté isolée par le pouvoir de l'intelligenee; d'une pcnséc ou conccption qui n'a point d'existenee réelle hors de l'entendement, par lá pruissanee disjonetive ct assoeiante duquel elle est erée; d'un termc qui exprime des idées ou des pensíes de ee genre; enfin d'un csprit qui possède it un degré éminent la faculté de crćer des alsstraetions, ou qui abuse de eette faeulté.

ABYME. V o $y$. A sîn.

ABSSIQUE, adj., abyssicus (aby.s. sus, abîme). Brongniart donne cetle épillicte à un ordre de terrains comprenant ceux qui constituent le fond des alimes de l'ancienne mer.

A GALELPLEs, adj. et s. m. pl., Aca-

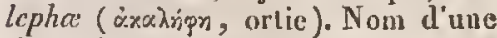
elasse du règne animal, dans les méthodes de Cuvier, Schweigger, Latreille, Ficinus et Carus, constiluant des groupes qui sont diversement délimités, mais qui tous renferment des animaux dont plusieurs ont lis propriété de eauser, quand on y touche, une sensalion brûlante, analogue ì celle que produit la piqûre des orties.

ACALIGAL, adj. , acalycalis ( $a$ priv., xร̊̀) par Lestihoudois à l'inscrtion des étamines, lorsque cellcs-ci parteut du réceptaele, sans contracter aucune adhérence avec le cilice.

ACALICIN, adj., acalycinus; kelch. los (all.) ; acalicino (it.) ; ( $\alpha$ priv., xálus qui est dépourvue de calice.

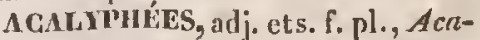
byplece. A. de Jussieu a formé sous ce nom, dans la famille des Euphorhiacées, une tribu dout le gुenre Acalypla est le type.

ACAMu'tosomes, adj. ct s. m. pl., 


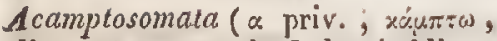
plier, oẅux, eorps). Ordre établi par Leach, dans la classe des Cirripèdes, et ainsi appelé parce que les animaux qui le constituent ont le corps entièrement enveloppé de pièces ealenires, dont la présence le rend immobile.

AGANACÉES, adj. et s. f. pl., Acanaccé; nom donné par Césalpin à la famille des Chicoracées. $V_{0 j}$. cemol.

ACANTIIAGĹES, adj. et s. f. pl., Acanthacce, Acanthi. Famille de plantes, ćtablie par Jussien, et qui a pour type le genre Acanthus.

ACANTIUÉES, adj. et s. f. pl., Acanthca. Nom donné par K. Sprengel à la famille des Acanthacíes.

ACANTHES, s. f. pl., Acanthi. Jussicu appelait ainsi la famille des Acanthacées.

ACANTIIInES, adj. ct s. m. pl., Acanthida. Sous ee nom, Leach désigne une famille d'inseetes hémiptères, qui a pour type le genre Acanthia.

ACANTUIODONTES, s. m. pl.,

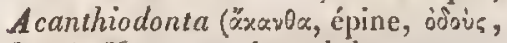
dent). Nom sous lequel les oryelographes déerivent des dents fossiles qu'on croit appartenir au Squalus Acanthias.

ACANTIIURE, adj., acanthiurus

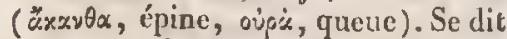
d'un animal qui a la queue chargée d'épines. Ex. Uromasty $x$ acanthiturus.

AGANTHOCARPE, adj. , acantho-

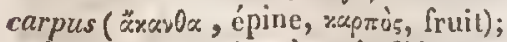
qui porte des fruits ehargés d'épines. Ex. Acacia acanthocarpa.

ACANTIOCÉPILAILS, adj. et s.

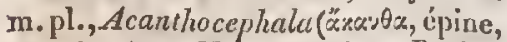

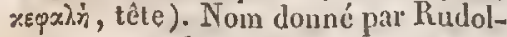
phi à un ordre, par Schweigger et Eichwald à une famille de la classe des Entomozoaires, par Blainville a une famille de l'ordre des Apodes Proboscéphalés, renfermant ceux de ces animaux dont la partie antéricure du corps ou la tête est armée d'aiguillons recourbés ou de erochets cornés. ACANTHOCÉPIALIES. $V_{\text {oy. ACAN. }}$ THOCÉPHALES.

AGANTHOCLADE, adj., acantho-

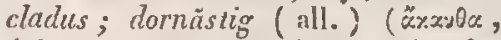
épiue, жixios, branche); qui a les ranseaux chargés d'épines. Ex. Gcnista acanthoclada.

AGAVTHODES, adj. et s. f. pl., Acanthoides. Synonyme peu usité d'Acanlhacées (voy. ce mot), dont s'est servi Veutenat.

ACANTIOPIORE, adj., acantliophorzs; dorntragend (all.) ( «ँxas0\%, épine, yiow, porter); qui est hérissé d'épines ou de gros poils rudes (ex. Fuctus acanthophorts). Synonyme de Spinigcre.

ACANTIOPODE, adj., acantho-

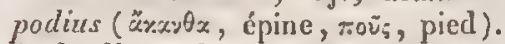
Se dit d'une plante qui a les pétioles très - ćpineux. Ex. Zygophyllum acanthnpodium.

$\triangle \mathrm{GANTHOPODES}$, adj. et s. m.

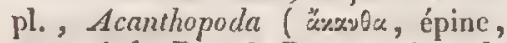
$\pi \circ v_{\text {, }}$ pied). Dans le Rìgne animal de Cuvier, ee nom est donuć à une tribu de Coléoplères Clavieornes, renfermantdes espèees dont les jambes sont très-épineuses.

ACLNTHOPOAES, adj. et s. m. pl., Acanthopomata ("*xs:ose, épine, $\pi$ öirs, opereule ). Duméril désigne sous ce nom une famille de poissons, dans laquelle sont comprises des espèces qui ont les opercules garnis de dentelures or d'épines.

ACANTuOPS, adj., acanthops

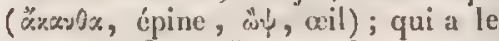
pourtour de l'oeil garni de piquans. Ex. Holoccnirus acanthops.

ACANTHORTERE, adj., acantho-

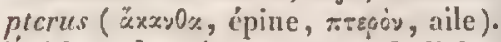
ispithète donuée par lés conchyliologistes à des eoquilles dont le bord dilaté est garni de varices terminées en pointe. Ex. Murex acanthopterus.

AGANTHOPTERES, adj. el s. w. 
pl. is Aeanthoptcri. Blainville donne ee nom à une famille de poissons gnathodontes hétćrodermes, qui ont la première nagcoire dorsale épinense. ACANTHOPTínYGIENS, adj. , scanthopterygitus; hartgrütig, hartsirahlig, slaehelstrahlig (all.) ("xrav-

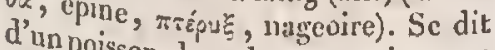
garnics dent les nageoiressont niquans.

AGANTHOPTÉRYGreNs, adj. et $\mathrm{s}$.

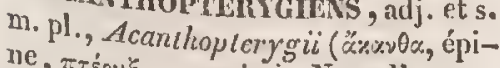
dre drépu métho la classe des poissons, dans les Cuviedes d'Artedi, de Gouan et de sons cons osseux, dans celle d'Eichwald, comprenant ceux de ces animaux qui ont des rayons durs et pointus, en forme d'aiguillons, à toutes ou à quelques unes de leurs nageoires.

ACANTHORHINEs, adj. et s. $m$. pl., Acanthorhina ("uservos, ćpine, piv, nez). Vicinus, Carus, Latreille et Eichwald donnent ce nom à une famille de poissons, comprenant ceux qui ont un appendice charnu, armé d'aiguillons, entrc les ycux.

ACARDE, adj. , acardinatus ( $\alpha$ priv, cardo, gond). Se dit d'une eom quillc ou d'rue valve de coquille qui n'a aucune trace de charnière. (Ex. Lingula anatina). Se dit aussi d'un monslie qui n'a point de cœur.

ACARDIE, s. f. , acardia ; Herzlosigkeit (all.) (a priv., zapdia, de déve. Bresclet désigneainsi un genre sie partion organique, ou d'agénél'absencec le, qui est curactérisé par ACAnes cour.

donné par I s, m. pl., Acari. Nom bit parmileach à une classe qu'il étales arani les animaux articulés, entre fondc sur lo et les iusectes, et qu'il Ac sur le genre Acartes.

ACAMIDES, adj. ct s. m. pl., Aca-
rides, Acaridae. une famille de la elasse des acares.
Le mềme nom est donné par Lamarck, Cuvier, Latreille, Eichwald, Ficinus et Carus à une famille ou à une tribu de la classe des arachnides. Toutes ees coupes ont le genre Acarus pour type.

AGAIIDIES, adj. ets, f. pl., Acaridic. Synonyme d'Acarides (voy. ce mot), dont Latreille s'est quelquefois servi.

ACAlisiss, adj. et s. m.pl., Acarina. Nom donné par Nitzsclı à la fanille des Acarides.

ACALLE, adj.; acaulis, acaulos, cxscapus; sliellos, stengellos (all.); accule (it.) (a priv., vavhos, tige). Se dit d'mue plante qui n'a point de tige, on dont la tigc est peu apparente, à causc de sa brièveté (ex. Silene acaulis, Astragalus exscapres, Parrya exscapa, Ornithogalum exscapum). On dounc aussi cet te épithète à un clianpignon qui est dépourvu de stipe (cx. Polysaccum acaule).

Accélínateur, adj., beschleunigcnd (all.); accelcruting (angl.); aceeleratore (it.). Les physiciens appellent force aeeélératriee eclle qui, contimuant à agir sur un corps mobile après son départ, exeree ainsi une impression qui le sollicite sans eesse et lui communique à chaque instant une nouvelle vitesse.

AGCh́línATION, s. f., aeceleralio; Beschlcunigung (all.); accelcrazione (it. ). Lues astronomes entendent par accélcration diurne des ćtoiles le temps que les étoilcs, dans une rúvolution diurne, auticipent sur la révo lution diurne moyenne apparente du soleil, qui cst de $3^{\prime} 55^{\prime \prime} 9$; accéléralion d'une plancte, l'cxeès de son mouvement diurne réel sur son mouvement diurne moyen; accélération de la lune, l'augmentation du moyen monvement de la lune dans son écart du soleil, mouvenent qui est un peu plus graud maintenant qu'il n'ćtait jadis. 
ACCẺL knk, adj., accelcratus ; bcschlcunigt (all.); acceleratcd(angl.); accelcrato (it.). Se dit : $1^{\circ}$ en astronomie, d'une planite, lorsque son mouvement diurne réel exec̀de son moyen mouvenuent diurne; $2^{\circ}$ en physique, du mouvement, lorsque l'aetion continue de la force on des forces qui sollicitent le mobile tend à devenir plus rapide. On appelle mouvement uniformément accélcré, celui qui résulte de l'application à un corps d'une force qui, couservant coustamment la même intcnsité, communique suecessivement à ee eorps des vitesses de plus en plus grandes pendant le temps qu'elle agit sur lui; or, lc ealcul dénontre que les espaces parcourus ainsi sont entr'eux comme les carrés des tcmps et les carrćs des vitesses finales, e'est-it-dire que l'espace parcouru pendant un temps d'un mouvement uniformćmont aceéléré, est la moitić de l'espace qui serait parcouru uniformíment daus lc même espace, avee la vitessc finale ; $3^{\circ}$ en minéralogic, d'un cristal dans le signe duqucl les exposans simples font partie d'une progression qui est complétće par les exposans relatifs à un décroissement mixte ou intermédiaire, en sorte que la progression paraît subir unc accélération ( $\mathrm{ex}$. Chaux carbonatće accélérée) .

ACGENT, s. m., accentus, sonus vocis; Ton, Ausspracke(all.); accent (angl.); accento(it.). On appelle ainsi tonte modifieation de la parole qui porte sur la duréc on le ton des syllabes et des mots dont le discours est composć. On distingue l'aecent grammatical, qui fait que le son des syllabes est grave ou aigu, et chaque syllabe brc̀ve ou longue; le logique ou rationnel, qui indique le rapport existant entre les propositions ct idées; lc pathétique ou oratoire, qui, parles diverses inflexions de la voix, cxprime les sentimens dont eclui qui parle est animé, et les communique aux auditeurs.

ACCENTUĚ, adj. , accentuatus ; accentuated (angl.); accentuato (it.). Se dit, en philologie, d'une langue dans laquelle certaines syllabes ou certains mols se prononcent d'un ton plus ou moins aigu ; ct en histoire naturelle, d'un corps qui porte des taches colorées scmblables aux accens de l'écriture (ex. Arantea accontuata, qui portc deux aecens circonflexes sur le dos de l'abdomen). Voy. Ecrat.

ACCis, s. 11., accessus; Anwandlung (all.); fit (angl.); adito (it.) (ad, vers, cclo, marcher). Newton appclait aecés de facile réflcxion les dispositions successives d'un même rayon lumineux à êtrc réléchi par différentes épaisseurs d'une lame mince d'air ou de toate autre substance, qui sont entr'clles comme les termes de la série des nombres impairs; et accís de facile transmission les dispositions suceessives d'un même rayon à être réfractć et transmis par différelltes épaisseurs qui correspondent aux termes de la séric des nombres pairs.

ACGESSOInE, adj., accessorius. Dans la langue géognostique, on nomme partics constituantes accessoircs d'une rochc colles qui se rencontrent quelquefois, disséminćcs uniformément et en quantitć notable, eonme, par exemple, le quarz dans le gneiss.

ACCIDENTEL, adj., accidentalis, adyentitius; zufïllig (all.); accidental (angl.); accidcriale (it.). Sc dit: $1^{\circ}$ en physique, d'une coulcur dont l'idće peut naître on se conserver sans la présence d'un objet qui l'excile; 20 en géognosie, des partics qu'on trouve quelquefois éparses dans les roches, et en quantitć moindre que celles qui eonstituent proprement ces dernieres.

ACCIPITnES, adj. et s. m. pl., Accipitres (accipitro, déchircr). Nom 


\section{ACCL}

donné par Linué, Cuvicr, Latham , Meyer et Wolf, Vicillot, C. Bonaparte, Duméril, Temminck et Lesson it un ordre de la classe des oiscaux; par Lherninier, it une simple famille de cette même elasse, renfermant les oiseaux de proie.

ACCIPITRES-GAL

et s.m famille. pl. Lesson appelle ainsi une prellant derdre des Accipitres, comquel des oisenux de proie qui ont ques rapports avec les Gallinacés. ECCIPITIIN, adj., accipitrinus. des anim dounće par les zoologistes à mauximax ou à des partics d'anioiscau qui ont des rapports avec un guration proie, quant à la confiPsiltacu généralc ou partielle. Ex. bec acus accipitrinus, à cause de son accipitrinu et très-robuste; $S$ trombus qui est rinus, à cause deson bord droit, une dilaté, et qu'on a comparć à aile d'autour.

Accipiarins, adj. et s. m. pl., Accipitrini. Nom imposć par Illiger, nus et Carus , Latreille, Eichwald, Ficigors à une tribus une famille, par. Vide proic.

ACCring

TEMENT. ACCL

tus; ACG a subi l'acelimatement.

$a_{\text {sizctudo. }}$ ATEMENT, s. m., climati profonde Modifientiou plus ou moins tion d'un qui s'opere dans l'organisatransporté être vivant, lorsqu'il est Ce terme s'un climat dans un autre. des animauploic surtout en parlant l'homme.

\section{ACCLIN:}

greifend (all.) (adj.; acclinatus; uclercher); qui est incliné, vers, clino, pen-
dit que les dents Illiger les marnmifents sont acclinces dans mâchoire couves, quand celles d'une correspondant dent par le côté le côté mâchoire.

\section{ACCO}

ACCOLLË, adj., accretus; angclcimt, aufgelcint (all.) (ad, ì, colla, colle). Sc dit, en histoire naturelle, et surtout en botanique, d'une partie qui est colléc ou soudée avec une autre, et qui croît avec ellc.

ACCOMBANT, adj. , accumbens; anliegend (all.). Candolle donne cette épithète à la radiculc, quand elle est couchée sur le bord des cotylédons, et aux cotylédons, lorsqu'ils sont appliqués de telle manière que la radieule redresséc correspond à la fente qui les sépare. Ex. diverses Crueifères.

ACCORD, s. m., contenodulatio; Zusammenklang (all.); tumablencss (angl.); consonanza. (it.). Union de deux on plusieurs sons, qui sont produits à la fois, et qui forment ensemble un tout larmonique.

ACCOVGHEMENT, s. m., partus,

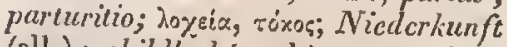
(all.); childlied (angl.); parto (it.). Expulsion hors de la matrice du foctus à terme ct de ses annexes. Synonyme de parturition, dont on ne se sert qu'en parlant de la femme. Lorsqu'il s' aryit du même phénomène chez la femclle de quelque autre mammifère, on dit : mcttrc bas (junge worfen, all.; to bring forth whelp, angl. ; partorirc, it.), à moirı qu'il u'y ait un terme spécial pour désigner l'opération dans telle ou telle espèce particulièrc, comme agneler (lanmen, all. ; to yean, angl, ; agncllare, it.), pour la brebis; chatter (jungc Katzen werfen, all. ; to killcn, angl, ; far'i mucini, it.), pour la chatte; chevroter (zickeln, all.; to kid, angl.). pour la chèvre; chienner, pour la chienne; cochonncr (ferkcln, all.; to farrow, to pig, angl.; trojarc, it.), pour lia truie; faonner (cin Hirschkalb sctzen, all. ; to fawn, angl.; far'un cervo, it.), pour la biche et la daine ; lcyretter (junge Hasen werfon, all.; to kindlc, angl. : far' $i$ veltri piccoli, it.), pour li fenelle du lièvre; louye- 
ter (wölfen; all. ; to whelp, angl.; far'i luppicini, it.), pour la louve; pouliner ( $f$ iillen, all.; 10 foal, angl.; fare'l polledro, it.), pour la jument; véler (kalben, all.; to calpe, angl.; vitellare, it. ), pour la vaehe. On dit pondre (cycr lcgen, all. ; to lay eggs, angl.; far l'zovo, it.), pourlcs oiseaux; frayer, pour les poissons et reptiles.

ICCOUCHEUR, adj., obstetricans. Épithète donnée à une espèce cle erapaud (Bufo obstetricans), dont le mâle aide la femelle ì se débarrasser de ses oufs, qu'il s'attnehe aux deux euisses, par le moyen de quelques fils d'une matière glutincusc.

ACCOUPLE, adj., zuzygius; gepaart (all.); couplcdl (angl.); accopiato (it. ); qui cst disposé par couples. Le Myrius zuzygitus est ainsi appelé it eause de ses rameaux fourehus et de ses feuilles disposécs deux ì deux.

ACCOUPLEMENT , s. m., copulatio,

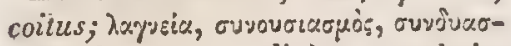

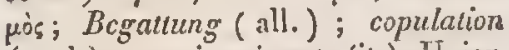
(angl.) ; congiugnimcnto (it.). Union des deux sexes dans l'acte générateur.

ACCOURGI, adj., abbrevialus; absckïrzt (all.); abbrcviato (it.). Les botanistes dounent cette épitbète aux cotylédons, lorsqu'ils sont courts, mais assez larges.

AGCRESCENT, adj., accrescens; fortwachsend (all.) 'ad, vers, cresco, croittre). Se dit, en botanique, des parties de la fleur autres que l'ovaire, qui prennent de l'nceroissement après la fécondation, comme le style des Clematis et le ealice du Physalis Alkekengi.

ACCROGHANT, adj., adhamans; anhakend (all.). Se dit: $1^{\circ}$ en botanique, des surfaees qui sont munies de petilcs aspérités erochues, comme les tiges ct feuilles du Galium Aparine, les fruits du Goum urbanum, les squames ealieinales de l'Arctium Lappa; $2^{\circ}$ en ornithologie, d'après Illiger, des pieds emplumés justgu'au talon, ayant quatre doigts parfaitementséparés, et lous ḋirigés en avant, ou dont un se trouve en arriçre, mais est versatile, comme dans les Colious.

ACCROISSEMTNT, s. m., auctus, accresccntia, accretio, incrcmentum; üuEูnoเs; Zuwachs, Wachsthum (all.); incrcase (angl.); accrescimento (it.) (ad augm., cresco, croittre). Auginentation de la masse et du volume d'un corps, par l'agglomération de nouvelles molécules constituantes; série des phćnomìnes qui se suecédent dans les corps organisés, pendant qu'ils augmentent de grandeur et de gosseur, pour arriver peu à peu au degré de développement qui est assigné àt chaeun d'cux.

ACÉLUPIIE, adj., aceluphus; 'sxé-

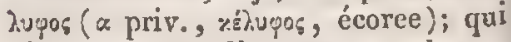
n'est couvert d'aueune enveloppe. Moquin-Tandon appelle improprement l'ouf hardic ( $V$. ce mot), ovum aceluphum.

AĆ́PIIALE, adj.et s. m., acephcto lus; àxiçàos; kopflos (all.); headless (angl.) (a priv., 火вọchì, tête). Se dit: $1^{\circ}$ en botanique, d'un ovaire qui ne porte point de style (ex. Borrago officinalis); $2^{\circ}$ en zoologie, d'un animal qui a la tête très-petite et peu distinctc (ex. Cyrtus accpha/us); $3^{\circ}$ en physiologie, d'un foet its qui vient au monde sans têtte, et, par extension, de eelui chez lequel on remarque, soit sculement une eon formation défectucuse du erâne, soit mène l'absenec d'une plus ou moin grande partic du tronse.

ACÉPIILLís, adj. et s. m.pl'? Accphalati (a priv., repalin, tètc). Nonl donné par Férussae et Menke à unb section des animaux mollusques, eon prenant tous ceux chez lesquels on $n^{0}$ distingue point de tête.

$\Lambda$ CÉPINLES, adj. cts.m. pl., $A c^{t^{2}}$

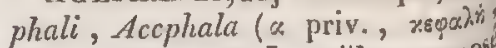
tête). Ce nom, que Latreille a prop $0^{5}$ jadis pour un groupe d'insectes cor' 


\section{ACÉP}

respondant à la classe actuclle des ârachnides, désigne aujourd'hui une classe du règne animal dans la méthodede Guvier, mn ordre de la classe des animaux mollusques dans celles de Duméril, d'Eichwald et de Schwcigger, une séric du règne animal dans celle de Latreille, groupes qui tous ont pour caractère l'absence d'une tête
distincte.

ACúPnaLIE, s.f, acephalia; Kopf-
losigheit (all.) ( $\alpha$ priv. tête). Les physiologistes désignent ainsi un gen physiologistes désignent ou d'agénćsie partielle, qui cst caractérisé par l'absence totale de la tête.

ACírialiens, adj. el s. m. pl., Acephalii. Pouchet donne ce nom it lá clisse de Malacozonires que Blainville désigne sous celui de Acéphalopleores . ce mol).

A CÉpHaLobracie, adj. ets.m.,

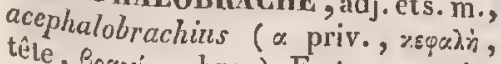

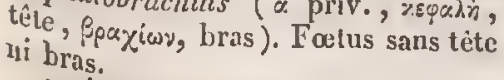

ACÉPHaxobracine, s. f., acephalobrachia ( $\alpha$ priv, , $x \operatorname{sq} \alpha \lambda \dot{n}$, tête, Ppoxiav, bras). Nom donué par.Breschet à un genre de déviation organique, ou d'agénésie particlle, qui est des bras.

ACh́Bín tele, racardius (a priv., xzpain, ni cour. Acti

phalocardia OCARDIE, s. f., ace-

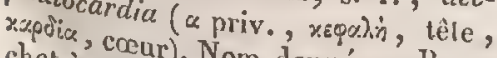
chet à un genr). Nom donné par bresque, ou denre de déviation organicaraelérisé "génésie partielle, qui est du coeur. Par l'absence de la tête et Aḉpi

acephalochirus (ane, adj. et s. m., $\chi \varepsilon i p$, main). Foetus ( priv., $x=\varphi_{\alpha} \lambda \dot{n}$, tète, AĆ́PI). Foctus sans tète ni mains. acephalogaster ( $\alpha$ priv. adj. et s.m., têle, yxơrig ventre). Foetus privédé

\section{ACÉP}

Ja lćte et de la partie supérieure du ventre.

acéplialogastrie, s. f., acephalogastria (a priv., $x \in \varphi \propto \alpha \lambda i$, tète, yoarìp, ventre). Nom donné par Breschet it un genre de déviation organique, ou d'agénésie partielle, qui est caractérisć par l'abscrice de la téte et du trone, jusques et compris la partie supéricure de l'abdomen.

ACÉPHALOPHOR:s, adj. ct s. m.

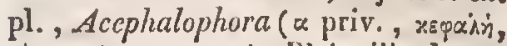
tềle, థiśsw, porter). Blainville doune ce nom à une elasse de son sous-type des Malacozoaires, comprenant ceux de ces animaux qui n'onl point do tête distincte du reste du corps.

ACÉPHALOPODE, adj. el s. m. , acephalopodus ( $\alpha$ priv., xspąìn, tête, $\pi \circ \tilde{s}$, pied). Foctus privé de la tête et des pieds.

ACÉPHALOPODIE, s. f., acepha-

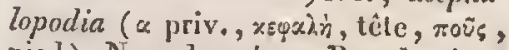
pied). Nom donué par Breschet à un genre de déviation organique, ou d'agénésic partielle, qui est caraclérisé par l'absence de la tête et des pieds.

$\Delta$ CípHILORAcuIE, s. f., acc-

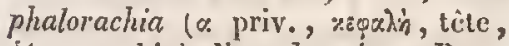
ṕx $x$ ‘s, rachis ). Noin donné par Breschict it un genre de déviation organique, ou d’agénésie partielle, qui est caractérisé par l'absence de la têtle ct de la colonne vertébrale.

ACÉPIIALOSTOME, adj. et s. m.,

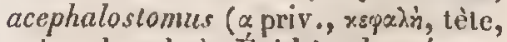
orópu, bouche ). Eipithète donnée aux foetus acéphales à la partie supéricure desquels on trouve unc ouverture semblable à une houchic.

ACÉPUALOTHORACIE, s. f. , ace-

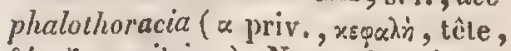
Ob́socă, poilrine). Nom donné par Breschet à un genre de déviation organique, ou l'agénésic partielle, qui est carnctérisé par l'absence de la tête et de la poitrine.

AChPHALOTHORE, adj. ct s. m., acephalothorus ( $\alpha$ priv., $x_{\varepsilon} \varphi \alpha \lambda \dot{n}$, 


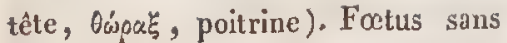
tête ni poitrine.

ACÉRAClées, adj. et s. f. pl., Accracca. Famille de plantes, qui a pour type le genre Accr.

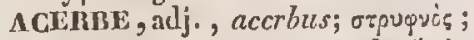
herb (all.); sour (angl.); accrbo (it.). Se dit d'une saveur désagréablc, âpre, un pcu acide et astringente, et s'cmploie quelquefois, conıme épithète, pour désigner des corps doués d'une semblable saveur (ex. Agraricus accrbus).

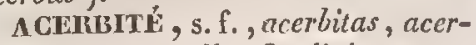
bitudo; Herbe (all.). Qualité en vertu de laquelle certaines substances, par exemple des fruits qui ne sont pas mûrs, produisent sur l'organe du goût une impression désagréable d'acidité, mêlcée d'astriction et d'un peu d'amertume.

ACÉrń́, adj. , acutzts; spitzig (all.); stecled (angl.). Épitliète donnée a toute partie animale on végétale qui est plus ou moins cylindrique, acuminéc et piquante, eomme les rayons des nageoires de certains poissons (ex. Pcrca), et les feuilles de diverses plantes ( ex. Asparagus acutifolius).

ACÉRÉ, adj., accras ( $\propto$ priv., หépaร, corne); qui n'a point de cornes. Blainville donne l'épithète d'acćrées aux néréides qui n'ont aueun tentacule.

ACÚnELLÉ, adj., acercllatus; qui se termine en une pointe peu aiguë.

ACEnes, adj. els. in. pl. , Acera (a priv., *épac, corrue). Nom donné par Dumcril à uue famille de l'ordre des insectes Aptères, conprenant ceux qui n'ont pas d'antenues; par Blainville, it une faunille de l'ordre des Monopleurobranclies, et par Menke, à une famille de celui des Pomatobranches, dans lesquelles ils rangent ceux dont la tête est dépourvue de tentacules, ou n'en porte que de rudimentitires; par Lalreille, à une famille de

\section{ACÉT}

l'ordre des Gastéropodes ; comprenant ecux qui ne portent pas de tentaeules à la tête; enfin par Blainville, à une famille de la classe des Chétopodes, compreuant ceux dont les anneaux céphaliques sont dépourvus de cirres implantés à la face dorsale et dirigés en avant.

ACEREU:, adj., acerosus; nadelig (all. ); rigido (it.) (axis, pointe): Se dit, en botanique, des feuilles qui sont allongées, menues, raides et aiguës. Ex. Phylica acerosa, Hypericum acerosum.

ACÉRINÉES, adj. et s.f. pl., Acerinea, Accrina, Acerinea. Synonyme de AcÉracíes. Voyez ce mot.

ACÉRIQue, adj., acericus. Scherer appelle ainsi un acidc qui existe, combiné avee de la chaux, dans la sève de l'Accr campestre, et qu'il croit former une espèce à part, tandis que Gmelin le regarde comme de l'acide malique.

ACESGENGE, s. f., acescentia; Säucrlichkeit (all.) (accsco, s'aigrir). Disposition à prendre les caractères de l'acide, à s'aigrir, à devenir légèrcment acidc.

ACESCENT, adj., acescens; sïuct lich (all.); qui s'uigrit, qui commence à devenir acide.

ACÉTABULARIÉES, adj. et s. f. pl., Acclabularice. Nom donné par Lamouroux à une famille de Polypiers, qui a pour type le genre Acctabnlaria.

ACÉTABLEE, s. m. , acciabulam; xотuдin; Pfanne, Saugschaale (all.). Ce mot exprime, en zoologie, l'exenvation d'unc coquille ou d'un polypier dans laquelle l'animal est fixé, le $e^{5}$ suçoirs qui garnissent les bras des mollusques céphalopodes, et l'espice de ventouse que les catopes réunie ${ }^{\varsigma}$ prodnisent chez certains poisson (ex. Lepadogastcr Goutanii). Kirby appelle ainsi la cavité de l'arrière-poitrine des inseetes dans laquelle s'im plante la patte de derrióre. 
ACËTABUL Ë, adj., acelabulostis; qui a la forme d'une coupe, comme la fructification de plusieur's lichens (ex. Lichen acetabulum), ou le chapeau de certains champignons (ex. Peziza acelabulum).

ACÉTABULEUx, adj., acetabulosus; qui a la formc d'un vase, comme le calice du Marrubium acctabulosim. Actetabularorve, adj., acelabuliformis; becherförmig, schalcnformig (all.) (acclabulum, gobelet, forma, forme) ; qui est excavé en forme de coupe, de gobelet, ou de ACÉTATE, s. m., acelas (acetum, vinaigre). Gemre de sels (essigsaurc Salze, all.) qui sont formés par la lembinaison dc l'acide acétique avec les bases salifables.

ACÉTÉ, adj., acelosus (acetum, vinaigre). Aigrelet, acidule, converti en vinaigre.

ACÉTEux, adj., acelosus ; cssigartig (all.); acclous (angl.); acetoso (it.) (acelum, vinaigre). Ic vinaigre distillé a ćlé appclé acide acćteux jusqu'au moment ou Adet d'abord et n'cstacq ensuite, ont prouvé qu'il n'cst pas moins oxigénć que lc vinaigre dit radical. La formentation acćlcuse est celle par laquelle de l'ncide acétique se produit dans une liqueuralcoolique, en verlnd'une transacctction qu'éproure l'alcool. Le mot accictix est quelquefois employé, nistes, quand ine d'acide, par les bolavégétal quand ils veulent désigner un prononcée Pelargonium (ex. Rumcx acetosa, tosella, Eum acetosum, Oxalis aceAcÉTIfrgcnia acetosans).

tio (acelum, vilon, s. f., acelificaOpération chiniagre, foo, etrc fait). quellc sc forme lue uaturelle par laACÉTRQ⿻上丨 l'acide acétique. tum, vinaigre) adj., acclicus (ace(Essigsïure, all.) Lacide acćtiqne la base du vinaigre. L'éther aeétique (Essigüther, all.), découvert par Lauraguais en 1759 , se produit quand on distille ensemble de l'alcool et de l'acide acétiquıe.

ACliTrTF, s.m., acetis (acetnm, vinaigre). Nom donnć aux acétates, quand on adınettait deux degrés d'oxidation del'acide du vinaigre.

ACĹTOSLLLÉES, adj. ct s. f. pl., Acetosella. Nom donné par Candolle à une section du genre Oxalis, comprenant les espices qui se rapprochent de l'Oxalis acetosella.

ACHALNE, s. m., achaina, achana, achena, achenizm, acenium; Schalenfrucht (all.) ( $\alpha$ priv., zaivw, s'ouvrir). C.-L. Richard appelait ainsi un fruit monosperme, ordinairement sec, dont le péricarpe est distinct du tégument propre de lngraine (ex.Synanthérćes, Dipsacées). Agardh conscrve le nom et la détinition, en faisant observer que l'achaine des Synanthérécs, par excmplc, cst le résullat du dévcloppement d'une seule des trois carpelles clont se compose originairement le fruit des plantes de celte famille.

ACILASGOPIYTE, s. m., achascophytum (a priv., $\chi \dot{\alpha} \sigma \% \omega$, s'ouvrir, ouróv, plante). Nom donnć par Necker a ux plantes qui ont des fruits indéhiscens.

ACHúmine, s. f. , acheiria ( $\alpha$ priv., $\chi$ sip, main). Nom donné par Breschet à un genre de déviation organique, ou d'agénésic partielle, qui est caractérisé par l'absence des mains. ACHìn. Voyez Achuine.

ACILIODE, s. m. , achenodium; Schalenfruchthranz (all.). Agardh donne ce nom à un fruit composé de plusieurs achaines disposés sur le même plan, et qui résulte de ce quaucune des earpclles primitives de l'ovaire n'a avorté (ex. Ombellifères). Voyez Poracuaine.

ACInÉTipes, adj. et s. mi. pl., 
Achetidec. Leach appelle ainsi une famille d'insectes orthoptères, ayant pour type le genre Achcta.

Acrirlútés, adj. et s. f. pl., Achillcce. Nom donné par Jussieu à un groupe qu'il admet dans la famille des Corymbiferes, et qui a pour type le genre Achillea.

ICUROMATIQUE, adj. , achromaticus; unfarbig , farbenlos (all.) (a priv., ypoinus, couleur); qui ne doune pas lieu an $x$ cnuleurs du spectre solaire. Se dit, en physique, d'un prisme qui dévic la lumière sans développer de cuuleurs; d'rue lentille qui forme en son foyer une image incolore des oljets; d'une lunctıc, qui fait voir les images des objets neltement terminées et sans aucune frange de coulcurs empruntées.

ACHROMLTISWE, s. m. , achromatismus ; Farbcnlosigkeit (all.) ( $\alpha$ priv., zpoupes, couleur). Destruetion des conleurs étrangères qu'on apereoit dans l'irnage d'un oljet quand on le regarde à travers un prisme ou un verre lentieulaire. Cettc destruetion, qui s'obtient en superposant deux corps d'une faculté dispersive différente, ne peut jamais être parfaite, parce que nul corps ne jouit d'une même faculté dispersive pour tous les rayons colorés; mais on peut achromatiscr par rapport ì deux couleurs, et alors on prend ordinairement les extrêmes, comme, le rouge et le violet oule bleu, parec que les petites aberrations qui exislent eneore dans les rayons intermédiaires snrt, en quelque sorte, eouvertes par la coüncidenee parfaile des extrèmes.

ACIInOPHYTy, s. m., achyroplytum ("xuosv, paille, gusc่, plaute). Noin donné par Necker anx plantes dont la leur se compose de glumes ou de paillettes.

ACICULAIRE, adj. , acicularis ; radelförmig (all.) ; aghiforme, agalo (it.) (acus, aiguille); qui est dur, étroit, fort aigu, et peu ou point anguleux. Se dit: $1^{\circ}$ en minérnlogie, d'un cristal tirant son origine d'un prisme qui s'est anuirei et allongé en forme d'aiguille (ex. Barytc sulfalic aciculaire); $2^{\prime}$ en hotanique, d'une fenille allongée, menue, raide ct piquante (cx. Dillwynia acicularis, Podolobium aciculare); d'unc ćpint grêle, allongée et puintuc (ex. Cactus coccellinifer); d'un filct d'étamine ou d'un stylc; d'une mousst dont l'npercule se termine en pointe (ex. Bryzum aciculare).

ACICULE, s. m. , aciculus (acts, aiguille). Nom donué par Saviguy ì des soics plus grosses que les antres et fort aiguës, qu'on observe, au nombre de deux, sur les rames des pieds situés aux côtés du corps de plusieurs Annelides.

ACICuLÉ, adj., aciculatus, aciculinus (acus, aiguille). En forme d'aiguille. Se dit: $1^{\circ}$ en botanique, d'une grainc (nadelgestrcift, nadelstrcifig, nll.) dont la surfaec est marquée de raies fines et sans ordre, qui scmblent avoir élé faites avec la pointe d'une aiguille; $2^{\circ}$ en zoologic, d'une coquills dont la forme géné rale se rapproehe de celle d'une aiguille (ex.Tercbra aciculina), on dont lin spire est terminéc en une queue longue et grêle(ex. Fusus aciculatus, Textularia aciculata).

ACICU.IFORHE, adj., aciculifor mis (aciculus, niguille, forma, for me); qui a la fortne d'une aiguille, counme l'opereule du Mracromitrium aciculare.

ACIDE, adj. , acidus; saucr (all.); sour (angl.); acido (it.) (äkı, pointe); qui jouit des proprićtés des acides, qui a une saveur aigre. Sc dit : $1^{\circ} \mathrm{ct}^{1}$ chimie, d'un oxisel qui coutient plus d'acide qu'il n'en faut pour saturt? lit base, ct danslequel le poids atomique de l'acide est multiple par un, un et demi, deux, trois ou dayantage, 


\section{ACID}

de celui de la base, soit que l'acide préllomine récllement pour les sens (ex. Bisulfatc polassique), soit que le sel soit tout-à-fait neutre, ou mème alcalin, lorsque le pouvoir ćlectrique de la base surpasse de beaucoup celui de l'acide (cx. Bisulfatc animonique). Berzelius donne aussi 'épilhète d'acidcs aux scls haloüdes, lorsque le sel nculre qui en fait la base se combinc avec l'hydracide du corps halogène qu'il contient, dc manière à produire un sel susceptible atix sulfarer sous forme solide, et tion sulfosels contenant une proporcelle définic de sulfide stpéricure à sidér qui existe dans le mêrne sel conducté comme neutre. Arant l'introlestion de la thćorie atomistique, Bchimisles appeliient acidcs, avec rerthollet, les sols seulement qui lesensd à la manière des acides sur végés du goûl el sur les couleurs blcues celte épites. $2^{\circ}$ En botunique, on donne une épithete à des plantes qui ont da, Limonia acide (ex. Ambclania acidescens Limia acidissima, Boletus aciAcriv. Voycz Acéteux).

acid(ane, s. m. acidum; Säure (all.); a successi. acido (it.). En climic, on bord tous les appelé ainsi : d'asaveur ais les composés qui ont unc sol, puis scul rougissent le tourneou oxidés quilenent les corps brûlés propriétés qui jouissent de ees deux dent la es, ensuite ceux qui possèceux qui, n'acre an moins, plus tard sont qui, n'ayant ni l'une ni l'autre, enfin ceax qui de saturer les bases, ces propriétés, n'ayant ancune de non plus d's, el ne contenant pis moins les bases exènc, dérruiscnt au les constituent dans les qualités qui cent la plupart du tes, mais commencomposer. Il suit temps par les détat actuel de lat de là que, dans l'ćdonner de la chimic, on ne saurait acide, qui duition générale du mot qui lui - même n'est propre qu'ì embrouiller les idées. La propriété de jouer le rôle d'acide ne tient ui à la substance à laqucllc on est obligé de l'altribuer pour s'entendre, ni à la manière dont la combinaison s'effectue. Elle iudique seulement un étal contraire à la propriété d'être basc, e'est-à-dire, comme cette dernière, une chose purement relative. Il est benucoup de corps appelés acides, qui nc manifesteut cetle propriété qu'à l'égard de certaines bases, et quelques uns même jouent lc rôle Iantôt de basc et tantốt d'acide, suivant les substances avec lesquelles on les met en contact.

ACIDES, s. m. pl., Acidi, Acida. Ce nom géuérique a été donué : $1^{\circ} \mathrm{en}$ minéralogic, à un ordre de substances minérales, par Haüy et par Hausmann ; $2^{\circ}$ el géognosie, à unc série de formations, par Brongniart. Tous ces groupes renferment les oxacides, en pelit nombre, qu'on trouve actucllement libres ì la surface de la terre.

ACIDIFERE, adj - acidiferus; sauer. tragend (all.); acidiferous (angl.) (acidum, acide, fcro, porter); qui conlicnt un acide quelconque. Iaiiy appclait substanees acidiferes une grande classe de miuéraux, compremant ceux qui sont composés d'une base salifiable unie it un acide. Un ordre do roches portc également ce nom dans la classification géognostique de Maraschini.

ACIDTFIBDIE, adj. süucrungsfïhig (all.) (acidum, acide, fio, être fait); qui est susecptible de se convertir en acide par sa combinaison avec telle ou telle autre substance, avec telle ou tellc proportion de cetle substance.

ACHDHIANT, adj. , acidificus; saucrmachend (all.) (acidun, acide, fio, être fait); qui a la propriétć de convertir en acide. Naguères encore on dounail celte épithète à plusieurs principes qu'on supposait être la sour- 
ce ou la cause des propriétés acides que manifestent en quelques circonstances leurs combinaisons avec certains autres principes. Elle ne fut accordće d'abord qu'à l'oxigène : on l'étendit cnsuite à l'hydrogène, puis au séléniun et au tellure. Le chlore, le brome et l'iode y auraient droit, au même titre que ces derniers. On ne peut plus admettre de principes acidifians: lorsque deux ou plusicurs corps donnent naissance à un acide, en se combinant cusemble, chacun d'eux contribue pour sa partà la production du nouveau corps, dont l'acidité dépend d'ailleurs souvent de leurs proportions respectives, et des circonstances dans lesquelles lui-mème est appelé à réagir.

ACIDIYICATION, s. f, acidificatio; Säurung (all.) (acidum, acide, fio, etre fait). Conversion $\mathrm{cn}$ acide, passage à l'état d'acide.

ACIDIFrí, adj., qui est converti en acide.

ACrDITĹ, s. f., aciditas , acor; Säure(all.); sourness (angl.); acidczza (it.). Dans le langage vulgaire, ce mot indique la qualité d'une substance qui est douéc d'vne saveur aigre ct piquantc. En chimie, il exprime aujourd'lui celle de détruire les propriétés earactéristiques des bascs dans les composés qui en sont doués. ACIDO-IBASIQUE. Voyez Basigène.

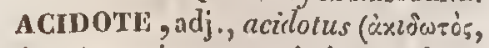
pointu); qui est terminé en pointe. L'Adelia acidoton est ainsi appelé parce que ses rameaux sont épineux.

ACIDULE, adj. ct s. m., acidulus; süuerlich (all.); acidulous (angl.) ("̌*เs, pointc); qui jouit d'une faible acidité. On appelle $1^{\circ}$ en gréognosie, eaux acidules, celles qui tiennent cu dissolution de l'acide carbonique libre $; 2^{\circ}$ en chimic, sels acidules, ceux. dans lesquels la quantité d'acide, reJativement à celle de base, dópassc le terme qui constitue l'élat neutre ou de saturation (voy. AcIDE.). $3^{\circ} \mathrm{En}$ botanique, plantes acidules, celles qui sont douées d'une saveur aigrelette (ex. Pemplis acidula). $V$. AcÉreux, ACIDE.

ACIDULE, adj, , acidulatus; qui a acquis des propricités légèrement acides, ou une saveur aigrclette, par l'addition ou la manifestation d'un acide.

Acrération, s. f. , chalybcatio. Opération par laquellc se produit l'acier; formation clle-même de ce composé.

ACrínÉ, adj., chalybeius. Épithète qu'on donne au fer, quand il a été converti en acier.

ACIĹREUX, adj. Sedit quel quefois du fer, quand il a reçu le caractère de l'acier.

ACIFORME, adj., aciformis (acus, aiguille, forma, forme); qui a la forme d'une aiguille, comme l'oper culc du Racomitrium aciculare.

ACRMCIFOLIÉ, adj. , acinacifolius; siibelblïttrig (all.) (acinaces, sar bre, folum, feuille); qui a des fcuilles acinaciformes. Ex. Conosper mum acinacifolizen.

ACINACHFORME, adj, , acinacifor mis; säbclformig (all.); coltclliform (it.) (acinaccs, sabre, forma, forme) en forme de sabre. Se dit, en lotanique, des feuilles, quand elles son! charnues ct aplaties de manic̀re présenter deux bords, l'un épais $e^{\prime}$ obtus, l'autre mince, très-haut d reeourbć en arrière (cx. Dimcri acinaciformis, Mesembryanthemin acinaciformc); des lígrumes, lors qu'ils offrent la même figure ( $c^{\text {s }}$ Phascolus lunatus). $V$. Evsirolit. ACINAIRE, adj., acinarius (aci nuts, grain de raisin) ; qui présente, ${ }^{16}$ long de sa tige et de ses rameaus dc pctites vésicules sphériques et $p_{d}$ diculces, semblables à des grains raisin. Ex. Fucus acinarius.

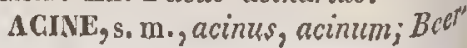


chen (all.); acino (it.). Nom donné par Gaertner it une baic molle, uniloculaire, transparente, pleine de sues, et renfermant des graines eouvertes d'une écorce coriace. Ex. Vitis vinifera.

AGINEUx, adj., acinosus (acinus, grain de raisin); qui est arrondi, en lorme de grain de raisin. Ex. Vor ticella acinosa.

ACNODENDRE, adj., acinodcn-

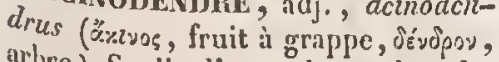
arbre). Se dit d'une plante dont les fruits sont disposés en grappes. Ex. Melastome acinodendrum. ACIPHonéEs, adj. ets.f. pl., Aci-
phoreas ( $\dot{x} \times \dot{n}$, pointe, $\varphi \dot{e} \rho \omega$, porter). Nom donné par Rohinean-Desvoidy à une famille de l'ordre des Myodaires, comprenant celles dont les femelles ont les derniers anneaux de l'aldomen solides et servint it introduire les oufs sous l'épiderme des
plantes.

ACHPULLE, adj., aciphyllus; $n a-$

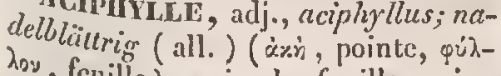
toy, fcuille); qui a des feuilles poinfues. Se dit d'une plante dont les (cx. Diant linéaires et acuminées ciniures Dianthus aciphyllus), ou les laLigu,strum desilles piquantes (ex. ACLum aciphylla).

Aclcidii Nom im ( a priv., *isis, clavicule). tion de l' par pesmarets à une secprenant l'nrdre des Rongeurs, comsont privés de ces mammifères qui ont que des de clavicules, ou qui n'en

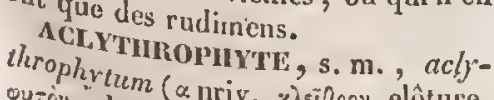

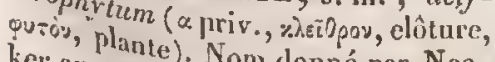
ker aux plantes . Nom donné par Necposait avoir les qui ont ou qu'il supAcoGILLDes graines à nud. Acochlides ( $\alpha$ priv. adj. et s. m. pl.,
quillc). Latreille et Menke co-
ainsi appellent ainsi uncfaıille et Menkc appellent phalopodes, dans laruelisse des Céecux de ces dans laquelle ils rangent I. pieds et qui sont dépourvus de eoquille.

Acoles, adj. et s. m. pl., Acola ( «ैxwhos, sans pieds). Nom donné par Latreilic ì une fansille de la classe des Elminthogames, comprenant eeux qui n'ont aueun appendice cxterne.

ACONITATE, s. m., aconitas. Sel formé par la combinaison de l'acide aconitique avce une base salifiable.

ACONITINE, s. f., aconitina. Al. caloïde que Brandes et Peschier disentavoir trouvé dans les Aconitums Napcllus et Paniculatum, qui ne differce probablement pas de eelui que Pallas prétend avoir rencontré diuns la racine de l'Aconitum Lycoctonum, mais dont l'existence a besoin encorc d'être confirınée par de nouvelles recherelses.

ACONITIQUE, adj., aconiticus. Nom donné par Peschicr ì un acide particulier, dont il a annoneé l'existence daus l'aconit. Bennerscheidt a trouvé aussi de l'acide aconitique dans le sue de l'Aconitum Stocrkianum.

ACorives, adj. et s. f. pl., Acorina. Nom donné par Link à la famille de plantes plus génćralement connue sons celui d'Aroïdócs.

ACORMOSE, adj. , acormosus ( $\alpha$ priv., cormus, tige). Willdenow don.. nait cette épithçte aux plantes dont les fcuilles et fleurs partent immćdiatement de la racine. Ex. Colchicam autumnalc.

ACOTrÉ́DON, adj , acotyledontes; saumenlappcnlos (all.); acotylcdone (ii.) (a priv., xosulingósy, colylédon)." Ce nom fut d'abord donné anx plantes qui, n'ayant pas de véritable entbryon, sont par conséquent dépourvues de cotylédons. Il était alors synonyine de cryptogame. Depuis il at été reconnu que certaines plantes $\mathrm{cm}$ bryonnées manquent de cotyledons (ex. Tropoenlum, Cuscula, Lecythis, 
Orobanche). C'est à celles-là que Fries réserve l'épithc̀te d'acotylédo$n c s$, donnant le nom de nćmécnnes ou évasculaires aux eryptogames qui l'avaient portéc jusqu'alors et que Candolle appelle cellulaires.

ACOTYLlidoví, adj. , acotyledoncus; saamenlappenlos (all.) ( « priv.,

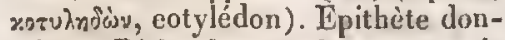
nće par Riehard aux embryons, quels qu'ils soient, qui n'ont pas de cotylédons, et reservće par Fries aux seuls végétaux vasculaires dont l'embryon est dépourvu de ces organes. A CotrLíivonis, adj. et s. ff. pl., Acotyledones, Acotyledonea. Classe du règne végétal, dans la inéthode de Jussieu, et division du même règne, dans celle d'A gardh, qui comprennent les plantes sans cotylédons, ì l'cxelusion des vasenlaires en petit nombre qu'on a déeouvert depuis être dans le mềme cas.

ACOTYLÉvONIE, s. f., acoty ledonia ( $\alpha$ priv., yorulnjís, cotylédon). Classe du systène lin néen modifié par Richard, qui comprend les végétnux cellulaires, ou némécns, ou eryptogames, ceu $x$ ehez lesquels on n'observe point de cotylédons.

ACOTrLES, adj. et s.m.pl., Acotyla ( $\alpha$ priv., xorvilin, envité). Nom donné par Latreille à une famille de la classe des Aealèjhes, comprenant ceux de ces animaux qui n'ont ni bouche centrale, ni eavités latérales.

A COUvitre, s. m., acoumelrum (àrov́w, entendre, $\mu \varepsilon \tau$ š́s, mesurer). Instrument inagrinc par ftard pour mesurcr l'élendue du sens de l'ouïe chez l'homme.

ncoustroue, s. f., acustica; Alizstik(all.); acoustics (ungl.) (dxoviw, entendre). Branche de la physique qui recherche les lois suivant lesquelles le son se produit et se transmet à nos organes.

ACOUSTIQUE, adj. , acusticus ; àxovsтเxós; akuslisch (all,); acouslick

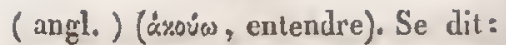
$\mathrm{r}^{0}$ en physique, d'un phénomc̀ne qui est relatif à la production ou à la propagation du son ; $2^{\circ}$ en physiologic, d'un orçane ou d'un appareil destiné à reeueillir les sons, à les rendre sen. sibles pour les auimaux doués du sens de l'ouie.

ACRANIE, s. f., acrania (« priv. , xprvio\%, crânc). Ábsenee totale ou partielle du crâne.

ACBE, adj., acer; scharf, beisscnd (all.); sharp (angl.); acro (it.) ("̋xpos, sommet). Se dit d'une saveur désngrćable, mordante, brûlante, presque caustique, et par extension de toute substance qui possc̀de uue saveur de ce genre. Ex. Ranunculus acris.

ACRÉmovires, adj. et s. m. pl.; Acrcmonii. Nom donné par Fries à une tribu de l'ordre des Conionycetes Mucorins, gui a pour type le genve Acrenionirm.

ACRetÉ, s. f. , acritas ; Schärfo (all.); sharpness (angl.); agrczza (it). Proprićté dont jouissent ecrtaines substances, végétales surtout, d'cxercer sur la langue l'action désagréable qui constitue la savcur âcre, et qui dépend soit d'une huile essentielle (ex. anćmone, crucifìres), ou d'un acide volatil (ex. noix vomique), soit d'un alcaloïle volatil (ex. daphne, tabae), ou, le plus sonvent, d'un principe qu'on n'est point encore parvenu à isoler.

ACnIDIEvs, adj. et s. m. pl., Acridii, Acridics. Famille d'iusectes orthoptères, achnise par Latreille, Goldfuss, Eichwald, Ficiuns et Carus, qui a pour type le genre Acridium.

ACHIDOPIIAE, adj., acridopha-

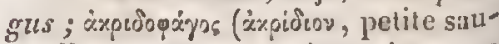
tcrelle, фxंyos, manger); qui mange des sauterelles, qui en fait sa nourriture.

$\Lambda$ CRITES, adj. et s. m. pl., Acrila (äxprтos, eonfus). Nom donuć pat 


\section{ACRO}

Macleay à une division du règne animal, comprenaut les infusoires, les polypes ct une partie des vers intestinaux, parce qu'il y règne encorc une grande confusion.

ACROB APTE, adj. , acrobaptus (axpos, soinmet, fartos, teint). Asilus acrobapius porte unc tache runc ì l'extrémité de ses ailes.

ACROCARPES, adj. et s. f. plur., Acrocarpi ("̈̌pos, sommet, 火aprò̀ fruit). Nom donnc par Bridel à unc classe de mousses, comprenanl cclles de ces plantes qui ont la fructification terminiale.

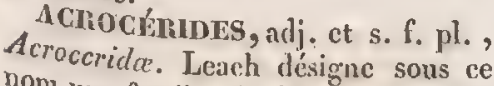
nom une famille de l'ordre des Diptères, dans laquclle il range ceux do le insectes qui ont du rapport avee genre Acrocera. :

ACRONACTYLE, s. m., acrodacty. lum; Zehcurikkcn (all.) ("̈upos, som-

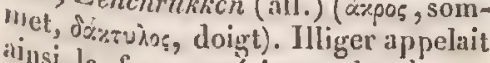
ajusi la face supérieure de chaque doigt chez les oiscaux.

ACROGLNE, adjeet., acrogenus ("x:pos, sommet, yะvขx́w, produire). Epithètc clonnée, dans la nomenclature minéralogique de IIaüy, ì un des qui dérive d'un rhomboïle par les becroissemens sur les angles et Uonatée acrérieurs. Ex. Chaux carA Cre acrogène.

Acrogrataes, adj.et s. f. plur., rond). Nom ("xpos, sommet, qupos, fougères dou donné par Bernhardi aux au sominet les fruits sont pourvus ACrionet d'une faussc roue. donnait cette adj., acronus. Necker ne s'élargissent épithète aux ovaires qui manière à formt point à la basc, dc que plus ou moin une espèce de disa Crovyoue charuu. (*apos, sommet, ", adj., acronychizs recourbé in lot, öv है, ongle); qui est commeles pét manière des ongles, nychia.
ACRONYQUE, adj., acronyctus; àxpóvvжros; alironylitisch (all.) (äxpos, somnet, v่乡 , nuit). Se dit, en astronomic, du lever des astres, quand il a lieu au coucher du soleil; de leur coucher, quand il coïncide avce le lever du soleil ; d'une étoile ou d'une planćle, lorsqu'elle est du côtć du cicl opposé à celui où sc trouve le soleil.

ACROPODE, s. m., acropodium; Fussrïcken (all.) (äxpos, sommet, noũs, pied). Nom donné par Illiger au côté supérieur du pied entier des oiscanx.

AGROSARQUE, s. m., acrosarcum

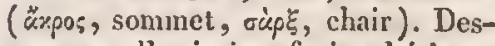
vaux appelle uinsi un frait sphérique, charmu et soudć avee le calice, qui souvent le couronne. Ex. Ribes rubrum.

ACROSRIRE, s. f., acrospira ( $\%$ -

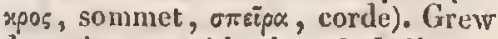
donnait ce nom à la plumule de l'orge, développée par la germination, en raison de sa forme et de sa situation.

ACROTARSE, s. m., acrotarsium;

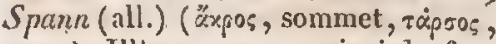
tarse). Illiger nomme ainsi la face antérieure de la patte des oiseaux, depuis le pli du pied jusqu'au genou.

ACRotenes, s. m. pl. , acroteria; ¿xpoтripta. Mot fort peu usité, qui exprime les extrémités du corps, la tête, les mains et les pieds.

ACTE, s. m., actus; That, Handlurg, $W_{\text {crk (all.); act (angl.) ; atto }}$ (it.) (ago, faire). Produit d'une action quciconque.

ACTIE, adj., activus; thätig (all.); active (angl.); attivo (it.) (ago, faire); qui exerce unc action, qui agit d'une manière vive et prononcér?

ICTINENGIINE, s. m., actinen-

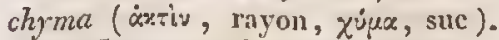
F. G. Hayne appelle ainsi le tissu celIulaire des végétaux, lorsqu'il est disposé sous la forme de rayous. 
ACTINIAIRES, adj. et s. m. plur., Actiniaria. Lamouroux donne ce nom à un ordrc de polypiers sarcoïdes, paree que eenx qui le constituent ont beaucoup de ressemblanee avee les Actinies, pour la forme.

ACTINIENS, adj. et s. m. pl., Actiniani. Nom donné par Blainville à une famille de la elasse des Zonnthaires, renfermant ceux de ces animaux qui ont le eorps mou ou con tractile dans tous ses points, et ayant pour type le genre Actinia.

ACTINIES, s.f. pl.,Actinice. Nom d'un ordre, suivant Goldfuss, d'une famille, selon Fieinus et Carus, de la classe des Radiaires, d'une famille de la classe des Cyelozoaires, d'après Eichwald, dont le genre Actinia est le type.

ACTINIFORHE, adj., actiniformis (áxriv, rayon, forma, formc) ; qui a une forme rayonnée. Quelques zoologistes disent animal actiniforme pour auimal rayonné (cx. Dendroplyyllia ranca). F. G. Hayne appclle tissu acliniforme, une modification du tissu ecllulaire végétal, résultant de l'agglomćration de cellules qui se réunissent par leurs parties latérales, et partent de la moelle pour se rendre en rayonnant à l'écorce, dans les plantes dicotylédones.

ACTINOCARPE, adj., actinocarpus (axriy, rayon, expros, fruit). G. Allmann donne cette épithète nux plantes qui ont les trophospermes on les ailes du trophosperne disposés comme les rayons du fruit.

ACTINonónines, adj. et s. m.

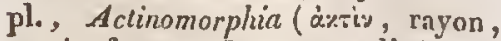

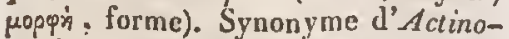
zoaires, cmployé pir Blainville, alin de désigner un sous-règne du règne animal, comprcnant des animaux qui ont une forme cireulnire et rayonuée, ¿ peu près comme les fleurs des végé$\tan x$.

ACTINOSTO.uE, adj., actinoslo-

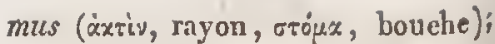
qui a la bouche rayonnée: Le $Y$ errucaria actinostoma a ses ostioles "garnies d'une poussière blanche disposée en rayons.

AcTivostomes, adj. et s, m. pl., Actinostomata (áxrì, rayon,

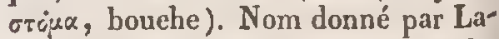
treillc à un ordre de la classe des Hélianthoïdes, comprenant des animaux dont la bouche est entourée de rajons qui portent des tentacules.

A CTINOTEuX, adj. Se dit, en géognosie, d'une roehe qui contient de l'aetinote disséminé. Ex. Leptynite actinotcux, Amphibole actinotique.

ACTNotiQue, adj. Synonyme d'actinoteux. Voycz ee mot.

ACTINOzOAIIES, adj, et s. n.

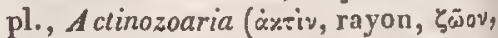
animal). Nom donné par Blainville à un type du regne animal, comprenant les animaux dont le corps régulier offre constamment une disposition rayonnée, soit en lui-nıc̀me, soit dans les organes de nature différente dont il peut être pourvu.

ACTINOzoÉs, s.m. pl., Actino-

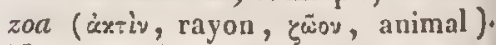
Nom donné par Latieille à un embranchement du règne animal, dan lequel il range les Aećphales gastriques qui ont les appendices du corp et souvent aussi les divisions ou aircs de sa surface rayonnés.

ACTION, s. f. , actio; Handlung (all.); action (angl.); azione (it.) (ago, faire). Manière quelcouque dont un eorps influe sensiblement sut un autre; effort que fait un corp pour mettre un autre corps en mou vement.

ACTIVITÉ, s. f., activitas; ¿̇vép

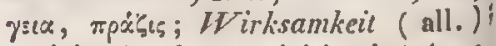
activity (angl.); attivitì (it.) (ago! faire). Faculté d'agir ou d'entrer et action; vivacilé, promptitude dan' l'action.

ACUITh, s. f., aculeness (angl.). 


\section{ACUT}

Se dit du son', en physique, pour exprimer le caractère qui le constitue à l'état aigu.

ACULÉIF ORME, adj. , aculeiformis ; stachclförmigr (all.) (aculeus, aiguillon, forma, figure); qui a la forme d'un aiguillon. Se dit, en zoologie, des écaill es de certains poissons, qui ont la forme de pointes recourbées (ex. Diodon Atinga); des tubercules qui garnissent diverses coquilles, de eqquilles mèmes qui sont minces et à spire très-pointue (ex. Fusus aculeiformis); enfin, d'apres Kirby, de a la forte des Hyménoptères, qui $d^{\prime}$ un forme et remplit les fonetions

a aiguillon.

ACUMINÉ, adj., acuminatn.s; $z u-$ spitzt (ang , langcspitzt, langzugcaiguill (all.); aruzzo (it.) (acumcn, et minn). Terminé en pointe longue des ferill Se dit : $1^{\circ}$ en botanique, avanterilles dont les deux bords, direction se joindre, changent de du point, et se prolongent au delà leur point où ils se seraient rúunis si (ex. direction n'avait pas changé $2^{\circ}$ en Sciodaphyllum acuminalum ; quand ellogie, des ailes des insectes, aiguë elles finissent en uno pointe Acuritongée.

(acunien LUX, adj., actuminosus quelquefois pointe). Epithète donníe prolonge à une sommitć qui se ACUM en pointe peu aignë.

rus (acum IIIE, adj., acuminifcSe dit, amen, aiguillon, fero, porter). le corps zoologic, d'un animal dont pointus. porte de pretits tubercules $\Lambda$ CuMr. Caprilla acuminifera. lius (acumentÉ, adj., acrminifofeuille). Epith, aiguillon, folirm, tes dont les fcuille donnée à des plan$\mathrm{Ex}$. Sperner.

AcUtravera acuminifolia.

spitzwinkelis , adj., acutangulus; (angl.); actig (all); acurangular aigu, angulusgulo (it.) (aculus,

donnée, dans la nomenclature minéralogique de Haüy, à un prisme hexië:Ire dont les angles solides sont interceptès par des facettes triangulaires très-aiguës. Ex. Chaux carbo natée acutangle.

ACUTANGULf, adj., acutangzulus, acutangulatus, acutc angulatus; scharfeckig, scharfkantig (all.); qui a des angles aigus. Se dit, en botanique, d'une lige offrant des angles, en nombre déterminé, qui sout tranchans (ex. Carex vulpina), des feuilles qui sont partagées en plusieurs lobes aigus (ex. Lysianthus acutangulus, Dombcya acutangula, Sisymbrium acutangulum), des fruits qui sont chargés d'angles tranchans sur leur longueur (ex.Cucumis acutangulus).

ACUTICAUDĹ, adj., aculicaudatus (acutus, aigu, cauda, queue). Se dit, en zoologic, d'un mammifere qui a la queue pointue (ex. Molossus acuticauda(ns), ou d'un oisenu qui a les plumes caudales étagées de manière que sa queue finisse cn pointe (ex. Psitlacus acuticaudatus).

ACUTICOSTŔ, adj., acuticostatus, acuticoslus (acutus, aigu, cosla, côte). Se dit, en zoologie, d'une eoquille dont la superfieie est cbargée de côtes aiguiës. Ex. Pccten acuticosta.

ACUTIFLONE, adj., acutiflorus ; spitzblüthig (all.) (acutus, aigu, flora, fleur). Se dit, en botanique, d'une plante qui a les lobes de sa eorolle aigus (ex. Mussaendca acutiflora), ou ses pétales terminés en pointe (ex. Unctia acutiflora), ou les segmens de sa corolle terminés en pointe aiguë au sonmet ( $\mathrm{ex}$. $\mathrm{Cu}$ vicra acutiflora), ou ses fleurs disposées en épillcts rudes au toueher, à causc des pointes qui garnissent les valves de ehacuuc (ex. Eragrostis acutiflora).

ACUTIFOLIÉ, adj., acutifolius; spilzisblättrig, stachelblütrig (all.) 
(acutus; aigu, folium, feuille). Epithète donnce à des plantes qui ont leurs fenilles acuminées. Ex. Scorpiurus acutifolius, Cassia acutifolia, Orthotrichutm acutifolium.

ACUTILOB :, adj, , acutilobus (acutus, aigu, lobus, Jobe). Se dit, en botauique, d'une plante dont les lobes des feuilles sont aigus. Ex. Thalictrum acutifolizm, Linaria aculiloba.

ACUTIPENNE, adj., aculipennis (acutus, aigu, penna, plime). Se dit, en zoologie, d'un oiseau dont les pennes de la queuc sont trèspointues et étagées. Ex. Trochilus caudacutus.

ACUTrRostRÉ, adj., acutirostralus (aculus, aign, rostrun, bec). Se dit, en zoologie, d'un animal qui a les mâchoires prolongées en un bec pointu. Ex. Balcinoptera acutirostrata.

ACUTO-LPINEUX, adj., acuto-spinosús. Epithète donnéc par les entomologistes à des chenilles qui ont sur le corps plusieurs rangécs d'épines niguës et rameuses, comme celles du papillon Vancsse.

ADACTYLE, adj , adactylus; fin-

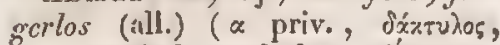
doigt); qui n'a pas de doigts. Ípitheté donnćc ì un crustacé dont les pattes antérieures sont dépourvues de pinee. Ex. Hippia adactyla.

ADAMLNTIN, adj., adamantinus ('ódxuxs, diamant); qui a la dureté ou l'éclat du diamant. On donnait jadis le riom de spath adamantin a une variété de corindon, parec qu'on eroyait, à tort, la poudre de ce minéral capable d'user le diamant. Iues minéralogistes appellent éclat adamantin celui qui, ayant beaucoup de vivacité, se rapproche de celui d'une lame d'aeicr poli, ì mesure qu'on inclinc lc corps sous un certain aspeet, jusqu'à ce que la force de réflexion ait atteint sou maximum, et cette épithète vient de ce que le diamant poli offre le type de cet effet de lumic̀re.

ADAMrouE, adj., adamicus. Nom donné par Bory à une race primitive de l'espìce humaine, qu'il suppose originaire de l'Abyssinic, où, par son interprétation des récits mosaïques, il place le berecan d'Adam.

ADDITIF, adj., additivis (addo, ajouter). Epithète donnée, dans la nomenclature minéralogique $\mathrm{dc}$ Haiiy, à un cristal dans le signe duquel un des exposans est plus grand d'une unitć que la somme des antres exposans. Ex. Corindon addirif.

ADDITIONNux, adj., addititits. Brochant appelle formes adlditionnet les d'un cristal, celles qui sont les plus petites, parce que leur présencc n'alıcre pas sensiblement la forme générale.

ADDUGTEUR, adj., adductor (ad, vers, duco, conduire); qui aınènc. Hedwig appelait vaisscaux addnc" tcurs des filamens très-déliés qui sout unêlés aux séminules dans les urnes des mousses et les capsules des hépa tiques.

ADDUCTrox, s. f., adductio; $A n^{-}$ ziehen (all.); adducing (angl.) (ad, vers, duco, conduire). Action de rapprocher un membre de l'axe du corps, ou une partie d'un membre di l'axe de ec dernier.

ADÉLOBRANCIES, adj. et s. m. pl., Adclobranchiata (üồnios, caché,

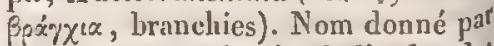
Duméril à une famille de l'ordre des Gastéropodes, par G. Fischer, ì une scetion de ce même ordre, et $\mathrm{p}^{\mathrm{a}^{5}}$ $\mathrm{G}$. IJartmanu, à un ordre de la classe des Gastíropodes, coupes comprenant? toules des Mollnsques dont les hran chies ne sout point visibles a l'exté ricur.

IDĹLODERMES, adj. ct s. m. pl-1

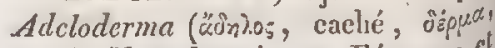
peau). Nom donné, par Fćrussac 


\section{ADÉN}

Menke, à un sous-ordre de la classe des Gastéropodes, eomprenant eeux dont les branchies ne s'aperçoivent point ì l'cextérieur du eorps.

ADĹLOGÉvE, adj., adclogenus

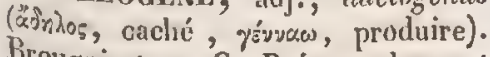
Broligniart et 'C. Prévost donnent ectle ćpithète aux roehes qui paraissent composées d'une seule sulstance, résultat d'un mélange de parties $\mathrm{cx}$ trêmement fines, n'offrant point les caractères positif' d'un minéral connu, de sorte que leur composition se dérolse en quelque sorte à l'oil.

ADÉLOPNEUMONES, adj.ct s. m.,

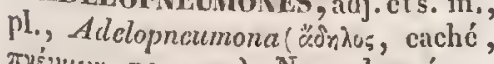

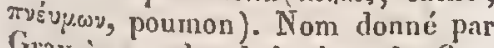
Gray ì un ordre de la classe des Gastćropodes, comprenant ccux qui respirent par des branchies aériennes cachées dans l'intérieur du corps.

ADELPIIE, adj., adclphus, adel-

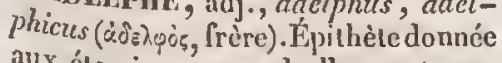
aux élamines, quand clles sont soudées par leurs filets en un ou plusieurs corps, dont ebaeun sert de soutien à plusieurs anthères.

ADELLPIIF, s. f., adclphia (àōèpòs, frère). Se dit, en botanique, de la réunion des élamines par leurs filets, quand on la eonsidère d'une manière générale.

ADELPIIQUE. Voyez ADELPITE. ADENANTHE, adj., adenanthus

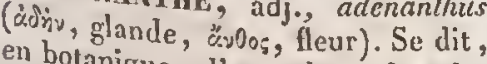
pédiconique, d'une plante dont les nes glandulssent de la base d'organanthus. AD

(ádì, glacALYCY, adj, , adcnocaly $x$ en botanique, rex'y calice est parse, d'une plante dont le leux. Ex. Eursé de points glanduAblex Eurenia adenocalyx. (ádin, glande, doméc plande, pépw, porter). Epithète plante qui porte botanistes à une qu'uae de ses parties; par exemple
qua

\section{ADHÉ}

sur ses capsules, eomme le Polygala adenophora.

ADENOPIYLLE, adj., adcnophyl-

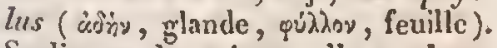
Se dit, en hotanique, d'une plante dont les feuilles sout hérissées de glandes sur leur face inféricure (ex. Rogeria adenoplyylla), ou parsemćes de points glanduleux, soit en dessous (ex. Polygonum adenophyllum), soit en dessus (ex. Rosa acterophylla).

ADÉrophulless, adj. et s. f. pl., Adenophyllea. Nom donné par Candolle à un groupe d'Oxalis, eomprenaut les espèces qui portent de petits tulercules globuleux au sonmet des fenilles.

ADĹTOPODE, adj., addenopodus

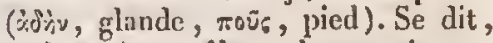
en lotanique, d'une plante qui porte des glandes sur ses pétioles. Ex. Pas. sifora arlenopola.

ADGXOSTÉMONE, adj., adcnosto-

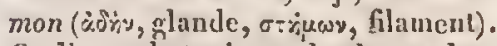
Se dit, en botanique, de plantes dont les filets des étarnines portent des glandes. Ex, MIacairca adcnostemon.

ADÉnostilúes, adj. et s. f. pl.,

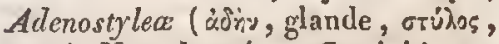
style). Nom douné par Cassini à une trilu de la famille des Synanthérées, qui a pour type le geure Adenostyles. ADÉPHAGES, adj. ct s. m. pl., Adephagi, Adephaga (ùơnqúryos, vorace). Nom donné par Clairville et par Eiehwald is une famille d'insectes Coléoplères, comprenant des espèees carnassic̀res et voraces.

ADFSMACÉs, adj. et s. m. pl., Ailesmaeca ( $x$ priv., oespuos, lien). Nom donné par Blainville à une famille de l'ordre des Aeéphalophores Lamellibranches, comprenant des espices dont la eoquille n'est point assc\%. grande pour couvrir tout le corps de l'animal, el dont le manteau est complètement fermé et tululenx.

aDmérexaE, s. f., adharentia, 


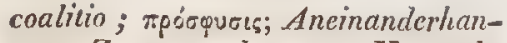
gen, Zusammenhangen, Vemvachsung (all.); adhcreney (angl.); appigliamento (it.) (ad, ì, hareo, tenir). On appclle ainsi : $\mathrm{I}^{\circ}$ en pliysiquc, l'union intime de dcux corps par leurs faccs, en vertu de l'at traction quc ces corps excrcent réciproquement l'un sur l'autre; $2^{\circ}$ en minéralogie, la manière dont les cristaux sont attachés à leur gangue ou à leur support; $3^{\circ}$ en botanique et en zoologie, l'union ou la soudure de parties qui originairement sont distinctes.

A DHÉRENT, adj., adharens ; nngewachsen, arhangend, anklebend (all.); adcrente (it.) (ad, à, hareo, tenir). Se dit, en lotamique et en zoologie, d'une partie quelconque d'un animal ou d'un végétal qui s'est réunie d'une manière plus ou moins intime avecles parties envirounantes. Amandc adherente, celle qui tient à l'enveloppe placće sur elle (ex. Graminées). Baie adhérente, celle qui fait corps avec le pćrianthe simple (cx. Musa paradisiaca), ou avec le calice (ex. Ribes rubrum). Calice adhérent, eclui qui est soudé avec la paroi extcrne de l'ovaire (cx. Synanthérées). Capsule adlićrente, celle qui fait corps alvee le calice (ex. Iris germanica), ou avec le pcrianthe simple (cx. Campanula arvensis), qui la recouvre entic̀renıent. Carcérule adhercnte, qui fait corps avec le périanthe (ex. Trapa natans). Diérésile adhérente (ex. Slierardia aryensis). Drupe adhércul (ex. Juglans regia). Induvie adhérente, qui fait corps avec lc fruit (ex. Basella). Máehoires adhéremtes, quand leurs bases sont réunies (cx. Phalangium). Nectaire adhérent, lorsque lc bord s'étend jusqu's̀ la surface de l'ovaire, et fait corps avec lui dans toute son étenduc (ex. Ruellia varians). Ovaire adhérene, qui, cnveloppé par le périauthe et faisant corps avee lui, est surmonté par. son limbe (ex. Iridées). Regmate adhérent, qui fait corps avec le ealice (ex. Phyliea crieoidles).

ADHĹSION; s.m., adhasio; Anhängung (all.); adesione (il.) (ad, ì, hareo, tenir). Force en vertu de laquelle s'opère le phénomène de l'adhérence; tendance de deux corps hétérogènes à s'attlachcr l'un à l'antre ; union plus ou moins intime que sont susceptibles de contracter entre eux, soit les corps solides mis en contact le plus exact possible, par des faces planes ct bien polies, soit les corps liquides ou mêne gazeux.

ADIANTIDÉES, adj. et s. f. pl., Adiantidece. Nom donné, par Kaulfuss, à une fimille de la tribu des $\mathrm{Po}_{0}$ lypodiacéss, comprenant les fougères qui ont pourtype le genre Adianturn.

ADLAPHANE, adj., adiaplianus (a priv., dixpavìs, transparent). Synonyme inusité de opaque. Voyez ce mot.

ADIPEXx, adj., adiposus; fettig , fellarlig (all.) (adeps, graisse); qui a les caractćres de la graisse, ou qui en admet duns sa composition : lissu adipeux, membrane adipeuse. Les ichiliyologistes appellent nageoires adipeuses, celles, remplies de graisse ct dépourrues de rayons osseux intéricurs, qui sont placées au voisinage de la queue, chez certains poissons (ex. Scomber seombrus).

ADIPIDE, s. f. (adeps, graisse). Fechner désigne sous ce nom une classe de principes immédiats des corps organisés qui, par leurs propriétés, se rapprochent des principes constituaus dcs graisses, comme l'ćthal, l'ambréine, la choléstćrine et la castorinc.

ADIPOCIne, s. f., adipoecra; Fetlwachs (all.) (adcps, graisse, ecra, cire). Mélange de plusieurs hydrates ct sels d'acides gras fixcs, qui se produit, soit par la déeomposition spon- 
tanée des corps gras (gras des cadal'act, gras des cimetieres), soit par base salion sur eux d'un acide, d'une

ADISCAL, ou de la chaleur.
ḯres, adiscalis (a. priv., l'insertion disyuc). Lestiboulois dit lorsque des étamines adiscale, l'inferme ces organes s'insèrent sans appelé Disquire de l'organe charnu ADjelsque. Voyez ce mot.

auprès, croff ap jaceo, être couché). Banqu'on appelle conleurs adjectives celles qu'on ne parvient i frxer sur les élofies que par l'intermédieire d'une atre substance. ADJOINT, adj., adjunctus (ad,
a, jungo, joiud par Kirby joindre). Epithète donnée quand il ì l'abdomen des insectes, tiole très cst uni au tronc par un pćris. AlDMINICULF, s. m., adminicn-
lum; Behelf (all.) (adminiculo, sou-
tenir). tenir). Kirby donne ee nom à une demi-conronne de petites dents qui garnissent l'abdomen des nymplies souterraines, et au moyen desquelles terre. dénoninati appliquait cette même gétaux que à tous les organes vécelle de que linné avait réunis sous ADMOTulcrum.

ver's, mow'so, adj., admotivins (red, chard appelait mouvoir). C.-I. Ricelle dans lait germination admotive fermant l'extrelle l'épispcrme, renou moins tuméfié du cotylídon plus ment près de la laé, reste fixé latéraleADNÉ, adj., adnate ce cotylédon. angewachsen (all.); adnatus, accrelus; auprès, nascor, nâ̂tre); (it.) (ad, ou le long de. Se ditre); attaehé à, que, des anthères, dit: $1^{\text {" en botani- }}$ rient au filet dans, quand elles tien(ex. Podophyllum peltatum); des
stipules et bractics, poursquelles
soudé soudées le long du pétiole et du sont doncule ; du placentairc, quand il est attaché dans toute sa longueur à la face interne de la boîte péricarpienne (ex. Orchidées), aux hords des valves (ex. Viola canina), aux bords des cloisons (ex. Tulipa syluestris), ou ì l'axe central (ex. Ixia chinensis). Le Stereodon adnatus cst ainsi appelé paree qu'il adlıère fortement aux ćcorces des arbres sur lesquels il croît ; $2^{\circ}$ en zoologie, des mächoires des insectes, quand clles ticnnent alssolument à la lèvre inférieure (cx. Frigane); du postfranum, d'après Kirby, quand il ticut aux côtés du métathorax (ex. Pentatome).

ADOL RSCENCE, s. f., adolescentia ; Jïnglingsalter (all.): youth (angl.) ; adolcscenza (it.) (aclolesco, croîtse). Pluase de la vie humaine qui est comprise entre l'enfance et la jeunesse, et qui dure depuis les préludes de la puberté jusqu'au temps uù le corps a acquis la totalité de son développement en hautcur.

ADOIESCENT, adj. ct s. m., adolescens; Jüngling (all.); qui est dans l'adolesernee.

ADONISTE, s. m., adonista.Linné appelait adonides ou adonista les bolanistes qui font la description ou dressent simplement le eatalogue des plantes cultivées dans un jardin de bo tanique public ou particulier.

ADOSSÉ, adj., adnatus; angelelent (all.). Synonyme d'adné. (Voyez ce mot). Se dit quelquefois, en zoologie, de l'abdomen d'mu insecte, lorsqu'il se joint avee le corps, à sa partie inféricure, par un court appendice. Ex. Araignées.

ADRAGANTIUNE, s. f., adraganthina; Traganthstoff (all.). Nom donué par Bucholz au mucilage vćgétal qui forme la presque totalité de la gomme adragant. C'est la même chose que la cérasine, la prunine de de John, le mucilage vćgéral (PRanzenschleim, all.) de Berzelius. 
adraganturTe, s. f. C'est le nom sous lequel Guibourt désigne l'adraganthine.

ADULAInF, adj., adularis. Pline donnait eette épithète, conservée par quelques minéralogistes modernes, à une variété de foldspath, qu'on trouve entre autres au mont Saint-Bernard, appelé autrefois $A$ dula.

ADULTE, adj. et s. m., adultus ; emwachsen (all.); adult (angl.); adulto (it.) (adolesco, croitre); qui est arrivé ou qui a rapport à l'époque où le eorps humain a pris son développement eomplet. Ce niot s'applique par extension à tous les eorps organisés, même végétaux.

ADUNCInOSTrES, adj . et s. m. pl., Aduncirostres (adunctus, erochet, rostrum, bee). Nom donné, dans la classification ornithologique de Sehaffer, à un ordre eomprenant tous les oiseaux qui ont le bee crochu.

ADUSTE, adj., adtustus; verbrannt (all.) ; overheated (angl.) (aduro, brûler); qui a été, ou qui a l'air d'avoir étć brûlé. Epithète donnée à des coquilles où le noir et le blane sont disposés de manière à leur donner la même apparence que si elles avaient été rôties. Ex. Murex adustus, Cypraca dusta.

ADVENTIF, adj, , adventitius; zufällig (all.); auventizio (it.) (ad, à, vcnio, venir). Se dit, en botanique, d'une partie développée sur ou plutôt dans un organe qui n'a pas coutume de la porter. C'est en ee sens qu'on dit bourgeons adventifs ( $\mathrm{Gcm}$ ma advertitice; zufillige Knospen, Lolddcn, Link). Les bourgeons produits par le développement de germes latens, n'ont pas eomme les autres de place déterminée. On en voit naître fort souvent sur le trone des arbres. II s'en développe sur les fenilles, dans le Rochea falcata, le Cardamine praicnsis, l'Eucomis regia, l'Ornithogalum thyrsoüdcs. On en voit aussi survenir à la surface supérienre des écailles des bulbes de lis. En ngriculture on nomme plantes adventices eelles qui croissent sans avoir été scmées.

ADVEILSE, adj., adversus, obversus' scituärtsgebogen (all.); ( $a d$, vers : vcrto, tourner); qui est placé à l'oppo site d'une chose, ou tourné vers ellè Se dit, en botanique, desanihères: quand elles sont attachées de manière que la suture de leurs valves regardi le centre de la fleur (ee qui a liev dans presque toutes); des colylédons, lorsque, dans une graine recourbic ou repliée, de sorte que le hile cor' responde à ses deux bouts réunis: l'embryon prend la mène courbuntr qu'elle, el que les extrémités cotylć donnaire et radiculaire se dirigent. chacune de son côté, vers le hil (ex. Ternstromia punctata); stigmate, quand il est tourné vers circonférence de la fleur, de manièr à regarder les étamines ou la plac qu'elles ont coutume d'oceuper (ex Cucurbitacées). Une coquille bival (Caprina adversa) est ainsi appelé paree que les sommets de ses valve roulés en spirale de dehors en do dans, sont tournés l'un en devanl l'au tre en arrière.

EDOIOGIMAPIIE, s. f. , adoif

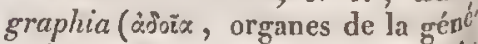
ration, ypx́ø, éerire). Descriptio des organes générateurs.

EDOROLOGIE, s. f., adoiolog (aiboix, organes de la génératio

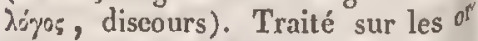
ganes générateurs.

NGIALITES, alj. et s. m. pl Nigialites (aiyeàós, rivage). Nom do né par Vieillot et Ranzani à une mille d'oiseaux échassiers, complit nant ceux qui vivent sur le bord de eaux.

AEGLOPINÉES, adj. et s. f. $\mathrm{pl}$ Agilopinea. I Link donne ee nom. une tribu de la fanille des Grat 
nées qui a pour type le genre Eggi-
lops.

AEGTHALES, adj. el s. m. pl., Égichali (aigetaxiòs, enneni des mouches à miel). Nom donuć par Vieillot, Ranzani et C. Bonaparte à une famille d'oiseaux, de l'ordre eoup passereaux, qui dćtruisent beaunoup d'abeilles, dont ils fout leur nourriture.

lus (äGPIALE, adj., agocepha-

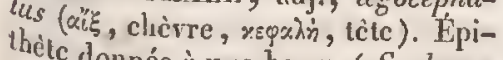
thètc donnéc à une barge ( $S$ colopax la lui phala), sans qu'on saehe ce qui a value.

EGOLIENS, adj. et s. m. pl., Élii (airodiò, hibou). Nom donné par Viejllot, Ficinus et. Carus à une bous ot d'oiseaux, comprenant les lichent.

Aleri, adj., acreus; luftig (all.); aired (angl.); aerato (it.) (aer, air); qui contient ou reçoit dc l'air, qui est alv grand air, et, par cxtcusion abusivc, qui reuferme du gaz aeide cardans iqu. Le mot aéré n'cst plus usité la réform dernic̀re acception depuis I reforme introduite en chimic par

air, colo, he, adj., aericola ( $a e r$, quel ques anciens naturalistes out foit usage pour désigner les animanx qui vivent dans l'air.

(aer, air dinche, s. m., aeriductus nom, air, duco, conduire). Kirby toires, ainsi des organes respirasur diverses pont foliacés, qu'on voit taines larves parties du corps de cerAÉlices ou nymphes aquatiques. air); qui a adj., cercuss; áépeos (aer, aćriennc), qupport it l'air (nature aérien), qui en cst composé (fuide qui en a la l'labite (mnimal aćrien), qui en la nature (Autide aćrien), réricnne), qui la la subtilité (conclie stion (aeide aćrien, ou acide carbo-
sans comp-
AERI

nique, parce qu'il $y$ en a toujours unc ccrlaine quantitć dans l'air atmosphérique). Les botanistes donuent cettc épillète aux plantes qui vivent en grande parlic, ou même quelquefois en totalité, aux dépcis de l'air. (ex. Aerides adorata), et aux racines qui naissen $t$ sur unc partie quelconquc exposée à l'air. Grew appelait les trachées des végétaux vaisscautx aćriens, parce qu'on n'y trouve le plus souvent que de l'air.

Á́Biens, adj. et s. m. pl., Acrei (aer, air). Nees d'Esenbeek donnc ce nom à une section de la classe des champigrions, comprenant ceux qui naissent a la surfacc de la terre.

AĹRIFtRE, adj., aerifcrus; lufturagend (all.); (acr, air, fero, porter). Epithète donnée aux vésicules rcmplies d'air qui garnissent les tiges de eertains fucus, et lcur donnent la faculté de surnager. On appelle aussi, en zoologie, conduits acrifcres ceux qui servent à l'introduction de l'air dans lc corps des animaux, comme l'arbre bronchial ct les trachées.

AÉRIFICATION, s. f., aerifieatio (aer, air, facio, faire). Action de convertir un corps cn fluide élastique. Synonymc peu usité de gazéificalion. Voyez ce mot.

ÁnIForuE, adj., aeriformis; lufformig (all.) (aer, air, forma forme) ; qui a la forme de gaz. Synonyme de gazeux. ( $/$ oy. ec mot.) On donnc souvcut aux gaz le nom de fuides aériformes, cmpruntć de l'air atmosphérique, qui, par son importanee et sa grande abondance, semble tenir le prcmier rang parmi eux.

AÉRIQULS, adj, et s. m. pl. Nom donnć par Oken á unc classc de minéraux, ceux qui, suivant lui, sont placés sous l'influence de l'air, c'està-dire aux combustibles.

AÉRITEs, adj. ct s. m. pl., Aerita. Macleay dome ce nom à unc division 
du règne animal comprenant tous les animaux qui vivent dans l'air.

AÉronyNAniQue, adj. et s. f.,

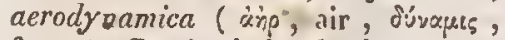
force ). Partie de la physique ayant pour oljet la recherche des lois qui président aux mouvemens des fluides élastiques, ou de celles qui règlent la pression qu'exerce l'air extérieur.

AÉROGaSTRES, adj. el s. m.pl.,

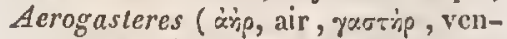
tre ). Noın donnć par K. Sprengel et par Nees d'Esenleck à une section de champignons charnus, comprenant ccux qui croissent à la surface de la terre.

A érogNosie, s. f. aerognosia,

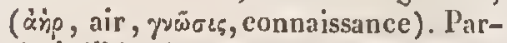
tie de l'histoire naturelle qui traite des propriétés de l'air et dı rôle qu'il joue dans la nature.

AÉnOGRAPIIL, s. f., acrographia; Lufibeschrcibung (all.) (áno, air, ypớy, écrire). Traité sur l'air, description de l'nir.

AĹRONYDRE, adj., acrohydricus

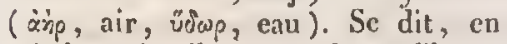
mincralogie, d'un corps, lorsqu'il renferme une goutte d'call qui rcmplit eu partie une cavité tubulée, dc manière que la bulle d'air qui ocenpe le vide monte et descend, comme dans un nivenu d'cau. Ex. Quarz hyalin aéroliydre.

AFROLITIE, s. f., aerolithon; $M e$ teorstein, Himmelstcin, Luftstein,

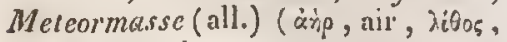
picrre). On donne ec noon, ou celui de bolide, mótéorolithe, uranolithe, à des masses ninérales qui tombent de l'atmosphère en certaines circonstances, et dont l'origiuc a été la source d'un assez grand noinlure d'hypothc̀ses, toutes peu satisfaisantes. Chladni a donné un cataloguc fort étendu des pierres tombées du ciel aux diverses époques historiques.

AÉroloGif, s. f., aerologia;

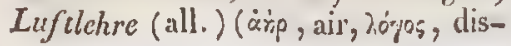

eours). Traité de l'air en génćral, de ses propriétés.

Aúnovítrie, s. f., aerometria ; Luftmessungskunde (all.) ( $\dot{\alpha} \mathrm{i} \rho$, air,

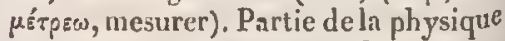
qui traite de la densitć et de l'expansibilité de l'air, et des mayens de les mesurer.

Á́rOPIONES, adj. et s. m. pl,

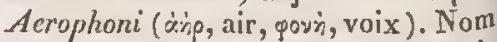
douné par Vieillot à une famille d'oiseaux échassiers, comprenant ceus qui remplissentl'air des éclats de leur voix retentissantc.

AÉROPIORE, adj., aerophorus; lufttragend (all.) (ànp, air, ęp pw, porter ); qui conduil de l'air, qui en transporte. C'est en ce sens que le nom de vaisscaux aérophores a élé donné anx trachées.

AÉROPIITE, s. f. , aerophytum

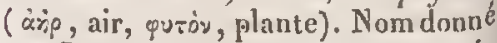
par Lamouroux aux plantes qui végètent dans l'air.

Af́nospmìne, s. f. , aerosphcera

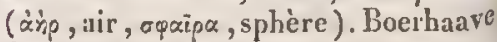
donnait à l'atmosphère ce nom expressif, dont il cst à rcgretter que l'usage n'ait point étè adopté.

A EROSTATIQUE, s. โ. , aerostatica

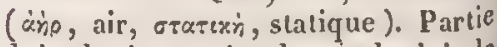
de la physique qui rccherche les lois $\mathrm{de}$ l'équilibre de l'air et de tous les fluides expansibles.

Aknozols, adj. et s.m.pl., $A c^{\prime}$

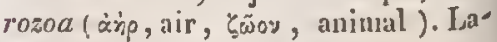
mouroux donnait ce nom à un $\mathrm{cm}^{-}$ liranchement du règne animal coı́prenant les animaux vertébrés et ar ticulés, auxquels l'air est indispensable.

ERUGriNEux, adj., aeruginosus; kupfcrgrin (all.) (arugo, vert do gris). Rigoureuscment parlant, $c^{\natural}$ terme ne devrait cxprimer qu'une nuance de la couleur verte (ex. $P$ sit tacus aruginosus); mais quelquefois on le prend par abus dans le sens di rouillé, et alors il désigne une teire 
AFFI

loussâtre ou de roux brun (ex. Circus aruginosus, Chama arnginosa, Grmnostomum ceruginosum).

AESCULINE, s. f., aesculina. Base salifiable dont Canzoneri avait annoneé l'existence dans les fruits de l'Aesculus Hippocastanum, mais que Chereau a reconnu n'être qu'unc combinaison insoluble d'ex traetif et de lius.

AETHatins, adj. et s. m. pl., EEpar Fries Tribu de champignons, ćtablie genre , qui y range ceux dont le genre El halium est le type.

AETUÉOG AYE, adj. et s. f., actheo-

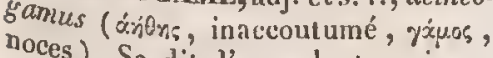
noces). Se dit d'une plante qui appartient a l'aéthéoganie. $V_{o y}$. ec
mot. AÉTHÉOGAMIE, s. m., aethcogamia. Mot par lequel Palisot-Bcauvois a propose de remplaeer celui de cryptesanie, admettant que la préseuce dc sexes est eertaine dans beaucoup se plantes que renferme cette grande selion du règne végétal, quoique le mentère n'cli soit pas encore parfaitcient connu.

AFFECTIF, adj. (afficio, émoucultés a qui touche ou émcut. Les fam pernettentives sont celles qui nous sionnés, mis d'ètre affectés, impressition par mis dans telle ou telle dispoAFFE les objets extérieurs.

tio ; ZuEGTION, s.f., affectus, affecfond qui gung (all.). Sentiment proune chose attache à unc personne ou a agréablese ; sentiment pénible ou sion ou par nous ćprouvous à l'occations que les souvenir de modificaopérées dans corps environnans ont dans nos viscènos organes des sens ou AFFINAGeres.

(all.); affuat, s. m., Feinmaehen des métaux ; sćrio (it.). . Purification exćcute pour oblenir ces corps à l'état de pureté.
AGAL

AFFINITÉ, s. f., affinitas, altractio electiva; Verwandschafi (all.); affinily (ang.); affinilà (it.) (affinis, voisin). On donne ce nom : $x^{\circ}$ en chimie, à une force qui s'exeree sur les atôınes eonstituans des corps, et les tient unis les uns aux autres, parce que lcs effets qu'elle produit sen blent indiquer une sorie de parenté entre les substances susceptibles de s'unir ensemble ; $2^{\circ}$ en botanique et en zoologie, anx rapports organiques qui existcut cntre les êtres vivans, et dont l'intimilité ou le nonbre détermine les groupes dans lesquels on doit les réunir.

AFFLEU RÉ, adj. Les géognostes disent la stratification afflcurée quand les couches qui reposent sur un plan incliné sont plus épaisses vers le bas que vers le haut, et tendent ainsi à prendre la situation horizontale.

ANTLULNT, s. m., Zuströmen, Anströmen (all.) (ad, vers, fluo, couler): Endroit où uı cours d'eau se jetic dans un autre.

AFFLUENT, adj., affluens; hincinflicssend (all.); falling (angl,); qui eonle on se porte vers. Une rivière afluentc est eelle qui se jette dans une atitre. Afluent se dit aussi des choses qui sc portent dans un certain sens déterminé (fluide affuent), et de eclles qui y arrivent en abondanee.

AFFOLE, ndj.; qui est dans l'état d'affolement. Voy. ec mot.

AF'OLEME.VT, s. m. Terme dont les marins, et, d'après eux, les physiciens, se servent pour désigner les anomalies subites ct fugitives que les variations de l'aiguille aimantée éprouvent en ccrtaines eirconstances, par exemple dans les temps d'orage, ou quand il paraît une aurore boréale, et qui portent évidemment le caractère d'unc cause perturbatrice, en sortc que l'aiguillle parnît être comme frappie de folic.

AGALOSTÉuiones, adj. et s, f. 


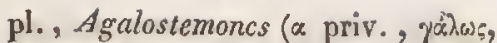

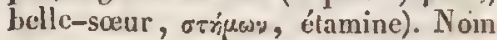
donné, dans la méthode botanique de Mœench, à une classe comprenant les plantes dont les étamines sont insćrées alternativement sur le ealiee et fin corolle, e'cst-à-dire ne partent pas d'un mème point.

AGALSSIEN, adj., agaljsius

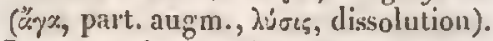
Le nom de terrains agralysicns est donné, dans la elassifiention géognostique de Brongrniart, à une elasse, ct dans eelle d'Ómalius à un ordre de terrains, eomprenant ceux qui n'offrent que des roches évidemment formées par roie de cristallisation eonfuse.

AGAME, adj. , agrames ( $\alpha$ priv. , ýxuos, noce). Neeker a donné cette épithète aux plantes qui n'ont pas d'organes sexizels, et dont les corpuseules reproductil's ne sont point de véritables graines.

AGAMES, adj. et s. m.pl., Agrami (a priv., r'yos, noce ). Nom donné par Latrcille à une lsranche du rìgne animal comprenant les Mollusques sans organe copulateur mâle, chez lesquels chaque individa se féconde lui-même.

AGAMIDES, adj.et s. m. pl., Agamida. Sous ce nom, J.-E. Gray désigne une famille de l'ordre des reptiles sauriens ayant pour type le genre Agama.

AGAMLL, s. f. , agrania (a priv., 'rx́os, noee). Teruic par lequel Necker a proposć de renplacer eclui de cryptogamie, et dont C.-I. Richard s'est servi, dans sa móthode linnécnne réforméc, pour désigner une classe comprenaut les végélaux qui sont dépourvus d'organes sexuels.

AGAwiENs, idlj. et s. m. pl., $A g a-$ mii. Nom donné par Cuvier à une scction de la famille des Iguaniens, ayant pour type le geure Agama.

AGAMOIDES, adj. et s. m. pl,
Agamoidea, Agamoidei. Nom donné par Blainville à une famille du sousordre des Bispéniens, Ipar P.-F. Fitzinger et Eichwald à une famille do l'ordre des Sauriens, ayant pour type le genre Agrama.

AGARICÉES; adj. et s. f. pl., Agrt ricea. Sous ce nom Ad. Brongniart désigne une section de la classe des Champignons, qui a pour type le genre Agaricus.

AGARICICOLE; adj. , agaricicoln (agaricus, agaric, colo, habiter) qui vit dans les agaries. Ex. Boleto phagus agraricicola.

AGARICIF ORUE, adj., agraricifor" mis, agaricitcs (agaricus, agaric , forma, forme); qui a la forme d'ul agaric. Épithète donnéc à plusicurt polypiers. Ex. Millcpora agaricifor mis, Pavonia agaricites.

AGARICIN, adj., agaricinus (aga" ricus, agaric); qui ressemble à ull agaric (ex. Spongia agaricina), qul vit dans les agaries (ex. Scaphidivint agaricinum), ou qui croît sur $l^{5}$ Agaries sees et à demi pourris (ex. Isaria agaricina).

AGAniCiNs, adj. et s. m. pl.! Agaricini. Nom donné par Persoon une famille de l'ordre des Exosporien? Pilomyces, par Fries à une tribu de l'ordre des Hyménomycìtes à elar penu, qui ont pour type le genre Agaricus.

AGARICOIDES, adj. et s. m. pl.s

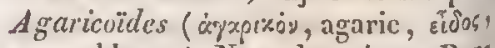
ressemblance). Nom donné par Pcre soon à une division de la famille det Champignons, qui a pour typele gent" Asarictes.

AGARICS, s. m. pl., Agarici. Mar" quis donne ce nom à un gुroupe de l: fanille des Champignons, dont li genre Agraricus est le type.

AGASTRALRES, adj. et s. m. pl. Agastraria (a priv., -yestrip, ventre) Nom donné par Blainvillc aux corp? organisés sans canal intestinal propre 
ment dit, dont les fonetions se bornent à l'exhalation et à l'absorption extćrieures, eomme les éponges.

AGASTRIQUeS, adj. et s. m. pl., Agasirica (a priv., yowinp, ventre). Nom donné par Latreille à une race du règue animal comprenant les animaux aećplalés qui n'ont aueune trace de canal intestinal.

AGaS'Tnozoaines, s. m. pl., Agastrozoa ( $\alpha$ priv,, yxotrip, ventre, Soosy, inimal). Synonyme d'agastraires. $\nu_{\text {og: }}$ ce mot.

AGATE, adj. (ćxárns, agate). Se dit, ell minéralogie, d'un jaspe dont la substance est interrompue par des portions de quarz agate.

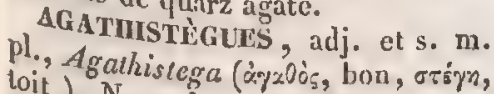
loit ). Nom donué par Orbigny et Menke à une famille de Céphalopodes
foraminifires.

AGATIIOPIOLIDOPHIDES; adj. ct

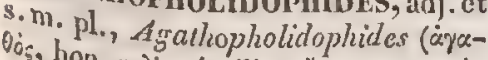
Ois, hon, yolic, écaille, öęts, sctpent). faunillonné par J,-A. Hilgen à une prenantle reptiles Ophidiens, compas de crserpens écaillcux qui n'ont de crochets à venin.

a toute rifere, adj. Épithète donnée AGAToebe qui coutient de l'agate. en agate. AG

mus. Se dit adj., agalhinus, achatiparence, d'une coquille qui a l'apde l'agate. Conugate. Ex. AYrtilus agallinus, AGATIS

Devenu agate, adj., achatisirt (all.). Bois agarisé. AGATOLE:

l'agate. Petrosilj.; qui resscmble à nommé, parce circuse, comme qu'il a nne cassure division des agntes. AGAT0 agntes.

qui a l'apparence, adj., agathoictes; donnće il une pla l'agate. Épithète ane plante marine (Chon- drus agathoicus) ayant une transparence nébuleuse qui rappelle celle des agates.

AGE, s. m., atas; मेhixes; Alter (all.); ycars(angl.); ctà (it.).On entend par là une période queleonque de la vic d'un corps organisé ( premier âse, äge de raison), ou le temps qui s'est écoulé depuis la naissance (ăgé de tant $d^{\prime}$ années), ou la dernière période de la vie, lu vieillesse (ĉtre sur l'áge, avoir. de l'âge), ou enfin la durée de la vie, le temps qui s'ćcoule entre la naissance et la mort (vivre un ou deux ägres d'homme). C'est à peu près dans ee dernicr sens qu'on dit äge de la lune, temps ćcoulé depuis la dernière nouvelle lune, ct agre du monde, temps écoulć depuis le moment de la prétcndue création. Agre est quelquefois employé counme synonyme de temps, siècle vu époque (étre le héros de son ăge).

AGE, adj., annostes; alt (all.); aged (angl.); qui a mu certain âge déterminé (ếre ägé de tant d'années), ou qui est avancé en âgc, e'est-à-dire plus près du terme que du commenceinent de la vie.

AGúnorTs, s. f. Nom donné par Robiquet à une substance existante dans le sue de réglisse, qui fut regardée comme un principe immédiat particulicr des végútaux jusqu'au moment où Plisson découvrit qu'elle n'était autre chose ţue l'asparagine.

AGINE, adj., agemes; asessmalo (it.) ( $\alpha$ priv., ₹̛́s, naitre). Epithète donnce par Lestiboudois aux végétaux cellulaires acotylédonés, paree qu'ils sont dépourvus d'une surface distinete d'accroissement où s'engendrent de nouvelles parties.

AGĹNĹLENS, adj. et s. m. pl.,

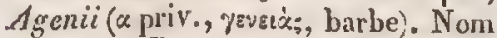
donné par Ranzani à unc famille de l'ordre des oiscaux grimpeurs, comprenant ceux qui n'ont pas de soies à la base du bee. 
AGÉNÉSIE, s. f. , agenesia, age-

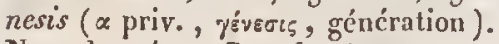
Nom donné par Breschet à un genre de déviations organiques qui sont caractérisées par l'absence de certains organes ou par un défaut dans leur développement.

AGENT, s. m., agens (ago, faire). 'Tout ce qui agit ou opèrc (agcnt naturel, agent chimique). En chimic, ce mot est quelquefois employé comme synonyme de réaetif.

AGúna TÉses, adj. et s. f. pl., Agcratece. Nom donnć par Cassini et par Lessing ì une section de la tribu des Eupatoriées, qui a pour type le genre Ageratum.

AGGÉDULE, s. f., aggedula (äryōs, urue). Mauvais mot dont Necker s'est servi pour désiguer l'urne des mousses et Hoffmann les cupules de certains champignons épiphytes.

AGgLOMÉnat, s. m., Trummergestein (all.) (agglomero, pelotonner). Réuniou de plusieurs substances qui, ayant été formées à divcrses époqucs et sćparées pendant long-lemps, se sont trouvées resserrées en masses plus ou moins considérables par un ciment quarzeux ou calcaire, déposé du sein des caux.

AGGLOMĹRATIGN, s. f. , agglomeratio. Réunion en massc, action d'agglomérer.

AGGLOMÉR', adj. , aggrlomeratus, slomeratus ; gelnauelt(all.); aggomitolato (it.); qui cst réuni en massc. Se dit, en botanique, des éta mines, quand elles sont ramassécs en boule (ex. Anona triloba); et des chatons, lorsqu'ils offrent la même disposition (ex. Pinus sylvestris). On donne aussi cctte épithète à des plantes qui out leurs fleurs (ex. Campanula glomerata, Anthodon glomeratum), ou lcurs feuilles ( ex. Bergia glomerata), agglomérées, ou qui forment elles-mêrnes des agglo- mérations de filamens ( $\mathrm{ex}$. Chat transia glomerata).

AG(iLOMĹnÉEs, adj. Nom donné dans la classification géognostique $d$ Maraschini, à une elasse de roche comprenant celles qui se sont formét par agglomération.

AGGLUTINANT, adj., agglutinan anklebend (all.) ( ad, ì, glutino collcr). Épithète domuéc à quelque coquilles qui agglutinent lcs corp mobilcs du sol sur lequel clles repo sent. Ex. Trochus agglutinans, $A$ pergillum agglutinans. Voy. Cos CHYLIOPHORE.

AGGLUTINÉ, adj. , agglutinatusi angcklebt(all.); qui cst rćuni en masse. Se dit, en botanique, des utricule du pollen, quand elles sont réunies $p^{2}$ une humeur quelconcue, de manict à former une pâte (ex. Serapias) Illiger appelait dents agghutinées cel les qui sont fixées au palais ou aut mâchoires, sans racines propres, d uniquement par l'intermédiaire d'un" membrane.

AGILE, adj., agilis; gewande(all, nimblc (angl.) (ago, faire); qui a de la souplesse, de la vivacité dans se monvemens. Ex. Lacerta agilis Anthrax celer, Tachina alacris.

AGILES, adj. ct s. m. pl., Agiliat Nom donné par Illiger et Goldfuss i une famillc de mamumilères compré nant ccux qui sc font remarquer $p^{\text {at }}$ la presicsse de leurs mouvemens.

AGISSANT, adj., thätigr, wirksall (all.); active (angl.); qui exerce unt action, qui se donne beaucoup mouvement. Bory appelle ćtat agis sant de la matic̀re, celui où elle $e^{s^{t}}$ composée de molécules sphériques! diaphanes, contractiles, mais non $e^{\prime}$ tensibles, qui s'agitent individuelle' ment avec une grande vélocité.

AGLOSSES, adj. et s. m. pl. Aglossa, Elinguia (a priv., $\gamma^{\lambda} \omega^{\circ} \sigma^{\alpha_{4}}$ lauguc). Nom donné par Degeer $\|^{1}{ }^{\|}$ sons-ordre de la classe des insect( 
comprenant eeux qui n'ont ni bec, ni dents.

AGNATIES, adj. et s. m. pl., Agnatha (a priv., yrí丿0s, natchoire). Nom donné par Duméril à une famille de l'ordre des insectes névroptères, comprenant ceux dont la bonehe, trop petite pour qu'on puisse l'observer à bules. AGompur, adj., agomphizs ( $\alpha$
priv., youpios, dent). Epithète appliquée par C.-G. Ehrenberg aux infusoires rotifères dont les mìchoires sout dćpourvues de dents. Ex. Ichthy.
dium.

AGONATES, adj. et s. m. pl., Agon nala (đ́yóvaros, sans noud). Nom donné d'abord par Fabricius aux crustamâcharce qu'alors il les croyait sans mâchoires, regardant les organes qui articulés.

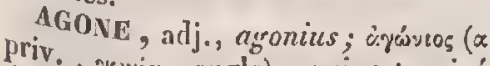
d'anglesic, angle); qui est privé nongles. L'Ostracion agonus doit ce pèces du qu'il diflère des autres cssun du genre par la rotondité de un corps elliplique.

Todeskamp, s. f., agonia; íjwyia ; nia (it.) (all.); agony (angl.); agoinstans (it.) (ćyc̀, combat). Derniers duelle de la vie, cxtinction gracomparée l'aetion organique, qu'on a et une arée à unc lutte entrel'organisme la vie puissance dćlétère, parce que temps, jusle se ranimer de temps en toul-à-fait. jusà cc qu'elle s'éteigne

AGRAFE, s. f., hanus; Haken
(all.). Les bonit. quefois, mais ranistes donnent quelpoils durs et rarcment, ee nom à des AGRíg et recourbés en crochet. AGRÉGAT, s. m. , grex; Haufen-
werk (all.); produite par agregate (angl.). Masse substanecs diveréunion de plusieurs glutinées diverses, qui ont èté agformation. I.
AGREGATION, s. f., aggregatio ; Zusammenfiigung, Zusammenhïufung (all.). Assemblage de parties sans liaison; proprićlé par laquelle les moléculcs des eorps sont assez attirées et rapprochées les unes des autres pour adhérer plus ou moins fortcment entre elles et opposer nu obstacle plus ou moins grand à Jcur séparation.

AGIUliḱ, adj., agorregatus, confertus, sregarius; angchïufi (all.); aggregated (angl.). Epithète donnée en général ì tout eorps dont les molécules sont adhérentes les uncs aux. inutres. Se dit : $1^{0}$ en minéralogie, de la texture d'une roche, quand les grains, formés isolément ou résultant dc la désagrégation d'autres ninéraux, ont été réunis, sans aucun eiment (ex. Arkose), ou avee un ciment a peine distinct (ex. Macigno) ; $2^{\circ}$ eu botanique, des parties qui naisscut à pcu de distance les unes des autres, se trouvent ainsi réunies en paquels plus ou moins serrés, el quclquefois même finissent par contracter adhérence ensemble, quand elles ont acquis lcur entier développement. On appelle feurs agrégées celles qui, simplement et distinetement pédicellćes, naissent plusieurs ensemble d'un même point de la tige (ex. Oxybaphus aggregatus, Evosmia aggregata), ou sout réunies de manière à paraître n'en former qu'une seule, innis alors ont leurs anthires distinctes (ex. Scabiosa succisa). Les fruits agrégés sont ceux qui provicnnent de plusieurs ovaires appartenant à des fleurs distinetcs, et d'abord séparés (ex. Morus nigra); $3^{\circ}$ en zoologie, d'animaux qui vivent en famille (ex. Fistulana gregaria. Voy. Social).

AGRúGLEs, adj. et s. f. pl., Agrcgata. Norn donué : $x^{0}$ en géoguosie, par Werner, aux roches composées de matériaux divcrs, qui se sont formées dans les lieux mênes où on les rencontre (ex. Granite); par Bonnard 
et Maraschini à une elasse, et par C. Prevost ì un ordre de roches, comprenant les roches composées de parties différentes, qui ont été enlevécs, déjà solides, ì des minćraux: ou roehes préexistans, et agrcégées méeaniquement, avec ou sans pâte ou ciment ; $2^{\circ}$ en botanique, par Linné, à une famille, et par Royen à unc elasse, comprenart les plantes qui ont leurs fleurs réunies en tête, mais leurs anthères distinetes; par Bartling à une elasse comprenaut les familles des Plantagincóos, des Plombiginées, des Globulariées, des Dipsaećes et des Valérianćes.

AGnéGrís, adj. ct s. m.pl., $A g-$ gregati, Gregarii. Nom donné par Cuvier à une famille de la classe des Aeéphales, renfermant des aninaux qui sout réunis cn une masse commune, et par Illiger à une famille d'oiseaux marcheurs, eomprenant ceux qui se plaisent à vivre en troun. pes.

AGIUESTE, adj., agrestis, agrarius; ländlich (all.); wild (angl.); (ager, champs). Se dit, co botanique, des plantes qui eroissent spontanément dans les lieux nou eultivés, et en zoologic, des animaux qui y vivent (ex. Mils agrarius, Barbula agraria, Aranea agrestis).

AGRICOLW, adj., agricola (ager, champs, colo, babiter); qui vil dans les ehamps. Ex. Meloloniha agricola.

AGIIDES, adj. ct s. m. pl., Agriala (äyptos, rustique). Nom donné par Robineau Desvoidy à une section de In fimille des Myodaires ealyptér'ées, comprenant des espicees qu'on rencontre partieulièrement dans les endroits arides et pierrenx.

Agrinuoviúles, adj. ct s. f. pl., Agrimonica. Nom clonmé parVentenat à une section de la famille des Rosacées qui a pour type le gence Agrimonia.

AGHIRENVE, adj., agripennis.
Eithète donnéc à un oiseau (Thamnophilus cauducatuss), parec que les pennes de sa queue ont la tige aiguë et conime usće par le bout.

AGROSTEES, adj. et s. f. pl., Agrosicce. Tribu admise par Nees d'Esenbeek, dans la fanille des Graminées, qui a pour type le genre Agrostis.

AGirostidíES, adj. et s. f. pl., Agrrostidca. Nom donné par Linné, Trinius et Kunth à une iriba de la famille des Graminées, qui a pour type le geure Agrostis.

AGROSTOGRAIHE, s. m. , agros-

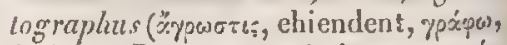
écrire). Botaniste qui s'oecupe speeialement des Graminées.

AGmostogharili, s. f., agros lographia. Partie de la botanique qui a pour objet les plantes de la famille des Graminées : ouvrage spéeial sur eelte branche de la scienee des végétaux.

AGROSTOGRA PHLOUE, adj., agroslographicus; qui a rapport à l'agrostographic.

AGrostonogLe, s. f. , agrostolo-

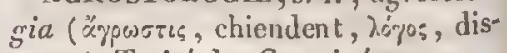
eonrs). Traité des Graminées.

AGUSTINE;, s. f., agustina ( $\alpha$ priv., gustus, gônt). Trommsdorff douna ce nom i une sulsstanec qui fut d'abord regardée comme une terre partienliele, unais qu'on a reeonuue depuis pour ètre du phosphate de chaux, lequel n'a effeetivement pas de saveur.

AGYNAIRF, adj. , agynarizes (* priv., yusi, feume). On donne cettc épithèlc aux fletres doubles dans lesquelles les tégumens et les étamines sont trausformés en pétales, et où le pistil manque.

AGXNE, adj. , agynues ( $\alpha$ priv. भurr, femme); qui n'a point de femme oul d'organe femelie. Fleur agyne $e^{\mathrm{st}}$ synonyme de fleur mále.

AGYNIQUE, adj. , agynicus (a priv., juyr, femme). Lestiboudo 


\section{ATGR}

appelle ainsi l'inscrtion des étaunines, quand ces organes ue contractent pas d'adhérence avce l'ovairc.

AIGLEDON, s. m., ou mieux Ëdrcdon, par corruption du mot allemand Eiderdunuen (dnvet d'oie). Duvet de l'Anas mollissima.

MIGRE, arlj, , acerbus. Terme vague dont on se sert pour désiguer : $1^{\circ} \mathrm{ce}$ qui exerce une irnpression désagréable soit sur l'organe du goût ( herb, saner', all.; cager, angl.; agro, it.), en l'affectant à la manicre des acides ( $l i$ quide aigre, savenr aigre), soit sur celui de l'odorat, cn produisant le même effet sur lui (odeur aigre), soit sur' celui de l'ouïe (scharf, hell, all.), en y faisant natitre la sensation d'un son aigu ct perçant (voix aigre, son aigre; störrisch, all., harsh, angl.);

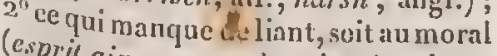
(esprit aigre, caracterc aigre), soit au pliysique. C'est dans ce ilernier sens qu'on appelle aigres les métaux qu'dn ne peut forger, parec qu'ils se briSent sons le choc du marteau (ex. Antimoinc, for aigre), et les roches compe cassent aisément (cx. Eurite terracte). Aigre se dit aussi d'un les pluies difilc à cultiver, parce que ela mares abondantes le transforment longées en que les séchcresses procomme en rendent la surface dure AIG de la picrec.

sauersüs-DOUx, adj., dulcamnrus; est composé d' soririsch (angl.); qui terme, commé d'aigre et de doux. Ce au physiqume le précédent, s'emploic lanum Dulcavelur aigre-douce; So. aigre-doulcarrara), et au moral (ton AIGRe

lich (all.); quide aigrclet est un peu aigre; $l$ aigrelei. Alci.

coma. On donte, s. f., pappus, lanugo, nique, à une réune nom : 1 "en botabraneuses ou fíminion de partics mem-

\section{AIGU'}

all., pappo, it.) qui surmontent le fruit ou les graines de certaines plartes, notamment des Synanthérées, où elles résultent d'un demi-avortement ou d'une déformation du calice, oceasioné par la pression des fleurs voisines; $2^{\circ}$ eu zoologie, à un faisccan de plumes qui orne le dessus de la tîte de certains oisenux (cx. Paon), 'ct it des touffes de poils (Haarbitischel, all.), qui sont disposées en manière de plumet sur une partie quelconque du corps d'un insecte.

AIGRETTŔ, adj., papposus; papposo (it. ) ; surmonté d'une aigretle. Le Plerocephahus papposus doit cette épithète à ce que le limbe: de son calice dégénère en une touffe de longs filanens plumeux, et l'Asterias papposa ì ce que le corps de ect animal est hérissé en dessus et sur les hords de tubereules soyeux.

AIGREUR, s. f. , acor ; Säure (all.) ; sourness (angl.); asprczza (it.). Qualité de ec qui est aigre, soit an physique, soit surtout au moral. Alou, adj., acuthes, acutatus ; spitzig, scharf (all,); pointed (angl.); acnto (it.). Terme dont on se sert pour désigner : $1^{0}$ ee qui est terminé elt pointe ou en tranchant; fenilles aiguës, quand leurs deux bords s'inclinent iusensiblement l'un vers l'au. tre ì lat base, de manière à former un angle aigu (ex. Stenostomum angutslatum), on qu'elles décrivent ì leur extrémité un angle moins ouvert que le droit (ex. Nerium Olcander); antheres aiguës (ex. Corinthe major); capsules aiguës (cx. Pedicularis palustris) ; filets d'ctamines aigus (ex. Scutellaria alpina); radicule aiguë (ex. Faba major); coquille aiznc̈, dont l'ouverture est aiguë aux deux extrémités (ex. Pleurocerus acutns); antcunes aiguës, dans les insectes, quand elles se terminent par un article aigu et raide $; 2^{\circ}$ ee qui produit sur nous une scusation aualogue ì 
celle que ferait naitre l'action d'un corps pointu, comme lorsqu'on dit un son aigru, c'est-à-dire elair et perçant ; une douleur aiguë, c'est-à-dire forte et vive.

AIGUILLE, s. f., acus; Nadel (all.j; needle (angl.); ago (it.). Nom donné, dans la géographie physique, à une cime de montagne qui s'élève en pointe aiguë et élaneée.

AIGULLÉ, adj., aculeatus; qui a la forme d'une aiguille, d'une pointe longue et mince.

AIGUILLON, s. m., aculeus; Stachal (all.); asting (angl.); pungolo, pungiglione, pruno (it.). Un donne ce nom : $8^{\circ}$ en botanique, it des exeroissances dures et pointues, qui naissent sur les tiges (ex. Rosa canina), le pétiole (ex. Rubus idaeus), le disque des feuilles (ex. quelques Halmiers), le caliee (ex. Cactus Optantia), ou autres parties des plante's, et qui n'ont de eouuexions qu'avec l'écorce, ou inême seulement avec l'épiderme ; $2^{\circ}$ en zoologie, à un instrument offensif ou défensif des insectes Hyménoptères, qui est situé à l'cxtrémité de l'abdomen, dans lequel il rentre : à des osselets aigus qui jouent le rôle de rayons dans les nageoires de certains poissons (ex. $V_{i v e}$ ); à des piquaus répandus soit sur les parties du eorps qui avoisinent la queue (cx. Acanthurus), soit sur tonte sa surface (ex. plusieurs Raics).

AIGUILLONNÉ, adj., acıleatus, acanthias; stachlig (all.); pungiglionato, imprunato (it.) ; qui est muni d'aiguillons. Le Paliurus aculeatus, le Schrankia aculeata, et le Polystichum aculcalum ont la tigc épineuse; le Mracrognalhus aculeatusa quatorze aiguillons devant la nageoire du dos; le Squalus acanthias en a un à chaque dorsile.

AIGULLONNEs, adj. et s. m.pl., Aculeati, Aculeata. Nom donné par Illiger, Goldfuss, Fieinus et Carus à une famille de Mammifères, comprenant ceux qui ont le corps hérissé de piquans; par Lamarek et Latreille à une famille d'insectes Hyménoptères dans laquelle se rangent ceux dont les femclles et les neutres ont un aiguillon caché dans le dernier anncau de l'abdomen.

AIGULLLONNEUX, adj., aculeosus, aculcatus. Épithète donnée par Mirbel aux plantes qui sont munies d'aiguillons.

AILE, s. f. , ala; $\pi$ repor ; Flügel (all.); wing (angl.); ala (it.). Nom donné : $2^{\circ}$ en bolanique, aux deux pétales latéraux des fleurs papilionaeées; à de minces appendiees, membraneux ou foliacés, qui garnissent une partie quelconque de certains végétaux (voyez Arué); à l'appendice comprimé que supporte le dos du eapuchon des Stapelia $; 2^{\circ}$ en zoologie, le plus généralement à des organes de locomotion dans l'air, qui tantôt procurent la faculté de voler récllement, eomme les bras des oiseaux, les maius des chauve-souris, et les membranes articulées sur le dos du tronc de la plupart des insectes hexapodes, tantôt II'agissent que comme des espèces de parachutes, en retardant la chute du corps, comme les expansions eutanées des Galéopithèques, Polatouches, Phalangers et Dragons, et les nageoires peetorales prolongées des poissons voluns. On donne aussi le non d'ailes à des organes construits sur le même plan que les ailes des oiseaux, mais que leur brièveté rend impropres au vol, et qui ne servent qu'à rendre la course plus rapide (ex. Autruche). Enfin, oul le donne encore aux membranes ou nageoires qui garnissent les parties latérales du corps de quelques gastéropodes $e^{t}$ ptéropodes, et il la lèvre externe de certaines coquilles univalves, quand, après l'entier accroissement de l'ani' mal, elle s'élargit et se prolonge d'une 
manière notable. Straus appelle ailcs du sternum une des deux paires d'apophyses du sternum antérieur des insectes, celle qui concourt à former l'enveloppe extéricure du eorselet. ALE, adj., alatus; geflïgelt, befiedcrt (all.); winged (ingl.); alato (it.); qui est garni d'ailes. Se dit: $1^{0}$ en botanique, d'une cipsèle qui est munie d'un rebord ninec et large (ex. Achillea millefolium); d'une feuille qui s'aceonpagne de phisicurs petites folioles attachées à un pétiole eonımun ( ex. Lophira alata); d'une graine qui porte des expansions larges et minees sur ses bords ou ses angles ( ex. Rhinanthus crista salli); d'un pétiole (ex. Wormir alata); d'une tige (cx. Lisianthus alatus, Corcopsis alata, Plerophylon alatum); de rameaux (cx. Minulus alatus), qui sont garnis dans leur longueur d'expansions meinbrancuses ou folineées; d'une Meur dout l'assemblage des diverses parties représente un oiseau qui a lucris) étendues (ex. Opirys vos'écis), ou dont dcux des pétales semblant au dehors de la corolle, horizontales former deux petites ailes zoologie (cx. Iris alala); $2^{\circ} \mathrm{en}$ dont l'âge a lève externe se dilate dans ou d'une (ex. Strombus 'gallus), l'un une bivalve dont la base, vers longée côtés dusommet, est très-proseaux ; des doigts de eertains oitoute leurand ils sont garnis dans étroite lour longueur d'une membrane pures ni lisse, qui n'offre ni découdin tibia postons (ex. Poules d'eau); Kirby postérieur des inseetes, selou pendiec étalé il est garni d'un apLygaus phril qui aide an vol (ex. rax de ees anipus), et du prothocôtés dila animaux, lorsqu'il a ses Tingis cucullés mauière d'ailes (ex. AILEROLN, s. m. spitze (all.); pinion (angl.); alctta (it.); petite aile. On appelle ainsi, en zoologie, une ćcaille convexe situće sous l'aile de eertains insectes diptères (voy. Cueillenon), et un bouquet de trois à cinq petites plumes raides qui sout implantées sur le pouce des oiseaux.

AIrE-PLEDS, adj. et s. m. plur. , Pleropodii. Nom dounć par Vieq.d'Azyr a une classe de Mammifères, comprenant ceux qui ont les membros transformés en ailes.

AILÉS, adj. et s. m. pl. , Alati, Alata. Noun douné par Degeer à une sous-classe, et par Latreille à uue section de la elasse des insectes, conprenant ecux qui ont deux ou quatre ailes, ì moins qu'elles n'avortent ; par Blainville à une tribu de l'ordre des oiseaux nageurs colyıbiens, renfermant ceux qui ont les ailes bien conformées; par Lamarck à une filmille de Mullusques, et par Latreille à une famille de Gastéropodes, eomprenant ceux dont la lèvre droite de la coquille se prolonge latéralement, avee l'àge, en une surte d'aile souvent digilée.

AMANTAInE, adj. Épithète donnée par les minéralogistes à une varićté de unine de fer peu oxidé qui constitue la pierre d'aimant ou l'aimant naturel.

ALMNTIN, adj., magnelicus; qui est propre à l'aimant. Synonyme peu usité de magnétique. Vertu aimanline, ou propriétć de devenir aimant. Cette proprićté appartient au fer, an nickel et au cobalt.

AMMAvTÉ, adj., magneticus; qui jouit des propriétés d'un aimant. Se dit prineipalement en parlant des substances auxquelles ces proprićtés ont étć cornmuniquées par l'art. Barreau aimantite, aiguille aimantćc.

ALNE, s. f., inguina; tV eiche (all.); groin (angl.) ; anguinaglia (it.). Portion du corps de l'homme et de di 
vors mammifères qui est comprise entre la cuisse ct le bas-ventre.

AIOPHYLLE, adj. , aiophyllas

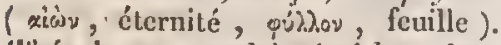
'J'héophraste appelait ainsi les arbres verts, qui ont leurs feuilles persisrantes. Dupetit-Thouars s'est égalesent servi de ce terme.

AIR , s. m., ä̈r ; ànp; Luf (all.); air (angl.); aria (it.) (aípw, cmporter). Nom donné à un mélange gazeux d'oxigène, d'azole et de quelques centièmes d'acide earbonique, qui constitue l'atmosphère de la terre, ct par extension à tout fluide élastique et invisible dont on n'a pas d'intérêt aetuel à spécifier la nature. Voyez GAZ.

AIRE , s. m., arca ; Hof (all.). Ce mot a plusicurs siernifications : $1^{\circ} \mathrm{en}$ astronomie, il désigne l'espace parcouru par le rayon reeleur, en un temps donné, et qui est toujours proportionnel an temps; l'espace compris entre les bords du solcil ou de la lune et l'intéricur des cercles lumineux qui constitueut les halos (voy. ee mot); chacun des vingt-quatre rayons qu'ou adinet du centre it la cireonférente de l'borizon, pour estimer la direction du vent ( $/$ indstrich, all.); $2^{\circ}$ en botanique, Cassini appelle ainsi la surface du clinanthe des Synanthérées, quand on la considèe dans soir cnsemble; $3^{\circ}$ en zoologie, on donnc ce nom au nid des grands oiseaux de proje, particulièrement à celui des aigles (Nest, Horst, all.; airy, angl.)

AISSELLE, s. f. , axilla; Achsel (all.) ; arm-pit (angl.) ; ascella (it.) (latin barbare ascella, assella). On appclle ainsi : $x^{\circ}$ cu zoologie, chez l'homme, le creux qui existe sous le bras, à l'endroit où il se joint a vec l'é. paule; chez lesoiscaux, la région des côtés de la poitrine qui estplacte sous la base des ailes; $2^{\circ}$ en botanique, l'angle rentrant situé au-dessous de l'attache d'unc feuille sur un rameau ou d'un rameau sur la tige. Employé seul, ce mot s'cutend toujours de l'aisselle des feuilles.

AIZOIDÉES, adj. et s. f. pl., Aizoidca. Nom donné par Sprengel à la fumille des Ficoïdes, et tiré du genre Aizoon, qui en fait partie.

AdLGOIDES, adj. et s. f. pl., Ajztgoidea. Non donné par G. Bentham à une tribu de la famille des Labiécs, qui a ponr type le genre Ajuga.

AKENT. $V$. ACMine.

AKÉNOGAMPE, alj., akcnocarpus. Se dit d'une planle qui a pour fruit un aclicne. Ex. Euphorbia akenocarpa.

AK véume, s. f., akncmia ( $\propto$ priv., xyrịun, cuisse). Noun donuć par Breschet à un genre de déviation organiquc, ou d'agénésie partielle, qui est caractériséce par l'alsence des euisses.

AKISTIQUES, adj. et s. m. plur., Acystica (a priv., xíctı́, vessie). Nom douné par Latreille à un groupe de la elasse des poissons, eomprenant e eux qui sont dépourvus de vessie natatoire.

ALABASTRE, s. m., alabastrus, alebasırum. I.ink, d'après Pline, appelle ainsi le bouton à fleur, avant son épanouissement.

ALAB.ASTRIN, adj., alabastrinus,

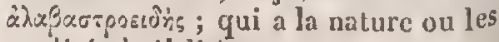
qualités cle l'albâtre.

ALAEFORUE, adj. ; alaeformis (ala, aile, forma, forme). Epithite donnée a une coquille qui ressemble grossièrcment à une aile d'oiseau ćtendue. Ex. Trigonia alacformis.

ALAIRE, adj.; alaris (ala, aile); qui se rapporte aux ailes. En botanique, alaire a quelquefois la mềnc signitieation qu'axillaire; ainsi ull pédoncule alaire est celui qui s'insirtc dans l'angle des luranehes (ex. Li numn radiola). En zoologie, on appelle tectriccs alaires les plumes q.1. couvrent le dessus des ailes des oi- 


\section{ALBI}

seaux, et crochetalaire, dans les Lépidopteres crépusculaires et diurues, unc sorle d'épine grèle, raide, un peu arquéc, qui, parlant de la base inférieure de chieune des sccondes ailes, et se glissant sons une petite saillie, en forme de boucle ou de demi-anneau, situce dans une partie correspondante dn dessous des premic̀res, sert ì maintenir les ailes daus lc repos.

ALAvGrúses, adj. ct s. f. plur., Alangica. Nom douné par Candolle à une famille de plavtes qu'il a ćtablic, et qui ne renferme que le gerure Alangium.

ALANTrNE, s. f., alantina. Quelques chimistes allemands donucnt ce noun à l'imuline qu'on retire de l'Inula Helcrium, appelé Alant dans leur langue.

ALASMUDEs, adj. ct s. m. pl., A las mielia. Nom donné par Rafinesque ì unctribu de la fímille des Pédifères, ayant pour type le grenre Alasmi-

ALAT1ON, s. f., alatio (aln, aile). Terme inusité, dont quelques cntomolo gistes se sont servis pour désigner in manière générale dent les ailes des insectes sont configurées ou disposćes sur le corps.

ALBIBARBE, adj., albibarbis (albarbe blanc, barba, barbc); qui a la barlis blanche. Le Tabanus albide la tête loas de la partic extéricurc la tête blanc.

bus, bICAUDE, adj., albicaudus (ald'un anic, caucla, quenc). Sc dit Ex. Leminal qui a la queuc blanche. bicauda. AI

bus, blanc, ade, adj, albicanlis (al. donnće à des caulis, tige ). Épithètc couverte d'un plantes dont la tige est Ex. Stachys ćpais duvet blanchâtre. AI achys albicrulis. Alancries, adj., alliceps (allus,
blanc, capul, tête); qui a la tête blanche. Ex. Seiurus albieeps. Voy. InUCoĆ́PIIALE.

ALBACOLLE , alj; ; albicollis(albus, blane, collum, col); qui a le col blanc. Ex. Caprimulgus albicollis.

ALBICONNE, adj., albicornis (albus, blane, cornu, corno). Se dit d'un animal articulć qui a les antennes blanches ou d'unc teinte pâle. lixx. Oniseus albicornis.

ALBICOSTE, adj., albicosius, albicostatus (albus, blinne, costa, côte). Epithète dounéc à unc coquillte marquéc de côtes oflrant unc raie blanche. Ex. Modiola albicosta.

ALBUDIPENNE, adj., albidipennis (allidıs, blanchâtre, penna, ailc); qui a les ailes blanchêtires. Ex. Myophora allbilipennis.

ALBBWLOHE, adj ., albiflorus; wcissblumig (all.) (albus, blane, flos, fleur ); qui porte des fleurs blanches. Ex. Didissets albiflorus, $\mathrm{Ga}$ latca alliftora, Delphinium albiforum.

ALBIEABIRE, adj . albilabris, albilabrus (albus, blane, labrum, lc̀vic ). Épithète dounnée ì des crustacés qui ont le museau tacheté de blanc (ex. Ceratina albilabris), ou d'un blane argenté à sa partic supérieure (ex. Ocrptera alluilabra), et à des coquilles univalves qui ont leur bord blanc (cx. Melix albilabris).

ALHIMANE, adj., albimanus (albus, blanc, manus, main ); qui a les mains blanches (cx. Lemur albima. $n u s$ ), on les tarses blanes (ex. Tipula allimana).

AT.BBIVERVE, adj, albinervius(albus, blane, nersus, 'nerf.). Se dit d'une plante dont les nervures des fenilles sont blanches. Tx. Ribes albinervium. Voyez Arß1visné.

ALEITISNE, s. m., albinismus (albus, blanc ). On désigne sous ce nom un genre d'anomalie de l'organisation animale et régétale, mais surtout de celle de l'homme, qui est cirracté- 
risé principalement par le défaut de coloration de la peau, celle-ci restant ou devenant d'un blanc plus ou moins blafard ou laiteux. Dans les plantes, cet état prend le nom d'étiolement. Voyez Leucḱthiopie.

ALBIONIENNES, adj. et s. f. pl. Albioniana. Nom donné pár Savigny à une section de la famillc des Hirudinées, qui a pour type le genre $A l$ bione.

ALBIPE'DE, adj., albipes (albus, llanc, pes, pied); qui a les pattes blanches. Ex. Tabanus albipes.

ALBIPLNNE, adj., albipennis (albus, blanc, penna, aile); qui a les ailes blanches. Ex. Cecidomya albipennis.

ALBIROSTRE, adj., albirostris (albus, blanc, ros(rum, bec); qui a le bec (ex. Anthrilus albirostris, Indicator albirostris) ou le prolongement du museau (ex. Macroccphalus albirostris.) blanc.

ALBITA1SE, adj, albitarsis (albus, blanc, tarsus, tarse); qui a les tarses blancs. Ex. Hermetia albitarsis.

ALBrvervé, adj., albivenius (albus, blanc, vona, vcine). Sc dit d'unc plante qui a les nervures de ses fenilles lanugineuses et blanches en dessous. Ex. Convolvulus albivenius. Voyez A LBINGR VÉ.

ALBIVENTRE, adj. , albiventer, albiventris (albus, blanc, venter, ventrc ); qui a le ventrc blanc. Ex. Trogon albiventer, Coecilia albiventris. Voyez Leucogastre.

ALBODACTYLE, adj., albodactylus (albus, blanc, dźxтu>.as, doigt). Epithète donnée à un papillon dout les ailcs digitécs sont blanches. Ex. $p_{\text {terophorus albodactylus. }}$

ALBUMEN, s. m., albumen. Nom latin francisé du blanc d'œuf. Grew, Gaertner et Candolle ont ainsi appelé le périsperme (voyez ce mot), soit par allusion à l'albumen de l'œuf, soit parce que ce corps a une couleur blanche, dans toutes les graincs.

ALBUWINE, s.f. albumen; Eiwciss, Eivccisstoff(all.). L'un des matériaux immédials des corps organisés, qu'ou trouve, chez les aniniaux, dans le blanc d'oul', les liquides appclés séreux, la natière cérébrale et nervcusc, qui existe aussi dans certains végétaux, où on l'a peu étudić cncore, parce qu'il est difficile de l'obtcnir pur et sans altération, qui varie beaucoup, et qui n'est probablement le même partout ni dans l'un ni dans l'antre règne.

ALBUMHNÉ, adj., albuminosus. Se dit, cn botanique, d'un embryon qui, aprìs la fécondation, absorlue la partie liquide de l'amnios, dont le résidu produit un albumen, en se concrétant.

ALBUMINEUX, adj., albuminosus; civveisssloffhaltigr (all.); qui contient dc l'albumine, quien a les caractères, les proprićtés, les réactions.

ALBUMININE, s. f., albuminina. Nom sous lequel Couerbe a d'abord désigné ce quc depuis il a appelé oonine. (Voyez ce mot).

ALBUMiNo-Caséeux, s.m. Payen et Henry ont donné ce nom à l'amygdalinc, parcc qu'elle leur a paru tenir à la fois de la nature de l'albumine et dc celle de la matière caséeuse.

ALGADES, adj. el s.m. pl, Alcades. Nom donnć par Vigors à une famille d'oiseaux qui a pour type le genre Alea .

ALCAIESCENCE, s. f., alcaleseentia (al, augm., kali, soude). Etat d'in corps dans lequel se développent des propriétés alcalines dont il nc jouissait pas jusqu'alors.

ALCALESCENT, adj., alcalescen.s; kalihaltig (all.). Se dit d'une substance dans laquelle les propriétés alcalines commencent à se développer, ou même prédominent dćjà. 


\section{ALCA}

ALCALI, s. m. alcali, alkali; Laugué d' (all.); alkali (angl.). Applirine abord à nomıner la plante mamerce qui fournit la soude du comgner , ee mot servit ensuite à désice vé prouluit de l'ineinération de les rugetal, et par exterision toutes pričtés chees qui posscident des prode ce chimiques analogutes à calles produit.

ALCaLIFIABLE, adj. Épithète bles de se corps qui sont suscepticertains convertir en alcali, comme avec l'o métaux par leur combinaison union loxigène, on l'azote par son ALCALIFI I'hydrogène.

Gíf.

caligenuLigkNe, adj. et s. m., aldrer). Dé ( alcali, үavvż, engensée pournomination qui fut propoépoque où désigner l'azote, à une entrait ou l'on supposait que ce corps tion de comme base dans la coinposiALCAL les alcalis.

irum (aldititTR:, s. m., alcalinc-

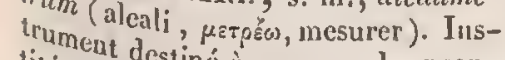
tilé d'aleali destiné ì mesurer la quantasse ou que renferme une po$\mathrm{d}^{\prime}$ après celle sonde du conmmeree, cessaire celle d'acide sulfurique néconnue pour" saturer une quantité ALCAL l'une ou de l'autre.

sus; lauLr, adj., alcalinus, lixiviotient à la genhaft (all.); qui apparmétalliques classe des aícalis (oxides che des ales alcalins), qui se rapprores alcalincs) ment, qui jouit ou, plus ycunéralelines (sel jouit des propriélés alcaqui a rapportin, substance alcalinc), alcalin, pport aux alcalis (caractcre lion alcaline). Alcaline).

dit du cartTE, s. f. alcalinitas. Se d'une manictère alcalin, considéré que substance générale ou dans quelALCALIve en particulier.

TERREUX, adj. , al- calino-terrosus; qui tient de la nature des alcalis et des terres. Base alcalino-tcrrcuse, ou serre alcaline.

AL,CALINULE, adj., alcalinulus. Nom douné à tout sel dans lequel la quantité d'alcali, relativensent ì eelle d'acide, dépasse le terme qui conslitue l'état neutre, sans toutefois s'ćloigner beaucoup de la limite qui répond à la saturatious.

ALGALISATION, s. f., alcalisatio; Alkalisirung (all.). Opération naturelle par laquellel'alealeseen ce se díveloppc.

ALCALISE, adj. alcalisalns; qui a pris le caractère alcalin.

ALCALOH)E, 5. 11) , alcaloides (al-

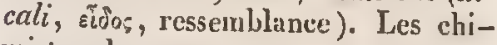
mistes donnent ce nom aux alcalis organiques, pour les distinguer des alcalis minéraux, dont ils diffèrent sous le rapport de la composition et de leurs propriétés générales, quoiqu'ils rivalisent avec eux sous celui de leurs proprićlés basiques.

ALCHMIL, s. f., alchymia, alchimia; Goldmacherkunst (all.); alchymy (angl.) ; alchiniia (it.) (al, augm. chymia, chimie). Art chimérique dont les adeptes reeherehaient les moyens de transmuer les métaux et de préparer un remède propre à prolonger la vie, à guérir toutes les maladies.

ALGICORNE, adj., alcicornis (al. ce, ćlan, corna, corne). Epithète dunnée à une éponge rameuse (Spongia alcicornis), paree que ses rameaux sont comprimés, ce quila fait ressenbler grossic̀rement ả une corne d'élan ; t̀ un insecte (Tabanus alcicornis) dont le troisième artiele des antennes porte unc dent recourbée.

ALCOHOL. Voyez Alco or.

AL.COOL, s. m., alcohol, spiritus vini rectificatissimus; Alkohol (all.); alcohol (angl.); alcoolo (it.); ( al, augm., kol, atténuer). Liquide léger et volatil qui est le principal résul- 
tat de la fermentation vineuse; produit de l'art qui exige des manipulations diverses pour être obtenu à l'état de purcté.

ALCOOLATE, s. m., alcoolas. Noin donné par T. Graham à des combinaisons en proportions défuies d'alcool ct de sels anliydres, dans lesquelles il admet que l'aleool jone le rôle de corps éiectro-négatif, et qu'il croit correspondre anx éthers.

ALCOOLWES, s. m. pl. Guilourt désigne sous ce nom une famille de composés ternaires organiques qui a pour type l'alcool.

ALCOOLIME, s. m. Non donné par Guibourt à l'alcool proprement dit.

ALCOOLIQUE, adj. , alcoholicus; qui conticnt de l'aleool (liqueur alcoo. lique), ou qui a rapport à l'alcool (fermentation alcoolique).

ALCOOLISATION, s. f., alcoliolisatio. Développenent, dans un liquide, des propriétés qui caractérisent l'alcool.

ALCOOList:, adj., alcoholisatus. Se dit d'un liquide qui contient de l'alcool, ou dans lequel il s'en est développé.

ALCOOLOMETRE, s. m., alcoho-

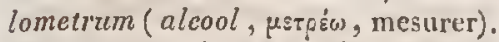
Instrument qui sert a délerminer la quantité d'alcoool absolu contenue dans un mélange queleonque de ce liquide el d'cau.

ALCORNINE, s. โ., alcornina. Nom donné par Biltz à une substanee particulicire, qu'il a découverte dans l'écorce d'alcornoque, et qu'il croit être intermédiaire entre la goraisse et la cire.

ALCYOVAInES, adj. et s. m. pl., Alcyonaria. Blainville appelle ainsi une famille de la elasse des Zooplyytaires, qui a pour type le genre $\dot{A} l$ cyonium.

ALCrovís, adj. et s. m. plur.; Alcyonea, Alcyonce. Nour dommé par

\section{ALÈN}

Lesson à uuc famille de l'ordre des Passcreaux, qui a pour type le genre Alcyon (Alccdo); par Lamouroux, Latreille et Schweiggrer à une famille de Polypes ayant pour type le genre Alcyonizm.

ALCYONIDríes, adj. et s. f. pl., Alcyonidice. Nom donnć par Lamouroux it un ordre des Thalassio phyles non articulées, qui a pout type lc genre Alcyonidium.

ArCioss, s. in. pl., Alcyones. Nom donné par Temminek et par Meyer à un ordre de la classe des $\mathrm{ni}^{-}$ seciux, dont le genre Alcjon (Alecilo) est le type.

ALECTORIDES, adj, et s. m. pl.,

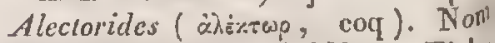
donnć par Illiger, Goldfuss, Eich wald et C. Bonaparte à une famille, par Temminek à un ordre, par J. A Ritgen à un sous-ordre de la elas ${ }^{s^{t}}$ des oiseaux, renfermant ecux de ceb animaux qui, par la forme de letls bec, se lient aux Gallinacés.

ALECTRIDES, adj. et s. m. pl.

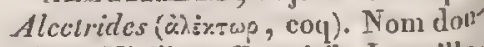
né par Vieillot, Duméril, Latreille? Ficinus et Carus, à une famille de classe des oiseaux, comprenant cen qui ont de l'analogic avec les Galli nacés.

ALECTRIMORPHES, adj. ct s, n pl. , Alectrimorphi (à)exтpis, poulc poopỳ, forme). Non donuć par Rar zani à une famille de l'ordre de Grimpeurs, comprenant des oiseat" qui, par la forme de leur corps, beaucoup de ressenblanee avee poules.

ALECTRURE, adj., alectrurth

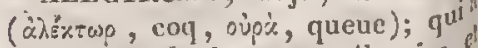
les plumes de la queue élargies disposées en éventail, à peu près cen me eelles du eoq. Ex. Museicap alcctrura.

ALÈNE, s. f. , festuca. Savion! appelle ainsi les soies subulées des nelides. 
ALẺNÉ, adj.; subulalus. Synonymol. peu usité de subulé. Voyez ee

Aléochlanides, adj.et s. m. pl., Aleocharides. Mannerheim donne ce sectes colve tribu de la famille des inpour coléoptères braclıélytres, qui a Alype le genre Aleochara. ungeplontw, adj., alcpidolus; priv. ichthy dexis, ceaille). Se dit, eu peau est ouic, d'un poisson dont la sans écail ou paraît nue, c'est-i-dire AIJiTrives. Ex. Rhombus alepidotus. Aletrincasés, adj. et s. t. plur., bach ì a. Nom donné par ReichenLiliacces une groupe de la famille des 1lactris.
qui a pour type le genre AlGACles, adj. et s. f. pl., Alsacea. Nom donné par Gleditsch Algues de Linné.

ler); freid, adj., algridus (algeo, geépithètes d, glacé. On donne celte par exendes plantes hyperboréennes, qui exoinple ì l'Agraricus algidus, au Draît en Danenarek et en Suc̀de: Jords de lo aleicla, qui croit sur les (Tachina mer Glacialc. Un insecte ce qu'il vit algens) est ainsi appelé parALGives vans l'Anérique du nord.

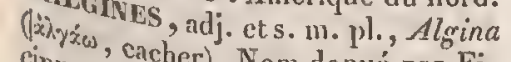
cinus et Carus a Nom donué par Fi-
classe des Lithe famille de la ceux qui Lithozoaires, comprenant se phytoide, saractérisés par une tiALG algue, ${ }_{10 \mathrm{GIE}}, \mathrm{s}$. f., algologia $(a l g a$, botanique qui discours). Partie de la alanique qui iraite spéeialement des
gues.

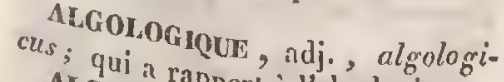
AIGOL a rapport a l'algologic.

Bolaniste qui, s. m., algologus. Ment a l'cetude se livre particuliereAlGues, s. f. ples Alges.
froid, ou algor, troid, ou alligo, pli., Algre (algror,
lier). Noul domé par Tournefort à une classe de plantes dans laquelle il a compris aussi quelques polypes, par Linné, Willdenow et Schreber à un ordre de la classe des Cryplogames, par Jussicu et Greville ì une farmille d'Acotylédones, par Fries à une classe des plantes qu'il appelle llomonćmécunes. Généraleneut, en France, ce sont les eryptoganes aquatiques qu'on désigne aiusi ; inais, counne le fait observer Iamouroux, il est probable que ce terme disparaîtra des ouvrages de botanique, et ne sera plus appliqué qu'aux débris rejetés par la mer, roulés par les vagues, et dont la bande variable indique la force des tempêtes et la bautcur croissante ou décroissante des marécs.

MLHAGĹES, adj. cts. f. pl., Alhagea. Nom donuć par Candolle à une division de la tribu des Légumineuses Hédysarées, rui a pour type le genre Alhagi.

ALiBri.E, adj., alibilis (alo, nourrir); qui est susceptible de nourrir. Synonyme de nutritr.

ALIF⿱一⿻上丨日, adj., aliferus (ala, aile, fero, porter). Chabrier appelle les deux segmens postérieurs du thorax des insectes tronc alifere, parce que les organes di vol y sont toujours fixés.

MLIF ORME, adi., aliformis; fiigeiformig (all.) (ala, aile, forma, forme); qui a la forme d'une aile. Kirby appelle tegmina aliformin, ccux dont la substauce approche de celle d'une membrane, et qui par eonséquent resscinblent un per à des ailes. Ex. beancoup d'inscetes hémiplères homoplères.

ALIMENT, s. in., alimentum; трофиं; Nalurung smillel (all:); food (angl.); alimento (it.). Toute substance quelcouque à laquelle un corps orgauisé pent emprunter les matériaux núcessaires à l'accroissement et au t'cnouvellement de ses organcs. 
ALIMENTAIRE, adj., alimentarius. Sc dit de tout ce qui peul servir d'aliment (substance alimentaire), et de ce qui a rapport aux alimens euxmêmes, considérćs d'une manièrc gćnérale (régime alintentaire).

ALIMENTEUX, adj., alens; nährend (all.); nutritive (angl.) ; nutritivo (it.) ; qui a des qualités alimentaires, qui nourrit.

ALIPEDES, adj. ct s. m. pl., Alipedes ( ala, aile, pes, pied). Nom donné par Duméril aux Chéiroptéres. Jor. ce mot.

ALISMLCíes, adj. et s. f. pl., Alismacece. Famillede plantes ćtablic par C. L. Richard, et qui a pour type le genre Alisma.

ALISMÉEs, adj. et s. f. pl., Alismea. Nom donnć par Bartling à une tribu de la famille des Alismacées, qui a le genre Alisma pour type.

ALISMOIDEs, adj. et s. f. pl., Alismoides. Famille de plantes, établie par Ventenat, ayaut pour type le genre Alisma, nais plus étendue que la précédente.

ALITionc, s. nı. , alitrunens (ala, aile, truneus, trone). Kirby appelle ainsi le segrment postérieur du trone des inscetes, celui auquel l'abdonien est fixé, ct qui porte les puttes de derric̀re, avec les ailes.

ALIZARINI, s. f., alizarina, erythrodanum ; Krapproth (all.) (aliza$r i$, nom de la garance dans le Lcvant). Collin et Robiquet ont appclé ainsi le principe colorant rouge de la garance.

ALIZARIQUE, adj., alizaricus. Zenneek donne le nom d'acide alizarique à l'alizarine, paree qu'il a trouvé qu'elle était faiblement acide.

ALIzí:, adj. Épithètc dounćc ì des vents (Passatwinde, all.) réguliers qui, entre les tropiques, soufflent de l'est vers l'ouest. IIs sont la consćquence mécnnique de la constante présence, au-dessus des régions équatoriales, du soleil, qui dilate lt eouches d'air à mesure qu'ellos présentent ì son influence, par mouvement de la terre; ces couch retombent alors au nord et au sut vers les pôles, d'où reviennent les colt ehes d'air froid, qui n'ayant qu't1" vitesse de rotation très-petite, " raison du parallèle d'où elles vien nent, arrivent suceessivenient à d'a tres parallèles dont la vitesse de $r^{p}$ tation d'occident en oricnt est bea" coup plus grande, de sorte qu'ell" ne tournent pas aussi vite quc points de ces parallèles, et clioquet eu seus inverse, e'est-à-dire d'o rient en occident, avec lout ec o lcur manque de vitesse, les obstac situés dans ces parages.

ALLAITEMLNT, s. m., lactat! Säugung (all.); suckling (angl.); ll tamento (it.). Action d'une fenc de mammifère qui nourrit ses pel de son lait.

ALLANTOATE, s. m., allanto Nom donné à un genre de sels (allo toissaure Salze, all.), qui sont for més par la combinaison de l'aeide lantoïquc avee une base salifiable.

ALLANTOIQUE, adj., allantoich Nom donné (Allantoissüure, al par Lassaigne ì l'acide amniotiql qu'il a prouvé exister dans la lique de l'allantoïde, et non dans cclle l'amnios, comme l'avaient eru Vall quelin el Buniva.

ALLANTOPHORE, adj , allanl

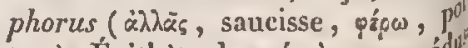
ter ). Épithète donnée à une méd (Equorea allantophora), dont cerclc ombrellaire est forme $d^{\prime}$ ganes eylindröides. $V_{\text {oyez Borel }}$ FÈnE.

ALLIACE, adj, alliaceus; $k \pi 0^{4}$ lauchartig, knoblauchdïfig ( all. (allium, ail); qui al'odeur ou la sare de l'ail. Ex. Agaricus alliace ${ }^{\text {s }}$ Petiveria alliacea, Agarieus of ceus, Agaricus scorodonius. 


\section{ALLO}

ALLLACÉES, adj. et s. f. plur., Reichea. Nom donné par Link et par mille denbach $\vdots$ un groupe de la fale des Liliacées, qui a pour type genre Allium.

ALLIAGE, s. m. , alligatio, conmixim metallicum, metallorum per(anglio; Legirung (all.); allaying de deux ; legagrgio (it.). Combinaisnn de deux ou d'un plus grand nombre nom átaux. Bcrzclius a étendu ce trop aux combinaisons de corps ćlecdrositifs, tels que azotc, soufre, liyélectre et bore, avec ecrtiins eorps métauxégatifs, silieium, arsenic et ALI életronégatifs.

ail); quAIRE, adj., alliarius (allium, simumi a l'odeur de l'ail (ex. Erybabituelliaria), ou qui se nourrit alliarius) ALLOD]

(a) aLLOnROME, adj., allodromus Nom dor bondir, spopes, coursc). allodromné à une araignée ( $L$ rcosa s'élanec s), paree qu'elle court ct ALLo sur sai proie.

ALLOCImRoe, adj., allochrous chang, autre, xpios, coulcur); qui tis alloch eouleur, comme lc Botrypeua à peuroa, dont la teinte passe n'est pas du blane au jaune; ou qui comme partout de la même conleur, jaunât l'Agaricus allochrous, qui cst sous de en dessus et garni en desAId.OGes blanehes.

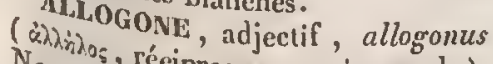
$\mathrm{N}_{\mathrm{Om}}$ so, réeiproque, $\gamma$ wix , angle). minéralnné, dans la nomenclature qui réunique de Haüy, à un eristal celle d'unit à la forme du noyau lìnes, dont dodéenẻdre à triangles scaobtus égal à hacun a son angle plan des faces du plus grande ineidence onales du noyau. Ex. Chaux carAILOPTone.

tera (a)d.lopreses, s. m. pl., allop-

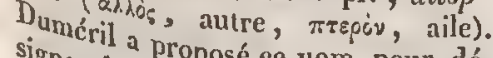
signer les proposé ce nom pour dénageoires peetorales des

poissons, dont la situation varie en effet beaucoup.

AlLOThÉTES, adj. et s. m.pl. , Allotrela ( $\alpha \lambda \lambda \dot{o}_{s}$, l'un ou l'autre, тpnrós, trou). C. G. Ehrenberg désigne ainsi deux familles de la classe des Polygastriques, qui ont la bouche ou l'anus terminal.

ALLURE, s.f., Gang (all.) ; gait (angl.); andatura (it.). Manière dont un animal (un eheval surtout) exerce les divers mouvemens progressifs qui le transportent d'un lieu à un autre. Marche d'un filon dans la roche ou le terrain qu'il traverse ; manière d'être de ee filon, considćré dans solr ensemble et relativement à ses trois dimensions.

ALLUVIAL, adi. , alluvialis. Werner appelait ainsi les roches ou couches qui sc sont formées à des époques très-modernes, el que produisent eneore tous les jours les matières charriées ou déposées par les eaux. On dit souvent dépót alluvial, sable alluvial, terrain alluvial, plaine alluviale.

ALLUVIEN, adj. , alluvius. Brongniart et Onalius donuent cette épithète aux terrains produits par voie mécanique, el principalement par l'action des eaux actuclles, aux dépôts meubles, dans les vallćes et plaines situées à l'embouchure des grands fleuves et sur les bords de la mer, qui porteut l'empreinte évidente du délaissement par les eaux, plutôt par dépôt tranquille que par transport violent.

ALLUvion, adj., alluvies; Anschwemmung, Anflössung (all.); alluvion (angl.); alluvione (it.). Nom donnć par les géognostes à des dépôts partiels et horizontaux de vase, d'argile, de gravice et d'autres matériaux, d'abord transportés et roulés par les fleuves et autres cours d'eau, puis déposés daus les lieux où la marehe de ces eaux s'est ralentie. 
ALIUVIUM, s. m. , allupium. Les géologues, surtout anglais, appellent ainsi tous leseffets, la plupart locan $\mathrm{x}$, des canses naturelles qui n'ont pas encore cessé d'agir en ce noment, et dont le résultat est la formation de nouveaux terrains par l'action des eaux.

ALLUX, s. f. G'est le nom que Kirby dome à l'avant-dernier article du tarse des insectes, quand il offre quelque chose de reniarquable. Ex. Curculio.

ALOítique. $P_{\text {oy. A }}$. AöQue.

ALOGANDLOMĹLE, s. f. , alogandromelia (älnopos, brute, avrip, homme, $\mu$ ślos, nuembic). Nom donné par Malacarneà unc classe de monstres chez lesquels il adne tait gratıitement gu'avec un corps de Jiule se trouvent des nembies d'homme.

ALOGHermanhodits, s. f. , aloghermaphrodilia (ànogrs, bıute , Éperepóótesos, hermaphrodite). Nont donné par Malacarne à une classe de monstres, comprenant les brutes ehez lesquels un même individu r'éumit les deux sexes, qui, normalement, devraient être séparćs.

ALOINE, s. f. , aloina. Meissner appellc ainsi un aleali organiquc, qu'il dit avoir trouvé dans l'aloës, mias dont l'existence demiude encore it être constatée.

ALorvíws, adj. ct s.f. pl., Aloinea. Niom donné par Link à u» groupe de la famille des Liliacées, qui a pour type le genre Aloc.

ALOIQUE, adj., aloicus. Braconnot appelle acidle aloïque on aloëlinue, une substanec obtenue en trálant l'aloës par l'acide sulfurique, que Chcvrcul regarde comme du tannin artificicl, et Gmelin conme de l'amer artificiel.

ALOmíes, adj. et s. f. pl., Alomica. Nom donné par Lessing à une sous-tribu de la tribu des Eupatoriacées, qui a pour type le genre Alomia.
ALONGE, adj., clongatus, prodil lus; verlängerl, langgeaogen (all.), lenglhened (angi.); slongalo (it. Se dit: $1^{n}$ en Lotanique, d'un of gane qui est environ deux fois et $d$ t mi plus long que large; du conne" lif, quand il a une longueur nolf ble (ex. Salvia pratensis); des col" lédons, lorsru'ils sont sensibleme plus longs que larges (ex. Salst raliata); des feuilles, quand ell sont longues et étroites; de l'ur' des monsses, lorsqu'elle est lony et cylindrique ( $\mathrm{ex}$. Coscinodon el galus); cufin, d'après Candolle, tissu cellulaire, quand il résulte eellulcs alongées, de manière à fol mer de petits tubes clos aux dev cxiréinités (dans le bois et les n vures des feuilles) ; $2^{\circ}$ en zoologil les entomologistes disent les élytr alungées, quand elles s'étendent jw quà l'anus ( ex. Trox). On don la mème épithè!e à une coquille wt valve ( ex. Cristellaria product" dont le deruier tour, au lieu d'et brasser tous les autres, s'alonge s'élargissant. Le Lomatia elongala ainsi nommé, parce qu'il a l'abd meu alongé.

AI.PESTRE, adj., alpestris. Se des plantes qui eroissent sur des no tagnes peu élevées ou sur la pat moyenuc des hautes monlagnes, Voohysia alpestris, Dicranum pesire.

ALPIIAULTAIRE, adj. et s. alphabelarius. Linné donnait épithète à tous les botanistes dans leurs ouvrages, n'ont emp que l'ordre alphabétique pour cla: 01 disposer les plantes dout ils tr $^{2}$ taient.

ALPICOLE, adj., alpicola ; vit sur les Alpes. Ex. Grimmia picola.

ALPIGLNE, adj., alpigentes; eroît sur les Alpes ou dans les bath 
montagnes. Ex. Eugenia alpigena, Xylosicum alpigenum.

ALPIN, adj., alpin port atN, adj., alpinus; qui a rap-
sic, ó Alpes. 10 En gćognogroupe appelle caleaire alpin un posése de terrains secondaires compares de chaux carbonatée compaete, Alpes qu'on a cru que les roches des reconn appartenaicint; mais il a ćté beannu qu'elles sont en général tinique plus nouvelies. $2^{\circ}$ En bohabitent alpir se dit des plantes qui mont vers le sommet des hautes Veronges (ex. Rhammus alpinus, num). ${ }^{\circ}$ alpina, Eriophorune alpimem). $3^{0}$ En zoologie, ce terme a la (ex. Lagnification qu'en botanique . Lagomys alpinus).

Alce. Tríses, adj., et s. f. pl., Alsi$l_{a}$ famille ćtablie par Candolle, dans a pour type daryoplyyllées, et qui Als type le genre Alsinc.

Alsocling. FÉE, adj. et s. f. pl., par R. Bre. Famille de plantes, établic une trilsrown, dont Candolle fait qui a pour de celle des Violarićes, et Alpour type le genre Alsodeia. dit, en inant, ndj., alternans. Se feuilletée inćralogic, de la strncture fevilletse d'une roche, quand les ture diffént altcrnativement de naAliférente. Ex. Gnciss.

natim-pinaTI-PENNÉ, adj., alterweclisclndnaths, allerni-pinnatus; ficdert (all.) nalo (it.); alternalivamente pend"une (it.). Se dit, con botanique, sont feuille pennéc dont les foliotes Ex. Amornes sur le pútiole cotumun. ALTorpha fruticosa.

was. En batriF, adj. allernatiallernalifotanique, on dit les pétales quand ils avee les parties du calice, séparent les lobes de celui-ci. Alors mot est synonyme d'alternc. Can-
dolle celle appelle estivation altcrnative tégument laquelle les partics d'un
tument floral sont vertieillées sur denx on plusicurs rangs, et placécs dans la mène direction, par rapport it l'axe, de sorte qu'clles se trouvent alterues entre elles, comme les sépalcs des Liliacées et les pétales des nymphćacécs.

ALTERNE - adj. , alternus, altcrnatus; abwecluselnd, wechselnd, wechselstãndig (all.) ; alternate (angl.); alterno (it.). Se dit : $1^{\circ}$ en mineralogie, d'un cristal ayant sur ses deux parties, l'ıne supérieure, l'autre inféricure, des faces qui alternent entre elles, mais qui se eorrespondent de part et d'antre (ex. Quarz prismé alterne). $2^{n}$ En botanique, on appelle alternes les parties qui sont disposées d'un et d'autre côté d'un axe, sur le mème plan, sans être l'une devant l'sutre; feuilles alternes, celles qui sont disposées d'un ct d'autre côté des hranclies, de manière qque la troisiène naît au dessus de la première, la quatrième au dessus de la scconde, et ainsi de suite (cx. Tilia éuropoea); rameauxaltcrnes, ceux qui naissent solitirires sur divers points, it des distances presque égales (ex. Acremonium alternatum, Alcea rosea, Hypnum altcrnans ); fleur's alternes, celles qui offrent la mème disposition ( $\mathrm{ex}$ : Vinca rosea); spathelles alternes, lorsque deux de ces organes, placés en regard, sont attachés l'un au dessus de l'autre (ex. Agrostis canina); ovules alternes, dins une loge biovulée, quand les points d'attache ne sont pas sur le même plan, quoique les avules se touclient latéralement (ex. Ponmier). $3^{\circ}$ En zoologie, on dit d'un polypier qu'il est alterne, quansl il offie des groupes de cellules alteroes sur les ramenux (ex. Amathia alternata). I:Anthrax alternata est ainsi nommée parec que les eôtés de son abdomen sont garnis de poils alternativement blanchâtres et noirs.

ALTERNIFLORE, adj., alterniflo- 
rus (alternus, alterne, flos, fleur); qui a les fleurs alternes. Ex. Cyperus alterniflorus, Myriophyllum alterniflorum.

ALTRENIF OLIÉ, adj., altcrnifolius; wcchsclblattrig (all.) (alternuts, alterne, folium, fuille); qui a les fenilles alternes. Ex. Valeriana alternifolia, Citrosma alternifolium.

ALTERNI-PENNÉ. Vojez ALterNATI-PENNÉ.

ALTIÍ́ine, s. f., altheina. Nom donné par Braconn ot à une base salifiable qu'il admettait dans l'Altheea officinalis, et qui n'est, selon Henry et Plisson, qu'une substance très-analogue à l'asparagine.

ALTHLOQUE, adj. , altiloquus (altus, ćlevé , loquor, parter) ; qui parle haut. ÜI oiseau (Sylvia altiloqua) a été appelé ainsi à eause de son bruyant ramage.

ALTrMétrí. Voyez IIypsonéTris.

ALTIROSTnes, adj. et s. m. pl., Alicrostres (altus, élevé, rostrum, bec). Nom donné par Blainville à une sectiou de la famille des Hétérodactyles, comprenant des oiscaux grimpeurs qui ont le bee plus hant que large.

ALTrvolE, adj., allivolus $($ altzs , ćlevé, volo, voler ); qui s'ćlève beaucoup. Le Rhodolana altiyola est un arbrisseau grimpant, qui parvient jusqu'nu sounmet des plus grands arlures.

ALUCITADES, adj. et s. m. pl., Alueitada. Nom dounè par Leteh à une famille d'inscetes lépidoptères ayant pour type le genre Alucita.

ALULE, s. f. , alula (ala, aile), petite aile. Nom donné, en ornithologie, à l'aileron (voyez ce mot) des oiseaux; en entomologie, par Kirby, à un petit appendice searieux et convexo-concave, fixé à la base de l'aile, dans quelques diptères, et à un petit appendice membraneux, anguleux, fixé d'un côté à l'élytre, de l'autre au frænum (ex. Ditiseus).

ALUVINALE, adj., aluminaris! aluminarius (alumen, alun). Epithète donuée par les minéralngiste aux pierres voleaniques qui contien nent de l'alun tout formé.

ALUMINATE, s. m., aluminas. Se daus lequel l'alumine joue le rôle d'u' acide combiné avec une base.

ALUMIVE, s. f., alumina; Alant erde, Thonerde (all. ). Terre qui ré sulte de la combinaison de l'alumi' nium avee l'oxigène.

ALUMINÉ, adj., aluminalus; thot" haltig (all.); qui contient de l'alt' mine; pierre aluminée.

ALUUInÉEs, adj. f. pl. Dans méthode géognostique, Omalius dés' gne ainsi un ordre de roches qui con? prend les pierres aluminées.

AIUMINEUSES, adj. C. pl., alum? noste. Les pierres aluminées formen un ordre de roches, sons ee non, dans la méthode géognostique Maraschini.

ALUMINEUx, adj. , aluminosus alaunicht (all.); aluminous (angl.) qui contient de l'nlumine (ex. Antpl" lite alumineuse). Le Decadia alumb nosa est ainsi appelé paree que les Co chinchinois employent l'écorce et fenilles de cet arbre, en guise d'alu' pour la teinture en rouge.

ALUviNIATE, s. m., aluminit Bonsdorff, dans sa méthode minér logique, substitue ec mot à cell d'aluminate.

ALUMiNico-AMmoniQue, adj. aluminico-ammonicus. Épithète do née par Berzelius à un sel double pr. duit par la réunion d'un sel alumin ${ }^{\prime \prime}$ que et d'un sel ammonique. Ex. F $/ l^{1}$ rure aluminico-ammonique (flu d'alumine et d'anmoniaque).

ALUAINICO-BARYTIQUE, adj. aluninico-baryticus. Épithète dol ${ }^{\prime \prime}$ née, dans la nomenclature climiq de Berzclius, à un sel double q 
résulte de la combinaison d'un sel aluminique avec un sel barytique. Ex. Silicale aluminico-barytique ( silieate d'alumine et do baryle).

Aluminico-calcique, adj. , aluminico-calcicus. Épithète donnéc, dans la nomenclature chimique de Bepzelius, à un sel double produit par la réunion d'un sel aluminique et d'un sel calcique. Ex. Silicatc aluminico-calcique (silicate d'alumine et de chaux).

ALUMINICO-HYDRIQUE, adj , aluminico-hydricus. Épithète donnée à un sel double qui résulte de la combinaison d'un sel aluminique et d'un composé hydrique. Ex. Chlorosulfurc aluminico-laydrique, qui est formé de ehlorure aluminique et de sulfure d'hydrogine.

ALUMINICO-LITIIOUE, adj., aluminico-lithicus. Épithètc don née à un sel double qui résulte de la combinaison d'un sel aluninique et d'un sel lithigue. Ex. Phospleate aluminicolithique (phosplate d'alumine el de
lithine). ALUMinico-MAGNísIQUL, adj.,
aluminico-magnesicus. Épithète donnée, dans la nomereciture chinique sont Berzelius, aux sels doubles qui d'un formés d'un sel aluminique et aluminico magnésique. Ex. Silicate lumine ctmagnésique (silicalc d'aAlue ct de magnésie).

ALUMiNICo-poTassioue, adj., née, dans polassicus. Epithète doude Berzelius, à un sel double qui résulte de la à un sel double qui réminique avec un scl potassique. Ex. drochlorale de potassect d'aluminc). ALUMale de potasse ct d'aluminc). minico-sodicus. Épithète donnée, dans lius, ì nelature chimique de Berzealuminique double formé par un sel que. Ex. Sulfate aluminico-sodique I. (sulfate d'alumine et de soude). ALUMINICO-ZINCIQUE, adj., aluminico-zincicus. Epithète donnée, daıs la nomenclature chimique de Berzelius, à un sel double qui résulte d'un sel aluminique combinć avec un sel zincique. Ex. Fluorure aluminicozincique ( fluate d'alumine ot de zinc).

ALCWINIDEs, s. m. pl. Beudant donne ee nom, dans sa classification minéralogique, à une famille de minéraux, qui a pour type l'alumine.

ALUMINIFtre, adj. , aluminiferus (alunen, alun, fero, porter); qui contient de l'aluminc. Ex. Chaux fluatée aluminifóre, qui est mêlée d'argile ferrugineuse.

ALUMiNio-SILIC.1TE, s. m., aluminio-silicas. Dans la classification minéralogique de Bonnsdorff, c'est le nom d'un groupe de sels, dans lesquels l'alumine et la silice sont considérées comme joụant ensemble le rôle d'acide.

ALUMivious, adj., aluminicus: Épithète donnće par Berzclius aux sels dans lesquels l'altamine joue le rôle de base: chlorure, sulfaie, hydratc aluminique. Ia seule combinaison connuc d'aluminium et d'oxigène porte aussi le nom d'oxide aluminique (alumine).

- aldunnisi, s.m., aluminium. Métal qu'il est douteux que Davy ait réduit mais qui a été obtenu pur et isolé par Woethler et OErsted, et qui fait la base de l'alumine.

ALUMuxoxiDE, s. m. Beudant appelle ainsi la combinaison d'aluminium et d'oxigc̀ne, ou l'oxide aluminique (alumine).

ALUNIFlÈnE, adj., alunifcrus; qui contient de l'alun : marne alunifêre.

Aldurioues, and. pl. Omalius appelle de ce nom uu genre de roches, contenant celles dans lesquelles il existe de l'alun tout fornté.

ALUTACE, adj., alutaceus; leder- 
arlig (all.) (alufa, pean mégisséc) ; qui ressemble à la peau molle prćparée par les mégissiers, comme lc champignon appelé Agaricus long $i-$ caudus.

AIvíoraIRE, adj., alvcolurius; qui apparlient aux al vćoles. Le Clerus alveolarius doit ce nom à ce que sa larve vit dans l'intćrieur des ruches d'abeilles, où elle cause de grands dégâts.

AIvíolaImes, adj. et s. m. pl., Alveolaria. Non donné par Latreille iे une fanville de la classe des Polypes, comprenant ceux qui forment à l'extérieur des polypiers polymorphes.

ALVÉolaRiroRue, adj. , alveolariformis (alveolus, alvéole, forna, forme). Un inseete (Ichneumon alveolariformis) a été ainsi nonmé parce que ses eoques, loutes posées les nines ì côté des autres, dans le sens de leur lon rueur, représentcnt, après la sortie de l'insecte, les cellulcs d'nn rayon d'abeilles.

ALVúor.E, s. m., alveolus, alveus, alsuis, alveolum, favicella, foveola, fossula. On appelle ainsi : $\mathbf{1}^{0}$ en botinique, de petites fossettes creusées sur diverses parties des plantcs, ct, d'après Gassini, une cavité produite par la rćunion et la soudure des cloisons du clinanthe de certaines Synanthérées ; $2^{\circ}$ en zoologic, les cavités des os maxillaires (Zahnfach, Zathrhöhle, all. ; hole, angl. ; alveolo, it.) dans lesquelles sont implantécs lcs racines des dents; de petites ecllulcs on loges que les abcilles et guêpes construisent ( Honigzelle, all.; celle, angl. ) pour déposer lcurs ocufs et leur miel et pour élever lcurs lar'ves; les replis de la matière gélatineuse dont certnins Orthoptères cnveloppent leurs œuls.

Alvkolt, adj., alvealus, alveolatus, favosus, faveolalus, impressus; zellig, zalunfïcherig (all.); faviforme (it.); qui cst creusé de fosseltes oul petiles cavités placécs sy- métriquement les unes à côtés des antres et approchant beancoup de la forme des alvéoles des abeilles. Ainsi, $\mathrm{x}^{\circ}$ en botanique, on dit : elinanthe alvéolé (ex. Onopordon ceanthium); graine alvéolice (ex. Papaver somniferunt); placentaire alvćolé (ex. Anagallis arvensis). Le Boletus favus doit ec nom a ce que si surface inférieure présente de très-larges pores semblables à des alvéoles de ruche d'abeilles. $2^{\circ}$ En zoologie, on donue le nom de Spongia favosa ̀̀ une éponge dont les cellules sont séparées seulement par des interstices nombrenx, et celui d'Amplitrite alveolata à tune annelide socinle qui forme avce le sable de grandes masses composécs d'une multitade de tubes plaeés les uns ì côté des autres, et clos chacun par un petit opereule.

ALVÉOLIF ORME, adj. , alveoliformis (alveolus, alvéole, forma, forme ); qui a la forme d'un al réolc d'abeille, comme les cellules de certains Polypicrs. Ex. Vàginipora frasilis.

ALvrN, adj., alvinus (alvis, basventre): qui a rapport ou qui apparticnt au bas-ventre. Le résidu de la digestion cst fort souvent appelé, chez.l'homme, maticres ou dejjections alvines.

ALVITHonsx, s. m., alvithorat (alvus, ventre, $\theta \dot{\omega} \rho \alpha$, poitrine). Mauvais mot que Litreille a introduit pour désigracr le têt des animaux ar ticulés convrant un trone séparé de la tête, qui supporte les six pieds-mâchoires, avec les cinq paircs de picds thorachiques, ct qui correspond all thoracide des Crustacés décapodcs, moins la tète.

ALXSSINÉEs, adj. et s. f. pl., Alyssiner. Nom d'une tribu que Candollc a établic dans la fanille des Crucifères, et qui a pour type le genre Alyssum.

ALISSOLD́Es, arj. et s. f. pl. 


\section{AMAN}

Alyssoidea. Nom donné par Candolle à unc section du genre Pleurandra, comprenant les espèces qui, par les poils de leurs feuilles, resscmblent à des Alyssum.

AMADELPIE, adj., amadelphus

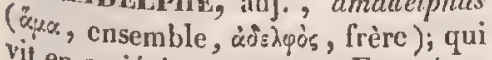
vit en société, cn troupes. Ex. $A_{g} a-$ ricus amadelphus. AMADOUVIEn, adj., fomentarizs,
igniarius. Épithète dounćc à divers champignons dont on se sert pour faire de l'amadou. Fx. Bolctus igniarius, Boletus fomentarius.

AMALGani, s. m. , amalgama

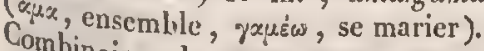
plubinaison dn mercure avec un ou plusieurs métaux.

Sedirgaví, adj., amalgamatus. du mern métal qui est combinć avec mercure.

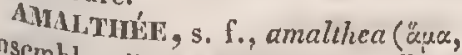
enscmble, a $\lambda \theta^{\prime} \omega$, augmenter). Desplusionne ce nom a la réunion de un eals fruits secs et cornés dans charnue qui persiste sans devenir A.ralti. A grimonia Eupatorium. Amalthei. tribu dei. Debuch appclait ainsi unc ayant de la famille des Ammonćes, Alr pour type l'A. Amalihezis. cleies; mond augrón, Mrandel (all.); almot, (angl.); mandorla (ii.). Ce ler lo qui désigne à proprement par\& peu une de l'amandier, a pris peu vul paine plus gronde extension. Le renferménend par lì toute grainc méme le dans un noyau, y compris mince péricarpe, quand cclui-ci est amande sec. Fn botanique, une (embryon, l'ensemble des orgaues sont contenus on périsperméj qui graine, dons dans le tégument de la citć. dont ils détermilicnt la eapa-

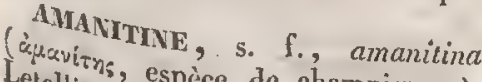
Letelliers dospèce de champignon). donne ec nom au principe
AMBI

vénéncux des champignons, qu'il n'a pu isoler des autres avec lesquels il sc tronve associć.

AMARANTUACÉES, adj. et s. f: pl., Amaranthacece. Famillc de plantes, établic par Jussieu, et qui a pour type le genre Amaranthus.

AMAMANTHOIDES, adj. et s. f. pl., Anaranthoïdew. Nom donnć par Ventenat à la famille des Amaranthacées.

AMAnINE, s. f., amarina (amarus, amer). Quelques personnes ont proposé ce nom pour désigner tıne matière particulière, à laquelle elles attribucnt la saveur amère.

AMARYLLIDÉEs, adj. et s. f. pl., Amaryllidere: Fumille de plantes, ayant pour type le genre Amaryllis, qui a étć établic par R. Brown.

AMATYLLIDIFORMES, adj. ct 3 . f. pl., Amaryllidiformes. Nom donné par $G$. Herbert à une section de la famille des A maryllidées, comprenant celles qui se rapprochent le plus des Amaryllis.

A vitS, s. m., Stock (all.); heap (angl.). Les géognostes employent ce termc pour désigner un masse informe, plus ou noins volumincnse, ì faces irrégulières, jamais planes ni paralleles, dont aucune dimension ne l'cmporte benuconp sur les autres, qui nc constitue pas ì clle seule un terrain, se trouve comme enveloppée par des maticircs d'un genre différent, ct forme ainsi des blocs plus ou noins irréguliers.

AMASTOzo AIBES; adj. et s. m.

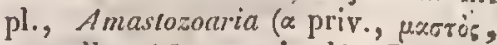
mamclle, ¿َ̧̄oy, animal). Dans la classification zoologicjue de Blainville, ce nom est cclui d'un sous-type du rigne animal, comprenant lcs animax vertébrés qui sont dépourvis de mamelles.

AMBIANNULATRE, adj., ambiannularis (ambo, les deux, annulus, anncat). Epithète donnée, dans la 
xomenelature minéralogique ds Haüy, à un prisme hexaëdre régulier, qui a des facettes disposées en anneau autour de-chaque lose et produites alternativement par deux décroissemens diff́rens. Ex. Chaux carbonatéc ambiannulaire.

AMBIANT, adj., ambiens; untgchend (all.); ambient (angl.) (ambio, entourer); qui enveloppe de toutes parts. Fluide ambiant est un terme dont on se sert très-souvent pour désigner l'atmosphere, qui enveloppe les corps terrestres de toutes parts. Kirby dit le prothorax ambiant, lorsque son sinus est assez large pour recevoir toule la lête (ex. Cluilocerus).

AMmIGEvE, adj., ambigrenus (ambo, les deux, નấvyzw, engendrer). Mauvais mot qu'on a quelquefois employé eomme synonyme de hermaphroditc. Mirbel appelle calice ambigene, celui dont la partie extcrne est de la nature ordinaire du ealice, et l'interne de eelle de la eorolle. Ex. Ornithogalum umbellatum.

AMBiGU, adj., ambiguus ; zweideutig (all.); ambiguous (angl.). Douteux, qui présente deux sens différcns à l'esprit. Se dit : $x^{\circ}$ en ninéralogic, d'un cristal dans lequel les positions relatives des faees qui naissent de différentes lois de déeroissement, offrent un problène ì deux solutions, dont la véritable ne peut ĉtre reeounue qu'i l'aide de la division méeanique (ex. Chaux carbonatie ambiguë). $2^{\circ}$ En botanique, cloisons ambigzuës, eelles qui, dans un périearpe iudéhiseent, font eorps à la fois avee l'axe central et avee la paroi du périearpe, de sorle qu'on ne peut les considérer eomme produites ni par l'expansion de la substance des valves, ni par celle de la subslance da plaeentaire (ex. Orange). - Corolle ambiguë, dans unc plante synanthérée, d'après Cassini, celle qui est interméliaire entre deux des fornes que ee bolaniste a détermiuées. - Hile ambigu, quand il correspond à la fois aux deux bouts réunis d'une graine recourbée on repliée. - Stipules ambigrës, lorsque leur's attaches sont très-marquées à la fois sur la tige et sul" le pétiole (ex. Lotus siliquosu.s). J,e Mercurialis ambigua doit eette épithète à ee qu'il porte des fleurs mílcs et des fleurs femelles sur le mème pied; le Seriphium ambiguum, ì ec qu'il tient en mème temps de quatre genres différens par leurs earactères; le Cleislostoma ambigurum, à ee que ses earnctires équivoques ne permettent pas d'assigner positivement la place qu'il doit oceuper. $3^{\circ}$ En zoolo gie ; la Lutraria a mbigua est une $0^{\circ}$ quille fossile qui se présente dans un tel état de dégradation qu'on ne saurait guc̀res dire comment elle était réellement.

AMBiguifLone, adj., ambiguiflorus (ambiguus, douteux, flos, fleur); qui a des leurs ambignës. $\mathcal{H}$. Cassini appelle ainsi les calathides, les disques et les couronnes qui, dans les Synanthérées, sont composés de fleurs à enrolles ambiguës.

AMBBPARE, adj., ambiparus (an" bo, lcs deux, paro, préparer). Epithèle donnée par les botanistes an bourgeol qui renferme à la fois des fleurs et $d^{5}$ feuilles.

AMBLÉMIDES, adj. et s. m. pl", Amblemider,Amblemide.s. Nom don par Ralinesque à une tribu de la $\mathrm{fa}^{-}$ mille des Pédifères, qui a pour type le genre Amblemas.

AMIBLÉOCARPE, adj., ambleocar" pus (àublow, avorter, жuprés, fruit): qui produit peu de semenees. Es. Carex amblcocarpa.

AMBLYGONE, adj., amblygonts

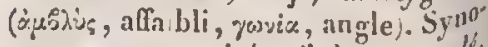
nyme peu usité d'obstusangralk $V_{\text {oyez ce mot. }}$

AMiBIXOPEs, adj. et s. m. pl.'

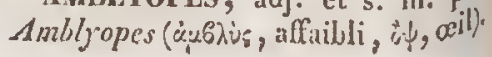


Nom douné par Goldfuss à une famille de Suuriens, comprenant ceux de ces reptiles qui ont les yeu $x$ petits et couveris de peau, en sorte qu'ils voient pen on point.

AMBLYTERE, adj., amblyterts. (àjểves, être émoussé). Epilhète donnéc, dans la nomenelature ninéralogique de Haiiy, is un crislal dans subisel tous les bords et tousles angres ception des décroissemens, à l'exde deux d'un bord situé a la reneontre un anglc faces qui forment ensemble amblytcre.

Ainorées, adj. cl s. f. pl., Amsection A. Richard appelle ainsi une dont le type famille des Monimiées, AMbripe est le genre Ambora.

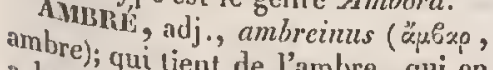
a la couleur tient de l'ambre, qui en ambrće culeur ou l'odeur. La cóuleur sucein, est celle de l'ambre jaune ou l'ainbre et l'odeur ambrée celle de

AMbrítite, s. m., ambreas lerfell, ambre). Geure de se!s (amformés pare Salie, all.), qui sont anbréiqur la combinaison de l'acide 4 Hique avec les bases saliliables. berfeut, Amb, s. f., ambreina; $A m-$ bre).Substrasiof (all.) ïّexp, amde l'anbluse grasse, qui fait la base vert par Pellets, et qui a été décott-

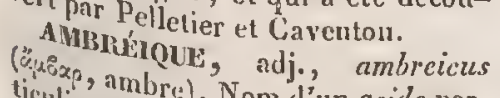
ticulier ambre). Nom (A'un acide parcouvert (Amberfeltsäure, all.), dél'on obar Pelletier et Caventou, que par l'arident en trailant l'aunbréine Ambror nitrique.

(óphis, ambrik, s. f., ambrologia de l'aubre.

AMBrosiackes, adj. ct s. f. pl.,
Ambrosiacece. Nom doun chard al une famille domé par Ripour type le ramille de plantes ayant

amibrosidente Ambrusia.

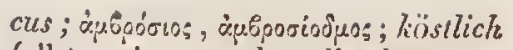
(all.); qui a nne odeur d'ambre, une odeur atríable. Ex. Chenopodium ambrosioülcs.

AMuBosribes, adj. et s. f. pl.; Ambrosiece. Nom donné par H. Cassini à une tribu de la famille des Synanthérées, et par Lessing à une soustribu de la tribu des Sénéeionidées, ayant pour type le genre Ambrosia.

AMrBULACRARE, adj., ambulacraris (ambulo, se promener); qui a la forme d'un ambulaere : aire ambulacraire.

AMBDULACRF, s. m., ambulacrum; Gang (all.). Ce nom a été donné, par comparaison avee une allée de jardin, tanlôt à l'espace compris entre les deux bandelcites d'unc paire, tanlôt ì chaque bandclette elle-mêne formée par les séries de petits trous qui se voient sur le test des oursins.

AMibulaCnifontme, adj., umbulacriformis (ambulacrum, anbulaere, forma, forme); qui a la forme d'un ambulaere, qui inite des ambulacres; sillon ambulacrifornze.

AMBULATORE, adj., ambulatoritus; wandelbar (all.); ambuiatory (angl.) (ambulo, se promener). O1z appelle mouvemens ambulatoires tous ceux qui s'exéeutent sur des eorps solides, eomme point d'appui, et qui ont lieu le plus souvent par le moyen. de patles, quelquefois aussi à l'aide d'organes spéciaux. 1lliger donnait le nou de pieds ambulatoires, chez les oiseaux, à ceux qui sont emplumés jusqu'aux talons, et munis de quatre doigts, trois devant et un derrière, dont les deux externes sont joints it la hase seulement de la première phalauge (ex. Corvus). Kirby employe la mếne expression pour désignicr les patles, chez les inseetes, quand les larses ont la plante spongieuse (ex. Cllurysomcla).

AMIBULIPĹDEs, s. m. pl., Ambulipedes (ambulo, se promener, pes, 
picd). Nom donné par Blainville à unc famille del'ordre des Mammifèrcs carnassiers, comprenant ceux dont lcs mombres, terminćs par des extrémités analogues, sout propres à la progression.

AME, s. f., animus, anima ; $\dot{v} \times \dot{y}$; Seclc (all.); soul (angl.); anima (it.). Ternie vague et indéterminé, qui exprime, en la personnifiant, la cause inconnue d'effets connus que nous éprouvons ell nous, la suite continuelle d'idées et de sentimens qui se succèdent sans intcruption pendant Ic cours de notre vie. - On appelle âme de la plume une séric de cônes cmboîtćs les uns dans les autrcs, que produit l'intérieur de la gaine desséchée, lorsque la plume a pris tout son accroisscment.

AMúivonés, adj. et s. m. pl., 'Ameipodece. Nom donnć par P.F. Titzinger à une famille de reptiles sauriens qui a pour type le genre $A$ meiva,

AMELLOIDLES, adj. et s. f. pl. , Amclloidcu. Iessing désigne sous ce nom une section de la sous-tribu des Astéroïdées Astérćes, ayant pour type le genre Amollus.

AvENTACḰ, adj. , amentaecus, strobilifcrus, juliforus (amentum, chaton). Se dit, en hotanique, d'une plante dont les fleurs sont disposées en forme de chaton. Ex. Acacia ameniacca.

AVENTACẺes, adj. et s. f. pl., Amentacea. Ce nom a ćté donné par Royen et par Guiart à une classe, par Jussieu à une famille, comprenant les plantes qui ont leurs organes de fructification disposés en chaton.

AMEI, adj, et s. nl., amarus; $\pi \iota-$ xpòs; bitter (all. angl.); (umaro (it.). $\mathrm{Ce}$ mot exprime, au sens propre, une saveur généralement désagréable, et qui n'est point susceptille de défnition. On le donne aussi pour épithète à des corps qui sont doués de cette sorte de saveur ( ex. Agaricus amarus, $G$ cn- tiana anärclla, Tetradium amarissimum ; Spath amer, ou chaux carbonatée inagnésifère). Au figuré, il devient synonyme, ou à peu près, de pénible (regrcts amers) et d'offensant (propos amers).

AMIER DE IVELTER. La substance que les chimistes désignent sous ce nom, et à laquclle donne naissance l'action de l'acide nitrique sur l'indigo, fut découverte en i 788 par Hausmann, et obtenue peu de temps après par Welter. Appelée ensuite acidc carbazotique par Liebig, clle l'a été depuis acide nitropicriquc par Berzelius. $V_{0} y$. cc mot.

AMERTUME, s. f. , amaritudo, amaritas, amarities, amaror ; $\pi$ ixpia; Bitterkcit (all.) ; bitterness (angl.); amarezza (it.). Saveur particulière, qui affecte toujours d'une manière désagréable, pour peu qu'elle soit intense.

AMIÉTABOLES, adj. et s. m. pl., amctabolia (a priv., $\mu \varepsilon \tau \alpha \beta_{0} \lambda \dot{\gamma}$, changentent). Noin donné par Leach à une sous-classe de la classe des inscctcs, comprenant ceux de ces animaux qui ne subisscnt pas de métamorphoscs.

AuÉtAmonpuose, s. f., ameta-

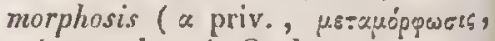
mćtamorphose). Quelques ertomologistes donnent ce nom au phénomòne présenté par certains insectes (ex. Arachnides), qui ne subissent pas de mćtamorphoses, et ne font que changer de peau.

AMÉTANORPIOTES, adj . et s. m. pl., Ametamorphota. Nom donné par Ray à une classe d'insectes, compré nant ceux qui ne subissent pas de mé tamorphoses.

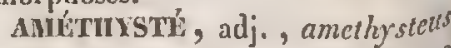

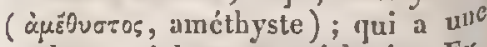
coulcur violettc on violacée. Ex. Agaricus ancthysteus, Clavaria amcthystea.

AUETIISTIN, adj, amethystinus; qui est de conleur violettc. Ex. Hya 
cinthus amethystinus, Boa anethys-
tina.

AMIANTací, adj. , amiantaceus (ćpizytos, amiantc); qui a quelque ressemblance avec l'amiante.

AMIANTOIDE, adj., amiantoides

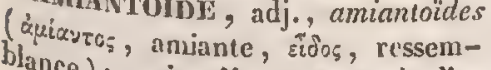
miante; qui a l'apparence de l'adont les comme l'arséninte de cuivie, disposés cristaux filamenteux sont Ayes par touffes.

AMIDIN, s. m., amidinuts. Chequi formelle ainsi le tégument lisse que grain la partie cxtérieure de cha-

donné INE, s. f., amidina. Ce nom, soluble par Cherreul a la sulisiance la gom, et de nalure analogue à chaque qui remplit l'intérieur de applique grnin d'amidon, avait été stance par Saussure à une subparticulicegardće par lui comme donnantere, qu'on obticnt en abandon de ant lui-mêtme l'cmpois d'amique cetroment. Raspail a démontré qu'un dernière sulsstanee n'était grains assemblage de tégrumens des AMID vides d'amidon.
MIDON,

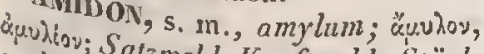
melle ; Satzmehl, Krafimchl, Stärk(it.) (all.); starch (angl.); amido

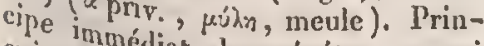
existe danédiat des végétaux, qui tes, et dont grand nombre de plauplusieurs dont les chimistes admettent pales sont variélés; les trois princiline ct l'amid'amidon ordinaire, l'inuAlIJ 0 idon de lichen.

signe so ONITE, s. f. Guibourt désure. AMILAcr. Foy. Amylacé.

d'un corps adj., attenuatus. Se dit $\triangle$ TTENOE. $^{2}$ long, étroit et grêle. Voy. AMMAPTÉnonytes, adj. et s. m.

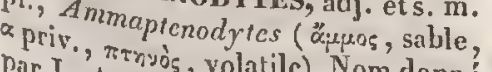
par J., Rty iòs, volatilc). Nom donné , Ritgen ì une firmille d'oi- seaux, eomprenant ceux qui ne volent pas, et qui habitent dans les sables, comme l'autruehe.

AMMINíEs, adj. et s. f. pl., Ammincer, Ammince. K. Sprengel et Candolle appellent ainsi une tribu de la famille des Ombellifères, qui a pour type le genre Ammi.

AMLODYTE, adj , ammodytes (äks$0_{5}$, sable); qui vit dans le sable. I'Astragalus ammodytes croit dans les collines sablonneuses de la Sibérie méridionale.

AMMOLIN. $V$ og. Amoline.

AMMOLINE, s. f. , ammolina (de la première syllabe des nots ammoniacum, anmoniaque, et oleum, huile). Base salifiable qu'Unverdorben a extraite de l'huile animale de Dippẹl non reetifiće.

AMUOIIQUE, alj. , ammolicus. Épithète donnée par Berzelius aux sels qui ont pour base l'anmoline.

AMmONACEES, adj. et s.f. pl., Ammonacea. Sous ce nom, Blainville désigne unc famille de l'ordre des Céphalophores polythalanacés, qui a pour typele genre Ammonites.

AMMONÉEs, adj. et s. f. pl., Ammonea, Ammoner. Nom donné par Lamarck, Eichwald et Orbiguy à une famille de Mollusques Céphilopodes, dont le genre $A$ mmonitcs est le type.

AMMONĹEN, adj. , ammoncantus. Épithètedont sesert Omalius pour désigner un ordre de terrains dans lesquels on trouve des fossiles fort differens des êtres actuellement vivans, et qui renferment le plus abondamment les Amnonites.

AMUONIAC, adj. , ammoniaczes ;

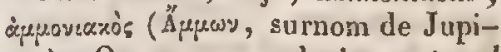
ter). On nornme vulgairement sel ammoniac le chlorure ammonique ou hydro-chloratc d'ammoniaque.

AMMONLCAL, adj., ammoniacalis; qui a rapport à l'ammoniaque, qui en contient, qui en a l'odeur; 
sel ammoniacal, odeur ammoniacalc, vapeur ammoniacale. - Berzelius appelle scl ammoniacal un sel, produit par la combinaison d'un acide anhydre avec de l'ammoniaque, qui contient cette dernière elle-mème et non de l'oxide d'anmonium. Ex. Carbonate ammoniacal.

AMMONLACĹ, adj, ammoniaccus; ammoniakhaltig (all.); qui coutient de l'ammoniaque.

AMMONLACo-MLGNésten, adj., ammoniaco - magnesicts. Épithéte donnéc par les chimistes aux sels qui contiennent de l'ammoniaque et de la magnésie.

AMMONLACO-MERCURIEL, adj., ammoniaco-mercurialis. On donnc cette épithète, en chimie, aux sels qui contiennent de l'ammoniaque et du mercure.

AMMONiAQUE, s. f. , ammoniaca; flüchtigcs Laugensalz, Ammoniak (all.). Alcali gazeux, composé d'hydrogène et d'azote, dins la proportion de trois parties du premier et une du second, et que Berzelius regarde comme un oxide d'ammonium.

AMNONLATE, s. m., ammonias. Klaproth donnait ce nom aux composés d'ammoniaque et d'un oxile métallique.

AMUONICO-ARGENTrQUE, adj. , ammonico-argcnticus. Épithète donnée, dans la nomenclature chimique de Berzelius, à un scl double qui résulte de la combinaison d'un scl annmonique avec un sel argentique. Ex. Fulminate ammonico-argentiqué fulminate d'ammoniaquc ol d'argent).

AMMONICO-CALCYQUE, adj , ammonico-calcicus. Épithète domée, dans la nomenclature chimique dé Berzelius, à un scl doublequi est produit par un sel annonique combiné avee un sel calcique. Ex. Malalc ammonico-calcique ( malate d'ammoniaque et de chaux).
AMMONICO-HYDRIQUE, adj., am" monico-lydricus. Épithète donnée, dans la nomenclature chimique de R̉erzclius, à un scl double qui résulte de la combinaison d'un sel ammonique avec l'hydracide du corps halogène de ce même sel. Ex. Fluorurc ammonico-hydrique (fluate acidc d'ammoniaque).

AMLIONICO-LITHIQUE, adj., ammonico-lithicus. Épitlète donnée, dans la nomenclature chimique de Berzelius, à un sel double résultant de l'union d'un sel anmonique avec un sel lithique. Ex. Phosphate a mmonico-lithique (phosphate d'ammoniaque et dc lithine).

AMMONICO-MLGNESIQUE, adj. , ammonico-magnesicus. Épithète donnée, daus la nomenclature chimique de Berzelius, ì un sel double qui rć sulte de la combinaison d'un sel ammonique avec un sel magnésique. Ex. Sulfale anmonico-magnésique (sut fate d'ammoniaque et dc nagnésie).

AMMONICO-MERCLREUX, adj. , ammonico-mcrcurosus. Épithète don" née, dans la nomenclature chimique de Berzelius, à un sel double qui ré sulte de la combiuaison d'un sel am" monique avec un sel mercureux. Ex. Nitrate ammonico-mercurcux ( $\mathrm{ni}$ tratc d'ammoniaque et de mercure).

AUMONICO-MER CURIQUE, a dj.। amımonico-nıcrcuricus. Épithète don née, daus la nonenclature chimiqu de Berzelius, ì un sel doublc qui rú sulte de l'union d'un sel ammoniqu' avec un sel mercurique. Ex. Sulfal ammonico-micrcurique (sulfate d'ant" moniaque ct de mercure).

AMMONICO-POTASSIQQUe, adj. ammonico-polassicus. Fipithèle dot" née, dans la nomenclature chimique de Jerzclius, is un sel donble qui ré sulte de la combinaison d'un sel ant' monique avec un sel polassique. Ex Oxalarc ammonico-polassique (o.th late d'ammoniaquc et de potasse). 
AMMONICO-SODIQUE, adj. , amdans Bcrzelius nomenelaturc chinique de sultc de, à un scl donble qui réanımonique la combinaison d'un sel Sulfarséni avec un scl sodique. Ex.

Alseniate ammonieo-sodique. moniconICO-URANIOUE, adj., $a m$ dans la ranicus. Epiıhètc dounée, Berzelius nomenclature chimique de la comb, à un scl double produit par avcombinaison d'un sel ammonique aminonico-runique. Ex. Carbonate moniaque zoranique (carbonate d'amAlaque et d'urane).

Grouvenio-azotune, s. m. P. qu'il croit appelle ainsi des composćs d'un azoturesulter de la combinaison Ex. Amre avec le gaz ammoniaque. sium. Ammonio-azolure de polasAlumoNio-chuorune, s. m. composés é par P. Grouvelle à des combina qu'il croit rćsulter de la gaz anson d'un chlorurc avec le clelorure d'niaque. Ex. Ammorio(live d'eicin.

Berzelius moniques donne le nom de scls amcombines à ceux qui résultent de la des acides de l'ammoniaque avec dans leur aqueux, parce qu'il entre on ne peut composition de l'eau, dont cau dont les separer sans les détruirc, en quant l'hydrogìne est précisćment l'arnmonité requise pour former de l'oxigène $m_{1}$ avec l'ammoniaque, et l'oxjyène clu quantité égale à celle de aurait sature toute autre oxibase qui cn sorle qué la même dosc d'acide, réunies que l'ammoniayne ct l'eau dical amanjósentent un oxide du raatomes du nonium eomposć de deux gèric. Lo radical ct d'un d'lydroammonique lème chimiste appel le oxide conmeque l'amunoninque consitérce fure aminoxide d'amnoniun, ct sulsoufre ctonique une combinaison de ct d'ammoniaque constituant une sulfobasc proportionnelle à l'oxide ammonique,

AMMONITES, s. in. pl. , Ammonila. Nom donné par G. de Haan et Mcnke à une fannille, et par Isatreille à une sous-tribu de l'ordre ou de la classe des Céphalopodes, qui ont pour type le genre Ammonites.

AMVONIUM, s. m. , ammonium. Berzclius appelle ainsi la base métallique hypotbétique de l'ammoniaque, qu'il suppose c̀tre un nilrure tétralyy. drique, et dont il regardc l'ammoniaque comme ćtant l'oxide.

AMMONIURE, s. nı., ammoniuretum. Composé d'ammoniaque ct d'un oxide métallique.

A.Movornes, s. m. pl., Ammonoides, Ammonoilea. Nom donné par Orlsigny ct Menkc à une tribu de la famille des Céphalopodes hélicostègues comprenant ccux chez lesquels les tours de spire ne se recouvrent pas, conme dans les Ammonites.

AMHOPHLE, adj., ammophilus

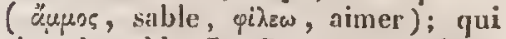
aime.le sable. Le Carex ammophilus est ainsi appelé parce qu'il croît dans les lieux sablonncux.

ANNESTOTHALli, adj., amnesto-

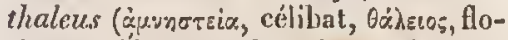
rissant). Epithètc donnéeppar G. Allmann aux plantes qui ont les sexes contenus dans des fleurs séparćes.

AMNIOS , s.m., ammios; sprios, curiov. Malpiyhi et Candolle ont donné ce nom, par analogic avec le rìgne animal, au liquide mucilagineux, qui, après Ia fćcondation, remplit lc spermoderme déjà bicn formé dr's ovules.

AMINIOTATE, s. m., amniolas. Nom donné autrefois à des sels (amlniossaure Salae, all.) qui portent aujourd'bui celui d'allantoale. Foyez ce mot.

AUNiQUE, adj., amnicus. Quelques chimistes ont donné ce nom à l'acide anniotique. 
AMNIOTIQUE, adj. : amnioticus. Vauquelin et Buniva ont donné cc nom ì un acide (Amniossäture, all.) dont ils avaient annoncé la présenee dans l'eau de l'amnios de la vehe, où Dzondi et Proust n'ont pu le reIrouver, mais que Lassaigne a prouvé exister dans le liquide de l'allantoïde, ce qui fait qu'on a changé son nom en celui d'allantoïgue. Voyez ce mot.

AMốuĹs, alj. et s. m. pl. Amocbeca. C.-G. Ehrenberg appelle ainsi une tribu de la classe des Polygastriques, qui a pour type le genre Amoeba.

AMovíls, adj. ets. f. pl., $A$ momea. Richard donnait ee norn, moins usitć que celui de Cannées, s̀ une famillc de plantes dont fait partiele genre Amomum.

AMORI'HE, adj., amorphus; äpop-

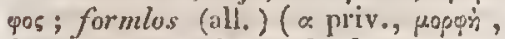
forme); qui n'a pas de forme bien déterminée ou bien distinete. Le $\mathrm{Pe}$ ziza amorpha est ainsi appelé parec qu'avee l'âge, ce ehampignon prend la forme de cupules irrégulières, qui se confondent souvent avec leurs voisines.

AMORLHE, s. f., anorphia; Formlosigkcit (all.). Défnut de forme, difformité, vice de conformation.

AMORPIIOIIY'JE, s. m., amor-

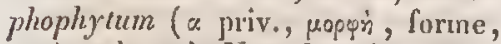

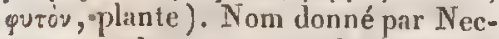
ker aux plantes qui ont des fleurs irrégulic̀res ou anomales.

AMORPHOSE, s. f., amorphosis. Contraction du mot anamorphose. Voyez ec ternic.

A иоприожо ARES, adj. et s. m.

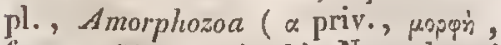
forme, Sürs, aniunal). Nom donné par Blaiuville à un type du règne aniinal comprenant des animaux informes, ou sans forme déterminée, comme les éponges.

AMOLHLANT, adj. Il se dit, en lermes vulgaires, d'une vache qui est prête à vêler on qui vient de vêler une vache qui amouille, qui est sil le point d'amouiller.

AMOULLE, s. f. Nom vulgaire di premier lait fourni par une vache $q^{\prime \prime}$ vient de vêler.

AMOUR, s. m., amor; plizi Liebe (all.); love (angl.); amore (it.) Sentiment impétueux qui porte tu personne d'un sexe vers unc persont d'un autre sexe. L'amour est ult $^{\text {tom }}$ passion bien différente de l'instinc qui pousse les sexes à se reebercher. malgré les lieus intimes qui l'unis" sent à ce penebant. C'est par abus on poétiquement, qu'on le eonfon avee ee dernier, comme Jorsqu'o" dit, en parlant des animaux, la sair son des amours, pour désigner l'épo' que du rut, l'entrée en chaleut' Amour s'entend aussi d'un tendr attachement pour une personne ( $a m$ onl flial, amour maternel). Au figure il exprime un désir ardent, un pen ehant irrésistible pour un objet qued conque, réel (amour des richesses) ou idéal (amour de la gloire). On dil que la terre cntre en amour ou th amitić, lorsqu'au printemps elle not eu aetion la foree végétative des plañ tes, et qu'elle est en amour tant qu la scve eireule avee vigueur dans végétaux.

AMPÉLIDES, adj. et s. m. pl! Ampelida, Ampelides ( $\ddot{\alpha}_{\mu} \pi \mathrm{z} \mathrm{\lambda}_{\mathrm{O}}, \mathrm{p}$, gne). Nom donné par Kunth à ut famille de plantes qui a pour type genre Filis.

AMPELOGRAPHE, s. f. , amp $t^{\prime}$

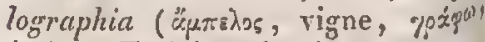
écrire). Traité sur lat vigne.

AMPHANTHE, s. m., amplan' thium; Fleischgehäuse, Blüthenfric

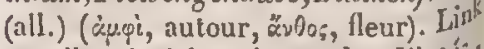
appelle ainsi les réceptaeles dilatés ? par évasement des pédoneules, $q^{{ }^{4}}$ supportent (ex. Synanthérées), qui renferment ( ex. Fictls) lit fleurs. 


\section{AMPH}

bius AMPIIBIE, adj. et s. m., amphiphibious ; press; ; beidlebig (all.); amde ious (angl.); anfibio (it.) (àjugis, $x^{0}$ en botant d'autre, (jios, vic). Se dit: sent indianique, des plantes qui croisdel'earifféremment dansl'eau on hors $2^{\circ}$ en (cx. Polygonum amphibium); quente l'ogie, d'un animal qui fréHourriture l'au, pour y chercher sa (ex. Hip ou pour d'autres motifs d'uin anippopolamus amphibius); ment aninal qui se tient habituelle$s_{u c c i n e a}$ les lieux humides (ex. qui, pourant allonia); d'un animil se tient le plonger très long-temps, Phoques) plus souvent (cx. les leinques), ou toujours (ex. les Baait besoin , sur ou dans l'eau, quviqu'il en temps de respirer l'air de temps rer que et ne puisse jamnis respirespire l'ee fluide; d'un animal gui sa vie et l'air à certaines époques de les $C_{\text {renowill }}$ l'air ecrtaines autres (ex. qui respouilles); enfin d'un animal Sirena lace à la fois l'air et l'eau (ex. le seul oucertina). Ce dernier eas est reusement mot amphibie soit rigouAMput appliealyle.

Amphibiib. Bass, adj. et s. m. pl. , une classe d'aninville désigne ainsi prenant ceux d'animaux vertébrés, eombranchies, soit qui respirent par des soit au moins pendant touteleur vic, de temps, pendant un certain laps des Batraciens correspondant ì l'ordre AMPrilibies, des autres zoologistes. Amphibia. Nos, adj. et s. in. pl.,

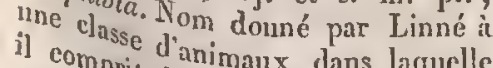
poissons ehit d'ahoraux des dans lacinelle reptiles ehouldrop dé reptiles et les
reuls. piens, puis les et Carus seuls; par MIerrem, Ficinus tous les à une elasse qui cmbrasse classe reptiles; par Latreille à une traciensus ine renferme que les ba-
une par Cuvier et une trilsu; par Cuvier et Desmarets it et Latreille ar Duméril, Tiedemann des Mammifeiles un ordre de la classe
ates
AMPH

AMPUIBIOLOGIE, s. f., amphi-

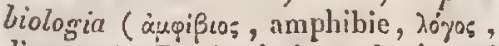
discours). Partie de la zoologie qui traite de l'histoire des repliles.

AMPIIBIOLOGUE, s. m. , amphibiologus. Naturaliste qui s'oceupo spécialement des reptiles.

AMPUIBOLEs, adj. et s.f. pl., Amplibola (àpqepétìas, ambigu). NoIn donné par K. Sprengel à une section des IIydrophyles qui correspond aux Dialomées d'Agardli.

AMPIIBOLES, adj. et s. m. pl.,

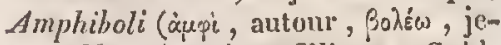
ter ). Noun douné par Illiger et Goldfuss à une famille, et par Savi à une tribu de l'ordre des Passereaux, renferniant des oiseaux qui ont deux doigts en avant et deux en arrière, dont le postérieur externe est versntile.

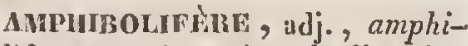
boliferus; qui contient de l'amphibole. Ex. Granile amphibolifére.

A MPHUDOLIeU, adj. , amphibolicus. Epithète dont lcs géognostess se servent pour désigner tnute roche dans laquelle l'amphibole eristalliséo entre comme partic eonstituante essentielle, ou dont elle fait la base (cx. Granile amphibolique, roche amphibolique). Les roches amphiboliques fornent un genre dans les elissifieations de Bonnard et d'Omalius, un groupe dans celle de Brongniart.

AMPUIBOLINS, adj. et s. m. pl., Amphibolini (èpopi, autour, Bodés. jeter). Nom donné par C. Bonaparte î la famille d'oiseaux que d'autres ornithologistes désignent sous celui d'Amphiboles. Voyez ce mot.

AMPIHLOLOSTILE, adj. , am-

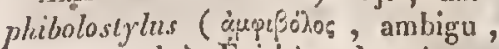

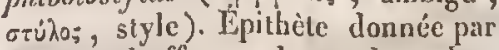
Wachendorff aux pluntes daus lesquelles le style n'est presque point apparent.

AMPHIGARPE, adj., amphicarpus, amphicarpos (iupois, de part et 


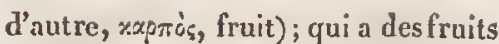
de deux sortes, soit quant a la forme, soit quant à l'époque de lemr maturation. Le Lathyrus amphicarpos est ainsi appelé pareeque ses légumes supérieurs sont linéaires, et les inférieurs ovales; le Milium amphicarpon, paree qu'indépendamment des flcurs de sa panicule, il en a d'autres radicales, dont les fruits mûrissent avant eeux des autres.

AuPIICUnTE, adj. , amphicurlus (àupixupsos, arrondi ). L'Equorea amphicurta doit cette épithète ì ce que son ombrelle est presque hémisphérique.

AMPIIIDE, adj. ( àmis, de part et d'autre). Berzelius appelie sels amphides eeux qui résultcut de la eonibinaisond'un acide avee une base, c'est-à-dire d'un oxacide avcc une oxibase, d'un sulfide avec un sulfure, d'un selénide avec un séléniure, d'un tclluride avee un tellurure, paree qu'ils sont dus ì la eombinaison de composés produits par des corps amphigenes.

AMPIIDESMITLS, adj. et s. m. pl., Amphidesmiles (aupor , de part et d'autre, jequóę, lien). Nom douné par Latrcille à une fautille de la elasse des Couchifères, eomprenant ceux qui out un doulle ligament cardinal.

AMPIIGASTRE, s. m., amphi-

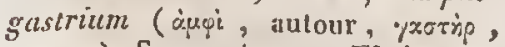
ventre). Sous ce nont, Ehrhart et Link désignent eelles des stipules de certaines jungermannies qui sont insérées sur la tige, gu'elles recouvreni et embras-ent.

AMPIIGASTRIÉ, adj., amphigastriatus. Lithète donnée par \$.-B. Linderberg aux jungermannies stipulées.

AMPIIGQkNE, adj. , ampligenus (jupis, de part et d'autre, زäyvjes, produirc). Berzelius doune ce nonı aux corps simples qui produisent des acides et des bases, Voyez Basigine.

\section{AMPH}

AMPIIGÉNIQ⿻日e, adj. , amphige niens; qui conticnt des cristan $\mathrm{x}$ d'am' phigène disséminés. Ex. Téphri amphigénique.

AMIPHIHEXAEDRE, adj. , amplis hexaedrus (áupi, autour, šç six Ėox, hase). Se dit, dans la nomen" elature minéralogique de Haüy, d'ul cristaldans leruel lcs faces, prises denx sens différens, l'un latéral, l'al tre longitudinal, eomposent le $\mathrm{cos}^{\mathrm{g}}$ tour d'un prisme hexaëdre. Es Epidoce amphihexaëdre.

AlpIInLÉTuQue, adj. , amph

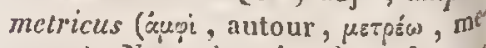
surer ). Nom donué, dans la $110^{\circ}$ menclature minéralngique de Haiif: à une varićté de chaux carbonat composéc de l'éçuiaxe et d'un do décaëdre produit par un décroisst ment sur les bords inférieurs, dal laquelle l'incidenee des deux faces ${ }^{\text {i' }}$ tućes de part et d'autre de l'un do mêmes hords est égale à l'angle pla obtus de l'équinxe.

A.MPIIMNLÉTIQUE, adj. , amph

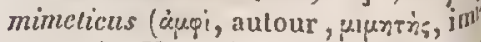
taleur ). Nom donné, daus la no nenclature miuéralogique de Haür à une variété de chaux carbonaté eomposée du rhomboïde primitif et deux dodéeaëdres, dont l'un a grand angle de ses faees égal à plus grande incidence des fuces? primitif, et l'autre la plus grande in cidence de ses faces double de la pla petite partic de eelle du primitif.

AMPHINOMÉEs, alj. et s. f. pl Amphinoma, Amphinomea, Am phinomea. Nom donné par Blainville une famille de la classe des Chétopo des, par Savigny, Lamarck et La treille ì une famille de la classe do Annclides, ayant pour type le genll Amphinome.

AMIPIIPNEUSTES, adj. et s. nit pl. Amphipnensta (suois, de purt

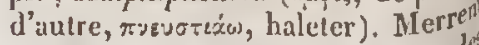
appelle ainsi une tribu de la elassed 
reptiles, comprenant ceux qui ont simultanément des branchies et des poumons, e'est-à-dire deux appareils respiratoires. AMprinpones, adj. et s. m. pl.,
Amphipoda (àq, , autour, $\pi 0 u \tilde{s}$, pied). Nom donné par Cuvier, Latreille, classe des et Straus à un ordie de la se des Crustacés.

phipodiformiforue, adj., ampode, formis (amphipodus, amplicette forma, forme). Kirby dome herbivores éte aux larves hexapodes, tennes, ont uni, avee de longues anet sauteur. un corps court, comprimé AMPir. Ex. Gryllus.

sarca (omoiroue, s. m. , amphiDesvarux (ápi, autour, ox̀p déliste appelait ainsi un fruit inligneux , multiloculaire, sec et térieur. à l'extérieur, pulprux à l'inAlr. Ex. Adarsonia Baobab.

pl. IIISBÉNIENs, adj. et s. m. Latreillephisbecnii. Nom donné par et Carus à une famille, par Fieinus a une i une trihu, et par Blainvillc ophidiens de l'ordre des reptiles Amphisb, qui ont pour typele genrc AMrengna.

pl. AMrisbínoines, adj. et s.m. noidei. Amphisbanoida, Amphisbeeger et Eichwald donnent à une fapour type reptiles ophidiens ayant AMpe le genre Amphisbana. ziveischationen, adj., amphiseius; \%ix, attig (ali) (cuppi, autour, peupl omble). Epilliete donnéc aux ride, qui habilent la zone tortournée parce qu'ils ont leur ombre vers le tintôt vers le midi et tantôt la lerre pard, suivant la position de AMPur rapport au soleil.

(aupi, autoum, adj, , amphistomus. cntoure la bour, oripx, bouche); qui phistoma bouche. La Clymene antbord demi-it eette épithète à un redessus de salindrique qui avance au
souche.
AMPHISTOMES, adj. et s. f. pl., Amphistomi. Nom donué par Bridel à un ordre de la fanille des mousses.

AMPLITRITÉES, adj. ct s. m. pl., Amphitriea, Amphitrita, Amphitritcs, Amphitritea. Non donné par Savigny, Lamarek, Latreillc , Goldfuss, Ficinus et Carus, à une famillc de la classe des Annclides, par Blainville à une famille de celle des Chétopodes, et par Eichwald à une fanille de celle des Grammazoaires, qui ont pour type le genre Amphitrile.

AMTHITROPE, adj., amphitropus (àrẹi, autour, rporśs, retourner). Richard donne ectte épithète à l'embryon végétal, lorsqu'il est tellement courbé, que ses deux bouts se dirigent vers le hile, et sont à peu press également voisins. Ex. Cruciferes.

AMPHITROPIE, s. f., amphitropia. Phénomène qui a licu lorsque, dans le développement progressif de l'ovule végétal, le hile, qui s'est confondu avec la chalaze, ne reste pas avec elle directement 'opposé it l'exostome, mais que la situation relative da hile, de la chalaze et de l'exostome change plus iard, l'ovule se courbant, dans le même temps qu'en se renversant il éenrte son hile de la chalaze.

AMPLIUMuDís, adj. et s. m. pl., Amphiumidea. Nom donné par J.-E. Gray à une famille de la classe des reptiles, qui a pour type le genre Amphiuma.

AMPHIU⿴囗十⺝⿱宀匕, adj. et s. m. pl.", Amplinemoidre. Fitzinger nomme ainsi une famille de la classe des reptiles, ayant le genre Amphiuma pour type.

AMPIIORE, s. f., amphora. Quelques botanistes ont donné ce nom, en raison de sa forme, à la valve in féricure et demi-sphérique des pyxides, après qu'clles se sont divisées en deux ì l'époque de la maturité. Ex. Anagallis arvensis.

AMPLECTIF, adj., amplccis'us, 
amplectans, amplexans (amplector, embrasser). En botanique, on dit la préfoliation amplective quand les feuilles sont pliées longitudinalcment, et qu'elles ont leurs denx bords serrés dans une autre feuille, qui est pliče aussi de la même manière. Ex. Iris.

AMPLEXATILE, adj., amplexatilis (amplector, cmbrasser). lichard domne cette épithète à l'embryon végétal, lorsque la radicule s'ćlargit au point d'embrasser tout le reste. Ex. certaines Graminées.

AMPLEXICAUD h, adj., amplexicaudatus (amplector, embrasser, cauda, queue); qui a la queuc embrassée, enveloppéc cntic̀rcment dans la membrane interfémorale. Ex. Molossus amplexicaudatus, Phyllostoma amplexicaudata.

AMPLEXICAULE, adj., amplexicaulis; umfassend (all.); ambraeiafusto, amplessicaule (it.) (ampleetor, embrasser, caulis, tige); qui embrasse la tige. Se dit : clu pétiole et du pédoneule, quand ils embrassent la lige par leur base ćlargic; des feuilles (ex. Loranthus amplexicau(is, Lamium amplexicaule) et des stipules (ex. Cardamine impatiens), quand elles sont sessiles, et qu'elles s'élargissent à leur insertion, de manière à se prolonger latéralentent pour cutourer en parlie la tige ou le ramean, sans que leurs lobes se soudent ensemble en devant.

AMPLEXIFLORE, adj., amplexiflorus (amplector, cunbrisser, flos, fleur); qui embrasse la flcur. Se dit des squanclles du clinauthe de ecrtaines Synanthérées.

AMPLEXIFOLL', adj., amplexifolius. (ampleetor, embrasser, folium; feuille); qui a des feuilles amplexicaules. Ex. Loranthus amplexifolius, Leptarrhena amplexifolia.

AMPLIATIELORE, adj., ampliatlflorus (amplio, agrandir, flos, fleur). Epithite donnće par H. Cassini à la couronnc des Synanthéréesi quand elle est eomposéc de flcurs corolles amplifiées.

AMPLIÉ, adj., ampliatus; erweit tert (all.) (amplio, agrandir). Kirby dit les élytres amplices, quand elles sunt disproportionnellcment larges leur extrémité. Ex. Lycus faseiatus.

A.IPLIFIÉ, adj., ampliatus; $\mathrm{er}^{-}$ weitert (all.); aumentato (it.) (amplio, agrandir). Nom donné par H. Cassini à toute corolle de Synanthérée don Je linbe, nolablement élargi ou dilaté, est évasé en tous sens. Ex. $C^{\circ} a^{a}$ nus setretum.

AMPLITUDE, s. f, amplitudo; IV eite (all.). Les astronomes appellen? ainsi l'are de l'horizon compris entre le vrai point d'orient ou d'oecident el le centre d'un astre, à l'instant de son lever ou de son coucher. L'ampli tude de la variation diurne d'une aiguille de déclinaison est l'angle que cetle aiguille parcourt depuis la station du matin jusqu'au maximum di déviation occidentale; cet angle, va riable ehaque jour, est le plus grand en été et le plus petit en hiver.

AMPOUI.E, s. f., ampulla; Blast (all.); blister (angl.); ampolla (it.). Wildenow et Link appellent ainsi les corpuseules globuleux et ereux qui se développent sur les racines de certaines plantes aquatiques (ex. Utricula ria), et procurent à ees végetaux la faculté de surnager. On donne également ce nom aux vésicules pleines d'air qui garnissent eertaines hydrophyle's (cx. Fueus vesiculosuss).

AMPOULk, adj., ampullatus ; blo sig (nll.); swelling (angl.); qui a la forme d'unc ampoule. L'Oxytropts ampullatus est appelć ainsi à cause de scs légumes renflés.

AMPULLACĹ, adj., ampullaceus, ampulla formis; flaschen formig(all.): ampollaceo (it.) (ampulla, ampoule); qui a la forme d'une vessic ou d'une bouteille. On dit : $1^{0}$ en botanique, 
corolle ampullacée quand ellc est renflée à la base (ex. Erica ampulla$c e a)$, ou quand son tube est gibbenx (ex. Loranthus ampullaceus). Ise $L i-$ chen ampullaceus a ses cupules grosses et reuflées. Le $S$ placlinum ampullongem a son urne garnie d'un proune pent renflé, qu'on a comparć à dit pu'te fiole; $2^{\circ}$ en zoologie, on dacé. Une hydatide a le corps ampul. épithète eoquille prend aussi cctte flée lorsqu'elle est ventrue et ren(ex. Cancellaria ampullacca).

AMPULLAILE, adj., ampullarius. ampullaircsue, on nomme glandes qui sont for des espèces d'ampoules l'épict formées par la dilatation de incolore el remplies d'un liquide cristallinum. Mrsembryantliemum ni d'ine une eoquille ayant la forme teille poire alongée ou d'une bouA (ex. Fistulana ampullaria).

NuYTES, adj. et s.f. pl., Amycles. "iu'il á établié par Oppel à une famille les chélablic dans l'ordre des reptiAluryiens.

rires ; mandLAIRE, adj., amy grlala-

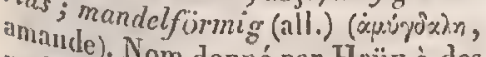
roches dont donné par Hiaüy à des cequelcs le caractère consiste en contiennent yarx ou amandes qu'elles cas que si se trouvcnt daus le mêmc "prìs co ces corps ćtaient venus préparées se loger dans des celluies parées pour les recevoir.

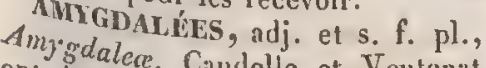
ont donné la famille ce nom ì une tribu de type le des liosacées, ayant pour Lindley, Spre Amygdalus, et que gce en famille. Alixgisale.

liferix (antwines, adj., antygdaporter). Se dit, en minćralo, fero, gcócle qui dit, en minéralogie, d'une (ex. Quarz agale prromaqu mobile que amygdalifere); et cn botanique, d'un plante qui porte des amandes (cx. Caryocar amygodaliferum).

AMYGDAIIN, adj., amrgdalinus, amygdalinaccus; mandelartig (all.): On dil, en minéralogic, qu'une roclee a une strueture amygdaline quand elle est eomposée de partiés ovoîdes, serrées les unes eontre les autres ct comme liées par un réseau (ex. Marbre Campan). En botanique, l'Eucalyptus amygulalina est ainsi appelé paree que ses fleurs ressemblent ì eelles de l'amandier.

A MYGDAIJNE, s. f., amygdalina. Substance cristallisable, que Robiquet et Boutron-Charlard out obtenue des amandes amères.

AMTGDALINÉES. Voyez AMrgDatéEs.

AMYGD.LOIDF, adj. , amygdaloüdes ; mandelsteinartig (all.)

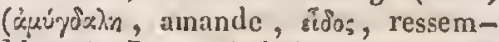
blance). Les minéralogistes disent que les roches ont unc structure amygdaloïde lorsqu'au milieu d'une masse prineipale elles renferment des noyaux plus ou moins arrondis ct en forme d'arnandes, qui paraissent s'c̀tre formés, postérieurement ì eetle masse, par suite d'une iufil tration dans des cavités qui y existaient avant son passagé à l'étal solide. Bronguiart ne donne cclte épithète qu'aux rockes formécs de pétrosilex compacte renfermant des noyanx eontemporains de la mème substance, qui en diffèrent sculement par la couleur.

AMTIACH, adj., amylaceus ; slärkmchlartig (alli.) (äpusov, amidon); qui tient de la nature de l'amidon. La feculc antylacée est l'amidon proprement dit. Saussure appelle ligneux anylacé (holzartigcs Stïrkmehl, all.) une substanee pulvérulente, obtcuue eu traitant l'amidon par la potasie et l'acide sulfurique, et que Raspail considère eomme des tégumens d'amidon à demi charbounós par l'action do ees réactifs, 
mais susceptibles encore de se eolorer par l'iode.

AMILIDEs, s. m. pl. Guihourt donne ce nom ì une famille de composés ternaires organiques qui a pour type l'amidon.

AMVOONINE, s. f. , amylonina. Ce nom a été imposé par Waltl à ufie substance particulière, qui est le produir de l'action réunie des acides sulfurique et nitrique sur l'amidon.

AUYRIDÉES, adj. et s. in. pl., Amyridece. Nom donnć par A. Richard et Candolle à une tribu de la famille des Térébinthacées, qui a pour type le genre Amyris, et que Kunth a érigée en famille.

AnYRINE, s. f., amyrina. Nom donné par Bonastre à une sous-résine ou résinule qui provient du sue résineux de l'Amyris clemifera.

ANABANTOUDES, adj. et s. m. pl., Anabantoidci. Nom donné par Eich wald à une famille de la tribu des poissons osscux acanthoptćrygiens, qui a pour type le genre Anabas.

ANabastés, adj. et s.f. pl., Anabasea. Nom donné par C.-A. Meyer i une tribu de la famille des Chénopodées ayant pour type le genre Anabasis.

aNABENes, s. m. pl., Anabcena (àvaßaivw, monter). J.-A. Ritgen désigne sous ec nom une fa-mille de reptiles sauriens, comprenant ceux qui grimpent au sommet des arbres, comme les camélćons.

ANABENODACTYIES, adj, et s. m. pl., Anabanodactyli (àvapaisw, monter, díx:ujos, doigl ). Nom donné par J.-A. Ritgen ì une famille de reptiles sauriens dans laquellc il range ceux qui ont les doigts propres à grimper, comme les caméléons.

aNAIB́nOSACRLENS, adj. et s. m.

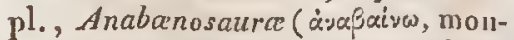
ter, caūpos, lézard). Nom donné par J. A. Ritgen à une fanille de reptiles, comprenant les sauriens qui, eommo
Tes eaméléons, grimpent atu somme des arbres.

ANABICE, s. m. , anabix (av

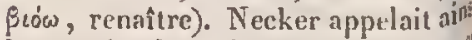
les parties des végétaux eryptogam? qui se trouvent hors de terre, la frull tification cxceptée, parce qu'elle meurent de bas en haut, et s'enl cinent à mesure par le côté qui rơ gardc la terre.

ANABLASTÈUE, s. m. , anablas tema; thallodische Lagersprosse (all

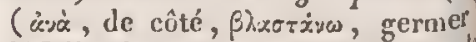
Wallroth désigne sous ce nom productions particulières de certail lichens que Gaerıner a appelées $p r^{\circ}$ pagines bracteolatce, et Dillenius fith bria farinosa crispa.

ANABLASTESE, s. f., anabll tesis ; Lagcrsprossenbildung (all. Non sous lequal Wallrotlı désig̨ la production des organes appl. par lui anablastemes.

ANA GAMPTIQUE, adj., anacam

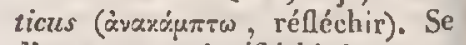
d'un corps qui réfléchit le son au Iumière.

ANACAMPTEE , s. m. , anaed

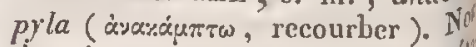
donné par Hedwig à des écrilles et lées, et recourbées au sommet, $q^{13^{10}}$ trouve dans quelques plantes erypl garnes, sur le chapeau de certat champignons (ex. Agaricus ot ceus), sur le thalle de plusieurs chens (ex. Lichen squaniosus).

ANACARDÍ́ES, adj. et s. f. pl, Anacardica. Nom donné par J uss el A. Richard et Candulle a une tri ou à une section de la famille Térébinthacées, ayant pour type genre Anacardium.

ANAGLASTIQUE, adj. , anacly

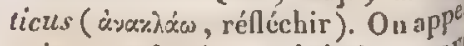
point anaclastique celui où un $\mathrm{r}^{\mathrm{a}}$ lumineux se réfracte.

ANADROME, adj., anadroth ( $\dot{\alpha} v \dot{\alpha}$, en dessus, ipojuos, couts Epithète par laquelle on désigne 
poissons qui remontent dela mer dans l'intérieur des fleuves.

ANAEME, adj. et s. m., ancemus

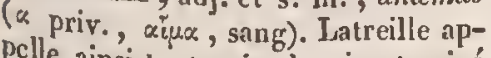
pclle ainsi tout aninal qui est privé d'organes eireulatoires et de sang. Ex.

ers inlestinaux.

ANAGLYPTIQUE, adj , anaglypticus; halberhobengearbeilet (all. ); dont la surface est garnic d'élévations régulières, et semblables à des bosselures ou à des sculptures. Synonyme peu usité de bosselé. $V$. ce inot: ANAL; adj., analis; qui a rapport anglas. On appellc, en zoologie, angle analde l'aile des insectes, l'analc interne de la base de cette ailc; arca analis, d'après Kirby, toute la partie de l'aile qui, dans les diptères, est situće cutre la nervure internomédiane, ou, dans les orthoptères, entre l'anale et le hord postérieur; crochet anal, le erochet d'uue valve l'extrémile bivalve, quand, il cst ì Lingula Kirbula); nervure anale, d'aprìs d'un , la principale nervure de l'aile ou insecte, voisine du bord interne les postérieur; segment anal, chez quel annelides, celui qui, dans vre ou mêtus de ces animaux, couanales même dépasse l'anus; tectrices qui garnissentla oiseaux, les plumes dessous de la queue des rectrices, aumalux ont la queue. Quelques aniz parce qu'ils recu l'épithète d'analis, nus d'une outs les alentours de l'adu corpse autre couleur que le reste ANA (ex. Necycialis analis).

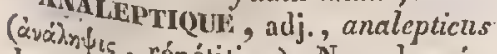
dans la nopépétition). Nom donné, de $\mathrm{H}_{\text {auijy, }}$ à une uature minéralogique bonatće dà une varićté de chaux carl'intersections laquelle, par suite de hexaëdre ave des pans du prisme inversc avec les faccs du rhomboïde degrés et les angles de cent quatrc ment sur ees qui existent naturelleI. placés par d'autres angles, pour reparaítre dans des partics différentes.

AnAluUvion, s. f. A. Eaton appelle ainsi les alluvions ou détritus produits par la déeomposition des roehes.

ANALOGIE, s. f., analogia, èvahópla; Ehnlichkcitswerhällniss (all.). Rapport, proportion. On cntend par là un ou plusicurs rapports de conformité ou de ressemblance entre des chosés distiuctes qui ont des points semblables el d'autres dissemblables; la perception actuelle de la similitude ox de la eonnexion de deux ou plusieurs ehoses présentes; l'aetion de saisir les propriétés communes; les caractères semblables des = objels matériels, la corrélation dé ceux-ci avec nos organes, dg nos ofiganes avec nos faeultés; 'Popération 'quini eonsiste, élant connu le rapportlde deux faits, à conclure de l'un l'existence de l'autre; une méthode qui foude des axiones et des forınules sur des eas particulicrs, qu'elle étend à tous les cas possibles, d'aprìs Ics lois de l'entendement.

ANALOGIQUR, adj. , analogicus. Se dit, dans la nomenelature minéralogique de Haüy, d'un cristal dont lit formc présente des analogies remarquables, soit en elles-mềnes, soit comparativement ì d'autres variétés. Ex. Chaux carbonatéc analogiquc. ANALOGISME, s. m. , analogis-

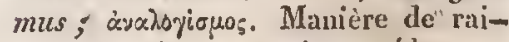
sonner qui consiste à procéder par voie d'analogie.

ANALOGUE, adj. , chalogus; ’̀vx́doyss; ïbereinstimmend (all.); analogons (angl.); qui a son pareil, ou à peu près; qui a de l'analogie, de la ressemblance avee quelque chose.

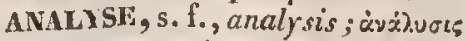
( $\dot{a} \dot{\alpha}$, à travers, $\lambda \dot{u} \omega$, délier). Méthode qui renonte des effets aux eauses, des consćquen̉ees aux principes. En botanique, ce terme est employé 
comme synonymed'anatomic, ou plintôt de dissection. Il a presque la même signitication dans la langue des chimistes, qui l'cmployent pour désigner la réduction d'un tout à ses principes ćlémentaircs, ct le font ainsi à peu près synonyme de décomposition.

ANALYTIQUE, adj., analyticus ;

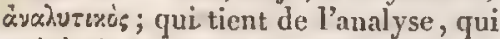
a été obtenu par analyse; méthodc, rćsultat analytique.

AxAMOIMIILUE, adj , anamor-

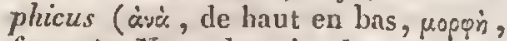
forme). Nom donné, dans la nomenclature minéralogique de Hauiy ; à un cristal dans lequel, quand on le place suivant sa' position la plus naturelle, le noyau se trouve renversé. Ex. Baryte sulfatéc anamorphique.

ANAMORPIIOSE, s. f., anamor-

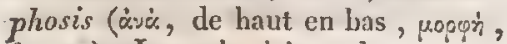
forme). Les physiciens donnent ce nom à des figures qui, envisagées sous un certain point de vue, ou avec le secours de certains verres, représentent tout autre chose que quand on les examine sous un autre point de vuc ou sans le secours de ces verres. Wallroth et Friesle donnent aussi à des dégénérations qque subissent fort souvent les plantes cry plogames, celles surlout de la section des algues, et qui les transforment en espèces atypiques, c'est-àdire dont la forme naturclle est altérće soit par un arrèt soit par un excès de dévcloppenent.

ANANUIBIIRE, adj., anandrarius ( $\alpha$ priv., àvir, honune). Candolle appelle feur anandraire la flcur double dans laquellc les tégumens et les pistils se sont mnltipliés pour la prodnire, et où manqzient les ćtamines.

ANANDRE adj, anander, anandrius ( $\alpha$ priv, ¿rvip, homme). Link donne ce nom aux planles qui sont privées de sexes, et de cette manière le rend synonyme de cryptogäme: Le T'ussita gro anandrius doit cette épi thète ì ce qu'il n'a point d'organcs mâles, quand il croît dans un clinat qui ne lui est pas favorable. Flet" anandre cst synonyme de flcur for mellc.

ANANDRIQUE, adj. , anandricts ( a priv., ¿̀vip, homme ). Fries donne cette épithète aux végétaus qui n'ont rien de comparable aux parties sexuelles, aux fleurs qui son privées d'étamines.

ANANTIIE, adj., ananthus; bliv-

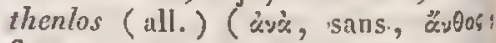
fleur); qui ne porte pas de fleurs.

ANAPURODLTIQUE, adj. , and phroditicus ( ¿̀vò, sans, Äọpoderth ? Vénus). Se dit d'un corps organist qui se développe sansle concours des sexes, c'cst-à-dire qui n'est pas le pro' duit d'une génération proprement dite.

ANARMOSTIQUE, adj., anarmos"

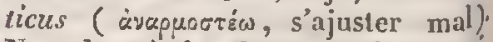
Nom donné, dans la nomenclature mí néralogique de Haüiy, à un cristal dans lequel tous les décroissements naissent sur les augles, excepté un qui a lieu sur les bords, ou réciprogue ment. Exx. Chaux carronatćc anar mostique.

ANASTATICÉES, adj. ct s. f. pl"s Anastaticcre. Nom donné par Carr dolle à une tribu de la famille des Crucifères, ayant pour type le gent? Anastatica.

ANASTOMOSANT, adj., anasto mosans ; anastomosirend, aderïstig zusammenniündend (all.) (civix, aveci бะópa, bouchc ); qui s'anastomose. Daus le Jussicea ancstomosans, le nervures latéralcs des feuilles se rét nisssent en une ncrvure unique, $\mathrm{p}^{\mathrm{g}^{\prime}}$ rallèle an hord. Daus l'Andromed anastonosans, les nervures se rétr nissent à la face inférieure des feuilless? par un point saillant.

ANASIOHOSE, s, f., anastomet 


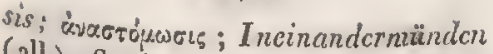
(all.). Sc dit, en botanique, de la réunion des diverses parties rameuses les unes arec les autres.

ANASTOMOTIOUE, adj., anasiomoticus; qui ćtablit unc anastomose ; banche ou ramcau anaslomolique. ANATIDís, adj. ct s. m. pl., Anatida. Vigors désigne ainsi une famille d'oiseaux palmipèdes qui a pour type genre Anas.

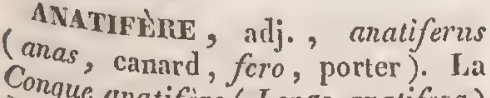
doit cet anatifèrc (Lepas analifera) surdette ćpithète à une croyanee abrope, des habitans du Nord de l'Eunaissau s'inaginent qu'clle donne sance aux canards sauvages.

Avatrférncís, adj., Anatiferamille Nom donnć par Menke à une faa pour la elasse des Cirripèdes, qui ANour type le genre Analifere.

Analifirianos, adj. ets. m. pl., Graliferida. Nom donné par J.-E. Cirrip une famille de la classe des Arripedes, qui a pour type le genre
Anale.

Férustares, s. m. pl. , Anatifa. famille désigne sous ce nom une ayant pour type le des Cirropodes, ANATr type le genre Anatife. canard); adj., anatinus (anas, canard. qui a des rapports avec le appeléc Ial Lingula analina a été imite la ainsi parec que sa coquille ANA forme d'un bec de canard. canard TPLDE, adj., analipcs (anas, une pattes, pied); qui ressemble à analipes. Aves.

tomia, aNIE, s.f., analome, ana\&usoun; athomia, ars anatonica; anatony. Zcrgliadcrungskunde (all.); (àd, à (angl.) ; notonia (it.) Science a travers, fśuve, couper). nombre, qui apprend à connaítre le les connexions et la structure des ders, vers organes ct tissus des animaux ct des végétaux.

ANATOMIUE, adj. , anatomicus; anatomisch (all.); anatomical (angl.); qui a rapport à l'anatomie. Le $M e-$ scmbryanthcnum analomicum est ainsi appelé parce que, quand ses feuilles meurent, il n'en persiste que la nervure seulement.

ANATONISTE, s. m., anatomicus, arliculator, disscclor, dissecator, proscclor, secator; Anatomiker (all.). Celui qui s'occupe d'anatomie,

ANATLOPL, adj., anatropus (àve-

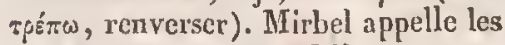
oyulcs anotropes quand l'exostome se rapproche du hile et lui devient contigu, tandis cue la chalaze se trouve diamétralement opposée à ce dernicr (cx. Liliacecs).

ANCIIONUÉES, adj. et s. f. pl., Anchonia. Nom donné par Candolle à une tribu de la famille des Crucifères, qui a pour type le genre Ancho nium.

ANCIIONTEs, adj. et s. m. pl.;

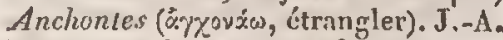
Ritgen appelle ainsi une famille d'oiseaux qui, comme ceux du genre $L n-$ nius, vivent de proie vivante, qu'ils ćgorgent et déchirent.

ANCiIUSINE, s. f., ancluzsina. On a proposć d'appelcr ainsi le principe colorant rouge de l'oreanette ( $\Lambda$ nchnsa tinctoria), que quelques' chimistes nomment acide anchusiquc, et que Pelletier regarde comme une sorte d'acide gras.

AncilusiQue. $V_{\text {oy }}$. Anchustxe.

ANCIPIT', adj., anceps; zweischncidig (all.); affilato, purnaliformc (it.); qui cst comprimé, avec les deux bords tranchans, comme un. glaive. Se dit, en botanique, 'de la tige (ex. Trachymene ancers), des rameaux (cx. Loranlhus anccps) et des feuilles (ex. Peyrousia anceps) ; cn zoologie, d'unc coquille oftrant la même forme (ex. Ranella anceps). 
ANCISTROPODES, adj. et s. m. pl.;

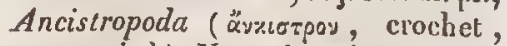
$\pi \circ \bar{u}_{5}$, pied ). Nom donnć par J.-A. Ritgen à un sous-ordre d'oiseaux, caractérisé par la longueur des ongles de ecux qu'il renferme.

AvCxú́s, adj. et s. m. pl., Ancylea. Nom donué par Menke à une famille de l'ordre des Gastéropodes hypobranehes, qui a pour type le genre Ancylus.

ANDICOLE, adj., andicolus; qui habite dans les montagues appelées Cordilières des Andes. Ex. Ceroxylon andicola.

ANDOUILLER, s. m., Augsprosse (ail.); antler (angl.). Nonı donné aux branches que chacune des perches du bois du cerf jette it dater de la troisiène aunée d'ìñe de cet animal.

ANDRALOGOVÍLIE, s. f. ; andralogomelia ( $\dot{\alpha} y \dot{p} p$, homme, àdayss, brute, $\mu \varepsilon \lambda_{\lambda} \varsigma$, membre). Nom donné par Malacarne à une classe de monstres ehez lesquels il supposait gratuitement qu'avee un corps d'honime se tronvent les membres d'unc brute.

ANDRANATOMIE, s. f., andranttonia; dंvơpaveroun (àvip, homme, $\dot{\alpha} \dot{\alpha} \dot{\alpha}$, à travers, тร் tomie de l'homme ; disscction d'un cadavre appartenant à un individu du sexc masculin.

ANDhentTes, s. m. pl., Andrenela. Nom donné par Latreillc à une tribu de la famille des Mcllifères, par Lamarek et Goldfuss à une fanille d'Hyménoptères, ayant pour type le genre Andrena.

ANDRENOIDES, adj. et s. m. pl., Andrenoides. Nom donné par Latreille à unc sous-tribu des Apiaires, à cause de la ressemblance des insectes qui la composent avee eeux du genre Andrena.

ANDRḱOILES, adj. et s. m. pl. , Andreoidce. Nom donné par Bridel à une famille de mousses qui a pour type le genre Andrecea.

\section{ANDR}

ANDROCEE, s. m., androcaum. J. Roeper, admettant que la plupart des fleurs sont composées de quatr verticilles de feuilles, propose d'ap peler ainsi le troisième, c'est-ă-dire l'ensemble des ćtamines, afin d'avoir un terme colleetif analogue à ceux do corolle pour lcs pétales, de calici pour les sépales et de pistil pour le e $^{9}$ earpelles.

ANDRODKNAME, adj., andrody" namus (àrip, homme, jovxurs, puis" sance). Fries appelle les végétaus dicotylédons plantes androdynames, à cause du grand développement que prennent chez eux les etamines et leurs analogues, les pétales.

ANDROGYNAIRE, adj., androg)"

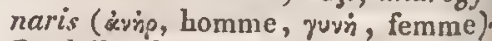
Candolle donne cette épithète aux flcurs doubles dans lesquelles la trans formation en pétales s'est opérée sur les deux sortes d'organes sexuels, sans que les tégumens floraux soient altérés.

ANDROGYNF, adj. el s. m., an

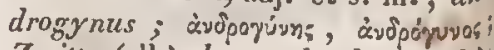
$Z$ witter(all.); hermaphrodite (angl.)i

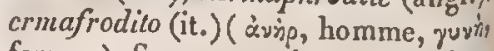
femme). Synonyme de Hermaphro' dite (voy. ce mot), quand on parlo d'une monstruosité humaine. En zo⿰ logie, on appelle androgyne to ${ }^{\text {th }}$ animal qui réunit les deux sexes, soil qu'il ne puisse se féconder lui-mên (cx. Limacon), soit qu'il ait eet faculté (ex. Huâtre). En botaniques cette ćpithete est donnée soit alls plantes qui ont les sexes dans de flenrs séparées, mêne sur nn selt pied (ex. Ruscus androgynus, Mniult androgynum), et alors elle est syno" nyme de Monoïque (voy. ce mol), soit à celles qui réunissent les dew sexes dans une même envcloppe flo rale, et alors elle est synonymed hermaphrodite.

ANDROGYNIE, s. f. , androgynit (ànp, homme, jurn, femme). Nom 


\section{ANDR}

imposé par Malacarne à une classe de monstres qui sont caractérisés par la présence des dcux scxes chez un mème individu. Breschet lui donne un sens plus vrai, en lui faisant désigner un genre de dévialions organiques, ou de diplogénèses, qui est caractérisé par la réunion d'organes plus ou moins imparfaits appartenant à des sexes différens. En botanique, le mot androgynie exprime la réunion des deux sexes soit dans une même fleur, soit seulement sur un même individu.

AVDROGYNIFLORE, adj., androJrniforus (androgynus, androgyne, fos, flcur). H. Cassini donne ectie des 'pithète à la calathide et au disque fleurs Synanthérées, quand toutes les Ars sont hermaphrodites.

androoGYNI-MASCULIFORE, adj., donnegrni-masculiforus. Epithète Synee par H. Cassini au disque des rieures cérées, quand les flcurs intéherma sont mâles et les extéricures quand des dites (ex. Chaptalia), ou diles son fleurs nuâles et herıaphroAmellus) entremêlées enscmblc (ex. ANDro.

ricus. HOGYNIQUE, adj. , androgygrniqu. Cassini appelle siyle androdes fleu, dans les Synanthérćes, celui offre la réunermaphrodiles, lc seul qui propres réunion de tous les caracieres Dichoga cet organe; et Sprengel, nique, lc camie (voy. ce mot) androgysent avant cas où les anthères mûrislum majus lesstignates (ex. TropccoAndus).

ment chimie, s. f., andronia. Éléthétiquemique de l'atmosphère lyypoSchubcrt, admis par Winterl et voir ce que sans qu'on puisse trop satendre par lì.

pelalarius (iNATAIRE, adj., andro-

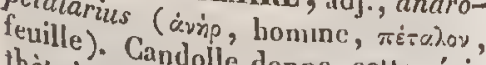
thète à toute fandolle donne celte épifeur double où la corolle
ANÉL

est multipliée, ct où les étamines sont changćes en pétales simples ou multiples, le pistil restant sain.

ANDROPIORE, s. m., andropho-

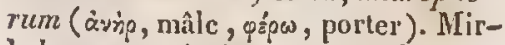
bel nomme ainsi le support des étamines, quand il en souticnt plus d'unc. Il donne également ce nom à la grappc fructifere du Salvinia, parce qu'clle n'est composée que d'involucres mâles.

ANDROPOGONÉES, adj. et s. f. pl. , Andropogonece. Nom donné par Kunth à une tribu de la fanillic des Graminćes qui a pour type le genre Andropogron.

ANIDIOSHME, adj. , andrcscmus

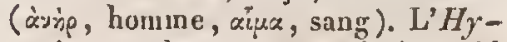
pericum androsamum est ainsi appelé parce que ses baies fraiches rendent un suc rouge comme du sang lorsqu'on les éerase entre les doigts.

ANDROTOMES, adj. et s.f. pl.,

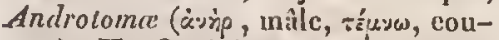
per ). H. Cassini propose d'appeler ainsi lcs Synnnthérées, parcc qu'elles ont les filets de leurs ćtamines divisés en deux parlics par une sorte d'artieulation.

ANDROTOMIE, s. f., androtomia;

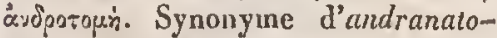
mic. Foy. ce mot.

ANÉLCTRIQUE, adj., anelectricus ( a priv., n̈) thète donnée à des corps que l'on eroyait incapables d'acquérir les propriétés ćlectriqués par le frottement ; opinion erronće, ear tous les corps sont électrisables de cette manière : sculement tous n'ont pas la faculté de retenir l'électricité qu'on y a développée.

ANúLOPTÉries, adj. et s. m. pl., Aneloplera (áveı aile ). Ray appelait ainsi les insectes ì qualre ailes dont les supérieurcs n'ont point la consistance d'élýlics.

ANÉLYTLES, adj. et s. m. pl.,

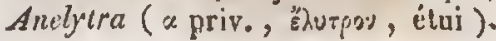


Lister et Charleton donnaient ee nom aux insectes ì deux ou quatre ailes no mbraneuses, nues ou recouvertes seulement soit de poils, soit d'écailles.

ANÉMOGRAPHIE, s. f., anemo-

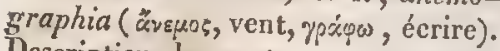
Description des vents.

AvEMOMt'TRE, s. m., anemome-

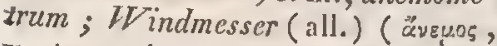

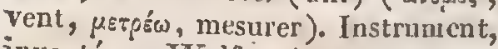
inventé par Wolf, qui sert à mesurer la vitesse du vent.

ANÉHovítrmiE, s. f., anemone--

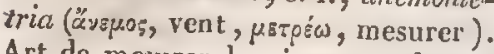
Art de mesurer la vitesse et de reconnaître la direetion du verıt.

ANLMOMÉTTIOGRALIIE, s. m. anemometrograpluts (čvspos, vent, $\mu s \tau \rho \dot{\varepsilon} \omega$, mesurer, ypó trument disposé de inanière à produire sur du papicr un tracé qui indique la durée et la vitesse du vent.

ANÉLONÉES, adj. et s. f. pl. Anemonece. Nom donuć par Guetlard à la famille des Ricnnnculacćes, et par Candolle à une tribu de cette même famille, ayant pour type le genre Anemone.

ANEMONELM, s. m. Nom donné par Heycr à l'anémonine. $V_{\text {oyez ce }}$ mot.

ANËMonine, s. f., anemonina. Stéaroptène, ou sorte de camplire, qu'on obtient en distillant les Anemone Pulsatilla, pratensis et nemorosa.

ANÉMONIQUE, adj., anemonicus. Nom donné ì un acide, encore peit connu, que Grossmann a trouvé dans l'Anenione praiensis, Heyer dins l'Anemone Pulsatilla, et Swarz dans l'Anemone nemorosa.

ANíluoscopr, s. m., anemoscopium ; Windweiser (all.) (《̈vapos,

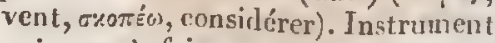
qui sert à faire connaituc les variazions de la direction des vents.

ANENCÉPHALE, adj. el s. mi., anen.

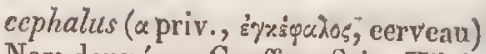
Nom donné par Geoffroy-Saint. Hilaire à un genre de monstres, comprenant ceux qui sont privés de cerveau et de moelle épinière.

ANENCÉPHALIE, s. f. , anenee-

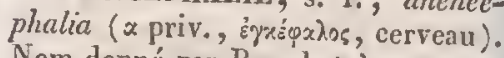
Nom donnć par Breschet à un genie de déviation organique, ou d'agénésie partielle, caractérisée par l'absenee du cervenu.

ANEvTÈnes, s. m. pl., Anentera

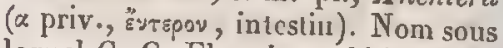
lequel C.-G. Ehrenberg désigne une section de la classe des Polygastriques, comprenant ceux qui ont plusieurs estomacs, sans anus, par conséquent sans canal intestinal.

ANERPONTES, adj. et s. m. pl.,

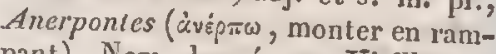
pant). Nom donné par Vieillot et Ranzani ì un farnille de l'ordre des Passercaux, comprenant des oiseaux ì qui leurs ongles aigus procurent la faculté de s'attacher aux corps et de grimper le leng des murs et des trones d'arbres.

ANERVÉ, adj., ancurosils ( $\alpha$ priv., vaüpoy, nerf). Les ailes anervées, dansles inseetes, sont, d'après Kirby, celles qui n'ont pas d'autres nervures que les marginales. Ex. Psilus.

ANESIPOMES, adj. et s. m. pl., Anesipoma (àvecia, liberté, $\pi \dot{\omega} \mu \alpha$, opercule). Nom donné par Isatreille à une tribu de la fanille des Siluroïdes, comprenant des poissons qui ont l'opercule mobile.

ANFRACTUECX, adj., anfractuosus; lerummgä̈ryig (all.) (anfractus, cirenit); qui offre des sinuosités. On doune cette épithète aux anihires quii, étant coutournées, présentent des especes de sinnosités d'un aspect remarquable. Ex. Eriodsndrum anfraetuosun.

ANGẂLCLES, adi. et s. f. pl., Angelirece. Nom donné par Caudolle ì une tribu de la famille des Ombelli- 


\section{ANGI}

fêres dont le type est le genre $A n$ selica.

ANGIOCARPE, adj., angiocarpus (áyyeiov, vase, yeprrís, fruit). Sous ce nom, Mirbel désigne les plantes dont les fruits sont recouverts par quelques organes étrangers qui les déguisent, ou réunis cutre eux de manière à ne pas ôtre reconnaissables au premier coup d'oeil. Ex.: Coniferes.

ANGIOCARPES, adj. et s. m. pl., Angiocarpi. C'est le nom que, dans sa scconde classifieation, Persoon impose à une classe comprenant les champignons dont les séminules sont contenues dans l'intéricur du végétal, qui est et reste elos de toutes parts.

ANGIOCAMPIEN, adj., angiocarpeus. Synonyured'angiocarpe. Voyez ce mot.

ANGIOGastres, adj. et s.m. pl.,

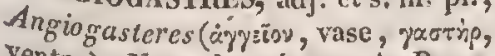
ventre). Nom donné par A. Brongniart à une tribu, par Necs d'Esenbeck et par Fries à une famille de champignons, eomprenant ecux qui ont leurs spores cachées dans un péridion menibraneux.

ANGIOSPERUE, adj., angiosper-

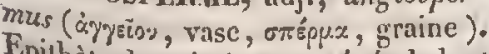
Epilhètedo, donée à tout végétal dont carpe distinet et bien apparent.

AVGIOSPERMIE, s. f., angiospermia. Linné donnait ce nom à un ordre de plantes didynames, comprenant celles qui ont leurs graines contenues daris un périearpe bien visible. ANGIOSPORE, adj,, angiosportus (doyysiov, vase, oriopos, semailles). Epithète donné, orropos, semar Meyer aux sporocarpes (vorez cc mol) des Lichens, lorsqu'ils sont renfermés dans des utricules appelés asci ou theca.

ANGIOSTOME, adj., an giostomus (àryziò, vase, бrópa, bouche). Epithète imposée anx coquilles univalves dont l'ouverture est étroite, c'est-àdire d'un égal diamètre partout, et
ANGU

de la longueur de la cocquille. Ex. Cyprea.

ANGIOSTOUES, adj. et s. m: pl.; Angiostomata. Nom donné par Blainville à une famille de l'ordre des Paracéphalophores siphonobranches, comprenant ceux dont la coquille a une ouverture en général fort étroite.

ANGLE, s. m., angulus ; xáv0 quvia; Ecke, Winkel (all.); angolo (it.). Intersection de deux lignes ou de deux plans, qui se rencontrent en un seul point ou on une seule ligne.

ANGUiCIDE, adj., anguicidus; sehlangentüdtend (all.) (angnis, serpent, ccedo, tuer); qui a ou passe pour avoir la propriété de tuer les serpens. Ex. Aristolochia anguicida.

ANGuIDrs, adj. et s. m. pl., $A n-$ gruidei, Angues. Nom douné par J.-E. Gray et Wagler à un ordre de la classe des reptiles, qui a pour typo lc genre Anguis.

ANGLIFORME, adj., anguiformis (anguis, nnguille, forma, forme); qui a la forme d'une anguille : poisson anguiforme.

AvGuiforurs, adj. et s.m. pl., Angruiformin. Non douné par Oppel, Latrcille, Ficinus et Carus, à une fanille de reptiles, comprenant les Sauriens qui ont le corps alongé comme celui d'un serpent; par Latrcille á une famille de la classe dès Myriapodes, dans laquelle sc rangent ccux dont le corps est ln plupart du temps linéaire.

ANGUWLAIRE, adj., angriillaris. Synonyme d'anguilliforme. Voyez ce mot.

ANGUILITFORME, adj., anguilliformis; aalartio (all.) (anguilla, anguille, forma, formc). Sc dit d'un poisson qui a la forme d'nne anguille. Ex. Gobioides anguilliformis.

NivGtuLLIFORMes, adj. ct s. m. pl., Angruilliformia; Angruillaformes. Nom domé par Guvier et Eich- 
wald à une famille de la elasse des poissons, et par Latreille à une familte de celle des Elminthogames, compregnant des espèces qui toutcs ont le corpśs grêle ct alongć.

ANGUIMORE , adj., angruilloidcs; qui ressemble d une anguille. Ex. Morriyrus anguilloides.

ANGULLLÓIDIS, adj. et s. m. pl., Anguilloides. Nom donné par Blain" villc et Latreillef ane famille de poissons qui a pour typc le genre $A n$ guille.

ArGUIN, adj., anguintls, angueus, anguineus; qui ressemble à une anguillé(ex. Oscillariaanguina).-Un polypier (Etea anguina) a la forme de filamens brillans et nacrés, qui serpentent autour des tiges et sur les feuilles dest plantes marines. - En parlant des mouvemens de certaines oseillatoires, Bory leur donne l'épithete asscz bizarre d'anguins, pour cxprimer qu'ils sont flexueux, comme ceux des serpens.

ANGUINOIDES, adj. et s. m. pl., Anguinoida, Anguinoidei. Nom donné par P.-F. Fitzinger et Eichwald à une famille de reptiles qui a pour type le gerire Anguis.

anguiviperes, s. f. pl., Anguisiperce. Carus, Ficinus et Latreille appcllent ainsi, les deux premiers une tribu, l'autre une fanilic de rep. tiles, eomprenant des serpens venimeux qui ont le corps anguilliforme.

ANGULAIRE, adj., angularis, angularius; eckig, winkclig (all.); ansular (angl.); angolare (it.) (angrelus, angle); qui a rapport aux angles. Ce terme s'emploie: $1^{\circ} \mathrm{en}$ physique, où l'on appclle vitesse angulaire celle d'un corps qui sc meut circulairement autour d'un axe fixc, les points qu'il parcourt décrivant des arcs terminés par des rayons qui font des angles égaux entre eux; $2^{\circ} \mathrm{cn}$ botanique, vil l'on nonme aiguillons angulaires

\section{ANGU}

ceuxx qui naissent dans les angles d'une tige.

ANGULÉ, adj., angulatus; winke. lig (all.); qui est pourvu d'angles en nombre déterminé et qu'on peut ou qu'on veut compter. On dit : tige an. guilée (celle des Labiées, qui a quatre angles; des Carex, qui en a trois, ete.); rameaux angulćs(ex. W allenia angularis); gorge angulée, dans une eorolle monopétale (ex. Vinca rosea); pédoncules angulés (ex. Vicia Cracca); feuilles angulées (ex. Abroma angulata); rtricules angulés de pollen (cx. Tropaolum majus); coquille angulée (ex. Orbiculina angulata); prothorax angule, quand ses côtés ou sa base offrent un ou plusieurs angles.

ANGULEUX, adjcet., angulostus ; kantig (all.); angulous (angl.); angoloso (ii); qui est pourvu d'angles en nombre indéterminé, qu'on ve peut ou qu'on ne veut pas conipter. On dit: baie anguleuse (ex. Sciodaphyllum angulosum); calice anguleux (ex. Nicandra physalodes, Gentiana angulosa); feuillc anguleusc (ex. Nar. dosniaangulosa); fruits anguleux(ex. $S$ candix odorata); graine angulcuse (ex. Allium Cepa); hampe anguleuse (ex. Iriglochin palustre); corselet anguleux, quand ses côtés sont terminés par des angles saillans (ex. Elater).

ANGULIFÈRE, adj., anguliforus (angulus, angle, fcro, porter); qui portc ou prćsente des angles. Se dit d'une coquille qui offre un angle sur ses dernicrs tours (ex. Phasianclla angulifera), ou qui est presque trigone (ex. Murex angulifcrus).

ANGULINERVÉ, adj ., angulinervius; winkelnervig (all.) (angulus, angle, nervits, nerf). Epithète donnée par Candolle aux fcuilles dans lcsquelles les fibres qui ćtaicnt réunies ensemble dans le pćtiole, se sćparent en formant, ou avce la base, ou avec 
son prolongement, un angle proprcment dit et le plus souvent aigu (ex. Dicotylédones).

pl., AvGULIROSTRES, adj. et s. m. rostrum Anulirostres (angulus, angle, ger, Goldfuss ). Nom donné par Illifamille, par st C. Bonaparte à une dre des Par Savy à une tribu de l'orde ces Passereaux, comprenant ceux leux.
leseaux qui ont le bec anguANGUSTrCoLr.F, adj., angusticolqui (angustus, étroit, collum, col); qui a le eol ou lc corsclet ćiroit. Ex. Avingusticollis.

ANGUSTIDENTÉ, adj., angustiqui (angustus, étroit, dens, dent); don ang dents ćtroitcs. Ex. Mastoangustidcrus.

lius; schTHF OLTÉ, adj., angustifoétroit, foliblätrig (all.) (angustus, feuill, folium, feuille); qui a des angustifoltroites. Ex. Cephalanthus Honialium anguslifolium. ANGUSTM anguslifolium.
nus (angustus, adj., angustimaEpithète dostus, étroit, manus, main). aux Clustannée par A.-H. Harvorth mains étroites maeroures qui ont les ANGUSTIP et non élargies. AnguSTIPENNES, adj. et s. m.pl.,
pengustipennes (angustus, étroit, ril à une fam. Nom donné par Dumćres, comprenantle d'inscetes Coléoptèélytres rétréenant, ccux qui ont les ANGUSTéeies à lcur cxtrémité librc. angustiremata rema, rame) (angustus, ćtroit, $\mathrm{A},-\mathrm{H}$. Harvorthe Eithéte donnée par chyures Harvorth aux crustacés brade derrière nageurs qui ont les pattes ćtroites. ANGi

rostris (angusture, adj., angustibec); qui a le bec étroit, rostrum, colaptes an gustirostris a le bec bexdromement comprimé fort étroit.
ANIM

ANGUSTISEPTE, adj, , angustiseptus (angrustus, étroit, septum, cloison). Ëpithète donnće par Candolle aux Crucifères qui ont la cloison du fruit très-étroite (ex. Thlaspi).

ANGUSTISILIQUE, adj., angustisiliquus (angustus, étroit, siliqua, silique ) ; qui a des fruits linéaires, comprimés, étroils. Ex. Cassia angustisiliqua.

ANIÉLEUX, adj. , anhelans (anhelo, haleter). La Spongia anhelans est ainsi appclée paree que les tubes qui la constituent par leur réunion exécutcnt continuellement dans l'eau des mouvcmens de diastole et de systole qu'on a comparés í ceux de la poitrine d'un homme cssouflé.

ANIIOMOḾ́nés, adj. et s. m. pl., Anhomomeri ( $\alpha$ priv., ókios, semblable, $\mu$ śsos, partic). Nom donné par Blainvillc à un ordre de la classe des Chétopodes, comprenant ceux de ces animaux dont lc corps est formé d'articulations dissimilaires.

ANIXDRE, adj., wasserfrei (all.) ( $\alpha$ priv., $\dot{v} \delta \omega p$, eau); qui ne contient pas d'eau : acide, alcool, sel anhydre.

ANHYDRo-sulFati, adj. Haiiy désigne sous ce nom une variété de chaux sulfatée qui ne contient pas d'eau de eristallisation.

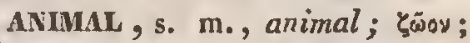
Thier (all.); animal (anglo); animale (it.) (anima, âme), Il existc une telle gradation dans le nombrc ct la perfection des organes, ainsi quc dans les facultés qui en dépendent, qu'on ne saurait donner de ce mot une dćfinition susccptible d'cmbrasser tous les êtres auxquels on l'appliquc. Ordinairement on appelle animal tout corps organisé qui peut se transporter d'un lieu dans un nutre, introduit cn lui-mềme des alimeṇs qu'il ćlaborc à loisir, et possedde la sensibilité à un plus ou moins haut degré. Ces trois qualités, ou quelqu'une d'cntrc elles, manquent à beaucoup d'êtres qu'ou 
range cependant parmi les animaux, et á juste titre, paree que des gradations insensibles les lient plutồt aux corps organisés dont l'animalité n'est point douteuse, qu'à ceux qui font partie du règne végétal.

ANIMLL, adj., animalis; thicrisch (all.); qui appartient à l'animal. Le règne arimal est l'ensemblc des animaux connus. Hory entend par là une collection d'ètres dans laquelle chaque individu, ayant la conscience de son existence, est doué de la faculté locomotive, et choisit, pour y vivre, le site convenable à son espece. On appelle substances animales les diverses parties des animaux, et lcurs produits, soit naturels, soit résultant de déeompositions chimiques et de combinaisons nouvelles entre leurs principes constituans. On dit aussi : appétitanimal, chaleur animale, chimie animale, électrieitćanimale, esprits animaux, fonctions animales, matière animale, mouvemens animaux, magnétisme animal, nature animale, ete.

ANIMLLGULE, s. m., animalculum; Thierchen (all.). Petit animal, qui n'est visible qu'avec le secours du microscope.

ANIMALCULiSME, s. m. Système physiologique dans lequel on suppose que l'embryon animal est produit par les animaleules spermatiques seuls.

Animalculiste, s. m. Physiologiste qui est partisan des doctrines de l'animalculisme.

ANmulavilovisine, s. m. Système physiologique dans lequel on suppose que l'embryon animal est produit par le concours des animalcules spermatiques et de l'œuf femelle. Dans ces derniers temps, Dumas a tenté de rcmettre eette hypothicse en crédit.

animalaUloviste, s, m. Phym
ANIM

siologiste qui est partisan des doctrincs de l'animalculovisme.

ANIMLLIFL̀RE, adj., animalifer । animaliferus (animal, animal, fero, porter); qui porte dcs animaux. Corps animalifere, Polypier animali ferc, ou portant plusieurs polypes.

ANIMALISATION, s. f. , animali satio; Animalisirung (all.). Conver sion des substances alimentaires in gérées par les animaux en leut propre substanee, au moyen de l'ac' tion vitale qu'exereent leurs diver organes.

ANIMALISÊ, adj., animalisatus. St dit d'une matière inorganique ou vic' gétale qui a pris les earactères do l'animalité.

ANIMALISTE, s. m. Système pby siologique dont les sectateurs admettent que l'embryon existe tout form dans le sperme du nâle.

ANLMALISTE, s. m. Physiologistt qui est partisañ des doetrines de l'at nimalisme.

ANIMALITE, s. m., animalitas, animalismus; Thierheit (all.); animality (angl.). Ensemble des attributs ou facultés qui 'distingnent la matière organique animale; naturt animale; activité vitale d'un corps animal considéré comme unité.

ANIMATEUR, adj.; qui donne ls vie; principe animateur.

ANIMATION, s. f., animatio; $B \ell^{\prime}$ seelueng (all.). Union de l'âme et du corps.

ANIMré, adj. , animatus ; besecll belebt (all.); animated (angl.); qu jouit de la vie, ct, par extension, qui en jouit à un haut degré. C'e dans ce dernier sens qu'on dit visağ animé, pour exprimer qu'il est rougo et turgescent.

ANiMiNe, s. m. ou f., animinl Nom donné par Unverdorben à un hase salifiable qu'il a dćcouverte dan ${ }^{9}$ l'huilc animale de Dippel.

ANLIIQUE, adj., animicus. Epir 


\section{ANIS}

thète donnée, dans la nomenclature chimique de Berzelius, aux sels qui ont pour base l'animine.

ANLMIISUE, s. f. Système physiologique dans lequel on attribue tous les acte de l'organisme ì un principe immatériel, ì l'âme.

ANuriste, s. m. Physiologiste qui est partisan des doctrines de l'a nimisme.

ANISANTIE, adj., anisanthus ("uvi-

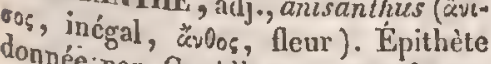
qui ée par G. Allman aux plantes verse.

AvIsk, adj., anisatus (anisum, Agaric qui a l'odeur de l'anis. Ex. sata, Illiciumatus, Collinsania aniAvicium anisatum.

Guibourt , s. m. Non donné par l'anis pour un genie d'odoride qui a Axison type.

( Epithèt inégal, "̣̈prooy, embryou ). bryons que H. Cassini donne aux emprimer monocotylédones, pour exfort que l'a l'un des côtés est plus que l'aulre d'aecroissement.

phalus (EIIIALE, adj. , anisoce-

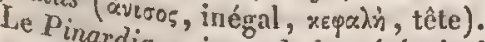
appelé pardia anisocephala a étć ainsi fort inégal que ses calathides sont Avisoces.

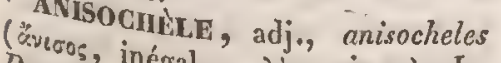

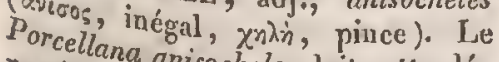
nominalio arisockieles doit eette dćANrSO à l'inégalité de ses serres. pl, Anisatives, adj. et s. in.

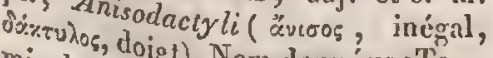
minck ì doigt). Nom donné parTemune tribu d'oisdre, et par Vieillot, qui ont les doints, comprenanl eeux gale. Latreille do de longueur inéthète à ruminans. ANISODONTE, adj. , anisorlon (ăvicos, inégal, ơờ̀, adj. dent). Luc Pristis anisodon est ainsi appelé à cause des
ANIS

dents fort inégales qui garnissent la seie de ce poisson.

- ANISODYNAME, adj., anisodyna-

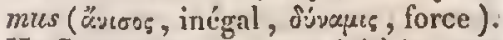
H. Cassini donne cette épithète aux embryons des plantes monocotylédones, pour exprimer que leurs deux côtés n'ont pas la mềme force d'accroissement. Voy cz Avisonué.

INISOML̀nE, adj., anisomerus

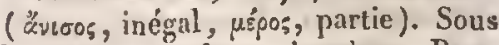
le nom de roches anisomères, Bonnard a établi un ordre renfermant celles qui sont formées en tout ou en partie par voie de eristallisation, et où une partie dominante, qui sert de base, de pâte ou de ciment aux autres, est eontemporaine ou antéricure aux partics qu'elle renferme.

ANISOMÉlirQte, adj. , anisomericus. Martius donne ce nom aux feurs dont les parties ne sont pas égales ou réguliëres.

ANISOMETRIQUE, adj., anisome-

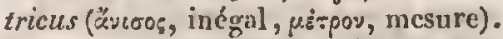
Neumann donrie le nom de système anisométrique à une réunion de formes eristallines dans lesquelles les plans eoordonnés sont perpendiculaires entre eux, et qu'on peut rapporter à un système d'axes, au nombre de trois, tous trois inégaux.

ANISOPÍTALE, adj., anisopeta-

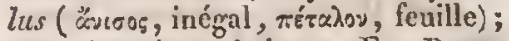
qui a des pétales inégaux. Ex. Prangos anisopetala.

A NISOPUIYLL, adj., anisoplyyllus

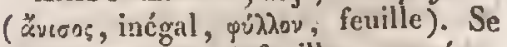
dit d'une plante à feuilles opposées, dont une des deux est très-petite par rapport à l'autre (cx. Ruellia anisophylla). Les feuilles sont dissemblables aussi dans le Blechnum anisophyllum.

ANISOPOGONE, adj. , anisopo-

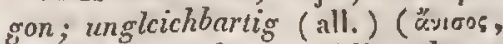
inégal, $\pi \dot{\omega} \gamma \omega \%$, barbe ). Illiger donne eettc épithète à nue plume dout un des côtŕs de la barbe diffère mnani- 
festement de l'autre, sous le rapport de la largeur.

ANISOSTKMONE, adj., anisoste-

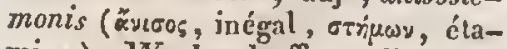
mine). Wachendorff appelle ainsi toute fleur dans laquelle le nombre des étamines n'a -aucun rapport avec celui des pétales libres ou soudés. Ex. beaucoup de Dipsacées.

ANISOSTÝMOPÉTALE, adj., ani-

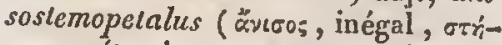

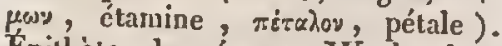
Epithcte donnée: par Wachendorif aux plantes dont les étamines ne sont point en nombre égal à celui des divisions de la corolle.

ANISOTIQUE, adject. , anisoticus ( ävıбos, inégal). Nom donné, daus la nomenclature minéralogique de Haiiy, à un cristal dans lequel les décroissemens ont lieu très-irrégulièrement, de sorte qu'un seul bord ou un seul angle en subit au moins trois, tandis que chacune des parties adjacentes n'en subit qu'un seul. Ex. $B a$. ryle sulfatée anisolique.

AvISTIOPHORES, adj. et s. m. pl., Anistiophori ( $\alpha$ priv., iฮrtóv, voile, $\varphi \dot{c} \rho \omega$, porter !. J. -E. Gray et Spix donnent ce $n$ nom à une famille de Chauve-souris, comprenant celles qui ne porlent aucun appendice sur le nez.

ANNEAU, s. m., annulus; xpíros; Ring (all.); ancllo (it.) (annus, cercle). On appelle ainsi : $1^{\circ}$ en astronomie, un eorps aplati, large et minee, qui entoure la planètc Saturne, en est séparé de toules parts, semble être lui-même composé de deux balldelcttes superposécs, et tourne d'occident en orient autour de la planète. $2^{\circ}$ En botanique : d'après PalisotBeaurois, le bourrelet élastique qui, le plus souvent, unit les deux valves par lesquelles s'ouvrent en travers les capsules des fougc̀res; la suture qui unit l'urne des mousses avec son opercule; l'espèce de colleretıe fran-.

\section{ANNÉ}

gée que laisse sur le stype, en se dé chirant par l'effet de l'accroissement, la membrane qui, dans la jeunessc unissait les bords du chapeau de cer tains champignons avee le pied; $d$ 'a près Cassini, un petit corps cireulaire qui bordc le plateau, au desit de l'ovaire, dans les Synanthérées! et qui porte souvent les squamme lules; un appendice qui entoure 10 stigmate des Lobelia. L'anneau de' fougères (Rad, all.) est appelé Gyrul par Bcrnhardi et Swarz, symplokium par Hedwig, fimbria par Willdenow, connecticulum par quelques auteurs. $3^{\circ}$ En zoologic, un assem blage de pièces qui, par leur réunio" en un eercle complet, forment la par tic extćrieure du corps des animaus articulés; des taches circulaires qu $s$ 'aperçoivent sur diverses parties di corps de certains animaux.

Avví:e, s. f., annus; है:-s5; Jaht (all.); ycar (angl.); anno (it.). Dure de la révolution d'une planète ol d'une comètc autour du soleil. Celle de la révolution d'un satellite autour de sa planète prineipale devrait porter aussi le même nom; mais elle est gé néralement désignéc sous celui de mois. A l'égard de la Terre, la longueur de l'anncé varie suivant le point de départ dont on fait choix et quelques au tres considérations accessoiresi L'annéc tropique (voyez ce mot) cst de 365 j. 5 h. $48^{\prime} 48^{\prime \prime}$; l'anuée sidé, rale (vorez ee mot) de 365 j. 6 h. 9 II" 5 ; l'année anomalistique (vores ce mot) de 365 j. 6 h. $13^{1} 58^{\prime \prime} 8$. L'année sidérale de Mereure est de $8_{7 j .969258}$; celle de Vćnus, do $224 j \cdot 700824$; celle de Mars de 686j.979619; celle de Vesta, do I327j.598293; celle de Junon, do $1593 \mathrm{j} .841740$; celle de Pallas, do 1683 j.545086; cclle de Cérès, do $168 \mathrm{rj}$.4009o8; celle de Jupiter, de 4332j.5063o ; celle de Saturne, do ro $588 \mathrm{j} \cdot 969840$; et celle d'Uranus do 
20688j.712687. L'année tropique de Vénure est de $87 \mathrm{j} \cdot 968439$; eelle de Vénus, de 224j.695480; celle de Mars de 686j.92967\% ; celle de Vesta, de $1327 j .402218$; eelle de Junon, de 1593 j.5 73619 ; eclle de Pallas, de 268 j.245589; eelle de Cćrès, de 1681 1j.101745; celle de Jupiter, de 433oj.6 ı. 88 ; celle de Saturne, de $107460_{j} .732780$; et eclle d'Uranus de $30589 j .357287$. L'année sidérale de la Lune est de 27 j. 7 h. $43^{\prime}$ I I " 559 ; Son année tropique de $27 \mathrm{j}$. 7 h. $43^{\prime}$ 4718 ; et sou année synodique (vor. ce mot) de 2 j. 12 h. $44^{\prime} 2^{\prime \prime} 858$. lite année sidérale du prenier satelcell de Jupiter est de $1 \mathrm{j} \cdot 7_{6913} 38$; du du second, de $3 \mathrm{j} .5511810$; celle celle droisiène, de $7 \mathrm{j} .1545528$; et Gelle du quatrième, de $16 j .6387697$. est de promier satellite de Saturne second $\mathrm{j}_{2} 22 \mathrm{~h} .3 \mathrm{f}^{\prime} 3 \mathrm{o}^{\prime \prime} 1$; eelle du du trois, de 1 j. 8 b. $53^{\prime} 8^{\prime \prime} 7$; celle celle dième, de 1 j. 21 h. $18^{\prime} 25^{\prime \prime} 9$; $5 \mathrm{l}^{\prime \prime} \mathrm{du}$ quatrième, de $2 \mathrm{j} .17 \mathrm{~h} .44^{\prime}$ 12 ; eelle du einquiène de $4 \mathrm{j}$. de $25^{\prime} 11^{\prime \prime} 1$; celle du sixième; septie 15 . 22 h. $4 \mathrm{I}^{\prime} 13^{\prime \prime} 9$; et eelle du Celle du de $79 \mathrm{j}$. 7 h. $54^{\prime} 37^{\prime \prime} 4$. est de 5 premier satellitc d'Uranus du second. 21 h. 25 ! $20^{\prime \prime} 6$; celle celle du t, de 8 j. 16 h. $57^{\prime} 47^{\prime \prime} 5$; $59^{\prime \prime}$; celle dusième, de $10 \mathrm{j} .23$ l. $3^{\prime}$ Io $h$. $56^{\prime}$ du quatrième, de $13 \mathrm{j}$. de $386^{\prime} 2 g^{\prime \prime} 8$; celle du einquième, de $10 \mathrm{j} . \mathrm{I} \mathrm{h} .48^{\prime}$, et celle du sixième, 107 j. 16 h. $39^{\prime} 56^{\prime \prime}$. gele (allet, adj., annulatus; gerinauneau ) anellato (it.) (annulus, purtie du Sc dit d'un animal ou d'une marqué eorps d'un animal, qui est d'anneaur taehes rondes, en forme Sciurus. Ex. Coluber annulatus, annulata. ANNELLis, adj. et s. m. pl., AnMulaia, Annulosa. Nom donnć par mal qui comprend les animaux arti- culés, ceux dont le eorps est eomposé d'anneaux unis les uns avec les autres.

ANNELIDAIRES, adj. et s. m. pl, Annelidaria. Nom donné par Blainville à une classe d'animaux; à eorps divisé en anneaux, qu'il regarde comme intermédiaire eutre les animaux articulés et les rayonnćs.

ANNELIDIS, s. in. pl. , Annulata, Annulosa, Annularia, Annelides. Sous ce nom, Cuvier, Lamarck, Goldfuss, Carus et Ficinus désignent une elasse du règue animal comprenant les animaux dont le eorps se eompose d'anneaux disposés à la suitc les uns des autres.

ANNUAIRE, adj. , annuarius (annus, année). Le Calao annuarius est ainsi noinmé à eause de l'aecroissement d'un feston que le easque de eet oiseau prend ehaquie annnée, jusqu'à ce que l'animal ait aequis l'âge de cinq on six ans.

ANvier, adj., annualis, annuus, annotinus; einjährig , jährig (all.) ; yearig (angl.); annuo, anmuale (it.). Ce qui revient ou se renouvelle au bout ou dans le eours de l'annéc. On employe ee mot : $1^{\circ}$ en botanique. Unc plantc annuelle est celle qui ne dure que l'espace d'un an, qui naît, fruetilie et meurt daus le eours d'une année (ex. Lessertia annua, Capsicum annuum) ; feuille annuelle, eclle qui tombe la première année, en automne; racine annuelle, celle qui se développe et meurt dans une année (ex. Papaver Rhceas); tige annuelle, celle'des plantes anuuelles, et celle aussi des plantes bisannuelles, qui ne pousse qu'ì la seconde aunée ( ex. Solidayo Virga aurea). On indique qu'une plante est aniuuelle eu la faisant suivre du signe $\Theta$, par allusion au temps que le soleil employe à sa révolution apparente. $2^{\circ}$ En zoologie ; quelques oinithologistes ont 
appelé oiseau annucl (avis annotina) celui qui mue deux fois dans l'année.

ANNULAIRE, adj., annularis, annularius; ringformig (all.); anellare (it.) (annulus, anneau); qui a la forme d'un anncau. Se dit : $1^{\circ} \mathrm{en}$ astronomie, d'une éclipse, quand l'ombre de la lune se projette entièrement sur le disque du soleil, qui la dćbordc de toutes parts, comme un anneau lumineux; $2^{\circ} \mathrm{en} \mathrm{mi-}$ néralogie, daus la nomenelature minéralogique de Haiiy, on donne cette épithète à un prisme liexä̈dre Jégulier qui présente autour de chaque base six facettes disposées en anneau (ex. Baryte carbonatéc anmulaire); $3^{\circ}$ en bolanique, ou dit: androphore annulaire, celui qui a la forme d'un anueau (ex. Anacardium cecidentale); nectaire annulaire, celui qui a la même forme (ex. Chironia frutcscens); embryon annulair'e, eclui qui est grêle, alongé et courbć, de manière que l'extrémité radiculaire touche à la eotylédonaire (ex. Salsola radiala). Candolle appelle vaisscaux annulaires des tubes eylindriques simples, marqués de raies transversales, qui les font paraître composés d'anneaux placés à la suite les uns des autres. L'Agaricus annularius doit eette épithìte ì ce que son stipe est muni d'un collet entier épanoui en forme de godet.

ANNULICAUDE, adj., annilicaudus (annulus, anneau, cauda, queue). L'Histrionella annulicauda est un infusoire dont la qucue semble formće d'anneaux, quand elle se eontracte.

ANNULICORNE, adj., annulicornis (annulus, anneau, cornu, corne); qui a les cornes annelées. Ise Pandalus annulicornis est un crustacé qui a les antennes latérales et inférieures annelées de rouge.

ANNULLLLRE, adj. , annulifer, annuliferus (annulus, anneau, foro,

\section{ANOM}

porter); qui porte des anneaux. Le Cidalis annulifera est un oursin dont les épines sont aunelées de blane et de rouge.

AXNULIPL̀E, adj. annulipes (annulus, anncau, pes, pied); qui a les jambes cntourées d'un anneau coloré. Ex. Myopa annulipes.

ANODONTE, adj. , anodontus, edentulus; zuhnlos (all.) ( $\alpha$ priv., odous, dent). Épitlète donuée à des coquilles qui n'ont pas de dents à la eharnière (ex. Lucina edcntula), ou qui n'en ont que de très-peu saillantes (ex. Unio anodonia). Voyez EDenté.

ANODONTES, adj. et s. m.pl. Anodonta. Nom donné par Latreille à une famille de lia classe des Elminthogames, comprenant ceux dc ees nnimaux dont la bouche n'offre ni erochets, ni épincs.

ANODONTIDES, adj., et s. m. pl., Anodonidac, Anodontidia. Nom donné par A. Simith à une famille de serpens qui a pour type le genre Anodon, et par Rafinesque à une triba de la famille des Pédiféres ayant pour type le genre Anodonta.

ANOLìnES, adj. et s. m. pl., Anolena (a priv., อ่̉.่vn, hras). Nom dounć par Ranzani à unc division de la classe des Acéphales, comprenant ceux de ces aninaux qui n'ont point
de bras.

ANOLAr, adj., anomalus ; ćvó-

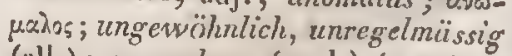
(all.); anonlalous (angl.) (a priv., ouchoós, égal). Se dit, en général, d'un êtrc qui, par son faeies, l'absence ou la présence de eertaines parties, s'éloigne de la grande majorití des êtres que leurs caractères généranx plaecnt auprès de lui at auxquels il doit être comparé (ex. Cricetzes anomalus, Cnidiun anomalume. Les botanistes donnent cette épithète aux corolles dont la forme insolite, bizarre, n’offre aucun 


\section{ANOM}

-moyen de comparaison avee des objets vulgairement eonnus (ex. Delphinium Consolida.)

ANOMALES, adj. et s. f. pl., Anomalo, Anomala. Nom donné par Tournefort à une classe de plantes, comprenant les herbes à eorolle polypétale irrégulière et non papilionacée; par D.-H. Guiart à une classe renfermant les plantes dont les fleurs sont ineomplètes, diffieiles à apercevoir, organisées différemment, mal déterminées ou ineonnues.

ANOMALIE, s. f., anomalia; $A b-$ wcichung (all.); anominly (angl.) (a priv., ouràòs, régulier). On appelle ainsi $: 1^{\circ}$ en astronomie, la distanee d'une planète an lieu de son aphélie ou apogéc, e'est-ì-dire, l'angle ou are que forme avee la ligne de l'apogce une autre ligne ì l'extrémité de laquelle la planète se trouve récllement, et qui sert à mesurer les irrégularités apparentes des mouvemens planétaires; $2^{0}$ en physiologie, toute partieularité offertc par un être orgauisé qui s'éloigne dı type spécifique, c'est-à-dire de l'ensemble des traits eommuns à la grande majorité des individus de son espèee, de son âge, de son sexe, de son pays.

A NOMALIFLORE, adj., anomaliflorus (anomalus, anomal, flos, (leur). H. Cassini donne eette épithète, dans les Synantliérées, à la calathide, au disque, à la couronne, quand ils sont eotnposés de tleurs à corolles anomales.

ANOMALIPL̀DE, adj. , anomalipes (anomalus, anomal, pes, pied); qui a les pieds différens. L'Oxyurus anomalipes est un insecte ainsi appelé parec qu'il a les pattes diverseinent eolorées.

ANOMALPEDES, adj. ct s. m.pl., Anomalipclcs (anomalus, anomal, pes, pied). Nom donné par J.-C. Schreffer à un ordre de la elasse des
ANOM

oiseaux, renfermant ceux dont le doigt intermédiaire est uni à l'externe par trois phalanges et à l'interne par une seulement.

ANOMALISTIQUE, adj., anomalisticus. En astronomie, on appelle révolution ou anníe anomalistique le temps qui s'écoule depuis l'instant où le soleil part de son apogée jusqu'à eelui de son retour apparent au même lieu, parce qu'on appelle anomalie du solcil la distanec angulaire de eet astre au périgée de son orbite. Le mois anomalistique de la lune est le tenıs qu'elle employe pour revenir à un périgíe ou à un apogée.

ANOMALOECIE, s. f., anoma-

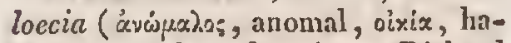
bitation). Nom donné par Riehard à une classe de plantes comprenant celles qui ont des fleurs hermaphrodites et des fleurs unisexuées sur le même pied ou sur des individus différens.

ANOMALOPLDES, adj. et s. m. pl., Anomalopedes (anomaltus, anomal, pes, pied). Nom donné par Klein à une famille de la classe des Mammifères, eomprenant eeux de ees animaux qui ont les einq doigts réunis par une membrane.

ATOMALOPORE, adj., anoma-

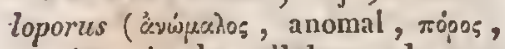
pore); qui a des eellules ou des pores de différentes grandeurs. Ex. Hetcropora anomalopora.

anoviaux, adj. et s. m. pl. Anomales, Anomalia. Nom donné par Lherninier et Lesson à une division de la elasse des oiseaux, eomprenant eeux dont le sternum est dépourvu de carène; par. Satreille à une section de la elasse des poissons, embrassant ceux qui diffèrent des antres par la disposition de leurs branehies en houppes arrondies, le long des ares qui les supportent ; par Ficinus ct Carus à une famille de poissons dans laquelle ils rangent 
eeux qui ont le corps irrégulier; par Cuvier et Latreille à une division de la famille des Crustacés décapodes macroures, comprenant ceux qui ont les deux ou quatre derniers pieds plus petits que les précédens.

ANOMIAL, adj., anomialis; qui ressemble ì une Anomie. $\mathrm{E}_{\mathrm{x}}$. Ostrea anomialis.

ANOMIDEs, adj. ct s. m. pl., Ano-

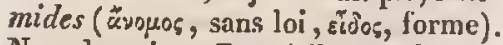
Nom donné par Duméril à une fanille d'Orthoptères, caractérisée par la forme bizarre des insectes qui la constituent.

ANOMOCARPE, adj. ; 'anomocar'

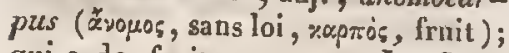
qui a des fruits anomaux. Le Canthium anomocarpum est ainsi appelé en raison de ses fruits, à la base latérale desquels est rejetée la cicatrice florale.

ANOMOCÉPIILE, adj. et s. m. , anomocephalu.s (ärop.os, sans loi, $\%$ ̣xhì, tête). Nom génćrique sous lequel Geoffroy-Saint-Hilaire désigne tous les animaux dont la tête offre accidentcllcment quclque difformité.

ANOMOIODIPÉLIANTIÉ, adj. , anomoiodiperianthus (ávógocos, dissemblable, dis, deux, $\pi \varepsilon p i$, autour, äv $\theta_{\circ \varsigma}$, fleur ). Epithète donnée par Wachendorff aux plantes dans lesquelles le nombre des divisions du calice diffère de celui des segmens de Ja corolle.

ANONACÉEs, adj. et s. f. pl., Anonacea. Famille de plantes, ctablic par Jussieu, et qui a pour type le genre Anona.

ANOvíes, adj. et s. f. pl., Anonea. Synonyme d'Anonacées. $V$. cc mot.

ANOPÉTALE, adj., anopetaltus

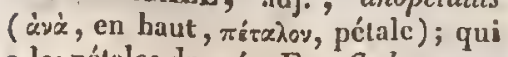
a les pétales dressés. Ex. Sedum anopetalum.

ANopISTHES, adj. et s. m. pl., Anopisthia (a priv,, iniotos, der-.

\section{ANOR}

rière). Nom donné par C.-G. Ehrenbcrg à deux familles de la classe des Polygastriques, comprenant ceux de ces animaux qui ont la bouche et l'anus contigus dans la même fossette, et qui, par conséquent, sont dépourvus d'extrćmité analc proprement dite.

AvorLures, adj. et s. m. pl.,

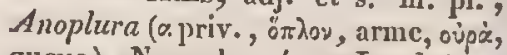
queue). Nom donné par Leach à un ordre de la classe des insectes sans métamorploses ; comprenant ceux qui ont la queue dépourvue de filamens.

ANOPLURIFORME, adj., anopluriformis. Macleay ct Kirby donnent cellc épithìte aux larves de coléoptères qui soat carnivores, antennfèrcs, à corps oljlong et déprimé. Ex. Coccinella.

ANORGANIQUE, adj., anorganicus, inorganicus (\& priv., öpravov, organe) ; qui n'a pas d'organes. Opposé d'organique, et synonyme peu usité d'inorganique.

ANORGANOGENIE, s.f., anorganogenia (a priv. , öpyavos, organe,

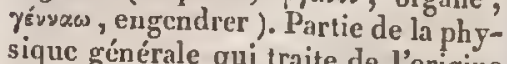
sique générale qui traite de l'origiue
des corps inorganiques.

ANORGANOGNOSIE, s. f., anorganognosia (a. priv, oै ö squov, organe, juw̃os, connaissance). Synonyme de minéralogie, dont se sout servis J.-L. - C. Gravenhorst et J. Reisinger.

AxongaNoGRAPIIE, , s. f, , anorganographia (a priv., op opxyov, organe, ypáp̧, écrire). Description des corps inorganisés.

ANORGANOLOGIE, s. f. , anorga-

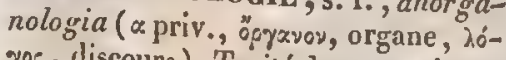
yos, discours). Traité des corps inor-
ganiques.

ANORGIQUE, adj., anorgicus. Par contraction d'anorganique. Voy. ce mot.

ANorgisuE, s. m., anorgismus. 
Ensemble de tous les corps ct de toutes les forces de la nature qui n'appartiennent pas au règne organique.

ANORMAL, adj. , abnormalis, abnormis (a priv., norma, règle). Irrégnilier, qui n'est pas eonforme à la regile.

ANOrMaLIE, s. f., abnormitas. Irrégularité, exeeption à la règle.

ANORRIIYNQUES, adj. cl s. m. pl.,

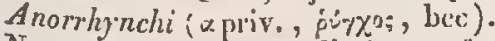
Nom dunnć par Blainville à une liamille de la classe des Sulannelidaires, comprenant ecux de ces animaux dont le renflement céphalique est dépourvu de mamelons proboscidifornes.

ANOSTÍblHores, adj. th s. m.

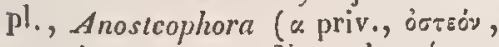
os, pร́ow, porter). Nom donné par J.-E. Gray ì un ordre de lia clisse des Antliobraehiophores, eompreuant ecux de ces animaux qui n'ont pas, dans l'intérieur de leur corps, la masse dure qu'on connaitl sous eclui d'os de seiche.

AvoSTÉozoAunEs, adj. et s. m. pl. Anoslcozoaria, Anosicozon (« priv.,

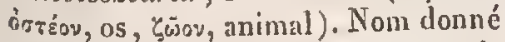
par Blainville à un type du règne animal, renfermant les unimaux qui a'ont pas d'os propremeut dits.

ANOSTOME, adj., anostomus (àx, en dessus, $\sigma: o \dot{u} 4$, bouchic); qui in la bouche en dessus da museau. Ex. Salino anostomus.

ANOURES, adj. et s. m. pl., Anoura (a priv., ovpó, qucue). Nom donné par Duméril, Latreille et Eiehwald à uue famille, par J.-E. Gray à un ordre, par Ficinus ct Carus à une tribu de la elasse des reptiles, eomprenant les liatraciens qui sont dépourvus de quicue dans l'âgc adulte.

ANSE, s. f. , ansa. Ce nom est donné par les astrononies aux proéminenees de l'amrean de Saturuc, qu'à certaines époques on aperçoit des deux côtés du corps de la planète ; ct par les marins, à une trìs-petile baic.
ANSERIDES, adj. ct si m. pl, Anscrides, Ansercs. Nom donné par Goldtuss à une famille d'oiseaux, eomprenant les Palmipides qui se rapprochent de l'oie, Anscr.

ANTARCTIQUE, adj, , antarclicus; àvtapxтเxiss; südlich (all.); southern (angl.) (cंvri, eontre, äprtos, ourse); qui est opposé a la coustellation de l'Ourse. Synonyme d'austral, ou méridional, en astronomie el en géographie (cerele, pólc antarclique). On donne cette épithète à des animaux et à des végétaux qui habitent dins les contrées méridionales (ex. Callorhyn. chus antarcticus, Endyptis antarctica, Disarrhenum antarclicum).

ANTÉCÉDENT, adj., antccedens (ante, devaut, cedo, s'cu aller). Nom donnć, dans la nomenclature miućralogique de Hä̈y, à un cristal de chaux carbonalée, composé du rbomboide equinxe qui préède le primitildans l'ordre dus rhomboïdes oltus, et de l'inverse qui a la même priorité dans celui des rhomboïdes aigus.

ANTĹCIEN, adj. et s, m., antecius; Gegenüberbcwolner (all.) (àvzi, devant, oikés, habiter). Épithète donnćc anx peuples plaećs sous le même méridien, et à la mème distance de l'équateur, mais dans deux hém isphères différens. Synonyme d'antipods.

ANTÉDILUViEN, adj. , antediluvianus (anté, avant, diluvium, déluge). Brongriart appelle ainsi les tcrrains de trass et d'alluvion antérieurs it la période animale. Quelques eoquilles fossiles (cx. Conus antediluviantu"), dont les analogues vivans ne sont plus connus, ont aussi reegu celte dénomination.

ANTEFURCA, s. f. Kirby appelle ainsi un prolongement vertieal interue de l'avant-poitrinc des insectes, consistant ordinairement en deux branehes, qui offrent un point d'attache aux unuscles des paltes intéricures. 
ANT bHULDIAIR , adj, antemediarius (anti , avant, medium, milieu). Les pétales antémédiaires sont, suivant Mirbel, ccux qui se trouvent opposés aux sépales du calice.

ANTENNAIRE, adj. et s. m. , antennaris (antenna, antenne); qui a rapport aux antennes (région antennaire). Robineau - Desvoidy nomme antennaires, dans les insectes Myodaires, deux petites pic̀ces, soudées ensemble, sur lesquelles sont implantées les antennes.

ANTENNAIZúlis, adj. et s, f. pl. , Antennariea. Nom donné par Lessing à une scetion de la sous-tribu des Sénécionidées gnaphaliées, qui a pour type le genre Autennaria.

ANTENNE, s. f., anlenna; Fühlhorn, Taster (all.); feeler (angl.). On appelle ainsi : $1^{\circ}$ dans lez crustacés ct les inscetes, des filamens articulés, mobiles et infiniment diversifićs pour la forme, souvent même selon les sexes, qui tiennent à la partie antérieurc et latér'ale de la têtc, et qui paraissent consacrés à un toucher délicat, ou peut-être même à quelque sens dont nous n'avons pas l'iclée; $2^{\circ}$ dans les $\Lambda$ nnelides, d'après Savigny, aux tentacules ou cirres qui s'attachent sur quelques uns des anneaux céphaliques, et se dirigent pour la plupart en avant; $3^{\circ}$ chez certains poissons (ex. Pterois antennatus), à des barbillons cylindriques et comme articulés, qui sont placés en dessus de la tête, et qui ressemblent aux antennes des insectes.

ANTENvÉ, adj., antennaltıs ; qui a des antennes. On donne cette épithète à des poissons qui ont des filamens charnus sur le devaut de la tête (ex. Diodon antennalus); à des insectes dont les antennes sont fort longues (ex. Eucera antennala); i des annelidess qui sont dans le inême cas (ex. Nereis antennata); à des erizstacés dont les antennes extérieures sont très-grandes (ex. Pencetls antennatus).

ANTENvǐes, adj. et s. f. pl., Antennata. Nom donné par Iamarck ì un ordre de la classe des Annelides, comprenant ceux de ces animaux qui ont des antennes.

ANTENVÉES-TTACIÉALES, adj. et s. f. pl., Antennala-lracheales. Nom donnć par Lamarek à un ordre dc la classe des Arachnides, comprenant ceux de ces animaux qui ont deux antennes ct qui respirent par des trachées.

ANTENNE-PITCE. Voyez CuúLIcìrre.

ANTENNIFH'RE; adj, , anlennifer, antennifertus (antenna, antenne, fero, porler). Une plante (Echium antennifernon) est ainsi appelée parce qu'elle présentc, entre ses pétales et son nectaire, dcux filets alongés et arqués, qui ressemblent aux anicnnes des searabées; une autre (Restrcpia antennifera), paree que deux des trois divisions de son calice sont linćaires, très-étroiles au sommet et antenniformes; une autrc encore (Trichoeeros antennifer), parce que la colonne des organes scxuels se prolonge de chaque còté en deux filets antennilormes.

ANTENNIFORUE, adj., antenniformis (antenna, antcnne, forma, forne); qui a la forme d'une antenne. On donnc partieulièrement ce nom aux palpes des insectes, quind ils sont longs, et simulent par là des antennes. Ex. Hyclrophilus pieeus.

ANTENNISTE, adj. et s. m., anlennislu; qui a des antennes.

ANTENNULE, s. f., rntennula. On appelle ainsi les palpes maxillaires des itusectes, parce qu’ils ressemblent à de petiles antennes.

ANTÉPECTOR 1 , adj, antepeetoralis (antè, devant, peetus, poitrine). Kirloy appelle pattes antépectorales, dans les insectes, les antérieures, 


\section{ANTH}

celles qui sont fixées à l'avant-poitrine, et spiracules antćpectoraux une paire de larges pores qu'on remarque à la membrane qui unit l'avant-poitrine avee la tnédi-poitrine.

ANTÉRIEUR, adj., anterior; vorhergehend (all.); qui est en avant, soit pour le temps, soit pour le lieu. On dit, en botanique, le sligmate antéricur, lorsque, dans une lleur irrégulière, il regarde la parlic antérieurc du périanthe (cx. Orchidées); et les stipules antćrieures, quind elles sont soudées par leur lase seulement à la partie antérieure du pétiole et libres dans leur partic supéricure, de manière à former une lane placéc entre la tige et le pétiole (ex. Trifolium pratense). R. Brown appeile anthères antérieures celles que liichard nom. mait introrses (morez ce mol).

AvTírRo-Dorisar, adj, anterodorsalis. Les enchyliologistes donnent cetle épithète au erochet d'une valve de coquille bivalve, quand il est plaeé plus en avant qu'en arric̀re, dans la longucur du bord supérieur de la valve.

ANTESCIEN, adj. et s. m., antiscius; gegensehattig (all.) (’ंvti, eontre, oxia, ombre). Synonyme d'antipode ct d'antécien, parce que les peuples ainsi placés géographiquement l'un par rapport à l'autre, ont leurs ombres opposées.

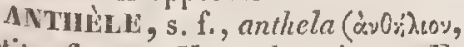
petile fleur). Nom donné par E. Meyer à une grappe eomposée et rameuse, dont l'axe est fort court, et dont les rameaux sont fort longs ou étalés. Ex. Jones.

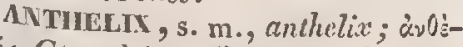
$\lambda_{i \xi}$; Gcgenleistc (all.) (ùvi, devant, 2he, limacon). Eminenec de l'oreille externe qui s'étend depuis la eonque jusqu'à la rainure de l'helix, ct qui est situće au devant de eelui-ei.

ANTHḰLIDĹES, adj. et s.f. pl., Anthomidece. Nom donné par H. Cas-
ANTH

sini et par Kunth à une tribu de la famille des Synanthérées, par Lessing à tine seetion de la sous-tribu des S $\mathrm{C}^{-}-$ nécionidées elrrysanthémées, qui ont pour type le genre Anthemis.

A VTHÚ:RAL, adj., antheralis (àyOnpós, fleuri); qui a rapport aux anthères. Le tube anthíral, dans les Synanthérées, est formé par la coalition des anthères.

ANTuLene, s. f., anthera, spermatocystidium, theca, capsula, apex, testiculus, lestis, capitulum; Staubkolben, Staubbeutel (all.); antera, borsclta (it.). Petit sac membraneux, contenant le pollen avant la fécondation, qui est la partie essentielle de l'étamine. Linné donnait aussi ec nom ì l'ztrne des mousses. Hedwig l'a appliqué également à des eorps oblongs, de forme variée, qu'on tronve, entremêlés avec des filamens, dans les roucttes on étoiles de ces dernières plantes.

ANTÚ́nićés, adj. et s. f. pl., Anthericea, Anthericea. Nom donné par Barrling ì un groupe de la famille des Asploodelées, par Reielienbaelı à un groupe de eclle des Liliacćes, ayant pour type le genre Antherierm.

ANTHÉnmùne, adj., antherifor, antheriferts (anthera, anthère, fero, porter); qui porte des anthères. Ox appelle tube anthérifere le eorps produit par la réunion des filets des étamines, dans les plantes monadelphes et diadel phes.

ANTwhn'T Orus, adj., antheriformis (anthera, anthère, forma, forme); qui a la forme d'une anthère.

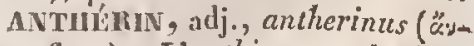
005 , fleur). I'anthicus antherinus est ainsi appelé parce qu'il vit sur les' fleurs.

AvTmb̈n®ou, adj, antherieus (anthera, anthère); qui a rapport aux anthères. Desvaux appelle nectaires anthériques ceux qui sont situés sur les anthères. 
ANTMÉROGÈVE, adj., antheroge.

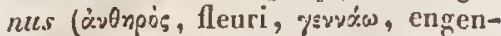
drer). Candulle donnc ectte épithèle aux fleurs doubles qui lc sont par la transformation des anthères scules en pétales corniculés. Ex. Aquilegria valgaris corniculala.

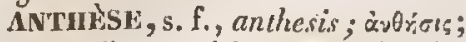
Blumenoffenseyn (all.). Eusemble des phénomènes que présentent les Aleurs, quand elles s'ouvrent et s'épanouissent. Quelquefois aussi on cutend par là le temps où tous les organes d'une fleur sont dans leur parfait accroissement.

ANTHIAHIE, s. f., anthiarina. Substance particulière qui semble constituer la partie active de l'upas anthiar (suc dc l'Anthiaris toxicaria), et que Pelletier ct Caventou croyent être un alcali végćtal.

ANTIIICIIDES, adj. et s. m. pl., Anthicides. Nom donné par Latreille it une tribu de la famille des insectcs coléoptères trachélides, qui a pour type le genre Anthicus.

ANTIIDUĹfES, adj. el s. f. pl., Anthidula. Nom donné par Robineau-Desvoidy à une tribu de la famille des Myodaires Mieromydes.

AntiIIES. Voyez Antirs.

ANTIOBIES, adj. et s. m. pl., Anthobii. Nom donné par Latreille à une section de la Iribu des Scarabćides, qui a pour type le genre $A n-$ thobium.

ANTIOBRANCHes, adj. et s. m.

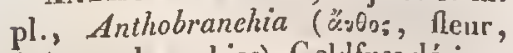

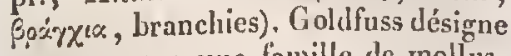
sous ce nom unc famille de mollusques, comprenani ccux de ces animax qui ont les branchies disposées en forme de panaches.

ANTHOCEPHALE, adj., anthoce-

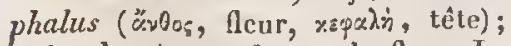
qui a la tète en lorme dc fleur. Le Tania anthocephala a une très-grande tête, à quatre lobes obtus, qui sont jlus longs qu'elle.
ANTHOCORYNION, s. m., antho-

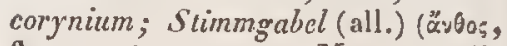
fleur, ropúm, nassue). Mrycr appelle ainsi une sorte de bractée claviforme, biturquée, qui est placée horizontalement, ct en quelque sortc à cheval, sur le pédoncule du Surubara guianensis.

ANTHODION, s. m., anthodium; Blithenkörbchen, Blumensammlung

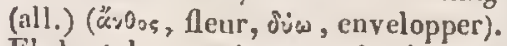
Ehrhart le premier a employe, pour désigner la fleur composée, ce mot, dont Willdenow et Cavanilles ont restreint la siguification, cn le rendant synouyme de calice commun. Cassini, lui conservant sun acception primitive, l'a changé en celui de calathide, bien préférablc au mauvais tcrme de céplaalanthe, introduit par Richard, qui aurait du dire anthocephale. Liuk distingue l'anthodion vrai (flores congregati), lorsque les fleurs s'épanouissent de la circonférence vers lc centre, et l'anchodion faux ( flores agregati), lorsque l'anthise ne suit pas ccttc marche, que l'ćpanouissement commence sur plusieurs points à la fois.

ANTHOLOGIE, s.f. , anthologia;

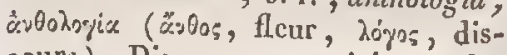
cours). Discours ou traité sur les fleurs; ouvrage qui traite d'un choix de fleurs.

ANTHOMYDes, adj. et s. f. pl. , Anthomydes (ä:Aos, fleur, puvix, mouche). Norn donné par RiobineauDesvoidy à une tribu de la lamille des Myodaires Mésoinydes, comprenant des espèces qui vivent généralement sur les fleurs.

ANTHOMYZES, adj. et s. m. pl.,

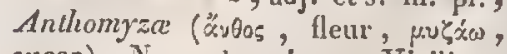
sucer). Nom donné par Vieillot, Ranzani et C. Bonaparte à unc famille de Passercaux, comprenant des oistaux qui sucent le sue sucré des fleurs.

ANTHOPHAGE, adj., anthopha- 
gus ( $\alpha_{2} 00 \xi$, fleur, $\varphi \dot{z} \gamma \omega$, manger ) ; qui mange des fleurs, qui vit de fleurs : insecte anthophage.

ANTHOPIILE, adj., anthophilu.s

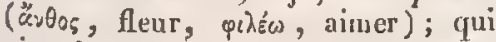
aime les fleurs. Le Saccomys anthophilus a été ainsi nosnmé parce qu'on a trouvé les abajoues d'un indivirlu pleines de fleurs de Securidaca; l'Erigone anthophila, paree que ec diptère est comınun sur les fleurs.

- ANTHOPHLEs, adj. et s. m.pl., Anthophila, Anthophila ("ustos, fleur,

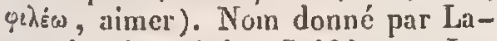
marck, Dumeril, Goldfuss , Latreille, Ficinus et Carus ì une famille d'insectes Hyménoptères, conprenant ceux qui vivent du sue rniclleux ou du pollen des fleurs; par Robineau-Desvoidy à une famille de Myodaires, comprenant eeux de ees insectes qui, à l'ćtal parfait, sc trouvent plus particulièrement sur les fleurs.

ANTHOPHORE, s. m., anthopho.

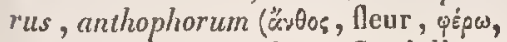
porter). Nom donué par Candolle et Nees d'Esenbeck it un prolongement du réceptacle de la fleur, qui part du fond du ealice, et porte les pétales, les étamines et le pistil. Ex. Silene.

ANTHOPHORE, adj., anthophorus; blüthentragend (all.). Se dit d'une plante, ou d'une partic de plante, qui porte une ou plusieurs fleups. Synonyme, en ee sens, de flurifère.

ANTHOPHXLLE, adj. , anthoplyt-

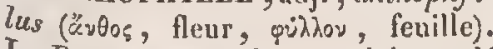
I. Pavetta anthophylla a été appelé ainsi parce qu'un des lohes de son ealice est alongé en forme de foliole.

ANTHOSPERVE, s. m. , antho-

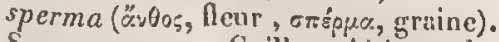
Sous ce nom, Gaillon désigne des agglomérations de petits globules qui, dans certaines thalassiophytes symphysistées, précèdent torjours le dé- veloppement de tubereules ou eonceptacles, parce que, dans ces êtres d'une organisation plus simple, elles présentent quelque analogie avee l'état floral des plautes phanérogames.

ANTHOSPERMLEs, adj. et s. f. pl., Anthospermece. Nom douné par Caudolle et $\mathbf{A}$. Richard à une tribus de la famille des Rubiacées, qui a pour type le genre Anthospermum.

ANTHOSPEIRHIQUE, adj. , anthospermicus. Épithète donnée par Gaillon au mode de fruetification de certaines thalassiophytes symphysistées que d'autres ont appelé capsulaire.

ANTHostonies, adj. et s. m. pl., Anthostoma ("̈.00\%, Heur, orókc, bouehe). Nom donné par Latreille à une famille de la elasse des Elminthaproctes, cumprenant ceux de ces aninaux qui ont quatre trompes ou quatre suçoirs saillans, auriculiformes ou pétaloïdes, ce qui donne à leur têle l'apparence d'une fleur.

ANTIOXANTIĹLS, adj. el s. f. pl., Anthoxanthca. Nom douné par Link ì une trilsu de la famille des. Graminées, qui a pour type le genre Anthoxanthum.

ANTHOzLSIE, s. f. , anthozusia. Nom donué par Lisk à un genre d'anamorphose des feuilles, qui a lieu quand ees organes prennent lc earactère des pétales, transformation rare, mais que Jaeger a obscrvie dans le Tulipa Gesneriana et le Rosa centifolia.

ANTHRACIDES, adj. et s. m. pl.,

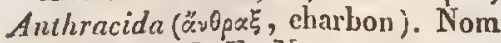
imposé par C.-F. Naumaun à une classe, et par Beudant à une famille de minéraux, comprenant eeux qui renferment du etrbone, soit pur, soit comlinć avec d'autres corps.

ANTHRACIENS, adj. et s. m. pl., Anthracii. Nom donné par Jatreille a une tribu de la famille des $\mathrm{Di}-$ 
ptères tanystomes, qui a pour type le geure Anthrax.

ANTIIRA GIVLEE, adj. , anthraci. fer, anthraciferus (\%opos, cliarbon, foro, porter ); qui contient du charbon: roche anthrucifêre.

ANTIRAGITES, s. m. pl. , Anthracites. Nom donné par Ampère à un genre de la classe des Gazolytes, qui comprend le carbone et l'hydrogène.

ANTIRAGITEUX, adj. ; qni a du rapport avec l'anthracite: houille anthracileuse.

ANTHRACOMETRE, s. m., anthracometrum; Kollensüturcmesser (all.) ( $\ddot{*}, \theta_{0} \alpha \xi$, charbon, $\mu \varepsilon \tau p \varepsilon ́ \omega$, mc. surer). Instrument propre ì déterminer la quantité d'aeide carbonique qui existe dans un mélange gazelux.

ANTMRAXIF bIE, adj , anthraxifor ( $*: 0 p \propto \xi \xi$, eharbon, foro, porter). Nom donné par Omalius a un groupe de roches, qui souvent sont colorées par de l'antbracite. Ce nom est mauvais : ear, outre que tous lcs systèmes qui composent le groupe, ne contiennent pas de l'anthracite, et que cette substance se trouve anssi dans d'autres terrains, il peut souvent donner lieu à quelque eonfusion, par son rapport avee celui du terrain houiller.

ANTIRAZOTIION, s. f., anthra. zothion (

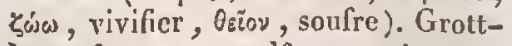
huss donne au sulfocyanogène ce nom qui exprime qu'il conticnt du carbone, de l'azote et du soufre.

ANTIIRAzOTIIONIQUN, adj., an* thrazothionieus. Synonyme inusité de sulfocyanique. Voycz ce mot.

ANTIIRAzoTIIONUIW, s. m. , anthrazothionuretum. Synonymeinusité de sulfocyanure. Voyez ce mot.

ANTIRIBIDEs, adj. et s. m. pl., Anthribides. Nom douné par Latreille à une tribu de la famille des
Rhynchoploores, et par Schocnherr à un groupe de la fumille des Curculionides, qui ont pour type le genre Anthribus.

ANTIILIBITES, adj. ct s. m.pl., Anthribites. Nom douné par E. Eichwald it une tribu de la famille des Rhyucliophores, ayant pour type le gcnre Anthibus.

ANTIROPOCHINIE, 5. f. , an-

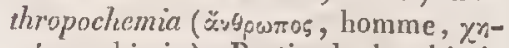
$\mu z i x$, ehinic). Partie de la ehimie dont l'objet est de faire connaîtrc les phénonıènes ehinniques qui ont lieu dans le corps de l'homme, ou les propriétés chimiques des parties qui entreut dans sa romposition.

ANTUROPOGŔvísIE, 5. f. , anthropogencsis ( «) 7ivests, origine). Synonyme d'anthropogénic. Voycz ce mot.

ANTIIROPOGLNIE, s. f. , anthro-

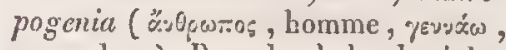
engendrer). Branche de la physiologic qui traile des phénomèues de la génération ehez l'homme.

ANTIIOPOGR.IPHE, adj. et s.

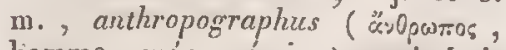
liomme, roxipe, écrire); qui ćcrit sur l'anatomie de l'homme, sur sa physiologie, et en général sur son histoire.

ANTIIROPOGRAPIIE, s. f. , anthropographia. A la renaissance des lettres, ee mot cxprimait l'ensemble des connaissances qu'embrassent l'anatomie ct la pliysiologie humaincs. On ne s'en sert plus aujourd'hui, ou tout au plus le prend-on comme synonyme d'anthropologic. Voyez ce mot.

ANTHMOPOLOGIE, s. f. , anthro-

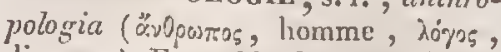
discours). Ensemble des connaissanecs relatives à l'hommc et à l'espéce humaine, tart sous le rapport de l'organisation, que sous celui des actions, des facultés et des moeurs, qui en découlcnt. 
ANTIROPONAGNétisNe, s. m., antliropomagnetismus (\%) me, magnes, aimant). Nom donué par Spindler au magnétisme animal, en raison des connexions qui existent entre l'homme el tousles autres corps de la nature, d'après les vues partienlières de la plilosophie dite naturelle.

ANTIIROPONİTALLISUE, s. m., anthropometallismus ("丷.)pwros, homme - metallum, métal). Non donné par Spindler à une des formes principales du magnélisme animal, qui faitqu'un homme doué d'une organisation spéciale peut, en vertu de sit ferme volouté, déterminer les grandes formes de la nature et leur faire exprimer eelles de sa spontanéité.

ANTIIROPOMĹtRIE, s. f. , an-

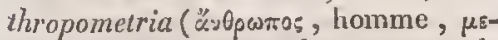
zрร́́ calculer et de déterminer les proportions respectives des diverses partics du corps bien conformé de l'homme.

ANTHIOPOMOLPHE, adj., anthropomorphus ( «ैQ

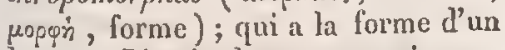
homme. Linné, daus ses premiers essais de classifieation, avait donné le nom d'Anthropomorphes à un ordre de la elasse des Mammifères. L'Ophrys ancliopomorpha est ainsi appelé parce qu'on a comparé sa fleur à un homme pendı par le bras.

ANTIIROPOMORPIOLOGIE, s.f., anthropomorphologia ( $\ddot{y} \theta 0 \omega \pi$ tos, lıom-

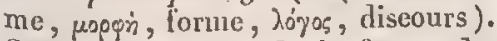
Science qui traite de la forme des diverses parties du eorps humain. Synonyme inusité d'anatontic.

ANTHRODONOUL, s. f., anthro-

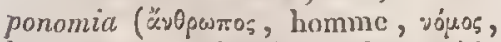
loi). Science qui traite des lois présidant it la formation de l'homme, on à l'excreice de l'aetion des parties qui le eonstituent. Synonyme, en ce dernier sens, de pliysiologic.

ANTHLOEONISME, s. m., anthro- ponismus. Nom donné par Spindler à une des formes prineipales du magnétisme animal, lorsqu'un individu admet en lui-mêtne les qualités de la spontanćité d'un autre, et le suit, en quelqne sorte, comme la lune suit la terre dans sa révolution annuelle.

ANTIROPOPILGE, adj. et s. m.; anthropophagus ; Menschenfresser

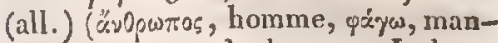
ger); qui mange des hommes. La larve de la Thyreophora anthropophaga dévore les préparalions anatomiques.

AN'UROPOPLAGL, s. f., anthropophagia; Mensehenfiesserci (all.)

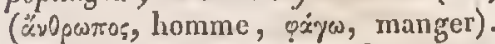
Penehant de quelques individus et de quelques peuples sauvages à manser de la chair humaine; action mène de manger eelte chair.

ANTIIIOPOPIORE, adj. , anthro-

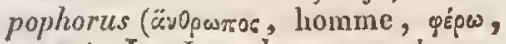
porter). Le Loroglossum anthropophorrem a élé appelé ainsi paree qu'on a ciu trouver de la ressemblanee entre le labelle de sa fleur et un homme pendu par le bras.

ANTIIROPOSOMATOLOGIE, s.f.; anthroposomatologia ( $\&$ \& 0 p $\omega \pi D s$, hom-

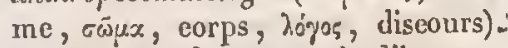
Deseription du corps de l'homme. Synonyme inusité d'anatomie.

ANTHROPOSOPIIE, s. f., anthroposophia ("丷opwros, homme, coẹix, connaissance). Seience ou connaissanee de la nature de l'homme, envisagé sous le point de vue physiologique.

ANTIIIOPOTOMIE, s. f., anthropotomia; Menschenzerglicderung

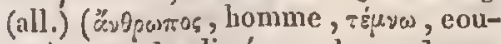
per). Art de disséquer les eadavres humains. Synonyme d'anatomie.

ANTnU1i:, subst. m., anthurtus ("0.00\%, fleur, oủpà, queue). Nom donné par Link aux pédoneules alongés qui portent des fleurs en faisceau.

ANTICHLORISTIQUE, adj. , ethi- 
chloristicus. On appclle théorie antichloristique l'hypothèse admise à la création de la climie pneumatique, fortement ébranlée en 1809 par GayLussac et Thénard, ct définitivement rejetée en 1810 par H. Davy, d'après laquelle le chlore, au licu d'être un corps simple, était censé résulter d'une combinaison d'oxigène et d'un radicul inconnu.

ANTIGLINANTHE, s. m. , anticlinanthus (civti, devant, xlivn, lit, ${ }_{\alpha} \nu \theta_{0 s}$, fleur). II. Cassini appelle ainsi la partic inférieure et squunifère du clinanthe des Synanthérées.

ANTUÉDRIQUE, adj., antiedricus

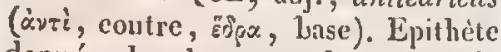
donnée, dans la nomenclature minéralogiqne de Haiiy, à un cristal eomposé de deux rhomboïdes dont chacun a ses faces lournées en sens contraire de eelles de l'autre. Ex. Chaux carbonatće antiédriquc.

ANTIENNÉAEDRE, adj. , anticn-

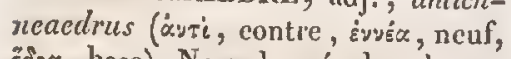
Ėopo, base). Nom donné, dans la nomenclature minéralogique de Haüy, à un prisme à douze pans, terminé par dcux sommets it neuf faces. Ex. Tourmaline antiennéaëdre.

ANTIES, s. f. pl. , aniia, anthia, anthiades, caprona; Schneppen (ill.). Nom donné aux cornes du front $\mathrm{cm}$. plumć des oiseaux, qui s'avancent de ehaque côté vers les narines, cntre l'angle frontal et la base de la mâchoire supérieure.

ANTILANUBANES, adj . ct s. m. pl.,

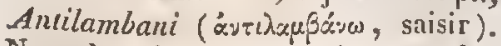
Nom donné par Rinzani à une famille de l'ordre des grimpeurs, conprenant des oiseaux qui se servent de Jenrs doigts pour saisir la nourriture et la porter au bee.

AXTIMOLNE, s. m. , antimonium, stibium; Spiessglanz (all.); antimony (angl.); antimonio (it.). Métal solide à la température ordinaire, dont la découverte parait aroil étć faite par Basile Valentin, vers la fin du quinzieme sicele, ct dont l'histoire a été perfcctionnéc par lés travaux surtout de Proust et de Berzelius.

ANTTMONIAL, adj., antimonialis. Se dit, en minéralogie, d'un métal qui est uni avec de l'antimoine métallique. Ex. Argent antimorial.

ANTIMONISTE, s. m., antimonias. Nom donné aux scls (antimonsaure Salze, all.) qui sont fornces par la eombinaison de l'aeide antimonique avec les bases salifiables.

ANTIHONICO-POTASSIQUE, adj., antintonieo-potassicus. Epilbète donnée, dans la nomeuclature ehimique de Berzelius, à un sel double qui résulte de la eombinaison d'un sel antinıonique arec un sel potassique. Ex. Tarlvate antimonico-polassique (tartrate d'antimoine et de potasse).

ANTIMONIDEs, s. m. pl., Antimonides. Ton donıć par Beudantà une famille de minćranx composée de ceux qui conticument de l'antimoine, seul ou combinć.

ANTIMONIÉ, adj. Se dit, en minéralngie, d'une substance qui contient de l'antimoine non mésallique. $\mathrm{Ex}_{\mathrm{x}}$ Argent antimonié sulfuré.

ANTIMONIEUX, adj., antimoniosus. Epithètt donnée à un acide (deuloxide d'antimoine; antimonige Siurre, all.), qui cst le second degré d'oxigyénatiou de l'antimoine, à un chloride et à un sulfide (antimoine crud; Doppeltschwc felantimon, all.), qui correspondent à l'acide antimonicux, sous le rapport de la composition.

ANTIMONIFÈRE, adj., antimonifcr, antinuniferus; spiessglanzhalligr (all.). Se dit, en uninéralogie, d'une substance qui eontient aecidentellement de l'antimoine. Ex. Plomb sulfurć antimonifère.

ANTLMONiQUE, adj., antimonicus. Nom donné, dans la nomenclature chimique de berzelius, it un 


\section{ANTI}

oxide (protoxide d'antimoine; Antimonoxyd, Antimonoxydul, all.), qui est le premier degré d'oxidation de l'antimoine; il un acide (tritoxide d'antimoine; Antimonsäure, all. ), qui est le troisiène; ì un sulfure ( $A n$ derthalbschwefelantimon, all.), qui est le premier degré de sulfuration de ce métal, et qui s'appellc ainsi quand il joue le rôle de sulfobase, car, lorsqu'il joue celui de sulfide, on le nomme sulfide hypantimonieux; à un sulfide (sonfre dorc d'antimoine; Spiessglanzschwefel, Goldschwefel, Drittehalbschwe felantimon, all.), qui correspond à l'acide antimonique, sous le rapport de la composition; ì uu oxisulfure (Anlintonoxyd-sehwefelantimon, all.), qui est une conbinaison, en proportions définies, d'oxidc et de sulfure antimoniques; à un iodosulfiers (Jodschwefelantimon, all.), qui est une combinaison définic d'iode et de sulfure antimonigue; aux oxisels qui ont pour base l'oxide antimonique; aux sels haloüdes qui résultent de la combinaison de l'antimoine avec un corps balogène (ex. Chlorure antimonique, chloride antimonique).

ANTMONITE, s. m., antimonis. Nom d'un genre de sels (antimoniogsaure Salze, all.), qui sont formés par la combinaison de l'acide antimonieux avee les bases salifiables.

ANTIMONLUHE, s. m., antimoniurelum. Nom douné par Beudant aux alliages de l'antimoine avec d'autres métaux.

ANTIMONOXIDE, s. m., antimonoxydum. Beudant donne ce nom aux combinaisons naturelles d'antimoine et d'oxigene.

ANTIOCHaLIs, adj. el s. m. pl., Antiochalina (avtio;, cn face, żìc\%oi, dents). Nom donné par Muller à une famille de reptiles Ophidiens, comprenant ceux qui ont les dentsantérieures renimeuses.
ANTIPATIIE, s. f., antipathia ;

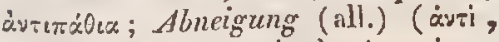
contre, тx́os, passion). Aversion, répugnance naturclle, et non raisonnéc, pour certaines personnes ou chnses.

ANTIPATIIQLE, adj. , antipathicus; qui répugne, qui est opposé, contrairc.

ANTIPHLOGISTIQUE, adj. , anliphlogisticus. Epithète donnée à la chimie pneumatique, c'est-à-dire à la théorie chimique créée par Lavoisier, paree qu'clle renversa la doetrine du phlogistique, dont Stahl avait été l'inventeur.

ANTIPIISIQUE, adj., antiphysi-

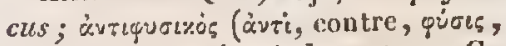
nalure); contraire ì la nature. Ce mol doit être bauni, parce qu'il exprime une idée absurde, rien de ce qui arrive ne pouvant être contraire it l'ordle et aux lois de la nature.

ANCIPIEDS, s. m. pl., antipedes (anté, devant, pes, pied). Nom donné par Illiger aux paltes de devant des mannifères.

ANTIPODAL, adject., antipodalis

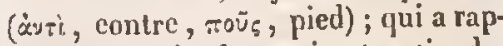
port aux antipodes, qui est antipode.

ANTurodes, adj. et s. m. pl., antipodes, antichtones, antichnites; Gegenfiissler (all.). Épithète donnée aux peuples qui solit diamćtralement opposés les uus aux autres, qui habitent sur des parallèles à l'équateur égalcinent éloignés de ce cercle, les uns du côté duSud, les autres du. côté du Nord, qui ont le nême méridien, et qui sont séparés par 180 degrés de longritude.

ANTHOITHINE, s. f., antepectus. Kirloy appclle ainsi le côté inférieur du manitrone des insectes, celui qui sert à l'inserlion des bras.

ANTIPYRÉETIQUE, adj. , antipyre-

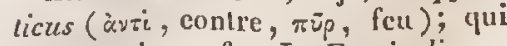
est contraire au fev. Le Fontinalis antipyretica a reçu ce nom parce qu'ati 
dire de Linnć, les Lapons en garnissent lcurs eheminées de bois, pour empĉcher que le feu n'y prenne.

ANTIRHunÉEs, adj. ets.f. pl. ; Antirrhince, Antirrhinea. Nom donné par quelques botanistes à la famille des Scrofularićes, par Bartling à unc tribu de cettc famille, ct qui cst tiré de cclui du genre Antirrhinum.

ANTISTATIQUE, adj., antistaticus ( $\alpha$ yri, contre, "̈rлnut, poser). Epithète donnée, dans la nomenelature minéralogique de Haüy, à un cristal dans lequel ecrtaines facettes additionnelles ont des' figures symétriques et d'autres des figures irrégulic̀res, par une suite des différentes positions qu'clles oceupent. Ex. Chaux carbonatce antistatique.

ANTISTIQUE, adj. , antisticus

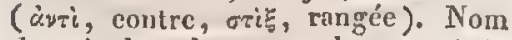
donné, dans la nomencliture minéralogique de Haiiy, à un cristal dans lequel les facettes de diverses rangées sont tournées cn sens inverse les unes des autres. Ex. Chaux carbonatée antistique.

ANTITHÉNAR, s. m. , antithenar;

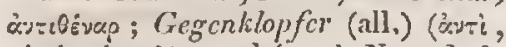
vis-à-vis, ósyap, thénar). Nom de la portion de la main de l'homme qui est opposéc au thénar, et qui s'étexd depuis la base du pelit doig't jusqu'au poignet.

AvTITRAGLS, 5. m., antitragus;

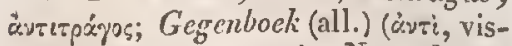

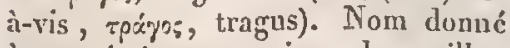
à une éminenee conique du pavillon de l'oreille extcrne, qui est située un peu an dessous et en face du tragus.

ANTITROPE, adj., antitropus

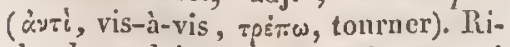
chard appelait ainsi les embrrons qui sont dans une direction contraire à eelle de la graine, e'est-ì-dire dont l'extrémitć cotylédonaire correspond au hilc. Ex. Theymélíes.

ANTLLAIIINIDES, adj. et s.m. pl.; Antliarhinides. Non donné par Schœenherr ì un groupe de la famille des Curculionicles, qui a pour type le geure Antliarlinus.

ANTLIATES, adj. et s. m: pl., Antliata (żvzitov, biberon). Fabricius donnait ce nom à un ordre de la elasse des insectes, comprenant ceux chcz lesquels il avait cru observer un sucoir articulé.

ANTLIE, s. f., antlia (àvzdioy, biberon ). Kirby donne ce nom à l'instrument oral des insectes lépidoplères.

ANTLIOBRACILPHORES, adj. et s. m. pl., Antliobrachiophora (àvthio\%, biberon, Bocuicos, bras, Qépos, porter ). Nom douné par J.-E. Gray à une classe de mollusques comprenant les Céphalopodes, parce que ces animaux ont les bras garnis de sucoirs.

ANTOLCIEN. Voyez Antescien.

ANTTE, s. m. , antrum; $\dot{\alpha} v t p i \dot{\alpha}_{\mathrm{E}}$; Hïllc (all.); grove (angl.); antro (it.). Enfoncement obscur et profond, qui sert de retraitc aux bêtes féroces. Moench donnait ee nom au fruit appelé pomme par Linné.

AVTRIADES, adj. et s. m. pl., Antriades (àvtoüs, caverne). Nom donné par Vicillot à une famille d'oiscaux Sylvains, comprenant ceux qui habitent dans les eavernes.

ANUS, s. m., antus, anulus, podex, ostium recti, culus ; àpròs; After (all.) ; anus (angl.)); ano (it.). On appelle ainsi l'ouverture extéricure et terninale du dernier intestin, qui livre passagac aux résidus de la digestion. Linné dounait ee nom à la dćpression qu'offre assez souvent, en avant du sommet, la partic dorsale de la face cxternc d'nne valve de coquille bivalve, quand on l'envisage sur les deux valves à la fois. Kirby appelle anus, dans les insectes, la terminaison de l'abdomen, les deux derniers des segmens qui le forment. 
ANYurmú, adj. ; anymphizs. 'Épithète donnée par G. Allman aux planles qui sont dépourvues de nymphion. Voyez ce mot.

AONYCHOPHORES, adj. et $\mathrm{s} . \mathrm{m}$. pl., Aonichaphori (a priv., वैuv है, ongle, $\varphi \dot{\varepsilon} p \omega$, porter). J.-A.Ritgen appelle ainsi les reptiles Ophidiens qui sont dépourvus de tubercules en forme d'ongles à la partie postérieure du corps.

APAGYNe, adj. , apagynus ("̈ro une fois, yuỳn, femme). Epithète donnée par Desvaux aux plantes qui ne fructifient, ou ne portent de graines qu'une seule fois dans le cours de leur vic.

APALYTTES, adj. et s. m. pl.,

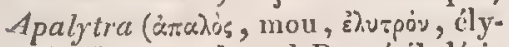
tre). Nom sous lequel Duméril désigne une fainille d'insectes coléoptères, comprenant cellx qui se font remarrucr par la mollesse de leurs élytres.

APARANIMPULÉ, adj. , aparanymphitus. Sous ce nom, $G$. Allman désigne les plantes qui sont dépourvues de paranymphion. Voyez ce mot.

APARAPĹtaroidE, adj. , aparapetaloüdcus. Épithète donnée par Moench aux corolles qui sont dépourvues de parapétale.

APARINES, adj. et s. f. pl., Aparince. Nom donné par Adanson à la famille des Rubiacées, en raison du genre Aparine, qui en fait partic.

APATIIE, s. f., apathia; $\alpha \dot{\alpha} \dot{\theta} \theta \mathrm{e} \iota \alpha$; Affekllosigkcil (all.); apathy (angl.); apatia (it.) (a priv., $\pi \dot{2} \theta 05$, affection). Etat d'une âme qui n'est agitée d'aucune passion, qui n'épronve ni peine, ni plaisir: indifférence profonde.

APATHIQU, adj, apathicus; qui est peu susceptible d'émotions.

APATHioues, adj. et s. m. pl., Apathica. Nom donné par Iamarels à unc de ses trois divisions primaires du règne animal, renfermantlcs ani- maux qui n'ont aucun organe spécial pour les sensations, et ne sentent même pas leur existence. Cette expression ne vaut rien, plusieurs des animaux auxquels elle s'applique ayant des nerfs et étant sensibles; dans le scns mène qu'on attache généralement au mot.

APURCEP'T1ON, s. f., aperceptio. Conscience immédiate d'une impression, soit interne, soit externe.

APb́liANTHACÉ, adj., aperianthaceus (a priv., $\pi$ spi, autour, "a.20 fleur). Sc dit d'une plante qui n'a point de périanthe.

APÉrinNTIA Gĺes, adj. et s. f. pl., Aperianthacea. Nom imposé par Mirbel à la famille des Cycadées, pour exprimer que les plantes qui la constitucnt sont déponrvues de périanthe.

AlúlispeLuÉ, adj. , aperisper-

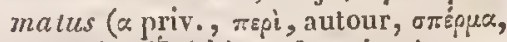
graine). Epithète donnée à une graine ou ì un cmbryon végétal qui manque de périsperıne. Ex. Salsola Tragus.

APĹiristomérs, adj. et s. f. pl.,

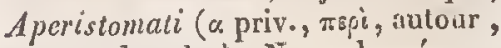
orópe, bouche). Nom donné par Bridel à unc classc de mousses comprenant celles qui sont privées de péristome, par l'abscnee de l'opercule. Voyez Astomes.

APliTALE, adj., apitalus, blutmenblattlos (all.); apetalous (angl.);

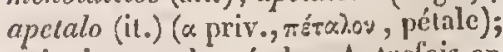
qui n'a pas de pétales. Autrefois on appelait apétalcs les flcurs qui n'ont qu'une seule enveloppe flornle verte et sans apparence de corolle, ou qui sont dépourvucs d'enveloppes florales. Aujourd'hui on donne ce nom aux fleurs qui nanquent du tégument floral appelé corolle. L'épithìte d'upétale est employée, comme nom spécifque, pour désiguer des plantes qui n'ont pas de pétales (cx. Rubus apetalus, Pomaderris apelala, Nasturtium apelalum), ou dont les 
pétales, beaueoup plus courts que le calice, sont très-peu apparens (ex. Lychnis apetala, Mesenbryanihemum apeialumt).

APÉTALES, adj. et s. f. pl. , Apetala. Nom donné par Tournefort et par Guiart à une elasse de plantes, par Jussieu ì une des trois grandes seetions des Dicotylédones, comprenant les plantes dont les fleurs sont dépourvues de eorolle.

aṕ́talie, s. f., apelalia. Nom d'une division, dans la mélhode hotanique de Jussieu, qui comprend les plantes privées d'enveloppes florales, ou dont la fleur n'en offre qu'une seule.

APÉTALIE - B́LEUTHérogYNiE, s. f., apeialia-eleuherogynia. Nom donné par A. Richard à une elasse de plantes, comprenant les Dieotylédones apétales dont l'ovitire est libre.

APÉTALIE-SYMPIISOGYNIE, s. fém., apetalia-symphysogynia. Nom donné par $\mathrm{A}$. Richard à une classe de plantes, eomprenant les Dicotylédoncs apétales dont l'ovaire est adhérent.

APÉTALIFLONE, adj. , apelaliforus (apetalus, apćtale, flos, fleur). Epithète donnće par H. Cassini ì la calathide et à la couronine des Synanthérćes, lorsque les fleurs qui les forment sont dépourỵues de corolle.

APĹtalostúviove, adj. , ape-

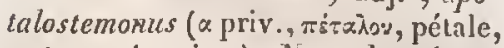
vтripwv, étamine). Nom donné par G. Allman aux plautes dont les étamines sont libres de toute adhérenee aree les pétales.

APHaniptikes, adj. et s. m. pl.,

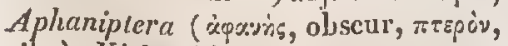
aile ). Kirby désirne sous cc non un ordre de la classe des insectes, comprenant les suceurs qui sont privés d'ailes.

APIIANITIQUE, adj., aphanilicus; qui contient de l'aphanitc : rocke aphaniliquc.
APHANoptìre, adj. ; aphano-

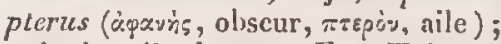
qui a les ailes brunes. Ex. Tabanus aphanoplerus.

APIÉLIE, s. f., aphelia ; Sonnen-

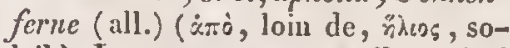
leil). Les astronomes appellent aiusi le point de l'orbite d'une planète ou d'une comète où clle se trouve à sa plus grande distance du soleil.

APHIDIENS, adj. et se m. pl., Aplidii. Nom donné par Cuvier, Iamarek, Goldfuss, Fieinus et Carus à une fanille, par Iatreille et Eichwald a une tribu d'insectes hémiptères, ayant pour type le genre Aphis.

APIIDIPIIAGEs, adj. et s.m. pl., Aphidiphagi (aøis, pueeron, фixye, manger). Jom douné par Cuvier, Laireille et E. Eichwald à une famille d'insectes eoléoptères qui vivent de pucerons.

APHIDIVOLE, adj. , aphidirorus (ácis, puceron, voro, devorer); qui dévore les pucerons. L'Hemerobus aphidivorus cst ainsi appelé parce que sa larve mange les pueerons.

APIILÉ, adj., aphlaeus (a priv., p̀otós, éeorce). G. Allman donne eette épithele aux plantes qui sont dépourvucs d'écorce.

APIILOGISTIQUE, adj., aphlogistieus (a priv., $\varphi \lambda_{0} \xi$, flamme). Nom donné à une lanpe imaginće par $\mathrm{Da}$ vy, et qui eonsiste simplement en un fil de platine incandescent, de manière qu'elle ne donne pas de flamme.

ApmLomidíns, adj. et s. f. pl.,

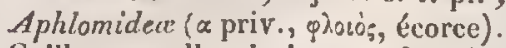
Gaillon appelle ainsi un ordre des Thalassiophytes Symphysistées, comprenant cclles dont les endochromes ne sont pas recourerts d'un tissu continu, celluleux ou parcnehymateux.

APHOTISTE, adj., apholistus $(\alpha$ priv., $\uparrow \tilde{\omega} \xi$, lumic̀re). Épithète donnée aux plaules qui végètent à l'abri de la lumière et de la chaleur du solejl. APURODITE, adj. ; aphroditus. 


\section{ÁPHY}

Gaertner et Borkhausen ont appelé ainsi les plautes agames, pour fairc entendre qu'clles ont, il cst vrai, des graines fécondes, mais que le liquide fécondateur n'a pas d'appareil propre, et qu'il est seerété par les mêmes organes ou dans les nuêmes cavités que celles où se trouvent les ovules.

APIIRODITES, s. m. pl., Aphroditce. Ce nom a été donné par Savigny, Lamarck et Latreille à une famille de la classe des Annelides, par Blainville à une famille de celle des Chétopodes, ayant pour type le genre Aphrodite.

apiroutTograpHe, subst. f., aphroditographia (Ạpoórìn, Vénus, jpóp, écrire). Description de la planète Vénus.

APIINODITOGRAPHIQUE, adj. , aphroditographicus.Schrocter a donué le titre de Fragmens aphroditographiques à son ourrage sur la plauète Vénus.

APIITIEUX, adj., aphthosus (ひैQ Oar, aphibes). Les expansions du Lichen aphthosus sont parsemées de petitcs verrues semblables aux ulccires qui portent le nom d'aphthes.

APHYLLANTIÉES, adj. et s. f. pl., Aphyllanthea. Nom donnć par Bartling a une tribu de la famille des Joncacées, qui a pour type le genre Aphyllanthes.

APIYLLE, adj., aphyllits; blattlos (all.); affillo (it.) (a priv., gúdhov, fcuille); qui est dépourva de feuilles, en totalité ou en parlic seulement.Ex.Stauracanthus aphyllus, Salsola aphylla, Epipogium aphyllum.

APIIYOSTOVES, adj. et s. m. pl.,

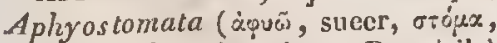
bouclıe). Nom donné par Duméril à unc famille de la classe des poissons, comprenant ceux de ces animaux qui ont un museau très-prolongé, offraut une petite bouche à son exirénitc.
APIC

$9^{3}$

APIATRE, adj., apiarius (apis, abcillc); qui a rapport aux abeilles. Le Clerus apiarius est ainsi appelé parec que sa larve vit dans les ruches des abeilles domestiques, où elle excree de grauds ravages.

APIAIRES, adj.ct s.m. pl.,Apiaria. Nom dunné par Duméril à une famille, par Lamarck ǹ une division, par Goldfuss el Latreille ì une tribu d'insectes Hyménoptères, ayant pour type le genre Apis.

APICAL, adj., apicalis (apex, sommet). Kirby appelle aréoles apicales celles qui se terminent à la pointc de l'aile des insectes, ou trèsprès de celte pointe. L'Anthrax apicalis est ainsi nommé parce que ses ailes noires sont diaphancs à l'extrémilé.

APICÉ, adj., apicatus. Terminé par un sommet bien apparent. Le $P a-$ licourea apicata a ses fruits couronnés par l'urcéole persistant du calice.

APICIFLORE, adj. , apiciflorus (apcx, sommet, flos, fleur). L'Opercularia apiciflora est ainsi nommé parce que ses fleurs sont disposécs en très-pelits capitules terminaux.

APICll Or.1E, adj., apiciformis (apcx, houppe, forma, forme). Epithète dounée, dans la uomenclature minéralogique de Haiiy, à des cristaux qui, étant très-délićs, imitent de petites louppes par la manière dont ils sont assortis. Ex. Fer oxidé apiciforme.

Al'ICILAIRE, adj , apicilaris(apex, sommel). Épithète donnće, en botanique, it tout organe qui est inséré au sommet d'un autre. On dit : arc̀te apicilaire, celle qui termine la glume (cx. Secalc ccreale); déhisecrice apicilaire, quand, le placenta élant central, et la capsule s'alongeant après la fúcondation, ec qui la fiat paraître uniloeulairc, au moins vers le sommct, les parties extérieures des carpelles restent soudées ensemble dans 
la plus grande portion de leur lon. gueur, mais que, par lcur extrémité supérịeure, clles tendent soit à se sćparer les unes des autres, soit à se fendre le long de leur nervure moyenue (ex. beaucoup de Caryophyllées ); embryon apicilaire, celui qui est placé à la partic dı nćrispernne la plus éloignéc du hile (éx. Colchicum autuninale); placcnlaire apicilaire, celui qui occupe le sommet de la cavité du péricarpe (ex. Ombelliferes).

APICULE, s. f. et m. , apicula, apiculus. Nom donnć, dans les végélaux, par Candolle, à toute petite pointe aiguë cl courle dont la consistance n'est pas très-grande; dans les animaux infusoires, par C.-G. Ehrenberg, aux prolongemens du corps de ces animaux, quand ils sont très-petits et pointus.

APICLLL', adj., apiculatus; spitzentragend, klcinspizign, stachlich (all.); qui est muni d'un apicule. Je Scandix apiculata a les folioles de son involucre mucronées à la pointe, qui se prolonge en apicule. L'opercule du Grimmia apicula $a$ et du $\mathrm{Ma}$ cromitrium apiculatum est apiculé.

APIFLRE, adj., apiferus (apis, abeillc, fero, porler). L'Ophrysapifera doit cctte épithè à cc qu'on a cru trouver quelque resscmblance cntre sa fleur et une abeille.

APIF OIWVE, adj, , apiformis (apis, abeille, forma, forme) ; qui a la forme d'une abeille. Ex. Sesia apiformis.

APIONIDES, adj. et s. m. pl., Apionides. Nom donné par Schoenhert à un grouppe de la famille des Curculionides, qui a pour type le genre Apion.

APIOSPORIENS, adj. et s.m.pl., Apiosporii. Noun donnć par Fries à une tribu de champignons ayant pour type le genre A piosporium.

APIROPODES, adj. et s. m. pl.,

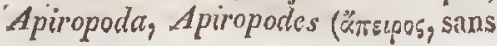

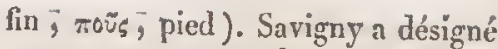
sous ce nom unc classe d'animaux sans vertèbres, el Latreille une section des condylopes, comprenant les invertébrés qui ont plus de six pattes, dont les pattes sont souvent trèsnombreuses et se multiplient d'ailleurs à l'infini par l'analyse.

APIVORE, adj. , apivorus (apis ; abeille, voro, dévorcr); qui dévore les abeilles. Lc Philanihus apivorus saisit les abeilles en l'air, el les entcrre pour scrvir de nourriture à ses larves. Lc Buteo apivorus nourrit ses pelits a vee des chrysalides de guĉpes.

APLANI, adj. , applanaties, depressus, explanatus, explanulatus, placunatus, planulatus, planatcllus, planatiss, planarius, placunarius; geclnct (all.); qui cst uni, sans inégalités. Ex. Agaricus applanatus, Tremclla complanata, Agaricia explanulala, Carocolla planaria, $M y$ tilus planulalus, Milioliics planulaia, Ostrca placunata, Anmonilcs planatella, Cyilhcrea placunclla, Paspalu.s complanatus.

ATLATI, adj., planus, complanatus; qui est moins haut que large (cx. Brachinus complanatus, Millcpora complanata). Les conchyliologistes disent que la spire d'une coquille spirivalye est aplatie, quand les tours rćunis forment une surface tout-àfait plane (ex. Conus cardinalis). Les entomologistes appellent corsclct aplati celui dont le disque n'est pas plus élevé que les bords (ex. la plupart des Cassides).

AI'LATIS, adj. et s. m. pl., Depressi, Dcpressa. Nom donné par Cuvier à une seclion de la famille des Brachélytres, et par Latreille à unc tribu de ectte même famille, renfermant des inscetes qui onl le curps trèsplat.

APLEURIE, s. f. , aplcuria (a priv., $\pi \lambda \varepsilon v \rho \dot{\alpha}$, plèvre). Nom donné par Breschet à un genre de déviation 
organique, on d’agénésie particllc; earactérisé par l'absence des plèvres.

APLOCLRES, adj. et s. m. pl.,

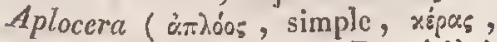
corne). Nom donné par Duméril à unc famille de Diptères renfermant des inscetes dont les antennes ne portent pas de poil latćral isolé.

AILONOME, adject. , aplonomus

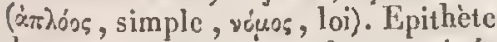
donnée, dans la nomenclature minéralogique de Haïy, à un cristal dont le signe offre la plus simple des lois illermédiaircs de déeroissement, ou les deux lois ordinaires les plus simples. Ex. Chaux carbonatée aplonome.

APLOPËriSTOMÉEs, adj. et s. f.

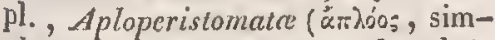
ple, $\pi \varepsilon \rho i$, autour , $\sigma r \delta \mu \alpha$, bouche). Nom donné par Bridel à une classe de mousses, comprenant celles qui ont un péristome simple ou composé d'uneseule rangrćc de dents.

APLOSTAGUÝ, adj. , aplosta-

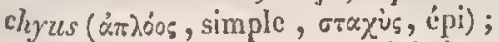
qui a les fleurs disposćes cu épi simple. Ex. Mclastoma aplostachya.

APLOSTILGUES, adj. ct s.m. pl.,

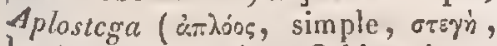
$\log \mathrm{c})$. Nom donné par Orbigny à une section des Céphalopodes foraminifèfires, eomprenant ccux qui n'ont qu'une seulc cavité par loge.

AP'LOSTOME, ndj. , aplostomus

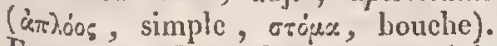
Ferussac et Menke dounent ectle épithictc aux cspèces du genre Helix qui ont le labre simple, et dont ils font une section distincte.

APLYSIAClis, adj. et s. m. pl., Aplysiacca. Nom donné par Menke a une famille del'ordre des Gastéropodes pomatobranches, qui a ponr type le genre Aplysia.

APLISIENS, idj. et s. m. pl. , Aplysiacea. Blainville désigne sous ce nom une famille de l'ordre des Paracéphalophores monopleurobran- ches, qui a pour type le genre $A p l y-$ sia.

APLYSIFORME, adj., aplysiformis; qui a la forme d'une aplysic. Ex. Actaon aplysiformis.

APNEUNUE, s. f. , apncumia (a

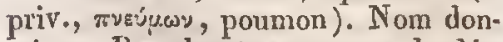
né par Breschet à un genre de déviation organique, ou d’agénćsic partielle, qui est earactérisé par l'absence du poumon.

APOCARPE ; adj., apocarpus (àmò, sur, rapтrò, fruit). Epithète donnće à une nousse (Grimmia apocarpa) dont la capsulc, presque sessilc, touehe à la plante même, et cst recouverte par les fenilles.

APOCIÉNATE, s. m., apocrenas. Genre desels qui résultent de la combinaison de l'acide apocrénique avee lcs bases salifiables.

APOCRÉNIQUE, adj., apocrenicus. Norn donnć par Berzelius à un acide organique nitrogéné qui, dans l'analyse des caux de Porla, d'où il a été retiré, prend naissance aux dépens de l'acide crénique (voyez ce mot), eonume l'apothème sc forme aux dépens d'mn extrait. .

Apocrvírs, adj. et s. f. pl. Apocyncee. Nom donné par Jussieu à unc famille de plantes, qui a pour type le genre Apocynum.

APOiE, adj., apodus; fusslos (all.) : feelless (angl.) ( $\alpha$ priv., $\pi 00 \tilde{5}$, pied); qui n'a pas de pieds. I ces larves de beaneoup d'insectes sont dans ce eas. I tatreille appelle apodes les chcnillcs qui a'out que de simples mamelous, sans pattes. Les poissons privés de nagcoircs ventrales sont dits apodes, parce que ces nagcoires correspondent aux pieds des autres animanx vertébrés. Lc Paradisea apoda doit cetle épithète à cc queles $\mathrm{Pa}-$ pous, qui le vendent aux eommerçans, lui arrachent préalablement les pattes, ee qui a fait croire pendant long-temps qu'il n'en avait pas. Le 
Trichomanes apodum est unc fougère qui a ses frondes la plupart du Icmps sessiles, et le Lycopodium apodum une mousse dont les épis sont sessilcs.

APODiME, s. m., apodema ( $\dot{\alpha} \pi \dot{0}$, sur, $\delta^{\prime} \mu \omega$, construire). Nom donné par Audouin à des pièces particulières qui naissent de quelques pièces du corps des animaux articulés, qui ne peuvent se mouvoir, et dont les unes (apodèmes d'insertion), situćes à l'intérieur du thorax, donnent souvent attache à des museles, tandis que les autres (apodèmes d'articulation) font fréquemment saillie à l'cxtérieur du thorax, et servent principalement à l'artieulation de quelques appendices du corps, les ailes cn particulier.

APODES, adj. et s. m. pl. , Apocla, Apodes. Nom donné, dans la elasse des reptiles, par Mayer et Blainville à unc famille d'Ophidiens, par Latreille à une famille et par Blainville à une seetion des Sauriens, par Merrem et Gray ì un ordre, par Oppel à une famille de Batraciens, animaux qui tous sont déponrvus de pieds, en totalité ou en partic; dans la classe des poissons, par Gouan et Latreille à un ordre, par Lacépède à huit ordres, par Cuvicr à un sousordre, par Blainville à une division et à une famille, comprenant ceux de ees animaux qui n'ont pas dc nageoires ventrales, ou eeux qui n'offrent aucune trace de membres; dans la classe des tíninodermes, par Cnvier à un ordre, renfermant eeux qui n'ont pas de pied vésiculeux; dans celle des Aunclides, par Lamarck, à un ordre qui embrasse celles qui sont sans pieds; daus eclle des Mollusques, par Goldfuss, à un ordre, comprenaut ceux qui n'ont aueun appendice locomoteur ; dans celle des Holothurides, par Latreille, à un ordre dans lequel sout compris ceus qui n'ont pas de tentaeules faisant offic e de pieds; dans celle des Thérozoaires, par
Eichwald, à un ordre, et dans celle des Microzoaires, par Blainville, à une classe eomprenant ceux dont le corps est dépourvu d'appendices quelcouques; dans le type des Entomozoaires, par Blainville, à une classe comprenant ceux qui n'ont aueun appendice quelconque.

APODIE, s. f., apodia ; Fusslos.

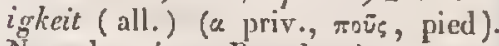
Nom donné par Breschet à un genre de déviation organique, ou d'agénésie particlle, qui est caractérisé par l'absence des pieds.

APODOCǴi'ruLE, adj., apodocephalus (\% priv., noūs, pied, xєex) tète). L'Oligactis apodocephala est ainsi appelé parec que ses ealathides sont agglomérćes et sessiles.

APODOGYNE, adj., apodogynus (a priv., тог̈, pied, үuуn, femme). Epithète donuce par Richard au dis. que, quand il n'adhère point à la base de l'ovaire.

APOGĹE, s. f., apogaa; Erdferne (all.) ( $\alpha \pi \dot{0}$, loin de, $\bar{y}^{n}$, terre). Lues astronomes donnent ce nom nu point de l'orlse d'un corps du système solaire où ce corps est placé à sa plus grande dislanee de la terre.

APOGONEs, adj., Apogones (a

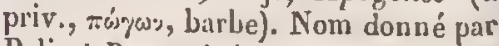
Palisot-Bcauvois ì une section de la fanille des Mousses, comprenant celles dont l'urne est privée de dents à soll orifice.

apomastones. Voyez A pomatosToues.

APONinTostones; adj. et s. m.

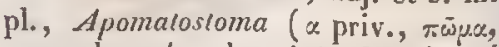
opereule, бтópec, bouche). Nom donné par Menke à un sous-ordre de l'ordre des Gastéropedes eténobranches, comprenant eeux dont la eoquille est dépourvue d'opcrcule. Férussae écrit apomastomes.

APONúsostours, adj. et s. m.

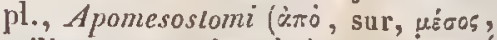

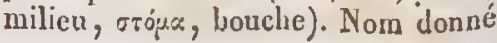


par Klein ì une section qu'il avait proposé d'établir dans la famille des Oursins, pour y ranger ccux qui n'ont point la bouche eentralc.

APOPIIANE, adj., apophanzes (d;roQsive, revêtir). Dans la nomenclature minéralogique de Haiiy, cette épithètc est donnée à un cristal dont eertaines facettes ou certaines arètes offrent quelques indications utiles pour reconnaître l'ordre de la structure, qui, sans cela, scrait difícile à deviner, ou mềne pour détcrminer, soit la direction, soit la mesure des décroissemens. Ex. Chaux carbonatćc apophane.

APOPIYSE, s. f., apophysis ; $A n-$ satz, Fortsatz (all.); apofisi (it.) (àmop̧us, naitre dessus). Terme générique exprimant tonte élévation quelconque qui paraît peu régulièrc. Les bolanisies donnent spécialement ce nom à un renflement situé à la laase de l'urne de quelques mousses (ex. Polytrichum communc).

APOPIISt', adj., apophysatus; qui est muni d'une apophyse : mozusse apophysic (ex. Saproma vogesiacum).

APOPIISIFORME, adj., apophysiformis. Bridel dome cette ćpithèle au renflement ordinairc, et en forme de réceptacle, que présente l'extrémité des rameaux fructifères des Sphagrnum, faisant oflice du pédieule, qui n'existe point dans ces mousses.

Aporobraxcmes, adj. ct s. m. pl., Aporobranchia, Aporobran-

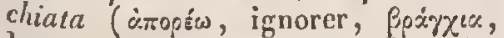
hrancliies). Nom donné par Latieille. à un ordre de la classe des Araehnides, comprenant celles qui n'ont point de stigmales apparens à la surface du Corps, et par Blainville à un ordre de la classe des Paraeéphalophores, dans lequel il range ceux dont les organes de la respiration sont souvent peu évidens.

APOrocípiraLlís, adj. et s. m. I.

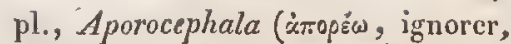
« $\varphi z \lambda \dot{y}$, tête). Sous ce nom, Blainville désigne un ordre de la classe des Subannclidaires, comprenant ceux dout la tête n'est jamais distincte ou séparée du corps.

APOSÉPĹ丶 IN, s. m. (àmò, sur, oทrésios, putréfaction). Braconnot appelle ainsi l'oxide casćcu $x$, parce "qu'il est le produit de la putréfaction du fromage.

Arosumes, adj. et s. m. pl,, Aposura ( $x$ priv., тог̈s, pied, oùpós, queue). Nom donné par Cnvier à une ltibu de la famille des Isépidoptères, comprenant ceux dont les elieuilles ont l'anus dépourvu de patles.

ApOTHÉcn:, s. f., apothecia;

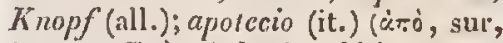
Orym, coflre). Acharius désigne sons ce nom les conecptacles qui, dans les lichens, renferment les corpuscules reproductcurs. C'est le sporangium de Hedwig, le thalamus de Willde now.

APOTHícion, s. m., apolleccium. Synonyme d'apothécie. Voyez ce mot.

APOTnÊME, s. m., apolhena

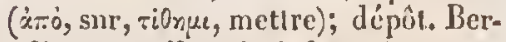
zelius appelle ainsi la substance, nommée extractif oxidé par d'autres ehimistes, qui se dépose, sous la forme d'une poudre brune, quand on soumet les extrait végélaux à une évaporation prolongée.

Aротоме, adj., apolomus ( $\dot{\alpha} \pi \circ-$ тóprs, coupé à pic). Epithètc donnée, dans la nomenclature minéralogique de Haüy, ì un cristal ayant des faces très-peu inclinécs à l'axe, de sorle qu'elles paraissent descendre rapidement des sommets. Ex. Baryte sulfatće apotome.

APPARENT, adj., apparen.s, rcvelatus (appareo, apparaitre). Se dit de ec qui frappe la vue (objct apparent; offenbar, sichtbar (all.); plain, obpious (angl.); chiaro, cvidente (it.); 
de ce qui est remarquable par son extéricur (maison apparcnie; ansehnlich, vornehm (all.); chicf, topping (angl.); cospicuo (it.), ou par son exposition (lieu apparent); de ec qui n'a que des dchors sans fondement réel (droit apparent, vertu apparente, mouvement apparent du soleil; augcnscheinlich, scheinbar (all.); secming (angl.); sembiantc (it.). Ce snot est employé dans le premier sens (revelatus) par les entomologistes, qui, d'après Kirby, appellent l'alitronc des inscctes apparent, lorsqu'il est autant et inême plus visible que le prothorax (ex. Névropteres); ct dans le second (apparens) par les astronomes, qui appcllent : conjonction apparentc, celle dans laquelle une ligne droite, qu'on suppose traverser le centre de deux astres, passc, non par lc centre de la terre, mais par l'œil de l'observateur; diamétre apparent d'un astre, le nombre de degrés sous lequcl nous le voyons ; éclipse appnrente, celle dans laquelle un corps céleste devient invisible pour nous, non parce qu'il perd sa lumièrc propre, ou cesse de réfléchir celle que d'autres astres lui cnvoyent, mais parce qu'un corps céleste opaque s'inLerpose entre lui ct nous, et empèclic sa lumière directe ou rélléehie d'arriver jusqu'à notre oil, comme dans les éclipses de soleil, celles des sntellites de Jupitcr par leur planète principale, les occultations des étoiles par les planc̀tcs, celle d'une planète par une planète, celles enfin des étoiles et des planètes par la lune; horizon apparcnt, le ccrele qui borne notre vue, lorsque nous regardons autour de nous; licu apparent d'un astre, le point de la sphère céleste où nous le rapportons, ne pouvant l'observer que de la surface et non du centre de la terre.

APPELANT, adj, vocans. Epithète donnée à ccrtaines cribes qui produi- sent une sorte de claquement en serrant les doigts de leurs pinces avcc rapidité, ct qui lèvent et baissent alternativement la serre avec laquelle ils causent ce bruit, mouvement comparable au signe que nous faisons du doigt pour appeler quelqu'un. Ex. Gelasimus vocans.

APPENDANT, adj., appendens (ad, vers, pendo, pendrc). Mirbel dit la grainc appondante, lorsque le hile, de niveau avec le placenta, ou à peu près, est situé au dessous du point le plus élevé de la graiue, à une distance qui ne dépasse pourtant pas la moitié de sa longueur totale.

APPENDICE, s. m., appendix;

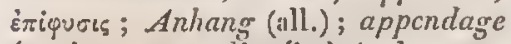
(algl.); appendice (it.) (ad, vers, pendo, pendre). Se dit, en général, de toute partie extérieurc d'un corps, qui, bien que faisant tout avec lui, semble cependant y avoir été surajoutée, à cause de ses dimensions moindres que les siennes. On appelle ainsi ; $1^{\circ} \mathrm{cn}$ botanique, toute partic qui, fixéc à un organe quelconque, paraît additionnelle ì sa structurc habituclle, commc les petits prolongemens membraneux qui garnissent la gorge de la corolle dans certaincs Borraginces (ex. Symphytum officinalc), les petits filcts qu'on observe quelquefois à la partie inférieure des loges de l'anthìre, ou les petits filets qui se prolongent parfois au-dessus de cette dernière, les écailles qui entourent l'ovaire des graminées, les prolongenens du limbe de certaines feuilles qui accompagnent lc pútiole jusqu'à son insertion, la partie supćrieure des écailles qui composcnt le péricline de certaines Synanthérées; $2^{n}$ en zoologic, on donuc ce nom it l'ensemblc des partics qui s'ajoutent sur les eôtés ou à l'extrémité du trone d'un animal, quel qu'il soit.

APPENDICÉ, adj. , appendiculatus; qui est muni d'un ou plu- 


\section{APPE}

sieurs appendices. Se dit, en zoologic, de la petite cellule tcrminale de l'aile des inseetes, quand la nervure situce au-dessous din cubitus prenant naissance au-dclà du eal ou carpe, eette cellule n'est que rudimentaire.

APPENDICÉs, adj. et s. m. pl., Projectifera. Nom donné par Latreille à un ordre de la classe des Gymuogènes, comprenant ceux de ces animaux qui ont tous des parties saillantes, poils, cornes on queue.

APPENDICIFOIVE, adj., appendiciformis (appendix, appendice, forma, forme) ; qui a la forme d'un appendice. II. Cassini dit la squame appendiciforme, dans les Synantlé́rées, quand la véritalsle est entièrement avortéc, et que l'appendice subsiste seul, eomne il arrive aux sqnames extéricures. Ce mot se dit aussi de la bordure d'une squame du péricline, quand clle est grrande et ne borde que la partic supérieure de la squame.

APPENDICULAIRE, adj. , appendicularis. Turpin donne celte épithète à un groupe primordial de végétaux, comprenant ecux qui produisent de leur tige des organes appendiculaires et rayonnans, tels que les feuilles cotylédonaires, les écailles, les fcuilles, les folioles composint les involueres, les calices et corolles, les étamines et phycostèmes, les feuilles ovariennes, enfin les feuilles soudćes et indéhiseentes de l'ovule, et dans lesquels la masse organique se compose de la réunion des tissus cellulairc et vasculaire (mousses, fougères, monocotylédones et dicotylédones.)

APPENDICULE, s. m. , uppendieulrem. Quelques zoologistes appellent ainsi les épines des astéries, ainsi que les branches cartilagineuses qui, partant de la colonne articnlée et raneuse des rayons, soutiennent
APPE

l'enveloppe extérieure du eorps de ces animaux.

APPEXDICUL', :udj., appendiculalus; mnuni d'un appendice, d'un prolongement queleouque. On dit : $1^{\circ}$ en botanique, antlière appendieuléc (ex. Centaurea eollina); tube appendieulc, dans une corolle monopétale, quand il est garni d'un appendice intérieur (ex. 'Cuscusacpithymum); filet d'étanine appendiculé, lorsquilit porte un appendice qui semble moins en faire partie qu'y avoir ćté ajouté après coup (ex. Borrago officinalis); squame appendieuléc du péricline, quand clle change brusquementde nature et de direction i un certain point de sa hanteur (ex. Artichaut). Le Pelargonium appendieutatum doit celle épithète à ses grandes stipules, qui sont conniventes it la base; le Thalictrum appendiculatun aux auricules scarieuses el arrondies qui garnissent la base de ses pétiołes, et le Gnaphalium appendiculatune, ì la petite menbrane scarieuse qui termine ses fcuilles. $2^{\circ} \mathrm{En}$ zoologie, on dit l'anus apperidiculé, dans un insecte, quand il est. terminé par quelque appendice (ex. Perle). Lc Tetrarrlynelus append eulatus a le corps muni d'un appendiec en arric̀re. Le Myrnieleon appendiculatum est ainsi appelé parce que les deux ou trois derniers anneaux de l'un des sexes out chacun deux appendices recourlsés.

APrTNDICULlís, adj. et s. m. pl., Appendiculata. Norn donné par Lamarek à un ordre de la classe des Infusoires, renfermant ceux de ees animaux qui ont à l'extérieur des parties toujours saillantes, ct par A.G. Harvorth à un ordre de la classe des Crustacés.

APPENDIGASTRE, adj. , appendigaster íappendix, appendice, gaster, ventrc). Epilliète donnée à un insecte (Evania appendigaster), it 
eause da long et minec pédicule qui joint l'abdomen au corselet, et cn fait comme un appendice de ce dernier.

APPERGEPTIBLLTÉ, s. f. Faculté de percevoir lcs impressions, tant intérieures qu'cxtérieures.

APPER CEPTION, s. f. Opération de l'esprit, quand il se consilère comme le sujet qui perçoit une impression.

APPlETENCE, appetentia; Naturtrieb (all.). Désir ardent et passionné d'un objet queleonque.

APPETIT, s. in., appetitus, appetitio ; öpsçıs, ópuñ ; sinnliclie Begierde (all.); appetite (angl.) ; apperito (it.). Désir des alimens, et plus généralerisent tendance vers un objet dont la possession est nécessaire à la satisfaction des sens externes ou internes. C'est dans ee dernier sens qu'on dit appetil vénérien, pour désir du coït.

APPÉTITIE, adj. , appetilivus ; begeltrend (all.); appetitive (angl.); qui fait désirer : faculté appétitive.

APPLTITION, s. f., Begehrungsvermögen (all.); appeleney (angl.). Action de désirer vivement, qui est mise en jeu par le réreil de quelque organe interne.

APPLICANT, adj. Dans la langue entomologirgue, les ailes applicanles sont, pendant l'état de repos, parallèles à l'abdomen. Ex. Tipule.

APPLICATIF, adj., applicativis. On dit, en botanique, In préfoliation applicative, lorsque les feuilles sont appliquécs face ì face, l'une contre l'autre, sans se ployer cn aueune manière. Ex. Aloe lingniformis.

APPLIQUR, adj., applicalus, adpressus; ancinandergclelunt, ange. driuckt (all.); applied (angl.). Se dit, en hotanique, de parties qui sont appliquées l'une contre l'antre, mais sans aroir d'adhérence ensemble, notamment d'une fetuille qui se re- lève pour suivre à peu près la direction de la tige ou du rameau, el des feuilles renfermćes dans le bourgeon, quand leur limbe est plane, droit, et qu'elles sont appliquées l'une contre l'autre (ex. Amaryllis).

APPOSÉ, adj., apposilus ; anliegend, nebeneinanderstehend (all.). Épithète donnéc, par les botanistes, aux loges de l'anthère, quand la déhiseence a lieu par la mème face sur les deux loges (ex. la plupart des plantes); aux ovules, quand il s'cn trouve deux dans une même loge d'ovaire, qui naissent du même point et à la même hauteur (ex. Euphorbiacées).

APPRESSÉ, adj., adpressus ; angedriickt (all.); appogiato (it.). Se dit, en botanique, des feuilles, quand leur lame est appliquée contre la tige (ex. Buchnera gesnerioides, Polytrielum appressum); des poils, lorsqu'ils sont appliqués dans toute leur longueur sur la partie qui les porte (ex. Malpighia zurens); des rameaux, quand ils sont rapprochés parallélement contre la tige (ex. Genista tinctoria); de la lige, quand elle cst étalće et serrée contre terre (ex. Sibbaldia adpressa).

APPInÉ, adj., adpressus; angedrïcke (all.). Synonyme inusité d'appressé. Voyez ce mot.

APPULSE, adj. Les astronomes disent une éclipse appulse, quand la lune ne fait qu'eflleurer l'ombre de la - terre par son hord, quand elle ne fait que toucher au disque du soleil. APPUX, adj., adnatus, insidens, imposilus, suffultus; aufsitzend, aufgeselst, unterstützl (all.); propped (angl.j; appogrialo (it.). Ce mot. est employé : ${ }^{\circ}$ en botanique. Quelquefois, mais rarement, pris comme synonyme d'adné (voyez ee mot), il sert ì désigner les feuilles sessiles dont la base de la surface supéricure cst enmanc appuyée sur la tige et tou- 


\section{$\triangle \mathrm{PTE}$}

che ì la feuille opposée ; $2^{\circ}$ en zoologie. Les conchyliologistes donnent l'épithète d'appuyecs aux crochels des coquilles bivalves, quand ils se touclient; et aux lères de ces mêmes coquilles, lorsque celle d'une des valves étant plus avancéc, elle recouvre l'autre dans toute sa longueur.

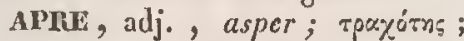
rauh, sireng, herb (all.); sharp (angl.) ; aspro (it.). Se dit, en phy sique, de ce qui cause une impression désagréable, soit sur le sens du goût (fruit apre, saveur apre), soit sur celui du toucher, par la viviacité de son action ( $f o u$ apre), ou par les inégalités de sa surface, dernière icception dans laquelle ápre est synonyme de rude (voye $\mathrm{ce}$ mot); au moral, de ec qui est violent, aigre, désagréable (earactère apre).

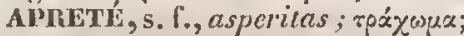
Rauhigkeit, IIcrbe (all.); harshness (angl.); asprezza (it.). Qualité de ce qui est âpre. Ce mol est fréquemment employé comme synonyus d'accrbité. Voyez ce mot.

APROSOPIE, s. f., aprosopia (a

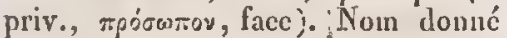
par Bresclict à un genre de déviation organique, ou d'agénésic partielle, qui est caractérisé par l'absence de la facc.

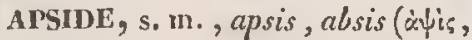
ccrele). Les astrononics appellent ainsi chacun des denx points de l'orbite des plançtes qui sont ì la plus grande et à la plus petite distance du centre des mouvemens de ces astres.

APTÉNODYTES, adj. et s. m. pl., Aptenodytes. Nom donné par J.-A. Ritgen à une famille d'oiscaux, qui a pour type le grenre Aptenodytes.

ADTLRE, adj. et s. m., apterus ; vengeflügrelt (all.) (a priv., тrspò, ailc); qui n'a point d'ailes. On dit, en botanique, fruit aptère (cx. Couania aptera), pétiole aptére. Fu zoologic, aptere (Olmflügler, all.), pris
APYR

$10 \mathrm{I}$

substautivement, est en général le synonyme d'insece aptère. Cottc épithète cst aussi donnée ì des iusectes qui n'out point d'ailes, quoique appartenant ì des ordres dans les caractères desquels cutre la présence de ces organes ( ex. Brachyeerns apterus, Lygaus apterus, Colliuris aptera).

APTÈres, adj. ct s. m.pl., Aptcra, Apterce. Notn donné par Schieffer à une classe, par Degeer à une sous-classe, par Latreille, Ficinus et Carus ì une section, par Duméril, Lamarck, Kirby, Goldfuss et Leach à un ordre de la classe des insectes, comprenant ccux de ces animaux qui sont privés d'ailes, par Latreille à un groupe de la tribu des Muscides, composé de ceux qui ri'ont point d'ailes.

APTÉrionicèriss, adj. et s. m. pl., Apterodiecra (a priv., , тzрóv, aile, oits, dcux, xapks, cornc). Nom donné par Latreille aux insectcs privés d'ailes ct munis de deux antennes.

APTÉIROLOGIE, s. f., apterologia

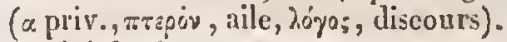
Traité des insectes aptères.

AITH́Rol.ogroue, adj. , apterologicus : qui a rapport à l'aptérologie.

APTHidoloGUr, s. m., apterologrus. Naturaliste qui s'occupe spécialemeut de l'histoire des iusectes aptères.

AP'TÉRTGLENs, adj. ct s. m. pl. ,

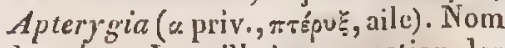
domué par Latreille ì nue section des mollusques phanérogames, comprenant ceux de ces auimaux qui sont dépourvus d'organes spéciaux pour exécuter la natation.

APYRE, adj., apyrus; foucrfest

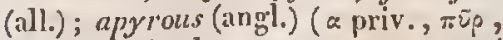
feu). Se dit de toute substance qui est inal tćrable et surtoụt infusible au fer, quelque élevée quic soit la tefupératurc à l'action de laqucllo on la soumet. 
102 AQUI

APYRÈNE, adj. , apyrenus (a priv,

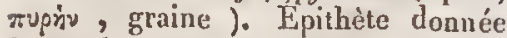
à un fruit qui ne contient point de graines.

AQUATILE, adj. , aquatilis. Synonyme inusité d'aquatiquc. Voyez ce mot.

AQUATIQUE, adj. , aquaticus, a quatilis; sumpficht (all.); aguatic (angl.); acyuajuolo (it.); qui vit dans l'eau (cx. Asellus aquaticus). En botanique, on appelle plantes aquatiques celles qui croissent dans les eaux mêmes, soit entièrennent immergées (ex. Conferva), soit flottantes à la surface (ex. Lcmna), soit fixćes au sol par leurs racines et flottantes du reste à la surface (ex. Nymphaca, Trapa), ou ćlevées au dessus de Jeur niveau (ex. Alisma Plantaso), et eclles qui croissent sur le bord des eaux courantes ou stagnantes (ex. Bignonia aquatilis, Nibora aqualica, Cerastiumaquaticum).

AQUATIQUES, adj. ct s. m. pl., Aquatilia. Nom donné par Boddaert à une section de la classe des Mammifères; par Latreille, Ritgen, Ficinus et Carus à une section de cclle des Oiseaux ; par Cuvier ì une famille de celle des Mollnsques; par Lal reille à une division de celle des Crustacés ; par Lamarek à une tribu de la famille des Cimicides, coupes comprenant toutes des animaux qui vivent dans l'cau, sur le bord des eaux, ou it la surface de l'eau.

AQUEUX, adj., aquosus ; wässcrig, wässerhaltig (all.); waterish (angl.); acquoso (it.) (aqua, eau); qui est de la nature de l'ean (liquide aqueux), qui en contient beaueoup (fruil aquenx), qui lui ressemble par quelques unes die ses propriétés ( savcur aqueztsc). Berzclius appelle acides aqucux ceux qui contiement de l'cau jouant, suivant lui, le rôle de base par rapport à cux.

AQUIFE⿱R⿴囗十⿱一口, adj., aquiferrs (aqua,
ARAC

eau, fero, porter); qui contient ou charrie de l'eau; trachies aquiferes.

AQUIF OLIACEES, adj. et s. f. pl., Aquifoliacce. Nom donné par Candolle à une tribu de la famille des Célastrinées, qui a pour type le genre Aquifolium.

AQULENK, adj., aquigcnus (aqua, cau, gento, produire); quị naît dans l'cau. Epithète donnée à un champiguon (IIelotium aguigenum) qui eroît sur les tiges des Charagnes.

AQuilarives, adj. et s. f. pl., Aquilarine. Nom donné par Candolle à une famille de plantes, qui a pour type le genre Aquilaria.

IQUILIN, adj., aquilinus; havlicd (angl.); aquilino (it.) (aquila, aigle); qui cst courbé comme le bec l'un aigle (nez aquilin; Habichtsnase, all.). Une fougère ( Ptcris aquilina) doit celte épithète à ce que la coupe trans. versale de sa racine offre l'image grossic̀re d'une aigle à deux tètes.

AQUILINS, adj. et s. m. pl., Aquilina. Nom donné par Vigors à une tribu de la famille des Faleonides, qui a pour type le genre Aquila.

AQUUPARES, adj. els. m.pl., Aquiparia (aqua, cau, paro, engendrer). Nom sous lequel Blainville désigne une division de l'ordre des reptiles batracieus, comprenant ceux de ces animaux qui déposent leur progéniture dans l'enu.

AQUOSITÉ, adj., aquosilas. Qualité de ce qui est aqueux.

ARIBIDErs, adj. et s. f. pl., Arabidea. Nom donuć par Candolle à une tribu de la famille des Crucifères, qui a pour type le genre Arabis.

AlABINE, s. f., arabina. On a donné ce nom à la portion soluble de la gomme arabigue et de la gomme dn Séuégal, ainsi qu'à la gomme soluble d'icajou.

Ali Alivides, adj. et s. m. pl., Arachnides (áṕx $\chi^{\prime n s}$, araignée). Nom donué par Launarek, Cuvier, 
Latreille, Straus et Blainville à une elasse du règne animal, renfermant ceux des animaux articulés qui, pour la forme et l'organisation, ont des rapports avee les araignées.

ARACHNODERMAIRES, adj. et s. m. pl., Araclinodcrma (à $\dot{x} \chi^{\nu n s}$,

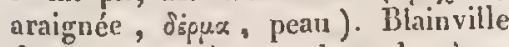
donne ce nom ì une classe du rc̀gne animal, eomprenant les Aetinozoaires qui ont la peau extrêmcment fine, peu ou point distincte.

ARACHVOIDE, adj. , arachnödcus, arancosus, arachnoïdes, araneoides ; spinncwebcnartig, spinnenwobig (all.) (àp’́xyns, araignée, ह̇ंठos, resscmblanee); qui ressemble à une toile d'araignée. On dit: $x^{\circ}$ en botanique, chapeau arachnoïdc, dans les champignous, eelui qui est uni au stipe par une membrane senblable à une toile d'araignéc ( $\mathrm{cx}$. Agaricus arancostes); poils arachnoïdes, eeux qui sont allongés et croisés, comne les fils d'une toile d'araignée, sur les feuilles (ex. Sempervivum araehnoïdeum), ou sur les feuillets du périeline ( $\mathrm{ex}$. Lophiolepis araneosa); tegmen arachnoïdc, eelui qui cst filarnentenx eornme une toile d'araignce (ex. Ixia chinensis). $2^{\circ}$ En zoologie, ectte épithète est donnée à un mammifère (Alcles arachnoïles), à eanse de ses membres qui sont très-grêles; à des coquil. les qui sont hérissées d'épines trèsJongues, grêles ou subulćes (ex. Spondrlus arachnoïdes), ou marquées de liućoles très-fines et colorées, qui imitent des fils d'araignée ( ex. Conus araneosus, Oliva araneosa); ì un insecte (Galeodes araneoïdes) qui resscmble à une araignée; ì des polypicrs off rant de petiles ccllules tormécs par des cloisous très-minces ct coneentriqucs qui imitent assez bien les toiles de certaines araignécs des jardins (ex. Astrea aranca, Astrea arachnoides). ARAGIINODES, adj, et s. m. pl. ,
Arachnoïlca. Nom donné par E. Eichwald ì la classe du règne animal qui est générniement désignće sous celui d'Arachnides. Voyez ce mot.

ARACIINOIDIEN, adj. , arachnoideus; qui a la finesse d'une toile d'araignée. Pour exprimer combien la peau des méduses est minee, on dit quelquefois qu'elle a une ténuité arachnoïdicnne.

AHACHNOLOGIE, s. f. , arachno-

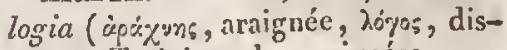
couris). Traité sur les araignées.

AIACIINOPIILE, adj. , arachno-

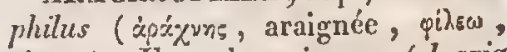
aimer). Un champignon (Isaria arachnophila) a été appelé ainsi paree qu'il croit sur le corps des araignées mortes.

ARALIACÉES, adj. ct s. f. pl.; Araliacce. Famille de plantes établie par Jussieu, et qui a pour type le genre Aralia.

aravíiDEs, adj. et s. f. pl., Araneidca, Araneides (aranea, araignéc). Nom donnć par Duméril et Goldfuss à une famille de la classe des inseetes, par Eichwald à un ordre, par Lamarek à une seetion, par Cuvier, Latreille et Leneh à une famille de la classe des Arachnides, renfermant les araiguées et les aninaux qui s'en rapproehent le plus.

ARANÉEUX, adj. , araneosus (aranea, araignée). Se dit, en botanique, des poils qui sont très-longs, mous, minces, el qui imitent les toiles d'2raignée par leur nature et leur entreeroisement. Un crustacé (Hyas aranens) a été ainsi nommé à eause de son corps long ct grêle.

MRANÉTFLiE, adj., araneifer, araneiferus (aranca, araignée, fero, porter'). L'O phrys araneifera est ainsi appelé paree qu'on a cru trouver de la ressenblanee entre sa fleur et une araignée.

AR ANLIFORME, adj. , araneiformis (aranca, araigué, forma, for- 
me). Epithète donnée par Kirby aux larves carnivores liexapodes, dont le eorps est très-court, qui ont de longues mandibules propres ù sucer, exéculent des mouveniens rétrogrades, et ressemblent, sous quelques rapports, à des araignées. Ex. Myrmeleon, Cicindela. 1

ATANÉIFORMEs, adj. et s. m. pl., Araneiformia (aranea, araignée, forma, forme). Nom donné par Blainville à une famille de la classe des Hétéropodes, à causc de la forme générale du corps des animaux qui la constituent.

ARANÉomes, adj., Araneoüdes (aranea, araignée, દiớa, ressemhlanec). Nom donnć par Ficinus et Carus à la famille d'insectes aptères qu'on désigne plus généralement sous eclui d'Aranćides. Voycz ce mot.

ARANÉLogie, s. f., araneologia (aranca, araignée, $\lambda 0^{\circ} \% 5$, discours). Traité des araignées.

MIAANÉOLOGUE, s. m., arancolosus. Naturaliste qui s'oceupe spécialement des araignćes.

ARAUCARIEES, adj. et s. f. pl. , Araucarice. Nom donné par Kunth à une tribu de la fanille des Conifères qui a pour type le genre Araucaria.

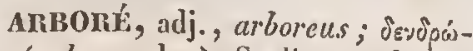
ons (arbor, arbre). Se dit, en botanique, d'une lige yui est ligneuse et nue par le bas (ex. Ulmus campestris); en zoologic, d'un oiscate qui se perche et niche sur les arbres (ex. Anas arborea), ou qui se tient habituellement dans les buissons (ex. Anthus arborcus).

ARBOLESCENGE, s. f. , arbores-

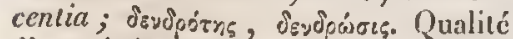
d'un végétal qui aequiert la hauteur on la grossenr d'un arbre.

ARBORESCENT, adj., arborescens, arborcus; jevopoions; baumartig (all.). Épithète donnéc aux plantes qui sont des arbres, on qui en

\section{ARBR}

ont le port (ex. Callipteris ärborescens, Malvusiseus arboreus, Datura arborea, Zygophyllum arboreum), aux zoophyles qui affectent la forme d'arbre (ex. Dendrophyllia ramea).

ARBONIFORME, adj. , arborifor-

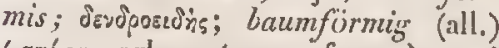
(arbor, arbre, forma, forme); qui a la forme d'un arbre on d'un arbrisseau. Ex Mtesembryanthemum arboriforme.

ARBORISATION, s. f., arborisatio. Les minéralogistes appellent ainsi : $1^{\circ}$ une aggrégation de cristaux représentant une espèce de pelit arbre, une touffe étendue à la surface des corps, et y formant soit une pelliculc assez épraisse, soit un mince cnduit qui nc se distingue que par sa coulcur; $2^{\circ}$ un dessin figurant des arbrissenux que présente la coupe de ecrlaius calcaires sehistoïdes ct quarz agates, et qui sont dus à dies infiltrations de fer ou de manganèsc entre les fcuillets de la pierre, ou à des substances enveloppées après coup par unc matière consolidée aulour d'clles.

ARBORISÉ, adj., arborisalus. Épithète donnée aux agates qui officnt, dans l'intéricur de leur pâte, des dendrites ou représentations d'arbres, ordinairement de couleur brune, dıesà l'infiltration d'un liquide chargé d'oxides métalliques.

ARBRE, s. m., arbor; jévopov; Baum (all.); tree (angl.); albero (it.). Plante dont la tige ligneuse, nuc et simple par le bas, rameuse seulement à la partie supéricure, dépasse cinq fois au moins la hauteur du corps d'un homme.

ARBRISSEIU, f. m. , frutex; divspısy; Büumehen, Strauch (all.) ; shrub (angl.). Plante dont la tige est ligneuse, ramense dès la base et peu élevéc. Ex. Plectranthus frutieosus, Crambe frutieosa. 
ARBUSGULAIRE, adj. , arbuscularis; qui est ramifié à la manière d'un petit arbre, comme les appendices p'acćs autour de la bouche des Holothurics.

Albuscule, s. m. , arbuscula; iEvôjúfiov. Petit arbre, dont la hauteur est pet considćrable ( ex. Erica arbuscula). Plante dont la tige se divise à la manière de celle des arbres (ex. Isothecium arbuscula).

ARBUSTE, s. m. , arbustum, fru-

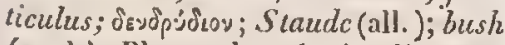
(angl.). Plante dont la tige ligneuse n'atteint pas trois fois la hauteur du corps d'un hoinme, et se ranifie pris de sa base.

ARuUSTiF, adi.; qui est placé contre un arbuste. On a donné le nom de vigncs arbustives à celles que l'on plante au picd dès arbres isolés, dans la seule intention d'en récolter la feuille pour la nourriture des bestiaux.

ARG-EN-CIEL, s. nı, , iris; ipę; Resenbogen (all.); rainbow (angl.); iridc (it.). Météore lumineux, consistant en un ou plusieurs arcs concentriques, formés de bandes colorées, qui lieu quand le soleil, ou quelquefois la pleine lune, darde ses rayons sur $\ldots$, nuage prêt à se résoudre en pluie, ct que l'observateur se trouve placé devant ce nuage, le dos tourné à l'astre éclairant.

arcacées, adj. et s. f. pl., Arcacece, Arcacca, Arcaccs. Nom donné par Goldfuss à une famille de MolIusques, par Lamarck, Munke et Latreille à une famille de Conchifères, par Blainville à une famille d'Acéphalophores et de coquilles, coupes qui toutes ont pour type le genre Arca.

ARCEAU, s. m. , arcus; Bogen (all.). Ce mot, qu'à tort on cmploye quelquefois comme synonyme d'anncrul, sert à désigner les deux demianneaux, joints par lcurs extrémités, ct composés enx-mèmes de plusieurs pic̀ces, qui constituent les anneaux du corps des animaux articulés.

ARCELLINes, adj. ct s. m. pl., Arccllina. Nom domé par C.-G. Ehrenlocrg ì une tribu de la classe des Polygasiriques, qui a pour type le genre Arcella.

ARCENDOLOGHE, s. f., arcendolo-

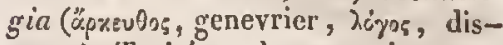
cours). Traité sur le genevricr.

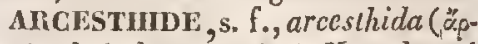
$\chi^{\approx 0} \theta_{15}$, baiede genevitier). Nom donné par Desvaux à un fruit sphérique, composé de plusieurs écailles charnues qui ne sc sćparcnt pas au terme de la maturité. Ex. Suniporus communis.

AncIIPIEL, s. m., archipelagus ; Insclmecr (all.); archipclago(angl. it.)

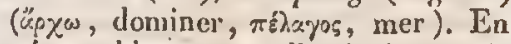
géographie, on appelle ainsi nne réuuion d'îles dans un espace de mer pcr ćtcndu, et par extension une mer entrecoupće d'un grand nombre d'îles.

ARCTIQUE, adj. , arcticus; bax?tx.ंs; nürdlich (all.); northern (angl.) (äpros, ourse). Synonyme de boréal et de septentrional (póle aretique, cercle arctique, tcrres arcliqucs, régions arctiqucs). Le Colymbus arcticus est ainsi appelé parce qu'il habite dans le nord; I'Hemisynapsium arcticum, parce qu'il habite l'île Melville.

AnCTOMYDES, adj. et s. m. pl., Arctomides. Nom donné par Latreille à une famille de la elasse des Manmifères, qui al pour type le genre Arctomys.

Anctotidétes, adj. et s. f. pl. , Arctotidca. Norn imposé par H. Cassini à une tribu de la famille des Synanthérécs, et par Lessing à une soustribu de la tribu des Cynarécs, qui ont pour type le genre Arclolis.

Arcture, adj., arcturtes ( $\alpha p \alpha-$ ro:, ours, ovjò, queue). Une plante (Celsia arclurus) est ainsi appelće 
parce qu'on a comparé à une queve d'ours sa fleur, qui est disposéc en une grappe allongée.

ARCYTHOPIIYTL, s. m., arcy-

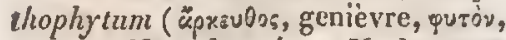
plante). Nom donné par Necker aux plantes qui portent des fruits semblables à celui du genevrier.

ARDÉIDÉs, adj. et s. m. pl., Ardeidea. Nom donné par Vigors à une famille d'oiseaux, qui a pour type le genre Ardea.

ARDENT, adj. , ardens; feurig , glühend (all.); glowing (angl.); ardente (it.) (ardeo, brûler); qui brûle, qui enflamme. On appelle fontaines ardentes, terres ardentes, celles d'où se dégagent, en Italie et en Persc, des gaz ou des vapeurs de pétrole, qui prenncut feu et continuentì brûler, quand ilss'entlamment accidentellcment. Ardent est quelqucfois enployé pour désigner le roux vif(ex. Dasypogon ardens).

ARDISIACÉEs, adj. et s. f. pl., Ardisiacea. Nom donné par Jussieu ane famille de plantes qui a pour type le genre Ardisia.

ARDISIĹES, adj. ct s. f. pl., Ardisiece. Nom donné par Bartling à une tribu de la famille des Ardisiacées, qui a pour type le genre Ardisia.

AMDOISÉ, adj., ardisiaecus, schistosus; schieferfürbig (all.); qui a la couleur de l'ardoise, ou dans lequel cette couleur domine. Ex. Ceblcpyris ardoisaceus, Sylvia ardisiacea, Coluber schistosus, Ardea ardisiacen. ARDOISIER, adj., ardisiaceus (ardosia, ardoisc). Nom donné par Omalius à un groupe de terrains comprenant ceux qui ont de la tendance à préscnter de grauds feuillets, à passer à l'ardoise.

Altécine, s. f. , arecina. Matière colorante rouge insoluble des fruits de l'Areca Calechu.

ARÉcrNÉES, adj. ct s. f. pl., Arecina. Nom dousé par Martius à une tribu de la famille des Palmiers, qui a pour type le genre $A$ reca.

ARLiva CE, adj., arenaceus; sandartig (all.) (arcna, sable). Se dit d'un mincral, quand il a la forme de sable (dípơt erénacé, assisc arćnacćc, päte arénacée, formation arénacéc, caractire arénacé, structure arénacée). Omalius donne cette épithc̀le à toutc roche calcaire ou autre qui a de très-petits grains, et qui est dans un état analogue à du sable, sans cohérence de ces grains. Il blâme, avec raison, lcs géognostes qui appellent roches arenaecics celles qui sont agglomérées à la manière du grc̀s. Le Flustra arenacea est ainsi nommé parec qu'il se composc de cellules asscz mal formées à la surface d'une couche de sablc.

ARÉNACŔES, adj., arenacea.Épithète donnée par Brongniart à un groupe de roches, comprenant celles qui ont une texture grossière, sont friables, et se désaggrègent facilement.

Arénacḱo-CALCALEE, adj. , arenaceo-calcarius. On appelle substence arćnacéo-calcaire un lit de sable cimenté par une infiltration calcairc.

ARĹNAIRE, adj., arenarius, sabillosits, ammodes, ammonytes, arenosus. Sc dit, en botanique, d'une plante qui croît dans le sable, dans les terrains sablonncux et arides (ex. Astragalus ammonytes, Paspalus ammodcs, Elymus arenarius, $V$ iola arcnaria, Hemimeris sabulosa, Fuiercna arcnosa, Phleum arcnarium); cn zoologic, d'une coquille qui se tient dans le sable (ex. Septaria arenaria); d'insectes qui aiment les cndroits sablonneux (ex. Scarilcs sabulostes, Iulus sabulosus, Sphex sabulosa, Opatrum sabulosum); d'ul mantmifère qui vit dans les plaines sablonneuscs (cx. Mus arenarius).

AndeNLUx, adj. , arenosus; sandig 
(all.). Synonyme peu usité de sablonneux. Vorez ce mot.

ARÉNICOLE, adj., arenieolus (arena, sable, colo, habiter); qui vit dans les endroits sablonneux. Ex. Lacerta arenicola.

ARĹNicoles, adj. et s. m. pl., Arenieola. Non donué par Blainville à une famille de Chétopodes, par Cuvier et Latreille à une section de la tribu des Searabéides, coupcs qui toutes deux renferment des aninuaux ayant pour habitude de ereuser des trous profonds dans la terre on le sable.

ARÉwLine, adj., areniferts (arena, sable, fero, porter); qui conticnt accidentellement du sable. Ex. Phyllade arénifère.

AlÉNIFORM:, adj. , areniformis (arena, sable, forma, forme); qui ressemble à du sable : mélange aréniforme

ARÉNULACÉ, adj., arenulaceus. Epithète donnée aux petits vers qui adhèrcnt ì la face interne de la vessie de l'échinocoque, paree qu'ils ressemblent à des grains de sable.

ARÉOLAIRE, adj, , areolaris (areo$l a$, aréole) ; qui est reınpli d'aréoles. Ce mot est employé quelquefois comme synonyme de cellulairc.

ARÉOLE, s. f. , areola; Höfchen (all.) (aren, aire). Pctite surfaee; interstice que les réseaux capillaires ou les faisceaux de fibres entreeroisées laissent entre eux. Kirby donne ce nom anx espaces étroits dans lesquels l'aile des insecles est partagée par les Mervures. En botanique et en zoologie, ce mot est généralement synonyme de cellule ou de petite cavité.

Inćouḱ, adj., arcolatus; felderig (all.). Se dit, en bolanique, d'une feuille qui est marquée d'inégalités ou de rides peu sensibles (ex. Erythroxylum areolatum). Kirby appelle arciolices les iniles des insectes, quand elles sont divisées en aréoles (ex. Diptères).

AREOMLTME, s. m., areometrum; Solwaage, Salspindel, Salzspindel,

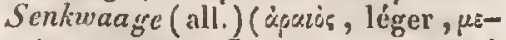
$\tau$ тв́ faire connaitrc combien un liquide est plus léger on plus pesant qu'un autre.

AnETT, s. f., arista, aeies. On appelle ainsi : $1^{0}$ cn minéralogie (Kanle, all., edge, angl.), la ligne de jonclion de deux surfaces on de deux plans, qui sont inclinés l'un sur l'antre ; $2^{\prime}$ en botanique, Link propose de substituer ce mot ì eelui d'angle, quand on parle d'une tige, d'un fruit, d'une graine. Du reste, arče (Granne, all., resla, it.) désigue gćnéralement un filet grêle, raide cl pointu, qui surmonte divers organes floraux, surtout daris la famille des Graninées. Palissot-Beauvois donne ce nom an prolongement filiforme, raide el coriace, qui naît subitement au sommet ou sur le dos des valves de la glume, el ne laisse aucun indiee de son origine au dessous de son point d'attaelie, e'est-à-dire n'est point une eontinuation des ner vures (ex. Agrostis canina). Raspail, au con traire, le réserve pour désigner le filet qui résulte d'un prolongement de plusieurs nervures (ex. Bromus seealinus). $3^{\circ}$ En zoologie. On np- pelle ainsi les os longs, minces et pointus qui se trouvent dans la chair des poissons (Fischgrüle, all.; fishbone, angl.; arresta, it.).

Alírilushils, adj. et s. f. pl., Arethusea. Nom donné par J. Lindley à une tribu de la famille des Orchidées, qui a pour type le genre Arethusa.

ARGGENT, s.m., ar gentum; äprupos, àprýpeov : Silber (all.); silver (angl.); argento (it.). Mrélal solide, d'un blane ćelatant, qui est connu de toute antiquité.

ARGLNTAL, adjeet, argentalis. 


\section{8}

Nom donné, dans la nomenclature minéralogique dc Haüy, à un métal qui est combiné avee de l'urgent nnćtallique. Ex. Mercurc argental.

ARGENTATE, s. m., argentas. Sel formé par la combinaison de l'anmoniaque avec l'oxide argentique, qui, dans ce cas, joue le rôle d'icide.

ARGENTĹ, adj., argentcus, argentalus, argyraeus, arsyratus, argentinus'; silbcrfarben, silbcrweiss (all.) ; qui a l'aspect, la coulcur ou l'éclat de l'argent. Ex. Evolvulus argenteus, Gnidiu argentea, Geranium argentcum, Natrix argentatus, Holocentrus argentinus, Oxytropis argyrea, Polypodus argyraccus, Marginaria argytrata, Lupinus argyreus, Aspalathus arsyrcia.

ARGENTICO-AMNONIQUE, adj., argentico-ammonicus. Épithètc donnée, dans la nomenclature chimique de Berzelius, à un scl double qui résulte de la combinaisou d'un sel argentique avec un scl ammonique. Ex. Chlorure argentico-ammonique ( hydrochloralc d'argent et d'ammoniaque).

ARGENTICO-CALCIQUE, adj. , argentico-calcicus. Nom donné, dans la nomenc!ature chimique de Berzelius, à un sel double qui résulte de la combinaison d'un sel argentique avec un sel calcique. Ex. IIyposulfatc argentico-calcique (hyposulfate d'argent et de chaux).

ARGENTICO-PLONIBLUE, adj., argentico-plumbicus. Epithète donnéc, dans la nomenclature chimique de berzelius, à un sel double qui résulte de la combinaison d'un sel argcutiquc avec un sel plombique. Ex. Hyposulfite argcnlico-plombique (hyposulfite d'argent et de plomb).

ARGEVTICO-POTASSIQUE, adj. , argentico-potassictzs. Epithète donnée, dans la nomenclature chimique de Berzclius, à un sel double tqui résulte de la combinaison d'un scl ar-

\section{ARGI}

gentique avec un sel potassique. Ex. Hyposulfate argentico-potassique (lyposulfate d'argent et de polassc).

ARG ENTICO-SODIQCE, adj., arsentico-sodicus. Epithète donnée, dans la nomenclature chimique de Bcrzelius, à un sel donble qui résulte de la combinaison d'un scl argentique avec un sel sodique. Ex. Chlorturc argentico-sodique (hydrochlorate d'argent el de soude).

ARGEVTICO-STRONTIQUE, adj., argentico-stronticus. Nam donuć, dans la nomenclature chimique de Bcrzelius, à un sel double qui cst produit par la combinaison d'un sel argentique avec un sel strontique. Ex. Hyposulfitc argentico-strontique (hrposulfited'argentet de strontianc).

ARG ENTIFEIIE, adj., argentiferus; silberhaltig (all.); qui contient accidentellement de l'argent. Ex. Plomb sulfuré argentiferc.

AIRGENTIN, adj., argcntinus; qui a l'apparcuce, la couleur éclatante (cx. Holocentrus argentinus), et surtout le son clair (voix argentine, timbre argentin) de l'argent.

ARGENTIQUE, adj., argenticus. Berzelius appelle oxide argentique (Silleroxyd, all.), le premicr degré d'oxidation de l'argent; sels argentiques, les oxisels qui ont pour base cet oxide, les haloscls ì base d'argent, et les sulfosels correspondans aux oxisels pour la composition.

ARGENTO - FULMINIQUE, adj. , argento-fulminictss. Nom douvé à un acide, qui, d'après Liebig, est composé des élémens de l'acide cyanique, arec moitié autant d'oxide argentique qu'il en cntre dans l'argent fulminant.

ARGENTURÉ, adj., argenturatus. Epithète donnée par Porrett ¿i un acide, l'acide chiazique argenturé, que d'autres chimistes ont appelé hydroargentocyanique. Voyez ce mot. ARGILACÉ, adj., ar gilacezts (ar- 
gila, argile); qui a la couleur de l'argile (cx. Agaricus argilaccus, Hclix argilacea); qui vit sur l'argile (ex. Pcziza armilacea).

ARGILEUX, adj., argillost.s; thonicht, thonartig (all.); clayish (angl.); ar'gilloso (it.); qui est de la nature de l'argile, qui contient de l'argile. Une roche argilcuse cst celle dout la pâte ou la masse principale est d'argile. Cependant Omalius appelle roclies argileuses un genre de roches comprenant les pierreuses qui ont une structure argileuse. On nomme odeur argileuse eclle qui, par le contact de l'humidité, s'exhale de ecrlaines matières sc̀ches et porenses, dont les unes ont l'apparenee argileuse ct les autres n'ont rien de ce qu'on appelle argileux. Cette odeur n'est pas duc à l'argile, puisque l'alumine pure ne la manifeste point et que plusieurs minéraux non argileux la dégagent; mais elle paraî̀ l'ètre au fer oxidé terreux.

ARGILICOLE, adj., argilicola argila, argile, colo, habiter); qui vit. sur l'argile. Ex. Opegrapha argilicola.

ARGILIFÈRE, adj., argilifcrus ; thonhaltign (all.) (argila, argilc, fero, porter); qui contient accidentellement de l'argile. Ex. Calcaire argilifêre.

AMGILIFORME, adj., argiliformis (argila, argile, forma, forme); quiressemble à de l'argile. Ex. Trass argiliforme.

ATIGILO - FERRLGINEUX, adj. , argilo-fcrruginosus; qui contient de l'argile et de l'oxide de fer (sable argilo-forruginer(x). Dolomieu appelait roches argilo-ferruginerses celles à base de trapp on de cornćenne, qu'il regardait comme formées principalement d'argile. Des infiltrations argilo-ferrugineuses se rencontrent souvent dans les fissures des roches.

ARGLL-GYPSEUX, adj., argilo- sypsosus; qui contient de l'argile et du gypse : dépổt argillo-gypseux.

ARGMOIDE, adj., argiloüdes; qui resscmble à de l'argile. On appcile bréche à päte argiloüde une roche dont la masse principale présente l'aspect ou les propriétés de eertaines argiles.

ARGILOLITHOUE, adj ., argilolithicus (argila, argile, $\lambda i 0_{\circ}$, pierre); qui cst formé d'argile endureic : rache argilolithique.

AnGLO-SABLEUX, adj., argiloarenosus. Brongniart appelle limon argilo-sablez $x$, un groupe de roches, dont le nom scul indique la nature.

ARGILO-SABLONNEUX, adj., argilo-arenaceus; qui est formé de sablc et d'argile : terrain argilo-sablonneux.

ARGLLO-TOUnBELx, adj. On appelle limon argilo-tourbeux, une argile délayée qni cst mêlée de parties végétales, dout les une sont eanservé leur forme, tandis que les autres sont cntièrement déeomposćes.

ARGOLIDES, adj. et s. m. plo, $A r$ goliclce. Nom donné par Leach ì unc famille d'Entomostracés, qui a pour type le genre Argulus.

ARGONAUTACEES, adj. et s. f. pl., Argonautacea. Nom donné par Blainville ì une famille de coquilles ayant pour type le genre Argonauta.

AR(iYhaNTuÈie, adj., argyran-

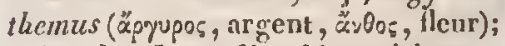
qui a des fleurs d'un blane éclatant. lix. Croton argyranthemum.

AnG VRLDES, s. m. pl., Argyrides. Nom donné par Ampèrc à un genre de corps sinples, par Beudant à une fanille de ninéraux, qui ont pour type l'irgent.

Ang Ylocinlitare, adj., argyro-

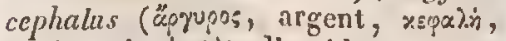
têtc); qui a la tc̀te d'un blane argentin. Ex. Araba argyrocephala.

AViGYROPÉE, s. f., argrropaca (ürqups, argrnt, тoisw, faire). Art 
prétendu de faire de l'argent. Synonyme d'alchimie.

ARGYROPIITILLME, adj., argyroplthalmus (öpqupos, argent, óposi$\mu \dot{s}$, ceil): qui a les yeux d'un blane d'argent. Ex. Garrulus argyropletlalmus.

AnGYMOPIIYLLE, adj., argyrophyllus; silberblïtrig (all.) ("̈́prupas, argent, quildov, feuille); qui a les feuilles couvertes d'un duvet serré, blanchâtre et brillant. Ex. Miconia argyrophylla, Croton argyrophyllum. Voyez Arennté.

ARGYROPYGE, adj., argyropy sus

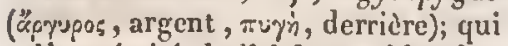
a l'extrémité de l'abdomen blauche. Ex. Anthrax argyropyga, Bombylus argyropygus. Voyez Ledcoprae.

AnGYROSTIGMÉ, adj., argyro-

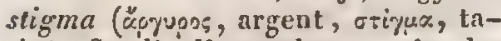
ehe). Se dit d'une plante qui a les fleurs marquées çà ct là de taches blanches. Ex. Begonia argyrostigma.

AnGYnostouE, adj., arsyrostomus (üprypoe, argent, aróks, bouche); qui a la bouche d'un blane d'argent. Ex. Turbo argyrostomus, Musca argyrostoma.

ARIIZE, adj., arhizus; wurzenlos (all.); arriso (it.) ( $\alpha$ priv., pič, racine). Epithète donnée par Rielıard à tous les végétaux sans radieule et par collséquent sans véritable embryon ; par N Nes d'Esenheek aux plantes dont la racine est très-petite ou d'une conformation extraordinaire.

AnHIZOHLASTK, adj., arhizoblas-

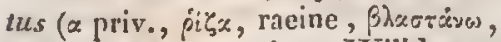
crotirc). Nom donné par Willdenow aux embryons qui n'ont pas de racine.

ARICNE, s. f., aricina. Base salifiable organique et cristallisable que Pelletier a découverte dans une écorce toute semblable à celle du quinquina jaune.

Anicives, adj. et s. m. pl., Arieines, Robineau-Desvoidy désigne ainsi une tribu de la famille des $\mathrm{MyO}^{-}$ daires Mésonydes, qui a pour type le genre Aricia.

AnIDE, adj., aridus, aridulus; Enposs; trocken, clürr (all.); dry (angl:); arido (it.). Se dit de la surface ou de la poussière d'un corps, quand elle présente une certaine aprefé au doigt qui passe dessus. On employe quelquefois ce mot comme synonyme de $s e c$, en botanique, où l'on dit, par exemple, que l'épi est aride dans l'Avena fatua, le périanthe aride dans le Gnaphalium.

AnIDIFolrúres, adj. et s. f. pl., Aridifolica. Classe de plantes, adnise par $\Delta$ gardl, qui renferme celles dont les feuilles sont généralement sèches, commic les Epacridées, Ics Ericées, ete.

ARIDITE, s. f., ariditas; క̌neroiz; Trockenheit, Dïrre (all.); dryness (angl.); aridità (it.). Synonyme de sécheresse. Voyez ce mot.

ARILLAInE, adj. , arillarius. On appelle innique ou pulpe arillaire l'arille tres-divisé, ct en forme de membrane pulpeuse, de quelques passiflorécs.

ARILLE, s. m., arillus; Saamenmantel, Saamendecke (all.); arillo, velo (it.). Nom denné par les botanistes à une expansion caroneulaire, capsulaire ou sacciforme, le plus souvent sncculente et membraneuse, que le funicule produit antour de certaines graines, qui les enveloppe toujours d'une manière incomplète, et qui n'y adhìre que par le hile.

AnILLÉ, adj., arillatus. Épithète donnéc anx graines qui sont revêtues d'un arille. Ex. Myristica aromatica.

ARISTE, adj. , aristatus; gegrannt (all.) ; restato (it.) ; qui est muni d'un appendice en forme d'aréte. $\mathrm{On}$ dit, en botanique, anthère aristée (ex. Nigrella aristata); braetées aristées (ex. Prenanthemum aristalum) ; feuilles aristécs, celles qui sont garnies de petites épines (ex. 


\section{ARMÉ}

Berberis aristata); fruit aristé, eelui à l'extrémité duquel persiste le style endurei (cx. Charophyllum aristatum); glumc aristće (ex. Ischcemum aristatum). En zoologie, antenncs aristices, eelles dont le dernier article portc un poil (ex. Musce). Un poisson (Labrus aristatus) est ainsi appelé parce qu'il a ehacune de ses écailles relevée de denx arc̀tes.

AnISTOLOCHES. Voyez AristoLOCHIÉES.

ARISTOLOcmíres, adj. et s. f. pl., Aristolochiar. Nom donné par Jussieu à une famille de plantes qui a pour type le genre Aristolochia.

MRISTULE, adj. , aristulatus; qui est muni d'mne très-petite arète, comme la glume de l'Uralepis aristulatus.

ARLEQUiví, adj. , multicolor. Epithète donnée à un oiseau ( $T_{i} \cdot 0-$ chilus multicolor), à un reptile (Agama multicolor), à une coquille (ex. Cypraca arlequina) et ì quelques autres animaux, à eause de la variété des couleurs dont ils sont ornés.

ARMATURE. $V$ ogcz AnMURE.

ARME, s. f. , arina; Gcwchr (all.); arm (angl.); arma (it.). Nom collectif de tous les moyens de défense des végétaux, de tous les moyens d'uttaque et de défense des animaux.

AnMÉ, adj. , armatus; bewaffnct, bewcht (all.); qui est muni d'armes. Epithètc donnée à des poissons dont le eorps est convert d'une forte euirassc (ex. Aspidophorus armalus, Amphisilc velitaris), on hérissé de pointes (ex. Silurus militaris); à des insectcs qui ont les mandibules longues et dressćes eomme deux cornes (ex. Anisotomn armatum).

AnvíEs, adj. et s. f. pl., Armatex. Noın sous lequel Debnch désignait une tribu de la famille des Ammonées, eomprenant eelles qui sont armées de plusieurs rangées de variees ou d'ćpines. anmentaires, adj.; ' Armentaria (armentum, troupeau). Nom donné par Robineau-Desvoidy ì une seetion de la famile des Museides, comprenant des espèces qui tourmentent ì l'excès les grands quadrupèdes'.

ARmíniacéES, adj. et s. f. pl., Armeriacece. Nom donné par Marquis a une famille de plantes qui a pour type le genre Armeria.

Anvicers, adj. et s. m. pl., Armicipiles (arma, armes, capue, tête). Nom donné par Latreille à uno tribu de la famille des Clupéides, comprenant des poissons qui ont la tête défendue par des pièees osseuses ou des éeailles pierreuses.

AmMiGives, adj. et s. m. pl., Armigence (arma, armes, gena, joue). Nom donné par Ficinus et Ca. rusà une tribu, par Latreille et Eichwald à une famille de poissons, comprenant ceux qui ont les joues euirasscées.

ARMIGLRE, adj., armigerus (arma, armes, gero, porter) ; qui porte des arnes. Une coquille (Purpura armigcra) a été appelée ainsi parce qu'elle est garnie de longs tubereules; un oiseau (Aquila armigcra), à cause de ses serres robustes.

ARMILLAIRE, adj. , armillaris (arinilla, bracelet). Les astronomes appellent armillaire une sphère artificielle composíe de cereles qui rcpréseuteut les orbes des eorps eélestes dont se compose le système solaire. Une plante (Jacquinia armillaris) doit ce nom à ee que ses branches sont entourées de feullles verticillées qui ressemblent à des anueaux, ou à ee que ses belles et odorantes fleurs servent it fairc des guirlandes, et ses graines des bracelets. Un animal (Ncieis armillaris) est ainsi nomné à cause des bandes transversales noirâtres dont son eorps est marqué.

ARMILLE, adj., armillatus ; qui est enlouré d'un anneau autrement 
eoloré que le reste du eorps, et imitant en quelque sorte un braeelet, comme le tibia postérieur du Prosopis annulata.

ARMuRE, s. f. , armatura. Les physiciens donnent ee nom à des lames de fer doux, qu'on assoeie anx aimans naturels, et qui, soumises continuellement à l'aetion des pôles auxquels elles sont appliquées, exereent sur eux une réaction capable non-seulement de eonserver la vertu magnétique, que le temps affaiblit quand on les abandonne à eux-mêmes, mais eneore d'augmenter en eux eelte vertu, qu'ils ne manifestent eommunément qu'à un degré médioere quand on les tire du scin de ln terre.

ARMUS, s. m. , armus ('́xpoís, jointure). Illiger appelait ainsi, d'après Pline, l'épaulc on la partie la. térale du corps des oisenux, dont le bas est contigu à la poitrine, et qui tonehe par derrière aux hypochondres.

ARNICINE , s. f. , arnicina. Nom donné à la rćsine amère qui paraît être la partie eflieace de l'Arnica montana.

AlioIDḱes, adj. et s. f. pl., Arödea. Jussieu désigne ainsi une famille de plantes qui a pour type le genre Arum.

ARomes, adj. et s. f. pl., Aroïdes. Synonyme d'Aroüdécs. 'Voyez ce mot.

AROMATrQUe, adj., aromaticus ; gewoürzhafigg (all.); qui exhale une odeur agréable. Ex. Caryoplyllus aromaticus.

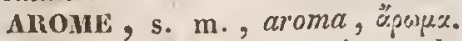
Nom génćrique des émanations subtiles qui s'échappent des eorps odorans, et qui, en frappant la membrane olfactive, produiscnt la sensatinn des odcurs.

ARPENTEU1, adj. Les entomologistes appellent chenilles arpenteuses
(Spannraupen, all.) eelles qui; ayant le corps très-long, avee un grand intervalle entre les pattes antérieures et intermédiaires, sont forcées de replier l'abdomen pour faeiliter le transport du corps dans la progression, d'où résultent des alternatives de courbes perpendieulaires et de lignes horizontales, ee qui rend leur marehe si singulière, qu'elles semblent mesurer le terrain en le pareourant.

MnQULí, adj., arcuatus ; bogenformig (all.); crooked (angl.); arcualo (it.) (arcus, are); qui déerit un are de ecrele. On dit: $1^{\circ}$ en minéralogie, stratification arquce, eelle des massifs formés de couehes peu inclinćes qui constituent une montagne en s'ćlevant d'un eôtć, dans le sens de la pente, se eourbant all sommet, et redescendant avee la penle opposee ; $2^{\circ}$ en botanique : anthìrc arquéc (ex. Rhexia virginica); grainc arquée (ex. Tournefortia mulabilis); lósume arqué (ex. Ornithopus pcrpusillus); siliquc arquce (ex. Raphanus rccurvatus) ; slyle arqué (ex. Pisum salivum ); tube arqué , dans une corolle labiće (ex. Ncpcta longifolia); feuilles arquées (ex. Dicranum arcuatum); $3^{\circ}$ en zoologie, coquillc ar$q u e ́ c$, eelle qui n'offre qu'une simple inflexion, plus ou moins considérable (ex. eertaines Bélemnites).

ArQuís, adj. et s. m. pl., Arcuala. Nom donué par Cuvier et Latreille à une tribu, par Eichirald à une section de crustacés braehiures, comprenant eeux qui ont le thoraeide en forme de segmeat de eercle et arquit en devant.

Aririthe-ĺcussov, s. m. , postscrulum. Latreille appelle ainsi un petit espaee carré que ie milieu du Inésothorax présente dans plusieurs insectes diptères.

ARRILIE-FAIX, s. m., secundi- 
na. Nom donné par le vu!gaire à la réunion du placenta ct des membranes du foctus, paree qu'en général cette massc sort de la matrice après l'eufant.

ARRILIRE-FLEUR, $s$. $f$. $O_{11}$ appelle vulgairement ainsi la fleuraison d'automne, c'est-i-dire le cas qui a liculorsque, dans un automnc ehaud et humide, les lleurs des arbres et des herbes à fleuraison printanière se développent de nouvcau.

ARRILRE-NEZ, s. m., posinasus. Nom douné par Kirby à la partic de la face des insectes qui est immédiatement eonlinue aux antennes, derrière le ncz. Ex. Sagra, Prosopis.

ARRIÈrE-POITRINE, s. f., postpectus. Sous ce nom, Kirly entend le côté inféritur du second segment de l'alitrone, et Latreille la partic inféricure du troisième segment du thorax des inseetrs.

ARRIËRE-STURNUM, s. m. Nom donné par Lattreille à la partie médiane inférieure du troisième segment du tholax des insectes.

ARRIÈRE-TERGUA, s. m. Nom sous lequel Audouiu désigne la partie supéricure des denx derniers anneaux réunis du thorax des insectes hexapodes, e'est-ì-dire la réunion du tergum du nésolhorax et de celui du métathorax.

ARROCHES, s. f. pl. , Airiplices. Quelques botanistes ont donné ec nom à la famille des Chínopodées. Voyez ce mot.

ARRONDI, adj., rolundus, rotundallts, subrotandus; zugerundet (all.); rounded (angl.); ritundato (it.); qui se rapproche de la forme orbiculaire, ou dont le contour appl'oche de celui d'un eerclc. On dit, en botanique; tracties arrondics (ex. Hyssopus thymifolius); drupearrondi (ex. Prunus spinosa); fcuillcs arrondies (ex. Mentha rotundifolia); graine arrondic (ex. Vicialulea); peiales arrondis (ex. Fragaria vesca); racinc arrondic (ex. Bunium bulbocastanum): radicule arrondic (ex. Fiscum album); stipules arrondies (ex. Spiraea Vlmaria).

Ans, s. m., Glied (all.) (artus. membre). $O_{n}$ appeile ars antérieser un repli do la peau du cheval yui, de Ia partic inférienre de la poitrine, sous le sternum, va gagner claıque extrémité antérienre, et ar.s postćrieur un repli cutané qui, du ventre, s'étend à chaque extrénité postérieure.

AIstiviate, s. m., arsenias. Ton d'un genre de sels (ar'scrilisaure Salze, all.), qui sont formćs par la combrinaison de l'acide alrscnique arec les bases salifiables.

AnSẂviATÉ, adj., arsenialus: Nom donné, en minéralogie, anx bases qui ont été eonverties îl l'état de scl par l'acide arsenique. Ex. Plomb arséniaté.

AnsFvic, s. m., arscnicum, fuligo metallorum, spectulum album, zenicum; cेoavexì,; Arscnik (all.); arscnic (angl.); arsenico (it.). Métal solide, d'un gris d'acier et volutilisahle, qui est connu depuis des temps fort aneiens.

ARSÉviCaL, adj., arsenicalis; qui a rapport ì l'arseuic (odeur arsénicalc, vapeurs arsćnicalcs), on qui contient de l'arsenic ( cx. Argent arsénical).

ARSíviCo-FERRIFL̀nE, adj. , arsenico-ferrifer; qui aceidentelleunent contient is la fois de l'arsenic et du fer. Ex. Bismuth natif arsínicoferrifere.

AISENICO-SuLfuribes, s. m. pl. Nom donné par Bonnsdorff anx combinaisous naturelles de sonfre et d'arsenie, qu'il appelle aussi sulfarsćniures.

AISŚ́xicoNides, s. II. pl. Nom donné par Bendant à un ghenre de minéranx comprenant les combinaisons de l'arsenic arec l'oxigène. 
ARSHNIDES, s. m. pl. Nom donné ' par Ampère et C. Pauquy à une famille de corps simples, yui a pour type l'arsenic, et par Beudant à une famille de ininéraux, qui eomprend l'arsenic, soit seul, soit à l'ćtat de combinaison.

ARsÉví́, adj., arseniatus; qui contient de l'arsenic (ex. Cuivre gris arsínié). Le gaz hydrogène arsénié (Ärsenikwasserstofgas, all.), combinaison d'hydrogène et d'arsenic, est appelé par Berzelius arsćniure trillydrique.

ARSENIEUx, adj., arseniostus. Nom donné à un acide (arsenige süure, all.), qui est le second degré d'oxidation de l'arsenic, et par berzelius à un sulfide (orpiment; $A n-$ derthalbsehwefclarsenit, all.), à un chloride (ehlorure d'arsenic; Chlorarserik, all.), à un bromide (Bromarsenik, all.), à un iodide (Jodarsenik, all.) et ì un fluoride (F/uorarsenik, all.), qui, sous le rapport de la composition, eorrespundent à l'acide arsenieux.

ARSÉETFÈRE, adj. , nrsenifer ; arsenikhallig (all.); qui contient accidentellement de l'arsenic. Ex. Ploml phosphaté arscinifère.

ARSEXIQUi, adj., arsenieatus. Nom donné à un acide (Arsenilsä̈re, all.), qui est le troisième degrré d'oxidation de l'arsenic, cl à un sulfide (Drittehalbsehwefelarsenik, all.) qui correspond it cet acide, sous le rapport de la composition. I'éther arsenique (Arsenikïlher, all.), découvert par Boullay, en $181 \mathrm{r}$, est identique avec les ćlluers snlfurique et phisphorique, Voyez HrDratroue.

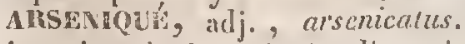
qui contient de l'arsenic. On dit quelquefois gaz hydrogène arseniqué pour gaz hydrogène arsénić.

AlisínITE, s. m., arsenis. Genre de sels (arsenigsaure Salze, all.), qui sont produils par la eombinaison de l'aeide arsenieux aree les bases salifiables.

ARSÉNIURE, s, m., arseniuretum, arsenictum. Alliage d'arsenic et d'un autre métal.

Arséviuné, adj. Epithète donnée à un neétal qui eontient de l'arsenic.

ArTtéuisuées, adj. et s. f. pl., Artemisiece. Nom douné par H. Cassini à un groupe de la section des Anthénidées chrysanthémées, et par Lessing à une sous-tribu de la tribu des Séuécionidées, qui ont pour type le genre. Artemisia.

ARTÉVISINE, s. f., artemisina. Quelques chimistes ont proposé de donner ce nom au principe amer de l'armoise.

ART'́RIEL, adj., arterialis, arteriosus; qui est relatif anx artères, ou qui en a le caractère. On appelle trachées artérielles, dans les insectes, celles qui naissent immédiatement des stigmates, reçoivent l'air d'uue manière directe, et le transmettent de suite dans toutes les parties du corps.

ARTHANITINE, s.f., arthanitina. Nom donné par Saladin à une substance cristalline partieulière, qu’il a trouvíc dans la racine du Cyclamen curopaun.

AxTHRION, s. n., arthrium (äefons, articulation). Nom donné par Kirby à un très-petit article situé i la base de la dernière articulation des pattes, dans heaucoup de colćoptères tétranérés et trimérćs.

ABTHROCÉpHALES, adj, et s. m. pl., Arihrocephala (upopos, articulittion, zsẹzito, tête). Nom dlonnó par Duméril is une fannille de la classe des cruslacés, comprenant ecux qui ont lia tète distincto et séparée du eorps.

ARTHROcḱraL, adj. et s. m.,

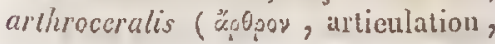


xépá, corne ). Robinean-Desvoidy désigne ainsi deux des neuf pièces de la vertćbre des animaux articulés, qui se développent en haut, et consistent en unc paire d'appendices articulés, formant les palpes, les antennes, les balancicrs et souvent une partic des ailes.

AnTHRODIfes, adj. of s. f. pl., Arthrodiece (Epopos, articulation). Nom donné parl Borry à un ordre de Jat classe des Phytozoaires, comprenant cenx de ees ètres qui sont eomposís de filamens articulés.

ARTHRONÉRAL, adj, arthromeralis. (ácopov, articulation, pápos; partie). Robinean-Desvoidy appelle ainsi deux ćlémens de la vertèbre des animaux articulés anxquels ehaque polergal donne naissance, dans la plupart des cas, qui se développent ordinaircuent en bas, et qui fournissent les organes de la locomotion, ou se transforment en pic̀ecs mobiles les unes sur les antres.

ARTICLE, s. m., articulus; Glied (all.). On donne ce nom, dans les aninaux articulés, les insectes surtoul, à différentes piéces, mobiles les unes sur les autres, qui, par lear réunion, constitucut les antenues, les palpes et les tarses; cn botanique, à unc portion de plante comprise cntre deux articulations (ex. tige des Prèles), et a l'intervalle compris entre les renflemens des Thalassiophytes diaphysistées.

ARTICULAURE, adj., arricularis ;

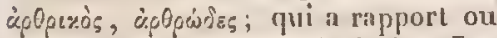
qui appartient à une arículution. Les botanistes appellent feuilles arriculaires celles qui naissent des nouds ou articulations de la tige ou de ses ramilications. Ex. Caryophyllées.

ARTICULATION, s.f., varticulatio, junctura ; ëpopov ; Gelenke (all.) ; juncture (angl.) ; articolo (it.). On appelle ainsi $: 1^{\circ} \mathrm{en}$ botanique, les points oì, à une eertaine époque de la vie, se font raturellement des solutions de eontinuité bien nettes, bien tranchées, et sans déchirement seusible; les renflemens eloisonnaires transversaux, ou sortes de diaphragmes, qui, daus les Thalassiophytes diaphysistées, résultent de l'application bout ì bout des eellules tulsuloïdes dont la plante est composée; $2^{\circ}$ en zoologic, la jonction de diverses pièces osseuses, cornées, ealcaires, les unes avec les autres, soil en dedans, soit à l'extérieur du corps d'un animal.

ARTICULÉ, adj. , articulatus; geglicdert (all.); articulated (angl.); articulato (it.). Composé d'articles altachés bout à bout. On dil : $2^{\circ} \mathrm{en}$ botanique, arcile arliculée(ex. Stipa); anthicre arliculée, quand l'union de l'anthìre et du filet est indiquée par un changement de forme on de eonleur, ou par un petit sillon transversal, en un mot par une marque quelconque (ex. Salvia pratensis); cotyledon aricule, quand il est comme articulé avece le blastème, sessile et resserré à sa base, de manière qu'on voit nettement son origine (ex, Alespilus grermanica); lisgume arliculé, quand il est comme formé de pièces rapprochées ct soudées à la suite les unes des autres, qui correspondent à un nombre égal de loges (ex. Hed)sarum coronarium); pétiole articulé, qui offre, à sou point d'altache, ou à. ses divisions, un bourrelet, ou un étranglemeut, ou un changement da direction, de couleur, de substance, cufin une marque queleonque qui le fait paraitre comme formé de picecs soudées les rnes il li suite des autres (ex. Robinia pseudo-Acreia); poils arliculés, cemx qui sont compés, de distince en distance, frar des lignes circulaires indiguant des cloisons intérieures (cx. Brunclla ovala); racine arliculéc, quand elle a de distance en distance des impressions qui 
ressemblent à des articulations (ex. Gratiola officinalis); tige articulice, quand clle est comme formée de plusicurs artieles rénnis bout à bout, avec ou sans nexuds (ex. Juncus arliculatus ). Le Dematium articulatum est un elatmpignon filamenteux, dout les filamens sont comme artienlés. $2^{\circ}$ En zoologie, on appelle articulecs les coquilles bivalves qui n'ont pas de dents nombrenses ì leur charnière; les multivalves, d'après Bhainvillc, qui sont placées à la suite les unes des autres d'une manière symétrique, dans la ligne muyenne du ceips de l'animal, et qui se touchent (cx. Oscabrion); les multiloculaircs, guand elles présentent à l'extérieur des traces de lenrs cloisous, et que ees traces ressemblent plus ou moins atx sutures qui uuissent les os du erînc.

AảTicuetes, adj. et s. m. pl., Arliculata. Nom donné par Lamarek i une division des animaux sans vertèbres, comprenant ecux dont le eorps est géuéralement artieulé et annclé dass sal longueur; par Cuvire et lis plupart des zoologistes modernes, à unı: grrande division du règne animal, cambrossant tous les animaux qui ont mu squclctle extérieur, disposé sous la forme d'unneaux dont le corps est entouré.

ARTICULEUX, adj., arliculosus. Tin cruslacé ( Cancer arliculostus) est ainsi appelé parce que la tige de ses antennes supérieures est composée d'un grand uombre d'articulations.

ARTMPCIEL, adj. , artificialis, fictitius; liüsstlich (all.). On appelle jour artificicl l'espace de temps compris entre le lever el le coutser du soleil. Eu histoire naturelle, on doune le noun de caracliere artificiel a celui qui cst énoucé dans la vuẹ stulenteut de faire distinguer les êtres naturels l's uuscles antres, et qu'on cinpruble: indifrírenment à telle ou telle de leurs partics, pourvu qu'elle soit bien apparente. Une métleodc artificiclle est celle qui, pour ses divisions correspondantes, emploie des caractères divers, ehoisis indifféremment dans tous les organes, snivant le besoin ou la commodité, et sans nul ćgard aux rapports naturcls qui peurent exister entre les êtres.

ARTIOMORPIIES, adj. et s. m. pl., Artiomorgha ("̈. \%тео, bien conformé, ropors , forme). Synonyme d'Artiozocaircs. Voyez ee mot.

ARTIOzOAIRES, adj. et s. m. pl., Arliozoa ("coreos, bien conformé,

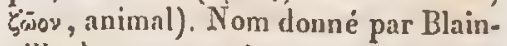
ville à un sous-règne, comprenant les animaux dont la forme est paire on symetrique.

ARTIPIYLLE, adj. artipliyllus (üpre, part. marq. la perfection, $\left.\varphi^{*}\right) \lambda . .2 \%$, feuille). Link donne eette épithète aux plantes à l'aisselle de toutes les feuilles desquelles on aperȩoit des bourgyeons ou des rameaux.

Antocanpúes, adj. et s. f. pl., Arlocarpea. Nom donné par A. Richard ì un groupe de la famille des Urtićes, qui a pour type le genre Artocarpus.

ARCNDINACÉ, adj. , arundinaceus; rolurartig (all.) (arundo, roseau); qui eroît sur les roscaux ( ex. Hypoderma arundinacea), ou qui se tient habiluellement dans les roseaux (ex. Falco arundinaccus).

arundivacées, adj. et s. f. pl., Arundinaccer. Nom donné par Kunth et Nees d'Esenbeek ì une tribu de la famille des Graminérs, qui a pour type le genre Arundo.

ARvicOLE, adj., arvicola, arvalis (arvum, terre labourée, colo, hnbiter ) ; qui vit dans les elamps moissonneux. Ex. Mus arvalis, Mclolontha arvicola.

APVIEN, adj. , arvensis ; qui eroît dans les terres libbourées. Ex. Anagallis a'ycns's, Trifolium arvensc. 


\section{ASCA}

ASARINE, s. f. , asarina. Sortc de stéaroptène déconvert par Gocrtz, Lassaigne et Fenculle dans la racine de l'Asarum curopcum.

ASARINÉles, adj. ct s. f. pl., Asariac. Nom donné par Kunth à uuc faville de planies qui a pour type le genre Asartum.

ASAROIDEs, adj. ct s.f. pl., Asaroïdes. Nom donné par Ventenat ì unc famille de plantes ayant pour type le genre Asarkm.

ASIBESTIVORME, adj., asbestifor.

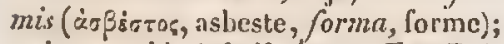
qui ressemble à de l'asbestc. Ex. Bois opalisé ashosciforme.

ASBESTOIIE, adj., asbesloïdes

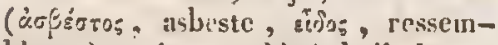
blance) ; qui ressemble à de l'asbestc. Ex. Pyroxinc asbestoülc.

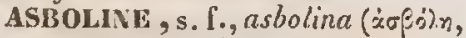
suic). Nom donné par Braconnot à unc substance qu'il a trouvée dans la snie, et qu'il croil former un principe immécliat partieulier, mais que Berzelins considère comme un simple mćlange de pyrétine acide avec l'espècc de pyrélaïne qui prend naissanec pendant la distillation de la pyrétinc.

ascalabotes, s. m. pl., Ascalabola (á $\sigma_{2 \times x} x_{x} \times \beta_{05}$, petit lézart). Nom donnó par Goldfuss à une fimille, par Merrum à une tribu de reptiles sauriens, comprenant ceux qui ressemblent le plus aux lézards proprement dits.

ASGALABotoInEs, adj. et s.m. pl., Ascalabotoïdea, Ascalabotoïdes

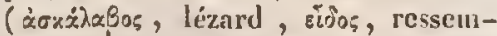
blance). P.-F. Fitzinger et Eichwald appellent ainsi une famille de reptiles sauriens.

ASCARIDAIRES, adj. et s.m.pl., Ascaridaria, Ascaridii (àrrapie, asearide). Sous ec noın, Blainville désigne unc seetion de la classe des Microzoaires, renfernant ceux qui ressemblent aux ascarides, pour lia forme générale du corps, et qui, suicant lui, apparliennent indubitablement à la clasic des vers apodes.

ascaridiens. $V$. Ascaridites.

ASCENDANT, adj. , adsecarlens, aseendens, assurgens, aufwiörts sicigend, anfstcigend (all.); asccading (augl.); risorgente (it.); qui val $\mathrm{cm}$ montant. On dit: $t^{\circ}$ en astronomie, ćloile asccadante, celle qui s'élève au dessus de l'horizon; latitude ascendaale d'une planète, quand celle-ci passe vers le nord; noud ascendant de l'orbite d'une planc̀te ou d'une comète, l'intersection de l'orbe de ect astre avec le plan de l'orbe terresire, quand lui-même s'éloigne an nord de l'éeliptiquc. $2^{\circ}$ En minéralogic, on appelle, dans la nomenclaiure de Haüy, cristal ascendant, cclui dans lequel tons les déeroissemens oint une marche ascendante en parlant des angles ou des bords inféricurs d'un noyau rhomboïdnl (ex. Chaux carbonatéc rsscendantc) . $2^{\circ}$ Jin hotanique, collct asccndant, lorsyu'èn se diveloppant, il s'élève avec lia plununle, et porte les colylédons it lal lumière, de sorte qu'il devient partie de la tige (cx. Mirabilis Jalapa); caudex ascendant (caudex adsceadens, Limné; truncus adscendens, Hedwig; adscensus, I'Hériticr; caulis, I Link; aufsteigender Slock, Sticl, all.), la portion du végétal qui s'élève hors de terre; clamiaes a.scendaries, celles qui se porlent ver's lil partie supérieure de la fleur (ex. Salvia); graine ascendante, quand le hile, de niveau avec le placenta, oul à peu près, est silué un peu au dessus du point le plus bas de la graine, dans la loge du péricarpe (ex. MYalus comminis); levre ascendaate, lorsque la lévre supcirieure d'une corolle labiće suit d'abord la direction du tube, et qu'clle sc relève par son extrémité (cx. S!rachys annua); pélales ascondens (ex. 


\section{$1 \mathrm{I} 8$}

ASCI

Cleome) ; poils ascendans, eeux qui sont dirigés vers le somuet de la partie qui les porte (ex. Papaser Argemone) ; style asccndant, lorsque, dans unc fleur irrégulière, il s'écarte de l'axe pour se porter ver's la partie supéricure (ex. Salvia); lige ascendante, eclle qui se dresse vers le ciel, après avoir marché un peu horizontalement (ex. Helichrysum adsccndens, Dicliptera assurgens, Astragalus adsurgens ).

AScrotichs, adj. et s. m. pl., Ascidiacca. Nom donné par Munké à une famille de l'ordre des Tuniciers Télhyes, qui a pour type le genre Ascidia.

ASCIDHDES, adj. et s. su. pl., $A s$. cidida. Nom donné par G.-S. Macleay à une famille de la classe des Tuniciers, qui a pour type le genre Ascidia.

ASCIDIŔ, adj., ascidiatus (àcrijo\%, petite outre); qui est façonné ou terminé en manière de vase. Uute feuille ascidice est eelle qui se termine par un appendiee ercux et en godet. Ex. Nepenthes destillatoria.

Ascionens, adj. et s. m. pl., Ascidiacea, Ascidice. Nom domé par Lamarek à un ordre de la classe des Tuniciers, par Schweigger à une seetion de eclle des Mollizsques, par Blainville à une famille de l'ordre des Hétérobranehes, et par G. Fischer a une elasse de ses Branchiopueunones, coupes qui toutes ont pour type le genre Ascidia.

ASCIDIFORME, adj., ascidiiformis. Épithète donnée aux braclées (ascidium bractealc, bracten ascidiiformis s. cuculliformis; Dectiblatlschlauch, Blumcnschlauch, schlauchförmiges Deckblatt, quand elles ont la forme d'un godet, eomme daus I'Ascium violaceum.

Ascidites, s. m. pl., Ascidites. Latreille donne ee nom it une famille

\section{ASCO}

de la elasse des Tunieiers, qui a pour type le genre Ascidia.

ASCIDHOCARPES, adj. ets. m. pl., Ascidiocarpa (èrriónov, petite outre, xартіゥ), fruit). Épithète donnée par Luhnemann aux hépatiques dont lc fruil s'onvere nu sommet. Ex. Riccia.

ASCWDON, s. 1m., ascidium; Schlauch (all.).. On nomme ainsi l'espèce d'outre ou de petit vase que la leuille des Nepenthes produit en se ronlant et se soudint par les bords, ct qu'on a considéré à tort eomme un simple appendice terminal dela f'cuille, ee qu'on reqarde généralemeut conme feuilles dans cettc plante, n'éłant qu'un pétiole phiglloulc.

ASCIEN, adj., ascius; unschaulig (all.) (a priv., gria, ombre). Dénomination imposée par les gćographes aux habitans de la zone torride, qui, ayant lc suleil perpendiculaire sur leur têtc dcux jours de elıqque annéc, sont alors sans ombre.

ASCHORME, adj., asciformis (ascus, petite outre, forma, forme). Linik appelle ainsi les fouilles qui, pliées sur elles-nuèmes, et soudées par les bords à leur partic inférieure, restent ouverles supéricurement, et produisent ainsi nue sorte de vase, comme l'outre terminale des Nepenthes, qui est la véritable fenille de cette plante.

ASCIG b'RE, adj., aseigcrus (ascus, petite outre, gcro, porter). Se dit d'un champignon dont les corpuscul:'s reproducturs sont renlermés dans de petits ulricules.

ASGLÉPIADÉES, adj. et s. f. pl., Asclepiadea. Nom donné par A. Rieliard ì une section de la famille des Apocynées, qui a pour type le gente Asclcpias.

ASCLÚPIADINE, s. f., asclepiadina. Substance particulière, nou alealine, que Fenculle a Irouvée dans laracine de l'A sclepias Vinccloxicum. ASCOMYCETES, si m. pl., Asco- 
mycetes (árxis, outre, ứzns, champignon?. Nom donné par Fries à une sous-classe de elampignons eomprenant ceux qui ont leurs sporidies renferimées dans des élytres.

ascopirytes, s. f. pl., Ascoplyta (d̀sris, outre, gízov, plante). Reiehenbach dúsigne sons ce nom une section de la famille des Hydrophytes, embrassant celles de ces plantes qui sout unnnies de vésicules aériennes.

ASCORF, s. m., ascorum. Necs d'Esenbeek appelle ainsi, ou stratum thecigerum, la portion du chapean des champignons qui renferme les élytres.

Ascosionés, adj. et s. ni. pl.,

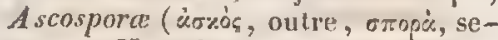
menec). Nom donné par Reiehenbach à un ordre de la elasse des Tiehens, comprenant ceux qui ont leurs eorpuscules reproducteurs renfermés dans des utrieules.

ASELLIDES, s. m. pl., Asellide. Nom donné par Lanrarck à une famille de Crustaeés, qui a pour type le genre A sellus.

ASELLIENS, adj. et s. m. pl., Asclli. Nom donné par Blainville à une famille de la classe des Tétradécapodes, qui a pour type le genre Asellus.

ASELLOTES, s. m. pl., Ascllota. Nom donné par Cuvier à une section, par Latreille et Eichwald à une famille de la classe des Crustieés, coupes qui loute's ont pour type le genre Ascllus.

ASEXE, adj., asexus; gechlechtslos (all.) (a priv., sexus, sexe); qui est privé de sexe.

ASTXEEL, adj. Synonyme d'asexe. Ce mot est aussi pou usité que le précédent.

ASHLDES, s. m. pl., Asiïila. Nom donné par Lench à la fomille des Asiliques. Voyez ee mot.

ASHLIFOnHE, adj., asiliformis ; qui ressemble à un asilc. Ex. Sesia asiliformis.
AsILIQUES, adj, et s. m. pl., $A$ silici. Ce nom est clonué par Latreille à une tribu, par Wiedemann, J. Maequart et E. Eichwald à une famille d'inseetes diptères, ayant pour type le ogenre $A$ silus.

aSINHive, s. f, asimina. Desvaux désigne ainsi un fruit composé, dans lequel les corpelles charnues sont plus ou moins soudées cnsemble.

ASIPUONOBRANGIES, adj. ct s. m. pl., Asiphonobranchia ( $\alpha$ priv:,

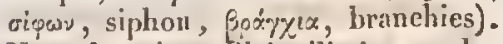
Nom donné par biainville à un ordre de la elasse des Paracéphalophores, comprenant cenx dout les branchies sont renfermées dans une cavité qui ne se prolonge point en siphon.

ASIPIONOInES, adj. et s. m. pl., Asiphonoïdea (a priv., oipwy, siphon, sijos, ressemblanee). Nom donné par G. de Ilaan à un ordre de Céphalopodes, comprenant ceux qui n'ont pas de siphon à leur coquille.

ASKULIIE, s. f., askelia (a privi,

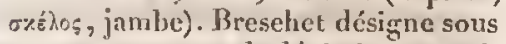
ce nom un genre de dévialion organique, ou d'agénésic partielle, qui est caractérisé par l'absence des jambes.

ASPAlaciolis, adj. et s. m. pl., Aspalacida. Nom donné par Gray à une famille de l'ordre des Mammifères rongeurs, qui a pour type le geure Aspalnx.

ASPARAGíE, adj. et s. f. pl., Asparage. Nom douné par Bartling il use tribu de la fanille des Smilaées, qui a pour type le genre $A s p a-$ ragusu.

ASPARAGINE, s. f., asparagina; Spargelsluff (all.). Sulstance eristalline que Robiquet a découverte dans l'asperge, et que Wittstoek regarde comme étant de l'aspartate ammonique. L'asparagine biliaire est connue maintenant sous le nom de taurine. Vorez ce mot.

ASPAPAGLUES, adj. et s.f. pl, Asparagince. Non donné par Jus- 
sieu a une famille de plantes, qui a pour type le genre Asparagus.

astallagique. Voj. Aspartique.

ASLARAGOWES, adj. et s. f. pl., Asparagoidece. Ventenat désignait sous ee nom une famille de plantes ayant le genre Asparagus pour type.

ASPARTATE, s. m., asparlas. Genre de sels (asparagsuure Salac, all.), qui sont formés par la combinaison de l'acide aspartique avee les bases salifiables.

ASPARTIQUE, adj., asparticus. Nom donné par Henry et Plisson á uı acide (Asparagsiurure, all.) dans lequel l'asparagiuc se transforme quand on la traite par une base.

ASPÉRELLINÉÉs, adj. et s. f. pl., Asperellince. Link appelle ainsi une tribu de la fanille des Graminées, comprenant celles qui se font remarquer par la rudesse de leurs feuilles et do leurs tiges. Ex. Leersia.

ASPERGLLIFORME, adj., aspergilliformis; sprengavedelf ormis (all.) (aspergillum, goupillon, forma, forme); qui a plus on moins de ressemblance avee un goupillon. On appelle, en hotinique, sligmate aspergilliforme eclui qui est garni de poils rambassés vers sa partie supérieure (ex. Arundo Phraymiles), et poils asperyilliformes ecux qui, d'espace en espace, ćmettent des vertieilles de petites ramifications simples (ex. Marrubium peregrinum).

ASPERGHLAIIE, adj., aspergillaris (aspergillum, goupillon); qui al li forne d'un goupillon.

ASPERICOLVE, adj., aspericornis (asper, rude, cornu, corne). $\mathrm{C}_{\mathbf{n}}$ zoophyte (Spongia aspericornis) est ainsi appelé paree qu'il se divise en ramcaux, que l'on a comparís à des corues, et qui sont aiguillounćs de toutes parts.

ASPERIFOLIÉ, adj., asperifolius; raspelblätrrigr, raubblïlırig (all.) (asper, rude, folium, feuille); qui a des feuilles rudes. Ex. Cenchrus as perifolius, Oryzopsis asperifolia, Pelargonium asperifolium.

ASPÉRIF OLIÉES, adj. et s. f. pl., Asperifolice. Nom douné par Linné à une famille de plantes qui toutes ont les feuilles tris-rudes au toueher. Ex. Borrago.

ASPERME, adj. , aspermalus (a priv., orípux , semenee). Epithèle donnée par Turpin aux végétaux axifères, ou de formation primordiale, à ecux qui paraissent ne pas avoir reęu de la nature la faculté de se reprodinire eux-mêmes.

Asperví. Voy. Asperme.

ASPERHE, s. f., aspermia. On désigne souls ce nom l'état d'une plante sur l'ovaire eneore jenne et délieat de laquelle une lumière trop forte a agi de manière à dessécher et tuer les ovules et à la rendre inféconde.

ASPŔnur.́́es, adj. et s. f. pl., Asperulce. A. Riehard désigne sous ce uom une tribu de la famille des Rubiacées, qui a pour type le genre Asperula.

ASPIIONÉLíes, adj. et s. f. pl., Asphodelca. Famille de plantes, établic par Jussieu, qui a pour type le genre Asphodelus.

ASPIIODKLLOIDES, adj. et s.f. pl., Asphodeloüdes. Synonyine d'Asphodélées (voyez ce inot), dont quelques hotanistes ont fait nsage.

aspidecintorís, adj. et s.m.

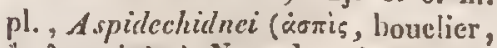
है. $(\delta \cdot v x$, vipère). Nom donné par J.-A. Ritgen a une famille d'Ophidiens, renfermant les serpens venimeux qui out des pliques sur la tête.

$\Lambda$ SPIDIACÉEs, adj. et s. f. pl., Aspidiacca. Nom que Bory propose pour une section de la famille des Fougères qui aurait pour type le genre Aspillium.

ASPIDIONÉES, adj. et s.f. pl., Aspilionea. Nom dunné par G. F. 


\section{ASPI}

Kaulfuss à une section de la tribu des Polypodiacées, ayant pour type le genre Aspidium.

ASPIDIOTES, adj. et s. m. pl. , Aspidiota (à $\sigma \tau i \xi$, bouclier). Latreillé a désigné sous cette dénomination un groupe de erustacés, coinprenant cenx dont le corps est eouvert d'une sorte de bonelier.

ASPIDIPIOIES, adj. et s. m. pl., Aspidiphora ( $\dot{\alpha} \sigma \pi i s$, bouclier, $\varphi s s \rho \omega$, porter). Non donné par Iatreille et Cuvier à une fanille de Crustacés, embrassant ceux qui ont le corps eouvert d'un test.

A SPIDISCLNES, s. m. pl., Aspidiscina. Nom donné par C.-G. Ehrenberg à une tribu de la elasse des Polygastriques, qui a pour type le gen re Apidisca.

ASPIDOACHIIES, adj. ct s. m.

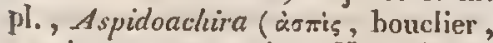
a priv., $\chi$ sip, main). Nom donné pur J.-A. Ritgen à uue famille dc Reptiles sauriens, renfermant ceux qui ont le eorps rouvert d'ćcailles et deux pieds de derricire, sans pieds de devant.

ASPIDOBRANCLES, adj. et s. m.

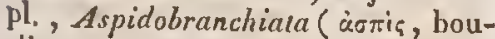
clier, $\beta_{p} \dot{x}_{\gamma} \chi^{2 x}$, branchics). Schweigger, G. Fiseher, Menke et E. Eichwald appellent ainsi une famille on un ordre de Mollusques gastéropodes, comprenant ceu $x$ qui ont les lranehies protégées par une eoquille en forme de bouclier.

ASPIDOCǴPHALES, adj. et s. m. pl., Aspidocephali (erris, bouclier, Requisin, tête ). Noun donné par J.-A. Ritgen à une section de Reptiles ophidiens, eomprenant ccux qui ont la lête garuie do platques.

ASIPDOCHLES, adj. et s. m. pl.,

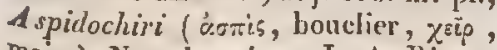
main ). Nom donné par J.-A. llitgen à une fanillc de Reptiles sauricus, compresant ceux qui ont le corps

\section{ASSI}

couvert d'éeciilles et deux pieds de devant seulement.

ASPIDOCOLOBES, adj. et $\mathrm{s} . \mathrm{m}$.

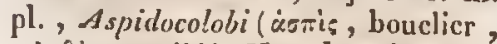
\%olofís, mutilé). Nom donné par J.A. Ritgen i une faunille de Reptilcs sauriens, comprenant ceux qui ont le corps convert d'écailles et plus ou moins rnutilé à l'égard des meubres.

ASLPDOTES, adj. et s. m. pl. , Aspidota (à $\sigma \pi i \xi$, bouelier). Sous ce nom, Goldfuss, Fieinus et Carus désignent une famille de Crustacés, dans liquelle ils eomprennent eeux qui ont le corps protégé par une sorte de bouclier.

ASPILONoTE, adj., aspilonotus

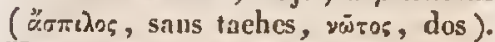
Une unéduse (Chrysaora aspilonota) a été appelće ainsi parce que son ombrelle est tonte blanche.

ASPISTES, adj. et s. m. pl., Aspistes (żoris, bouelier). Non donné par J.-A. Ritgen à un sous-ordre de la classe des Reptiles, comprenant les serpens dont ic corps est nuuni de plaques.

ASPLÉNIOIDÉEs, adj. et $s$. $f$. pl. , Asplenioüdea. Nom donné par G.-F. Kaulfuss di une seetion de la tribu des Polypodiaećes, qui a pour typc lc genre Asplenium.

ASPONDYLOIDE, adj. , aspondy-

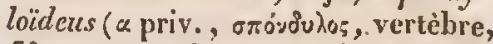
हidos, ressemblanec); qui n' a pas de vertèbres. G. Fischer propose do substituer cette dénomination à celle de Invertébré.

ASPORE, adj. asportus (a priv., orop's, semence); qui n'a pas de spores, ou de eorpuscules reproducteurs.

ASSIMTLABLE, adj ; ; qui est susceptible d'assimilation.

ASSLMILATEUT, adj. ; qui assimile : faculté assimilatrice.

ASSIMILATION, s. f. , assimilatio; opoiwass; Aneignung, Verähnlichung (all.) (ad, à , similis, semblable). 
Acte par lequel un corps organisé s'appropric des molécules ćtrangères à sa composition, el les convertil en sa propre substance.

ASSIMINE. Voycz $\Lambda$ su MiNe.

ASSISE , s. f., Stcinschichte (all.); lcyer (angl.). Lesgéognostes appellent ainsi les grandes ou premières subdivisions d'unc couche de tcrrain solide, lorsqu'elles sont opérées par la nature elle-même, ct qu'ellcs sont toutes de même cornposition.

ASSOcrant, adj. Nom donné, dans la nomenclature ruinéralogique de Haüy, à un cristal dans leqquel plusicurs faceltes, qui font des angles obtús avec la base du noyau, remplacent l'angle obtus de cette base, ou dans lequel des facettes, qui font des angles aigus avec la même basc, remplacent son angle aigu. Ex. $B a-$ ryte sulfatée associante.

ASSORTi, adj. Nom donné, dans la nomenclature minéralogique de Haüy, à un cristal prísentant l'accord ou l'issorliment d'une loi de déeroissenent qui est nne des plus simples en ce genre, et d'un rapport également simple avec les dimensions du solide prises dans le scns horizontal et dans le sens vertical. Ex. Corindon assorti.

ASSULE, s. f., assula, seutulum; Feld, Schildchen (all.). Illiger nomme ainsi chacune des pièces d'unc cuirasse de uatnmilère, quand elle sc compose de plusicurs écailles réınics en une sorte de table aréolée.

ASSURGENT, adj., adsurgens, as. surgens; aufgebogen, aufstrebend, aufsteigend (all.); assorgente, risorgenic (it.). Synonyme peu usité d'ascendant. Voyez ce not.

ASTACIDES, alj. et s. m. pl., Astacida. Nom donné par A.-H. Harvorth a une famille de Crustacés, qui a pour type le genre Aslacus.

ASTAGIENS, adj. ct s. m. pl., Astacii. Nom donné par Limarck á une famille de Crustacés ayant lc genre Astacus pour type.

ASTACIFOnME, adj. , astaciformis (astacts, ćcrevisse, forma, forme). Se dit d'un crustacé qui a la forme d'une écrevisse.

ASTACINeS, s. m. pl., Astacina. Dénomination sous laquelle Latreille désigne une tribu, E. Eichwald une scction, Goldfuss, Ficinus et Carus une famille de Coristacés, ayant pour type le genre Astacus.

ASTiCOIDFs, adj. et s. m. pl., Astacoïdes. Nom donuć par Duméril à un ordre de la classe des Crustacés, par Blainville à une fanillc de celle des Décapodes, renfermant le genre Astacus et les animaux qui s'en rapprochent.

ASTASrÉS, adj. et s. m. pl., Astasica. Nom donné par C.-G. Ehrenberg à une tribu de la classe des Polygastriqnes, qui a pour type le genre Astasia.

ASTATIQUE, adj., astaticus ( $\alpha^{\alpha}-$

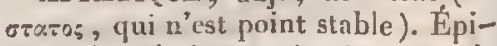
thìtc donnée à une aiguille aimantée qui est sonstraite ì l'action de la terre et qui n'a plus de position statique où clle se trouve en équilibre sous l'inAluence de celle force.

ASTŔRBES, adj. ct s.f. pl. , $A s-$ terea. Nom donné par 1I. Cassini et Kunth à unc tribu de la famille des Synani hírées, par Luessing à une sous tribu de la trilua des Astéroidées, ayant pour type le genre $A$ stcr.

ASTĹREVCRINENS, adj. et s. m. pl., Astcrencrinea. Noin donné par Blainville à une famille de l'ordre des Cirrolterunaircs stcllćrides, renfermant les encrinites qui ont le corpl pourvn de cinq rayons.

ASTÉRLL, adj., astcrialis. On appelle colonnes asiérinles des fossiles, très-communs dans les terrains secondaires, qui sont des débris d'animaux appartenant à la famille des Crinoïdes. 
ASTŕñoes, adj. et s. m. pi.; Asterides. Sous ce nom, Blainville désigne une famille de Pordre des Cirrodermaires stellérides, renfermant ceux qui ont le corps plus ou moins profondément divisé en eint lobes, et ayant pour type le genre Asterias.

AstúnIE, s. f. , Rsteria (ü.гою, astre). Phénomène de lumière qu'on observe dans certains minćraux, par réflexion (ex. quelques variétés de corindon), ou pal rúfraction (ex. gre$n a t$ ), et qui consiste dans l'apparition d'une étoile à six rnyous, blanchâtre ou d'une teinte très-vive.

Astbites, s. l. pl., Asteria. Sons ee nom, Goldfuss désigne un ordre de la classe des Radiaires, Ficinus et Carus une fanille de celle des Oozoaires, ayant pour type le genre Asterias.

AStínisme. Voyez ConstemlaTION.

ASTERNIE, s. f., astcrnia (a priv., oте́prov, stcrnum). Breschet désigne aiusi un genre de déviation organique, ou d'agéisésic partielle, qui est caractérisé par l'absence dn sternum.

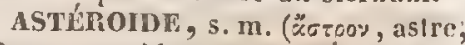
Eifos, ressemblance). Les astrouomes donnent quelquelois ce nom collectif aux quatrc planètes moy enures, I Iunon, Vesta, Céri's et Pallas, parce que la plupart de lenrs propriétós les ćloj-gnent benneoup des autres planètes.

ASTERonves, arj. et s. f. pl., Asteroülece. Non d'unc des tribus que Lessing admet dans la famille des Synanthérées, et dans lnçuelle il range celles de ces plantes quinise rapprochent plus ou moins du geure Aster.

Astutromes, adj. et s. m. pl, Asteroida. Nom donué prar Latreille à un ordrc de la classe des Eehinodermes, renfermbnt conx qui ont de la ressemblance arce les astćries.

AS ẂnOPHIDEs, adj. et s. m. pl., Asterophidea (äธrpo\%, astre , öpes, serpent). Nom sous lequel Blainville désigne une famille de l'ordıe des Cirrodermaires stellćrides, renfermant ceux de ecs animaux dont le corps est pourvu ì sa circonférence d'appendices plus ou moins alongés et serpentiformes.

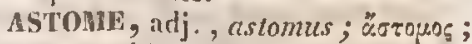
mundlos (all.) (a priv., stók, , bouclue); qui n'a point de bonche.

ASTOILS, adject. et s. m. pl., Astoma, Astomata, Astomi. Nom donnć par Duméril à une faunille d'inscet es dipteres clicz lesquels la bouche parait être remplacée par trois tubereules; et par Bridel à un ordre de mousses reniermant celles dont les eapsules sont dépourvues d'ouverturc.

ASTRAGaLḱES; adj. et s. f. pl., Astragalca. Nom sous lequel Candolle designe une section de la tribu des Lotées, ayant pour type le genre Astragalus.

AS'TRAGALOGHE, s. f. , astragalogir. 'Traité sur les astragales.

ASTraties, adj. et s. m. pl., Astrarice. Nom donné par Lamouroux ì un ordre de Polypiers lamellifères, comprenant ceux dont les cellnles ressemblent ì de petites étoiles, el ayant pour type le genre $A$ strea.

ASTRAL, adj., astralis, astrictis ("̈бтроу, astre); qui apparlicnl aux astres, qui en dépend. Année astrale ou sidérale. Voyca ce dernier nut.

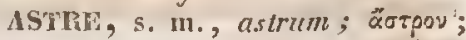
Gestirn (all.); star (angl.); astro (it.): Dénomination imposće à tous les corps lorillans qu'on apercoit an ciel et qui suivent le mourement apparent de sa rotation journalière. Ces eorps sont des étoiles ou soleils, des planètes, des satellites et des comètes.

astrí́:s. Voyez Astraires.

ASTRICTION, s. f., adstrictio;

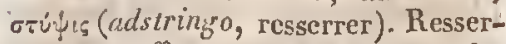
rement; cffet produit par une substance astringente. 
ASTRINGENCE, s.f. , adstringentia. Qualité de ce qui est astringent.

ASTRINGENT, adj. et s. m. , adstringens; бтuџis; zusammenziehond (all.); qui a la propriété de resserrer; corps astringent, sapcur astringente.

ASTROGNOSIE, s.f. , astrognosia;

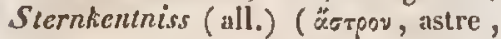
guöss, connaissance). Synony me iunsité d'astronomie. Westphal a publié un traité d'astrononic sous ce titre.

ASTROIDE, adj., astroïdeus ( $\alpha_{\sigma} \sigma-$

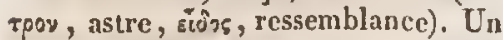
lielsen (Parmentaria astroildca) est ainsi appelé parce que ses apothécies sont disposées en ćtoiles.

ASTroNovE, adj. et s. m. , as -

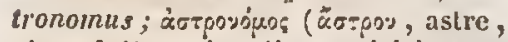
vợs, loi); qui se livre spécialement à l'ćtude de l'astronomie.

ASTRovoviE, s. f. , astronomia, institutio astronomica, mathentatica coelestis, scientia cosmica ; غ̇a-povouix; Sternkunde, Himnelskunde (ali.); astronomy (angl.); astronomin (it.). Science qui porte ses recherehes sur les corps placés daus les espaces eélestes, détermine leurs situations respeetives, établit les preuves de la stabilité des uıss et de la mobilité des autres, cxamine les divers mouvemens de ecs derniers, et étudie le genre de courbe qu'ils déerivent autour de leur centre de mouvement.

ASTRONOMIQUE, adj., astronomicus; qui a rapport ì l'astronomic: anné, jour, obserwation astronomique.

ASTnoscopiE, s. f. , astroscopia

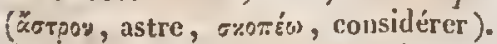
Synonyme inusitéd'astronomic.

ASTrosopine, s. f. , astrosophia

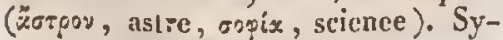
nonyme inusité d'astronomic.

ASTROTRRQUE, adj., a.strotrichus.

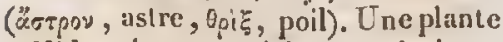
(Cliclesmia astrotricha) est ainsi appelée parce quela plupart de ses poils se partagent au sommet en rameaux
ATÉT,

étalés de manière à figurer une étoile.

ASTYLE, adj, astylus ( $\alpha$ priv., orúdos, style). Epithète donnée par Wachendorf aux plantes dont les fleurs sont dépourvues de style.

ASYMLÉ'TRANTHE, adj., asyme-

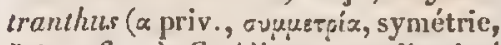
$\ddot{\alpha}, A_{3 ;}$, fleur). G. Allman appelle ainsi les plantes dont les fleurs sont dépourvues de symétrie, et ne forment pas denx moitićs égales.

ASYMÉTRIQUE, adj ., asymmetrieus ( $\alpha$ priv., auppsspia, synıétrie). Epithète dounce par les eonchyliologistes à toute coquille univalve dont les côtćs ne sont pas égaux par rapport ì un axe rationnel étendu du sommet à la base.

ASYMÉTROGARPE, adj. , asym-

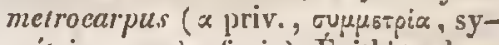
métric, zxorió, fruit). Epithète donnée par G. Allman aux plantes dont le fruit, coupé cn deux, n'offre pas deux moiliés égales et symérriques.

ATAVISHE, s. m., alavismus (atavus, aïeul). Sageret appelle ainsi la ressemblance que les plantes et les animaux peuvent avoir avec leurs ascendans, mème éloignnés.

ATACTONONPIOSE, s. f. , alactontorphosis ( $\ddot{x}$ ×x.75s, inflexible,

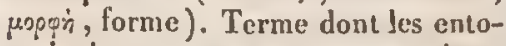
mologistes se servent pour exprimer le cas où une larve passe son état de nymphe daus une paralysic presque absolue, d'où elle ne sort que quand elle est arrivée a la condition d'insectc parfait.

ATAXACANTIE, adj., ataxacan-

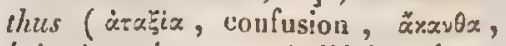
épine) ; qui est garni d'épines éparses sans ordre sur les rameaux et les pétioles. Ex. Acacia ataxacantha.

ATÉLÉOPODEs, adj. et s.m. pl.,

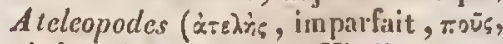
pied). Nom donné par Vieillot à une tribu d'oiseartx nageurs, comprenant ceux qui n'ont point de pouecs aux pattes. 
ATHALAMES, adj. et s. m. pl.;

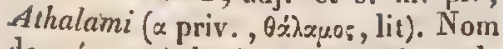
donné par Acharins à une elasse de Iichens, dans laquelle il range eeux qui manquent de eoneeptacles, ou cher lesquels on n'en in point encore déconvert. Ex. Lepra.

ATHALI.E, adj., athallus ( $\propto$ priv., $\theta_{2} \lambda_{2.0}$, fcuillage); qui n'a point de thalle. Ex. Endocarpon athallon:

atilanasiées, adj. et s. f. pl., Athanasiece. Nom donné par Lessing a une section de la sous-tribu des Sénécionidées artémisiées, qui a pour type le genre Athanasia.

ATUÉRICÈRES, adj. et s. m.pl., Athericera ( $\dot{\theta} \theta \dot{\text { isp}}$, pointe, xisps; corne). Nom donné par Cuvier, La. treille et Eiehwald à une famille d'insectes dipteres, comprenant ecux ehez lesquels le dernier artiele des antennes a le plus souvent la forme d'une palette sétigère.

atuĺnospenuées, adj. et s. f. pl., Atherospermece. Nonn donné par A. Richard a une seetion de la famille des Monimiées, et par $R$. Brown à une fanille de plautes, ayánt Pour type le genre Atherospermum.

ATIioraciQues, adj. ets. m. pl., Athoracica (a priv, osiso $\xi$, poitrine). Nom donné par Blainville à un ordre de la classe des Déeapodes, renfermant les crustacés qui paraisseut n'àvoir. pas de thorax.

ATMROZOPHYTE, s. m., athrozophytum ( ¿.0poi̧w, rassembler, 甲uTór, plante). Nom douné par Neeker aux algues dont les frondes s'aecumulent par l'effet d'une évolution suceessive et continue.

ATLANTIQUE, adj. ; atlanticus; qui vit dans la mer Allantique (ex. Dentex allanticus), ou qui croît sur les moutagnes de l'Atlas (ex. Barbula allantica). Érate

ATMIDONLERE. Voycz Aтmo-

ATMIzomiQUE, adj., almizonicus

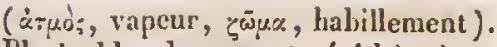
Blnekadder donne eette épithète à un hygromètre de son invention, qui consiste en deux thermometres, dont l'un indique la température extérieure, tandis que l'antre a sa boule couverte d'une mousseline tenue eontinuellement humide par de l'enu, qui ecule goutte à goutte d'une bouteille.

ATMOMETRE, s.m., atmonetrum; Ausdïnstungsmesser, $V$ erdïnstungrs-

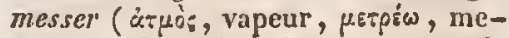
surer). Nom donné aux appareils dont on se sert pour déterniner la quantité d'eau qui se vaporise dans des cirronstanees données.

ATMOSPIÈRE, s. f., atmosphara; à-uóog̣ąo; Dunstkreis, Dunstkugel, Lufiliress, Lufisce (all.); atmosfera (ii.) (àre⿳亠े, , vapeur, op̧aipx, sphère). Masse d'air qui environne la terre de toutes parts ; masse de fluides élastiques qui entoure un corps solide queleonque; espaee qu'oeeupe ectte masse. A l'aide de la róflexion oceasionée par le erépuseule, ou a trouvé qu'en ealeulant la hauteur de l'atmosphère qui correspond à un abaissement du soleil de dix-huit degrés au dessous de l'horizon, elle est i peu pris de soixante mille mìtres. Cela prouve seulement qu'à cette hauteur la densité de l'air est eneore assez grande pour renvoyer une lumière sensible, et que l'atmosphère s'étend au moins jusque là, sans qu'on puisse assigner d'une nuanière précise sa dernière limite.

ATMOSPIĹnIQUe, adj. , atmospharicus; atmosferico (it.); qui a rapport à l'atmosphère : air, météore, phínomene, picrre atmosphérique. Brongniart établit un ordre de terrains atmosphériques (!), qui comprend les pierres atrnosphériques, et Stokenstrand un régne a mosphérique, qui embrasse tous les gaz connus.

ATMOSPHÉliologie, s. f., at- 


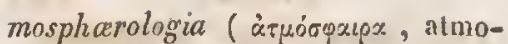
sphère, 7.óys, discours). Traité de l'air atmosphérique eonsidéré en masse.

ATOMLIRE, adj., afomarius (ä:o$\mu .05$, atome); qui est parsemè de points colorés, comme les ailes de la Phalana atomaria, les ćlytres da $N y$ cetophagus alomarius et du Mi elolontha atomaria, le eorps du Planaria atomala, les rameaux et pétioles du Cassia alomaria.

ATONE, s. m., atomus ; "ँт $\mu_{5}$; Grunilkörperchen (all.) (\& priv., тінуш, couper). On donne ce unm ì des particules infiniment ténues et indivisibles, dont on suppose tous les corps formés, et entrc lesquelles on adinet que s'effectuent les combinaisons, quand il s'en fait. On le donne en outre aux partieules qui résultent de ees eonbinaisons, et qui sont moins petites que les préeédentes, puisqu'clles doivent naissance à leur réunion, mais dont le volume n'est eependant point encore assez eonsidérable pour qu'on puisse les aperecvoir.

ATOWIFER, ndj. , atomiferts (atomus, atone, foro, porter). Se dit d'un corps qui est chargé d'atomes. Voyez Aromalr.

ATOMilus, adj. , atomicus. On appelle attraction atomique, une force qu'on suppose ètre inhérente allx atoanes de la matière, et fairc qu'ils ont de la tendance à se eomliner ensenble. Les quantités suivant lesquelles les diverses subslances se rénnissent, sont entre elles dans une proportion fort exuete, et on peut assigner à chaeune de ces substanees un poids déterıniné, appelé poids atomique, qui exprime la proportion daus laquelle elle sc combine avec une quantilé détermincée d'une autre substance. Ces poids élant puremeut relatifs, on prend pour unité celui d'un eorps quelconque, à partir duquel on eal- cule tous les autres. Pour cette unité on ehoisit, soit le poids de l'hydrogène, parce qu'il est le plus faible, soit eelui de l'oxigc̀ne, parce que ee eorps est celui de tous qui contraete le plus de combinaisons. Les proportions sont telle's que I poids atomique d'unc substauce se cambine avee $1 / 6,1 / 4,1 / 3,1 / 2,2 / 3,3 / 4,1$, I $1 / 3,11 / 2,2,21 / 2,3,4,5,6$, 7 ou p'us poids atomiques d'une autre.

ATOMusue, s. in., atomismus, philosophia s. pliysica corpuscularis; Corpuscularphitosophie (all.). Systc̀me philosophique dans lequel on explique la formation de l'univers par le moyen des atomes.

ATONHSTE, s. m., atomista. Physieien qui est partisan des doctrines de l'atomisme.

ATOMISTIQUE, adj., alomisticus. Épithète donnée à une théric universellement employée aujourd'hui en ehinie, qui eonsidère les corps cornme formés de particules matérielles infuniment petiles eu égard à nos sens, et dont lcs formes ainsi que les propriétés particulières constituent la nature chimiquc de chaque corps. Celte theorie admet en prineipe que tout corps inorganique est un agrégat de unoléenles et d'alomes égaux. ell poids, et que, dans toute combinaison elimiqque, des noubres déterminćs d'atomes d'espèces diverses s'unissent intimement pour donner naissance à des atomes plus composés.

ATOMOGNNE, s. f., alomgrnia ( ฉ־ou. Nom donné par lichard à un urdre de la didynanie, comprenant les plantes de cette elasse qui ont un fruit capsulaire, et corrêspoudant à l'angiospermie de Linné.

ATOUIQUE, adj., a toxicus (a. priv., ročt:xiv, poison ). Épithc̀te donnée quelquefois aux serpens qui ne sont point venimeux.

ATRACUÉLIES, adj, et s. m. pl. , 


\section{ATRÉ}

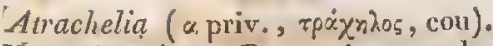
Nom donné par Degeer ì un ordre d'insectes aptères, comprenant ceux qui n'ont point de cou, lenr tète élant confondue avec le corselet.

ATRACTOSONES, adj. et s. m. pl., Atractosomata (éтрuxsos, fuseau, $\sigma \bar{\omega} \mu x$, corps). Dumćril appelle ainsi unc famille de poissons, renfermant ceux qui ont le corps fusiforme; et Blainville donnc ce nom à tous ceux de ces animaux qui ont le corps épais au milien, évidé et aplati aux extrémités.

ATRAMENTAIRE, adj., atramentarius; dintig (all.) (atramentum, encre). L'A garicus atramentarius cst ainsi nommé parce qu'il se résout en nine liqueur nnire, avec laquelle Bulliard est parvenu à fairc de l'enere pour lavis.

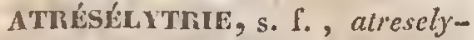

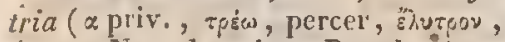
vagin). Nom douné par Breschet à un genre de déviation organique qui est caractérisé par l'imperloration du vagin.

AThÉSENTÉRIE, s. f., atresen-

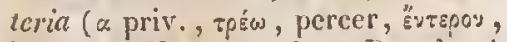
intestin). Nom dounć par Breschet à un gence de déviation organique qui cst caractérisć par l'imperforation de quelque partic du tubc intestinal.

ATRÉsie, s. f., alresia; ḋzpnacó (๔ priv., tfós $\omega$, percer). Nom donné par Breschet ì un genre de déviations organiques comprenaut celles dont le caractere consiste dans l'imperforation d'un organe qui derrait êtrc crellx ct permé:ilile.

ATRÉSOnLĹPHARE, s. f. , atreso-

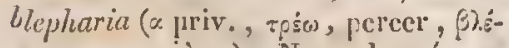
uxpov, paupière). Nom donné par Bresclet a un genre de déviation organique qui est curactérisé par Ia non séparation ou l'uecollement des paupières.

ATRÉSOCXSIE, s. f., atrcsocysia (o. priv., тpsos, pereer, ruo

\section{ATRÉ}

Nom donné par Bresehct à un genre de déviation organique qui est caractérisé par l'imperforation de l'anus.

ATlísocystie, s. f., atrcsocystia

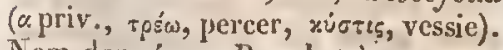
Nom donné par Breschct à un genie de déviation organique qui est caractérisé par l'imperforation de la vessic.

ATrísOGASTHE, s.f., atreso-

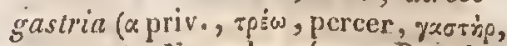
estomae). Nom donné par Breschet à un genre de déviation organique qui est caractérisé par l'imperforation de l'estomac.

ATrésolínir:, s.f., atresolemia

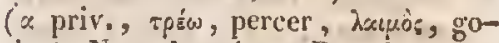
sicr). Nom donuć par Breschet à uı genre de déviation organique qui cst caractérisé par l'imperforation de liı partie supérieure des voics digestives, Ic pharynx et l'oesophage.

AThísontinn E, s.f, atresome-

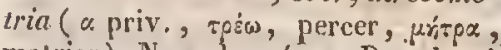
matrice). Nouı donné par Breschet ì un genre de déviation organique qui est caractérisé par l'imperforation de la matrice.

ATRésorsu, s. f. , atresopsia

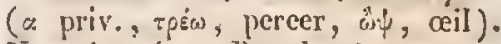
Non donné par Breschet à un genre de déviation organique qui est caractérisé par l'imperforation de la pupille.

ATR ESORHINE, s. f., atresorhi-

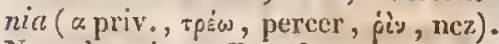
Non donné par Breschet à un genre de dévialion organique qui est caractérisé par l'imperforation du nez.

ATnisosTOmL, s. f. , atresosto-

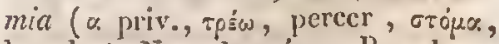
bouche). Nom donuć par Breschet is u11 geure de déviation orgauique qui est carractérisé par l'imperloration de la bouche.

ATRÉsunt:Tine, s. f., alrcsuréthria (z priv., трร் Oo\%, urètre): Noni donné par Bresehet à un genre de déviation organi- 
que qui est caractérisé par l'imperforation de l'urètre.

ATRICALDE, adj., atricaudatus (aler, noir, cauda, queue); qui a la queue noire. Ex. Crotalus atricaudatus.

ATRICOLLE, adj, , arricollis (aler, noir, collum, col); qui a le col noir. Ex. Trogon atricollis.

ATRICORNE, adject., atricornis (a/cr, noir, cornu, corne); qui a les antennes noires. Ex. Eucera atricornis.

ATRIGASTIE, adj. , atrigaster (ater, noir, gaster, ventrc); qui a le dessous du corps noir. Ex. Trochilus atrigaster. Voyez Mélanogastru.. ATRIPEDE, adj., atripes (ater, noir, pes, pied); qui a les picds noirs. Ex. Diccum alripes.

atrupliclés, adj., Atriplicea. Nons donnc par quelques botanistes à la famille des Chénopodées, et par C.-A. Meyer à une tribu de cctte famille, qui a pour type le genre $A$ iriplex.

atmiplicinḱes, adj., Atriplicinea. Synongmed'Atriplicces. Voyez ce mot.

A TROCÉPHALE, adj , atroccphalus (ater, noir, жspudin, tête); qui a la tête noire. Ex. Fringilla atrocephala. Voyez MélanocépHale.

ATROGULAInE, adj., atrogularis (atcr, noir, gula, gorge); qui a la gorge noire. Lx. Turdus atrogularis.

ATROMARGINE, adj., atromarsinatus (ater, noir, margo, bord); qui est bordé de noir. Ex. Doris alromarginala.

ATR OPÉES, adj. et s. fo pl., Atropec. Quelques botanistes donnent ce noin à une tribu de la famille des Solanées, qui a pour type lc genre Atropa.

ATRopise, s. f., atropina. Alealoïde que Brandes dit avoir trouvé dans l'Atropa Belladonna.

ATROPIQUE, adject., atropicus. Nom d'un acide, encore problémati- que, que Peschier admet dans l'Atropa Bclladonna, et des sels ayant pour base l'atropine, si l'existenee de cet alcali végélal se confirıne.

ATROPIVORE, adj., alropivorus. Se dit d'un diptère dont la larve vit dans la chrysalide du Sphinx Atropos.

Ex. Sturnia alrepiyora.

ATROPTL̀nE, adject., alroplerus (aler, noir, $\pi \tau \varepsilon p$ ò , aile); qui a les ailes noires. Ex. Himantopus atropterns. Voyez Mélayoptíre.

ATRYPTODONTOPHOLIDOPHIDES, adj. ct s. m. pl., Atryptodontopholidophides (a priv., тpiritw, trouer, ojos, dent, polis, écaille, ợes, serpent). Nom donné par J.-A. Ritgen a une famille de reptiles, comprenant les serpens ćeailleux qui n'ont pas de crochets à venin.

ATTílaABID rs, adj. et s. m. pl., Attclabielcs. Nom donné par Sehoenherr à un groupe de la famille des Curculionides, par Latreille et Eichwald à une tribu de celle des Rhyncliophores, ayant pour type lc genre Attclabus.

ATTENTIF, adj., attentivus; aufmerksam (all.); heedful (angl.); qui fail altention.

ATTENTION, s. f., allentio; Aufmerlisamkeit (all.); hecdfulnes.s (angl.) (ad, vers, tendo, tendre). Applicntion de l'esprit à une pcreeption ou d une idée.

ATTínuḱ, adj., altenuatus ; verdïnnt(all.); attenuteated (angl.); assottigliato (it.); aminci. Se dit, en botanique, d'unc partie qui, m'ayant pas la unème épaisscur dans toute son ćtendue, va cn diminuant dc la basc au sommet ou du sommet à la base, comme les feuilles du Mancttia attenuata, les chatons du Fagus Castanea. Le Striaria allenuala est ainsi appelé à enuse de sal fronde filiforme.

A'TTERRISSEMENT, s. m. Nom donné par les géognostes aux dépôts suecessifs des Cleuves et de toutes les 


\section{ATTR}

eaux agitées, qui, tenant en suspen sion des substances terreuses, les déposent quand leur inouvement se ralentil.

ATTIRABLF, adj.; qui est de nature à être attiré. Le fer cst altivable à l'aimant.

ATRTUDE, s. f., situs corporis. Situation durable du corps, position qu'il eonserve pendant un eerlain laps de temps.

ATTRACTIP, adj., attractisus; anzichend (all.) (ad, vers, traho, tirer). Les physicieus donnent le nom de réfraction altractive à la double réfraetion, lorsyue le rayon extraordinaire se trouve rapprochí de l'axe ct situé entre lui et le rayon ordinaire.

ATTRAGTION, s. f., attractio; Anziehung (all.) (ad, vers, traho, tirer). Tendance que les eorps célestes paraissent avoir à s'attirer les uns les autres en raison direete des masses et inverse dı earré des distances, sans qu'il existe en eux ou autour d'eux aueune cause sensible à laquelle on puisse la rapporter. Outre eette attraetion céleste, appelée aussi de gravitation ou $\dot{a}$ distance, on en admet une autre, moléculaire ou de cohésion, qui sollicite les molćeules des eorps à adbérer entre elles, tendanee mutuelle apparente qui n'a lieu que trés-près du contaet, à des distanees infiniment $p$ tites, de telle sorte qu'elle eesse quand l' $\propto$ il peut saisir le moindre intervalle entre les eorps qui s'attirent. Pour ramener ees deux genres d'attraction à une méme loi, Laplace suppose que, dans les corps, les diamètres des moléeules sont ineomparablement plus petits que les intervalles qui les séparent, en sorte que, quand l'intervalle entre les corps devient appréeiable ì l'œil, il est infiniment grand par rapport aux molécules. Au reste, le mot attraction exprine un fait et non une cause. $\triangle \mathrm{UCH}$

C'est en ee sens seul que Newton l'a cmployé, et qu’il faut toujours le prendre.

A'T YPOMORPIIOSE, s. f., alypomorphosis (a priv., тúmos, type, pspon, forme). Expression dont les entomologistes se servent pour désigner un mode de métamorphose dans lequel les larves perdent tout-ǹ-fait lemt forme prinilive, et se contractent eu une boule alongée, sans aucune apparenee exlcirieure de I'insecte qu'elles reuferment. Ex. la plupart des Diptires.

AUBE, s. f., diluculum; Morgendämmerung (all.); dawning (angl.); alba (it.). Premiére lueur du jour : point du jour.

AUBIER, s. m., allurna, allurnum; Weisshole, Spline (all.); sap (angl.); alburno (it.). Partie du corps ligneux qui n'i pas cheore acquis toute sa dureté; ensemble de ses couches les plus extérieures, de eelles qui se sont formées les dernières.

AUCHínaTEs, adj. et s. m. pl., Auchenates (aن่xìv, cou). Nom donné par Degeer à in ordre de la classe des inscetes, eomprenant les apteres marcheurs qui ont un eol, ou une tc̀te distinete du eorselet.

AUGHÉvION, s. m., auchenium ( $\alpha \dot{u} \chi^{\gamma} y$, eou). Illiger appelle ainsi la région du eol qui est situće au dessous de la nuque.

AUCIÉnOPTHRES, adj. et s. m.

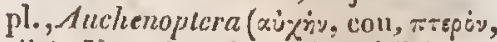
aile). Nom domé par Dunéril à une famille de poissons, comprenant ceux don les nageoires inféricures préeèdent les thoraciques et sont placées sons le cou.

AUCHENorinvQUES, adj. et s. m. pl., Auchenorhynchi ( $\alpha \dot{x} x^{\prime}$ ', cou, fóy $0^{\circ}$, bec). Nom danué par Durnéril ì une famille d'insectes bimiptires, comprenant eeux dont la base du bee semble niître du cou. Го оуе CoLLIIOSTRES. 
AUGE, s. f. Espace compris entre les deux ganaches, est-à-dire entre les deux branehes de la mâchoire inférieure, dans le cheval.

AULADIBRANCHES, adj. et s. m. pl., Auladibranchia (àùós, flûte, Bpx́yxıe, branebies). Nom donné par Latreille à une fumille d'I chthyodères, par Fieinus et Carus à uıte famille de poissons, comprenant ceux dont les branchies eommuniquent à l'extćrieur par des trous latéraux scmblables à ceux d'une flûte.

AULOSTONID ES, adj . et s. m. pl., Aulostomides (ảulós, tlute, oróuce, bouche). Nom donné par Latreille, Ficinus, Carus et Eiehwald, à une famille de poissons, comprenant eeux dont la tête se prolonge de manière à former un long tube qu'on a comparé ì une flûte.

AURADE, s. f., aurada. Non donné par Plisson ì une matièrc grásse, voisine de la myricinc et de la céraïne, qu'il a extraite de l'huile essentielle de fleurs d'oranger.

aUrantiacées, adj. et s. f. pl., Aurantiacca. Quelques botanistes donnent à la famille des IIespéridćes ce nom, qui est tiré de eelui d'Aurantium, oranger.

AURANTHCOLLE, adj, autantiicollis (aurantius, orangé, collum, col); qui a le col de couleur orangée. Ex. Saltator aurantiicollis.

AURANTINE, subst. f., aurantina. Nom donné au prineipe amer des oranges non mûres. Voycz HrspénDINE.

ACRATE, s. m., auras. Sel formé par la combinaison d'uıe base salifiable avee l'oxide aurique jouant le rôle d'acide.

AURATICOLLE, adj., auraticollis (auratus, doré, collum, col); qui a le col doré. Ex.Sylvia auraticollis.

AURÉLLE, s. f., aurclia. Les entomologistes ont donné ee nom aux nymphes des lépidoptères, à cause de
AURI

l'éelat doré qui brillc sur l'enveloppe de cellcs de quelques papillons diurnes.

Auríotís, adj. et s. m. pl., Aurcoli. Nom donné par Vieillot à une famille d'oiseaux Sylvains, reufermant des espèces qui se font remarquer par le brillant ct l'éelat de leurs couleurs.

AULkLx, adj. , aurosus, Dans la nomenclature chimique de Berzelius, on appelle oxide aurcux (protoxide d'or; Groldsuboxydul, all.) le premier degré d'oxidation de l'or ; sulfure aurcux (Drittclschwof flgold, ali.) lc premicr degré de sulfuration de ce métal; oxiscls aureux eeux dont l'oxidc aureux est la base; chlorure aureux celui qui ecrrespond à l'oxide aureux pour la composition.

AURIBARBE, adj. , auribarbis (aurum, or, barba, barbe); qui a des poils dorés en forme de barbe. Ex. Ommatius atuibarbis.

AULICO-AMIONIQUE, adj. , aurico-ammonicus. Épithète donnée, dans la nomenclature ehimiquc de Berzelius, à un scl doublc qui rísulte de la combinaison d'un sel aurique avce un sel amenonique. Ex. Chlorure aurico-ammonique (hydrochlorate d'or et d'ammoniaque).

AURICO-BAISTIQUE, adj. , aurico-bary-licus. Epithète donnée, dans la nomenclature chimique de Berzelius, ì un sel donblequi est produit par la combinaison d'un sel aurique avee un sel barytique. Ex. Chlorure aurico-barytique (lydrochlorate d'or et de baryte).

AURICO-CADNIQUE, adj. , aurico-cadmicus. Fipithète donnée, dans la nomenelature ehinique de Berzclius, à nu scl double qui rćsulte de la conibinitson d'un sel aurique avee un sel cadmique. Ex. Chlorurc aurico-cadmiquc (by drochlorate d'or et de cadmium).

AURICO-COBALTIQUE, adj., all- 
rico-coballictus. Épithète donnéc, dans la nomenclature chimiguc de Berzelius, à un sel double qui résulte de la combinaison d'un sel aurique avee un sel colsaltique. Ex. Chlorurc anrico-cobaliquc (hydrochloratc d'or $\mathrm{cl}$ de cobalt).

AUIICO-LTTHQUE, adj., antrico-lithicus. Épithète donnée, dans la nomenclature chimique de Berzelius, à un sel double qui résulte de la combinaison d'un sel atrique avec un sel lithiquc. Ex. Chlorure auricolithique (hydrochlorate d'or et de lithine).

AURICOLLE, adj., auricollis (aurum, or, collum, col); qui a le col d'un jaunc doré. Ex. Sylvia auricollis.

AURICO-MAGNíSIQUE, adj. , autrico-magnesicus. Épithète donnce, dans la nomenclisture chimique de Berzclius, à un sel double qui résulte de la combinaison d'un sel aurique aree un scl magnésique. Ex. Chlorure aurico-magnésique (hydrochloratc d'or el de magnésic).

AURICO-MANGANIQUE, adj. , atırico-manganicus. Épithète donnée, dans la nonenclature chimique de Berzelius, à un sel double qui est produit par la combinaison d'un sel anrique avec un sel manganique. Ex. Chlorurc aurico manguniquc (hydrochloralc d'or al de mangancse).

AURICO-NICCOLIQUL, adj. , artrico-niccolicus. Épithète donnée, dans la nomenclature chimique de Berzelius, à un sel donble qui résulte de la combinaison d'un sel aurique avec un sel niecolique. Ex. Chlorure aurico-niccolique (hydrochlorale d'or ct de nickel).

AURICO-POTASSIQUE, adj., aurico-potassicus. F́pithète donnce, dans la nomenclature chimique dé Berzelius, à un sel donble qui résultc de la combinaison d'un sel auriquc avec un sel polassique. Ex,
Chlorture aurico-potassique ( hydrochloratc d'or ce de potasse).

AUnICOInE, adject., auricornis (aurum, or, cormu, corne); qui a des cornes d'un jaune d'or. Le Mrascicapa auricornis est ainsi appclé parce qu'il a une touffe de plumes jaunes au dessus de chaque oreille.

AURICO-SODIQUE, adj. , auricosodicus. Epithète donnće, dans la nomenclature chimique de Berzelius, à un sel double qui est produit par la combinaison d'un sel aurique avee un sel sodique. Ex. Chlorurc aurico-sodique (hyllrochlorale d'or et de soucle).

AURICo-STrontiQue, adj. , aurico - stronticus. Épithète donnée, dans la nomenclature chimique dé Berzelius, à un sel double qui résulle de la combinaison d'un sel aurique arce un sel strontique. Ex. Chlortere aurico-strontiquc (hydrochlorate d'or ce de strontiane).

ADRICo-zINCIQUE, adj. , auricozincicus. Epithète donnéc, dans la. nomenclature chimique de Berzelius, it unsel double qui ŕcsulte de la combinaison d'un sel aurique avec un sel zineique. Ex. Chlorture aurico-zinciquc (hydrochlorate d'or ct de zinc). AURiculacís, adj. el s. m.pl., Auriculacca. Non sous lequel Blainville et Menke désignent une famille de l'ordre des Céphalophores pulmobranches, qui a pour type le genre Auricula.

ANICULAIRE, adj., auricularis (auris, oreille). En forue d'oreille, qui alppartient à l'orcille. On dit : doigt auriculaire, le petit doigh, celui avec lequel on se gratte l'oreille; plumes auriculaires, celles qui garnissent les oreilles des oiseaux. Un insecle (For ficula auricularis ) est ainsi appelé parce qu'un préjugé populaire lui attribue unc grande tendance à s'introduire dans le conduit auditif; une eoquille (Limnara auricularia), parce 
qu'elle a l'ouvcrture très-évasée ; comme la eonque d'une oreille; in oiseau (Vultur auricularis), parce qu'il porte au-devant des oreilles un appendice membraneux qui lui pend sur les cốtés du eou.

AURICULAIRES, adj. et s. m. pl., Auricularii. Nom donné par Marquis ì un groupe de champignons hyménothéeiens, renfermant ceux qui ont la forme d'une orcille.

AURicuLAItivs, adj. et s. m. pl., Auricularini. Nom donné par Fries à unc tribu de l'ordre des IIyménomycètcs à chapeau, qui a pour type le genre Auricularia.

AURICULATO-PENNḰ, adj. , allriculato-pinnatus. Lipithète donnéc par Link aux fenilles pennées dont les folioles sont auriculées.

AURICULE, s. f., auricula; AEhrchon (all.). Petite oreille. En général, ce mot cxprime, dans la langue botanique, tout appendice latéral qui est court et arrondi, comme lc bout de l'oreille. Ainsi on donne le nom d'auricule aux appendices arrondis qui occupent la base de eertaines feuilles (ex. Salvia officinalis). Link appelle ainsi les appendiees foliacés de certains pútioles ́ex. Citrus Artrantium), et Willdenow les stipules des Jungcrmannies. Les ornithologistes donnent le même nom aux crètes dont les pennes élevées sont placées au-dessus des ycux, sur lc vertex (ex. plusienrs Chonettes).

Auricull:, adj., auriculatus, auritus; geolerlappt, geohrt (all.); arecchiuto (it.); qui est muni d'oreillettes. Ond dit $: 1^{\circ}$ en bolanique, fcuille auriculće, celle dont le disque se prolonge inférieurement en deux appendices sćparés du pétiole (ex. Pelargonium auritum, Senecio auriculatus, Bisculella auriculata, Solanum auriculatum); $2^{\circ} \mathrm{en}$ zoologie ; coquille bivalue auriculéc, toutes les fois que, de chaque côté des crochets, ou d'un côté seulement, elle présente des appendices saillans (cx. Pccten) ; dents aturiculées d'une charnière de coquille bivalve, quand elles offrent un aplatissement considérable et une eavité plus ou moins arrondie, pour reevoir le ligament (ex. Lutraria); corselet auriculé, quand il supporte des élévations comprimées et arrondies (ex. quelques Membracis); prothorax auriculé, lorsqu'il s'épanouit de ehaque eôté en deux appendices qui ressemblent à des orcilles (ex. Ledra aurita); élytres auriculées, lorsqu'elles offren tun prolongement ì leur base (ex. Cassida aurita); main articulée, dans les insectes, quand chacun des joints cst dilaté extérieurement en un appendice auriforme (ex. Taupegrillon).

AURICULIFÈRE, adj. , auriculiferus (auricula, auricule, fero, porter ); qui porte des auricules. Se dit, en eonehyliologie, d'une coquille dont l'impression musculaire forme une saillie à bord auriculé (ex. Cucullaea auriculifcra), ou dont les tours de spire sont hérissés de tubereules en forme d'auricules.

AURICULIFORWE, adj , auriculiformis; ohrförmig (all.) ( auricula, auricule, forma, forme); qui a la forme d'une petite oreille, comme les suçoirs du Tétrarbynque.

AURIDES, s. m. pl., Aurides. Nom donné par Beudant à une famille dc minéraux, qui comprend l'or et ses combinaisons.

AURIFṫE, adj., auriferus; goldhaltig (all.) (aurum, or, fero, porter); qui a l'éelat brillant de l'or (ex. Palmyra aurifera), qui contient de l'or disséminé imperceptible. ment (ex. Tellure aurifere).

AURIFORME, adj., auriformis (auris, oreille, forma, forme); qui a la forme d'une oreille. Sc dit du crochet d'unc coquille bivalve, quand il est peu saillant, tourné eu spirale et 


\section{AURO}

appliqué sur le ventrc de la eoquille.

AuRIGASTRE, adj. , aurigaster (aurum, or, gaster, ventre); qui a le ventre d'un jaune doré. Ex. T'urdus aurigaster. Voyez Gurysogastre.

AURIGÈRE, adject. , aurigerus (aurum, or, gero, porter). Un liehen (Lecidea aurigera) est aiusi appelé paree que son thalle est couvert de tubereules gris, d'un jaune doré à l'intéricur.

AURIQUE, adj., aurieus (aurum, or). Dans la nomenelature chimique de Berzelius, on appelle oxide ou plutôt aeide aurique (deutoxide ou peroxide d'or; Goldoxyd, all.), le second degré d'oxidation de l'or, qui ne jouit qu'à un très-faible legré des proprićtés basiques; sulfure ou sulfide aurique (Einfacluschwe folgold, all.), le second degré de sulfuration de l'or; telluride aurigue. la combinaison de tcllure et d'or qui correspond il l'oxide aurique pour la eomposition; sels auriques, ceux qui sont également dans ee eas, ou dont l'oxide aurique fait la base.

AUROCÉPIILE, adj. , aurocephalus (aurum, or, xequalin, tête); qui a la tête d'un jaune doré. Ex. Coecyzus aurocephalus. Voyez CrrrsocépHALE.

AUROFERRTh'HE, adj., auroferriferus (aurum, or, ferrum, fer, foro, porter). Epithète donnée, dans la nomenelature minéralogique de Haüy, ì un minéral qui contient aceidentellement de l'or et du fer. Ex. Tellure natif auroferrifere.

AUnOPLomisifère, adj. , auroplumbiferus (aurum, or , plumbum, plomb, fero, porter). Epithète donnée, dans la nomenclature minéralogique de Haiiy, à un minéral qui contient aecidentellement de l'or et du plomb. Ex. Tellure natif auroplombifere.

AUROPUBESCENT, adj., auropubeseciss (aurum, or, pubes, duvet);
AUTO

133

qui est couvert de petits poils d'un jaune doré. Ex. Aphritis auropubeseens.

AURORE, s. f., aurora; Morgenröthe (all.); dawning (angl.); aurora (it.). Crćpuscule du matin; lumière qui précéde l'apparition du soleil sur l'horizon. Au figuré, début de la vie.

AURORE, adj., aurorus, aur'oreus; qui a la eonleur jaune du sa fran. Ex. Cypraca aurora, Sylvia aurorea.

AUWURE, s. m. , aururetum. $\Delta \mathrm{l}-$ liage, en proportions définies, d'or et d'un aufre métal.

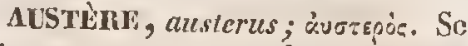
dit, au sens propre, de tout ee qui produit sur l'oregane du goût le plus haut degrré de l'inpression désagrćable désignée sous le nom d'astringence el d'acerbitć (saveur austère); au figuré, de ce qui est rudc et pénible (vic austère) ou sévìre (vertu alcstère).

AUSTÉnité, s. f., ausicrilas. Qualité de ee qui est austcre. Cc mot est fort peu usité au sens propre.

AUSTRAL, adj., australis; südlich (all.); soulhern (angl.) ( $\alpha$ "vw, sćeher); qui est situé, pour nous, au delà de l’équateur. Synonyme de méridional. On appelle, en astronomic, constellations ausirales, celles qui sont situées au midi de la ligne équinoxiale; en physique, maguétisme austral, celui qui doniac dans l'hémisphèrc méridional de la terre. Les naturalistes donnent eette épithète à des êtres qui vivent dans les pays chauds (ex. Mactra australis), et fort souvent, surtont en botanique, à ecux qu'on trouve dans les parties méridionales de l'Europe (ex. Eriea australis, Conostomum australe).

AUTOCARPIEN, adj. , autocarpianus (åuròs, seul, харті்', fruit). Epithète donnéc au fruit, par Desvaux, lorsque, l'ovaire se développant sans conlracter aucune adhć- 
rence avee les parties environnantes et sans être immédiatement recouvert par elles, le fruit ne se trouve modifié par aucune addition de parties.

AUTOCIITHONE, adj., autochthosus, terrigena, aborigena; $d$.

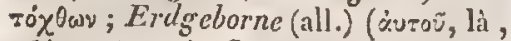
$\chi^{\theta \omega} \omega$, terre). Synonyme très-peu ulsité d'aborigène. Voyez ce mot.

AUTOMLTIQUE, adj. , automa-

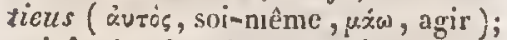
qui s'opère de soi-mème, de son propre mouvement, sins concours, apparent au moins, de la volonté.

AUTOMATISBE, s. m. , automatismus. Mouvement machinal, qui a lieu sans qu'on y fasse attention, sans que la volonté y participe.

AUTOMNAL, adj. , autumnalis; herbstlich (all.); autumnal (angl.) (autumnum, automue); qui se manifeste en autonne (équinoxe automnal), qui croit en automne ( $\mathrm{ex}$. Callitriehe autumnalis, Colchicuns autumnale), qui parait en automnc (ex. Fringilla autumnalis).

AUTOMNATION, s.f., autumnatio. Influence de l'automne sur la végétation, qui se manifeste spćcialement par la maturation des fruits, la dispersion des graines et le changement de couleur des fcuilles, suivi bientôt de leur chute.

AUTOMNE, s. In. ; autumnum, autumnus; Herbst (all.); autrenin (angl.); autonno (it.). Troisic̀me des quatre saisons de l'année, qui date du jour où le Soleil atleint à l'équa teur, et finit quand il arrive au tropique, qui, pour notre hémisphère, s'étend depuis le 23 septembre jusqu'au 21 ou 22 décenbre, et pendant laquelle la Terre parcourt les signes de la Balance, du Taureau et des Gémicaux. Au figuré, anlomne de la vie signifie l'àge qui précéde la vicillesie.

AUTOXOMIE, s. f., autonomia;

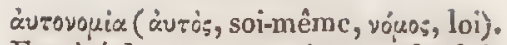
Faculté de se tracer soi-même les lois d'après lesyuclles on agit. Synonyme de liberté. On ne s'en sert qu'en philosophie.

AUTOPSIDES, adj. , autopsides ( ¿̀urós, soi-même, örtousı, voir). Nom donné par Haiiy à une classe de substanees métalliques renfermant celles qui naturellement sont donées de l'éclit métallique dans un ou plusicurs de leurs élats.

AUXOMìtra, s. m., auxometrum

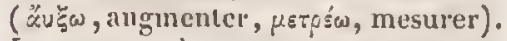
Instrument dont on se sert pour mesurer la force grossissante d'un appareil optique. On employe quelquefois le mot dynantomitre dans le même sens.

Avalavcue, s. f. , Selneelauwine (all.). Masse de neige qui, par l'effort des vents ou la fonte de ses parties inféricures, se détache du sommet glacé des liautes mantagnes, et roule jusque dans les plaines, cn détruisant tout sur son passage.

AVaLÉ, adj. Lorsqu'uu cheval a le ventre trop volumineux, et plus ample vars les parlies inférieures que vers les flancs, qui sont creux, on dit qu'il a le ventre avalé, ou qu'il a un ventre de vache.

AVANGe, adj, , productus. Kirby donne cette épithète au prothorax des insectes, lorsqu'il se termine postérienrement en un long avancement scuteliforme, qui couvre le mésothorax, le métathorax et une grande partie de l'abdomen. Ex. Acrydium.

AVANT-BRAS, s. u., cubitus, antibrnchium; Vordcrarm(all.). Parlie din mcmbre thorachicpuc qui s'élend depuis le conde jusqu'au poignet.

AVANT-PIEUS, s. m. pl. , prepedes. On donne quelquefois ce nom à la paire antéricure des paltes des insectes.

AVANT-POITRINE, 5. f., antipectus. Nom donné par Latreille à la 
partie inférieure du premier segment du thorax des insectes. Voyez AntiPOITRINE.

AVANT-STERNUM, s. m., antisternum. Latreille appelle ainsi la partie moyenne inféricure du premier segment du thorax des inseetes.

AVELLANAInE, adj., avellanarius (avcllana, noisette). Epithète dounée par les géognostes aux grains d'une roche greme, quand ils sont de la grosseur d'une noisettc. Le Myoxus avellanarius est ainsi nommé paree qu'il fait sa nourriture prineipale de noisettes.

Avínaclí, adj., avcnaceus; hafrartig (all.) (ayena, avoine); qui a du rapport avec l'avoine. Ex. Eriodia abcracea.

AVENACíes, adj. ets.f. pl., Avenacere. Nom donné par Kiunth, Nees d'Esenbeck ct Link à une tribu de la familie des Graninées, qui a pour type le genre Avena.

AVENAINE, s. f. , avenaïna. Hermbstaedt a appelć ainsi le gluten de l'avoine.

AVÉNIF ORแ世, adj., aveniformis (avena, avoine, forna, forme); qui a la forme et le volume d'un grain d'avoine. Ex. Ancilla aveniformis.

AVENTUnIní, adj. Epithète donnée à un minćral qui, après avoir été taillé et poli, offre, sur un fond jaune ou brun, des points brillins, dorés ou argentins, dont les reflets sont fort celatans.

AVEuGLE, adj. , cecns ; blind (all. angl. ); cicco (it.); qui est privé de la vue, qui n'en a jamais joui. L'Aptcrichlus cacus est ainsi appolé parce qu'il n'a point d'yeux visibles au dehors.

AVICULAIRE, adj. , avicularis, avicularius (avis, oiseau) ; qui sert à la nourriture des oiseaux (ex. Polygonun aviculare), qui dévore les oiseaux (ex, Mrgale avicularia); qui habitc dans le nid des oiseaux et sur leur eorps (ex. Hippobosca avicularia).

Avicules, s. m. pl., Aviculo: Nom donné par Goldfuss, Férussac et Munke à une farnille de mollusques, qui a pour type le genre Aricula.

AVILLON, s. m. On désigne ainsi les doigts de derrière des oiseaux de proie.

AVIRON, s. m., pes natalorius: C'est le uom qu'on donne aux pattes de certains insectes aquatiques ( $\mathbf{e x}$. Notoncctes), quand elles sont aplaties, larges, cilićes sur lesbords, et qu'clles servent comme de rames pour nager.

AVInOSTRE, adj., avirostris (avis, oisenu, rostrum, bec) ; qui ressemble à un bec d'oiseau. Ex. Lepadites avirostris.

AvisuGes, adj. ct s. m. pl., Avisuga (avis, oiseau, sugo, sucer): Nom donné par Duméril à une fámille d'insectes aptères, comprenant ccux qui sucent les oiseanx.

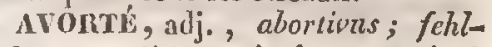
sellagen (all.); qui n'a pu venir ł maturité, ct, par extension, qui est grêle et naigre, qui est d'unc nature imparfaite. Voyez Aвontr.

AVORTEMTNT, s. m., abortus; äp (j) (all.); abortion (angl.); aborto (it.). Aete par leçuel un être organisé ou quelqu'nuc de ses parties cesse de prendre le développement que sa nature aumit comporté, lorsque cette altération l'emprehe de reinplir les fonctions auxquuelles il est appelé. En zoologie, avortenent exprime la misebas des petits avant terme.

AvorTon, s. m. Né avant terme; petit, mal bîti, mal conformé, contrefait.

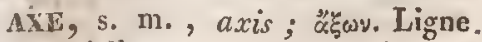
Aroitc, réellc ou inaginaire, qui passe ou qui est censée passer par le centre d'un corps, auquel elle sert comme 
d'essicu; toute ligne à laquelle on rapporte une figure ou un corps, soit pour cn détcrminer la forne ou la position, soit pour en assigner l'état de repos ou de inouvement. On dit : $1^{\circ}$ en astronomic, axe du monde ou de rotation, une ligne idéale autour de laquelle on suppose quc s'exécute lc mouvcment du systeme solaire. $2^{\circ}$ En cristallographie, axe d'un cristal, la ligne idéalc par rapport à laquclle les plans qui composent ce dernicr sont en général coordonnés symétriquement, soit tous ensembje, soit par partics. $3^{\circ} \mathrm{En}$ botanique, axe signific la partic alongcee d'un pédoncule sur laquelle sout attachćes plusieurs flcurs, quelquefois seulement le pédoncule central de l'épi; les botanistes donnent aussi ce nom ì la ligne idéale qu'on suppose aller de la base au sommet du fruit, et le long de laquelle seraient les points d'attiche des graines. $4^{\circ} \mathrm{En}$ zoologic, Kirby appelle axe certaines pièces osseuses ou cornćes par le moyen desquelles l'aile supćrieure est mise en connexion avec lc dorsolitm.

AXICORNE, aldj., axicornis \{axis, axe, cornu, corne?. Le Murex axicornis est ainsi appelé parce qu'il a des digitations mentues et longues, qu'on a comparíes ì celles des cornes de l'axis.

AXIFERE, adj, axiferus (axis, axc, fero, porter). On appelle: $1^{\circ} \mathrm{en}$ hotanique, végétaux axiféres, d'après 'Turpin, ceux dont l'organisation ne se compose que d'une tige ou d'un axc diversement modifié, dans l'intérieur duquel on ne trouve guères que du tissu cellulaire ( $\mathrm{ex}$. Champignons, Algues et unc partie des Ilépatiques); trophospcrme ou placenta axifere, celui qui naît de la hase ou du sommet de l'ovaire (ex. Primulacées). $2^{\circ}$ En zoologie, un Polypier axifere est celui dans lequel les polypes n'habitent que la pulpe corticiforme étenduc sur l'axe plein ct central.
AXIFORVE, adj., axiformis (axis; axe, forma, forme); qui a la forme d'un axe ou d'un essicu; corps axiforme.

AXIFUGE, adj., axifugus (axis , axe, fugo, fuir). Synonyme inusité de centrifuge. Voycz ec mot.

AXIGRAPHE, adj., axigraphus

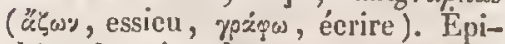
thc̀tc donnée, dans la nomenclature minćralogique de Haïy, is une varićté de chaux carbonalée qui a celte propriété que le sommet de l'axe du noyau et d'unc des parties excédantes est à cette deruière partie dans le rapport des deux termes de la fraction $\frac{1}{4}$ qui donneut l'exposant du signe.

AXILE, adj., axilis; qui forme un axc. En hotanique, on appelle embryon axile, d'après Mirbel, celui qui, placé au milieu du périsperme, se porte d'un point de la périphérie dc la grainc au poiut diamétralcment opposé, de sorte qu'il occupe le centre dc la graine (ex. Conifcres); graines axiles, d'après Richard, celles qui sont attachées vers l'axe rationnel des fruits ; placentaire axile, celui qui s'alonge de la base au sommet du péricarpe, dans la direction de son diamètre (ex. Lilium).

AxILli, adj., axilatus. Ayant un axe. Nirbel dounc cettc ćpithète aux fruits disposés autour d'un axc commun qui devient libre par lent chute (ex. Cynoglossum lavigratum).

AXILLAURE, adj. , axillaris ; achselstïndig, winkelstïndig (all.) (axilla, aissellc); qui a rapport à l'aisselle, qui cn est voisin, qui $y$ rait. On dit: $1^{\circ}$ en botanique, feuilles axillaires, celles qui sont attachces au point internc de l'angle foriné par le rameau ct la tige (ex. Drymis axillaris ); flcurs axillaires, celles qui sont fixécs au point intcrne de l'angle compris entre la feuille et le ramenu; ćpines axillaircs (ex. Citrus 
AXYL

medica); grappe axillaire (ex. Cytisus Laburnum); panicule axillaire (ex. Lygistum axillare); vrille axillaire (ex. Passiflora carulea). $2^{\circ} \mathrm{En}$ zoologie, ce unotindique que l'aissclle de l'animal auquel on l'applique présente quelque particularité remarquable de formc ou de couleur. Airsi, le Cimbex axillaris a une tache jaunc sur chacun des côtćs du corselet; le Circus axillaris portc un faisceau de longues plumes noires qui recouvrent toutes les parties inférienres de l'ailc; le Myrmothera axillaris a les moyennes eouvertures des ailes blanches.

AXILLIBAIBU, adj. , axillibarbatus (axilla, aisselle, barba, barbe). Se dit des feuilles et des pédoncules, quand ils sont munis de poils à l'nisselle.

AXILLIFLORE, adj., axilliflortus; achsclblïthig (all.) (axilla, aisselle, flos, fleur); qui a des fleurs axillaires. Ex. Portulaea axilliflora, Delphinium axilliforum.

AXIOMORPHIQUE, adj. , axiomor-

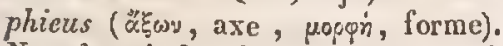
Nom donné, dans la nomenclature minéralogique de Haüy, à une variété de chaux carbonatée qui offre la réunion du noyau, du rhomboïde équiaxe et du dodécaëlre mélastaliçue.

AxIPÈTE, adj., axipetus (axis, axe, peto, aller). Synonyme inusité de eentripéte. Voyez ce mol.

AXONOPIITE, s.m. , axonophy-

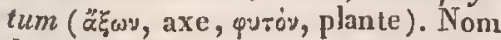
donné par Necker aux plantes amentacées, dont les flcurs couvrent un axe commun.

AXYLE, adj. , axylus ( $\alpha$ priv. , छyjhov, bois). Schultz donne cettc épithète aux végétaux cellulaires, parce que leurs fibres, quand ils on $q$ quelque chose de comparable à des fibrcs, ne sont composées que de cellules alongées, et ne peuvent jamais être assimilées aux véritables fibres ligneuscs.
AZOT

azédaracis: Voyez Méliacées.

AZELIDES, adj. et s. m. pl., Azelida. Nom donné par Robineau-Desvoidy à une section de la tribu des Myodaires Mésomydes Antliomydes, qui a ponr type le genre Azelia.

AzInUT, s. m. Les astronomes appellent azimut d'un astre l'are de l'horizon compris cntre le méridien et le cercle vertical qui passe par cet astrc.

AzIMUTAL, adj.; qui représente ou mesnre les azimuts. Le compas azimulal est un instrument qui sert pour trouver l'azimut ou l'amplitude d'un corps eéleste. On nomme cercle azimulal cclui qui, passant par le zénith et le nadir, coupe l'horizon à angle droit.

AZOGARIBIDE, s. m. Nom employé, eomme synonyme de cyanide (voyea es mot) par Guibourt, qui appelle l'acide hydrocyaniquc ou cyanide hydrique, azocarbide bydrique.

AZOCANBIQUE, adj. Guiliourt appelle l'acide chloroeyanique chloride azocarbique, par contraction d'azotide carbonique.

Azocalibure, s. m. Mot que Guibourt employe comme synonyme de cyanurc. Voyez ce mot.

Azootieve, adj., azoolicus ( $\alpha$

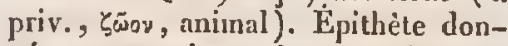
néc aux tcrrains qui ne contiennent aucun débris de corps organisés.

-azotate, s. m., azotns. Nom que portcraicnt les nitrates, si l'on donnait à l'acide nitriquecelui d'acide azotique.

AzOTE, s. m. , czotum, azotieum, nitrogenium; Stickstof (all.) (a priv.

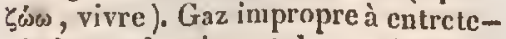
nir la combustion et la respiration, dont l'existence fut entrevuc dès $177^{2}$ par Rutherford, et que Scheele a le premier isolé vers 1777 .

AzoTí, adj. , azolatus; qui contient de l'azote. Ex. Gazhydrogène azoté ou ammoniaque. 
Azoteux, adj., azotosus. On a proposć de donner ce nom à l'acide nit reux.

AZOTIDE, s. m. Guibourt appelle lc cyanogène azotide carboniquc.

AzOTIDES, s. nu. pl. Nom donnć par C. Pauquy à une famille de corps simples, qui a pour type l'azote, et par Beudant à une famille de nincraux, comprenant ceux qui contiennent de l'a zote.

AzOTIODrQue, adject. Guibourt donne le nom d'oxidc azoliodique à un composé d'acide nitrique et d'acide iodique.

AZOTIQUE, adj., azoticus. Nom Tu'on a propusé de donner à l'aeide nitrique. Oken appelle l'air élément azolique, parce que l'azote y est en exeès.

AZOTITE, s. m. Cc nom appartiendrait aux nitrites, si l'on adoptait celui d'acide azoteux pour l'acide nitreux.

AZOTOXIDES, s.m. pl. Norn donné par Beudant à un grenre de minéraux comprenant les combinaisons de l'azote avec l'oxigène.
BACC

AzOTURE, s. m. Synonyme inusité de nitrure. Voycz ce mot.

AZULMNIQUE, adj., azulminicus. Nom donné par Boullay à un acide qui a de l'analogie avee l'alumine, Inais qui contient de l'oxigène, ct qui se forme par la décomposition spontancé de l'acide liydrocyanique.

AzURÉ, adj., azurcus (du persan ladsurdi, bleu) ; schmallau, himmclblau (all.); qui a la couleur de l'azur, la lejute bleue du ciel. Ex. Cuivre azuré, Ixos azureus, Ccanolhus azurca, Delphinium azurcum.

AZURIN, adj., cosius; qui est d'un bleu pâle, lirant un peu sur le gris. Ex. Colubcr coesius, Motacilla casia.

AzLroR, adj., azurciurcus , corulaurcus. Bleu avec un reflet dorć. Ex. Casia carulaurcos.

A7. GOCÉres, adj. ct s. m. pl.,

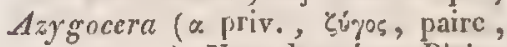
xepas, corne). Nom donnć par Blainville à une scetion de la famille des Néréidés, comprenant ceux qui ont lc systc̀me tentaculairc impair.
BABIL, s. m. , garritus ; Geschwätz(all.). Se dit du gazouillement particulier de la corneille.

BACGAULAIRE, adj., baccaularis, baccaularias (bacca, haic). Epithèe dounée par Desvaux ì des fruits composćs de plusieurs ovaires distinets et baeciformes, qui proviennent d'une seule fleur ct sont portés sur un dis.. que peu apparent, non charnu. Ex. Drymis.

BACCHAILDÉEs, adj. et s.f. pl., Baccharidece. Nom douné par H. Cassini à une seetion de la trihu des Astérées, et par Lessing à unc sonstribu de la tribu des Astéroildées, qui ont pour type le genre Baccharis.

BACCIEN, adj., baccatus, baccausus, baccans; beerartiǵs (all.); baccuto (it.). Epithète par laquelle on désigne, en général, tout fruit char nu qui, bien que formć par la réunion de plusicurs ovaires, a de la resscmblanee avec une baic (ex. Junipcrus communis). On l'applique quelyuefois a des plantes dont le fruit est légèrement charnu (cx. Ochradenus baccalus, Leptospermum baccatum), ou même à des végétaux dont la corolle globulcuse ressemble à une petite baie (ex. Erica baccans. Foyez Baccifíre). Mirbel la donne à 
tous les fruits simples et indéhiseens qui contiennent plusieurs graines séparées, parfois renfermées dans des nueules. Ainsi il appelle diérésilebaccicnne, celle dont la pannexterne. est d'abord sueculente (cx. Sapindus); étairion baccicn, eclui qui résulte de plusicurs camares succu. lentes, dont l'entregrelfement et la réunion produiscnt une sorte de baie (ex. Rubus); strobile baccion, eelui dont les braetces constituantes sont succulentes et se soudent les unes avec les autres (ex. Juniperus).

BACCIFÈR, adj. , baccifer, bacciferus; beertragend, becrentragend (all.); bacciferous (angl.); baccifcro (it.) (bacca, baie, fero, porter). Epithète donnéc ì des plantes dont le fruit est une baie ou ressenble à une baie (ex. Cucubalus baccifcrus, Urtica baccifera, Hypcricum bacciferum), ou qui sont garnies de renflemens vésiculaires arrondis (ex. Sargassum baeciforum).

BACGIFOnME, adj., bacciformis; beerig, bcerförmig (all.) (bacca, tuaie, forma, forme); qui a la forme d'une baie. Se dit, en botanique, d'un fruit qui a l'appareuee et à peu près la strueture d'une baie, sans en présenter les véritables caraetères. Synonyme de baccicn. Voyez ce mot.

BACCIVOnES, adj. el s. m. pl., Baccivori (bacca, baie, voro, devorer). Fom donné par Vieillot à une fámille de l'ordre des Sylvaius, eomprenant des oiseaux qu'il suppose vivre tous ćgalement de baies.

BACLLAIRE, adj., bacillaris; stangartig (all.) (bacillus, baguette). Celte épithète est donnée, par les minéralogistes, à des minéraux eristal. lisés en prismes dont les pans sont oblitérés, de manière qu'ils ressembleul à des baguelles (ex. Baryle sulfatće bacillaire); par les botunistes, ì certaines plantesdont les fruits sont très-longs, grêles et cylindriques (ex. Cassia bacillaris); par les zoologistes, tic du corps droite, grêle ct alongée, coume le fourreau de la Tcredina bacillum, le col du Tachia bacillaris, ou lis coquille du Bulimus bacillaris.

BACLLLARÍ́s, adj. et s.m. pl., Bacillaria, Bacillaria. Nom donné pat Bory à une fanille d'Infusoires, et par G.-G. Ehrenberg à une tribu de Polygusiricues, ayant pour type le genre Bacillaria.

BACILLE, s. nı., bacilla, bacillus; Siöckichen (all.). Ce nom a été appliqué par Acharius an podétion des lichens, ct par quelques auteurs aux bulbilles qui se développent dars eertains péricar pes.

HACHLIFORME, adj. , bacilliformis, baculosus (bacillus, baguette , forma, forme); qui a la forme d'une baguetle. Celte épithète est donnée aux épines des oursins, quand elles ont une certaine longueur. Ex. Cidarites baculosa.

BACTnulíses, adj. et s. f. pl., Bactridica. Nom clonné par A. Brongniart à une trilu de la famille des Urédinées, qui a pour type le genre Bactridinum.

BACULIWERE, adj. , baculiferus (baculus, eanne, fero, porter). Le Gynestum baculiferum est un arbrisseau tris-recherché paree qu'on fait des eannes avec ses tiges.

BENODACTYLES, adj. et s. m. pl., Banodactyli ( $\beta$ aiv(), marcher,

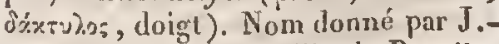
A. Ritgen à une fanille de Reptiles sauriens, eomprenant ceux qui se servent de leurs pattes pour mareher.

Banosaurueas, adj. et s. in. pl., Banosaurii ( $\beta$ aivw, marcher, oxipos, lézard). Nom donné par J.A. Ritgen aux Sauriens dont les pattes servent d'organes ambulatoires.

13 EON cRES, adj. et s. f. pl., Bacomycea. Nom donné par Zenker t̀ une tribu de la famille des Lichens, 
qui a pour type le genre Bcoomyces. Voyez Boemrcées.

BAI, adj., spadiceus; hellbraun (all.); bay (angl.); bajo (it.); qui est d'un rouge brun. Ex. Clinus spadiceus, Leciclea spadicea.

BAIE, s. f., baeca; Beere (all.); berry (angl.); bacca (it.). Nom générique par lequel les botanistes désignent tous les fruits simples, mous, charnus, indélisecns, sams noyau, qui contiennent une ou plusieurs graines, soit éparses dans la pulpe (ex. Vitis vinifera), soit renfermées dans une ou plusieurs loges (ex. Atropa Belladonna).

BAILLANS, adj. et s. m. pl., Hiantes. Nom donné par Savy à une tribu, et par Goldfuss à une famille de l'ordre des Passereaux, renfermant des oisenux qui, comme les engoulevens, ont le bec largenient fendu.

BAILLANT, adj., hians, hiascens; llaffend (all.) (hio, bâiller). Richard donne eette épithète ì un péricarpe qui, au moment de la maturité, se rompt par une ouverture apicilaire ou latérnle non dentée. Le $\boldsymbol{S} a$ tyrium lians est ainsi appelé parce quel'un de ses pétalcs est eapuchonné, très-élargi et ouvert comme une bouche qui loâillc. Cette épithètc est appliquée aussi, par les zoologistes, aux coquilles bivalves qui ne sout point exaetement closes (ex. $Y_{\text {cnus }}$ hiantina, Vulsella hians).

BAIN, s. m., balncum; Bad (all.); bath (angl.); bagno (it.). Les chimistes désignent ainsi un milieu quelconque dans lequel on plonge un vase, principalement pour en faire chauffer le contenu; ils font trèsfréquemment usage du bain de sable fin (Sandbad, all.), et du boin de vapeur aqueuse ou bain-marie (IV asserbad, all.).

BALEENIDES, adj. et s. m. pl., Balanida. Nom donné par J.-E. Gray à une famille de la classe des Mammi- fères, qui a pour typele genrè Ballana:

BALENOLOGLE, s. f. , balanologia (balana, baleine, ló\%os, diseours). Trailé sur les Cétacés en gé néral et les baleines en partieulier.

BALANAIfE, adj. , balanaris, balanarius; qui a rapport à la baleine. La Coronula balanaris est aiusi appelée parce qu'elle vit sur la peau et dans le lard de la baleine.

BALANCIER, s. m. , halier, libramentum; Scluvingkolbe (all.). Sous ce nom, les entonologistes désignent deux petits appendices filiformes, terminés par un boutou ovale ou triangulaire, et susceptibles d'un mouvcment vibratoire très-rapide, qui sont placés, un de chiaque côté, î la base de l'aile des diptères, dans l'anglc de réanion de l'abdomen avee le corselet. Considérés par les uns comme des rudimens d'ailes, ils sont regardés par d'autres, notamment par Latreille, connme jouant un rôle dans l'aete du vol et servant à maintenir l'inseete en équilibre.

BALANIDES, adj.et s.m.pl., Balanidea, Balanida, Balanea, Balanea. Nom donné par Leach, Gray, Menke ct Férussac à une famille de la elasse des Cirripèdes, par Blainville à une famille de celle des Nématopodes, ayant pour type le genre Balanus.

BALANIFERES, adj. et s. m. pl., Balaniferce (balanus, gland, fero, porter). Nom sous lequel Marquis a proposé de désigner la famille des Quereinées, ct qui exprime que les plantes coinprises dans ee groupe ont pour fruits des glands.

BALANOPIIORÉES, adj. et s. f. pl., Balanophorea. Nom donné par C.-L. Riehard et Kunth à une famille de plantes qui a pour type le genre $B a-$ lanophors.

BALANTIOPIITHALIE, adj. , balantiophthalmus ( $\beta a \lambda \dot{x}$ тto:, bourse, ípoxyuos, aeil); qui a la forme d'une bourse. Terme que Schneider propose 


\section{BALS}

de snbstiluer à celui de cruménophthalme. Vor. ce mot.

BALAUSTE, s. f., balausta ( $\beta a \lambda d \dot{v} v$ те०, fleur de grenadier). Desvaux appelle ainsi un fruit pluriloeulairc poly. sperme, couvert d'une écorce dure et coriace, couronné par les dents du calice, et renfermant, dans des compartimens peu réguliers, des graines presque en forme de noyau, qui ont un épiderme drupacé.Ex.PunicaGranatum.

BALA YEUR, adj. H. Cassini donne celte épithète à des poils particuliers, dont le style des plantes Synanthérées est garni, et qui, en irritant les anthères, en font sortir le pollen.

BaLE. Vor. Balle.

BALISIEnS. Voy. Axomérs.

BALISIOIDES. Voy. АMOMÉEs.

BALLE ov BALE, s. f. , gluma, tegmen. Nom donné par PalisotBeauvois à l'cnveloppe extéricure des fleurs des Graminées, c'est-àdire à une sorte d'involucre oceupant la base de l'épillet, renferntant une ou plusieurs fleurs, et ordinairement composé de denx pièces; par d'autres botanistes, au périgone propre de chaque fleur, celui qui entoure immédiatement les organes génitaux. Ce terme vague est peu usité aujourd'hui. Voy. Glemf.

BALLON, s. m. Les géographes appellent quelquefois ainsi les cimes de montagnes qui ont une forme arrondie.

BaLlotine, s. f. Terme proposé pour désigner le principe amer particulier du Ballota nigra, dont Grassmann a déerit le mode de préparation et les proprićtés.

BALSAMADENE, s. f. , balsamadena ( $6 \dot{x} \lambda \sigma \alpha \mu o v$, baume, $\dot{\alpha} \delta \dot{y} y$, glande). On a proposć d'appeler ainsi les glandes sous-cutanées des végétaux, eelles qui contiennent des liquides odorans et la plupart du temps une huile volatile mélée avec un peu de résine.
BALSAMIFE'RE, adj. , balsamife. rus (balsamum, baune, fero, porter); qui produit du baume. Ex. $A m y$ ris balsamifera, Croton balsamiferum.

BALSAMUTLUES, adj. et s. f. pl., Balsamifluxe(balsanum, baume, fueo, couler). Nom donué par Blume et Kunth á une famille de plantes, comprenant celles qui, comme le Liquidainhar, fournissent les produits désignés sous le nom de baumes.

BaAsSAMivíes, adj. et s. f. pl., Balsaminca. Nom donné par A. Richard et par Kunth à une famille de plantes qui a pour type le genre Balsamina.

BaLtinioníles, adj. et s. f. pl. , Baltimorea. Nom donné par H. Cassini à un groupe de la seetion des Héliantbées Rudbeckićes, et par Les$\sin g$ à une seetion de la sous-tribu des Sén céeionidées Ambrosiées, qui ont pour type le genre Baltimora.

BAvibuSACEES, adj. et s. f. pl., Bambusacea. Nom donné par Kunth et par Link à unc tribu de la famille des Graminées, qui a pour type le genre Bambusa.

BAMIBUŚ́ĹS, adj. et s. f. pl., Bambusea. Tribu de la famille des Graminćes, admise par Nees d'Esenbeck, qui a pour type le genre Bambusa.

Banaviens. Voy. Musaeŕes.

BANANIVORE, adj., bananivortes; qui fait sa nourriture principale de bananes. Ex. Motacilla bananivora.

BANG, s. m. On appelle ainsi : $1^{\circ} \mathrm{en}$ minéralogic (Lager, all.; bank, angl.; banco, it.), les assises dont les conches de pierres sont formées; les couches cohérentes, de nature particnlière, qui sont intercalées dans un systènie de couches d'une antre espèce; les anıs de sable et de gravier, de matières meubles ou de débris de roches, qui apparaissent à la surfaee de la mer, le plus souvent 
aux atterrages des côtes et ì l'embouchure des grands flcuves. $2^{\circ} \mathrm{En}$ \%oologie, des troupes innombrables de poissons, tels que thons, maquereaux, harengs, poissons volans, elc., de mollusques (cx. Hyalea papilionaeen), ou de roophytes (ex. Pyro.soma).

BANDE, s. f., faseia; Sireif (all.). Très-usité en histoirc naturelle, ce mot y sert principalement à désigner une large raie iransversale d'unc couleur différente de celle du fond.

BANDEL ETTE, s. f., striga. Cette épithète cst fréqucmment employćc pour désigner des zones colorées trèspetites ct expilliformes.

BANDEHOLLF, adj., taniolatus; qui est marqué de bandes transversales d'unc couleur différente de celle du fond. Ex. Coluber taniolutus.

BANISTÉIí́ES, adj. et s. f. pl., Banisterice. Nom donné par Cauldolle à une tribu de la famille des Malpighiacées, qui a pour type le genre Banisieria.

BARHE, s.f., barba; $\pi$ wowy; Bart (all.); beard (angl.); barba (it.). On donne ce nom : $1^{\circ} \mathrm{cn}$ lontanique, à des poils qui sont réunis en touffes sur une partie quelconque ; vulgairement à des file!s plus ou moins longs et aigus qui garuissent les loalles dc ecrtaines Graminces ; ct, suivint H. Cassini, aux appendices des squamelinles dont se compose l'aigreite de la cypsèle des Syuanthérées. Rivin appelait barbe la lèvre infórieure des corolles bilabićes; $2^{\circ}$ en zoologic, chez les Mammilères, aux poils qui garmissent les joues, les ceuvirons de la bouche et le menton de l'honme; à un petit bouquet de longs poils qui se trouve au niveau du menton, dans lc bouc par exemple; ì des crins qui garnissent les fanons des baleines, et qui, dans quclques espères, dépassant les mâchoircs, paraissent ì l'extéricur quanıl la bouche est fermée; chez les oiseanx, à des faisccaux de petites plimes qui pendent de la base du bee clans quelques especes, mais surtout aux petites lames de substance eornéc qui sont implantées sur les côlés de la tige des plumes; chez les inscctes, à des poils longs et assez raides, qui garnissent le front de certains dipleres (ex. Asilus), et entourent la base de la trompe.

BAn!É, adj. , barbalus. Épithc̀te donnce par H. Cassini aux squamelJules des Synanthérćes, quand elles émettent des ramifications très-longues, flexueuses et capillaires. Ex. Cirsium.

BARBELE, s. f., barbella. II. Cassini appelle ainsi les squamellules de l'aigretle des Synanthérées, quand elles sont assez courtes, raides, droites, eylindriques et épaisses, comme dans les Centauriées.

BARBELIא, adj. , barbellatus. Épithète donuće par H. Cassini aux squanellules, quand elles sont munies de harbelles. Ex. Centaurées.

BARBECLULE, s. f. , barbellula. H. Cassini désigne sous ec noin les squamellules de l'aigrette des Synanthérécs, quand elles sont petites, coniques, pointues et semblables à des épines. Ex. Aster.

BARBELLLLÉ, adj. , barbellulatus. Épithète donnée par H. Cassini aux squamellules, quand elles sont garnies de barbellules.

BARHICORve, adj. , barbicornis (barba, barbe, cornu, corne). Épithète donnéc à des insectes qui portent un faisceau de poils à la base de leurs antennes, comme les mâles du Ceratopngon barbicornis.

BAlibugrine, adj., barbigerus ; barliragend (all.) (barba, barbe, gero, porter). Ëpithètc donnée à des plantes qui ont des pétales velus en totalité (cx. Diosma barbigcra), ou en dcdans seulement (ex. Mrargaris barbigera), ou qui n'ont qu' une partic de leur corolle velue, par exem- 
ple la suture de la earène dans le Gompholobium barbigerum.

BARBLLION, s. in., tentaculum; Fiillifade (all.); beurd (angl.). On désigne sous ee nom des filamens déliés, mous et flexibles, qui sont situés auprès des lìvres de eertains poissons, par exemple de l'esturgeon. Quelques entomologistes l'ont appliqué aux palpes des insectes; mais il est inusité anjourd'hui dans ee dernier sens. Dans le langage vulgaire, on nomme barbillon une sorte de manclon situé à l'orifice extérieur du conduit des glandes maxillaires du eheval, près du frein de la langue.

BALBINERVE, adj. , barbinervis, barbinervius (barba, barbe, nervus, nerf). Se dit, en botanique, de quelques plantes qui ont les nervures de leurs ferilles garnies de poils en dessons, soit à l'extrémité seulement (ex. Laplacea barbinervis), soit dans toute lenr longueur, sur les côtés (ex. Palicourca barbinervia).

BARBIROSTRE, adj., barbirostris (barba, barbe, rostrum, bee); qui a le bec garni de poils. La Rhina barbirostra a la trompe couverte de poils. Une eryptogame (Spharia barbirostris) a ses ostioles alongés en forme de bec ou de massuc et pubescens.

BARBIPLDE, adj. , barbipes (barba, barbe, pes, pied); qui a les pieds barbus, comme les tarses postéricurs de l'Asilus barbipes.

BARBU, adj., barbalus, barbalis, barbatulus, cirrhatus; barthaaris, gebartet, bartig (all.); bearded (angl.) : barbuto, barbato (it.); qui a de la barbe. Se dit: $1^{\circ}$ en botanique. Celtc épithète est donnée ì toute partied'un végétal qui offre des poils disposés en touffes, comme les anihères du Ternstroemia dentata, les filets des ćtamines de l'Hydroplyyllum virginicum, le style du Salvia formosa, la gorge de la corolle du Chiococca barbata, l'exlérieur de la corolledu Microcorys barbata, les pétales alaires de l'Aconitum barbatum. Les botanistes l'employent quelquefois comme synonyme d'aristé.

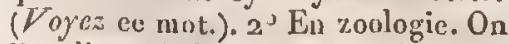
l'applique à des oiseaux qui ont le bec garui de soies à li base (ex. Sylvia barbata), ou le bas des joues de chaque côté nuni d'une sorte de moustache (ex. Psillacus barbalulatus); à des poissons dont la mâchoire infériemre porte des barbillons ou de lorigs filamens pendans (ex. Ophidium barbaum, Pimelodes barbus, Pristis cirrhatus); à des coquilles bivalves dout l'épiderme se divise en un grand nombre de pointes raides, eomme dans quelques Alehes ; ì des insectes dont les euisses antérieures sont garnies d'une epaisse touffe de poils (ex. Herminia barbulis), ou dont la tête est munie de poils imitant unc barbe (ex. Asilus pogonias).

BALBULE, s. f. , barbula (barba, barbe). Neeker appelait aiusi le petit eorps barbu, formé par la réunion des eils du péristomic soudés ensemble, qu'on remarque dans les mousses du geure Tortula. Les ornithologistes donuent aussi ce nom aux produetions cornées, courtes et eu forme de petits erochcts, qui garnissent les barbes des plımes, cliez les oiseaux.

BArBuLt, adj. , barbulatus; qui. est gurni de poils disposés en touffes, comune la base de la surface supérieure des feuilles du Pyxidanthera barbulata.

BARBULOHDES, adj. et s. f. pl., barbuloides. Nom donné par Bridel à une famille de Mousses, qui a pour type le genre Biarbula.

BAlabus, adj. et s. In. pl., Bar $\rightarrow$ bati. Vieillot désigne sous ee nom une famille de l'ordre des Sylvains, comprenant les oiseaux qui ont le lec garni de soies à la base, et Latreille 
une section de la tribu des Carabiques, à laquelle il rapporte ceux qui ont le côté externe des mâchoires cilié à sa base.

BARÉGINE, s. f., Baregina. Nom donné par Longcharnp à une substance, voisine du mucus aninal, qui se trouve dans les eaux minérales sulfureuses chaudes, par eouséquent dans celles de Barèges. Elle est plus connue sous celui de glairine.

BARIUI, s. m., baryum, barium, plutoniune (Bápos, pesanteur). Métal, découvert par H. Davy, qui fait la base de la baryte, et qui doit son nom, comme cette dernière, à sa grande pesanteur.

BARNADÉSIÉES, adj. et s. f. pl. , Barnadesiea. Nom donné par H. Cassini à une section de la tribu des Carlinées , par D. Don et par Kunth à une tribu de la famille des Syuanthérées, qui ont pour type le genre Barnadesia.

BAROMETRE, s. m., barometrum, barometron, tubus Torricellianus; Luftwaage, Schweremesser, Lufischweremesser, Wetcrglas, Lufidruckmesser (all.) ( $\beta_{\text {x́pos, pe- }}$ santeur, $\mu \varepsilon \tau p \varepsilon \dot{E} \omega$, mcsurer). Instrument, imaginé par Torricelli, dont on se sert pour mesurer la pression que l'air exerce sur un point qnelconque de la surface de la terre ou de la hauteur de l'atmosphère. Biot assigne $0^{\mathrm{m}} \cdot 7629\left(2.8^{\circ} 2^{\prime} 7 / \mathrm{ro}^{\circ}\right)$ pour bauteur moyenne du l,aromètre au bord de l'Oeéan, ì o 8 th. c. On a calculé quc la totalité de la pression de l'atmosphì̀re sur la surface entière du corps d'un homme de moyenne grandeur surpasse trente-trois millions de livres, chaque point de la surface d'un objet exposć à l'air étant pressé par celni-ci comme il le serait par le poids d'unc colonue d'cnviron trente-dcux pieds d'eau ou vingt-hnit pouces de mereure.

BAROMĹTRIQUE, adj., barome.

\section{BARY}

tricus; qui a rapport au baromètre. Se dit surtont des observations de météorologie faites à l'aide de cet instrument.

BAROUÚTROGRAPHE, s. m. , ba. rometrographium ( $\beta \mathrm{Bupos}_{3}$, pesantenr, $\mu \varepsilon \tau p \varepsilon$, mesurer, ypóxpe, écrire). Instrument disposé de manière qu'il inscrit lui-même sur un papicr les variations de la pression exercée par l'atmosphère.

BAROSA NÈME, s. f. , barosanemion ( $\beta$ x́pos, pesanteur, ävęus, vent). Instrument dont on se sert poir connaître la force d'impulsion du vent.

BAROSCOPE, s. m. , ba roscopiun

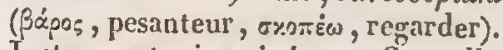
Instrunient, imaginć par Casswell, qui n'cst qu'un baromètre sensible à de très-légùres variations atmosphériques, ct par cela même applicable surtont aux usages de la marine.

BAlRIE, s. f. On appelle ainsi : $1^{\circ}$ en géognosic, un amoncélement de sable en travers de l'embouchure d'une rivière, et une ligne ou vague ćlevée, transversale, constante, quoique sujette à des mouvemens irréguliers, que produit le clioe des eaux des grands fleuves dcscendant avec une grande quantité de mouvement, contre les eaux de la mer qui rcmontent par l'effet de la marćc ; $2^{\circ}$ en zoologie (bars, angl.), un cspace plus ou moins grand, qui sépare les canincs des molaires, chez la plupart des mam. mifères, l'homme et l'anoplotherium exceplés. Vorez Drastome.

BARRnGTONIÉES, adj. et s.f. pl., Barringtoniece. Nom donnć par Candolle à une tribu de la famille des Myrtacées, qui a pour type le genre Barringtonia.

Bantraniones, adj. et s. f. pl., Bartramioidece. Nom donné par Fururohr à nu groupe de la famille des Mousses, qui a pour type le genre Bartramia.

BARYPLOTİRES, adj. et s, m.pl, 
Baryploteres (eapis, pesaut, thoshp, nageur). Nom donné par J.-A. liitgen à une familie d'oiseanx aquatiques, comprenant ceux qui se fint resuarquer par la maniére lourde dont ils nageut.

BARYTE, s. f., baryla, baryles ( $\beta$ xipos, pesauteur). On donne ce nom (barote; terre pesante; icrra ponderosa; Barylerde, $S$ chworcrde, Schwerspatherde, all.) au protoxide de bariun (Barrumoxid, all.).

BARYTICO-ARCIENTIOUE, arj. , barrtico-argenticus. Eppillète donnée, dans la nomenclature elimique de Berzelius, à un sel double qui résulle de la eombinaison d'un sel harytique avec un sel argentique. Ex. Fulminate barylico-argentique ( fulminate de baryte et d'argent).

BARYTICo-SODIQUE, adj. , barytico-sodicus. Épithite donnée, dans la nomenelature chimique de Berzelius, à un sel double prodnit par la eombinaison d'un sel barytique avec un sel sodique. Ex. Sulfale barysico-sodique ( sulfate de bary'le et de soude).

BAMYTIFine, adj. , bar)tiferus (baryia, baryte, fero, porter). Dinsla nomenclature minéralogique de lläty, cette épithète désigne des minéraux qui contiennent accidentellemeut de la baryle. Ex. Mangranc̀se oxidé barylifere.

Banytringue, adj. , barytiniczs. Fipithète donaće par Omalius ì un genre de roches pierreuses sulfatées, qui eomprend ta barytine, ou le sulfatc de baryte.

IBMISTIQUE, adj,, baryticus; qui a rapport it la baryte. Dans la nomenclature chiminue de Berzclius, on appelle oxide barytique le premier d.gré d'oxidation du barium on la baryte, ct scls burytiques les eombinaisons de ec métinl avec les corps éleetro-négatifs, ou de la baryle avec les acides.
Baryum. Voyez Barium.

BAS, adj. demissus. On appelle basse mer, la fin du reflux. Les botanisies, d'après Mirbel, appliquent cette épithete à la radiculc, quand elle se dirigge vers la base du fruit (ex. Plantarga stricta). En zoolngie, victere bas se dit d'une femelle d'animal," lorsqu'elle fait ses petits. On dit anssi que le eerf met bas, lorsque son hois tombe au printemps.

BASAL, adj, , basalis (baris, base). L'llalomya basalis est ainsi appelée parce quie son abdomen noir est rouge i) la base : la Clidonia basalis paree que ses ailes elaires sont noires à la base.

BS.ILTIFORvE, adj. , basaltiformis; qui ressemble au bissalte, qui s'en rapproche par ses qualités extéricures, comme le grïnstein basaltiforme par son aspect îpre et terne.

DASALTIGWNe, adj. , basaltigenus; qui maît et eroît sur les roches Hissaltigues on basaltiformes. Ex. Lecirlca basaltigena.

BASALTIQLT, adj., basalicus ; qui a rapport all basalte, qui en est formé ; agrégation, chaussée, éruption, filon, lave, pie, rocke basaliqque. Sons le uom cke terrain basaltique, Omalius forme un groupe ayant pour carietère le plus marqué d'ètre principalement composé de basalte.

VBSILTOHE, adj., hasaltoïdes; qui a l'apparence ou l'aspect da basalte. Ex. Diorite basaltoüde.

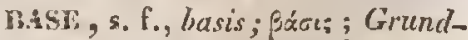
friche (all.) ( Privas, marcher). Ce snot a un grand nombre d'acecplious diverses dans les seienees physiques. $1^{\circ}$ En chinie. Envisagé d'une manière générale, il a servi à désigner toute substance qui entre dans une combinaison en conservant sa nature primitive, ou du moins quelques uncs de ses propriétés primoriliales, et forme la partie la plus solide, la plus fixe, seuvantla plus alsoudante ou la plus 
caractéristique de cette combinaison. On ne l'cmploye plus dans ee sens vague et contraire aux données aetuclles de la seience. On s'en est servi ensuite pour désigner non senlement tout corps comprosé qui est susceptihle de neutraliser plus ou moins complètenient les propriétés des acides, mais encore toute susbtanee, simple ou eomposée, qui acquiert les proprićtés d'un acide en s'unissant à l'oxigène, à l'hydrogène ou à tout autre corps. Dans ce dernier sens, base est synonyme de radical, dont on fait bien plus fréquenunent usage. Aujourd'hui, depuis l'introduction de la théorie électrique en chimie, on entend par base tout eorps qui, dins une combinaison donnće, joue le rôle électro-positif, quoique, dans d'autres composés, il puisse joner celui d'élément électro-négatif , comme il arrive à l'eau, par excmple, dans ses combinaisons avee l'acide sulfurique d'une part, avec les oxides mćtalliques de l'autre, ou ì l'oxide manganique dans celles avec les oxacides d'un côté, avec l'oxide manganeux ct les alcalis de l'autre. $2^{\circ} \mathrm{En}$ géognosie. L'espace occupé par unc montagnc est ec qu'on nomme sa basc. On appelle aussi base d'une roche, celle de ses parties constituantes qui y prédomine toujours, et très-sensiblement, par sa quantité et ses qualités, comme le mica dans le micaschiste. $3^{\circ} \mathrm{En}$ botanique. On doune le nom de base au point par lequel un organe tient à sou support, et par où passent les vaissenux dc celui-ci qui s'y distribuent; quelquefois aussi au support d'un fruit. Ainsi la base d'un péricarpe est indiquée par le centre de son point d'atlache ou par son extrúmité la plus voisine du pédoncule, et celle de la graine l'est par le hile. Ad. Brongniart appelle encore ainsi le tubereule que certai- nes Fusidices font unitre sur le végé- tal qui les nourrit, dont la surface porte les sporidies, qui paraît souvent indépendant du champignon, et qui semble être alors un développement de la plante même. $4^{\circ}$ En zoologic. Ia base d'une coquille univalve, suivant Linné et la plupart des conchyliologistes, est. l'extrémité opposée au sommet, la coquille étant placée rerticalement, le sommet en haut et l'onverture en devant; selon la manière de voir plus rationnelle de Blainville, e'est la partic toutc entièrc qui appuye plus orz moins obliquement sur le dos de l'animal, celle dans laquelle est percée l'ouverture, et qui se trouve ordinairement opposée au sommet. Les entomologistes donnent le nom de base à l'origine des ailes, des élytres, des balanciers, des antennes, au haut des cuisses et des jambes, chez les inscctes, et à la partie inférieure de l'aiguillon des hyınénoptères.

IBASí, adj. Épithète donnée, dans la nomenclature minéralogique de Hatiy, a un cristal dérivé d'une forme à sommets pyramidaux, dont chnein cst remplacé par une face perpendiculaire à l'axe, faisant fonetion de hase. Ex. Plomb molybdaté basé.

BASIAL, adj. et s. m., basialis. Sous ce nom, Robincau-Desvoidy désigne 111 corps impair, qui est la pièce ceutrale des neuf dont se compose la vertèbre des animanx articulés.

BasicITÉ, s. f. , basicitas. Fitat de ce qui est base. On dit qu'un corps est docié de la basicité, quand il a la propriété de jouer le rôle de base dans certaines conbinaisons, ou mêtne dans toutes.

Basificatrion, s. f. Acte parlequel un corps passe à l'étit te base. On appelle degrés de lasilieation d'un corps celles de ses diverses combintiisons définies ayee un autre corps 
qui, dans les composés, jonent le rôle de basc ou d'ćlément électropositif.

BASIFIXE, adj., basifixus. Se dit, en bolanique, d'après Mirbel, d'une partie qui est atlachée par sa base. liantliere lasifixe tient au filet par son extrémilé inférieure (ex. Iridées). Le Placentaire basifixe ue tieut qu'a la base de la paroi dis péricarpe, i l'ćpoque de lít maturitó (ex. Primula).

BASIGENE, adj., basigenu.s (basis, base, seno, engendrer). Berzelius donne cette épillic̀te aux corps électro-nigatifs qui ne neutralisent pas les mélaux, et produisent an eontraire avee cux des composés ćlectronégatifs (acideś) et électro-positifs (Lases), commel'oxigène, le soufre, le sélénium a le tellure.

BASIGINE, s. m., basigynizm

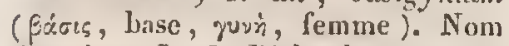
donné par L...C. Richard au support du pistil, quind il est dû au prolongement aminci de la base de l'ovaire et ne s'articule point aree lui. lix. Capparis. Voyez Gynophore.

BASILAIRE, adj. et s. m., basilari.s (basis, base ). Nom donné par Straus à l'une des six pièecs du crâne des inseetes, celle qui oceupe la parlie pos'éricure et inféricure de la tête.

BASILAIRE, adj. , basilaris, basalis; grundsï̈ndig (all.) : basilare (ii.); qui est placé à la ba:e d'une partie queleonque, qui y prend naissanee. On dil: $1^{\circ}$ en holanique, $a p-$ pendice basilaire, ceini qui est fixé ì la lase d'mu organe; arcole basilaire, d'après 11. Cassini, edle qui, dans l'ovaire des Synanllérées, occupe la base du péricurpe fulu; boterrelet basilaire, d'apres le mêuse, celui qui entou'e souvent l'aréole; aréte basilaire, dans les Graminécs, relle yui se fixe a la base de l'écaille par laquelle elle cst supportée (cx. Poly- pogon ); déliseenee basilaire, d'après Candolle, celle qui a licu quand les enrpelles sont plus sundées par le som. met que par la base, ct sc séparent à la maturité par leur cxtrémité in lérieure (ex. Cuscuta); embryon basilarie, celui qui cst logé tout entier daus la portion du périsperme la plus voisine du hile (ex. Omliellifères); placentaire basilaire, celui qui oecupe la base de la cavité périearpienne (ex. Berberis); slyle basilaire, celui qui naîl à la base de l'ovaire (ex. Hirlella perusiana). Trinius donne le nom d'écailles basilaries ou extonium à la glune ealicinale des Gramiuées i épillets multiflores. $2^{\circ}$ En zoologie, arcoles basilaires, dans l'aile des insectes, eelles qui sont parallèles à la base. Ia Iimnobia basilaris est ainsi appclée parce que ses ailes brunes sont jaunes at lil base.

BASIL.í, adj. , basilalus. Les botanistes, d'après Mirbel, appellent poil basilé eclui qui est élevé sul" une bise, sur un manclon eelluleux. Ex. Urlica dioïa.

BASIXERVÉ, adj., basinervis ( basis, base, nerpus, nerf). Epithète dounée par les botanistes aux feuilles dont les nervures parlent de la base et se dirigent ver's le sommet, sans épruuver de division sensible. Ex. Gramines.

BASIQUE, adj. , Lasicus. Autrefois les chimistes appelaient sels basiques, avec Berthollet, ecux qui exereent une réaction alealine, ou du moins contiennent plus de base qu'une autre comlinnison díji neutre des denx mênes substanees. Anjourd'hui, on domne ec nom, d'apr'is L. Grolin, ì tout sul dans leguel plusicurs poids allomiques de la base soull combinćs avec un seul poids atomique de l'aeide, ou, sclon Berzelius, à cenx dans lesqucls l'oxigcine de la lase est muliple ì un degré quelconque de 
celui qui entre dins l'acide. Ce deruier chimiste applique aussi la mène épithète aux sels ltiloìd's noulres conthiues avecl'oxide du mèıne métill.

BASISOLUT'́, adj. , basisolutus (basis, basis, solvo, délaclier). Se dit, en botanique, d'une partic qui est prolongée par sa basse. Oll emploie rarement ce terne. Une feuille basisolutée est celle dunt la base se prolonge en uu prtit appendice non adhérent. Ex. Sedum reflexum.

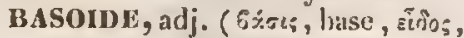
ressemblance). Lipithète donnée, dans 3a nomenclalure minéralogique de Haüy, a un prisme bipyramidé, dont une des faces de chaque pyranide a pris beaucoup plus d'ae:r'oissement que les autres, en sorte que le cristal se présente au prenier aspect sous la forme d'un prisme terminć par nue basc oblique. Ex. Quarz prismé basoüde.

BASSIV, s. m., pelvis; Becken (all.). On nomme ainsi : $1^{\circ}$ cu géognosie, une surface de termin plus on moins étendue où les eaux, suivint des versans divers, finissent par se réunir en un seul canal, qui les conduit soit à l'océan, soit ì unc mer intérieure ou a quelgne lac; $2^{\circ} \mathrm{cn}$ zoologie, une ceinture osseuse servant d'attache aux membres qui forment le bas ou l'arrière dis trone, et ainsi appeléc, chez l'houme, à cause de sa figure, chez lez alutres verlébrés, à eause de l'analogiè qu'clle présente toujours daus sil composition, malgré les diversités infiuics de ses formes.

Bassonne, s. fo, bassorina. Vauqueliu a désigné sous ce nnm le mueilagc végétal qui existe dans la gomme de Bassora, et qqui, lorsqu'on traite cettc dernière par l'cau, reste sous la forme d'une gelée goonlléc.

B.ASSOUITE, s. fi. Nom donné par Guibourt à la bassorine.

BaS-VENTRE, s. m., alvers. Terme poptraire, dont on se sert particulierement pour dósizner la partie inl'ciricure de l'aldumen, ou l'hypoystre, cher l'bomme.

BAT. Voyez Clit fllum.

BATARD, adj. ct s. m. spurius, adullerinus; bastard (all. angl.); bastarto (it.): qui u'est point légitime, qui n'rst pas de bonne espéce, qui ticnt de diux cspèces différentes. Ori emploie plus souvent le mot liybride, en botanique, et méris en zooloric. L'aileron (vojez $\mathrm{ec} \mathrm{mot}$ ) est quieliquelois appelé ailc uâtarde. Sons le nom d'amphilbies bätards ou facax (Amphibia spuria) Schneider avait établi mue lamille d'amphibics comprenant les poissons entlilaginenx. Ie Passiflora adulterina est ainsi nommé parce que la lorme de son calice et de sa corolle diffíre de celle qu'ont ces parties daus les autres esperes don genre.

B.1TŔMAECTORES, adj. ct s. m. pl., Batcralecturcs ( $\beta a r i n$, marcheur, $\dot{\lambda} \lambda \dot{\varepsilon} \%=\omega$, , cor ). Nom donuć par J.-A. Ritgen is unc famille d'oiseaux, comprenant lis Gallinacés ordinaires ou unarcheurs.

BATÉRAPTODACTYLS, adj. et s. m. pl., Bateraptoductyli (6xisp,

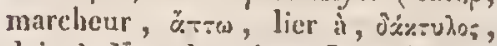
doigt ). Noin donné par J.-A. Ritgen à une fanille d'oiscanx, qui, conme les perroquets, marchent et ont des doigts propres it suisir li's corps.

B.1TÉROCIIOHOPTÈNES, adj. ct s. m. pl., Batcrochoropteni (Farrio,

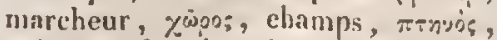
volatile). Nom dlonné par J.-A. Rituren ì nue fiumille d'oi eanx, compremant les Gallinacés ordiuaires, qui vivent dans les champs, et qui narchent.

BATroustuE, s. m., bathome-

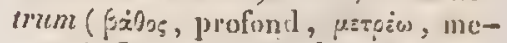
surer). Instrument qu'on a nroposé de substituer i la sonde ordiuaire, pour mesurer de crantes profondear's rlans la mer. 
BATHYRHYTQUE, adj. , bathy-

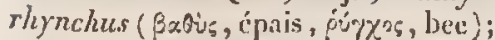
qui a le bee ćpais. I.e Larus batyrlyyncluzs est ainsi appelé parec que son lec prísente une bosselure de chaque côté , près de la pointc.

BATRACHOCRIPHLE, adj. , batrachoccphaluss ( $\beta$ si-poxp; grenouille, xżqzìn, têtc); qui a unc tète seınblithle à celle d'une grenouille. Ex. Gobius batrachocephatus.

BATRACUOGHAPHE, s. in. , batracloggraplius (fótpayss, grenouille, "yófus, écrile) ). Naturaliste qui s'uccupe spécialement des grenouilles et animanx voisins.

BATRACIOIDES, adj. ets. m. pl., Batrachoüdes. Nom donnć par Blainville ì une familic de poissons, qui a pour type le genre Betrachus.

BATMACHOPHDEs, adj. $\mathrm{ct} \mathrm{s} . \mathrm{m}$. pl., Batrachophides ( f́xтpayos, grenoville, öts, serpent). Nom donné parr Ficinus, Carus et Latreille à une division de l'ordre des reptiles opbidiens, comprenant ceux qui tiennent des Ophidiens par la fornic de lenr corps et des Balraciens par leur peau surs écailles, lisse el virqueuse.

BATRACHOSPEn!:ÉES, adj. et s. f. pl., Batrachospermea. Nom donné par Reciehenbach à une tribu de la famille des Nostochinées, pir Agardh à une fimille de l'ordre des Confer voïlées, par Friers a une trilu de la fimsille des Hydrophycces, qui ont pour type le genre Bairachosperma.

BATRACIENs, ulj. et s. in. pl.,

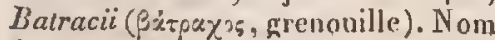
dounć par Cuv ier, Duméril, Goltlluss et Eichwald a un ordre de la classe des reptiles, par Blainville à un ordrc de celle des Amphibiens, et par Merrem à nne clisse du rigne aninal, coupes diversement délimitées par ces différensauteurs, et qui toutes ont pour type le genre Grenouille. Cette coupe, primitivement indiquéc par Laureuli, a été ćtablic par
A. Brongniart sous le nom et avec les limites que lui atssigne Cuvier. Elle vient d'etre l'objet d'un travail important de Muller.

BATr'TANT, s. m., valva. Ce nom est quelquefois donné par les conchyliologistes aux deux pic̀ces de l'enveloppe calcuire des nollusques acéphules, et par les botanistes aux val res des capsu!es plurivilves. C'est aussi cclni des deux pièces mobiles qui garnissent l'avant et l'arrière dn plisirnn dans quelques Chéloniens.

BAUERACís, adj. et s. f. pl., Baucracea. Nom donné par Lindley ct Kunth à une famille de plantes, qui a pour type le genre Bauera.

Bausréses, adj. et s. f. pl., Bauerex. Nom donué par Candolle ì une tribu de lia famille des Saxifragćes, ayant ponr type le genre Bauera.

BACGE, s. f. Gîlte du sanglier. Nid de l'écureuil.

BDALLIPODOBATRACIENS, adj. et s. m. pl., Bdallipodcbatrachii

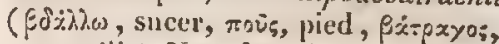
grenouille). Nom doıné parJ. -A. Ritgen à unc famille de reptiles, comprenant ccux qui, comme les rainettes, ont les doigts des pattes armés de ventonses.

BDELLAIRES, adj. et s. m. pl., Bicllaria ( fixizia), sueer). Nom donné par Blainville à une famille d'rotomozoaires apodes dont la locomotion s'exécute an moyen de ventouses placées aux deux extrénités du corps, comme dans les sangsues.

BDELLIEXNEs, adj. et s. f. pl., Bdelliance. Nom donné par Saviguy á une section de la faunille des Hirudinées, qui a pour type le genre Bdclla.

BEAU, adj. Ce mot, fréquenment cmployé contume nom spéeiligue, est renlu en litin par toutes les cxpressions celpables de peindre les diverses nuances de l'idéc qui s'y rattache, et dont vaici quelques unes : Kolbia clegans, Gnuphalium eximium, Gus- 
tavia augusta, Maclridea pulehra, Poineiana pulcherrima, Psillacus pulelellus, Platylobium formosum, Pipra superba, Orobanche insignis, Tifolium orratum, Turdus splcndidus, Wallichia speetabilis, Maca. cus speciosus, Columba magnifica, Psittacus venustus, Mcsem bryanthemum mieans, Tachyphonus somptuosus.

BEC, s. m., rostrum; ṕryxss; Schnabcl (all.); beak (angl.); becco (it.). On appelle aiusi : $1^{\circ}$ en botanique, d'après Jacquin, une pointe dressée qui surmonte les corries par lesquelles se termine le capuchon der Stapelia; $2^{\circ}$ en zoologie, les prolongemens eornés qui eonstituent la bouehe des oiseaux; une proéninence qui ressemble à celle-lá, pour la forme et pour la substanee, daus l'Ornithorbynque, certains poissons, les tortues et les eéphalopodes; une avanee cornće, dure el amineie, au hout de laquelle sont plicćes les parties de la bouehe dans eerlaius inset:tes (ex. Leptura rostrata, Ly'cus proboscideus); l'espèce de sucoir qui est propre aux insectes hémiptères.

BEG-MovGues, s. f. pl. Nom donné par Duméril à une famille d'insectes diptères dont le front se prolonge en une sorte de bec ou museau. Voy. Hydromses.

BLCQUiLLON, s. m. $\mathrm{O}_{12}$ appelle ainsi le bee des jeunes oiseaux de proie. Les flenristes donnent le mème nom, ou celui de béquillon, aux petits pétales qui, dans les anémones donbles, remplaeent les pistils.

BĹGONICÉES, adj. et s. $\uparrow$. pl., Begoniacere. Nom inposé par Bonpland et Kunth ì une famille de plantes, qui a pour type le genre Begronia.

BSELEWLET, s. m. , balatus; Blïlen (all.); bleating (angl.); belamento (it.). Crides béliers, des che- vres, des brebis, des moutons et des agncaux.

BĹLEMNITIQUE, adj., bclemnitieus; qui a rapport ou appartient aux Bélemnites. Matière bélcmnitique.

BĹLEMNitologie, s. f., lelemnitologia. Terme dont Faure Biguet s'est servi pour désigner l'hisloire nirturelle des Bélemnites.

IBÉLIDES, adj. et s. m. pl., Belides. Nom donné par Schœuherr à un groupe de la famille des Cureulionides, qui a pour lype le genre Belus.

BELIERS; s. m. pl., Arietes. Sous ee nom Detuch désignait une tribu de la famille des Ammonées, compreuant eclles qui ont le dos caréné et bosselé, ce qui les fait ressembler à une corne de bélier.

BELLID ́́ES, adj. et s. f. pl. , Bellidea. Nom donné par H. Cassiui à une seetion de la tribu des Synanthérées astérées, ayanl pour type le genre Bellis.

BELLUE, s. f. pl., Linné désignait ainsi un ordre de la classe des Mammifères, comprenant le cheval, l'hippopotame, le eochon et le rhinocéros.

BÉLOGLOSSES, adj. et s. ni. pl.,

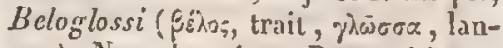
gue). Nom donné par Ranzani à une fimille d'oiscux grimpeurs, comprenant ecux qui, comme les pies, ont la langue lombrieiforme, trèslongue et protraetile.

Beluistés. Voy. Belvisiacées.

BELTISIACÉES, adj. et s. f. pl., Belsisiaceer. Nom douné par Kunth, d'après R. Brown, à la famille des Napoléonces, en raison du genre Belvisia, dénomination substituée par Desvaux à eelle de Napolcona, qu'avait introduite Palisot.Beauvois, auleur dc ee genre.

BEMrícides, adj. et s. nı. pl., Bcmlecidcs. Nom elonué par Goldfuss, Latreille et Eichwald à une trilu d'inseetes hyminopteres fonisseurs, qui a pour lype le goenre $B c m b c x$. 


\section{BERO}

BÉNTTIERS, s. m. pl. Sous te nom, La in inck et Schweigger désignent une fanille de l'ordre des Acéphates conehilères, rcufermant l:ı plus grande et la plus pesante des coquilles connues, la Tridacna gigas, dont le poids va jusqu'ì einc cents livres, et dont sont formés les bénitiers de l'église de Suint-Sulpice, donnés à Trançois Ier par la république de Venise.

BENZOATE, s. m., lenzoas. Genre de sels (benzocsaure Salze, all.), qui sont produits par la eombinaison de l'acide benzoïque avec une base salifiable.

IBENZOIQUE, adj., benzö̈cus. Nom d'un acide (Benzocsiïure, all.), obtenu dès 1608 par Blaise de Vigenère, en distillant le beujoin, et d'un éther (Benzocäther, all.), décourert par Seheele, qui se prépare en distillint ensemble de l'aleool, de l'acide benzoïque et de l'acide hydroehlorique.

BERBfiridéES, adj. ets.f. pl., Berberidea. Non dunné par Jussieu à une famille de plantes qui a pour type le genre Berberis.

BERBERINL, s. f., berberina. Substanee particulière, extraetive, azotée, jaunc et amère, que Buchner et Herherger ont truuvée dans la racine $\mathrm{du}$ Berberis vulgaris.

Béndeviciotes, adj. et s. m. pl., Berenicidei. Nom sons lequel F. Escheuholtz désigne une famille de la classe des Aealèphes, qui a pour type le geure Berenicc.

BERGE, s. f., molcs. On désigne ainsi un terrain qui borkle un eours d'enu, quand il présente des bords csearpés.

Bknoús, s. in. pl. Nom donué par Goldfuss à une famille de l'ordre des Médusines, par Ficinus et Carus is un ordre de la classe des Aealephes, par Eichwald à une famille de celle des Cyclozonires, compes qui toutes ont pour type le genre Beroe.
BÉTU

$15 \mathrm{c}$

BẺKOIDĹs, adj. et s. in. pl., Beroidu. Sous ce nom Rang et Eschenholiz désignent un ordre de la famille des Acalèphes, ayant pour typo le genre Berac.

BBRTUOLEMU:TRE, s. m. , berthollimetrum. Quelques ehinistes ont appelé ainsi le Chloronière. $\mathscr{V}_{\text {oy }}$. eet mot.

BER'riḱnÉES, adj. et s. f. pl.; Bertierea. Nom donné par A. Richard à une tribu de la fanille des Rubiacées, qui a pour type le genre Bertiera.

BĹRlLLÉ, adj. Les physieiens donnent eette épithète à la double réfraction, quand le rayon extraordinaire est écarté de l'axe et situć entre lui et le rayon ordinaire, eomine dans le béryl.

BERYLLUM, s. m. , berylïum. Fom donné par les Allemands, en raison de son existence dans le béryl, au glucium (vo)" ce mot), et qui conviendrait micux que ce dernier, le plomb, l'yttria et l'oxide cércux produisant également des sels sucrés.

BlísIMENCE, s. m., besimen. Nom imposé par Neeker aux corpuseules reprothicleurs des plantes agames.

BISIĹRIĹES, adj. et s. f. pl., Besleriece. Nom donné par Bartling à une tribu de la famille des Gesnériées, qui a pour type le genre Besleria.

BESTIAUx, s. m. pl., Pecora. Sous ee nom Jinné et G.-C.-C. Storr ont désigné un ordre de la classe des Mammifères répondant à eelui qu'on appelle anjourd'hui Ruminans.

Bútonte, s. m. C'est le nom par lequel on désigne vulgairement des eavilés ou trous coniques situés sur les bords ou au fond mène d'une rivière, dont les eaux s'y enfoucent et s'y perdent, le plus souvent en partic seulement, mais quelquefois aussi en totalité.

BítULACÉES, adj. el s. f. pl., Betulacex. Nom douné par Marquis 
à une famille de plantes, qui a pour type le genre Betula.

BÉTULINE, s. f., betnlina ; Birkenkampher (all,). Sorte de stéaroptène, ou d'huile volatile solide, que Lowilz a découvert dans l'épiderme du Betula alba.

BÉTULINÉES, adj. et s. f. pl., Betulinece. Nom donné par A. Richard et par Kunth à une famille de plantes, ayant pour type le senre Betula. Synonyme de Betulacies. Voy. ce mot.

BEUGLEMENT, s. In., boatus; Brüllen (all.); lowing, bellowing (angl.) ; maglio, muggrito (it.). Cri du bouf, de la vache. Synonyme de meuglement, mugisscment.

BEzOARDINE, s. l'. , bezoardina; $B c z o a r s t o f f($ all.). Jolıu désigne sous ce nom une matière parliculière qui forme la base des concrétions calculeuses appelées bezoards urientanx.

BEZOARDIQUE, adj. , bezoardicus. Cettc épithète a été donnée par Guyton-Morvenu à l'aciele urique.

BIA CUMINÉ, adj. , biaruminnuus (bis, deux, acumen, pointe). Épithe'te par laquelle les botanistes désigntent, d'apris Mirbel, lespoils à deux branches opposées par leur hase, de mavière qu'ils paraissent ètre attachés par le milieu. Ex. Malpighia urens.

biaiguillonvé, adj., biaculea. tus; qui porte dcux áiguillons, eonnme le Balistes buaculcatus, poisson dont ehaque nageoire ventrale est armée d'un aiguillon.

BIAILÉ, indj., bialatus; aweifiugrelig (all.) (bis, deux, ala, aile). Épithite domice pal les holanistes aux fruits qui sont garnis de drux ailes ou appendices incmbraneux. Ex. Dodonara bialata. Voyez DiptíuE.

BIALUMINIQUe, ndj., bialuminicus. Nom donné, daus la nomenclature chinique de Berzelius, aux soussels à base d'alunine dass lesyuels l'oxigène de la base est unulti- ple par deux de eclui de l'acidc. Ex. Sulfate bialuminique.

BIAMIONLCAL, adj., biammoniacalis. Se dit d'un sel qui eonticnt de l'ammoniaque multiple par deux de son acide. Ex. Sulfate argentique biammonincal.

BIANGULí, alject. , biangulatres (bis, deux, angulus, angle); qui est muni de denx arigles. Ex. Arca biangula, T'ellina biangularis.

BINTHÉnIFERE, adj., biantlerifcrus (bis, deux, authera, anthère). Les holanistes donnent ce nom aux filets des ćtamines, quand ils supportentdeux antheres. Ex. Melhania decanthera.

IBLNTHYONATE, s. m., biantimonias. Nom douné, dans la nomeneliture chimique de Berzelins, aux sursels daus lesquels l'oxigine de l'acede antimonique est multiple par deux de eelui de la hase. Ex. Biantimoniate potassique.

BrapiCULE, adj., biapiculatus (bis, denx, apiculus, sommel). II. Cassini donne cette épibcite aux poils de l'ovaire des Synanthérées, qui sont le plas ordinairement fendus ou échanerés au soinmet.

BIARISTÉ, adj., biaristatus (bis, deux, arista, arète). Les botanisles désignent ainsi les stipules, quand ellas sont terminces par deux prolongemens en firme de soie. Ex. Psychotria biaristata.

BIARSF́nIATE, s. n)., biarscrias. Nom douné, dans la nomenchature elimique de Berzelius, à des sursels dans lesquels l'oxigène de l'acide arsénique cit multiple par deux de celui de la base.

BIARTICULE, adj. , biarticulatus; zsveigliedrig (all.) (bis, deux, articulus, arliclo). Se dit, en zoologie, des antennes des insert's, quand elles sont lormérs de deux articles sculcmeut; de l'abdomen de ces animanx, quand il est dans lc mérue cas (ex. 
Nycteribia biariculata); et du bec de certiins héniptères (ex. Belostoma), lorsqu'it a la mème conformation.

Biatomeut, adj. , biatomicus (bis, deux, atomus, atoine). Se dit, dans la nomenclature ehimique de Berzelius, d'un corps qui, ayant la mêue eomposition qu'un aulre, renferme, sous un meme volume, un nomlire double d'alounes simples. Ex. Carbure dily driquic bialonique.

BLURICULL', atj , biauriculatus, biauritus bis, deux, auricula, auvien e); qui est muni de deux appendicesen forme d'a u ricules, conne li's valves de l'Ostrea biauriculata, ou comme le Ptcris biatrita, fougère dont les pinuules inférienres sont doublu's el en forme d'oreill's.

BIAXIF Ėre, adj. , biuxiferus (bis, deux, axis, axe, fero, portar ) ; qui a deux axes. Turpiu ippelle infloresecnce biaxifore celle qui présente deux axes ou deux degrés de végélation. Ex. Anethum Foniculum.

BIBASIOUE, adj., bibasicus (bis, deux, basis, base). Nom douné, dans la nomenelature ehimique de Berzelius, nux oxisels qui contien-. nent deux fois autant de bise que les mêmes sels ì l'état neutre, ou à des sels halrindes résultant de la combinaison d'un atome du sel neutre avec deux atomes de l'oxide du mème radical.

BIBINAIRE, adj. , bibinarius (bis, deux, binarius, double). Nomdon né, dans la noinenelature minéralogique de Haiiy, ì un cristal produit en vertu de deux décroissemens, l'un et l'antre par deux rangées. Ex. Chaux carbonatec bilinaire.

Bibivo-ANiulaire, adj. , bibino-annularis (bis, delix, hinarius, doul,le, anriulus, anneau). Nom donné, dans la nomenclature minćralogique de Hiaiiy, ì un prisme hexä̈dre régulier, dont la base est entourće de six faeettes également inclinées, eł produites en vertı de deux décroissemens pir deux rangées, l'uu sur lesi bords, l'autre sur les augles de bá mème basc. Lix. Mica bibino-annulairc.

BIBISALTLR.v', adj. , bibisaller-o nus. Nom douné, daus la nomenclat ure minébalogiçue de Haüy, à un prisme hexaëdle régulien avee six ficcettes obliques, situres au contour de chaque base, sur deux rangs, et qui allernent par rapport tant aux pans qu'anx fices de f'autre rommet. Ex. Mercure sulfuré bibisalterne.

iBmonATE, s. m., bibnras. Nom donue, dans la nomenelature ehimique de Berzelius, à des sursels dans lesquels l'uxiggène de l'acide borique est multiple par deux de eelui de la base.

BrBOSSU, adject. , bigibbus; qui porte deux bosse's. Le Kyphosus bigibbus en a nuc entre les yeux, et une autre sur la minue.

BIBncctóotê, adj., bib-àctcolalus; qui est muni de deux hractéoles.

BDBRACTETĹ, adj., bibracieatus; qui rst muni de deux bretées. Ex. Nelensia bibractcata, Mclastoma bibracteatum.

BICALENUX, adj. , bicallosus (bis, deux, callus, cal); ( qui est muni de deux callosités. Ex. Diplecthrum bicallosum.

BICAPSULAInE, adj. , bicapsularis (bis, deux, capsula, crapsulc). Se dit du fruit, quind il est formé par la réunion de deux capsules. Ex. Cassia bieapsularis.

BICARBONATE, s. m., bicarbonas. Nom donú, dans la nomenclature chimique de Berzelius, à des sursels flans lesquels l'oxigène de l'aeide carbonique est multiple par deux de relui de la bise.

Bicanisow, adj., bicarbonatus. On appelle gaz liydrogéne bicarboné le secrod degré gazeux de carbona- 
tion de l'hydrogène, eclui qui congient deux fois autant de carbone que l'autre.

\section{BICAMbURE, s. m., bicarbure-} zum. Carbure dans lequel la proportion du cirlone est double de celle qui existe dans un antre. Faraday appelle bicarbure dihydrogéne un corps que Berzelius nomme carbure dihydrique triatomique, et qui a la mène composition que le giz oléfint, mais renferme, sous un mème volume, un nombre triple d'atomes sin. ples.

BICARÉNÉ, adj., bicarinatus (bis, deux, carina, earène); quiest marqué de denx carènes, eommela valve inférieure de la Grypheca bicarinata. Raspail donne cetté épithite à la pitillettesupérieure des Graninées, quand elle est marquée de deux nervures placées plus près des bords que du centre, ou à une égale distanec l'une de l'autre.

BICAUDE, adj. , bicaudalus, bicaudalis; zweischwünsig. (all.) (bis, deux, cauda, queue); qui a denx queues ou deux appendices eandiformes. L'Oniscus bicaudntus a le corps terminé par deux appendiees aussi longs que lui ; la Perla bicalldata porte deux longs filets à l'extrímité de l'ahdomen; l'Ostracion bicaudalis offre deux aiguillons au-dessous de la queue.

BICERGLÉ, adj., bicinctus, bicingulatus; qui oflice deux raies colorées en forme de eercles; comme la Ganga bicincıa, qui a deux colliers demi-eirculaires remontant sur ledos; lc Trochus bicingulatus et la Tiurritclla bicingulnta, dont les tours de spire offrent deux bandes colorées au milieu.

BICIROMLTE, s. m., bicliromas. Nom donné, dans la nomenelature chimique de Berzelius, à des sursels daus lesquels l'oxignène de l'acide ehromique est multiple par deux de eclui de la base.

BICIPITÉ, adj., biceps; zwciköpfig (all.) (bis, deux, caput, tête). Se dit, en botanique, de la carene des légumiueuses, quand les deux pièees qui la constituent sont soudées par le haut et libres par le has.

BICLAVÉ, adj. , biclavalus; doppelukculig (ill.) (bis, deux, clasus, clon). Un insecte hémiptère (Pachly's biclavatus) est aiusi appelé paree que lus deux avant-derniers artieles de ses antennes sont épais à l'extrúmité.

BICOLLIGE, adj. , bicolligattus; doppeltgelteft (all.) (bis, deux, colligro, ramasser). Illiger donne eette épithète aux pieds des oiseaux, quand les doigts antérieurs sont réunis à la lase par une membrane. Ex. Cigogne.

BICOLOR, adj. , bicolor, bicolorus, dicolorus; zweifirbig (all.) (bis, deux, color, conleur). Ofrrant deux coulcurs bien tranchées, comme le Holcusbicolor, qui a les ealices noirs et les semences blanches; le Tropceolum bicolorum, qui a deux pétales jaunes et trois rouges; le $\mathrm{Ca}$ ladium bicolor, dont le eentre de la funille verte est marqué d'une brillinte tache rouge; le MCsembryanthemum bicolorum, dont les pétales sont jaunes en dedans et pourprés à l'extérieur. Sc dit aussi d'un animal elsez lequel prédominent denx eouleurs prinejpales, comme le jaune ou l'orangé et le noir dans le Sciurus bicolor et le Rampliastos dicolorus. Voyez Dicirrome, Discolor.

BICOLOHINE, s. f., bico'orina. Non donné par Raab à une sulsstanee, cncore problématique, trouvée d'abord par Martius dans la teinture de quassia, la dissolution de sursulfate de quinine, ete., puis par George dans la teinture spiritueuse de stramoine, qui donne aux liqueurs dans lesquelles elle est tenue en dissolution la propriété de produire une eot- 


\section{$\mathrm{BICO}$}

leur bleue par réflexion, tandis qu'elles ne font paraître par transinission que celle qui lenr est propre.

BICONCAVE, adj., biconcauts. Se dit d'un corps plan, dont chacune des deux faces est exeavée; verrc biconcave.

BICONJUGAT0-PENNÉ, adj., biconjugato-pinnatus. Foycz BrDigrtíPENNÉ.

BICONJuGué, adj., biconjugatus (bis, dcux, conjungo, joindre). Epithète donnce aux feuilles dont le pétiole eommun cst bifurqué au somrmet, chaqure bifurcation portant une paire de folioles. Voyez Bigéminé.

BICONTOURE, adj., bicontorlus, bistortus; qui est tordu deux fois sur soi-mêtne, conme les légumes de l'Hippocrepis bicontorta $\mathrm{ct}$ la racine du Polygonum Bistorta.

BICONVEXE, adj., biconvexus. Sc dit d'un corps plan, dont les deux faces sont lombees ou convexes, comme les feuilles du Rochea liconvexa.

BICORDÉ, adj. , bicordalus (bis, deux, cor, cour). Un oursin (Ananchytes bicordata) est ainsi appelé paree que son test obovale offre une sorte d'échancrure à chaque extrérnité.

BICORNE, adj., bicornis; zuxeihörnig (all.); qui est terminć par ou garni de deux pointes semblables ì des cornes, eomme les antheres de l'Erica vulgaris, les capsules du Martynia proboscidca, la silicule du Thlaspi ceratocarfum, les cypsciles du Sylphium, le casque de l'Orchis bicornis, le chapcron de l'Osmia bicornis, l'abdomen de l'Aranca bicornis.

BICORNES, adj. et s. . pl. , $B i$ cornes. Nom donué par Linné à unc famille de plantes dont les élamines sont garnies de denx larges pointes, et parVentcnat ì la famille des Bruyères, dans laquelle cette partieularité est earactéristiq̨ue.
BICY

BICOSTÉ, adj., bicostatus, bicostalis (bis, denx, cosıla, côte); qui est marqué de dcux côtcs, on élćvations longitudinalcs, comme la valve supérieure de la Crenalula bicostalis.

IBICOUnt', adj. , bigeniculatns. qui oflie denx condes ou denx inflexions, comme la trompe de l'Ensine pralensis.

Brcounovili, adj., bicoronatus (bis, denx, corona, couronnc). H. Cassini donne ectte épithicte à la calathide des Synamthérécs, quand clle contient trois sorles de flcurs diffćrentes sous le rapport de la corolle, les unes intérieures, les autres externes, et d'inutres intermédiaires, ecs denx dernières formant une double couronne. Ia Voluta bicoronata est aitrsi nomméc parce que le sommet de chneun de ses tonrs porte une double conronue de dents.

BICURAAssts, adj. et s. m. pl., Bipeliata. Nom donné par Latrcille, Cuvier el Eichwald à une famille de l'ordre des Crustacés stomapodes, comprenant cenx dont le thoracide est divisé eu dcux boucliers, J'un antérieur, qui forme la tête, l'antre postéricur, qui répond à l'alvithorax.

BLGUIVIuQUe, adj. , bicupricus. Épithète donnée, dans la nomenelature elimique de Berzclius, à des soussels dans lesquels l'oxigène de l'oxide enivrique est mulliplc par deux de eelui de l'acide. Ex. Carbonatc licuivrique.

BICUSPIDÉ, adj. , bicuspidatus ; zix'cispitzig (all.) (bis, deux, cuspis, pointe); qui offre dcux pointes, comune le Jungrormannia bicuspidata, dont les frondules se terminent par uze échancrure bidentéc, et la $S \mathrm{cr}-$ tularia bicrsppidata, dont le polypiex rameux offere de petits nœuds bien distinets, formés de dcux cellules à pointes divergentes en dehors.

BIGYANATE, s. m., bicyanas. Nom domé, daus la nomenclature ehimi- 


\section{6}

B1DI

que de Berzelius, à des sursels dans lesquels l'nxigène de l'acide cyanique est multiple par deux de celui de la hase.

BDACTYLE, adj. , biakactylus (bis, deux, oxxtudos, doigt); yui a deux doigts. Mauvais synonyme de DuscTYLE.

BHDENTŔ, adj., biden.s, bidenlatus, bidentorius, bidentatis, biserratns; zueigezalint (all.). Se dit: $y^{\circ}$ en botaniqne, d'une partie qui offre sur ses boods des divisions plins ou moins profundes, d'où rísulteut denx saillies en forme de dents, par exemple des spathelles du Trilicum hybernum, des spaihrollules de l'Agrosiis canina, dis feuilles du Cambessedia bidentala el du Limndorum bidcnlatum; ou d'une partie, déjà dentće, dont les deuts sont flles-mèmes dentelées, comme le's fcuilles du Clidesmia biserrata. $2^{\circ}$ En zoologie. L'Hyperoodon bidenatum a deux petites dents en avaut de la mâchoire inférieure; le Falco bidentalus offre une double échancrure sur chayue hord de la mandibule supéricure; le Diodon bidentalus a le bec ariné de deux fortes dents; le Crypturus bidentorius a les mandibules garnies de dents a leurs extrémilés. On dit les anicnnes des insectes bideniecs, quand elles sont deuscées des deux côlés.

HIDENTIDĹES, adj. "'s. f. pl., Bidentidece. Nom dounć par Lessing à une section de la sous-triln des Sénécionidées héliantlićes, qui a pour type le genre Biderts.

BIDENTIGÈRE, adj., bidenligerus (bis, deux, dcres, dent, gero, porter). Illiger donne cetle épithète an bec des oiseaux, quand la mandibule supérieure est arméc laléralement de deux dents.

BIDIGITrí, adj. , bidigitatus (bis, deux, digilus, doigt). Ies botanistes sppellent ainsi unefeuille dont le pétiole commun se termine par deux

\section{BIFA}

folioles. Ex. Zygophyllum Fabago. BIDIGITI-PENNE, adj. , bidigitipinnalus. Eipithete donnce aux feuilles clout le pittiole commun porte à son sommet deux pétioles secondaires, le long de'squels les folioles sont allachérs. Ex. Aimosa purpuria.

B1DOUßLAN'T, adj., bidluplicans. Nom donué, dans la nomenclature minéralogique de Haiiy, à un cristal dout le sigue est composé d'exposans qui formeraicnt nue progression, si deu x d'entr'eux n'élaiını doulles. Ex. Chan carbonatice bidoublante.

BIDUCTULExx, arlj. , biductulosus. Se dit d'une feuilie sur laquelle on apercoil deux nervures. Ex. $P_{i-}$ lotrirhum biduculosum.

nuĺcessoxé, adj., biscutalus. Le Crocodilus bisculatus est ainsi appelé parce que sa nuque est armée seuleneut de deux grandes p'aques pyranidales sur son milieu.

BIEMBRYONE, adj., biembryonatus. Se dit d'une graine qui contient deux cmlsryous. Ex. SEsculus Hippocastanum.

BIÉPEIONx̌́, adj., bicalcaralus. Se dit d'un oistau dont le mâle a les tarses garnis de deux éperons (ex. 'Telraobicalcaratus), on d'une plante dont la corolle est munic de deux éperons ì sa base (ex. Corysantlics bicalcaraia).

BIÉPILLÉ, adj. , bispicalus. Dont les fleurs l'orment deux ćpis par leur disposition. Ex. Scirpus bispicatus.

BIílinleux, adj. , bispinosus; qui offie deux épines, comne le corselct de la Formica bispinosa, la partie moyenne de chaque côté du test du Gonoplax bispinosus, et la carapace de la Chely's bispinosa, qui est lourehue en alricre.

Búliémí, adj. , biercmalus. Nom domé par Mirbel à un fruit composé de deux érèmes, eomme le $c \hat{c}-$ nobion du Cerintle major.

BIFAREMANGHES, adj, et s. m. 


\section{BIIT}

pl., Bifaribranchia (bifariuts, double, Próv (xes, branchics). Nom donuć par Litreille à une famille de la elasse des Gastéroporles, comprenant cenx qui ont les branchics situées sur les deux eôtés inlérieurs lu corps.

BIFARLE, adj. , bifarius; zweireihig (all.). Se dil, on bolanique, des parties qui naissent ou se disposent en général sul deux faces opposées, en deux séries ou files, eomane les feuilles du Donax bifurius.

BIF ASCZḱ, adj. , bifascianus (bis, deux, fascia, bande); qui offre deux bandes eoloréts sur un fond d'une aulrc leinle. Ex. Cercopis bifnsciata, Myrmeleon bifassiutnu, Tabanus ditaria.

BIFENDU, adj-, bifissus (bis, deux, fissus, fendur). Isis Sicutella bifissa est nin actinozoaire dont le test offre deux entailles profondes.

BLEENESTR í, idj., bifenestraths. La Chiroscelis bifenestrate offre, sur le second anueau de son ventre, deux taches roussîtres, dont la dernière paraît ètre membraneuse, et non eornćc, comme le reste du corps.

BHFinE, adj , lifertus (bis, deux, fero, porter). Se dit, en minéralogie, d'un cristal dans lequel ehaque angle solicle et ehaqne bord de la Corme prinitive subit drux deroissemens (ex. Cuive gris bificr) ; en botauique, d'apris' Candulle, d'un végectal qui porte hleur deux fois dans l'espince d'un an.

BWWRIQUE, inljet., biferricus. Epithète donníe, dins la nomenelature chim: (que de Berzelius, à sles sousseis dims lesquils l'oxigène de l'oxide frique est multiple par denx de celni qui entre dims le sel neutre. Ex. Sulfate biferrique.

BIFEARUGINEUS, adjeet., biferruginosics. Bendaut appelle hydrosulfute biferrugineux le sulfulc lifer- rique naturel contenant de l'eau, ou pittizite.

RIFIDE, adj. , bifidus; astrispaltig: Se dit, en botunique, d'une partie qui est divisce jusqu'à moitic, nu it peu pres, en denx portions égales, eomme le calice du Pedicularis palusiris, les pétales du Draba verna, le style dir Salicornia, le stigmate du Salix allo, les antheres du Sparganium er ctum, l'arille du Latlyress palustris. I'Asilus bifidus a le deruier article de ses antennes tubulé ct eliargó d'une soie qui les fait paraitre lifiles.

BIFISSILE, alj., birimosus. Se dit des antheres, quand elles sont $\ddot{i}$ loges, et qu'clles s'ouvrent par une fente longitudinale placée sur le milieu de chaque loge (eas le plus ordinare ), nu par une fente transversalte (ex. lavasurlula).

BIFISTULEUX, adj., bifistulosus,: ziveirïhrig (all.). Se dit d'une feuille. qui offre deux cavilés diuns toute sa longneur. Ex. Tobelia Dortmanna.

BIflaABLLé, adj. , biflabellasiss (bis, deux, fubellum, éventiiis). Epithète dounce anx antennes des insectes, quand elles sont braretues de deux cốtés.

BIFLORE, adj. , biforus; zweiblïthig, zwciblümig (all.); bifloro (it.) (bis, deux, flos, llour); qui porte on qui renferme deux feur's, comme le pédoncule dn Mniaram bifornm, la cupule dn Fagus, li calatkide dn Senecio biflores, la glrtme de l'Aira caryophly-llea, la spathe du Nareisstus biftortus. Voyez D D the, Difcorigíge.

BIFOL1Ĺ, , idji., bifoülus, bifoliatus ; zweibliattrirg (alt.) ; bifillo. bifoglinto (it.). Se dit d'une plante dont la tige est garnie au milien de deux feuilies opposées. Ex. Orchis bifolia, Diplyyllum bifolium, Miruella diphiylia. Voyez DirurLes.

BHOLIOLS, arj., bifoliolatus. 
Se dit d'une ferillle composće, dont le pétiole comnum porte deux folioles. Ex. Cassia bifoliolata.

BIFOLIGUere, s. m. , bifolliculus. Fruit provenant d'un ovalire d'ahord simple, quii se partage jusgun'ì sa base en deux parlies, lesquelles devionnent deux follicules on boîles péricarpiennes, formées chacune d'une seule valve pliće daus sa longneur et soudće sur les bords. Lix. Apocynées.

BrFOnf, adj, , bifortes, biforatus, biperforatus; yni est peree de deux. trous. Les anthercs liforées sont celles gni s'ouvrent par deux pores (ex. Solanum). La Scutella bifora est un oursiu dont le lest offie deux ouvertures oblongues postérieures.

BIFOnís, adj. et s. m. pl., Bifora. Nom domné par Isatreille ầ une famille de Cirripiedes diloranches, dont l'opereule du tube est is deux battans.

BLORLPALLES, adj, et s. m. pl., Biforipalla (bifortus, biperforé , pallium, manteatu). Latreillc appelle ainsi un ordre de la elasse des Conchiferes, comprenat cenx dont le mantean offie deux ouvertures, l'une pronr le passige du pied, l'autre propre anx dijectiuns.

BHFOHNE, adj. , biformis ; doppeligestaltig (all.) (bis, deux, forma, forme). Eppithète donnée, daus la nomenclature minéralogicyue de Haiiy, i un cristal qui offre, dans l'ensemble de ses faces, la combinaison dedeux formu"s (cx. Barylc sulfutćc biforme); en bolanigne, d'apres H. Cassini, il lit calathide des Symanthérées, quand elle renferme denx sortes de fleurs de forme dificirnte (ex. Camomille).

Brrurcatron, s. f., bifurcutio (bis, deux, fiurca, fourche). Fil. droit ou nus partic se divise en dens, de manière it offirir l'aspect d'use fourche.

Hewegut, noljet, bifuratus; zwcigabclig, gabclförmig (all.); biforcalo (it.). Divisé en deux parties qui partent da mème point ; comme lis lige du Valeriana, les pédoncultes du Sicnostomum bifurcatum, les feuilles du Ceratoplyollum demer. su: a, le style du Cordia Myxa, les poils du Thrincia lispida, les filets des ctaminrs du Crambe.

BıGkMntí, adj., bigcminus, bigeminatus, biconjugatus; doppeltzwcizïhligr (all.); bigeminato (it.) (bis, deux, gemints, gémeau). Se dit : $1^{\circ}$ en minéralogie, dausla nomenclature de llaiiy, d'un cristal dont les faces offrent la combinaison de quatre formes qui, prises deux is deux, sout de la même espèce, comıne deux rhombö̈les el deux dodćcaëdres (ex. Chaux carbonalée bigéminée); $2^{\circ}$ en botanigne, d'une feuillc dont le péliole commun se termine par denx pétioles sceondaires, et où chaemu de ceux-ci porte unc paire de folioles (ex. Ingra bigemina).

BIGWME, adj., bigenus (bis, deux, geno, eugendrer). Nees d'Eseubeck dome celte ćpithète anx arbres qui, sur la fin de l'étí, prodnisent une seconde mais faible pousse de feuilles. Ex. Prous.

BGLNERE, adj., bigeneris (bis, deux, genus, genre). Linné appelitit ainsi les bybrides ou mét is nés d'individus apparteuant à deux goenres différens.

MGGBBELX, adject. , bigribbosus; qui porte deux bosses, comme le bas su pétale inférieur de l'Ionidium bigibbosum.

BHER:ATELEL, adj. , biglanelu. losus (bis, deux, slandula, glande). L'Hecateu biglandulosa a ses fenilles munies de denx giandes un peu audessus de leur hase.

malomuliux, adj, , bigrlobostes. I'linga biglobosa a ses fleurs disposćcs en ćpis, qui sont resserrés dans le milien, el semblent par couséquent 
eomposés de deux sphères superposées.

BIGLUML, adj. , biglumalus. Se dit d'une locuste qui renferme deux glumes. Ex. Panicum.

BIGNovincíss, adj. et s. f. pl., Bignoniacca. Finnille de plantes, établic par Jussien, et qui a pour type le genre Bignonia.

BIGNONÍ́ES, adj. et s. f. pl., Rignonick. Nom donné par A. Riehard à une section de la famille des Bignoniacées, ayant le genre Bignonia pour type.

BIGRANUTAIRE, adj. , bigranularis (bis, deux, granum, grain). L'Echinus bigranularis a ses tubercules disposés partont sur deux sćries.

BIILSTE, adj. , bihastatus (bis , deux, hasta, liache). I, Rhinolophus biliastatus a sur le nez deux appendices foliacés, tous deux en formc de lance.

ISHYDRIQUE, adj., bilydricus. Berzclius appelle phosphure bilyyllique celui qui contient deux fois antant d'hydrogìne que le premier degré de combinaisou définie des denx corps. I'existence de ce corps n'est que présumce. Le seul qui s'en rapproche, et qui a ćté déronvert par H. Davy, pariầt être un mólange des phosphures monolydrique et biliydrique.

BHITDOSELATE, s. m. , biliydrosulfas. Nom douné jar Beudant à nisulfatequi contient de l'ean de cristallisatiou.

BUYPOSULFARSENITE, s, m., bihyposulfarsenis. Nom douné, dins la nomenchaturc chimique de Berzelins, it un sursulfosel dans lequel te sullide hyparsénicux cst en proportion double de eclle qui existc dans le sct consiléré conme neutrc. Ex. Bilirposulfarscnit potassique.

แก01บน⿰ , s. m., biiodurclum, biodrtum. Composó gfui contient denx fois autant d'iode qu'un iodure simple. Ex. Bïodure ammonique.

"Bwugur, adj., bijugalus; zixiciprarig (all.); accopiato (it.) (bis, denx, jugum, paire). Épilhère donnée, en minéralogrie, daus la nom enelature de Ilaüy, $\hat{i}$ un eristal dans lequel les décroissemens naissent deux à deux sur les bords ou sur les aligles (ex. Chaux carbonací bijnguée); en botaniçue, ì une feuillc composée, qui a denx paires de folioles opposćes deux à deux (cx. Melicocca bijuga).

BLABIE, adj. , bilabianus; zqueilippis (all.) (bis, deux, labium, lévre). Se dit, en botanique, d'une partic qui a dux portions prineipales, l'une supéricure, l'autre inféricure, entr'ouvertes et disposées à la manie:e des levres des auimaux, conme le calice des Salvia, la corolle des Rhinantlus, l'indusie du Trichomanes bilabiatum, les pétales tubulés, avee un limbe à deux lèves, du Nigrella sativa.

BHEAMELTE, adj. , bulamcllatus (bis, deux, lamella, lamelte); qui est composé de denx lamelles, comme le sligmate du Marlynia proboscidea. Cette épithète est donnée aux cloisons marginailes, quand elles sont formées chneune par deux valves contiguës, dont les hords rentrans péuétrent daus l'intéricur de la capsule, en sorte qu'cłles se súparent en denx lames, à l'époque de la déhiscenee (ex. Dirgiralis purpurea). La Spongria bilamcllata est une sorte d'entonnoir pédieulí, yui se termine par deux grandes lames parallèles.

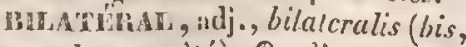
denx, latus, còté). On dit, en botanique: feuilles bilatéralcs, d'après Mirbel, celles qui, partant de points différens, se dirigent de deux côtés opposés ('x. Taxus baccala); placcntaire bilatéral, cehai qui est placé sur deux eôlés opposés dn péricarpe (ex, 
¿Ribes rubrum); lobes d'anthères bilatéraux, eeux qui sont séparés et placés de denx eótés npposés du filet (ex. Bigonia dichoroma), on du ron. nectif (ex. Tradescantia virginica). Un animal bilatćral est cclui qu'on peut. parıgcr en deux eòtés similaires, situćs ì droite et à gauche dı plan séeant qui passerait par la longueur du corps.

BILICIUNaTE, s. m., bilichenas. Sursel qui conticut deux fois autant d'acide lichénique que le lichénate neutre de la neêne lase.

BILIGULé, adj.. biligulatus (bis, deux, ligula, laniere). H. Cassini donne retie épilhète is la corolle des Synauthérces, lorsque le liube sc prolonge en deux languettes, l'une extéricure nu postéricure, l'autre interne ou antëricure. Ex. Gammariliron biligulatum.

irLIGULIFonve, adj. , biliguliformis. Épithète donuce par $H$. Cassini à un genre indéterminć de corolle de Synamthírécs, dont le limbe scmble se prolonger en deux languettes.

BILINGLE, adj. , bilinguis (bis, doux, lingua, langue). Le Jodamia bilinguis est un testaé fossile dont le moule de la valve inférienre a la plus grande ressemblance avec le bout d'une langue de limenf.

BILOB', adj. , bilobus, bilobaius; zwcilappig (all.) (bis, dinx, lobus, lohe). Se dit, en botaniquse, d'une partie qui offre deux divisions sćparées par un siuns olitus plus on moins arrontli à sa base, qui est divisée jusqu's̀ moitié it pen pris en deux porions d'une longuenr et d'une épaisscur notables; comme les anthires de la plupart des plinntes, les cap-

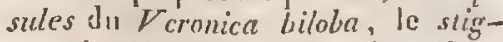
mate du Chelidoniunt staucium, l'embryon des plantes dicolylélones, les coujlédons du Brassica oleracea, le périsperme du Coccoloba. On appelle en zoologie Aurata bilobata un poisson qui a la nagenire candale fourchue, et Terebratula bilobata une coquille dont la valve iulérieure offre un excavation médiane qui la rend presque bilobée.

BHoCULAInE, adj. , bilocularis; zweifücherig (all.) (bis, denx, loculus, loge). Se dit: en botanique, d'une baie (ex. Ligustrum vulgare), d'une capsule (ex. Syringa vulgaris), d'une pyxide (ex. Hyoscyamus niger), d'un érème (ex. Cerinthe major), d'andlices (cx. Orrhis bifolia), d'un norau (ex. Zizipluzs sativus), d'un légume (ex. Astragalus cxsscapuss), d'une carcérule (cx. Circcea lutetiana), qui unt deux loges'; d'unc feuille qui est étroite, presque cylindrique, ayant irtćrienrement drux cavités à côté l'unc de l'antre, dues prebablement à l'snroulement des bords (ex. Lobelia Dortmannia). En znologie, le Mrorlus bilocularis cot aiusi nomnté à eanse d'une lame septiforme qui convre it l'intéricur une partie de la cavité da crochet.

BILOPIF, adj., bilophus (bis , deux, ieops, huppe). Le Trochilus bilophos porte un paquet de longues plunes iffilées derriorg charue acil.

BMUNerb, adj., bilunulatus (bis, deux, lunula, croissant); qui est marqué de deux taches en forme de croissant. Ex. Labrus bilunulaus, Leia bilunula.

131\%ACetí, adj, , bimacuialus, bimaculosus (bis, dellx, macula, tirche ); qui est marqué de deux taches d'unc eouleur aratre que celle du eorps. Ex. Gnbiesox bimaculans, Nitidula bimaculala, Noclua bimaculosa.

mimaLATE, s, m., bimalas. Nom donnć ì un sursel qi!i conlicut deux lois antant d'acide malique que lc st.l neutre de la même base. Ex, Dimalate zincigue. 
BLMANES, adj. et s. m. pl., $B i-$ manes (bis, deux, manus, main). Blumenbaeh, Cuvier, Duméril, Ranzani, Latreille et Desmarest donnent ec nom à un ordre de la elasse des Mammifères, comprenant eeux qui n'ont de mains qu'aux extrémités antérieures seules, ou les hommes; Bory, au même ordre, anquel il assoeic le genre Orang; et Blainville, à une famille de reptiles sauriens, daus laquelle il range eeux qui n'ont que des pattes antérieures, sans pieds de derric̀re.

BIMARGARATE, s. m. , bimargaras. Épillsète par laquelle on désigue un sursel qui eontient denx fois autant d'acide margarique que le sel neutre de la même base. Ex. Bimargarale polassique.

BHMARGINÉ, adj. , binzarginatus (bis, deux, margo, bord). $L^{3} E_{u-}$ genia bimarginata offre une double nervure contiguë au bord externe de ses feuilles. Le Pleurotoma bimarginala a ses tours de spire bordés en haut et en has.

BDMÉTRIQUE, adj., binctricus

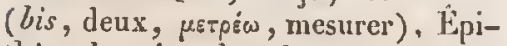
thète donnée, daus la nomenclature minéralogique de Haüy, ì us cristal dans lequel deux dćcroissemeus font naitre des faces relalives à deux solides de dimensions très-différentes, conme lorsque la forme de l'uu est très-surbaissée ct celle de l'au tre ćlaneée (ex. Chaux carbonalée bimćtrique).

BIMIXTE, adj., bimixlus. Epithète donnćc, dans la nomeuclalure minéralogique de Haüy, à un cristal qui résulte de deux lois mixtes de déeroissement. Ex. Chaux carbonatée bimixle.

BIVOE ITHATE, s. in., bimolyldas. Nom donné, dans la romencla. ture chimique de Berzelius, ì un sursel dans lequel l'oxigène de l'acide molybdiquc est muliple par deux de eelui de la base. Ex. Bimolybdace ammonique.

BIMUCRonê, adj. , bimucronatu (bis, denx, mucro, pointe). Lc Cellepora bimucronala a les ouvertures des cellules de ses polypes garnies de deux pointes opposées.

BINAIRE, adj., binarius. Épilhète donnée, par les chimistes, à un composí qui résulte de li combinaison de deux corps simples, el par les miuéralogistes, d'après Haüy, à un crislal produit en vertu d'une seule loi de décroissement par deux rangées (ex. Chancx carbonatée binairc).

BINÉ, adj., binus, binalns; gezweil, zueizühlig ( all.). Epithète donnée à des feuilles qui sont divisées profondément en deux parties (ex. Droscra binala), ou fendues du sommet ì la base en deux lobes (ex. Jeffersonia binata), ou eomposées et formées d'un púliole eommun qui ne porte qu'iue senle pare de folioles (ex. Hardwickia binala).

B1NEnví, adj., binervalus, binervius, bicluctulosus; qui est muni de deux nervures longitudinales, comnse les phyllodes de l'Acacia binervatum, les feuilles du Pilotrichrm bidactulosum et du Lepidopilum binerwe.

BINERVuLí, adj., binerpulalus: Mirbel donne eette épithète au placentairc, lorsqu'il offre deux nervures ou cordons vasculaires, formés par la réunion des vaisseaux condncteurs et nourriciers.

BIMELORE, adj., biniflorus (binus, double, flos, fleur); qui porte deux fleurs rapprochées l'une à côté de l'autre, comme les pédoneules du Rhamnus biniforus.

BiNithatr, s. m., binitras. Epithete dounce à un sursel dans lequel la quantite d'ucide nitrique est donble de celle qui existe dans le sel neutre de la mêne base. Ex. Binitrale strychnique. 
BiNOANNuLAIrE, adj., binoannularis. Épithète donnée, dans la nomenclature minéralogique de Haüy, ذ un prisme hexaëdre régulier, modifié par des facettes disposćes en anneau autour de eharque base et qui proviennent d'un décroissement par deux rangúes. Ex. Chaux phosphatée bino-annulaire.

BINOCULis, adj. et s. m. pl., Binoeuli. Lister donnait cette ćpithète à ure division des insectes aptères, contprenant les araignées ì deux yeux.

BINOQUABRIUNITAIRE, adj., binoquadriunitarius. Nom douné, dans 1a nomenelature minćralogique de Haüy, à un cristal qui résulte de cing déeroissemeus, l'un par cing rangées, et ehacm des quatre antres par une scule rangée. Ex. Buryle sulfatce binoquadriunitaire.

- enosevame, adj. , binoscnarius. Eipithète donnée, dans la nomenelature xninćralogique de Hä̈y, ‡u un cristal qui est produit en vertu de deax déeroissemens, l'un par denx, l'autre pal six rangées. Ex. Chaux carbonatéc binosénaire.

BINOTERVAIRE, adj., binoternaritis (binzes, double, ternarius, triple). Non domé, dans la nomeneliture minéralogique de Haïy, à un crisfal prodait en vertu de deux décroissenens, l'un par denx, l'autre par trois raugées. Ex. Fer oliggiste binoternaire.

BivothuswTAIR, adj. , binorritunitarius (binus, double, tres, trois, unitas, unité). Nom dounć, dans la nomenclature uninéralogique de Ilaniy, à un cristal provenant de quatre décroissemens, l'un par deux rangées, ef rhacun des trois autres par une seulc. Ex. Chanx earbonate binotrimitaire.

BNOXAEATE. VoY. Blosalats. BIOCWUL, adj., biocellans; qui est inarqué de deux taches cn forme

\section{Btot}

d'œeil, noires et entourées de blane. Ex. Chironectes bioecllatres.

BIOCHIMIQUE, adj., biochymicus (Pios, vic, znusia, chimic). Harless appelle foree biochimique l'action que les corps odorans exercent sur la matière organique animale et sur la force nerveuse, pour produire la sensation. des odeur's.

B1OCUt: adj., bioculatus (bis, deux, oculus, veil) ; qui offre denx taches d'une autre couleur que celle du corps, comme le Crioecris bioculata, dout les élytres portent deux tatches jaunes bordées de noir, ou l'Eplemera bioculata, dont la tête est chargée de deux tuberetiles jaunes; qui présente deux trous, comme l'Hippurites lioculala, coquille univalve cloisonnée, dont la dernic̀re loge est forncéc par un opercule percé de deux trous rapprochés l'un dé l'antre.

BIODYNA MiQUU, adj. , biodyna-

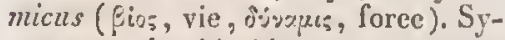
nonyme de biochimique (voy. ce mot), employé par Harlcss.

BIOGWNE, adj. , biggenus ( jios, vic, jहขขx́(s), prodtuire). Epithète donnéc par Candolle anx plantes parasites cryptomenes intestinales qui vivent sous l'épiderme des végélaux vivans, comme les Uredo, les Ecidium, les Puecinia, ctc.

BHOLEATT, s. m. , bioleas. Nom douné à des sursels qui conticunent deux fois autant d'acide oléique que les sels neutres de la mène basc. lix. Bioliate potassique.

B!OLOGL, s. f., biologia; Lebenslelure, Lebensliunde, Lebenswissenschaft (all.) (fiog, vic, hóvos, discomrs). Partic de la plyysiologic qui traite de ha vir: ent generrat, on de's diverses formes de lia vie considéréc d'une manière générale.

MIOEOGDeri, alj. , biologicus; qui est relatif a la biologic.

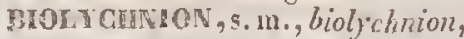

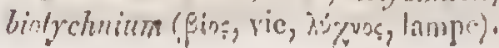


Synonyme inusité de chaleur vitale.

BIOXGUICULÉ, adj., biunguiculatus (bis, denx, unguis, ongle). Se dit d'un tarse d'insecte, quand il est terminé par deux erochets.

BIOSOPHIE, s. f., biosophia (Bios, vie, ooyia, science). Synonyme de Biologie (voy. ce mot), dont s'est scrvi Troxler.

BIOSIHLilie, s. f. , biosphara; Biosphäre, Lebenskugelchen (all.). Nom donné par Mayer aux atomes élémentaires, de forme globuleuse, qu'il suppose être la base de tous les corps vivans, ct produire par leur réunion tous les êtres organisés.

BIOTES, s. m. pl., Biota. Mill réunit sous ee nom les Méduses, les Actinies et les Hydres, dont it forme un groupe fort singulier.

BLOTIQUE, adj., bioticus (Bios, vie). Quelques plyysiologistes clonnent eette épithète à une sulistance impondérable bypothétique, qu'ils supposent être l'agent ou le prineipe vital matćriel.

BIOVuLt, adj., biopulatus; zuveyeicris (all.) (bis, deux, ovum, oul). Se dit, en botanique, d'une loge d'ovaire qui eontient deu $x$ ovules, comme dans les Euphorbiacées.

BIOXALATE, s. m. , bioxales. Epithète domice à des sursels qui contiennent deux fois autant d'acide oxalique que les sels neutres de la même base. Ex. Bioxalatc potassique.

BIOX:DE, s. m., bioxydum. Oxide au seeond degré d'oxidation. Ex. Bioxide uranique.

BIPALÉOLÉ, adj., bipalcolatus (bis, deux, palea, paillette). Epithète donnée par Mirbcl à la lodicule, quand elle est formée de deux jalćoles. Ex. I'ripsacum dactyloüdes.

BHPALME, adj., bipalmntus (bis , deux, patma, palme). Une fcuillc composée est dite bipalméc, quand les pétioles partiels naissent en divergeant du sommet du pétiole commun, et portenl eux-mêmes des folioles distribuées d'après le même système. BLPLL'́, adj., bipalpatzis (bis, deux, palpo, toueher). Kirhy donne cette épithìte à une bouchc imparfaite d'insectes, qui offre senlement des palpes maxillaires. Ex. Tabanus.

BLPARTI, adj., bipartitus (bis, deux, pars, partie). Se dit, en botanique, de toute partie qui est divisée en deux jusqu'au dessous du milieu, ou jusqu'auprès de sa base, comme le calicc des Orobanches, les pétales du Silene bipartila, les stipules du ricia bipartita, le placontaire du Ribes nigrum, le slyle du Casuarina, les feuitles du Cyclanthus bipartitus. Les entomologistes appellent biparties les antennes des inseetes qui sont divisćes jusqu'ì la base en deux branelies presque égales.

BHARTIBLE, adj. , bipartibilis (bis, deux, pars, jartic); qui est susecptible dese divisers pontanément en deux parties, eomne le crémocarpe des Ombelliferes, la capsule des Scrofulaires, le placentaire des Astragales.

BIPARTIS, adj. el s. m. pl. , $\dot{B} i-$ partiti. Nom donné par Latreille, Cuvier et Eichwald à une seetion de la tribu des Carabiques, comprenant cenx qui ont le corselet séparé de l'abdomen par un intervalle bien prononeé.

BHECTINR, adj., bipcctinatus; dnppeltgekïmmt (all.) (bis, deux, pecten, peignc). Épithète donnće aux antennes des insectes, quand elles sont pectinées des deux côtés, comme celles des mâles de l'Atychió chimera.

BIPLDE, adj. et s. m., bipes (bis, (eux, pes, pied). Sedit d'un animal qui marehe sur detex picds seulement, comme l'homme, les oiscaux et plusicurs reptiles.

BILÈDES, adj. et s. m. pl. , $B i$ pedes. Nom domné par Latreille à une 
seetion de la elasse des Mammifères; comprenant eeux qui sont privés de meinbres postérieur's, et qui n'ont par conséquent que deux membres.

BIPELLTís. Vyayz Bicuirassés.

BIPENNATIFWE, adj. , bipennatifidus; doppeltficderspaltig (all.). Se dit, en botanique, d'une feuille pinnée dout les divisions sont ellesmêmes pinnatifides. Ex. Phacelia bipennatifida, Lepidium bipennatifidum.

BIPENNE, adj. et s. m., bipennis (bis, deux, penna, aile). Quelques naturalistes ont employé ee terme en place de diptère. Voyez ce mot.

BIPENNÉ, adj. , bipinnatus, duplicato-pennatus ; doppeltgefiedert (all.); bipcnnato (it.). Epithète donnée par les botanistes à une feuille dont le pétiole commun fournit latéralement des pétioles secondaires, sur les côtés desquels sont altachóes les folioles. Ex. Didesmus bipinnatus.

BIPENNES, adj. el s. m. pl., $B i$ pennia. Latreille désigne sous ee nom une coupe de la division des insectes anélytres, eomprenant ceux qui n'ont que deux ailes.

BIPERF Onk, adj., biperforatus. Se dit d'un organc qui offre deux ouvertures ou perforations, comme le nez, par exemple.

BIPÉTALÉ, adj., bipetalus; qui a deux pétales sculement, conme le Tropceolum bipctalum, espèce remarquable par l'avortement de deux de ses pétales.

BIPIIOnES, adj. et s. m. pl. , $B i$ phora. Nom donné par Cuvier à une fimille de la classe des Acéphales, comprenant ceux dont le mantea cylindracé est ouvert aux deux bouts.

BIPIIORIDÉsis, adj. et s. f. pl., Biphorida. Nom donné par G.-S. Maeleay à une famille de la classe des Tuniciers, qui a pour type le genre Biphore (Salpa).

BIPIOSPIrATE, s. m., biphos- phas. Épithète donnée, dans la nomenelature chimique de Berzelius, à des sursels dans lesquels l'oxigène de l'aeide phosphorique est multiple par deux de celui de la base. Ex. Bipleosphate calcique.

BIPHOSPIITE, s. m. , biphosphis. Epithète donnée, dans la nomenclature chimique de Berzelius, à des sursels dans lesquels l'oxigène de l'aeide phosphoreux est multiple par deux de celui de la base. Ex. Biphosphite barytique.

BipHosivune, s. m. , biphosphuretum. Nom donné à une eombinaison de phosphore avee un autre corps simple, dans laquelle le phosphore est en proportion donble de celle que contient une autre cembinaison de ees deux mèmes corps.

BLPLIÉ, adj. , biplicatus (bis, deux, plica, pli). Candolle donne ectte ćpithète aux cotylédons, quand ils sont pliés deux fois sur euxmêmes transversalement. Les conehyliologistes l'appliquent aussi ì des coquilles qui portent deux plis i la columelle (ex. Eusus biplicatus, Fasciolaria biplicata).

BIPLISSÉ. Voyez BIPLIÉ.

BIPLOMIQUE, adj., biplumbicus. Nom donné, dans la nomenclature ehimiçue de Berzelius, à des soussels dans lesquels l'oxigène de l'oxide plombique est multiple par deux de eelui de l'acide. Ex. Chromate biplombique.

BIPLUMĹ, adj. , biplumatus (bis, deux, pluma, plume); qui porte deux plunies. L'Arethusa biplumata a deux des einq divisions de son périgrone longues, grèles et garnies latéralcment au sonımet de cils qui imitent les barbes d'une plume.

BipoINTU. Voye: Bimucrové.

BIPOLAInE, adj.. bipolaris (bis, deux, polus, pòle). Épithète donnée par Erman alux corps conducleurs imparfuits de l'éleetricité, à ceux 
qui n'exercent qu'une action faible ou simplement partielle sur la pile misc en communication avec eux, c'cst-ì-dire qui, en même temps qu'ils déterminent une circulation d'un pôle à l'autre, ont leurs deux moitićs constituées dans des états électriques opposés.

BIPOLARITÉ, s. f. , bipolaritas. État d'uu eorps ćlcetrique ou magnétique qui manifeste deux pôles doués d'une vertu contraire.

BIPONCTUÉ, adject., bipunctatzs (bis, denx, punctum, point); qui est marqué de deux points eolorés. Ex. Bruchus bipunctatus, Coccinella bipunctata, Acrydium bipunctatum, Anchrax distigma.

BRPOREUX, adj , , biporostus (bis , deux, porus, pore). Se dit, en botanique, des anthcress, quand elles s'ouvrent à leur sommet par deux pores. Ex. Solanum nigrum.

BIPOTASSinUE, adj., bipotassiczss. Épithète donnée, dans la nomenelature chimique de Berzelius, à des soussels dans lesquels l'oxigène de la hase est multiple par dcux de celui de l'acide. Ex. Borate bipotassique.

BIPUPILLF's, adj. et s. m. pl., Bipupillati (bis, deux, pupulla, pupille). Latreille appelle ainsi une tribu de la famille des Cyprinides, comprenant les poissons qui, eomme l'Anableps, ont deux pupilles, la cornée el l'iris étant divisés en deux parties par une bande transversale.

BUPUSTULÉ, adj., bipustulatus (bis, deux, pustula, pustule); qui offre deux points rouges sur un fond noir ou d'une teinte olsseure. Ex. Elater bipustulatus, Nitidula bipustulata.

BIRAuÉ, adj. , bircmalus. Savigny et Blainville donnent cette épithète à l'appendice des Chćtopodes, qui est en forme de deux rames, l'une supérieure ou dorsale, l'autre inférieure ou ventrale.

BIRAYÉ, adj. , biradiatus, bilineatus; qui est marqué de deux raies eolorécs. Ex. Cardizm biradiatum, Pleteronectes bilineatus.

DIRÉFRINGENT, adj. , birefringens. On donue ec nom à un prisme de chaux earbouatéc ou de cristal de roche, achromatisé avec du verre, et travaillé de telle sorte qu'cn donnant des inclinaisons convenables aux faces latérales, on obtient deux images plus ou moins séparées.

ISIRHOMBOIDAL, adj. , birhomboïdalis. Épithète donnće, dans la nomenclature minéralogique de Haüy, à un cristal dont la surface est composée de douze faces qui, étant prises six à six et prolongées par la pensće jusqu'à s'entrecouper, formeraient deux rhomboïdes différens. Ex. F'er oligiste birhomboüdal.

BIRONCINÉ, adj. , biruncinalus. Le Laminaria biruncinata est ainsi apjelé paree que sa lame produit sur les bords des pinnules roucinees.

BHKOSTRE, arlj. , birostris, birostratus (bis, deux, rostrum, bec). Se dil, en botanique, d'une graine qui est surmontéc de deux pointesformées par la base du style (ex. Briza media); en conchyliologie, d'une coquille dont ehaque extrémité se prolonge en un long tube droit (cx. Ovula birostris).

BISADDITIF, adj., bisadditious. Épithète donnée, dans la nomenelature minćralogique de Haity, à un cristal dans le signe duquel le plus fort exposant surpasse de deux unités la somme des autres. Ex. Baryte sulfatée bisadditive.

IBSALTLIRN, adj:, lisalternus. Epithète donnée, dans la nomenclature minéralogique de Haiiy, à un cristal qui a vers chaque somnet des faces de deux mesures d'angles, situées alternativement, en sorte que 
celles de chaque espèce alternent aussi cntre elles d'un sommet à l'autre. Ex. Chaux carbonatée bisalternc.

BISANNUEL, adj., biennis; zweijührig (all.); bicnnc, bicnnale, bisannualc (it.) (bis, deux, annus, annćc); qui vit pendant deux années. On dit, en. botanique, plante bisannuclle, eelle qui pousse des feuilles la première année, fructifie et meurt la seconde (cx. Columclla bicnnis, Bryum binutu ); racinc bis annuclle, celle qui ne meurt que la scconde année de son développement (ex. Daucus Carotta); fcuilles bisannuclles, d'après Candolle, celles qui tombent la seconde année, après la pousse des nouvelles feuilles (ex. Qucrcus Ilex). On désignc les plantes bisannuelles par le signe de Mars, $c^{x}$, parce que cctte planète emploie deux années à accomplir sa révolution.

BISDECEMPONCTU1́, adj., bisdecompunclatus; qui est marqué de vingt points colorés sur un fond d'une autre tcinte. Ex. Coccinclla bisdecempanciata.

BISDECIMAL, adj., bisdecimalis (b.s, deux, deccnt, dix). Epithète donnée, dans la nomenclature minéralogique de Haïy, à un prisme à dix pans, qui est terminé par des sommels à cinq faces. Ex. Arscnic sulfuré bisdécimal.

IBSEAU, s. m. Les cristallographes appellent ainsi l'ensemble de denx faces adjacentes, qui remplacent unc arète, un angle ou une face de la forme dominante d'un cristal.

BiSET, s, in. On donne ce nom aux sursels qui coutiennent denx fois autant d'acide que les sels simples, potur la mème quantité de hase, et quelquefois aussi aux soussels qui, pour nne même quantité d'acile, contiement deux fois autant de base.

BISSÉLENATTE, s. m., bisclcnios. Epithite dounée, dans la nonienclature chimique de Berzclius, il des sursels dans lesquels l'oxigéne de l'acide sćlénique est maltiple par deux de celui de la basc.

BisḱLÉNrTE, s. m. , biselcnis. Epithète donnée, dans la nomenclature chimique de Berzelius, à des sursels dans lesquels l'oxigène de l'acide sélénieux est raultiple par deux de celui de la base.

BISÉLÉviune, s. m., biseleniuretum. Nom donné à une combiuaison de sćlénium avec un antre corps simple, dans largnelle le sélénium est en proportion double de celle que contient une autre combinaison de ces denx mêtnes curps.

BISELLEMENT, s. m. En cristallographie, on appelle ainsi un retranchement fait a la forme primitive d'un niuéral, et d'où il résulle que les parties retranchées sont remplacées par deux faces adjacentes, en biscan.

BISÉQuê, adj., bisscctus (bis, deux, scco, couper). On donne cetle épithète à un inscctc dont le tronc et la tếle ne sont pas séparés l'un de l'autre par une suture, en sorte que le corps de l'aninal semble formé de deux pieces senlcment (cx. Aranca). Kirby appelle l'alitrone biséqué, quand il est susceptible de se sćparer cn deux segmens (ex. Colćoptères lamellicornes .

BISERIAL, adj., biserialis; doppelrcihig (all.). La Sepia biscrialis est ainsi appelćc parce que les sucoirs de ses appendices tentaculaires sont disposés sur deux rangs.

Wist́nLATION, adj., biscriatio (bis, deux, series, série). L.-C. Richard cmployait ce terme pour désigner la disposition des graines dans le péricarpe, quand clles y sont rangées sur deux sćrics.

BISt́rié, adj., biserialtus; qui est disposé sur deux rangs ou ligues longitudinales, eomme les ovules d'une loge polyovulée (ex. Iris ger. 
manica) ; qui est disposé sur deux rangées conecntriques, comrne les squamellules d'une aigrettc de Synanthérée, ou commic les squames du périclinc autour de la ealathide de certaines plantes appartenant à cette famille.

BISETAC:́s, adj. et s. m. pl., Bisetacei. Nour douné par Duméril à une famille de l'ordre des Entomostracés, comprenant ceux dont l'abdomen se termine par deux soics.

BISÉTIGL̀RE, adj., bisetigerus ; zweiborstig (all.) (bis, deux, scta, soic, sero, porter); qui porte deux soies, commc les antennes intermédiaires des Crangons et des Pandalus.

BISEXE, adj., bisexius. Terme peu usité, qu'on emploie pour désigner un corps organisé qui réunit les deux sexes sur un même individu.

BISEXUEL, adj. , bisexualis, bisexuinus (bis, deux, sexus, sexe). Se dit d'unc plante qui a les deux sexes réunis dans une même flcur, et alors lc mot est synonyme de hermaphrodite, ou qui les porte séparés sur un noême individu, et alors il est synonyme de monoïque.

BiSicLONNÉ, adj]., biszleatus; qui est marqué de deux sillons, comme le fruit du Veronica officinalis.

BISINUf, adj., bisinuatus (bis, deux, sinzts, échancrure ). Une coquille (Tercbratula bisinuata) est ainsi appelée parce qu'clle offre dcux plis en dessus.

BISIPHTE, adj., bisiphites (bis, deux, sipho, siphon ). Epithète donnée à une eoquillc polythalame qui est munie de deux siphons. Ex. Nautilus bisiphites.

BISNUTII, s. m., bismuthusr, wismuthum, mareasita. Métal solide, déjà mentionné par Agricola, et dont les propriétés ont ćté suceessivcment étudiées par Pott, Geofiroy, Berzclius, Lagerhielm et J. Davy.
BISMUTHIDES, adj. et s. m. pl., Bismuthides. Nom donné par C. Pauquy à une famille de corps pondérables, par Beudant à une famille de minćraux, ayait pour type le Bismulh.

BISMUTHEthe, adj., bismuthifertus. Epilhète donnée, dans la nomenclature minéralogique de Haiiy, à des minéraux qui conticnnent aceidentellement du bismuth. Ex. Tellure sélèniẻ bismuthifère.

BISMUTUIQUE, adj. , Jismuthicus: Dans sa nomenclature chimique, Berzclius appelle oxide bismuthique le sceond degré d'oxidation du bismuth, et sels bismuthiques, ceux qui ont pour basc eet oxide.

BISOCTOSEXVIGÉSNHAL, adj. ; bisoctosexvigesimalis. Nom donné dans la nomenelature minéralogique de IIaüy, à un eristal qui présente quarante-deux faces. Ex. Idocrase bisoctosexvigésimal.

BISPATIIELLÉ, adj. , bispathellatus; qui est composé de deux spathelles, comme la glame du Triticuer satipum.

BISPATIELLULË, adj., bispathellulatus; qui est formé de deux spalliellules, comme la glumelle de l'Arrostis dulcis.

BISPÉNIENS; adj . ct s.m. pl., Bis. penii (bis, deux, penis, verge). Nonx donné par Blainville à un ordre dela classe des Reptiles, comprenant ceux dont les mâles ont le pénis double.

BISQUINDÉCINAT, adj. , bisquindecimalis. Epithète donnée, dans la nomenclature minéralogique de Haiiy, ì un prisme ì neuf pans, avec un sommet à six faces et l'autre à quinze. Ex. Tóurmaline bisquindécimale.

MISSEPTENTPUSTULÉ, adj., bisseptempustulatus (bis, deux, septem, sept, pustula, pustule); qui est marqué de quatorze points rouges sur un fond d'une autre coulcufa' 


\section{d 68}

Ex. Coccinella bisseptempustulata. BISSEXDEGIMAL, adj., bissexdecimalis (bis, deux, scx, six, decem, dix). Nom donné, dans la nomenelature minéralogique de Haiì, à un prisme à seize pans, terminć par des sommets à neuf faces. Ex. Etain oxidé bissexdécinal.

BISSOLSTRACTIF, adj., bissustractivus. Nom donnć, dans la nomenelature minéralogique de Haüy, à un cristal dans le signe duquel un des exposans est moindre de deux unités que la somme des autres. Ex. Barylc sulfatée bissoustraerive.

BISTÉARATE, s. m., bistearas. Nom donné à un sursel dans lequel la proportion de l'acide stétrique est multiple par deux de eclle qui existe dans le sel considéré comme nautre.

BISTIPELLí, adj., bistipellatus. Epithète donnée, par les botanistes, au pétiole, quand il est mnni de deux stipelles. Ex. Indigofera monophylla.

BISTOURNi, adj., tortuosus. Sc dit d'un corps qui est contourné sur lui-rnême, eomme la coquille de l'Arca tortuosa.

BISTRIÉ, adj., bistrialus (bis, deux, stria, strie ), qui est marqué de deux stries, comme le Baceinum bistrialum, entre deux grosses stries duquel s'en trouvent cinq ou six autres plusfines; ou l'Haliotis bistriata, dont la coquille offre des stries transversales doubles.

BISULCES, adj. et s. m. pl., Bisulci, Bisulca (bisuleus, fourehu). Nom donné par Blumenbnels et Xlliger à un ordre de manmifères comprenant ceux qui ont le pied partigé extérieurement en deuxsabots.

BISULFARSENIATE, s. nı. , bisuipharsenias. Nom donné par Berzelus ì des sulfosels qui contiennent deux fois autant de sulfide arsenique que le sel neutre.

BISLLFARSENITE, s. m., bisulphl-

\section{BISU}

arsenis. Nom donné par Berzelius : des sulfosels qui contiennent deux fois autant de sulfide arsénieux que le sel neutre.

IBISULFATE, s. m. , bisulphas. Dans la nomenclature chimique de Berzelius, ce nom est donné à des sursels dans lesquels l'oxigène de l'acide sulfurique est multiple par deux de celui de la base.

BISULCITE, s. m., bisulphis. Berzelius donne ce nom à des sursels dans lesquels l'oxigène de l'acide sulfureux est multiple par deux de celui de la base.

BISULFOBASIQUE, adj. , bisulphobasicus. Épithète donnée par Berzelins à des sels haloïdes qui sont combinés avec une quantité de sulfosel multiple par dcux de la leur. Ex. Chlorure hydrargyrique bisulfobasique.

BISULFONOLYRDATE, s. m., bisulpliomolybdas. Nom sous lequel Berzelius désigne des sulfosels qui eontienuent deux fois autant de sulfide molybdique que le sel neutre de la même base.

BISULFOTUNGSTATE, s. m., bisulphotungstas. Nom donné, dans la nomenclature ehimique de Berzelius, à des sulfosels qui contiennent deux fois autant de sulfide tungstique que le sel neutre de la même base.

BISULFUnE, s. m. , bisulpluretum. Nom donné a une comlinaison de soufre avee un autre corps simple, dans layuelle le soufre est en proportion double de celle que contient une autre combinaison des deux mêmes corps.

IISUNIBINATRE, adj ., bisunilinarius (bis, deux, unus, un, binus, double). Nom donné, dans la nomenclature minérologique de Haiiy, crislal résultant de quatre déeroissemens, dont deux par une seule rangée et les deux autres par deux man- 
gées. Ex. Baryte sulfatée bistunilinaire.

BISUNISÉNATRE, adj., bisunisenarius (bis, deux, unus, un, sex, six). Nom donné, dans la nomenclature minéralogique de Haiiy, ì un cristal résultant de irois déeroissemens, dont deux par unc seulc et un par six rungées. Ex. Chaux earbonatée bisunisénaire.

BISUNITAIRE, adj., bisunitarius (bis, deux, unus, un ). Nom donné, dans la nomenelature minéralogique de Haïy, à un eristal produit en vertu de deux déeroissemens par une senle rangéc. Ex. Strontiane sulfatće bisuniternaire.

BITARTRATE, adj. , bitartras. Nom donné à des surscls qui contiennent deux fois autant d'acide tartrique que les sels neutres des mêmes bases.

BITERNÉ, adj. , biternatus, duplicato-ternatus; doppeltdreizühlig (all.) Les holanistes donnent cette épithète aux feruilles dont le pétiole commun se termine partrois pétioles seeondaires dont chacun porte trois folioles. Ex. Loranthins biternatus, Lardizabala biternata.

BITESTACK, adj., bitestaceus (bis, deux, tesia, coquille). Adanson appelait ainsi les eocuilles nnivalves operculées, parce qu'il comparait lopereule à la valve plate et opereuliforme de certrines bivalves.

BITESTACés, adj. et s. m. pl., Bitestacea. Nom donné par Duméril à une famille de l'ordre des Crustacés cntomostracés, comprenant ceux dont le corps est renfermé dans un test bivalve. Voyez Ostracins.

BitrlFlors, adj., bitriforus. Epithète donnce par H. Cassini à la couronne des Synanthérées, quand elle se compose de deuxà trois fleurs. BITUBERCULÉ, adj. , bitubercularis, bituberenlalus (bis, deux, unberculum, tubereule); qui offre deux tubercules. Épithète donnée à des eoquilles qui présentent deux tuhercules sur le dos de chacun de leurs tours (ex. Ranella bitubercularis), dont les deux derniers tours offrent chacun deux rangécs de tubereules pointus (ex. Purpura bitubereulata), ou qui sont hórissées de tubereules et dont le dernier tour en supporte deux plus gros et d'une autre forme (ex. Strombus bitnbereulatus); à des insectes qui ont deux tubercules eharnus sur l'abdomen (ex. Aranea bituberculata), ou qui en présentent un au dessous de ehaque intenne (ex. Chennium biuberculatum).

BrTUMINEUx, adj., bituminosus; erdpechartig(all.) (bitumen, bitume); qui a les qualités etentr'autres l'odeur du bilume. Ex. Calcaire bitunincux.

BITUNINIFEIRF, adj., bituminiferus (bitumen, bitume, fero, porter); qui est imprégné de bitume (ex. Clanx earbonatéc bituminifere), ou qui exhale une odcur de bitume par l'action du feu (ex. MFercure sulfuré bituminifere).

BITUMINISATION, s. f., bituminisatio. Conversion des matières organiques en bitume.

BITUNGSTATE, s. m., bitungstas. Nom donné, dans la nomenclature chimique de Berzelius, à des sursels dans lesquels l'oxigyène de l'acide tungstique est multiple par deux de celui de la base.

BITUNIQUí, adj., bitunicatus (bis, deux, thniea, tunique); qui est revêtu de deux enveloppes.

BHURATE, s. in.; biuras. Nom donné à des sursels qui contiennent deux fois autant d'acide urique que les sels neutres des mêmes bases.

BIVALVE, adj., bivaluis; zweililappig (all.) (bis, denx, valpa, valve); qui a deux valves ou deux battans, comme la capsule dn Microlicia bivalvis, le noyau du Prunus, la silique du Roemeria bival- 
vis. Un champignon (Physarum bivalve) est ainsi appelé parce qu'il sc compose de denx lames coriaces unies par un rćseau filamenteux. Les zoologistes appellent bivalve toute $\mathrm{co}^{-}$ quillc qui csi formée de dcux pièces calcaires distinetes.

BIVAI.VES, adj. et s. f. pl., $B i$ valucs. Blainville donne ce nom à un ordre de coquilles, renfermant celles qui sont formées de deux valves.

BIVALVULí, adj., bivalvulatus. Mirbel applique ectle épithète aux anthices, quand elles ont deux pores fermés par dcux valvules qui s'ouvrent, au moment de l'anthèse, pour laisser échapper le pollen. Ex. Berbcris.

BIVANADATE, s. m., bivanadas. Nom donmé, dans la nomenclature chimique de Berzelius, à des sursels dans lesquels l'oxigène de l'acide vanadique est multiple par deux de celui de la base.

BIVARIQUex; adj. , bivaricosus (bis, denx, varix, varice). Ia Marginclla bivaricosa est ainsi nommée parce qu'elle porte deux varices on bourrelets, une sur le bord droit, et l'autre sur' le gauche.

BrvennuQueux, adj., bivcrrucosus (bis, deux, vcrruca, verrue). Ial Coccinella biverrucosa doit ce nom aux deux taches rouges dont ses élytres sont marquécs.

BLIvíes, adj. ets.f. pl. , Bixinca. Non d'une famille dc plantes qui a pour type le genre Bixa.

BIzINCIQUE, adject., bizincicus. Nom donné, dans la nomenclature chinique de Berzelius, à cles soussels dans lesquels l'oxigène de l'oxide zincique 'st multiple par deux de celui de l'acide. Ex. Carbonate bisincique.

Mrzmconoue; adj, birairconicus. Nom donné, dans la nomencliture chimique de Berzclius, à des soussels dans lesquels l'oxigène de la

\section{BLAN}

zircouc est multiple par deux de celui de l'acide. Ex. Sulfate bizirconique.

Brzoví, adj., bizonatus (bis , deux, zona, zone ); qui cst marqué de deux zones, comme le $S$ cytalus bizonalus, dont chaque côté du dos offre une ligne longitudinale en zigzag.

BLACKWELLIACÉE. Vojaz HOMIALINÉES.

BUAFAHD, adj. , pallidus, pallidulus; blcich (all. ); blcack (angl.); qui est d'un blanc terne, qui a perdu ses couleurs naturelles. Vorcz PALE.

BLANC, adj. et s. m., albus, can-

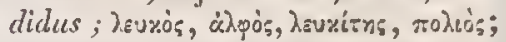
veeiss(all.); whitc (angl.); bianco (it.); qui n'a aucune couleur. Il est trèsdonteux qu'il existe dans la nature aucune fleur d'un blane pur; d'après les observations chalcographiques de Ricdouté, physiologiqques de Roper, chimiques de Schubler el Funke, "clui qu'elles offrent semble n'ètre que l'uuc des rouleurs réduites à $5 a$ plus faible teinte, ce que Candolle attribne au développement incomplet de la ehromule. Quoi qu'il en soit, lorsqu'on parle du blanc en général, on le désigne par le mot albus ( $\mathrm{ex}$. Gonolobus albus, Plumcria alba, Zygophyllum album). Le blanc très. pur est cxprimé par candidus; rcinweiss (all.) (ex. Coluber candidus, Dalca candida, Cymbidium candidum, Adcnostylis candidissima, Macrocncmum candidissimum). Très. souvent, on employe des comparaisons pour rendre les diverses nuances du blanc. Ainsi on distingue le blanc ćclatant, on argenté(voyez ce mot); le blanc de neige (schnocwciss, all.), qui est très-pur (ex. Ptcrocephalus. nivcus, Coccoloba nivea, 'Tuber niyeum, Coleoramplus nivalis, Ery. thraus nivosus, Acropodium nivalc), et qu'on nomme quelquefois blanc virginal (Agaricus virgincus); 
le Zlaned'ivoire(elfcnbcinuciss, all.), qui cst pur et un peu lisse (comme celui des ćpines de l'Acacia cburnea, ou du plumage du Larus eburncus); le blanc dc lait (milcluweiss, all.), qui est mat et un peu transparent (ex. Draba lactea, Noctua lactinea, Geometra lactearia, Colymbus lacteolus, Astragalns galactitcs); le blanc de chaux (kreidcwciss, all.), qui cst mat ct opaque (cx. Bulimus calcarcus, Agaricus ecrussatus); lc blanc terne (ex. Stomatia obscurata, Teucrium Polium).

BLANG DE GHAMPIGNON, s. m., mycclium, carcythium. Substamee blanche, filamenteuse, forméc d'unc multitude de fibrilles, qui parait être l'ćlat rudimentaire des champignons, d'après les observations de Ehrenberg.

BLANGIMATRE, arlject., weisslich (all.); whitish (angl.) ; bianchiccio (it.); qui est d'un blane un peu sale (cx. Cistus albidus, Goodenia albide, Xyphidium allidum, Aspalathus albens, Ocypodus albicans, Mergus albellus, Carocolla albella, Ncrita albicilla, Pleurotoma albina, Tellina albinella, Mugil albula, Cyathodcs dealbata, Agaricus dcalbatus, Racodium dealbatum, V cnus exulbida, Cotuber subalbidus, Clausilia candidescens, Clansilia albesccns); qui parnit blane parec qu'il est couvert de poils ou de duvet (ex. Larus canus, Botrytis cana, Lcucosccptrum canum, Cheircunthus incanus, Goodcnia incana, Solanum incanzem); qui tend à devenir blanc, par la superposition de poils peu nombreux (ex. Desmodium cancscens, Capparis incanescens).

BLANGHEUR, s. f. , albor, albcdo, albitudo, albities; $\lambda$ sงッór hcit (all.); whitcncss (angl.) ; bianchezza (it.). Qualité de ce qui est blanc : coulcur blanche.

BLANGUININE, s. f., blanchinina.
Alcaloide dont N. Mill a annoncé avoir fait la découverte dans le china bianca (Cinclona macrocarpa).

Bhan avinlue. $V$. BLaficuinine.

IBLALSIDES, adj. et s. m. pl., Blapsides. No in donné par Cuvier, Latreille ct $\mathbb{E}$. Eichwald a une tribu de la famille des Colcoptères Mélasomes, qui a pour type le genre Blaps.

BL.ASTR, s. m. , blastus; $\beta \lambda \alpha_{0} \div 0_{5}^{5}$,

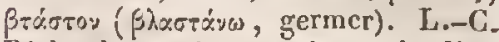
Richard appelle ninsi la parlie d'un cmbryon à grosse radieule qui est susecptihle de se développer par l'effet de la germination, comme la partie cxterne de l'embryon du miïs.

BLASTLME, s. in. , blastcnia;

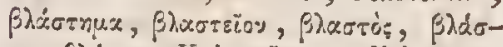

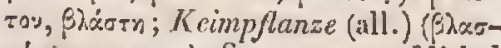
$\tau \dot{\alpha} \nu \omega$, germer). Sous ce nom, Mirbel désigne l'embryon végétal, abstraction faite des cotylédons, savoir le collet, lis radiculc et la plumule. Wallroth l'applique au thalle des licheris (Flcchtenbrutlager, Flechten lagcr, all.)

DI.ASTESE, s. f., blastcsis. Wallroth désigne sous ec nom le développement des lichens, c'est-ì-dirc la formation de leur thalle, par suite de l'aceroissement d'un corpuscule reproducteur ou d'une gonidic hors du système qui lni a donné naissance.

BASTOCARIE, adj. , blastocar-

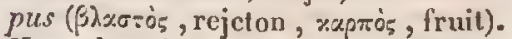
Nom dorné par Richard à l'embryon qui germe et commence à sc développer avant d'ètre sorli du péricarpe.

BLASTODERUIC, s. m., blasto-

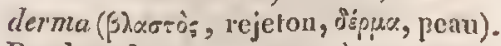
Pander donne ce nom it un corps membraniforne situé an dessous de la cicatricule de l'ocuf, et dont le développement produit toutes les parties du corps dw poulet.

musTOGLVísIE, s. f. , blastogrc-

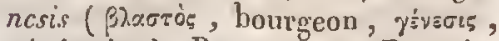
génération). Par ec terme DupctitThouars entend la mulijplication des 
plantes au moyen de bourgeons.

BLASTOGRAPIIE, s. f., blasto-

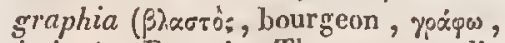
ćcrirc). Dupetit-Thouars appelle ainsi une partie de la hotanique qui a pour objet la considération du bourgeon, qui en déterninc l'apparence, l'essence et le développeinent.

BLASTOPIIORE, s. m. , blasto-

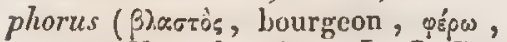
porter). Nom donué par L.-C. Kichard à la partie d'un embryon à grosse radicule qui porle lc blaste.

BLASTOSPONES, adj. et s.m.pl.,

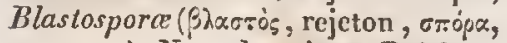
semenee ). Nom donné par Reichenbach à une section de l'ordre des $\mathrm{Li}$ chens gymnospores, comprenant les deux familles des Pulvérariées ct des Coniocarpées.

BLATTAuRES, adj. ct s. m. pl., Blattarice. Sous ce nom, Latreille, Eichwald, Ficinus, Carus el Goldfuss désignent une farnillc de l'ordre des insectes Orthoptères, qui a pour type le genre Blatla.

BLEGIINOIDES, adj. et s. f. pl., Blechnoüdca. Non donné par G.-F. Kaulfuss à une section de la tribu des Polypodiacées, qui a pour type le genre Blechnum.

BLÊME, adj., pallidus, exalbidus; bleich (all.); blcak (angl.); smorto (it.). Sylionyme de pále (voyez ce $\mathrm{mot}$ ), qui ne se dit guère qu'en parlant de la eouleur du visige de l'homme : teint blëme.

BLENDE, s. f. (de l'allemand blcnden, tromper). Quelques minéralogistes, Hausmann, Mohs, Breithaupt, ont proposé de donner ce nom aux sulfures métalliques privés de l'éclat métallique, comme celui de ziuc, qui le portc d'une manièrc spéciale, et qui le doit ì ce qu'ayant l'apparencc du sulfure de plomb, il en impose aisément aux mineurs peu expérimentés.

BLENNIOIDES, adj. et s. m. pl.,

\section{BLEU}

Blennioidds. Nom donné par Blain= ville à une famille de la classe des poissons, qui a pour type le genre Blennius.

BLÉPHARE, s. m. , blcpharon,

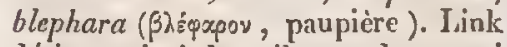
désigne ainsi les cils ou dents qui bordent quelquefois le péristome de l'urne des mousses.

BLGPHANOGLOTTE, adj., blcpha-

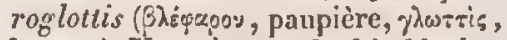
langue). Unie plante (Orclis blepharosslottis) est ainsi nommée parce que la lèvre de son nectaire forme une languette garnie de poils.

BĹ́pHARopIORL, adject., blepharophorus ( $\beta$ ¿̇́papov, paupière, eípes, porter). Le Paspalus blepharow phor'us est appelé ainsi à cause de ses fcuilles, qui sont eiliées sur les bords.

BLESSISSEMENT, s. m. Modification partieulière que subit lc parenchyme de certains fruits charnus, et qui paraît consister tantôt en un phénomènc de simple maturation, ef tantôt en un véritablccommencement de putréfaction. On l'observe surtont dans les fantilles des Pomacées et des Ebénacécs, parfois aussi dans celles des Annonées et des Vaccinićes. Gertains fruits, tcls que ceux du sorbicr, du néflier ct du diospyros, ne peuvent être mangés qu'après qu'ils l'ont subie.

BLET, adj., teig (all.); solf(angl); fracido (it.). Epithète donnée aux fruits qui ont subi l'altération spéciale appelée blessissement. Voyez ce mot.

izLítissurie. Voyez BuessisseMENT.

BLEU, adj. et s. m., caruleus,

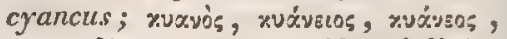
xuxvosidx's, xucvósıs; blau (all.); blue (angl.); turchino (it.). L'unc des sept couleurs primitives. On distiugrac le blcu en général (ex. Gobius caruleus, Passiflora carulea, XYphidium carulcum), le blcu foncé (ex. Agaricus cyaneus, Eqquorea 
eyanea, Turnus cyanus), le bleu céleste ou usurté, qui est vif, mais un peu clair (ex. Eupatorium colestinum), voycz Azoné; le bleu päle, tirant sur le gris (ex. Gonotrichium casium). Très-souvent on cxprime l'idée de bleu par le nom d'un objet qui porte cel te couleur (ex. Troelitizes lazulus, Psittacus ultramarinus, Actineetaultramarina, Helops amethystinus, Trochilus saphirinus, Porphyrio hyacinthicus, etc.)

BLEUATRE, adj., carulescens, carulans, corrulatus, subcoruleus, calestinus; \%uavirs, blüulich, blassblau (all.); bluish (angl.); qui cst d'un bleu pâle. Ex. Edolius corulescens, Acrydium corulans, Praniza carulata, Sylvia subcorulea.

BLEUISSANT, adj., cyanescens; qui tend ì devenir bleu. Le Boletus cyanescents et quelques autres bolets, quand on les coupe, devicnnent d'un beau bleu sur la tranehe, phémomène qui a élé remarqué d'aloord par Bonnet, et depuis éludié arec soin par Saladin et Macaire.

BLeuissemen', s. m. Passage d'une couleur au bleu.

BLOG, s. m., Klotz (all.) ; lump (angl.); rocclio (it.). Masse de roches eohérentes, qu'on trouve sur lc sol, enfoncées dans d'aulres masses d'une nature et d'une texture différentes, et qui ont un volume considérable.

BODIANITES, adj. et s. m. pl., Bodianites. Latreille désigne sous ce noon une tribu de la famille des poissons Sparoïdes, qui a pour type le genre Bodiunus.

BOEHMÉnlées, adj. et s. f. pl. , Boehmerice. Nom donné par A. Richard à un groupe de la famille des Urlicées, qui a pour type le genre Bochmeria.

BOEMT CEES, adjeet. et s. f. pl., Boemycece. Sous ce nom, Fce désigue une tribu de la famille des $\mathrm{Li}$ - chens, ayant pour type le genre Boemyccs. Voyez Baomycées.

BOIDÉs, adj. et s. ni. pl. , Boida. Nom donnć par J.-E. Gray à une famille de l'ordre des Reptiles ophidiens, qui a pour type le genre Boa.

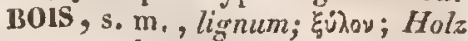
(all.) ; wood (angl.); legno (it.). Ce mot a plusicurs signifientions : $\mathfrak{L}^{\circ} \mathrm{cn}$ botanique, on appelle bois, en géućral, le corps ligneux ou toule partie d'un végétal dont la eonsistanee est ferme. Strictement parlant, on ne donne ee nom qu'à la portion du eorps ligneux lui-même qui a acquis toute sa dureté, conume le centre des Dicotylédoncs et la circonférence des $\mathrm{Mo}_{0}$ nocotylédones. $2^{\circ}$ En zoologie, on nonumc bois les cornes solides et couverles de peau qui garnissent la tête de eertains ruminans, soit qu'elles persistent loujours, eomme dans la girafe, soil qu'elles tombent ì une eertaine éproque de l'annéc, pour re. naître à une autre, comme celles du cerf, du daim, du ehevrcuil, du renne, de l'élan.

BOITE A S.AVONNETTE, s. f., capsula eircumseissa. Nom donné quelquefois, à cause de sa forme, à une eapsule bivalve qui s'ouvre transvelsalement, conme le meuble auquel on l'a comparée. Ex. Hyoscyainus.

BOLĹtate, s. m., boletas. Genre de sels (schwammsaurc Salze', all.) qui résultent de la combinaison de l'acide bolétique avee les bases salifiables.

BOLÉTITORME, adj., bolcliformis (boletus, bolet, forma, forme). Epithèle donnée à quelques polypiers qui ont un peu de ressemblance avee des bolets. Ex. Pavonia boletiformis, Alcyonium boletiforme.

BOLÉrroUs, adj. , boleticus. Nom donné par Braconnot à un acide particulier (Schwantmsäure, all.), qu'il a déeouvert dans le Bolelus pseudoisniarius. 
- BOLÉroIDES, adj. et s. m. pl. ; Bolctoïdes. Nom donnć par Persoon à une division de la elasse des ehampignons, qui a pour type le genre Boletus.

BoLETS, s. m. pl., Bolcti. Marquis donne ce nom il un groupe de la famille des Champignons hyménothéciens, ayant le genre Bolctus pour type.

BOLIDE, s.m., bolis, globus ardens; Fcuerhugel (all.) ; fire ball (angl.). On appelle ainsi des météores jgnés, assez fréquens, qui consistent en des masses de feu iraversant ou paraissant traverser l'atmosphicre avec une grande rapidité.

Bonibacúrs, adj. el s. f. pl., Bombacea. Nom donné par Kunth à une farnille de plantes, qui a pour type le genre Bombax.

iзомiвнт, s, m. , bombias. Sel produit par la combinaison de l'acide bombique avee une base salifiable.

Bombicioue. Vorez Bombique.

BOMEIVATOHOIDIS, adj. et s. m. pl, Bombinatoroüdea. Nom donné par P.-F. Fizinger ì unc famille de reptiles batraciens, ayant pour type le genre Bombinator.

BoMmeve, adj. Nom donné par Chanssier it un acide partieulier, (Raupensüure, Seidenwürmersüure, all.), qu'il a trouvé dans le ver à soie, et dont l'existence est eneore problématique.

BOMDOMYDEs, adj, et s.f. pl., Bombonydes (fiupos, bourdonnemeut, uuise, movehe). Nom donné par Rubineau-Desvoidy à unc section de la famille des Myodaires Calyptérées, comprenant des espèces qui font entendre un fort bourdonnement durant le vol.

BOMByCIDEs, adj. et s. m. pl., Bombycida. Icach désigne ainsi lá famille des Bombycites. Voyez ee mot.

boMbrartes, adj. ct s. m. pl,g
Bombycites. Nom donné par Cuvier, Lamarck, Latreille , Goldfuss , Eichwald, Ficinus et Carus à une famille ou tribu de Lépidoptères nocturnes, qui a pour type le genre Bombyx.

BOMBYCIVORE, adj. , bombyciyorus (bomby'x, bombyx, voro, dévorer); qui vit dans les ehenilles de Bombyx. Ex. Salia bombycivora.

IBOMis YLIAIRES, adj. et s. m. pl., Bombyliarii. Eichwald et Wiedemanu appellent ainsi une tribu de la famille des Diptères tanystones, ayant pour type le genre Bombylizs.

BOMBYLines, adj. et s. m. pl., Bombylida. Leach donne ce norn à la famille des Bombylicrs. Voyez ee mot.

BONBYLIERS, adj. et s. m. pl. , Bombyliarii. Nonı sous lequel Lamarek et Latreille désignent une famille de l'ordie des Diptères, ou une tribu de la famille des Tanystomes, ayant pour type le genre Bombylizs.

BOvisYins, adj. et s. f. pl. , Bombylia. Nom donné par J. Maequart à la fanille des Bombylicrs. Voyez ce mot.

BOMBILIFI:RE, adj. , bomlylïferts. Une plante (Oplirys bombyliifera) a élé nomméc ainsi parec que ses fleurs représentent l'espece de monche eonuue sous le nom de Bomb) lius.

BONNET, s. f., pilctus. Les ornithologistes appellent ninsi toute la surfaee du dessus de la tête des oiseaux, depuis la base du bec jusqu' a la nuque.

BONNÉTtées, adj. et s.f.pl., Bonnctice. Nom donné par Bartling à une tribu de la famille des Ternstroemiacées, qui a pour type le gcure Bonnciia.

BOOPDĹEs, adj. et s. f. pl. H. Cassini at prosé de désigner ainsi, ì eause da genre Boopis qu'elle renferme, la famille des plantes is la 
quellc L. - C. Richard a donnć celui de Calycérées.

BOOPS, adj., boops ( $\beta$ oüs, hœuf, äl, neil); qui' a des yeux très-grands eu ćgard à sa taille. Lx. Cheilodiplerus boops.

BORACIQUE, adj. Épithète donnćc autrefois ì l'acide borique, parce qu'on le retire du borax. La magnésic boratée est uommée spath boracique par quelques minćralogistes.

BOrASSÉES, adj. et s. f. pl., $B_{0-}$ rassece. Norn sous lequel Nartius désigne une triba de la famille des Palmiers, qui a pour type le genre $\mathrm{Bo}$ rassus.

BORATE, s. m., boras. Genre de sels (boraxsaure Salze, all.), qui résultent de la combinaison de l'acide horique avec les bases salifialles.

BORATé, adj. Les ninérılogistes de l'école d'Haüy disent qu'unc basc est boratée quand ellc est combince avee de l'acide borique. Ex. Magnésie boratéc.

BORD, s. m., margo; Rand (all.); edge (angl.); orlo, bordo, margine (it.). On appelle ainsi, d'une manic̀re générale, la lisière qui joiut les deux faces des parties planes, et qui en dessinc le contour, soit qu'elle n'offre rien de spicial, suit qu'elle se fass' remarquer par son mode de colorition. Les conchyliologistes donnent ce hom à la terminaison inférieure de la cogguille, ou à ec qui en forme l'orifice.

BOMDANT, adj., marginans. Cotte épithèle est donnée, par les botanistes, à l'aiogrette d'un áchaine, quand clle ne constitue qu'un léger rebord inembraneux.

IONDḱ, adj., marginatus, marginalis, marginulatus, limbalus; $g c-$ ranflet, gesin̈umt, cingefasst (all.); edged (angl.); orlato, marginato (it.). Se dit: $1^{\circ}$ en minéralogic, d'un culie dont ehaque bord est remplaeć par deux faceltes tres-inclinces sur les faces adjacentes, de sorte que leur asscmblage semble former une bordure antour de es faes (ex. Chaux fuatée bordée); $2^{\circ} \mathrm{en} \mathrm{botanique,}$ d'une plante dont le loord des fenilies se fait remal'quer par son épaississcmeut (ex. Chcetanthera limbata), par sa nature scarricuse (ex. Loranthus marginatus), pardes poils hlanes Iui le garuisseut (ex. Leplospermum marginatum), ou paree que c’est presque uniquement aupres delui que se trouvent placés des sores solitaires (ex. Polypodium marginale); $3^{\circ} \mathrm{en}$ zoologie, d'uue surface dont le bord diffère du reste, soit par sa substance, comme la lunule d'une eoquille bivalve, quand elle cst limitée par un bourrelet saillant, et le bord supéricur des tours d'unc coquille univalve, lorsqu'il est un peu épais; soil par sa forme, comme le corselet des Boụcliers, dont les côtés sont relcrés; soit par sa coloration, diflérente de celle dn reste, comme dans l'Arara marginata, qui a les couvertures des ailes bleucs et bordées de jaune, le Labrus marginalis, dont les nagenires dorsile et peelorales sont bordées de roux, la Blalla maryinala, qui a les élytres noires ot bordées de blane, le Glomeris limbatzes, qui est noir, à bords jaunes, le Dasypogon limbatus, quiale thorax bordé de jaume.

Botovere, s. f. H. Cassini donue ce nom aux bords de la squane du péricline des Symanthérées, quand ils sont d'uue antre nature que la partic moyenne, la différenee étant uotable et la transition brusque.

BOPW, s. 1i., bora, boracium, borium, boron; Boron, Boraxstuff. (all.); boro (it.). Corps simple, qui a été déconvert en 1808 par Gay-Inssac et Thénard, et dont l'existence avait été soupconnée dès $1807 \mathrm{par}$ Davy, d'après quelqques expériences galvauiques. 
BORÉ, adj., boratus; qui contient du bore. Davy admet un gaz hydrogène boré, que $\mathrm{L}$. Gmelin a cru observer aussi, mais dont l'cxistence est encore problématique. Voyes Boruré.

BORÉAL, adj. , borcalis, psychodes; غ.prrtxós; nördlich(all.); northern (angl.); boreale (it.). On appclle ainsi : $x^{\circ}$ en astronomie, tout ce qui se trouve au nord de la ligne équixıoxiale, comme le pöle borćal et les constellations boréales, qui sont, parmi les zodiacales, le Bélier, le Taureau, les Gémcaux, l'Écrcvisse, le Lion et la Vierge. $2^{\circ}$ En physique, le magnétisme boréal est eclui qui domine dans la partic boréale du glohe terrestre. On nomme Aurore boréale, aurora borealis s. septcntrionalis, lumen boreale, lucula borcalis, lux. Boreu; Nordschein, Polarlicht (all.); northern light (angl.), un phénomène Iumineux qui s'observe dins l'un et l'autre hémisphère, ver's les pôles, et dont on a donné plusieurs explications, dont aucune n'est complètement salisfaisante. $3^{\circ}$ En histoire naturelle, l'ćpithètc de borćal est donnée à des plantes qui croissent dans les contrécs septentrionalcs des deux mondes (ex. Linnea borealis, Galium boreale, Alyssum hyperborcum, Orehis psychodcs), ou à des animaux qui vivent dans lc nord (ex. Stellerus borealis). Voyez Algide, Gracial et Irperboréen.

B̈ORICO-ALUMNIQU. Nom donné, dans la nomenclaturc chimique de Berzelius, à des sels doubles qui résultent de la combinaison d'un sel horique avec un sel aluminiquc. Ex. Fluorure borico-aluminique (fluoborate d'aluminc'.

BORICO-AMMONiq̨UE, adj., borico-ammonicus. Nom donne, dans la nomenclature chimique de Berzelius, à des scls doubles qui résultent de la combinaison d'un sch borique avec un sel ammonique. Ex. Fluorure borico-ammonique (fuoborate d'animoniaque).

BORICO-BARXTIQUE, adj., borico-baryticus. Nom donné, dans la nomenclature chimique de Berzelius, à des sels doubles qui sont produits par la combinaison d'un sel borique avec un sel barytique. Ex. Fluorure borico-barytique ( $/$ uoborate de barytc).

BOLICO-CALCIQUE, adj. , borico-calcicus. Nom domé, dans la nomenclature chimique de Berzelius, à dos sels doubles qui rćsultent de la combinaison d'un sel borique avec un setralciquc. Ex. Fluiorure loorico-calcique ( (nuoborate de chaux).

BORICO-CUIVRIQUE, adj. , borico-cupricus. Nom donné, dans la nomenclature climique de Berzclius, à des sels doubles qui sont produits par la combinaison d'un sel borique avee un sel cuivrique. Ex. Fluorure borico-cuivrique (fluoborate de cuipre).

BORICO-LITIIQUE, adj. , boricolithicus. Nom donné, dans la nomenclature chimique de Berzelius, à des sels doubles qui résultcut de la combinaison d'un sel borique avec un scl lithique. Ex. Fluorure borico-lithique (fuoborate de lithine).

BORICO-MAGNíSIQUE, adj. , borico-magnesicus. Nom donné, daus la nomenclature chimique de Berzclius, à un sel double qui résulte de la combinaison d'un sel borique avec un scl magnésique. Ex. Fluorareborico-magnésique (fluoborate de magnésie).

BOnYCO-PI.OABIQUE, adj. , borico-plumbicus. Nom donné, dans la noniencliture chimique de Berzelius, à un sel double qui résulle de la combinaison d'un sel borique arce un sel plombique. Ex. Fluorure borico-plombique (fluoborate de plomb). 


\section{BORI}

FORICO-POTASSIQUE, adj., borico-polassicus. Nom donné, dans la nomenclature chimique de Berzclius, à un sel double qui résulte de la combinaison d'un scl borique avec un sel potassique. Ex. Tartrate borico-potassique.

BORICO-SODIQUE, adj. , boricosodicus. Nom donné, dans la nomenelature ehimique de Berzelius, à un sel double qui rćsulte de la combinaison d'un sel borique avec un sel sodique. Ex. Fluorure borico-sodique (fuoborate de soude).

Bonico-STRONTIQUE, adj., borico-stronticus. Nom donné, dans la nomenclature chimique de Berzelius, à un sel double qui résulte de la combinaison d'un sel borique avec un sel strontique. Ex. Fluorure boricostrontique (fluoborate de stroniane).

BORICO-YTTRIQUE, adj., boricogetricus. Nom donné, dans la nomenclature chimique de Berzelius, 'à un sel double qui résulte de la combinaison d'un sel borique avec un sel yttrique. Ex. Fluorure borico-yttrique (fuoborate d'yttria).

BORICO-ZINCIQUE, adj., boricozincicus. Nom donué, daus la nomenclature chimique de Bcrzelius, à un sel double qui résulte de la combinaison d'un sel borique avec un sel zincique. Ex. Fluorure borico-zinciquc (fluoborate de zinc).

Borides, s. m.pl., Borides. Nom donné par C. Panquy à une famille de corps pondérables ayant le bore pour type, par Ampère à un genre de corps simples qui comprend le bore et le silicium, par Beudant à une fimille de miıćraux, dans laquelle il range l'acide borique et ses diverses combinaisous.

BORIQUE, adj., boricus. Épithète donnée à un acide (Boraxsäure, all.), qui résulte de la combinaison du bore avec l'oxigène, et qui a élé décou- vert par Hombcrg, en r 702. Berzelius appelle chloride borique (Chlorboron, all.), Ja combinaison du chlore avec le bore, sulfide borique (Seluwefelboron, all.), celle de ce dernier corps avec le soufre, el fluoride borique(Fluorloron, all.), celle avec le fluor, ou l'acide fuoborique d'autres chimistes.

BOR0-FLCOHURE, s. m., borofluoruretum; Fluorboronfuormetall, (all.). Composé qui résulte de la combinaison du bore et du fluor avec un métal électro-positif, ou de celle d'un fluorure métallique avec le fluoride borique.

BOnonires, adj. et s. f. pl., $B o$ ronica. Nom donué par Bartling à une tribu de la famille des Diosmées, qui a pour type le genre Boronia.

BOROSULICIQUE, adj. , borosilicicus. Berzelius, dans sa nomenclaturc chimique, appelle fluoride borosilicique(Fluorborfluorkiesel, all.), une combinaison de fluoride borique et de lluoride siliciqque.

BORIAGINÉES, adj. et s. f. pl., Borragince. Nom d'une famille de plantes, établic par Jussieu, qui a pour type le genre Borrago.

BolkurE, s. m. , boruetum. Composé qui résulte de la combinaison du bore avec un autre corps simple.

Borunk, adj., boruretus; qui eontient du bore. I. Gmelin eroit avoir oblenu un gaz liydrogine boruré (Boronwasserstoffsas, all.), e'cst-à-dire tenant du bore en dissolution.

BOSSE, s. f., gibbositas, gibba, gibbus, tubcr, umbo; Buckel, Höcker (all.); bunch (angl.); gobba (it.). Ce terme est employé : $2^{\circ}$ en lotanique. Mirbel appelle aiusi des appendices en forme de petits saes renversés, qu'on trouve à l'entrće de plusicurs corolles (cx.Borrago officinalis), et is l'éperon, quand il est tres-court et abtus. $2^{\circ} \mathrm{En}$ zoologie, on donne ce nom à des proé- 
ninenees arrondies qui s'élèvent att dessus d'une surface queleonque. Kirby appelle bosses deux protubérances mobiles, surmontées d'une épinc, dont le prothorax des Macropus cst armé.

BOSSEut́, adj., torosus, corulosus, umbonalus, giblerosus; gebiickele (all.) ; crimpled (angl.); imbossalo (it.). Se dit d'un corps cylindrique qui est relevé ou renflé ęà et lit en bossclures. Ies Crassatella gibbusula, Dolhidea gibucrosula, Strombus sibubcrulus, Buccinun gibbosulum, Lytherea umbonella, sont des coquilles plus on moins renflées et comme bossues: Le Geodia gibbcrosa est un polypier tubérilorme. Le Clidesmia umbonata a des feuilles qui offreut en dessus des soies renflées à lcur base.

BOSSETTE, s. f. Nom vulgaire qu'on donne aux deux tuberenles qui paraissent, à l'âge d'environ six mois, sur l'os frontal du faon.

BOSSU, adj. , siblus, gibbius, mibbosus; hoshgcwijlbt, höckcrigr (all.); gibbons (augl.); gobbo (it.). Se dit, en général, d'un unimal qui a le dos tris-convexe et en forme de bosse (ex. Ostracion gibbosus, Emys gibba, Diacope gibbus). Quelques coquilles on treçu eette épithète parec qu'clles sont comme reuflées ( $\mathrm{ex}$. Cytherca giblia, Bulla gibbosa). Les entomologistes l'appliquent au corselet des insectes, quand il est élevé ct très-eonvexé (ex. quelques Buprestes).

HOSTRICHKS, adj. et s. m. pl., Bostrichini. Nom donné par Latreille, Gola'fuss, Eichwald, Ficinus et Carns à une tribu de la famille des coléoptères Xyloplanges, qui a pour type l' genre Bostrichus.

BOSTIICHORODES, adj. et s. m.

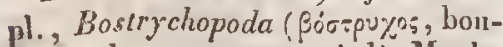

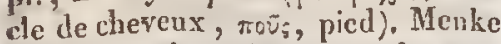
désigne la classe des Cirripèdes sous

\section{BOTH}

ce nom, à eause de la forme des pieds des animaux qu'clle renferme.

BOTAXIQUE, s. f. , bolanica, botanice, res herbaria; Pfanzentiunde, Gewaichskunde, K, äuterkunde (all.); botany (angl.) ( (jorxim, herbe). Scicnce qui a pour objet la connaissance des végétanx, de leurs caractères, de leurs différences et de leur classifieation méthodique.

BOTANIQLE, adj., botanicus; $\beta$ oTxvixos; qui a rapport aux plantes. La géongraphic bocanique est l'étnde méthodirgue des faits relatifs à la distribution des végétan $\mathrm{x}$ sur le glohe, et des lois plus ou moins générales qu'on peut en déduire. Caudolle appelle région botanique l'espace qui, si l'on fait abstraction des espéces introduites à dessein ou par hasard, offre un eertain nombre de plantes qui lui sont particulières et qu'on peut considérer conıme en élant véritablement aborigènes.

BOTANISTE, s. m. , botanista, bolanicus; for-xvtGris. Naturaliste qui se livre à l'étude de lia botanique, qui possède ectle science.

BOTANOGHAMLUE, adj. , bolanographicus ( écrire). Se dit d'un ouvrage destiné ì la deseription d'un certain nombre de plantes.

BOTANOLOGIE, s. f., botanologia (Sorźvn, lierbe, hígse, disconrs). Synonyme inusité de: Botanique.

nOTAXOilHAGi, adj. , botano-

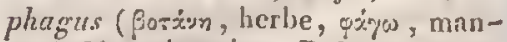
ger). Nom donné par Robineau Desvoidly aux Myodaires Callyptérées dont les larves vivent de matičres végétales.

BOTRLLIF VIIn, adj., botclliforus (botellus, sancissc, fero, porter). Une éponge ( $S$ pongia botellifera) est ainsi appelée parce qu'elle a des anmeaux droits, tubereuleux et bouillonués, quion a comparés a des saueisses. $V_{\text {ojez }}$ Allantopisorf.

BotunocúpIALES, adj. cl s.m. 


\section{BOƯC}

pl., Bothrocephala ( $\beta$ óoos, trou, revarhin, tête). Nom donné par Blainville à un ordre de la classe des Subannélidaires, comprenant ceux dont le renfement eéphalique est prourvu de fossettes plus on moins profoudes.

BOTRYLACÉS, adj. el s. m. pl., Botryllacea. Nom donné par Meuke à une famille de l'ordre des Tuniciers Téthyes, qui a pour type le genre Botryllus.

BOTRYLLAIRES, adj. ct s. m. pl., Botryllaria. Nom donné par Lamarck ì un ordre de la classe des Tuniciers, qui a pour type le genre Botryllus.

BOTnYllides, adj. et s. f. pl., Botryllidea. G.-S. Macleay désigne sous ce nom une famille de la classe des Tuniciers, comprenant les Téthyes composées de Savigny, ct ayant lc genre Botryllus pour type.

BOTRYOLEL, adj. , boiryoïdes;

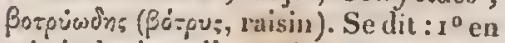
unituéralogie, d'un minéral ayant la forme de graius qui imitent une grappe de raisin par leur disposition (ex. Chaux boratée siliceuse botryoïde); $2^{\circ}$ en lootanique et en zoologie, d'une cryplogane (Lepraria botryoüdes) qui a ses globules disposés presque en forme de chapelet, et d'uno époinge rameuse (Spongia botryoides) dont les lobules sont ovales et diffus.

BOTRYTIDÉEs, adj. et s.f. pl. , Botrytidce. Nom donné par Fries et par Ad. Brongniart à un groupe de la tribu des Mueédinées, qui a pour type le genre Botrytis.

bovcrie, s. f., os; бrómx; Mund (all.); mouih (augl.); bocca (it.). Orifice du canal alimentaire, par lcquel les animaux introdnisent dans leur corps les substances dont ils se nourrissent. Ouverture des coquilles univalves, qui livre passage au corps del'animal. Dans le langage vulgaire le mot de bouche est pris daus une acecption moins génerale, ou du moins appliqué d'une manière fort arbitraire.
Ainsi on dit la bouche de l'homme, du cheval, du mulet, de l'ànc, du bocuf, du cliameat, de l'éléphant, ct en géméral des bêtes de sonme et d'attelage; mais on dit la grueule (Maul, all.) d'un chien, d'un loup, d'un chat, d'un lion, d'un erocodile, d'un lézard, d'un serpent, d'une vipère, d'un brochet, d'une truite. Cependant on dit aussi la bouche d'un saunon, d'une earpe, d'une grenouille. Il paraîtrait que le mot de guculc entraine plus que celui de boucke l'idée de la voracité et d'un naturcl sanguinaire.

BOUCLE, s. f., clavus. On appelle ainsi des masses cartilagineuses, com. pactes, lenticulaires, d'un blane pur, armées de crochels cornés et recourbís, qui, dans quelques poissons, sont cachées en grande partie sous lcs tégumens, retenues et affermies par
eux.

BOUGLÉ, adj., clavalus, spinasus. Epithètc donnce à des poissons qui ont le eorps armé de poiutes recourbées, adhérentes à de lar'ges et ronds tubercules logés dans la pean. Ex. Raja clavala, Scymnus spinosus.

BOUCLIER, s. m. , eljpeus, scthtellum, scutellulum. On appelle ainsi : $1^{\circ}$ en botanique, une sorte de conceptacle à surface large et aplatic; per coriaec, qui se développe au bord du thalle de certains liehens, $n^{\prime a}$ point de bordure, ou présente une bordure accessoire trìs-étroite, et est couvert, avant son développement, par une membrane mince et gélatinense (ex. Physcia Islandica); $2^{\circ}$ en zoologie, un épaississement charnu qui seremarque sur le dos des limaces, et qui cst lc rudiment d'un manteau; la grande écaille qui recouvre la tête, le thorax proprement dit'et lé préabdomen des crustacés binocles; Ia partio antéricure des Trilobites, qui paraît répoudre au céphalothorax ; une partie de la tête des insecies, 


\section{0}

qu'on désigne plus ordinaircment sous le nom de chaperon (voyez ce mot); suivant Straus, une des six pièces du corselet des insectes, cellc qui en occupe toute la partie supéricure, et qui se replie latéralement en dcssous, pour aller a la rencoutre du stcrnum, avce lequcl clle s'unit; d'après C.-G. Ehrenberg, le têt de certains Infusoires, quand il est assez solide, rond ou ovale, ct placé sur le dos seulcment de l'animal (ex. Euplotes).

BOUEUX, adj., lutarius, lutosus. Nom donné à des auimaux qui vivent dans la bouc, le limon, la vase, comme l'Eburna lutosa, l'Enys luttaria, la larve du Sialis lutarius.

BOUFFI, adj., turgidus; qui est renflé, sans être pour cela aminci; comme la camare des Paonia, le $l \dot{e}-$ gume des Crotalaria, la silique du Raphanus sativus.

BOULET, s. m. , commissura ; Kölc (all.); fetlock (angl.); nocca (it.). On appelle ainsi, dans le cheval, la région des mocubres qui est située entre lc canon et le pâturon.

BOUQUET, s. m., sertulum. L.-C. Richard donnait ce noon à un genre d'inflorescence produitc par un assemblage de pédoncules uniflores partant tous d'un même point ct alrivant presque à la mème hauteur. Ex. Primula.

BOURDONNANT, adj., bombylans; qui bourdonne. Ex. Cenogaster bombylans.

BOURDONNEMENT, s. m., bombus, murmur, susurrus ; Sumsen (all.); humming (angl.); susurro (it.). Bruit que font entendre les oiseau $x$-mouches, lcs colibris ct les insectes, quand ils volent, et plusieurs de ces derniers quand on les saisit.

BOURGEON, s. m., gemma, oclllus; Knospe, Auge (all.); bud (angl.); gemma, bottone, pollonc (it.). Pour le vulgaire, ce mol désiguc les jeutues
BOUR

productions ou branches des végétaux vivaces ( voyez Scion), quclquefois aussi les boutons à fleurs. Les bolanistes appellent ainsi l'ensemble des ćcailles ou tuniques qui entourent la jcunc pousse, la protègent dans sa jeuncsse, et sont ou des fcuilles avortćes (cx. Daphne Mezereum), ou des bases de pétioles dilatées en forme d'ćcailles (ex. Juglans regia), ou des stipulcs avortées ( cx. Magnolia glauca), ou des stipules et des pétioles soudés ensemble ( ex. la plupart des Rosacécs).

BOURGEONNEMENT, s. m., gemmatio; Ausschlagen (all.). Époque du developpement des bourgeons; ensemble des phćnomènes qui accompagnent ce développement. Candolle entend par la l'ensemble des bourgcons d'un arbre.

BOURRE, s. f., tomentum ( $\pi$ uppóós, roux). Nom donné aux poils courts ct soyeux des quadrupèdes qui en ont de dcux sorles, et par analogie anx poils qui recouvrent quelques vćgétaux, au duvet cotonneux qui revct les bourgeons de certains arbres.

BOURRELET, s. m. , tubera; orliccio (it.). On appelle ainsi : $\iota^{\circ}$ en botanique, dcs grosseurs ou renflemens visibles, qui apparaissent accidentcllement ou naturcllement sur le tronc d'un végétal ligneux, et des appendices divers, en général un peu arrondis, qui proviennent de l'épaississenent de l'organe destiné it les porter ; $2^{\circ} \mathrm{cn}$ zoologie, des épaississemens ou cordons longitudinaux, situés sur lc bord, la spire ou la face externe de certaines coquilles spirivalves, et qui coupent les tours de la spire trausversalement ou à angle droit.

BOURSE, s. f. , bursa. ( $\beta \dot{p} \rho \sigma \alpha$, cnir). Membrane qui enveloppe quelques espéces de champignons en entier, pcndant leur premier îge, et qui se déchire par l'effel de la crois- 
sance? Bourses est le nom qu'on donne vulgairement au serotum chez l'homme. Les mammifères de l'ordre des Marsupia ux sont tris-souvent appelés animaux à bourse, à cause de la poche abdominale dont ils sont pourvus pour reeevoir et loger pendant quelque temps leurs petits.

BOURSOUFFLi, adjeet., bullatus. Dont la surface cst relevée cà et là en bosselures ; dout la masse est pleine de cavités arrondies, on de collules très-rapprochées, séparćes par une cloison mince, surtout lorsque les cellules ont crevé les unes dans les autre's.

BOUTOIR, s. m., Rüssel (all.); snout (angl.); grugno (it.). Nom sous lequel on désigne le nez prolongé, tronqué au hout et noobile du cochon et de la taupe, dans l'intérieur duquel se trouve un osselet particnlier, appelé os du boutoir, qui lui donnc de la solidité et lc rend propre à fouiller la terre. Voyez Groin.

BOUTON, s. m., alabastrum. Nom donné à toute fleur, avant son épanouissement. Les agriculteurs prennent ec mot dans une acception plus étendue, et s'en servent pour désjgner l'ocil ou le bourgeon qui a pris un certain degré d'accroissement, qui a une forme plus ou moins arrondic ou ovale.

BOUTONNIĖRE, s. f. Quelques auteurs ont cmployé ee terine pour désigner les stignates (voyez $\mathrm{ce} \mathrm{mot)}$ dins les chenilles.

BOUTURE, s.f., talea; Stcckreis, Stcckling, $S_{\text {prössling (all.); slit, cut- }}$ ting (angl.); tallo, barbatella, majuolo, piantone (it.). Petite et jenne branche qui, coupce et fiehée dans un terrain convenable, $y$ poussc des racines et produit ainsi un nouvel individu.

BOvinís, adj. ct s. m. pl., Bovida. Nom donné par G.-E. Gray à mue famille de la classe des Mammi- fères"; qui a pour type le genre Bos.

BRACELET, s. m., armilla. On. appelle ainsi, dans les oiscaux, un anneau coloré qui est situé proche du talon el au-dessus.

BRACIÚL_YTRES, adj. et s. m.

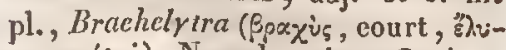

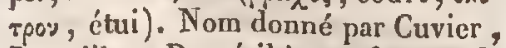
Latreille et Duméril a une fanille de l'ordrc des Coléoptères, renfermant des inseetes qui ont les élytres plus courtes que l'abdomen, quoiqu'elles recouvrent entièrement les ailes.

BRACHIAL, adj. , brachialis (brachium, bras); qui a rapport ou qui appartient au bras. On donne cctte épithète à plusieurs nervures, autres que la cubitale et la radiale, qui, dans l'aile des inseetes, naissent du mêmc point que celles-ei, c'est-ì-dire du thorax.

BRACHIDE, s. m. , braehida ( $\beta p \alpha-$ $\chi^{i(\omega), ~ b r a s, ~ E ์ \delta o \xi, ~ r e s s c m b l a n c e) . ~ A p-~}$ pendice en formc de bras. Blainville désigne sous ee nom la paire externe des tentacules des véritables Néréides, à cause de la forme, quelquefois trìs-singulière, des deux articles qui les composent, et de leur apparence, qui permet de les eomparer ì de petits bras.

BRACIIDÉ ; adj. ; qui a la forme d'un petit bras; appendice brachide. JBRACIUÉ, adject. , brachiatus; arnfirmig, armig, doppeltarmig, gearmt (all.); bracciuto, incrociato (it.) (brachiun, bras). Ce terme est employé : $1^{\circ}$ en bolanique, où il désigne des parties qui sont très-ouvertes et opposées en croix, à l'instar des bras étendus d'un homme, comne les rarons de l'ombelle dans le Daucus $\dot{C}$ arotta, et les rameau $x$ du $T c-$ trapilus brachiatus, du Banisteria brachiata, du Mesembryanthomum brachiatum; $2^{\circ}$ en zoologie, où il s'applique ì des poissons qui ont leurs nageoires supportíes par des appen- 
dices en forme de petits bras (cx. Diodon brachiatus).

İRACIIÍs, adj. et s. m. pl., Brachiala. Noun donné par Poli à un ordre de la classe des Mollusques, comprenant ccux qui ont des bras à la manière des Hydres, ou les Céphalopodes, et par Schweigger ì un ordre de Zonphytes monohyles, dans lequel il range ceux dont le corps cst Inuni d'appendices en forme de bras.

BRAGUIOGÉPHALES, adj. ct s. m. pl., Brachiocephala 'Bpayi(w), lras,

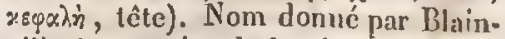
ville à un ordre de la classe des Céphalophores, eomprenant ceux dont la têle est pourvue de quatre ì cinq paires de longs appendices tentaculaires coniqnes.

BRACHOLtí, adj. , brachiolatus. Une Astérie(Comatula brachiolata) est ainsi appeléc parce que ses rayons pinnés, assez ćpais, quoique courts, ressemblent un peù à de petits bras.

BRACIrIONís, adj. et s. m. pl., Brachioncea. Nom donné par C.-G. Ehrenberg a l'unique trilu de la division des Infusoires Rotilères Zygotroques, qui a pour type le genre Brachionus.

BRACHIOnives, adj. et s. m. pl., Brachionides. Sous ec nom, Bory désigne une famille de l'ordre des Mi. croscopiques Crrustodés, ayant pour type le genre Brachionus.

BRACHOPONES, adject. et s. m. pl., Brachiopoda (Bpaxiwy, bras, тоüs, pied). Nom donné par Cuvier, Schweigger et Goldfuss ì un ardre de la classe des Mollusques, par Lamarck à un ordre de eclle des Conchifc̀res, par Eichwald à un ordre de cellc des Thérozoaires, par Intreillc, Menke, Ficinus et Carus a une elasse du règne animal, renfermant des animaux mollusques qui, au licu de pieds, ont deux bras charnus cxtensibles.

BuACLIOPTÈns, adj, et s, m.

\section{BRAC}

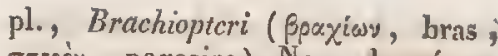
$\pi$ zвóy, nageoire). Nom donné par Blainville à une famille de poissons gnathodontes hétérodermes, renfermant cenx quiont les nageoires pec. torales pédiculées.

BRACHOSTOMES, adj. et s. m. pl., Brachiostoma ( $\beta p \alpha p i \omega \nu$, bras, atípx, bouche). Nom donné par Latreille à un ordic de la classe des Polypes, comprenant ccux dont la bouclic est entourée dlc ientacules.

BRACIYYCANTIE, adject. , brachyacanthus ( $\beta$ pxyis, court, $\ddot{\alpha} \times x, \theta \alpha$, épine); qui a des épines courtes. Ex. Acacia brachyacantha.

BRAGIYANCALOPTÈNES, adj. et s. m. pl., Brackyancalopteni ( $\beta$ p $\chi^{2} \dot{s}$,

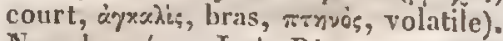
Nomdouné parJ.-A. Ritgen à urre famille de l'ordre des Halicolynulies ou Pygopodes, comprenant des oiseaux qui ont les ailes très-courles.

BRACIYCARPE, adj., brachy-

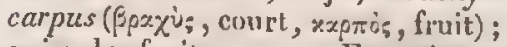
qui a des fruits courts. Ex. Astragalus brachyearpus, Alliaria brachycarpa, Scseli brachycarpum, Hymcnostomum bractiycarpon.

BRACHYCARPÉES, adj. et s. f. pl., Brachycarpea. Nom donné par Candolleà une tribu de la famille des Cruciferes, qui a pour type le genre Brachycarpaa.

BRAGIICENTnE, adj. , brachy.

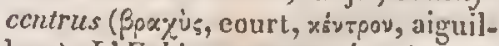
lon). L'Echinospermum brachyccntrum a des fleurs beaucoup plus longues que les pédicelles qui les supportent.

BRACHYClRE, adj. , brachyceratis, brachycertls ( $\beta p \alpha \chi_{i}$, , court, xśpxe, Corne). Une orchidée (Habenuria brachyccratis) est ainsi appclée parce que son éperon ou corne n'est pas plus long que Ic germe; un inscete diptère (Macquetria brachycera), parce qu'il a des antennes courtes.

Bucurcétiéss, adj. et s. f. pl., 
Brachyeerala. Nom donnć par Robineau-Desvoidy ì une section de la fanille des Myodaires Calyptérées, comprenant ceux de ees inseetes qui ont les antennes courtes.

BRACHYCh́lines, adj. et s. $m$. pl., Brachycerides. Nom donné par Sehoenherr ì un groupe de l'ordre des Curenlionides olthoeères, qui a pour type le genre Brachyccrus.

BRACITYCLADE, adj., braclycla-

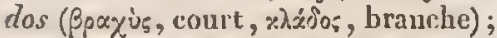
qui a des rameaux eourts. Ex. Ptcrigynandrum brachycladon, Leskia brachyclados.

BRACHYDACTYLE, adj., brachy-

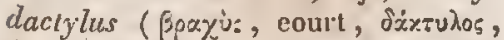
doigt); qui a des doigts eourts. Ex. Alauda brachydactrla.

BRACHYDERIDE, adj. et s. m. pl., Brachyderidcs. Nom donné par Schœuherr à un groupc de l'ordre des Curculionides gonatocères, qui a pour type le genie Brachyderes.

BR ACIIYGLOSSE, adj. , bracliy-

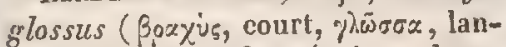
gue). Epithète donnée à quelques plantes synantbérées qui ont les calathides courtement radićes. Ex. $\mathrm{Fe}-$ licia brachyglossa.

BRACHYOPODE, adj. , brachyo-

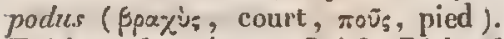
Epithète donnée par L.-C. Riehard aux embryons dont la radicule est très-courte.

BRACHYOTE, adj., brachyotos ( $\beta$ poxiss, court, oús, oreille). Une chouette (Strix brachyolos) doit cette épithètc à ce qu'elle est munie de huppcs très-petites, peu apparentes dans les mâles et nulles dans les femelles.

BRACHYPE, adject., braclyypus

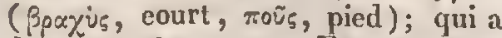
des pédicules eourts. Ex. Barbula brachypus.

BRACIIYPETALE, adj., brachype-

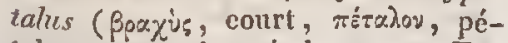
tale); qui a des pélales courts. Ex.
Actoed brachypctala, Cerastium brachypetalum.

BRACIITPIYLLE, adj. , bracliy-

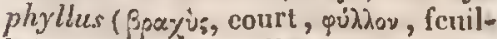
le); qui a des feuilles courtes. Ex. Crusea brachyphylla, Pogonatum brachyphylluni.

IHA CIIYOOUE, adj, , brachypodus (Bpxభus, court, rov̄s, pied); qui a des pétioles courts. Ex. Loniccrá brachypoda , Cephalanthus brachyparlus.

BRAGIrYPOME, adj., brachypomus ( $\beta \rho x \chi \dot{v}$, court, $\pi \tilde{\omega} \mu x$, opereule). Se dit d'un poisson qui a l'opereule court. Ex. Myletes brachypomis.

BRACHYPORE, adj., brachyportus

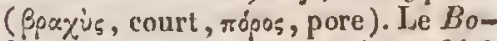
lctus brachyporus est áinsi appelé à eause de la brièveté de ses tubes.

BHA CHYPTÈRE, adj., brachyplc-

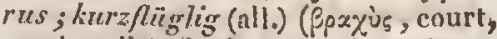
$\pi \tau z p \circ v$, aile). Sc dit : $1^{\circ} \mathrm{en}$ botanique, d'une plante dont une partie queleonque, par exemple les carpelles, est surmontée d'une aile très-eourte (ex. Banisteria brachyptera); $2^{\circ} \mathrm{en}$ zoologie, d'un oiseau dont les ailes n'atteignent que sur les côtés du croupion (ex. Anser brachyptertes), ou d'un insccte dont les ailes n'ont que la moitié de la longueur de l'abdomen (cx. Mantis brachyptera).

BHACUYP'TÈnEs, adj. ct s. m. pl., Braclypleri.Nom donué par Mochrıng à une classe d'oiseaux, par Cuvier, Duméril, Latreille, Lesson, Fieinus et Carus à une famille de l'ordre des Palmipèdes, par Vieillot à une famille de l'ordre des Nageurs, par Ranzani à une famille de l'ordre des Ratites, renfernant des oiseaux dont les ailes sont trop eourtes pour poutvoir servir au vol.

BRAGIYMUYNQUE, adject., bra-

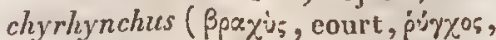
bec ); qui a le bec eourt. Ex. Nucifraga braehyrhyneus. 
BIRAHYRIYYNQUES, adj. et s. $m$. pl., Brachyrhynchi. Nom donné par Schœnherr à une légion dc l'ordre des Curculionides gontocères, comprenant ccux de ces aninıax qui ont lc bec court.

BRACIISCIEN, adj., brachyscius (Bpxxús, court, oxiá, ombre). Nom donné par les géographes anciens aux habitans des régions où le soleil n'arrivc jamais au zénith, parce qu'en ćté, à midi, leur corps projette une ombre courte.

BRACHYSTACIYE, adject. : brachystachyus; kurzährig (all.) ( $\beta$ po-

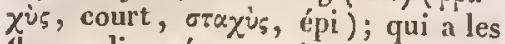
fleurs disposécs en épis minces et courts. Ex. Campulosus brachysiachyus, Carex brachystachya, $\mathrm{Pa-}$ nicum brachystachyum, Pedicularis brachystachys.

BRACIYSTÉLONE, adject., bra-

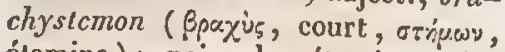
étamine); qui a lcs étamincs plus courtes que les pélales. Ex. Draba brachysiemon.

BRACHYSTOME; adj., brachys/omus ( $\beta$ payis, court, бтó $\mu \alpha$, bouche). Se dit d'unc coquille univalve dont l'ouverture a peu de hauteur (ex. Achatina acicula). L'Asciabrachystoma est ainsi appelée parce que le bord de sa.bouche ne fait pas de saillie en forme de trompe.

BRA CIIYTELOSTYLE, adj. , brachytelostylus (Ppaxis, court, ss்os, fin, бтน์ภo:, souticn). Epithète donnéc par J. Hill aux cristaux qui sc composent de deux pyramides séparées par un prisme court.

IRACINYTOPHYTE, s. m., brachytophytum ( quió, plante ). Nom donné par Necker aux plantes crucifères qui out des fruits courts ou siliculeux.

BRACIYYUR, adj. , brachyurus; kurzschwänzig (all.) ( (3pox's, court, ovjox, quene); qui a la quue courte.
BRAC

Ex. Coluber brachyrurus; Fringilla brachyura.

BRACIYURES, adj. et s.m. pl.; Braclyyura. Nom donné par Cuvier, Iatrcille, Leach et Eichwald à uue famille de l'ordre des Crustacés décapodes, par Lamarck à une section de l'ordre dcs Crustacés homobranches, comprenant ccux dont le postabdomen est replié en dessous ct plus court que le trone.

BRACTÉAIRE, adj. , bractearius. Epithète que Candolle donne aux fleurs permutcics, quand le changement a lieu dans les bractées.

BRAGTÉ, s. f. , bractca; Nebenblatt, Dcckblalt (all.); braltca (it.) Jinné, le premier, a distingué sous ce nom les feuilles qui accompagnent les fleurs, lorsqu'elles diffèrent des autres par leur forme ou par leur couleur. Candolle l'applique aux feuilles à l'aisselle desquclles naissent les branches florales, ou leurs rimifieations, on les pédicelles eux-mêmes, et qui diffèrent des autres par la grandcur, la forme, la coulcur, ou, ce qui est plus constant, parce qu'clles ne portent pas de vrais bourgeons à lcurs aisselles.

BRACTEEN, adj., bractcanus. Mirbel donne cctle épithète au sirobile, quand il est formé par des bractées. Ex. Betula Alnus.

BRACTÉFÈRE, adj., bracteifcrus (bractea, bractéc, fcro, pobter); qui porte une ou plusieurs braclées, comme lc calice du Gcum urbanum.

BRACTÉLFORME, adj., bracteiformis (bractea, bractée, forma, forme ); qui a la forme ou l'aspect d'une bractée. Epithète donnéc par H. Cassini aux squancs du péricline des Synanthérćes, quand elles sont analogues à des bractées d'involucre.

BRA CTÉoculdoIÉ, adj., bractcocardius ( braclea, bractée, xapoía, cocur) ; qui a des bractées en cocur à labasc. Ex. Cephalis bracteocardia. 
BRACTÉOGAME, adj.; brácteoganus ( bractca, braetée, ๆ'xuos, noees). Se dit d'une plante (Hydrocotyle bracteogama) dont les folioles de l'involuere sont rétunies en un dis. que orbiculaire.

BRAGTÉoLAIRE; adj. , bractcolaris; qui a de très-grandes bractées. Ex. Spatalla bracteolaris.

BRACTEOLE, s. f. , bracteola; Deckblättchon (all.). Petite bractće. On donne cette épithète aux plus intérieures des bractées, quand il y en a plusieurs rangs, ct à celles qui viennent sur les pédicelles, ou ì leur hase. Daus le cas, dit Candolle, où les derničres ramifications d'une inflorescence composée partent de pédicules terminés par un seul pédicelle, ou, comme on s'exprime vulgairement, lorsque les pédicelles sont articulés dans leur longueur, les petites bractées qui se trouvent ì cette articulation prement le nom de bractéolcs. Candolle n'adopte done ce mot que dans le dernier des deux sens qu'on a coutume d'y attacher.

BRAGTÉOLÉ, adj. , bractcolatus. Se dit d'une plante qui a ses pédoncules (cx. Commelina bractcolata), ses vertieilles de fleurs (cx. Hedcoma bracteolata), ou ses feuilles (ex. Polygala bracteolata) aceompagnés de petites bractées. H. Cassini donne cette épithète au péricline des Synanthérées, quand il est accompagné de bractées très-petites, comme demiavortées, très-pen nombreuses, peu constantes, variables et irrígulièrement disposécs.

BRAGTÉTÉ, adj. , bracteatus, bractcosus; ncbcnblättrig, deckblättrig (all. ); bratteato (it.) ; qui est uluni d'une ou plusieurs bractécs, comme l'ćpi du Lavantula spica, les verticilles du Ballota nisra, les calathides de l'Edmondia bracteala, les Acurs du Modeeca bracteata, de l'Hibiscus bractcosus, du Pelargo- nium bracteosum; qui porte des bractées longues, foliacées, découpées (cx. Corydalis bracteata, Diclytra bracteosa).

BMACTIFÈnF. $V$. Bractérfère BRADYPLDES, adj. et s. m. pl., Bradypedce. Nom donné par G.-E. Gray à une famille de la classe des Mammifères, qui a pour type le genre Bradypus.

BRADYPODES, adj. ct s.m. pl., Bradypoda. Nom donné par Goldfuss et Tiedemann ì une famille de la classe des Mammifères, qui a pour y pe le geure Bradypus.

BRALLEMENT, s. m. Cri importun et fatigant de eertains animaux, par exemple du chien.

BRALMENT, s. m., ruditus. Cri de l'âne. On dit plus souvent le braire.

MHAMER, s. m. ( $\beta p \dot{\mu} \mu \omega$, mugir). Cri du cerf en rut.

HHANCIIE, s. f., ramus, apex;

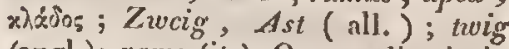
(angl.); ramo (it.). On appelle ainsi : $1^{\circ}$ en géognosie, les ramifieations d'un filon, lorsqu'après l'avoir aceompagné dans une certaine étendue, elles semblent $y$ rentrer et former comme des espèces d'anses; $2^{0}$ en botanique, les divisions primaires d'une tige quelconque.

BHANGIEILILNNES, adj. et s.f. pl., Branchclliance ( $\beta p \dot{x}^{\prime} \gamma \chi^{\llcorner} \alpha$, branehies). Non donné par Savigny à une scetion de la fanille des Hirudinées, eomprenant eulles qui ont des branchics saillantes.

IBHANGHAL, adj. , Branclialis

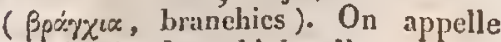
respiration branchiale celle qui s'exéeute au moyen de branchies. Branchial cst parfois pris eomme synonyme de pulmonaire, lorsque, par exemple, on donne cette ćpithc̀te aux A rachnides qui respirent par des saes aëriens. L'Animoceetus branchialis est ainsi appelé parce que, dit-ou, il introduil l'cxtrémité de sou museau 


\section{BRAN}

sous l'opercule des gros poissons, pour s'atticher à leurs branchies.

BruNGHE, s. f., branchia ; Bpóy$\chi(x ;$ Kienc, Fischohr (all.); gitt (angl.) ; branchia (it.). Organe qui sert à respirer an moyen de l'air tenu en dissolution dans l'eau. C'est par abus qu'on a admis des luranchies aëriennes, chez certains animaux, tels que les limaces. Voyez Pounon.

BMANCHUÉs, adj. et s. in. pl., Branchiata. Nom donné par Ficinus et Carus à un ordre de la elasse des Amphibies, comprenant ceux qui respirent par des branchies.

BravcIIIFIIR, ad; , branchife-

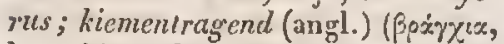
branchies, fero, porter); qui porte des branchies. Organe branchifcre.

BRANCUIFLRES, adj. et s. m. pl., Branchifcra. Nom donné par Hartmaun à un ordre de liı classe des Gastéropodes, et par Blainville à une famille de l'ordre des Cervicohranelics, renfermant ccux de ces animax dont lcs organes respiratoires consistent on deux grands peigncs branchinux égaux.

BRANCHIODELES, adj. ct s. m. pl., Branchiodela ( $\beta \rho \dot{\gamma} \gamma y \mathrm{r} \alpha$, bran-

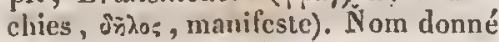
par Duméril à une famille de la classe des Vers, dans laquelle il range ceux qui ont des organes respiratoires, ou branchies, visibles à l'extérieur.

BRANCHOGASTRES, adj. et s. m. pl., Branchiogastra ( $\beta$ pórycex, branchies, jzotino, ventre). Nom donné par Latrcille à un ordre de la classe des Crustacés, comprenant ceux qui ont les branchies sous le ventre, et qu'il a depuis coupé cn deux, ceux des Stomapodes et des Amplipodes.

BRANCHIOPNONTES, adj. et s. m. pl., Branchiopnunla ( $\beta$ ódyzız, branchies, $\pi$ ขé désigne ainsi un groupe d'animaux sans rertèbres, cmbrassant tous ceux qui respirent par des branchies, comme les Miollusques, les Anelides ct les Crustacés.

BRANGHOPODES, adj. et s. m. pl., Brancliopoda ( $\beta p \dot{\gamma} \gamma \chi \varepsilon \alpha$, branchies, roüs, pied). Nom donné par Cuvier, Lamarck, Desmarets, Goldfuss, Straus, Eichrrald, Ficinus et Carus à un ordre de la classe des Crustacés, par Blainville à une famille de la classe des Hétéropodes, comprenant ccux dont les branchies sont placées sur les paltes.

BRAXGIIOPODHORUE, adject., branchiopodiformis. Kirby donne cette épithète aux larves apodes, antennées, à tête distincte, qui ont lc corps transparent et flexible, avee un tube respiratoire à la queue. Ex. Culex.

BRANCHIOSTEGE, adj. , bran-

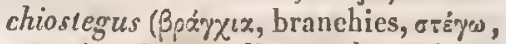
couvrir). On appellc membranebranchiostège (Kiemenhaut, all.) cclle qui, chez certains poissons, garnit le bord inférieur des opereules des branchies. La Coryphana branchiostcga est ainsi nommée parce qu'elle a l'ouverture de ses branchies peu distincte.

BRANCHIOSTLìGES, adj. et s. m. pl., Branchiostegi. Nom donné par Artedi, Gouan et Linnć à une classe de poissons, comprenant ceux qui ont le squelette cartilagineux et lcs branchies libres, couvertes seulencnt. d'une membrane.

BRANGHOSTOUE, s. m., branchiostoma ( $\beta$ poxizice, branchies, oróux, bouche). Latreille a proposé ce norn pour désigner les ouvertures par lesquelles les pneumobranchies, out branchies aëriennes, communiquent au dehors.

BRANGIIUnOMOLGES, adj. et $s$. m. pl., Branchiuromolgai ( $\beta p \dot{x} \gamma \chi \varkappa$, branchies, oivos, queue, usiyós, salimandre). Nom donné par J.-A: Ritgen à une famille de reptiles, coinpreuant les salamandres qui respirent toujours par des branchies. 


\section{BRE̊C}

BRAYCIU, adj., ramosus; $r \lambda \alpha d \dot{\mathrm{b}}$ Sys; iistig (all.); ramous (angl.) ; ramoso (it.); qui est divisé en branehes; qui en a beaucoup. Voyez Rameux.

BRAS, s. m. , brachium; Bprxiwv; Arm (all. angl.); braccio (it.). On appelle ainsi: $1^{0}$ en géognosie, uı rameat de montagne qui dépassc lc pied génćral de la chaine et se porte en avant dans la plaine; $2^{\circ}$ en zooiogie, le membrc thoracique tout entier des animaux vcrtébrés, on seulement son premier article; le troisième arliclc de la pince des Crustaeés; la premic̀rc pairc de patles des inscctes hcxapodes, d'après Kirloy; les appendices qui garnissent la partie supérieure du corps des Céphalopodes et des Polypes ì tentacules; eeux de la face inlérieure du corps des Meduses, quand ils sont libres des la base.

BRAS-DE-MER, Voyez DÉrrotT.

BRASSICEES, adj. et s. f. pl., Brassiccee. Nom donné par Candolle à une tribu de la famille des Crucifères, qui a pour type le genre Brassica.

BRECGIOLAIRE, adj., brccciolaris. Épithète donnée par les géognostes à une roche qui enveloppe des corps étrangers dans sa pâte. Ex. Rcitinite brecciolaire.

BRlarE, s. f. (de l'allemand brechen, rompre). Nom générique sous lequel on désigne, en minéralogie, loute les roches à structure frigmentaire, quand les grains agglomérés qui les constituent sont des fragmens anguleux à bords aigus.

BRECIIIPORWE, adj., brecciformis. Sc dit, en minéralogic, d'une modification de la texturc des roehes, quand cclles-ci sont formées par la conglomération de fragmens anguleux, ou d'unc roche qu'on prendrait au premier abord pour unc brèche. Ex. Petrosilex bréchiforme.

\section{BRTV}

BRÉTive, s. f., lreina. Nom donné par Baup à une substance eristalline qu'il a extraite do la résine de l'ar-bol-a-brea, et qui paraít ètre identique avee la sous-résine que Bonastre en a retirće.

BRENTIDWs, adj. et s. m. pl., Brcntides. Nom donné pas Latreillé à une tribu de la famille des Rhynchophores, par Schoenherr à un groupè de l'ordre des Curculionides orthocères, ayant pour type le genic Brentus.

BRÉSIrive, s. f., bresilina. Chevreul nomme ainsi une matière colorante rouge, aualogne à l'hématine, et encore pett connuc, qui existé dans le bois de Brésil (Casalpinia cchinata).

Bnívic aUde, adj. , brcvicaudatris (brevis, court, cauda, queue). Se dit, en botinnique, d'une plante qui a les pédoncules plus eourts que les feuilles (ex. Clematis brevicaudata) en zoologie, d'un mammifère ou d'un oisean qui i la queue courte (ex. Sorex brevicaudatus, Coccothraustes brcvicaudaia, Pachysomá brevicaudatum).

BRLvicaunis, adj. cts. m. pl. , Brcvicaudati. Nom donné par Blainville à une famille de l'ordre des oiseaux marcheurs, comprenant ceux qui ont la quene trc̀s-courtc.

BRÉvicaULE, adj. , brevicazlis (brcvis, court, caulis, tige); qui a la tigc eourte. Ex. Desmatodon brevicaulis, Pogonatum brevicaule.

BRÉvICOLLE, adj. , brevicollis (bresis, court, collum, eol). Se dit d'un inscctequi a le eorselct court (ex. Mclocbrevicollis), d'une mousse dont les pédicules sont eourts (ex. Trematodon brevicollis).

BnúviCORNE, adj., brevicornis (brcuis, court, cornu, eorne); qui a les autennes courtcs. Ex. Elatcr brevicornis.

BHLVIDENTÉ, adj. , brevidens 
(brevis, court, dens, dent); qui a les dents courtes, comme le poisson appelé Hydrocynusbrcvidens.

BRÉviFLonE, adj. , breviforus; kurzblïthig (all.) (brevis, court, flos, fleur). Epithc̀te donnée à des plantes qui ont les fleurs courtes (ex. Astragalus brcviflortes, Pavelta breviflora), ou petites(ex. Corydalis bruvifora).

BRÉvir OLle, adj., brovifolius; kurzblätırig (all.) (brcvis, court, folium, feuille); qui a des feuilles courtes. Ex. Thymus brevifolius, Arabis brevifolia, Sedum brevifolium.

BREviptoE, adject., brcvipes; kurzfïssig (all.) (brevis, court, pes, pied ). Se dit, en botanique, d'une plantc qui a les pédoncules (ex. $H_{y p-}$ tis brevipes), ou les lampes (ex. Loxodon brevipes) courts; cll zoologie, (kurzbeinig, all.), d'un oiseau qui a les pieds courts (ex. Totanus brevipes).

BRLVIPÈDES, adj. et s. m. pl., Brevipedes. Nom donnć par J.-A. Scopoli à un ordre d'oiseaux, comprenant ceux qui ont les pattes courtes, et par A.-H. Harvorth auxreptiles sauriens qui, comme les Scinques, ont les pattes très-courtes.

BRÉVIPENNE, adj., brcvipennis (brevis, court, penna, aile); qui a des ailes courtes. Ex. Asilus brevipennis.

BRÉviPENNES, adj. et s. m. pl., Brevipennes, Brevipennia (brevis, court, penna, ailc). Nom donné par Cuvier, Duméril, Latreille, Lesson, Ficinus et Carus à uue famille d'oiseaux qui ont les ailes très-courtes et impropres au vol, par Dumćril à une famille d'insectes coléoptères qui ont les élytres courtes. Voyez Brachyptènes.

BRÉviRostre, adj., brevirostris, brcvirostrus, brcvirostratus (brcvis, court, rostrum, bec); qui a le bec (ex. Ptcroglossies breviros- tris), le museau (ex. Acipenser brcvirostrum), ou l'opercule (ex. Hypnum brcvirosirum) court.

Buḱvurostrés, adj. et s. m. pl., Brcvirostrala. Nom donné par Latrcille, Ficinus et Carus à une famille de l'ordre des Marmmifères éden. tés, comprenant ceux qui ont le museau court, par Latrcille à une division de la triba des Charansonites, dans laquelle il range ceux qui ont le bec court.

BREVISCAPE, adj., breviscapus (brepis, court, scapus, tige); qui a une tige ou une hampe courte. Ex. Hypoxis brcuiscapa.

BRÉVISETE, adj , breviselus (brevis, court, scta, soie ); qui a des pédoncules courts. Ex. Dicranum brevisctum.

BRÉVISTYLE, adj. , brevistylus (brcvis, court, stylus, style); qui a le style très-court. Ex. Osmorhiza brevistylis , Hutchinsia brevistyla, Hypericum brevistylum.

IBRÉYiSTYLES, adj. et s. f. pl. , Brevistyla. Nom donné par Agardh à une tribu de plantes phanérocotylédoncs complètes, hypogynes et polypétales, qui ont le style très-court, comme les Guttifères, les Berbéridées, les Podophyllées, les Papavéracées, les Crucifères.

BRÉVWLVE!, adj. , brevivalvis (brevis, court, valva, valve). L'Erianthus brevivalvis est ainsi appelé parce que les poils qui entourent sa balle calicinale sont beaueoup plus courts que les valves.

BRÉviveNTRE, adj., breviventris (brevis, court, venter, ventre); qui a le ventre court. Ex. Tipula breviventris.

BRExLcíes, adj. ct s. f. pl. , Brexiacea. Nom donné par Lindley et Kunth à une fomille de plantes, qui a pour type lc genre Brexia.

BRIDE, adj. , capistratus, frenatus; qui offre une ou plusietrs 
rẩes colorées descendant du dos vers la tête et simulant une sorte de bridc. Ex. Chetodon capistratus, Scarus fienatus.

BIILLANT, adj., nitens, fulgidus, micans; glänzend (all.); shining (angl.); risplendente (it.). On dit une couleur brillante lorsque, sans pouvoir ehanger de nuance par les diverses incidences de la lumière, elle a un éclat analogue à celui des corps polis. Par extension, on appellc brillans les corps dont la surface reflète la lumic̀re comme le ferait un métal poli. C'est ce qu'on observe, par exemple, dans les pelites taches dont les fleurs du Lavatera micans sont marquées sur les bords, et qui brillent au soleil. Cette expression est fréquemment employée par les naturalistes, et rendue en latin d'une foule de manières diverses, dont voici quelques unes : Chrysis fulgida, Lobclia fulgens, IIedrchrum fervidum, Cueulus lucidus, Capraria lucida, Pterygrophyllum lucens, Hedychrum lucidulun, Bülimus lubricus, Trichia nitcus, Cellepora nitida, Trisetun nitidum, Planorbis nitidulus, Unona nitidissima, Athanas nitescens, Drassus relucens, Cibicides refulgens, Falcinellus resplendescens, Corvus splendidus, Hesione splendicla, Diclydium splcndens, Phalacrus corruscus.

BRNDILLE, s. f., ramulus. Dernière ramilieution d'une branche. Synonyme de ramille. $\mathrm{On}$ donne quclquicfois ce nom à des petites branches à fruits qui portent des lleurs ramassćes en touffes.

BRIQUETh, adj., lateritius; qni a la couleur de la brique pilće, c'estì-dire un rouge plus on moins mêlé de jaunc. Ex. Auricularia latcritia.

BRISE, s. f. On appelle ainsi des vents périodiques qui se font sentir en mer à l'approche des côtes, ct dont la direction ehange deux fois en vingt-quatrc heures, c'est-à-dire qui soufflent de la mer pendant la jouruće, et de la terre pendant la nuit.

Brociss, s. m. pl. (brochus, dont les dents avaneent liors de la bouchc). Nom donné par Ficinus et Carus à une famille de l'ordre des Mammifères Pinnipèdes, contenant les Morses, dont les canines font wne énorme saillie hors de la houche.

BnocIIs, s. f. pl. Nom vulgaire des défenses du sanglier.

IBRONATE, s. m., bromas. Genre de scls (bromsaure Salze, all.), qui sont formés par la combinaison de l'acide borique avee les bases sal:fiables.

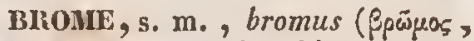
fétidc). Corps simple, découvert en. ${ }_{1826}$ par Balard, et ainsi appelé à cause de l'odeur forte et désagréable qu'il exhale.

BROvú, adj. , bromatus; qui contient du brome. Suivant Sérullas, lis brome condense le gaz oléfiant, et donne ainsi naissance à de l'éther bra$m e ́$.

BRovées, adj. et s. f. pl., Bro.. mece. Nom donué par Kunth à une tribu de la famille des Graminées, qui a pour type le genre Bromus.

BROMĹLIACÉES, adj. et s. f. pi.., Bromeliacece. Famille de plantes,. établie par Jussieu, qui a pour type: le genre Btomelia.

Broú́LLúres, adj. et s. f. pl. :, Bronuclice. Synonyme de Bromélia: ećes.

BRomílromes, adj. et s. f. pl.., Bromelioïdes. Synonyme de Bromé.. liacées.

BROMIDE, s. m. Nom donné par : Berzelius aux combinaisons du bro. me avee đes corps moins électro-négatifs que lui, dans lesquelles les: rapports atomiques sout les mêmes: que dans les acides.

BroMuQUE, adj. , bromicus, Itipi- 
thètedonnée à un acide (Bromsïzure, all.), qui est le senl deg'ré comm d'oxigénation dubrome, et à un chlorture, qui résulte de la combinaison de ce deruier corps avee le brome.

BRONO-ALRATE, s. m., Lromo-auras. Nom donné par Bonnsdorff anx combinaisons du bromisle d'or avee les bromures des métaux électro-positifs.

BROM0-HVDRARGVHATE, s. m., bromo-lydrargyras. Nom donné par Bonnsdorff aux combinaisons du bromide de mercure avee les bromures des métaux éleetro-positifs.

BHOMO-PLATINATE, s. m. , brom mo-platinas. Nom donné par Bonnsdorif anx combinaisons du bromide de platine avec les bromures des métaux électro-positifs.

BROMUnE, s. m. , bronuretum, brometum. Berzelius donne ee nom aux eombinaisous du brome avee les métaux électro-positifs dans lesquelles les rapporis atomiques sont les mèmes que dans les hases.

BRONTOMèTRE, s. m., brontometrum ( $\beta$ povis, tonuerre, usto surer). Synonyme de fulgurometre. Voyez ce mot.

BRONZÉ, adj., aneus, arezss; qui a la couleur du bronze. Ex. Cuculus areus, Hister aneus, Diaperis anea, Sepedon aneseens.

BROSSE, s. f., prelvillus; Bürsıc (all.); brush (angl.); scopetta (it.). On appelle ainsi, à eause de sa formc, une grosse toufte de poils raides et serrés qui, ehez presque tous les inseetes eoléoptères, intoure la moitié inférieure de la facette molairc des mandibules; les poils raides et paral. lèles, disposés sur plusieurs rangées transversales, qui garnissent la face interne du premier article du tarse des pattes postéricures des abeilles -ouvrières; les faiseeaux de poils raides qui surmontent le eorps de quelques chenilles et l'extérieur de l'ab-

\section{BRUC}

domen de eertaines larves; les poils longs et disposés en forme de manebeltes, qui se voyent aux jambes antéricures de certains mammifères, prineipalement des ruminans à eornes creuses.

Brov, s. ni., naucum. Ce nom, donpié d'abord à l'enveloppe demicharnue qui couvre la noix, a été en. suite étendu à tous les eorps peu charnus ou peu pulpeux qui entourent un noyau osseux selitaire. Les botanistes l'appliquent aujourd'hui au mésocarpe, quand il est épais, mais de consistanee sèehe et fibreuse, plus exoriace que eharnue.

BrouĺE, s. f. Pelite pluie passagère; bruine.

BROUILLARD; s. m., nebula; ขย́ตั (angl.); nebbia (it.). Amas d'eau i l'état de vapeur vésiculaire, sonvent odorante, et parfois mène douée d'une saveur très-sensible, qui flotte à une plus ou moins grande élévation dans l'atmosphère, mais toujours très-près de terre, et trouble lia transparence de l'air.

BnoviLLE, adj. L.es géognostes disent qu'une roche est de lexture brouillée, lorsque des parties anguleuses sont liées ensemble par un ejment, et que le tout est traversé par des veines dans toules sortes de directions, ce dont quelques brèches ollirent ụn cxemple.

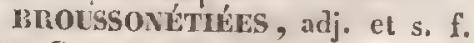
pl., Broussonetiene. Nom donné par A. Richard à un groupe de la famille des Uiricées, qui a pour type le genre Broussonetia.

Broveurs, adj. et s. n. pl. Epithète donnce par Lamarek à une sous-classe de la elasse des inscetes, comprentant cenx qui ont des mấchuires propres ì triturer les alimens, et disposées par paires lalérales placées au devant les unes des autres.

BRUCueLES, adj, et s. m. pl., 
Bruchela. Nom donné par Latreille et Eichwald à une tribu de la famille des Rhynchophores, par Sehoenherr à un groupe de la fanille des Curculionides orthoceres, ayant pour type le genre Bruchus.

Brucine, s. f., brucina. Nom donné à un aleali végétal, dont la découverte est due à Pelleticr et Caventou, parce Gu'on le croyait exister dans l'ćcorce du Brucea antidysenteriea, tandis que c'est dans celle du Strychnos $N$ ux vomiea qu'il se rencontrc.

BRUcipue, adj., brucicus. Epithète donnce par Berzelins aux sels qui ont pour base la brueine.

BRulN1E, s. l., Staubregcen (all.); rime (angl.); sprużaglia (it.). I'luie extrêmement finc et serrée, qui résulte de la condensation des brouillards, et qui tombe très-lentement.

BRUISSEMENT, s. m. Bruit sourd, confus et prolongé.

BHUIT, s. m., sonus; Geräteseh (all.); noisc (angl.); rumore (it.). Sensation que produit, dans l'organe de l'oüe , toute émotion ou agitation de l'air qui n'est point sonore et appréciable. Du bruit a lien soil lorsque les vibrations dn corps agité se terminent brusqquement, soil quand l'oreille éprouve un mẻlange de sensations différentes produites par nne suite de pelits coups successif's dont elle reconnait l'irrégularité, snit lorsqu'ellc éprouve la sensation d'un mélange confus de sous ayant entre cux des'rapports licn suivis, mais se suecédant avce trop de rapidisć pour qu'il soit possible de les distinguer.

BRLLANT, adj. , astuans, urens; brennend (all.). Epithète donnéc à des plaates armées d'aiguillons dont la piquire cause une doulenr cuisinte. Ex. Malpighia urens, Urtica astuans.

BRUL'́, adj., combustus, ustulatus. En chinic, ce mot cst synonyme de axigéné, dans la théorie pneuma- tique, et sert à désigner un corps eombustible qui cst combiné avec de l'oxigćne. Lorsqu'on l'enploie, comrne dénomiuation spécifique, en histoire naturelle, il exprime presque toujours une coulcur noire on noirûtre (ex. Turbo ustulalus, Hclotoma uslulata, Bembidium uslulatum.) Le Barbula deusla esı ainsi appelé parce qu'il croît sur les roches volcanisées de l'île d'Isehia.

BRUMAL, adj. , brumalis; qui croit en hiver. Ex. Polyporus brumalis.

BRUve, s. m. Ce mot sert principalcment à désigner les brouillards qui ont lieu sur mer. On l'emploic aussi quelquefois pour exprimer un brouillard épais qui règne sur terre.

muUnwex, adj .; qui est couvert de brouillard (cicl brumeux), qui amène le brouillard (saison brum meuse).

BRUN, adj. et s. m., brunncus; braun (all.); brown (angl.); bruno (ii.). Conleur qui se rapproche plus ou moins du rouge foncé et du noir, dont elle est pour ainsi dire un mélinge. On en distingue plusieurs nnances; le brun foneé, qui se rapproche du noir ( $\mathrm{cx}$. Xylophagus brunneus, Contalium brunncum, Musea brunnea); le brun sombre et livide (tristis, voy. TRiste); le brun terne (cx. I.ichen pullus, Musea pilla); le brun foncé, tirant un pen sur le vert (ex. Garrulus fuscus, Grus fusca); le brun tirnit sur le jaunâire ( forrug̣inculs, vog: FERnuGivet ) ; le brun foncé, tirant sur le rouge (hepalicus, voy. Hட́prtique); lc brun un peu lusisont (ex. Trifolium spadiecum, voy. BaI); le brun clair, tirme un peu sur le rouge ou marron (ex. Capillaria baelia, sporotrichum badium, Pieus badius); le brun pâle (rufus, voy. Roux); lé brun couleur de tabac rapć (tabacinus); le brun semblable à celui des 
bêtes fauves (fulqus). Il y a encore une foule d'autres épithc̀tes pour désigner les innombrables nuances du lrun : Polyporus umbrinus, Isaria ambrina, Cardita plurenitica, Cucujus piceus, Anisotoma piccum, Lagotrix infumatus, Ilimantia helvola, Natica helvacca, Surex cinnamomcus, Cricetus phaus, Dasypogon coffeatus, etc.

BRUNATRE, adj., fuscatus, fuscesccns, subfuscus; qui tire sur le brun. Ex. Ocyplcrus fuscalus, Cyrena fuscata, Buccinum fuscalum, Anas fuscescens, Patellaria subfusca, Pales brunicans.

Bruni cées, adj. et s. f. pl., Bruniacece. Nom donné par R. Brown à une famille de plantes, qui a pour type le genre Brunia.

BRUNNIBARBE, adj., brunnibarbis (brunneus, brun, barba, barbe) ; qui a la barbe brune. Ex. Calliphora brunnibarbis.

BRUNNICORNE, adj., brunnicornis (brunneus, brun, cormu, eorne); qui a les antennes brunes. Ex. $N c$ morce brunnicornis.

BRUNNISQUAME, adj., brunnisqua mis (brunneus, bruu , squarna, éeaille ); qui a les cucillerons bruns. Ex. Elophoria Urunnisquamis.

BRUNNIPLìe, adj. , brimnipes (brunneus, brun; pes, pied); qui a les pattes d'un brun ferrugineux. Ex. Bibio brunnipes.

BirunISSANT, adj., fuscescen.s. Les minéralogistes donnent le nom de Spath brunissant à la chaux carbonatée ferromanganésifère, parce que le manganèse qu'ellc contient la rend susceptible de noircir ou brunir lorsqu'on l'expose à l'action du feu.

BRUNONıACLES, adj. et s. f. pl. , Brunoniaccee. Nom donné par Lindlcy à unc famille de plantes, qui a pour type le genre Brunonia.

BRUTE, adj., brutus. Au sens propre, ee mot cxprime tout ce qui est âpre ou raboteux, inachevé (didmant brut). Au figuré il s'entend de ce qui n'a point de politesse (homme bru(t), ou mềme de ce qui n'n point ćtć perfectionné par le travail (génie brut ). Les naturalistes appellent bruts les corps, simples ou composés, dans lesquels on n'aperçoit aucune trace d'organisation, et qui peuvent être produits sans la présence d'êtres vivans, quoiqu'il $y$ en ait quelques uns auxquals l'exereice de la vie donne naissanee.

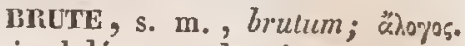
Animal dépourvu de raison.

BRUTES, s. f. pl. , Bruta. Nom donné par Blainville à̀ une famille de l'ordre des Mammifères ongulogrades, renfermant le tapir et le rhinocéros, animaux chez lesquels les facultés intellectuelles sont fort peu développées.

BRUYANT, adj. , clamosus, strepitans; qui fait du bruit, qui en fait beaucoup. Une multitude d'animanx ont droit i cette épithète ; mais presque toujours on leur applique un nom qui peint plus ou moins exactement la nature ou le genre du bruit qu'ils produisent. En voici quelques exemples : Malurus clamans, $\mathrm{Cu}-$ culus clamosus, Saxicola cachinnans, Lorius garrulus, Columba locutrix, Pcnclope pipile, Barita tibicen, Turdus polyglottus, Fringilla mclodia, Crotalus sircpilans, Falco tinnuncultus, Turdus tinnicns, etc. Voyez Chantedr.

BRuvines, Voycz Ericinées.

BRYACÉES, adject. et s. f. pl., Bryacea. Nom donné par Bartling à une famille de plantes ayant pour type le genre Bryum. Synonyme de Broyoides.

BRYANTIE, adject. , bryanthus. L'Andromeda bryantha est ainsi appelé parce qu'il couvre lcs rochers de gazons épais ct scrrés, commeecux que forment les Bryum. 


\section{BUCC}

BRYOIDES, adject. et s. f. pl., Bryoïdci, Bryoüdca. Nom donné par Arnotl, Furnohc et Reichenbach a une famille or à un groupe de mousses, ayant pour lype le genre Bryum.

BHYOLOGIE, s. f., bryologia (Ppioy, moussc, hìgos, discours). Traité des mousses. Titre de l'ouvrage de Bridel.

BRYOLOGIQUE, adj. , bryologicus (Bpiov, mousse, hóryos, disenurs); qui a rapport aux mousses; obscrvations bryologiques.

BRYONINE, s. f., bryonina. Substance partieulière, vénéneuse et anc̀re, que Vauquelin a découverte dans la racine du Bryonia alba, et qui a été ćtndiće depuis par Braconnot, Firnbaber et Dulong.

BuYOPHIL. , adject., bryophilus (Bpúoy, mousse, юi हw, aimer); qui croît sur les mousses (ex. Sporotriclum bryophilum ), on an milicn des mousses (ex. Gyalacta bryophila, Merulius bryophiluss).

BUBULINE, s. f., bubulina (bululus, de boauf'). Nom donné par Morin à une matière extractive qu'il a obtenue des excrúnens de bètes ì eornes, mais qui paraît ne point être exclusive à ces animaux, ct entrer, connue prinejpe eonstituant général, dans les exerémens d'animaux de diverses espèces, ce qui en rend la dénomination vicieuse.

BUCGAL, adj. , buccalis (bucca, bouche); qui a rapport à la bouche, et plus particulièrement aux joues. Le Psinacus buccalis a les joues, e'est-à-dire les plumes comprises cntre les yeux et le bee, grises.

puccELLés, ađj. et s. m. pl., Bucellati (buccella, petite bouche). Nom donné par Duméril à une famille de l'ordre des Névropteres, compre$\mathrm{n}$ nnt des insectes pui ont la louche très-pelite, et distincte sculement par des palpes.

BUCCINAL, buccinalis (bucgina, I,

\section{BUDD}

trompelte); qui a la forme d'une trompette, comme les coquilles appelécs Bulimus buccinalis, Fusas buccinatus, Cancellaria briccinula, Plcuroloma buccinoides, ou connme le Laminaria bnecinalis, dont te stipe listuleux, aminei vers la base; se renfle en s'alongeant.

BUCCINÉs, adj. et s. m. pl, , Buccinea. Nom donnć par Mlenke à une famille de l'ordre des Gastéropodes Clénobranches, qui a pour type le genre Buccinum.

BUCCINIDES, adj. el s. m. pi., Buccinides. Nom donné par Cuvier à une famille de l'ordre des Gastéropodes, par Latreille à une fimnille de l'ordre des Pectinilrauchrs, ayant pour type le genre Buccinum.

IBUCCIYordes, adj.el s. m. pl., Buccinoiddes. Non douné par Guvier à une famille de l'ordre des Gastéropodes Pectinilirauches, qui a pour type Je neure Buccinum.

Bucconés, adj. et s.m. pl, Bucronei. Noun donné par Lesson à une famil'e du sous-ordre des oisenux Grimpeurs, qui a pour type le genre Bucco.

BUChiriaLE, adj. , bucephalus ( ressemble à celle d'un taureatu, sous le ripport de la grosscur (ex. Ana.s bucephala), ou sous celni de la configuration, comme eclle du Phylliroe buccplialum, qqui est avancéc ell muthsenu, et surmontéc de deux tertacules analogues it des eornes.

BuCÉBIDÉs, adj. et s. m. pl., Buccrider. Nom donné.jar Lesson ì une famille du sous-ordre cies oiseaux Passereaux marcheurs, qui a pour type le genre Buccros.

Bucrnlies, adj. ct s. f. pl. , $B u$ cidea. Nom donné par Sprengel a la famille des Myrobolinuées.

BUDDÉ Butdlcjea. Nom donnć par Bartling à une tribu de la famille des Serofu- 
194

BULB

larinées, qui a pour type le geure Buddlcja.

BUYONOIDES, adj. ct s. m. pl., Bufonoidea. Nom donné par P.-F. Fitzinger à une famille de reptiles batraciens, ayant pour type le genre Bufo.

iBUTSSON, s. m. , dumus, dumetum;Busch (all.): bush (angl.); cespugglio (il.). Arbrisseau las et trèsrameux dès sa base, dès la surfaee même du sol.

BUISSONNEUx, adj., dumetosus; qui a la forme ou l'aspeet d'un buisson ; arbrisseau buissonneux.

BUISSONNTER, adj. , dumicola; qui vit ou habite dans les buissons: Lapin buissonnier. Les merles à plastron (Turdus torqualus) sont appelés Merles buissonniers, probablement à cause de l'habitude 'ju'il sont de nicher au pied des buissons.

BULBE, s, m. et $f$, Bulbus; $Z$ wiebel (all.); bulbo, cipolla (ii.). On appelle ainsi : $\searrow^{\circ}$ en botanique, des or ganes divers, savoir: des renflemens en manière de tubereules que préseute, au-dessus du collet, la tige de plusieurs dicotylédones, et qui sont recouverts par les pétioles aplatis et plus ou moins élnrgis ì leur base (ex. Ranunculus bulbosus, Fumaria bulbosa); des amas de féeule et de germes qui se développent le long des raeines de certaincs plantes (ex. $\mathrm{He}$ lianthus tuherosus, Solanum tuberosum, Saxifraga granulata); les tıbereules reprodueteurs des Orehis; des tiges souterraines très-courtes, réduites à un simple plateau, d'oủ naissent en dessous des raeines, en dessus des feuilles qui, en se reeouvrant les unes les autres, forment un corps ovoïde ou arrondi, et dont les extérieures sont on des ćeailles charnues, rétréeies à la base (ex. Liliun album), on des gaînes membraneuses courtes et tronquées (ex. Hyacinthus orientalis). Ces dernie-
BULB

res parties méritent seules le nom de bulbe; elles constituent un vrai bourgeon terniual, situéau sommet d'une tige souterraine cxtrêmement courte, et se développent sous terre ou à rezterre. $2^{\circ}$ En zoologie, on donue ee nom à l'assemblage de nerfs et de vaisseaux qui forme le noyau des dents et des poils, et qu'on a comparé à un ognon; ehez les inseetes, d'après Kirby, à la base du preuier article des antennes, par laquelle elles tiennent au torulus, qui est souvent subglobuleuse, et quii constitue le pivot sur lequel tourne l'antenne.

BULBEUx, adj., bulbosus; zwiebclig , zwiebelartig (all.) ; qui porte une bulbe. Autcefois on donnait improprement le nom de racines bulbeuses aux bourgeous partieuliers qui portent aujourd'hui eelui de bulbe (voyez ce mot). On l'applique aussi aux champignonsdont la base du pédicule est renflée en forme d'ognon (ex. Agaricus ceraceus), et aux planles qui onl soit leur tige renflée an-dessus du collet (ex. Ranunculus bulbosus, Fumaria bullbosa), soit leur raeine enflée et lubéreuse (ex. Laniinaria bulbosa, Ophioglossum bulbosum:).

BLLBIFÈE, adjeet., bulbiferus; zuviclbeltragend (all.) (bulbus, bulbe, fero, porter). Épithète donnée aux plantc.s qui porlent des bulbilles (v. ce mot) sur un point quelcouqrie de leur surface. Turpin a ppelle cmbryons bulbifêres les bulbilles, qu'il considère comme étant intermédiaires entre les embryons fixes et les embryons graines.

BLLIIFORME, adj. , bulbiformis; asvicbelfömig (all.) (bulbus, bulbe, forma, forme); qui a la forme d'un ognon, comme le Fusus bulbiformis, ou conme l'assemblage des feuilles du Barbulabulbiformis. A. Riehard donne le nom d'cmbryons bulbiformes aux prétendues bulbilles qui se dévelop- 
pent dans l'intérieur des capsules de quelques espèces d'Agave, d'Amaryllis et de Crinum; par des canses inconnues, ees embryons prennent un aecroissement si cousidérable, que leur grosseur est ì pcu près cinquantc fois plus grande que celle des graines ordinaires; on y découvre toutes les partics qui composent une graine, tandis que les bulbilles n'offrent jamais ancune trace de radicule.

IBULBILLE, s. f., bulbillus; Knospcnzwiebel (all.). Ce nom cst donné, en botanique, ì de petits tuberculcs luulbiformes, sćparables de la plante mère, et susceptibles de produire des individus nouveaux, qui se développent, soit entre les pédoneules de l'ombelle, comme de vrais bourgeons (ex. Allinm roseum, Allium oleraecum, Allium panientattms), soit à l'aisselle des feuilles, où its sont enveloppés d'ćcailles (ex. Lilinum bulbiferum, Cicula bulbifera, Saxifraga bulbillaris, Ixia bulbifera, Arum bulbiforum, Allium viviparum, Begonia bulbillifera, Dioscorea bulbifera, Dioscorea alata, Diosco. rea pentaply lla, Saxifraga bullifora, Dentaria bulbifcra, Lilium itgrinum, Ornithogalum bulbiforum), soit sur le rever's des frondes des fongères (ex. Asplenium bulliferum, Woodwardia radicans), soit dans les sinus des crénelures des feuilles (ex. Bryophyllum ealycinum), soit enfin à la base de la face supérieure de chaque foliole, et rarement au milieu de cette face (ex. Cardamine pratensis) : aux corps lentiformes du Marchantia polymorplea; aux boules du Tctraplics pellucida; aux bourgcons problématiques du Mnium annotinum.

BULBHLLFLE, adj., bulbilliferus, soboliferts; bulbillentragend (all.). Se dit d'une plante qui produit des bulbilles (voyez ce mot) dans une queleonque de ses parties.
BULBIPARE, adj. , dulliparzs (bulbus, bulbe, paro, produire). Syuonyme de gemmipare (voyez ce mot), dont on s'est quelquefois servi pour désigner les polypes, comparant alors leurs bourgeons aux cayeux qui naissent des oguons.

BULBO-TURER, s. m., tuller regu. lare (Medicus); Zwiebelknollen, Knollcnzwicbcl (all.). Gawler désigue sous ce nom, dans lesplantes monocotylédones, une tuhérosité sphérim que, placée au collet, qui tient à uu renflement de la base de la tige, et qui le plus souvent est recouverte par la base élargic des fcuilles (ex. Crocus salions). I e mềne renflement s'observe chez cerlaines dicotylédones, oì on le désigne sous le non de Bulbe. Yoyea ce mot.

BULLL', adj., bullatus, bullosus, blasig (all.); bollato, bolloso (it.). Se dit d'une fcuillc dont la fuee supéricure est relevéc en bosselures correspondantes à des enfoncemens de la face inféricure ( ex. Ranuneiilus bullatus, Zostcra bullata, Ocymum bullatum, Uloa bullosa, Melastoma bullostum); d'une coquille qui est renflée, ovale et subcyliudracée (ex. Conus bullatusj. Une algue (Aspcrococcus bullosns) est ainsi nomméc parce qu'elle ressemble ì une petite vessic.

BULLEENS, adj. et s. m. pl. Bullaacce. Nom donné par Tamarck is une famille de l'ordre des Mollusques gastćropoles, qui a pour type le genre Bullaa.

BULLESCENCE, s. f. , bullescen tia; Rlasigwordcn (all.). Etat d'une plante dans laquelle, le parenchyme in terposé en tre les nervures des feuilIes acquérant un grand développement, les feuilles semblent avoir été soufflées ou ćtre couvertes de bulles, comme dans la plupart des Clioux.

BULLEUX, adj., bullosus. Les minéralogistes donnent cetlećpithèle 
à une varićté de quartz, qui est remplic de bulles renfermant des nıtières gazeuses ou lipuides. En botanique, clle est synonyme du not Luellé, dont on se sert plus souvent.

BULL1FirRE, adject. , bullifertus (bulla, ampoule, fero, porter). Le Tococa bullifera est ainsiappclé parce qu'il a ses pétioles renflés en vésicules alungées.

BULLULÉ, adj., bullulatus. Ise Crassula bullulata doit cette épithète ì ce que ses feuilles ct ses tiges sont hérissées de petites boursouflures hlanchâtres.

BUNGAROIDES, adj. ets.m.pl., Bungaroïlea, Bungaroüdci. Nom donné par P.-F. Firzinger et Eichwald ¿ une famille de reptiles ophidiens, qui a pour type le genre Bungartes.

RUNIADíes, adj. et s. f. pl., Buniadca. Nom donné par C'andoile à une tribu de la famille des Crueifères, qui a pour type le genre Bunias.

BUNOGASTRE, adj., bunogister

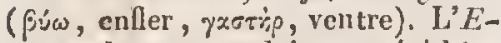
quorea bunogaster doit cette épithète à cc que sa protubćrance ccntrale est fort élevée.

BUPHAGís, adj. ct s. m. pl. , Butphagi. Nom donné par Lesson à une famille de l'o rdre des oiseaux Passereaux, qui a pour type le genre $B u$ phagus.

BUPHTLALuÉ:s, adj. et s. f. pl., Buphthalmece. Nom donnć par H. Cassini à une section de la tribu des Inulćes, et par Lessing à une soustribu de la tribu des Astéroïdées, ayant pour type le genre Buphthalmum.

BUPLEURINÉEs, adj. et 5. f. pl., Bupleurinea. Nom souslequel Sprengel désigne une division de la famille des Ombellifìres, qui a pour type le genre Bupleurum.

BUPRESTIADES, adj. et s, m. pl., Buprestiada. Leach désigne ainsi une famille d'insectes coléoptères, ayant pour type lc genre Buprestis.

BUPRESTIDES, adj. et s. m. pl, Buprestides. Nom donué par Cuvier, Latreille et Eichwald à une tribu de la famille des Coléoptères Serricornes, qui a pour type le genre $B u-$ prestis.

BUPRESTIENS, adj. et s.m.pl., Bupresti. Nom donné par lamarck à une tribu de l'ordre des inscetes coléoptères, ayant pour type le genre Buprestis.

BURMANMACÉES, adj. ets. f. pl., Burmanniacce. Nom donnć par Bartling à une famille de plantes, qui a le genre Burmannia pour type.

BURuANví́:es, adj. et s. f. pl., Burmanniea. Noin sous lequel Sprengel ct Lindlcy désignent une famille de plantes, qui a pour type le gienre Burmannia.

BURSAIRE, adj. , bursarius; qui a la forme d'une bourse (ex. Spontgia bursaria). Le Cricctus bursareus est ainsi nommé ì eausc de la grandeur de ses abajoues.

1BUIRSĹRACĹEs, adj. et s. f. pl. , Burseracea. Nom donué par Kunth à unc famille de plantes, par A. Richard et Candolle ì une section ou tribu de la famille des Térébinthacées, ayant pour type le genre Bursera.

BURSÉníEs, adj. ct s. f. pl., Bursercex. Nom donué par Bartling ì une trilsa de la famille des Amyridées, qui a pour type le genre Bursera.

BURSËrRNE; s. f. , burscrina. Sous cc nom Bonastre désigne la sousrésive qu'jl a extraite du baume de l'Hedvigia balsanifera.

BURSICULE, s. f., bursicula (bur$s a$, lourse). lichard appelle ainsi la partie cxtrême da rostcllum des Orchidćes, excavée en forme de sac, et dans laquelle sont nichés les rétinacles simples ou doubles.

BURSIGuLḱ, adj. , bursiculatus; 
BUXB

sachformig (all.); qui est muni d'une petile bourse. Se dit des rétinacles des orchidées, quand ils sont renfermés dans de petites poches.

BUTÉONINS, adj. et s. m. pl.; Butconina. Nom donné par Vigors à une tribu de la famille des Faleonides, qui a ponr type le genre Butco.

BUTOMEES, adj. cls. f. pl., $B u-$ toncee. Nom sous lequel A. Richard désigne une famille de plantes, qui a pour type le genre Butomus.

BUTYIIA Cí, adj., butyracens, butyrosus (butyrum, beurre). lipitbète donnée à dus plantes dont l'amande donne une grande quantité d'huile ayant la consistance du beurre (ex. Bassia bulyracea, Cocos butyraeca, Pelica butyrosus).

BUTYRATL, s.m., butyras.Genre de sels (buctersaure Salie, all.), qui sont formés par la combinaison de l'aeide butyrique avee les luases salifiables.

BUTYliEUX, adj., butyrosus; butterartig (all.) (butyrum, beurre); qui a rapport, on qui est rulatif au beurre. Consistance, odeur, substance butyreusc.

BUTYRIVE, s. f., butyrina; Butterfett (all.). Nom donné par Chevreul à une graisse partieuliere qui, avec de la stéarine el de l'oléine, constitue le beurre, mais qu'on n'a point cncore pu obtenir à l'état de pureté parfaite.

BUTYRIQUE, ndjeet. butyricus. Nom donné par Chevreul à un acide (Butlersäure, all.), qui se produil par la saponificalion de la butyrine, ct qui existc aussi dans l'urine, dans le sue gastrique el dans la transpiralion de certaiues régions du corps humain.

BUXBAUMHOHDS, adj. ct s.f. pl., Buxbaumioidca, Buxbaumoidea. Nom donné par Furmiohr à un groupe, cl par G.-A.-G. Aruolt à une tribu de la famille des Mousses, ayant pour ty pe le genre Buxbaumia.
Euríus, adj. ct s. f. pl, Buxca. Nom donné par Bartling à une tribu de la f'anille des Euphorbiaećes, qui a pour type le genre Buxus.

BUXINE, s. f., buxina. Alcali végétal que Faure a dćcouvert dans le Buxus sempervirens.

BUXINÉEs, adj. et s. f.pl., Buxinea. Nom donné par A. de Jussieu à une tribu de la famille des Euphorbiacées, qui a pour type le gcarc Buxus.

IBYiriuEs, adj. et s. m. pl., Byrrhï. Nom donné par Cuvier, Lamarek, Latreille et Eichwald, it une tribu de la famille des Colcoptères clavicornes, qui a pour type lc genre Byrrhizs.

BuSSiCli, adj., byssacen.s; schimmelartig (all.); qui ressemble ì un byssus (ex. Clavaria byssacea). On donne celte épilicte aux racines qui sont très déliées el qui ont un aspect cotonueux, comme celles de la plupart des agaries.

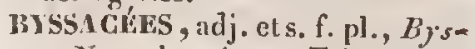
sacea. Nom douné par Fries ì une eohorte de la famille des $\Lambda$ ggues, et par Ad. Bronguiart ì une tribu de la famille des Mucédinées, ayant pour type le genre Byssus.

BrSSÉEs, adj. et s. $\int$. pl. , $B y$. sca. Nom donué par Fries à unc tribu de la eoliorlc des Byssacées, qui a pour type le genre Byssus.

BXSSES, s. m. pl., Byssi. Marquis désigne sous ee noin l'unigue groupe qu'il admet dans la famille des Nématolhéeiens, et Ner's d'Esenbeck l'un des trois groupes dans lesquels il divise l'ordre des végétaux Nyećloïdes Nématomycicns, coupes qui ont pour type le geure Byssus.

BISSIFEnEs, adj. et s. m. pl., Byssifera (byssus, byssus, fero, porter ). Nom donné par Goldfuss, Ficinus et Carus à une famille de l'ordre des Mollusques Pćlacypo- 
'des, eomprenant ceux qui s'altaehent aux corps marins par des filamens dont ils fournissent la matic̀re.

BYSSINÉEs, adj. ets. f. pl., byssinea. Nom donné par Ad. Brongniart à une section de la tribu des IIIucédinées Byssacées, ayaut pour type le genre Byssus.

BSSSOIDE, adj., byssoïdcus ( $\beta \dot{\sigma} \sigma-$ -os, byssus, sido qui ressemble à un byssus. Ex. I saria byssoïdea, Spongia byssö̈des.

BYSSOIDLs, adj. et s. m. pl., Byssoüdes, Byssoüdca. Nom donné par Link ì une série de l'ordre des Mucédinćes, et par Agardh à une famille de l'ordre des Confervoïdes.

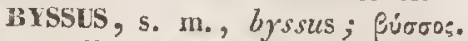
On appelle ainsi les filamens à l'aidc

\section{CACT}

desquels se fixent, au fond des mers qu'ils habitent, un assez grand nombre de coquillages bivalves appartenant aux genres Pcdum, Lima, Pinna, Mytilus, Modiola, Pcrna, Mallcus, Avicula, Tridachne, Saxicola. Ceux des espèces du genre Pinna ćtaicnt déjà counus des anciens : ils servent encore aujoturd'hui, en Sieile, ì faire des bas et des gants.

BruTnGliLCéEs, adj.ets.f. pl., Byttneriacce. Nom donné par R. Brown à une famille de plantes, qui a pour type le genre Byttncria.

BrTTNÉanéEs, adj. et s. f. pl., Byttnerica. Nom donné par Candolle à une tribu de la fanille des Byttnériacées, cellc qui renferme immédiatcment le genre Byttrcria.
Gabonibúes, adj. et s. f. pl., Cabornlece. Nom donué par L.-C. Richard à unc famille de plantes, qui a pour type le grenre Cabomba.

CACALIÍLS, adj. et s. f. pl., Cacalice. Nom donné par Lessing à une section de la sous-tribu des Sénécionidécs Séuécionécs, qui a pour type le genre Cacalia.

CACASI'ISTES, adj. et s. m. pl., Cacaspistcs (rxais, manvais, ḋris, serpent). Nom dont J.-A. Ritgen s'est servi pour désigner une famille de reptiles ophidiens, renfermant les serpens venimeux qui ont le corps garni de plaques.

GACOCHONDnITES, adj. et s. m. pl., Cacochondrites (xaxós, mauvais, zòvojpos, grain). Noun donné par J.-A. Ritgen à une famille de reptiles ophidiens, renfermant les serpens venimcux qui ont la peau grenuc.

CACOPHOLIDOPIUDES, adj. et s. m. pl., Cacopholidophides (raxo's, mauvais, yodis, ćcaillo, öprs, ser- pent). Nom donné par J.-A. Ritgen à unc famille de reptiles ophidicns, renfermant les serpens venimeux qui ont la peau écailleuse.

CACú́, adj., inclusus, latcbrosus, reconditus, occultatus; verborgen, vcrsteckl (all.); hilddcn, conccalcd (angl.); nascosto, occulto (it.). Sedit, en botanique, de la radicule, quand elle est couverte par la base prolongéc des eotylédons (ex. Tropacolum majus). L'Hcdrsarum latcbrosum ust ainsi appelé parce que son pédicule est garui d'une bractée folincée, jaunâtre, roulée en nacclle, et qui enveloppe la fruetifieation.

CACOGENESE, s. f., cacogenesis

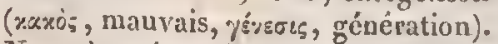
Nom donné par Breschet aux déviations organiques envisagécs d'une manière générale.

CACTRES, adj. et s. f. pl. , Cactca. Famille de plantes qui a pour type le geure Cactus.

GaCites, Cacriers, Cacyulores, 
adj. ct s. m. pl., Cacti, Cactiflores. Noms donnés par diverses botauistes à la famille des Cactécs.

GACTIFORME, adj. , cactiformis. La Spongia cactiformis est ainsi appelée paree que ses expansions sont ramassćes, aplaties et épaisses, de sorte qu'elle ressemble à certains Caclus.

GACTOIDES, adj. et s. f. pl., Cactoïdea. Nom donné par Ventenat à la famille des Cactées.

GADAVÉnELX, adj., cadaverosus; cadaverinus; vexolxiśs; qui tient du cadavre. L'odeur cadavéreuse (Leichcngeruch, all. ) est le premicr produit de l'acte de la putréfaction.

GADAVínis , adj. , cadaverinus ; qui vit sur les eadavres. Ex. Lordatia cadaverina.

CADAVÉLIQUE, adj., cadavcricus; qui a rapport au eadavre: phénomène eadavérique.

CADAVRE, s. m. , cadaver, corpus exanimatum ; vexpòs; Leichnam (all.); corpse (angl.) ; cadavero (il.) (cado, tomber, ab eo quod peri mortem cadat (saint Jérome), ou par contraction des premic̀res syllabes des trois mots caro data vermilists). Corps organisé privé de la vie. On n'employe presque jamais ce mot qu'en parlant d'un animal mort, et on le réserve presque tonjonrs pour désigner l'bomme qui a cessé de vivre, les cadavres des antres animaux étunt vulgairement appelés charogncs.

CADnifkRE, adj., cadniforus. Se dit, dans la nomenclature minéralogique de Haiiy, d'un mićtal qui eontient aceidentellement du cadmium. Ex. Zine cadmifêre.

CADVIOUE, adj., cadmicus; qui appartient au cadmium. L'oxide cadmique est la combinaison du mélal avee l'oxigènc, et le sulfure cadmique eelle de ce même métal avec le soufre. Berzelius appelle sels cadmiques les combinaisons des oxacides avee l'oxi- de eadmique, des corps halogènes avec le cadmium, et des sulfides avec le sulfure cadmique.

CADMIUNi, s. m., cadmium. Métal solide et blanc, qui a été déconvert en 1818 par Stromeyer et Hermann.

CADLC, adj. , caducus, decidurus; hinfiallig (all.) (cado, tomber); qui est sans foree (homme cadric, voix caduque), ou vieux (áge caduc), ou de mauvais aloi (santé caduque $)$. Ce terme est employé : $x^{\circ}$ en botanique, oì l'on appelle cadnc ee qui est périssable et de pen de durée, les partics qui ne persistent pas pendant le développement des organes dans la composition desquels elles entrent d'abord; calice caduc, celui qui tombc an moment de l'épanouissement de la fleur (ex. Papaver Rhocas); style caduc, eelui qui se délrnit après la féeondation, sans qu'il en restc de vestiges sur l'ovaire ehangé en fruit (ex. Scilla maritima); feuilles caduques, eelles qui ne subsistent pas long-temps (ex. Prinos decidures, Sodada decidua, Dicranum caducum, Sescli defoliatum ); stipules caduques, celles qui tombent arce les feuilles, ce qui est le eas de la plupart; pannexterne caduque, celle qui tombe à la maturité du drupe (ex. Juglans regia); arćte cadıque (ex. Stipa pennata) corollc cadluque (ex. Thalictrumfla$v u(m) .2{ }^{\circ}$ En zoologie, Kirby appelle paltcs caduques eelles que l'inscete n'a pas danis tous les états par lesquels il passe.

CADtcíe, s. m. , caduccus. Nom donnć par Trinins à un mode d’inflorescence des Gramiuées, qui eonsiste en un axe régulièrement articulé, dont chaque articulation porte à son somnet, ct non ì sa base, des épillets sessiles ou munis de courts pédoncules. Ex. Hordeum.

CADUCIBRANCHES, adj. et s. m. 
pl., Ceducibranchia (cadueus, endue, Ppx́zyı , branchies). Norn donné par Latreille $\dot{a}$ un ordre, par Fieinus et Carus à une famille de la classe des Amphibies, comprenant ceux chez lesquels les branchies disparnissent quand l'animal parvient à l'âge adulte.

CADUCIFLORE, adj, , cadnciflorus (cadueus, caduc, flos, fleur). Dout la corolle tombe de tres-bonne heure. Ex. Cinchona caduciflora.

CADUcitŕ, s. f. , caducitas; Hinfälligkeit (all. ) ; craviness (angl.); caducità (it.). Etat de ce qui est caduc. Vicillesse débile. Pćriode de la vie humaine qui commence vers la soixantc. et dixiène année et s'étend jusqu'à la quatrevingtième. Cadrucité cst moins que décrépicude. Il s'emploie aussi quelquefois, mais rarement, el parlunt de choses inanimées.

CFrothaLAVues, adj. et s. m. pl., Cenothalami ( rotvòs, commun, Oż̀apos, lit). Nom donné par Acharius à une division de la famille des Lichens, comprenant ecux dont les apothécies sont formées en partic par la fronde et en partic aussi par une sulsstance spéciale.

CASALINÉES, adj. et s. f. pl., Cossalpinca. Nom donné par Candolle à une tribu de la famille des Iuégimincuses, qui a pour type le genre Casalpinia.

CAESALPINLES, adj. et s. f. pl., Casalpiniea. Kunth donne ce nom à la tribu des Ccesalpinées. $V$. ce not.

CAFÉATE, s. m. , cafeas. Sel formé par la combinaison de l'acide caféique avec une hase salifiable.

Caféine, Cafféine, Cofrérate, s.f., cafeina; Coffcin, Koffecbiltcr, Koffecstoff (all.). Substance particuličre, que Runge a découverte en 1820 dans le café, et qui depuis a été étudiće par Robiquet, Pelletier, Cayentou, Garot et Plaff.
GAF́́IQUE, adj., cafeicus. Nom sous lequel Pfaff désigne un acide particulicr qui existe dans le café.

CAINU, s. m. , brelbulus (Jink), nuclers, adnascens (Tourncfort), adnatum (Richard); Knospenzwiebel, Zwiebelbrnt, Brutzwicbel, Kindel (all.); off-set (angl.); bulbetto (it.). Petite bulbe que produit une antre bulbe, qui la remplace, el qui nait, soit dans sa substanec même ( $\mathrm{cx}$. Crocus sativus), soit à côté (ex. Tulipa), au dessus (cx. Gladiolns) ou aul dessous (ex. quelques Ixia). Candolle regarde les caïenx comme des bourgeous axillaires des bulbes, com ine de jeunes branches qui se développent à l'aisselle des feuilles; ils ne sont attachés à la tige que par un filet mince, qui sc brise aisćment et souvent de lui-mêne. Ayaut leurs écailles charnues, ils peuvent se développer par eux-mênes, après avoir été séparés de la bulbe qui leur a donué naissance.

GALLLBOTí, adj., congulaus; geronnen (all.); qui est coagulć, réuni en grumeaux.

GAILLOT, s. m., coagulum ; BlutKuchen (all.); clod (angl.); grumo (it.). Petite masse de sang caillé; masse composće de la fibrine et de la mitière colorante du sang, qui se produit par la coagulation de ce liquide.

GAILLOU, s. m., silex; Kicsclsicin (all.); pepple (angl.); selcio (it.). Les gréognostes dounent ec nom à des fiagmens de roches peu volumineux, et eu géuéral plus ou moins arrondis, sans étranglemens, qui se trouvent soit ì la surface du sol, soit dans des dépôts meubles. Quclquefois aussi on l'applirque à des fragmens de pierres dures, qui font feu suus le choc du briquet.

Callo outerux, adject. ; qui est plein de cailloux. Un dépól caillouıcux diffère des graviers parce que 
les fragmens qui le composent sont plus gros, quoique d'ailleurs ordinairement arrondis. Brougniart donne celte ćpi thète ì un groupe de ierrains, comprcnant ceux qui sont composés de eailloux, depuis les fragunens asscz petits pour constituer le gravier, jusqu'aux masses atteiguant au plus le volume d'un cuf, qu'on appclle galets.

Garuans, s. m. pl. Nom donné par Blainville à une famille de reptiles Enydosauricus, comprenanit ceux dc ces animarx qui ont un museau large et court.

CAINCATE, s. m., caincas. Sel formé par la combinaison de l'acide eainneique avec unc base saliliable.

GAINGIQUE, adj., caincicus, Nom donné par François, Pelletier et Caventou à un acide particulier, qu'ils ont découvert dans la racine du Chiococca racemosa.

CakILINÉEs, adj. ct s. f. pl., Cakilinea. Nom douné par Candollé il une triba de la fanille des Giucifìres, qui a pour type le genre Cakilc.

CAL, subst. m. , callus, callum; Schwiele (all.). Masse cndureie et ferme, qu'on observe quel(quefois sur les végétaux, et qu’ou a comparéc aux durillons qui se forment dans la main des ouvricrs.

Calaniagostinḱes, adj. et s. f. pl., Calamagrostidea. Nom donné par Trinius à une tribu de la famille des Craminées, qui a pour type le genrc Calamagrostis.

GALAמunićes, adj. et s. f. pl. , Calamaria (calamus, roseau). Linné dósignait ainsi une funille de plantes, qui ressemblent aux Graminées pour le port, mais dont la tigc cst dépourvue de nouds.

GALAMírs, adj. et s, f. pl., Calamece. Nom donné par Kunth et par Mátius à une tribu de la famille des Palmiers, qui a pour type le genre Calamus.

CAL.Anionss, adj. ct s. m. pl., Calamides. Sous ce nom, Latrcille désigne une famille de la classe des Polypes, comprenant ceux de ecs animaux qui ont le corps disposé en forme de plinnc.

GALAMHFÈSE, adj., calami/crus (calamns, roseau, fero, porter). La Spongiz calamifora est ainsi appeléc paree qu'elle se compose de tulies cylindriques comme des plumes ou des rosenux et rimuis en touffes.

CALAMTEOR.ME, adj., calamiformis; federförnig (all.) (calamus, plume, forma, forme). Epithète donnée uu corps des pennatules, à eause de sa ressemblanec avec une plume. Le Mescmbryanthcmum calamiforme doit ce nom ì la forme de ses feuilles, qui sont grêles, roudes et subulćes.

CALAMUNAIRE, adj., calaminaris (calamina, calaminc). Les minéralogistes appcllent picrres calaminaires des masses conerétionnées ou tcrreuses, qui sont composées d'oxide dc zine aceidentellement uni à dc l'oxide de fer, à de l'argilc et à d'autres substanecs étrangères.

CALAMOPHLLES, adj. et s. m. pl., Calamophylli ( $\% \dot{\alpha} \alpha \mu 05$, roseau,

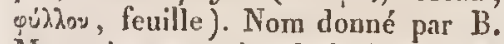
Meyer à une seetion de la famille des Jones.

CALAMULE, s. f., calamula ( $c a-$ lamus, plumc). Les zoologistes désigneut sous ce nom les longs appendiees filiformes, fistuleux, calcaires, terminés par cing à huit godets empilćs les uns sur les autres, dont I'animal de la Fistulare a deux qui font saillie par la partic ouvertc de son fourreau testacé.

Galdandéiors, adj. cts. m. pl., Calandraides. Nom domé parSelıon. herr ì un groupe de la fiumille des Gurculionides, renfermant ceux de 
ccs inscetes qu'on désigne vulgairement sous le nom de Calandres, et quelques espèces voisines.

GALATHu)E, s. fo, calathidis, $c a$. lathidium, calathis, anthoclium, cephalanthium, flos compositum ; Bliithenkorb (all.) ( $x \alpha \lambda \times \theta i$ i , petit panier). Mirbcl et Cassini désignent ainsi un mode d'inflorescence qui se compose de fleurs sessiles, ou à peu près, serrées sur un réecptacle qu'cntoure un involucre commun ( ex. Synanthćrées). Link adopte ce nom, mais veut qu'on ne l'applique qu'aux fleurs dites composées, qui, avant la fleuraison ou pendant la nuit, sont enveloppées totalement par le calice commun.

GALATIIDDIFLORE, adj. , calathidiflorus (calathus, corbeille, flos, fleur). Se dit de l'involucre, quand il entoure un clinanthe chargé de fleurs sessiles, ou à peu près, et qu'il ressemble en quclque sorte à une pctite corbcille.

GALATHIFLIR, adj. , calathifcrus; qui porte les calathides, ou qui cn est composć, coinme le corymbe des corymbifères, et jusqu'à un certain point l'ombclle de l'OEnanthe.

CALATHIF OLuE, adj., calathiformis (calathus, corbcille, forma, forme). Terme introduit par Salisbury, qui désigne ainsi, dans les végétaux, les parties hémisphériques et concaves, ì bords droits.

GALATIIIN, alj., calathinus (calathus, coupe). Le Narcissus calathinus a été appelé ainsi à cause de sa couronne, qui cst très-grande, cyathiforme, ou en forme de coupe.

CALATHIPHORE, s. m. , calathiphorum (xa)xois, petit panier, pśpw, porter). Nom donué par Cassini à la partie qui, dans les Synanthérées, porte les calathides du capitule.

GALCAIRE, adj. et s. m. , calcareus, calcarius ; kalkartig (all.) ; calcarcous (angl.); calcareo (it.) (calx, chaux); qui contient de la chaux (picrre calcaire), qui est principalement formé de chaux (spath calcaire), qui vit dans les terrains calcaires (ex. Urceolaria calcaria, Polypodium calcareum). En minéralogie, on donnc cette épithète à toutes les rockes qui sont essentiellement. composćes de chaux carbouatée, à l'état soit cristallin, soit sédimentaire. Brongniart appelle formation calcaire l'ensemble de tous les calcaires concrétionnés ou incrustans qui se sont déposés depuis les tenıps historiques, et qui se déposent encore aujourd'bui dans des cavilés de la terre ou au fond de certaines eaux.

GALCAYÉO-F ERIRUGINEUX, adj., calcarco-ferruginosus; qui contient de la chaux et de l'oxide de fer. Ex. Amphibole calcaréo-ferrugineuse.

GALCARÉo-MAGNíSIEN, adj. , calcarco-magnesianus; qui conticnt de la chaux et de la magnésic. Ex. Amphibole calcaréo-magnésienne.

GALG.ARío-SABLELX, adj., calcareo-sabulosus. Nom donné par Brogniart à un groupe de tcrrains sédimenteux, dans lesquels dominent les roches calcaires et les débris de roches quarzeuses.

CALGARÉO-SILIGELX, adj. , calcareo-siliciosus; qui contient de la chaux et de la silice. Ex. Titanc calcuréo-siliccux.

CALCALÉO-TRAPPĹEN, adj. Épithète donuce par Brongniart aux terrains qui sont formés de couches calcaires sédimenteuses séparées pardes dépôts trappéens plus ou moins abondans.

CAlGAREux, adj., calcaroszes. Nom donné par Omalius à un gcure de roches, comprenant celles qui ont pour base lc carbonate calcaire; et par Brongniart ì un groupe de $t e r$ rains hémilysiens dans lequel il range ceux qui sont abondans en roches calcaires. 
CALCARIFERT, adj. , calcariferus (calx, chaux, fero, porter). Epithète donnée par les minéralogistes aux minćraux qui sont mélangés de carbonate caleaire. Ex. Gypse calca. rifcre.

CALCARIFÈIE, adj. , calcarifer, calcaratus (calcar, ćperon, fero, porter). Se dit d'un animal qui porte des aiguillons qu'on a comparés à des éperons, la plupart du temps à eause de leur situation. Le $V$ espertilio cal . carifcrzss offre une sorte d'éperon à lo. partie interne de la prenière phalange de son pouce. Le "Ty rannus calcariferus a les genoux garnis de sept ou huit épines. Le Plcctropomus calcarifer a les opercules aiguillonnćs. La Leptura calcarata a les jambes postérieures armées de longucs épines. La Cancellaria calcarata est une eoquille garnie de pointes.

GALCARIFORuE, adj. , calcariformis (calx, chaux, forma, forme). Epithète donnée, daus la nomcnclature minéralogique de Ilaïy, à une stćatite qui présente la forme d'emprunt de diverses variétés du enlcaire rhomboïdal.

CALCARIFORME, adj. , calcariformis (calcar, éperon, forma, forme); qui a la forme d'un éperon, comme les pétalcs de l'Aquilegia.

CALCÉDONibux, adj., calcedonius. Se dit d'une substance ou d'une pâte qui a les caractìres extćrienrs de la caleédoine.

CALCÉDONi@Ue, adj. , calcclonicus; qui a les caractères, les propriélés de la calcédoine; malière, caillou calcédlonique.

CALcíolés, adj. et s. m. pl., Calceolati. Nom donné par Desmoulins à la scule famille qu'il admctie. dans la classe. des liudistes, et qui a pour type le genre Calceola.

CALChIFOLME, adj. , calceiformis; schulfformig (all.) (calceus, soulier, forma, forme). Se dit du nectaire, quand il est renflé et imite. en quelque sorte la forme d'une pantoufle. Ex. Cypripcdizm.

CALCÉOLIFOPUE, adj., calccoliformis (calccolts, soulier, forma, forme); qui est oblong ct un peu rétréci au milieu, ayant la forme ct'un sabot renversć, comme l'abdomen du Sigalphus irrorator.

CALCICO-AMMONIQUE, adj., calcico-antmonicus. Epithète par laquelle on désigne, dans la nomenclature chimique de Berzelius, des sels doubles qui résultent de la conbinaison d'un sel calcique avec un sel ammoniquc. Ex. Mralale calcicom ammoniquc (malate de chaux el d'ammoniaque).

CALCICO-ARGENTIQUE, a dject. , calcico-argenticus. Nom donné, dans la nomenclature chimique de Berzclius, à des sels doubles qui résultent d'un sel calciquc eombiné a vec un sel argentique. Ex. Fulninate calcico - argentique ( fulminate da chaux et d'argent).

GALGICO-BBATTIOUE, adj., calcico-barylicus. Épithète qui désigne, dans la nomenclature chimique de Bcrzclius, des sels doubles résultant de la combinaison d'un sel calcique avee un scl barytiquc. Ex. Carbonale calcico-bary tiquc (carbonate de chaux. et cle baryle).

CALCico-MAGNíSIQUE, adject., calcico-magnesicus. Epithète dont on se sert, dans la nomenclature chimique de Berzelius, pour désigner des sels doubles qui sont produits par la conbinaison d'un sel calcique avec un sel maguésique. Ex. Silicale calcico-magnésique ( silicate de chaux et de magnésie).

CALCICO-POTASSIQUE, adjeet. , calcico-potassicus. Nom donné, dans la nonenclature chimique de Bcrzelius, à des sels doubles qui résultent de la combinaison d'un sel calcique ayee un scl polassique. Ex. Silicate 
calcico-potassique (silicate de chaux cl dc polasse).

CALCICO-SODIQUE, adj., calcicosodicus. Epitlète dounée, dans li nomenclature ehimique de Berzclius, à des scls donbles qui résultent d'un sel caleique combiné avec un sel sodique. Ex. Sulfalc ealcico-sodique (sulfale de chaux et de soude).

CALCICO-STIRONTIQUE, adject., calcico-stronticus. Épillìte donnée, dans la nomenclature elimique de Berzelius, ì des sels doubles qui résultent de la combinaison d'un sel calcique avec un sel strontique. Ex. Carbonate calcico-strontique (carbonate dc chaux et de strontiane).

CALCIDES, adj. et s. mi. pl., Calcides. Ampère donne ee nom à un genre de corps simples, el C. Pauquy ì une famille de corps pondérables, ayant pour type le Calciune. CALCIFLEL, adj. , calcifcrus; kalkhaitig (all.)(cal.c , claux, fcro, porter); qui eonticnt du carbnnate calcairc (ex. (uarz hyalin calciférc); qui est mélungé avec du carbonate de chaux (ex. Calcédoine calciférc).

CALGIrÈnes, adj. et s. m. pl., Calcifera. Nom donné par Lamouroux aux polypicrs qui résultent d'une substance calcaire unélangée avec la maticre animale, ou la recouvrant.

CALCIFIÉ, adj. Epithc̀te imposće par E. Eichwald aux ossemens fossiles, qui, ayant perdu lcur matic̀re animale et en même temps leur dureté naturclle, sont devenus légers et friables.

GALCIGLENE, adject., calcigcnus (calx, ehaux, rigno, produire), qui nait sur la chaux. Le Sporotrichum calcigena se développe sur les murs peints à la clianx.

CALCINABLE, adj. ; qui est susceptible d'ètre calciné ; ntatiöre calcinablc.

CALGINATION, s. f., calcinatio;
Verlialkung, Kalcinirung (all.); calcining (angl.); calcinazione (it.). Rćduction des pierres calcaires en chaux par l'action de li chaleur; opération dans laquelle on soumet à une challeur très-élcvée une substance infusible, mais sensiblement altćralle sous le rapport soit deson mode d'agrégation, soit surtout de sa composition chimique.

CALCIPIYTES, adj. ct s. m. pl., Calciplysta (calx, chaux, putoy, plante). Nom donnć par Blainville à une classe de Pseudozoaires, renfermant des corps orgauisés phytoïdes, qui sont composés d'une substance intéricure fibrcuse et d'une cxtćricure crćtacée, comme les Corallincs.

CALCIQUE, adj., calcicus; qui apparticnt iu ealcium. L'oxide calcique est une combinaison de ee métul avec l'oxigère, vulgairement appelće chaux. Berzclius nomme sels calciques les combinaisons de l'oxide calciguc a vee les oxacides, celles du calcium avec les corps halogrènes, et celles du sulfurc de calciun avec lcs sulfides.

CALCiouss, adjeet. pl. Epithète donnce par Brongniart à un groupe de lcrrains agalysicns, ayant pour base les roches calcaires.

CAlCITRA péES, adj. et s. f. pl., Calcitrapca. Nom donné par H. Cassini à un groupe de la section des Synantbérées ecntauriécs protolypes, qui a pour type le genre Calcilrapa.

Calcium, s. m., calcium. Mćtal solide et blane, dont la eombinaison avee l'oxiggène donne naissance à la chaux, et qui a été mis en évidence, pour la premic̀re fois, par Davy.

CALlíes, adj. et s. f. pl., Calca. Nom douné par Lessing à une section de la sous-tribu des Sénécionidées hélć. nićes, qui a pour type le genre Calea.

CALÉIDOPHONE, s. m., caleido- 
phonum ( $k$ hiòs, beau, Eions, apparence, ழ̧véw, l'ésonncr ). Instrument d'optique ct d'acoustique, que Wheatstone a inaginé pour rendre visibles à l'ouil les vibrations qui sont nécessaires à la production des sons.

GAĹ́rvís, adj., Calcinea. Nom donné par H. Cassini ì un groupc de la seetion des IIélianthées héléniées, qui a pour type le genre Calca.

GaLENDUlaciées, adj. et s. . pl., Calendulacca, Calcndulea. Nom donné par H. Cassini à une tribu de la famille des Synanthérćes, par Lessing à une sons-tribu de la tribu des Cynarées, ayant pour type le genre Calendula.

\section{Gallendulíes. Voy, Calendu-} LACÉES.

CalenDuline, s. f. , calendulina. Substance découverte par Geiger dans les fleurs du Calendula officinalis, que Stoltze a étudiée depuis, qui paraît appantenir, d'après Berzclius, à la classe des mueilages végćtaux, et que Gmelin croit voisine de la zéine ou de l'anidon.

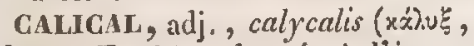
calice). Epithète donnéc à l'inscrtion des étamines, par Lestibondois, quand ees organes sont atdhérens aut ealiec, par A. Richard, lorsque les étamines et les pétales, si ceux-ci existcnt, sont insérćs au calice, plus liaut que le point de jonction de cc dernier avec l'ovaire partiellement infère. Ex. Polyanthes tubcrosa.

GALICE, s. m., caly $x$; xx́du Kelch (all.); calice (it.). La signification de ce mot a varié, ou plutôt est restée dans le vague, en botanique. I.I a toujours exprimé Ia partie externe du périanthe, quand celui-ci est double; mais les opinions sc sont partagécs au sujet du sens qu'on doit y attaeher dans le cas de périanthe simple. Tournefort et Linné n'appelaient généralęment ce dernier calice que quand il èst vert, tandis que Jussieu lui applique toujours cette dénomination, quclles que soient sa couleur, sa forme et sa consistance. Cependant Tournefort nommait calice dans le nareisse ce qu'il appelait corolle dans la tulipe, ct Linné calice dans Ic Chenopodium et le Juncus ce qu'il nommait corollc dans le Daphac. Suivant Sprengel, le caliee cst toujours pourvu de glandes, quoique, d'après Link, celles-ei manquent souvent. Causdolle laisse la question indécise, ct donne le nom de périgone à tout périanthe simple.

G.sLIClí, adj., calycatus, calycinus, calycasus. Se dit d'une fleur qui cst pourvue d'un calice, et quelquefois l'unc plante qui a un grand calice (cx. Kydia calycina, Hypericum calycinum), ou un caliee renflé (cx. Astragalus calycinus, Saboatia calycosa). Se dit aussi d'une mousse dont les feuilles périchétiales sont roulécs en cylindre, de manière à imiter un calice (ex. Barbula calycina).

Calucí́es, adj. et s.f. pl., $C a-$ licicce. Nom douné par Fries à une tribu de l'ordre des Liehens gymnocarpes, qui a pour type le geure $\mathrm{Ca}$ licium.

GALICIF LORE, adj. , calyciflorus (calyx, calice, flos, flcur). Le Faramea calyciflora a été appelé ainsi à causc dc son calice, dont le limbe est tubuleux, ample et persistant.

CALICIFLOnes, adj. et s. f. pl., Calyciforce. Nom donué par Candollc it une scetion des plantes dicotylédones, comprenant celles dont les pétales, libres ou plus ou moins soudés, sont insérés sur le calice. Royen avait déjà appliqué ce nom à une classe de plantes dans laquelle il rangeait celles qui ont les étamines insérécs sur le calice, et Linné à une 
famille comprenant celles qui n'ont qu'un calicc sans corolle.

GALIGIFORNE, adj., calyciformis; lelchformig (all.) ( $x$ xhúg, calice, forma, forme); qui a la forme d'un calice, comme l'involucre des Anentone.

CALICIN, adj., calycints ; kclchartig (all.); qui tient de la nature du calice. Se dit d'un périgone unique qui paratt se rapportcr plutôt au calice qu'à la corolle. Ex. Dapline.

GALICNNAIRE, adj. , calycinaris. Epithète donnće, par Desvaux, au nectaire, lorsgu'il est placé sur le calicc ; par Candollc, aux flcurs doubles dans lesquelles les pétales sont dus à la multiplication des sépales du ealicc.

GALICINAL, aldj., calycinalis; qui apparticnt au calice ( poils calicinaux, écailles ou fcrullcs calicinales). Dunal appelle verticillc $c a-$ licinal celui qui est formé d'un nombre déterminé de sépalcs, asscz souvent munis à leur base de lépales calicinaux, on ćcailles glandulcuses, libres ou soudćes ensemble, lesquelles recouvrent plus ou moins la facc externc des sépales, et débordcut souvent les folioles du calice.

GALIGIVIEN, adj. , calycinianus. Epithète donnće par Mirbel ì l'induvie, quand elle provient du calice. Ex. Rosa.

CALICISTK, adj. ct s.m., calycista. Epithète donnée par Linné aux botanistes qui ont fondé leurs méthodes de classification sur le valice, comme Magnol.

GALICULAIrE adj., calicularis. On appelle cstivation caliculaire celle dans laquelle, les pièces étant sur deux rangs, le rang cxtcrne ne rccouvre ou n'embrasse que la base du rang intcrne, comme dans l'involucre des Sénecons. La Caryophyllia calycularis est ainsi appelée parce que son polypier porte des cellules en forme d'étoiles excarées.

CALICULE, subst. m. , calyculus; Kelchchen (all.); calicello (it.). Les botanistes appcllent ainsi un calice très-pctit, ou accessoire, qui est placé en dehors du vrai calice (ex. Malva); quclquefois une petite rangéc de bractćoles qu'on aperçoit à la base d'un involucre (ex. ecrlaines Synanthćrécs); parfois aussi un involucre qui uc renferme qu'une seule flcur, ct qui adhìre par sa base avec le rrai calice. F. Campden donne ce nom aux enveloppcs florales externes des Rumex.

CALICULF, adject., calyculatus; gctielcht (all.); qui est pourvu d'un second calice. On dit l'involucre caliculé lorsqu'il est muai à l'cxtérieur d'une rangée de braclécs qui constituent en quelque sorlc un second involuere (cx. Crepis biennis), et l'aigrette caliculce quand, outre les poils qui la composent, elle offre en dehors une petitc eouronne membraneuse resscinblant ì un petit calice (ex. plusicurs Inula). Le Marsippospcrmum calyculatum cst ainsi appelć parce qu'il a uu calice composé dc trois folioles tris-longues, et le Loranthus calyculatus, parce qu'il porte unc bractée cupulaire sous chaque fleur.

CALIGIDES, adj. et s. m. pl, Caligides, Caligida. Nom donné par Lcach et Latreille à une famille de l'ordre des Crustacés branchiopodes, qui a pour type le genre $C a$ ligus.

GALIGULE, s. f., caligula ; Sticfel (all.) (caligula, bottine). Illiger appelát ainsi la peau qui recouvre le tarse dans les oiseaux.

GAIISAYNe, s. f., calisayna. Alcali végétal, que Pclletier et Caventou- ont découvert dans l'écorce du China Calisaya.

GALISAYQUE, adj. , calisaycus. 


\section{CALL}

Épithète dounće, dans la nomenclature chimique de Berzclius, aux sels qui ont pour hase la calisayue.

GaLlacées, adj. el s. f. pl., Callacea. Nom donné par Bartling à une famille de plantes, qui a pour type le genre Calla.

GALLv́Es, adj. et s. f. pl., Callece. Nom donné par Bartling à une tribu de la famille des Callaećes, ayant pour type le genre Calla.

CALLIEUX, adj., callosus; schwiclig (all.); callous (angl.); calloso (it.) (callus, cal); qui est plein de callosités, endurci, racorni. Épithète donnée à des parties dont la consistance est plus ferme et la compacité plus grande que celles des autres. Se dit: $1^{\circ}$ en botanique, des ramearux, lorsqu'ils sont couverts de proéminences arrondies (cx. Aspalathus callosus), et des (euilles, quand clles sont couveries de taches calleuses (ex. Cheiranthus callosus), ou garnies de petits durillons sur les bords (ex. Suxifraga Cotyledon) ; $2^{3}$ en zoologie, d'une coquille bivalve, lorsqu'à l'endroit de la charnière, ou remarque un bourrelet arrondi et inégal, au lieu de dents (ex. Pholas callosa); du corselet, cluez les insectes, quand il a des rebords épais, qui paraissent formés d'une substance différente de la sienne.

CALLIANInIDES, adj. et s. m. pl., Callianirida. Nom donné par I. Esehenlioltz à une famille de la classe des Acalèphes, qui a pour type le genre Calianira.

CALLICHionis, adj. et s. m. pl., Callichromi ( $x \dot{\alpha} \lambda_{\lambda .05}$, beauté, xpöux, coulcur). Nom douné par Savi it une tribu de l'ordre des Passercaux, comprenant cerx qui, comme les Coracias et nutres, se lont remarquer par la beauté et l'éeliut de leurs couleurs.

CALLIFÈE , adjeet., calliforus (callus, cal, fero, porter). Se dit
CALL

d'une coquille bivalve dont les erochets sont calleux (cx. Area callifora), el d'une eoquille univalve dont l'ombilic est marqué d'une callosité (ex. Troclus calliferus), on qui pnrte une couroune de callosités sur le dernier tour de sa spire (ex. Purpura callifera).

GALLIPYGl', adj., callipygus (xó)los, beauté, $\pi \cup \gamma \dot{n}$, fesses ). La $V e-$ nus callypiga est ainsi appelée parce qu'elle porte une tache blanche, en forme d'étoile angulaire, à sa base.

CALLPTIICIúES, adj. ct s. f. pl., Callitrichea. Nom douné par Bartling à une tribu de la famille des Haloragées, qui a pour type le genre Callitriche.

GaLLITRICHINÉES, adj. et s: f. pl., Callitrichincre. Noin donné par Candolle à une tribu de la famille des Haloragées, par Liuk, Lindley et Kunth, à unc famille de plantes, ayant pour type!e genre Callitriche.

GALLOSITE, s.f., callositas; Sitzschwiele (all.); thiclincss (angl.); callosilà (ii.). On donne ee nom, chez ecrtains maumuifères, ì des parties du eorps dures, ordinairement rases, eouvertes d'une peau épaisse, et parfois colorées, dont le développement est attribué à l'usage de s'asseoir ou de s'appuyer sur les régions qui en sont le siége. Telles sont eelles qu'on observe aux fesses de quelques singes, a la poitrine et aux genoux des chameaux. Le môme nom est appliqué it des protubérances planes qui se voyent sur diverses parties d'un grand nombre de coquilles, et à des dépôts ealeaires, souvent semblables à de l'émitil, qui s'observent sur la calumelle de quilques unes.

Gallos, s. m., callus. Organe polymorphe, adıis par Trinius, daus les Graminées, et qui, suivant Raspail, est tout simplement la base de la paillette inférieure, laquelle, en se renversant quelquefois, détermine 
là une espèce de bourrelel (cx, Bromus, Ficstuca).

CALOCÉPHALE, adj, caloccpha-

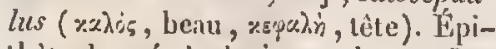
thète donnéc à plusicurs plantes Synauthérćes, 'n raison de la beautć de leurs calathides. Ex. Psephellis calocephalus, Lophiolepis calocephala.

CALOPE, adj., calopus ( beau, $\pi 0_{5}$, pied); qui a un pied on un stipe beau, comme celui du Peaiza calopus, qui est long et rose.

CALOPHYLLN, adj., ealophyllus ( $x \times \lambda_{0}$, heau, quijioy, feuille); qui a dc belles feuilles, un feuillage élégant (ex. Elsasia calopleylla). Iu Cladodium calophyllum est ainsi appelé, parce qu'il forme de beaux gazons; l'A garicus calophyllus, parce que ses lames sont d'nn beau rouge.

CALOPII'LLIES, adj. et s. f. pl., Calophyllea. Noun donné par Choisy et Candolle à une tribu de la famille des Gutlifères, qui a pour type le geire Calophyllum.

CALOPIY'TES, sı m. pl., Caloplyta (raitos, beau, yurov, planie). Nom donné par Bartling à une classe de plantes, qui conprend les familles des Pomacées, des Rosacécs, des Dryadées, des Spirénećes, des Amygdalées, des Chr'ysobalanées, des Papilionacées, des Swartzićes, des Césalpiniées et des Mimosées.

Galopone, s. m., Calopodium;

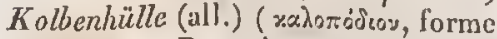
de soulier). Rumph appelle ainsi la spathe des Aroïdécs, cul raison de sa forme.

GALOPS, adj., calops ( walis, beau, $\omega \psi$, ceil ); qui a l'ocil trèsgrand et trìs-brillan'. Ex. Labrus calops.

CALOPTL̀nE, adject., calopierus

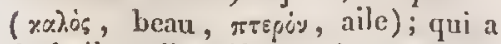
de belles ailes. Ex. Eriopicra caloplera.

Galonicité, s. f., caloricilas (ealor, ehaleur). Faculté dont jouissent les corps vivans de produirc et dégager la quantité de calorique nécessaire à l'entretien de la vie.

CALORIVICATION, s. f., calorificatio (ealor, chaleur, fucio, faire). Faculté de prodnire et de développer de la chaleur.

CALORIFiQUe, adj., calorificus; eraviëmcrud (all.) (calor, chaleur, facio, faire); qui éelıautfe. Les physieiens donucnt cette épithète à ecux des rayons lumineux qui produisent de la ehaleur. Dans l'hypothèse de Rumford, où, pour se conformer au langage recu, on appelle rajons les mouvemens reetilignes à l'aide desquels les vibrations sc prolongent, l'épithète de calorifiquc est donnée à ceux de ees mouvemens dont l'aetion rst aceéléritrice.

CAROHML'TRE, s. m., calorimetrum; Wïrmcmesser ( all.) (calor,

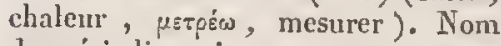
donné a divers instrumens au moyen desquels on détermine la quantité de chaleur spécifique que contiennent les différens corps, et dont les principaux sont ceux de Lavoisier et Laplace, de Rumford et de Tillotson. On appelle de même un autre instrument, imaginé par Mongolfier, et perfectionué pas May, qui sert à déterminer la quautité de chaletur produite, dans un temps donné, par diverses substanees combustibles.

GaLonnútrite, s. f. , calorimetria; Wirmenesscrkunst (all.). Par! tic de la physique qui a pour objet la mesure du calorique libre.

Cacorivotrur, adj. et s. m., calorimotor (calor, elhaleur, moveo, mouvoir). Appareil ćlectrique, imaginé par R. Hare, qui est ainsi appelé à cause de la propriété qu'il a de produire, par sa décharge, des températures tris-élevées et tous les phénomères qui en dépendent. 
CALORIQUE, s. m., caloricum; Würmcstoff, Warmematcric (all.). Canse inconnue de la sensation de ln chaleur, que les uns croyent êire un fluide impondérable, et que les autres regardent, avec Rumford, comme un mouvement vibratoire, qui agite les molécules de tons les corps, dont la vitesse est accéléréc suivant les circonstanees, et qui se communique à distance par l'intermédiaire de l'éther, les vilırntions qui affectent les molécules d'un corps excilant dans celui-ei des ondulations analogues à celles que les corps sonores font naître dans l'air, et qui, susceptibles de se propager, suivant toutes les dircetions, produisent les eleangemens de tempírature anxquels sont dus le trouble et le rétablissement de l'équilibre thermométrique cntre les corps placés dans la sphère de ees ondulations.

CALPE, s. f. , calpa ( $: \lambda_{\lambda \pi n}$, urne). Necker appelait ainsi l'urne des Inousses.

GALIBION, s, m. , calybio (*xivProv, petite cabane). Non donnć par Mirbel à un fruit formć d'un ou plusicurs glands eontenus en entier ou cn parlie dans unc cupule. Ex. Quercus.

CALYGamnnir, s.f., calycan-

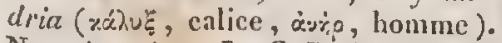
Nom donné par Is.-G. Rielıard à une classe de son système scxuel modifié, qui renferme les plantes ayaut plus de dix étamines insérécs au caliee, l'ovairéctant libre on pariétal.

CALYCANTHíses, adj.ets. f. pl., Calycanthece. Nom donnć par Lindley et Candolle à une fanille de plantes, qui a pour type le genre Calycanthus.

CALTCANTuEviv, adj., calycan-

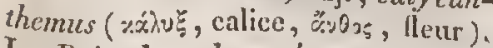
Lc Primula calycanthema est ainsi nommé parce que son calice s'épsnouit, à la partie supćrieure, en un limbe coloré et pútaloĭde, de telle sorle que la fleur semble avoir deux corolles.

CaLYGanTHìues, adj. et s. f. pl. , Calycanthcme. Nom donné par Linné à une famille de plantes qui se font remarquer en raison de leurs belles fleurs, par Agardh à une classe de plantes phanérocotylédones à fleurs completes périgynes, comprenant les familles de Salicariées, des Hamamélidécs, des Sanguisorbées, des Onagrariúes, des Combrétaeées et des Mélistomées, par Venteuat à la fitmille des Lythraeées.

CaIYCANTIIńées, adj. et s. f. pl. , Culycanthinex. Nom donné par Barlling ì une classe de plantes, qui comprend les familles des Granatées et des Calycauthées.

carrcínlís, adj. et s. . pl., Calycerca: Nom donné pirr I.-C. Rirhard à une famille de plantes, dont Correa avait conçu l'ilée, et que $H$. Cansini a établic ensuite sous celui de Bonpidies. Elle a pour type le genre Calyccra.

CALYGIE, s. f., calycia. On appelle ainsi une apotheccie qui est stipitće ct seyphatiforme.

Calvcrúbs, adj. et s. f. pl. , $C a$ lyciecc. Nom donnć par Zenker à une. tribu du la famille des Lielıens, qui a pour type le genre Calycium.

GaLYciouns, adj. et s.m. pl., Calycioïlcs. Nom donné par Fee à unc tribu des lichens, ayant pous type le gente Calycium.

caricostrenoves, adj, ct s. f. pl. , Calycostemones ( $x \dot{x} \lambda u \xi \xi$, calice, бтripes, étamine). Nom donné par Gleditsch et par Mocnch à une classe de plantes, comprenant eclles qui ont les étamines insérúcs sur le calice.

C.LMPTÉríres, adj. et s. f. pl., Calyplcrata. Nom donné par Robineau-Desvoidyà une famille de Myoditires, eomprenant eevx de ces insectes qui ont des cucillerons larges, 
assez épaịs, ì double squame et récouviant les balanciers.

CAIIPTMZRES, s. m. pl., calypteriu; Schwanzdelikcn (all. ) ('àuтrip, converele). Illiger appelait ninsi les couvertures de la yueue des oiseaux.

CALVPTLA CITSS, adj. et s. m. p1., Calypiracen. Nom donné par Lamarck ì une famille de l'ordre des Mollusques Gastéropodes, el par Blainville à une famille del'ordre des Paracéphalophores Seutibrauches, ayaul pour lypo lo genre Calypera.

CALYPTSANOLEN WS, adj. ut s.

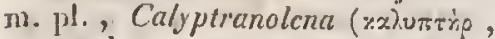
couvercle, \& priv., (i) ¿̇ंun, bras ). Non donné pill Ramzani à un ordrc de la classe des Mollusques acéphales, comprenant ceux qui ont une tète, mais point de bras.

CALNPTRÉACEs, adj. ct s. m. pl. , Calyptracacca. Nom domé pal' Menke à un sous-ordre de l'ordre des Gastéropodes aspidobranches, qui a pour type le genre Calyptraa.

GALYPTIŔ, adject. , calyptratrs (calyptra, cape). Iipillicte qu'on donme à la racinc, quand clle est munie d'unc sorte de coiffe à son exsrémiléinfécieure. Ex. Lemna minor. Voyez Colfá.

C.MLYPRÉES, adj. et s. f. pl., Calyptrate, Calyptrati. Quelques hotanistes, entr'autres Weber el Mohr, ont lonnć ec nom aux mousses, a catuse de la coiffe qui surmonte leurs urues.

CAIIDTRLFORME, adj. , calyptriformis (calypira, cape, forma, forme). Fn forme de coiffe, cominc les pétales de la vigne.

CAMAcís, adj. el s. m.pl., Cluamacea. Nom donné par Lamarck et Iratreille à un: famille de Conchifères, par Cuvier à une famille de Mo! lusques acéphatles, 'par Biainville à unc famille de coquilles el d'A écolaJophores Seutiluawehes, coupes qui touks ont pour type le genre Chama.
CAMARD, adj., simus; stumpfnasig (all.); Ralnosed (angl.); camuso (it.); qui a le nez plat et écrasé. Le Crolalus simus est ainsi appelé, parec qu'il a le unuscan comme tronqué, el la Daphnia sima parce qu'clle a la tète olstuse.

CAMARE, s. f. , camara (xaux́px, areade). Firuit plus ou moins mernbraneux, composé de deux valves soudées ensembic, el renfermant une ou plusicurs graines, qui sont attachées il l'angle interne. Ex. Renoneulacées.

CAMARIEN, adj. , camarius; qui a de l'analogie nvee ume cumare. Mirbel appelle baie camarienne celle qui offre à l'cxtéricur un sillon longitudinal, el à l'jutérieur un placentaire latéral correspondant à ec sillon. Ex. Acteca spicata.

CAHHIUR, s. In. , cambium; Bildungssafi (all.). Sue ćlaboré par les organes du végélal, et qui paraît desliué immédialemenl à la nutrition de ses parties; suc. mucilagincux qui suinte entre l'écorce a le bois, ou Dulanel supposait qu'il produit une nouvelle couche, en s'orranisant. Dupetit-Thouars le croil destiné i anasiomoser les nombreuses fibres, pour ainsi dire radiculaires, que les hourgeons, à mesure qu'ils deviennent des rameaux, laissent échapper inféricurement, entre le bois el l'écoree.

CAMŕLÉondDEs, adj, cts.m.pl., Cuma!conida. Nom douné par J.-E. Gray à unc famille de reptiles sauriens, qui a pour type le genre $C a$ molio.

Canéléontens, adj. el s. m. 13. , Camaleonii, Camcleona. Nom donné par Cuvier et par Eatreille i une famille de replil's sauriens, dont le genre Camceleo est le type.

C.MTĹk0xor?ss, adj. el s. m. pl., Canalennoidca, Camoleonidei. Nom donú par P,-li', I itzinger 


\section{CAMP}

et Eichwald ì une famille de reptiles souriens, ayant pour type le genre Camalco.

CAMH́riens, adj. et s. m. pl., Camclii. Blainville désigne sous ce nom une section de la famille des Mammilères ruminans, qui a pour type le genre Camelus.

CAMLELINLES, adj. ct s. f. pl., Camelincer. Nom donné par Candolle it une tribu de la famille des Crucifères, qui a pour type le genre $C a-$ melina.

Camelcá́es, adj. et s. f. pl. , Camelliee. Non sous lequel Candolle désionne une famille de plantes, dont le geure Camellinest le type.

canulonkirnes, s. m. pl. Camelornilhes (xjuzings, chaneau, ösvts, oise:tu). Non do:ıné par J.-A. Ritgen à une famille d'viscaux, comprenaut l'autruclie, it conse de la facilité el de la promptitude aree lesquelles cet aninal pareourt les déserts, comme le chamcau.

CAMĹRITLLLS, adj., Camerirela, Camcrarice (camera, chamlure, tela, toile). Épithète appliquece anx araignées qui font des toiles scrrées, dans l'intéricur desquilles clles se ticunent.

CAMUROS'ONL, s. nu, camero-

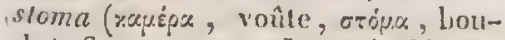
che). Sous ec noin, Latreille désigne la partic antéricurc du corps des Arachnicles, qui forme nue sorte de toit on de vonitc au-dessus des organes de la mandiestion.

Gathónuse, s.f., camerula (camera, chambre). L.. C. Richards'cit servi de ce mot pour désigner une petite loge d’unc partie d'un végétal. CAMANAĆ́ces, adj. et s. f. pl., Campanacere (campann, cloclie). Nom donué par Linné à une lanillo de planles, dans laquelle il range colles qui ont les flcurs cn cloche. ¿ CAMPANELLE, alj., companellalus, Liuls donne cette épillacte à la

\section{CAMP}

corollc, quand cllc est tubulcuse à 1 a base, gInbulense au milieu, ct de nouvea tubulcuse au-dessus, comme daus Irs Synınthérécs.

CAMPANIFLORE, adj., campaniflorus (camprnn, cloche, flos, fleur); qui a les fleurs cn cloche. Le Clcmatiscampanifora a lc calice cam. panulé.

CAMPANTORME, adj., campaniformis; glochenfimgig (all.); accampanato (it.) (campana, cloche, form ma, forme); qui a la forme d'une cloche. Se dit d'un calice ou d'une corolle unonopétale régulière qui, n'ayaut pass de tulue, val cu s'evisant insensiblenent, de la base an sommet, de manière à imiter la forme d'une cioche. Ex. Campanula Trachelium.

Gampanmonmes, ndj. et s.f. pl., Campaniformes. Nom douné, dans la métbude de Tournefort, à une classe de plantes renfermant les herbes yui ont des corolles en eloche on en grelot.

CANBIANTORWES, adj. et s.m. pl., Campanulata. Isatreille donie ce nom a une famille de la clisse des Polypes, daus lirpuelle il range ecux. qui ont le corps urcéolé.

CAMPANUıAcé, adj. , campanzlaccus; yui a la forme d'une petite cludic. Syuonyme de campanacé, de crmpanulé.

CAMIPANULACŔLS, adj. el $s$. f. pí, Crmpanulacea. Noun donné par Jussicu à une famille de plantes qui is pour type le genre Campanula.

CAMPAVULATRE, adj., campanu. laris; qui est en forme de eloche. li Arthrostemma campanularc a ses flcurs en clocher.

CAITPANEĹ, adj., compamiatus, companacerss; glockigs, glochenfürnicr (anll.); qui a la forme d'une clache. Sc dit du caliee (cx. Statice Armeria), de l'impolucre (cx. Lampsana lyrata), de la corolle 
(ex. Stapclia campanulata, Limum campanulalum), de la coiffe (ex, $P_{0}$ gonatum campamulatum).

GAMPAveléEs, adj. et s. f. pl., Campanulca. Nom donné par quelques botanisles à la famille des Campanzlacées (voyea ee mot), et par A. Richard ì une tribu de cette famille, ayant pour type le genre Campanula.

CAMPANULIFLORE; alj., campanuliflorus; glockenbliulhig (all.); qui a les fleurs cn cloche. Ex. II/cdiolis campanuliflora, Coceocypsclum campanuliflorum.

Gameanulinges, adj. et s. f. pl., Campanulina. Nom donné par Bartling à une clisse de plantes qni eomprend les faunilles des Goorlénovićes, des Stylidécs, des Lobéliacécs et des Campannlacérs.

CAMPÉPHAgins, adj. ct s. ni. pl., Campephagina. Nom donné par Vigors à un groupe de la tribu des Dentirostres Laniades, qui a pour type le genre Campephaga.

Gampesthe. Poyez Champêtre.

Gamploghive, s. m. Nom don né par Dumas à un corps composé de carbone et d'lyddrogéne, qui a été isolé par Opperman. Ce corps produit le camphre ordinaire et la clıoléstćrine en se combinant avec la vapeur d'eau, le camplare artificiel avec l'acide hydrochlorique, les acides caproïque, caprique ct camphorifue avec des proportions diverses d'oxigène.

CAMPIORATE, s. m., camphoras. Genre de scls (comphersuurc Salze, all.), qui sont formés par la combinaison de l'acide camphorique avec les bases salifiables.

CAMPHORIDE, s. f., camphorida. Nom générique donué par Fechnec à des sulsstances, d'originc végétale, qui se rapprochent du enmplire par les proprićtés, comme l'alcornine, la bétuline, lit cérine, le camphre succinirue ct celui d'amandes amères.

GAMPHORIME, s. m. Noin donné par Guibourt is un genre d'odorides.

CAMPIORIQUE, arj., camphoricus. Epithète douncéc ì un acide (Camphersïtre, all.), qui se produit par l'action de l'acide nitrique i chand sur le camplere.

CAMPronorof, s. m. Quelques chimistes ont désigné sous ce nom générique les malièrcs à odcur camphrée que déposent les huiles volatiles des Labiées, et qui ont été prises souvent pour du camphre. Syronyme de sléaroptène.

CAMPIIIE, s. m. , camploora; Kampfor (all.); camphire (nngl.); canfora (it.). Substance volatile, sorte de stéaroptìne qui existe dans pllusicurs especes de Laurzes, notainwient dans le Lauris Camphora. Quelques chimistes ćtendent ce nom a toutes les huiles volatiles concrìtes; mais, suivant la remarque de Berrelius, cet usage a l'inconvénient de dounerà un noin bien connun d'une substance généralement cmployće, une signification différente de.celle qu'il a eue de tont temps.

GAMPIIĹ, adj., camplonatus, camphorinus; qui contieut du camphre (alcool camphrci), pui a l'odeur du canphre (ex. Myrtadenc camphoralus, Osmilcs camphorala, Camphorosma monspclicnsis).

CAMPICOLE, adj., campicolus (campus, champ, colo, habiler); qui vit dans les champs. Ex. Dclia campicola.

CA MPSICHROTES, adj. ct s. m. pl., Campsichrolcs (צ'цетте), plicr, xporin, corps). Nom donnć par J.-A. liitgen à un ordre de la classe des repliles, comprenant ccux qui ont la pean plus ou moins molle et le corps flexible, comme les sauriens et les balracicns.

CAMPULITROPE, adj. , campte-

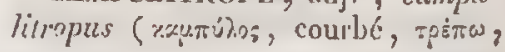


(ourner). Épithèle donnéc par Mirbel à l'embryon, lorsque, dans le développemeni progressif de l'ovule, le hile, qui s'est confondu avec la chalaze, ne reste pas avec elle direetement opposé à l'exostome, mais que cette situation relative du hile, de la chalaze et de l'exostome ehange plus lard, l'ovule se eourbant sur luị-même, de nuanière ì amener son sommet près de sa base.

CAMPYLOCilLE, adj. , campylo-

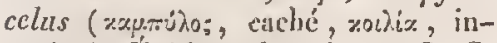
testins). Epithète donnée par C.-G. Ehrenbergrax in unsoires entérodèles dont le eanal intestinal, muni de deux ouvertures, ne se borne pas is suivre la longuenr du corps, mais oflie des courbures ou flexuosités.

GAMPYLOIIYTE, s. m. , campy-

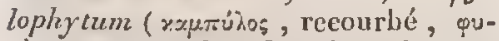
тò, , plante). Nom domné par Necker aux flantes dont la partic supérieure de la corolle est obliquement infléchic ct le plus souvent contournéc en spirale avant l'épanouissement.

cavpyopones, adj. , Campy-

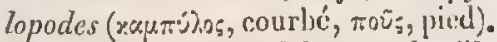
Noun donné par Bridel à une famille de mousses, qui a pour type le genre Campylopus.

CAMPYLOPTÈnE, adj., campy-

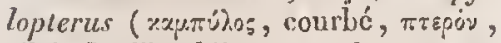
aile). Le Trochilus campylopterus est ainsi appelé parce que quelyues unes des grandes pennes de ses ailes ont des tuyaux élargis et courbès on forme de lame de sibure.

GAMPYLOSOMES, adj. et s. m. pl., Campylosomala (roputrìns, courbé, $\sigma \omega \tilde{\omega} \mu \alpha$, corps). Noun douné par Leach à un ordie de la elasse des Cirripèdes, comprenant ceux qui ont le corps flexible.

CAMPILOS1'hlimérs, adj. et s. f. pl., Campylospcrincer ( $\left.к \alpha_{p} \pi \dot{2}\right)_{0 ;}$, courbé, arépux, graine). Nom donné par Candolle à une section de la famille des Onbellifères; renfermant celles de ces plantes qui ont l'cmbryon recourbé.

Gampylozomates. Voyez CampYLOSONES.

Carits. Voyez Camard.

CANar, s. m., canalis. On appelle ainsi le passage d'une mer à une antre, entre deux terres, lorsqu'il est long et étroit.

CANALICULAIRF, adj., canalicularis (canalieulus, petit conduit). Le Conferva canalieularis est ainsi appelé piaree qu’il étend ses filets verts sous la forme de tapis dans les tuyaux de conduite des ciux.

CaxAliculé, adj. , canaliculaius; gchohllichli, rinnig, rinncnförmig, gerinnelt, gerinnt (all.) (canaliculus, petit canal); qui est creusé ou prolongé en forme de canal. Se dit : $1^{0} \mathrm{en}$ botanique, du péfiole, quand il est creusé en dessus et dans sa longueur d'un sillon ou d'une gouttièrc : de la feuille, lorsqu'elle est alongée el ereuséc ou pliće en manicere de goultière, dans le seris de sa longueur (cx. Tradescantia virginica); du légune, lorsqu'il est relcvé d'une double marge, qui forme un canal le long de la suture placentaire (ex Pisum ochurus); de la grainc, lorsqu'elle est creuséc en gouttière dans sa longucur (cx. Avena sativa); $2^{\prime \prime}$ en zoologie, d'une coquillc univalve dont l'ouverture se prolonge antúricurement en un canal plus ou woins long, qui reçoit le tube des organes respiratoires (cx. Fusus.s); du corsclct des animaux articulés, quand il présente une fossettc alongée (cx. Lyctus canaliculatus), ou plusicurs sillons (ex. Palamon canaliculatus), dans son milicu.

GANALIFEIIE, adj., canaliferus (canalis, canal, fero, porter). Épithète donnée aux coquilles dont la base présente un canal ou siphon plus ou moins prolongé. Ex. Spalan- 


\section{4}

grus canaliferus, Delphinclla canalifira, Tritonium canaliferum.

GANALIFires, adj. et s. m.pl., Canalifera. Nom donné par Lamarek à une famille de Mollusques, qui offrent un canal plus on moins long ì lir base de l'onverture de leur coriuille.

CANALIFONME, arlj. canaliformis (canalis, canal, forma, forme). Épithète donnée par Kirby au postscutellum, quand il s'ćtend, cn minière de canal, du postlorsolum is l'abdomen Ex. Colćopteres.

CANCELLE, adj., canccllatus, clalluatus, decussalus; rillerartis, siltcrförmig (all.) (canccllo, griller); qui cat en lorme de grillage. Se dit: $x^{\circ}$ en botanique, d'un champignon dont le chapeau est garui de cellules peu profondes à sa surface (ex. Clathrus canccllatus), ou qui est environné de filcts pirallèles, semblables anx harres d'une grille (ex. L)'coperdon cancellatum); d'une planic qui se empose uriquement de filets entrecroisés (ex. Byssusts canccllalu); d'un calicc dont les folioles très-minces ct courbées forment wne sorte de grillage ou de filet autour dela fleur (ex. Atractylis cancellata); d'une ferillc sans parenchyme, dont les nervures et veines anastomoses forment un réseau percé i jour (ex. Hydrogreton fcnestralis). La racinc de l'Altium clathratum est couverte de membranes éléganment réticulécs; $2^{0}$ en zoologie, d'une coquillc dont la surface présente des stries ou côtes perpendieulaires qui en reneontrent d'antres transversales (ex. Turbo cancellatus, Venus cancellata, $C_{c-}$ rithium cancellatum, Bulla clathrata, Butimus decussatus, Cassis decussata, Cerithium elccussatum ); d'un polypicr qui offre la même disposition (ex. Antipathes clathrala); d'un malacostracç dont la têtc est rćliculée (cx. Daplinia elathrata).

C.INGúlRIDÉ, adj. , canccrideus (cancer, erabe); qui ressemble à un crabe. Ex. Avicularia canccridea.

CANCúlinEs, adj. et s. m. pl., Canccrides. Nom donné par Laumarck, Goldfuss, Ficinus et Carus in une fimille de Crustacés, qui a pour type le gewre Canccr.

GANCRASTACOIDES, adj.et s.m. pl., Cancrastacoides (canccr, crabe, àstuxó; , écrevisse, Eĩons, ressemllance). Nom donné par Blainville à unne famille de lia classe des Décaporles.

CAnchifonwh, adj., cancriformis (canccr, crabe, forma, forme); rui a la forme d'un crabe. Ex. Limulus cancriformis.

CANChironars, adj. et s. m. pl., Cancriformcs, Cancriformia. Nom donné par Duméril à une famillo de l'ordre des Crustacés décapodes, qui a pour type le genre Cancer; $\mathrm{et}$ par Latreille à une fanille de Polypes trichastones, reufermant ecux qui ont le corps contenu dins un fourrcau ou revcotu d'un test.

CAxcrivone, adj., cancrivores (cancer, crabe, voro, dévorer); qui se nourrit de erabes. Ex. Procyon canerivorus, Didelphis cancrivora. Voy. Cangromage.

GANCROIDE, alject., cancroïdes (cancer, crabe, हiंगे , ressemblance); qui a quelque ressemblance avee un crabe. Ex. Chelifer cancrö̈dcs.

Carcinotoes, adj. et s. m. pl., Cancroides. Nom donné par Blainville ì une famille de la ilasse des Décapodes, et par Degecr à une falmille d'araigncées classeuses, qui russemblent un peu à des erabes.

CANCROLOGE, s. f. cancrologria (cancer, crabe, גóys, discours). 'Traité sur les crahes.

CAYcrologreue, ndj., cancrologicus; qui a rapport à l'histoire les crabes.

C.MNCROPIAGE, adj., cancrophagus (canccr, erabe, фứrw, manger); 
qui vit de crabes. Ex. Alcedo eancroplatga.

Gavdollúaníses, adj. et s. f. pl., Candolleanece. Nom douné par Candolle à une section du geure Pleurandra, comprenant les espèces qui resscmblent aux Candollea.

GANELLÉ, adj. , cinnamomcus, caryophyllaceus; immelfarbig (all); qui a une teinic brune analogue is eclle de la canelle. Ex. Anas caryophyllacen, Thamnus cinnamomeus, Osmunda cinnamomca. Vor. Brun.

GANLLLINE, s. f., canellina. Non donace par Fechner à une unatière sucréc, cristallisable, qui existe dans la canclic.

CANICULAIRRE, adj., canicnlaris (canis, chien); qui a rapportà la canicule. Les jour's caniculaires (Hundslage (all.); dogdays (angl.); giorni canicolare (it.), qui s'étendent du 23 juillct au 23 août, sout ainsi appelés, paree que, ehez les Grees, ils étaient déterminés par le lever de Sirius. La eaniculc est, chez nous, lc temps le plus chaud de l'année, surtout au début; ear, vers la fin, la chaleur a déjà seusiblement diminué. Un insecte diptère (Philinta canictilaris) est ainsi nommé parce qu'il est très-commun sur la lia de l'ćté.

CANIN, adj., caninus; qui a quelque rapport avec la strueture du ehien. On appelle dents canines, ehez les mammifères, celles qui sont placćes entre les molaires et les incisives, ì causc de leur développement dans les espèces du genre Chien. Kirby donne le même nom à celles des mandibules de quelques insectes, parec qu'elles sont longues, coniques et aiguës (ex. Forficula).

CANINS, adj. et s. m. pl., $\mathrm{Ca}$ nina. Nom dọné par Goldfuss et J.E. Gray i une famille de la classe des vammifères, qui a pour type le genreranis.

CANYBINÉES adj. ct s. f. pl,
Cannabinew. Nom donné par A. Kichard a un groupe de la famille des Urtieces, qui a pour type le genre Cannabis.

cannacíns, adj. ct s. f. pl., Cannacce. Nom donné par Bartling ì une famille de plantes, qui a pour type le genre Canna.

Canvírs, adj. ets. f. pl, Cannea, Cannce. Nom donuć par Riosroe à la famille des Anomíes (voyez ce mot), par R. Brown à nue faunille de plantes qui a pour type le genre Canna, et par $\Delta$. Richard à une seclion de la liunille des Amomées,

CANvELL, adj., striatus; gericft (all.); qui est marqué de cannelures', c'est-ii-dire de côtes et de sillons. Voycz Cavaucucé.

CANNELIS, adj. et s. m. pl., Canaliculata. Nom donné par Latreillc a une farnille de la elasse des Échinodermes, renfermant ceux de ces animaux qui ont le corps grarni de rayons creusés longitudinalement, en forme de goultière.

CANON, s. m., Bcintöhre (all.). Partic de la jambe du cheval et des ruminans qui est comprise entre le genou ou le jarret et le boulet.

CANTIIARIDIENS, adj. et s.m. pl., Cantharidiani. Nom douné par Lamarck ì une division de la famille des Coléoptères trachélides, qui at pour type le genre Cantharis.

CANTILARIDIES, adj. ct s.f. pl., Cantharidic. Sous ec nom, Cuvier, Latreille, Goldfuss, Eichwald, Ficinus et Carus dlésignent une tribu de la famille des Trachélides, ayant le genre Cantharis pour type.

CANTIIAlinINE, s. f., canllaridina. Subslanec partieulic̀re, quie Robiquet a découverte dans les cantharides, et ì laquelle sont dues lis joroprićlés vésicantes de ces inscetes. Dana et Brctonneau surtout l'ont retrouvée dans beaucoup d'autres coléoptères. Ziicr a fait des recherches 
curieuses sur celles des parties du corps de la cantharide où elle cst le plus abondante.

GAOUTCHOUC, s. m. , gummi clasticum; Fedcrluarz (ill.). Sub:tance très-élastique, qui se forme dans le sue laiteux de diverses plantes, notamment de l'Hevea guianensis et du Jatropha clastica.

CAP, s. m., promontorium; $V_{\text {or- }}$ gcbirg (all.); licadland (angl.); capo (it.). Avance considéruble d'un rivigge qui se termine brosquement dans la mer, et qui est formée par des terres élevées, ou par la ter minaison abrupte d'une chaîne de montingnes.

GAPA GITÉ, s. f., capacilas (capio, prendre). Éfenduc on volume d'une elose qui peut en enutenir ou qui en conticut une autre; par cxtension, le contenu lui-mème, on le volume de l'espace yu'un corps vecupe; ct au figuré, étenduc, portíc de l'esprit, ćtendue des comnaissinces théoriques. Les plyysiciens nomment capacilé pour lc caloriquc la disposition particulic̀re de chaque corps à prendre plus ou moins de culorique ponr élever sa tempériture. En éhimic on appelle capacitć de saturation d'un acide le nombre exprimant lit quantité d'oxigcine qui se trouve dans la quantité de base quelconque nécessairc pour saturer cet acide, on la quantité d'oxigène qu'il filut dans cette hase pour 'qu'clle puisse donner naissance à un sel parfaitement neutre.

CAPLÉ, adj. Epithète donnće par Ies minéralogistes à un corps offrant un aspect analoguc à celui du bois qu'on appelle piqué. Ex. Quar: molairc piqué.

CAPILACÉ, adj., capillaceus; haarfein, haarformig (all.) (capillus, cheveu). Se dit d'un corps Irc̀sgrồle, ayant presque la finesse des cheveux, connme les fuilles de l'Arcnaria capillacea et du Didymodon capillaccus.

\section{CAPI}

GAPILLAIRE, adj , capillaris, capillatus, pilosus, pilaris; toexúdins; haarformig, haarfasrig, haarbreit (all.); qui a la forme d'un cheven plus ou moins fin. On cmploic ce snot : $1^{\circ} \mathrm{cu}$ physique; les phérnmènc.s capillaircs sont ceux d'iscension et de dépression que présente la colonne d'un liquide dans lequel on plonge l'extrémité inférieure d'un tube délié, en pénćtrant dans lequel il ne s'arrête presque jamais au nivcau extéricur, et l'on indique par lì que le diamétre des tubes servant à produire ees phéuomènes, doit approcher de la fincese d'un cheven. L'action capillairc est l'attraction, force on cause de laquelle dépendent les phéumèènes capillaires; $2^{\circ}$ en minéralogie, on appelle capilluires les crislaux prismatiques qui sont alongrés de manière ì ètre déliés comme des chevenx (ex. Antimoine sulfuré capillairc); $3^{\circ}$ en hotauique, on nomme racine capillaire, celle qui est composće de filets très-dúliés (ex. Anthoxanthum odoratum); aigrette capillairc, celle qui est formée de poils simples; stismale (ex. Zea Mays), pédonculc (ex.Lavradia capillaris), axc (ex. Briza media), slyle (cx. Cucubalus baccifcrus), tigc (ex. Scirpus capillaris), filet d'ctamine (cx. Graminées), fcuilles (cx. Discopleura capillacea), capillaircs, ceux de ces organes qui sont alongés, grèles, flexibles et semblaljles en quelque sorte à des cheveux.

CAPLLLAnITĹ, adj., capillarilas, altractio capillaris; Haarrölurchenanzichung (ail.) ; capillarity (angl.). Les plyysiciens désignent ainsi la foree de laquelle dépendent les phénoméucs eapillaires, et qui s'exeree al' contact de toutes les parcelles is plus ténues de la matière pondérale.

CAPILLIFOLIÉ, adject. , cpillifolius; haarbläurig (all.) (spillus, cheveu, folium, feuille) ujui a des 
fouilles capillaires. Ex. Polygala capillifolia, Sphagnum capillifolium.

CAPILLIFOnME, adj. , capilliformis; haarformig (all.) (capillus, cheveu, forma, forme); qui a la forme d'un cheveu.

CAPLLLITIE, s.m. , capillitium; capcllizio (it.). Non donné par Persoon, dans li famille des Lycoperdacées, au tissu filanenteux entre les ramifications duquel se trouvent les sporules, à l'intérieur du péridion.

CAPISTRATE, adj. , capistratus (capistrum, licou); qui porte un licou, une musclière. Epithète donuée it plusieurs animanx (ex. Psillacus capistralus, Sciurus capistratus, Lartus capistratus), à cause de la manière dont sont disposées les couleurs qui peignent on encadrent leur face. Vurcz Bıtนé.

CAPISTRUM, s. m., capistrum; Halficr (all.). On appelle ainsi, dans les oiscaux, la partic de la tète qui entoure la base du bee.

CAPITÉ, adj., capilalus, capitiformis, gongylodes; zegriwro; ; lopffirmig, liolbig, knopfig, gcknopft (all.); headed (angl.) (caput; tète); qui a la forme d'une tête ou d'une petite boule. $1^{\circ}$ Ines botanistes appellent filcı capicé, dius les étamines, celui qui est renllé un manic̀te de tète (ex. Dianclla); poils capités, ceux qui sont renflés au sommet (ex. Diclamnus albus); stigmatc capité, relui qui est épais el plus on moins alrondi (cx. Airopa Belladona). Quelques plantes ont reçu ec:te épithète parec que leurs fleurs sont disposées en têtes (ex. Blilum capilatum ). $2^{0}$ Eu zoologie, on l'cmploie quelquefois pour exprimer qu'un animal a une grosse tête (ex. Colu$b_{e r}$ capilatus), ou lat tète d'une autre crouleur que le corps (ex. Apis capilala).

GAPITÉEs, adj. et s. f. pl., Capilalce. Linné donnatit ee nom à une section de la famille des Synanthérées, qui correspond aux Cynarocéphales, parce que le péricline est la plupart du temps globuleux dans les plantes qui s'y rapportent.

CAPITELLE, adj. , capitcllalus (capilcllum, petite tête). Epithète donnće ì des plantes dont les fleurs sont prisque en tête (ex. Eucalyp(us capicellata), à des Synanthérécs dont les capitules sont fort petits ́ex. Helichrystum capicellatum), i des algucs dont les fructilieations globuleuses sont portćes sur de longs pédienles délićs (ex. Calycium capitella(um), it des animaux qui ont une très-petite tête (ex. T'conia capitcllata).

captTulania Gress, idj. et s. f. pl., Capilulariacere. Nom donné par Reielienbach it un groupe de Lichens, comprenant les genres Stcreocaulon, Cladonia et Bacomyces.

GAPTULE, s. m. , capilulum; Kopf (all.); capolino (it.) (caput, tête). Ce not est employé : $]^{\circ}$ eir hotanique, où on le prend dans plusienrs sens différens. Généralement ou entend par là antôt un assenblage de flururs sessiles, ou à peu près, que de loin on pourrait prendre pour une seule fleur, tartôt une réunion de fleurs nombreuses sur le sommct d'un pédoneule commun dilaté, où elles constituent une tète globuleuse, ovoïde on alongée. Ainsi on a confondu sous cette dénominatiou plusieurs modes d'infloresecnee qui n'ont de commun que d'offrir des fleurs trìs-scrrécs, sans pédicules, ou à pédicules fort courts. Roeper, Candolle et $\Lambda$ gardh l'appliquent aux épis qui, au lien d'un axe alongé, en ont un oroïde ou globuleux, autonr duquel les fleurs sont trìsserrées (ex. Plalanus); aux grappes dont l'axe est très-eourt et chargé de fleurs nombreuses portécs par des pédoneules fort courts (ex. Cephalan- 


\section{8}

thus): aux ombelles dont les pédicelles sont très-courts et les fleurs très-serrées (ex. plısieurs OEnanethe ). Cassini appelle capitule une réunion de plusicurs calathides. On a aussi donné quelquefois ce nom aux rosettes des monsses et au péridion de eertains champiguons (ex. Stilbium), quand il est petit, arrondi et pédicellé. $2^{\circ} \mathrm{En}$ zoologgie, Kirby nornme le dernicr article des insectes capitule, lorsqu'il est plus large que les autres.

CAPITULb, adj. , capilulatus; qui est ramassé en capitules. Le $M i^{2}$ metes capiutata a ses fleurs disposéces en capitules.

GAPITULIFORME, adj., capituiliformis ; capoliniforme (it.) (capitulum, petite tête, forma, forme); qui a la forme d'une petite têle, comme le renflement antéricur des tacuias, le réceptacle des chompignons appelés Phallus, ou certains assemblages de fleurs très-scrrées les unes contre les autres.

CAPNOPThai, adj, capropterts (жатио's, fumce, ттвроу aile); qui a les ailes jauntitres. Ex. Dasyposon capnopterus, Leptis capnoptera.

caprafíks, adj. et s. f. pl., Capparca. Nom donué par Candolle ¿t une tribu de la famille des Capparidées, qui renferme le genre Capparis.

CAPRARIDÉES, adj, ct s. f. pl., Capparidex. Nom dunné par Jussicu à une famille de plantes ayant le genre Capparis pour type.

GAPRATE, s. m. , capras. Genre de sels (caprinsaure $S a l i c$, all. ), qui sont formés par la combinaison de l'aeide eaprifuc aveeles loases salifiables.

Capleclins, adj. et s. m. pl., Caprcllina. Num donné par Lamarek à unc fanille de l'ordre des Crustacés hétérobranches isopodes, qui a pour type le genre Caprella.
CApréotili, adj., eapreolatus (capreolus, lien de vigue). Le Funaria caprcolata a été appelé ainsi en raison de ses pétioles subeirreux.

CAPréoles, s.m. pl., Capreoli (capreolus, chevrcuil). Illiger et Eichwald désignent sons ce nom une fauille de la elasse des Manmiferes, comprenant les gen res Cervus et $\mathrm{I}_{\mathrm{O}} \mathrm{s}$ chus.

CapIIFICATION, s. f., caprificatio (caprificus, figuier sauvage). Opération dont l'usage, général ehez les anciens, s'est conscrvé dans le Levant, qui consiste à placer sur un figuier des figues pleines d'une espèce de Cynips qu'on suppose hâter la maturalion, soit en transportaut le pollen avec eux, soit en irritant le peiricarpe par leur piqûre et y déterminant un afllax plus considérable de liquide. Cette opèration est au moins inutilc ; car les figues mûrissent trèsbien dans les pays où l'on n'y a pas recours,

CAPRIFOLICÉES, adj. et s. f. pl., Caprifoliacca. Nom donné par Jussieu à unc famille de plantes, qui a pour type le genre Caprifolium. CapniFor.tées, adj. et s. f. pl. , Caprifolice. A. Riehard désigne ainsi une section de la famille des Caprifoliacées, qui renferme le genre $\mathrm{Ca}$ prifolium.

GAPRIMULGIDEs, adj. et s. m. pl., Caprimulgidae. Nom donné par Vigors à une famille d'oiseaux, पqui a pour type le genre Caprimulgus. C.MPRive, s. f., caprina; Caprinfcu (all.). L. Gmeliu admet, sous ee nom, conne ayant une existenee probable, une substance grasse qui, par la saponification, se transforme en acide caprique et en glycérine.

GAPRINÉLEs, adj. et s. f. pl., Caprines. Nom donné par Candolle it une section du genre Oxalis, comprevant les espèces qui ont plus ot moius d'aflinitéavec l'O xalis caprinch. 
CAPAIQUE, adj, capricus (capra, chèvre). (Chevreul a donné cette épithète à un acide particulier (Caprinsiiure, all.), qu’il a découvert dans le beurre de chère et de vache.

CAPROATE, s. m., caproas (capra, chèvre). Genre de sels ( $c a-$ pronsaure Salzc, all.), qui sont foruncs par la combinaison de l'acide caproique avec les bases silifiables.

GAPROLNF, s. f. , caproina; Capronfett, (all.). Sous ee nom, L. Ginelin admet, comme existant probablement, une substance grassc que lit saponilication transforme cn acide caproïgue et en glycérine.

CAPROIQUE, adj., crproicus icapra, chèvre). Nom douné par Chevreul à un acide particulier (Capronsiiure, all.), (gu'il a deeouvert dans le Leurre de ehevre.

CAProma, s. m. , caproma. IIliger appelle aiusi, dans les Marnmifères, les poils alongés et un peu droils qui gamissent Je vertex ct se rejettent en avant.

CAPSICINE, s. f., capsicina. Substance âcre, oléngineuse ou résinödc, que Braconuot a trouvéc dans le Capsicum annuum, mais qui avait déjà élć vue awant lui par Bucholz.

GAPSELLE, s. f., capsella (capsa, boîte). Liuk appelle ainsi foute capsulc qui est petile et monosperme.

CAISULAIIE, adj. , capsularis; hapsclartiś (all.); casellarc (it.) (capsula, capsule); qui a des rapports avec une capsule; qui se fait remarquer par la forme de ses eapsules, comme le Corchorus capsularis, gui les a rondes. tandis qu'elles sont longues dans les autres espèces du mème genre. On donne généralement l'épithètc de fruits capsulaircs aux fruits sces qui s'onvrent d'cux-mémes par un certain nounbre de pieces, ou par des trous dont divers points de leur surface viennent i se perforex. $\mathrm{O}_{11}$ a appelé fructification capsulairc, un mode de fructification propre a cerlaines thalassioplisytes, quir eonsiste en pelits graius colorés, répandus cì et lì daus le lissu uème de la plante, rarement visibles ì la vuo simple, qu'on a regardés, tantôt comme les premicrs d'udiuens de la fruclitieation proprentent ditc (Mcrtcus), tantôt eomme une fructification avortće (Lat mouraux). Gaillon adopic la preinière de ces deux opinions.

Carsull, s. f., capsula; Kapsel (all.); casella (it.) ( $x \dot{\alpha} \%$, cassetlc). Ge mot, d'une siguification tresvague, exprinc d'une manière générale un l'uil simple, sec et polysperne, q:ıi sourre par des trous, par des lentes, ou par la séparation, soit totale, soit seulement particlle, de pićes distinctes les unes des autres. Ine capsule est pour liuk tout péricarpe see, membraneux ou coriace; pour Agardh, une réunion de plusicurs earpelles intimement soudées eusemble, de manic̀e at former un lout libre et non charnu. La dénumination de capsule a été dounéc aussi par Bridel a l'urne cles mousses, par PalisotBeauvois à la columelle silućc au centre de cetle urne, ct qu'il considérait eomme le réceptacle des séminules, par Malpighi aux anthères, par divers autenrs aux sporanges des fougères et aux eorps reproducteurs des Floridécs.

CAPSULIERS, adj. et s. m. pl. Oken désigne sous ce nom une classe du rigne végétal, comprenant les végétaux ì eapsules.

CAPSULIFIIE, adj., capsuliferus (crapsula, cispsule, fero, porter). Épithète donnée aux tulereules des Floridées, parce qu'ils renferment les eapsules, contenant elles-mèmcs les corps reprodinctcurs.

CAluchov, s. m. , cizcullus, stylostegium, saccus, corona; Карpc (all.). Oı donne ce nom, cu botani- 
que, à des pétales ou à des sćpales qui sont concaves, et dont la forme approche plus ou moins de celle d'un capuchon ( $\mathrm{ex}$. quelques $\Lambda$ eonits). Link l'appliqgue à un évasement particulier des filets des étamines, qui sont soudés enscmble et recouvrent l'ovairc comme un capuchou (ex. Asclcpias syriaca).

CAPUCHONN kappenförmig (all.); cocollato, incappucciato (it.) (cucullus, capuchon ) ; qui of fre un capuchou, comme le Basiliscus cucullatus, dont lia têtc est surmontée de liggues saillantes réunics de manière à figurer un bonnet, et le Phoca cristala, au sommet de la tète duquel adhìre une sorte de capnchon mobile, ou comme le Cornucrpia cucullatum, dont les pédoncules se terminent par un cornet infundibuliforme qui renferme plusicurs flcurs. On appelle pćlales capuchonnćs ceux qui ont la forme d'un capuchon, et coiffe capuchon$n e ́ c$, celle qui se fend latéralement de manière ì produire la même apparence (ex. Wcissia), Voyez CucelLIFORME.

CAPULÉs, adj. et s. m. pl., Capulea (capula, tasse). Nom donné jar Menke i unc famille de l'ordre des Gastéropodes Aspidobranches, comprenatut ceux qui, comme les Crepidula, les Calyptrca, out une coquille en forme de tasse.

CAPULOIDE, adj., capuloidcus (capula, tasse); qui a la forme d'une tasse, comme la coquille appelće Vclutina capuloidca.

CAPULOIDES, adj. ct s. m. pl. Capuloüdcs. Nom donıé par Cuvier à une famille de l'ordre des Mollusques gastéropodes, qui a pour type le genre Capulus.

CAQUETEUR, adj., baúceculus, garrulus; qui babille beaucoup. Ex. Sylvia babcecula.

CARABIENS, adj, et s. m. pl. ,
Carabici. Nom donnć par Lamarek à une fantille de l'ordre des Colćoptères, qui a pour type le genre $\mathrm{Ca}$ rabus.

CaRABIQUes, adj. et s. m. pl., Carabici. Nom sous lequel Cuvier, Lat reiile, Goldfuss, Eichwald, IFicinus et Carus désignent une tribu d'insertes colcoptères, ayant pour type le genre Carabus.

GAIACTL̀RE, s. m., character; $\chi^{x-}$ pa:stip; Kennzcichen, Merkmal (all); charceter (angl.) ; carattcre (it.);

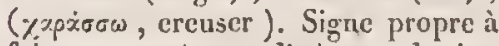
faire reconnaître el distinguer les individus les uns des autres; toute particularité organique qui établit entre eux une différence ou une ressemblance queleonģuc; cc qui, quant aux qualités moriles, distingue nue persoune d'une autre. "Le caractère est formé de nos idécs et de nos sentimeus; or il est très-prouvé qu'on ne se donne ni sentimeus, ni idées; done notre caractère ne peut dépenJre de nous.... Peut-on changer do caractère? Oui, si on cliange de corps. " (Voltaire.)

CARM CTĹRISTIQUe, adj. ; qui caractérise, qui scrt à faire reconnaître, à distiuguer. En géognosie, on appclle fossilcs caractéristiques, ceux qui signalent une especce de terrains parce qu'ils s'y rencontrent plus fréquemnent que d'autres. Deshayes propose de réserver cette épilhète anx fossiles, non les plus commuus, mais Ies plus constans dins chaque formation, à ceux qui se trouvent dans les diverses couches de cette formation, "1'en dépassent jamais les linites, lui appartiennent et 11'appartiennent qu'à elle, comme la Lucina divaricata pour les terrains marins supérieurs à la craic, et le Cardium porulosum pour les terrains marins parisiens.

CARAPACE, s. f., clypeus, testa. Yoûte résistante, le plus souvent os- 


\section{CARB}

seuse, qui protégc le dessus dı corps des reptiles chćloniens, et qui résulte de la soudure des pièecs aplaties du rachiset des côles; face supérienre du corps des crustacés, lorsqu'elle est formée d'une seule pièce. Voyez Botchier.

Caral'ine, s. f., carapina. Nom donné à un alcaloïde qui a ćté trouvé dans l'huile de carapa par Boulliay, dans l'écorce du Curapa gluianensis par Petroz et Robinet.

CarbazotaTe, s. m., carbazotas. Genre de sels (liolulenstichstoffsaure Salze, all.), qui sont formés par la combinaison de l'acide carbazotique avec les bascs salifiables. $V$. Nitropicrate.

CaribazotlQue, adj. , carbazovictes. Épithète donnće par Liebig ì un acidlc (Kollensticksïure, Kohlenstickstoffsäure, all.), qui jusqu'alors avait été appelé Amcr de Weleer. Bcrzelius a changć ec nom en celni d'acide nitropicrique.

CARBOHYDHQUE, adj. , carbohrdricus. Sous le nom de sulfide carbohyilriquo (Kohlenschwefelvassersto ff, all.), Berzelius désigne un corps acide, découvert par 'Leise, qui résulte de la combinaison du sulfide hydrique avec le sulficle carbonique, et qu'on appelle aussi acide hydrosulfo-carbonique ou hydrothiocarboniquc.

GARBONATE, s. m., carbonas. Genre descls (Kohlensaure Salze, all.), qui résultent de la combinaison de l'acide carbonique avee les bases salifiables.

Carbonatú, adj. Se dit, en minéralogie, d'une base qui, par sa combinaison avec l'acide carlsoniquc, a été transformće en carbonatc. Sous le nom de roches carbonatées, Omalius établit, dans la classe des roches pierrenses, un groupe comprenant celles qui se composent de carbonates.
CARBONE, s. m., carbonium; Kohlenstoff ( all.); carbon (angrl.); carbonio (il.). Corps simple, qui est très-répandu dans la nature, et qui, à l'élat de pureté, constituc la plus précieuse des pierres gemmes, le diamant.

CARBONÉ, adj. , carboneus ; qui contient ducarbone. On connaît denx gaz hydrogene carbone (Kohlenwasscrstoffgas, all.), qui diffèrent l'un de l'autre par la proportion dc carbone qu'ils reuferunent eu égard ì celle de l'hydrogiene, supposée la même dans les deux.

CARBONEUX, adj., carbonosu. Dobereiner a proposéd'appeleracide carboneux (kohlige Sïurc, all.) l'acide oxalique, qui contient en cflet moins de carbone que l'acirle carbo. nique. Berzelins appelle chloride carboncux (Anderthallschlorkahlcnstoff, all.) le premicr, et chlorure carboneux (Halbchlorkolelcn.sioff, all,) Ie troisic̀me des trois degrés de combinaison du carbone avec le chlore.

GarbonIDE, s. m., carbonida. Sous ce nom Dulong admet des combimaisons d'acide carbonique aver le ploml et le zine métalliques, que l'analogie oblige à repousser.

CARBoniors, s. m. pl. Nom donné par C. Pauquy à une famille de corps poudérables, qui a pour type le carbone.

CAIBBONIELRE, adj., carbonifcrus (carbo, charbon, fero, porter). Iscs géognostes appellent tcrrain carbonifere un systène de couches arénacées qui est interrompu d'une manière irrégulière par des lits ou des amas de cluarbon de terie. Le calcaire carbonifère est celui qui se trouve con liaison avec le terrain houiller, qui le recouvre en stratifientions concordantes, et dont les couches supérieures contiennent déjà quelques couches subordonnées de houille, comme dans les mines de ploml) du 
Cumberland et du Derhyshire. Brongniart donue cette épithète ì un groupe de terrnins alyyssiques, correspondant ì eclui qu'Omalius appeile antraxifère.

CARBONIQUE, adj., carbonictes. On appelle oxide carbonique ou gaz carbonique (Kohlcnoxydgas, all.), le premier degré d'oxidation du carbone, qui a été découvert par Priestley et Woodhouse; acide carbonique (Kohlcnsïzere, all.), la combi-. naison du earlone avee la plus grande quantité d'oxigène qu'il puisse al,_sorber, dont Paracelse el Vanhelmont avaient déji connaissanee, et qui depuis a été ćtudiće par Hales, blaek, Pricstlcy et Bergman ; clilorure carbonique ( Einfachchlorkolilenstoff, all.), lc second des trois degrés de combinaison du chlore avec le carbone; nitrure carbonique, le cyanogine (vorez ce mot); sulfide carbonique (Schwefeilohlenstoff, all.), le carbure de soufre liquide, qui est susceptible de se comliner avec les sulfobases; sélónide carbonique ( $S_{\mathcal{C}-}$ lenkolulenstoff, all.), une combinajson présumée de sélénium el de carbone, dont l'existenec est probable ; oxicluloridc carbonique (gaz plosgenc, acide chloroxicarbonique; Phosgengas, all.), un gaz qui est produit par la combinaison de volumes égaux de gaz oxide carbonique et de chlore gazenx.

CARBONISATLON, s. f., carbonisatio. Action de réduire en charbon; transformation par la nature ou par l'art d'une matière végétale on animale en charbon.

CARBONITy, s. m., earbonis. Nom quc prendruieut les oxalates, si l'on adoptait celui d'acidc carboneux pour l'acide oxalique.

CandoNoxide, s. m., carbonoxydum. Beudant appelle aiusi les combinaisons uatureles du cabbono et de l'oxigrinc,

\section{CARC}

CARBOSULFURE, s. m. , carbosulphuretum ; Scluvef clkohlenstoffkali (all.). Nom dounć par Berzelius i une combinaison de carbure de soulire avec un alcali.

CARBOSULFUREx, adj, carbosulphurosus. Sous le nom d'oxichloride carbosulfurcux (Saucrstoffchlorschwefelkohlensto (f', all.), Berzelius désigne un corps qui a ćlć découvert cn 18 I2 par Wareet, c $\downarrow$ qu'il croit ĉtre unc combinaison d'oxichloride carbonique avec un composé correspondint de soufie qu'ou pourrait appeler oxiehloride sulfureux.

GAPEURE, s. m., carbreretum. Counbinaison du carbonc avec un autre corps simple.

Chliburḱ, adj. On appelle $h y-$ drogéne carburé le gaz lyydrogènc protocarloné. Les minćralogistes donnent l'épithìte de carburé an f'er qui cst miućrałisé par du carhone, et celle de phy-llade carburé, à un phyllade qui est noir et tache les doigts.

C.InCǴRULAIRE, adj. , carccrrtlaris (carcer, prison). Mirbel appelle ainsi les fruits secs, iudéhisceus, qui renferment un petit nombre de semences, et qui sont libres, e'cst-àdire non enveloppés par des organes étrangers.

CARchinete, s. f. , carcerula. Nom donné par Mirbel à des fruits seces et indéliseens, qui ne sont ni des cypscles, ni des cérions.

CaHCINOIDES, adj., Carcinoides (racrivos, crabe, Einos, ressemblanee). Nom donué par Cuvier et par Dumćril à unc tribu on famille de Grustacés.

carcivologie, s. 1., carcinolo-

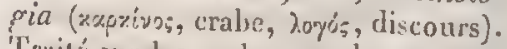
Triaté sul les erabes ou les crustacés.

CARGinologrque, adj. , carcinologicus; qui a rappopt à la carcinologic. Bibliollieque earsinologiquc. caricytae, s, m., careythium. 


\section{CARD}

Neekcr appelait ainsi le parenehyme le plus délié des végétaux qui, ehangé par l'influence des agens exiéricurs, devient suivant lui le rudiment des champignons. Foyez Blanc de crasmPIGNON.

Garduchis, s. m., Cardiacen. Nom donné par Cuvier à une famille d'Acéphalęs testaeés, par Lamarck et Iatreille a une famille de Conchifüres, par Fúrussac à une famille d'Acćpluales lamelliluranehes, par Sehweigger', Goldfuss, Ficiuus et Carus à une famille de Mollusques, par Eichwald à une famille de Thérozonires, par Blainville ì une famille de coquilles bivalves, par Menke à un ordre de la elisse des lilatobranclies et à une famille de cet ordre, eoupes qui ont tontes pour type le genre Cardium.

CARbINAT, adj., cardinatis (rap$\delta \dot{x}(\omega$, monvoir). Les astronomes appellent points cardinaux (Hauptgesenden der TVelt, all. ) conx du nord, de l'est, du sud ct de l'ouest, dans deux desquels l'horizon est eompé par l'équateur, et dans deux des autres par le méridien; signcs cardinaux, eeux du Bélier, du Canecr, de la Balauee el du Capricorne, dont le eommencement se trouve dans les points cardinnux de l'écliptique. Les eonehyliogistes noument dents cardinales eelles qui se trouvent placées immédiatement vis-î-vis les sommcls d'une coquille bivalve, et qui sout ordinairement les prineipajes. liépithète de cardinale est o u vent donnéc a des plantes (ex. Gladiolus cardinalis), ou i des aninaux (ex. Sparnes cardinalis), à canse de leur conleur rongc, qui est celle du vêtement des cardinaux, ou nnc des plus saillantes du spectre solairc.

GAnDrwelire, adj., cardiniferus (cardo, charmière, fero, porter). Se dit des enquilles bivalves dont les valves s'articulent en façon de eharuière.

CARDIOCRADEs, adj. cls.m. pl. (xxpoì, cour, gradior, marcher). Nom donué par BAarirville à un orkre de la elasse des Arachnodermaires, parce que le mode de loenmotion $y$ cst prineipalement le résultat d'un mouvement alternatif de systole et de diastole, analogue à celui qu'exécute le cocur des animaux plus élevés dans l'échelle.

CAnDIOPLTLE, adj., cardio-

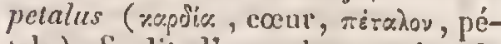
tale). Se dit d'une plante qui a lo limbe de ses pétales cn coeur à la base. Fx. Delphinium cardiopetalum.

CARDIOPATrde, adj., cardiopliyllus (rupoica, cxur, oíknov, fcuille); qui a les feuilles en eœur. Ex. Raminculus cardioplyyllus.

CArublotum:, adj., cardiopte.

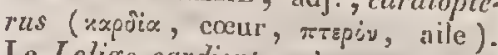
Le Loligo cardioptera a sa nageoire échancrée en cour.

GARDITACÉs, adj. ct s. m. pl., Carditacea. Non domé par Menké ¿̀ une famille de l'ordre des Elatobranches inytilacés, qui a pour type le genre Cardita.

Candopatíes, adj. et s. f. pl., Cardopatca. Nom donné par Iessing à une sons-tribu de la tribu des $\mathrm{Cy}_{y}$ narćes, qui a pour type le genre Catdopatium.

Caribuacles, adj. et s. r. pl., Carduacca. Nom donnć par Richard à un ordre de son systems sexuel réformć, par Candolle ì une tribu des Cynarocéphales, par Kunth à une division les Synanthérées, ayant pour type le genre Cariluus.

CAMDUINESE, adj. et s. f. pl., Carduince. Nom donné par H. Cassini ì une tribu de la fanille des Synasthérées, par Lessing à une sousIriju de la tribu des Cynarées, ayant pour lype le genre Cardurus.

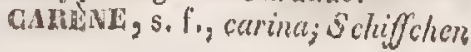


(all.); carena, navicclla (it.). On nomme ainsi, en général, une arc̀te qui est produite par la réunion de côtés affectant des directions diverses. Les botanistes donnent celte dénomination aux deux pétales inférieurs des fleurs papilionacécs, qui sont ordinaircment rapproehés l'un eontre l'autre et soudés par leur bord inférieur, de manière à offirir quelque ressemblance avce la quille d'un vaisseau.

CAnĹNÉ, adj., carinatus, navicularis; kiclförmig, gchiclt, gefalze (all.); carcnato (it.). Se dit de tout organe qui offre une crête longitudinale, de manière à ressembler un peu à la carène d'uu vaisseau; comme le caliec du Lysianthes carinotuss, les spatellcs du Dactylis glomerata, les bractécs du Gomplirena globosa, les stipules du Pelargmium carinatum, les valves de la silieule de l'Isatis tinctoria, le dos du Coluber carinatus, le corselet du $P_{a-}$ lcemon carinatns. Une faille carcinie est celle qui, étant eanaliculće, offre une saillie longitudinale en dessous (ex. Hcmerocallis fulva). On donne cette épithète ì unc coquillc zinivalve sur le milieu de la spire de laquelle s'élève une eòte saillante et aiguë, et à unc coquillc bivalve dont une partie présente une côte aiguë ct saillante, semblable à une crète.

cart́nt́s, adj. cl s.m. pl. , Carinati. Nom sous lequel Merrem désigne les oisfaux qui ont le stcrnum garni d'un loréchet, ou les oiseaux proprement dits.

GAnETTOIDES, adj. et. s. m. pl., Carcttoilca. Nom donné par P.-F. Fitzinger à une famille de reptiles chéloniens, qui a pour type le genre Caretta.

CARIClés, adj. , Caricce. Nom donné par Lestiboudois à une tribu de la famille des Cypéracęes, qui a pour type le genre Carex.

CAnrarivíss, adj. , Caricinca. Nom sous lequel Kuntli désigne une tribu de la famille des Cypéracées, ayant pour type le genre Carcx.

CARICICOLE, adj., caricolus ( Carex, laiche, colo, habiter); qui vit sur les laiches. Ex. Cania carieicola.

C.IRICOLOGIE, s. f., earicolygia. Traité sur les Carcx.

CARIDES, adj. et s. m. pl. (r.zpis, squillc). Nom donné par E. Eicliwald à une famille de Crustacés décapodes macroures, qui comprend les Salicoques.

GARIDIOIDES, adj. et s. m. pl. , Caridioides (xxpis, squille, sidos, ressemblance). Nom donné par Jatreille à unc fanille de Crustacés, dans laquelle il range plusieurs de ces animaux qui, par la forme du corps, se rapprochent beaucoup des Salicoques.

Cinnú, adj., cariosus, cxcsus; ausgefresscn, wurmfriissigr (all.); carious (angl.); cariato (it.). On dit, en minćralogic, qu'une roche a une structure cariée lorsqu'clle est percée de cavitćs irrégnlières, semblables parfois à des tubulures, qui donnent au minciral unc sorte de ressemblanee avec un os frappé de earie.

Carithovveur, adj. Épithètc donnce à un oiscau (Myrmothera campanclla), cn raison de sa voix éclatinte et scmblable à un tocsin.

CAIIINACílis, adj. ct s. f. pl. , Carinaces. Nom donné par Blainville à une famille de l'ordre des coquilles univalves, ayant pour type le genre Carinaire.

CARIVAL, adj. , carinalis. Candolle donne eette épithète à l'une des côtcs du fruit des Ombellifìres, celle qui représente la carène ou nervure principale des sćpales du calice adhírent il l'ovaire.

CAIRINIFÈLE, adj. , carinifcrus. (carina, carène, fero, porter); qui 
porte une earène. Ex. Naztilus carinifcrus, Melania carinifcra.

CARINurtí, adj., carinulatus; qui est muni d'une très-légère carène. $\mathbf{E}_{x}$. Tellina carinuiata.

CARIOPSE, s. f., cariopsis; Korn. fruch (all.) ; cariosside (it.) («spon, tête, nommé ainsi un fruit see, monosperme, indéhiseent, dont le péricarpe très-mince cst tcllement adhérent qu'il semble se confondre avee l'enveloppe propre de la graine et ne peut en ĉlre distingué. Ex. Graminćes.

Cantorsive, s. m., cariopsidium; Kornfiuchthranz (all.). Nom donné par $A$ gardh à un assemblage de cariupses disposces virculairenient (ex. Malvacées). C'est le sterigina de Desvanx.

CArissées, adj. et s. f. pl. , Carissea. Nom douné par Bartlingà une tribu de la famille des dpocynées, qui a pour type le genre Carissa.

Canduveres, adj. el s. f. pl., Carlinece. Nom doriné par II. Cassini à une tritu de la famille des Syuanthérées ct par Lessing à une section de la sous-tribu des Cynarées carduinées, ayant pour typc le genre $C a r-$ lina.

GARMINE, s. f., carninum; Coccusroth, Cochenillcnstoff, Karminstoff (all.). Nom donné par Pelleticr et Caventou au principe colorant de la cochenille et du kermès, parce que e'cst ì lui que le earmiu doit sa couleur.

GARNAIRE, adj. , carnarius (caro, chair). La Mresca carnaria est ainsi appelće parce que sa larve vit sur la viande. CARNASSIER, adj. , carnivorze;
ficischfressend (all.); carniporous (angl.) ; carnacciaro (it.); qui vit de chair, qui cn estavide, qui cn mange benucoup, qui ne fail pas usage d'autre aliment.

Carnassiens, adj. et $\mathrm{s}, \mathrm{m}, \mathrm{pl}$.,
Adephagi, Fera. Nom donné par Boddaert, Linné, Blumenbach, Cuvier, Desmarets, Blainville, Duméril ct Latreille, ì un ordrede la classe des Maminiferes, comprcrant ceux qui vivent généralement de matières animales, quoique plnsieurs soient onnivores ; par Duméril, Cuvier et Latreille is une famille de l'ordre des Colćoptires, embrassant ceux dc ces insectes qui font leur nourriture de matic̀res animales.

Carnation, s. f. Coulcur des chairs, apparence extérieute de la pean, eu ćgard à sa coloration.

Carivivore, adj. et s. m., carnivorus; oxpropxixys; fleischfresscnd (all.); qui mange de la viande. Ex. Dermeslcs carnivartus, Tyrannus carnivorus.

CAanivores, adj. et s. m. pl., Camivora, Sanguinaria. Nom donné par Cuvier, Desmarest, Latreille, Fieinus et Carus to une famille de l'ordre des Mammiferes carnassiers, coinprenint ceux de ces animaux qui vivent exclusivement de ehair.

Garnivorité, s. f. Condition d'un animal que son organisation appelle à vivre de matières animales.

canvi, adj., carneus; fleisch. farb (all.); couleur de chair, rouge, pâle un rosć. Ex. Ascobolus carncis, Erylhrina carnea, Finsidium carncum, Foluta carneolata, Trochus carncolus.

CamONCULAIRE, adj. , caruncularis (caruncula, caroncule). Epithète donnéc par Mirbel ì l'arille, quasd il est formć d'un ou de plusieurs caroneules. Ex. Polygala vulgaris.

GAPONCULE, s. f., caruncula; caprion; Flcischwarac (all.) (caro, chair ). On appelle ainsi, en botanique, un renflement de la surface de certaines graines qui entoure le hile (ex. Phascolus communis) ; en zoologic, une excroissance charnue, I5 
molle, dénuéc de plumes, qui sce voit au front, au vertex, à la nuque, au cou, aux snurcils, it lit gorge, an menton, aux augles de la bouclse, à la base du bec, etc., chez les oiseaux.

CARONCULÉ, adj., earunculatus; qui est muni d'une caronculc, c'està-dire d'un appendice fougueux ou pulpeux, conme la graine du Ster-. culia Balanghas; on d'une masse de peau nue sur Ic front (ex. Arapunga carunculata, Charadrius bilobus), sur la base du bee (ex. Crax globicera), aux angles du bee (cx. Gris carunculata, Sturnus eartuncuiatus), mutour des yeux (ex. Charadrias myops), sur chaque côté du cou, au-dessous de l'ail (ex. Creadion carunculatzes), sous la mîchoire inféricu:c (cx. Hydrobates lobahzs), sur la tète, le front et la gorge (ex. Gracula carunculaia).

Calrovculés, adj. et s.m. pl. , Caruneulasi. Noun donné par Vieillot à une famille de la tribu des Sylvains anisodactyles, comprenant ccux de ces oiscaux qui out la tête ou la mandibule inférieure garnie de caroncules.

Garotitine, s. f. , carollina. Nom donnć par Wackenroder ì une matic̀re cristallisable qu'il dit avoir trouvée daus l'extrait du suc frais de carotte, sans en indiquer ui le mode de préparation, ni lés propriétés.

CARPADLise, s, m., carpadelium ( rapriòs, fruit, ø̋onnos, couvert). Nom donné par Desvaux à un fruit létérocarpien sec, bi ou pluriloculaire, envcloppé par le calice, à loges distinetes, monospermes, opposécs. Ex. Ombrllitères.

GARPantrrítes, adj. et s. l. pl., Carpanthea. Nom sous lequel Raflinesque a proposé de désigner la famille des lihizospermes, à eause du genre Carpanthus qu'elle renferme.

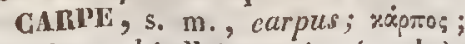
Handwurzel (all.); wrist (angl.).
Portion du membre thoracique des animaux vertébrés qui est comprise entre l'avant-bras et la main ; quatric̀me article de la pinec des crustacés. Juriue doune ce nom à la partic du hord externe de l'aile des insectes qui offic ples d'épaisscur que le reste, parce que, suiva ut lui, elle est située à la terminaison des os de l'avantbras.

GARPELIAIRE, adj., carpellaris (xapròs, (ruit); qui appartient aux earpclles. Candolle doune celte épithète aux fcuilles qui produisent les cirpelles, soit en s'affleurant par les bords, après s'être courbées cn cylindre (ex. Colchicum autumnale), s'ètre roulées en cornct (ex. Isopyrum), on s'être ployćes sur la nervure moyenne (ex. Pistum), soit en se courbant ou se ployant, mais de manière que les bords soient plus ou moiss repliés en dedans (cx. Astragalus), ou ayant la ncrvure mogenne repousséc et saillante à l'intérieur (ex. Oxytropis). Dunal l'applique an quatricme verticille floral, celui qui cnveloppc les ovaires ou jeunes carpelles, et les réunit en un seul corps. Enfin Candolle appelle bractécs carpellaires de petites écailles qu'on observe quelquefois à la base des carpelles, disposées en épi autour d'une colome centrale (ex. quelques Renonculacíes).

CARPELLE, s. f., carpclla ( $\times x .0-$ $\pi \grave{o s}$, fruit). Candolle appelle ainsi les organcs élémentaires, tantôt libres, tantût adhérens ensemble, dont la réunion donne naissance au pistil, et dont chncun peut êtrc considérć comme une petite fenille ployée en dedans sur elle-même, qui renferme Ies germes que la fécondation doit développer, On donne aussi ce nom d̀ chacuin des fruits partiels qui proviennent d'une seule flenr on d'un seul pistil, comne dans les Renoncules, 
CARTESÍ́es, adj. et s. f. pl., Carpesica. Nom donné par Jessing ¿l une section des Sénécionidées Relhaniées qui a pour Iype le ǧenie Carpcsium.

CAIRIDEE, s. f., carpidium. On a proposé ee nom pour désigner, dans un fruit agrégét, chacun des fruits parlicls qui se sont soudés enscuble, par exemple pour produire la mûre.

CARPINICOUE, adj., carpinicolus (carpinus, ebarmc, colo, habiter); qui vit on erôit sur les feuilles des ehnrmes, comme le Spheria carpinicola.

GARPIQUE, adj , carpicus (xsp$\pi \dot{s}$, fruit). Candolle appelle cicatricc carpiquc une large eicatrice produile, a la base de certains fruits, an monent de leur séparation, par la large adhérence que cette hase uvait avec l'involucre foliacé (ex. noisellc) qui semble fairc parlie du fruit, ou par l'involucre en forme de enpule qui entourail sa base ( ex. gland du Chêne ).

CARPOBOLÉEs, adj. et s. f. pl. , Carpobrilca. Nom donné par $A$. Brongniart à une section de la tribu des I,ycoperdacées angiogastu'cs, qui a pour type le genre Carpobolus.

CARIPOBOLES, adj. et s. m. pl., Carpoboli. Norn donné par Fries ì une tribu de l'ordie des Gastérounyeèles angiogastres, cunprenant ceux dont les sporanges solitaires sortent avec élasticité du pévidion.

GARPOBONTELS, adj. et s.f. pl., Cerpodontece. Noin donné par Bartling à wne tribu de la famille des Gareinices, qui a pour type le grenre Carpodontos.

CARPOEOGE, s. f. , carpologia (xxprós, fivit, róyss, discours). Fitude du fruit, considéré dans son ensemble et ses détails. Partie de la botanique qu'a crééc Gartner, à qui l'on doit la premiere deseription exncte qu'on possède de fruits et de graines.

CAIRPOLOCIOUE, adj., carpologicus; qui a lapport ì la earpologic.

CAHFOLOGUR, adj. et s. m., carpologus. Rotaniste qui se livre spućcialenarnt à l'étude des fruits.

CARBOMOLPHE, adj. , carponorphus (raptos, fruit, poparn, forme). bi dit des apollécions des lichens, qui ressembleut à des fruits, quoiqu'il ne soil pas pronvé qu'ils résultent d'une fécondation.

CARIOMYzES, adj. et s. m. pl.,

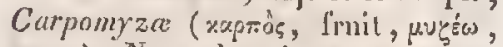
sucer'). Nom douné par Cuvier et Jatreille à un groupe de la tribu des Muscides, comprenant des inseeles diptives qu'on suppose vivre des sues des plantes sur lesquelles la plupart se tiennent habituellement.

GARPOPHAEE, adj., carpopha-

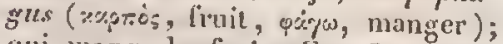
qui mange les fruits. Ex. Gcophilus carpophagus.

CAIPOPHAGES, adj. et s. m. pl., Carpophaga. Nom donné par Latreille, Fieinus et Carus ì une fímille de l'ordre des Marsupiaux, comprenant des mammiferes qui vivent principalement de fruits.

CARPOHILE, adj., carpophilus (xupròs, fruit, piséw, aimer); qui eroit sur les fruits. Ex. Peziza caipoplitia.

GARPOPHORE, s. m. , carpophorum (zsoris, fruit, pópw, porter). link domait autrefois ee nom it un support né du récéptacle, qui sou! ève la pistil seul, sans les étamines ni les pétales, et pour lequel il prófère maintenant la dénomination de $g y$ nophore, introdnite par Nlirbel.

CATPOPIILLE, s. 11., carpophollum; Fruchulalt (all.) ( fruit, pishov, feuille). Nom donné par Arardh ì toute fcuille qui, par son plissement, jroduit une carpelle.

cosiré, adj. , quadralas; твтриं- 
yw: sร; viereckig (all.); square (angl.); qui offrc quatre côtés et quatre angles droits, comme le corselet de quelques Buprestes, l'urne du Glyphocarpus quadratus, la tige de I'Acisanthcra quadrata, une tache brune qu'on voit sur les ailes de la Leptis quadrata.

CARTACÉ, adject. , charlacens; papierähnlich (all.). Se dil d'un corps organisé qui croît sur le papier humide (ex. Sporotrichum chartaceum2), et plus sonvent d'un être (cx. Eschara chartacea) qui est étalé en feuilles minces, ou d'une partie qui est sèche, flexible, unie et tenace, à l'instar du parcheni in ou d'une carte, comme le péricarpe de l'Anagallis arvensis, le noyau de l'Areca fanfil, le togmen du Pyrus communis.

CARTIA MÉEs, adj. et s.f. pl., Carthamca. Nom donné par H.Cassini à unc section de la tribu des Carduinées, qui a pour type le genre Carthamus.

CARTIAMINE, s. f., earthamina. Nom donné par John au principe colorant rouge des fleurs du Carthamus lincturius.

CARTHANIQUE, adj. , carthamicus. Docbereiner désigne la carthamine sous le nom d'acide carthamique (Carthaminsüure, all.), parce qu'elle a la propriélé de saturer les alcalis.

CARTILAGINEUx, adj. y cartilaginosus, carlilagineus; Xovóping

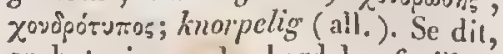
en botanique, du lord des fouilles, quand il est dur, élastique ct d'une autre coulenr que le reste ( $\mathrm{ex}$. Vaccinium Vitis Idcra), on garni de crenelures plus dures, comme cartilagineuses (ex. Veronica cartilaginca), ct du périspcrme, lorsqu'il est tonnace comme un cartilage (ex. $0 \mathrm{~m}$. bellifères). Lc Sisymbrium cartilagincum cst ainsi appelé à cause de ses fouilles coriaces, et l'Agaricus cartilagincus, en raison de sa consistance.

Cartulagineux, adj. et $\mathrm{s}$. m. pl., Cartilaginosi. Fipitiète donnćc par Lacćpède el Duıéril à unc sousclasse de la classe des Poissons, comprenant ceux dont le squelette est mou, flexible, élastique, peu inprégné de scls calcaires.

CARTONNIER, adject., chartaceus. Nom donné à eertaines Guêpes, qui construisent des nids avec des parcelles de végétaux tellement lićes cnsemble qu'il en résulte un corps scmblable à du carton. Ex. Polistes chartaria.

CARYOBnivcues, adj. et s.m. pl., Caryobranchiala (zxpux , noix, Bpx́ryix, liranchics ). Nom donné par Mcnke à un ordre de la classe des Gastéropodes, qui répond exartement aux Nucléobranches (voyez ce mot) de Blainville.

GARTOGARPE, adj., earyocarpus (rap'sx, noix, xxpros, fruit); qui a lc fruit renflé et semblable ì une noix. Ex. Astragalus caryocarpus.

GARYOCATICTE, adj., caryocatactes ( $x$ ariz, noix, xхтхxтn;, qui brise), Un oiscau (Nucifraga caryocatactes) est aiusi appelé parce qu'il vit des amandes des cônes de pins, qu'il épluche avec adresse.

CARYOPIILLAIRES, adj. et s. m. pl., Caryophyllaria. Nom donné par Lamonroux à un ordre de la section des Polypicrs lamellifères, qui a pour type le genre Caryophyllia. CARIOPHYLL, adj., caryophyllatus; ncllicnartig (all.); cariofilíaceo (it.). Épithite donnée aur corollcs régnlières qui se composent de cing pétales, dont les onglets trèslongs sont entic̀rement cachús par le tube du calice.

CARTOPHYLLES, adj. et s. f. pl., Caryophillece. Nom donné par 


\section{CASÉ}

Tournefort ct par Guiart à une classe, par Linné et tous les botanistes actucls, s̀ une famille de plantes, ayant pour tspe le genre OEillet, et renfermant des plantes dont la corollc est earyophyllée.

CARI OPHYLLINE, s. f., caryophyllina; Nelkenkampfer" (all.). Quelques chimistes désignent sous ee nom le stéaroplène qu'on extrait de l'huile essenticlle du Carrophyollus aromaticzes.

CARxorintLinfes, adj. et s. f. pl., Caryophyllince. Nom donné par Bartling ì une classe de plantes, qui comprend les familles des Chénopodées, des Amarnnthacées, des Phytolaceées, des Scléranthées, des Paronyehiées, des Portulaećes et des Alsinées.

CaIRYOPSE. Voycz Cariopse.

CARYOPSIDE. VoYcz CaRiopside.

CASCADE, s. f., aqua dejectus; xarx́doumos; Wasserfall (angl.). On appelle ainsi une chute d'eau pen imporlante, due à un ruisseau qui se préeipite d'un lieu fort élevé.

CASÉATE, s. in., caseas (cascum, fromage). Genre de sels (kiässaure Salze, all.), qui sont produits par la combinaison de l'acide easéique avee les bases salifiables.

Caséatron, s. f., caseatio. Congulation du lait, sa réduetion en fromage.

CASt́́nUx, adj., cascosus; käsig (all.); qui est de la nature du fromage. On appelle matière casćcuse le magma qui se produit pir! la coagulation du lait, et qui fait la base du fromage.

CASÉrTOLuE, adj., caseiformis ; qui ressemble à du caséum, à du fromage : précipilé caséiforme.

CASÉIQUE, adj., caseicus. Lipithète donnée à un acide (Küssüure, all.) et à un oxide qui sont les produits de la déeomposition du fromage, et dont la découverte cst due à
CASQ

Proust. L'oxide casćique (Küsoxyd, aIl. ) a été appelé aposépédine par Braeonnot.

CASt́olaIre, adj., caseolaris. Le Rhizophora caseolaris a été nommé ainsi eu raison de la mollesse de son bois, qu'on a comparce à celle du fromage.

CASEUM, s. m., caseum; Kässtoff (all.). Prineipe immédiat du lait, matière animale partienlière, qui fait la base du fromage.

CASISPERIE, adj., casispermus

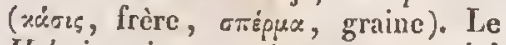
Helmisporium casispermum a été appelé ainsi paree que ses sporidies sont adhérentes de tous less eôtés.

CASPIEN, adj., caspizs, caspicus. Cutte épithète, réscrvée jusqu'iei à une senle mer intérieure, est étendue par Bory à tous les amas d'eau salće que lia terre emprisonne dans leur circonférence entière, et que nul détroit, nul cours d'eau un peur considérable ne met en rapport, soit a vee l'Oeéan, soit avec unc Mćditerranée.

CASQue, s. m., galea, pilcus, mitra ; Helm (all.); celata, cimiero, morione (it.). On appelle ainsi : $1^{\circ} \mathrm{en}$ botanique, l'ćperon des fleurs, quand il est Jarge et plus ou moins en forme de casque ; la lèvre supérieure d'une corolle personnéc, lorsqu'elle est voûtće et concave intérieurement; la division supéricure et redressée du périgone des orchidées; $2^{\circ}$ en zoologie, le tubereule ealleux, rceouvert d'une sulstance cornée, qui oecupe le sommet de la tête de cerlains oiseaux, par exemple du Casoar d'Asic ; d'après Lyonnet, l'ensemble des parties solides qui eomposent l'enveloppe extćricure de la tète des insectes; suivant Réanmur, une espèce de masque eonvexe et arrondi que portent sur le front les larves des libellules, et qui oecupe le devant ct le dessus de leur tète. 
CASQUĽ, adj. , gaieautus, mitratus; gchelmt (all.). Épithc̀te donnée ì des animaux qui ont la têlc garnie de lames dures, qu'on a comparées à un casque (cx. Pimclodes galcatus, Coryphana saleala, Dendrobium galcatums, Numida mitrata), et quclquefois à des oiseaux qui ont la têtte d'une autre couleur que lc corps (ex. Banksiantss galeatus, Psittacus mitralus).

CASSANT, adj., fragilis ; sizhaбroe; sprödig, zerbrechlich (all.); brinle (angl.); qui est sujet à sc casser, qui se brise aisément.

CASSIDAMIS, adj. et s. m. pl., Cassidarice. Nom donné par Cuvier, Latreillc et Eichwald à une famille de l'ordre des Colćoptc̀res, qui a pour type le genre Cassis.

CASSIDITES, adj. ct s. m. pl., Cassidites. Nom donıé par Iatreille à une famille de l'ordre des Gastéropodes pectinibranches gymnocochlides, qui a pour type le genre Cassidea.

CASsIÉEs, ad. et s. f. pl., Cassica. Nom donné par C.-II. Ebermaier ct par Candolle à une tribu de la famille des Légumincuses, ayant pour type le genre Cassia.

CassinIées, adj. et s. f. pl., Cassiniex. Nom donné par H. Cassini à un groupe de la scction des Inulées guaphaliécs, et par I cssing à une section de la sous-tribu des Súnćcionidées guaphaliées, ayant le genre Cassinia pour type.

Cassitúrmines, s. m. pl., Cassi-

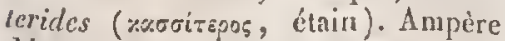
désigne sous ce nom un genre de corps simples, dont l'ćtain est le type.

CASSURE, s. f., abruprio, fractura;

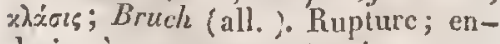
droit nù un corps cst brisé.

Cassuviées, adj. et s. f. pl., Cassuviea. Nom donné par Candolle à une tribu de la famille des
Térébinthacées, qui a pour type le genre Cassuvium.

GASTANOCARPE, adj., casiano-

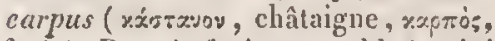
fruit). Dont le fruit ressemble à cclui du chât aignier. Ex. Polembryum cas. tanocarpum.

C.ASTANOPTÈlle, adj., casıano-

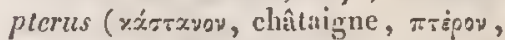
ailc). Il se dit d'un oiscâu dont les ailes (cx. Strix castanoptcra), ou d'un insecte dout les élytres (ex. Staphylinus castanopierus) sont de couleur marron.

CASTELÉes, adj. et s. f. pl., Castelea. Nom donné par Bartling à une tribu de la famille des Ochnacées, qui a pour type le genre Castela.

CASTORATE, s. m., castoras. Sel produit par la combinaison de l'acide castorique avec une base salifiable.

CASTOMINE, s. f., Castorina; Bibergeillampher (all.). Nom donné par Biandes à une graisse cristalline, déja cutrevue par lourcroy, qui cxistc dass le castoréum.

C.ISTORIQUE, adj., castoricus. Brandes donue cette épithète à un acide (Castorinsïurc, all.) que produit l'action de l'acide nitrique sur la castorine.

GASUarinéES, adj. ct s. f. pl., Casuarince. Nom donné par Mirbel, $\mathrm{R}$. Brown et Kunth une famille de plantes, qui a pour type le genre Casuarina.

GatabopiYTe, s. m., Catabophytum ( $x<x<$ ใ plante). Nom donné par Nccker aux plantes qui vivent submergées par Ics callx.

GATACLÉSIE, s. f., cataclesia ( $x \alpha \tau \dot{\alpha}$, au dessous, $x \lambda \dot{\varepsilon} \pi \tau \omega$, recouvrir ). Fruit monosperme, indéhiscent, à pćricarpe coriaee, non ligneux, recouvert par le calice, qui 
ne devient jamais charnu. Ex. Chénopodées.

CATACLISHE, s. n., cataclys-

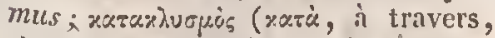

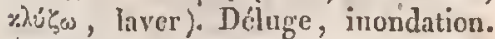
Autrefois on avait recours, pour expliquer les phénomènes géologiques, ì ces bouleverscmens violens, généraux ou particls, dont on ne peut douter en effet que plusieurs n'aient excreć leur influence sur notre globe, au moins dans certaines localités; nıais, en général, on a renoncé à ces hypothèses, pour rentrer sous l'influence des causes naturelles habituelles; plus in accord avec l'ordre ct l'harmonie qui régissent l'cnscinble de notre système planétuire. Vulcanisme primitif et ses suites, formation des entux par condensation des vapeurs, abaissement de leur niveau par suite de l'infiltration qui s'est opéréc proportionnellement au rcfroidissennent et à l'épaississement de la croûtc terrestre, et diminution de la température à la surface du globe, par l'effet de ce refroidissement, telles sont les causes primordiales d'où découle, par un enchaînemcnt de conséquences et sans efforts, l'explication de tous les faits gćologiques.

CATACI ISMOLOGTE, s. 'f., catcclysmologia. Histoire des déluges ou des révolutions de la surface du globe terrestre.

Catacoustique, s. f. , catacoustica ( $x \alpha \dot{x}$, en bas, árov́w, entendre). Branche de la physique qui a pour oljjet les sons rélléchis, ou les propriétés des ćchos.

CATADIOPTRIOUE, adj., caladioptricus ( $x \times \dot{\alpha}$, cul bas, dic̀, à travers, örtopax, voir). S Spithète donnée a ccrtiins télescopes, parce qu'ils réunissent les effets combinćs de la réflexion ct de la réfraction.

GATANANCÉES, adj. et s. f. pl., Catanancece. Nom donné par H. Cas- sini à un groupe de la section des Lactucées scorzonérées, qui a pour type le genre Calanance.

CatanavcuĺEs, adj. et s. f. pl.; Catrananchea. Nom donné par D. Don a unc tribu de la sectiou des Chicoracécs, ayant pour type le genre Catanance.

GATMPLTALE, adj. , catapetalus

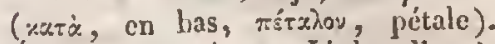
Épithète donnée par Link, d'après Liuné, à une corolle qui, étant monopútale, a ses pćtales lćgèrement adhércns par leur base à l'androphore, de manière qu'ils ne tombent pas séparément après la floraison. Ex. Malvacées.

CATARHONQUe, s. f., , catapho-

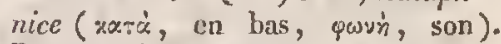
Branche de la pliysique qui traite de la réflexion du sou.

GATAPHIACTE, s. fém., cata :

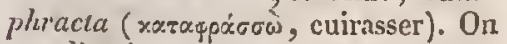
appelle ainsi, chez certains poissons, l'espèce de cuirasse produite par leurs écailles qui, bien que distinctes, sont cependant collées les uncs ì côté des autres.

CATAPHRACTís, adj, et s, m. pl., Cataphracti. Non donné par Ficinus et Carus à une famille de poissons Zeugoptérygiens microstomes, qui ont le corps enveloppé d'une cuirassc.

CATARA GTE, s. f. , cataracta; xorapórens; W Wasserfall (all.); waterfall (angl.); cataratla (it.) (raræ̀, en bas, ṕxøew, rompre). Chute plus ou moins élevéc qu'un cours d'eau épromve quand son lit aboutit ì une pente trés-rapide, ou à un escarpement, et que le liquide franchit brusquement la différence de niveau.

CATARRIUNs, adj. et s. m. pl., Catarrhini (rarc, auprès, p̈i\%, nez). Nom donné par Geoffroy-Sajut-17ilaire, Desmarest el Latreille, à une famille de l'ordre des Marnmifères quadrumanes, comprenant ceux qui 
ont les narines rapprochées, la cloison qui les sćpare élant étroite.

CATÉNIFÈre, adj., catcnifcrus (calena, chaîne, fero, porter). Se dit d'un corps dont la surface est marquée de lignes colorées initant des chaines par leur disposition. Ex. $\checkmark$ enus catenifera.

CATÉNULAURE, adj. , catenularis; ketlenförmig (all.) ' catenula, chainclcttc) ; qui offre des rugosités arronảies et situées les unes à la suite des autres, comme les anncaux d'unc chaine (ex. Pletroloma catcnata), ou des lignes colorécs affectant la même disposition (ex. Coluber. catenularis). Voye Excinîné.

CATÉnULE, s. I., catenula; Kettchcn (all.) (calcna, chaine). Quelques botanistes ont appelé ainsi les petits filamens cotorlillés qu'on trouve dans les capsules des Hépatiques.

CATÉNULÉ, adj. , catcnulatzs ; 'zellcnartig, kettenfiormig (all.)'; qui offre des points enfoncés situés ì la suite les uns des autres (ex. Tachypus catcnulatus), ou des branches comme frisies par l'enroulement de lcurs petites ramifications (cx. Ccllaria crenulata). Voycz JasenownÉ.

GatuARtine, s. f., calihartince (xa0uprìs, qui purge). Nom donné par Lassaigne et Fenculle au principe actif el purgatif du Cassia Senna.

CATIzopIIYTE, s. m., catizo-

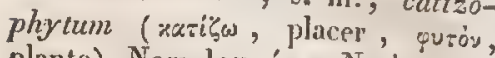
plante). Nom donné par Necker aux plantes dont les étamines nombreuses sont insćrécs sur le disquc.

CATODONTE, adj., catodon ( $x<\tau \dot{\alpha}$, en bas, jojois, dent); qui a les dents recourbées en bas, comme les dents inféricures du Playsetcr calodon.

CATOPE, s. li. , catoptes ( en dessous, roũs, pied ). Duméril propose de donner ec nom aux nageoires ventrales des poissons, qui

\section{CAUD}

correspondent aux membres pelviens des autres vertébrés.

Catopode. Voyez Catope.

CATOPODLS, adj. et s. m. pl., Catopoda. Non donné par Ficinus et Carus à un ordre de poissons osseux, comprenant ceux qui sont pourvus de nagenires ventrales.

CATOPTIIQUE, s. f. catroptica;

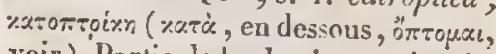
voir ). Partie de la physique qui traite de la lumière réfléchic à la surface des corps, parce qu'elle sc comportc alor's comme si ellc tombait sur un miroir.

Catoptrieue, adj., catoptricus. Epithète donnée par Groethe à des conlcurs qui sont dues à un effet de miroitement, et qui rentrent dans la catćgoric des phénomènes lunineux que Young explique par son principe des interlérences.

CATOTAPIYTE, s. m., calolaphy-

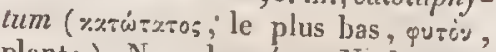
plante). Nom donné par Neckcr aux plantes dont les étamines sout insćrées it la base du calice ou au disque.

Catotretses, adj. et s. m. pl., Catolretra (xasd, en bas, tpntos, percé ). Nom donnć par C.-G Ehrenberg à deux familles d'Infusoires polygastriques, comprenant ceux de ces animaux qui n'ont ni la bouche ni l'anus terminal.

CATrologie, s. f., callologia (catlus, chat, 2o.jos, discours ).
'Traitć sur lc chat.

CAUCALIDĹES, adj. et s. f. pl., Cancalidea. Nom donné par Sprengel à une tribu de la famille des Oubcllifères, qui a pour ty pe le genre
Caucalis.

Cavcalivírs, adj. ct s. f. pl., Caucalinea. Nom sous lequcl Candolle désigne unc tribu de la famille des Ombellifires, ayant pour type le genre Caucalis.

CAUDAL, adj. , caudalis (cauda, queuc); qui a rapport ì la queue. 
Un appendice eaudal est un prolongennent aninei situé à l'extrémité postéricure du corps. On appelle nageoirc caudale, dans les poissons, celie qui termine la queue.

CAUDÉ, adj., caudatus; geschwönzt (all.); codato (it.); qui a une queue. Se dit : $1^{\circ}$ ell astronomie. On appelle les comètes étniles caudées, parce qu'elles snit souvent munics d'une queue. $2^{\circ}$ En bolanique, celte épithète est donnée à des parties qui sont alongées en forme de queue, comme les anthères des Stceticlina, es camarcs du Clcmatis erccta, les fercilles du Diplochila caudala, les siliques du Raphanus caudatus, les ipis floraux de l'A Amaranthus caudaius, l'extrémité des frondes du Ptcris caudala et de l'ddiantum cauda. tum, trois des pétales de l'Epidenclrum caudaum. $3^{\circ} \mathrm{En}$ zoologic, se dit d'un aninal qui a la queue trèslongue (ex. Oriolus caudalus, Pipra caudala); dn postabdomen d'un crustacé, lorsqu'il se prolonge en queuc (ex. Trilobites caudalus); de l'anus d'inn inseete, quand il est terminć par une queue (ex. Saulerelle), des niles d'un papillon, lorsque leur bord postérieur se termine en une poimte alongée ou en un appendiee qui les dépasse plus ou moins (ex. Papilio Machaon ).

Caudés, adj. et s. m. pl. Nom donné par Latreille a une famille de l'ordre des Polypes trichostomes, comprenant ceux dont le corps se rétrécit postérieurement, et se termine en pointe ou en queue.

CAADEX, s. m., caudex; Slock (all.); caudicc (it.). Ge mot, employé par Ruclle et Tournefort, pour exprimer la tige des arbres, désigne suivant Linné, la tige et la partie la plus épaisse de la racine, d'après Link, la base persistante et rabougric de certaines tiges annuelles, par exemple de la Gentiane, d'après
Willdenow, le trone des Palmiers et des Fougères arboreseentes, selon Bernhardi, le collet, ou la porlion de la plante intermédiaire entre la tige et la racine.

CAUDICIFORME, adj. , caudiciformis (caudex, tige, forma, forme). Epithète donnce à une tige qui ne se ranifie point.

CAUDiculN, s. fém., caudicula. L.-C. Iichard appelle ainsi le prolongement solide, en forme de filament, qui porte les masses de pollen, dans les Orehidées.

CAUDIFÈE, adj., caudifertes (cauda, queue, fero, porter). Dans le Glossopleaga caudifor, la queue déborde la membrane interfémorale, qui est très.conrte.

CAUDIGÈR, adj. , caudigerus (cauda, queue, gero, porter); qui a des feuilles terminées par une partie Innirae et étroite (ex. Micania candigcra); qui offre à l'une de ses extrémités un appendice en forme de queue (ex. Mfodiola caudigera); qui a des ramilications miuees et alongécs, semblables ì des queues (ex. Spongia eaudigera).

CACDIMANE, adj. , cazdimanus, candivolyulus (eanda, queue, manus, main ). Se dit d'un animal qui peut einployer sa queue eomme unc main, pour saisir les objets, aiusi que font les Sapajous.

CAUIULE, s. f., eaudula. Kirby donne ee nom aux organes filiformes ou sétacés qui garuissent l'anus des Lepisina.

Caulenpúes, adj. et s. f. pl., Caulerpea. Nom domné par R.-K. Greville à un ordre de la famille des Algues, qui a pour type le genre Caulerpa.

CAdLESCENS, adj. et s. m.pl., Caulescentia. Nom donné par Latreille à une fanille de l'ordre des Echinodermes astéroïdes, comprebant ceux qui ont le corps porté sur 
une tige articulée et terminée par des rayons rameux.

CAULESCENT, adj., caulcsccns; stengeltragend, bcstengelt (all.) (caulis, tige ). Se dit d'une plante qui est munic d'une tige, qui a une tige très-visible. Ex. Polentilla caulescens.

CAULICINAI, adj. , caulicinalis ; qui croît sur les tiges et les rameaux secs. Ex. Asaricus caulicinalis.

CAULICOLE, adj., caulicolus, caulincolus (caulis, tige, colo, habiter). Epithète donnéc par Candolle aux plantes parasites phanérogames qui, comme la Cuscute, aspirent leur nourriture au moyen de suçoirs latéraux, placés sur lcurs tiges, et qu'elles implantent dans la tige des autres végélaux. Ce mot est employé aussi comme nom spécifique de quelques plantes agames (ex. D́cpazca caulincola).

CAULICULE, s. f., cauliculus; scapus (Gertner), scapellus (Link); Sticlchen, Stengelchen (all.); L.-C. Richard appelle ainsi la partie intermédiaire de l'embryon qui a gerné, celle qu'on aperçoit cntre les cotylédons et la racine. Link donne le même non à ehacune des tiges qui sortent, au nombre de plusieurs, d'une seule racine.

CAULIFLORE, adj., cauliflorus; slanımblütlig (all.) (caulis, tige, flos, fleur). Epithète donuée aux plautes dont les fleurs naissent sur la tige. Ex. Lecanocarpus cauliflorus, Baccaurea cauliflora.

CAULIFLORírs, adj. et s. f. pl., Cauliflorce. Nom donné par Candolle à une section du genre Oxalis, comprenant les espices qui ont les pédoncules axillaires ct uniflores.

CAULIE ORNE, adj., cauliformis; stengelförmig, stengclartig (all.) (caulis, tige, forna, forme); qui a la forne d'une tige.

CAULINAIRE, adj. ; caulinaris,

\section{CAUS}

caulinarius, crulinus, stirpalis; stammständig, stcngclständig (all.); caulino (it.); qui appartient à la tige, qui naît sur elle; cornme les racincs du Lierre, les ćpines du Gleditsia ferox; les aiguillons des Roses; les fleurs du Cynometra cauliflora. On appelle stipules caulinaircs celles qui u'adhèrent aree les feuilles que par un point à peine sensible, tandis qu'il cxiste une union très-apparente entre elles et la tige ( $€ x$. Laihyrus Aphaca). L'ćlongation caulinairc, suivant Dutrochet, est celle qui résulte du développement en longueur de la racine ou de la tige, après leur formation.

CALLINICOLE, adj., caulinicola (caulis, tige, colo, habiter); qui eroit sur les tiges, comme le champignon appelé Actinonema caalinicola.

CAULIRIIzE, adj., caulirhizus ( d'unc plante dont la tige émet des racines. Ex. Acmella caulirhiza.

CAClOCARPIEN, adj., caulocarpous; stanumfruchlig ( $x x v \lambda_{0}$ s, tige, xхртој, fruit). Epithète donnée par Candolle aux végetaux dont la tige persiste et porte plusieurs fois du fruit.

CAULOGARPIQUE, adj. , caulocarpicus. Voy. Caclocarpien.

CALSAL, adj. , causalis (causa, cause); qui annonce un rapport de cause á effet.

Causalite, s. f. , causalitas. Qualité, manière d'agir d'une cause.

CAUSE', s. f., causa; caitix, aitiov; Ursachc (all.) (cavco, prendre gardc). Ce qui fait qu'une ehose cst, qu'ulı phénomène a lieu; prineipe, source, originc.

CAusticrté, s. f., causticitas; vis caustica; AEtsbarkcit, AEtzlirufi (all.) (raiw, brûler). Faculté qu'ont diverses substances de faire subir aux matières animales et végétales un changement tel que leur continuité s'en trouve 


\section{CAVI}

détruite, et qu'elles sont par consćquent cerrodćes.

CAustrQue, s. f., eaustica; rayottròs; Brennlinic (all.). Les pliysiciens appellent causitique par r'́flexion unc courbe produite, derrière un niroir convexe, par les prolongemens des divers rayons réléchis et divergens qu'envoie un point lunineux placé à unc certaine distauce vis-à-vis le miroir; et caustique par réfraction une antre courbe, analogue à la précédente, qui est l'cffet de la rérraetion du rayon lumincux.

CAUSTIQUE, adj. , causticus ; $\ddot{\text { l }}$. zend (all.). Se dit en chimie des alcalis lorsque, dégngés de loute eombinaison avee d'aulres corps, ils manifestent pleinement l'action destructive qu'ils ont la puissance d'exercer sur les matières organiques.

CAVERNAInE, alj., cavernarius (cavo, ereuser). Epithète donnée à quelques plantes, qui croissent dans les cavernes nur antres lienx snuterrains. Ex. Byssus cryplarum.

GAVEREE, s. f., spccus, spclunca; orrìnarov; Höhle (all. ). Canvité sontterraine, irrégulière, sinucuse, d'une certaine étendue, et ordinairement composée d'une sćric de renflemens ou étranglemens, e'est-à-dire de salles plus ou moins vastes, corumuniquant ensemble par des eouloirs plus on moins resserrés.

CAVERNELX, adj., eapernosus; Grnhasuionns; hïhlig (all.); qui est plcin de petites cavités, de cavernes. Ex. Anthracitc caverneux.

CAVICOLES, adj. et s. m. pl., Capicola. Nom donné par Clark à une famille d'OEstres, eomprenant ceux de ces insectes dont les larves vivent dans les cavités du eorps d'autres animaux.

Cavicornes, adj. et s. m. pl.;, Cavicornia (cavus, cavité, cornu, corne). Nom donné par Eichiwald, Goldfuss et Illiger à une famille de

\section{CÉDR}

l'ordre des Mammifères ruminans, comprenant ceux qui ont les cornes ereuses à l'intérieur, ct appliquécs sur un axe ossenx.

CAVITAIRES, adj. ct s.m. 'pl., Cavilaria (cavitas, creux). Nom donrić par Cuvier et Schweigger à un ordre de la elasse des Vers intestinaux, compreuant ccux qui ont un canal intestinal flottant dans une envité aldoninale distincte.

Gavitŕ, s. fo, cavilas; \%otica, xoìs, roìape ; Höllung (all.). Grenx ou vide dans un corps solide.

Cayeu. Voy. Caïet.

Cúbiens, adj. ct s. m. pl., Cebii: Nom donné par Goldfuss à une faznille de l'ordre des Mammifères quadrumanes, ayant pour type le genre Cebus.

CÉBmIONIDES, adj. et s. m. pl. ; Cebrionides. Leach désigne ainsi la fannille suivantc.

Cóbruonites, adj. et s. m. pl., Cebrionitcs. Non donné par Cuvier, Latreille ct Eicliwald à une tribu de la famille dez Culéoplères serricornes, qui a pour type le geure: Cebrio.

ctciminis, adj. et s. m. pl., Crecilialea. Norn donnć par J.-A. Gray à la seule famille qu'il admette dans l'ordre des Amphibiens apodes, et qui a pour type le genre Cacilia.

CúGILIOIDEs, adj. et s. m. pl., Coceilioides, Cocilitoidei. Nom donné par P.-F. Fitzinger et Eichwald à une fimille de reptiles, ayant le genre Creilia pour type.

cúchopítes, adj. et s. f. pl., Cccropiere. Nom sous lequel A. Richaril désigne un groupe de la famille des Urticées, qui a pous type le genre Cceropia.

chonćcies, adj. et s. f. pl., Ccdrclcar. Nom donné par Candolle ì unc tribu de la famille des Méliaeées, par Kunth et Brown à une famille de plantes, ayant pour type lo genre Cedrela. 
CEINTURE, adj., cingulalus, cinctus; qui a le milieu du corps d'une autre couleur que le reste. Ex. Xylophagus cinctus, Pamphitius cingulatus. Voy. Cerclí.

CÉLÁSTRIvíES, adj. et s. f. pl., Celastrincee. Nom douné par $R$. Brown et Kunth à une fanille de plantes, qui a pour type le genre Celastrus.

CÉLERIGRADES, adj. et s.m.pl., Celerigrada (celer, rapide, gradior, marcher). Nom donné par Blainville à un ordre de la classe des Mammifères, reufermant les Rongeurs, dont la plupart se font remarquer par la prestesse de leurs mouvemens.

GĹLESTE, adj., coelestus; oủpóveg;; himmlich (all.); qui a rapport au ciel (corps céleste, phénoméne célestc); qui en a la couleur, eomme les rayons de l'Agathaca ccelestis.

CELLA, s. f. , cella. Seopoli appelle ainsi une sorte de fruit ayant trois péricarpes, l'externe ligneux, le moyen pulpeux, l'interne débiseent et membraneux. Ex. Tuntoppodana.

Gelcaruérs; adj. et s. f. pl., Cellariea. Nom donné par Lamonroux à une famille de l'ordre des Polypiers cellnlifèrcs flexibles, qui a pour type le genre Cellaria.

CELLARIÉs, adj. et s. m. pl, , Cellariaa. Nom donné par Blainville a une famille de la classe des Polypiers, comprenant ceux dont les animaux sont contenus dans des cellules aplaties, à ouvertures lilatérales, et qui a pour type le genre Cellaria.

CELLÉPonéles, adj. et s. f. pl., Celleporce. Nom donné par Lamouroux à un ordre de Polypiers eellulifùres flexibles, ayant pour type le genre Ccllepora.

CELLICOLE, adjeet., ecllicolus (cella, cave, colo, habiter); qui habite dans les eaves. Ex. Nemesia cellicola.

\section{CELL}

CELlula Lre, adj. $\vec{a}$ cellularis ; zellgewebartig (all.). On emploie ee mot: $1^{\circ}$ en minéralogie, où l'on dit qu'une roche a une texture cellulaire, quand elle offre de nombreuses cavités arrondics, à parois lisses; $2^{\circ}$ en botanique, où l'on appelle cloisons cellulaires, eelles qui ne sont formées que par du tissu cellulaire, et enveloppe cellulaire, les couclies de tissu cellulaire qui recouvrent les couches corticales, au dessous de l'épidermc. Candolle nomme plantes cellulaires, eelles qui sont composćes uniquenent de tissu eellulaire arrondi ou alongé. On donne le nom de tissu ecllulaire (contcxlus ccllulosus, tcla cellulosa, complexus cellulosus; Zcllowewebe, all.), dans les vegétiux, à un tissu membraneux composé d'un grand nombre de eellules à peu près hexagones, closes de toutes parts; et dans les animaux, à un tissu mueilagineux naturellement partagé, ou susceptihle de se réduire par l'insufflatiou, en cellules irrégulières, qui communiquent toules les unes avec les autres.

CELluhaines, adj. et s. m. pl. , Cellularia. Sous ce nom, O.-F. Muller désignait un ordre de la classe des Vers, eomprenant les Lithopliytes et les Zoophytes de Linué.

CELLLLE, s. f. , cellula, faous, fasulus, faveolus, favicella, alveolus, alvcolum; Zclle (all.). Nom donné: $1^{\circ} \mathrm{cn}$ botanique, à l'un des vides produits, dans le tissu cellulaire végétal, par le dédloublement des membranes, vide qui est fermé de toutes parts, et offre une coupe presque toujours hexagonale; $2^{\circ}$ en zoulogie, aux petites cavilés ou loges que les abeilles et guèpes pratiquent dans leur nid, pour déposer lc miel et élever les larves; aux intervalles, de forme et d'étendue variables, que circonscrivent les ramifications anastomoscés des nerpures 
de l'aile des insectes, et que remplit la membrane de l'aile.

CELLULÉ, adj. , ccllulatus. Epithète donnéc à une coquille univalve dont la cavité est séparće en plusieurs loges par autant de eloisons.

Celcutés, adj. , Cellulosi. Nom donné par Canvier à une famille de Polypes, eomprenaut les espèces où ehaque polype adhère dans une cellule cornée ou ealcaire, et ne communique avec les autres que par une minec tunique extćricure, ou par des pores traversant les parois des cellules.

CELLULEUX, adj. , cellulosus, foveatus, favulosus. Se dit de toute partie qui présente de petites eavités ou des enfoncemens, commele thalle du Glyphis fapulosa, on le corselet dn Brentis foveatus.

CELLuLIFÈRE, adj., celluliferus (cellula, cellule, fero, porter); qui porte des cufoncemens celluleux, comme le périthécion des Cytisporées.

CELLULIFĖres, adj. ct s. m. pl., Cellulifcra. Nom donné par Lamouroux à une section de l'ordre des $\mathrm{Po-}$ lypiers flexibles, comprenant ceux dont les polypes sont contenus dans des cellules non irritables.

CELLULIFORME, adj. , ccllaliformis (cellula, cellule, forma, forme); qui a la forme d'une eellule.

GELLULOSITh, adj., cellulositas. Amas de cellules.

CELLULLTELES, adj.et s. f. pl., cellularia (cellula, celiule, tela, toile). Épithète donnée aux araignées qui filent des toiles serrées, formant une cellule. Ex. Aranca fulgens.

CELTIDĹLS, adj. et s.f. pl. , Celtidea. Nom domé par A. Richard à un groupe de la famille des Ulınacées, ayant pour type le genre Cellis.

CúMENT, s. m., eamentum; Cïment, Cümentpulver (all.). On appelle ainsi : $1 .{ }^{\circ} \mathrm{en}$ chimic, le corps en poudre dont on entoure un autre, ou qu'on dispose par eouches avec lui, afin de soumcttre le tout à l'action du feu; $2^{\circ}$ en zoologie, une substance (indumentum corticale) extérieure à l'émail, remplissant les intervalles des lames ou des lobes qui, par leur groupement, forment les dents composées et une partie des dents demi-composées.

GÉMentatrov, s. f., canentatio; Cämentiren (all.). Opération qui a pour but de changer la nature ehimique d'un eorps solide, d'un métal surtout, en le faisant rougir avec un autre corps solide, ct dans laquelle ni l'un mi l'autre de ces deux corps ne se liquéfic.

CÉNANGIENS, adj. et s. m. pl., Conangci. Nom donné par Fries à une tribu de l'ordre des Pyrénomycètes phacidiacés, qui a pour type le genre Cenangium.

CENDRE, s. f. , cinis; répox; Asche (all.); ashes (angl.). Matières qui restent après la counbastion de la plupart des matières organiques. Matic̀res terreuses pulvérulentes que les voleans projellent en si grande quantité ct à une si grande hauteur, qu'clles se répandent au loin el sur une vaste étendue de pays.

CENDrús, adj. , cincreus, gilvus; $\sigma \pi 0 \delta 0 \varepsilon v^{2}, 5 ;$ asch grau (all.). Couleur de cendre, gris. Ex. Sparvius cincreus, Glaucopis cinerca, Citharexylum cinereum, Faleo cincraceus, Labrus cinerascens, Trochuscincrarius, Andranacincraria, Pjrrhulacincreola, Turdus gilvus, Conoplea gilva. Les astronomes appellent lumiere cendrée unc clarté faible el sombre ì l'aide de laquelle on distingue, surtout prés des néoménies, la pirtie du disque lunaire non éclairée par le soleil, et que, depuis Ićonard de Vinci, on regarde eomme l'eflet de la lumic̀re terrestre réfléchic à la lune et renvoyéc arec perte à la terre, au licu 
de la considérer, avee les anciens, comne la lumière propre de la lnue.

CÉNESTúbisie, s. f., concesthesis (ratvis, comınun, äsonals, sensibilité). Nom domé par licil à l'espèce de sentiment vague que nous avons de l'ćlat de notre corps, indépendamment du eomeorirs des seus, et qui résulte des pereeplions obseures que reçoivent les membranes muquenses in téricures.

GúNOBroN, s. m., cenobium (zotข่ง, cominun, fios, vie). Mirbel appelle airsi un fruit régulier, qui est partugé jusqu'a sa base en périearpes privés de styles et par eonséquent de sommets ormaniques. Ex. Lahiées.

CĹTOBION.NARE, adj., cenobionnaris. Epithc̀te donnée par Mirbel aux fruits composés provenant d'ovaires qui ne portent point de siyles.

chroblonvres, adj., cenobionneus; quia des rapports avee le cénobion. Mirbel appelle diérésile cénobionnicine eelle dont les coques, peu différentes des érèmes, sont attachées à un axe snillant. Jx. Cynonoglossum officinalc.

CÉNOMYCEns, adj. et s.f. pl., Cenompeca. Nown donné par Fee à une tribu de la famille des vrais $\mathrm{Li}-$ chens, qui a pour type le genre $\mathrm{Ce}$ nomrec.

ChNoranisues, adj. et s.m.pl., Cenoramphi (xsyos, vide, pruoss, bec). Nom donné par Duméril el Ranzani a une famille de l'ordre des oiseaux Grimpeurs, renfermant eeux qui ont le bee ville à l'intérieur, ct irès-léger, inalorré son volume.

Centaunés, Cevrauiuies, sdj. et s. f. pl., Ccntaurice, Centaurea. Nom donné par II. Cassini à nne tribn de la famille des Synanthérces, par Candolle it une division de eelte famille, par I.essing a une sous-trilun de la tribu des Cynarées, ayant pour type le genre Centaurea, ou le genre Centaurium.
CEVTTPL̀DE, adj., centipes (centum, eent, pes, pied). Épithète donnée par Kirby aux insectes qui ont pius de einquaute pattes et moins de denx eents, comme les Scolopendres.

CENTRAL, adj., centralis ; mittelstïndig (all.) (centrum, centre): qui est au eentre. Se dit : $x^{0}$ en astronomie. On appelle conjonction contrale de deux eorps célestes, eelle qui a lieu quand ils se trouvent dans le même degré de longitude et de latitude, en sorte qu'une ligne droite, tirée du centre de la terre par l'un d'eux, passe par le centre de l'autre. Une éclipse centrale est eelle dans laquelle le eentre de la Lune coïneide avec l'axe mème du eone de l'ombre torrestre, ou, quand l'observatenr se trouve au centre de l'ombre, avec la ligne quijoint les centres de la Lune et du Soleil. $2^{\circ}$ En physique, on nomme choc central, eelui qui a liet quand les corps se meuveut sur une même ligne, qui joint leurs centres d'inerte. $3^{\circ}$ En botanique, on appelle cmbryon ccrtral, celui qui oecupe le centre du périsperme (ex. Taxus) ; périspcrme central, eelui qui forme, au centre de la graine, une masse environnée par l'eubryon (ex. Mirabilis) ; placentaire central, eelui qui oceupe le eentre du périearpe (ux. Antirrhinum).

CRNTIE, s.m. , centrum; résтроуі Mitlelpunkl (all.). Milien d'une chose. On appelle, en physique, centre do srravité, centrc d'incrtic, le point d'un eorps par lequel passe constamment la résultante des forees parallites dans les diverses positions qu'on lui firit prondre suecessivement par rapport il la direetion de ces forees ; centre d'action, le point dans lequel il faudrait supposer que toute les partieules d'un eorps se tronvassent rassemblées porr que leur action totale fût encore la mome que quand elles 
étaient disséminces dans toute l'étendue de ee eorps; ccntre des forces parallèles, le centre de gravité.

CENTRHuGE, adj., centrifugus; eentrifugal (angl.) (centrum, ceutre, fugio, fuir). On se sert de ce not: $x^{0}$ en physique. Une force contrifuge est eelle qui, Jorsqu'un mobile se trouve assujéti à se mouvoir dans une eourbe donnce, se dirige à chaque instant suivant la normale au point que l'on considère, d'où il résulte une tendance continuelle du mobile à s'cehapper par la tangente au cercle qu'il decrit. Cette force est en raison direete du rayon de eerelc décrit et inverse du earré dn temps employé à déerire la circonfúrenec entière. $2^{\circ} \mathrm{En}$ histoire naturelle. On dit la radicule cenirifugc, quand elle se dirige horizontalement vers la paroi du fruit (ex. Cueurbilacćes). Roper appelle évolution centrifugrc celle qui a lieu dans les infloresecnces définies on terminćes, où la floraison va du eentre à la eirconférence, la lleur ecntrale de elaque degré de ramificintion s'épanouissant toujours avant eelles qui terminent les rameaux nés au-dessous d'elle. Le Lichen centrifugus est ainsi nommé parce que ses expansions semblent partir toutes d'un même centre.

CENTRPLiTE, adj , centripetus ; ccntripetal (angl.) (centrum, centre, pelo, aller.). On enxploye ce not: $r^{0}$ ell physique. Une force ecntripettc est une force accélératrice qui, infléchissant à chatque instant le mourement, est constamment dirigée rers un point fixe, où clle tend à ramener le mobile : dans ce cas, les aires décrites autour du point fixe par le rayon vecteur dh molilesont proportionnelles anx temps employés à les décrire. $2^{\circ}$ En listoire naturelle. Les bolanistes disent la radicule ccntripète, quand elle se dirigc vers le centre du fruit (ex. OEnolhera). Roper nomme épanouissement ccntripète, eelui des inflorescenees indifinies, où partout les fleurs inférieures ou externess'épanouissent les premières, en sorle que la fleuraisour va de bas cn haut, commedans l'épi et la grappe, on de dehors en dedans, eomne daus la grappe corymbiforme et l'ombelle.

CENTRIS, s. m., centris; жsvтpis. Aiguillon. Kirby désigne ainsi le dernier artiele renllé de la queue des scorpions, qui se termine par un dard.

Centhisponíes, adj. et s. f. pl., Centrisporea (x.vтpì, centre, oropì, grainc). Nom donné par $\Lambda$ grardh à une elasse de plantes Phanérocoty lédones complètes hy pogynes polypétales qui, comme les Caryophyllées, Linćes, Oxalidécs et Hypérieinées, ont l's graines fixées au centre du. fruit.

CENTRODONTE, adj., ccntrodontus (rรvтpis, aiguillon, órov่, dent), qui a des dents aiguës et subulées. Ex. Boops centrodontzes.

CENTHOLÉpldíEs, adj. et s.f. pl., Centrolepidece. Nom donné par A. Richard a une tribu de la famille des Restiacées, ćrigée en Camille par Desvaux, qui a pour type le genre Centrolepis.

cLvinovils, adj. et s. m. pl.,

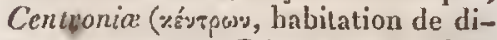
vers morcean $x$ ). Dénomination elassique des oursins selon Hill; nom que Pallas propose de donner aux animaux rayounés, les zoophytes exceptés.

CENTROSTONLs, adj. et s. m. pl., Ccntrostonrata ( ozjux, houehe). Nom donné par Blainville à une famille de l'ordre des Eehinodermaires Echinides, eomprenant ecux qui ont la bouche parfaitement eentralc.

cópací, adj., ccpacces (ecpa, ognon ); qui a l'odeur de l'ognon ou 
de l'ail (ex. Tulbagia cepacea); qui a une forme globuleuse et déprimée, à peu près semblable ì celle d'un ognon (ex. Natica crpacea).

CÉPIIELIDLES, adj. et s. f. pl., Cephalidea. Nom douné par Candolle à un groupe de la famille des Rubiacces, qui a pour type le genre Cepliatis.

CÉphalaclèes, alj. et $\mathrm{s}$. m. pl., Ceplaalacena ( rẹoginì, tête, áxaivz, épine ). Nom clonné par Latreille à tue tribu de la famille des Pereöides, reufermant des poissons dont la plupart ont des dentelures ou des épines sur quelque partie de la tête.

GÉPILLEODES, adj. et s. m. pl., Cephalceoda ( $* \varepsilon \varphi \alpha \lambda$, tc̀te, oờiw, mareher). Nom domué par $G$. Fischer à une elasse des Mollusquaes Branehiopneumones, comprenant ceux qui marchent au noyen de tentacules fixés au-dessus de la tôte.

CÉPIILAIRE, adj., cephalarius (rap̧ain, tête). Eppithéte donnée aux grains d'une roche grenue, quand ils sont gros comme la tête d'un homme.

CEPHALANTHE, s. m., cephalanthizm ( Nom donné par L.-C. Richard à la fleur composée de Linné, ealathide de Nirbel.

CÉPHALANTuE, adi, cephalanthus; qui a ses fleurs disposées ou réunies en têtcs. Ex. Carduus cephalanthus, Astragalus cephalanthus.

CÉpilatuANTHÉES, adj. et s. $\int$. pl., Cephalanthece. Nom donné par Candolle ì une sous.tribu de la famille des Rubiacées, qui a pour type le genre Cephalanthus.

CíPIALASIDOBJENES, adj. et s. m. pl., Cephalaspidobence (repa)in, tète, $\dot{\alpha} \sigma \pi i s$, plaque, Grive, mareher). Nom donné par J.-A. Tiiggen à une tribu de la fiunille des Gécosauriens, on Sauriens morcheurs, comprenant ceux qui ont la tête garnie de plaques.

CÉPHALÉs, adj. et s. m. pl.,

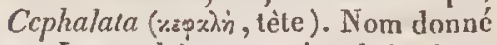
par Lamarekà une section de la classe des Mollusques, eomprenant eeux qui sont munis d'une tête.

CÉPILLELYYES, adj. et s. m.

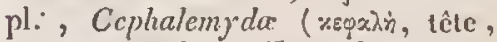
puixx, monche). Nom donué par Robineau-Desvoidy i une famille de l'ordre des Diptères myodaires, com. prenant ceux qui ont une grosse têtc.

CEPHALIDIENS, adj. et s. m. pl., Cephalidia ( «sẹxhiớr\%, petite têle). Nom donné par Latreille à une série du règne animal, eomprenant les animaux sans vertèbres qui ont une petitc tête, ou dont la partie qu'on appelle ainsi porte improprement eetle dénominatinn.

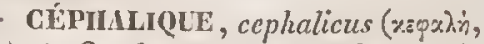
tête). On donne eette épithète à la charnière d'une coquille bivalve, quand elle cst située à l'extrémité où se trouve la tête de l'animal, et au crochee d'une eoquille bivalve, quand il veeupe l'extrémité antérieure de la vilve (ex. Pectcn).

CEPIIAOBIRANCIES, adj. ct s. m. pl., Cephalobranchia ( Bpx́:vy 18\%, branchies). Nom douné par Latreille ì un ordre de la elasse des Annelides, comprenant ceux quiont les branehies à l'extrémitć antérieure du enrps.

CÉPIIALODE, s. m. , ceplaalo. dium; Knöpfchen (all.) (rę̧⿻і丨, tête). Aeharius appelle ainsi un apothécion bombé, sans bordure, ni bourrelet, et qui prend naissance sur un podútion. Ex. Sicreocaulon.

CEPHALODIENS. Voyez CépHaLOIDES.

CÚPIIALOIDE, adj. , cephaloides; kopfartiğ (all.) (nzpriǹ, lête, sidos, resscublance). On donne cette épithète au renflement antérieur des Amphistoma, qui simule une tête. Se dit quelquefois aussi desflours, lors- 
qu'elles sont réunies en eapitules.

CÉPIILLIDES, adj. ct s. m. pl., Cephalodei, Cephaloidei. Nom douné par Acharius it un ordre de Jichens, comprenant cenx dont les conceptacles presque gibluleux sont placés à l'extrémitédes ramifieations du thalle, ou portís sur des pédieules.

CÉPILLOPIOHE, s. m., cephalophorum ( $z \varepsilon \varphi c \lambda \dot{n}$, tête, $\varphi \frac{s}{s} \omega$, porter). Nees d'Escubeck appelle ainsi, chas les champignons ventrus ct fililormes, la base on le pédiculc.

cÉpiLlophote, adj., cephalophorus; qui porte ses fileurs disposćes en prlotes ou en tètes. Ex. Crassula cephalophora.

Cípiracophones, adj. et s.m. pl., Cephalophora. Nom donné par Biainville a une classe de Malacozoaires, comprenant ccux qui ont une tête bien distincte du reste dı corps et pourvuc de tous les organes des sens spéciaux.

CËPHALORHAGME, s. m. , cephalophragma ( laic j. Kirhy appelle ainsi la cloison qui divise intérieurement la tète des insectes en d̀cux chambres, l'une antéricurc et l'antre postéricurc.

CEPIILOPOnEs, adj. et s.m. pl., Cephalopoda (xzęx)in, têtc, тоü , pied). Nom donné par Cuvier, Lamarek, Goldfuss et Schewcigger a un ordre de la classe des Mollusques, par Blainville a un ordre de eclle des Céphalophores, par Latrcille, Menke, Ficinus et Carus, à une classe du rigne animal, comprenant des animaux invertébrés qui ont la tête couronnéc de lunit à dix appendices servant à la locomotiou ct à la pré-
hension.

CÉPIAU OpTtRe, adj., cephalo-

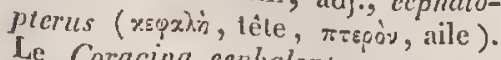
Le Coracina eephaloptera est appelé ainsi, parce qu'il a la tête garnie d'un bonquet de longues plumes grêtles, reconrbées d'avant en arric̀re, en façon de parasol.

CHPHALOSOME, adj., cephalusomatus (repai).n, tìte, oüus, corps). Épithete donnée par Blaiuville anx poissons qui ont le corps gros en avant ct la tète volumincusc.

CÉPHA: OSTONES, idj. ct s. $\mathrm{m}$. pl. , Cephalosiomata (repsini, tète, arejux, bouche). Non dounć par Jeach it une fanille de l'ordre des Arachnides trachéennes.

CiPHAIOTE, adj., ceplanloles;

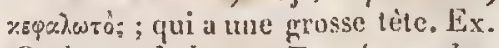
Crabro cephalotes, Formica ecphalotes, Lethrus ecphalotcs.

CEDmaLOTES, adj. ct s. m. pl., Cephalotes. Nom donné par Duméril, Goldfuss, Ficinus et Carus a une famille de poissons, en raison du volume gériéralement considúrable de la teten de ccux qu'clic reulicrme. cipincotuleus, s. f., cephalotheca (rẹxin, tête, (xim, loîtc). Kirby appelle ainsi l'extrémité antéricure des chrysalides, qui convre ct prolége la têle de l'insccte.

cimiliotionax, s. m., cepha-

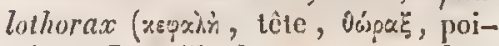
trine). Latreille donuc ce nom, daus les Arachnides et les Entomostracés, a la partie qui répond au thoracide des cruslacés décapodes, et qui résulte de la lête confondue avec le tronc.

CEPHALOTnICHENs, adj. et s. m. pl., Ceplualotricliei. Nom douné par Fries ì une tribu de l'ordre des Coniomycètes tubercularias, ayant pour type le genre Cephalotrichum.

chPOLOmEs, adj. ct s. m. pl., Cepoloüdcs. Nom donné par Blainville ì une faunille de l'ordre de poissons thorneiques, qui a pour type le genre Cepola.

CiRACr, adj., cercens; ; wachsartig (all.); qui a la consistance on l'aspect de lin cire.

GíR:ANE, s. f., ccraina. F. Bou16 
det et Boissenot appellent ainsi une matic̉rc grasse qui est produite par l'action des alealis sur la cérine.

CERAuBYciDES, adj. et s. m. pl., Ceranbycidee. Leach appelle ainsi la famille suivante.

CÉRAMbycins, adj. , Cerambycinii. Nom donné par Lamarck, Cuvier, Latreille, Goldfuss, Eichwald, Ficinus et Carus à une famille ou à une trilsu de l'ordre des Coléoptìres, qui a pour type le genre Corambrx.

céramiacées, adj. el s. f. pl., Ceramyacere. Nom donné par Reichenbach a une tribu de la fanille des Floridées, qui a pour type le genre Ceramium.

CĹRAmines, adj. et s.f.pl., Ceramiaria. Famille d'Hydrophytes, établie par Bory, et qui a pour type le genrc Ceramium.

CérantúEs, adj. ct s. f. pl. , Ceranica. Nom sous lequel Agardh dćsigne une fanille de Confervacées, et Bonnemaison une famille d'Hydrophytes loculées, ayant pour type le genre Ccramium.

CÉRANOIDE, adject., ceranoides (xépos, cornc, fíos, ressemblance); qui a des rancaux disposés en manic̀e de cornes. Ex. Cladonia ceranoides.

Glinasine, s. f. , ccrasina. John a désigné sous ce nom le mucilage végétal qui existe dans la gomme de cerisier.

CERAsPIOAE, s. m., ccrasphorium, tuber; Stuhl, Rosenstokk (all.) (répxs, corne, $\varphi s \hat{p} \omega$, porter). Nom donué par Illiger, daus les mammiferes, à une conric apophyse de l'os frontal qui porte une corne solide à l'extrémité.

CÉrATurque, s. f., ceratolheca (x.́po.s, cornc, $\theta$ rixn, boîte). Kirlyy appelle ainsi la partie dela chrysalide qui loge les anteunes de l'insecte parfail.

CERATHOPHTUALME, adj., ce.

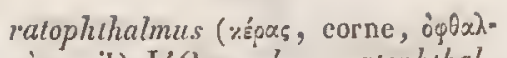

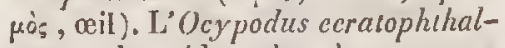
mus a les pédoncules de ses yeux prolongés, an delà des globes oculaires, cn une pointe conique et crense.

Chinatoukves, adj. ett's. m. pl.,

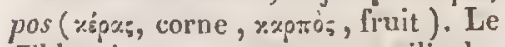
Thlaspi ceralocarpon a ses silicules trẻs-échancrées, cequi les fait paraître chargices de deux cornes.

CÉILTOCARPE, adj., ceratocarCeratolena ( $x \dot{\rho} \rho \alpha$; corne, $\omega \lambda \lambda \dot{\varepsilon} v n$, bras). Nom donné par Ranzani à un ordre de la classe des Acéphales, comprenant ceux qui on $t$ des bras voisins de la bouche et articulés.

cénatophtralvies, adj. et s. m. pl., Ceralophthalma. Noni donné par Cuvicr et Latreille à une famille de Crustacés décapodes, comprenant ccux qui ont les yeux placés le plus souvent à l'extrénité de deux pièces mobiles.

CÉRATOPHYLLE, adj. , ccrato-

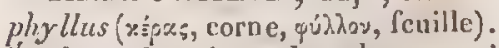
Epilhète donnée à des plantes qui ont les feuilles simples, linéaires et subulécs (ex. Certuurea ceratoplyylla), ou les feuilles pinnatifides, a pinnules linćaires (ex. Valcrianella ccratophylla, Nasturtium ceratophyllum).

CERATOPHYLLÉES, adj. et s. f. pl., Ceratophyllea. Nom donné par Gruy, Caflin, Candolle et Kunth à une famille de plantes, qui a pour typele genre Coratophyllum.

CÉRAtophy tes, s. m. pl., Ceratophyla (xípa; , cornc, pusór, plante). Non donné par Cuvier et Schweigger à une fimille de l'ordre des Polypes corticaux, par Ficinus et Carus it une famille de la elasse des Polypes, par Goldluss à une famillc de celle des Protozoaires, par Bory à un ordre de la classe des Phytozoaircs, comprenant des polypiers dont l'axe 
intéricur a l'apparence du bois ou de la corue.

CÉRatoptúrines, adj. et s.f. pl., Ceralopterides (xépuc, corne, $\pi$ repie, fougère). Nom douné par Kaulfuss à la famille des Equisétaeées, à cause de la forme générale des plantes qui la constituent.

CEncanrés, adj. et s.m. pl., Cercaria. Nom douné par Bory à une famille de l'ordre des Mieroscopiques gymnodés, qui a pour type le genre Cercaria.

CERCVES, adj. et s. f. pl., Cercex. Noun donné par Candolle à une section de la famille des Légumineuses, qui a pour type le genre Cercis.

CERcinron, s. m., ccrcidlum. Ehrenberg a donné ee nom au blanc de champignon. Voyez ce not.

CERCLF, idj. , cinclus, doliatus, alligatus, circinatus, circinalis, ligatus, succinctus, doliorius. Epithète donuée à des plantes dont les feuilles naissent roulées sur ellesmêmes, cornme eelles des fougères (ex. Lycopodium eireinale), dont la tige est forméc d'anneaux, de protubérances ou de cercles implantés les uns sur les autres (ex. Cycas circinalis), dont les semenees sont $\mathrm{cm}$ ployées ì faire des colliers et des bracelets (ex. Mimosa circinalis); i des oiseaux dont le plumage est marqué de raies transversales coloríes (ex. Thamnophilus doliatus), à des serpens dont le eorps offre des lignes transvorsales ou des cercles irréguliers colorés (ex. Coluber doliatus, Disteira doliata), ì des coquilles qui présentent des ligues edlorées, enfoncées, ou saillautes, co necutriques (ex. Fusus alligatus, Afurex cingulalus, Cyclostoma ligala, Trochus doliarius, Balanus circinatus, Monoccros cingulatum, Triton succinctum, Cerithium cincturn, Fasciolaria alligata). Voyea Ceistruré.
Ciercodíes, Cerdodianéts, Cercodiennes, adj. et s. l. pl., Cercodianea, Cercodea. Nom donué par Jussieu à une famille de plantes, par Candolle à une tribu de la fanille des Haloragées, ayant pour type le genre Cereodea.

CEnCOpIDEs, adj. et s. m. pl., Cercopida. Nom donné par Leach à une lamille de l'ordre des Hémiptères, qui a pour type le genre $\mathrm{Cer}$ copis.

CEIC OPITHÈQues, s. m. pl.,

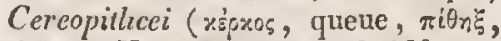
singe). Nom dounć par Goldfuss à une fanille de l'ordre des Mammifìres quadrumases, comprenant les singes qui sont pourvus d'une queue.

CEnLAL, adj. ct s. m., ccrcalis. Terme générique dout on se sert, dans le langinge vulgaire, pour désigner toutes les graminées qui servent à la nourriture de l'homme et des animaux.

CÉRÉ $\Lambda N$, adj., cereanus icera, eirc). La Galleria cercana est ainsi appelée paree que sa larve vit dans la circ des gâteaux d'abeilles.

CÉn LibruL, adj., eerebralis (eere. brum, eerveau) ; qui vit dans lc ecrveau, comne le Conurus cerebralis dans celui des moutons, auxquels il donne la maladie appelée tournis.

CÉ́RÉBIFonwE, adj. , cerebriformis, cerebrinus (eercbrum, eerveau, forma, forme). Epithete donnée à des zoophy tes (ex. Mrcandrina ccreluiformis) dont la surface est parseniée d'anfractuosités, et à des eryptogames (ex. Opegrapha cercbrina) dont la croùte est semée de rides irrégulières, offrant grossièrement l'apparence de la superficic da ecrveau.

Chnumus, s. f., ccrcbrina; Hirnfcu (all.) (ecrebrum, cerveau). Noni donnć par Kulin à la stéarine cérébrale lamellense.

clíúbORMF, adj., cereiformis 
(ccrcus, cielge, forma, forme); qui a la forme d'un cierge, comme l'Euploorbia cerciformis, ainsi appclé à cause de ses tiges minces, charnues et eylindriques.

Cúrúntum, s. m., Cererium. Nom donné par Klaproth au cćrium, qui lui-même avait été ainsi appelé paree que sa découverte coïncida avce celle de Cérès par Piazzi.

Cónìs, s. f., ccres. Planète découverte en 1801 par Piazzi, qui l'appela Fcrdinandca. Elle apparait connme une étoile de neuvième grandeur, un peu rougeâtre, et dont on a peine à distinguer le corps, an milieu du nuage épais qui l'enve!oppe. Celte planète, l'un des quatre astéroïdes compris entre Mars et Jupiter, déerit un orbe inelinć de $10^{\circ} 37^{\prime} 51^{\prime \prime}$, 2 sur Je plan de l'éeliptique. Elle emploie 1681,4 jours pour sa révolution autour du Soleil. On la désigne par le signe?

CÉRELx, adjeet., ccrosus. Nom donné, dans la nomeuclat ure chimique de Berzelins, à un oxidc (protoxide de cerium; Ceriumoxydul, all.), qui est le premier degré d'oxidation du cérium, à un chlorure (Chlorcerium, all.), et ì un sulfurc (Schwcfolcerium, a11.), qui sont des combinaisons de ee métal avec du ehlore et du soufre eorrespondaules à l'oxide éreux pour la cornposition, ì un oxisulfure (Schwefelccritmoxydul, all.), qui est une combinaison de sulfure et d'oxide áéreux, enfiu à des scls qui résultent de la eombinaison du eérium avee les corps halogienes, de l'oxide ećreux avee les oxiteides (Ceroxydulsalzen, all.) el du sulfure céreux avec les sulfides.

CúRICO-iotassiove, adj., cerico-potassicts. Nom dounć, dans la nomenclature chinnique de Berzelius, ì des sels doubles qui résultent de la combinaison d'un sel eérique avec un sel polassique. Ex. Sulfate céricc- potassique (sulfate de cérium el de polasse).

céribes, s. m. pl., Cerides. Ampère désigne sous ee nom un grcure de corps simples, qui a pour type le é́rium.

CĹRIFL̀E, adj. , ceriferus (ccra, cire, fero, porter); qui produit de la cire, comme le Myrica cerifera, ou le Ccroxylon andicola.

CÉRIGÈRE, adj., cerigertus; bckleideter (all.) (cera, cire, gcro, porter). Épithète donnée au $b e c$ des oiseaux, quand il est garni d'une cire.

Cḱrive, s.f., ccrina. Nom donné par John à l'une des deux substanees qui existent dans la cire d'abeilles, et par Clievienl à une autre substance, la graisse eristalline qui est produite par l'action de l'acide nitrique sur le liége.

Cíluon, s. m., cerio (yipoov, cellule). Mirbel désigne ainsi un périearpe contenant une graine périspernice dont l'embryou est rejeté sur le côté.

Cirioce, adj. , cericus. Nom donné, dans la nomenclature ehimique de Berzelius, à un oxide ( $\mathrm{Cc}$ riumoxid, all.), qui est le second degré d'oxidation du eérium, à un chlorurc (Cerchlor, all.), un sulfure (Cerschwefcl, all.) et un fluorure (Cerfuor, all. ), qui correspondent à ect oxide pour la composition, à des scls (Ccraxydsalzen, all.) produits par la eombinaison de l'oxide cérique arec les oxacides.

CWRIROSTRE, adject., cerirostris (ccra, eire, rostrum, bee). Se dit d'un oiseau dont, le bee est muni d'une membrane ou d'une eire ì sa base.

CÉrituracís, adj. et s. m. pl., Cerilhiacea. Nom donné par Menke à une famille de l'ordre des Gastéropodes clénobranches, qui a pour type le genre Cerithium. 
CÉRIUM, s. m., ccritum, cercrium. Métal qui a étć déeouvert, en 1804 , par Berzelius et Hisiuger.

CERMATIDES, adj. et s. m. pl., Ccrmatidcs. Nom donné par Leach à une famille de l'ordre des Myriapodes, qui a pour type le genre $\mathrm{Ccr}$ matia.

CEROIDE, ceroideus; «wachsïhnlich (all.). Se dit, en minéralogie, d'un corps qui ressemble à de lin cire, dont il a la légéreté et la demitransparence.

CÉROPHones, adj. et s. m. pl, Cerophora (x'́pas, eorne, písos, porter ). Nom donné par Blainville à une seetion de la famille des Ruminans, eomprenant ceux qui ont les cornes rondes, à cheville osseuse compaete.

CÉROSO-CÉnoUE, ccroso-ccricus. Foun donsté, dans la nomenclature chimique de Berzelius, à un chlorure et in un oxidc (Ceriumoxydoxvdlul, all.) qui résultent de la combinaison du ehlornre ou de l'oxide céreux avee le chlorure ou l'oxicle é́rique.

CEROSO-pOTASSIQUE, adj., ccroso-potassicus. Nom donné, daus la nomenclature chimique de Berzelius, à des sels donbles qui sont produits par la combinaison d'un sel cé-. reax avec un sel potassique. Ex. Sulfatc cćroso-potassique (sulfate de cćrium el de polasse).

CÉroxyrune, s. f., ccroxylina. Bonastre a désigné sous ce nom une sulstance cristalline qu'il est parvenu à cxtraire de la cire obtenue en gratlant l'écorec du Ceroxylon andi-
cola.

CERQUE, s. m., ccrcas; ;épros. Kirby appellc ainsi deux organes courts, et en forme de queue, qui garnissent l'anus des Blattes, ct aux appendices analogues qui existent eliez les Grillons.

CEnTHADEs, adj. et s. m. pl., Certhiada. Nom donné par Vigors a une tribu de fa famille des Oiscaux grimpeurs, qui a pour type le genre Certhia.

CErune, adj., cocrulcus; qui a unc teinte hleve ou bleuâtre.

CÉnulises, adj. et s. f. pl. , Cocrulcre. Nom douné par RobineanDesvoidy à une section de la tribu des Museides, comprenant des espèces généralement azurées.

GÉRULE-SULFATE, s. m., corulco-sulphas. Nom donné par Crum aux scls (cïrulinschwefelsaure Salse, all.) que Berzelius a appelís depuis sulfoindigotates. Voycz ec mot.

CinuLEo-SuLfurrove, adject, coerulco-sulphuricus. Nom donué parc Crum ì un acide (Cörulinschnvefelsïure, all.), que Berzclius appelle sulfoind igrotiguc.

cónuidexe, s. f. , carulina.Crum appolle diursi la malière colorante Jileue qui est contenue dans les sulfoindigotates, le bleu d'indigo soluble, ou acide sulfoindigotique de Berzelius.

CÉRULIPENNE, adj., carulcipennis (cortulcus, bleu, penna, aile); qui a les ailes bleues ou bleuâtres. Ex. Ilydromy a corulcipcnnis.

CEnvEaU, s. m., cerebrum; oxhos; Gichirn (all.); brain (angl.); cercbro (it.). On donne ee nom, tantôt à toute la masse pulpense qui remplit le crâne des animaux vertébrés, lantôt seulcment à la partie antérieure de cette masse, et alors on réserve a ia postérieure celui de

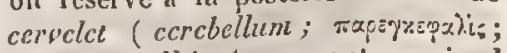
Hirnlein, all.). Aucun autre animal n'a de véritable cerveau, et c'est par alus qu'on applique cette dénomination à des ginglions nerveux situés, clicz cux, dans la tête oư dans son voisinage. C'est par le cervau et dans le cerveau que nous pensons.

CERVICAL, adj, ccrvicalis (cerwix, nuque). Epithète par laquille les ornillologistes désignent les plumes 


\section{6}

du sommet de la têtc, ct divers oiseaux qui ont la nuque autrement colorée que le reste du corps (cx. Psillacus ccrvicalis).

CEIVICOHRANCIIES, adj. et s. m. pl., Cervicobranchiata (cervix, nuque, $\beta p \dot{\alpha} \gamma \chi^{e \alpha}$, liranchics). Nom donné par Blainville à un ordre de la classe des Paracéphalophores, comprenant cenx qui ont les branchies contenues dans une cavité située au dessus du con.

CERVICorne, adj., cervicornis (ccrvus, cerf, cornu, corne). Un insecte (Ontophagus cervicornis) est ainsi appelé parce qu'il a la tète arInéc de deux eornes droites et subrameuses; un autre ( T'abanuls cervicornis), parce qu'un long prolongement recourbé part de la buse de ses antennes.

CERvicuné, adj., cerviculatus (cervix, ruque). Kirby donne cette épithète au prothorax, quand il cst alongé, atténuć et distingué de l'avant-poitrine par une sulure, de manière à forner unc nuque longue et bien manifeste.

CERvins, adj. et s. m. pl., Ceryina (cerulus, ccrl'). Nom donné par Groldfuss à une famille de l'ordre des Mammifères ruminans, qui a pour type le genre Cerwus.

CESTOMES, adj. et s. m. pl. ,

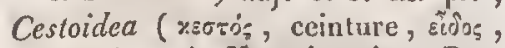
ressemblanee). Nom donné par Pudolphi et Scliweigger à un ordre de la classe des Entozoaires ou Enthelminthes, par Cuvier, Schweigger, Ficinus et Carus à une fanille de celle des Vers intestinaux, par Latreille à un ordrc de celle des Elminthaproctes, par Eichwald à une fitmille de celle des Grimmazoaircs, comprenant ceux de ces animaux qui ont le eorps alongé et déprimé, cornme un ruban.

CESTRIFORME, adj., cestriformis; meisselförmig (all.) (cestrum,

\section{CÉVA}

dard, forma, forme). Epithète donnée par Illiger aux dents incisives, quand elles sont longucs et étroites, el que leur tranchint lorme un angle presque droit de chaque côté.

CÉTACÉs, adj. et s. m. pl., $\mathrm{Ce}-$ tacea, Ceta ( $x_{\bar{s}}=0 s$, balcine). Nom donné par Linné, Cuvier, Duméril, Desniarest, Goldfuss, Tiedemann, Gray, Eichurald, Ficinus et Carus à un ordre, par Blumenbach, Blainville, Illiger ct Latreille à une famille de la classe des Édentés, ayant pour type le genre Balcinc.

CÉTINE, s. f., cetina; Wallrathfelt (all.) ( ar̃̄os, baleine). Chevreul donne ce vion à une substance grasse particulière, qui fait la base du blane de baleine.

CÉTIQQUE, adj., ceticus. Sous le nom d'acidle cérique, Chevreul a désigné pendant quel que temps le produit de la saponification de la cétine. que depuis il a reconnu n'être qu'un nélange d'acide margarique, de cétinc non saponifiée et de cétine altéréc.

ch́tograpme, s. f. , cetogra-

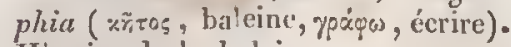
Histoirc de la baleine.

GÉTOLOGE, s. f́., celologia ( $x \tilde{x}_{-}$ -05, baleine, dégses, discours). Traité sur la baleincet les autres cćtacés.

CÉTOSAURIEss, adj. el s.n.pl.,

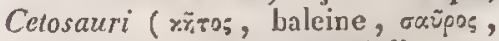
lézard). Nom sous lequel Muller propose d'établir, dans la classe des reptiles, un ordre ou une famille, pour y comprendre les genres Ichehyosauras et Plesiosaurus.

CEVAD.1TE, s. m., cevadas. Genre de sels (sabadillsaure Salze, all.), qui sont produits par la combinaison de l'acide cévalique arec les bases salifiables.

CEVADIQUE, adject., ceradicus. Nom donné par Pelletier ct Caventou à un acicle (Sabadillsäure, all.) particulier, qu'ils ont découvert daus lia 
cévadillc, graine du $V$ eratrum $S a-$ badilla.

CHenotruoue, adj. , chcenotri-

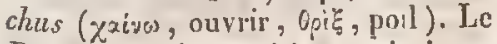
Psychotria chenotricha est ainsi appelé parce que la gorge de sa corolle est très-voluc.

Cuntantulerses, adjo et s. f. pl., Chatantherece. Nom donné par D. Don à unc tribu de la famille des Labiatiflores, qui a pour type le genie Chatanthera.

CILATAmivéles, adj.ct s.m. pl., Chatarince. Noin donné par Link à une tribu de la famille des Graminées, qui a pour typele genre Chatarus.

CIIETOCÉPHALE, adj., chatocephalus ( $x_{x i-n}$, chevelure, хередin, tête). Le Spermacoce chactocephala a rcç cc nom parce que lcs capitules de ses fleurs sont garnis de feuilles et de soies longues.

CHETODONOIDES, adj. et s. m. pl. , Chatodonoidei. Nom donné par Eichwald à une famille de la tribu des poissons osseux acanlhoptérygiens, qui a pour type le genre Chatodon.

Cirmenodontes, adj. et s.m. pl.,

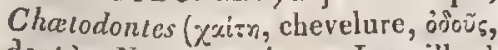
dent). Nom donné par Latieille à une tribu de la fanille des poissons squamipennes, comprenant ceux qui ont les dents très-lincs, eu velours ou en rape, et ayaut pour type le genre Chatodon.

Cllaglisí, adj. , granarius; qui a l'apparence du claagrin, qui est grenu, commo la coquille du Murex granarius. On appellc ehenilles chagrinées celles dont la pcau est hérissée d'une infinité de petits grains durs, qui font sur le doint passant dessus la mêtne impression que causcraient les aspérités du chagrin. Le Campylopus exasperatus cst ainsi appelé parce que ses urues sont chagrinées à la base.
CHALLETÉacḱes, adj. et s. f. pl., Chailletcaccar. Nom donné par Candolle à une famille de plantes, qui a pour type le genre Chailletea.

CHDHLLETHiEs, adj. et s. f. pl. , Chailletiea, Chailletica. R. Brown appelle ainsi la fanille précédentc, qui pour Bartling est une tribu de celli's des Ulmacées.

CHAINE, s. f., catena. On appelle labitucllement chaines de monlagnes (Gebirgstelle, all.; tract of hills, angl.) celles qui forment un grand massif de terrain ćlevé au-dessus du sol environnant, diversement découpé par des vallons ct des points d'où s'ćlévent encore des cimes particulicres , quoique, strictement parlant, celle dénomination ne convienne qu'à celles de ces masses qui sont étendues en longuevr.

cIIUIVí, adj. , catcnulatus. Terme per usité, dont on se sert quelqucfois pour désigncr ce qui est formé de parties attachécs bout à bout. Voyez Caténulé.

CIIAINON, s. m. Les géologues appellent ainsi des ćlévations particulières de terrain, qui sont placées les unes à côtés des autres.

CIlAIR, s. f., earo; бג் p ; Fleisch (a!l.) ; flesh (angl.); carne (it.). Nom populaire de toutes les parties musculaires des animax, en tant qu'elles servent d'alinent. Candolle appelle ainsi lc mésocarpe, quand il est développé, imbibć de sue et cependant d'une consistance asscz ferme. Cette acception du mot chair cst tirée du langage populaire : c'est en l'adoptant qu'on dit la chair d'un fruit, d'un melon par exemple. Les botanistes se servent ordinairement du not pulpe pour rendre la mêtue idée.

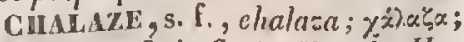
Keimfleck, Spitafleek, Hagcl, $\mathrm{Ha}_{-}$ gelfleck (all.); calaza (it.). Les botanistes, d'apres Gaertser, donnent ce non à l'ombilic interne de la se- 
mence des plantes, au point, marqué sur'la tnnique internc, qui indique le lieu on le cordon ombilical la pergiat. On l'applique aussi, en zoologie, aux deux cordons ligamenteux qui reliennent le jaune cu situation dans l'œul.

CHalcioes, s. m. pl., Chalcides. Non domné par Goldfuss à nne famille de la classe des reptiles, et par Merrem à une famille de celle des Amphibiens, ayant pour type le genre Chalcis.

chalcinidis, adj., Chalcidide. Nom donué par J.-E. Gray ì une famille de reptiles sauriens, qui a pour lype le genre Chalcis.

CHaLCIDIES, adj. et s. m. pl., Chalcidia. Oppel appelle ainsi une famille de reptiles sauricns, ayant lc genre Chalcis pour type.

CIILCIDIENs, adj. ct s.m.pl., Chalcidii. Norn donné par Bory à une famille de reptiles sauriens, ajant pour type le genre Chalcis.

CHALCIDiTEs, adj. et s. m. pl., Chalcidites, Chalciditer. Nom donné par Cuvier, Salreille et Eichwald at une tribu de la fanille des inscetes hyménoptères pupipares, qui a pour type le genre Chalcis.

CIALCIDOHES, adj, cts. m. pl., Chalcidoidea. Nom clonné par P.-F. Fitzinger ì une famille de reptiies, qui a pour type le genre Chalcis.

CHALCOGASTre, adj, , chalco-

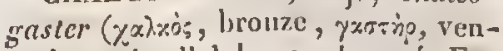
tre); qui a l'ablomen bronzé. Ex. Asilus chiclcogaster.

CHAL Coptine, adj. , chalco-

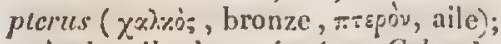
qui a les ailes bronzécs (cx. Columba chalcoptcra), ou violettes (cx. Cursorius chalcopterus).

CIIALCOPYGi, adj, , chalcopygus ( $\% x \lambda x_{5}$, bronze, $\pi$ un a l'extrémité de l'abdomen bronzíc. Ex. Eristalis chalcopysus.

CHaleur, s. l., cellor; ośpun;
Wiarme (all.); heat (angl.); calore (it.). Ce mot, dans lequel on enferme ordinaircment l'idée vague et confuse d'unc cause, n'exprime en rẻalitć que la sensation éprouvée par nous lorsque nos organes enlèvent du calorique aux corps dont la tempéralure est supéricure à la nôtre, et, par extension, celle qu'il pourrait produirc sur des organes plus résistaus, ou mème sur des corps non organisés. Dans le langage vulgaire, chalcur (frega, foja, ut.) cst souvent employé comme synonyme de Rut, en parlant des animaux domestiques surlout, qu'on dit étre cn chaleur (hitigy seyn, liiufig seyn, all.), à l'époque où le besoin de l'accouplcment se fait sentir chez eux.

CIIALINASPISTES, adj. et s. m. pl., Chalinaspistes ( $\chi_{z}$ גevoi, dents, érxis, plaque). Nom domé par J.A. Ritgen à un groupe de l'ordre des reptiles ophidiens, renfermaut ccux qui ont des plaques sur le corps, et des dents venimeuses à la mâchoire supérieure.

CIALINOPHDFs, adj. et s. m. pl., Chalinophides ( $\chi x)$ rysi, dents, "ọıs, serpent). Nom donné par J.-A. Ritgen aux serpens qui ont des crochets à venin.

GHALINOPIOLIDOPHIDE, adj. et s. II. pl., Chalinopholidophides

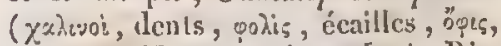
serpent). Nom domé par J.-A, Ritgen à un groupe de l'ordre des reptiles ophidicus, comprenant ceux qui ont le corps couvert d'écailles et les - mâuchoires almées de erochets à venin .

Chllumeau, s. m. , calamus ;

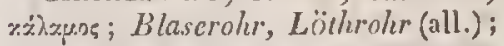
canncllo (it.). Instrument au moyen duquel on conduit un courant d'air sur la flanıme d'une lampe, pour la diriger vers une substance qu'on vent soumettre ì l'action de la chaleur. Candolle donnc ec uom aux tiges simples, berbacécs, qui sont sans nouds 
et plus ou moins fistuleuses, eomme cclles des jones.

CHALVB⿱⺊́, adj., ehalybans, chalybeatus (chalybs, acier); qui a la tcinte grise du fur. Ex. Trochilus chalybeus, Auricularia ehalybea.

CIIAL YBúLIF OHME, adj. , ehalybeifornis (ehalyls, fil de fer, forma, forme). Le Liehen ehalybeiformis a ćté ainsi appelé parce qu'il est formé de filamens bruns et cylindriques, qui ressemblent à du fil d'archal.

Chamacées, adj. et s. m. pl., Chamacea. Nom donné par Menke à une famillc de l'ordre des Elatobranches cardiacés, comprenant ccux qui ont pour type le genre Clamla.

Chanisuaucilís, adj. et s. f. pl., Chamalauciea. Nom donné par Candolle à une tribu de la famille des Myrtacées, qui a pour type le genre Chamalaucium.

cilaniagrostrmútes, adj. et s. f. pl., Chan:agrostidece. Nom donné par Link à une tribu de la famille des Gramincées, qui a pour type lc genre Chamarrostis.

CHAMbrÉ, adj , eameralu.s, coneameralus. Epitlièe donnćc ì une coquille univalve dont la cavité est parlagée cn plasieurs loges par des cloisuns (cx. Ammoniles), et à des coquilles bivalves qui offrent un feuillet détaché de leur fond et formant une petite loge au milien (ex. Cardila concamcrala), ou un repli septiforme à la basc deleurs valves (cx. Mrtilus bilocrularis).

CHAneprres, adj., campestris; qui vit dans les champs. Ex. Gryllus campestris, Parinarium Eampestre. CILAmílitis, adj. ct s. ni. pl., Campestres. Nom donné par Illiger à une fumille de l'ordre des oiscaux
coureurs.

Champignoxs, s. m.pl., Fungi. Nom d'un ordre dans les systèmes de Linné, Willdenow et L.-G. Richard, et d'une famille diuns tous
Ics auleurs qui ont adopté la méthode naturelle cn botanique.

Cilanerein, s. m. Partic comprise cutre le bas du front et le museau, dans les Mammifères. On donne ce uom, chez lcs oiscaux, à l'ensemble des plumes effilées, en génćral assez rudes, qui sont placées à la lase du bec, se dirigent d'arrière en avant, et courrent les narincs cn totalitć on seulement en partie (cx. Corvess).

ChaNgeans, adj. et s. m. pl., Mutabilia. Nom donné par Merrem a une tribu de l'ordre des reptiles batracieus, dans laquellc il range ceux de ces animaux qui subissent des métamorphoses.

CHANGeAvT, adj., mulabilis, variabilis, versieolor, varians, mutans; veränderlich (all.); ehangeable (angl.); cangiente (it.). On appelle étoiles changeuntes celles dont l'ćclat auginente et dininue pćriodirfuement; comme cntr'autres Algol, qui dans l'espace de 2 j. 20 h. 49' passe de la scconde à la quatrième grandeur, sans qu'on puisse expliquer ce phénomène d'une manière satisfaisante, et coulcurs changreantes, celles dont la nuance varie suivant l'angle decrit par le rayon lumineux qui les produit (cx. Spalh changeant Voyea Chatoyant). On donnc cette épithetc à diverses plantes, soit à cause des viriélés de coulcur que la culture a produitcs en elles (ex. Georgina variabilis), soit parce que leurs flcur's ne sont pas loujours de la même couleur, eomme celles du Gladiolus mutabilis, qui, brunes le matin, changent de nuance dans la journée, deviennent d'un bleu chir vers le soir, reprennent dans la nuit la couleur qu'elles a vaient le matin, et reproduisent journellcment Ic mènc phénoméne jusqu'à ce qu'clles soient ferniées, c'est-ìdire pendant huit ou dix jours; soit 


\section{0}

CHAN

parce que leurs fleurs, d'abord d'une couleur, en aequièrent une autre au bout de quelque temps, conme celles du Tourncforria mutabilis, qui du blane vert passent insensiblemert à un noir très-foncé, celles du Zapania mulabilis qui, d'abord écarlates, deviennent rosées, colles du Kelmia mutabilis, qui sont d'abord blanches, puis roses et ensuilc pourpres, eelles du Gaura mutabilis, qui, du jaune, passent au rouge, celles du Chciranthus mutabilis, qui de jaunes deviennent purpurines; soit enfin parce qu'un mênue pied porte des flcurs colorćes diversement, conmo le Cistus mulabilis, qui en a de jaunes ct de rouges. On l'applique également ì des animaux dont le pelage varie suivant les saisons, comme le Lepas mutabilis, qui cst brun en été et blanc en hiver, ou dont le plumage est glacé, comme celui du Corvus varians, qui est noir, ì reflets verdìtres, ou dont le plumagge est très-sujet à varier pnur la nuance, comme celui du Coccolliraustcs mulans.

GHANT, s. m. , cantus; wìn; Gesang (all.); singing (angl.); canto (it.). Sorte de modification de la voix qui pernict de produire des sons variés et appréciables; suite d'inflexions de voix, agréables à l'orcille, qui procèden! par des iutervalles admis dans la musique et dans les règles de la modulation.

CHANTERELLE, s. f. Nom donné à un champignon (Agaricus cantharellus), paree qu'on a cru trouver quelque ressemblance entre sa forme et celle de la tète d'un coq qui chante.

CHaNTLull, adj. canorus, canrans, musicus; à des oisenux qui ont la voix plus ou moins harmonieuse. Ex. Nisus canorus, Coccothraustes canora, Loxia canlans, Muscicapa canlalrix, Sparvius musicus, Ptpra musica.

CHanteurs, adj. et s. m. pl.,

\section{CHAP}

Canori, Oscincs. Nom donné par Scopoli, Illiger, Mcyer et Wolf, Goldfuss, Vieillot et C. Bonaparte à un ordre ou à une famille, comprenant des oiseaux dont la plupart ont un chant plus ou moins harmonicux.

Chanteuses, adj. et s. f. pl., Stridulantes. Nom donné par Latreille à une tribu de la famille des Cicadaires, dans laquelle il range les espèes dont les mâles ont un organe musical de chaque côté de la base du ventre.

Cnasvreux, adj., cannabinus. Épithète donnée á une plante (Daphne cannabina) avec l'écorce de laquelle les Cochinclinois font du papier, à une autre (Althea cannabina), dont la tige fournit de la filasse dans certaines contrées, et à une autre encore (Datisca cannabina) qui a des rapports extérieurs avec le chanvre.

CIISODINíes, adj. et s. f. pl., Chaodinea. Nom douné par Reicheinbach à une tribu de la famille des Nostochinées, et par Fries à unc fanille de la classe des Algues.

CHAOtique, adject., chaoticus ( $\chi^{\dot{x} s_{5}}$, choos ). Quelques écrivains modernes se sont servis du mot élémens chaotiques, pour exprimer les rudimens hypothétiques de l'état prćsent de la matièrc.

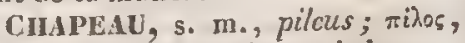
mißnnux. Partie d'un filon qui s'approche de la surface du sol. - Les botanistes domnent ce nom, dans les champiguons gymnocarpiens (Hut, all. ; cappello, pileo, it. ), au péridion ou réceptacle des corps reproducteurs, quand il ternine le stipe sous la forme d'un disque, d'une calotte ou d'un renflement quelconque. - Illiger l'applique à la partie supćricure du erânc des oiseaux, depuis la racinc da bec jusqu'à la nuque.

CHAPERon, s. m. , clypeus. Ce nom, d'une signification très-variée, 
est donné : dans les poissous, à un corps plane, marginé, garni de lames parallèles et pectınées, qui se trouve sur la tête des Echeneis; dans les crustacés déeapodes, ì l'intervalle qui sépare les yeux, quand le bord extcrne de lit tête ne se prolonge point eu rostre; dans les insectes, d'après Latreille, ì la partie la plus avancíe du front des coléoptères, celle qui touche immédiatement ì la bouche ou à la lèvre supérieure; d'après Fabricius, au labre ou à la lèvre supérieure des orthoptères, névroptc̀res et hyménoptères; suivant Straus, à l'une des six piècés du crâne, qui est placée au devant de l'épierane, avec lequel elle se soude et dont elle fait la continuation, et qui a été ainsi appelée parce que, dans beaucoup d'insectes, clle eşt trìs-considérable, et s'avance surles partics de la bouclıe, qu'elle recouvrc en enticr.

CHAPERONNÉ, adj., pilcatus. Le Pipra pileata est ainsi appelé parce que les plumes noires qui garnissent sa tête se relévent en une sorte de chaperon.

CIIARACí́ES, adj. et s. f. pl., Characece. Nom donné par Sprengel à unc section de la famille des Hydrophyles, par Agardl à une lamille de l'ordre des Confervoïdées, ayant pour type le genre Chara, et que L.-C. Richard a érigée en une famille, admise par Kunth et Bartling.

CuARscress, adj. et s. m. pl., Characini. Nom douné par Latreille ì une tribu de la famille des Salmonides, qui a pour type le genre Cluaracinus.

CHARADRTAD is, adj. et s. m. pl., Charadriadece. Nom donné par Vigors a mue famille de l'ordre des oisenux Echassicrs, ayant le genre Charadrius pour type.

Clialiadués, adj. , Charadriot.
Nom donné par Lesson à une famille du sous-ordre des'vrais Echassiers, qui a pour type le genre Charadrius.

CHARANSONITES, s. m. pl., Curculionites. Lamarck et Latrcille désignent sous ce nonı une famille ou une tribu de l'ordre des Coléoptères, qui a pour type le genre Charanson.

CHARBONNÉ, adj., carbonarius ; qui est de couleur noire, ou marqué de noir. Ex. Cerobatus carbonarius, Andrena carbonaria.

ChaRdonis, s. m., chardoninum. Morin a désigné sous ce nom nn principe amer partieulier, qu'il a trouvé dans le charilon bénit.

Criantes, adj. et s. f. pl., Charece. Non donné par Bartling à une famille de plantes, qui a pour type le genre Chara.

Chamintmíes, adj. et s. f. pl., Charianthere. Nom donné par Candolle à une seetion de la famille des Mélastomacées, ayant pour type le genre Charianthus.

CuAnvière, s. f., cardo; Angel, Schloss (all.); hinge(angl.); cernicra (it.). Les zoologistes appellent ainsi la partie du bord supérieur d'une coquille bivalve qui est modifiée diversement pour assurer plus de solidité à l'articulation des valves, en lcur permettant de se pénétrer réciproquement.

CHaltNu, adj., carnosus; fleischig (all.); fleslyy (angl.) ; carnoso (it.). Se dit en botanique d'un fruit dont le salcocarpe est mou ou d'une consistance pulpeuse, ou de tout antre orrane qui est formé en grande partie d'un ti-su cellulaire succulent, comme l'arille du Mryristica, l'axe du Bromclia Ananas, les cotylćdons du Faba, la noix du Juglan.s, les fouilles du Pieroncurum carnosum et du Cineraria carnosa, le placentaire du Saxifraga granulata, le spadix du 


\section{2}

Calla palustris, le péricarpe de la pomme, le stigmate du Lilium eandidum, la racine de la bryone, le périsperme du ricin, la plante tout entière dı Tuber cibarium.

CHASMATOPIYTE, s. m., chas-

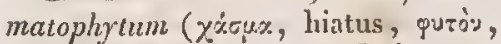
plante). Nom donné par Necker aux plantes didynames dont la fleur irrégulic̀re représente une sorte de grueule.

CIIASSEUSES, adj. et s. f. pl., $V c$ natoria. Lister donnait eette épithète aux araignées qui ne filent pas de toiles pour attraper leur proie, et qui la preunent à la eourse.

CiIA taigne, s. f. Espèee de corne placée au côté interne de la partie inférieure de l'avaut-bras dı cheval. Il y en a souvent uue aussi à la partie interne et supérieure de ehaque eanon, en arric̀re, au dessus du jarret.

CHATAIN, adj., castaneus; kastanienbraun (all.); qui a la couleur d'une châtaigne ou d'un inarron, le brun plus ou moins foneé, le roux plus ou moins vif. Ex. Molossus caslanetus, Eimgs cástanea, Anisoloma castanetum.

CHATON, s. m., amentum, calulus, iulus; Kätzchen (all.); amento, gattino, gatto (it.). Candolle appelle ainsi un mode d'infloreseence indélinie, dans laquelle les fleurs naissent à l'aisselle de feuilles sessiles ou légìrement pédicellées, et où, après la floraisou, s'il s'agit de fleurs mâles, après la fruelifieation, s'il est question de fenielles, l'axe se dessèche et se désartieule à sa base. Le chaton est ainsi appelé à cause de sa ressernblanee grossière avee la queue d'un ehat.

Cinatoyant, adj., versicolor; schillernd, selimmernd (all.). Se dit, en minéralogie, d'unc pierrc demitransparente qui a des reflets variés et lirillans, suivant l'aspeetsous lequel on la voit (cx, Quarzchatoyant). Le

\section{CHÉI}

Coluber versicolor est ainsi appelé á eause de ses éeailles ehatoyantes; la Musca varicolor, paree que son eorselet est d'un gris perlé.

Cinatolemint, s. m. Accident de lumière qui consiste en des reflets blanchâtres, satinćs, soyenx ou naerés, qui semblent flotter et se jouer dans l'intérieur d'un cristal, à mesurc qu'ou ehange de position. Ce mot fait allusion aux yeux du ehat, qui brilleut dans l'obseurité.

CIIAUME, s. m., culmus; Halm (all.); haum (angl.); culmo, canna, stoppia (it.). Les botanistes donnent ee nom oे une tige eylindrique, garnic, d'espace en cspaec, de noeuds compactes, de chacun desquels naît une feuillc dont le pétiole forme une gaine (ex. Graminées).

CIIUUVE, adj., ealsus, mulicus; lahl (all.); bald (angl.); calvo (it.). Se dit, en botanique, d'une graine qui est dépourvue de chevelure (cx. Vinca), d'une cypsile qui ue purte it son somnet ni aigrette, ni arète, ni paillettcs (ex. Lampsana communis); en zoologic, d'un oiseau qui a la tête dégarnie de plumes (ex. Tanlalus caluzs, Columba calva), d'un poisson qui est eonvert de pièees osseuses dures, comme éeorchées (ex. Amia calva). Le Lichen calvus est ainsi appelé paree qu'il forme une croûte lisse, et que ses tubercules sont luisans.

CחÉILANTIE, adj., cheilanthus

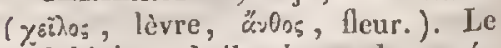
Delplinium cheilanthum a deux pétales infléehis sur eux-mèmes, et qui sernblent se border.

CIILininTuEres, adj. ets. f. pl., Cheiranthea. Noin donné par Salisbury à une tribu de la fanille des Cnncifères, ayant pour type le genre Cheiranthus.

CHÉROHTÈR, adj. et s. m.

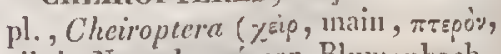
aile). Non domé par Blumenbach, 
Cuvier, Illiger, Duméril, Tiedemann, Goldfuss, Blainville, Latreille, Ranzani, Fieinus el Carus à une famille de la classe des Mammil'ères, comprenant ecux qui ont les doigts des mains fort alongés et réunis par unc membrane, de unanière à eonstituer des ailes propres au vol.

cmúlicène, subst. f., cheliccra (Xnhin, pince, xiépes, corve). Latreilic appelle ainsi, dans les arachnides, deux pieces de la lête, représentant les antennes intermédiaires des Crustacés décapodes, souvent eonfigurées en pinees, quelquefois aussi larninées et faisant partic d'un sueoir, qui coopèrent toujours dircetement à la mandueation.

CULICORNE, adj., chelicornis ( $\chi_{n \lambda \dot{n}}$, pince, cornu, corne). Un insecte (Galcodes chelicornis) est áinsi appclé, parce que les pinces qui terminent ses mandibules sont garnies de soies.

CuĹLIDINES, adj. el s. m. pl., Chelidina. Nom donué par Th. Bell à une section de la famille des Emydides, qui a pour type le genre Chelys.

GHímoniexs, adj. et s. m. pl., Chelidoncs ( $\chi^{\varepsilon \lambda e d^{2} \omega}$, hirondelle). Nom donné par Ranzani i une famille de l'ordre des Passcreaux, qui a pour type le genre Firondellc.

Gub́libovive, s. f., chelidonina. Maier appelle ainsi le principe narcotique du Chelidonium majus, que d'autres chimistes prísument n'ètre que le véhieule de la substance volatile à laquelle cette plante doit ses propriétés narcotiques.

cnĺbnoss, adj. et s. m. pl.,

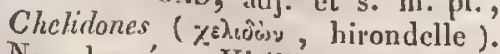
Nom donué parr Vicillot, Tenaminek, Meyer et Wolf, C. Bonaparte et Lesson à une famille ou tribu de l'ordre des Passereanx, ayant pour type le genre Hirondelle.

CinbLIFène, adject., chelifcrus; schcerentragend (all.) ( $\chi$ niǹ, pince, fero, porter). Kirhy applique cette épithète à la queue des insectes, quand elle est terminće par nne pince ou tenaille, conme dans les mâles du genre Panorpa.

CllÉLFOHM, adj., eheliformis ( $\chi_{\text {nhin, }}$, pince, forma, formc). Les palpes des insectes reçoivent cette épithete, lorsque leur dernier article est divisé en deux pièces, dont l'une se neut sur l'autre, de manière à produire une pinee. Ex. Scorpion.

Cuéconradés, adj. et s. m. pl., Chcloniada. Nom donné par T. Bell et par J.-E. Gray à une famille de l'ordre des Reptiles rlićloniens, qui a pour type le genre Chelonia.

Culílovrdes, adj. et s. m. pl., Chelonida. Nom donné par Gray à une famille de Reptiles ehéloniens, qui a pour type le genre Chelonia.

Cub́Loviexs, adj. et s. m. pl., Chelonii, Testudinata. Nom donné par Brongniart, Cuvier, Goldfuss, Blainville, Duméril, Latrcille, Ritgen, Eichwald, lieinus el Carus à un ordie de la elasse des Reptiles, comprenant toute's les tortues.

ciĹLONOGRAPHE, s.m., chelo-

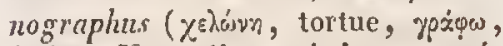
écrire). Naturaliste qui s'oceupe spécialement des tortues.

CHÉroNognapure, s. f., chelonographia. Deseription ou traité des torlues.

CuílOPODES, adi. et s. m. pl.,

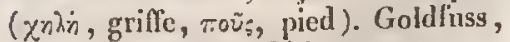
Ficinus el Carus désignent sous ee nom un ordre de Mammiferes, comprenant ceux qui ont les doigts armés d'ongles trochus, et répendaut aux carnassiers de Cuvier.

Crírrvornes, adj, et s.m. pl., Chelydoidca. Nom donné par I.-F. Filzinger à une famille de Reptiles, qui a pour type le genre Claclys.

CHEMISE. $V$ oye Induvic.

CHLNANTuOPHones, adj.. et s. 


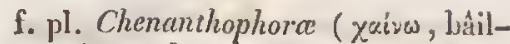

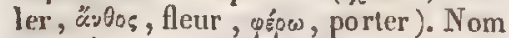
donné par Lagasca à un groupe de Synanthérées, le même que celui qui a été appelé labjatiflores par Candolle, comprenant celles de ces plantes dont la corolle est divisée en deux lèvres.

GrunNes, s. m. pl., Chenes ( $\chi$ '่v, oic). Nom donné par J.-A. Ritgen à une famille d'Oiseaux, qui a pour type le genre Oie.

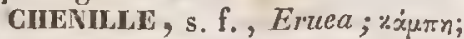
Raupe (all.); caterpillar (angl.); bruco, ruca(it.). Larve des insectes Lépidoptères.

GHÉNOCOLYMBEs, s. m. pl., Chenocolymbi (yinv, oie, noduufie, plongeon). Noun donnć par J.-A. Ritgen à une famille d'oiscaux conprenant le genre Alca.

CuÉNOPODÉes, adj. et s.f. pl., Chenopodece. Noin douné par Jussieu à une familte de plantes, qui a pour type le genre Chenopodium.

Cuévoponú́es, adj. et s. f. pl., Chenopodieo. Nom donué par C.-A. Meyer à une tribu des Chénopodées, celle qui renlerme le geure Chenopodium.

CrúnopIILLLíes, adj. ets. f.pl., Charophyllece. Nom donné, par A. Richard à une tribu de la famille des Ombellifères, qui a pour type le genre Charophyllum.

GHERSOCIÚ́LONES, s. m. pl., Chersochelones ( $\chi$ Epocaios, terrestre,

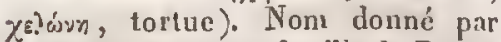
J.-A. Ritgen à une famille de Reptiles, comprenant les tortues qui vivent sur terre.

CIIERSODOLOEES, adj. et s. m. pl., Chersodolopes ( $\chi$ Epocuios, terrestre, dobloe, perfidie). Nom dounć par J.-A. Ritgen à une famille de Reptiles ophidiens, comprenant les serpens venimeux qui vivent sur terre.

CHERSOHXDOCHÉLONES, adj. et s. m. pl., chersohydrochelones
( $\chi$ apecaios, terrestre, widwo, ean, $\chi \underline{-}$ hं́wn, tortue). Nom donné par J.-A. Ritgen à une famille de Reptiles, qui comprend les tortues d'eau douce.

CHERSONEsE, s. f., chersonesis ;

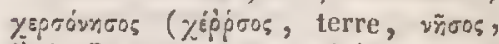
île). Synonyure peu usité de péninsule ou presqu'île.

ChERSOPIYOLDOpHIDEs, adjec. et s. m. pl. ( $\chi_{8}$ \% 0 aios, terrestre, polis, éeaille, öprs, serpent). Non donné par J.-A. Ritgen à une famille de Serpens, eomprenant céux qui ont le corps couvert d'écuilles et qui vivent sur terre.

CHÈTE, s. m., chelum (yairn, soie). Nom donné par RobineauDesvoidy à une pièce triartieulée de l'autenue de certains Myodaires, que les entomologistes désignent ordimairement sons celui de soie ou filet.

CrÉtocìnes, adj. et s. m. pl., Chelocera (zaín, chevclure, xépas, corne). Nom donné par Duméril a une famille de l'ordre des inseetes Diptères, comprenant ceux qui ont un poil isolé sur le còté de chaque antenne.

Ciltrononids, adj. et s. m: pl., Chatodonides. Norn donnć par Blainville à une famille de l'ordre des Poissons thoraciques, qui a pour type le genre Clicetodon. Voyez CusTODONTES.

Chítoloxes, adj. et s. m. pl.

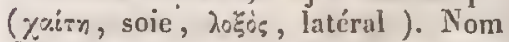
donné par Duméril à une fanille de l'ordre des insectes Diptères, comprenant ceux dont les antennes portent un poil isolé latéral. Voj'ez LATERISETES.

CHÉtopones, adj. el s.m.pl., Chetopoda (yairn, chevelure, тоüs, picd). Nom donné par Blainville à une elassed'Entomozoaires, comprenant ceux qui ont le corps garni d'appendices non articulés.

CHEVALCLANT, adj., equilans. Se dit, en botanique, de feuilles ployées 
en gouttière, qui s’emboîtent réciproquement les uues dans les autres.

CIIEvLU, s. m., capillitium. Ensemble des fibrilles (fibrille, Candolle, radicula, Smith) qui garnissent les dernières ramificatious des racines très-divisées.

CIIEVELU, adj. , capillamenlosus, comatus, crinilus, comosus, jubatus; schopfig, schopfartig (all.); capclluto (it.). Ce mot est cmployé: $1^{\circ}$ en botinique, ou l'on appelle racine chcoclue, celle qui est garuic de ramificatious eapillaires nonibreuses (ex. Erica), et grainc chcvelue, eelle qui porte une touffe de poils, laquelle est, dans quelques espèees, un appendice particulier de la tunique séminale (ex. Tamarix), daus d'autres, le produit du funicule desséché et divisé en une rnultitude de filamens déliés ( $\mathrm{cx}$. Asclcpias). On donne cette épithéte à des plantes qui ont leurs femilles divisées cn segmens eapillaires (ex. Euryops comosus, Daucus crinitus, Athamanta crinita, $S_{i s o n}$ crinitum), leurs bractées ciliées (ex. Justicia crinita), Jeurs pétioles hérissés de poils (ex.'Trichocladus crinita), les éeailles des eupules de leurs fruits garnies de longs lilets, lcurs fenilles eouvertes de longs poils (ex. Grimmia crinita). Ic Hyacinthus comosus doitee nom à ee que les pédicules colorés et très-illongés de ses fleurs supéricures, qui sont stériles, forment une cspèce de houppe ou de couronne au soumet de lat grappe, et l'Uraria crinica, à ee que l'cusemble de ses fleurs, par la ríniou des poils qui les garuisscut et des minees pédicules qui les supportent, offie l'image d'une sortc de crinière touffue. $2^{\circ}$ En zoclogic. Le Prpio comatus a deux toutfes de longs poils qui lui deseendent de l'oeeiput. Le Cypsclus comatus a les côlés de la tête garnis de longues plumes étroites, qui se rabattent cn houppe sur la nuque. L'Anas jubata a de longues plumes eflilćs, qui naissent sur sa nuque, el lui ombragent une partie du col. Le Pyrrhocorax crinitus porte une large huppe composće de plumes molles et délićes. Le Picus villosus a unc bande de plumes eflilées et plus longues le long du milieu du dos. Le Buceros jubatus a les plumes de la tête et du dessus du col hérissées en forme de crinic̀re. L'Anisony $x$ crinitum a le corps hérissé de poils.

CIIEVELURE, s. f. , coma; $\chi$ xirn; chioma, ciuffo (it.). Les bolanistes donnent ce now à de longs poils nıous, qui sont situés à la base des organes, principalcment des semenees; à des anas ale braclées serrées au dessus des fleurs, et eontenant des fleurs qui avortent, ou n'en contenant pas du tout. Voycz Cosia.

Cuever, s. m. Les inineurs appellent ainsi la face inféricure d'un filon.

CHEvILLḰ, adj. , clauostts; qui a la forme d'un clon. Ex. Cerithium clasus, Corithium clavosum, Ccrithium clavalulum.

CIIEVILIURE, s. f. On donne ee nom à tous les andouillers du bois du cerf qui sont situés au dessus du sceond.

CHEMLETDES, adj. et s.m. pl., Chcyletida. Nom donné par Leaeh à une famille de la elasse des Arachnides, qui a pour type le genre Cheylctus.

CHICORACE, arlj., cichoracezts. Se dit d'un coquille univalve, dont le bord ganehe offre une dilatation divisée cn plusieurs pointes de forme diversc. Ex. plusiewrs Murcx.

Cricoruclies, adj. et s. f. pl., Cichoracex, Lastesccntes. Nom donné par Césalpin et Vaillant à nuc famille de plantes, ayant pour type le genre Cichorium, que D. Don a rétablie, mais dont Jussien, L.-C. Richard, Lagasca, Candolle, Kunth 
et Lessing font seulement un groupc, une section ou une tribu de celle des Synanthérćes.

CIIIFr ONNE, adj. On appelle branches chiffonnes, en agriculture, celles qui sent grềles, mal constituées, et qui nuisent à l'arbre.

CHIFTONNÉ, adj., corrugatus, contortuplicatus, plicativus; zusammengerunzclt (all.); qui est ployé sans aucun ordre, comme les pétales du Punica, avant leur épanouissement. On dit l'estivation chiffonnée, lorsque les pièces floralcs sont plissées irrégulièrement, comme dans la corolle des pavots; et les cotylédons chiffonnés, lorsqu'ils sont repliés cn différens sens, à l'instar d'unc ćtoffe froissée, comme ceux du Combretum laxum.

GIIGNON, s. m., cervix ; $\mu \varepsilon \tau \chi u-$

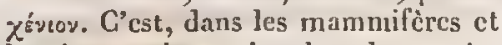
les oiseaux, la portion du col comprise entre la nuque et le commencement du dos.

CIILLANTIE, adj. , chilianthits ( $\chi^{i} \lambda_{\text {roe }}$, mille, $\ddot{\alpha}^{\prime} \theta_{0 \xi}$, fleur). Se dit d'une plante qui est couverte de fleurs innombrables. Ex. Entada cliliantha.

CHILOGLOsses, adj. els. m. pl.,

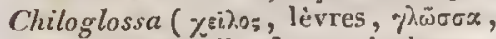
langue). Latreille donne également ce nom aux Chilognathes (roycz ce mot), à eause de leur langue, qui forme une grande lèvre juférieure crustacće.

CIILOGNatiles, adj. ets. m. pl.,

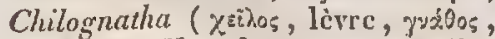
mâchoire) . Nom donné par Latreille, Leach et Straus à un ordrc de la classe des Myriapodes, par Eichwald à une famille de l'ordre des Crustacés myriapodes, comprenant ceux qui ont une bouche composće de deux mandibules et d'une langue formant une grande lèvrc inféricure.

CIILOGNaTHIF OR!HE, adj. , chilognathiformis, Epithète donuée par
Macleay et Kirby aux larves de coléoptères qui sont herbivores, subeylindriques, alongées, et comparables pour la forme à des jules. Ex. $L u$ canus.

GHILONE, s. m., chiloma; Maul (all.). Illiger a nommé ainsi le muffe des mammifères, c'cst-a-dire l'extrémité labiale du nez, prise collectivement avec la lèvre, quand elle est tuméfiée et humide.

CIII OPOdes, adj. et s. m. pl.,

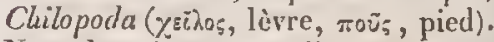
Nom domué par Latreille à un ordre de la classe des Myriapodes, comprenant ceux qui ont une lèvre forméc par une paire de patles.

CIILOPODIFOR.ME, adj. , chilopodiformis. Macleay et Kirby donnent cette épithète aux larves de colénplères qui sont sulshexapodes, arec le corps alongé, déprimé, linéaire, et qui ressemblent un peu ì des Scolopentres. Ex. Carabus.

CHIME , s. f., chemia, chymia, clymica, spagyria, ars spagyrica; MI ischliunde, Fichcidelunst (all.); chi-

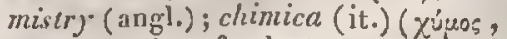
suc, on $\chi^{j} \omega$, fondre). Science qui rccherche les principes constituans des corps, examine les proprićtćs particulières de chacun des élémens qui les composent, indiquic toutes les comliuaisons qu'ils peuvent contracter les uns avec les autres, iait connaître toutes les formes sous lesquelles ces combinaisons peuvent sc manifester, et détermine les lois suivant lesquelles les molćcules élẻmentaires de tous les corps agissent les unes sur les autres, à des distances peil considérables.

Cimniove, adj., chemicus. Les proprietés chímiques des corps sont toutes eclles qui dépendent d'une action que ces corps n'exercent qu'al1 contact appareni, el qui appartiennent aux pareelles les plus ténues 
CHIR

dans lesquelles nous pouvons les supposer réduits.

CHIMISNE, s. m. , chemismus. Ensemble de tout ee qui, dans les phénomènes naturels, est explieable par des ehangemens de eomposition d'aprìs les lois que la ehimie a déeonvertes.

CHIMonútrie, s. f., chemonetria; chemische Messkunst (all.). Synonyme inusité de stcchiométric. Voyez ce mot.

CHINOIDINE, s. f., chinoidina. Sertuerner appelle ainsi un nonvel alealoüde, qu'il annonee exister dans les quinquiua jaune et rouge, et qui, suivant Henry et Delondre, est un mé́lange de einehonine et de quinine avee une matière partieulière difficile aे isoler.

CIIILAGnE, adj , chiragrus (ysip, main , ̈̈ypo, prise ). Epithète donnée à un crustacé (Lissa chirasyra) dont les pieds sont noduleux; it une cogtuille (Ptcrocera chiragra) dont les digitations sont renflées de distanee en distance; ì des insectes ( $M e$ rodon chiragra, Cordlylura poslagrica, Calobata arthritica) dont les cuisses postérieures sont renflées.

CUIRODYSMOLGES, s. m. pl., ( $\chi \varepsilon_{i}$, main, $\mu_{0} \lambda_{y j} \dot{\sigma}_{5}$, salamandre), Nom donné par J.-A. Ritgen à une fanille de la classe des repliles, renfermant les Batraciens qui n'ont que des membres antérieurs.

CImmopote, adj., chiropolss

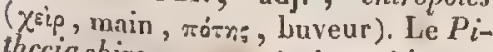
thcciachiropotes est ainsi appelé paree qu'il a l'habitude de boire dans le crenx de sa main.

CIIIROpTitre; adj., chiroptcrus ( $\chi$ sip, mail, $\pi \tau$ ípov, aile). Illiger donne celle épithète aux pieds cles nuarnmifères, quand ils sont conformés en manière d'ailes, comme ccux de devant des ehaure-souris.

Chmonnithes, s. m. pl., Chir-

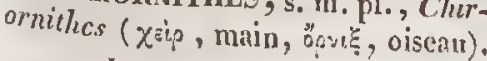
1.
Nom donné par J. - A. Ritgen à un ordre de la elasse des oiseaux, eomprenant eeux qui se servent de leurs pieds comsne de mains, pour grimper on saisir leur nourriture.

CHISMOBRaNCIIES, adj. et s. m. pl. , Chismobranchiata (xiбun, fente, Epá'7xia, branehies). Nom donné par Blainville à un ordre de la elasse des Paraéphalophores, conprenant eeux de ees aoimaux qui ont les branehies dans une eavité eommuniquant au delors par une large fente.

CHismopuís, adj. et s. n. pl., Chismopncre ( $\chi$ isun, feute, $\pi v \varepsilon^{2} \omega$, respirer). Nom donné par Duméril it un ordre de poissons eartilagineux, eomprenant een $x$ dont les branehies, sans opereules, sont eouvertes par une membrane perée d'une fente de chaque eôlć du eour.

CIITINE, s. f., chitina ( $\chi$ เง pourpoint). Nom donné par Odier à la croûte dure qui forme le tégument extérieur des insectes el en particulier les élytres des eoléoptères.

CHLAMYDOBLASTES, adj. ets.f. pl., Chlamydoblastere ( $\chi$ Xxuivg, sur-

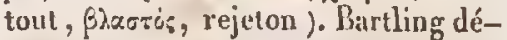
signe sous ee nom un groupe de l'ordre des plantes dieotylédonées, comprenant eelles qui ont leur embryon renleermé dans un sae propre.

CILĹnaCÉEs, adj. et s. f. pl., Chlenacea ( $\chi^{\lambda}$ räis, surtout). Nom donné par Dupetit-Thouars et Kunth à une fantille, eomprerrant des plantes dont la capsule est enveloppée par l'involutere épaissi.

CHLORACHE, s. m., cluloracidrum ( $\chi^{\lambda \text { apò̀s }}$, verd, acidum, acide ). Terme peu usité, qu'on a proposé pour désigner les acides dans lesquels on suppose que le chlore joue le rôle de principe acidifiant.

GILOHANTIE, adj. , chloranthus

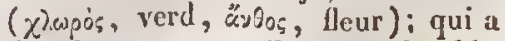
des fleurs vertes, Ex. Pyrola chlo. 
rantha, Solanum chloranthum. Voy. VIRIDIFLORE.

Chllorantuées, adj. el s. f. pl., Chloranthea, Nom donnć par R. Brown à une famille de plantes qui a pour type le genre Chloranthits.

CHLorantuie, s. f., chloranthia ( $\chi^{\lambda \omega p i \xi}$, verd, "ैuOss, fleur). Nom donnć par Dupctil-Thouars à une monstruosité on luxuriance végétale, qui consiste dans la transformation des organcs floraux en véritables fleurs. Ex. Tctragonia expansa, Arabis alpina, Diplotuxis tenuifolia.

CILLORATE, s. m., chloras. Genre de sels (chlorsaure Salze, all.), qui sont formés par la combinaison de l'aeidcchloriquc avec les bases salifiables.

CHLOHE, s. m., chlorum; chlorine (all. et angl.); cloro (it.) ( $\chi^{\lambda}$ wos ${ }^{2}$, verd). Corps simple, decouvert en 1774 , par Schecle, qui doit ce nom, créć par H. Davy, à ce qu'on a cru trouver une nuance de verdâtre à sa conleur, qui cst le jaune foncé.

Crisonk, adj. , chloratzes; qui eontient du chlore. Le gaz hydrogine chloré est le graz acide hydrochlorique. Le chlore donne uaissance à dcux éthers, dont l'un, celui qui conlient le moins de chlore, est appelé éther chloré, ct a ćić déeouvert par Schrele. On emploie quelqueíois le mot chlore ou chloraté, en histoire naturellc, ponr désigner des corps jauaûtres, verdâtres ou olivacés, soit en tolalité, soit seulement par taches ou par vcines(cx. Loxia chloris, Terebra chlorata, Iscpraria ellorina, Voluta chlorosina).

CHLorisex, adj., chlorosus. Le gaz oxidc chlorcux (protoxide de chlore, euchlorine; Chloroxydul, all.), déconveri en 1811 par H. Dilvy, qui l'appela euchlorinc, csi le premier degré d'oxidation du chlore. L'acide chloreux (chlorigc Süure, all.), déconvert en 1814 par H. Davy et Stadion, cst le second.

CHLonictène, adj., ehloricte-

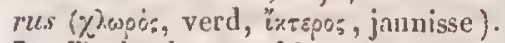
Le Taehyphonus chlorietcrus a son plumage d'un jaune de safran foncé.

CHIONIDE, s. m., chloridctum, chlorilum. Nom donné, dans la nomenclature chimique de Berzelius, aux combinaisons du chlore avec des corps moins électronégatifs que lui, dans I csquelles les rapports atomiques sont les mìmes que dans les aeides.

Cinconidérs, adj. et s. f. pl., Chloridece. Nom clonné par Trinius, Link, Kunth et Nces d'Escn becks à une tribu de la famille des Graninées, qui a pour type le genre Chloris; par A. Brongniart à une section dc la tribu des Mucédinćes Byssacćes, qui a pour type le genre Chloridium.

CHLORIDES, s. in. pl. Ampère ct C. Panquy donnent ee nom à un gentc ou à une famille de corps simples, Beudant à une famille de minćraux, eomprenant le chlore ct scs dérivés.

CHLORIOHIQUe, adj., chloriodiezs. Dary a donué le nom d'acide chloriodique au chlorure d'iode, qu'il considérait comme un acide, à cause de sa saveur et de sa propriété dle rongir le tournesol.

CImorieue, adject., ehloricus. Liacide chlorique (Chlorsüute, all.), dont Gay-Lussac a le premier démontré l'existence, est le troisiène degré d'oxidation du chlore. Le quatricme, ou acide chlorique oxigéné (oxydirte Chlorsäure, all.), est plus sonveut appelé acide oxichtorique.

GIIORISTIQUE, alj., chloristiczes. La thérie chloristique cat celle, iutroduite par Gay-Lussac, Thćnard ct Davy, dans laquiclle on admet que le chlore est un corps simple, avec 
toutes les consćquences qui découlent de ec principe.

ChLOrite, s. m. , chloris. Genre de sels (chlorigsiüre Salze, all.), qui sont produits par la combinaison de l'acide chloreux avee les bases salifiables.

CHLOH I'T', alj, ; qui contient de la chlorite. Ex. Grès chlorité, Sable chlorité.

CHLOruteux, adj.; qui contient de la chlorite, qui en est formé. Ex. Schiste chloriteux, Couchc chloricuse.

CH. OrITIQUE, adj. ; qui est mêlé de chlorite. Ex. Stéaschiste chloriiique.

Guloto-Antimoniate, s. m., chloro-antimonias. Bouliay appcilc ainsi les combinaisons du chlorure antimonique aree des chlorures de nétanx élcetro-posilifs.

CHEORO - ARGENTATE, s. m. , chloro-argentas. Boullay donne ce nom aux combinaisons du chlorure argentique avec les chlorures des métaux électro-positils.

CHLORO-AURATE, s, m., chloroauras. Nom douné par Binusilorf aux combinaisons du chloride aurique avec les chlorures des mélaux électropositils.

CHLOROBORURE, s. m., chioroboruretum. En se combinant ou sc naêlant cosemble, les gazchloride borique et ammonique produisent um colps qu'ou a appelé chloroborure ammoniacal.

\section{cheonogarbonigue, Voyez Chloroxicarbonione.}

CHLOROcarev, adj., chlorocar-

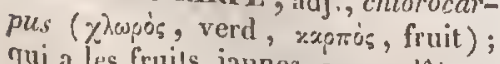
qui a les fruils jaunes ou verdatres. Ex. Cercus chlorocarpies, Torilis chlorncarpa.

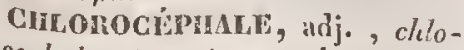
rocephalus ( $\chi$ howon, verd, regshin, tète); qui a la tête verte. Fx. Charadrius chlorocephalus, Labia chlo- roccphala. Le Sicus chloroccphalus a les joues jaunes. Le Leotia chlorocephala a le clapeau jauue.

CHLOHDCUPRATE, s. m. , chlorocupras. Nom donné par Boullay à des combinaisons de rhlorme cuivrique avee des chlorures de métaux électro-positifs.

CILOH0-CYANIQUS, adj., chloro-cyanicus. Gay-Lussas donne lc nom d'acide chloro-cyanique, parce qu'il rouyit lc touruesol, à l'une des combinaisous du chlore avec le cyanogène, celle que Berthollet a appelí aciele prussique oxigénć, el Berzclius chloride cyancux.

CHLOROCYANUHE, s. m. , chlorocyanurcum. Mćlange ou combinaison d'un chlorure el d'un cyanure, par exemple du chlorure argentique avec lc cyanure potassique.

CiLORUFEROCYANQUE, adj., chloroferrocjanicus. Non douné par Johnston ì un aside dont il admet l'existence, et qu'il supposc composé de chlore, de cyanogene ct de fer.

CilsoROFLEOBUHE, s. in., chlo. rofuorurctum. Nom donné, dans la nomenclature ehimique de Berzelius, à un sel double résuliant de la combinaison d'un fluortue avee un chlo. rure.

Culorogastrie, adj., chloro-

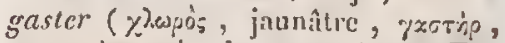
ventre); qui a le ventre jaune. Ex. Bufo chlorngasler. Foyez LutéoVENTRE.

CHLOROGONIDIE, s. f., chlorogonidium (zhwoos, jaune, yovin, seneuce). Nom donuć par Wallroth aux gonidies (voycs ce mot) qui ont une conleur jaune doréc.

CILOnOGowinuer, adj., chlorogntimieus. Wallool appelle couche chlorogronimique ( stratum chlorogonimon), dans les lichens, celle qui rímlic t'un assemb!age de chlorogonidies.

CHLOROIIYDARGYRATE, s, m.g 
chlorohydrargyras. Nom donné par Bonnsdorff à des sels que le chlorure mercurique forme en se combinant avec unc grande partie des chlorures de métaux électro-positifs.

CHLOROHYDRioves, adj., chlorohydricus. Quclques chimistes ont proposé de donner à l'acide hydrochlorique le nom d'acide chlorohydrique, qui serait en effut plus régulier.

CHLOROLÉPIDOTF, adj., chloro-

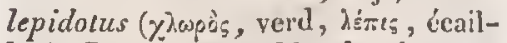
lcs). Lc Psitlacus chlorolepidotus est ainsi appclé parce qu'il a le plumage jaune, avec le bord des plumes verd.

CHLOROLEUQUe, adj. , chloroleucus ( $\chi^{j}$ woròs, verd, i.suros, blanc); qui est blanc et verd; comme l' $A$ garicus cleloroleucus, qui a son chapeau verdâtre en dessus et blanc cn dessous, ou la Tcllina chlorolcuca, qui est blanche en alchors et d'un jaune verdâtre en dedaus.

CIILOROLOPLE, adj., chlorolo-

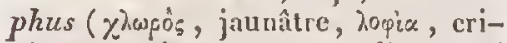
nière); qui al une luppe d'un verd jaunâtre sur la tête. Ex. Piczis chlorolophus.

CHLOROnètre, s. m. , chloro-

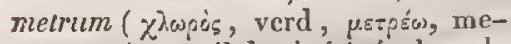
surer). Appareil destiné à évaluer la quantité de chlore qui est en combinaison avec del'eau ou avce une base, et qu'on peut estimer de plusicurs manières, naais de préférence par le procédé de Deseroizilles, fondé sur Ia proprićté qu'a le chlore de décolor'er l'indigo.

CILORONITE, s. f., chloronila. Nom donné par Desvaux à la chlorophylle.

CHLONONOTE, adj. , chlorono-

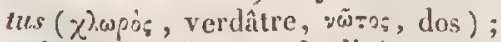
qui a le dos d'un verd olivâtre. Fix. Diccum rluloronotos.

CHLOROPALEADATE, s. m. , chloropalladas. Nom donné par Bonnsdorff à des sels doubles qui risulient de la eombinaison du chlo- rure de palladium avec des chlorures de métanx électro-posilifs.

CHLOROPE, adj., chloropus ( $\chi^{\lambda} \omega=$ pòs, vcrdâtre, Toũ, pied); qui a les pieds verdâtres (ex. Gallinula chloroptus), ou les pédoncules jaunes (ex. Ccratodon chloropus).

CrILOROPIIANE, adj., chloropha-

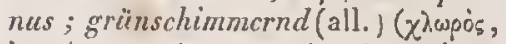
jaunâtre, quìve, paraître); qui est jaune ou jaunâtre (ex. Agaricus chlorophanus). Wallroth donne eette épithètc au blastème ou thalle des lichens, quand, à travers sa teinte gćnérale blanche ou grisâtre, on voit pereer une nuance de verd plus ou moins prononeće.

CHLOROPHOSPIORECx, adject., chlorophosphorosus. Quelques chimistes ont donné le nom d'acide chlorophosphorcux au proto-chlorure de phosphore, parce qu'il rougit le papier de tournesol, mème see.

CHLOHophosphorique; adj. , chlorophosphoricus. Quelques chimistes ont donné le nom d'acide chlorophosphorique au deuto-ehlorure d phosphore, parce qu'il rougit le papicr de lournesol humide.

CHLOROpHOSPHLRE, s. m. , chlorophosphurctum. Coniposé dans lequel il entre du phosphore et du chlore, plus un autre corps, comme danslechlorophosphure ammoniacal, qui est composé de chloride phosphorique et d'ammoniaçue.

CHLOROPHILLE, s. $f$, , chloro-

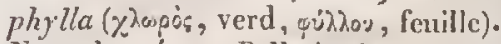
Nom donuć par Pelletier à une substance qu'il regarda d'abord conıme un principe immédiat des véggétaux, et comme la cause de la eouleur verte de ecs derniers, priucipalement de lcurs fcuilles, mais que depuis il a reconnu ĉtre un mélange de plusieurs substances.

CHLOROPHLLE, adj. , chloro-

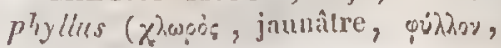


feuille); qui a les feuilles verdâtres ou jaunấtres (ex. Clcilanthus chlorophylla.). Candolle donne l'épithète de chloroply lle's aux plantes parasites phanérogames qui, comme le gui et la plupart des Loranthacées, sont pourvues de fcuilles vertes.

CILLOROPIYTE, s. m. , chloro-

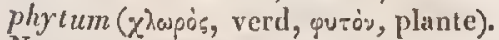
Nom donné par Fries a toutes les plantes dont l'évolution se fait d'une manière suecessive, et qui ont des parties ou des cxpansions vertes.

Cillorophatinate, s. m., chloroplatinas. Nom sous lequel Bonnsdorff désigne des sels produits par la combinaison du ellorure płatinique avee les chlorures des métaux éleetro-positifs.

CILOROPODE, adj., chloropo-

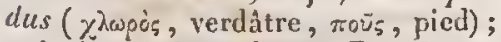
qui a les pieds verdâtres. Ex. Sicrna chloropoda. Voyez CnLorope.

CULOROPTERE, adj. , chloroptcrus ( $\chi$ hwopos, verd, тripov, sile); qui a les ailes (ex. Thamnophilus chloropterus, Tanagrachloroptera), les nageoires (ex. Girella chloroptera), ou les ćlytres (ex. IIaltica chlorop(era) vertes.

CMLOROPYGE, adj., chloropygius

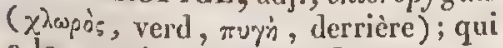
a le croupion verdâtre. Ex. Totanus chloropygitus, Musca chloropyga.

CIILORonmyeue, adj., chlororhyncus ( $\chi$ inworis, jaune, puryos, bee); qui a le bee jaume. Ex. Diomedca chlororhynchos, Pufinus chlororlynncluzes. V oycz Flavirosirre.

CmLorioser, s. m. Nom générique imposé par Boullay aux combimaisons des ehlorures des métaux négatifs avee ceux des métaux positifs.

Clllonosocrucí, adj., chlorosochrus ( $\chi$ ).wpis, verd, कxखpos, jaune); qui est verdâtre, nuaneé de rouge. $\mathrm{E}_{\mathrm{X}}$. Crenilabrus chlorosochrus.

Circonosta CHYÉ, adj., chorosta-

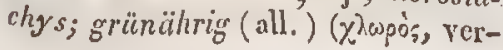

dàtre, $\tau \tau \alpha \dot{z u s, ~ e ́ p i ~) ; ~ q u i ~ a ~ d e s ~ e ́ p i s ~}$ de couleur verte. Ex. Amaranthus chlorostachy.s.

CHLOROSTONE, adj., chlorosto.

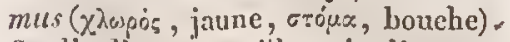
Se dit d'une eoquille qui a l'ouverture ou la bonche jaune (ex. Trilonium chlorostoma), on d'un insecle qui a la bouche verte, comme le $C_{y}$ phus chlorosiomus, dont le rostre est vert au bout.

culonostrils, adjeet., chloro-

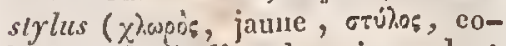
loune). Se dit d'un elampignon dont le stype est jaune. Ex. Clavaria chlorostyla.

Cillonosurfure, s. m., chlorosulphuretum. Nom donné, dans la nomenelature ehimique de Berzelius, à la combinaison d'tin chlorure avec un sulfure. Ex. Chlorosulfure aluminico-hydrique.

CHLOnOSULFUniQue, adj., $c h l a$ rosulphuricus. Quelques elimistes ont douné le nom d'acide chlorosulfurique au chlorure de soufre, paree qu'il rougit le tournesol.

CIIronoure, adject., chlorouros ( $\gamma$ )wojos, verd, oujà, queue). Un poisson (Cheilinus chlorouros) est ainsi appelé paree qu'il a la nageoire eaudile verte.

CHLORoxalate, s. m., cleloroxalas. Scl produit par ld combinaison de l'acide chloroxalique avec unc base salifiable.

CILOROXiciQue, adj. , chinroxalicus. Dumas donne ee nom it une combinaison d'acides oxalique et hydrochlorique, qu'il a déconverte, et qu'il regarde comme constituant un aeide particulier.

CIllonoxantrie, adj. , chloro-

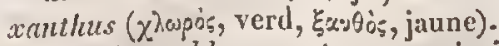
I'Agaricus chloroxanthus est ainsi appelé paree qu'il a son elapeau couvert d'écalles olivâtres et ses lamelles jaunâtres.

ChLOROXICARBONIQUE, adj. ; 
chloroxicarbonicus. Quelques chimisles ont dome le nom d'acidc ehloroxiearbonique au gaz plosgène, appelé oxichloride earbonique par Berzelius, qui se produit par l'aetion des rayons solaircs sur un mélange ì volumes égnux de elilore gazcux et de gaz oxide carbonique.

CHLOHoxicanunn, subst. m. , chloroxiearburetum. Berzeliusappelle chloroxiearbure ammoniacal $\mathrm{nn}$ sel double anhydre produit par la condensation de quitre volumes d'ammoniaque gazeuse par un volume de gaz oxichlaride earbonique.

CHL OROXISLLFURE, s. m. , ehloroxisulphuretum. Berzelius nomme chloroxisulfure ammoniacal un conposé qui s'obticnt, simultanément avec le elloroxicarlure ammoniacal, cn introduisant dans du gaz ammoniaque le corps blane et eristallin qui résulte de l'action de l'eau régale sur le sulfide enrbonique.

CHLOROXIL1, adj., chloraxylus ( $\chi$ haspòs, verdattre, şưloy, bois); qui a un bois d'un jaaunc verdâtre. Ex. Laurus chloroxylon.

CHLOROXYLINIQUE, adj., chloroxylimus. Dobereiner a appeléacide chloroxylinique une sulssince résineuse verte que lui et. Witting ont extraice des morcenux de bois pourris et colorés en verd qu'on trouve assez sonvenl dans les grandes forêts.

CHLORURE, s. m., chloruretrm, ehloretum. Nom domé, dans la nomenclature chimique de Berzelius, aux combinaisons du chlore avee les mélaux électro-posilifs dans lesquelles les rapports atomiques sont les mènes que dans les linses.

CuLoRuné, adj. Omalius, sous le nom de rockes chlorturées, établit un ordre et un genre comprewant les dépots de sel genumc ou chlorure sodigue.

CHOLATE, s. m., cholas. Genre de sels (cholsaure Salze, all.), qui sont produils par la combinaison de l'acide cholique avec les bases salifiables.

CrroLELOGLE, s. fém., cholelogia (yolin, bile, ićros, discours). Histoire de la bile.

CHOLúporìs:, s. f., cholepoiesis

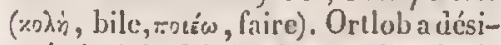
gné ainsi la fabrieation ou la sćerćtion de la bile.

CHOLÉSTÉnATE, s. n., cholesteras. Genre de sels (gallenfettsaure Salze, all.), qui résulicnt de la combinaison de l'acide choléstérique avec les bases salifialules.

CIIOL f́STh́nLUE, s. f. , cholesterima. Nom donué par Guibourt à la choléstérine.

Crout́STĹRINE, s. f., eholesterina; Gallenfett, Gallenconcretionen-

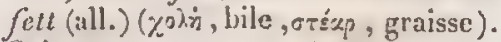
Substance grasse particuličrc, que Grcen a découverte en 1558 daurs les caleuls biliaires, et dont Chevreul a depuis démontré l'existence aussi dans la bile fratelsc.

CHOLÉSTúniQue, adj. , cholestcricus. Épithicte donnéc à un acide particulier (Grallenfeltsüure, all.), qui est produit par l'action de l'acide nitrigque sur la choléstérine.

CHOLIDES, adj. et s. m. pl., Cholides. Nom donué par Latrille à un groupe de la fanille des Charansonides, par Scboenherr à un groupe de cel'es des Gonathocèrr's nuécorhynques, ayaut pour type le genre Cholus.

CHOLIQUE, adj., cholieus ( $\chi_{2} \lambda_{\text {in }}$, bile ). L. Gmelin désigne sousec nom un acide particulier (Cholsäure, all.), qu'il a diconveri dans la bile.

CHONbRrTes, adj. et s. m. pl.,

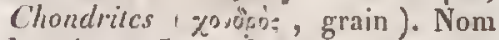
dounce par J.-A. Riigen à un sousordre de l'ordre des reptilss Ophidicns, renfermant les serpens qui ont la pean grenue.

CHONDROGRADEs, adj. el s.m. pl., Chondrogrades (Xoyopos, carti- 


\section{CHRO}

sage, gradior, marcher). Nom donné par Blainville à un ordre de li classe des Arachnodernaires, comprenant ceux de ces animaux qui ont, dans l'intérieur de leur corps, une pièce solide destinćc à soutcnir lcur ombrelle ou leur corps.

CHONDRoprerigms, adj." et

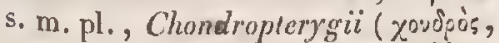

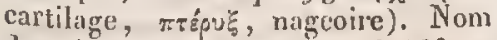
donné par Artedi, Cuvier, Goldfuss, Willbrand, Ficinus el Carus à une division, à un ordre, ou à un groupe de la elassc des poissous, qui se compose de ceux dont le squelette est entièrement cartilagineux.

Chondiosiacéks, adj, et s. f. pl., Chrodrosiacea. Nom donné par Link à une tribu de la famille des Graminées, qui a pour type le genre Chondrosium.

Chomagioes, adj. et s. m. pl., Choragida. Nom donné par Kirby à une famille de l'ordre des Colćoptères, ayant pour type le genre Choragus. Cilorap'TExonY'Tes, adj. et s. m. pl., Choraptenodyles ( $\chi_{\text {ciosos, }}$

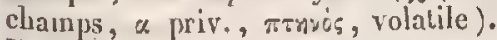
Nom donné par J.-A. Ritgen à une famille de l'ordre des Pédinornithes, compremant des oiseanx qui vivent dans les lieux cultivés, et qui u'ont par d'ailes, comme le Casoar.

Crrondanúrs, atj. et s. f. pl., Chordarica. Now donné par Agardh à une section de l'ordie des Fucoïdées, par Rcichenbach à une division de la tribu des Batraehospermées, et pár R.-K. Greville ì un ordre de la famille des Algues, ayant pour type le genre Chmiaria.

CHORDormlze, adj., chordorhizus (xopón, corde, picc, racine); qui a uue racine mince, alongéc, filiforme. Ex. Carcx chordorhiza.

CHORELIÉES, adj. et s. f. pl., Chorellea ( $\chi$ apo's, chour). Nom donné par Robineau-Desvoidy à unc section de la tribu des Myodaires mésomydes anthomydes, comprenant des especes qui se balancent et dansent cn grandes troupes dans les airs.

cilonion, s. m., chorion; xóptov,

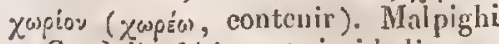
et Candulle désignent ainsi la liqueur pulpeuse, qui, avant la fécondation, semble former toute l'amande de la graine des végétaux, et qui disparaít avant la maturité de cette dernièrc.

CHORYovvaIrE, adj., chorionnarius. Mirbel a ainsi appclé pendant quelque tomps une partic des fruits que depuis il a désignés sous le nom d'ćtairionnaires.

CHOLISANTUĹRIE, s. f., .chorism antheria ( $\chi$ wois, séparément, dovonpòs, fleuri). Nom donné, dans la méthode de Jussieu, à une classe de plantes renfermant celles qui ont les anthères distinctes.

CIOnISOLÉPLE, adj. , choriso-

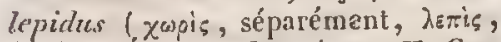
écaille). Epithèle donnée par H. Cassini au péricline des Synanthérées, quand les squames qui le forment sont libres.

CHOHISOPIXTE, s. m., choriso-

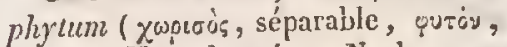
plante). Nom donné par Necker aux plantes qui ont les étamines libres ou distiuctes.

CHORISPOnúEs, adj. et s. f. pl.; Chorisporece. Nom donné pär Meyer et Bunge it une tribu de la famille des Crucifères, ayant pour type le genre Chorispora.

CHonoptenes, adj. cts. m. pl.;

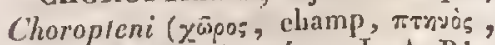
volatile). Nom donnć par J.-A. Ritgen ì un ordre de la section des Xérornithes, comprenant les oiseaux qui vivent dans les champs.

GIORTODHHYTE, s. m. , chortodiphylum ( $\left.\chi^{0} \operatorname{t\omega }^{2}\right)^{2}$, qui ressemble au foin, quió, plante). Nom donné par Necker aux plantes qui se rapprochent des Graminées. 
CHORTONOMIE, s. f. , chortonomia (xópros, herbe, yóus, loi). Desvaux appelle ainsi l'art de fairc des herbiers.

CHRorcolytes, subst. m. pl., Chroicolytes (ypoix, couleur, גบ:ós, soluble). Nom donné par Ampère ci Beudant à une classe de corps simples ou de substances minérales qui fournissent des dissolutions colorées avec Jes acides, du moins à certains degrés d'oxidation.

CIIRONAdoTE, s. m., chromadolum ( $x$ pespex, couleur, dów, donner). Noin donné par le mécanicjen Hoffmann à un instrument de son invention, qui cst destiné à rendre plus faciles à observer les phénomènes de l'inflexion de la lumière. Voyez INYLEX10scope.

GIROMASCOPE, s. m. , chroma-

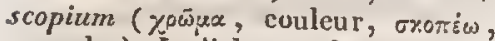
regarder). Ludicke a indiqué sous ce nom un instrument qui paraît être destiné à déterminer les rapports de réfraction des différens r'ayous colorés.

CHROMATE, subst. m., chromas. Genre de sels (chromsaurc Salzc, all.), qui sont produits par la combinaison de l'acide chronirye avec les bases salifiables.

CHRomarts, adj.; qui cst converti en chromatc. Terme nsité eu minéralngie. Ex. Plomb chromaté.

CHROMATIQUE, adj., chromaitcus (xpōux, couleur). Epithète donnée à une échelle musicale composée d'une succession de douze demi-tons sur treize sons consécutifs d'une octave à l'autre. Cetle ćpithète lui vient de ce qu'elle est moycnne entre les deux autres, comme la couleur entre le blanc et le noir, ou plutôt de ce que les deni-tons font en musique lc même effet que la variété des couleurs en peinture. Pour la former, on partage on deux intervalles égaux, ou supposés tels, chacin de ceux qui, dans l'ćchelle diatonique, portent le nom de tons entiers; les cinq sons ainsi ajoutés ne forment pas de nouveaux degrés dans la musique, mais se marquent sur le degré le plus voisin, par un dièze si le degré cst plus haut, pa! un bémol s'il est plus bas, et la note prend toujours le nom du degré sur lequel elle est placée.

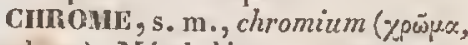
couleur). Métal déconvert en 1797 par Vauquelin, et qui a été ainsi appelé à cause des belics couleurs qu'affeetent la plupart de ses combinaisons.

CHnoute, adject., chromatus; qui contient du clırome. En minćralogie, on appelle plomb chromé une combinaison d'oxide de plomb et dc chrome.

GIIRONICO-AMMONIQLE, adj. , chromico-ammonicus. Non donné, dans la nomenclature chimique de Berzelius, à des sels doubles qui résultent de la combinaison d'un sel ehromique avec un sel ammonique. Ex. Fluorure chromico-ammonique (Aluate de chrone et d'ammoniaque).

CHronico-potassiQue, adj., cleromico-potassieus. Nom donné, dans la nomenelature chinique dé Berzelius, à des sels doubles qui résultent de la combinaison d'un sel chromique avec un sel polassique. Ex. Fluorure chromico-polassique (fuate de chrome et de polasse).

CIIROMICo-SODIQUE, adj., chromico-sodicus. Noun donné, dans la nomenclature chimique de Berzelius, a des sels doubles qui sont produits par la combinaison d'un sel chromique avec un sel sodique. Ex. Fluorure chromico-sodique (fluate de chrome et de soude).

Cunouides, s. m. pl., Chromides. Sous ce nom, Ampere désigne un genre de corps simples, et Beudant une famille de minéraux, ayant le chrome pour type. 
CUROVIrènE, adj., chromiferus;; chromhaliend (all.). Épithète donnée, en minéralogie, à des corps qui contiennent aceidentcll cment du ehrome. Ex. Tilanc oxidé chromifere.

Chrovique, adj., chromicus. On appelle oxide chromiguc (protoxide de chrome; Chromoxydul, all.) le premier, et aeide chromique (Chromsäurc, all.) Je troisis̀me degré d'oxidation du ehrome; sulfidc chromi que son troisic̀me degré de sulfuration, et sels chromiques (Chromoxydulsalzcn, all.) eeux qui résultent de la combinaison de l'oxide ehromique avee les oxacides, ou du ehrome avec les corps halogènes.

CHROMite, subst. m., chromis. P. Gronvelle appelle ainsi un sel résultant de la combinaison de l'oxide chromique avec un oxide, comne par exemple le fer chromé des minéralogistes.

CimOMOPIIORE, s. m., chromophorum ( $\chi$ pesuru, couleur, yśpw, porter). San-Giovanui a désigné sous ce hom les follieules ou globules colorés qui garnissent le corps des Céphalopodes, et qu'il a observés le premier.

CHRomule, subst. f. , chromula ( $x$ püux, couleur). Candolle a proposé d'appeler ainsi ta chlorophylle, parce que, d'aprìs Macnire, e'est la même matière verle des feuilles qui, diversement colorée, se retronve dans les calices, les corolles et autres parties de la fleur, et qui, même dans les feuilles, les colore en ronge ou en jaune, pendant l'automne.

Chromuraie, s. f., ehromurgia ( $ү$ pwp.x, coulcur, épgov, travail). Branche de la chimie qui s'occupe des matieres colorantes et de leur applicetion aux besoins des arts.

CImovilyovetrne, s.m., chronhromclium (хpóros, temps, iz:ós,

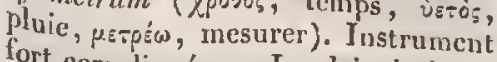
fort compliqué, que Landriani a imaginé pour nesurer le temps que dure la pluie et l'époque où elle eommence.

CIRoxometre, s. m., chrono-

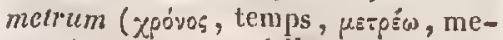
surer); Zeitmesser (all.); timckeeper (angl.). Sous ce nom, synonyme de farde-temps ct de montre marinc, on désigne des moutres d'unc grande perfection de travail, qui servent pour déterminer les longitudes géegraphiques. Lorsqu'apurcis avoir réglé la montre sur le passage du soleil atu méridicu d'un lieu, on se trouve avec elle daus un autre endroit, la différenee entre elle ct le chronomètre de ee dernier lien indique la distanee des deux méridiens en heures, minutes et seeondes, qu'on peut réduire en degrés et fraetions de degrés, à raison de 24 heures pour 36 o degrés, ou de $1: 15$.

CIIRISAIIDE, s. f. , chrysatis; yourcidis (xousos, or). On nomme ainsi un insecte qui, parvenu à son second ctat, est tout-à-fait inaclif, ne prend plus de nonrriture, et se trouve enfermé dans une coque transparente, laquelle le cache eutic̀rement, et ne présente pas l'apparenee d'un unimal immobile quand on $y$ touche (ex. Lépidoplères). Ce mot est tiré de l'éelat métallique qui brille sur l'enveloppe de quelques chrysalides.

Chissalidío - contoutinè, adj., chrysalidco-contortuplicalus. Se dit, en botanique, des colylédons, lorsqu'ils sont chiffonnés à la fuçon des elirysalides d'inseetes. Ex. Dipırocarpus costalus.

CiIrISANTIU, adj., chrysanthus (xpusós, or, «00os, fleur). Epithete donnée ì des plantes qui ont des fleurs jaunes. Ex. Loranthus chrysanthus, Phaseoluschrysanthos, Hamelia chry. santha, Erodium chrysanthum.

CIMISANTIIEL, adj., chrysan-

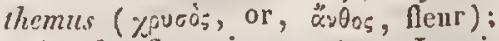
qui a des fleurs jaunes. Ex. Jasminum chrysanthemum. 
CIBIXYANTHÉMEES, adj. et s.f. pl., Chrysanilemece. Nom donné par H. Cassini à une section de la tribu des Authémidées, par Lessing à nuc sous-tribu de la tribu des Sćnéeiunidées, ayant pour type le genre Chry. santhcmum.

CIRrskibées, adj. ct s. f. pl., Chryscillece. Nou donnć pár II. Cassini à une section de la tribu des Centauriées, qui a pour type le geme Chryscis.

CIIRISIDES, adj. et s. m. pl., Chrysidcs. Non donné par Cuvier, Lalreille et Eichwald à une tribu de la famille des Pupivores, par Duméril à une famille de l'ordre des Mymémoptc̀res, ayant pour type le genre Clirysis.

CIIISIDes, s. m. pl., Chrysides

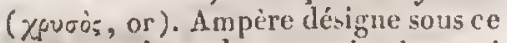
nom une classe de corps simples, qui a l'or pour type.

Crrixssomris, adj. et s. m. pl., Chrysididcs, Chrysidida. Nom douné par Leneh, Goldfuss, Ficinus et Camus à une farnille de l'ordre des $\mathrm{Hy}$ ménoplères, ayant pour type le genre Chrysis.

CHRISIDIFORWL, adj. , chrysidiformis; quia la forme ou l'apparence d'une Chrysis. Ex.Scsia chrysidiformis.

Chrysitricées, adj. et s. f. pl. , Chrysitricca. Lestiboudois á désigne sous ec nom une tribu de la fauille des Cypéracées, qui a pour typc lc genre Chrysitrix.

CIHXSOBALANELS, adj, et s. f. pl., Chrysobalanece. Nom donné par Candolle à une trihu de la famille des Rosacées, qui a été ćriģée en famille par $R$. Brown, et qui a pour type le genre Chrysobalanus.

CHRISOCARPE; adj., chrysocarpus (хpuris, or, хертое, fruit); qui a les fivits d'un jauue d'or. Ex. Hedera chrysocarpa.

CHLYSOCEPHALE, adj. , chryso- ceplealus (youròs, or, uspain, tĉte); qui a la têle d'un jaune ćclatant (cx. Oriolus chrysoccphalus, Motacilla aurcocapilla, Laxia flaviccps), (crruginense (ex. Musca chrysoccphala, Jurinia chrysiccp.s), de couleur orangé (ex. Sylyia chrysocephala), d'un roux jaunâtre (ex. Staphylinus chrysoccphahus).

CHRYSOCHLORE, adj., chrysu-

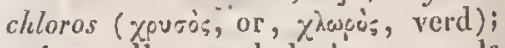
qui est d'un rerd dori, comme le pelage de la Chrysochloris capensis, et lc plumage du Picus chrysochloros.

CursSOCOME, adj., chry socomus (xpusoi;, or, rojun, chevelure). Le Pcaiza chrysocoma est ainsi appelé is cause dc ses eupules dorées.

CHIISOcouiEs, adj, ct s.f. pl. ? Chry socomcce. Nom dounć par H. Cas. sini à un groupe de la section des Astérées baccharidécs, qui a pour type le genre Chrysocoma.

CMRISODONTE, adj., chrysadon

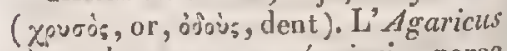
chrysodon est nommé ainsi, paree qu'il a son stipc jaunàtre.

CHIISOGASTRE, adj., chryso-

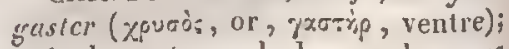
yui a le ventre ou le dessous du eorps d'un jaune orangé. Ex. Hydromy's chrysogaster. Voyez LotÉoventrE.

CHRISOGENE, adj., chrysogcnys (Xouros, or, yévu:, menton); qui a les joues jaunes. Ex. Cinnjris chryso. genys.

CIIRISOGONIDIE, s. m., chrysogronidium (xpuròs, doré, youn, semence). Nom donué par Wallroth aux gonidics (vores ce mot) qui out une coulcur veric.

CHRYSOGONIMLUE, adj., chry" sogonimicus. Wallrolb appelle couche chrysogonimiquc (stratum chrysoganimon), dans les lichens, culle qui résulte d'un assemblage de chrysogonidies.

CIRISOLEPIDES, adj. et s. m. pl., Chrysolepides ( $x$ pvoos, or, $\lambda \mathrm{E}^{-}$ 


\section{CHRY}

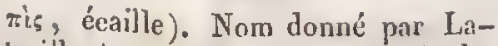
treille à une tribu de la fanille des Sparoïdes, comprenant des poissons qui ont l's éeailies dorées.

Cnrisororis, adj., chrysolophus (xpueis, or, lopiz, crinière). L'Ornismya chrysolopha a deux huppes dorées sur la tête.

Curxsonemas, adj. , chrysomc-

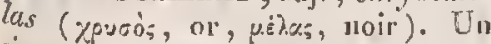
singe (Hapalc chrysomelas) est appelé ainsi parce qu'il a le pelage noir et d'un roux doré vit.

CHnsanúLIDEs, adj. et s. m. pl., Chrysomcliclo. Leach nounme ainsi une famille de Coléoptcires, ayant pour type le geme Chrysomcla.

Cirrisoníndives, adj. et s. m. pl., Chry:somclina. Nom donné par Lamarek, Cuvier, Latreille, Goldfuss et Eichwald à une famille ou à une tribu de l'ordre des Coléoptères, qui a pour type le geure Chrysomela.

ChrusOres, adji., chrysopes ( ove ov , or, $\pi \circ \tilde{u}_{\xi}$, pied); (qui a les pieds jannes, Le Sylvia chrysopus a les tar'ses d'un jaume doré.

CInsopmine, alj., chrysophamus; goldgelbschimmernd (all.). Épithètedonnce par. Willioth au blistème ou thalle d's lichens, lorsqu'à travers sa teinte générale blanche ou grisâtre, on voit percer une nuance de janne doré.

CInIsopuore, adject., chryso-

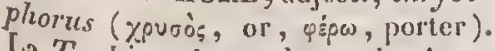
La Tachina clirysophora a la tête et l'anis dorés.

Clinssopunys, adject. , chrysophrys (xpusis, or, äpú, sonreil); qui a les sourcils jaunes. Ex. Embcriza chrysophrys.

CHRISOPITIALME, adj , chrys-

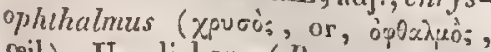
oil). Un lichen (Borrera chrysophthalma) a ses conceptacles larges, arrondis et ciliés.

CIIRISOPHYLLE, adj., chryso-

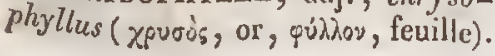

Se dit d'une plante qui a ses feuilles couvertes il'une pulieseence dorée, soit en dessous sculement (cx. Diospyros chrysophyllos, Frezicra chrysophylla, Panax chrysophyllum), soit partout (ex. Sophora chrysophylla). Se dit aussi d'un champigron qui a ses lames dorés (ex. Agaricus chrysophyllus).

CHRSOPROCTE, adj., chryso-

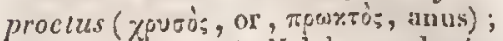
qui a l'extrénité de l'abdomen dorée. Lix. Tachyna chrysoprocta.

CunisoPs, adj., clerysops ( $\chi_{\text {pu- }}$ ò่, or, $\dot{\omega} \psi$, oeil ): (qui a les yeux d'un verd doré (ex. Hemerobius clurgsops'), on d'un jaune doré (ex. Crcrilabrus chrysops).

Curwsoptikn, adj., chrysoplc-

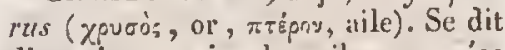
d'un oisean qui a les ailes orangées (ex. Ncops chrysoptera), on enuverles de taches d'un jamne orangé ( $e x$. Philcmon chrysoptcrus;); et d'un poisson yui a les nigeoires dorées (ex. Cheilodiplerus chrysoptcrus).

CumsopyGu, adj., clryssopygus

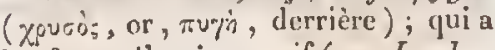
les fesses d'un jaune if (ex. Jacchus chrysnpysus), ou le bout des élytres jaune (ex. Lamprosoma chrysopygium).

CIIRSORIIZE, adj., chry sorhizus (zpuoós, or, pič, racine); qui a les racines jaunes. Ex. Morinda chrysorhiza.

Curnsoninú, adj., chry sorrhcetes (xpurós, or , $\rho^{\prime} s$, entiler); qui a le derrière jaune. Le Phalangista chrysorrlacezes a la eroupe d'un jaune doré. La fenelle du Bomby $x$ chrysorrhata a l'anus garni d'un gros paquet de poils dorés, qu'elle aırache putur recouvrir ses neuts.

CImxsosta CuYÉ, adj., chryso-

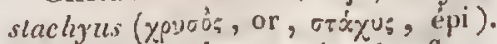
Se dit d'une plante qui a les fleurs jaunes et disposées en épi, Ex. Pas 
palus. chrysostachyus, Disa chrysostaclyya.

CIIMYSOSTEnNE, adj., chryso-

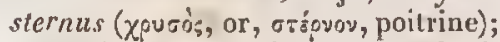
qui a la poitrine d'un jaune doré. Ex. Picus chrysosternus.

CIIRISOSTOME, adj., chrysostomus (you oc;, or, cropx, bouche); qui a la bouelie jaune (ex. Turbo chrysostomus), les joues et le tour des ycux jaunes (ex. Psittactus chrysostomtus).

CHinsote, adj., chrysotis (xpuoùs, or, ovं, oreille). Le Philcmon chrysotis a un demi-croissant jaunc sur les oreilles.

CHRISURE, adject., chrysurus, chrysouros (xpucò, or, oujos., queue); qui a la queue jaune (ex. Histrix chrysuros, Stentor chrysurus), on la nageoire caudale jaunc (ex. Diptcrodon chrysouros).

CIITHONOPLASTE, adj., chtho-

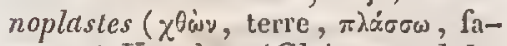
conner). Une algue (Gloioncma chthon noplastes) est ainsi appelée parce qu'elle forme sur le sable humide des couclies qui dessinent les sinuosités du terrain.

GIYYZATE', s. m. , chyazas. Synonyme inusité de Hyorocyanate. Voyez ce mot.

CIIYAzIQUE, adject. , chyazicus. Ce nom, formé de C. $H y$. Az., initiales des mots carbone, hydrogène et azole, a été proposé par Porrett pour désigner l'acide hydroeyanique, et n'a point été adoplé. I'acirle chyazique sulfurć est appelé hrdrosulfocyaniquc.

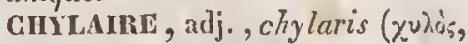
chyle). Synouyme inusité de clyyleux.

$\because$ CIYYLeU, adj. , chylosus; qui concerne le chyle, qui a du rapport avec lui; suc chyleux.

CIIYIFICATION', s. f., chylificatio ( $\chi$ uliós, chyle, fio, être fait). Formation du chyle. chyuivones, adj. et s. f. pl., Chylivora (chylus, chyle, voro, dévorer). Clark désigne sous ce nom une famille d'OEstres, dont il suppose que les larves vivent du chyle des animax dans le corps desquels elles se tiennent.

CMYLOLOGUE, s. f., chylologia

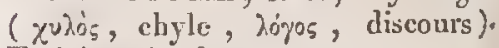
Traité sur le chyle.

GHY OPOItSE, subst. f., chylopoicsis. ( $\chi^{u h \omega^{2}}$, chyle, тsiś, faire). Formation duchyle.

GuYLOSE, s. f., cliylosis. Formation du chyle.

CIIMILERE, adj. , chymiferus ( $\chi \nu \mu \dot{o}^{\prime}$, suc, fero, porter). Hedwig appelait vaisscaux chymiforcs les tubes en spirale ct pleins de suc qu'il admettait, dans les trachées, à la surface d'un autre tube central, droit et plein d'air, suivant lui.

CHIMIFICATION, s. f., chymificatio ( $\chi$ upos, suc, fio, ètre lait). Formation du chyme.

CIIYUOSE, s. f., chymosis. Formation du chyme.

CIBAIRE, adj., cibarius (cibo, nourrir). Quelques entomologistes ont nommé, assez improprement apparcil cibaire, les organes de manducation et de déglutition des insectes.

GICADAInES, adj. et s. f. pl., Cicadarice. Nom donué par Cuvier, Lanıarek, Latreillc, Goldfuss, Eich. wald, Ficinus et Carus à une fámille de l'ordrc des Hémiptères, qui a pour type le genre Cicada.

GICADELLES, s. f. pl., Cicadella. Nom donné par Lat reille et Eichwald à une tribu de la famille des Cicadaires, contenant des insectes qui différent des Cigales, cntr'autres carac ${ }^{\circ}$ tères, par la petitesse de leur taille. GICADIADES, adj. et s.f.pl. Cicadiada. Nom donné par Leacls à une famille de l'ordrc des Hémiptè res, ayant pour type le genre Cicada. 
GICATRICE, s. f., cicatrix; oùh. Marque plus ou moins apparente que toute partie artieulée d'un végétal, une feuille surtont, laisse, après sa ehute, sur l'organe qui lit portait.

CICATmiguL, s. f., cicatricula, hilum. Taehe blanche qu'ou apercoit, sur la membrane du jaune de l'ouf, dans l'cudroit où sc trouve le germe. Traec que le funieule laisse sur la graine des v'ćgétaıx, après que celle-ei s'en est détaehée. Cassini donne ce nom aux marques qu'on apercoit sur le clinanthe des Synanthẻrées, et qui résultent de la ruplure des pédieellules, quand l'ovaire est pédieellé, on de celle des vaisseaux, lorsqu'il est sessile.

cicatrist, adj., cicatricosus; scnarbl, narbig. Un lichen (Glyplis cieatricosa) est appclé ainsi parce que ses apothéeies ollrent d's impressions qui imilent des cicatrices.

CIĆ́rioue, adj. , cicericus. On a donné le nom d'acide cicérique à un aeide qui exsude des poils de la tige du Cicer arietinum. Il est regardé comme un aeide particulicr par Dispan, eomme de l'aeide oxalique par Deyeux, comme un mćlange d'aeides oxalique, malique et aeélique par Vauquelin, comme un mélange d'aeides acétique et malique par Dulong.

CICIIORúEs, adj. et s. f. pl., Cichorea. Nom donuć par D. Dou à une tribu de la f́mille des Chicoracées, qui a pour type le geure Cichorium.

GICINDELetres adj . et s.m. pl., Cicindeleta. Non donné par Cuvirr, Latreille, Goldfuss, Eiehwald, Ficinus et Carus à une trilu de la fa mille des Colćoptères earnassiers, ayant pour type le genre Cieindela.

CICINDELIADES, adj. et s. m. pl. , Cicindeliata. Leaeh désigne Sous ee nom une famille de Coléoptères, qui a le genre Cicindela pour type.

Giconiens, adj. et s. m. p!., $C_{i}$, conii. Nom donné par Blainville à une famille de l'ordre des Echassiers, qui a le genre Ciconia pour type.

GicuTMRIÉEs, adj. et s. f. pl., Cicularica. Nom donné par A. Riehard à une seetion de la famille des Ombellifères, ayant pour type le genre Cicularia.

GICUTINE, s. f., cicutina. Synonyme de conćinc. Vayez ce mot.

CIDAnHOHME, adj., cidariformis (xidapts, bonnet, forma, forme); qui a la forme d'un bonnet, comme le fruit du Cucurbita cidariformis.

GILL, s, m. , coolum, calus ; rothov, oujpavòs; Himmel (all.); Heascn (angl.); ciclo (it.) ( «oìo૬, ereux). On appelle ainsi l'étenduc incommensurable dans laquelle les étoiles, les planìtes et les eomètes aceomplissent leurs révolutions eonstatées ou présumées. Ce mot vient de ce que, n'ayant aueun moyen de déterminer la longueur réelle des lignes étendues de nos yeux anx corps eélestes, nous éprouvons une tendance naturellc à les considérer toutes comme ćtant de longueur égale, ct à nous figurer les astres attaehés en quclque sorte ì un segment de sphèce creuse dont la base reposerait sur notre horizon. - Les mineurs donnent le nom de ciclà la fitee supérieure d'un filon.

CIL, subst. m., cilium; rupró; ; IVimperhaar (all.); ciglio (it.). On appelle ainsi : cn bolanique, des poils un peu raides qui sout placés sur lc bord d'me surfaee et dans le même plan qu'elle, sans faire partie d: l'une ou de l'autre face; sourent anssi celles des petites lanières bordant, après la ehute de l'opercule, l'orifice de l'urne des mousses, qui provicnnent de la paroi interne de celle dernière (ex. Sporangidium). Bridel ne donne eependant la dénomination de cils à ees lanières que quand elles sont grandes; dans le eas eoniraire, il les appelle cilioles. En 
zoologie, on nomme cils les poils qui garnissent le borl des pitupières, dins un grand nombre d'aniniaux verlébrés, et les poils raicles qui se voyent sur certaines parlics du corps d'une multitude d'insectes.

CILIMIRE, adj., ciliaris; qui est garni de eils. Le Megastachya ciliaris a les gânes de ses feuilles, le Puspalum ciliare se's Acurs, l'Astrantia ciliaris ses feuilles, et l'Aconilume ciliare sis pétales ciliès.

CILLATIOLIÉ, adj., ciliatifolize; wineperblïttrig (all.) (ciliune, cil, folium, feuille); qui a les feuilles cilices. Ex. Scirpus ciliatifolius, Olyra ciliatifolia.

CInIT TOPH́tAl:, adj., ciliatopetalus icilium, cil, pctalum, pétale); qui a les pétales ciliés. Ex. Rosa ciliatopetala.

CHIĹ, aclj., ciliatus; wimperig , gewimpcrt (all.); cighliato (it.) (eilium, cil); qui est garni de.cils, comme les anthices du Galcopsis Ladanum, les paléoles du Secralc Ccrcale, Je calice du Metrosideros ciliata, lcs stipules du Coffea ciliata, les bractées du Brunella vulgaris. On appelle gruinc ciliéc, celic qui est marginée ct qui a le rebord découpé en fines lanières comparalules à des cils (ex. Menyanthes nymphö̈des); feruilles cilices, celles qui sont bordées de poils droits, disposés en série, comme les cils des paupières (ex. Ocluna ciliala, Tackymitrium cilianum); stigmate cilié, celui qui est garni à son coutour de fincs lanièrcs ou de poils (ex. Sanguisorba media); cypsèle cilicic, celle qui cst surmon tée de poils disposés en manićre de cils (ex. Echinols); gerge de corollc cilice, celle qui est absliuće par des cils (ex. Cientiana ectmpestris); poils ciliés, ceux qui sunt implantés sur le bord mèrne de la lame, et se prolongent dans sou plan, imitant in ecla les cils des paupières (ex.

\section{CILI}

Ruellia ciliata). En zoologie on dit: écailles cilicés, dans les poissons, quand elles sont finement dentelées (ex. Holocentrus ciliautus, Holacanthus ciliaris); corsclet cilie, dans les insertes, lorsqu'il est chargé de poils raides, assez longs et parallèles (ex. Trox); ailesciliées, quand elles sont terminées à leur bord par quelques proils très-serrés, en forme de cils (ex. plnsicurs Mouches). La Mutilla ciliaia a les bords des anneaux de soll abdomen ciliés de blane.

CIr.Iés, adj. et s. m. pl., Ciliata. Noun douné par Lamarck à un ordre de la classe des Polypes, coinprenant cenx dont la bouche est munic de cils mouvans ou d'organes gyratoires; pa: Scluwcigger à un ordre de celle des Zoophytes monohyles, daus lequel il range ceux qui ont le corps lomogìne et garni de eils; par Latreille i une famille de l'ordre des Acaliphes Poecilomorphes, embrassant ceux qui offrent souvent des cils; par Blainville à une section de la division des Microzoailes hétéropodes, comprenant ceux qui ont le corps pourvu d'appendices locomotcurs latéraux en forme de eils.

CILPELE, adj., ciliferus ( $c i$ lizme, eil, foro, porter); qui porte des cils ; ramule cilifère.

GILIF OnWE, adj., ciliformis (cilium, eil, forma, forme); qui a la forme d'un cil, par sa direction et sa raideur; prolongement ciliforme.

CLIGEnE, adj, , ciligcrus (cilizm, cil, gero, porler); qui pol te des cils, comme la Zenillia ciligera en a sur la faec.

CILIICONXE, adject., ciliicornis (cilium, cil, cornu, corne); qui a les antennes velues, comme les crustacés appirtenant aux genres Atelecyclus el Thia.

LIOBRANCrES, adj. et s, m. pl., Ciliobrunclia (cilium, cil, $\beta_{i} \dot{x}_{7} \chi^{1 \alpha,}$ 
CIMI

branehies). Férussae propose d'établir sous ee nom un ordre de la elasse des Mollusques, pour y placer le genre Allas, qui a le manteau bordé de eils, qu' on suppose, d'après Lesueur, ètre des branchies.

CILlogrades, adj. et s. m. pl., Ciliograda. Nom donné par Blainville à une classe ou famille de farux zoophytes, dont le corps est pourvu d'ambulaeres formés par deux séries de eils ou eirres appendiculaires servant ì la locomotion.

CILfole, s. m. , ciliolum. Nom donné par Bridel aux dentelures ou prolongemens du péristome interne des mousses, quand ees appendiees sont très-petits.

CHLIOLE, adj. , ciliolatus; qui est garni de petits cils; eomme les feuilles de l'Hedyotis ciliolatn, et les pétioles du Monnina ciliolata.

GLLPLDE, adj. , cilipes (cilium, cil, pes, pied); qui a les pattes garnies de cils. Ex. Culcx cilipes.

CrMe , s. f. , cacumon; Wipfel (all.); top, ridge (angl.); cima (ii.). Partie supérienre d'une montagne. Protubéraneeque le faíte d'une chaîne de montagnes lorme entre deux cols voisins. Protubćrance qui, dans les ehâines ou masses de montamnes, s'élève brusquement sur un faîte ou unc erête, au-dessu; des partics adjaeentes. Il serait plus régulier de n'appliquer ee nom qu'aux sommités qui se distinguent an milieu d'une chaîne de montagnes.

CIMEN'T, s. m. Les géoguostes appellentainsi tout corps qui sert à unir des fraginens d'un autre corps, comme par exemple cenx qui constituent les briches et certains agglomémts.

CIMEvTl, adj. Bomnard donne cette épithice atix roches dont les parties sont lices par un ciment peu appirent. Ex. Psammite.

CIMICInES, adj. et s. m. pl., $C i$ micide, Cimicides. Nom donné par
Latreille, Goldfuss, Ficinus et Carus, à une famille de l'ordre des Hémiptères, qui a pour type le genre $\mathrm{Ci}$ mex.

CNARties, adj. et s. f. pl., $C_{i-}$ narece. Nom donné par H. Cassini à un seetion dela tribu des Carduinćes, et par Lessing à une tribu de la famille des Syuanthérées, ayant pour type le genre Cinara.

CINAROCEPHALES, adj. et s. f. pl., Cinarocephales ( revxpo, arti-

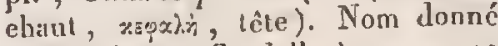
par Vaillant et Candolle ì un groupe de la famille des Synanthérées, érigé en famille par Jussicu, et eomprenant des plantes qui, par la forme générale de leurs eapitules, se rapproehent plus ou moins de l'artichaut.

Cinchonacíses, adj. et s. f.pl., Cinclonacea. Nom douné par Canndolle à une tribu de la famille des Rubiacées, qui a pour type le genre Cincliona.

CINCHONEES, adj., Cinchonea. Nom donnc par Kunth et A. Richard à une tribu de la famille des Rubiaeées, par Candolle à une sous-tribu de la triba des Cinchonacées, ayant pour type le genre Cinchona.

CINCnonive, s. f. , cinchonina. Alcali végétal qui a ćté déeouvert par Pelleticr et Caventou, et qui existe dans presque tous les quinquina, mais en plus grande quantitć que partout aillenrs damsle gुris.

CrNGHONıuE, adj., cinchonicus. Bcrzelius donne felte épithète anx sels dans lesquels la cinchonine joue le rôlc de base. On appelle rousge cinchonique une substance, de couleur ronge foneéc, qui résulte d'une eomhinason de tamnin d'éeorce de quinqquina et d'apothème, et qui reste sans se dissundre quand on traite par l'eau le produit de l'évaporation à ehaud et ì l'air de la solution aquense de ce tannin.

GINCXIPEDE, adjeet., cinctipes 
(cinclus, entouré, pes, pied); qui a les pattes entonrées d'un anneau coloré. Ex. Limnobia cinclipes.

CINÉRíicOLLE, adj., cinereicollis (cinereus, eendré, callum, col) ; qui a le devant du col gris. Ex. Cinnyris cinereicallis.

CINÉRÉIFRoNT, adj. , cincreifrons (cinerens, cendré, frons, front); qui a le front de couleur eendrée. Ex. Alcedo cinercifrons.

cINǴrides, adj. et s. m. pl. , $\mathrm{C} i$ nerides. Noun donné par Leach à une famille de l'ordre des cirripèdes campylosomates, qui a pour typele genré Cineras.

CIvGutês, adj. et s. m. pl., Cingulata. Nom donné par Illiger à une famille de l'ordre des Fonissenrs, par Goldfuss à un ordre de la classe des Nammifères, par Ficinus et Carus à unc tribu de la famille des Edentés Longirostres, renfermant des mammifères dont la peau osseuse est disposće de manièrc à former autour du milieu du corps plusieurs londes suseeptibles de glisser el de se mouvoir les unes sur les autres.

GINGULIFÈR, adj., cinguliferus (cingula, ceinture, foro, porter : Epithìte donnée à des coquilles qqui sont marquées de eôtes suillantes ou de raies colorées simulant une sorte de ceinture. Ex. Murex cinguliforts, Turbinella cingulifera. Voy. CensTURÉ.

CINGULUM, s. m., cingulum. Hedwig appelait ainsi l'anneau artieulć qui entoure les eapsules de quclques fongères.

Cinipsaizes. $V_{\text {oy. Cyntpsatres. }}$ CINNABARIN, adj., cinnabarinus; zinnaberroth (all.) (cinnabaris, einabre); qui cst d'un rouge de cinabre. Ex. Aranca cinnabarina, Coniocarpon cinnabasinum.

CINvYRIDES, adj. et s. m. pl., Cinnyride. Nom donné par Vigors à une tribu de la famille des Ténui- rostres, par Lesson à une famille de l'ordre des Grimpeurs, ayant pour type le genre Cinnyris.

CIONIDEs, adj. et s. m. pl., Cionilles. Nom donné par Sehoenherr à un groupe de la section des Curenlionides Gonatoeères Mécorhynques, qui a pour type le genre Cionus.

CIPOLIN, adj. (de l'italien cepola petit ojgnon). Epithète donnée à une roche cristalline à base calcaire, paree qu'elle a unc structure fissile, et qu'on a cru trouver de la ressemblanee entre la disposition de ses feuillets et eelle des tuniques des oignons.

GIICÉLACÉEs, adj. et s. f. pl., Circaccere. Nom donné par lindley à la famille des Onagraires, à eause du geure Circa qu'elle renferme.

crincées, adj., Circaea. Nom donné par Candolle à une tribu de la famille des Onagraires, qui a pour typc le genre Circáa.

CIRCELLE', adj. , circcliatus (circcllus, petit cercle). L'Agaricus circcllatus est ainsi appelé paree qu'ila son chapcau zoné en dessus.

CHLCWML, adj., circinalis, circinans, convolvans; kreiselnd (a 1.); accliocciolalo (it.) (circino, rouler); qui est roulé sur soi-mène, transversalement et du soinmet à la base, comme une boucle de chevcux sur un compas, ce qui a lieu pour le légume de l'Adcnanthcra circinalis, ctle lobe terminal des feuilles pinnatifides du Sinapis circinala. Le Leolia circinans est un champignon terrestre qui se groupe circulinircment; le Lituites convolvans, une coquille remarquable par l'enroulement de ses tuurs de spire; le Balanus circinatts, un cirripède marqué de zoncs concentriçues; le Merops circinatus, un oiseau dont les plumes des oreilles descendent sur la poitrinc, en se frisant.

Gincurs, adj., circinalus; auf- 
gerollt (all.) (circino, rouler). Se dit, en botanique, de l'cstivation, lorsque les organcs flornux sont roulés en crosse sur eux-mêmes, oul cu spire sur un seul plan, comme le style du Salinara; des corylérlons, quand ils sont roulés en spirale de haut en bas (ex. Koclreutcria paniculata); des fouilles, dius le loourgeon, quand elles sont roulées on crosse ou en volute, du solumet ve:'s la base (cx. Fougères); des feuilles développées, lorsqu'elles se prolongent en une longue pointe roulée sut ellc-même (cx. Flagellaria indica), ou qu'elles se roulent sur clles-mèmes parla dessicention (cx. Dicranum circinnatun ); des verticilles de flcurs, quand ils sont roulés en crosse (ex. Heliotropium); des grappes de flenrs, lorsqu'avant ct aprés l'anthèse, clles sont roulćes en spirale (cx. Solcnanthus circinnatus).

CIRCONMĹLIDIEN, adj., circtemmericlianus. On appelle larucurs circomméridicnnes celles des ćtoiles qu'on olsserve ux voisinage du míridien. Elles servent lorsque, par défant d'instrumens fixes, on ne peut point obtenir la vraic hatuteur méridienne avec unc exactitude parfaitc.

CIRCOMPOLATR:, adj., circumpolaris (circum, autour, polus, pôle). Cette ćpithète est dounéc aux étoilcs qui sembleot tourner journcllement autour du pôle, sans jaunais s'abaisser au dessons de l'horizon du licu où on les observe.

CIRCONSCISSILE, adj., circumscissilis (circum, autour, scissilis, susceptible de se fendre). Epithète donnéc par L.-C. Richard aux péricarpes qui s'ouvrent en deux partics par une scissure transversale eireulaire. Ex. Anagallis arecnsis.

CIrconscurT, adj., circumscriptus ; umschrieben (all.) (circum, autour, scribo, écrire). Ce norn est donné : dans la nomenclature minéralogique de Haiiy, à unc variélé de mâcle dans laquelic le prisme est entièrement noirattre, ì cela près d'une pellicule d'un blane nacré qui cn recouvre les pans.

Circonvolutiox, s. f., anfractus (circum, nutunr, volpo, tourner). Irévolution compléte du cone spiral. d'une coquille spirivalve. Synonyme peu usité de tour do spire.

chrocuande, adj. , circularis : zirkelfömigr (all.); circolare (it.) (circmlus, cerele); qui est fait cut cercle, e'est-a-dire dont tous les points sont également éloignés du ceutre, comme la gorge de certaines corolles monopétales, des Phlox par exemple.

CrICUNAXUL, adj., circumaxilis (circum, nutour, axis, axe). Mirbel donne cette épithère aux nervules du placentaire, quand elles sout appliquées contre un axe eentral, dont clles se sćparent ì l'époque de la déhisenec. Ex. Epilobiunt.

Clive, s.f., cera; mpo; ; Wach,s (all.) ; wax (angl.) ; cera (it.). Substance particulière que produisent les abeilles, dont le ruode de séerétion, découvert par $G,-C$. Horubostel, reprodnit par Riem et dunuć par Hunter comine une déconverte it lni, a été confirmé par Huber et Mile Jurine, et mis hors de doute par G.-R. Treviranus. Beancoup de végétaux sécrìtent aussi de la eirc.-On appelle circ (ccra, ceroma; Schnabclhaut, IV achshaut, all.), dans les oiscaux, une membrane ordinairement eoloréc qui, chez plusicurs de ces animaux, recouvre la base du bee et surtout celle de la mandibule supćrieure.

GHiner, adj. , cercarius. Huber donne l'ćpithète de ciriëres :uxx abeilles qui, dans les ruches, s'oceupent uniquement de la constructiou des gîtcanx. 
cmpUe, s. m., circus. Nom donné à la terminaison d'une vallée voisine do faîte, lorsqu'en eet endroit elle s'ćlargit et prend une forme arroudie. On l'applique aussi aux bassins de montagnes, lorsqu'ils sont disposés circuhairement de manière à rappeler la forme des théâtres de l'antiquité.

CImRAL, adj., cirrhalis. On appelle ascidium cirrhale (Rankenschlauch, Stcngelschlauch, all.) le godet d'une fenille ascidiće, quand il est formé par une vrille fnliaire, comme dans le Nepenthes phyllamphora.

CInRe, s. nı., cirrus, cirrhus, caprceolus, claviculus, hclix. On appelle ainsi : $x^{0}$ en botanique, des appendices filiformes, simples ou rameux, diversement tortillés ou roulés, au moyen desquels ecriaines plantes s'attachent aux corps voisins. Voy. Mats , Vritce. $2^{\circ}$ En zoologic, ce inot a plusieurs acceptions différentes. Merrem l'cunploie pour désigner des pernes longues, en forme de crins, qui, partant du dessus des yeux, retombent le long du cou, ct Illiger des plumes à tige très-longue, sans barbes, out pourvues de barties très-courtes, et qui souvent n'en portent qu'à l'extrémité. On donne quelquefois ee nom aux barbillons des poissons. Pline appelait cirres les pieds des Céphalopndes. B̉aainville donne cette épillsète ì de petits prolongemens culanés, cylindriques, vermiformes, plus ou moins irritables et contournés, qui sont répandus d'une manière régunulière ou irrégulière sur diverses parties du corns des Mollusques, spécialement sur les bords du manteau, dans lés lamellibrancles; et à des espèces de filamens nou vasculaires, de forme et de longueur très - variables, qui, dans les Chétopodes, existent, soit à la partie supérieure de l'appendice, immédiatement au dessous de la branchie, quand il y en a une, soit à la partic inférieure ou ventrale de ce mème appendice. Enfin on appelle cirres les appendices articulés des Cirripèdes.

CIRRÉ, adj., cirratus; rankentragcnd (all.o). Bouclé, frisé, frangé, velu, vclouté. Se dit, $\mathrm{I}^{\circ}$ en botanique, d'une partie qui affecte la forme ou remplit les fonctions de cirre, eomme la pointe grête et prolongée des feuilles de ecrtaines plantes, ou divers pédoncules communs; $2^{\circ}$ en zoologie, cirré veut dire qui est muni d'un prolongement, comme le trés-long filament qu'on voit en avant de l'ouverture postérieure du corps de la Filaria cirrata; ou qui porte une huppe retombant sur le col (ex. Falco cirratus). Dans ce dernier cas, il est synonyme de huppé.

GIInEux, adj., cirrosus; rankig(all.); vilicciato (it.). Se dit, en botanique, d'une plante dont une partic remplit l'office de vrille, comme les pédoncules de l'Adlumia cirrosa, ou qui a des vrilles remarquables, soit parce qu'elles sont très-rameuses (ex. Lalhyrus cirrosus), soit à cause de leur origine, étant dues, conme celles du Clematis cirrosa, aux pétioles persistans de l'année précédente. Le Macromilrium cirrhosum doit eelte épithète à la flexuosité de ses feuilles, ainsi que le Wcissia cirrhata. Le Cyprinus cirrosus est airsi appelé parec qu'il porte deux barbillons à ln mâchoire supéricure. Blainville donne le nom de tentacules cirrcux anx prolongemens en forne de bras du corps des higdres.

cintroctemiLe, adj., cirrho-

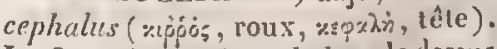
Le Sparvius cirrhocephalus a le dessus de la tète d'un gris cendré; le Larus cirrhocephalus a la tête d'un cendré bleuâtre. 


\section{CIRR}

CIRRHOCHLORE, adj. , cirrhochloris (xpopós, roux, $\chi$ lowpos, verd). Lc Trochilus cirrhochloris a le plumage vert et gris.

CIRIRIOGRAPIIQUe, adj. , cirrhographicus ( rpöṕs, roux, ypáow, écrire). Nom donné par Haüy à unc variélé de fer oxidé, la terre d'ombre, qui donne une conleur listre.

CIRritovelas, adject., cirrho-

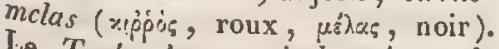
Le Tachyphonus cirrhomclas a le plumage noir et fauve.

CmRIFène, adject., cirrifcrus, cirrifer, cirriger (cirrts, boucle, fero, porter ); qui porie une touffe de cheveux, comme le Cebus cirrifer, sur le devaut de la tête duquel on voit un toupet de poils très-élevés.

Cirrarlone, adj., cirriflortes (cirrus, vrille, flos; fleur); qui a les pédoncules changés en virilles, munis de vrilles, on faisant fonetion de vrilles. Ex. Passiflora cirrifora, Unearia cirriflora.

CIRRIF ORME, adj., cirriformis (cirrus, vrille, forma, forme). Se dit du pétiole, quand il est contourné et remplit les fonctions de vrille. Ex. Fumaria caprealata, Clcmatis orientalis.

Cirrigetre. Foycz Cirrifère.

CirRigrades, adj. et s. m. pl. Cirrigrada (cirrus, cirre gradior, marcher). Noun donné par Blainville à un ordre de la classe des Arnchnodermaires, comprenant ceux dont la face inférieure du corps est garnie de cirres tentaculiformes trés-cxtcnsibles et eontratiles.

CIRRIPLEDE, adj. et s. m. pl. Clrripcdes (cirrus, cirre, pcs, pied). Nom donné par Lamarek, Latreille et Schweigger à une classe d'animaux sans vertèbres, par Eichwald ì un ordre de la classe des Thiérozoaires, comprenant ceux qui ont lc corps pourvu d'appendices en forme do cirres, fort longs, cornés, arliculés, et qu'on peul considérer comme des rudimens de membres.

CHiRobraxciles, adj. ct s. m. pl., Cirrobranchiala (cirrus, circ, Beáryzes, branclies). Norn donné par Rlainville à un ordre de la classe des Paracéphalophores, comprenant ceux dont les organes branchiaux ont la forme de longs filamens.

CilRopones, adj. et s. m. pl., (cirrus, cirre, touis, picd). Nom donuć par Cuvier à une classe d'animaux mollusques, par Straus à une clisse d'animaux articulés, par Groldfuss à un ordre de la classe des Mollusques, comprenant ceux qui ont le long du corps des filets ciliés représentant des espèces de pieds ou de nageoires.

CISELCL, adject., insculptzs; qui offre des enfoncemens semblables à de profondes cisclures, comme le bec du Buccros insculueus.

Cisinles, adj. el s. m. pl. , $\mathrm{Ci}-$ sidce. Nom dounć par Leach à une famille de l'ordre des Coléoplères, Iui a pour type le genre $C$ is.

CISTE, s. f. , cisıa ( Non donnć par Scopoli à une triple enveloppe de graine, dont l'externe et la moyenue sont membraneuses, ct l'interne fongueuse ou charnue, et qui ne s'ouvre pas (cx. Passiflora, Ligustrum) ; par Bernhardi à un péricurpe à la voûte duquel sont attacliées les semences.

Cistúes, adj. cl s. f. pl., Cistca. Spreugel désigne sous ce nom une fumille de plantes, qui a pour type le genre Cislus.

Costélénils, adj. et s. m. pl., Cistelcria. Non douné par Goldfuss, Ficinus el Carus á une tribu de la famille des Coléoptères hétérolytres, ayaut pour type le genre Cistcla.

CISTÉLIDES, adj. et s. m. pll., Cistclides. Nnm sous lequel Latreille et Eicluwald dé ignent ume tribu de la 
famille des Coléoptèrcs sténélytres, qui a pour type le genre Cistela.

Cistelle. Voyez Cistule.

CISTIFLORES, adj. et s. f. pl., Cistiflora. Nom douné par Barting a une classe de plantes qui comprend les familles des Flacourtianćes, des Marcgravićes, des Bixinécs, des Cistinécs, des Violariées, des Droséracces et des Tamariseinées, et qui a pour type le genre Cistus.

CISTINÉES, adjcet. et s. f. pl., Cistinca. Nou donnć par Candolle à une fanille de plantes, syant pour type le genre Cistus.

CISTOIDĹes, adj. et s. f. pl., Cistoidca. Non dounć par Ventenat à une famille de plantes, dont le genre Cistus est le type.

CisTOPHLLE, adj., cistophilus; qui croît sur les cistes, comme l' $A n$ tennaria cistophila sur les tiges des cistes frutescens.

CISTULE, s. f., cistula, eistella; Bläschen (all.); ccstella (it.). Willdenow appelle ainsi les conceptacles de lichens qui sont orbiculaires, creux et parfaitement clos dans leur jeunesse, surmontent un podétion de la substance duquel ils ne sont qu'un dévcloppement, se fendent irrégulièremeut à leur unaturité, et laissent apercevoir alors dans leur centre une fongosité fibreuse qui scrt de placentaire ì des séminules groupécs en pctites masses. Ex. Spharophorum.

GITHARowlies, adj. et s. f. pl.,

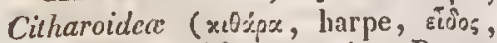
ressemblance). Nom donné par Bory ì une famille de l'ordre des Mieroscopiques crustodés, à cause de la forne du test des animaux qui la constituent.

CITigrades, adj. et s. f. pl., Citigrades (citò, vitc, sradior, marcher). Fpithète donnée par Latreille à unc tribu de la famille des Aırancides, renfermant ceux de ces animaux qui se distinguent par la vélocilc de lcurs mouvemens.
Cithate, s. m., citras. Genre de sels (citronensaure Salze, all.), qui sont produits par la combinaison de l'acide citrique avec les bases salifiables.

CITRICOLE, adj., citricolus (citrus, citronier, colo, habiter); qui crồtsur les citroniers. Ex. Loranthus cilvicola.

CITRIx, adj., citrinus, citreus ; citronengelb (all.) (ciirus, citron); qui a la couleur jaune du citron. Ex. Bulimus citrinus, Gorgonia citrina, Coremium citrinum, Aranca citrea, Motacilla citreola, Agraricus citrinellus.

CITRIQLE, adj., citricus (cilrus, citron). Epithète donnce à un acide (Citronensïurc, all.), que Scheele a découvert, en 1784 , dans le suc de citron, ct à un éther, qui l'a été par 'Thénard.

civic, adj., civilis. On appelle jour civil, parce qu'il sert à fixer lcs dates dans les transactions civiles, le temps qu'emploie le soleil a revenir au méridien, soit supérieur, soit inférieur, c'est-à-dire la révolution diurnc tout entière de cet astre. Les Grecs appelaient cette période $v \chi^{\theta}{ }^{-}$ ;uspor; elle porte le nom de dygn en suédois, et de schebarruz en persan. On la divise en quatre portions, matin, midi, soir $\mathrm{ct}$ minuit, qui sont déterminécs par les passages du solcil à l'horizon et au méridicn. ( $V_{0 y}$ ez Jour). L'année tropique (vayez ce mot) porte aussi le nom d'année civile, parce que c'est la seule dont on fasse usage dans la vie civile, quoique les inégalités auxquclles clle est astreintc eussent dû faire préférer l'année sidérale, qui ne varie jamais. Gependant l'annce civile n'est pas l'annéc tropique tout en lière, on du moins ne se met cn accord avec cctte dernière qu'au moyen des intercalations. Voyez ce not.

Cr LDOCAuPes, adj. et s, m. pl., 
Cladocarpi ( $\% \dot{x} \delta x$, massue, xхpлtí, fruit). Nom donné par Bridel a une classe de Monsses, comprenant celles qui ont leur fructificalion terminalc et en forme de massuc.

CLADochines, adj. et s. m. pl.

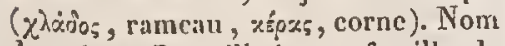
donné par Latreille à une famille de l'ordre des Crustacés lophyropes, renfermant ccux dont la lête porte de chaque côté une grande antcunc, en forme de luras, diviséc en deux ou trois branches.

CLADODial, adi., cladodialis ;

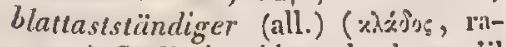
meau ). Se dit du pédoncule, lorsqu'il naît sur un phylloclade ou phyllode, comme daus le Ruscus aculcaltus.

ChADONIACÉEs, adj. ct s. f. pl., Cladoniacce. Nom donnis par Reichenbach ì une fanille de Jichens, ayant pour trpe le genre Cladonia.

CLADONiÉs, adj. et s. f. pl., Cladonice. Nom donné par Zenker à une tribu de la famille des Lichens, qui a pour type le genre Cladonia.

CLADONiométes, adj. et s. f. pl.,

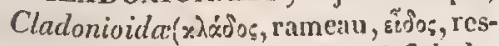
semblance). Nom sous lequel Schultz. désigne un ordec de la classe des Lichens, comprenint ceux qui affecteut la forme d'cxpansions dendroïdes.

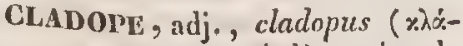

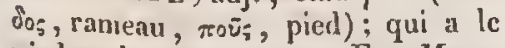
pied ou le stipe rameux. Ex. Merulius cladopus.

CLADOPONES, adj. et s. m. pl., Cladopoda ( pied). Nom douné par G.-E. Grily à un ordre de la elasse des Conchophores, correspondant anx Conchifères dymiaires crassipèdes de Litmarck.

CLADontuzE, adj., cladorhizus, cladorlizans ( $\%$ x) xंo;, rumeau, $\dot{p} i \zeta \%$, racine); qui a unc racine très-rameuse. Ex. Fragosa cladorliza, Neckera cladorhizans.
CLADOSTACHY̌́, adj., cladostacliyus ( qui a ses rameaux floraux rapprochés en forme d'épi. Ex. Carcx cladostachya.

CraIr, adj., clarts. Ce mot a un grand nombre d'acceptions diverses. Il signifie : $1^{\circ}$ en physique, ee qui est éclairé (liez clair), ce quui éclaire bien ( fcu clair), ce qui est luisant oul poli, ce qui cst transparent (verre clair), pen foncé en coulcur (lcinte clairc, Falco clartes), pur, ou screin (cicl clair), sonore et net (voix claire), per épais, peu serré, écarté, sins eonsistance, non trouble: $2^{\circ}$ au figurć, ce qui est distinct, évident, manifcste, franc, pénétrant. On appelle auf clair (ooum zephirium), celui qui a été poudu par une femelle d'oisear non fécondéc.

CLAInIDIs, adj. et s. m. pl., Clcrida. Non douné par Kirby à une fanille de l'ordre des Colćoptères, ayant pour type le genre Clerus. Y̌o. Cuénuns.

CLAmoNs, s. m. pl., Clcrii. Nom donné par Cuvier, Latreille, Goldfuss, Eichwald, Ficinus et Carus à une tribu de la famille des Coléoptères serricornes, ayant pour type le geurc Clcrus.

CLANDISTIN, alji, , clandestinus. Secret, rachć. Le Laihr aa clandestina cst ninsi appelé parce qu'il croit dans les licux ombragés; le Panicum clandestinum, parce que ses ćpis sont cachés dans les gaines des feuilles.

CLANGUEUR, s. f., clangor. Bruit produit par une voix aigre et sifflante. Cri retentissant de plusieurs oiseaux palmipèdes.

CLAPLE, subst. m. Terrier que crense le lapin, et qui lui sert de retraitc.

CLARIPENVE, adj., claripennis (clarus, clair, pcnna, aile); qui a les ailes claires. Ex. Tachina claripennis. 
ClaSSIFICATION, s. f. (classis, classe, facio, faire). Distribution méthodique d'une collection d'ètres naturels. "II n'y a de distinct que l'individualitc. Toutes l's divisions cn espèces, genres, familles, cohortes, sont notre onvrage, des choses plus on moins arbitraires, Hacher un peu plus ou un peu moins lc tableau gradué dc la nature, est entièrement une affaire de goût. " (Turpin.)

CLASTIOUE, adj., clasticus ( $\alpha \lambda_{\alpha \sigma-}$ $\tau \dot{\alpha} \omega$, casser). Brongniart donnc cettc épithète à denx groupcs de terrains, les uns clysmiens, les auires thalassiques tritonicns, qui, dans leur position ct dans lours parties, présentent tous les caractères de fiacture.

Clatiranákés, adj. ct s. f. pl., Clathracca. Nom douné par Brongniart à une tribu de la famille des Champignons, qui a pour typc le genre Clathrus.

CLATILRODES, adj. et s. f. pl., Clathroidcs. Nom donné par A. Brongniart à un groupe de la tribu des Clathracées, celui qui renferme le genre Clathrus.

CLAUSiconques, adj. et s. m. pl. , Clausiconche (clausus, fermć, concha, coquille). Nom donnć par Latreille is une section de l'ordre des Conchifères tubulipalles uniconques, comprenant cux dont la coquille est composée de deux valves appliquées l'une eontre l'autre sans bâillement.

ChaCsILE, adj., elausilis ( clausus, fermé). L.-C. Riehard donuc cette ćpithète à l'cmbryon dont la radicule, soudće par ses deux bords, renferne complètement le reste.

CLALsTinditciles, adj. et s. f. pl., Claustrarice (claustrum, clòture, tela, toile). Fipithète donnée aux araignées qui filent des toiles cn ccllules ovales, sous les picrres.

GLAVAIRes, s. f. pl., Clavarice. Marquis appelle ainsi un groupe de la

\section{CLAV}

famille des Hymćnothćciens, qui a pour type le genre Clavaria.

Clavariées, arlj. et s. f. pl., Clavariece. Nom donné par A. Brongniart à une scetion de la famille des Champignons ayant pour type le genre Clavaria.

CLAVATULÉ, adj., elasatulatus (clavus, clou); qui a un peu li forme d'un clon. Ex. Buccinum clavatulum, Cerithium clavatulatum.

CLAVli, adj, clavalus, herculeus; keulcnförmig (all.) (clava, ınassue); qui est fuit cu forme de massue, c'est-à-dire qui va en grossissant de la base au sommet, comme le légume de l'Astragalus clavatus, la silicule du Rapistrum clavalum, le filat des étamines du Thalictrum clavatum, l'abdomen de la Libellula clavatu, le haut du stipe du Lyeoperdon herculeum.

CLAVELLE, adj., clavellatus, clavillosus; quia la forme d'une massuc, comme les feuillıs du Mesembryanthemum clavellatum, la coquille du Fusus clavclialus, les branches terminales de la fronde du Gastridium clavellosum.

CLAVís, adj. ct s. m. pl., Clayaci. Nom donné par Fries à un ordrc de la clisse des Hyménomycètes, comprenant ceu $\mathrm{x}$ de ces champignons dont le réceptacle est claviforme.

CLAVICEPS, adj., claviceps (clava, massue, caput, lète); qui a la léte en forme de massue. Ex. Botryocephalus clariccps.

Claviconxe, adj., clavicornis (clava, inassue, cornu, corne); qui a lcsantennes (ex. Mylabris clavicornis), les autennules ou palpes (ex. Hydracline clavicornis) en massue. Clavicornes, adj. et s. m. pl,, Clavicornia. Nom donné par Cuvier, Lamarck , Latreille, Duméril et Eichwald ì une famille de l'ordre des Coléoptères, comprenant ceux qui ont les antennes en massuc. Latreille 


\section{CLAV}

propose de substituer ee nom à celui dc Lépidoptères diurnes, en raison de la forme des anteunes de ces inscetes.

Claviculainis, adj. et s. m. pl., Claviculares (clavicula, pelite massue). Nom donné par Frics à une tribu de l'ordre des Ilyménomyeètes elvellacés, comprenant ceux qui ont le réeeplacle tuberculeux, sublenticulaire.

GLAviculE, subst. f., clavicula (clavis, elef). Quelques anciens anteurs ont donnć ce nom à la columelle des coquilles spirales, etil a été parfois aussi appliqué aux pointes d'oursins. Kirby appelle ainsi le premier article des bras ou pattes antérieures des insectcs hexapodes.

Claviculé, adj., claviculatus (claviculus, cirre); qui est tcrminé en vrille, comme les feuilles supéricures du Fumaria clnviculata. Se dit aussi en parlant d'une coquille univalve dont l'ouverture esl garnie de lames (ex. Clausilia corrugata).

CLAVIFOLIń, adj. , clavifolius (clavis, elef, folium, feuille) : qui a des feuilles claviformes. Ex. Crassula clavifolia,

CLAVIFORUE, adj., clasiformis; clavalo (it.) (clara, massue, forma, forme); qui a la forme d'une massue, c'est-ì-dire qui ust renflé de la base an sommet, comme le spadix de l'Arum maculatum, le calice dis Silanc Armeria, la corolle de l'Erica pinea, le tube de la corolle du $S p i-$ gelia marylandica, les poils du Dic. tamniss albus, les filets des élamines du Thalietrum atropurpureum, le siglc du Cucullaria excclsa, Ic sligmate du Jasione montana, le fruit du Cucurbita claviformis, les feuilles dn Mesembryanthemum claviforme, la radicule du Ceriscus malabaricus, l'embryon du Hyacinthus non scriptus, l'urne du Leiothcca clapellaia, les antennes des Scarabies, les pal-

pes des Vrillctles, l'abdomen de l'Evania appendigaster, la coquille du Conus clavatus et de la Pholas clavata.

Cl.ATimane, adj., clavimanus (clava, massue, manus, main). Le Plagusia clavimana est ainsi appelé parce qu'il a la main renflée, grosse et conrte.

CLAVIPALPES, adj. et s. m. pl., Clavipalpi, Clavipalpata. Nom donné par Cuvier, Latreille et Eichwald à une famille de l'ordre des Coléoptères, comprenant ceux qui ont les autennes terminées cn massue.

CLA VIPL̀DE, adj. , clavipes (cla$y a$, massue, pes, pied). Se dit d'un insecte qui a les cuisses postérieures renflćes. Ex. Chalcis clavipcs.

CLAVIVENTRE, adj., claviventris (clava, massue, vcntcr, ventre); qui a l'abdomcn en forme de massue. Ex. Musca elaviventris.

CLAVOLE, s. f., clavola. Kirby donne cotle épithète à l'ensemble des articles de's anteunes, dans les insectes, déduction faite des deux premiers.

GLAVuLÉs, adj. et s. m. pl., Clavulati. Nom donné par Fries à une tribu de l'ordre des Hyménomycètes elavés, qui a pour type le genre Clavaria.

CLAvULigerre, adj., cluouliger (clavulus, petit clou, /cro, porter). Un champignon (Conoplca clavuligcra) est ainsi appelé à cause de sal forme.

CLĹnintidées, adj. et s. f. pl., Clcmatidea. Nom donné par Candolle à unc tribu de la famille des Renouculacées, ayaut pour type le genre Clematis.

CLENATITÉEs, adj. et s.f. pl. , Clcmalitex. Now donné par Calin à une fanille de plantes qui a pour type le gicnre Clcmatis.

CLÉ Oñ́ís, adj. et s. f. pl., Cleomea. Nom donné par Candolle à une 
tribu de la famille des Capparidées, ayant pour type le genre Cleomc.

CLEONIDES, adj. et s. m. pl., Cleonides. Schœuherr lésigne sous ce non un groupe de la famille des Curculionides gonatocères brachyrhynques, qui a pour type le genre Cleonus.

CLEPTIOSES, adj. et s. m. pl., Cleptiosa. Nom donné par Latreille à une famille de l'ordre des insectes Iyménnptères, qui a pour type lc genre Clcptes.

Chatuoes, adj. et.s. m. pl., Clerida. Nom donné par Leach ì une fanille de l'ordre des Coléoptères, ayant pour type le gemre Clcrus. Voy. Cuamides et Clairons.

CLIGNOTANT, adject., nictitans. On appelle mombrane clignotante la troisième paupière des oiseanx, qui est fixée à l'angle interne de l'œil, jouit d'une demi-transparence, et pent se tirer sur l'iris comme un rideau ; on lui suppose la fonetion de diminuer l'inteusité des rayons lumineux.

CLIMAT, s. m., clima, regio terra, inclinatio coli ; xhipa; Himmelstrich, Erdstrich (all.); climate (angl.); clima (it.) (rìivw, ineliner) On a successivement désigné sonts ec nom des espaees, d'une étendue arbitraire, compris entre denx cercles parallèles à l'équateur terrestre, puis une élendue de pays dans laquelle toutes les eireonstances qui influent sur les êtres vivaus sout à peu prìs les mèmes, enfin la réunion de lnutes les conditions, autres que la texture organique, d'où la viedépend, ct qui exercent sur elle une infuence sensible.

ClimatérıQue, adj. , climatericus; qui a rapport an elimat. Constirution climatcrique d'une contréc.

CLIMATOLOGIF, s. f., climito-

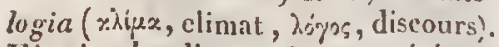
Histoire des elinats. Ce mot a été pris quelquefois dans le sens de météorologie.

CLINANDRE, s. m., clinandrium ( «iin, lit, àrip, homme). L.-C. Richard désigne sous ec nom l'exenvation du sommet du gynostème de certaines Orchidées, au-dessus ou audessous du stigmate, dans laquelle l'anthère est nichée.

CLINiNTIE, s. m. , clinanthiur.

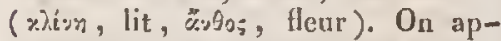
pelle ainsi le sommet élargi et converti en plateau d'un pédoncule commun, qui donne insertion à plnsieurs fleurs scssiles (cx. Synanthérées). Mirbel applique ce nom à la partic qui, dans les Mousses, porte le périchèze, la gainule et le pédicelle.

CLioinís, adj. et s. m. pl., Clioiden. Nom donné par Menke à une famille de la classe des Ptéropodes, ayant le genre Clio pour type. Voy. Chonés.

ChinotivniQue, adj., clinoedri-

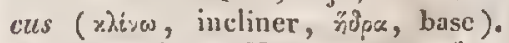
Nom donné par Naumann aux formes cristallines duns lesquelles les plans coordonnés ne sont pas perpendiculaircs entr'eux.

CLINomètre, adj., clinometrum ( Nom donné à de nombreux appareils dont on se sert pour inesurer l'inclinaison d'nne ligne ou d'un plan par rapport is un plan horizontal.

CLINOSCORE, s. m., clinoscopium

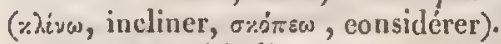
Instrument qui indique l'inclinaison d'un plan sur un autre, sans fournir les moyens de le mesurer.

Chovís, adj. et s. m. pl., Clionea. Noun domé par Blainville à une famille de l'ordre des Céphalophores plérobranches, qui a pour type le geure Clio. V ny. Clionés.

CLIOSTOMÉENS, adj. et s. m. pl., Cliostomica. Nom donné par Fries à une tribu de l'ordre des Pyrénomy- 
cètes Phacidiacés, qui a pour type lc genre Cliostomum.

CLITARnIL̀NE, adj., clitarrhe-

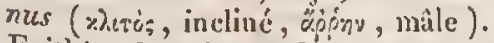
Epithète donnée par G. Allman aux plantes qui ont les antberes versaliles.

CLLTELLUM, s. m., clicellum (clitcllus, bât). On nomnuc ainsi quclques anneaux serrés, plus colorés et protubérans, qui forment unc ccinturc vers le milieu de la longueur du corps des Lombrics terrestres, et qui permettent a l'individu de se fixer contre un autrc pendant l'aete de la copulation.

CLtTorives, adj. et s. f. pl., Clitoriea. Nom donné par Candollc à une seetion de la tribu des Lotces, qui a pour type le genre Clicoria.

CLITOHIS, s. m., clitoris ; xhiro-

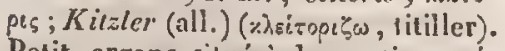
Petit organe situé à la partic supérieure de la vulve, dans les mimmifères, ct qui représente, chez les fcmelics, le corps cavernenx de la verge des mûles.

Clivage, s. m. (de l'allemand klocben, klowen, fendre du bois). Espèce de cassure, à surface plane, que présente le diamant. On appelle ainsi le phénomène nflert par un grand nombre de minéraux, à l'élat cristallin, qui se laisseni diviser dans des dircclions planes, e'est-j-dire en lames. On se scrt aussi de ee mot pour désigner les fissures planes qu'on obscrve dans eertains eristaux, sans que pourtant la eassurc en suive les direetions.

GLOAOUE, s. m., cloaca (cluco, purger). Poche qui, ehez les mamnifìres de l'ordre des Monotrèmes, les oiseaux, lcs reptiles ct beaucoup de poissous, forme l'extrémité inférieure du caunl intrstinal, et dans laquelle se mèlent les exerélions liquirl-s et solides de ces aninanx. Cloison, s. f., septum, dissepi-
mentum; ; poźl. ; ; Seleidewand (all.).
Les botanistes appellent ainsi des lames verticales, plus ou moins épaisses, qui partagent l'intérieur d'un fruit en plusieurs esavités distinetes, ou qui s'y prolongent à une plus ou moins grande profondeur sans le diviser entic̀rement, et qui sont formćes, soit par la soudure plus ou moins intime des laces rentrantes de deux carpelles contiguës, soit par l'endocarpe sculcment et une expansion très-falible du mésoearpe. H. Cassini donne ce nom anx appendiees du elinanthe des Synanthérécs qui sont produits par les côtés des mailles du réseau, quand celui-ei fait une saillie notablement élevée, non interrompue et peu épaisse.

GLOISONví, adj. , scptatus. Se dit, en minéral ogie, d'un corps offrunt un assemblage de cloisons produites par l'interposition de sa matière propre dans les fissures d'une sulsalance différentc (cx. Fer oxidé cloisonne); ou d'un fiion qui rst parlngé dans son épaisseur en plusieurs compartimeus par des espèces de cioisons de nature différente de celle des partics exploitables. La Spongia septosa est ainsi appelée parce que son tissu a la forme d'un réseau.

CLOPONTIDES, adj. ct s. m. pl., Oniscides. Nom douné par Guvier, Lamarck ct Latreille it une famille de Crustacés, qui a pour type le genre Cloportc (Oniscuss).

CLOS, adj. , clausus; verschlossen (all.); chiuso (it.); qui est fermé. Se dit: ${ }^{\circ}$ en botanique, du ealybion, quand le gland est entičrcment renfermé ct caché par la cupule (ex. Fagus sylvestris); de la calathide, lorifuc l'involucre est resserré audessus des fleurs, et, n'ayant gu'un très-petit orifice, les caehe entiurement (ex. Ficus) ; $2^{\circ}$ cu zoolngie, d'unc coquille bivalve dont les bords rapprochés nc laisseut entr'eux aucun intervalle (cx. Mytilus). 
CLossement. Voyez GlousseMENT.

CLOSTÉrocìres, adj. el s. m. pl. , Closterocera (\%) «trip, fusen, répos, corne). Nom donné par Duméril à une famille de l'ordre des Lépidoptères, renfermant ceux de ces insccles qui ont les antenncs en forme de fuseau, c'est-à-dirc renflées au milieu.

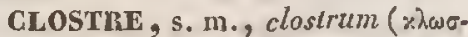
zrip, fuseau). Dutrochet appelle ainsi des cellules amincics aux deux extrémités, et par consćquent en forme dc fuseau, qui entrent dans la composition du bois et des couches corticales. Ce sont les petits tubes de Mirbel, les cellules tubulées de Candollc, les tubilles de Cassini ; Saftröhren, Baströluren, Fasergefüsse (all.).

CLUNIPL̀DEs, adj., clunipedes (clunis, fesse, pes, pied). Les ornithologistes donucnt quelquelois cette épithete aux oiseaux g $q 11$, coinme les Plongeons, ayant. les pieds placés lout à l'arrière du corps, semblent en quelque sorte marcher sur le croupion.

Clupíes. Voyez. Clupéldes.

CLUPÉIDES, adj. ct s. m. pl., Clupcides, Clupeider, Clupeoides, Clupeoidei. Nom donné par Cuvier, Latreille et Eichwald à une famille, par Ficinus el Carus à unc tribu de la elasse des poissons, ayant pour type le genre Clupea.

CLUSrÉES, adj. et s. f. pl., Clusica. Nom donné par Choisy ct Candolle à une tribu de la famille des Guttifères, qui a pour lype le genre Clusia.

CLYPÉACÉs, adj. ct s. m. pl., Clypcacea (clypeum, bouclier). Nom donnć par Latreille et Duméril à unc famillc d'Eutomostracés, renfermant ceux de ces animaux dont le corps mou est couvert d'un test en forme de bouclier.
CLYPÉASTRIFORUE, adj., clypeastriformis ( clypeum, bouclier, forma, forme); qui est en forme de bouclier, comme les scutelles d'uu grand nombre de lichens.

CLYPÉHF OnME , adj. , clypeiformis, clypeatus; schildfürmig (all.) (clypeum, bouclier, forma, forme); qui a la forme d'un bouclier, comme lc cliapeau de l'A garicus clypeatus, le fruit de l'Hibiscus clypealus, la coquille des Parmophorus. Kirlyy donne cette ćpithc̀tc au cubitus des inscetes, quand il porte sur le côté une plaque convexo-concavc (cx. Crabro clypeatus), et à leur prothorax, lorsquc, par sa grandeur et sa séparation, il forme une des pièces les plus apparcntes du côlé supérieur du trone, de manic̀rc à représenter tout le thorax, le mésothorax et le nétathorax ćtant cachés par les ćlytres (ex. Coléoptères). L'dnas clypeata cst appelé ainsi à cause de son bec aplati, arrondi et dilaté par le bout en manic̀re de cuiller, disposition dont se rapproche celle du bec de l'Anas platalea.

CLSPÉOLAIRE, adj., clypeolaris (clypeum, bouclier); qui a la forme d'un bouclier, comme l'Agaricus clypeolarius.

GLYPELS, s. m. Straus appelle ainsi une grande piece, fortement bombée, qui recouvre presque entièrement le dessus du métathorax des insectes, et qui est l'analogue de l'écusson du corselet. Illiger donnait le même nom aux écrilles à cinq ou six pans qui, cher quelques oiscaux, couvrent certaines partics de la base des pieds ct même les doigts.

CLXSIADES, adjcct. et s. m. pl., Clysiada. Nom donné par Leach ì une famille de l'ordre des Cirripèdes acamptosomes, ayant pour type le genre Clysia.

CLISMIEN; adject., clysmianzs ( xhj́̌̌, laver). Épithète donnéc par 
Brongniart à une classe de terrains, comprenant ccux de transport et d'al. luvion, ou d'inondation et d'alterrissenıent, parce qu'ils sont évidemment le produit d'un transport et d'un dépốt ntécanique dont l'eau a été l'agent.

CNIEMIDION, s. m., cnemidizm (xynui , bottine). Illiger nomme ainsi In partic inféricure dénuće de plumes d'une jamlse à demi nuc d'oisenu.

CNiDES, s. m. pl. , Cnidre (*iín, ortie). Schweigger a désignce sous ce nom la classe des Acalèplies, par allusion à la douleur cuisante que eausent, quand on y touele, les animaux quila composent.

COADNE், adj., coadnalus, coalitus, connalus, cohcercns, coadunatus; vcrcinig! (all.). Se dit, en botanique, des fercilles opposées ou verticillées, quand elles sont sessiles et soudées ensemble par la partie inférieure. Ex. Saponaria officinalis.

COADNÉEs, adject. et s. f. pl., Coadunata. Limné désignait sous ce nom une fanille de plantes, dans lesquelles plusieurs fleurss se réunissent ensemble pour n'en former ell apparence qu'une seule.

COAGulation, s. f. , coagulatio;

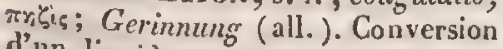
d'un liquide en une miasse plus ou moins molle; phénomène qui a lieu quaud uneliqueur se trouble et semble passer à l'état solide, quoique cet effet n'arrive réellement qu'à une ou plusieurs substances qu'elle tenait en dissolution.

COAGULL, adj. , congulatzs; qui a subi la coagulation.

COAGUrum, subst. m., coagrulum. Ce mot qui, chez. les Latins, désignait la présure ou l'une des substances emiployées pour détcrminer la coagulatiou du lait, exprime abusivement chez nous le produit de la coagulation, et par conséquent est synonyine de caillot.
COALESCENT, adject, , coalescens (cum, avec, alo, nourrir). Jes botanistes donncnt cette épithète aux bractées, lorsqu'elles sont soudées avec le pédoncule (ex. Tilia europaca). On dit, en zoologie, l'alitronc coalescent, d'après Kirby, quand il ne forme qu'une seule piece, et qu'il n'est point séparable en deux scgmens, la médi-poilrine et l'arrièrepoitrine (ex. Cimex); l'abdomen coalcscent, lorsqu'il n'est pas divisé en segrnens (ex. Aranca); le scutellum coalescent, quand il n'est point sćparé da dorsoluı par une suture (cx. Coléoplc̀res).

COARCTE, adject, coarclatus, strangulatus; gedrïngl (all.); coartato (it.) (coarcto, rétrécir); qui est resserré, rétréci. Le Nigclla coarctala est aiusi nommé parce que ses sépales sont droits et connivens; l'Ormosia coarctata, parce que sa panicule est serrée; la Hyas coarctala, paree que son test est échancré de chaque côté, dans le milieu, ce qui l'y lait parấre plus étroit; $l^{3} O r$ thotrichum coarctalum et l'Orthotrichum strangulalum, paree que leurs urnes sont resserrées et eomme étranglées au dessous de l'orifice. On appelle chrysalide coarctéc celle qui offre la larve enfermće dins sa peau desséchée, à la surface de laquelle on ne peut distinguer aucune des partics de l'insecte parfait qu'elle contient (ex. la plupart des Diptères). L'Haemalopola coarctala à l'abdomen resserré à sa base.

Conrcinume, subst. f., coarctura (coarcto, rétrécir). Nom sous lequel Grew désignait le collet des plantes, ou la partie intermédiaire entre la plumule et la radicule, parce qu'on olsserve quelquefois un rétrécissement en cet eudroit.

COASSEMENT, s. m., coaxatio, ranarum clamor; кpaugn ; Quaken (all.); croaking (angl.); cra- 
cito (it.). Bruit que font entendre les grenouilles et quelques crapauds.

COBALT, s. m., eobalt (de l'allemand kobold). Mćtal solide, obtenu pour la premic̀re fois, mais non encore à l'état de purcté parfaite, par Brandt, en I 755 .

CObALTATE, s. n., cobaltas. Ce nom devrait désigner les sels produits par la combinaison de l'acide cobaltique avec les bases salifiables; mais, comme ils sont peu connus, on le donne à d'autres sels, qui résulicnt de la combinaison de l'oxide cobaltique avec cerlaines hases.

COBALTICO-AMMONIQUE, adj., cobaltico-ammonicus. Nom donné, dans la nomenclature chimique de Berzelius, à des sels doubles qui résultent de la combinaison d'un sel cobaltique avee un sel ammonique. Ex. Fluorure cobaltico-ammoniquc (Aluatc de cobalt ce d'ammoniaque).

COBALTico-POTASSIQUe, adj., cobalico-potassicus. Nom donné, dans la nomenelature chimique de Berzelius, à des sels doubles qui résultent de la combinaison d'un sel cobaltique avec un sel potassique. Ex. Fluorure cobaltico-polassique (fluate de coliall et de polasse).

Cobatrioes, s. m. pl., Cobaltides. Nom sons lequel Beudant désigne une famille de minéraux, qui comprend le cobali el ses combinaisons.

COBALTIFldRE, adject., cobaltiforus. Se dit, dans la nomeuclature ninćralogique de Hatiy, d'un minéral qui contient accidenlellement de l'oxide de cobalt. Ex. Magnésie sulfatéc eobaltifere.

COBALTIQUe, adj., cobalicus. On appelle oxide cobaltique (Kobaltoxyd, all.) le premier, et acidc cobalique(Kobaltsiïurc, all.) le troisienıe degré d'oxidalion du cobalt; sulfure cobaltique le premicr degré de sulfuration de ce métal; oxisulfurc

\section{COCG}

cobaliique (Koballoxydschwcfelkobalt, all.) unc combinaison du sulfure et de l'oxide; scls cobaltiques (Kobaltsalzcn, all.) les combinaisons de l'oxide avec les oxacides, du métal avec les corps halogènes $\mathrm{ct}$ du sulfure avec les sulfides.

COBÉACÉES, adject. et s. f. pl., Cobacca. Nom dounć par D. Don à une famille de plantes, qui a pour type le genre Cobcea.

CoBITIDEs, adjecl, et s. m. pl., Cobitidcs. Nom donné par Blainville à une famille de l'ordre des Poissons abdominaux, qui a pour type le genre Cobitis.

COCArDI, s. f. Geoffroy appelait ainsi les tentacules rétractiles qu'on aperçoit sur les parlies latérales dn corps des Nialachies.

Coccinis, adject. el s.m.pl., Coccidce. Nom donuć par Leach à une famille d'Insecles bćmiptères, coinprenant les Coccus.

CocCIFLेßs, adject., cocciferts (coceus, gallinsecte, et жirкos, rouge, fro, porter ?. Le Quercus coccifera est ainsi appelé, paree que c'est sur lui qu'on recueille l'insecte appclé graine d'écarlate; le Scyphophorus coeciforus, ̀̀ cause de la couleur rougre éclatante de ses apothécies; l'Acinaria cocciffera, à eause de sa fructification en grains mous, arrondis et rouges, qui ressemblent à de petites galles.

COCGINE, s. f., coceina. Lassaigne donne ce $110 \mathrm{~m}$ à la matière animale des Coccus et des insectes de la nême famille.

COCCINELLIDES, adj. et s. m. pl., Coccinellida. Nom donné par Leach, Latreille, Goldfuss, Ficinus et Carus à une tribu d'insectes coléoptères, ayant pour type le genre Coccineila.

COCCINIGASTRE, adj. , coccinigaster (coccinuls, cicurlate, gaster, ventre); qui a le ventre d'un rougc foucé (ex. Motacilla coccinigastra), 
ou d'un bleu pourpre éclatant (ex. Ccrilia coccinipastra).

Coccoctośrítés, adj. et s. f. pl., Coccocypsilece. Nom donné par Chamisso et Schechtendil à une Iribu de la famille des Rubiacées, qui a pour typc le genre Coccocypsilum.

COCCOGNIDIQUE, adjeet., coccognidicus. Nom donné à un acidc (Coccogninsäurc, all.), encore problématique, admis par F. Gobel dans le Coccus gnidius (Daplenc Gnidium).

CoccotirnaUSTE, adject. , coccothraustes (rórxoc, graine, opxisw, briser). Le Loxia coccollrausics est ainsi a ppelé, parce qu'en rapprochant ses mandibules ollirquenent et an sens contraire, il peut briser les noyaux des fruits on la pellicule de graines dures, pour en retirer l'amande, dont il se nourrit.

coccurivlies, adj. ct s. f. pl., Cocculina. Nom domé par Bartling à unc classe de plantes, qui a pour type le genre Cocculus, et qui renferme les familles des Berbćridées et des Ménispermées.

COcCYCIPPIALE, adj. et s. m., coccyccphalus ( rórruร, coccyx, «вwxin, tète). Nom donné par Gcolfroy Saint-Ililaire ì un genre de monstres scéphales, comprenant ecux chez lesquels lés os de la sommité du corps ont la forme d'un coceyx.

COCHL Ralle, adj. , cochlcaris, cochlcutus ( cochica, limaçon); qui cst tourné en spirale. On dii, en botanique, l'cslivation cochléairc, quand une partie étant plus grande que les autres, et courbée en forme de casque ou de cuiller, elle les recouvre loutes (ex. Aconitum). L'Agaricus cochleatus et l'Agaricus conchatus ont leur chapeau contournć.

Cociléarmées, adj. et s. f. pl., Cochlearice. Noun douné par SaJisbury à une tribu de la famille des Crucifères, qui a pour type le Eenre Cochlearia. cocmúarifolué, adject. , cochlearifolius (cochlsar, cuiller, folium, feuille); qui a des feuilles presque arrondies et concaves, ou en forme de cuiller. Ex. Bryunu cochlearifolium.

COCHLEARIFORME, adj. , cochlcariformis (cochlcar, cuiller, forma, forme) ; (yui a la forme d'une cuiller, comme le corps déprimé, plus large ct un peu excavé en avant, di Fcsiucaria cochicarifornics.

cochulunoune, adj. , cochlciforniis, cochleatus; sclencckenfornig (all.) (cochlca, linaçon, forma, forme); qui est roulé on contontné en coquille, comme un des pélales de l'Epidendrum coclelcatune, les feuillcs du Panax cochlcatun, les légumes de l'Inga cochlcata.

COCIILIACANTHE, adj. , cochliacanthus (ro\% his, coquille, "ärov0s, épine); qui a des épines recourbées et concaves. Ex. Acacia cocliliacantha.

COCHE LOCARPL, adj., cochliocarpus ( $\times 0 \% 2 i 5$, coruille, raptio; , fruil); qui a des fruits tournés en spirale, comme les légumus du Mimosa cochliocarpa.

CochlonIryeues, adj. et s. m. pl., Cochlorhynchi ( xćxidas, cuiller, pứzxos, bec). Nom donné par Lesson à une famille du sous-ordre des vrais Echassiers, comprenaut ceux qui ont le bec large, déprimé et quelquiciois en forme de cuiller.

coconvíes, adj. "t s.f. pl., Cocoince. Nom donné par Martius à une tribu de la fanille des Palmiers, qui a pour type le genre Cocos.

COCON, s. m., bomlycis folliczlus ; Poubuit.ov; Puppc (all.); cod of a silkworm (angl.). Enveloppe de soie que se filent les chenilles de plusieurs Bonlyx $x$ et quelques araignées pour y renfermer leurs ocufs ct pour s'y transforiner en clirysa- 
lides, ainsi que certaines autres larves, comme celles du Fourmilion.

CODARION, s. m., codarium ; xwòxprov; Wollpelz (all.). Nom donné par Illiger à l'ensemble des poils courts et doux et des poils longs et épais, qui sont entremèlés dans le pelage d'un eertain nombre de rnammitères.

CODIOPHYLLE, adj., codiophyl.

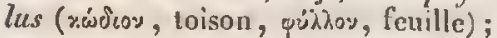
qui a des feuilles velues, enmme le sont en dessous eelles du Nelumbium codiophyllun.

COECIF OLML, adj., cociformis (cæecus, borsne, forma, forme). Candolle appelle réservoirs caeciformes des tubes courts, pleins d'huile volatile, que Ramond a observés dans l'écorce du fruit des Ombellifères.

COELOGASTRIQUE, adj. , coelogastricus (roikc, inlestins, yxornip, ventre). Epithète donnce par $C . \cdot G$. Ehren berg anx in fusoires rotifères qui ont des organes de inastieation, avee un cesophage très-court et un intestin simple. Ex. Hydatina.

COELOl'NÉs, adj. et s, m. pl., Coclopnor, Ceelopncer, Cilopnoa

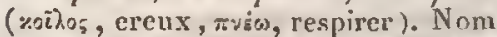
donné par Sthweigger ot Eichwald à une famille de l'ordre des Mollusques gastéropodes, eomiprenant ccux qui ont une eavité pulmonaire pour organe respiratoire.

COELORIIINQUE, adjeet. , coelorhynchus ( roìlos, ereux, poryzos, bee). Un poisson (Lepidaleprus colorhynchus) a un museau'déprimé qui s'avance au dessus de la bouche.

COELORHIZL, adj., ceclorhizus ; hohlwuralich (all.) (xoïos, creux, ilgo, racine). Epithete donućc par Illiger aux dents qui ont des racines creuse's.

COELOSienters, adj. el s. f. pl., Coclospermece ( woil.os, creux,

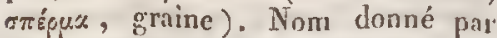
Candolle it une seetion de la famille des Ombellifires, comprenant celles qui ont l'albumen recourbé de la base au sommet.

COENOGONE, adj., ccenogonus ; vermischt-gebührend (all.). Sc dit d'un animal qui à une époque pond des ocufs, et à une autre produit des petits vivants.

COEXOGONÉES, adj. ets. f. pl., Cocnogonece. Nom donné par Fries à une tribu de la famille des Byssaées, qui a pour type le genre Canogonium.

COENOPASSAIE, adj. , conopassalus (zocvos, commun, trxorahos, pieu). Epithéle donnéc par G. Allinan aux plantes qui ont des passales (voycz $c c$ mot) joints à la base.

cowiothas tues, adj. et s. m. pl. , Conothalami (xolvès, commun, oxiauns, lit). Nom donné par Acharius à unc classe de Liehens, comprenant ceux dont les coneeptaeles sont en partie de mème nature que le thalle.

COEKOTIQUE, adj., canoticus ( rovขó, commnus). Epithète donnée par C.-G. Ehrenberg aux ehampignons où un graud nounbre de filamens fruetiè̀res, délevés du même point du rhizopodc, se réunissent, s'entrecroisent et se soudent, pour former ce qu'on appelle communément le champignon.

COENoTroprosperue, adject. canotropleospermius. Nom donné pal G. Allman aux plantes qui ont un tropuosperne commun à la lisse de l'ovaire, ou plusieurs trophospermes joints le long de l'axe de l'ovaire.

COERCIBLE, adjeet., cocrcibilis; zuriecklealibar (all.) (cocrcco, contenir). Epithètedonućc aux gaz qui conservent l'état aćriforme sous la pression et à la tempériture ordininires, mais qu'on parvient à colldenser quand on les soumct soit à une pression qui doit équivaloir au moins à trois atmosplières, soit à un froid considérable. 
COERULEOCÉPHALE, adj. , $c t-$ ruleoccphalus (corruleus, bleu, \%:pràn, lête); qui a la tête de conleur bleue. Ex. Attclabus carulcocephalus, Alcedo corrulcoccphata.

COETONION, subst, m., catonium ( $x$ witc่y, ehambre à coucher). Trinius appelle ainsi la glume calicinale des Graminées à épillcts multiflores.

COEUR, s. m., cor; rapoix; IIcrz (all.); hearc (angl.) cordc (it). Dans l'homme, les mammifères et les oiseaux, on nomme ainsi un organe composé de quatre eavités aceolées, dont deux, appelées orcillettes, rccoivent le sang des poumons et du corps, tandis que les deux autres, nommces ventricules, les renvoyent aux poumons et à toules les parties du corps. Dans les reptiles écaillenx, le cour se compose de deux oreillettes, l'une ponr le sang veineux du corps, l'autre pour le sang artérialisé des ponmons, et d'un seul ventricule, qui distribue le sang aux poumons et an reste du corps. Le coeur des repliles à peru nue n'a qu'une scule oreillette et un seul ventrieule, mais préside tonjours aux deux eirculations. Lues poissons 'n'ont de mềme qu'une seule oreillette et un seul rentrienle, mais leur eceur ne sert qu’à Ia eirculation branehiale; il n'est que pulmonaire, tandis que les deux premières elasses ont un cour pulmonaire et un conr aortique, et que le cour des reptiles remplit les fonetions de l'un et de. l'autre. Chez les Céphalopodes, il y a deux ecrurs pulmonaires ou branchiaux et un seul cceur aortique. Les autres mollusques n'ont qu'un coeur pulmonaire, sans cocur aorlique. Il n'y a an contraire qu'un cour aortique, sans cour pulmonaire, elicz les Crustacés et les Arachnides. On a voulu aussi regarder le vaisscau dorsal des insectes comme un cour; mais e'est par alsus qu'on l'appellerait ainsi. A partir des
Arachnides, il n'y a plus de véritable cœur, et jusque là même ect organe affecte tant de nuances différentes, qu'on ne saurait en donner une défuition gétsérale, que celle surtout qui lui convient chez les mammifères et les oiseaux ne pent s'appliquer aux aulres classes du règne animal. - En botınique on appelle cour (cor, lignum, duramen; Kern, Hlarthol, all.) les eouches centrales du bois, eelles qui sont les plus dures, les plus eolorées, les plus âgées, et qui souvent ont une autre couleur que l'aubier.

COFFéacrís, adj. et s. f. pl., Coffcacca. Nom donné par Candolle, Kunlh et A. Rıchard a une tribu de la famille des liubiacées, qui a pour type le genre Coffca.

COFrés, adject. et s. f. pl., Coffect. Nom donné par Candolle à une section de la tribu des Cofléacécs, celle qui renferme le genre Coffeca.

COHÉRENGe, s. f. , coltarentia; evyxpsix; Zusammenhang (all.) ; coerenza (it.) (cum, avec, hareo, être collé). Liaison de deux corps, ou des diverses parties d'un mème corps.

COUbnENT, adject., cohcerens; susammenhangend (all.); coerente (ii.). Se dit, en botanique, des étamincs, quand elles tiennent les unes aux autres, soit par des poils, soit par une substance glutineuse. Ex. Erica vuluraris.

contsion, s. f. , cohasio; Zïhigkeit, Zusammenhang (all); coesione (it.) (cum, avec, harco, être collé). Union des partics composanles des eorps durs; force avec laquelle les particules adhirent entre clles de manicre ì opposer plus ou moiris de résistanec à leur séparation; force qui tend à réunir les atomes intégrans ct de mêne nalure d'uu corps. Dans ce dernier sens, cohésion est synonyme d'affinite. 
COHFE, s. f. , ealyptra, corolla;

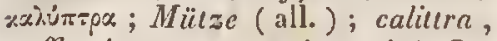
cuffic, berrello, spcgnitozo (it.). Organe en forme de bonnet pointu, qui recouvre l'opercule ct quelquefois l'urne entière des mousses, comme un éleignoir.

COHFÉ, adj., calyptralus; qui est muni d'une coifle. Le Mclastoma calyptrala a un enlice conique qui, lors du développement de la corolle, se sépnre de sa base, eumme une coiffe. Foyez Calyptre.

COIT, s. 11., coilus, coitio, concubitus, congressus, colablitatio, Venus, res venerea, aphrodisia,

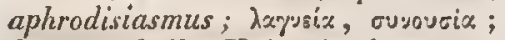
Beischlaf'(all.). Union des deux sexes pour l'acte de la génération. L'acte du coït est appelé aussi acle vénérien, copulation chez les animanx, et cohabitation daus 'espcec humaine. Il prend le nom de monte chez certains animaux, particulicrement chez lis chevaux. $S$ "accoupler est un tcrme général qui l'exprime chez les animaux pourvus des desx scxes. On dit, d'un quadiupide mâle, qu'il convre sa funelle. Cependant il $y$ a aussi dus termes propires à quelques espéces, comme mátiner puar le chicu, saillir pour le cheval et le taureau, coeher pour tes oiseaux, et surfout pour le enq.

COL, s. m., collum; aùx'่rs ; Hals (all.); neek (augl.); collo (it.). On appelle ainsi : $1^{\circ}$ en géographic, une échancrure arrondie que le faîtc ou la erĉtc d'un rameau de montaghues préscute, il la naissance d'une vallée, lorsque les sillous qui domnent licu à cclle-ci sembleut avoir cmporté une partie do ce faîte, en y aboutissant. $2^{\circ}$. En botanique. Cassini donne ee nom ì un prolongement que le fruit des Synanthérécs offre assez souvent au dessus de la partic occupée par la graine, ct qui a la forme d'un cylindre plus ou moins étroit. $3^{\circ}$ En zoologie. On appelle col, dans les animaux vertćbıćs, la partie du corps qui est située enıre la tète et la poitrinc; dans les ins ctes, la partie effilće qui sépare la tète du corsclet, et quelquefois ce dernier lui-ınême, quand il est long, grêle et arrondi.

COLCIIC 1 CÉES, adj. et s.f. pl., Colchicarece. Nom douné par Candollc à une famille dont l'établissement appartient à Mirbel, et qui a pour type le grenre Colelicum.

Corcurricies, adj. et s. f. pl., Colchiceo. Quelques bolanisles appellent ainsi la famille des Colchicacées. Reichconbach a élabli sous ce nom un groupe dans celle des Liliacécs.

COLEANTIINEES, adj. et s. $f$ :

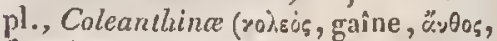
fleur). Nom donné par Link à une tribu de la famille des Graninées, renfermant eclles de ces plantes dont $l^{\prime}$ inflorescence est enveloppée de braetées.

COLLODERUE, adj., colcoler-

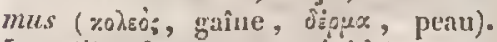
Latruille donne eette ćpilhète anx nymphcs dont l'cnreloppe générale est ippliquée immédiatement sur le corps el les membres, ou détachée de ce corps, auquel clle forme une coyue on capsule.

COLLOPHYLLE, s. m. , coleo-

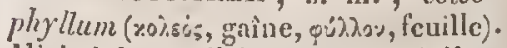
Mirbel donua d'abord ce nom à l'organe qu'il a appelé depuis coléoptile. Voyes ce mot.

COLBOPHYLLE, adj., coleophyllalus. Foyea Colíoptile.

COLLCRODES, adj. el s.m. pl., (\%力sis, gaîne, Toüs, pied). Nom donné par Latreille à une tribu de la famille des Crustacés décapodes nacroures, parce que, chez ceux qui la composent, le test scrt comme d'étui ou de gaîne aux patles.

Coriontiní, adj., colcopte-

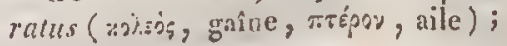


qui ressemble à un coléoptère. La Corixa coleopterata est brunc, avec les élytres bordées de jaune en dehors.

contoptines, adj. et s.m.pl., Coleoptera. Now donné par Degeer, Linné, Cuvier, Latreille, Kirby', Leach, Lamarck, Goldfuss, Blainville, Eichwald, Ficinus et Carus à un ordie de la classe des insectes, renfermant ceux qui ont les ailes ployées en travers, et couvertes de deux éluis cornés ou coriaces.

CoLtépténologit, s. f. , coleopterologia. Traité sur les coléopteres.

Coléoptérologue, s.m., coleopterologus. Naturaliste qui se livre spécialement à l'ćtude des coléo. ptèrcs.

COLÉOPTĖRO-MAGROPTÈnES, adj. et s. m. pl, , Coleoptero-maeroptera. Schxffer donne ee nom à une elasse d'insectes, renfernant ecux qui ont les élgtres plus longues que la moitié du ventre.

COLÉOPTÉRO-MICROPTìRES, adj. ct s. m. pl., Colcoptero-mieroptera. Nom donné par Schaffer à une classe d'insectes, renfermant ceux qui ont les élytres moins longues que la moitié du ventre.

COLIOPTILE, s. f., eolcoptiter

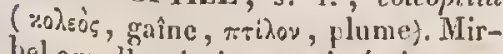
hel appelle ainsi un petit ćtui menbrancux ou charnu, provenant des colylćdons, qui enveloppe quelquefois la base de la plumule, Ex. Liliacécs.

COLÉopturi, adj., eoleoptilatus. Se dit d'une plumule qui est munie d'une coléopiile, et qu'on ne peut en conséquenee apercervir que par la dissection.

COLPOPThIFORM:, adj., coleoptriformis, subcoleoptratus. Un diptère (Plasia subeoleoptrata) est appclé ainsi parce qu'il a sur les ailes une bande transversale noire, quj les eoupe condeux.

Cocionumes, adj. et s. m. pl., Coleoramphic (xol.zùs, graînc, pás905, bee ). Nom douné par Vieillot à une famille de l'ordre des Eehassiers, comprenant un seul oiseau, dont la basc de li mandibule supérieure est recouvcrte par un fourreau de substanee cornće.

COLE்OnInE, s. f. , colcorhiza (ròris, gaùc, pił̌x, racine). Mirbel désigne sous ce nom une espèce d'étui clos de toutes parts qui cnveloppe certaincs radicules, de manière qu'on ne peut apercevoir ces derniè̀res qu'au moyen de la dissection. Ex. Graninées.

Cocéorurzé, adj, eoleorhizatus. Se dit d'une radieule qui est munic d'unc coléorhizc.

Corisume, s. f., eolesula (no$\lambda . \varepsilon \dot{s}$, fourleau). Nom donné par Necker à unc petite bourse nembrancuse de lanuclle sortent les spores des Hépatiques.

corinacís, adj. et s. m. pl., Colimacea. Sons ee nom Lamarck désigne une famille de l'ordre des Truchélipodes Phytiphages, parce que lc colimaçon en fuit partie.

COLLAIRE, adj., eollaris , collarius (collum, col). Epithète donnéc, par les ornithologistes, aux plunes gui,garnissent le cou des oisearx, et dont on se sert assez souvent pour désigner des animaux qui offrent ì la base du col une lande coloréc figurant plus ou moins bien un collier (ex. Bueco collaris, Chatodon collare), une cogrille spirale qui décrit des tours très-nombreux, conme un collier (ex. Clausilia enllaris), ou une autre dont l'onsbilic est ceint d'une zone coloríe, en manic̀re de colliel. (cx. Natica eollaria).

COLLECTELR, adj. , colleetor , colligens (eolligo, tceucillir). H. Cissini donnc celte épithète à des 
poils ou papilles qui garnissent les styles des fleur's hermaphrodites et eeux des fleurs femelles, dans toutes les Synanthérées, parce que leur usage consiste à reeucillir les grains du pollen.

COLLECTEUR, s. m., collector ; Elektricitätssammler (all.). Instrument inuginé par Cavallo pour déeouvrir des quantités d'aillcurs insensibles d'électricitć, en les aceumulant et les condensaut.

COLLECTIFÈn, adj., collectiferus. H. Cassini nounme appendicc collectifère la partie supérieure des deux branehes du style, quand le stigmate nese prolonge point sur cette partie, qui ne porte que des collecteurs. Ex. Astérées.

COLLERETTS, s. f., involucrum, collare; Halslirause (all.). On appelle ainsi, en botanique, l'involucre des Ombellifères, qui, étant composé d'un scul rang de bractées verticillées, ressemble au vêtement dont il porte le nom; les franges que laisse sur le stipe, en se déchirant par l'effet de la eroissance, la membrane qui, dans la jcunesse, uxissait les bords du chapeau du thanigignon avec le pied; lesonmet de la gaînc des fuilles des Gramipuées, qui porte l'appendiee membraneux appelé languette ou lignle.

COLLuUACEES, adj. et s. f. pl., Collemacea. Sous ee nom Fries désigne une tribu de la famille des Lichens, qui a pour type le genre Collema.

Colliviatíles, adj. et s. f. pl., Collematere, Collcmacea. Nom donné pas Fee, lieichenbach et Zenker à une tribu de la fanille des Lichens, qui a pour type le genre Collema.

COLLET, s. m., collum, coarctura, nodus vilalis, fundus planta, limes eommunis, cingulum; Hals, Wurzelhals, Wurzcllrone (all.). Plan situé contre la tigc et la racine, où les fibres eommeneent d'un côté î̀ monter et de l'autre à descendre; point de réunion du limbe de la feuille et de la gaîne, dans les feuilles dites engainantes; Lamarek l'appelle noud vital. On donne aussi le nom de collct à une ligne dont le contour marque la sćparation de la couronne et de la racine, dans certaines dents de maınmifères, paree qu'elle est la limite inférieure de l'émail.

COLLETERION, s. m., colleterium ( $x) \lambda x_{2}+\dot{r} 5$, qui colle). Sous ec noin, Kirby désigne l'organe dont sont pourvus certains insecles, et qui séercite un liquide jaune, destiné, selon Réaumur et liérold, à vernir ou gomnicr les oeufs, alin qu'ils adhèlent aux corps sur lesquels l'animal les dépose.

CoundCuLwx, adj., colliculosus; hügclig (all.). Se dit d'uu eorps qui, sur unc petite surface, offre plusieurs lossettes rapprochées les unes des autres, eomne le réceptacle du Mar. chantia quadrota.

COLLIER, s. m. On appelle ainsi : $1^{\circ}$ en botanique (collare, annulus, ligula), une sortc d'enveloppe proprc à ecrtains agarics et à quelques bolets. Voyez Colleretre. $2^{\circ}$ En zoologie (collare, torques; Kragcn, Halshau, Halsring (all.), un chapelet de plumes, d'écailles, de plis on de eallosités, qui cnvironne quelquefois le col des oiscaux; d'après Merrem, les longues plumes qui, chez ccrtains oiseaux (ex. Colymúus auratus), pendent de la joue et de la tempe sur le côté du coú une bande de eouleur tranchante qui ceint une partic du cou chez des mammifercs (ex. Callithrix torquatus, Sorex collaris), des oiseaux ct des reptiles (ex. Coluber natrix); la partie da corps des hélices qui déborde le pied, sous laquelle eelui-cise retirc, qui remplit l'ouverture de la coquille, el cuntient 
l'anus el le tubc respiratoirc. Klug et autres entomologistes dounent ce nom au prolhorax, ou segment qui porte les deux premières pattes; Kirly, à la pièce première ou antéricure du mésolhorax, ec qui revient au mène; Latreille, au premicr segment du thorax des insectes, quand il ne surpasse pas notahlement Jes snivans en étenduc; Wiedemanu, à une ou quelques síries transversales de poils raides, qui garnisscut l'extrémitéantéricurc du dos de eertilus diptères (ex. Anthrax).

COLLIFine, adject., colliferus (collum, col, foro, porter). Epithite donnée, en botanique, à l'ovaire, quand il est muni d'un eol; an stipe de certains champignons, lorsqu'il porte une collerette; à la cypsélc, lorsqu'clle offre un prolongetuent en forme de eol.

COLLIYORHE, adj., colliformis (collum, col, forma, forme). Kirby donne ce non au prothorax des insectes, quand il est conrt, étroit ct moins apparcnt que les autres pièces du trone. Ex. Libellula.

COI.tuGs, adj., colligatus; gehefec (all.) (cum, avec, ligo, liev). Illiger appelle pieds colligés, dans les viseaux à janbis demi-nues, cenx dont deux ou trois doigts antérieurs sont joints ensemble par unc courle memlirane qui s'avance a peine an deli de la première phalange. Ex.
Echassc.

COLdINAIRE, adj., collints; qui eroît. sur les collines. Ex. Dianthus collinus, Daplene collina. COLIINE, s. f., collina; rx́gss;
Hiigrel (all.); hill (angl.); collina (it.). Elévation du sol qui diffère pritucipalement d'une montagne par Sa hanieur moindre, celle-cin'excédant gueres deux ou trois cents mètres au dessus du pied.

COLLIROSTRES, adj. el s. m. pl., Collirostres (collum, col, ros- trum, bec). Nom donné par Duméril à une famille d'insectes hémipières, comprenant coux dont la base du bec semille naitre du cou. Foy. АuснÉNORUY NQUES.

COLto-kíprex, adj., collospinostls. Epithète qu'on applique aux chenilles qui out deux très-longues épines sur le con, eomme eelles des Nacrés.

Collunioxs, adj. ct s. m. pl., Colluriones (m)lupiay, pie grièche). Nou clonné par Vieillot, Ranzani et Savi in une famille de l'ordre des Passcreaux ou Sylvains, qui a pour type le genre Lanius.

COLOBANCALOPTÈNES, adj, et s. m. pl., Colnbancalopieni (xolobòs,

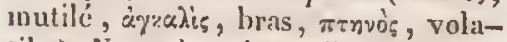
tile). Nom douné par J.-A. Ritgen a uue fantille de l'ordre des Halyeolymbes, renfermant les oiseaux qui, comme les Manchots, n'ont que des rudimens d'ailes.

COLOBaTHROPONES, adj. et s. m. pl., Colobathropodes (

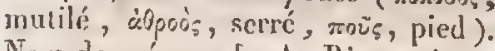
Nom donné par ,.-A. Ritgen à un ordec de la section des Mydalornithes, renferinant des oiscaux qui onl les jambes très-longues et grêles.

COLOBOPTHIE, arjj. , colobo-

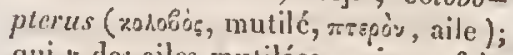
qui an des ailes mutilćes on imparfaites, comme la Vespa colobopicra, dont les ailes se reduisent à des rudimens trìs-eourts.

COLOCVNTHINE, s. f., colocynthina; Coloquinthenbiuter (all.). On dome ce nom ì l'ancr de coloquinte gui s'extrait du parenchyme des fruits du Cucumis Colocynthis.

COLODACTYLS, adj. ct s. m. p., Colntacryli ( xános, mulilé, dx: tùn, , loight). Nom donné par J.-A. Ritģen à unc section de l'ordre des Reptiles sauricus, comprenant ceux qui ont les menbres plus ou moins incomplets. 
coromites, adj.; Columnatce. Nom donné par Linné à la famille des Malvacées, ì eause de la réunion des filets de leurs ćtanines en une sorte de colonne ou eylindie.

COLONBATRE, adj., columbarius (columba, colombe). On donne eette épithète aux grains d'une roche grenue, quand ils sont de la grosscur d'un ocuf de pigeon. Le Falco columbarizus est ainsi appelć paree qu'il fait la guerre aux pigeons.

GOLOUBATE, s, m., columbas. Synonyme inusité de tantalate. $V$. ce mot.

COLOMBrDIs, adj. et s.m. pl., Columbida. Nom donné par Vigors à unc famille de l'ordre des Gallinacés, ct par Lesson à une famille de celle des Passereaux, ayant pour type le genre Columba.

CoLombriss, adj. et s. m. pl., Columba, Columbini, Sponsores. Nom donné par Duméril, Illiger, Vieillot, Goldfuss, C. Bonaparte, Latreille, Eichwald, Ficinus et Carus à une famille, par Meycr, Wolf et Blainville à un ordre de la classe des oiscaux, ayant pour typc le genre Columba.

colondeue. Foyez TantaliQUE.

Cozonbrum, s.m., colimbium. Nom donné par Hatchett, en l'honneur de C. Colomb, à un métal qu'il a découvert en 1 Sol, et qu'en i $\mathrm{Sog}$ Wollaston reconnut ètre le même que celui anquel Ekeberg donna en 1802 la dénomination de Taniale, qui a prévalu injustement.

COLOMNAInE, adj., columnaris; sïulenförmig (all.) ; colonnare (it.) (colunina, colomne). Les botanistes disent l'androphore colomnaire, lorsqu'il s'élève verticalement du centre de la flcur et ressenble is une petite colonne (ex. Malva). Un champignon (Clalhrus columnarius) cst appelé ainsi parce qu'il est formć de quatre

\section{COLOO}

branches droites, semblables à des colonnes et réunies par leur sommet ; et une coquille (Lymnaca columnaris), parce qu'on l'a comparée à une colonne torse.

Colonsiwtènes, adj. et s. f. pl., Columnifera. Nom donné, dans le système de Royen, à une classe comprenant !es plantes dont les filets des étamines sont réunis en un scul eorps, et dans celui d'Agardh, à une classe de plantes phanérocotylédones complétes lypogynes poly pétales qui offrent la mème disposition.

COLOPHOLlQue, adj., colopholicus. Epithète donnce par Unverdorben is un acide qui forme la base de la colophane, à eause des propriétés électro-négatives dont jouit cette résinc.

COLOnL, adj. , coloralus; gefiirbl (all.); coloured (angl.); coloratc (it.) (eolor, couleur); qui offre une couleur quelconque. On employe ce mot : ${ }_{10}$ en physique. Les anneaux colorćs sont une série de ecreles diversement colorés que présente uuc lame d’air très-mince emprisonnée cntre la courbure d'un objectif légèrement eonvexe et la surface d'un autre objectif qui est plan-convexe. $2^{\circ}$ En botanique, coloré se dil de toutc partic qui n'est pas verte, comme le calice du Tropceolum majus, l'involucelle du Charoplyyllum coloratum, les bractées du Salpia nemo rosa; dont la eoulcur difrère de celle des parties aree lesquelles elle fait corps, conme la claulaze du Citrus medica; ou qui offre une autre conleur que celle qu'elle présente ordinairement, comme les feuilles de l'Atriplex hortensis rubra.

conombes, s. f. pl., Colorides (color, couleur). Guibourt désigue ainsi une famillc de composés ternaires organiques, eomprenant les principes colorans. 
COLOnifiQue, adj., colorificus (color, couleur, facio, faire); qui donne lieu à des coulenrs. On dit pouvo ir colorifique des rayons lumineux.

COLORIGRADE, s. m., colorigradus (color, couleur, gradus, degré). Instrument que Biot a imaginé pour déterminer le degré de coloralion des corps.

COLORisation, s. f. Manifestation d'une couleur quelconque dans unc substance.

COLOSAUHIENS, adj. et s. m. pl., Colosaurï (xò)os, mutilé, бxüpos, lézard). Nom donné par J.-A. Ritgen à unc scetion de l'ordre des Reptiles sauriens, comprenant ceux qui ont les membres plus ou moins imparfaits.

COLOSSAL, adj., colosseus, colossicus ; rлиоббuis;; "̈̈bcrgross (all.); qui surpasse de beaucoup les proportions ordinaires. Ex. Fusus colosscus. Poyca GEant.

COLOSTRUM, s. m., colostrum; тpoparic. Premicr lait que sécrètent les glandes mammaires chez une femelle de mamnifóre qui vient de mettre an monde ses petits.

COLUBÉriens, adj. et s. m. pl., Colubcrini. Non donné par Latreille, Ficinus ct Carus à unc famille ou tribu de Reptiles ophidicns, qui a pour type le genre Colubcr.

COLUBRIDES, adj. et s. m. pl., Colubride. Nom donné par G.-E'. Gray il une famille de Reptiles ophidiens, ayant le genre Colubcr pour typc.

COLUBar, adj., colubrinus (coluber, couleuvre); qui a l'apparcnee d'une couleuvre (ex. Ery $x$ colubrinus, Herpestes colubrina); qui est replié sur soi-même comme un serpent (cx. Ostrea colubrina); qui a sa surface garnie d'unc multitude de petites taches semblables à des écailles de serpent (ex. Conus colubrinus); qui passe pour posséder des vertus médicamenteuses contre la morsure des serpeus (ex. Sirychnos colubrina).

Corubrins, adj. et s. m. pl., Colubrini, Colubres. Nom donnépar Oppel et J. - A. Pitgen à unc famille de reptiles $O_{p}$ hidicns, établie sur le genre Coluber.

coLUBROIDES, adject. et s. m. pl., Colubroidea, Colubroides. Nom donué par P.-F. Fitzinger à une famille de reptiles, ayant pour type le genre Coluber.

COLUMBive, s. f., columbina: Subslance cristallisable particulièrc, que Wittstock a trouvée dans la ravine de columbo (Menispermum palmalum).

COLUNELLAIRE, adj. , columellaris (columella, columellc.). Les conchyliologistes nomment léure columellaire, ou bord gauche d'une coquille univalve, celui qui se trouve du côlé de la columelle. La Purpura columcllaris est ainsi appclée, parce qu'elle offre un pli au milieu de sa columelle.

COLUMELLAIRES, adj. et s.tm. pl., Columellaria. Nom donné par Lamarck et Latrcille à unc famille de Gastéropodes, compremant ceux dont la columelle est garnic de plis.

COLUMELLE, adj. , columella, columnella, columnula; Sïnlchcn (all.); colonnella (it.). On nomme ainsi : $1^{\circ} \mathrm{en}$ hotanique, un pelit axe filiforme situć aut centre de l'urne des mousses, ct auquel les semenees son l at lachées; l'axc qui persiste après la chute des fruits auxquels il servait de support (ex. Geranium) ; suivant Candolle, l'axe central d'un fruit résultant de la soudure de plusieurs carpelles, quand il est réel, et non ficlif; $2^{\circ}$ cn zoologie, une espèce de petite colonne plus ou moins torse, qui fait l'axe d'une coquille spirale, qui résulte de l'euroulcment du cône qu'on peut concevair la former, 
quand les tours se'touebent, ct qui fait partie de l'axe de la coquille, ou mieux s'applique dessus.

COLUMELLtí, adj., columellatus. Se dit, en botanique, d'une mousse, ou d'un fruit qui est muni d'une cnlumelle; on zoologie, d'une coquille univalve dout la columelle est solide, torsc, plissée. Fúrussate et Menke, sous le nom de columellées, columellatee, établissent dans ic genre Helix une section comprenant les espèces dont la colunuclic offie ce dernicr earactèrr.

CoLumelurúes, adj. et s. f. pl. , Columellica. Nom donné par D. Don à unc famille de plantes, qui a pour type le genre Columellia.

COLUMNanTuÉníes, adj. et s. f. pl., Columnariherea (columna, colonne, anthera, anthère). Nom donné par Agardh à une classe de plantes planérogames incomplètes, compreuant celles qui ont les filcts des étamines rćunis en colonne, conme les Pistiacées, Asarinces et Myristicées.

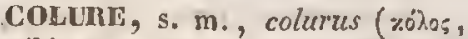
mutilé, ợod, queue ). Nom donnć à deux grands cercles de la sphère qui passent l'uu par les érquinoxes, l'autre par les tropiques, et qui sont appelés ainsi parce que nous les voyons loujours tronqués, n'apereevant point la partie la plus voisine du pöle inférieur.

COLYmBines, adj. et s.m. pl., Colymbide. Nom donné par Vigors à une famille de l'ordre des Palmilièdes, ayant pour type le geure Colymuris.

COLMBBENs, adj. et s. m. pl., Colymbi, Colymbii. Nonn donué par J.-A. Ritgen à une famille de l'ordre des Halycolymles, par Blainville à une finnille de celui des Oiseaux nageurs, ayant pour type le genre $\mathrm{CO}_{\mathrm{O}}$ lymbus.

COLYMBOPLOTLRES; adj. et s. m. pl., Colymboploteres (xotupüis, plongeon, Tiwrip, nageur). Noul donné par J. -A. Ritgen à une famille de l'ordre des Halyptèues, comprerant des oiscaux qui, comme lés Mersus, plongent et nagent beaucoup.

COLYMEOPTK̀丶NeS, adj. et s. m. pl. , Colymbopteni (rodup Fits, plongeon, тravos, volatile). Nom donbé par J.-A. Ritgen à une famille de l'ordre des Halyptènes, comprenant des oiseaux qui à la fois volent et plongent.

Coni, s. f., coma ; Schopf (all.). On nomme ainsi, en botanique, des faiscenux de bractées (cx. Fritillaria imperialis, Bromelia Ananas, Salvia Horminum) on de fleurs stériles (ex. Hyacintlus comostis), qui couronnent la sommité de certains modes d"iuflorescence, et à des touffes ou houppes de poils qui snnt fixées à la pellicule de quelques scmences.

ConisatTanT, adject., pugnax, pugilator. Cctte épithèe est donnée à un oiseau (7ringa prignax) dont les individus aiment it s'cntrebaltre, et à un crustacé (Gelasimus pugilator) qui ordinairement a la pince droite plus grosse que la gauche.

COMBIVAISON, s.f., compositio, unio; Verbindung (all.); combination (angl.); combinazione (it.). Réaction que deux ou plusieurs corps exerecnt l'un sur l'autre, de manièrc à produire un tout dont la plus petite partie renferme les composans dans la mène proportion que la masse totale. Union de plusieurs corps en un certain nombre de proporitions, toutes déterninées et constantes, d'où résulte un composé possédont des propriétés très-différentes de eclles de ses composans. Résultat de cet acte. En minéralogie, Mohs donne le nom de combinaisons aux formes cristallines composées, parce qu'elles résultent de l'assemblage de différentes 
sortes de faees appartenant ehacune à une forme simple partieulièrc.

CONBinati-VEINEUX, adject. , combinale-venosus. Épilloc̀te donnée par Link aux fouilles dont les nervures latérales s'anastomosent ensemble avant d'arriver au bord.

COMBINF, adj. Épithète donnéc, dans la nomenclature minéralogiquie de Haüy, à des eristaux qui sont composés de plusicurs ordres de lacettes, dont les eombinaisons deux à deux ou trois ì trois détcrminent des analogies ou des proprićtés remarquables. Ex. Chaux carbonalée combinée.

COMBrétacées, adjent. et s. $\hat{f}$. pl., Combrelacea. Nom donné par R. Brown à une fanille de plantes, qui a pour type le genre Combretum.

Combretées, adj. et s.f. pl., Combretere. Nom sous lequel Candolle désigne une tribu de la famille des Combrétacées, qui renferme le genre Combretum.

COMBURANT, adj., comburens; brennend, verbrennend (all.) (comburo, brûler). On appelle principe comburant ull eorps qui, en se combinant avee un autre corps, donne lieu an phénomène de la combustion.

Covbustibilití, s. f., Verbrenn. lichkeit (all.) (comburo, brûler). Proprićte de brûler, dont Stahl avait fait une substance, le phlogistique, qui, en se dégageant des eorps, produisait suivant lui le phénomène de l'ignition.

COMBUSTrBLE, adj., combustioni obnoxitus; xzuqiuos; brennbar (all.). Dans le langage vulgaire, cet te épithète caractérise les substanecs qui, en certaines circonstances, donnent lieu à la prnduction du fen.

Conibustubles, adj. et s.m. pl., Combustibilia. Ce nom cst donné par Haïy et Hausmann à une elasse de minéraux, par Omalius et Marasehini à une elasse de roches, comprenant les débris de matières organiques végétales qui sont susceptibles de brû̉ler.

COMnustion, s. f., combustio, ambustio, ignilio; xaṽoเs; Verbrennung (all.). Ce mot exprimait jadis et rend encore aujourd'hui, dans le langage populaire, l'idée d'uu corps qui se dissipe en produisant de la chalenr el de la lumière. On supposait alors que le feu est une matière fixée dans les corps, et dont le dégagement entraine et dissipe peu à peu les molécules de la substance embrasée. Stahl, générulisant el systématisant cette idée, fit consistcr la combustion dans la séparation totale ou particlle de la matic̀re du fcu, le phlogistique, d'avec les bases auxquelles il est uni. Maequer modifia eette thcorie, en supposant que la eonbustion tient à ee que le phlogistique est expulsé des corps par la partic la plus pure de l'air, gui en prend la place. Lavoisier enfin Ja réduisit à n'être que la combinaison des corps avecl'oxigène de l'air ambiant. Dans ces deux théories, la production du feu n'est pas considérće conme un résultat nécessairc de la combustion, puisqu'il y a des cas où celle-ci a lieu sans feu, ce qui change tout-à-fait le sens qu'on attache au mot. Aujourd'hui on sait que le phénomene de l'ignition n'appartient pas uniquement aux combinaisons de l'oxigène, et qu'il peut, dans des cireoustances favorables, s'observer presque toutes les fois qu'une combinaison queleonque a lieu; car l'expérience a dćmontré qu'il se dégage de la chaleur à l'oceasion de toutc combinaison ehimique faite dans des conditions propres a rendre ce dégagement sensible, et que, par la saturation des affinités les plus fortes, la température monte souvent jusqu'à l'incandescence, tandis quo les plus faibles ne font que l'élever de quel-. 
ques degrés. On sait de plus que, quand on expose certains corps à une tcmpérature élevée, il y ćclate subitement du feu, comme s'il s'y opérail une combinaison chimique, sans que, dans la plupart des eis, lenr poids augmente ou dimione, mais avee changenent daus lcurs proprictés et le plus souvent dins leur couleur. On explique ce dernier phénomène par un degré plus grand d'intimité qui s'effectue dins lit combinaison de leurs élćmens.

CONESTIBLE, adj., edulis, esculentus, ciburius; essbar (all.); eatablc (angl.) (eomedo, manger); (1ui est susceptible d'ètre mangé. On donne eeltc épithète à un assez grand nombre de corps organisés que l' homme fait servir ì sa nourriture. Ex. Agaricus edulis, Mesembryanthenum edule, Ostrea colulina, Hibiscus cseulcntus, Rana esculenta, Arum esculentum, Tuber cibarium, Psidium supidissimum, Agarieus deliciosus, Morchella deliciosa, Iguana ilclicatissima.

COvitte, s. f. , cometa, stclla caudata s. crinita; roprirn;; Schwanzstcrn (all.) ; comet (angl.) (rókn, ohevelure). On appelle ainsi des astres qui tournent autour du soleil dans toutes les direetions possibles, en décrivant des orbites souvent fort alongés, qui ue deviennent visibles pour nous que vers leur passagr au périhélie, et qui sont aceompagnès d'une truince de lunic̀re à laquellc on donne le nom de ebevelure, barlse ou queue.

Conḱtograpiere, s.f., cometographia (nоurirns, comète, yox́.gow, écrire). Description des coméles.

COMIFÈriE, alj. , comifertus (co$m a$, elievelure, fero, porter). A gardh appelle bourgcous comiferes (Blattro. senknospen, all.) ceux qui ne produiscnt qu'une rosette ou un comrsion.
COMHOPHYTE, s. m. ; conizophytum ( «uič w, porter). Nom dunné par Necker aux plantes dont la corollc porte les étanines.

Comúlsivicíes, adj. et s. f. pl., Comneclinaceas. Nom donné par Bartlius a unc famille de plantes, qui a pour type le genre Conmelina.

ComuluLnées, adj. et s. f. pl., Commclinece. Nom donné par $\mathrm{l}$. Brown à une famille de plantes, qui a pour type le geure Commclina.

Connunsonives, adj. et s. f. pl. , Commersionect. Nom donné par Caffin à uve famille de plantes ayant pour type le geure Commersiona.

COMnISSURAL, adj., commissuralis. Épithètc donnée par les botanistes à l'insertion des étamincs ou d'une corolle staminifèrc, quand elles sont fixées au point où l'ovaire, seulcment iufère en partic, counucuee ì se distinguer du ealice. Ex. Samolus Falerendi.

COVMISSuRE, s. f., commissura. Point où plusieurs partics se réunissent enseruble. Hofmann doune ce nom ì la surface intérieure, ordinairement planc, par laquelle les deux akènes des Ombellifères s'appliquent l'un contrc l'autre, dans toutelenr longueur.

Commev, adj., communis ; ratvô̈; gemeinsclafilich, allgemein (all.). Ce mol, synouyıne, eu holanique, de général, primaire, principal, se dit: du péliole qui, dins les feuilles composćes, supporte à la fois plusieurs foliules ou plusieurs pétioles secondaires (ex. Cassin occidentalis); du calice, lorsqu'il se compose d'un assemblago de bractées entourant un ccrtain nombre de petites fleurs, quc l'on considère alors comme n'cu formant qu'unc seule composćc (ex. Synanthérérs); du réceplacle, d'apris Linné , lorsque, produit par l'évasement de la partie supérieure du pó- 


\section{COMP}

tiole, il supporte plusieurs fleure sessiles (ex. Synanthérées); de l'involucre, lorsqu'il accompagne plusieurs fleurs à la fois (ex. Ombellifères); de la spathe, quand elle renferuse plusieurs fleurs (cx. Alliam); du pédonculc, lorsqu'il sert de support à plusieurs pédoncules partiels.

COMMUNIR'̀DE, adj., communipes (communis, ordinaire, pes, pied). A.-II. IIarvorth donue cette épithète aux reptiles sauriens qui ont des paltes ordinaires sous le rapport de la longueır, ct aux Crustaećs déeapodes dont les pieds n'offrent rien d'insolite dans lenr' conformation.

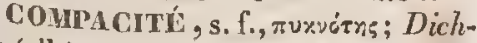
te (all.); compactness (angl.). Qualité de ce qui est compaet.

COVPACT , adj., compactus; $\pi u x$. vos; fest, dicht (all.); compact (angl.); compatte (it.) (cum, avee, pango, fielrer). Se dit: $1^{\circ}$ en minéralogic, d'un zninciral dont les partieules constituantes sont si étroilement serrées les unes contre les autres, $q$ 'il ne présente nucun indice de tissu (ex. Chaux carbonatce compacte); $2^{\circ}$ en bolanique, du chaton, lorsque l'axe est tout couvert de fleurs serrées les unes eontre les autres (ex. Salix caprea); de l'épi, quind les leurs, serrées les unes contre les antres, cacheut tolalement l'axe (cx. Typha laifolia); de la plante elle-meine, quand toutes ses parties sont tres-resserrées (ex. W $W_{\text {cis- }}$ sia compacta, Sphagnum compaclume); $3^{\circ}$ en zoologic, du corps d'un insecte, lorsque la lète, le trone et l'abdomen ne sont point séparés par des incisures (ex. Buprcstis).

COMPLECTT, adj., complexivus (complector, eurelore). Les botanistes donnent cette épithète à la préfolia tion, quand les disques des feuilles', en s'umbrassant les uns les autres, se recouvrent par les côtés el par lé sommet.

COMPLEBMENTAIRE; adj. , com-

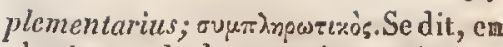
physique, de deux couleurs, simples ou composées, toutes les fois qu'elles produisent du blane quand elles viennent à ètre mêlées ensemble; en minćralogie d'un cristal dans le signe durjuel les termes d'un exposant fouetionnaire contiennent unc proportion commeneée par d'autres exposans qui sont simples (ex. Barylc sulfatco complénientairc).

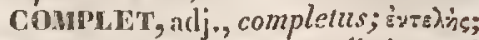
vollstündig (all.); conpiıo (it.) ; qui est muni de toules ses parties. On employe ce mot: $I^{\circ}$ en botanique. Une flcur complète est celle qui réunit les organes des deux sexes entourés d'un périantle double. Un arille complet est celui qui recouvre la graine en totalité (ex. Oxalis). Les cloisons conplètes d'un péricarpe sont eclles qui séparent el divisent complètement la eavité de ce dernier (ex. Chciranthis). $2^{\circ}$ En zoologic. Linné appelait nymphes complètes celles qui sont agiles et qui ont toutes les parlies de l'inseete parfait (ex. Araignécs). Falbricius nomme mélamorphose complète le eas où les inscetes ne subissent pas le moindre changement de formes, excepté peutôtre dans le nombre des pattes et le développeneut des organes sexuels (ex. Araignécs). Blainville donne l'épithète de complètc à la tểte des annelides, quand clle est composée de ciny anneaux, libial, oral , frontal , syncipital et occipital.

COMPL EXE, adject. , complcxus. Dans la nomenclature minéralogique de Haäy, on nomme ainsi des cristaux dout la struclure est compliquéc, et résulte de lois peu ordinaires. Ex. Chaux carbonatée complcxe.

Complí, adject., complicalus, complicans; zusammengefaltce (all.); qui est plić sur soi-même. Kirby donne eettc ćpithète aux élytres des coléoplères, lorsqu'elles avancent un 
peu l'une sur l'au're. Ex. Meloe. COMPOSANT, adj. Épithète que, quand plusieurs forces qui ne se font pas équilibre, agissent simultanément sur un point natériel, on donne à chacune de celles qui sollicitent ce point au mourcment.

Composé, s. m. Corps qui résulte de la combinaison chimigue de deux ou plusieurs antres corps, et dont on peut, pir l'analyse, retirer plusieurs malicives de nature différente.

Comrosí, adject., compositus ; zusammcrigesctzi (all. ) ; composed (angl.); composto (it.); qui contient plusieurs partics. On cmploye ce terme : $7^{\circ}$ en minéralogie. Mohs appelle formes composées celles qui résultent de l'assemblage de différens ordres de faces, dont chacune appartient à une forme simple particulière. $2^{\circ}$ En botanique. Il y désigne ce qui est formé de plusicurs parties dont la réunion constitue un organe quelconque qui, an premier coup d'œil, paraît simple. Il est donc synonyme d'agrérsć, et quelquefois de commun. On dit feuille composíc, celle qui est formée de parties articulées les unes sur les autres of susceptibles de se séparer sans déchirement, à la fin de leur vie; fleur composíe, cclle qui résulte d'une agglomération de fleurs; la plupart des botanistes donnent ce nom au eapitulc (voyez ce mot); fruit composé, eclui qui provient de plusicurs ovaires; pétiole composé, cclui qui se divise cu pétioles partieuliers portant des folioles (ex. Epimedium alpinum); pédoncule composé, celui qui se partage en plusienrs pédoncules secondaires (cx. Onbellifères) ; ombelle composée, celle dont les pédoncules primitifs se partagent chacun à son sonmet en une petite ombclle (ex. Daucus Carotla); chaton composé, celui dont l'axe produit de courtes ramilications qui servent de

\section{COMP}

support aux bractées florifères (ex. Juglans regia) ; épi composé, celui dont l'axe est ramifié, l'axe et les ramifications étant tout couverts de flenrs sessiles ou presque (ex. Heliotropium ); bulbe composéc, celle qui est formćc par la réunion de plusieurs cayeux (ex. Allium salivum); bouton composé, celui qui, sous une pérule générale, contient plu-ieurs rudimens de branches, distinctes et séparćcs même avant le bourgeonnement (ex. Pinus maritima); aigrette composéc, ceile dont les poils se subdivisent ì la manière des plumes. $3^{\circ}$ En zoologie. On appelle accouplement composé, celui qui a lieu quand un hermaphrodite est fécondé par 111 individu de son espèce, et qu'il on féconde un autre à son tour; dents composécs, cclles qui sont formćes de dents simples très-plites, ayant chacune son bulbe, qui finissent par n'en faire qu'une seule, en raison de leur soudure au moyen d'une nouvelle substance appelée cément (ex. Eléphant).

Conpostés, adj. et s. f. pl. , Composite. Les minéralogistes appellent roches composées les masses minérales qui résultent de l'assoriation des minéran $x$ simples en proportions à peu près déterminables. Brongniart donne ce nom à une classe de roches, comprenant celles dans lesquelles on observe un mélange de plusicurs minératix d'espèces différentes. La plupart des bolanistes, depuis Royen, nomment composíes les lleurset plan. tes qu'on désigne aujourd'luvi par l'épithère de Synanthérées.

Conposites, adj. et s. m. pl., Compositi. Nom donné par Link à une série de l'ordre des Gastéromyciens, comprenant ccur qui sont solides et formés par la réunion de plusieurs sporanges.

ConirosrTIFLORES, adj. et s. f. pl., Compositiflora, Compositiflo- 
res (composius, composé, flos, fleur). Gærıner et Wachendorff désignaient sous ce nom la familie des Synnanthérées.

COMPOSITION, s. f., compositio. Action de composer : résultat cle cette action; proportion dans laquelle les élémens sont unis ensemble, abstraction faile de tonsle considération sur les propriétés de ecs corps.

COMPRESSIBIITt s. $\int$, compressibilitas;Znusmmmendrïckbarkcit (all.); compressibleness (angl.). Propriété qu'ont certaiss corps de se réduire à un moindre volunse par l'action d'une cause extérieure, conme pression ou percussion, qui en rapproche les inolécules.

COMPRESSIBLE, adj., compres-

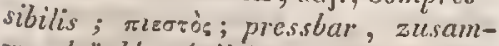
mondrückbar (all.); qui est susecptible de liminues de volume par l'action d'une cause cxtéricure.

COMTRESSIC.AUDE; adj. , contpressicaudatus (compressus, comprimé, cauda, queue); qui a la queuc compriméc. Ex. Agama compressicauda.

COMPRESSICAULE, adj. , compressicaulis (compressus, comprimé, caulis, tige); qui a la tige comprimée. Ex. Cisstzs eompressieazlis.

COMPressiox, subst. f. , com-

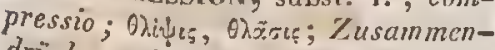
drickung (all.). Action qu'exerce sur un corps une puissanee située lisors de lui et qui tend à rapprocher ses molćcules.

COMPRtute, adj., compressus , compianatus ; zusammengedrïekt (all.); schiaccialo, compresso (il.). Se dit, en général, d’unc partie qui a plus d'étendue dans le sens de sa largeur que dans eelui de son épaisseur, et aussi de eelle dont la coupe présente la forme d'une ellipse; conmesi elle avait été serréc dans le sens d'un côté à l'autre. I ${ }^{\circ}$ En minéralogie. $\mathrm{On}_{\mathrm{n}}$ appelle eristal comprimé celui dans lequel deux faces opposées sont rappruchées, de manière que la forme subisse en ce sens un aplatissement qui altère sá symétrie (ex. Quñ z prismé comprimé). $2^{\circ}$ En botanique. On dit : anthere compremic, eelle qui est aplatie sur scs faces (ex. Iris); calice aplati (ex. Rhinanthus crista galli); camare aplatis: (ex Hellebortes viridis) ; capsule comprimce (ex. Veronica verna); cnrcérule comprimée (ex. Fraxinus Ornuss); coque de dićrésile compriméc (ex. Alisma Plantago); crémocarpe comprimé (ex. Apium Petroselinum) ; cypsc̀le comprimée, celle qui est aplatic latéralement (ex: Zinnia); ćpi comprimé (ex. Trilicum aristalum); fcuilles eumprimées (ex. Mesembryanthemum dolabriforme); grainc comprimée, cclle qui est plus large qu'épaissc (ex., Cassia fistula); hamepe comprimée (cx. Pan. cratiunn declinatum); leggume eomprimé (ex. Vicia lulea); lèvre comprimée, daus une corolle labiéc, celle qui est ployće en denx dans lé sens de sa longueur et aplatie latéralement (cx. Rhinanthts crista galli); noyau comprimélex. Prumus domestica): ovaire comprimé, celui dont leplus grinnd diamcitre est d'avant en arrière; rameaux comprimés ( $\mathrm{ex}$. Pachyncma complanatum); silieule comprimée, cclle qui est aplatie latéralement (cx. Thlaspi arveruse), ou par ses farcs (ex. Alyssum campesire); silique compriméc, celle qui est aplatie dans le sens de ses valves ( $A r^{\prime} a-$ bis turrita); spathelle comprimée, celle qui est pliée cn deux dans sa longneur (cx. Plcum pratense); spailacllulc compriméc (ex. Or)za sativa); tige comprimée (cx. hes(ii) compressus, Poa compressa, Potamogeton compressum); ube comprimć, dans les corolles monopétales (ex. Justicia quadrificla). $3^{\circ} \mathrm{En}$ zoologie. On dit les coquilles bi- 
valves comprimées, quand la cavité comprise entre les deux valves est pcu eonsidérable cı épaisseur (ex.Tellina complanata, Hamites adpressa. Voye Aplani, Aplati). Lc Thlips comprcssa a l'abdomen aplati.

CONCAVE, adj., concavus; ;oïlos; ausgeliölt, loohl (all.). Se dit, en botaniquc, de toute partic qui est crcusée et courbée sans former d'angles, et qui ne peut être rendue plane sans qu'il s'y produise des déchirures ou des plis. On applique cette épithète au clinanthe (ex.Ambora); aux fcuilles (ex. Drosera rotundifolia); an hile (ex. Alpinia occidcntalis); à l'ombclle, quand les ombellules sont disposées de manièrc ì laisser un creux dans le milieu, après la maturation du fruit (ex. Daucus Carotta); aux pétales (ex. Ruta graveolens); anx spathelles (ex. Briza minor); aux spathellules (ex. Mclicanutans); aux valves (ex. Alyssum utriculatum). Le Trocluus concavus cst ainsi appclé à cause de sa coquille calyptriforme.

CONCAVIFoliri, adj., concavifolius (concavus, eoncavc, folium, feuille); qui a les feuilles concaves. Ex. Rosa concavifolia.

CONCAVO-conCAVE, adj., concavo-concavus; qui prćsenle deux faces, toules deux concaves.

CONGAV0-CONVEXE, adj., concavo-convexus; qui est concave sur unc de scs faces et convexe sur l'autre.

CONCENTRATION, s. f., concen-

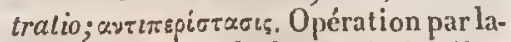
quelle on rapproche les molćcules d'un corps, en diminuant, par l'aetion de la chaleur, on autrement, la proportion du liquide qui les tient dissoutes.

CONGEPTACLE, s. m., conceptaculum. Linné donna d'abord ce nom ì l'espèce de fruit qui depuis a été désignce sous celui de folliculc. Jung, Medieus et Mœnch l'ont ap- pliqué aux pćricarpes pulpeux, et Desvaux au fruit appelé follicule par Candolle. En général, on nomme ainsi les cavités qui contiennent lcs séminules des cryptogames.

COXCEPTACULAIRE, adj. , conceptacularis. On nomme fructification conceptaculaire eelle qui se fait au moyeu de conceptaeles.

CONCEPTA GuLIFÈnE, adj. ; qui porte des conceptacles, comme les filamens de l'Isaria et du Cephalotrichum.

CONCEPTION, s. f. , conceptio,

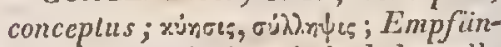
gniss (all.). Action vitale de laquelle il rćsulte que, par suite du coït, un nouvel être se produit dans le scin d'une femelle d'animal; acte de l'intclligence qui nous fait apercevoir ecrtains rapports entre les idées et les objets anxquelselles se rapportent.

CONCHACés, adj. et s. m. pl., Concliacea. Nom donné par Blainville à une famille de coquilles et à une famille de l'ordre des Lamellibranches, comprenant des mollusque? à coquilles bivalves dans le nombre desquels se trouvent la plupart de ceux que les anciens réunissaicnt sous le nom générique de Concha.

CONCHICOLE, adj., conchicolus (concha, coguille, colo, habiter). Épithitc donnće à un entozoairc $\left(A s^{-}\right.$ pidogastcr conclicola) qui vit dans les moules d'enu douce.

CONCUUÈ̀E, adject. , conchifer. (concha, coquille, fero, porter); qui portc une coquille ou quelque partic ayaut la figure d'une eoquille, comme Ic Polyporus conchifer, dont le chapeat est conchiforme.

CONCIIIFÈnEs, adj. et s. m. pl., Conchifera (concha, coquille, fero, porter). Nom donné par Lamarck, Schweigger et Latrcille a une classe d'animaux mollusques, comprenant tous ceux qui ont des coquilles bivalyes. 


\section{CONC}

CONCuIF OnME, adj . , conchiformis (concha, coquille, forma, forme). Kirby donne eetle épithìte aux tógulcs, quand ils sont demi-cireulaires, eonenvo-eonvexcs, et en quelque sorte semblables aux valves d'unc eoquille bivalve. Ex. Hyménoptercs.

CONCIOIDAI, adj., conchoilalis (xory), eoquilla, Eifos, ressemblanee). Les minéralogistes disent la cassurc conchoidalc, quand elle présente, sur un des fragmens, une eavité arrondic, à stries eoneentriques, et sur l'autre un relief qui en cst la eontre-épreuve, de manière que la eavité ressemble un peu à l'empreinte que pourraient produire certaines coquilles.

CONCIIOIDE, adj., conchoidcus, conchoides; muscluclig (all.); con-

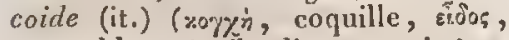
rcssemblanee). Se dit, en minérstlogie, d'un assemblage de eristaux divergens par lcurs grandes faces, à pen près comme les rayons d'un éventail, de manière que le tout présente l'aspect d'une eoquille bivalve. Ex. Prclinite.

\section{CONCHOLOGIE. Voyez Conciry-} LIDLOGIE.

Concirologiste. Vo oyc $\mathrm{Conchy}$ IIOLOGISTE.

CONGHOPHORES, adj, et s. m. pl., Conchophora (ror $\chi^{\dot{n}}$, eoquille, 巳́pw, porter). Nom douné par J.-E. Gray à une elasse d'animaux mollusques, comprenint les aećphales qui sont munis d'une coquille bivalve.

CONCIIYLIEN, adj. , concliylianus (roy zuin, coquille). Epithète domnée par les minéralogistes au calcairc qui conticnt des eoquilles fossiles. $V$ ojcz Copquller.

CONCHILIFLE, adj. , conchyliferus (conchylum, connille, foro, porter). Se dit d'un mollusque yni porte une coquille.

CONCIIYLIOIDE, adject. , conchy.

lioides ( semblanee); qui a la forme d'une coguille. On donne cette épithète, en minéralogie, à unc conerétion pseudomorphique, lorsque c'est une eoquille qui a été remplacćc. Un lichen (Thelotrema conchylioides) est ainsi appclé parce qu'il for'me des verrues qui, après la ehule des conceptacles, resscmblent ì de petites eoquilles.

CONCINLIOLOGIE, s. f., conchyliologia ( $x$ cyijin, eoquille, dö\%as, discours). Art de disposer et de déerire les enveloppes des animaux testacés de naniçre à les reconnaître sûrement, sans qu'il soit nécessaire d'avoir égard aux animaux qu'elles ont pu contenir.

CONCHYLIOLOGIQUE, adj., corr chyliologicus; qui a rapport à la conchyliologie.

CONCIIYLIOLOGISTE, subst. m., conchyliologrista. Naturaliste qui s'oceupe spécialement de l'histoire des eoquilles.

COXCHYLIOPUORE, adj., con-

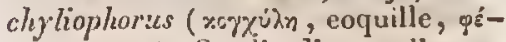

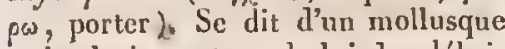
qui aglutine autour de lui des débris de eoruilles on de petites eoquilles enticres. Ex. Trochus conchyliophorus, Terebclla conchylega. Voycz Agglutinant.

cONcolon, adject. , concolor, concoloratus; glcichfarbig (all.). Epithìte donnée à un corps dont le dessus et de dessorrs sont de la muême eouleur, commc les ailes des papillons danaïdes ou Ic pelage du Ficlis concolor.

CONConitANT, adject., concomilans; qui aecompagne. On appelle sons concomitans eeux que l'oreille distingue, outre le son principal, quand on fait vibrer une corde, et qui, d'apris 10. Bernoulli, dépendent de la division de la eorde en des partics rendant toutes un son indépendant de eelui de la corde totale. 
CONCOBDANT, adj., concordans. En minéralogie, stratification concordante siguifie que deux on plisieurs systemes de couches sont pusés l'un sur l'autre, en conservant lcur parallélisme. Les fissures de superposition sont ditcs concordantes, lorsqu'elles sont parallèles à celles de stratification de la roche fondamentale et de la roche superposée.

CONCRET, adj., concretus; qui a pris la forme solide, qui s'est solidifié.

CoNchítion, s. C., eoncretio. Action de se snlidifier. On appelle ainsi, en minćralogic, une sulsstance solide, preş̧ue toujours irrégulière, dont les parlicules se sont réunits avec plus on moins de lenteur.

GONClisturié, idj. Se dit d'un minéral qui a été formé par voie d'infiltration ou de dépôls successifs, sur les parois des cavités qu'on observe dans les grandes masses pierreuses. Ex. Agrate.

CONDENSABIMTX', s. f., eondensabilitas; Verdichuarlicit. Propriété de pouvoir se resserler sur soi nitine, de manièle à occuper moins d'espace.

CONDENSABBE, adject. Dont les molécules sont susceptibles de so ritiprocher. les uncs des autres, et qui pent par conséquent êlre réduit à tu moindre volume.

CONDERSATEUR, s. m., eondensator ; condenscr (angl.). Instrument de pliysique, dû à Kinus et Volıa, et modifié ensuite heureusement par. Cuthberson, dout on se selt pour rendre sensililes les quantilés triesfaibles d'électricité, en les aceuInulant.

CONDERSATION, s. . , condensa. tio. Rapprochement des molécules d'un corps, diminution de volunse et augmentation de densité que ec dernier acquiert par l'accroissement de la pression ou l'abaissement de la température.
COMDENSi, adj., eondensatus. Ce mot est quelquefois pris daus le sens de serré. Ise Sphagnum condensalum a ses rameaux très-rapprochés les uns des autres. L'Athamanta condensaia a ses fleurs en ombelles serrées.

CONDrTIPEDE, adj. (conditus, caelié, pes, pied). Epithète donnée par A.-II. Harvorth aux Crustacćs dćcapodes brachiurcs dont la carapace produit une avance qui loge et recouvre les dernic̀res paires de pattcs, quand l'auiraial les contracle. Ex. Calappa granuluta.

Conduoublé. Voy. Conduplioué. CONDUCIBILITÉ, s. f., conducibilicas. Propriété dont jouissent les corps de proparger la chalcur et l'électricité dans livur masse ou à leur surface, et de les communiquer ainsi aux corps voisins.

CORDUCTEUR, adj., eonducens. Se dit d'un corps qui conduil le calorique, on qui transmet librement l'électricité. Anguste Saint-Mllaire nomme filets conducterus des tuhes qu'il a ohservés dans les styles des Cirgophyllécs, Porlulacées et autres planles, et qu'il regarde comme destinés à conduire la matière fécondante aux ovules.

CONDUCTEUR, s. m., conductor. Cylindre métallique, soulenu par des colonnes de verre, qui se trouve au devant du plateau dela machine électrique, et a li surface duquel se rassemble l'électricité.

C(NODLPLICATH, Covdeploué, adj. , conduplicatus, conduplicati'us; doppelliegend, zusammengeleurt (all.); qui est ployé en double dans le seus de sa longueur (ex. Loranthus ronduplicalus). On donne cette épithèle atux coryledons, lorsqu'élant appliqués face à face, ils sont ensemble ployés en deux dans leur longueur (ex. Brassica oleraeea), et d'après Candolle, aux fercilles dans le 
bourgeon, lorsqu'étant ployées sur leur longucur, elles ne s'embrassent pis, rnais sont placées l'une à côté de linutre (ex. Fagus).

CONDYLOiss, adj. et s. m. pl.,

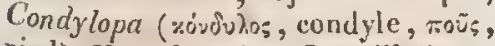
pied). Nom donné par Latreille d̀ une race de la séric des animaux céphalidiens, eomprenant ceux qui sont pourvus de pieds articulés.

CONDYLOpHOwe, adj. , condy-

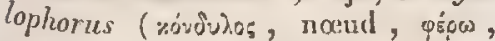
porter); qui porte un noud, comme l'Eclinospermum condylophorum, dont les pédoncules les fruits sont alongés et reullés.

CONE, s. m., conus, strobiliss; หล̄ंyos; Zapfon (all.). Candolle définit le cône un eorps coniqne formé par Une infloreseence intléfinie, où les fleurs naissent ì l'nissel'e de bractées sc̀ches, très-grandes ou suseeptibles de grandir après la floraison, et qui semiblent ainsi quelquefois former un tout unique. Ex. Pinus.

Conúrne, s. f., concina. Nom donné par Brandes à un alcaloïde pen comnu, qu'il dit avoir retiré des feuilles du Conium nuaculatum.

Conḱs, adj. et s. m. pl., Conca. Nom donné par Menke à une famille de l'ordre des Gastíropodes etćnohranches, qui a pour type le genre Conus.

CONFúdúnté, adjeet. On appelle ainsi les actinozoaires rénnis à leur pied par une partic comnune, ce qui les fait ressembler un peu à des lichens couverts de lcurs cupules (ex. Zoanthus socialis), ou serris ct rapprochés au point que leur développement réciprnque soit gèuć et qu'ils se deforment plus ou uoins (ex. Caryopleyllia cyathus).

CONEERTIELORE, adj. , conferliforus (conferlus, serré, flos, flcur); qui a des fleurs serrées, comme celtes du L-pcopsis confertiflora, qui sont sessiles et presque inbriquées en grappes.

CONFERTIFOLIÉ, adj., confertifolius; dichtblïtrig (ali.) (conferitus, serré, folium, feuille); qui a des fenilles serrées, comme eclles du Chloris confertifolia, qui sout trèsserrées et imbriqucies.

COMEEIVACEes, adjeet. et s. f. pl., Confervacea. Nom douné par Reichenbach à une section de la division des Algues gongylophyces, comprenant celles qui, comme les Conferves, ont lo forme filamenteuse.

Confertiles, adject. ets. f. pl., Confervece. Nom donné par Agardh is un groupe de la tribu des Algues eonlervïlus, par Reichenbach ì un groupe de la section des Confervaeécs, par Bonneuraison à une section des Alrues articulées, par Bory à une famille d'Algues aqualiques, eoupes uni ont tontes pour type le geure Confersea.

CONFERVICOLF, adj., conforvicola (conferva, eonferve, colo, habiter) ; jui vit parmi les conferves. Ex. Tabicolaria confervicola.

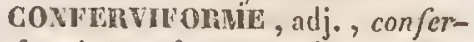
paformis (conferva, conferve, forma, forme); qui ressimble un pea it une conferve. Ex. Scriularia conforweformis.

Conwenvmors, adj. ets. f. pl., Confervinca. Nom donné par K. Sprengel à une tribu de la famille des Algues, ayant pour type le genre Conferva.

CONFERVOIn, adjeet., conforvoüdes; qui ressemble à une eonferve, qui cu a la physionomie. Ex. Hypnum conferpoides.

Conirervomides, adj. et s.f. pl., Confervoidere. Nom donué par Ag:arilh it une tribu de la famille des Algues, par Wiegmanu à une seetiou dil groupe des Hydronématées, ayant pour type le genre Conferea.

CONYLUENT, s. m. , confluens 
(eum, avec, fuo, couler). Réunion de ảcux cours d'eau.

CONFLUENT, ndject., confluens ; ineinanderfliessend, zusammenfiessend (all.); qui se réunit ct sc confond. Se dit : $1^{\circ}$ en minéralogie, d'une variété prismatique d'Arragonite, composce de plusieurs octaëdres cunéiformes, dont les parties saillantes aux endroits, des bases se réunissent en un seul corps. $2^{0} \mathrm{Eu}$ botanique, des antheres, lorsque leurs deux lobes, unis l'un à l'autre, paraissent n'en former qu'uil scul (ex. Plectranthus); des colylédons, lorsqu'étant sessiles, ils se coufondent absolument par leur base, de manière qu'on n'en pent distinguer l'origine (cx. Heliantlus annuus); des nervures des feuilles, quand elles sont simples et réunies au somnict de celles-ci.

Conglíation, s. f., congelatio; $\pi \bar{z} \iota_{\iota}$; Ausfrieren, Gefrierung (all.). Réduction d'un liquide à l'ćtat solide par la soustraclion d'une partie de son calorique latent.

CONGESTIF, adject. (congeslus, amassé). Fípithèle donnćc par les botanistes à la préfoliation, quand les disques des feuilles sont repliós irrégulièrement sur cux-1nèmes.

CONGLOBí, adj., conglobatus; geball, zusammengeballt, zusammengehüufl (all.). Ramassé en boulc. Ex. Coecinella eonglobata.

Cosglomiss, adj. et s. f. pl. , Conglobatc. Pontedera appelait ainsi les Synanthérécs.

CONGLovítiat. Synonyme peu usité d'Agglomérat. Voyez ce mot.

Concribí, adj., congregatus. Gacrtner donuait eetle épithète à celles des Synauthérées dont les ealathicles sont éloignées les unes des autres.

CONGRÉGĹEs, adj. ct s. f. pl., Congregatce. Haller réunissait sous ce nom les Dipsacées et les Syuanthérćes.

CONicrse, s. f., conicina. Alcali existant dans le Conium maculatum, et auquel Braudes attribuc les propriélés vénéneuses de cctte plante.

CONICIQLE, adj. , conicicus. Épithète donnée à un acide dont Peschier admet l' existenee dans le Conium maculatum, ct aux sels produils par la combinaison de la conicine avec les acides.

Coxico-rNcenvinostnes, adj. et s. m. pl., Conico-incurvirostres. Nom sous lequel J.-A. Schaeffer désignait un ordre d'oiseaux, comprenant ceux qui ont le bec çonique et un pen crochu.

CONICO-PROTENSIROSTRES, adj. ct s. m. pl., Conico-protensirostres. Nom donné par J.-A. Schaeffer à un ordrc d'oiseaux, comprenant ceus qui ont le bec conique et alongé.

CoNico-subulinostres, adj. ct s. m. pl., Conico-subulirostres. Nom douné par J.-A. Schaeffer à ull ordre d'oiscaux, comprenant ceux qui ont le bec conique ct subulé.

CONICO-TÉNumOSTRES, adj. ct s. m. pl., Conico-lenuirostres. Nom donné par J.-A. Schacffer à un ordre d'oiseaux, comprenant ceux qui ont le bec conique et grêle.

Coxrnre, s. f., conidium ; Keimpulver (all.) (r.\%, , poussicre). Nont sous lequel Sprengel, et d'après lui plusicurs autres autcurs, ont désignć une poussic̀re farincuse qu’ils croyaient être produite, dans les lichens, par l'aggolonćratiou des gemmules cxtrêmement fines de ces plan" tes.

CONuE⿱R⿴囗十 fentragend (all.) (contes, cône, fero, porter). Unc Synanthéréc (Leuzed conifora) est ainsi appcléc parce que son involucre a été comparć à une poinme de pin; unc antre plante (Leucadendrum coniferum ), parce 


\section{CONI}

que ses fleurs sont disposées en un eône solitaire.

CONIFines, adj. et s. m. pl., Coniferce. Nom donné à une fanille de plantes, comprenant celles qui ont leur inflorescente disposéc en eône ou chaton.

CONIrLoris, adject., coniflorts (conus, cồne, flos, fleur). Le Silenc coniflora est aiusi appelé paree que ses calices sont eylindraećs on plutôt coniques.

CONHORIIE, adj., coniformis (conus, cône, forma, forme). Se dit d'une eoquille qui a une forme eonoïde (ex. Peclipes coniformis) ou eonique (ex. Auricula coniformis).

CONIGlive, adj. , conigentes (comus, eône, şrignno, naître); qui croît sur les cônes de sapin (ex. Agaricuts conigenus, Pezisa conigena, Hystcrium conigcnum). Conigéne veut dire aussi qui engendre de la poussière, ou qui cu est ehargé, comme l'Agaricus conigents, dont le stipe est pulvérulent.

Coniocarpless, adj. et s.f. pl. , Coniocarpex (novix, poussiere, rap$\pi \dot{c} \xi$, fruit). Nom donné par Fec à une tribu de la famille des Liehens, qui a pour ty pe le genre Coniocarpon.

Coniocanpes, adj. et s. m. pl., Coniocarpi (rovix, poussière, «хрто丶, fruit). Nom donné par Meyer et Reichenbach a un ordre de la classe des Liehens, ayant pour type la senve Coniocarpon.

CONIOCTMATIEIs, adj. et s. m. pl., Coniocymatii (zovis, poussicre, Yuuśrts2, cymation). Nom donné par Wallroth à une tribu de la fanille des Lichens, eomprenant ecux qui ont leurs corpuscules reprodueteurs à nud, et eorrespondant aux Coniocarpes de Meyer.

CONOCYSTE, s. f., coniocystis (rovix, poussière, ruozls, vcssie). Agrardh désigne ainsi les tuberules on corps reproducleurs des fougeres.
Covtoncron, s. m., conioecium (rovia, poussic̀re, oixix, maison). Nom donuć par Ehrhart au fruit du genre Andrexa. Voyez Sporangr.

CONBolchevies, adj. et s. f. pl., Coniolichenes (roviz, poussière, j.sıy̆v, lichen). Nom donné par Zenker is un ordre de la famille des Lichens, comprenant eeux qui ont la forumc d'une poussière, comme les Lepra.

CONıOMYCLTES, adj. et $s_{\text {- }}^{-}$. pl., Coniomyectes, Coniomyci (xovix, ponssière, $\mu$ úxn, champignon). Nom donné par Fries et Nees d'Esenbeek à un ordre de la famille des chanpignous, eomprenant cenx qui sont formés de capsules groupcées sous l'épiderme des plantes, ou éparses sur une base charnue ou filamenteuse.

coniosporites, adj. ets. m. pl., Coniosparia (rovia, poussic̀re, бropò, semence). Nom donné par Link ù une tribu de l'ordre des Hyphomyeètes, qui a pour type le genre Coniosporium.

CONIOTrLALAuES, adj. et s. m. pl., Coniothalami (rovia, poussière, óxizuns, lit). Nom donné par Fries à un ordre de la eahorte des Lichens, comprenant eeux dont les corpusculcs reproducteurs sont à nud, sans organe particulier ni réservoir qui les renlerme.

CONIOUE, adj., conicus; $\%(2) \times \dot{0}_{5}$; kegelfürmig, kescelig (all.); qui a la forne d'un eône, e'est-à-dire qui diminue insensiblement de la base au sommet, lequel est en pointe. Se dit, en botanique, des aigutillons (ex. Zanhoxylum Ciava Herculis ); du calice (ex. Stuchrs coccinea); du clinanthe (ex. Ruelbeckin laciniala); de la coiffe d'une mousse (ex. Bryun cxlinntorium); de son opercule (́cx. Grmnostomim costicum); du cluapear d'un champiguon (ex. Agaricus sxtincloriles); de l'embryon (ex. Curfore Thebiäa) ; de la ra- 
erne (cx. Daucus Carotta); de la radieule (ex. Labices); du stigmate (ex. Heliotropizem); du strobilc (ex. Pinus sylvestris); diu style (ex. Lccythis). On dit d'une coquille univalve, qu'elle est conique quand une de ses extrémités est élargic el conme coupée carrément, tandis que l'autre, pointue, forme le sommet (ex. Trochus). L'Aranca conica a l'abdomen terminé en pointe conirue.

CONmostues, adj. el s.m. pl., Conirostres (conus, eòne, rostrum, bec). Nom donné par Cnvier, Meyer, Duméril, Vigors, Blainville, Latreille, Lesson, Fieinus el Carus à une fimille de Passereaux on de Perehcurs, comprenant ceux qui ont le bee ćpais, robaste et conique. Poyez Conorasuphes.

Covisponutes, adj. et s. f. pl., Conispora (ròs, poussière, arcos, semence). Nom donnć par Link à une tribu de l'ordre des Mucédiuées, ayant pour type le genre Conisporium, et comprenant eelles qui ont leurs conteptacles libres et pulvirnlens à la surface. $V$. Contsponté es.

CONJOINT, adj, , coalnatus, connatus, coalitus, coadunatus, conjunctus; verbunden (all.) Se dil ginéralement ro porties, idlentique's pour la uature, qui sont soudées ensemble : par excmple, des cristar $x$ acieulaires, quand les aiguilles adhèrent les unes aux autres dans le sens de leur longuenr (ex. Arragonite conjointe); des ctamines, quand elles sont réunies par les anthères (ex. Synanthérées), ou par les liless (cx. Malvacées); des Yerilles, lorsqu’elles sont soudées à leur parlie infërieure (cx. Saponaria officinalis); des pétales, quand ils sont soudés ensenthe par le bord (ex. Statice monopetala), par leur sommet (ex. Fitis), ou par leurbase (ex. Vaccinium Oxycoccus); des sparhelles, quand, opposćes l'nuc à l'aulrc, elles sont soudées sur les bords (ex. Alopecurus bulbosus); des spallallules (ex. Alopccurus agrestis); des slipules (ex. Humulus Lupulas); des valves, quand elles sont eonliguës, rentrantes, et soudées les unes aux autres par la parlie qui s'enfonce dans l'intérieur du péricarpe (cx. Rhododendrum ponticum). $V_{0 y}$. CoInvé.

CONJOXCTIF, adj., conjunctivus. Cette épithicte est domnéc à l'insertion des étamines, quand, celles-ei étant fix ées sans décurrence à la face externe ou latéralc de la substance niĉme du disque, les pétales sont également altaclás à ce dernier. Ex. Rutacécs.

CONJONCTION, s. f, conjunctio;

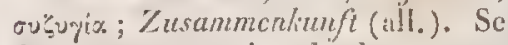
dit, en astronomie, de deux astres quand, étant vus de la terre, leurs ares perpendiculaires à l'éeliptique coïncident pour se rendre au nume point de celte courbe, e'cst-à-dire qu'ils ont la mème longilude.

CoNJugue, adject., conjugatus, jusalis, opposite pinnalus; gepaart (ail.); uceopiato (it.) (ctent, avec, jugo, accoupler). On appelle ainsi les fouilles perrées dont les folioles sont allachćes par paires, c'est-à-dire opposies deux à deux, et les épis qui sont attachés deux par deux (ex. Paspalis conjugatus). Le Conferpa jugalis.s est ainsi nommé à cause de la disposition de ses flocons.

Cowstrates, adject. et s. f. pl., Conjugrata. Nom donné par Bory à une tribu de la lauille des Arthrodiérs, eomprenant celles dont les filaunens se joignenl et s'unissent à une certaine époryue de leur vic, pour ne plus faire qu'un seul ct même être.

Covinn CTORIU:, s. m. Ehrhart designc sous ce nom le petit opereule permanent quii, daus l'dndreæa, couvre le sommel de l'urne.

convajickécs, adj. et s. f. plo, 
Connaracex. Nom douné par Can dolle et A. Richard à une tribu de la famille des 'Túrélinthacées, qui a ponar type le gene Connarus, el qui a ćlé érigée en famille par R. Brown et Kunth.

COXXATSQUARE, adj., connatisquamus. (connalus, réuni, squama, écilille). Epilhère domńc par H. Cassini au periclinc des Synaultérécs, lorsque les squames sont entregref-
f'es.

Conví, adject., connatus; verwachsen, zusammengcwachsen (all.); congiunto (it.). Synonyme de conjoint (voyez ec mot), dont on se sert, surtont en lintimique, pnur désigner les feuilles opposées quir sont soudées par la base (ex. Falcriana connata). I.es cntomologistes disent les mấchoires connces, quand elles ticnnent à la lèvre inférieure jusqu'un peu au dela de leur milieu (ex. Hynénoptères ).

Coviecticuxe, s. $\mathrm{m}$, connecliculum. Quelques botanistes out donnéce nom à l'annéur élastique des folt gires.

CONNECTIF, s. m., conneclivum (cum, avee, necto, nouer). L.-C. Pichard appelait ainsi un corps eharnu plarticulier, distinct du filet des étaunines, qui unit l'une à l'autre les loges séparécs de l'anthère, dans ecrlaines plantes. Ex. Salvia.

CONvExs:, adj., connexus, connexivus; vcrbunden (all.) (cum, avec, necio, noner). Epilhète Jounéc, dans la nomenelature minćralogique de Häiy, ì nn cristal dins lequel diverses faces remplacent les bords d'une forme dominante, de manière quelles font contimuté autour de celle-ci (ex. Baryle sulfutéc connexe). Link appelle feuilles conncxes eelles dans lesquelles ies pútioles opposés se sondent ensemble par lia seule, et où la soudure ne s'opere pas seulement aux dépens do la lane, ec qui constitue pour lui les feuilles cornécs.

CONNIVEN' , arlject., connivens; zlusammenneigend, gesteneinandergcbosch, gcgeneinandergeneigrt, zusammenstosscrd (all.) (connivco, cliguoler); qui se rapproche par le sominet. Oi cmploye ce ternie: $1^{0}$ en hotanique. Calice connivent, eelui dont le bord entier du limbe cst contraeté d'unc manière remarquable, our clont les dents du bord convergent vers le centre de lia fleur, ou dont les sépales sont rapprochés entre cux ou tendent il se rapjeracher par introflexion (ex. Trollius curopaus); corolle comnivente, eelle dont les pétales sont convergens (ex. Cissus connivens); feuilles conniventes, eelles qui, étant opposées, s'appliquent l'une contre l'autre par leur face supérieure, pendant la nuit (ex. Atriplex loor(ensis); $2^{\circ}$ en zoologie. On dit, en entomologic, que les ailcssont eounirentes, lorsque, ćlan redressées, elles se touchent par leur sommet ou par un point quelconque de leur fice supérieure (ex. I $a$ nessul .

CONOCARPE; adj., conocarpus

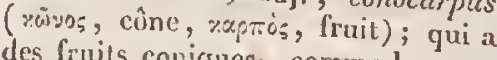
des frnits coniques, comme les capsules du V crbascum conocarpum.

CONOInAL, adject., conoidalis; qui a la forme d'un cône, comme les eoquilles de la IIarpa conoidalis et dn Cerilhium conoidale.

CONOLDE, adj., conoideus; rw-

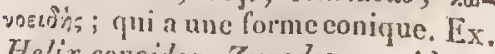
Helix conoidea, Zygodon conoideus, Bulimus.s conulus.s.

CONormes, adject. et s.m. pl., Conoidea. Noin dunné par Latreille à une famille de l'ordre des Gastéropules pectinibranches, qui a pour type le genre Conus.

Covors, adj., conopus (xwyos, cone, $\pi 2 \bar{z}_{5}$ pied); 'qui a le pied on le stipeconique, Ex. Agraricus conopus, 
conorSAIRES, adj. cl s. m. pl., Conopsaria, Conopsuria, Conopsariï. Nom donné par Cuvier, Lamarck, Latreillc, Wiedemann ct Eichwald à une famille ou à me trilju de Diptères, ayant pour type le genre Conops.

Covopsmes, adj. el s. m. pl., Conopsida. Leach désigne ainsi unc famille de Dipteres, qui a pour type le genre Conops.

Covoliamencs, adj. et s. m. pl.,

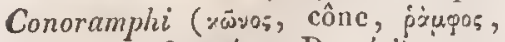
bec). Nom donné par Duméril et par Ranzani à une famille de l'ordre des Passercaux, comprenant ecux qui ont lc bee eonique. Voyez ConirostrEs.

CONQUE, s. f., concha; xoryh. Aristote désignait les coquillcs bivalves sous ec nom, que plusieurs naturalistes modernes, Adanson cntr'autres, ont adoptć dans lc même sens. On appellc égalemcnt ainsi une portion du pavillon de l'oreille des Mammifères.

Coveues, s. $\int$. pl., Concha. Nom donné par Latmarek à une famille de l'ordre des Conchifères dimyaires lamellipedes, comprcnant leo luivalves dont Linné avuit formé le genre Venus.

CONSíouent, adjeet. On appelle points consíquens un ou plusieurs points où il se réunit deux pûles opposés, qui se forment quelquefois dans le barreau qu'on aimante, et qui sont cause qu'il présente des irrégularités dans sa minière d'agir.

CONSISTANCE, s. f., consistentice (crem, avee, sisto, retenir). Résistanee qu'en vertu du raporuchement ou de la liaison de lenr's molécules, les eorps opposent ì ccux qui font effort pour les désunir on les briser.

CONSONNANeE, s. $\int$. , ipooparia; Gleichlaut (all. ). D'après sou étymologic, ec mot indique l'eflet produit en nous par deux ou plusieurs

\section{CONS}

sons qui se font entendre à la fois; mais, dans la pralique, on le rcstreint à exprimer l'intervalle formé par deux sons dont la sinultanéité flatte l'oreille. Deseartes ct Dalembert attribuaient ce plaisir à ce qu'alors l'esprit saisit aisément le rapport de l'un à l'autre son. Estève et Rousseau, sans ehereher à l'expliquer, le font dépendrc de ce que la nature ayant voulu qu'un son queleonque füt tonjours associé à d'autres sons agréables, et portǻt avec soi son accompagnemeul (voyez Harsonioue), qui lui est essentiel, qui en fait la douceur et la mélodie, l'àme cst sensible à une perfeetion de laquelle il résulte que les harmoniques de ehaeun des deux sons eoncourent avce cclles de l'autre, qu'elles se soutiennent mutuellement, deviennent plus sensibles, durent plus long-temps et augnentent par cela même l'harmonie géuérale, en rendant plus prononeć l'aceord des sons qui les donnent.

consteldation, s. [., conslellatio; Stcrnbild (all.) (cum, avec, stclla, étoile). Les astronomes appellent ainsi des groupes d'étoiles auxquels on a donné des noms tirćs de la fable, de l'histoirc, des rìgnes de la nature ou mène des objets d'art, et qu'on a lićs, pour aider la mémoire, ì des figures diverses d'homines, d'animaux, ete.

CONSTITUANT, adj., constituans (cum, avec, statio, position). On nomme, en chinie, atómes constituans des eorps composćs, ecux qui résultent dc la combinaison dcs atômes intégrans, et en géognosie partics constituantes (Bestandtheile, all.) d'une roche, celles qui sont dissérninées uniformément el en quaritités à peu près ćgales dans eette derliiè $r$.

CONSTRETES, adj., constrictor (constringo, serrer). Un serpent (Boa consirictor) est ainsi nommé à 
eause de la force avec laquelle il serre et ćerase dans les replis de son corps les animaux dont il veut fairc sa proie.

CONSTRicteuns, adjeet. et $\mathrm{s} . \mathrm{m}$. pl., Constrictores. Nom donné par Oppel à une fanille de reptiles $\mathrm{O}_{\mathrm{ph}} \mathrm{i}-$ diens, qui renferme les genres $B o a$ et Eryx.

CONTIGU, adj., contiguus ; anstehend, aneinandergeklappt (all.) (eum, avec, tango, toucher); qui est voisin, qui se touche sans adhćsion. Les botanistes diseut les sépales eontigus, quaud ils sont rapprochés longitudinalement, et ne laissent point d'intervalle notable entre leurs côtćs (ex. Raphantes); cotylédons eontigus, lorsqu'ils sont appliques cxactement l'un contre l'autre par leur face interue (ex. Rosacées).

CONTINENT, subst. m., continens (eum, avec, teneo, tenir). On nomme ainsi, en géographie, les terres qui embrassent une grandc étcndue sans êlre interrompucs oll coupćes par des masses d'cau considéribles.

ContinentaL, adj. , qui a rapport aux continens. Les caux conlinentales sont celles qui appartienuent., counme partics accessoires, à unc vaste étcndue de terre fermc, tels que les fleuves, rivières, lacs et autres amas, eourans ou stagnans, de liquide.

CONTINU, adj., continuus; ununterbrochen, fortlaufend (all.) (eum, avec, teneo, tevir); qui nc fait qu'un, qui ne prescnte pas d'interruption. Se dit: $1^{\circ}$ en minéralogie, d'un eristal dont le signe est composé de quatre exposans cu proportion contiuuc (cx. Chaux earbonatée continue). $2^{\circ}$ En botanique. On appelle ainsi en général les parties qui font suitc l'une ì l'autre, qui sont soudées ensemble Sans articulation. Organes continus, eeux dont les fibres et le tissu ccllu- laire sont tellement disposés que, dans aucune parlie de lcur longueur, on ne pcut, à nulle époque, les séparer sans déchirenent bicn sensible. Tiǵc continue, celle qui, jusqu’à la cime de la plante, forme un axe prineipal d'où partent les ramifications (ex. Abies Picea). Feuilles eontinues, ealles dont le disque cst sans interruption depuis son origine jusqu'à son sommet, ct dont le pétiolc, s'il existe, sc continuc sans articulation, pour former la nervure médiaire du disque.

CONTORTO-CONVOLUTIF, adj., contorto-conpolutivus. Epithètedonnée à la préfloraison, quand elle est à la fois convolutive el tordue, ou internédiaire entre ces deux modes d'arrangement, comme dans la plupart des Diosmées.

CoNTOURnÉ, adject., contortus, contortuplicaties; verworren, gewunden, gedreht (all.) ; contorto, storto, attortigliato (it.). Se dit: $x^{\circ} \mathrm{cn} \mathrm{mi-}$ néralogie, d'un prisme hexaïdre dont un des pans subit un détour, de sorte qu'une de ses moitiés forme un angle reutrant avee l'autre (ex. Arragonite contournée), ou d'un cristal dont les faces ont éprouvé des inflexions qui les font paraitle de travers (ex. Chaux earbonatéc ferro-manganésifere contournée); $2^{\circ}$ en botanique, d'une partie qui sc reploye sur clle-mème, comme la racine du Polygonum Bistorta, la plupart des siliques du. Sisymbrium contortuplicatum, les legrumes de l'Astragalus contortuplicains.

Contounnícs, adj. ets.f. pl., Contorta. Ijinnć a établi, sous ce nom, une fanille de plantes, dans laquclle il range celles dont la corolle cst torse, comme le Nerium, l'Aselepias.

CONTMATA, adj., contractus; zusammengezogen (all.) (cum, avee, traho, tires $)$. Sc dit: $1^{\circ}$ el minéra- 


\section{CONV}

logie, d'un cristal dodécaëdrique, dans lequel les bases des pentagones extrêmes éprouvent une sorle de contraction, en conséquence de l'incjinaison des laces latérales ( $\mathrm{ex}$. Chaux carbonaléc contractic); $2^{\circ} \mathrm{eu}$ botanique; du conncclif, quand il est extrêniement court et lient les lobes de l'antlière rapprochés (ex. Liliunz); de la cymc, lorsque la fleur. centrale a avorié, ct que les branches latérales sout trís-cenrtes, de sorte que les fleurs se trourent agglomérées ensemble (cx. Dianthus barbatus); du nectairc, quand, étant placé sur la réceptacle, il ne déborde pas la base de l'ovaire (ex. Citmus). Voyez Ressentí.

CONThACTLL, adj, , contractilis; qui est susceptib!e de se contracter. On n'applique guères cette épithète qu'aux parties organiques auxquelles le rapprochement de icurs molécules imprime des monvemens plus ou moins manifestes, comme a la fibre musenlaire.

CONTractiltis, s. f. , contractilitas. Faculté dise raecourcir en se resserıänt ou revenant sur soi-mème. On n'employe ec mot qu'en parlant des corps organisés jonissaut de la vie.

conThictrov, s. f., ronercetio; Zuzammenzichun' (all.). Resserrement, ripproclacmeut des molécules d'un corps, qui a pour rísultat de diminuer le volume, en augmentant la densité. En physiologie, ee not cst généralcment pris comme synonyme, ou à peu près, d'action mus culnire.

CONTRALRE, adj., contrarizs. Fort peu usití en histoire naturelle, ec terne cst quelquefois employé par les bolanistes comme synongine d'opposé, ct par les conehyliologistes comme l'équivalent de sćncstre.

CONTRASTANT, adj., contrastans. Se dit, en minéralogie, dans la nomenclature de Fiäy, d'un rhomboïde

très-aigu, dans lequel une inversion d'angle, relativement au noyau, présente une sorte de contraste, en ce qu'ellc se mpporte à un rhomboïde beatucoup plins obtus que ee dernier (ex. Chaux carbonatće contrastante); cu gćoguosie, des fissures de superposition, yuand clles ne sont point paralliles a celles de stratifieation de la roche foudamentale et de la roche silperposice.

CONTRE-COURANT ou ReMou, s. m. Courant qui marclie en sens contraire d'un autre conrant situé à eôté de lui, soit qu'il résulte de la rencontre de deux courans ayant des directions différentes, soil qu'il provieuns d'un même courant repoussé, cn tout ou en partie, dans un sens contraire à sa direction primitive.

CONTHE-IMPREINTE, s. f. Terme dunt les géognostes se servent ponr désigner l'apparence qui a lieu lorsqu'm corps fossile ayant disparu par une cause queleongue, une matière étrangìre inorganique s'est infiltrée et mouléc entre le moule et l'empreinte, de manic̀re à représenter avee la plus grande exactitude le corps fossile lui-même.

CONTRE-FORT, s. m. Les géognostes donnent quelquefois ce nom à des rangées de collines ou à de petites montagnes qui se trouvent en avant d'une chaine de hautes montagnes.

CONTRE-PENTE, s.f. Andréossy appelle ainsi le versarit le plus abrupte d'zune chañe do montagnes.

CONVERGENT, conpergens; zusammonlaufond (all.). Se dit de parlies qui, dès leur base, tendent à se rapproeher les unes iles autres.

CONVWRGINERVí, adj. , conoerginervius, conicrgcnli-nervosus. Se dit d'vue fenille dout les nervures décrivent une courbe dans leur prolongement. Ex. Planlago media.

CONVLXE, adjcet., convexus ; 
gequölb (all.); convesso (it.) ; qui est bombé ou rclevé sans former d'angles, comme le clinanthe de l'Aster chinensis; le chapeare de quelques champignons (ex. Peziza convexula); la coquille du Signrelus convexus; cerlains cristaux qui présentent la forne primitive dont les faces sont bumbées (cx. Chanx fluatée con$v_{c x c}$ ) les feuilles de l'Ocymum Basilicum; le hile de l'Asculus; l'ontbclle de l'Asclepias syriaca; le réccplaclc des Rubus.

CONVEXO-CONCAVE, adj., convexo-concavus. Se dit d'un corps dont l'une des surfaces est convexe et l'iulre concave.

CONVEXO-CONVEXE, adj. , convexo-conecxus. Se dit d'un corps dontlesdenx surfaces sont convexes.

CONVEXuLE, adj., convexulus; qui est très-légèrcment convexe. Ex. Peziza convcxula.

CONvolUT'́, adj., convolulus ; zusammengerollt (all.) (cum, avec , volvo, tourner); qui cst roulé sur soi-mềme oul autour d'un autre corps. On dit: ailes consolutćes, dans les inscctes, celles qui enveloppent le corps de maniçre à lui douner une forme cylindrique (cx. Crambus); cotylćdons convolutés, ceux qui sont roulés en spirale sur eux-mèmes dans le sens de leur longueur (ex. Punica Granatum); feuilles consolutees, celles qui, avant leur entier dévcloppeinent, sout roulćcs sur ellesmêmes, de telle sorte que l'un de leurs bords représente un axe autour duquel le reste du limbe décrit une spirale (ex. Canna); pétiole convoluté, cclui qui a la forme d'une lame roulée en giaine autour de la tigc (ex. Graminées).

Convolutri. Foyez Convoluté. CONvolvulidíés, adj. et s. f. pl., Convolvulacea. Nom donné à une famille de plantes, qui a pour type le genre Convolvulus.
CONvoLVulicole; adi. , conyolvulicalus; qui vit ou croît sur les liscrons, comme le $S$ phecria convolmulicola sur le Convolvulus sepium.

CONizírs, arlj. et s. f. pl., Conyzce. Nom donné par Lessing à une section de la sous-tribu des $\Lambda$ stéroidées baccharidées, qui a pour type le genre Conyza.

coominonní, adj. Fipithète donnée, dans la nomenclaturc minéralogique de llaüy, à un cristal dans lequel des facettes prodnites par différeutes lois ont entre elles nne sorte de corrćlation, en s'élevant les unes au dessus des autres, de manière que les arètes qui les séparent sont paralleles. Ex. Chaux carbonatée coordonzée.

COPAl INE , s. f., copalina. Sousrésine que John a extraite de la copal.

COPACI.IN, adj. , copallinus; qui produit de la copal. Rhus copallinum.

COPIDOPTÈNES, adj. et s. m: pl. , Copidopicni (xortis, sabre, $\pi \tau x-$ vós, volatile). Nom donné par J.-A. Ritgen à un ordre d'oiseaux Hyg̣rornithes, comprenant ceux qui ont les ailes en forme de sabre.

COPRIDES, adj. et s. m. pl., Coprida. Sous ce nom Leach désigne une famille de l'ordre dos Coléoptères, qui a pour type le genre Copris.

COPnivone, adject., coprivorus ( қо́тро; , fumier, voro, dévorer); qui vit sur le crottin. Ex. Spliarocera coprivora, Lordatia coprina.

COPROBIE, adj., coprobises ( $\because 0^{-}$ $\pi 00 ;$, fumicr, \&ios, vie). Nom donné par Riobincau-Desvoidy aux Myodaires Calyptérées dont les larves vivent dans les cxcrémens.

COPRoplinGes, adj. et s. m. pl.,

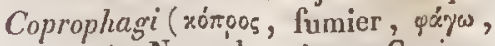
manger). Nom donné par Cuvier, Latreille, Goldfuss, Ficinus et Carus 
à une section de la tribu des Lamellicornes searabéides, comprenant des Coléoptères qui se tiennent et vivent dans le fumier et les cxerémens.

COPROPHLE, adj. , coprophilus

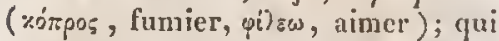
croît sur le fumier. Ex. Agariczes coprophilus, Spharia coprophila.

COPULA TIF , adject., copulativus (copulo, accoupler). Épithc̀te donnée par les botanistes aux cloisons du péricarpe, quand elles ne se séparent bien ni de l'axe ni des parois.

COPULATION, s. f., copulatio. Union des deux sexes pour produire un nouvel individu. Voycz Coïr.

COQUE, s. f., coccum; róko; ; cocco (it.). Les botanistes appellent ainsi les loges closes d'uu péricarpe pluriloculaire qui se séparent les unes des autres à l'époque de la maturité. Candolle donne ce nom aux carpelles, quand, étant formées par une feuille courbée longitudimalement sur ellemème, clles ne présentent qu'une seule suture résnltant du rapprochenent des bords de celte fenille, et que l'ouverture de la suture a lieu aree élasticité.

COQULLEE, s. f. On appelle ainsi : en botanique (putamen) la pur'ic osscuse qui entomro la graine, ou paroi de l'endocarpe, dans les drupes, les noix, les nuculaines; en zoologie (cochlea, concha; Muschel (all.); shell (angl.); concligglia (il.), des corps crélacés, plus ou moins minces, durs, eassans d'une mavic̀re nette, faciles à conserver, et toujours en rapport avec la pean, qui servent d'abri ct en quelque sorte de logement i un grand nombre d'animaux mollusques.

COQunLLis, adject. , muschelig (all.). Se dit d'une roche ou d'nn terrain, qui contient des coquilles fossiles. Calcairc coquiller, Marne coquillcre. Poycz ConcuxuEN.
Cor. Synonyme d'andouiller. $V$. ee mot.

CORACES, adj. et s. m. pl, Coraces (corax, corbeau). Nom donné par Vicillot à une tribu d'oiseanx sylvains, par Illiger à nne tribu d'oiseaux marcheurs, par Meyer et Wolf à un ordre de la classe des oiscaux, par Goldfuss ì une famille et par Savi à une tribu de l'ordre des passereaux, par J.-A. Ritgen à une familie de Xérornithes, ayant pour type le genre Corbeau.

CORACievs, adj.ct s.m. pl., Coraciana. Nom sous lequel Vigors désigne une tribu de la famille des Corvidés, qui a pour type le genre $\mathrm{Co}_{\mathrm{O}}$ racias.

COR.ALLIFORIE, adj., coralliformis (corallium, corail, forma, forme); qui cst en forme de corail.

CORALLIGENE, adj., coralligenus (corallium, corail, giyno, produire). On donne cette épithète aux polypes qui produisent le corail.

CORALILN, adj., corallinus (corallium, corail); qui a la couleur rouge du corail (ex. Cancer coralliuus, Tortrix corallinus) ; qui est rameux conme lui (ex. Isidium corallinem).

CORALLINées, adj. et s. f. pl. , Corallinca. Nom donné par Goldfuss a une famille de l'ordre des $\mathrm{Li}-$ thozoaires, par Lamouroux à une famille de Polypiers flexibles, ayant pour type le genre Corallina.

Corsterives, adj. et s. f. pl., Corallina. Nom donnć par Blainville à une famille de la classe des Calciphyles, par Ficinus et Carus à une fanille de eclle des Lillızoaires, ayant pour type le genre Corallina.

Coralliograpile, s. f. , co-

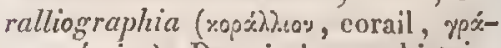
(๖), écrire). Description et histoire du corail.

CORALlopllage, adj. , coral-

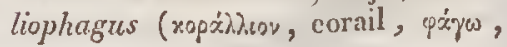


manger). La Cypricardia coralliophaga est ainsi appelée parce qu'clle habite dans les masses madréporiques.

CORALLOIDE, adj., coralloüdes. Se dit en minéralogic d'un corps concrétionné ( ex. Arragonilc coralloïde), en holanique d'un champignon (ex. Clavaria coralloïdcs), on d'un lichen (ex. Sphorophorits corallö̈des), qui se ranific à la manière du cornil.

CORALLORMIEE, adj., corallorhizus (ropóxhicov, corail, piל̧x, racine); qui a des racincs rameuses, imitant une branche de corail pour la forme. Ex. Ophrys coralliorhiza.

coraux, s. m. pl., Corallia. Nom donné par Schweigger à un ordre de Zoophytes hétérohyles, par Biainville à une famille de la classe des Zoophytaircs, comprenant des animaux irrégulic̀rcment épars à la surface d'un polypicr, réunis à une partic commune ave: laquelle chacun d'eux est en communication de substanee, et ayant pour type lc seure Corallium.

CORBEILLE, s. f. Les entomologistes appellent ainsi la face externe de la jambe postérieure des abeilles ouvrières, parce qu'elle est légèrement concave et bordée de longs poils.

CORBiculé, adj., corbiculalus. Eithète donuée par Kirby au tibia des insectes, quand on y remarque unc corbeille. Ex. A pis.

Conbults, adj. el s. m. pl., Corbulaca. Nom donné par Lamarck à une famille de Conchiféres dimyaires tenuipèdes, et par Latreille à une famille de l'ordre des Conchifères tubullipalles, ayant pour type Je
geure Corbula.

CORCelet. Voycz Corsezer. (all.); cuoricino (it.). Linné ct Cé- alpin ont employé ce terme pour désigner l'embryon végétal.

CondÉ, adj., cordatus ; herzformig (all.) (cor, cour); qui a la forme d'un cocur de carte à jouer, comme les feuilles du Seboa cordata, Je corselet de la plupart des carabes, et un assez grand nombre de coquilles bivalves. Corclé se dit aussi, dans le langage vulgaire, d'une partic végétale, et surfout d'une racine, lont le tissu devicut filamenteux, comme il arrive à la carotte, par les progrès de l'ûge.

CORDELÉ, adject. , funiculosus, succinctus, ligatus, filosus. Se dit d'une coquille qui est garnie de côtes peu élevécs, ou entourée de cercles saillans. E.s. Fasciolaria funiculosa, Purpura suecincta, Purpura ligata, Mritra filose, Purpura fiscclla. $V$. Cormonné.

Connréntes; adj. et s. f. pl., Cordicrea. Nom donné par Candolle à une trilsu de la famille des Rubiacées, qui a pour type le genre Cordiera.

COHDIFoure, adj., cordifolius ; hcrabliturig (all.) (cor, cour, folium, fenille); qui a des feuilles ou des folioles en cocur. Ex. Rubus cordifolins, Acicen cordifulia, Plarnaccum cordifolium.

CORDLF OLME, adj ., cordiformis, taxiformis; herzfïrmig (all.); cuoriforme (it.) (cor, coeur, forma, forme); qui a la furme d'un cocur de carte à jouer, comme les anthicres de l'Ocymum Basilicum, les bractécs du Salvia bicolor, les cotyledons du Coffea arabica, le hile du Cardiospermum. On appelle embryon cordiformc, celui qui, presque aussi long que large, se retrécit en angle aigu à l'une de ses extrémités, et se dilate i l'autre en deux lobes arrondis (cx. Asartm curopaum); fcuilles cordiformcs, celles qui sont plus longues que larges, et partagées à leur 
lase en deux lobes arroudis (ex. Tamnus communis); pétales cordiformes, ceux qui sont échancrés au sommet (ex. Parnassia palustitis).

CORnIGline, adjeet., cordigcrus ( $\mathrm{cor}$, cocur, gero, porter). Le Marcetia cordigera a ses feuilles en cour; le Scrapias cordirer n la lame de son labelle lar'ge et cordiformc; Ie Cymbidium cordigerum, un de ses six pétales à trois lobes, dont l'un en cour; lc Cryptocephalus cordi$\mathrm{ger}$, une tacle en cocur sur le corselet.

CoRDIUANE, adj., cordimants (cor, cour, manzls, main). Se dit d'un crustacé quii a les serres cu formede cour. Ex. Ocypoda cordimann.

Conorteles, adj. et s. fi. pl., Laqucolaria (chorda, corde, tela, torle). Sipithète donnée aux araignées qui ne font pas de toiles, et se bornent à jeter des fils solitaires, tendus en naanirire sle cordes.

CORDONNÉ, adj., funatus, torosus, tortulosus. Se dit d'une coquille qui est marquíc de saillics en forme de eordons. Ex. Fllipsolithes finnatus, Murex torosus, Cerithium torulosum.

CORDYLOIDEs, adj. et s. m. pl.. Cordyloidca. Nom donné jar P.-F. Fitzinger à une tamille de Reptiles saluriens, qui a pour type le genre Cordylus.

ConÉIDEs, adj. et s. m. pl., Corcida. Nom sous lequel Leach désigne une famille d'inscetes lıćniptères, qui a pour type le genre Corcus.

Conconsméces, adj. et s.f. pl., Corcopsidca. No in douné par H. Cassini à me section de la tribu des Hélianthées, par Lessing à une section de la sons-tribu des Sénécionidécs Hélianthées, ayant pour type le genre Corcopsis.

CORIACE, adj., coriaceus; leterartig (all.); asciutto, coriaceo (it.) (corium, cuir); qui est dur et tenace comme du cuir. Se dit, cn bo- tanique, de l'érème (ex. Phlonis fruticosa), de la lorique (ex. Camellia Japonica), des fcuilles (ex. Loranthes coriaceus, Anamenia coriacea, Pittosporum coriaccum), du piricarpe (ex. Arachis hypogaa), du placentaire (ex. Papaver Rhacas) des spathelles (ex. Bambusa arundinacea), des spathellules (cx. Olypa panciflora). On appelle plantes coriaces celles qui sont d'uue substance ténace, flexible, el plus ou moins ćpaisse, comme du cnir (ex. Patcllaria coriacea). Un poisson (Cyprinzes coriaceus) est aiusi nonuné parce qu'il a la penu nue, dure et épaisse. Les ornithologistes diseut les pieds des oiscaux corinces, quand la peau en est épaisse (ex. Pigcons).

ConLCÉ, adj. , coriaccus. Epithète donné par les minéralogistes à des corps composés d'un assemblage de filamens tellement entrelacés cnsemble qu'ils imitent un morecau de cuir. Ex. Asbeste coriacé.

CORACES, adj. et s. m. pl., Corincea, Coriacea. Nomı donné par Cuvier, Latreille et Eichwald à une tribu de la famille des Diptères pupipares, comprenant ceux dont les parties du corps paraissent ètre sculcment coriaces, et par Blainville à une famille de la classe des Zoanthaires, dans lapuelle il range ceux de ces animaux qui ont le corps cncroûté ou solidifié par des corps étrangers, et formant par la desiccation une sorte de polypier coriace.

Coniandrées, adj. et s.f.pl., Coriandrece. Nom douné par Koch ct Candolle : une tribu de la famille des Onbellifires, qui a pour type le genre Coriandrum.

Comiruées, adj. et s. f. pl., Coriaricce. Caffin et Candolle désignent sous ce nom une famille de plantes, ayant pour type le genre Coriaria.

CorLdine, s.f., coriarina, Al- 
cali que Peschier dit avoir reneont ré dans les feuilles du Coriaria myrtifolia, nıais que Nces d'Esenbeck n'a pu y retrouver.

CORINDONipues, adj. el s.f. pl. Nom inposé par Omalius à un genre de roches pierreuses dans lequel il place l'énerì.

Comron, s. nı., corium. Kirby appelle ainsi, dans les insectes, la portion cornće ou coriace de l'hémélytre.

COrropnone, alj., coriophorus (ropis, punaise, ழ̧şes, porter); qui a une forte odcur de punaisc. Ex. Orchis coriophora, Stenoglossum coriophorum.

CORISANTHIRH, s. f., corisantheria. Nom domné, dans le système de Jussicu, à une classe de plantes dicotylédones monopétales, à coroile épigyne, qui ont les anthères distincles.

COnrsies, adj. ct s. f. pl., Corisice. Nom douné par Latreille, Goldfuss, Ficinus et Carus à une famille de l'ordre des insectes Hémiptères, ayant pour type le genre Corets.

Cortules, s. m., cormus; xopuòs ; sliel (all.). Willdenow appelait ainsi toute la portion d'une pluste cryptogame qui se tronve hors de terre, la fructification exceptée. Ce mot exprime, pour Bernbardi, la portien d'une tige qui tcrmine le trone, et qui porte presque toajours la flenr et le fruit, médiatement ou immédiatement.

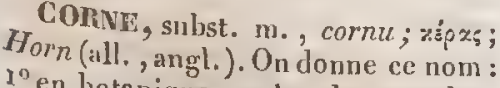
$1^{0}$ en botaniguc, an bec des capsules, quand il est recourhć; aux éperons dé certaines fleurs (ex. Linaria); suiVant Jacquia, anx appendices qui terminent le eapuchon des Stapelia; à certains appendices qui naissent sur Ia fructification de plusieurs cryptogames; $2^{\circ}$ en zoologie, à des éminenecs coniques et dures qui najssent sur le front (ex. Bauf, Cerf), ou le nez (ex. Rhinoceros), chez certains mammiferres; à deux éminences pointnes que lc céraste d'égyple porte, une au dessus de chaque œil ; à tu prolongement plus ou moins considérable qui surmonte la tète ou le corselet de divers inscetes; à une protubérance charnu: que certaine's clic nilles (ex. colles des Sphinx) portent sur le onzième anncau. C'est aussi lc nom que le vulgaire donne aux antennes des insectes, et aux pédieules qui supporlcut les yeux des limacons. Oa donne également ectle épilhçte à la substance solide, sèebe el insensible qui recouvre le pied de cerlains animaux (ruminans, solipedes, pachydermess, ct qui, considéréc eu égard à sa forme el à ses usages, prend celle rle sabot.

Corvé, adj., cornets, hornartis (all.); corneo, (it.); qui a la consistance, la dureté, la compacité, lá llexibilité, la demi-transparence, la couleur, en un mot l'aspect de Ia corne, conme la corpulle des Planorbus corncus, Helix cornea et Buccinum corneum; l'opercule de eertaines coquilles univalves; le périsperme des Rulviacées; les pieds des oiseaux rapaces; le pollen de l'Asclepias, la tige el les expansions de plusicurs Fucus.

COnvé, s.f. , cornea. Memlirane transparente qui forme la partic antéricure de l'oeil chez les animax pourvus de cet organe, el qui permet i la lumière de s'introduire dans son intérieur. On donne le même nom a loute la partic extérieure de l'oeil des insectes.

Comvérs, adj. et s.f. pl., Cornece. Nom donné par Kunth à une section de la fimille des Caprifoliacées, el par Cautolle à une famille de plantes, ayant pour type le genre Cornus.

CORNÉo-CALCAIIE, adj., cor- 


\section{I 6}

neo-calcarius. Épithète qu'on donne à l'opcrcule des coquilles univalves, quand il est formé par unc couche cornée à l'intérieur, qu'épaissit au dehors un dćpôt calcaire souvent considérable.

CORNET, s. m., cucullus. On appellc ainsi, en botanique, certains épcrons qui sont roulés sur cuxmĉmes comne un cornet; et, cn zoologie, une lame plus ou noins recourbée, qui partage incomplètement la cavité de certaines coquilles uniloculaires en deux parties (ex. Crepidula).

CORNicOLE, adject., cornicolus (cornus, cornouiller, colo, habitcr); qui croît sur les cornouillers, comme le Spharia cornicola sur le Cornus sanguinea.

Corniculariéres, adj. et s. f. pl., Cornicularia. Nom donné par Fee à une tribu de la famille des Lichens, qui a pour typc le genre Cornicularia.

CORNICULE, subst. f., cornicula. Quelques anciens cntomologistes se sont servis de ce terme peu convenable pour désigner les antennes des inscctes.

CORvICuct, adj., cornicularus; hornförmig, sackfism.rigg (all.). Candolle dunne cettc épithèle aux ficurs dans lesquelles les anthères seules sont transformées en pétalcs ayant la forme de cornets (ex. Aquilesia vulgaris corniculala). Le Dendrolobium corniculalum cst ainsi appelć, parce qu'il a scs fleurs courbécs en manière de cornes; le Mescmbryanthemum corniculatum, parce que ses fenilles offrent la mèmc disposition; lc Lolus corniculatus, parce que scs gousses sont cylindricues, droites et raides ; le Creadion corniculatus, parce qu'il porte sur le front unc protubérance courte et obtuse, en forme de cornc; le $S$ wertia corniculata, parce qu'il a sis corolles munies de quatre éperons.

\section{CORN}

ConNiculíes, adj. et s. f. pl., Corniculala. Nom donné par Candollc à une section du genre Oxalis, comprenant les espc̀ces qui sc rapprochent de l'Oxalis corniculata.

CORXICULIFÈRE, adj., cornicteliferus. Se dit, cn botanique, de la gorme d'unc corolle monopétale, quand elle offre des cornets creux et ouverts infirieurement. Ex. Symphytum tuberosum.

CORNIF ORME, adj., corniformis (cornu, corne, forma, formc); qui a la forme d'une corne. Ex. Fistulana corniformis.

CORNIGÈE, adject., cornigertls (cornu, corne, gero, porter); qui porte des cornes sur la têtc (ex. Diaperis cornigera), ou des tubercules semblables à des cornes (ex. Trilobiles cornigcrus, Turbinella cornigera); qui a des épines si grosses et si contournćes qu'on les a comparćcs aux cornes d'un aninal (cx. Mimosa cornigera).

CORNU, adj., cornutus, chclatus; xерхов ; gehörnt (all. ); qui a des corncs ou des appendices comparables à des cornes. Se dit : $1^{0}$ en hotanique, d'une plante dont lis styles (ex. Saxifragra hircina) oll les anthères (ex. Solanum cornutum) sont en forme de cornes, ou dont lc calice est muni à la base d'ap. pendiccs semblables à des corne ${ }^{9}$ ( ex. Lithaspernum cornulum ); $2^{\circ}$ en zoologie, d'un oiscau qui porte une corne surle front (ex. Palamedea cornuta), dont la tête est garnie de longues plumes qu'il pcut releverà volonté en uwe double huppe (ex. Coc-

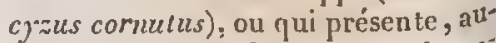
dessus de l'cil, des pelites plumes courtes et droites ayant la forme de $\mathrm{pe}^{-}$ tites coroes (ex. Caprimulgus cornut tus ); des crochcts d'une coquille bivalve, quand ils sont fortement pror longés, et tournés en spirale plus ou moins r'ćgulière (ex. Chama unicor". 
nis) ; d'un insecte qui a des tubćrosilés aiguës sur lc chaperon (ex. Osmila cornuta), ou sur le eorselet (ex. Bosiriehus cornutus ); d'un polypier rameux, dont les ramenux ont élé comparés ì des eornes, pour la forme (ex. Cellaria cornula, Cellaria clelasa),

CORNUPIEI), adj., eornupes (cor$n_{u}$, corne, pes, picd). Vieux mot, tombé en lésućtude, dont on s'est servi pour désigner les manmifères qui ont les pieds garnis de sabots.

COnOLLACÉ, adj. , corollaceus. Synonyme peu usilć de pétaloüde. voyez ec mot.

COROLLAIRE, adj., corollaris; qui est de la naturc des eorolles. On appclle Reurs doubles corollaires celles dont les pétales surnuméraires sont dus à la multiplication des parties de la corolle; partics corollaires, d'après Candolle, la corolle ct les parties mâles des fleurs, ou les étamines, qui sont de nature analogue; vrilles corollaires, les pétales ou segmens de la corolle qui se prolongent en appendices tortillés (ex. Sirophanthes).

COROLLE, s. f. , curolla; Blumenkrone (all.). Une grande partic de ce qui a été dit du calice (vorez ce mot) peut soppliquer aussi à la corolle. Tournefort donnait ce nom à l'cuvcloppe extéricure de la fleur, quand il $y$ en a dcux, et, lorsqu'il ne s'en trouve qu'unc scule, à celle qui n'est point adhérente. Linné appelait ainsi toute enveloppe floralc qui n'est pas verte et qui it unc texture délicale. Mais il y a beancoup dc cas oì la base de l'enveloppe cat verte et ferne, tandis que le sommet en cst délicat ct coloré. Aussi Limné a-t-il cmployé assez arbitrairement le nom de corolle. On a prétendu dcpuis que la eorolle élail privée de stomates, ct qu'à ee caractìc on pouvait la distinguer du ealice; mais les faits sont encore veuus renverser ee moyen diagnostique. Dès lors on a cru, avec Ehrhart, devoir proscrire tout-ii-finit les deux mots, et se servir du terme de périgone dans le cas d'unc scule cnveloppe florale. Link a proposé un moyen difficile de distinction, qui consiste en ce que les divisions de la eorolle alternent avec les étamines, tandis que celles du caliec leur sont opposées. Le nom. de corolle avait étć donnć par Lécluse à la partie qu'on appelle collcrette (voyez ce mot) dans les agaries, ct par Hedwig à la membrane délieate qui, dans les inousses, produit la coiffe et la vaginule.

Comolle, adj., corollatus, petalodes. Se dit d'nne fleur qui est munie d'une corolle.

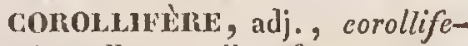
rus (corolla, corolle, fero, porter). Epithète donnée au gynophore, on réceptacle de la fleur, quand il fait une saillie qui, indépendamment du pistil, supporte aussi la corolle. Ex. Dianthus.

COROLlfFlores, adj. ct s. f. pl., Corolliflore (eorolla, corolle, flos, flcur). Nom douné par Candolle à une sous-classe de la elasse des Dicotylédones, comprenant les plantes ì cornlle monopélitle insérée sur le réceptacle.

COROLLIFOHME, adj., corolliformis ( corolla, corolle, forma, forme). On opplique celte épithète à l'androphore, quand il a l'aspect, la con. sistinee ct la forme d'unc corolle. Ex. Gomplurena globosa.

COROLLIN, adj., corollinus (corolla, eorolle). Candolle appelle poils corollins, ceux qui sont situćs sur les pélales (ex. Menyanthes), périgone, étanines et style corollins, ceux qui sont de la mème nature que les corolles. Desvaux nomme neetaires corollins eeux qui ont leur siège sur la eorolle. 
COrOLLIOUE, adj., corollictes. Epithète donnce par: Lestilioudois à l'inscrtion des étamiucs, quind ecs organes sont soudís avec la corolle.

COROLLISTY, adj, ct s. m. , corollista. Epillicłe dunnée par Link aux botanistes qui, conme Rivin, Ludwig, Tournelort, Plınier et Púntcdera, ont tiré de la cololle les caractères distinctifs des clasies dans l'élablissement de lenra méthodes.

ConotruLE, s. f. , corollula; Blumcnkrönchen (all.). Petilc corollc. On doune quelquefois ce nom aux flem rons des Symaulićrés.

Conovinizs, adj. et s. m. pl., Coronali (corona, cutronne). Debuch désigne ainsi une tribu de la famille des Ammonées, comprcnant celles dont lo côlé est arué d'une rangéc de tubercules ou de pointrs qui paraissent s'élever au-dessus des tours de spire en forme de couroune.

CORONAHES, adj. el s. f. pl., Coronarice (corona, couronne). Nom donné par Linné i une famille de plantes, comprcuant les Liliacces qui ont six pétales, sans spalhe, comme la tulipe.

COnoxar, adj. : coronalis ( corona, couronue). Maryu is appel'e ainsi lc gúmianhe proprement dil, qui enveloppc cireulairement les organes sexucls, en formant autour d'enx unc sorte d'anneau ou de couronnc.

CORONares, adj. et s. [. pl. , Coronales (corona, couronne). Nom douné par Lamarek e. B'anville aux coquilles multivalves, forsqu ćlant di-posics d'une manic̀replus on moins réguliere ailour d'mu axe commun, elles sont solidenent cugrenées $\mathrm{cn}-$ tre clles par los lourds, de manicre à former une cavisé complète.

CORONLOMnE, adj., coroniformis; kronenförmig (all.) (corona, couronuc, forma, forme): qui a la forme itume couronne. II. Cassini

\section{CORP}

đonne cette ćpithc̀te, dans les Synanthérées, au bourr elet apicilaire, quand il est trc̀s-ćlevé, imitant une aigrette en couronne (ex. Sparganophortes); et à l'aigrette, lorsqu'elle consiste cn unsimple rebord continu, qui cntoure et surmonte l'aréolte apicilaire du fruit.

COronluLÉes, adj. et s. f. pl., Coronillece. Nom donné par Candolle à rinc section de la tribu des Hédysarées, par C.-H. Ebermaier à unc tribu de la famille des Papilionacées, ayant pour type le genre Coronilla.

conovuricís, adj.el s. m. pl., Coromulacea. Num donné par Menké à une famille de la elasse des Bostryclsopodes ou Cirripedes, qui a pour type le genre Coronula.

CORONUL.IDES adj. ct s. m. pl. , Coronuladre. Nom donné par Leach à mne fimille de l'ordec des Cirripides acmmplosomes, ayant pour type le genre Coronula.

COmONuLE, s. f. , coronula; coronclia (it.)(corona, couronue). Kirliy donne cc nom à une couronne ou demi-courome d'ćpines qui garnit le sommet du cubitus ou du tibia de quelques inscetes (ex. Fulgora candelaria). On l'applique aussi (Saamentirönchen, all.) au rebord membraneux de certains fruits (ex. Seabio.sa.)

CGRonumiés, adj. et s. m. pl., Coronulidee. Nom donné par J.-.E. Gray et Menlic à une famille de la elasse des Cirripèdes, qui a le genre Coromula pour type.

COBPORAIITE, s. f., corporalitas. Itat de ee qui est corps.

Conponíté, s.f., Körperlichkcil (all.). Ce qui constitue un corps tel qu'il est.

COEPOzOAIRES, adj, et s.m.pl.,

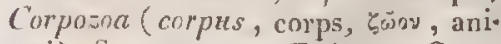
mal). Sous ce nom, Ficinus et Carlus désignent un embranchement du règine animal, embrassant les animaux 
qui ont un systime sanguin et un systeme nerveux simples, et qui possèdent essenticllement les organes de la vutrition (du corps) de l'homme.

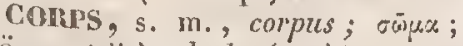
Körper (all); body (angi.); corpo (it.). Étendue limitée cl imuónétrable, qui pent produire en nous certaines implessions, en agissant sur les organes de nos seus. I,es conchyliologistes appellent corps, dins les coquilles mnivalves, tout ee gui se trouve compris entre le sommet et l'ouveriure, quelquelois aussi le deruice tou de spire, quand ou ne déconrre que lui, qui est alors orclinaircment le plus gros, et oit se trouve l'onverture. En zoologie, corps sc preud lantôt pour l'anintual tout entier, tantôt aussi punr sa partie la plus epaisse, ahsiraction fitic des menbres ou appendices; dans ce dernier sens, le not est synonyme de trone.

CORIUSCUAARE, adj., corpresctelaris. La thérie atomistique est appeléc quelquefois thcoric corpusculaire. Cepeudant ee mol est phis usité en philosophie que dans les sciences physiques.

CORPUSCULE, s. in., curpascuhem. Petit corps. Synonyme d'alome. Porez ce mot.

CORBELATIA, adj. Épillicte donnéc par les plıysiciens à deux ou plusicurs proplićtćs, lorqu’elles sont tellement dépendantes l'uve de l'atutre gu'clles ne penvent cxister ou q'on ne saurai les délinir séparément.

COREIGIOLE, adj., corrigioln-
latus (corrigia, conrroic). Un insecte (Ceyx corrigiolanss) est ainsi ¿ppelé parce qu’il porte au dessus des fenoux une bande bruncen forme de jurrelicie.

COMSRzDT, s. m. Les conchyliologistes appellent ainsi la partie antérieure et ovalaire des crochets d'une eoquille bivalve, it laquelle s'insère le ligament quand il est externe, el dont une moitié se trouve sur chaque valve. La signification du motcorselet (Vorderleib, Mruststiuck, all.) a varić en en tomologie. Geoffroy et autres donment ce nom it toutes les, partics découvertes dn thorax des in. sectes, Straus alt prothorax, Latrcille au prolhorax, quand il surpasse notablement. tes pièrcs suivantes cn éteudns: et que eclles-ci, réunies avre l'abdomen, semblent en faire partie intégrante. Ainsi on a appliqué cette dénomination tantôt an prensier segment seul du trone (Colcoptèros, Orthopicres et plusicurs Hémipiéres); tantôt à la partie supérieure comprise entre la léte et l'ibdomen, tandis qu'iulérieurement on ne la donuse qu’à la portion placée entre la tête et. la poitrine; tantùt enfin au dos de la poitrine, e'crst-il-dire à l'cspace compris entic le prenier segment du trone et l'aludonen. Depuis que les partics constituautes de l'enveloppe solide des insectes ont élé analysées anatomirunement, la conservation du mot corselet n'est plus propre qu'à porter de la confusion et du vague dans les deseriptions.

CORTICAL, s. in., indumentum corricale (corlex, écorce). Quelques anatounistes ont appelé ainsi la substance existante dans plusieurs dents enmposées, à laquelle on donne plus géuéralement le nom de cément. Voyez ee mol.

CenTRCAL, alj., corticalis (coricx, écoree); qui appartient ou qui adhère à l'écorce. On nomme counches corticalcs les ecreles concentriques qu'oul observe, souvent avec peine, dans l'écorce des plantes ligneuses; pores corticaux, des ouvertures ovales qui s'aperçoivent sur la surface des végétiux destinés ì vivre hors de la terre ou de l'eatu; planies corticales, celles qui naisscnl 
et végètent sur l'écorce ( $\mathrm{cx}$. beaucoup de lichens et de mousses, le $P c-$ ziza corticalis, l'Agraricus corticalis). L'Aradus corticalis est ánsi appelé parce qu'il vit sous l'écorce.

COHTICATÉ, iulj., corticateus ; rindig, rindenartiog (all.) (cortcx, écorce). Épithète donnée par Palisot-Beauvois à la graine des graminées, quand elle est recouverte par la paillette supéricure, fortement adhérente. Unc plante (Knema corticata) doit cette épillète à l'épaisscur de son ćcorce.

ConticuUx, adj. et s. m. pl., Corticatia. Nom donné par Cuvier à une famille de l'ordre des Polypes à polypicrs, comprenant ceux qui se tiennent tous par une substance communc enveloppant un axe de forme et de nature variables.

CORTICICOLN, corticicola (cor$t e x$, écorce, colo, labiter ); qui vit sur les ćcorces. Ex. Agaricus corticicola.

Conticicoles, adj. et s. m. pl., Corticicola. Noul donné par Savi à une tribu de l'ordec des Passereaux, comprenant ecux qui cherchent leur nourritul'e sous les écorces des arbres; par Lamarck ì unc farxille de Coléoptères. dians laquelle il range ceux dont les larves vivent, pour la plupart, sous l'éeorec des arbres.

CORTICHELES, adj. ets. m.pl., Corticifera, Corticosa. Nom donnć par Schweigger ì une fimille de Zoophytes cératophytes, par Latreille à unc tribu de la fanilles des Alvéolaires, par Eiehwald à unc famille de la classe des Phylozoaires, par Lamotroux à une section de la division des Polypiers llexilles, comprenant ccux qui ont un axe corné ou calcaire reconvert d'une croûtc contractile el vivante.

CORTICIFORNE, adj., corticiformis; rindcnarlig (all.) (cortex, ćroree, forma, furme): qui a l'ap- parence d'une écorce, comme l'cicroûtement gélatincux des polypicrs corticiferes.

CORTICINE, subst. f., corlicina (cortex, écorce). Bracounot propose de donner cc nom à l'apothc̀me du tannin, parce qu'on le rencontre assez générale ment dans les ćcorces.

Contink, s. f., cortina; Manschetle (all.) (coriina, ridcau). Sorte de frange filamentcuse qui borde le chapeau de plusieurs champignons, ct qui est produite par les débris du volva déchiré. Ex. Agaricus araneosus.

CORTRQUEUx, adject., corricosus; rindig (all.); cortecciato (it.) (cortex, écorce). On donne cettc épithète aux baics, quaud la pannexterne formc à lcur superfieie une écorcc ferme, épaisse et sèche, ou peu succulente. Ex. Arbustus Uncdo.

Convmís, adj. et s.m.pl, Corvida. Nom donné par Vigol's à une famille de l'ordre des Dentirostres, par Lesson il une famille de l'ordice des Passereaux, ayaut pour type le genre Corvits.

convixs, adj. et s. m. pl, Co:"virue. Nom donné par Vigors à une triluu de la famille des Corvidés, qui renferme le genre Corpus.

CORMDALEes, adj. et s. f. pl., Corydalca, Corydalcs. Caffin et Marquis dounent ce nom à la famille des Fumariacécs, en raison du genre $\mathrm{Co}^{\circ}$ rydalis qu'clle renferme. Limné avait déjil ćtabli une famille de plantes sous celte dénomination, et il y ratigcait celles qui ont les flurs éperonnces on de lorme particulière.

CORITALINE, s. f., corydalina. Alcali végćtal qui a ćte découverl par Wackenroder dans la racinc da Corydalis bulbosa.

COHYDAL10L2, adj. , cory.dalicus. Épithicte donućc par 13crzelius anx sels qui ont la corydaline pont bisc. 
CORTMPE, subst. m., corymbus; Doldentraube (all.) ; mazzctio, corimbo (it. ) (rópußßs, sommel). Assemblage de fleurs qui sont toutes placécs à peu prés au mền niveau, mais dont les pédoncules ne partent pas du méme point, ou sc ramifient irrégulièrement (ex. Sambucus); inflovescence daus laquelle l'axe central se comporte à la manière des iullorescences terminecs (voyez ce mot), et où les rameaux latéraux suivent la loi des inflorescences indefinics (voyez ce mot), comme dans la pluparl des Synanthérées.

CORMMве;, adj., corymbosus; doldentraubig (all.); corimboso (il.). Se dil d'unc plante, quand ses branclies el rameaux sont disposés en corymbe. Ex. Knoxia corymbosa, Cardiopathiem corymbosum.

Coryabeux. Voyez Congusí. CORYMBIFERE, adj., corymbiferus (corymbus, corymbe, fero, porter); qui a des fleurs disposées en corymbes. Ex. Cuphea corymbiféra, Linum corymbiferum.

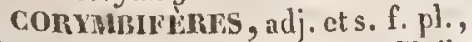
Corymbiferre. Nou donné par Vaillant à un groupe qu'il a élabli dans la famille des Symanthérées, d'après Morison et liay, qui a clé adopté par Jussien, L.-C. Kichard el Candolle, et qui eomprend la plupart de ces plantes dont les fleurs sont disposées en corymbes.

CORYMizLLORE, adi. , corymbiflorus (corymbus, corymbe, flos, fleur); qui a les lleurs disposces en corymbes. Ex. Slornea corymbiflora.

CORYMTHEORM:, a dj., corymbiformis (corymbus, corymlic , forma, forme). Epithélc donsée par Candolle à la grappe simple, lorsque les pédicelles inféricurs sont très-lonoss el les supéricurs forl courts, d'où résuite que les fleurs, quoique partant de points différens, allcigneut toutes ì pell près au mêne niveau (ex. Omithogalum umbellatum); à la grappe eomposée, soit que les branches latćrales inférieures soient plus longues que les supérieures, soit que chacune d'clles, considérée isolénent, présente les mêmes phénomenes, quant à la longueur de ses pédicules (cx. Viburnum Lantana).

COHYMBULEUX, adj. , corymbulosus; qui a ses fleurs disposées en petils corymbes. Ex. Crassula corymbulosa.

CORYuminions, adj. et s. m. pl., Coryphanides. Non donné par Lalreille à une famille de l'ordre des Acautoptérygiens kystophores, et par Ficiuus et Car'us à une famille de l'ordre des Sternoptérygiens orthosomes, qui a pour type le genre Coryphena.

CORYIUINERs, adj. et s. f. pl., Coryplina. Nom donné par Martius et Tiusth a un groupe de la famille des Palmiers, ayant pour type le genre Corypha.

CORYuHOHIYTE, s. m., cory-

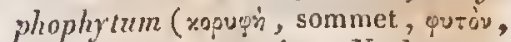
plante). Nom donné par Neeker aux plaules dont les étamines peu nombreuses sout insérécs au sommet du calice.

Coristrinton, s. m. ( xоpuatris, cosqué). Kirlyy désigne ainsi, dans les insecles trichopteres et dans quclques diplères, l'organe sćcrétoire du gluten qui scrt comme de basc ou de nid pour leurs oufs.

COMISTIDEs, adj. et s. m. pl., Corystide. Nom donné par Lcach à une funille de Crustaeés déeapodes, qui a pour type le genre Corystes.

convToulere, s. m., cory-

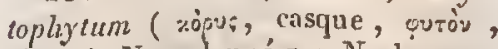
plante). Nom donné par Necker aux plantes dont la partic supéticure de la corolle a la forme d'un casque.

COSNIQLE, adj., cosmicus; kosmisch (all.) (rocuss, muivers). Les as- 
tronomes donnent cette épithéte aux phénomènes célestes qui coïneident avec l'instant du soleil levant, par exemple au coucher et au lcver des astres.

COSHOGénie, s. f., cosnogenia

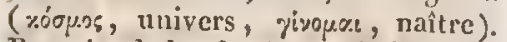
Branche de la physique générale qui s'occupe des hypothéses rclatives à l'origine et à li formation de l'univers.

Cosmogonie, s. f., cosmogonia;

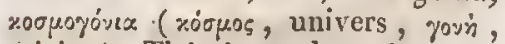
origine). Théorie ou hypothèse sur la formation de l'univers.

Cosmograpile, s. f., cosmo-

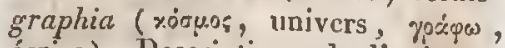
écrire). Deseription de l'univers, tel qu'il s'offre à nos sens ct à nos moyens d'investigation.

COSMOLOGIE, s. โ., cosmologia,

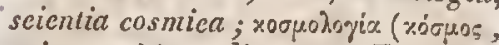

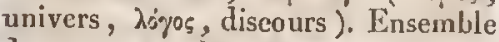
de tout ce que les sens nous apprennent sur l'univers et des conséquences que notre csprit en déduit.

COSMONOMIE, s. $\mathrm{f}$, cosmono-

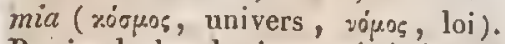
Partie de la physique générale qui traite des lois auxquelles l'univers est soumis.

Cosuosopine, s. f., cosmosophia (róouos, univers, copio, seience). Etude de l'univers, instituée d'aprìs des prineipes et dans des vues mystiques.

Cossoniwes, adj.cts.m. pl., Cossonides. Nom donné par Schœuherr à un groupe de la légion des Cureulionides gonatocères mécorlyynques, qui a pour type le genre Cossonus.

CossYPIiENes, adj. et s. m. pl., Cossyphenes, Cossyplones. Nom donné par Cuvier et Latreille à une tribu de la famille des Coléoptères taxicornes, qui a pour type le genre Cossypluzs.

CossrPnins, adj. et s. m. pl., Cossyphina. Nom donné par Vigors à une tribu de la famille des Mértilides, ayant pour type le genre Cossypha.

COssripiones. Voyez CossYPIİ̀ES.

COSTAL, adj., costalis (costa, côte). Robineau - Desvoidy appelle costaux des paires de pièces qui, partant de la face supérieure du basial, dans la vertèbre des animaux articulés, représentent les côtes sternales des aninaux supérieurs, et forment l'areeau dorsal, le tergum de l'animal. Kirly nomme nervure costale, dans l'aile des insectes, la première et la principale ncrvure, celle qui forme le bord antéricur, dent cependant elle est quelquefois éloignée : aréole costale, la partie de l'aile situće entre le bord antérieur ct la nervure postcostale.

COSTE, adj., costatus; gerippt (all.) (costa, côte). On dome cette épithicte aux coquilles univalves, quand elles offrent des élévations, des protubérances convexes ou aiguës, qui descendent en suivant l'axe de la coquille, ou dans le sens de l'axe (ex. Turbo costatus, Cerithium costatum ); aux coquilles bivalves dont la surface présente de grandes élévations, séparées par des enfoncemens profonds. Linné et Bruguière la réservaient pour le cas où les côtes suivent la direction des bords de la coquille, et lui sont parallèles. Un insecte (Helluo costatus) est ainsi appelć parce que ses élytres portent trois côtes saillantes.

COSTIFÈnE, adj., costiforus (costa, côte, fero, porter ); qui est marqué de côtes longitudinales. Ex. Spongia costifera.

COSTIPLDE, adj., coslipes (costa, eôte, pes, pied). Se dit d'un oiseau dont les jambes sont placées de manière que le corps se trouve en équilibre parfait.

costule, s. f., coslula. Petite 
côte, semblable aux stries d'aecroissement qui se voyent ì la surfaec de certines eoquilles, de eelle du limacon, par exemple.

COTre, s. f. I.es greographes appellent ainsi (littus) les portions de terre déenuvertes qui sont frappécs et baignées par' la mer. Cólc (clivus) exprime aussi le penchant d'uue montagne. En hotanique, on donne ee nom (costa) à la nervure qui passe par le milieu d'une feuille, quand elle est ineomparablement plus forte que les autres, ct aux lignes saillantes (juga) du fruit des ombellifères.

COTE. Voyez Costí.

COTEAU, s. m., collis; Abhang (al.) hillock (angl.). Flane d'une eolline.

COTELE, adj., costulatus, costulosus, costcllaris, costularis, craticulatus. Se dit t'uno enquille qui est eouverte desaillies longitudinales. Ex. Fusus costulatus, Clartsilia costulata, Ccrithium costulatum, Tur$b_{0}$ costulosus, Murcx cosiularis, Mitra costcllaris, Trochus cosiclla'tus, Petricola costellata, Turbinella craticulata.

COTEUX, adj., costosus, costatus; qui est relevé de eôtes ou nervures saillantes, comne le calice du Ballota nigra, le crémocarpe du Conium maculatum, le disque de l'Euryalc costosiun.

COTHUiné, adject. , collurnatus (colhurnus, cothurne). Un insecte (Coyx colhurnatus) est ainsi appelé parce qu'il a les quatre derniers gcloux noirs.

COTON, s. m., tomentum, gossypium, "ैp plos; Baumwolle (al!.); cotton (angl.); bambagria (it.). Duvet composé de poils longs, crêpus et entrecroisés, qu'on remarque sur diVerses parlies d'un assez grand nombre de végétaux.

Cotovneux, adj, , tomentosus, lanatus. Se dit d'une varićté d'asbeste, qui est en filamens déliés, commé eeux du coton; du corselct des inm scetes, quand il est couvert de poils très-fins, trìs-serrés et assez. longs (ex. Bombyx. Vojez Tomentrox, Visu ). On dit de eertains fruits qu'ils devienuent cotonncux, lorsque leur parenchyme se dessecche et prend une apparentec filandreuse. L'Agaricus gossypinus cst ainsi a ppelé à eause dle son stipe velu.

cotulás, adj. et s. f. pl. , Cotulca. Nom donné par H. Cassini à un groupe de la section des Anthémidées chrysanthémées, et par Lessing à une section de la sous-tribu des Sćnéeionidées artémisiées, ayant pour type le genre Cotula.

CoTYLE, s. f., colyla ( хогง่⿰n, ereux). Péron appelait ainsi des organes qui paraissent avoir quelques rapports de forme avec les cotylédons des végétaux, et dont lesbras de certaines espèces de méduses sont garnis.

CoTyuldov, 3. m. , cotylcdon; rotuhnis̀y; Sancnlappe (all.); cotilcdone (it.). Les botanistes désignent sous ee nom des organes, adhérens à la plumule de la graine, qui représentent les premières feuilles de la plante, et servent à lui fournir un aliment tout préparé, quand ils sont charnus, ou à lui en préparer, dès l'instant de sa naissanee, quand ils sont Coliacés.

COTYLÉDONARE, adj., cotyledonaris. On appelle corps cotylédonairc (Samenlappcnliörper, all.) une masse plus ou moins charnue qui, dans ecrtaines plantes, est formée par la soudure ou le rapproehement intime des cotylídons. Ex. Eisculus. CoTrúdonḱ, adj., cotyledoneus. Se dit d'uue plantc dont la graine est pourvine de cotylédons. Ce not a ćté pris par. Jussieu et Fries comme synonyme de planćrogame, parce qu'on ne trouve de cotylédons que dans les plantes à sexes distinets, quoique toutes n'en aient point. 
cOTYLFIIORE, adj. , cotylepho.

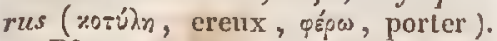
Le Platystacus cotylephorus est ainsi appelé, paree qu'il a unc partie de son eorps eouverte de petites eupules.

COTYLFERE, adj., cotyliferus ( rotúin, ereux, fero, porter). Se dit des bras des méduses, quand ils sont garnis de cotyles.

COTYLIFORME, adj., cotyliformis ; napfförnig, lassenförmis (all.) ( хогน́n, éeuclle, forma, forme). Épithète donnée par Salishury aux corolles qui sont munies d'un tube eylindrique évaséc d'un limbe dressé.

cov. Voyez CoL.

COUCIE, s. f., Sclicht (all.). En géognosie, on donne ce nom à des masses minćrales, plus ou moins épaisses, dont les deux faces sont scnsiblement parallèles, et qui sont posćes les unes sur les autres, sans croiser ni couper d'autres nuasses. Cclle expression manque d'exactitudc, puisque les couclies minérales ne sont pas toujour's coucheies, e'est-àdirc à peu près horizontales, et qu'il y en a de vertieales. Les couches des terrains de sćdiment sont nommées Flöt $z$ en allemand.

Coccuk, adj., supinus, prostratus, procumbens, humifusus, incumben.s, incubitus; aufliegend (all.). Se dit d'une plante qui élale ses rameaux sur la terie, sans que ceux-ei y euvoyent de raeiues. Ex. MIicropus supinus, Sisymbrium supinum, $0 x$ j. baphus prostratus, Alsine prostrate, Echium prostratum, Conocarpiss procumbens, Castela depressa, Helichrysum declinatum. Voyez HumFUSE.

COLCHER, s. m., occasus, siderum obitus; Untergang (all.). Disparition d'un astre au dessous de l'horizon, e'est-i-dire des points de la terre ou de la mer oì la vuc est limitée par la courbure du eorps de notrc planète. COUDÉ, adj., geniculatus. Se dit d'une coquille bivalve, quand elle est comme ployée dans toutes ses parties, et que sa forme approehe plus ou moins de cel!e d'un demi-ecrelc. Ex. une Modiole fossile. YoyezGenounzí.

COULANT, subst. nı., flagellum, sarmentum, viticula. Jet de plante qui manque de feuilles et de raeincs dans un espace délerminé, et qui, a des places fixes, émel des touffes de feuilles ou de raeines. Ex. Potentilla flagellaris.

COULEE, s. f. Or appelle aiusi, en géognosie, un tcrrain sans stratifieation, ayant pour forme extérienre eelle que doit prendre une maticue pâteuse qui sort par une ouverture déterminée, et qui, en se répandant sur des surfaces diversement configurées, y prend un aspect et des formes différentes, comme un torrent qui se serait solidifié d'une manière snlite.

COULEUR, s. f., color; yoüux; Farbe (all.); colour (angl.); colore (it.). Impression que produit sur l'organc de la vue la lumière incomplèlement rélléehie et déeomposéc par la surface des corps qu'elle frappe.

Colmanive, s. f., coumarina. Nom donné par Boullay et BoutronCharlard à un stéaroptène d'où dé pend l'odeur de la fève de Tonka (Dipterix odorata, Coumarouna d'At" blet.)

COUPELLATION, s. f., cupellá, tio; Abtreiben (all.). Opération qui consiste à séparer l'argent, par sil fusion avec du plomb, de tous le inćlaux, l'or exeepté, avec lesquets il peut être allié, et qui tire son non du vase particulier, coupelle, dant lequel on l'exécute.

Coumant, s. m. Portion des eans de la ner qui se menvent, d'une mar nière ineonstante ou presque cont stante, dans un sens déterminé, sem blables a des fleuves qui eouleraient avee plus on moins de vitesse au scin de la masse liquide. 
COUR

COURbarive, s. f., courbarina. Guibourt donne ce nom à la résine du Courtaril.

Courubí, adj., eurvis, eurvalus, rceurvatus, incurvus, torguescens; gekrïmmt (all.); qui est infléchi sur soi-même, comme les aiguillons du Rosa museosa, les erpseles du Calendula, les légumes de Medicago falcata, le pćpon du Cucumis flexuosus, les palpes des Tipules, les pédoncules du Grinmia ineurva, dn Dryptodon ineureus ct du Cantpylopus eyerneus, l'opereule conique du IV eissia torquescens et du Weissia recurvata; les feuilles du Dicranum curvalum.

COvReur, adj., cursorizs; qui est propre à la course. Illiger appellc ainsi les oiseaux dont les jambes sont à demi nues, garnies de deux ou trois doigts anlérieurs, confondus ou léunis à la base par une meinlorane, et privées de ponce (ex. Autruche). On donne la mème ćnithète ì ccrtaines araiguées qui sont vagabondes ct ne filent pas de toiles. Kirby nomme pieds eoureurs, dans les insectes, ccux qui nc peuvent servir qu'à la progression, comune chez les Carabes. coureuns, adj. el s. m. pl., Cursorcs, Cursorii. Nolu donné par Blainville à une famillc de l'ordre des Pongeurs, renfermant des mammifères qui, comme lc lic̀vre, ont une grande aptitude à la course; par Illiger, Meyer, Temminck, Lacépède, Blainville et Eichwald à un ordre de lia classe des oiseaux, comprenant ceux qui ne sout en grande partie aples qu'a marcher ou courir, ou qui mème nc peuvent jamnis volcr; par Cuvier et Latreille à une famille de l'ordre des Orthoptères; par A.-H. Harvorth à une fanillc de Crustacés, renfermant ceux de ces animanx dont les picds sont uniquement propres à la course, ou. qui se font remarquer par leur agi-
COURONNANT, adjcet., eoronans (corona, couronne); qui se termine en courohne. On donne celle épithète, en botanique, aux brastées qui forment use couronne au dessus des flcurs (ex. Fritillaria), aux feuilles rosclécs qui terminent la tige et ses divisions (cx.Palniers), aunectaire, quand il forme une couronne sur l'ovaire (ex. Synanthérées).

Counonvis, s. f, corona; Krans (all.); corona (it.). On emploie ce mot : $1^{\circ}$ en astronomie. Le $n o m$ de couronnc est donné quclquefois aux halos. On l'applique aussi au foycr d'une aurore boréalc vers lequel s'élancent les gerbes de fcu quisemblent partir de l'horizon on de l'arc élincclant lui-même. $2^{\circ} \mathrm{En}$ un inćralogie. Delue appelle ainsi les cratc̀res de volcans portant une sorte de rempart circulaire qui rcnlerme le cratère ct qui de loin ressemble ì un cylindre placé surr un cône tronqué. $3^{\circ}$ En botanique. Les botanistes désignent sous le nom de couronne (scyphizs, paracorolla) des appendices librcs ou soudés qui surmontent la gorge de la corolle (cx. Nareissus) on l'intérieur du périgone (ex. Passiflora), ct qui ont plus ou moins de ressemblinec avec une pelite couronne; le limbre persistant ct: desséché au dessus du calice des fruits provenans d'ovaircs soudés avec ce dernier (ex. P.rus) = d'après Cassini, un assemblage de fleurs à corolles non masculincs, c'cst-ì-dire femellcs ou neutres; qui, dans une culathide de Sy manthérće, occupent la bordure; d'après Adausou, la partie supérieure ou l'orificc de la gaine des gaaminées. $4^{\circ}$ En zoologic. On appelle eouronne les protubćrances qui paraissent, dans les premiers temps, sur l'os frontal du fuon de six mois, croissent, s'alongent, deviannent cylindriques, et se terminent par une surface concavc sur laquelle porte l'extrémité 
inférieure du bois; l'extrémité supérieure du bois des eerfs âgés de quatre ans et plus; la partie supérieure des dents, eelle qui fait saillic hors des parties molles de la bouche; le bord supérieur des sabots, eelui qui entoure l'orteil; le duvet qui culoure la base du bee d'un oiseau de proie; le bouquet de plumes redressées qui surmonte la tête de eertains oiseaux.

Counonvi, adj., coronatus; belranzt (all.); coronato (it.) (corona, couronne). Se dit: $1^{\circ}$ en botanique; d'un arbre, dont le sommet de lia tige périt, en sorte que les branches qui l'avoisinent s'étalent en une sorte de couronne; de la calathidc, d'après H. Cassini, lorsqu'elle contient des corolles masculines dans son milieu et des eorolles non masculines à sa cireonférenee ; du calice commun d'une Synanthéréc, quand il est disposé en rayons, de maniè̀e à former une espice de couronne (cx. Gnaphalium coronatum); de l'ćpi, lorsqu'il est terminé par des feuilles (ex. Bromelia Annnas), ou par de grandes bractées (ex. Salvia Horminum); du fruit, quand, faisant corps avee le calice, il eonserve à sou sommet une partie du limbe de ce dernier (ex. Pyrus;, ou quand la base du style persiste at son sommet (ex. Scscli coronalum): de l'ombclle, quand elle offre des fleurs régulières au centre et des fleurs irréçulières à la eirconférence (cx. Coriandruin) $2^{\circ} \mathrm{E}_{11}$ zoologie. On dit que la spire d'une eoquille univalve est couronnée, quand. les bords de elangue tour sont armés de pointes, de tubercules ou d'épines (ex. quelques Volutes). Le Delplinus coronatus est ainsi appelé parce qu'il a deux cercles jaunes conceutriques sur le front; l'Otaria coronata, parec qu'clle a une bande jaune sur la lête; le Ccruus coronatus, parce que ses bois, sans perehes ni meules, sont formés d'une simple empaumure naissant immédiatement des frontaux; l'Oryssus coronatus, paree que le sommet de sa tête est couronnć de quelques pointes; le Circactus coronatuts, paree que les plumes de sa tête sont lâches ct relombent, comme une sorte de huppe, derrière l'abdomen; l'Euphrosine laureala, paree que ses branehics forment des soies très.longues, élargies à l'cxtrénité, et imitant une couronne de laurier.

COURONNEMIENT, s. m. Se dit en parlant d'un arbre couronné (voy. ce mot); eet élat est désigné par Rei sous le nom de cladanodistrophie.

COuns, s. m., cursus. On appelle coutrs de la lune, le temps qui s'éeoule depuis l'apparition du premicr quartier jusqu'á la pleine lune, et pendant lequel l'étendue de la partie éelairée de cet astre augmente graduellement jusqu'à ce que son disque entier devienue lumineux. On dit aussi le cours d'un astre, du soleil entr'autres (solis cursus s. circuitus), ou sa révolution, soit réelle, soit apparente; le cours d'un flouve (fluminis cursus), ou le mouvenent que la pente du terrain imprime à ses caux; le cours de la vie (vitce cursus s. spatiunt) ou sa durée.

COURSION, s. m. , con:a; Blallrosc (all.) Dupetit-Thouars appelle ainsi les sions tellement raeeourcis que leurs feuilles, parnissant sortir du même poiut, forment une roselte. Ex. Míleze.

ConnT, adj., brcois; corle (it.). Ce terme s'employe toujours, comme moyen d'exprimer une relation, pour désigner un organe qui est moins long qu'un autre semblable ou analoguc. Ainsi on dit que l'Ixia $c x$ cisa a des feuilles courles, que le Desmatodon curtus a uue tige courte; que la radicule est courte, quand sa longueur n'ćgalc pas celle des colylédons (ex. Cassia fistula). Les ornithologistes disent les pieds des oi-. 
seaux courts, quand ils ont à peu près lc cinquième de la longueur du corps (cx. Cotinga), et très-courts, lorsqu'ils n'en exeèdent point le douzièmc (cx. Martinet).

COLSSINLT, subst.m., pulvinus ; W Fulst (all.). Les botanistes donnent ce nom, d'après Candolle, à un petit renflenent de la lige qui est situé sous la feuillc, lui scrt eomme de support, ct est trì-risible surtont dans les légumineuses; c'cst lc bourrclct du pétiole de Dutroehet.

COuvaGE, s. m. Quelques écrivains ont employć ce terme, au licu du mot incubation, qui seul est usité.

COuvaIv, s. m., Brut (all.). Ensemble des oeufs ct des larves des inscetes qui vivent en soejété ; rayon de cire des abeilles, qui ne contient que des coufs et des larves ou des nymphes.

COUVAISON . Vugez Incubation. COuvÉE, s. f. Totalité des aufs soumis à l'ineubation (c่⿰冫; Brut, all.); époque à laquellc cetle opérntion a licu; ensemble des petits nćs d'une même ponte (pullatio, pullitics).

COUvercLe, s. in. Autrefois on dounnit ce nom à l'opercule des coquilles univalves.

COLVERT, adj. , tectus, oltcctus, opertus, occullatus, roconditus, indusiatus; bedeckt, verdcckt, zugedeckt (all.); coperchiato, copcrto(it.). Sc dit, en hotonique, du fruit, quand le caliee, sans adliérer à l'ovaire, porsiste autour de lui d'une manièrc lâtche, tend a se fermer vers le sommct, et enveloppe cu cutier le fruit (ex. Physalis); en zuologie, des ailes des inseetes, quand "clles sont tout-à-fait cachées sous les élytres.

CouverTuRes, s.f.pl., tccirices. Plumes qui rccouvrent le dessus ct le dessous des pennes des ailes et de la queue des oiscaux, dans une partie de leur longueur.

CRABE-ARAIGNles, s. f. pl. Latrcille a établi şous ce nom une classe d'animaux articulés, comprenant ceux dont il avait formé antérieurement les crustacés branchiopodes pœcilopes.

CRabes, s. f. pl. Nom donné par Lamarck à une tribu de la fanille des Aranćides, renfermant ceux de ces animaux qui ne font pas de toiles, et jettent sculement quel ques fils pour arrèter leur proie, en altendant laquelle ils sc tiennent parfaitement tranquilles.

CRABrovines, adj. et s. m. pl., Crabronida. Nom donnć par Leach à une famille d'inseetes hyménoptères, qui a pour type le genre Crabro.

ChaBnoniFüE, adj., crabronifcrus (crabro, crabron, fero, porter). Epithètc donnce à une orchidée (Ophrys erabronifera) dont la fleur a paru ressembler un pcu à l'inscete appelé Crabron.

CRARnovites, adj. et s. m. pl., Crabronites. Noun donné par Latreille, Goldfuss et Eichwald à une tribu de la famille des Hyménoptères porte-aiguillons, ayant pour type le genre Crabro.

CrACIDis, adjcet. et s. m. pl., Cracida. Nom donné par Vigors à une fumille de l'ordre des Gallinacés, qui a pour type lc genre Crax.

CraIN, s. m. Les mincurs appellent ainsi les fissures de sćparation des couches, lorsqu'elles sont perpendiculaircs ou très-fortement inclinécs à celles de stratifieation. $V^{\circ}$ y. FaILle.

CRAMBrites, adj. et s. m. pl., Crambites. Nom donnć par Iatreille et Eichwald à une tribu de la famille des Lćpidoptères nocturnes, ayant. pour type le genre Crambus.

CRAvorsi, adj., chermesinus; qui a la couleur rouge du kermès. Ex. Peziza chermesina.

CRAMPON, s, m., fulcrum, alligator; Klammer (all.). Candolle appclle ainsi les appendices de la tigo 
qui servent à l'accrocher aux corps voisins, sins être roulés en spirale, ni pomper de nourriture. Ex. $\mathrm{He}_{e}$ dera.

CRANE, s. m., crantium. Lyonnet donne ee nom à l'enscmble des parties solides qui constitucnt l'enveloppe extérieure de ln léte des insectes, et Straus à l'eusemblc des six pieces fixes ou soudées ensemble qui forment eette tètc.

CRAvGES, adject. ct s. m. pl., Crangi (xparyou, pic). Nom donné par J.-A. Ritgen ì une faurilie de lordre des Hyloptènes, qui a pour type le genre Picus.

CRANGONIDES, adj. et s. m. pl., Crangronida. Nom donné par $\Lambda$.H. Harvorth à une famille de Crustacés décapodes macroures, ayant pour type le genre Crangon.

CRaniaces, adj. et s.m. pl., Craniacea. Nom donné par Menke à une famille $\mathrm{de}$ la classe des Brachiopodes, qui a pour type le genre $C r a-$ nia.

Chisioridine; adj., craniolaris (cranium, erâne); qui a quclque ressemblance avec un cråne, commc l'oursin appelé Fibularia craniolaris.

CRANiologie, s. f., craniologia

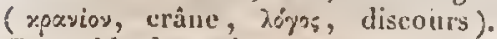
Ersemble des inductions que Gall et ses partisans prétendent tirer des protubérances de la surface du crânc, relativement aux penchans, aux dispositions morales et aux ficultés intcllectuclles.

CRANIOSCOPIE, s. f. , cranio-

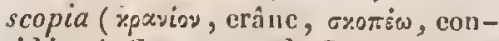
sidérer). Synonyme de Craniologre.

Crasplin ríes, adj. ct s. f. pl., Craspcdica. Noun dounć par Lessing à une scetion de la sous-tribu des Sénćeionidées-Gnaphaliées, qui a pour type le genre Craspedic.

CRASSATTLLACḰS, adj. et s. m. pl., Crassatcllacca. Nom donné par Menke a uue fanille de l'ordre des
Elatobranches mytilacés, qui a pour type le genrc Crassatella.

CRASSATELLLS, adj. et s. f. pl., Crassatella. Nom donné par Férussac à une famille de la elasse des Mollusques, qui a pour type le genre Crassatclla.

CRASSICAUDE, adi., crassicaudus (crassus, épais , cauda, queue); qui a la quene épaisse ou touffuc. Ex. Sorex crassiraudus, Tacchus crassicaudatus, Didelphis crassicaudala.

CR.ISSICAULE, adj., crassicaulis (crassus, épais, caulis, tige); qui a la tige épaisse et charnue. Ex. Sanicula crassicaulis, Pclargonium crassicaule.

CLASSICERS, adj., crassiceps (crassus, épais, caput, tète); qui a une grosse tête. Ex. Tania crassiccps.

CRISSICOLLE, adject., crassicollis (crassus, épais, collum, cou); qui alc col épais. Ex. Fasciola crassicollis.

CRASSICORNE, adj., crassicornis (crassus, épais, cornu, corne). Se dit d'un insecle qui a deux arlieles des antennes plus gros que les autres (cx. Dclphax crassicornis), ou les antennes plus épaisses il la partic moyenne (ex. Nolcrus crassicornis) ; d'une actinie dont les tentacules sont épais (ex. Actinia crassicornis).

CRASSICORNES, adj. et s. m. pl., Crassicorncs. Nom donné par Latreille it une tribu de ln famille des Coléoptères taxicornes, comprenant ceux dout les antennes se terminent en massue d'une manière brusque.

CRASSICOSTí, adje, crassicosia. ıus (crassus, épais, costa , côte) . Se dit d'une coquille qui est marquíe de grosses côtes. Ex. Cardita crassicosia.

CliaSSIDENTḰ, adj. , crassidentatus (crasstus, ćpais, dens, dent); qui a des dents épaisses. Ex. Latra- 
rua crassidcns, Flustra crassidentata. CRASSIF OLIÉ, adj., crassifolius; elickblïttrig (all.) (crassus, épais, folium, feuille), qui a des fcuilles épaisses. Ex. Loranthus crassifolius, Erucaria crassifolia, Bcllium crassifolinm.

CLASSIJUGué, adj. , crassijugatus (crassus, ćpais, jugam, cylindre). Nom donné a une Ombellifére dont le fruit est relevé de côtes ćpaisses. Ex. Pachyplcurum alpinum.

CRASSilabRE, adj., crassilabrus (crassus, épais , labrum, lèvre). Se dit d'une coquillc dont le loord droil offre un épais hourrelct ant-dessous du limbe. Ex. MLonoceros crassilabrum, Clausilia crassilabris.

CRASSILOBÉ, adj., ciassiloba(uzs (crassus, ćpais, lobus, lohc); qui a des lober volumineux. Ex. Spongia ciassiloba.

CRASSINwLVÉ, adj., crassinersius (crassus, épais, neruus, nerf). Sc dit d'une feuille qui a les nervures tres-saillantes. Ex. Ficus crassiuervia, Phascum crassinervium.

CRASSIPL̀DE, adject., crassipes (crassus, épais, pcs, pied). Épithèlc donıce à des insectes qui ont les cuisses renflées. Ex. Musca crassipes, Melolontha arthritica, Meloloutha grouagra. Voyez Churagre.

CriASSIPẼDES, adj. et s. m. pl., Crassipedes. Nom donnć par Lamarck à une section de l'ordre des Conchifères dimyaires, comprenant ceux de ces animaux qui ont le pied épais.

CRASSIPENNE, adj. , crassipennis (crassus, épais, penna, aile) ; qui a les ailes épaisses. Ex. Mrusca crassipcnnis.

CRASSIPETALE, adj. , crassipetalus (crassus, épais, petalum, pćtalc); qui a des pétales épais. Ex. Unona crassipctala.

CRASSIROSTRE, adj. , crassirostris (crassus, épais, rostrum, bec); qui a le bec épais. Ex. Dcndrocolaptes crassirostris.

CRISSIROSTIRES, adj. et s. m. pl., Crassirostres. Nom donné par Linné cl Goldfuss à une fanille de l'ordre des grimpeurs, comprenant ccux qui ont le bec gros et fort.

CRAssispinx́, adj. , crassispinus (crassiss, épais, spina, épinc). Sc dit d'une coquille qui est hérissée de lorigues épines épaisses a la basc. Ex. Murcx crassispina.

CRASSISQUANE, adj., crassisquamatus (crassus, épais, squama, écaillc). F́pilhète donnéc à une coquille dont le sonmet csı garni de six ou sept rangées d'écailles épaisses. Lx. Spondylus crassisquama.

CRASSISULCE, adj., crassisulcus (crassus, épais, sulcus, sillon). Se dil d'une coquille qui est marquée de larges sillons. Ex. V cuus crassisulca.

CRASSULACḰES, adject. et s. f. pl., Crassulacea, Sempervisce, Sucm culenta. Famille de plantes qui a pour type le genre Crassiela.

Crissules, adj. , Crassulca. Nou donné par Candolle à une tribu de la famille des Crassulacées, qui renferme le genre Crassula.

CRATERE, s. m., cralcr, craecra; xpartip. Dépression plus ou moins profonde, en forme de coupe ou de bassin, qui cst creuséc au sommet d'une monlaginc volcanique, et qui livre issuc aux déjections de tontes espèces fournies par le foyer dont cllc est en quelque sorte le soupirail.

CRATÉRIFORvE, adj., crateriformis (crater, coupc , forma, forIne). Se dit d'un corps qui est coneave, hémisphérique et retréci à sa base, comme le squeletie fibreux du Spongia crateriformis ct les apothécies des Calyciun.

CRATÉIOIDĹEs, adj. ct s. f. pl., Crateroidece (xpatrip, coupe, sisos, 
ressemblance). Nom donné par Reichenbach à une famille de Lichens, comprenant ceux qui portent des réceptaeles de corps reproductcurs en forme dc eoupc.

CRATOOPHYTE, s. m. , cratoophytum ( «paraiow, fortifier, фuvtós, plante). Noun douné par Necker aux plantes réputées propres à fortifier.

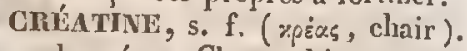
Nom donné par Chevreul à une substanče particulière qu'il a retirée de l'extrait aqueux de la chair museulaire.

CRẺbricostê, adj , , crcbricoslatus (crebcr, serré, costa, côte). Se dit d'une eoquille qui est marquée d'élévations longitudinales, ou de côtes, très-rapprochćcs les unes des autres. Ex. Fusus crebricostalus, Mitra crebricosia.

CRÚBBRISULCE, adj. , crebrisulcus (crcbcr, serré, sulcus, sillon). Épithète donnce à une coquille qui est marquée de sillons transversaux très-rapprochés. Ex. Venus crebrisulca.

CRÉnASTRE, s. f., cremastra;

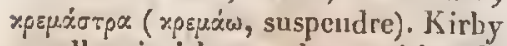
appelle ainsi les crochets voisins de l'anus par lesquels certaines chrysalides se suspendent.

CRÉMOCARPE, s. m. , cremocar-

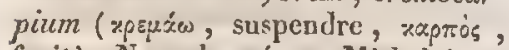
fruit). Nom donné par Mirbel à un fruit simple, faisant corps avec le caliee, et se divisant en deux coques indéhiseentes, monospernses, qui restent quelque temps suspendues, par leur somnet, à un axe central grêle. Ex. Ombcllifcrcs.

CRÍMOSierve, adj. , crcmo-

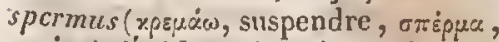
graine). Épithète donnée par G. Allman aux plantes dont les grainessont attachées par le sommet ou par la partic moycune.

CRÉNATE, s. m., crenas. Genre de sels qui résultent de la combipai- son de l'aeide erénique avec les bases salifiables.

CRĹNÉ. Voyez Crénelé.

CuENELE, adj. , crenalus, serratus, crenulatus, crenularis ; gekcrbt, kerbzälınig (all.); crcnato, intaccato (it.); qui présente des crínclueses (vojez ce mot), comme les pétules du Dianthus Caryophyllus et du Ranunculus crcnatus, le calice dı Guarea trichilioides, le stigmate du Crocus sativus. On donne cette épithète aux filets d'étamines qui sont marqués au eôté interne de sillons transversaux formant des crénelures (ex. Urtica); ì l'androphore, lorsqu'il a son limhe découpé en crénelures (ex. Gomphrena globosa); aux feuilles dont lc bord présente des crénclures (ex. Pothos crenata, Saurauja cresulata, Elaocarpus scrratus, Splachnum serra(um); aux coquilles qui sont marquées de lignes saillantes ou de côtes hachées ( ex. Venerupis crenala, Cerithium crenatum, Trochus crenulatus, Venus crcmulata, Trochus crenularis); aux ailcs des insectes, lorsqu'cllcs sout légerement incisćes sur les bords (ex. quelques Sphinx); au corsclct de ces animaux, quand le bord en est terniné par de petites deuts rapprochées et obtuses (ex. la plupart des Priones). Un chéiroptère (Phyllostoma crenulata) est ainsi appelé parce qu'il a sa fcuille nasalc créneléc sur les bords.

CRÉnenüre, s. f. , "crena, crescatura; Kcrbzahn (all.). On donne ce nom à de petites parties saillnutes et arrondies qui sont séparées par des angles rentrans.

CRÉNICOLLE, adj., crenicollis (crenatus, crénelć, collum, col). Le Scotinus crenicollis est appelć ainsi à cause de son corsclet crénelé sur les deux bords latéraux.

CMÉNIFÈRE, adject., crenifertus (crena, crénelure, foro, porter). 
Une coquillc' (Mitra crenifera) doit ce nom à ce qu'clle est marquée de zones colorées dont le bord supérieur offre des crénclurcs semblables à celles des aneienues fortifications.

CRĹNIQUE, adj. , creniczs (หgirn, source). Nom dounć par Perzelius à "n acide organique nitrogénć, dont il a déccuvert l'existence dans les eaux de Porla.

Créninostres, adj. et s. m. pl., Crenirostres (crena, crénelure, rostrum, bec ). Nom donné par Duméril et par Blainville à une famille dc l'ordre des Passereaux, comprenant ceux qui ont une ou deux échanerures au plus près de la pointe du bec.

Cnlívulé, adj., crenulatus; fcingeherbt (all.); qui offrc de très-petites erénelures.

CRÉophages, adj. el s. m. pl. ,

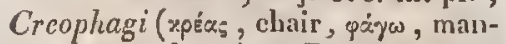
ger). Noun donné par Duméril à nue famillc de l'ordre des Coléoptères, comprenant ceux qui vivent de matières animales.

CRÉpHurs, adj. et s. m. pl.,

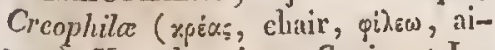
mer). Nom donné par Cnvier ct Latreille à une sous-tribu de la tribu

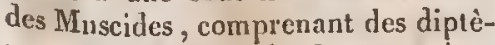
res qui vivent de viande ou se ticnment dessus.

CRÉpIDítes, adj. et s. f. pl., Crecpidea. Nom donné par H. Cassini à une section de li tribu des Lactucées, ayant pour type le genre Crepis.

CREPIDOpoves, adj. et s. m. pl., Crepidoyoda (xpmris, sandale, Toüs, pied). Nom donnć par Goldfuss, Ficinus et Carus à un ordre de la classe des Mollusques, comprenant ceux dont lc dessous du corps est formé par un disque charnu semblable à une semclle.

Crépiovut́, adj. , crepidulatus (crepidula, soulicr). Epithète donnće à une coqguille qui a la forme d'un petit soulier ou d'un sabot. Ex. $A s=$ táculus crepidulatus.

CRÉPITACLE, s. m. , crepitactlum. Nom donué primitivement par Desvanx au fruit conuu aujourd'hui sous celui de regmate, parce qu'il s'ouvre avec ćlaslicitité et bruit.

CHÉPITANT, adj. , crepitans (crepito, eraquer). Nom donné à un oisean (Psophodes crepitans) dont le chant imitc Jc bruit éclatant et aigu d'un fonet de cocher, a un autie (Psophia crepitans) qui fuit entendre des claquemens sourds, à des insectes (cx. Brachyntzs crcpitans) qui, lorsqu'on les saisit, produisent une petite explosion duc à une vapeur acide lancée brusquement par l'anus.

CRÊPU, adj., crispus; crispo , increspato, ricciuto(it,). Se dit d'une fouille dosit la lame est irrćgulic̀rement plissćc sur toute sa superficie (ex. Rumcx crispus, Malua crispa, Hypericum crispum, Arabis crispata, Gnaphalium crispatulum, Weissia crispula); des sépales du calice, quand ils sont ondulés par des rides trimsversales ( $\mathrm{ex}$. Clcmatis crispa); des pćtales, lorsqu'ils sont dans le même cas (ex. Ptcrocarpus crispatus); des coquillcs, lorsque, lcur surface étant lamelleuse, les lames sont déeoupécs régulièrement et quelqucfois traversćes à angle droit par des sillons (ex. Venus reticulata). Link n'appelle feuilles crêpues que celles qui sont ondulées sur les bords, ct dont les ondulations sont cllesmêmes onduleuses.

CIŔPUSCULAIRE, adj ., crepuscularis. Se dit d'un animal qui sort de sa retraite à l'approche du crépuseule du soir. Ex. Noclua crepuscularis.

chépusculaines, adj. et s. m. pl., Crepuscularia. Nom donné par Cuvicr, Larnarck et Latreille à une famille de l'ordre des Lépidoptères, comprenaut les papillons qui ne vo- 
lent guères que le soir, ou aussi le matin, et restent tranquilles pendant la journée.

CRÉPUSCULE, s. m., crepuscrllum; Düntmcrung (all.); twilight (angl.). Espacc de temps qui s'écoule entre la nuit et le coucher ou le lever du soleil. On appelle crćpuscule du matin, ou aurore (Morgenröthe, all.), la clarté qui précède le lever da soleil, et dont le commenecinent est l'aube, le point du jour; et crćpuscule du soir (Abendrölhc, all.), celle qui suit le coucher de cet astre jusqu'à la nuit close. Dix-huit degrés d'abaissement du solcil au dessous de l'horizon paraissent être l'extrème limile du crépuseule astronomique; mais le crépuseulc civil finit bien plus tôt, suivant lc genrc d'occupations auquel on fait allusion; il commence, pour le vulgairc, à l'instant où l'on cessc de pouvoir se livrer à ses oecupations ordinnires dans les maisons, sans le secours d'une lumière artificielle, el finit à l'instant ou l'on peut discerner les petitcs étoiles à la vue simple.

CRÉTACÉ, adj., cretaceus (creta, craie ); de la nature de la craie. Omalius ct Brongniart désignent sous ce nom un groupe de terrains où ils rangent ccux dans la composition desquels il entre en général de la craie et d'autres roclies, ordinairement frialiles, qui sc lient avce la craie. Cette mênie épithête est donnée à des plantes qui croissent dans les cndroits crayeux (cx. Medieago crctacea, Hcdysarum crctaceum), qui ressemblent à des dépôts de craic (cx. Auricularia cretacea), ou qui ont la couleur blanche de la craie (ex. Agaricus cretaccus, Auricularia calcea).

CRÊTE, s. f., crista; ’opòs; Kamm (all.j; cresta (it.). Trinius désignc sous ce nom, dans les Graninècs, un axe plat ou triangulaire, poriant à son côté inférieur de nombreux épillets à courts pétioles, disposés sur deux sćries (ex. Digitaria). Les ornithologistes l'appliquent ì la caroncule charnue qui s'ćlève sur la tête du coq et de certaines poules; les géognostes, au sommet d'une chaîne ou d'un ramcau de montagne qui ne corrcspond point à un plateau.

GRİTÉ, adj. , crislatus; kammförmig (all.). Se dit: $1^{\circ}$ en minéra logie, de cristaux indéterminables, qui, étant minces et arrondis sur les bords, imitent jusqu'à un certain point des crêtcs de coq (ex. Baryte sulfatée crếtée ) $2^{\circ}$ En zoologie : d'un oiseau, dont la plaque charnue du frout sc rclève ct forme une véritable crête (ex. Fulica cristata); d'une coquille relevéc d'une large côte (ex. Strombus cristatus, Cerithiun cristatum); du corselet d'un insecte, quand il porte des poils ramassés en faisceaux représentant une crète (ex. quelques Noctuelles), ou quand il est relcvé cn carène (cx. Acridiunz cristatum); d'un mammifére, lorsqu'il a sur lc cou de très-longs poils formant une sorte de crète (ex. Caviacristata); d'un polypicr dont les expansions forment des plis imitant des crêtes (ex. Explanaria crisiata).

CREUX, adj. , cavus; xoì..s ; holl (all.). En botanique, cette épithète cst donnée à des parties qui n'offrent qu'uu seul enfoncement, comme le rćcptacle de la Rose, ou une seule cavité intérieure, comme le pćrisperme du Cocos nucifera, les fcuilles de l'Allium Cepa.

CREVASSÉ, adj., rimosus; rissig (all.); scrcpolato (it.); qui offre des fentes ou des fissures, comme le pirisperme de l'Anona, la tige de l'Ulmus, le squelette fibreux de la Spongia rimosa.

CliEVETTINES, adj. et s. m. pl., Gammarine: Nom donné par Cuvier et Latrcille a une famille de l'ordre 
des Crustacés amphipodes, qui a pour type le genre Crevette.

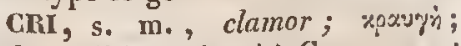
Sclrei(all.); $\operatorname{cry}$ (angl.). Craquement particulier que l'ctain fait entendre Jorsqu'on le ploye. Explosion de la voix qui exprime une émotion vive et soudaine.

CRIARI, adj., clamator, clamosus. Se dit d'un animal qui a le eri fort (ex. Caprimulgus clamator), ou dont les cris se font entendre à une grande distance (ex. Cucculus clamosus).

CRIBRIFORME, adj. , cribriformis (cribrum, tamis , forma, forme). Un polypier (Adeonia cribriformis) est ainsi appclé parce qu'il a la forme d'une lame pereée à jour eomme un erible.

Gnic ẺTres, adj. et s. m. pl, , Cricetini. Nom dunné par Desmarest à une famille de l'ordre des Riongeurs, qui a pour type le genre $\mathrm{Cr}$ cctus.

CIICOSTOME, adj. , cricostonuls (xpízos, anneau, бrópux, bouche). On applique cette épithète aux eoquilles univalves dont l'ouverture est ronde (ex. Cyclostoma).

CiTicostovirs, adj. el s. m. pl., Cricostomata, Nom douné par Blainville à une famille de l'ordrc des Paracéphalophores asjphonobrancles, renfernaut ceux dont l'ouverture de la coquille est à peu près circulaire.

CnIN, s. ru., crinis. On appelle ainsi, chez les mammifères, des poils assez longs et épais, raides, mais ecpendant flexibles. Candolle donne aussi cc nom, dans les végétaux, à tous les poils raides comme un erin, quelle qu'en soit la position.

CRIVAL, adj. , crinalis; qui est de la grosscur d'un crin de cheval. Ex. Gelislium crinale.

CRINICORNE, adj., crinicornis (crinis, erin, cornu, eorne); qui a les antennes terminées par une lon-

gue soie lisse (ex. Psilopus, crintcornis), ou les antennes velues (ex. Saperda crinicornis).

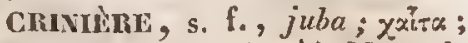
Mälne (all.); manc (angl.). Masse de longs poils qui garnissent une étendue plus ou moins considérable de la ligne dorsale (ex. Cheval, Sanglier), ou toute la région antérieure du cou (ex. Lion, Felis jubata, Otaria jubata). On appelle aussi de ee riom, dans les oisenux, une crête hérissée sur l'occiput et le long du con (ex. Buceros jubatus), ou une huppe de plumes effilées sur la tête (ex. Anas jubala).

Crintruone, adject. , criniflorus (crinis, crin, flos, fleur). Le $\mathrm{Me}$ sembryanthemum criniforum a un ealice divisé en cinq lobes, dont trois très-longs.

CRINIF ORME, adj., criniformis (crinis, erin, forma, forme); qui a la forme d'un erin. Ex. Rhizomorpha criniformis.

CRINITALSE, adj., crinitarsis (crinis, crin, larsus, tarse); qui a les tarses velus. Ex. Poccilnia crinitarsis.

CRINOIDES, adj. et s. m. pl., Crinoides (xpivoy, lis, हiơos, ressemblance). Nom donné par Muller à uuse famille. d'animanx rayonnés, eomprenant ceux dont le corps se compose d'une eolonne artieulée, au sommet de laquelle on voit une série de plaques formant un corps qui ressemble à une eoupe ou à un lis.

CRINILL, s. f., crinula (crinis, erin). Mirbel appelle ainsi les filets hygrométriques que renferme l'ovaire du Marcliantia, et qui servent de support aux séminules.

CHIOCinnes, adj. et s. in. pl., Crioccrides. Nom donné par Cuvier, Latrcille et Eich wald à une tribu de la famille des Coléoptères Eupodes, qui a pour type le genre Crioceris.

Crigue, s. f. En terme de ma- 
rine, ec nôl désigne une très petite baie.

CRISPATIF, adjcet. , crispativus (crispus, frisé). On dit la préfoliation crispative, quand le disque de la feuille est replić fort irrégulièrement, et en quelque sorte frisé.

CnISpé, adj, , crispues, crispatus; kraus, gckrïuselt (all.); qui est muni de lanières fines et eourtes, dirigées en différens scus. Le Melastoma crispata a sa lige munic de quatre angles, dont chaeun porte une membrane ercipue, et l'Ulota crispa, le Dicranum crispum et le Brachypodium crispalum ont des feuilles gui se crispent par l'effet de la sécheresse. Un oiseau (Pyrrhula crispa) est appelé ainsi parec que les plumes des parties inféricures de solı corps sont reeourbées en sens inverse; un autre (Phasianus crispus), paree que toutes ses plumes sont retournées en haut et eomme frisées. Voycz Cấpu.

CIRSPILLOnE, adj. , crispiflorts (crispus, crêpu, flos, fleur). Se dit d'une plante dont les pétales sont ondulés el comme frisés sur les bords. Ex. Chorisia crispiflura, Cynanclutm crispiflorum.

is CRISprwoun', adj., crispifolius; krausblättrig (allo) (crispus, erêpı, folium, feuille). Les feuilles de l' $I-$ sothecium crispifolium se erispent par la dessieeation.

CRISSLM, subst. m. , crissum. On nomme ainsi, daus les oiseaux, l'extrénité de la partie inférieure du corps, depuis les euisses jusqu'à la queue, qui est couverte par les plumes anales.

Cnistucús, adj. et s. m. pl., Cristacea. Nom donné par Lanarek à une famille de l'ordre des Mollusques eéphalopodes, par Blainville à une famille de celui des Céplraloplıores polythalamaeés, renfermant des animaux dont la coquille est aplatic de manière à représenter une caréne ou à pen près.

CAnSTAL, subst. m., crystallum ;

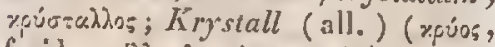
fioid, $\sigma: \dot{c} \lambda . s \sigma 0 a$, ćtre arrêté). Autrefuis on n'appelait ainsi que les produits de la eristallisation qui sont trausparens comme le eristal de roche, qu'on croyait produit par une opération naturelle semblable à celle qui détermine la formation de la glaee, ear dans l'origine on n'appelait cristal que la glace, et c'est en ec sens seulement que les Grees ont pris le mot jusqu'au temps de Platon. Aujourd'hui on donne ec non à tout solide poly'édrique terminé par des facettes planes, unies, régallières, qui sont plaeées symétriquement les unes par rapport atux autres, el dont les in elinaisons mutuelles suivent des lois délerminables, mais non pas eependant invariables eomme on l'a cru pendant long-temps. En effet il a été eonstaté par Mitseherlieh et. Bendant que les angles sont eonstans seulement pour des températures égales dans tous les points de la masse et ponr des eompositions identiques.

CRISTALLIFERE, adj., crystalliferus (cryslallum, eristal, fero, porter). Se dit, en minéralogie, d'une géodc dont l'intéricur est garni de cristaux.

CRISTALLIN, adj. , crystallinus; krystallinisch (all.). On emplnye ee mot en plusieurs sens divers : ${ }^{0}$ en minéralogie, on appelle système criscallin d'un minérnl, l'ensemble des lois systématiques prineipales auxquelles les différeutes parties de ses formes eristallines paraissent être assujélies; et texturc cristalline, eelle qu'une roche présente lorsque ses parties ont élé réunies par voie de cristallisatioir confuse el simultanée. Bory, parmi les élats primitifs de la matière, cul admet. un, qu'il nommé cristalline, et gुu'elle affecte suivant lui quand 
ellc est dure, pesante, translucide, laminairc, anguleuse, et que, par le desséchement, clle adopte une multitude de formes déterminubles, mais jamais rien d'anguleux. Sous le nom de roches eristallines, C. Prevost désingne un ordre de roches, comprenant celles qui sont composées de dilfórentes parties discernables à l'œeil nud, lesquelles ont élé préeipitées ensemble, après avoir ćté préalablement dissontes. $2^{\circ}$ En botanique. Le Pilobolus crystallinus est un champiguon dont les filamens se tcrminent au sommet par unc vésicule reuplic de liquide. Le Riccia erystallina a des fenilles dont la face supéricure offre un aspect cristallin, đư̂̀ à une nuttitude de petits points, que quelques observateurs discnt être des trous irréguliers. Le I'rianthema crystallina et le Mescmbryanilamum crystallinum sont cliargés de petites vésicules remplies de liquide.

CRISTALLINE, s. f. , crystallina. Une base salifiable oléagineuse, que Unverdorben a dćcouverte dans l'huile empyreumalique d'indigo, a reçu de lui ce nom, parce qu'elie forme avec les aeides des sels qui sont susceptibles de cristalliser.

CRISTALIISAlzLLITÉ, s. f., Krystallisirbarkeil (all.). Propriété de cristalliser, d'affecter la forme cristalline.

CRistaldisAne $\mathbf{E}$, adj., kryslallisirbar (all.); qui a la propriété cie prendre une forme eristalline.

CIISTALLISATION, s.f., cryslat lisatio; Ansclicessen, Krystallisirung (all.); cristallizazione (it.). Cc mot est pris daus quatre acecptions différentes. 11 exprime : I l'opération par laquelle les eorps prennent des formes polyédriques régulières on symétriques, soil en passant de l'ẻtat liquide ou gazeux a l'étal solide, soil en se séparant d'une dissolution ou d'vne combinaison dont ils faisaient partic, aree assez de lenteur pour que leurs partienles puisscnt sc récunir dans le sens où elles exereent la plus grande action muluelle; $\mathbf{2}^{\mathrm{o}} \mathrm{l}^{\prime} \mathrm{en}$ scmble des observations qu'on peut fairc sur les divers cristaux d'une mème suluslince; $3^{\circ}$ l'ensemble des observations quc présentent tous les cristnux qui ont été reconnus dans la nature $4^{\circ}$ tout ce qu'on pent dire collcctivement des formes polyédriques qu'affectent les minćraux ct des observations auxquelles ces formes donnent lieu.

CMISTALI.O-ḰLECTRIQUE, adj., crystalio-clectrieus. On a donné cette épithète aux phénomènes électriques que manifestent certains cristanx soumis a l'action de la chaleur. La propriété d'acquérir la polarité éleetrique par l'applieation de la chaleur était connue depuis long-temps dans la tournaline et la topaze: Haüy l'a eonstatéc dans le boracite, la prehnite, la mésotype, le zinc silicaté et le sphèue, Brard dans l'axinite, Brewster dans la seolezite, la mésolite, le spall calcaire, lc diamant, l'orpiment, l'analcime, l'améthyste, le béril, le sulfate de bary te, le sulfate de strontiane, le carbonate de plomb, la diopside, le spath fluor, le quarz du Dauphiné, l'idocrase, le soufre naturcl, le grenat et la diehroitte.

CRISTALLOGENE, s. f., crystal-

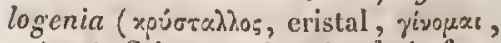
naîtıc). Science qui traite de la formation rles crislaux ou de la manière dont ils se produisent.

ChISTALLOGRAPIIE, s. f, crys tallographia; Krystallographic(all.);

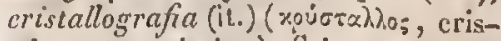
tal, yox́ow, ćcrirc). Science qui apprend i déerire les cristaux avec le sccours d'nne languc de convention, composée de mots et de signes.

CHISTALLOGRAPHQUE, adject, qui a rapport à la cristallographie; 
caractèrc, langage, système cristallographique.

CRISTALE OIDE, adj., crystalloi-

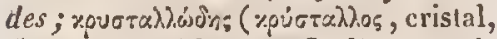

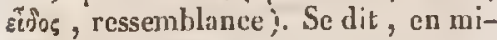
néralogic, d'une concrétion pseudomorphicue, lorsque e'est un cristal qui a étć remplicé.

CMISTALOLOKIE, s. f., crys-

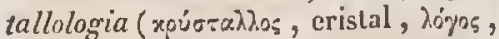
discours). Science ayant pour objet tout ce qui se rapporte a la connaissance des cristaux.

CRISTALIOMHTRIE, s.f., crys-

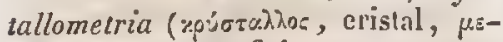

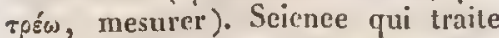
des propriétés mathématiques des cristaux.

CRISTALCONOWIE, s. f., crystal-

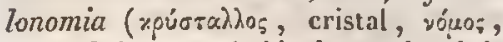
loi). Science qui développe les lois d'où dépendent les diverses propriétés géométriques des crisıax.

Cristarconometi, adj, , ctystallonomicus; qui a rapport à la cristallonomie.

CRYSTALLOPHISIQUE, adj. Épithète quelquelois donnée aux phénoinc̀nes qui coneernent tc clivage des minéraux, les effets de la double refraction, ceux de la polarisation de la lumic̀re, et l'influenee de la chalcur sur cux.

CIRSTALL OTECHNIE, s. f., crys-

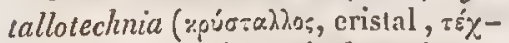
ขn, art). Art d'oblenir des cristaux complets et les diverses modifications dont chacun d'eux est susceptible.

CRISTÉ, adj., cristatus ; crestato (it.) (crista, crête); qui cst muni d'appendices en forme de crêtes, comme les anthères de l'Erica triflora. Lc Cachrys cristata a ses graines burmoutées de cinq crêtes; le Merisma cristala a ses rameaux comprimés en manièrc de crêtes; le Nepenthes cristata offre, à la partic antérieure de ses urnes, deux crêtes longitudinales erénelées. Ø oycz Câ̂TÉ.
CROASSENENT, s. m., crocitus; xpwquos ; Krächzen (all.); croaking (angl.). Cri des oiseaux qui appartiennent au genre corbeau.

CROCÉIVENTIE, adj. , crocciventris (crocus, safran, ventcr, ventrc); qui a le ventre jaune de saliran. Ex. Laphria croceiventris.

CROCHET, s. m., hamus, hamulus, apcx, uncus, unguis; Haken (all.); amo, oncino (it.). On appelle ainsi : $2^{\circ}$ en botanique, des espèces de pointes courbes qui, dans les Acanthacées, naissent sur le placenta, ct retieunent les graincs, auxquelles elles servent en quclque sorte de support; $2^{\circ}$ en zoologie, dans les coquilles bivalves, une protubérance conique, qui couronne la charnic̀re, et qui doit ec nom à ce qu'ordinaircment celle d'une valve se recourbe plus ou moins vers celle de l'autre valve; dans les insectes, d'après Latreille, les mandibules des aptères masticateurs, et, d'après Kirby, deux paires d'organes robustes et recourbés dont l'anus des Locustes est garni; on donne égalernent ce nom aux pièces plus ou moins crochues et aiguẻs qui terninent les tarses, à de pelits appendices recourbés que l'on voit au nilieu du bord antérieur des ailes de quelques hyménoplères, et qui fixent l'aile inféricure à la supéricure; $\mathrm{i}$ un appendice semblable qui est fixé à la nervure costale, pres de sa base et vers son côté iuférieur, sur l'aile de certains lépidoplc̀res; dans les Annclides, à des soies beaucomp plus courtes que les autres, dont l'exlrémité se termine par un croclict plus ou moins recourbé et dentelí.

Crocul, adj., aduncus, uncinatus, hamatus, retinaculatus, hamosus; àyavios; hakig, hakenförmig' (all.); hooked (angl.); amoso (it.). Eu minćralogic, on dit qu'un minéral a la cassure crochue, quand elle présente à sa surface de polites 
aspéritćs pointillées et contournẹes, ce qui est le cas des métaux cristallisés confusément ì l'iutérieur. On donne ectte épithète à des plantes qui ont quelque partic recourbée et crochue, en forme de hamecon, comme les grousses de l'Astramalus hamosus, les fouilles du MTacromitrium uncinatum, Ies rameaux du Stcrcodon aduncus et du s'icrcodon uncinatus, la lèvre supérieure de la corolle du Pedicularis uncinata. En zoologie, on dit les antennes crochues, dans les insectes, lorsgin'elles sont recourlées ì l'cxtrémité qui se turmine en pointe, de manière à firgurer un crochet aigu (cx. Papillon I'rotćc). Les crochets d'une coquille Livalve reçoivent cette dénomination quand ils s'inelineut l'un vers l'autre, en se dirigeant vers l'axe perpendieulaire de la coquille (ex. Pitoncles). Un polypier (Plumnlaria nncinata) cst appelé ainsi, parce que sus rameaux sout faleiformes et recourbés en crochet; l'Antilope redunca, parec que ses cornes se recourbent un peu en avant ì la pointe.

CRocirton, adj., crocipes (crocus, safran, pes, pied); qui a les pattes de couleur saliranéc. Ex. Elater crocipcs.

GROCODHLENS, adj. et s. n. pl. , Crocodilci. Nom donnć par Blainvilic, Latreille et J.-E. Gray it une famille de l'ordre des reptiles Enydosauriens ; par Curjer, Goldfuss et J.-A. Ritgen i une famille de l'ordre des reptiles Sauriens, ayant pour type lc geure Crocodilzs.

Crocobirones, adject. et s. m.pl., Crocodiloidea, Crocodiloillci. P.-F. Fizinger et Eiclowald dísiguent sous ce nom une famille de reptiles, qui a pour trpe le genre Crocodilus.

Croconate, s. m., croconas. Genre de sels (lirolionsaurc Salze, all.), gui sont produits par la combi- naison de l'acide croconique avee les bases salifiables.

CRoconious, adj., croconicus (xícy. safran). Nom donné par L. Gmelin à un acide (Krolionsaürc, all.) particulier, qu’il a découvert, ct qai, ćtant lui-même jaune, a la proprićté de formice des sels d'un jaune rougreâtre ou d'un jaune citrin.

Cronoxtur, s. m. Non donné par Trommsdorff ì une substance qu'il crut d'ahord constituer un métal particulier, et gu'il a reconnue depuis n'être que de la nagnésie cuprifère.

CROISÉ, adj. , crucintus, dectessatns; krenzfiurmign (all.); incrociato (it.). Se dit, en botanique, des paires de parties, quand elles se suivent et se eroisent à angle droit, comme les feuilles da Veronica decuss.satr, ou les rumeanx du Syringa vulgaris. Le Scnecio cruciatus est ainsi appelé, parec que, ses feuilies ćtant à demí découpécs en dents égales ì la feuille mêne, il al l'nspect. d'nne croix. On donne celle épithète anx ailes des insectes, quand le sommet de l'une recouvre entiereunent celni de l'autre, tst ì leur prothorax, quand il présente deux lignes longitudiuales élevées, dont les angles s'approchent dans le milicu, de manière ì figurer une croix de suint André (cx. I.ocusta). On l'applique aussi à des coquilles dont la surface est marquée de slries croisées (cx. Bulimus decussatus, Buccinum dectrssatum).

Chomsh-ObLuQuaghe, adject. cruciato-obliquangulus. On appelle ainsi, dans li nomenclature minérnlogique de lintiy, une variété de stiurotide, composće de deux prisumes qui se croisent sous des angles de 120 et de Go degrés.

CROISE-HECTA NGUYAHE, adj., rruciato-rectangularis. Nom donné, daus la nomenclature minćralogique 
de IIaiiy, à une variété de staurotide, composée de deux prismes qui se croisent sous l'angle de go degrés.

CRONOGFAPIIE, s. f., cronosraplia («póros, Saturne, yoxices, écrire). Description de la planète Saturne.

Crovographious, adj. , cronographicus. Selsrocter a publić un travail sur la planète Saturne, en 1808 , sous ie titre de Fragmens cronograpliques.

CROSSETTE, s. f., mallcolus; Aúrcis (all.). Nouvelle pousse qui porte as sa base un tronçon de vizux bois, et qui est susceptible de reprentlre racine lorsqu'on la met en terre. Ce nom est plus particulierement destiné à désiguer les boutures de la vigne, paree qu'elles ont la figure d'une petite crosse, ce çui leur a valu aussi les noms vulgaires de mailiole et malléole (de malleolus, petit maillet), plus faciles à expliquer que ceux de broclic et de cluapon, usités dans quelques endroits.

ChossopitiLE, adject. et s.f. pl., Crossopctule (rpoocos, frange, $\pi \varepsilon \dot{-x h o \nu, ~ p e ́ t a l e) . ~ N o m ~ d o n n e ́ ~ p a r ~}$ Frochlich it une section du grenre Gentiana, comprenant celles qui ont les eorolles eiliées sur les hords de leurs divisions.

CROTALDES, andj., Crotalidci. Nom donné par J.-E. Gray à une fámille de l'ordre des reptiles Ophidiens, ayant pour type le genre Crotalus.

ChOTMLIDES, adj. et s. in. pl., Crotaloidca, Crotaloidci. Nom sous lequel P.-F. Fizinger et Eichwald désignent une famille de reptiles, yui a pour type le genre Crolalus.

CROTALURES, adj. el s. m. pl., Crotaluri. Nom donué par J.-A. Ritgen à une famille de lordre des reptiles Ophidiens, ayant le genre Crotalus pour type.

CRotonATE, s, m., crolonas.
Genre de sels (crotonsaure Salze, all.): qui sont produits par la combinaison de l'acide crotonique avec les bases salifialiles.

Crotovies, adj. et s. f. pl., Crotonca. Nom donné par A. Jussicu à une section de la famille des Euphorbiacées, qui a pour type le genre Croton.

CIOTONINE, s. f., crotonina. Aleali qu'on trouve, d'après Brandes, dans lis graine du Croton Tiglium.

ChoroniQue, adj., crolonictus. Nom donué par Brandes à un acide particulier (Crotonsüure, all.), que Pelleticr et Careuton unt découvert dans l'huile de C'roton Tiglium, et qu'ils avaient appelć jatrophique. Cette dénomination appartieudrait nussi, dans la nomenclature elimique de lierzclius, aux sels ayaut pour base la erotonine.

GROdPION, s. m., uropyoriun; Stciss ( all.) ; rump (angl.). Extrémilé du tronc des oiscaux, qui se compose des dernières vertibres dorsales et de l'os candal, et qui ressemble a un soe de charrue on it un disque comprimé.

cnovtedx, adjeet., crustatus; schorfig (all.) (crusta, eroutle). Lipithètc donnéce à quel ques cliampignous qui forment des plaques semblables à des crouttes. Ex. Nylomyzon crustosum. Vojez Cristacé.

CrU, adj., crudus. On appelle caux. crues, celles qui, conterant plus de sels ealeaires qu'il ne s'en trouve dans les enux de rivière en général, ne peuvent ni euire les légumes, ni dissoudre le savun. On les déponille aisément de lcor crudité, en décomposant et précipitant le sel calcaire par le moyen d'un sel de potasse.

crudrato - COnPLIQU', adj. , cruciato-complicatzes. Épithète donnée par Kirlıy aux ailes des insectes, quaud elles sont ì la fois eroisées et plisśées, Fx. Pentatoma. 
CRUCITO - INCOMBLNT, adj . , cruciato-incumbens. Kirly doune cetle épithèle aux ailes des inscetes, lorsqu'clles sont croisérs, meris non plissécs, et yu'elles enurrent l'abdousen. Ex. Apis.

Cuucirruss, adj. el s. f. pl., Crucifere. Famille de plantes, ainsi ippeléc parce que les vígétaux qui la constitucnt ont les pétales disposés en eroix.

CRUCIFORME, adj., cruciformis, cruciatus, crociforme (it.); qui a la forme d'une croix. Se dit: $1^{\circ} \mathrm{en}$ minćralogie, d'un crisılal composé de deux autres qui se croisent de manicre que les paus de l'un soicul perperdiculaires sur ecux de l'antre (ex. Harnotomc); $2^{n} \mathrm{cn}$ botanique, des pinlies d'nne plante qui sonl siluées sur le mône plan horizontal el disposées cu manière de eroix, comme lit corollc des Cruciferes, ou le ncetaive du Picrygodium cullolicum.

CRUChORNES, adj. ct s. f. pl., Cruciformes. Nom donné par Tournefort à une classe renfermant les plantes qui ont les pétales opposés en croix.

CIUCIGHEE, adj., crucigerus (crux, croix, gero, porter); qui porte une eroix. Le Bignonia crucigera est ainsi nommé parec que la roupe iransversale de ses tiges présente la ligure d'une eroix; la $T$ cllina crucigera, parcequ'elle offe une croix pourpre sur les sommets de sa coruille; l'Aurclia crucigcra, paree Yu'on voil une croix roussâlre sur lo eentre de sou disque; !a V cspa crucigcra, parce qu'elle a unc croix noire sur le dos de l'aludomen.

CRUCInOSTRE, adj., crucirostris (crux, croix, rostrum, bee). Se dit d'un oiseau dont les mandibules sont croisees l'une sur l'autrc. Fx, Corvus crucirostra.

CRuMLNridis, adj. , crumeniferus (crumena, bourse, fero, porter); qui porte une bonrse, semblible it celle gu'on voit sur le front, en arrière de la feuille nasale, dans le Rhinolopluss crumeniferes.

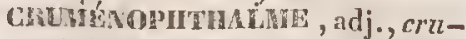
munophthalmus (crumena, hourse, oygajuòs, wil); qui a les ycux entomós d'une sorte de hourse memlirameuse, percée an centre, comme Ic Caranx crumenophthalmus.

CRiUpHOD triES, adj. ct s.m. pl., Crmphodera (rpupzios, caché, sépos, peau). Nom (loumé par Dunćril à une liunilic de l'ordle des Oiseaux rapaces, renfermaul ceux qui ont la tête et le col garnis de plumes. Voyes PI.UMICOI.IES.

CIISWACl, adject., crustacens; scleorfig (all.) (crusta, croûtc). Sc dit, en lotanique, des parlies qui sont ferunes, dures et fragiles, comase l'ereme du Salvia, lit lorique du Papaver, le péricappe du Passcrina, le cesmen de l'Areca faufil; ou d'une pianle yui csl ítendue sur les corps en forme de croute mince, comme le Systotrenta crustaccum. Foycz Crourteux.

CLUST ACRENTES, adj. et s.f. pl., Crustacea. Nom domé par Lamarck i une scetion del'ordre des Arachnides anteunćes trachéennes, compremant celles qui ont le corps souvent écailleux, et qui constituent unc branche isolce, qu'on peut regarder conme la lige des crustacés.

CRUSTACÉS, adj. et s. f. pl., Crustrecep. Nom sons lequel Schultz Łésigne un ordre de la classe des Lashens, comprenant ceux qui affectent la forme de eroûles.

CLISTA CHOF,OGL, s. f., cristaccologia. Histoire spéciale des animitux de li classe des cutustacés.

CBUSTACis, adj. et s. m.

Non donuć par Cuvier à une classe du régnc animal, qu'il a le premicr établie, et que depuis tous les natu: r.lisics ont adoptéc, quelquefois 
la suldivisant en plusicurs autres, ou la désignant sous un autrc nom, notammentsous celui de Malacostracés. Elle renferme des animaux sans vertèbres, mais articulés, dont le corps est protégé par un test solide.

Crustoderines, adj. et s. m. pl., Crustodermata crusta, croûle, Jép $\mu x$, peau). Blainvillc propose d'ippeler ainsi, à cause de l'enveloppe dure qui les recouvre, les poissons composant l'ordre des Branchiostèges de Linné.

CRustodés, adj. el s. m. pl., Crustodca. Nom donné par Bory ì un ordre de la classe des Microscopiques, renfermint ceux de ces animaux qui onl le corps protégé par un test capsulaire, univalve ou bivalve.

CRUSTULIF ORvie, adj., crustuliformis (crustula, échuudé, forma, forme). Tipithète donnće à un champignon (Agaricus crustuliformis) qui ressemble à un ćchaudé pour la forme et la couleur.

CRYEROSE, subst. ul., cryerosis (rovepòs, froid). Hermann propose de donner ee nom aux repliles, à cause du froid qu'ils font ćprouver quand on y touche, ct de l'horreur qu'cn général ils inspircnt.

Griolichlisés, adj. et s. f. pl., Cryolichenes. Nom donné par Zenker à un ordre de la fanille des Lichens, comprenant ccux qui affectent la forme de eroûtes.

CRYOPHOHE, s. m., cryophorus (xpúss, glace, $\varphi^{2}$ pes, porter). Nom donné par Wollaston a un instrument au moyen duquel l'cau est amenée à se congeler par l'cffet de sa propre ćvaporalion.

ChYPT ANDLE, adj. , cryptander (xpuлtòs, caché, èvrip, homn:e). Firics propose de donner cette ćpithète aux végétaux qu'il appclle hétéronémécns, parce qu'ils ont des organcs jusqu'à un certain poiut analogues aux par- ties sexuelles des plantes phanérogames.

CRYPTANDRIQUE, adj. , cryptandrichl. Voyez Criptandre.

CRXPTANTIE, adj., cryptanthus

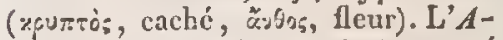
gardhia cryptantha cst ainsi nommé à eause de la petilesse de ses fleurs.

CRMPTANTIíníes, adj. ct s.f. pl., Cryptantherce (xpunsós, caché, «2Onpos, fleuri). Royen donnait ce nom à une classe de plantes, comprenant celles dont on ne connaît point les sexes.

CRIPTANTIIEs, adj. et s. f. pl., Cryptantha. Non donué par Wachendorffà une section de végétaux, comprenant ceux qui ont des fleurs obscures, ou dont on ne connaît pas les fleurs.

CRIPTINLÉE, adject. ets. f. pl. , Cryptinece. Nom donné par Rafinesque à une famille de plantes, qui a pour tyre le genre Cryptina.

CRIPTOBIOTE, adj., cryptobiotus (xquasòs, caché, fios, vie). Quelques physiciens désignent ainsi les corps dans lesquels la vie est eachée, ou à l'élat latent.

CRYptomRaNCmEs, adjeet. et s. m: pl., Cryptobranchia, Cryptobran-

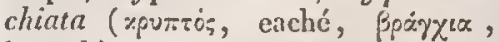
lranchies). Nom donnć par Duméril a un ordre de la sous-classe des Poissons osseux, comprenant ceux qui n'ont point d'operculc, mais sont pourvus d'une membranc loranchioslège; par Goldfuss, Ficinus ct Carus à une famille de l'ordre des Crustacés isopodes, renfermant ccux dont on nc connait point les loranchies ; par J.-E. Gray à une sous-classe dc la classc des $\mathrm{G}$ astéropodophores, renfermant cenx qui ont les branchies eachées.

Chiptobranchomes, adj. ct s. in. pl. , Cryptobranchoidea, Cryptobranchoidei. Nom donné par P.-F. Fizinger et Eicliwald à une fomille 
de Reptiles, ehez lezquels les branehies, qui persistent toute la vie, ne sont point visibles à l'extérieur, et qui a pour type le genre Cryptobranchus.

CRXPTOGARPE, adject. , cryptocarpus, cryplocarpos (rivtrós, caché, भхото́s, fruit); qui a les fruits eachés. Ex. Astragalus cryptocarpos.

GRYPTOCARPES, Mij. et s. w. pl., Cryplocarpa. Nom donné par F. Eschenhollz a une seetion de l'ordre des Aealiphes discophores.

CRYPTOCbPHALk, adj. et s.m., cryptocephalus (rouтrós, eaché, r. $\varphi x$ xin, tête). Nom donné par Gcoffroy Sain t-Hilaire à un genre de monstres, comprenant ceux ehez lesquels la tête est réduite à un assemblayge de très-petites pièces osscuses non apparentes au dehors.

CRXPTOCh́phales, adj. et s.

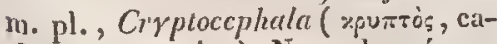
ché, xequxì̀, têtic). Nom donné par Latreille á une famille de l'ordre des Ptéropodes mégaptérygiens, dans laquelle il range ceux de ces aninaux dont la téte ne fait point de saillie.

GRYPTOCOCHLIDES, adj. et s. m. pl., Cryplocochlides (rov ché, roxhic; coquille). Non donué par Latreille à une division de l'ordre des Gastéropodes pectinibranchies, comprenant ceux dont la coquille est renfermée dans le manteau de l'animal.

CRIPTOCOTYLEDONES, adj. ct s. f. pl., Cryplocotyledonea (xpur-

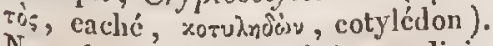
Nom donné par Agardh à une divi-. sion du règue végétal, embrassant les plantes dont en gúnéral les cotylédous reslent dans la semence, ne se développent point, ou sont méconnaissables.

CRYptodibrancires, adj. et s. m. pl., Cryptodibranchiata, Cryptodibranchia (zpurtòs, caché, dies, deux, Bó́gxica, branchics). Nom donuć par
Eichwald à un ordre de la elasse des Mollusques: par Orbigny, Blainville et Mcnke à un ordre de celle des Céphalopodes ou Céphalophorcs, eomprenant ceux de ces animaux dont les brauchies sont eachées dans le sac qui euvcloppe le carps.

CRTPTOGAHE, adj. et s. f. ; cryptogamus ; crillogramo (it.) (жритtos, caché, F'xuos, noce). On donne ce nom, tantôt aux plantes qui n'ont pas d'organes sexuels, ou n'en ont que de pen apparens, et dont on ignore le mode de reproduction ; tantôt à celles dont les fleurs, quand elles cn ont, ne sont visibles qu'au microscope, qui sont peu ou point: symétriques, ou chez lesquelles on ne distingue pas les organes sexuels. Une Sy nanthérée (Leibnitzia cryptogama) a ćté appelée ainsi paree que ses corulles sont entièrcment caclićes par les aigrettes, qui les dépassent de beaucoup, et par lc périeline, qui est fermé sur elles.

GRYPTOGAMIE, s. f. , cryptogamia; crillogamia (it.). Nom donné, dans le système de Iinné, à une classe renfermant les plantes dont les organcs sexucls sont cachés. Les Cryptogames, ainsi appelées par Linné, qui eroyait qu'elles ont des fleurs, quoiqu'on ne les ait point encole découvertes, sont nommées incmbryonćes, e'est-il-dire privées d'embryons, par L. - C. Richard; acolylédonécs, oli dépourvues de cotylédons, par Jussicu ; cethéogames, on résultat d'un mode insolite de fécondation, par Palisot-Beaurois; agames, ou sans fócondation, par Necker'; aphroülcs, e'est-à-dire, renlermant en elles-mêmes leurs organes gévérateur's, par Gæertner. Tous ees noms reposent sur des hypothèses plus on moins inexactes.

GIIPTOGAMIQUE, adj. , cryptogamicts. Synonyme de cryptograme. Voy, ce mot. 
CRYPTOGAMISTE, S. M., cryptogramista. Naturaliste qui se livre spécialement à l'étude des plantes cryptogarnes.

CRYHOGAMOLOGIE, s. f., cryptogamologia. Truité un histoire des plantes eryplogaun.

CRIPTOGASTRES, adj. et s. $\mathrm{c}$. pl., Cryptogastra (жсuлrós, eaché,

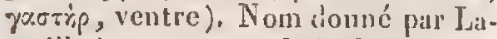
treille à un groupe de la famille des Muscides, comprenant ceux de ces insectes dont l'écusson recouvre tout le dessus de l'abdomen.

CRYHTOGHNES, adj. et s. m. pl.,

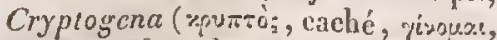
naîre). Nom dommé par Latrcille à une classe d'animaux acéphales, comprenant ceux qui vivcut dans l'intérieur du corps de divers autres animaux, comme les animalcules spermatiques et les acéphalocystes.

CRYPTONEUR LS, adj. , Crypto-

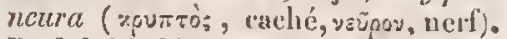
Rudolphi désigne sous ec nom nue serie d'animnux daus laquelle il range ceux dont le systinue nerveux est mêlé et confondu avec la masse en apparcuce homogène qui les constitue, comme les Zoophytes.

Cliypromuin, alj., cryptophi-

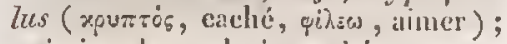
qui aime les endroits cachés, comme beaueoup de plantescryptogames. Ex. Sporourichum latehrarum.

CHITTUHIITE, s. $11 .$, cryplo-

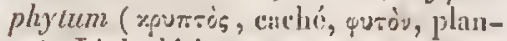
te). Jimk désigne sous ce nom collectif les $A$ grues, les Licheus et les Chanıpiguons, qui sout les plus inparfaites des plantes, celles dont on comaît le moins bien l'organisatinn ct le mode de reproduetion.

CIIYTOPOHLS, adj. et s. m. pl., Cryptopoda (zритrós, caché, тоūs, pied). Nom donné par Meyer ì une lamille de reptiles ophidiens, conprenant ceux qui ont des rudimens le pieds, mais non visibles au de-

\section{CTEN}

hors; par Latreille et Eichwald à une famille de l'ordre des reptiles chéloniens, dans laquelle il range ceux qui peuvent faire rentrer la tète et les pieds sous leur carapace; par Latreille et Eichwald à une seetion ou tribu de la famille des Crustacés Décapodes Nacroures, cmbrassant ceux de ces aninaux dont les pieds, à l'exceptinn des serres, peuvent se retirer sous des dilatations latérales et postéricure du test.

CRYPTOPORE, adj. , cryploporus ( жел:0ं, caché, ropos, pore); qui a des pore's peu apparens. Ex. Hctcropora cryptopora.

CHIPTOE'SIDES, adj. et s.m. pl., Cryptopsides. Nom donué par Schøen. herr it ur groupe de la famille des Curculionides, ayant le genre Cryptops pour type.

CRTPTOMHNENS, adj. et s. m. pl., Cryptorhini ( routrós, caché, fì, nez). Nom donné par Blainville à une farnille de l'ordre des oiscaux nageurs, dans laquelle il comprend ecux qui ont des narines linéaires, à peine visibles.

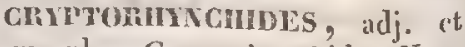
s. m. pl., Cryprorhynchides. Nom donné par Latreille et Schœenherr i un groupe de la tribu ou faumille des Curculionides, qui a pour type le genre Cryptorhynchus.

Ciriptostcinoves, adj. ct s. f. pll., Cryptostemones (xpu-rís, caché,

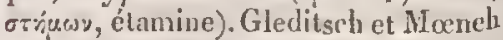
nnt ćtabli sous ee nom une elisse de plantes, comprenant celles qui n'ont point d'étamines visibles.

ClRverunins, adj. et s. m. pl.,

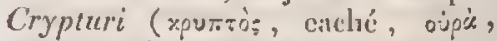
queue). Nom donne par Illiger et C. Bonaparte à une famille d'oiseaux, de l'ordre des Rasores, eomprenant ceux dont la queue est très-courte, ou qui n'en ont pas.

CTÉNobranches, adj. et s. m. pl., Clcnobranchia, Clenobranchiala 


\section{CUBI}

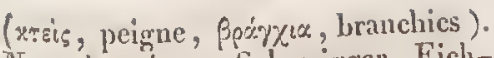
Norn donné par Schweigger, Eichwald, Fischer, Menke et Gray à une fanille ou à un ordre de Gastéropodes, rcufermant ceux de ces mollusques qui ont des branchies pectinées.

CTÉNophones, adj. cl 5. m.

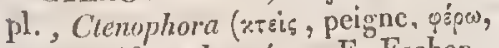
porter). Nom dumué par F. Eschenholtz ì un ordie de la elasse des Acalèphes, comprenant ceux qui ont une grande cavité digestive au centrc des rangées extéricures de filamens natatoires.

GTONOGLNe, CuthonogLine, adj. ct s. m., chlhonogenus ( $x^{\text {Oày, }}$ terre, yivoper, produire). Brongniart désigne par cettc épithète les métaux qui, en s'unissanl à l'oxigc̀ne, produisent des terres ct des alcalis.

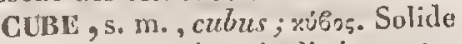
à six fices carrécs, inclincés cntrc elles de go degrés, ayant huil angies égaux, et douze arètes égales ct semblablement plaećes. Les faces sont inclinées ì chacun des quatre axes ou diagonales qu'on peut miener d'un angle solide à son opposé, de $35^{\text {, }}$ $15^{i} 52^{\prime \prime}$, et les arètcs sont inelinées iो ces mêmes axes de $54^{\circ} 47^{\prime} 8^{\prime \prime}$.

cubrous, adj., cubicus; qui a la forme d'nn cube, coinme la graine du Vicia lathroïles, ou le corps quadrangulaire, commc l'Ostracion eubicus.

CUBisar, adj., cubitalis. Jurine appclle cellule cubitale, dans l'aile des inseetcs, un espace membraneux formé par le lord postérieur de la nervure radiale et par unc autre nervure qui, néc de l'extrémité du cubitus, près dn carpe, sc dirige vers le bout de l'ailc.

CuBrtus, s. m., cubitzs. Nom donné par Kirby au g̨uatrième article des pattes antćicures des inscctes hexapodes, et par Jurine à la nervure interne ou postérieure de leurs ailes.
CUBO-DODÉGAEDRE, s. m. Cristal ayant la forme d'un cube dont les douzc bords sont remplacés par autant de faceltes, qui, prolongées jusqu'à s'eutrecouper, produiraient un dodécaëdrc rhomboïdal.

CUBO-ICOSAEDRE, s. m. Cristal qui participe de la forme du cube et de celle de l'icosaëdre.

CUBO1DE, adj. et s. m., cuboi-

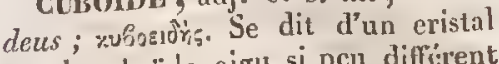
en rhomboïde aigu si pcu diftérent du cubc, que l'oil pent s'y tromper. Ex. Chaux earbonaléc cuboïdc.

cuiso-OCTAEDRE, adjcet. Nom donné, dans la nomenclature minéralogique de IIaiiy, ì un cube dont les luit angles solides sont remplaeés par anlaut de facettes qui, prolongées jusqu'ì s'entrecouper, produiraicnt un octaèdre régulier. Ex. Fer sulfuré eubo-octaëdre.

CUbo-PRISMatiQUe, adj., cuboprismaticus. Nou donné, dans la nomenclatureminéralogique de Haüy, à un cuboïle qui a ses deux sommets séparés par six faces parallèlcs à l'axc. Ex. Chaux earbonate cubo-prismaiique.

CURO-TÉTRAEDRE, adj. Nom donné, dans la nomenelature minéralogique de Haïy, à un cristal offrant la combinaison des faces du cube avec eclles du tetraëdre primitif. Ex. Cuivre prriteux eubo-tćtraëdre.

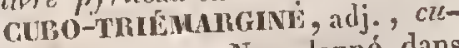
bo-triemarginalus. Non donné, dans la nomenclature minćralogique de Hiniiy, à un cristal ayant la forme d'un cube dont chaque bord est remplacé par trois facettes. Ex. Chaux fluatée eubo-iriémargince.

GUBo-Tuíporviri, adjeet. Nom donné, dans In nomenclaturc minéralogityue de ITaüy, à un cristal cubique dont chaque angle solide est remplacé par trois faceltes. Hx. Chazlx fluatée eubo-trićpointéc.

GUCUJLPÈUES, adj. et s. m. pl. , 
Cucujipedes. Nom donné par Goldfuss, Ficinus et Carus à une tribu de la famille des Colćoptères xylophages, qui a pour type le genre $\mathrm{Cu}$ cujiss.

CucuLís, CuCULDEs, alj. ct s. m. pl., Cuculci, Cuculida, Cuculides. Nom domé par Vigors, Latreille, Iesson, Ficinus et Carus à une famille d'oiseanx grimpeurs, ayant pour type le genre Cuculus.

CUCUL1ves, adj. et s. f. pl. , Cuculina. Nom donné par Lallreille à un groupe de la tribu des Apiaires, comprenant ceux de ees hymenoplères qui ont les halbitudes du concon, c'est-à-dire qui déposicnt leur oufs dans les nids de divers autres Nellifères.

CUCULLIFER, adje, cuculliforus ( cucullus, cornet, foro, porter). Mirbel donne ecte épilliète à l'androphorc, lorsqu'il porte des appendiecs en forme de cormel. Ex. Asclepias syriaca.

CUCULbiF OLıÉ, adj. , cucullifolius ; kappcnblïutig' (ali.) (cucullus, capuchon, folium, feuille); yni a des fenilles en forme de eapuchon. Ex. Gcranium cucullatum.

CuCularForne, adj. , cuculliformis, cucullaus, cucullaris, convolutus (cucullus, eornet, forma, forme); qui est ronlé en cornet, qui a la forme d'un capuchon, comme les biactécs du Lotanthus cucullaris, les fouilles du Geranium cucullaum, les pciales de l'Aquilegia vulgaris, la spathe des Acum. Kirly appelle ainsi !c prothocax des iusectes, quand if est ślevé en forme de voûte, qui recoit la tête (ex. Tingis cucullalus). V̆ oyez Carucironsé.

Cucumeroris, adj., cuctmiformis (cacumis, concombre, forma, furme); qui a lin forme d'un conconn. brc. Ex. Alcyonium cucumiforme.

Cucunmtackes, adj. cts. f. pl., Cucurbiacer. Familte de plantes qui a pour type lc genre Cucurbita. CuCURBITLEs, adj. et s. f. pl. , Cucurbitea. Nom donné par Candolle à une tribu de la famille des Cucurbitacces, qui renferme le genre Cucurbila.

CUCUribris, adj., cucurbilinus. On applique cette ćpitlı̀te aux baics, quand rlles sont éparses, arrondics, el qu'clles resscmblent ì un potiron. Ex. Crescentia Cujetc.

CULILLERoN, s. m. , squama, hallerum, alula; Kolbendecke (all.). Sorte de lane cornée, voûtćc, composée de deux squannes réunics en forme de valves de eoquille, qui, dans les inseetes diptère's, se voit au dessous de l'origine de l'aile, sur les parties lalérales du corselet. Robineau appelle cet appareil calypta; il le regarde comme destiné à soutenir le corps pendaut le vol, et à donner plus d'étenulue à la base de l'aile.

CUIr:isse, s. f., lorica. Sorte de revêtcment osseux que produisent les éciilles de certains poissons, qui sont scrrées et unies de manière ì ne former qu'ure seule pièce. Ehrenlerg donne le mème nom à loute enveloppe protectrice queleonque de ecux des infusoires qui n'ont pas le corps nud.

CETHSSSl, adj., loricalus, cataplraclus, sculalus. Epitliste donnéc à plusicurs animaux, notamment ì des poissons, quise font remarquer par des lanes cornées ou de fortes écaill's snr quelque partie de leur corps, eomme sur les flines de l'Antplisile sculata, ou par une forte cuirasse osseuse qui les enveloppe entièrement (ux. Coltus calaphractus, I.oricuria calaphracta , Pceisledium calapheractum ), ou par des" pointes qui lićrissent leur corps de toules parts (ex. Silerus milituris).

CurnsSés, adj. et s. m. pl., Cingulata, Calaphracta, Loricala. Nom douné par liligger à unc famille 


\section{CUIV}

de l'ordre des Mammifères, qui porte aussi celui de Cingulćs (vor. ce mot); par Latreille et P.-F. Fitzinger ì unc section de lit classe des Reptiles, comprenant ecux dont le corps est emprisonné entre deux bouclicrs, ou couvert en dessus de grandes plaques d'une scule sorte et alignées; par C.-G. Ehrenberg, à un ordre de chacune des deux sections de la elasse des Polygastriqnes, el à un ordre de eclle des Rotil"eres, dans Iesquels il range ceux de ces animaux qui ont le corps protégé par un test.

CUISSE, s. f. , crus , femuer, coxo; pryojo Première pièce du membre pel. vien d'un aninal vertébré ; troisième d'une patte sinuple de crustacé. Inatreille donnc ce nom an sceond des quatre principaux articles d'une pattc d'insecie hexapode, et Kirby au premicr article de leurs pattes de derrière.

CUIVRE, s. nı. , cuprum, $\alpha s, v c$ -

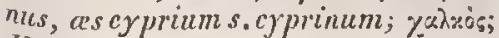
Kupfer (all.). Métal rouge, connu dès la plus haute antiquité, et dont le nom vient de l'ile de Chypre, d'où les anciens te tirnient principalement.

CUIVIrÉ, adj. , cupraus; qui a la coulcur rouge du cuivre. Ex. Cuculus cuprazes, Cotinga cuprea, Oxycera cupraria.

Curvreux, adj. , cuprosus. Dans la nomenclature chimique de Berzelins, on nomme oxide cuivrcux ( $p r o-$ toxide de crivre; Kupferoxydul, all.) lc premier degré d'oxidation du cuivre; sulfure cuivreux (Scluwefclliup$f(r$, all.), son promier degré de sul- furution; et scls cuivrcux (Kup.ero.rydulsalzen, all.), ccux qui resullent de la eombinaison de l'oxide cuivrcux avec les oxacides, du cuivre avee les corps halogenes, et du sulfure cuivreux avec les sulfides.

CUIVIrCO-ALUMINIQUE, adj., cuprico-aluminicus. Nom donné, daus
la nomenelature chimique de Berze- lius, à des sels doubles qui rés ultent de la combinaison d'un sel cuivrique avce un sel aluminique. Ex. Fluorure cuivrico-aluminique (fluatc de cuin'e el d'aluminc).

CUIVRCO-AMUONIQUE, adject., cuprico-ammonicus. Nom donné, daus la nomenclature ebimique de Berzelius, à des sels doubles qui résultent de la combinaison d'un sel cuivrique avec un sel immonique. Ex. Clalorurc cuivrico-ammonique ( hydrochlorate de cuirre et d" ammoninque).

CUIVRICO-COBALTIQUE, adj. ; cuprico-coballicus. Nom donné, dans Ia nomenclature climique de Berzelius, à des sels doubles qui résultent de la combinaison d'un scl cuivrique avce un sel cobaltique. Ex. Sulfate cuivrico-cobaltique (sulfate de cuivre et de cobalt).

Clivnico-potassieue, adject. ; cuprico-polassicus. Nom donné, dans la nomenclature chimique de Berzelius, à des sels doubles qui résultent de la combinaison d'un sel cuivrique avec un sel potassique. Ex. Sulfute cuibrico-polassique (sulfate de cuistre et de polasse).

CUIVRICO-sODIQUE, adj., cuprico-sodicus. Nom donné, dans la nomenclature ehinique de Berzelius, à des sels doubles qui résultent de Ja combinaison d'un scl cuivrique avec un sel sodique. Ex. Oxalatc ctcivrico-sodique (oxalate de cuivre et de soude).

- cuivneuf, adj., cupricus. Dans la uomenclature chimique de Berzelius, on donne le nom d'oxide cuivrifuc (deutoxide de cuivre; $K$ upferoxyd, all. ) au sccond degré d'oxidation du cuivre; de sulfure cuivrique (Kupferschwefel, all.), à son second degré de sulfuration; de scls cuivriques (Kupferoxydsalzen, all.), aux combinaisons de l'oxide cuivrique avec les oxacides, à celles du 
cuivre avee les corps halogènes qui correspondent à l'oxide cuivrique pour la composition, et à celles du sulfure cuivrique arceles sulfides.

CUIVhioso-pOTASSIQUE, adj. , cuproso-potassicus. Nom donné, dans lat nomenclature chimique de Berzelius, à des scls dowhles qui résultent de la conbinaison d'un sel cuivreux avec un sel potassique. Ex. Sulfite cuivroso-potassique ( sulfite de cuipre et de potasse).

CULASSL, s.f. Nom sous lequel les agronomes désiguent la partie de la racine qui sc trouve inmédiatement au-dessons du collet.

CULICIDES, adj. el s. m. pl., Culicides. Nom donné pir Latreille et Eichwald à une tribu de la famille des Diptères némocères, qui a pour type le genre Culcx.

Guliciforves, adj. el s. f. pl., Culiciformes (culcx, cousin, forma, forme). Nom dommé par Latreillc à une section de la tribu des Tipulaires, renfcrmant cenx dc ces insectes qui ressemblent ì des cousins.

Curvifines, adj. et s.f. pl., Culmifcre (culmus, chaume, fero, porter). Morison appelait ainsi l's Graminées, á cause de leur tige.

CULMighve, adj. , cylmigcnes (culmus, chaume, gigno, produire); qui naît ou croît sur les chaumes. Ex. Peziza culmigena, Hystcrium. enlmigenum.

CLLMiNANT, adj. , culminans. On dit qu'un astre est à son point culminant lorsque, par l'effct du mouvement apparcut du cicl, il atteint sa plus grande haulcur, sa hauteur méridienne, e'cst-i-dire qu'il passe par le méridicn supéricur de l'observateur.

Culmixation, s. f., culminatio; transit (angl.) (culmen, sommet). Passagc d'unc étoile dans le plan du méridien, c'cst-i-dire point le plus élevé de sa course apparente.
CẼLOT, s. m. Masse métallique qui se trouve au fond du crcuset, après une fonte en petit qu'on a exécutée dans un laboratoire.

Culotté, adj., braccatus. Epithète donnée par Jlliger aux pieds des oiseaux, lorsque les plumes des cuisses sont alongées et pendantes.

CUL'TRICOLIE, adj., cultricollis (culter, coutcau, collum, col) ; qui a le col ou le thorax comprimé et muni d'une carc̀ne aiguë, ee qui lui doune l'apparence d'un couteala. Ex. Cypluts cultericollis.

CULTRIFOL1E, arlj., cultrifolizs (culter, contcau, folium, feuille); qui a des feuilles ensiformes ou falciformes. Ex. Cassia cultrifolia.

CuLThmon.ve, adj., cultratus; messerförmig (ill.) (culter, couteat, forma, forme); qui est aminci et trunchant, en manière de couteau, comme les feuilles du Mesembryanthemum cultratum, et le ventre di Cyprinus enleratus.

CLLTRHiostrues, adj. et s.m. pl., Cultrirostres (culter, contean, rostrum, hec). Nom donné par Blainville à une fanille de l'ordre des Passereaux, par Cuvier, Duméril, Ficinus, Carus et Latreille à une famille de celui des Échassicrs, conpretiant des oiseaux qui ont le bec comprimé eu forme de couteau, oll long, fort et tranchant.

cuninés, adj., Cuminea. Nom donné par Candolle et Kunth à nue tribu de la famille des Ombellifères, qui a pour type le genre Cuminum. CUNÉLILE, adj., cuncarius, cttncalus (czuncus, coin). Se dit, cll botanique, d'une partie qui va en s'ćlargissant de la base au sommet, lequel est très-obtus ou inême tronqué, conme les pétales du Linum austriacum, les feuilles de l'Isopogone cuncatus, du Josephinia cuncata el du Delphiniunt cueneatum, la coquille de la Crassatella cuneata. 


\section{CUNI}

CUNÉICEPS, adj., cuneiccps (enneus, coin, cuput, tête); qui a la tête en forme de eoin. Ex. Tania cureicrps.

Cunín OLIÉ, adj. , cteneifolius. (cuneus, coin, folium, fcuille); qui a les levilles en coin (cx. Rumex cuneifolius, Pavonia cuncifolia, Tralinum cuncifolium). 11 se dit aussid'un champignou dont les limes ont la même forme (ex. Agaricus cuneifolius).

CUNLEF ORML, adj., cunciformis; keilfirmic (all.) (cunctes, coin, forma, forme). Sc dit, cn minéralogie, d'un octaëdre, quand il a subi un alongement dans le sens de deux faces parallèles, d'où il résulte que les autres ne sont phus des triangles, mais des trapizzes, conme les deux eôtés d'un coin; en looranique, d'un filet d'ćtamine (ex. Thalicirum petaloüdeum), ou d'une fcuille (ex. Verbena euneiformis), qui a la forme d'un eoin; cn roologie, d'une coquille, qui is la même forme (ex. Gastrochena cuneiformis).

CUnbinostuns, adject. el s, m. pl., Cuncirostres (culneus, eoin, rostrum, bec). Nom donné par Scheffer a un ondre, par Dumćril à une famille de l'orilec des Passcreaux, eomprcnant iles oiseaux qui ont lc bee en lorme de coin.

Cuniculands, adj., cunicularius (cuniculum, terrier). Epithete donuée à un oisean (Alauda cunicularia) qui creuse des trous en tcrre pour y déposer ses anls?

CuNiculatres, adj. cl s. m. pl., Cunicularia (cuniculus, lapin). Nom danné par Illigrer el Goldfuss à une farnille de l'ordre des Rongeurs, qui renferme le lapin et les mammifères voisins.

CUNiCULE, adject., cuniculatus; gehohllkchli (all.); qni est muni d'mu enfoncement dont le diamètre va en eroissant vers l'intérieur.
CUPR

Cuvonacúes, adj. ct s. f. pl., Cunoniacca. Nom donnéparR. Brown à une famille de plantes, par Kunth et A. Richard à une lribu de la famille des Saxilragées, ayant pour type le genre Cunonia.

Culovises, adj. el s. f. pl., $\mathrm{Ou}$ nonice. Nom dome par Candolle á une tribu de la famille des Saxifragées, qui a pour type le genre Canomia.

Cupressivites, adj. ct s.f. pl., Cupressinea. Nom donné par Kunth et A. Richard ì une tribu ou scetion de la fanille des Coniferes, qui a pour type le genre Copressus.

CuR̃ico-Aldmingeve. Voyez Cuivnico-alumigue.

CUPIICO-AMIONIQUE. Voyez

Cuivnico-amimonigue.

CUPRICO-GOBALTIQUE, Voyez

Cuivrico-robatituee.

CUPIICO-POTASSIQUE. Voyez

Cuivrico.potassinge.

CURMICO-SODIQUE. Voycz CUIvRico-sodiQue.

Curvines, s. m. pl., Cuprides (euprum, euivre). Nom domne par beudaut á une famille de minéraux, qui comprend le euivre et ses combinaisons.

GUPhatse, adj., cuprifortes; kupferhaltend (all.) (cuprum, euivre, fero, porter). Se dit, en minćralogie; d'un corps qui contient accidentellement du cuivre (ex. P'lomb carbonaté cupriférc), ou qui est coloré par da cuivrc (ex. Soude murialce euprifire $)$.

CUPRIPENNE, adj., cupripennis (cuprum, cuivre, pcnna, aile); qui a les ailes ou les ćlytres d'une conleur de cnivre. Ex. Pacilus cupripennis.

CUPRINOSTRL, adj. , cuprirnstris (cuprum, cuivre, rostrum, bec); qui a le bec ou la trompe de couleur cuirreusc. Ex. Rlyynchanus cuprirosiris.

CUPROFULIINIQUE, adject. En 
faisant bouillir ensemble de l'cau, de l'argent fulminant ct du cuivre, on obtient du euivre fulminant, que Liebig rcgarde conme un cuprofulminate de cuivre, e'cst-ì-dire une combinaison de euivre et d'acide cuprofulminique.

CUPRoso-potassiQue. Vo'ez

\section{Curvroso-potassigur.}

CUPROXIDE, s. m. , cuproxydum (cuprum, cuivre, oxydum, oxide). Beudant appelle ajnsi les combinaisons du cuivre avec l'oxigène.

CUPULAIRE, adj. , cupularis (cupula, petite cuve); qui a la forme d'unc petite coupe ou d'un godet, comme l'arillc de l'Evonymus verrucosus, le calice du Laurus cupularis, l'involucre de l'Achillca Plarmica, le péricline du Gymnanthomum cupalarc, la chalaze du Citrus medica. Les bractćes cupulaircs sont celles qui forment une cupule ovale et nembraneuse sous la baie (ex. $V$ is cum cupulatum).

Cupulanies, adj. et s. m. pl., Cupulares. Nom donné par Fries à une tribu de l'ordre des Hyménomycètes trenelles, comprenaut ccux de ces champiguons qui ont un réceptacle en forme de cupule.

CUPULE, s. f. , cupula ; Hüllkätzchen, Becher, Becherhülle (all.); cupolc (it.). On nomme ainsi, en bolanique, un assemblage de petitcs bractées éenilleuscs, soudées entre elles par la base, formant une espèce de conpe, qui entoure les fleurs ct persiste autour du fruit, qu'elle enveloppe cu totalitć (ex. Corylus), ou i la base seulement (ex. Qucrcus); d'après Mirbel ct Schubert, la partie externe des enveloppes de l'ovaire dans les fleurs femelles des Cycadées et des Conifères; la partie creuse de tous les champignous appartenant à la tribu des P'ézizées; les apothécions sessilcs ct ereusés cn godel.

CUPULÉ, adj, , cupulatus; qui est muni d'une cupule, comme le fruit des Qucrcus, les flcurs des Conifères. On appelle poils cupulés ceux qui sc terminent par unc glande concave, comme dans le Pois-Cbiche. L'Orlhotrichum cupularum est nommé ainsi à cause de scs coiffes demiglobuleuses.

Cupures, adj. et s, m. pl., Crtpulati. Nom donué par Frics à une tribu de l'ordre des Hyménonnycc̀tes elvellacés, comprenant ceux qui ont le réceptacle cnpulé.

GUPLIEÈRE, adj., cupulifcrus (cupula, cupule, fero, portcr). Le Loranthus cupulifer est ainsi appelé, parce que ses pédicelles sont amplement dilatés en eupule au dessous du fruit.

CLPULIFÈnes, adj. et s. f. pl.; Cupulifcree. Famille de plantes, ćtablie par L.-C. Miehard, qui y range Jes plantes dont le fruit cst enveloppé en tout ou en partie par une cupule.

CUPULIEORME, adj. , cupuliformis; napfformig (all.) (cupula, cupule, forma, fornc); qui a la forme d'une cupule, comme la glume de l'Alopecurus agrestis.

CuRCLLIONides, adj. et s. m. pl., Curculionides. Nom donné par Scloenherr et Eichrald à une famille de l'ordre des Coléoptères, ayant pour type le genre Curculio.

CuTAMINE, s. f., curarina. Boussingault et Roulin ont appclé ainsi un alcali découvert par eux dans le curara ou urari, poison dont les Indiens d'Amérique se servent pour garnir lcurs flèches.

CURARIQUE, adject., curaricus. Cette épithète appartient, dans la nomenclature chimique de Berzelius, aux sels qui ont pour base la curarine.

Cuncunive, s. f., curcumina. Chevrcul nomme ainsi une matière colorante jaune que contiennent les rlizomes du Curcuma longa.

CursoliludDE, adj., cursoripes 
(cursorius, courcur, pes, pied). On donne cetle épithètc aux oiseaux qui ont trois doigts en avant, fendus jusqu'ì la base, on à ceux qui, comme l'autruche, ne peuvent que marcher et courir.

CURTIPL̀DE, adj., curtipcs (curtus, court, pes, picd); qui a le pied ou le stipe court. Ex. A garicus curtipes.

CURVATIF, adject., curvativus (curvo, courber). Candolle donne cette épithète aux feuillcs renfermées daus le bourgeon, lorsque le roulement est à peine sensible, à cause de leur peu de largeur.

CURVEMißnYe, adject., enrvembryus (curves, courbé, cmliryo, embryon). Nom donné par Candollc à unc division de la faunille des Légumineuses, comprenant celles qui ont la radicule infléchie sur la comrnissure des cotylćdons.

CURVIGAUDE, adj., curvicaudus (curvus, courbé, cauda, queue). L'Epeira curvicauda a l'abdomen terminé par deux grandes cornes recourbées en dedans.

CURViCaule, adj., curvicaulis (curves, courbé, caulis, tigc); qui a la tige courbée, comme l'est à sa basc celle du IVeissia curvicaulis, qui pnsuite se redresse.

CURVICOLLE, adj., curvicollus; qui a le col courbé. Les pédoncules qui supportent les urnes du Phascum curvicollum sont recourbés, et penchés vers la terre.

CurVICOSTE, adj., entrvicostalus (curwus, courbé, cosla, côte); qui est marqué de petites côles courbes. Ex. Pleurostoma curvicosta.

CURVIDENTÉ, adj., curvidens (curvus, courbé, derss, dent); qui a des dents rccourbées. Tue Tomicus curvidcns a les ćlytres chargécs de dents nombreuses, dont trois plus grandes sont recourbécs.
CURVIFLORE, adj., curvifloru.s (curvis, courbé, flos, fleur); 'qui a la corollc courbe. Ex. Erica curviflora.

CuRvifourí, adj., curvifolius; krummblaturig (all.) (curvus, courbé, folizm, feuille); qui a les fenilles infléchies ou recourbées. Ex. Dryptodon curvifolins, Armeria curvifolia, Mescmbryanthemum curvifolium.

CURVINERVÉ, adj., curvinervis ; krummnervig (all.) (curvals, courbé, ncruts, ncrf). Se dit d'une fcuille dont les nervures sont courbées de manic̀re à suivre presque le bord de la feuille, ou se prolungent en déerivant une courhe. Ex. Plantago media.

CUnVIrlide, adj., curvipes (cursus, courbé, pcs, pied); qui a les jambes courbes. Ex. Nomia curvipcs.

CURVIROSTRE, adj., curvirostrus (curvus, courbé, rostrum, bee); qui a le bee recourbć (ex. Columba curvirostra, Rosicllaria curvirostris, Dendrocolaptes proculviss). Le Gymnostomum curvirostrum el le IVeissia curvirostra ont l'opercule de leurs urnes en bec recourbé.

curivinostrus, adj. et s. m. pl., Curvirostres. Linné désignail sous ee nom une section de l'ordre des Echassiers, comprenant ceux de ces oiseaux qui ont la mandibule supérieure un pen courbée au bout.

CURVISÈTE, adject., curvisctus (curvus, courbe, scta, soie). Le Gymnostomum curvisetum et le Pohlia curviscla ont des pédoncules recourbés.

CuSCUTÉES, adject. et s. f. pl., Cuscuter. Nom douné par Bartling à une famille de plaules, qui a pour type le genre Cuseuta.

CuSpartíes, adj., Cuspariea. Nom donné par A. Jussicu à un groupe de la section des Rutacées diosmées, qui a pour type le genre Cusparia. 
CUSPIDE, subst. f., cuspis; harte Spitae (all.). Petite pointe acérée, alongée et un peu raide.

CuSPubé, adj., cuspidatus; foingespitzt (all.); apprunituto (it.); dont le sommet se termine en une pointe aignë et dure, eomme le bont drs feuilles du Loranthus cuspidatus, de l'Aealypha cuspidata, du Plasscum cuspidatum, et les angles postirieurs de la coquille de l'Hyalaen cuspidala.

GuSPIDIFine, adj., cuspidifer (cuspis, pointe, frro, porter); qui porte des pointes. Ex. Ophiura crispidifera, Alcyonum cuspidiferum.

cusprDIrouw, adj., cuspielifolius (cuspis, pointe, folium, fenille); qui a les fertilles euspidées. Ex. Coprosma cuspictifolia.

Cuspinf ORME, alj., cr.spidiformis (cnspis, pointe, forma, forme); qui a la forme d'unc petite pointe.

CUTrcoles, adj. ct s. f. pl., Cuticole (cutis, pear, colo, habiter). Nom donné par Clark à unc Camille d'OEstres, comprenint ceux de crs insectes dont les larves vivent sous la peau des animaux.

cutrcuse, s.f., cuticula. Candolle appelle ainsi la membrane qui revét les jeanes pousses et les fenilles des plantes, et ne se renouvelle pas quand on l'euteve; Gacrtner, le tégument qui enveloppe les grains du pollen; liernhardi, la pellicule extćrieure des graines. Grew employait ce mot eomme synonyme d'épiderne des plantes.

CUTICULEUx, ndj., cuticulosus (cuticula, petite peau). Le Pciza culiculosa est appelé ainsi, paree que sa eoupe ou eupule est membranaeće.

CYAMOLDE, adjeet., cyamoides

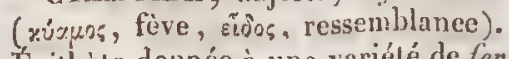
Épithète donnée à une variété de fer oligiste, paree qu'elle resscmble '่ ane pelite fève.

CYANATre, s. nı., cyanas. Genre de sels (cyansaurc Salzc, all.), qui sont produits par la combinaison de l'acide cyanique avec les bases saliliables.

cYaNér, adj. et s. f. pl., Cyanece. Nom donné par H. Cassini ì une section du groupe des Centauriciss jutcéinces, qui a pour type le genre Cyanus.

CYLNEICOLLE, adject. , cyaneicollis (cyanczs, bleu, collum, col); qui a le col bleu. Ex. Porphyrio cyancicollis.

CrANEL, adjeet., cyanosus. On appelic acide cyancux (cyanigcs äure, all.) Ic prenier degré d'oxidation da eyanngène, soupçonné par Vauquelin, ut démontré par Wobler, qui en a fait cunnaitle la composition; chloride cyaneux (Chlurcyan, all.), l'une des combinaisona dia ehlore avee le cyanoginc; sulfide cyanezu: (Schrvefelcyran, all.), d'après Berzelius, le sulfocyanogène considéré comme jouant le rôle d'acide.

CVAMBSAE. s. f. On a proposé d'appeler ainsi les cyannres de fer doubles, qui forment avee l'neide sulfurique des sels dans lesquels lenr eyunogèc joue, par rapport anx deux mćlaux avee lesquels il est combiné, le necme rôle que l'oxigène à l'égard des oxibases, dans les oxise?s.

CYAVICORNE, adj., cyanicornis (cyaneus, bleu, cormu, corne); qui a les antenues bleues. Ex. Staphyliuus cyanicornis.

CYANICTERE, adj., cyanielerus (cyancus, bleu, iclerus, jaune); qui a le corps bleu et jaune. Ex. Pyranga eyaniclera.

CYAMIDE, sulst. m., cyanidium. Nom donné par Berzelius anx combinaisons du eyanogène avec des corps simples, dans lesquelles les 


\section{CYAN}

rapports atomiques sont les mêmes que dans les bases.

CYaneèD, adject., cyanipes (cyanczs, bleu, pes, pied). L'Acridium cyanipes a les jambes postéricures jumnes, avec l'extrémité bleue.

CYAMIPENNE, adj., cyanipennis (cyaneus, bleu, penna, aile); qui a les ailes bleues, comne les élytres du Ceutorynchus syaniponnis.

CVAMIQUE, adject, cyanicus. On appelle, en chimic, acille ryanique (Cyansïurc, all.), le second degiés d'oxidation du cyanogène, qui a été oblemu par Scrullas; chloride cyanique (Cyanchlor, all.), l'une dos combinaisons de ee dernirr corps avee le chlore; sulfide cyanique (geschtwe. fele Schwefelcyan), d'après Berzelius, l'hypersulfoeyanogine, eonsidéré eomme jouñ le róle d'acide; ther cyanique, un éther solide, découvert par Woehler, qui se produit quand on fait passer des vapeurs d'aeide cyanique à travers de l'aleont anbydre._Candolle donne l'ípithète de cyaniques aux feurs de la munee desquelles la couleur bleue cst le type.

CYANIROSTRE, adj., cyanirostris (cyancus, bleu, rostrun, lses); qui a le bee bleu. Ex. Dotacilla cyanirostris.

Crantite, s. in., cyanis. Genre de sels (cyanigsaurc $\$ a / z c$, all.), qui sont produits par la eombinaison de l'acide cyancux avec les bases salifiables.

CHANOCARPE, adj., cyanocarpus (xisvo;, bleu, xxeто;, fruit); qui a des fruils azures nu bleuâtres, conme les haies du Drjmophila cyanocarpa et du Mclastoma cyanocarpon.

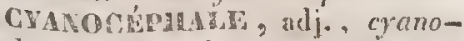

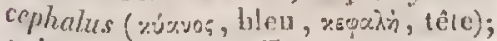
qui a la tête bleuc. Ex. Cinczlus cyanoceplualus, Columba syanocephala.

GrATOCOLEH, adj., cyanocollis

(cyaneus, bleu, collum, eol); qui a la gorge bleue. Ex. Sylvia cyanocollis.

GMNOFERIBE, s. m. , cyanoferrum; (yancisen ( all.). Gay-Lussac admet sous ce nion un corps comburaut, ou radical d'acide, composé de eyanogène et de fer, qui, suivant lui, en se combinant avec l'hydrogèn, produil l'aeide hydrocyanoferrique.

CYavorwindRe, s. m., cyanofrrurctum. Combinaison du eyanoferre avec un corps simple.

CIANOEASTIB, adject. (xúavos, bleu, yxstip, ventrc); qui a le ventre bicu. Ex. Psillacus cyanogaster, Certhia ganogasira. Voy. CxANOVENTRT.

CiAxOGLNe, subst. m., cyanogenium; Cyan (all.) (ruxvos, blen, yivopex, engendrer). Combinaison de carlone et d'azote, découverie en 1814 par Gay-Iussac, quilui donna ce nom parce qu'elle est un des principes constituans du bleu de Prusse.

CINNOGYNE, adj., cyanogynus ( «ंxvos, blen, үư⿱ , fenme); qui a le style bleu. Jix. Hibiscus cyanogynus.

CYANOLEUQUE, adj., cyanoleu-

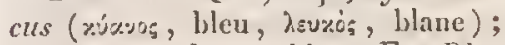
qui a le eorps bleu et blane. Ex. Platyrlynchos cyanoleucus, Hirundo cyanolcuea.

CYANOMELAS, adj., cyanomelas

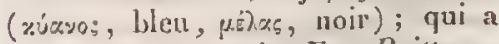
le eorps bleu et moir. Ex. Psillacus cyanomelas.

CYANOVERTE, s. m., cyanome-

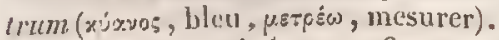
Instrument imaginé parr Saussure pour déterminer les différens degrés d'intensitć du bleu que nous offre la voate cóleste.

CWNOPATIE, s. f. , cyanopathia (xuัas, bleu, тros, maladic). Élat anomal, dans lequel, par des 
eauses qu'on ne connaît pas bien encore, la peau de l'homme offie unc teinte blcue.

GYANOPILLCTE, adj. , cyanophlyctis (xن் tule); qui a des pustules ou taches bleues sur le corps. Ex. Rana cyanophlyctis.

CYANOPITHALIE, adj. , cyanophthalmus ( av́avos, bleu, òpocisuos, oil ); qui a les yeux l,leus. Ex. Musca cyanophthalma.

CYANOPOTASSIQUE, adj., cyanopotassieus. Grotthuss admet l'existenee d'un gaz crano-potassique, c'est-à-dire d'unc combinaisoun gazeuse de cyanogène et de potassium.

GYanoptrine, adj, , cyanopterus

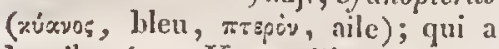
les ailes (ex. Vespertilio cyanopterus, Saltator cyanopterus, Anthrax cyanopler $a$ ), ou les nagcoires (ex. Cheilodipterus cyanoptertis) bleucs.

CYANOPODE, adjeet., cyanopus

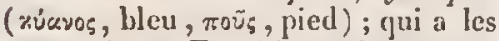
pattes bleues. Ex. Numcnius cyanopus.

CYANOPYGE, adj. , ejanopygius

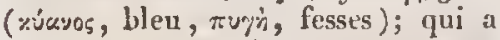
le croupion blcu. Lx. Psittacts cyanopygius.

GXNOPYuRE, adj., ryanopyrrus (xicะos, blcu, тuipos; roux); qui a le corps blcu et roux. Ex. Hirundo cyanopyrra.

CYANOROSTRE, allj. , cyanorostris (cyancus, bleu, rostrum, bec); qui a le bec blcu. Ex. Anas cyanorostris.

CYANOTE, adj., cgranotis (*v́xvos, bleu, ouss, oreille). Ite Philcmon cyanotis a les oreilles d'une couleur de plomh foncée.

CYANOURE, adi. , cyanturtus ' yن́zsos, bleu, ovpó, queuc); qui a la queuc blcue. Ex. Trochilus yanurus, Ardea cyanura.

CYANOURINE, s. f., cyanoutina ( xizos, bleu, cũpoy, uriuc). Bra- connot donne ee nom à des matières colorantes qui teignent quelquefois l'urinc en bleu, et qu'il considère conme constituant une base salifiable particulière.

CYANOVENTRE, adj., cyanoventris (crancus, bleu, venter, ventre); qui a le ventre bleu. Ex. Alcedo cyanoventris. Voyez Cravogastre.

CYANCRATE, s. m., cyanuras. Sel produit par la combinaison de l'acide cyanurique avee une base salifiablc.

CYANURE, s. m., cyanurelum, cyanetum. Combinaison du cyanogène avce un corps simple autre que l'oxigène, dans laquelle les rapporls atoniques sout les mèmes que dans les hases.

CYAXURIQLE, adj., cyanuricus (de la pronière syllabe des nots cyanogine et urine). Nom donné par Wochler et Liebig à un acide qui s'obtient en soumeltant l'acide urique à la distillation sèchc. Cet aeide, déjit ohservé par Schecle, fut appelé ensuite pyro-urique par Chevallier et Lassaigne, puis assimilé par Woehler à celui que Serullas nomınait acide cyanique et auqual on a donné ensuite le non d'acide cyancux. Woehler ct Liebig ont enfin reconntr qu'il diffère de ce dernier en ec qu'il contient de l'hydrogène,

Cratríaces, adj. et s. f. pl., Cyalicacea. Nom donué par Kaulituss à une tribu de la fanille des Fougères, qui a pour type le genre Cyathca.

cratnkoweses, adj. et s. โ. pl., Cyallcoider. Nom donné par líaulfuss à une seetion de la tribia des Cyathéseces, qui renferme le genre Cyathea.

CrATHFORUE, adj. , cyatliformis; becherförming (all.); ciatiforme scodcllare (it.) (cyathus, coupe, forma, forme); qui a la forme d'un gobelct, e'cst-i-dire qui cst concayc ct ressemble ì un cône renversí, 


\section{CYCL}

comme le fruit du Drepanocarpus cyathiformis, la tête du Tania cyathifurmis, l'éponge appelée Spongia cyathina, et la I'urbinalia cyathoides. On donnc eette épithete à la corollc, quantl clle a son tube cylindrique un peu dilaté ver's la partie supérieure, et son limbe droil (cx. Symphytum talicrosum) ; aux glandcs, lorsqu'clles eonsistent en un disque charnu, ereusé d'unc fossette ì son eentre (ex. Prumus Ccrasus). L'Agaricus cyalhiformis el l'Agaricus trulla formis sont ainsi appclés ì cause de leur chapeau infundibaliforme.

CYATHOIDE; adj., cyahoideus (rice0os, tasse, Eidos, resscmblance); qui a la forme d'une tasse on d'uac soucoupe. Ex. Pesiza cralhoidca.

GYATHOHHORE, adj. , cyalho-

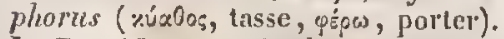
Le Passiflora cyathophora est appelé ainsi parcequ'il porte sur ses pétioles deux grandes glandes excavécs en forme de coupe.

CXCaDies, adj. ets. f. pl., Cycadcre. Famille de plantes, institućc par L.-C. Richard, qui a pour type le genre Cycas.

CYClaDÉs, adj. el s. m. pl., Cycladca. Nonı donné par Férussac ì une tribu de la famille des Pédifères, par Menke à une famillc de l'ordre des Elatobramehes eardiacés, ayant pour type le genre Cyclas.

CYCLADrves, adj. el s. m. pl., Cycladina. Noın donné par Latreille a une famille de l'ordre des Conchifères tubulipalles, qui a pour type le genre Cyclas.

CYCrantumées, adj. ct s. f. pl., Cyclanthcre. Poitcau álabli sous ce nom une famille de plantes, qui ne renferme encore que le genre Cyclanthus. C'est pour Bartling unc tribu de la fimille des Callacées.

CYCLE, subst. in , cyclus.s ; xizzos; Zeitkrcis (all.). Les clironologistes I, dounent ee nom à une période de temps après laquelle los mêmes mouvemens ou les mênies phénomìnes se reproduisent dans le mème ordre.

CYCLERInEs, adj. et s. f. pl., $C y$ clcmidcs. Nom dounć par RobinenuDesvoidy at unc tribu de l'ordre des Myodaires ealyptérćes.

craciouss, adj. et s. m. pl., Cyclica (xúx>os, eerele). Nom clonné par Guvier, Latreille et Eichwald à une famille del'ordre des Colćoptères, comprenant ceux des Tétramérés dont le eorps est ordinairement arrondi.

CXChomincues, adj. et s, m. pl., Cyclobranchiata (xúxdos, cer-

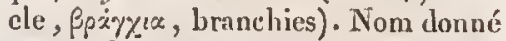
par Schweigger, Goldfuss, Eichwald, Ficinus et Carus a unc famille de l'ordrc des Mollusques gastéropodes, par Cuvier, Fiseher et Gray à un ordre de la classe des Gastéropodes, par Blainville à un ordre de celle des Paracéphalophores, par Jatreille à un ordre de eelle des Peltoeochlides, comprenant ceux de ces animaux qui ont les branehies rangées en eo:don sous les rebords du manteau, ou rassemblées symétriquement auprès de l'anus.

GYCLOCARPE, adj., cyclocarpus

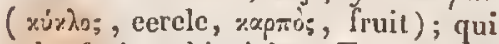
a dles fruits orbieulaires. Ex. Gouania cyclocarpa.

GXCLOCHLE, adjeet. , cyclocrelus

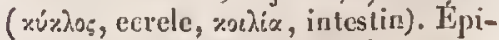
thète donuéc par C.-G. Ehrenluerg aux infusoircs entérodéles dont le eanal intestinal est disposé en forme de cerele, de sorte que la bouehe et l'anussc eonfondent cusemble. Ex, Vorlicclla.

CXCROGASTRE, adj., cyclogasicr

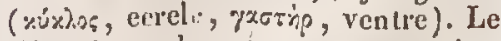
Liparis cyclogasler a les nageoires abdominales réunies en disque.

CYCrorDEs, adj. et s. m. pl.,

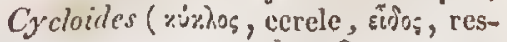
23 
semblance). Nom sous lequel Blainville a désigné un ordre de Cératodermaires, comprenant ceux dont le corps a tune forme circulaire.

CYCLOLOnís, allj. et s. f. pl.,

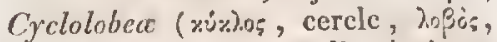
lobe). C.-A. Meyer appelle ainsi une section de la famille des Chénopodées, renfernant celles de ecs plautes qui ont un embryon périsphérique.

Crcronmes, adj. el s. m. pl., Cyclomidcs. Nom donné par Selioenherr à Curculionides gonatocères, qui a pour type lc genre $C_{\text {joclomus. }}$

crctovonpues, adj. et s. m. pl., (yclomorpha ( xن่zhos, ccrelc, popyón, forme). Nom donué par Latrcille it un ordre de la classe des Acaléphes, dans lequel il range ceux de ees animaux qui ont le corps orbienlisire ct déprimé.

CYCLONOTE, adj. , cyclonolus

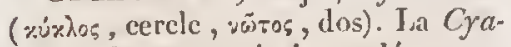
nca cyclonota est ainsi appelée parce qu'elle portc un anueau central roux.

CrCLOPHONE, adj., cyclopho-

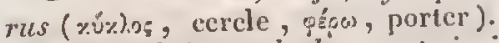
Le Sphecrabolus cycloplion'tes est ainsi appelé parce qu'il ason péridion marqué d'un ecrele rouge dans le milieu : la Lernaca cyclophora, parce qu'clle porle un renflement discoide en avant de sou corps; la Cepheacyclophora, parec quelle a le corps liémisphérique.

GYCKOPIYLLE, adj. , crclophyl-

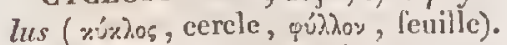
La Phorcynia cycloplyylla a le corps bordé d'un large limbe entier.

CYCLorini:s, adj. et s. m. pl., Cyclopida. Nom dunué par Ixpeh et par Demarcst ì une fumille de l'ordre des Entomostracés lophyropodes, ayant pour type le genre Cyclops.

Cracopie, s. f., cyclopia ( $x$ 's twi, cyclope). Genre de nonstruosité qui consiste dans la fusion des deux yeux en un seul placé au milieu du front.

CYCLOPTÈre, adj., cyclopterus

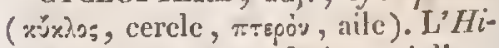
reacycloptera a son fruit garni d'une grande aile presque orbiculaire.

CrCLOSE, s. f., cyclosis (*ưkios, cercle). Schultz désigne ainsi, pour éviter de la confondre avec la cirenlation génerale des animaux supéricurs, l'espèce de eirculation, qui semble locale pour chaque organe, dont il a fait la découverte dans les plantesà suc laitcux, et dont la réalité a ćlé constatce par Surirny, Meyen et Amici, quoique Dutrochet ait prétendu qu'on doit l'attribuer à une simple illusion d'optique.

CTCLOSPERIE, adj., cjclosper-

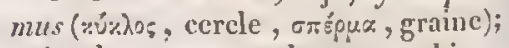
qui a des semences planes el arbiculaires. Ex. Acacia cyclospcrma.

CrCLOSTOMACis, adj, et s. m. pl., Cyclostomacca. Nom donué par Menke à une famille de Gastéropodes coelopnés, qui a pour type le genre Cyclostoma.

GYCLOSTOME; adj., cyclostomus (x'sk.0s, cercle, eróps, bonche). Se dit d'un poisson qui a la bouche trèsronde (cx. Bodianus cyclostomus), on d'une coquille dont l'ouverture est ronde (ex. Bulimus cyclostoma, Solarizm cyclostomum, Trochus cyclostomus).

Crecostones, adj. et subsł. $\mathrm{m}$. pl., Cyclostoni, Cyclostomala. Noun doné par Duméril à une fanille de l'ordre des poissons cartilagineux trémalopués, par Goldfuss à une famillc de celui des Chondroptérygiens, par Ficinus et Carus ì un ardre de la classe des poissons, par lijebwald ì une famille de l'ordre des poissons lolmiuthoïles, renfermant ecux de ces animaux qui ont unc bouche circulairc.

CICLOTHLLE, adj. , cyclothelis

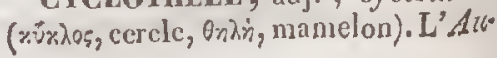




\section{CYLI}

ricularia eyclothelis est ainsi appelé à causc des papilles orbiculaires et de couleur plus foncée qui garnissent sa surface.

Cyclozonires, adj. et s. m.

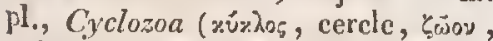
animal). Nom donné parle. Eichwald a un type de l'organisation animale, comprenant les acalèphes et les radiaires, e'est-à-dire les animaux dont le corps est généralement eonstruit sur un plan circulairc.

CYCLURE, adj., cyclurus (x'viros, cercle, ovjpà, queuc); qui a une qucue orbiculaire. Ex. Loligo cyclura, Uromastix cyclurtes.

GYLADES, adj. et s.m. pl., $C y$ lades. Nom donné par Schœnherr à un groupe de la section des Curculionides orthocères, qui a pour type lc genre Cylas.

CYLINDRACÉ, adj., cylindraccts (cylindrus, cylindre). Se dit d'une partic qui est à pen près cylindrique, dont la coupe n'offire pas tout-à-fait un cercle, comme la capsule de l'A loe perfoliata, la coquille du Balanus cylindraccus et de la Spirula cylindracea, l'épi floral de l'A sirasalus cylindraceus, le folliculc du Ceropegia, l'involucre du Senecio vulgaris, le léguma du Lotus corniculatus, le "loyaudu Cornus mas, le placentaire dil Silene, le spadix du Cialla cethiopica, le strobile de l'Abics Picca, l'ur'ne du Dicranum cylindraccum.

CYlindranthúnítes, adj. et s. f. pl., Cylindrantherea. Nom donné par Wachendorfl' ì la famille des $S y$. nanthérécs, à cause du cylindre produit par les antheres réunies ensemble.

CYLINDRICORNE, adject., cylindricornis (cylindres, cylindre, corlin, corne); qui a des antennes cylindriques. Ex. Brentis cylindricor-

CILINDRIFLORE, adject ., cylindriflorus (cylindrus, cylindere, fos, flcur) ; qui a des flcurs eylindriques, counme les ealices du Silene cylindriflora.

CYLINDRIFonne, adj., cylindriformis ( cylindrus, cylindre, for$m n$, forme) ; qui a la forme d'un eylindrc. Synonyme peu usité de $c y-$ lindrique.

CVLINDRIFORMES, adj. et s.m: pl., Cylindriformes. Nom donné par Dumćril à une famille de l'ordre des Coléoptères, rcnfcrmant ceux de ces insectes qui ont le corps arrondi. $Y$. Cruindroïnes.

CYLINDRIQUe, adj., cjlindricus; walzenförmig, walig (all.); cilindrico (it.). Se dit : $1^{\circ}$ en botanique, d'unc partie dont la coupe transversale offre partout l'image d'un cercle, comme l'andlrophore du Hura crepitans, l'axe du Zea Mays, le calice du Dianthus, la capsule du Silene acaulis, le chaton des fleurs mâles du Fagus sylvatica, l'embryon de l'Antirrhinum majus, l'épi du Phyicuma spicata, les fouilles du Sedum album, la hampe du Tulipa, le légume du Cassia fistula, les pédonculcs de l'Atropa Belladonna, la pyxide du Lecythis, la racine du Dictámnus albus, le silique de l'Erysimum Barbarea, le style du Cynoglossum linifolinm, la tige de l'Arundo Donax, le tube de la corolle du Mirabilis Jalapa, l'urne du Trichoslomum cylindricum. $2^{\circ}$ En zoologic, d'une partie dont le diamètre cat ì peu près égal dans toute sa longuear, comme l'audomen de l'Empis cylindrica, les antcnnes des Criquets, lc corsclel des Saperda, les palpes des Ichncumons, le corps du Bcroe eylindricus. On donne cette épithète aux coquilles univalves, quand les tours comprimés s'enveloppeut presque entièrement les uns les autres, de manière que le dernier les couvre tous, ct ne laisse voir qu'une portion de lcur bord supéricur (ex. Hamiles 
cylindricts , Bulla cylindrica) ; aux coquilles bivalves qui sunt également bombées de deux côtés, et qui présentent ì peu près la forme d'un eylindre (ex. Pupa cylindrus, $V \mathrm{cr}$ tigro cylindrica).

CreINDIRoues, adj. et s.m.pl., Cylindrici, T'reles. Nom donné par Latreille à une famille de l'ordrc des Ophidiens idiophides, comprenant ccux qui out lc eorps presque cylindrique.

CYLINDRISTACHÝ, adj , cylindristacleyus (*ủit.vopos, cylindre, $\sigma \div \dot{x}-$ zus, ćpi); qui a les fleurs disposées en épis cylindriques. Ex. Acana cylindristachya.

GYLINDHOBASIOSTËnONE, adj.,

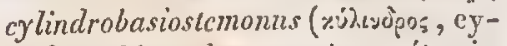

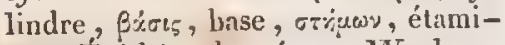
ne). Épithète donnée par Wachendorff aux plantes dont les élamines sont soudées eusemble par la base ou lcs filets.

GYLINDROCARPE, adj., cylin-

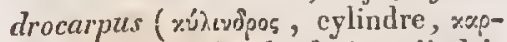
тоे , fruit ); qui a des fruits eylindriques, comme les léguncs du Crolalaria cylindrocarpa.

CYLINDROIDL, adj., cylindroi-

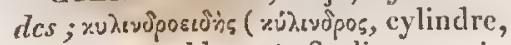
sĩos, ressemblance). Se dit, en minéralogie, d'un eristal dérivant d'un prisme qui s'est arrondi à peu près en cylindre. Ex. Emcruadc cylintdroüdc.

GYLiNDRoInes, adj. et s. m. pl., Cylindroïdes. Nom donné par Duméril à une famille de l'ordre des Coléoptères, par Blainville ì un orIrc de la elasse des Cératodermaires, renfermant eeux de ees animaux qui ont lc corps arrondi ou eylindrique. Voyez Crusmatronses.

CILINDrosones, adj. $\mathrm{cl} \mathrm{s} . \mathrm{m}$. pl., Cylindrosomi ( a'veróon;, cylindre, aw̃ux, corps). Nom donné par Duméril à unc famille de l'ordre des Poissons osseux liulobranches, com-

\section{CYME}

prenant eeux qui ont le corps cylindrique.

Cvurtrov, s. m. , cymalizm;

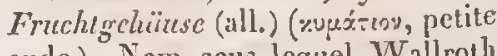
oude). Nom sous lequel Wallroth désigne les apothćcics des Lichens.

CYMATOPHORE, adj., cymaloplorus. Se dit, d'après Wallroth, d'un lichen rui porte des cymations, ou des apothécics.

CTMPILOIDE, adj., cymbaloidctı.s

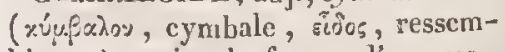
blanee); qui a la fornc d'une nacelle. Ex. Occania cymbaloidea.

CrTBb́canipe, adj. , cymbrecarpus ( $x^{\prime} j e$, nacclle, \%xpros, fruit). L'Astragalus cymbeccarpos a ses légumes renflés à la base.

CTMBÉFORUE, adj., cymbaformis (xify, macelle, forma, formc). L'A spalaihus cymbaformis a les divisions de son ealice ovales, obtuses et naviculées.

CXuiricocillors, adj., Cymbicoclulides ( eoquille). Nom donnć par Latreille ct Menke ì une fanlle de l'ordre des Céphalopodes octopodes, comprenant ccux qui ont une equille uniloculaire, en tout ou en partic externe, faisant office de nacelle poul l'animal.

CMUBIFOLIL, adj., cymbifoliths (xujein, nacelle, folium, fcuille); qui il des feuilles oblongues, coneaves et creusées en naeelle. Exenl. Splagnutu cymbifolizm.

CrubreoruF, adj., cymbiformis ; nachenfömig , kalenförmig (all.); cimbiformc (it.) ("xuen, 11 celle, forma, forme); qui a la forme d'une nacelle; comme la eoquille de la Carina cymbium, el les valves de celle du Cardium symbulare. On donne citite épithète au corps des insectes, lorsque les bords du thorax et des élytres sont recombés en dessus (ex. Cossyphitus).

crive, s. f., cyma; Aficrdolde, 


\section{CYNI}

Trusgdolde (all.); cima (it.). Ensemble des branches qui terminent la tige nue des arbres; assemblage de pedoncules qui partent d'un point comnuur, s'ćtalent ì peu près horizontalement, et produiscut des pédoncules particls nés ì des hautcurs différentes, quoique les fleurs arrivent toutes ì peu prìs an mème niveau (ex. Sambucus nigra). Candolle et Rioper définissent la cyme un mode d'inflorescence qui consiste en ec qu'une tige ou maîtresse branche, termince par une fleur, offre, à la base du púdicelle de celle-ci, deux ou plusieurs loractées opposées, de l'aisselle de chacune desquelles part un rameau égalcment terminć par dcux bractćes, qui, ì lear tour, produisent deux ramcaux, ct ainsi de suite, en sorte qu'il résulte de là une séric de bifurcations au eentre de chacune desquelles se trouve une flcur solitaire.

CVMEUx, adj. , cymosus ; trumdoldcnblüthig (all.); cimoso (it.); qui a ses fleurs disposées en cyme. Lx. Tournefortia cymosa, Helichrysum cymostum.

GrMONIOADEs, adj. et s. m. pl., Cymothoada, Cymoihoada. Nom donné par Cuvier, Latreille, Leach et Eichwald à unc famille de l'ordre des Crustacés Isopodes, qui a pour type le genre Cymothoa.

CYNAPINE, s. f., cynapina. Alcali que Ficinus dit avoir découvert dans l'AEthusa Cynapium.

cruariès. Voyez Cirarées.

cinatiocúluales. Voyez CinaROCÉPUALES.

CYNARHBDT, s. m., cynarhodium. Desvaux appeilc aiusi un fruit charnu, composé d'un grand numbre d'ovaires à péricarpe solide, renfermés ditus un calicc charnu et presque clos, mais nou adhérens aux parois de ce calice. Ex, Rosa.

CYNIPSALES, adj. ct s.m. pl.,
Cynipsera. Nom donné par Latreille at une famille de l'ordre des insectes hyménoptères, ayant pour type le genre Cynips.

CYNOCEPIIALE, adj. , cynoce-

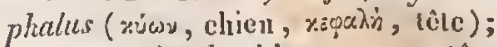
qui a une tëte de clien, ou une tête semblable à cclle d'un chien. Ex. Sinia cynocephalus, Didelphis cynoccphala.

GTNODINE, s.f., cynodina. Substance cristallisalle particulière, que Semmola dit avoir trouvée dans le Cynodon dactylon.

CYNODONí́es, adj. et s. f. pl., Cynodontea. Nom donné par Link à unc tribu de la famille des Grani nées, qui a pour type le genre $C y-$ nodon.

ClNOGRAPUIE, s. f. , cynogra-

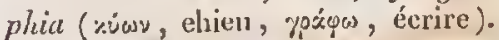
Hisloirec du chien.

CrNOMOLGE, adj., cynomolgus

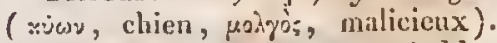
Le Macacus cynomolgus a probablement été ainsi appolé à cause de sa pétulauce el de sa ressemblance atvec un shien.

CYvomonpues, adj. et s.m. pl.,

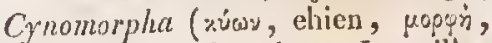
forme). Nom dome par Latreille, Ficinus et Cátus à une famille de l'ordre des Mannuifires amplaibies ou Pinnipèdes, parce que les animaux qu'clle reuferme ont quelque rapport avec le clien, par la forme géućrate de leur léte surtont.

CXNOPHALLOBHORE, adj. , ç-

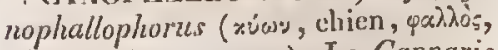
pénis, pípw, porter). Le Capparis. cynophallophora a élé appelé ainsi parce qu'on a comparć au pénis d'un chieu ses fruits, qui sont longs, arrondis ct a chair d'un rouge vif́.

Gronsire , idj., cynophilus ( plère (Thyreophila cynophila) doit ce nom à ce qu'on le trouve sur les cadavres des chieus. 
CYNOSIENS, adj. el s.m. pl., Cynosii (xúw, chicn). Nom donné par Desmarest à une famille de Mammifères carnassicrs, ayant pour type le genrc Chicn.

GYvOSunE , adject, cynosurus ( xíw, ehien, oùpà, qucue); qui n une qucue semblable à celle d'un chien. Ex. Cereopilhecus cynosurus.

GYNOSURINÉEs, adj. et s. f. pl., Cynosurinea. Non downé par Link à une tribu de la famille des Graminées, qui a pour type le genre Cynosurus.

CYPÉrACÉES, adj. et s.f. pl., Cyperacece. Famille de plantes, établie par Jussieu, qui a pour typc le genre Cyperus.

GYPÉRÉES, adj. et s. f. pl., Cyperea. Nom donné par Kunth ct par Lestiboudois à une tribu de la famille des Cypéracćes, qui renferme le genre Cyperus.

CYPÉRINÉES, adj. et s.f. pl., Cyperina. Bartling désigne sous ce nom unc tribu de la famille des $\mathrm{Cy}$ pćracces, qui a pour type le gence Cyperus.

GYPÉnOIDÉEs, adj. et s. f. pl. , Cyperoidea. Quelques botanistes ont donné ce nom à la fanille des Cypéracées.

CIPIELLE, s. f. , cyphella; $B e-$ chorchen (all.); cifella, cifcllo (it.) (züyos, gondole). Fossette orbiculaire el bordée, qu'on observe à la face inférieure de eertains Lichens (ex. Sticta), et dont l'usage est incomu.

CYPRInÉs, adj. et s. m. pl., Cyprida. Nom donné par Leach à une famille de lordre des Entomostracés Lophyropes, qui a pour typc le genre Cypris.

CYPRINIDES, adj., Cyprinides, Cyprini. Nom donmí par Cuvier ct Latıcille à une famille de Poissons abdominaux, par Ficinus ct Carus à une famille de l'ordre des Poissons ossenx Gastéroptćrygiens, ayant pour type le genre Cyprinus.

CIPRINOIDEs, adj. ets. m. pl., Cy. prinoides, Cyprinoidei. Nom donné par Blainvilleet Eichwald à une famille de l'ordrc des Poissons abdominaux, qui a pour type le genre Cyprinus.

CIPRINOSALMES, adj. ct s. m. pl., Cyprinosalmi (cyprinus, cyprin, salmo, saumon). Nom donnć par Latreille à une tribu de la famillc des Salmonides, eomprenant ccux de ees poissons qui tientent des $\mathrm{Cy}$ prins et des Saumons pour les caractères.

CYPRILÉDLées, adj. et s. f. pl., Cypripediea. Sous ce nom, Lindley désigne une tribu de la famille des Orchidées, qui a pour type le genre Cypripedium.

GXPSELE, s.f., cypsela, cypsella

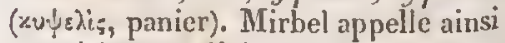
un péricarpe adhérent, qui conticnt nue graine dressée, sans périsperme, dout la radiculc regarde lc hile. Ex. Synanthérées.

CYTTANDRACÉES, adj. et s. f. pl., Cyrtandracece. Nom donné par G. Jack à une famille de plantes, ayant pour type le genre Cyrlandra.

CIRTANDREEs, adj. ets. f. pl., Cyrlandrea. Nom donné par Bartling à une tribu de la famille des Aeanthacées, qui a pour type lc genre Cyriandra.

GXITANTIFOnUES, adj. et s. f. pl. , Cyrtanthiformes. Nom donné par $G$. Herbert à une section de la faunille des Amaryllidées, ayant pour type le genre Cyrtanthus.

CYRTOCÉPHALES, adj. et s. mn. pl. , Cyrlocephala (xupris, bossu, xzyaiǹ, tète). Nom donné par Goldfuss à une famille de l'ordre des Poissont Gastéroptérygiens, comprenant ecux qui ont la tềtc courte et ramassée.

CYRTOSIPIYTE, s. m., cyrtosi-

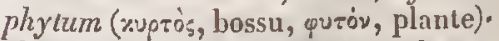
Nom donné par Necker aux plantes 


\section{CYST}

dont le fruit est formé de plusieurs loges formant bosse.

CYSTENCÉPIILE, adj. ct s. m. ,

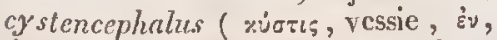
dans, xeqcshn, tête). Non donné par Geoffroy Saint-Hilaire à un genre de Monstres, comprenant ceux chez lesquels le eerveau, restreint dans son développement, a la fornic d'une vessie mamelonnée.

CXSTIBR A NCurs, arlj. et.s. m. pl.,

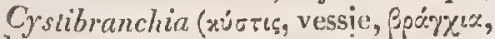
branchies). Nom donné par Lamarck, Goldfuss, Ficinus et Carus à une famille ou division de l'ordre des Crustacés Isopodes, eomprenant eeux qu'on présume avoir des branchics dans des cavités vésiculaires.

CXSTIDION, s. m. , cystidium

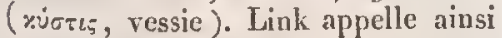
นi fruit monosperme, non adhérent au calice, et dont le péricarpe est pen apparent, qunique le eordon onbilieal soil distinct. Exx. Amaranthes.

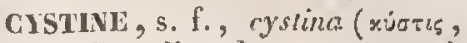
vessic). Berzelius donne ce nom a l'oxide eystique, parce que ce n'est point un caraetère distinctif d'une sulsstance organique de eontenir de l'oxigène, ce corps entrant dans la composition de la plupart d'entre elles.

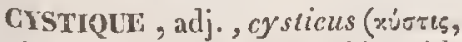
vessie). Wollaston a appelé oxide cystique (Blasenoxyd, all.), parce qu'elle se dissout tant dans les acides que dans les alcalis, et qu'elle ressemble sous ce rapport à quelques oxides métalliques, unc substance animale particulière, qu'il a déconvertc, et qu'on trouve dans eertains ealeuls urinaires de l'homme.
CrstiQues, adj. et s. m. pl.,

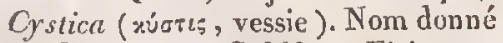
par Schweigger, Goldfuss, Ficiuns et Carus à une famille ou à un ordre de la classe des Entozonires ou Enthelminthes; par Jatrejlle à un ordre de la classe des Elminthaproctes, runfermant ecux dont Je corps sc termine en arrière par une vésicule.

CISTOIDEs, adj. et s. m. pl., Cystica. Rudolphi donne ec nom it un ordre de la elasse des Entozoaires, comprenant eeux dont le corps se ternine en arrière par une vessie propre à chaque individu ou eonmune à plusienrs.

CYTEOPIYTT, s. m., cyloophytum (xiros, cavité, quтóv, plante). Nom donné par Necker aux plantes qui ont une carène, ou papilionacées.

GrTivéEs, adj. el s. f.pl., $C_{\gamma} t i-$ nex. Famille de plantes, ćtablie par R. Brown, et qui a pour type ic genre Cytinus.

CITisine, s. f., cytisina. Nom donné par Chevallicr et Lassaigne au prineipeamer du Cylusus Laburnum, dont Pesehier et Jacquemin ont reconmu l'jdentité avce la cathartine.

crtisponús, adj. el s. m. pl., Cytisporci, Cylisporca. Nom donné par Frics à un ordre de la eohorte des Pyrénomycètes, par $\Lambda$. Brongniart à une tribu de la famille des Hypoxylées, ayant pour type le genre Cylispora.

GYToTuloue, s. f., cytotheca (xisos, eorps, orixn, eoflre). Kirby appelle ainsi la partie interméliaire de la chrysalide, eelle qui couvre et protége le tronc de l'inseete. 
DACRYOIDE, adj., dacryoideus;

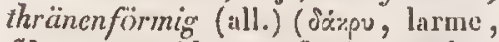
Eidos, ressemblance). Se dit, en botanique, d'une graine arrondie, oblongue et légèrement pointue ì l'unc de ses extrémités. Ex. Pyrus.

DACTYLE, adjeet., dactylosis

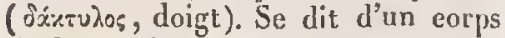
de forme oblongue, à peu près cylin. drique, et qui ressemblc un pen ì un doigt, comme l'épi du Paspalum dactylon, la corzuille de la Cyprexa daciylosa, dn Pleolas dactylus ol du Pholas dactyloides.

DACrutís, adj, et s. m. pl., Dactylati. Nom donné par Duníri] à une famille de l'ordre des poissons Holobranches, comprenant ceux yui ont quclques rayons isolés aux uageoires pectorales.

DACTLLEERE, adj., dactyliferus (S'x́rutos, datte, fcro, porter); qui produit on porte des dittes. Ex. Phacnix dactylifcra.

DACTYIIN, adject., dactylinus

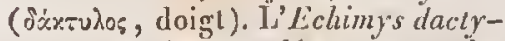
linus est ainsi uppelé paree que les doigts internédiaires de ses pattes de devant sout beaucoup plus longs que les autres.

DACTYLOBES, adj. el s.m. pl.,

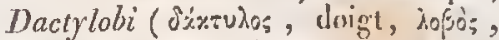
lole). Nom dommé par Lirson à un sous-ordre de l'ordre des Échassicrs, dans lequel il range ceux yni ont les doigts antérieurs soudés jusqu'ả la seconde phalange, et dont la membrane se dilatc cu festou arrondi, pour envelopper l'cxtréuilé de ces appondiece et border le ponee.

DACTILOLES, ndj. et s, f. p].,

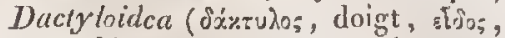
ressemblance). Sehcuchzer désiguait sons ec nom un groupe de la famille des Graminées, comprenant celles de ces plantes qui ont des épis digités. DACTYLOPTEेRE, adject. , dacty-

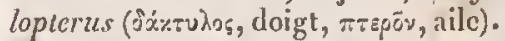
Un poisson (Scorpena dacty loptcra) cst appclé ainsi, parce que les rayons inférieurs de ses nageoires pectorales sont libres dans une partie de leur longneur.

DACTY.OTHڤQUE, s. f., dacly-

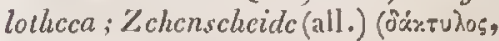
doiggt, Oryn, gुaînc). Illiger noınmait ainsi, dans les mammiféres, la portion de la pcau qui recouvre chaque doint.

DAGLE, s. f. Bois du eerf après la premic̀re' anuée, quand il commence àsc former, et gu'il n'a qu'unc simple tige, sans aucuue branche.

DAILINE, s. f., dahlina. Nom domé par Payen a l'inulime qu'il a extritic des tubercules radicaux du Dahlin (Georgina variabilis).

DALDEIiGLÉs, adj. ct s. f. pl., Dalbergica. C.-H. Ebermaicr et Candolle désigneut ainsi une seetion de la famille des Légumincuses, ayant pour type lc genre Dalbergia.

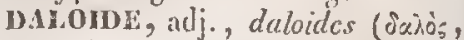
tison, Eijo;, ressemblance). Haïy dounail ectte ćpillète à unc variélé de howillc, pour exprimer qu'elle a l'aspcet d'un tison ou d'un charbon ćlcint.

DAMrCORXE, adj., damicornis, damacornis (dama, daim, cornu, corne); qui a la formuc d'unc corne de daia, c'est-à-dire qui est élargi au snmmet, comme les rancanx de la spongia damicornis, ou les lobes que préseutent les lamelles du Chama damacornis. Le Tabanus damicornis porte une dent recourbéc à l'un des anneaux de ses antennes.

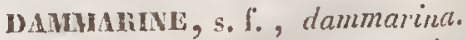
Sous-résine que Brudes a extraite 
de la résine de Dammar (Dammara alba).

DAMOGRAPHE, s. f., damographia (dama, dain, ypóęo, ćcrire). Traité sur le dain. A. Lehwald a publié un onvrage sous ce titre.

DANAEACúES, adj. et s. f. pl., Danaacca. Nom donné par $\Lambda$ gardh à unc triba de la famille des Fougères, qui a pour type le genre Danaa.

DAPINIDES, adj. et s. m. pl., Daphnides. Nom donné par Strans à unc tribu de l'ordic des Crustacés lophyropodes, ayant le genre Daplnia pour type.

DAPIININE, s. f., daphnina. Vauquclin appclait aiusi un alcali dont it admettait l'existence dans ic Daplene II č̃ercum. C.-G. Gmelin cı Baer ont donné le mème nom ì une substance particulic̀re, ni acide, ni alcaline, qu'ils ant rencontrée daus cette nuême plante ct dans le Daphinc alpina, sans pouvoir confirmer les donnćes de Vauquelin relativement à la présence de l'alcali.

DAPINOIDÉES, adj. et s. f. pl., Daplinoidece. Nom donné par Venlenat et guelques aútres bolanistes à la famille des Tliynéléces, en raison du geure Daphine qu'clle renferme; et pal. Candolle i une section du genre Plcurandra, renfermant des espèces qui ont un port analogue à celni de cerlaius Daplune.

DARSILOPIYTW, s. m., dapsilo-

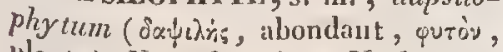
plant(). Nom domé par Necker aux plantes qui ont de nombreuses étamines.

DARD, s. m., spicula ; «в́ขтроу. Ce nom a quelquetois été douné anx poils piquans de l'ortie et de plusieurs autres plantes. Les zoologistes s'en servent pour désigner unc sorte de poiute crochue qui Lerminc la queue des scorpions, ainsi que la partic essentielle de l'aiguillon des hyménoplères, constituce par deux longs stylets délićs, adossés l'un à l'autre, et laissant entre eux un léger sillon ou canal.

DARINYPII TE, s. m., dariny-

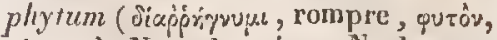
plante). Nom donné par Necker aux plantes dont le fruit sec s'ourre de lui-mềne.

DASYANTHE, adj., dasyanthus (Jxris, velu, $\left.{ }^{\prime \prime}\right) 005$, fleur). I' Astragalus ilasyonthus et lc Kochia dasyanlha ont lcur calice villcux, et lc Campanula dasyantha lc limbe de sa corolle garni de poils sur le bord.

DASYCARPE, adj., dasycarpus

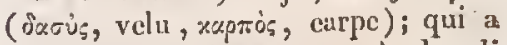
des poils au poignet, on pres da pli du poignet. Ex. Vespertilio dasycarpus.

DASYCARPE, adj., dasycarpus (iseri;, velu, вaprios, fruit); qui a des fiuits velus. Ex. Ormosa dasycarpa, Alyssum dasycarpum.

DASI CAULE, idject. , dasycaulon

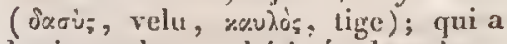
la lige volue on hérisséc de tubercules. Ex. l'elargonium dasycaulon.

DASTGASTRES, adj. et s. m. pl., Dasygastra (jacus, vclu, yzotrip, ventre). Nom donué par Latreille à une sou s-tribu de la tribu des A piaires, comprenant eclles dont les femelles ont le ventre garni le plus souvent d'un duvet soyenx, qui leur sert à rćcolter le pollen.

DASKGKOTTE, adj., dasyglottis

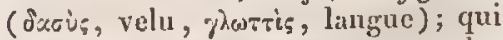
a des légumes velus. Ex. Listragalus dasygrlotlis.

DASYMALLE, adject. , dasymallus

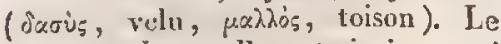
Pteroptes dasynallus est ainsi nommé à cause de son poil généralement long et laineux.

nASTwirne, sulbst. m., dasymetrum; Dichligkeitsmesser (all.)

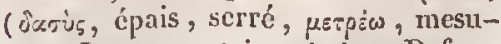
rer). Instrument imaginé par Defoucliy pour mesurer les variations de 
la densité de l'air, et qui, au fond, ne diffère pas du manomc̀tre de Guerike.

DASIPE, adj., dasypus (facis, velu, $\pi \circ \bar{u}_{5}$, pied); qui a les jambes hérissées de poils. Ex. Epicharis dasypus, Laphria dasypus.

DAsIPIIYL.1., adj., dasyplyllus

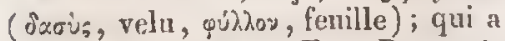
les fcuilles velues. Ex. Bytuncria dasyphylla, Paspalum dasyphyllum.

DASIPIDES, adj. ct s. m. pl., Dasypida. Nom donné par Gray à une tamille de l'ordre des Mammifćres ongulés, qui a pour type le genre Dasypus.

DASYPLEURE, adj. , dasyplcurus

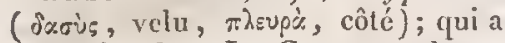
les côtés velus. Le Geotrupes dasyplcterus a le corselet cilié sur les hords.

DASYPOInEs, adj. et s. m. pl., Dasypoidea. Nom donné par Jatreille ì une fanille de l'ordre des Mammifères rongcurs, comprenant ceux qui , ̀̀ certains égards, ont des rapports avec le genre Dasypus.

DASISTACHÉ, adj. , dasysta-

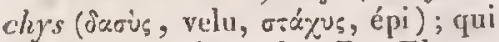
a les fleurs en épis velus. Ex. Elymus dasystachys.

DASISTÉMONE, adj., dasysle-

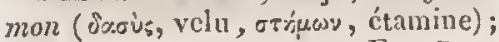
qui a des étanines velnes. Ex. Rosa dasystemon.

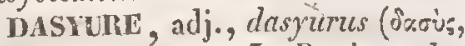
velu, oùò, queue). Le Panicum dasyurum est ainsi appelé à cause de ses épis alongés et doux au toucher.

DASIUrins, adject. et s. m. pl., Dasyurini. Nom donné par Gofdfuss à une farnillc del'ordre des Mammifères marsupiaux, ayant pour type le genre Dasyurtes.

DaTiscíés, adj. ct s. f. pl., $D a$. tiscere. R. Brown propose d'élablir sous ce nom une famille de plantes, qui aurait pour typele genre Dotisca.

Datiscine, s. f., daliscina. Sub- stance, voisine de l'inuline, que Braconnot a retirce du Datisca eannabina.

DATiscivérs, adj. el s. f. pl., Datiscinec. Nom donné par Caffín à une fanille de plantes, ayant ic genre Datisca pour type.

DATURINE, s. f., daturina. Alcali dont Brandes avait annoncé la présence daus le Datura Stramonium, ct que Lindbergson a reconnu êtrc de la polassc mèlée avec une substance narcotiquc.

DATURIQUE, adject. , daturicus. Nom d'un acidc problématique $\mathrm{cn}-$ corc, que Peschier croit avoir trouvé dans Ic Datura Stramonium.

Daccivíes, adj. et s. f. pl., Daueinea. Nom donné par Koch et Candolle à unc tribu de la famille des Ombellifères, qui a pour type le genre Daucus.

DALCIPìDE, adject. , daucipes (daucus, carotte, pes, pied). L'Agaricus daucipes est ainsi appelé ì cause de son stipe fusiformc, qu'on a comparć à unc carotte.

DAVALLoméEs, adj. et s.f. pl., Davallioider. Nom donné par G.-F. Kaulfuss à une tribu de la famille des Lycopodiacées, qui a pour type le genre Davallia.

DÉBLE, adj., debilis; schwach (all.); fceble (angl.). Se dit, en botanique, d'unc tige qui est trop faible pour pouroir se tenir droite sans appui. Ex. Anagallis tcnella.

DËBORDANT, adj., marginans. Épithètc donnée par Mirbel au ncctairc, quand il cst sensiblement plus large que la base de l'ovairc. Ex. Borrago officinalis.

DÉbisis, s. m. pl., reliquia, ramenta. On appelle ainsi les portions des feuilles adhérentes ct non articulćes qui restent implantćes sur la tige après la mort du restc.

DÉCABIACIIDE, adject. ( ớz $\alpha$, dix, $\beta$ pr $\chi^{i \omega y,}$ bras). Blainville donne 
cette ćpithète aux cćphalopodes qui ont dix appendices en forme de bras sur la tête.

DÉCACANTIE, adj., decacan-

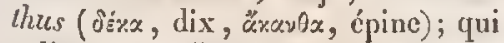
a dix ćpincs, Le Bodjanus dccacanthus porte dix rayons épincux à sa nagcoirc dorsale.

DÉGACÈRES, adj. et s. m. pl.,

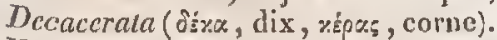
Num donné par Blianville et Menke à une famille de l'ordre des Céplialophorcs cryptodiloranches, comprenant ceux qui ont cing paircs d'appendices tentaculaires atlachés sur la tĉte.

DECADACTYLE, alj. , decadac-

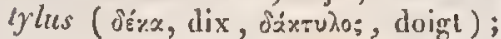
qui a dix doigts. Un poisson ( Polynemus decadactylus) portc dix rayous libres à claque natgcoire pectorale. Lc test d'un oursin (Scuiclla decadactylos) offre en arric̀re dix loburcs ou digilations.

DEGAEDRE, adj. , dccacdricus ( $\delta z^{2} x \alpha$, dix, surface qui se conıpose de dix faces et d'un même nombre de côtés.

DÉCAFIDE, adj., decafidus. Se dit, en botanique, d'un calice ou d'une corollc dont le limbe est partagé en dix découpures qui s'étendent au moins jusqu'au milieu de sa hauteur.

DÉCAGONE, adject., decagonus;

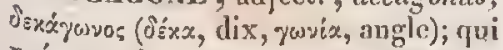
présentc dix angles, eomme le test de l'oursin appelé $S$ cutclla decagonalis.

DÉCAGYNE, adj. , decagynus; zehnweibig (all.) (òंrx, dix, yuvं, fomme). Epithète donnéc au x plantes qui ont dix pistils.

DÉCAGINIE, s. f., decagynit, zehnsw cibercy (ali.). Linné donnait ce nom à un ordre dc la dixic̀me classe de son système, comprenant les plantes qui ont dix pistils.

DÉCALOBÉ, adj., decalobatus

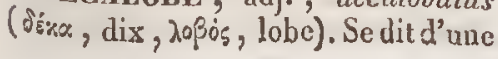

partie dont lc limbe présente dix divisions ou lobes arrondis.

DÉCAANDRE, adj. , decander, decandrus; zchnmännig (all.) ( Jíxe, dix, ג̇vñ , homme). Se dit d'une plantc ou d'une flewr qui a dix ćtamines. Ex. Icica decandra, Combrelum decundrum.

DECANDRiE, s. f. , decandria. Noin donné par Linné, dans son système sexuel, à une classe ct à un ordre de quatre classes, comprcnant desplantes qui ont dix étamincs.

DECANTATION, s. f., decantatio;

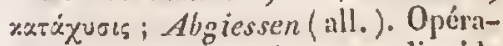
tion qui consiste à séparer un liquide d'une matière solide qui s'y est déposée; on l'exécute en inclinant le vase pour fairc couler lc liquide nageant à la surfice du dépît.

DÉCAv'TuLRE, adj. , decantle-

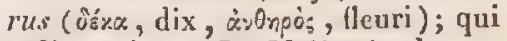
a dix anthìres. Le Mclhania decanthera a dix élamines, dont cinq stériles ct cint portant chacunc deux anthères.

DÉCAPAGF, s. m. Opération qui consiste à rendre la surface d'un nétal nette et brillante, en enlevaut, au moyen d'un dissolvant, ordinairement de nature acide, la couche d'oxide qui s'y est formce ct qui la ternit.

DÉCAPARTI, adj., decapartitus (d'\%, dix, pars, partie). Se dit, en holauique, d'un organe, tel qu'un ealice ou une corolle, qui est divisé jusqu'à la base cn dix parties.

IUGCAPTTAL, adj., dccapelalus;

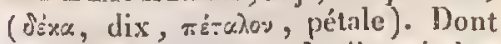
la corolic se compose de dix pétales. Ex. Reichardia decapetala, Alangium dccapc lalum.

DÉCAPIILLI: adj., decaphyllus; zchnbliuttrig (all.) (d'szos, dix, púh$\lambda_{0 \%}$, fenille). Les pédieules de l'Oxalis decaphylla portent chacun huit à dix foliolcs.

DÉGAPODE, adject. , decapodies 


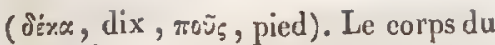
Nä̈s decapoda se termine en arric̀re par cinq paires de lobes charnus.

Dlicapodes, adj. et s. m. pl.,

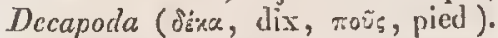
Nom donné par Leach, Orbigny, Latreillc et Eichwald ì une famille de Céphalopodes, cornprenant ccux qui ont la tête couronnée de dix bras ; par Cuvier, Latreille, Goldfuss, Straus, Ficinus, Carus et Eichwald à un ordre de la fimille des Crustacés, embrassaut ccux qui ont dix pieds thoraciques; par Blainville à unc. classe d'animaux entozonires dans laquelle il comprend ceux qui ont cinq paires d'appendices articulés, et qui répond à l'ordıce précédent.

DÉCAPONFonie, adj. (decapo. dus, décapode, forma, forme ). Kirloy donne cetle épithète à des larvesde colćoptères qui sont caruivores, hexapodes, anteunées, et dont le corps, étruit, alongé, convexe ct contprimé, est garni de lames uatatoires. Ex. Drtiscus Agrion.

DÉcaptún rilitss, adj. ct s.m.

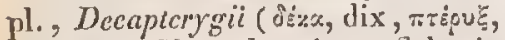
nageoirc). Nom donné par Schneider à une clisse de poissous, renfcrmant ccux qui ont dix nagcoires.

DECARBONATE, adij. Il se dit d'mu oxide métallique qui a perdu l'acide carhonique avec lequel il ćtait combinć. On décarbonate la magnésie cu la chauffont : la chanx se décarbonate par l'action de la chaleur.

Décalibuiation, s. f. Destruction de l'itat de carburation d'une substance. L'acier, par exemple, se décarbure, e'est-à-dire perd une partie de son carbone, sous l'iufluence d'unc haute température.

DÉCASPELUL', adj., decaspermus

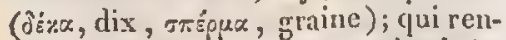
ferme dix semences, comne les baies du Psidium decaspernum.

DÉCATONES, adj. et s. m. pl., Decatoma. Nom donuć par Cuvicr à unc tribu de la famille des Notacanthes, comprenant ceux qui ont les antennes composées de trois articles, dont le dernier est divisé en huit anneaux.

DÉCEMDENTÉ, adj. , dccemdentatus (decem, dix, dens, dent) ; qui esl terminé par dix dents, comme le calice du Lezecas decemdentata.

DĹCENIFIDE, adj ., dccemfidus. Sc dit du calice, quand il est divisé eu dix découpures égales à la moitié de sa longucur totile. Ex. Poicntilla anserina.

DÉCEMLOCULAIRE, adj. , decemlocularis (decem, dix, loculus, logette). Tipithète donnée à un fruit qui est divisé en dix loges. Ex. Cucumis sativits.

DÉCEMnACULÉ, adj., deccmmaculatus (decen, dix, macula, tache); qui est marqué de dix taches, comme les eljetres du Cienodes decentmaculatus.

DECLMPLDES, adj , ct s. m. pl., Decempedes (decem, dix, pes, pied). Nom donné par. Cuvier, Latrcille et Eichwald ì une famille de l'ordre des Cruslacés amphipodes, compre'nant cenx qui u'ont que dix pieds.

DícEmponctué, adj., decempunclatus (decem, dix, punctum, poinl); qui est marqué de dix points color'és, comme les élytres du $M Y y c c-$ tophagus decompunciatus el de la Crioceris decemprenctata.

DECHIQUETÉ, adj., laciniatus; gerissen (all.). On donne cettc épithète aux feuilles découpées dont les découpures sont elles-mêmes parlagécs plus on moins prolondément en segunens de forme irrégulière.

DÉcunné, adj., erosus, laceratus; serschlitat (all.). Se dil, eu botanique, d'une foruille, on de tonte autre partic d'une plante, dont les bords présentent des déeoupures inégales et anssi difformes que si on les avait déchirés, comme les expansions du Col- 


\section{DÉCT}

lcma lacerum; en zoologie, des ailes des insectes, lorsqu'on y aperçoit sur le bord des incisuresirrégulières, qui nc gardent entre elles aucun ordre, n'out aucune proportion ensemble, et paraissent comme le résultat d'vne déelirure (cx. qquelques Noctuelles).

DĹCIOU, adj., dcciduus; abfallend (all.); citscantc (it.) (dcciduo, tomber). Epithéte donuée, en botanique, à lout organc qui ne sc détache que plus ou moins long-temps après son développement, counne les corollcs qui tombent après la fécondation, les calices qui sont dans le même cas, les fcuillcs dont la chute a lieu en aut omne seulcment, ou avant la nouvelle pousse.

Déccouonécinat, adj., deciduodecimalis (decem, dix, duodccim, douze). Nom donné, dans la nomenclature minéralogique de Haïy, ì nune variété de topaze, qni ne présente qu'un seul sommet à douze faces, avec un prisme déceèdre.

DÉcroctovaL, adj., decioctonalis (dccem, dix, octo, huit). Nom donné, dans la nomenclature minćralogique de IIaiiy, à un crislal qui présente dix-huit faces. Ex. Feldspath dicisctonal.

DÉcIOUATUORDÉcrmaL, adj. , deciquatuordecimalis (deccm, dix, qualuordccin , quatorze). Se dit, dans la nonenclature minéralogique de Haüy, d'un crislal qui a viugtquatre faces. Ex. Fcldspath diciquatuordécimal.

DÉCISEXDícimaL adj., decisc $x$ decimalis (dccem, dix, scxdecim, seize). Nom donné, dans la nomenclature minéralogique de llaüy , à un cristal dont la surfiec peut ĉtre sousdivisćc en denx assor timens, dont l'm de dix r't l'aulre de scize faees. Ex. Laryle sulfatéc décisexdécimale.

DéCIIN, s. m. , flcxus ; тxрaxun'; Abnchmen (all.); decay (angl.). Elat d'une chose qui penche vers sa fin: ¿éclin du jour (diei inclinatio), de l'ugc (aclatis flexus). En parlant de la lune, déclin est synonyme de dícours. $V$. ce mot.

dícerrarson, s. f., declinatio ; Ablcnkunir, Abwcichung (all.); dcelination (angl.). On appellc ainsi : $t^{\circ}$ en astronomic, la distance des astres à l'équateur, mesurće sur un cercle perpendiculaire it ce dernicr. $2^{\circ}$ En physique, l'angle que le plan vertical qui passe par l'axe di harreau aiman té fait avec le plan du nséridien d'nn licu, ou l'angle compris entre le méridien magnétique et le méridicn astronomique. La déclinaison a ćté observée pour la première fois en $149^{2}$ par $\mathrm{C}$. Colomb, et en I522 Ginnter a reconnu qu'clle n'est pis toujours la même dins un même lieu. On ne connaît sur le glohe qne quatre points où elle soit nulle, c'est-à dire oú les pointes de l'aiguille se dirigent exactement vers les pôles; partout ailleurs ellc est scnsible et variahle, non seulement d'un lica à un autre, mais encore dans la même localité, ct elle a lien vers l'est pour les uns, vers l'ouest pour les autres.

DÉCLINÉ, adject., declinatus, niedergcbogen (all.). Se dil du style et des élamincs, lorsque, daus une fleur irrégulière, ils se portent vers la partic inférieure de cette fleur placée horizontalcment (cx. Hcmerocallis fulva). Ic Regmatodon declinalus a la tige procombente.

DECocrion, subst.m. , decoctio; d.ę́: Unuac; Abkochung, Alsiedcn (all.) (coquo, euire). Opération par laquelle on soumet une substance à l'action d'un liquide bonillant, pour la dissondre en tout ou en partic, pour en extraire les parties qui sont solubles a cette température. On donne le inêıne nom au produit de l'opération, au liquide qui a bonilli ainsi, et que Chaus- 
sier a proposć d'appeler decoctum.

DÉCOCTUN, s. 11. , decoctum. On a voulu introduire ce mot dans notre langue pour désigner tout liquide qui a bouilli avec une substance dont il a dissous quelyue principe, et pour distinguer ainsi l'aete de la dćcoction de son résultat, qu'autrement on est obligé d'cxprimer par un même terme.

DécollE, adj. , dccollatus. Se dit de la spire d'une coquille spirivalve, quand, à la suite de l'âge, son extrémité se brisc et se casse. Ex. Bulimus dccollatus, MIclania dccollata.

DÉcoloration, s.f., decoloratio; Entfübung (all.). Perte de la couleur naturelle d'un corps, qui devient blanc, ou aequiert une teintc plus ou moins rapprochée du blanc.

DÉcoLorí, adj. , decolor, decoloratus, exolctus ; ơंrypous ; entfärbt (all.); discolourcd (anyl.); qui a perdu sa couleur. Ex. Colubcr cxolctus.

DECOMBANT, adj., decumbens; nicderlicgend (all.). Épithc̀tc domnéc is la tige des plantes, quand elle s'élève d'abord un pcu à sa naissance, et qu'elle tombe ensuite sur la terre par débilité (ex. Olis'cria decumbens); aux ćtamines, lorsqu'elles sc portent vers la partie inférieure de la fleur (ex. Dietammus albus). Dans ce dernier eas, décombant est synonyme de décliné. Voyez ce mot.

DÉCOMHUSTION, s. f., decombustio. Foureroy considérait ce mot, maintenant inusité, comınesynonyme de désoxidation, parce que, pourlui, combustion et oxidation étaient deux termes de mème valeur.

DÉCOMPOSABLE, adj. , zcrsetzbar (all.) ; qui est susceptible de se laisser décomposer.

Dícompost, adj., dccompositus, dissolutus. Épithèle donnce, en chimic (zersetzt, all.), à tout eorps qui a subi une décomposition; en botanique (doppellizisammengesctzt, all.), à la ligg des plantes, lorsgu'ellc se divise en une multitude fle ramifications dès sa base, de sortc qu'clle s'ćvanouit pour ainsi dire (ex. Ulcx europans); de leurs feuilles, quand elles sont partagées en nomlircuses divisions irrćgulières (ex. Lindsca decomposila, $P$ Panax dccompositum).

Dŕcomposition, s. f., dissoluttio; غ่vż่ขฮเ ; Zcrsetzung, Auflösung (all.). Destruction d'un eorps composé, par la séparation des diverses principes ou des différentes substances qui le constituent.

DÉCORTiouavt, adject., dccorticans. Un champignon (Auricularia decorlicans ) cst ainsi appelé parce qu'il croît sur les branches sìches du chẻne, dont il sépare et détruit l'écorec.

DECOUPE, adj., incisus. Se dit des parties minces ct foliacées des plantes, quand leur bord semble avoir été rogné en divers sens.

Décolpunz, s. f., incisio. Terme général dont les botanistes se servent pour exprimer la division quelconque des bords d'une expansion mince et foliacéc.

D f́coliant. Voycz Décurnent.

Dúcouls, s. In., dccurstls; $A b-$ nchmen (all.); dcereasc (angl.); scorrimento (it.). On appelle déeour's de la lune (lune dccresccntia), le temps qui s'ćcoule depuis la pleine jusqu'à la nouvelle lune, c'est-à-dire depuis que le disque éclairé de cet astre commenee à diminuer jusqu'ì ce qu'il disparaisse tout-i-fait.

i) EcodvenT, idject., dctectus, cxscrtus, apcrtus, nudus; aufscdcekl, naclef (all.); uncovercd (angi.); scoperto (it.). Epithète donnéc par les botanistes aux fruils qui ne sont masqués par aucun organe étranger, et ne contractent aucune adhérence capable de les rendre méconnaissables (cx. Cerise); par les cntomologistes, aux ailes des inseetes, quand elles 


\section{DECR}

dépassent les élytres (ex. Forficule), et aux élytres, d'après Kirlsy, lorsqu'elles ne sont pas couvertes par un mésothorax scutelliforme (ex. beaucoup d'Hémiptères homoptères ).

DÉCnúPIT, adject., decrcpitus; absgclebt (all.); qui est dans la période de la décrépitude.

DÉCRÉprTATION, s. f., decrepilatio ; Wóros; Knislern, Abknistern (all.). Petit bruit, pćtillement que certains sels font entendre lorsqu'on les soumet à l'action de la chaleur, et qui tient à l'évaporation de l'eau simplement interposée entre leurs molécules, laquelle brise l'obstacle que les parties salines opposent à son passage, et les projette au loin avec plus ou moins de force.

DÉChíp'TuDE, s. f., decrepiludo, cetas decrepila s. stemma, ullima se-

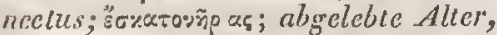
Algcleblheil (all.); decrepitness ( angl.); decrepitì (it.). Dernier terme de la vieillesse, période de la vie humaine qui eommence à quatrevingts ans.

DÚCRESCENTE-PENVE, adject, decreseente-pinnaltes. Se dit d'une feuille pennée dont les folioles dinjinuent insensiblement de grandeur de la base au sominel. Ex. Vicia scpizm.

DÉCROISSE VIENT, subst. n., de-

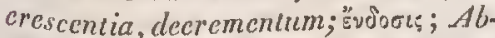
nahme (all.); dccrease (angl.); dccrescimento (it.). Afin d'expliquer la manière dont la natures'y prend pour produire les diverses modificalions qu'on observe dans les différens snlides que les minéraux cristallisés llous offrent, Haïy a imaginé une hypothèse forl ingénieuse, qui consiste à admettre que les choses se passent comme si cet:e nature, alprès avoir fait me certaine forme fondamentale, l'avait ensuite enveloppée de lames successives à chacune desquelles il manquait un certain nombre de molécules, e'est-i-dire de lanes

\section{DÉCU}

déeroissantes, depuis la première jusqu'à la dernière, suivant certaines lois.

DÉCunRevcE, s.f., decurrentia. Etat de ce qui est décurrent.

DECUnRENT, adj., decurrens; herablaufend, ablaufend (all.); decorrente, seorrente (it.). Epithète donnéc par les botanistes à toute fauille dont le limbe se prolonge d'un et d'autre côté en langucttes foliacées qui semblent naître de la tigc clle-mème, soit que la feuille adhère à ectle dernic̀re par la face supéricure de sn nervure moyenne, de manière qu'elle paraisse n'en sortir qu'à l'endroit où la soudure cesse, et que la partie du limbe qui naît de la partie de la nervure collée à la tige semble naître de cellc-ci mìme (ex. Rucllia decurrens), soit que la feuille se prolonge à la base en oreillettes qui se dirigent le long de la tige et sont collées contre elle (ex. Prenanthes viminen, Cullumia decurrens). Le dernier cas est, pour Link, le seul qui constitue la feuille décurrente.

víCunsIF, adjeet., decursinus. I.-G. Richard donnait ectte épithète au style, quand sa base descend en. rampant sur un des côtés de l'ovaire, jusqu'au point correspondant au hile die l'ovule (ex. Rivina). Quclques botanistes l'appliquent anx forilles qui se prolongent inférieurement sur la tige. Link la réserve pour le cas où le pétiole est collé à la tige, surr laquelle il produit une ligne saillante, c'est-i-dire pour le premier des deux modes de décurrence qu'admet Candolle, et dont il a été parlé dans l'artiele précédent.

DEGURSIVE-PENNí, adj., decursipc-pinnatus; herablaufendgefiedert (all.). Sc dit d'une feuille pennée dont les folioles se prolongent par la base sur le pétiole qui les porte. Ex, $M_{c}$ lianthus major. 


\section{DEFL}

DÉCuSSaTIF, adj. , decressativits; kreutzweisstehcnd (all.) (decusso, croiser). Se dit des parties opposées, dont les paires se eroisent ì angles droits.

DÉDIDUDÉCAEDRE, adj. , dedidodecaedricus. Épithète donnćc par Haüy à des cristaux ayant vingt-deux faces. Ex. Feldspath dédidodécrëdre.

DÉFÉCaTION, s. f., defecatio. Série d'opérations vitales qui ont pour but de sćparer des substances capables de nourrir le corps, eelles qui ne sont pas susecptibles d'assimilation, et d'en proenrer l'expulsion par l'extrémité inférieure du canal intestinal. Défécntion (liquoris $\dot{e}$ fecibus purgatio ; zutupequios; Abliairen, all.) s'emploie aussi en chimie, et la plupart du tenıss alors conıme synonyme de décantation.

DÉFECTiF, adjeet., defectivus (deficio, manquer). Nom donné, dans la nomenclature minéralogị̂nue de Haüy, à un cristal dans lequel quatre angles solides du eubc primitif sont remplacés par autant de facelles, tandis que les angles opposés restent inlacts par une cspèce de délaut. Ex. Masnésie boratée défective.

DEFENSE, s. f. On donne ce nom à de grandes dents qui, chez certains mammifères, tels que le sanglier, l'éléphant, le morse, fout saillie hors de la bouche, en suivant des directions diverses, et servent de moyens d'atlaque ou de défensc.

DÉFEUL, MISON, s. f., defoliatio. Chute des feuilles qui garnissent les plantes ligneuses; époque à laquelle s'opère ce phénomène, qui, pour la même plante, a lieu en des temps différens selon les elimats. Voyez Défolintron.

DÉF EUILI:, adject. , dcfoliatres. Le Sescli defolianenz a ćté appelé ainsi, paree que ses feuilles radicalcs tombent de trìs-bonne beurc.

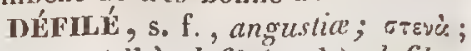
Engpass (all.); dcfile (angl.); defilato

(it.). Dćpression ou cretux dans une chaînc de montagnes, qui se rétrćcit au point de rendre le passage diffieile.

DlifiNI, adj., definitus. Ce terme est employé : $1^{\circ}$ en minćralogie, où l'on appelle proportions définies, pour les substanees naturelles, celles qui se présentent constamment dans un assez grand nombre d'analyses faitcs sur des échantillons de localités diverses, et qui offrent des rapports simples d'un atome à un, deux, trois, quatre, elc., rarement de deux à trois, de trois à quatre, etc. $2^{\circ}$ En bolanique, on nomme étamines $d c f i$ nies, celles dont le nombre ne dépasse pas clouze et se montre constant dans une espèce donnée; inflorescence définic, d'après Candolle, celle dans laquelle la tige ou maîtresse-branche, au lieı de se prolonger indéfiniment en ligne droile et de ne porter dis fleurs que latéralement, se trouve tcrminée par une fleur qui ne naît pas de l'aisselle d'une branche, mais porte à la base de son pédicelle deux bractécs opposées et quelquefois plusicurs verticillécs.

DÉFLAGITEUR, s. m., deflagrator. Énergiqueappareil excitateur de la puissance éleetro-magnélique, dont l'inveution est due à R. Hare, et avec lequel on produit des effets surprenans de combustion et de déflagration.

DÉfLAGRation, s. f. , deflagr

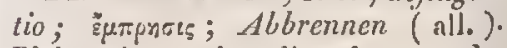
Phénomene qui a lieu lorsque des corps, en réogissant fortement l'un sur l'autre, produiscnt, avec beaucoup de bruit, un degré considérable de feu, entrent en fusion ct lancent autour d'cux des parcelles cmbrasćcs.

DÉFLECHI, adj., deflexus, declinatus; herablüngend (all.). Se dit, en botanique, de li tigc, qui, après s'être élevée à une certaine hauteur, relounbe vers la terre en décrivaul un 


\section{DÉEG}

are. Ex. Eehinospermum deflexum.

DÉLORE, adj. , defloralus ; $a b-$ greblïht (all.). Fipithète donnéc à l'anthère, après l'émission du pollen qu'clle contenait.

DEFOLIATION, s. f. , defoliatio, roliorum demissio ; puxhejponss; Ablauben, Ensblittern (all.); defogliazione, sfogliamento (it.). Chute des feuilles. $V$. Dertulchison.

Déporuation, s. f., deformatio. Altéralion de la lorme des organes d'une plante oud'uu animal, duc ì une cause accidentelle et visible.

DEGEL, s. m., glaciei solutio;

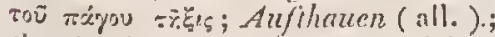
lhrewing (angl.); disgclo (it.). Phénoniene dru passag̃e de l'can glacéc ì l'état liquidc.

Dég THERTION, s. f. , degene-

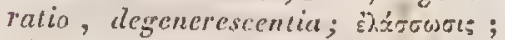
Ausartung, Entartungr ( allen.). Changement qu'épronve un corps organisé, Iorsqu'il vient à passer sous l'entpire d'autres circonstanees, et dont le résultal est de lui enlever son caractère génésique, de luifaire acqueérir des formes, quaJités on proprićtés antres que celles lont il jouit sous l'inlluence t?es cireonstances an milien desquelles il sc trouve le plus ordinairement. Coun. me on atliclic ure importance exagérée ì ec qu’on alppelie caractìre gé Icrique, nature primitive on originelle, on regarde ordinairement tontc dégénéresecuec comme 121 passage à "n étnt pire ou inférieur, ct c'est en Ce sens que le mot a passc daus la lingne usuelle. Mais, loin que les dégénérations soient toujours des deigralations, il lewr arrive fréguemuent d'ètreprofitables s̀lêtre quiles subit, et de tourner ò son avaulage. Rien ne prouve micux quelles combien les rireonstances extérieures influent sur l'organisation, dont ou peut les regarder an moins comme le principal rógulatenr.
DGGódhescence. Voyez DÉGÉNÉRATION.

DÉGríneSCENT, adj., degenerescens. Se dit d'un organe qui subit on a subi nue dégénérescence.

DécruTtrion, s. f., deglutitio;

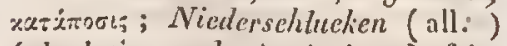
(deglutio, avaler). Aetion de faire passer les alimens et les boissons de la bouche dins l'estomac, à travers le pharyux et l'cesophinge.

DÉursance, s. f., dehiscentia. Mimière dont s'effectue l'ouverture des anthères d'une plasste, pour livrer passage au pol!en, on eclle d'un fruit, pour haisser édhapper les graines. Action par: laquelle les parties distinetes d'un lout ou d'un organe clos se sépareut sans déchirement et le long de la sulure d'union. Phénomène que des organes elos, au moins dans leur jennesse, présentent ì une certaine époque de leur existence, et eonsistant en nuc rupture déterminée et régulière qui s'opire en cus.

DSHLSCXNT, adjeet., dehiscens ; aufreisscnd, zerspringend, aufspringend (all.). Se dit : en bolamique, d'mn frcit qui s'ouvre de lui-mème, à l'époyue de la maturité, comme les légumes dı Genista; en zoologic, des étytres d'un colíoptère, quand elles s'écartent un pen l'une de l'autre à l'extrémilé (cx. Pyroehroa).

Dúdection, s. f., dejoctio. Nom collectif de toutes les matičres qui sont laucées dans l'atmosphère on vomies sur la terre par les volcaus, et de crlles qui sont le résidn de la digestion rhez les mimaux. I,e mot déjertion (نrroxúpniex; Stullelgang, all.) se preud atussi ponr l'acte an moyen durquel les animaux expulsent c s dernicres matières de leur corps.

DEunucétes, adj. at s. f. pl., Delimacee. Non donné par Cirndolle a une triłm de la famille des Dilléniacces, qui a pour type le genre Delima. 
Búdués, adj. et s. f. pl., Delimex. Synonyme de Délinacées.

Diflousscexci, s. f., deliques. centia; $\tau \bar{\varkappa}_{\bar{\xi}} \mathrm{rg}_{5}$; Zerfliessbarkcil, ZcrRicssung (all.) ; liquescency (anml.) (deliqucsco, fondre). Plicnomène offert par certains corps solides qui, exposés à l'air launide, absorbent assez de vapeur aqueuse pour s'y dissondre, après l'avoir ramence à l'état liq̨uide.

DERIOUESEENT', adj., deliquescens; zerfiessend (all.); liquescent (angi.). Sedit d'un scl qui attire l'hulnidité de l'air, ct s'y résont en liyueur: de certains ehampignons (ex. Agaricus alramcnlarius) qui se eonvertissent promptement en liquide.

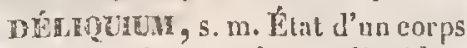
qui, de solide, est devenu liquide, en absorbant la vapeur d'eau contenue dans l'air atmosphérique.

DSLITUGCENCE, s.f., dclitcscentir. Phénomène quia lieu lorsq̨u'me? substance cristallisée en lames superposées perd son ean de cristallisation, de sorfe que les lamesse détachent et se brisent en pareelles, on quand un corps, en absorbant de l'cau, perd son agrération et lombe en poudre.

weressacis, s. f., sceundinarum cxprulsio, pertus sccundarius. Sorte spontance du plicenta et des membranes qui constituent l'ecuf ehez les Mammiferes.

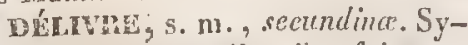
nonyme populaire d'arricre-faix.

DifODUNTE, adject., delodonta

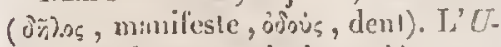
nio delodonla est ainsi sppelée pirres qu'clle a une dent cardinale trisprononcéc.

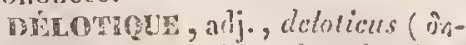
jow, échiarer). Nom donué, dans lit nomenclature minéralogique de Hairy, à un cristal dans lequel l'existenes des fices du noyau semble celaircir un paradoxe que présente une autre variété qui diffire de eclle-lì

\section{DELP}

par l'absenee de ees faces. Ex. Chaux carbonatéc délotique.

DELTODE, adj. , delioideus, deltoides, dchoidalis; deltaförmig (all). Se dit d'un corps aplati dont la forme s'approche de celle d'un $\Delta$, par exemple des camarcs (ex. Ranunculus bulbosus. , et des ailes d'un lépidoptere, lorsyuell s sont obtuses et comme tronquécs postéricarement (ex. quelquues Prrales) : ou d'un corps épais dout la eoupe présente ettle roêne forme, ('omme les fouilles du Proctiva clellordes, du Crassula deltoidea et da Mescmbrjanthemum deltoiderm; ou enfin d'un eorps dont la lorme générale se rapproehe plus ou moins il ceclle d'un triangle, comme les coquilles des 'Tcllina deltoidalis, Mactra deltoides et Nucula iclloidea.

DELTOIDEs; adj. et s. m. pl., Delloidea. Nom douné par Cuvier à nne tribu de la fanille des Lépiloptères noctmrnes, comprenant ceux. dont lez niles forment avce le corselet, sur les côtés duquel elles s'étendent horizontalement, une sortc de $\lambda$.

DEEDHNATE, s. m., delphinas. Nom que Cherreul a ehange en eelui de Phocévate. Voyez ce mot.

DELPHYS, s. f., delphina, detphinina, delphinium. Alcali végélal que Brandes , Lassaigne et Feneulle ont tronvé dans le Delphinium Siaphysagria.

DOLERHANIES, adj. et s. m. pl., Delphinida. Nom donné par J.-E. Gray à une fanille de l'ordre des Mimmiferes cétices, quia pourtype Je genre Delplinus.

DELawneroys, adj., delphinicus. Nom que Chevreul arait donné d'ahorel is un acidc (Detplinsï̈urc, all.), 'lu'il a depuis appelé phoccinique (voyez ce mot), alin d'éviter les équivoques auxquelles pourtait donner lien une dénomination qu'on a 
l'habitude de dériver du mot Delphinium, et qui vient ici de Dolphinus.

DELPHIQUe, adject., delphicus. Épitlicte donnée par Berzelius aux sels qui ont pour hase hn delphine.

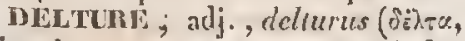
triangle, ovpa, queue), qui a l'al,domen terminé par une lane deltoïde, en forme de queue. Ex. Gebia cllura.

DEMETnIUM; s. m. Quelques eliiinistes ont donué ee nom au cérium.

DEMI-AMPLEXIGALLE; adj., semi-amplcxicaulis. Se dit d'une fcrille sessile dont la base embrasse notableınent la moitié à peu près de la tige.

DEMI-ARPENTELSE; adj. f. On dome cette épithète aux chenilles qui ont quatorze pattes, et à celles qui en ont seize, mais chez lesquelles quelques unes des pattes membraneises sont plus courtes que les antres.

DEMI-CABSULE, s. f., scmi-cap. sula. Quelques botanistes ont ajpelé ainsi la crepule. Voyez ce mot.

DEMI-CLOLSON, s. m., semi-septum. Candolle appelle ainsi les cloisous d'un l'ruit formé par l'agrégration de plusieurs carpelles dont les parties rentrantes natteigneut pas jusqu'à l'axe. Ex. Papaver.

DEMI-COMPLIT', adj., semi-completus. Faluricius donue cette épithète au genre de métamorphose que subissent les inscetes dont les formes restent à peu près les mêmes, c'esti-dire qui ne different des nymphes que par la taille et les dimensions des parties, ou par l'absence, l'état rudimeutaire ou le déveluppement complet des ailes, et qui, sous les trois étals, conservent les mêmes moeurs ct le même genre de nourrturc. Ex. Orthoptères, 1Iémiptères et quelques Névroptères.

IEM-COvPOSÉ, adj, , scmi-contpositus. On nomme ainsi, dans les
Mammifères, les dents où, eomme dans les inolaires des ruminans, les replis de l'ivoire ne pénètrent que jusqu'it une certaine profondeur, au dessous de laquelle les coupes transversales ne montrent qu'une seule substance ceufrale entourée par une autre extérieure.

DEmI-COLnoNn', adj. , somicoronatus. Cetle épithète est donnée par H. Cassini it la calalhide des Synanthérées, quand les fleurs extermes, qui diflèrent des internes par la corolle, sont situées d'un seul còté de la ealathide.

DBMII-GM LINDRYQUE, adj., semiteres, seni-cylindricus; qui eonserve à pea près une grosseur égale dans tonte sa longueur, et présente une faes: bombée, opposée à une autie plus ou moins pline.

DEMi-WMURASSÉ, adj., semi-am. plexus. Candolle appelle ainsi les fezilles contenues dius le bourgeon, lorsefue, n'étant pas tout-à-fait opposées, elles sont pliées sur leur nervure, de sorte que la moitié de chaque feuille est placée entre les deux pans de In feuille opposće. Ex. Sapom naria officinalis.

DEWH-WNROULE, adj., scmi-convolutus. Se ditd'unc eqquille univalve qui est enroulée de manière que les tours de spire ne se touchent point. Ex. Spirula.

DEMI-TEULLET, s. m. , semilamclla. On noume airusi les lames qui garnissent le dessous du chapeau des agaries, quand elles ne s'étendeut pas depuis le centre jusqu'à la eirconfírenee.

DEMI-FLEULON, s. f. , semi-flosw culus. Nom douné a une corolle de Synanthérúe dout le limbe se termine par une lane unilatérale, en forme de languette. Ex. Lcontoton.

DEMI-FLEURONWhi, adj., scmifosculosus. Se dit d'une ealathide qui contient des demi-fleurons, ou 
d'nne corolle qui a la forme d'un demi-fleuron.

DLMI-r cOSCerLux, adj., semiflosculosus. Se dit d'une fleur composée qui résulte de la réunion d'un eertain nombre de deuni-flcurons seulement.

DEVII-LARVE, s. గ., scmi-larva. On appelle aiusi les larves des orthopteres, des hémiptè es et dc certains névroptères, parce qu'elles n'offrent pas, comme eclles des insectes appartenant aux autres ordres, un corps alongé, vermiforme et couvert d'unc peau molle, au moins sur le trone.

DEMI-I.OGE, s. f., scrii-loculns. Candolle donne ce now aux eavités d'un fruit qui, ćlant formé par l'agrégation de plusieurs carpelles dont les partics reutrantes se prolongent dans lintérieur, sans altcindre à l'axe, laisse un vide dans son centre, et offre à sa cireonlérence aulant de lnges ouvertes a l'intérieur qu'il y a de earpelles aggomónées. Ex. certains Papaver.

DEM-MITAL, s. n., semi-metallum. Autrefois on appelait ainsi l'arsenie, lc eobait, lc hismuth, le nickel, l'antimoine et le zine, parec qu'ćtant doués de l'ćclat métallique, ils sont plus ou moins cassans, plus ou moins volatils, et ne jonissent par conséquent que d'une partic des propriétés des nétaux, parmi lesquelJes on rangeait alors la malléabilité et la fixité au feu.

DEMT-MÉTsturove, adj., scmimetallicus. Se dit de l'ćclat des minéraux, quand il uc p:ésente l'aspect d'un métal qu'ii un degré moyeu. Ex. Schiclin ferrugincux.

DEMT-PARMÁ, alj., scmi-palmetus. Epithrite que les ornithologistes donnent aux doigts des oiseanx, lorsqu'une membranc tenduc entre eux ne s'étend que jusciu'à la seconde phalange senlement. Ex. Sterne.
DEMI-PL'MLONE, alj., scmipetaloideus. Se dit du calice, quand ses divisions ressemblent à une corolle par leur téunité ou par leur coloration.

DEMT-TRANSPARENCE, sulst. f., semi-pellnciditas; Halbdurchsichtigkcil (all.). Propriété dont jouissent eerlains corps de se laisser péuétrer par les rayons luminenx, mais en trop petilc quantité pour permettre qu'on aperçoive les objets à travers leur épaisseur, autrement que d'une manière peu distincte.

DEMI-TRANSPARENT, adj. , scmi-pellncidus; halbdursichtig, durchscheinend (all.); qui jouit de la demi-transparcuce.

DEMI-VERTICHLL, adj., scmivcricillatus. Se dit des fcuilles, lorsqu'clles n'entourent qu'à moitié l'axe qui les porte. Lix. Musa Sapientium.

DEXURTER ORE, adj., dendrifor-

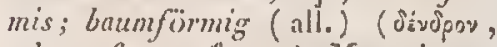
arbre, forma, forme). Minuvis synonynic, pen usité, de dendroüdlc. Voyez ce mot.

DENDIITE, s. f. , dendrites. Dessin naturel qu'on obscric sur me substance minéralc, et qui représente assez bien de petits arbrisseatux très-ramifiés, scmblahles à des bruyeres (phylicides, iricides), à des lichens (lichcnides), ì des eharagnes (charolites), ì des arbres indéterminćs (nćmolithes), à des lentilles d'cau (limnitcs), ou sculement à des taches (stigmiles).

DENisnirrioue, adj. , dentriticus (jévojpor, arbre). Se dit d'un minéral dont la surface présente des dessins prodnits par les molécules ordiuairement métalliques, et semblabies à de petits arbrissenux (ex. Quarz agate dendritique). Se dit uussi d'un champignon (ex. Himantia dentritica), ou d'un lichen (cx. Graphis dendritica), qui a la forme d'un petit arlore. 
DENDROGRAPIIE, s. f., den-

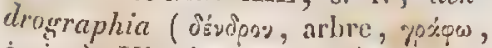
écrire). Histoire on traité des arlires. J. Jonston a cerit un ouvrage sous ce titre.

DENDROHEL, s. f. dendroides,

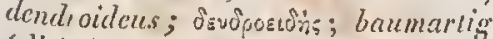

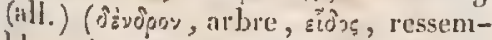
blanec); qui ressemble à un petitabloc par ses liges raulilices (ex. Bryum dendroides, Astrea dendroiles). Se dit anssi d'une plante yui s'ćlève au rang d'alurissea a, daus un genre où lil plupart des especes sont herluaées (ex. Sedum dendroideum), ou d'une autre dont la tige est abboreseente (ex. Eiphorlia dendroides), dont la tige se divise a la manic̀re de eclle des arbres (ex, Isollecium arbiscula).

DENDTOEICIREERS, adj. el s. f. pl., Dendrolichenes (jèjoso, allure,

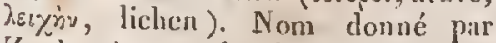
Lenker à un ordre de la fimille des Lichens, comprenant reux qui affecteut la forme d"expansionsdendroïles.

DERBROLITHALIES, adj. ol s. m. pl., Dendrolillaria (Osvojpos, all-

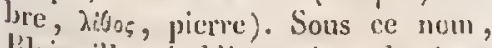
13lainville a ćtabli une elasse du rògue auimal, qui eomprend les corallines, dont la forme est arborescente ct dont la substance se rapproehe de eelle des polypicrs.

DENDROLOZiE, s. f, dendrolocria (óvopov, arbre, hicyos, discours). Traité des arbres et arbustes. J. IIowcl, U. Mldrovande et P. Hatin orit publie rles ouvrages sous ce titre.

DENBronogiour, adj., dendrologicus; qui a rapport ì la dendrologie.

DENDrPOMHDS, adj. et s, m. pl., Dendrophida. Nom lonné par F. Boic à une famille de l'ordre des Ophidiens, rui a pour type le genre Dendrophis,

DENSE, adj., densus; diclit (all.); qui renferme beasucoup de miljère sous un petit volume, en vaison du grand rapprochemeut des molécules. Se dit quclquefois d'une plante dont les feuilles sont très-serrécs (ex. Dicrannm densum, Jestia densa).

DENSIFEOHE, adj., densillorts (densus, dense, flos, lleur). Se dit d'une planti dont les fleurs sont serjécs les unes conlre les autres. Ex. Fiunturia áensifora, Thalictrum densiflormut.

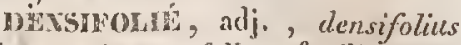
(densus, dense, foltum, feuille); qui a des feuilies nombreuses et serrées. Lx. I'laea den.sifolia.

DEN5120STlili, adj., densirostris (densus, donse, rostrum, bee); qui a le bec très-lort el dır. Ex. Turdus densirostris.

DEXSITE, s. f., densitas; Diclutigkeit (all.); density (angl.); densika (it.). Qualice des corps qui dépend de la somme des parties unatérielles qu'ils renferment suus un volume dounć, e'es:-à-dice du rapport de In masse atu volume, d'oi il suit qu'ì volume égal des corps elle est proporlionnelle à leur poids, et qua i poids rgal elle est en raisou inverse du volume.

DENT, s. m., dens; jojove, youoios; Zahn (all.); tooth (angl.), dente (it.). On nomuc ainsi: $1^{\circ} \mathrm{en}$ botanique, les pelites découpures du bord des calices d'une sculc piece ; les pièces clans lesłpuc!les un péricarpe valvaire se divise à l'époque de la maturito, quand elles sont aiguis et eourles rchalivemest i la partic qui restc indivise; les parties saillantes du hord de certnines fruilles, quand elles ue s'inclinent ni d'un côlé ni de l'au11 , et qu'elles ne vout pus au-dela des devuicres ramifientions des nervures; les f́cuilles avortíes qui garnisscunt les racines ou plutôt les tigges souterraines de quelques plantes (ex. Lahhraa); les lanières qu'on voit à l'orifice de l'urne des mousses, 
quand elles proeèdent de la paroi externć, et qu'elles lc bordent apris la chute de l'opercule (ex. Sporangium). $2^{\circ}$ Lin zoologic; les petits corps compaets et très-dur's qui sont implantés dans l'une et l'autre mùchoire, chez les animaux vertébrés, et plus ggèuéralement tous les organes plus ou moins durs, calcaires ou cornés, que les animaux présenteut, le plus souvent à l'eutrée du canal intestinal, quelquefois aussi plus on moins profondément dans son intérieur, et qui servent à retenir, saisir, déchirur, mâcher, broyer une proie; les ininences qui contribuent à former la charniere des coquilles bivalves, on qui se trouvent quelquefois dans un point du contour de l'onverture d'une soquille unisalive; d'après Kirby, les pointes qui terminent les mandibules des insectes; enfin, parfois, et en raison de leur forme, les granulations ou protubérances plus ou moins marquées dont est souvent garni le bord interne des deux doigts de la pince des erustacés.

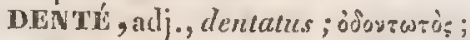
gczïhnt (all.); notched (angl.); dcntato (it.); qui est garni de dents. Se dit : $1^{\circ}$ en botanique. Axedcnté, cclui qui est artieulé, et dont les articulations se portent alternativement is droite et à gauche, laissant chacune à son point d'allache une saillie à laquelle sont fixćes les fleurs (ex. Triticum); feuilles denteses, celles dont le bord offre de petites saillics poiniues qui ne s'inclinent ni d'un côté ni de l'autre (ex. Mclicoeca dentaia, Dianthus dentosus); sligmale dcnté (ex. Hura crcpiluns); racine dentic, celle qui est garnied'uppendices en forme de dents, qui sont des bases de feuilles avortées (cx. Dcntaria pentaphylla); stipules dentées (ex. Mcdicugo polymorpha); $2^{\circ}$ en zoologie. On doune celte épithète aux ailes des insectes, lorsqu'elles ont les bords garnis de découpures distantes (ex. quelques Papillons); à la charnièrc des coquilles bivalves, quand on y remarque des dents; au corsclc des insectes, lorsqu'il porte des prolongemens poinlus (ex. quelques $P$ riones); à la lunule des coquilles livalyes, lorsqu'elle est circonserite par des dents on des crénclures; aux mandibulcs des insectes, quand clles sont armées de dents (ex. Cicindcla); enfin ì des animaux qui ont deux petites den ts entre les ycu x (ex. Corystcs dentatus), ou des dents très-fortes aux mâchoires (ex. Cyclopterus dentc $x$ ), ou le corps couvert d'écailles dentelćes (rx. Plcuronectcs dentatus).

DENTÉES, adj. et s. โ. pl., Dentate. Epitlic̀tc dounće piar Debuch à une tribu de la famille des Ammonćes, renfernant celles qui cut des plis ou des côtes saillantes sur le dos.

DEvtruatines. Voyez PlombaGiNéEs.

DENTLLE, adj., serralus; тptovผт); dentellato (it. ); qui offru des dentelures, comme la carapace de la Tclphusa serrata.

DFNTLLURE, s. f., serra, serratura. Nom donné à de petites partics saillantes, aiguës, qui sont inclinées vers le sommet de la lane d'une feville, et qui garnissent le bord de eetle dernière.

DENTICIDE, adj. On applique cette épithète a la dissémination des graines d'une plante, lorsque les dents, d'alıord rapprochécs, s'écarteut les unes des autres, au sommet du péricarpe, pour jroduire une ouverture. Ex. Primula.

DENTICOLLE, adj., denticollis (dens, dent, collum, col); qui a le col ou le corsclet dentelé. Ex. Cryptorkynchus denticollis.

IENTICOnXT, adj., denticornis (dens, dent, cornu, corne) ; qui a les antennes dentées ou pectinées. Ex. P'tinus denticorrits. 


\section{DENI}

DENTICRunes, adj. et s. m. pl., Denticrura (dens, dent, erus, cuisse). Nom donné par Cuvier à une seetion de la famille des Brachélytres, reufermant coux de ces coléoptères qui ont les jambes de devant an moins dentées ou ćpineuses au eôté exteruc.

DENTICULE, subst. f., denlicula (dens, dent). Dent cxtrèmement pelite.

DENEICULí, alj. , denticulatus, serrulatus, subscrvalus, crenulatus; gezïlnelt (all.); qui est garni de trìpetiles donts, eomme le stigmate du Fumaria sempervirens, bes feuillos du Fuchsia denticulara. de I'Epilobium denticulatum, du Rliamus eremulatus, de l'Alnus serrulatus, du Polyosma serrulatum et du Citharexylum subserratum. On donue eette épithète à un poisson (Searzes denticulatus) dont les mâchoires sont garnies de dents tres-fines.

DENTIFOH.UE, adj., dentiformis (dens, dent, forma, forme). Le Balanus tentifornu's est ainsi appelé parce que la bise ealcaire de ses valves a lil forme de la racine d'une dent, dont les six valves réunies de la coquille constitueraient la couronne.

DENTIGLIILE, adject., dentigerus (dens, deut, gero, porter). Épithète donnce par Illigger an lice des oiseaux, lorsqu'il offre une ou plusieurs dents de claıuc côté.

DENTELimE, adj., dentipes (dens, dent, pes, pied). Se dit d'un insecte dont les cuisses de derrière (cx. Melolontha dentipes) ou les jambes de devant (ex. Buprestis dentipes) sont munies d'unc épine on d'une petite dent à leur partic interne.

DENTIPORE, adjeet., dentiporns (dens, dent, portus, pore). Le $P_{0-}$ lyportus dentiportus est garui en dessous de pores dont un des bords est saillaut et denté.

DENTIIOSTRES, adj. et s. m. pl.,
Dentirostres (dens, dent, rostrum, bee). Nom donné par Cuvier, Illiger, Duméril, Goldfuss, C. Bonatparte, Vigors, Latreille, Ficinus et Carus ì une famille de l'ordre des Passereaux on des Perchcurs, contprenant ceux de ces oiseax qui ont Je bec échancré près du bout.

DENTITION, s. f., dentitio; ìdov:oguio: Zahnansbruch (all.); toolhing (angl.). Sortic des dents hor's des alvéoles et des gencives, ou plutût ensemble des phénomènes qui caractérisent les diverses périodes de leur formation et de leur accroissement, jusqu'à leur apparition au dchors.

DÉNUDÉ, adj., denudatus; cretblïsst (all.); snudato (it.). Se dit d'us organe ou d'un corps qui, devant ĉtre recouvert, se trouve privé accidentellement de son enveloppe aceessoire, ou qui n'offre pas les parlies dont sont garnis d'autres or ganes ou corps qui se rapprochent de lui. Ainsi le Myriophyllum denudatum doit cette épithète à ee qu'il est absolument sans feuilles.

DÉNeDĹEs, adj. et s. f. pl., De mudata. Linné désignait sous ce nomı une famille de plantes, dans laquelle il rangeait celles dont les fleurs sont dépourvues de calice. Ex. Crocus.

DÉLuDES, adj. et s. m. pl., De nurlati. Nom donné par Duméril à une farnille de l'ordre des Entomos. tracés, comprenant ceux qui ont le eorps entièrement uud. Voyez Gra. Noxiecres.

DÉOEERCULÉES, adj. ct s. f. pl. Quelques botanistes, entr'autres We ber et Mohr, ont appelé les bépati ques Calyplralce deoperculala, par ce qu'elles sont privées de l'organe qu'on appelle opercule dans les mous ses.

DÉPART , s. m., separalio; Scheidung (all.). Opération par laquelle on sćpare certains métaux, l'or et l'argent suriout, d'autres substanees mé- 
talliques, par des moyens chimigues, tcls que l'cmploi de l'acide nitrique ou de l'cen régale.

DÉPILEGMATION, s. ז., dephlegmatio. Općration dont le but cst d'enlever, par un moyeu quelconque, principalement par la distillation, l'cau gui sc trouve mêlée avec un atrtre corps liquide.

DúPhLOGISTIọuce , adj., dcphlosisticalus; qui a perdu son phlonistique. L'air dépllogistiqué de l'ćcole de Stahl est l'oxigène des chinistes modernes.

DÉPILANT, adject., depilans. La Laplysia depilans est ainsi nommcio, parec que Liuné attriluaait à la liqueur blanchâtre et âcre qu'clle cxhale la propriété de faire tomber les poils, ce qui est une crrctir.

DÉrolarisation, s. f. , depolarisatio: Phénomene gui a lieu lorsqu'un faisceau polanisé de lumicre traversc un prisme birćlingeeut dans une cerlaiuc dircetion, e'est-r̀-dire que le faisceau analysé a rec ce prisme donuc dans tous les sens deux images blanches et d'égalc intensitć. Cependant la dépolarisation n'est qu'apepilrentc dans ce cas, et le frisccan n'est pas véritablement naturel; car il diffère de ce qu'il serait alors par plusieurs caractères essentiels.

DĹPOullLE, s. f. , cxusice; бхйo\%. On emploie souvent ce terme pour désigncr la peàu d'une bêtc féroce, unais plus fréquemment pour exprisner l'cnveloppe épidc rmique que r'cjettent il certnines épeques les serpens (anguina vernatio; ieprois), et certains animaux articulés, conunc jes araignérs.

DḰPĹDATEURS, adj. ct s. ul. pl., Pradones. Nom donné par latreille, Goldfuss, Ficinus et Callus ì une section de l'ordre des Hyménoplères, compremant ceux qui, comme fes Mutilles, Fourmis, Splese et
Guêpes, causent beaucoup de dégâts, et que depuis Latrcille a dispersés.

DEPIRSSICOLLE, adj. . depressicollis (deprcssus, dépriné, collum, col) ; qui a lc col ou le corselct aplati. Ex. Ceutorlyrnchus depressicollis.

DÉPLESSICORNE, adj., depressicornis (elepressus, déprimé, cornu, corne); (qui a des cornes déprinécs, comme le sont, à leur base, celles de l'Antilupe depressicornis.

DEPIniní, adj., depressus; nicdergetliücht (all.); depresso (it.). En lotanique, ec mot est pris dans le seus de couclić, d'aplati et d'cnfonci. La radicule dépriméc de l' Egrle Marmelos est enfuncée an dessous du niveat des parties roisiues. La capsule déprimic de l'Illiciun anisalum et la carcerulc dépriméc du Ncurada prostrala offrent une conpe transversale plus grande que la !ongitudinale, connrse si elles avaient subi une pression dans le seus verticil, ou du somunct à la hase. Li Antichorzes dcpressus est ainsi appelé à cause de sa tige couchée, ct le Plerjogophyllum depressuin, parce que ses rameaux sont abaissés vers la terre. En zoologic, le mot diprimé veut toujours dire aplati de haut en bas, comme la coquille de la Calypiraa depressa, le corselet des Cucujus, le corps de l'Acanthia depressa, le bec d'un assez grand nombre d'oiseaux, tels que les canards.

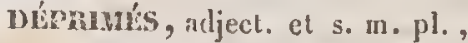
Depressi. Youn donné par Eichwall à une tribu de la famille des Colcioptc̀res brachély tres, conıprenant ceux qui ont le corps aplati de haul en has.

Depenatroy, s. li., elepuratio; xisbupots; licinigumg (all.). Opération par laçuelle on délarrasse une substance de eelles qui, par leur mélange arec clle, altéraicnt sa pureté; résulltat on coffet de cecte opération.

DERAEUh, subst. m., derceum; Unicrhuls (all.) (òzro, cou). Non 
donné par Illiger à la portion inférieure du cou des oiseaux, celle qui est au ảessous de la gorge et de la lluque.

DÉrhatoptìnes, adj. et s. m.

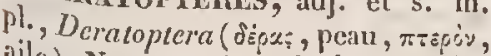
aile). Nom sous lequel Clairville désignail une section de la elasse des insectes, comprenant cenx à élytres simplement coriaces, qu'on appelle atjourd'hui Orthoptères.

DEREvCLPIME, adj. ot s. m., Derencephalus (orgn่, cou, हैy, dans, reprìn, lête). Non donné par Gcoffroy Saint-Hlilaire ì un genre de monstres, comprenanl ecux qui ont un tris-pelil cerveau, enveloppé par es vertebres du cou.

Defanaptines, adj . el s. m. pl.,

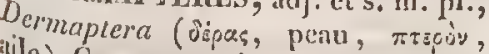
aile). Ce nom, qui pour Degecr était synonymed'Orthopteres, estappliqué Par Kirby, Leacls et Isitrcille à un ordie de la elasse des insectes, comprenaul ccux qui ont les élytres presque entièrement crustacécs el loujours horizonlales.

DERUATOBRaxcues; itlj. et s. nı. pl., Dermalobranchiala (óspse, peau, fpiryzo, hranchies). G. Fisde l'ésigue sons ce nom une section podes lea des Mollusques gastéropares, comprenant ceux qui respirent par une cavitć pulmowaire, par me anchie aérienne.

pl., DEMATOCARPES, adj. cl s. m. (o'sourmatucarpei, Dermatocarpea

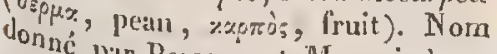
ordre de Persoon el Marquis ì un de la de la clisse ou à une famille carpestion des Chanpignons angiodaus leomprenaut les parasites qui, l'ćpideur jeunesse, sont prolégés par vipent de da plinte sur laquelle is colont; par F.-G. Eschweiler ì une "yant pour la famille des Lichens, carpon. type le genre Dermato-

DERMATODONTE, adj., derma- todon (dépus, peau, ơơvis, dent). L'Hydnum dermatodum est appelé ainsi a canse des dents submembraneuses qui gan'nissent le dessous de son chaperau.

DERMATOGASTRES, adj. et s.m. pl., Dermatogasteres (ớzuce, peau, 7xorip, ventre). Nom donné par Nees d'Esenbeck à unc tribn de champiguons appartemant à la section des Gustromyees gingastres.

nEmiratoun, adj., dermatoi-

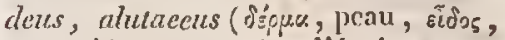
ressemblance); qui a l'épaisscur ou la consistance du cuir, conme la fronde du Laminaria dermatoidea, le chapean du Dolyports alutaceus, du Peziza alutacea ct de l'Hydnum aluiaecum.

DERMATOPHIDES, adj. et s. m. pl., Dermatophilles (ö:pec, pean, öpıs, serpent). Nom donné par J. $\Lambda$. litger i une section de l'ordre des reptiles Ophidiens, comprenant ceux qui ont la peau nue.

DERMITOPNONTES, adj. el s. m. pl., Dermalopnunta ( $\delta$ śpux, peau, тvن์ $G$. Fischer désigne un groupe d'animaux invertébrés, comprenaul cenx qui, comme les polypes et les iufusoires, respirent par la surface du corps.

DERUATOPOnEs, adj. et s. ni. pl., Dermatopodes (déppa, peau, roüs, pied). Noin don nć par Mochring a unec'asse d'oiseaux, dans laquelle il rangenit ceux qui ont les pieds couverts d'une peau coriace et rugueuse.

DERUE, s. m., derma, corium,

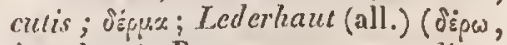
écorcher). Peau proprenient dite; couche la plus profonde, la plus épaisse et la plus vivante des tégumens comnums des animaux, partieulièrement des mammifères.

DERMÉENS, adj. et s.m. pl., Dermei. Noun donné par Fries à un sous- 
ordre de l'ordre des Phaeidiacés, ayant pour type le genre Dermea.

DERWLSTroEs, adj. et s. m. pl., Dermestida. Nom donné par Leaeh à unc famille d'inscetes Colćoptires, qui a pour type le genre Dermestes.

DERanstriss, adj. et s. m. pl.: Dermestini. Cuvier, Latreille et Eichwald désignent sous ce nom une tribu de la famille des Clavicornes, ayant le genre Dermestes pour type.

DERMOB.ASTE, s. m., dermoblastus; IIaulkeim (all.) (dópux, penu,

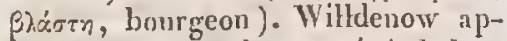
pelait ainsi un embryon végétal dont le cotylédon est forrué d'une mombrane qui se rompt irrégulièrement, cas dans lequel il croyait que se trouvent les ehampignons.

DERwobranches, adj. et $\mathrm{s} . \mathrm{m}$. pl., Darmobranchiata (jępps, peau, Bpx́rycx, liranchies). Nom douné par G. Harimaun à un ordre, et par Duméril à une farnille de Gastćropodes, comprenant ceux qui respirent par des branchies extérieures ayant la forme de lames, de filamens ou de panaches.

DEIIMODONTES, adject. el s. $m$.

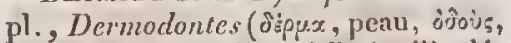
dent). Nom sous lequel Blainville désigne une sous-classe de poissons, dan: laquelle il rangc eeux qui n'ont point de dents implantées dans l'épaissenr des os maxillaires.

DERMOGRAPחL, s.f., dermo-

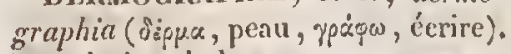
Deseription de lia penu.

Denmologie, s. f., dermologia

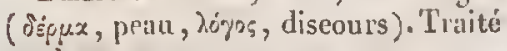
sur la peat.

DERnoptinis, adject. et s. m. pl., Dermopteri, Dermoplera (ó,pus,

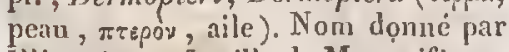
Illiger à une famille de Mammifères, eomprenant ceux qui voltigent à l'aide d'une membrane étendue des bras aux jambes; par Duméril à une famille de l'ordre des poissons Holo-

\section{DÉSA}

branehes, dans laquelle il range eeux qui ont la nageoire dorsale adipeuse; par Degeer et Clairville à un ordre de la classe des insectes, comprenant ceux qui ont les ailes supérienres eoriaces.

DERHORHYXQUES, adj. cl s. m. pl., Dermorhynchi (oipuce, peall, pryzo, bee). Vieillot et lianzani désignent sous ee nom une famille de la tribu des oiseaux nageurs lćléopodes, eomprenant ccux qui ont le bec reesuvert d'un ćpiderme, comme les oies et les eanards.

DEnMosponés, adj. et s, m. pl., Dermosporii. Nom dontué par Fries à un sous-ordre de l'ordre des Tubereularins, ayant pour type le genre Der" mosporium.

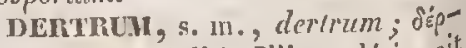
тор ; Kuppe (all.). Illiger désignait ainsi le bout de la mandibule supérieure des oisentx, lorsqu'il est distingué du reste par sa forme ou $\mathrm{pat}^{\text {at }}$ un sillon.

DÉSA CCOLPLIENT, subst. mp Cessation de l'accouplement, sépara ${ }^{2-}$ tion des deux sexes qui s'ćtaient upi pour l’acte de la génèration. Ce ternuc cst surtout usité en économit ruralc.

DÉSAGGIÉLAT10N, s. f. , desag" gregatio. Séparation des parties d'u minéral, par l'action d'unc foree $g^{\mathrm{ut}^{\mathrm{t}}}$ réduit ce dernier en grains on $e^{\text {pl }}$ poussière.

DESAnvit, adject., inermis; $q^{\mathrm{u}}$ $n$ 'al point d'armes, comme l'Ag nciosis incrmis, dont les narines sol dépourvues de cornes. $V$. In ERME.

DESASSMIILATEUR, adjcet.; qu produit un effet contrairc à l'assinnt lation. Facullé désassimilatrice.

DÉsassmur.ATION, s. f. Aetiol organique qui a pour résultat, $\mathrm{s}^{\circ} \mathrm{O}^{\circ}$ la destruction de l'iudividu, soit l' $\mathrm{c}^{\mathrm{l}}$. tretien de l'espèee, et qui parvient ${ }^{3}$ ce but en délruisant les rapports diverses parties qui forment un eor $p^{9}$ vivaut, on en isolant quelques $u^{\mathrm{n}}$ 


\section{DESE}

de ees parties, pour produire un nouvel être.

DESGENDANT, adj. , descendens; herabsteigend, absteigend (all.); descending (angl.). On emploie ce mot: $1^{\circ}$ en astronomie, ou l'on appelle nocud descendant, l'intersection du plas de l'orbe d'une planète ou d'une eomete avee celui de l'orbe terrestre, lorsque ee corpa passe au côté sud de In terie. $2^{\circ}$ Eu botanique. Caudex descendant (Candex desecridens; Truncus subierrancis, Hedwig; Descensis, l'Heritier; Cormus descendens, Candolle), d'aprés Linné, la partie du végétil qui se dirige vers le centre de lit terre, et qui, en se subdivisant, produit les radicules destinées à pomper la nourriture de la plante. Collet deseendant, celui qui, en se développant, s'enfonce dansla terre avec la radicule, de sorte qu'il devient parlic eonstituante du caudex descendant (ex. Daniasonirem stellatum). Poils descendans, ceux qui sont dirigés vers la base de la partic qui les porle (ex. Feronica spicala).

DESCENSION, s. f., descensió; Absecigung (all.). Les astronomes appellent descersion droite d'ume étoile, l'are de l'équateur compris entre le point de l'éguinoxe du printemps et celte de déclinaison qui passe par de l'étoile; descension oblique, l'are de l'cquateur compris eutre le point compluinoxe du printemps d'oúl'on pointe les degrés de l'équatcur et le point de l'ćquateur qui sc couehe en mênc temps que cette étoile. DESCENSronvel, adject. On
comme difference descensionnelle, celle qui existe entre la deseension étoile.

DísERT, s. m., desertum; Wiiste, Einöde (all.); desert (angl.); deserto et souve espace, géuéralcunent uni gravier, qui n'est traversé par aucun

\section{DÉSO}

eours d'eau, et dans lequel les corps o rganisés ne penvent s'établir.

DiSHIDROGENATION, subst. f. Soustraction de l'hydrogènc qui entre dans la eomposition d'une substance.

DÉSIIDROGÉr, adj. Sc dit d'un corps ou d'une substanec qui a perdu son hydrogène.

DESIVENCE, s. f., desinentia. Manière dont se termine un organe ou nne partic d'organc, principalement chez les végétaux.

DESIn, s. m., cuptdo, eupidilas;

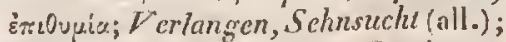
desire (angl.); brama (it.). Sentiment intéricur par lequel nous sommes portés vers une chose, agrénble ou néeessaire, qui nous manque. "Tout désir est un liesoin, une douleur commencéce." (Voltaire.)

DESMATONONTOHIEES, adj. et s. f. pl., Desmalodoninidece. Non donné par Furnrohr \& ull groupe de la famille des Monsses, ayant pour type le genre Desmatodon.

DESHOGOUPlW, adject. , desmo-

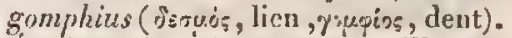
Jipilhèle Innnée par C.-G. Ehrenberg aux infusoires Rotiferes dont chaeme des mâchoires a la forme d'un étrier sur lequel sont étendues les dents, qui y tiennent à la fois par la base et pir le sommet. Ex. Rolifer.

DRSHYTSOl'ODES, adj. et s.m. pl., Desmypsopodes (dzбpos, lien, v̛os, hanteur, roüs, pied). Nom donmé par J.-A. Ritgrn ǹ une famille de l'ordre des Colubathropudes, comprenant des oiscaux échassicrs ì doigts unis par une memlirane.

Dísorganis.tTION, s.f., desorgranisatio. Altération profonde dans la texture d'une partie organique, qui lui fait perdre la plupart uu lá tolalilé de ses caraetères distinctifs; eflet qui résulte de cctle altération.

DÉSOXIDation. Foyez DésoxiGÉNATION.

DÉSOXIDE, Vyea DésoxIGĹNÉ. 
DĹSOXIGLNATION, s. f.; Entsaucrsioffung (all.); desossidazione (it.). Soustraction totale ou particlle de l'oxigene qui entre dans la composition d'une substance.

DÉSOXIGÉNÉ, adj. ; qui a perdu tout ou partie de son oxigrenc.

DESSICCATION, s. f., siccatio; Éripwet; ; Austrocknung (all.). Opération par laquelle on dépouille une matière solide de l'cau ou d'un autre liquide quelconque dont ellc ćtait imbihéc.

DíSUNI, adj. , diseretzs, sejunctus; getrennt (all.). Nom donué, dans la nomenclature minćralogique de Haiiy, à unc varićté dans laquelle des faceltes produites prar une loi compliquéc s'interposent entre d'autres facettes produites par des lois trèssimples. Ex. Chaux earbonatée dészinic.

DÉTAGuĹ, adj., solutus; lose, abgclöst(all.). Se dit, cu botanique, des slipules, quand elles ne tiennent au pétiole que par lia base.

DÉTARIÉEs, adject. et s.f. pl., Dclarica. Nom donné par Candolle à unc tribu de la famille des Léguminenses, qui a pour type le genre $D_{c}-$ tarium.

\section{DÉTERHuné. Voýcz Dépran.}

DÉtonation, s. f., detonatio ; $V$ erpuffung (all.). Bruit plus ou moins violent qui se fait entendre, soit dans le cours des combinaisons on décompositions chiniçues qui s'accomplissent avec rapiditć, soit quand un eorps change brusquement d'état ou de volume, sans ćprotuser de changement dans sa naturc.

nÉtritrous, adject., detritietus (detero, brojer). Tipitlète donnće par Brongniart et par Omalins à un groupe de terrains, postéricurs à la dernière révolution du glolse, qui résultent d'un assemblage , ordinaircment meuble, de fragmens plus ou moins recomnaissables de roehes et de débris de enrps organisćs.

DE்TnOIT, subst. m. , fretum; Mecrenge (all.); streight (angl.); strelto(it.). Bras de mer resserré entre deux côtes, qui fait conmuniquer enscinble deux mers (ex. détroit de Gibraltar), ou deux portions d'une mêne mer (ex. Pas-dc-Caluis).

DEUiL, s. m. On employe trèssouvent ectte épithètc, en histoire naturelle, puur désigner des êtres qui, daus leur coloration, offrent un nélange de noir et de blane, et présentent en quelque sorte l'aspect d'up drap mortuairc ou d'un vètement de deuil, comme le MTorea lugens, qui, sur six pútales, en a trois noirs et trois blanes alteruant cnscmble, ot le Resico elegria, dont les anthères sont noirâtres, avec une liordure blanehe. On la rend en latin de manieres très-varićes, dont voici quelques excmples : Centropus aleralbus, $\mathrm{OH}^{\circ}$ talis moerens, Noetuza leucomelas, Noctua vidua, Actinice viduata, $H \sigma^{-}$ mopis luctuosa, Noclua lristis, Ta china orbata.

DEUTAENOTHONIOUE, adject." deutcenothionicus (dॄersepos, second, oivo;, vin, Osiov, soufre). Sertucrner a nommé aiusi le sccond des trois acides que l'acide sulfurigue produit en agissant sur l'alcool pour former" l'éther, et qui, comme les dettr autres, n'est que de l'neide sulfovinique.

DEUTḰROLOGiti, s. f. , deuterologia (Jázeogy, arriere-faix, 2.opos? discours). Truité sur la nature, les nsages et les connexions de l'arrièrefaix. J.- $\Lambda$. Friderici a pub!ić un otlvroge sous cectitre.

DEUTLROMÉS $A \mathrm{~L}$, adj., deutcró

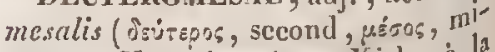
toyen). Nom donné par Kirby a la seconde série des arcoles moyen $n^{5}$ de l'aile des insectes, qui le pl us sol" vent se compose de deux. 
nEUTIODURE, s. m. , deutiaduretum. Synonyme de biodure. Voy. ee mot.

DEUTOcarbové, alj. , deulocarbonatus. Le gaz lydrogene dentocnrboné 'st la seconde dés combinaisons de l'hydrogène avec le carbone, le carbure diliydrique de Berzelius, ou gaz olćfiant.

DEUTOGH,ORURE, s. m., deutochloruretum. Seconde des combinaisons que le chlore forme avec un eorps simple, quand i! est susceptible d'en produire plusieurs. Ex. Dentochlorure de mercure.

DEUTOSĹliviure, s. m., deutoseleniuretum. Scconde iles combinaisons auxquelles le sélénium donne naissance en s'unissant ì un corps simple avee lequel il peut se eombiner en plusicurs proportions différentes.

DEUTOSUh ATE, s. m., deutasulpluas. Sel produit par la combinaison de l'acide sulfurique avee un deutoxide.

DEUTOSULFURE, s. m., deutosulplauretrm. Seconde des combinaisons guc le soufre forme avec un corps simple, quand il est susceptiblc d'en produire plusieurs. DEUTOxine, s. m., deutoxidum.
Second degré d'oxidation d'un corps simple qui peut se combiner en plasieurs proportions diverses avee l'oxigene.

Itivis, adj. , deviatu.s. Se dit, en bolanique, des fenilles, quand elles sont contournées sur elles-unèmes, de manière que la face supérieure ne se trouve plus regarder le ciel. Ex. Allium obliqumm.

DHXTris, wlj., dexter. On dit qu'une coquille spirivalve est dextre, quand son bord terminal se trouve placé à la droile de l'animal, et que le sommet d'unc eoyuille univalve est dexire, lorsqu'il penehe i droite,
la coquille élant supposée oblique- ment sur le dos de l'animal. Ex. Cabackon.

DEX'riovoluBILE, alj., dextrovolubilis, dextrorsumwolnbilis. Epithite donnce à une lige on ì une vrille qui toume de gauche à droite. Cetlc disposition a étć observé daus les genres Basella, Calyptrion, Dioscarea, Llunulus, Lonicera, Morinda, Paljgonum, Rajania, Tamnus et Ugena.

DIACANTIIE, adj., diacanthus (ơts, deux, "xav0x, épine). Se dit, en botanique, d'une plante qui préseute denx épines au dessous de chaque feuille (ex. Ribes diaeamiha), ou à l'aissellc de chaque foliolc (ex. Limonia diaeantha), dont le péricline est formć de deux squames, toules deux armúes d'une épine (ex. Rolardra diacantha), ou dout les feuilles sont garnies sur les bords d'épiues gérniuées (ex. Lamyra diacantha); en zoologie, d'un poisson qui offre deux rayons aigits à l'une de ses nageoires, l'anale par exemple (ex. Holocentrus diacanthus), ou deux aiguillons à chaque opercule (cx. Perea diacantha).

DIACHAINE, s. m., diachenium. Fruit simple, formé par un ovaire adhérent aver: lc ealice, qui, à sa maturité, se sépare en deux loges ou aehaines. Ex. Ombelliferes.

DHAHENE. Vay. Diachaive.

DrAGIruE, s. m., diaclyma (six, ì travers, yupos, suc). Link appelle ainsi le parenchyme des feuilles, le tissu collulaire disséminé eotre les divisions du péliole.

DI constigur, s. f., diacoustica (vid, à travers, csrys, entendre). Branclue de la plysique qui soscupe des proprićlés da son réfrneté dilis son passage a travers des milieux de densilé différente.

DIID 1 CTYLOBATR 1CIENS, adj. et s. m. pl., Diadactylobatraelii

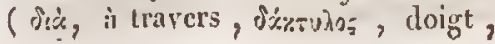


(jx́rpa. $0^{05}$, grenonille). Nom douné par J.-A. Ritgen à une famille de Reptiles Pygomolges ou Géobatraciens, conprenant ccux qui ont les doigts fendus.

DIADELPAE, adjcet., diadelphus (ơis, deux, àdètẹ́s, frère). Epithète donnée aux étcamines, lorsqu'ell's sont réunies par leurs filuts en deux faisceaux égaux (ex. Funaria) ou inégaux (ex. Nissolia diadclpha).

MaDeripile, s. f., diadelptia. Nom d'unc classe, dans le systìme de Linné, qui renferme les plantes dont les étamines sout réunics en deux faisceanx par la base.

DLADELPITOUE, adj. , diadelphicus. Se dit d'une plante ou d'une fleur à ctamines diadelphes.

DIAGONLTRE, s. m. , diagome-

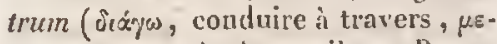

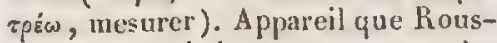
seau a imaginć pour comparer les conducibilités éleetriques des diverses substinuces.

Diakene. Voy. Diacitane.

DIALAAGIQUe, adj., diallagicus. Se dit d'une roche qui contient de la diallage. Ex. Syénite diallagique.

DIANDnE, adj., diander, diandrus; zweimännig (all.) (o's, deux, àrono, hommc). Epithète donnéc à une plante ou flerr ayant deux élamines. Ex. Scleranthus diander, Anuranthus dirndrus, Seabiosadiandra.

DIANDRIE, s. f. , diandria. $\mathrm{Ce}$ nou apparlicut, daus le système de Limné, ì une classe et à trois ordres, contenant des plautes à deux étamines. - Malacarne le donne à une elasse de monstres, qui sont carractérisés par la présence du sexe masenlin double chez un mème individu.

vIANERIQun, adj. , diandricus. Se dit d'une Reut qui ne conticut que deux éta mines.

DIANMME, adj., dianema (òंs, deux, vĩux, fill). Lc Lonchiurtes diancma est ainsi appelé parce que le premier rayon de ehacune de ses catopes se termine par un long filament.

DIANGLÉEs, adj. et s. f. pl., Diangrie (bis, deux, àyaiov, vase). Norn donné par Boerbaave à une classe de plantes, comprenant eclles aux fleurs desquelles succède un péricarpe biloculaire ou double.

DIANTHE, adj. , dianthus (ois,

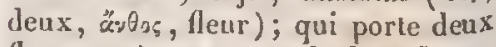
fleurs, qui se compose de deux fleurs, commie les onbelles de l' $H_{y}$ clroeotyle diantha. $V$. Biflore, Diflorigtere.

DIANTISES, adj. et s. f. pl., Dianthcee. Nom donné par A. Richard à une section de la lamille des Caryouhyllées, par Caffin à une fainille de plantes, ayant pour type le genre Dianthus.

DINTHìnE, adj., diantherus (ôi:, deux, ḋanoos, heuri); qui a deux anthères. Le Polanisia dianthera, sur huit étumines, en a six stériles, et deux seulement anthérifères.

DRANThirwes, adj. ct s. f. pl., Dianthinea. Candolle appela d'abord ainsi la tribu de la famille des Caryophyllées que depuis il a nommée Silénérs.

Dripiriles, adj. et s. m. pl., Diaperala, Diaperales, Diaperiales. Non donné par Cuvier, Latreille et Eichwald it une tribu de la fanille des Coléoplères Taxicornes, par Gold. fuss, Ficinus el Carus it une tribrt de la famille des Hétérolytres, ayant pour type le genre Diaperis.

DISPÉRIIEs, adj. et s. m. pl., Diaperida. Lcach appelle ainsi la tribu des Diapérales.

DIAPIARE, adj., diaphanes, dinphaneus, diaphanus, perincidus, trunshucidus; juxpxons; ; durchsichtis (all.); diaphanous (angl.); diafano (it.) ( $i \dot{x}$, i travers, pxivw, voir). Se dit d'un corps qui laisse passer la 
lumière et permet qu'on aperçoive llettement la forme des objets à travers sa substance. Ex. Turbo diaphanus, Lenticulina diaphanea, Barbula diaphana, II icracium diaphanum, Yediantius crystallus. Synonyme de transparent.

DIPInNírité, s. f., diaphanei-

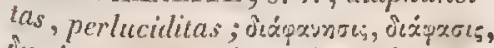
itacxivera; Durchsichtigheil (all.); dictfanita (it.). Qualité de ce qui est diaphanc. Synowyme de transparence.

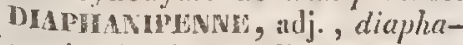
nipennis (diaphentes, diaphane, penna, aile); qui a les ailes diaphanes. Lx. Tachina diaphanipennis.

DLPJINUMLTRE, s. m., diaphanometrum. Appareil que Saussure aproposé pour cxarninget apprécier les différences de diaphantité de l'atnosphère en des temps divers.

DIAPHNOPIYTE, s. m. , diaphnophytum (ơtaẹeneses), être différent, фuтò, plante). Nom donné par Necker a un groupe de plantes qui different les uncs des autres sous le rapport de la fructification.

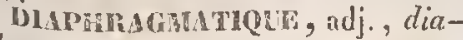

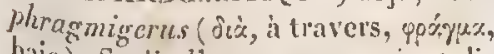
haie). Se dit d'une goutsse qui est diVisée en denx ou pilusieurs loges par des cloisons transversales. Ex. Cassia fistula. Vog. Phragmigere.

DIAPTRAGUE, s. m., diaphrag-

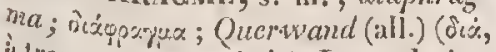
is travers, goéryja, haie). Lame droite, plus ou moins étendue, qui partago la cavité de ecrtaines coquilles uniloculaires en deux seulement et d'uuc minicire incomplète (ex. Scptairc). Plan perpendiculaire qui divise en deux on phisicurs loges une silique, une silieule, un finit. $V$. ExidoPHAGME.

DLMPrXSESTLES, alj. et s. f pl., Diaphysisten (ôtagvio, naitre parnii). Gaillon donne cette épilhete à une stetion de la famille des Thalassiophytes, comprenant eelles, générale- ment filamenteuses, qui présentent de distance en distance, à lintérieur, des eloisons on des renflemenz cellulaires transversaux, donnant aux filamens, dans leur continuité, l'apparenee d'interruption transversale.

DIASTÉMATELTTRE, s. f., diastentatelytria (diarsmp.x, intervalle

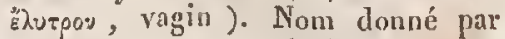
Breschet ì un geure de déviations orgauiques, caractérisé par la scission longiturlinale dn vagin.

DIASTÉnaTFNCÉPIIALIE, s. f. ,

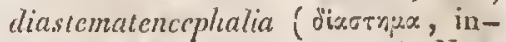
tervalle, Éryécexios, cerveau ). Nom donné par Breschet à un genre de déviations organiqques, qui est earatetérisć par la seission du eerveau, jusqu'à sa lo:se, sur la ligne moyenue.

DustimuTIE, s. [., diasiematia (oiarrnux, intervalle). Nom donné par Breschet aux déviations organiques qui ont pour caraclère la présence d'une fissure ou fente sur la ligne médianc du eorps.

DIASTLimatoganle, s. f., diastcmatocrulia (öiarmnu, intervalte, zaviogs, tronc). Noun clouné par Breschet ì un genre de déviations orga-niq̨nes qui est earactérisé par la scission du trone, dans le sens de sa - longueur.

DLAstéduatncmíllie, subst.f., diastemazocheilia (oixarnux, inter-

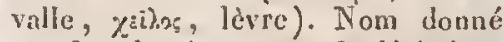
par Breschet à un genre de déviations organiques qui a pour caractère la scission longitudinale des lèvres, ì leur partie moyenue.

DIASTÉHATOCR.INE, subst. f., diastematocrania ( Diartnus, intervalle, xps:vio\%, erâne). Nom donné par Breschet it un genre de déviations organiques qui est caractérisé par la scission du crûne sur la ligne médianc.

DHSTEMTTDCYSTIE, s. f., dic-

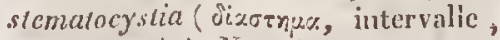
xं́สเร, vessie). Nom donné par Bres- 
chet à un genre de déviations organiques qui est caractérisé par la scission de la vessie sur la limne médiane.

DUASTEMATOGASTIRE, subst.f., diastemalogastria (jiserzua, intervalle, yzotrip, ventre). Nom donné par Breschet à un genre de déviations organiques qui a pour caractère la scission des parois du ventre à leur partie moyenne.

DIASTÉnATOGLOSSIE, subst.f., diastemaloglossia (jixoтnuz, intervalle, yhēeox, langue). Nom donné par Breschet à un genve de déviations organiques qui a pour caractire la scission de la langue en deux moitiés.

DIASTEMATOGNATIIE, s. f. , diastemalognathin (Jixurnjs, intervalle, yuj6os, machoire). Nom donué par Breschet à un genre de déviatious organiques qui a pour earactère la scission des nutichoires sur la lingne médiane.

DIASTËатопитRIE, sulst. f., diastematometria (diacrstse, inter-

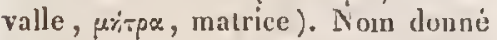
par Breschet à un genıc de dévialions organiques ayaut pour carıctère la scission de la matriec en deux sur la ligne médianc.

DIASTEMATOPYELIE, subst. f. , diastematopyctia (oisernux, intervalle, $\pi \dot{v}=2.05$, bassin ). Noin donné par Breschet à un genre de déviations organiques qui a pour caractère la seission du bassin sur la ligne médiane.

DIASTÉMATORA CIIE, snbst. f, , diastematorachia (Sixrsnus, in!ervalle, ṕźzıs, rachis). Nom douné par Breschet à un geure de déviations organiques, caractérisé par la scission longiludinale de la colnnne épinière.

OIASTEMITORHINIE, sulust. $f$. , diastematorhinia (jizotrus, intervalle, pity, nez). Nom donné par Breschet à un genre de déviations organiques qui a pour caractère la scission du nez sur la ligne médiane. DIASTÉMATOSTAPIIYIE, s. $\int$., diastematostaphylia (Jixrrnus, inter-

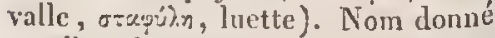
par Bireschet à un genre de déviations organiques, caractérisé par la scission de la lieite.

DLASTÉMATOSTERNIE, sulst. f., diastemalosternia (Jiksonuse, inter-

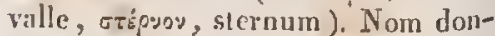
ué par liresehet a un genre de déviations organiques qui a pour caractère la scission longitudinale du sternum.

DIASTlME, s. m. (öizernex, interstice). Nom donué par Balcells aux pores accidentellemcut épars sur la surface du corps, et qu'on peut seulenicnt démontrer par la pénétration des fluides dans les solides; ces pores, qu'il appelle anssi secondaires ou physiques, variant suivant la forme des parties qui composent les corps et la manic̀re dout elles sont ríunies, ne donnent licu qu'ì quelques aetions physiques, et soot peu propres à produire de grandes différences dans les propriétés des eorps.

vIASTkMIE, s. f., diastema; Zahnlïcke (all.) (ồ, en travers, i $\sigma: n u i$, se tenir). Nom donné par llliger ì l'intervalle qui, chez le plus grand nombre des Mammifères, existe entre les dents caunes et les molaires (voyez BarRE) ; par Savigny, dans les Arachnides, à la portion de la tête qui précède immédiatenent le ehaperon, ou vérilable épistomc, et où sont insérées les chéliceres ou forcipules.

DIASTEMENTÉnIE, s. ศ., diastc

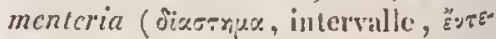
pos, iutestins). Nom donué par Bréschet à un gente de déviations organiques qui a pour caracterc ln seission longitudinale du canal alinentaire.

DIASTROPIILLE, adj, , diastro-

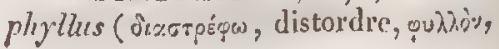


feuille). L'Hypnum diastrophyllum a scs fcuilles élégamment rejetćes vers l'un et l'autre côlé.

DIATOMÉEs, adj. el s. f. pl., Diatomea. Nom donnce par Agardh ì un ordre de la famille des Hydrophytes el par Fries à une famille d'Al gues, ayant pour type le genre Diatoma. QUE.

DiaTomique. Foyez Biatom-

DIATONIQUE, adj. , diatonicus (ois, par, Tóros, ton). On appelle échelle diatonique celle qui n'admet d'autres intervalles que ceux qui marquent les rapports réciproques des huit sons successifs de la ganime. I e nombre des vibrations qui produisent l'ut étant exprimé par s, le ripport entre Jui et celui des vibrations d’où maissent les autres notes est 8 à 9 d'ut à ré, de fa à sol, et de la à si; 9 á ro de ró a mi et de solà $l a ; 15$ à 6 , de mi à fa ct de $s i$ à $u t$. De ces intervalles, qui sout autant de sceondes, les trois premiers et les deux suivans, qui sont 'juax entr'eux, sont appelés tons onliers, et les denx derniers, qui sout à peu près la moilié des autres, sont nommés deni-lons; ou appelle tons majeur's les intervalles 8 ì 9 , et lons mincurs les intervalles 9 it io. Ainsi l'échelle diatonique se compese de cinq tons, dont trois najeurs, dcux mincurs, et de deux deni-tons. I licrecest majetre, quand elle renforme deux tons entiers $\frac{u t}{m i t} \frac{f_{i}}{I_{i}} \frac{\mathrm{sol}}{\mathrm{si}}$, t mincurc quand elle renferme un tou et un demi-ton $\frac{\mathrm{mi}}{\text { sul }} \frac{\mathrm{red}}{\mathrm{iti}} \frac{\mathrm{ka}}{\mathrm{u}}$; la quarte est simple quand ellc est formée de deuxtons et d'un demi-ton tht $\frac{\text { the }}{\text { fa }} \frac{\text { ini }}{\text { sol }} \frac{\text { sol }}{\mathrm{ut}}$, et superfuc, lorsqu'elle renferme trois tons $\frac{\text { ut }}{\text { sol }}$; la quinte se compose de trois tons ct d'un demi-ton $\frac{\text { ut }}{\text { sol }} \frac{\text { ré }}{\mathrm{lat}} \frac{\mathrm{mi}}{\mathrm{si}} \frac{\mathrm{f}_{\mathrm{A}}}{\mathrm{ut}}$; la sixle peut être mineurc, quand clle contient trois tons ef un demi-lon $\frac{\text { mi }}{\text { it: }}$;

I, majeure, lorsqu'elle se compose de quatre tous et d'un demi-ton $\frac{u t}{\mathbf{l}} \frac{\mathrm{red}}{\mathrm{si}}$; la septïme peut être majcurc, si elle conticnt quatre tons et deux demim tons $\frac{\text { nf }}{\text { it }}$, ou mineure, si elle renferme cinq tons et un demi-ton, $\frac{\text { ut }}{\text { si }}$.

DIAZEUXYCES, adj. el s. f. pl., Diazeuxiea. Nom donné par D. Don á une tribu de la famille des Labiatiflores, qui a pour type le genre Diazeuxis.

DHROTHRIDE, adj. , dibothrydus (ôl, deux, fioptor, fossette). Epithéte donnée nux hothryocéplales qui ont derx fosscttes sur les eôtés de la tète.

DHBhaxches, adj. ct s. m. pl. ,

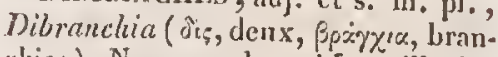
chies). Nom sons lequel Latreille désigne un ordre de la classe des Cirripedes, comprenant ceux dont les branchies consistent cn dcux feuillets.

DICAMUE, adject., dicarpus (dis, deux, ххржоs, finit). Sc dit d'une bulle, lorsqu'elle peut produire dcux liges l'une apress l'autre (ex. Colcliirum). Le Fissillens dicarpos a ses pédoncules ordinairement géminés.

DICARTES, adj. et s. f. pl, $D_{i}$ carpa . Nom domuć par Irailer à une fanille de plintes, dont le fruit se compose d'un double follieule : elle répond ì peu prìs aux Apocynées.

Drchidurie, adject., diceluphus

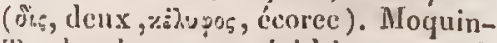
'landon donnc cette épithète au $x$ oufs monstruenx qui ont une donble coquille.

DCriphiLe, adject., dicephalus (dis, deux, xiszì̀, tète). Se dit, d'apres Mirbel, d'une capsule pmvenaul d'un ovaire qui a deux somuncts organiques (ex. Saxifraga). Se dit aussi d'une plante dont la tige se pirtage en deux rameanx terminés chacun par une calathide solitaire (cx. Drosin dicephala). 
DICERATE, adj. , diceralus (őts, deux, xદ́pas, corne); qui a deux eornes, comme l'Isocardia dicerata, dont les somniets très-éeartés se roulent de dedans en dehors.

DKCWRE, adjeet., dieerus (Sis, deux, rźpss, corne). Menke donue cotte ćpithìte aux mollusques gastéropodes qui n'on! que deux tentacules à là tête. Ex. Partula pudiea.

DIClres, adj. et s. m. pl., Dicerala (òis, deux, xépas, eorne). Nom donné par Blainville ì une famille de l'ordre des Paracéphalophores polybranehes, comprenanl ceux qui ont deux tenlacules sur la tête. Qnelques auleurs se sout servis aussi de ce terme pour désigner les insectes, parce que ces animaux n'ont que deux antennes.

DICIITNists, adj. et s. f. pl., Diehanci. Nom donné par Fries à une tribu de l'ordre des Pyrénonycèles sphariacées, qui a pour type le genre Wichena.

DICMOEN'TALE, adj. , dichopela-

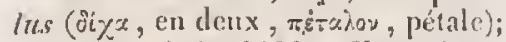
qui a des pétales bifides. Ex. Chailletia dichopelnla.

DICISELYSUPONES, adj. et s.

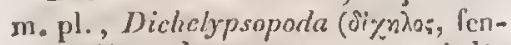

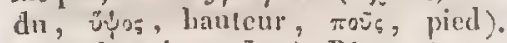
Nom donnć par J.-A. Ritgen à mue famille de l'ordre des Paralimnoptènes, comprenant des oiscuux qui ont les pieds lendus et robustes.

HCCHurs, adj. et s. m. pl, , Di-

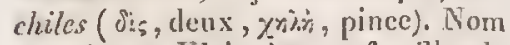
donné par Klein à une famille de Mammifures, comprenant cetux qui ont les pieds garnis de denx sabots.

DICHOGAMEE, s. . , dichogamia ( $0 * \% \%^{x}$, en denx, yxus, noces ). C.-C. Sprengal s'est servi de ce terme pour désigner le mode de féeondation qui a lieu dars les régélaux unisexur's, lorsque leurs fleurs mâles et femelles ne se développent pas en mêne temps; il pense qu'alors les inseetes déter- miient une fécondation artificielle, en opérant le transport du pollen.

DICHOGANI0UE, adj., dichogamicus; qui a le caractere de la dichogamic.

DTCHOPTERE, adj., dichoplerus

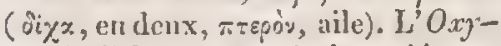
tropis diehoptera est ainsi appelé paree que ses ailus sont échancrées.

DICIOTOMIL, adj., dichotomalis ( Ji $\chi^{2}$, en deux, zíus, couper). Epithèle donnce au pédoncule, quand il naît de l'angyle formé par deux rameaux sur une tige dichotome.

DrCIOTOME;, adj., dicholomus; dizórous; gabelfirmig, zweilhcilig, gabelarigr, gabelspalig, gabchlicilig, gabclïstig, zwcizinkig, zweiselig, gezwveilheilt, zweifuchsetheilt (all.); dicolomo, forculo, forcelluto (it.); qui est coupé en deux. Se dit: $1^{\circ}$ en astronomic, de la Lane, lorsqu'e!le cst coupée par le nilien, e'est-a-dire quand, à l'époqued'un de ses quarticrs, elle parait sons la forme d'um demi-cercle, la ligne des cornes étant, dans toille sa longueur, la limire de la partie lumineusc. $2^{\circ}$ En histoire muturclle, dichotome signifie qui se divise et se subdivise de deux en derx, ou par bifurcation. Il se dir de la eyme (voyez ee mot), quand la fleur est munie de deux bructées, et que les rameanx vout en se bifurquant sans cesse; des fenilles (ex. Coralophylum demersum), de la fronde (ex. Spongodium dichotomum), des pédinncules (ex. Cueubalus Behen), de certaisis polypes (cx. Isis dichotomu), ales poils (cx. Alyssum), des ramonux (cx. Allagopappus dichotomus), du slyle (cx. Cordia), de la tigo (ex. Ramenculus dicholomus, Varronia dicholoma, Phrynium dicholomum).

DICBROÉ, adj., dichruus, dichroos; zweifürbig (all.) (vils, deux, $\chi_{i}^{\circ} 0^{\circ}$, cou!eur); qui est de deux couleurs. Le Joranthies dichroos a des 


\section{DICL}

fleurs pourpres, dont le sommet est vert; 1 'Auricularia dichroa est blanc, avec des papilles rousses; l'H $H^{\prime} d n u m$ dichroum, d'une icinte pâle, avee des dents coulcur de chair; le R,aphria dichroa, jaune, avec le corselet et les antenues noires.

DICHROISME, adj. , dichroismus. Propriété qu'ont certains minéraux trausparens d'offrir unc conlcur différente suivant qu'on les regarde par réflexion ou par réfraction. Ex. Cordiérite, Tourmaline.

DICIrRorte, adject., dichroites. Fithètc donnéc par Beudant aux minéraux qui ne montrent que deux couleurs, n'ayant qu'un seul axe de réfraction.

DICIIRONE, adject. dichronus; ziveyzeitis (all.) (ơs, deux, ypóvos, teups). Epithètedonnéc par Wallroth aux plantes dont la végétation dans nos climats est suspendue pendant une purtie de l'année ct active pendant l'autre.

DICHROOPHTE, s.m., dichroophyrum (dixposs, fourchu, yuro's, plantc). Nom douné par Necker aux plantes dont les anthères sont bifurquées.

DICHnURE, adj., dichrurus (dis, Jeux, xpós, couleur, avjá, queuc). Dont la queue est de deux couleurs, comme celle du Mus diclururts, qui est brune en dessus et blanche en
dessous.

DLCAPODEs, andj. et s. m. pl., Diclapoda (òie, deux, riciw, fermer, тoüs, pied). Nom clonné par Catreille à un ordic de la classe des Crustacés, compreuant ceux dont les deux pieds antéricurs au moins ct les appendies qui les précèdent sont divisés cn deux branches à leur extrémité.

DICLESIE, s. f. , diclcsium (òis,

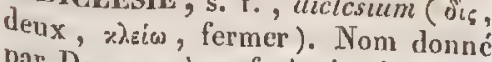
par Desvaux à un fruit simple, conposé de la graine soudée avee la base de la corollc endurcie et persistante. Ex. Mirabilis.

DICr.INE, adj., diclinis, diclinicus (òis, deux, rhim, lit). Se dit d'une planle dont les individus n'ont chacun yu'uu seul sexe, chez laquelle les sexes sont répartis sur des individus differens. Ex. Lychnis diclinis.

DICLNES, adj; et s. f. pl., $D_{i-}$ clince. Nom donné par Link à une tribu de la fanille des Graminées, comprenant celles qui sont diclines.

DICLINE, s. $\int$. , diclinia. Nom collectif sous lequel Linné cmbrassait tuutes les plantes diclines.

DICLINISNE, s. m. , diclinismus. Séparation des denx sexes, dont chacun appartient à un individu distinet.

DICEROEDIRIQUE, adj., diclinocdricus (dis, deux, xhivn, lit, हैofx, hase). Naumanu donne cette épithète à un systcme de cristallisation dans lequel, les plans coordonnćs n'étunt pas perpendiculaires cntr'eux, deux des angles sont aigus ou obtus, lc troisièmc ćtant droit.

MICOLOR. Voyez Bicolor.

DIfONQUF, adj., diconchus (dis, deux, roqxin, coquille). Klein a employé ec mot, comme synonyıne de bivalve, en parlant des coquilles.

DICOQLE, adj., dicoccus; zspciknöpfig (all.) (òis, deux, rórxos, coque). Se dit d'un fruic qui est formé le deux coques accollées l'une contre l'autre par leur côté interne. Ex. Psydrax dicoccos, Bifora dicocía.

DrCotyLfoov, adj., dicotyle-

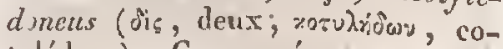
tylćdon). Communément on applique cetle épithète aux embryons qui sont munis de deux cotylćdons, aux plantcs dont la graine contient deux cotylédons. Gándolle appellc embryon dicotylédon celui dont les cotylédons sont opposés, c'est-à-dire situés sur un même plan horizontal. 
DICOTYLEDONí, adj. , dicotyledoneus; qui a deux cotylédons.

DICOTYLEDONES, adj. et s. f. pl. Jussicu et Macleay admettent sous ce nom uue grande division du règne végétal, comprenant les plantes à deux cotylédons, quoirqu'ils y fassent entrer des végétaux qui n'en ont qu'un, d'antres qui en ont plus de deux, et quelques uns qui n'eu ont pas du tout.

DicotyLes, adj. ct s. f. pl., Dicotyles. Link proposc de sulustituer ec mot ì celui de dicotylédons.

DICRANTIÍÉÉ, adj. , dicrantherus (Sixpavos, fourehu, dutunpos, fleuri). L'Arthrostemma dicrantherum est airsi appelí parce qu'il a son connectif alongć en une soie néc de Ia base même.

DICRANOBRANCHES, adj. et s. m. pl., Dicranobranchia (sixpeyos, fourchu, , $\beta$ sxizex, branchies). Nom donné par J.-E. Gray ì un ordre de la sous-classe des "Gistéropodophores cryptobranches, comprenant cenx qui ont les branchies fourehues.

Dicranomeies, alject. et s. f. pl., Dicranoider. Non dounć par Greville, Arnott et Bridel ì une tribu de la farnille des Mousses, ayant pour type le genre Dicranum.

DICruirins, adj. cts. nı. pl., Dicrurina. Nom donné jar Vigors à un groupe d'oiseaux, de la tribu des Laniades, qui a pour type le genre Dicrurus.

DICTAMNíks, adj. et s.f. pl., Dictamnea. Nom donné par Bartling à une tribu de la famille des Diosmées, qui a pour type le genre Diciamnus.

DICTYOCArPE, aij., diclyocat-

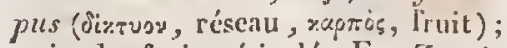
qui a des fruits réticulés. Ex. Zornia dictyocarpa, Delpleinizm dictyocarpum.

DICTYODE, adj., dietyodes (jixsusy, réseau, eidiss, resscmllance); qui a les ailes réticulées. Ex. Tetanocera dictrodes.

DICTYoptìnes, adi. et s. m. pl. : Diclyoplera (ôizusv, réseau,

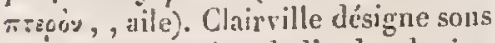
ce nom une seetion de l'ordre des insectes prírophores, comprenant ceux qui ont les ailes réticulées, ou les Névroptères.

DICTYOHHzE, adj., dictyorhi-

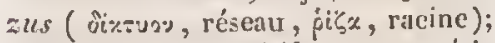
qui a des racines rétiformes our réticulées. Ex. Agraricus dictyorhizus.

DiCTrotís, adj. et s. f. pl., Dictyotece. Nour donnć par Reichenliach a une tribu de la famille des Fucoidées, par R.-K. Greville à un ordre de celle des Algues, par Lamouronx à uึı ordre de celle des Thalassiophyles symphysistées, ayant pour type le genre Dietyola.

DIDICTriL, adj., didactylus; zweizchig (all.) ( vis, denx, ç̇yruion, (loigt); qui n'il que deux doigts, comne l'Autruche, parmi les ciscaux, ou le Sircne didaclylum, parmi les reptiles. Le P'cropliostus didaclylus a ses aliles snpérieures divisíes en denx parties ou doigts. La Grilloıalpa diclacty la ue porte que deux dents à ses jambesantérieures. Ceriaines arachnides ont des mandibules didactyles, c'est-ì-dire composées de plusicurs articles, dont le deruicr e.t moluic en forme d'onglet, et je précédent se prolonge aussi en une dent plus ou moins torte, de manière quue la mandibulc représente une espice de pince.

DIDACTILES, adj. cts. n. pl., $D i$ dacıyli.Nom donné par Klein à une famile de Manmifèrcs, dans lacquelle il range ceux qui ont denx doigts ì chaque pied.

DIDÉCAEDRE, adj. , didecacdrus

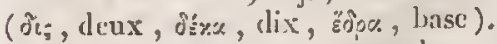
Nom donué, daus la nomenclaturc minérnlogique de haüy, à unc varićlé dout les faces oftrent, par lcur cnsemble, la combinaison de denx 
solides à dix faces. Ex. Feldspath didécaèdre.

DIDELPIIEs, adj. et s. m. pl., Didclplii (dis, deux, jeiţus, mitrice). Blainville désigne sous ee nom une sons-classe, et Tiedemann un ordre de la elasse des Mammiferres, comprenant eeux qui ont nu rlouble utérus, c'est-à-dire au dehors une sorte de poche abdomiuale servant ì recevoir les petits, qui naissent étant encore ì l'état d'embryon.

DIDELPUINES, adj. et s. m. pl., Widclphille. Nom donné par J.-E. Gray ì la fimille des Didclphes.

DIDIPLAST, adj., didiplasus (ois,

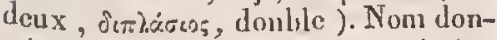
ué, daus la nomenclature minéralogique de llatiy, ì une varióté de chaux carbonatée, romposce de deux rhomboïdes dans lesquels, la perpendiculaire sur l'axe élant supposcé égale de part et d'autre, le rapport entre les axes est rehii de un it deux, et de deuxdodécaèdres ì trinngles sealènes, dans lestucls les partics de l'axe qui exeèdent celui da noyau ont entr'elles le uneme rapport.

DIDODFCALDLE, adj. et s. m.

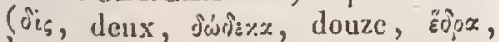
hase). Non douuć, daus la nomenclature uinúralogique de Ilaiiy, ì une viriété dont la surface est composée de vingt-quatre faces qui, pris:s donze ì donze et prolongées par la penséc, formeraient deux dodécaëdres diférens. Ix. Claux carbonatće didodécaëdrc.

DDVME, adj., didymus; jiòp.o ; zuciköp/ig (all.). Se dit d'une pirtie yui est composée de deux lobes arrondis, réunis par un seul point, et qui pirait ainsi forméc de deux segmens distirels, comme les antheres du Spinacia olcruceu, le fruit du Biscutella didyma et du Centhium didymun, les tubercules de l'Orchis militaris; ou d'une partic qui est partagée en deux, comme les aréoles de l'aile le sont par une nervure dans le Cyclostoma. Le Monarda didyma est ainsi appelé, parec que ses fleurs ont souvent une seconde paire d'étamines stériles; le Botrytis didjma, paree que ses sporules sont eloisounces. Nees d'Esenbeck donne l'épithète do didymes anx lames des agaries, lorsque, de claque côté d'unc lame entière, s'eıl lıouve une qui ne s'étend que jusqu'à la moitié de la largeur du chapeatu.

DroYuocanpe, adj., didymo-

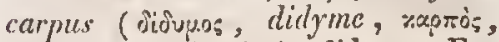
(ruit); qui a des (ruits didymes. Ex. Ronabea didymocarpos.

InovMOcanelies, adj. et s. f. pl. , Didymocarpce. Nom donné par D. Dou is la famille des Cyrtandracées, ì cause du genre Didymocarpus, qu'elle renferme.

DIDYNIME, alject., didynamus; stvcimiiclutig ( all.) ( ois, deux,

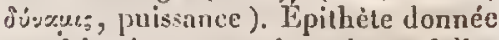
par Liméc aux ćtamincs, lorsqu'elles sont au nombre de quatre, dont deux plus longues scmblent dominer les autres. Fx. Rosmarints.

i) Iinunis, s. f., didynamia. Nom d'une classe, dans le système sexuel de Linné, qui renferme les pliules ì ćlamiues didyames.

DID YNANHQU:, adj., didynamicus. Se dit d'une plante ou d'une flerr à ćlamines didynames.

DIDVNAMSTE, idjret., didynamista. Synonyme de didynamicque.

vHCGASITE, adject., dieclasite. (dit , denx, है\% domne, dans la nomenclature minéralogique de Haiiiy, à une variélé qui résufte de denx déeroissemens sur un unêne bord ou sur un même angle, l'un en largeur, l'antre on hanteur. Ex. Chance cerbonatice dicctasitic.

DEETEAEDRE, adj., diennca-

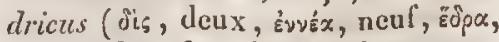
base). Nom donuć, dans la nomenclaturce minérạlogique de Haïy, à 
un eristal terminé par dix-huit faces, qui sont silućes neuf a nenf vers ehaque sommet. Ex. Chaux carbonatée diennéaëdre.

DIÉRÉSHLE, subst. f., dieresilis (ócupéar, diviser). Mirlsel appelle ainsi un fruil capsulaire sec el régulier, formé de plusienrs loges rangées autour d'in axc et produites par les valves rentrantes. Ex. Galium verum.

DIÉnEsTLuen, adj., dieresilizes, dieresileus. Épilhète donn néc par. Mirbel aux fruits simples qui, a lenr maturité, se divisent en un plus ou moins grand nombre de graincs; aux capsules dont les loges, formées par des valves rentrantes, se partagent à la maturité en plusieurs boites onvertes intéricurement, qui ne diffèrent des coques de diérésile qu'en ce qu'clles ne se séparent pas complètement après la débiscence. Ex. Linum pererne.

DIFFLULis, adject, ct s. m. pl., Diffucentes. Nom dounć par Nres d'Lisenlicek à une division de la trilin des champignous Aérogistres sporom mestes, eomprenant ccux qui se résolvent on mucus peu de temps après leur apparition.

DIFFLdENT, adj., diffuens. Se dit des choses qui se confondent nsemblc. Les ćloiles de l'Astrea diffluens sont diffluentes, e'est-à-dire se confondent entre elles.

DWFORBE, adj. , difformis, deformis ; astdrs; ; ungestallet, unfïrmlich, ïbelgebildel (all.); deforme (ii.). Sc dit d'un corps organisé qui présente une forme générale hizarre, conume la graminćc appelée Chaetospora deformis, ou d'une partie qui n'a pas la forme et les proportions qu'elle devrail avoir, comme les antheres du Justicia hyssopifolia, dont la figure est singuliere, ou cornme les pétales de l'Epimedium, dont la forme irrégulière ne peut ctre com-

\section{DIGEे}

paréc à aucunc de celles qu'on connaît.

DIFEORMES, adj. cl s. m.pl., Difformes. Nom dounć par Duméril à une famille de l'ordre des Orthoptc̀res, comprenant ceux de ces insectes qui se fout remarquer par la bizarrerie de lenrs formes.

DHFHACTE, adi., diffraetives (diffringo, briser). Eipithète donnće à toute action dout le résultat est de produire le phénoniene de la diffraction.

DIFFACTION, s. f., diffraetio. Plićnomène, découvert par Grimaldi, qui consiste dans les inflexions que les rayons lumineux épronvent lorsqu'eu passant près des extrénités des corps, ils s'écartent de Jeur route directe.

DIFIES, adj. , diffusus. On donne cclle épithèle ì ec qui manque de coliérence (idées diffuses), de précision (sty/e diffus), de neltcté (objets diffus), et, cu botanique, aux parties qui sout ćtalées lıorizontalement, suns direction fixe, commc lez rameaux du Crpertus diffusus, du Threlkeldia diffusa et de l'Alyssum diffusum. H. Cassini l'applique aux squames du périclinc des synanthérees, lorsqu'ćlant sur plusieurs rangs, elles sont à peu près égules en longricur ou irrégulièrencut inégalcs.

MFLORIGERE, adj. , diflorigerus (òts, deux, flos, fleur, gero, porter); qui porte deux flenrs. $V$. Biflore, Diantue.

DIGAME, adject., digamtzs ( $\delta^{\circ} ;$, deux, ๆxises, noce). Nom donné par H. Cassini à la calathide des synanthérćes, quand elle contient deux sortes de fleurs de sexc différent. Ex. Aster chinensis.

DIGÈvE, adject., digenus (òį, dcux, $\gamma^{\prime}$ yos, race). Lestibondois propose d'appeler ainsi les plantes dicotylédones, parce qu'elles ont denx surfaces d'aceroissenent. 
DIGĹvis, s. f., digenia, generalio digenea; paarige Zeugung, geschlechlliche Zeugung (all.). Nom sous lequel Burdach désigne la géuération qui s'effeetue par le concours de deux sexes.

DIGESTEUR, s. m., ou machine de Papin, Olla Papiniana. Gylindre de fer dont le couverelc est fortement vissé, ec qui pernet de faire rongir les liquides qu'on y renferme, sans qu'ils se volitilisent.

DIGESTION, s. f. , digestio ; ùv'-

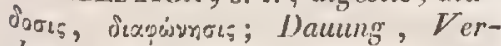
daureng (all.). Općrstion par larjuclle on expose un corps liquide a l'action d'une douce chalcur pendant un laps de temps plus ou moins long. Série d'actions qui s'exécutent dans l'intéricur du corps d'un tres-grand nonbre d'animaux, et qui ont pour but de séparer, d'assimiler et d'absorber les parties des alimens capables de servir à l'entretien des organcs, à leur accroissement, à la réparation de leurs pertes.

DIGITAL, adject. , digitalis. Une méduse (Mclicerla digilalis) est ainsi appeléc parce que son estomác libre et pendant se prolonge en un pédoncule garni d'une multitude de bras.

Digitaluomin, adject. , digritaliformis (digilus, doigt, forma, forme); qui a la forme d'un dé à coudre ou d'unc cloche alongéc, à bords droits, comme le champignon appelé Verpa digitaliformis.

DIGITALINE, adject., diggitalina. Aleali organique qui a été découvert par Leroyer dans les fcuilles du Disitalis purpurea.

Digitalroue, adj., digitalieus. Epithète que portent, dans la nomenclature chimique de Berzelius, les sels à base de digitaline.

DIGIT⿱⺊一 ròs ; fingerförmig (all.); dilato (it.). Se dit : I ${ }^{0}$ en botanique, d'un épi qui est divisé jusqu'à la base en plu- sicurs rameaux simples (ex. Carex digilata) ; d'unc fronde qui est découpée en plusienrs lames (ex. Laminaria digilala); d'unc fcuille composée, dont le pétiole commun porte des folioles qui la terminent comme autant de cligitations, au lieu d'ètre disposées sur ses deux eôtés (ex. Asseulus) : d'une racine tubéreuse qui est divisée profondément en lohes eomparables à des doigts (ex. Dioscorca aliernifolia). $2^{\circ} \mathrm{En}$ zoologie, desailes des insectes, quand leur bord présente des incisions profondes, et qu'il résulte de là des espèces de lanières figurant les doigts de la main (ex. Pterophorus); du cubious de ces unimaux, d'après Kirby, lorsque sou extrémitć est divisće en plusieur's longues dents (ex. Gryllolalpa); d'une coquille univalve, quand son bord droit est garni de longs appendices (ex. P'terocerus).

DIGITÉ-PENNÉ, adj. , digitalopennatus. Se dit d'une feuillo dont le pútiolc counun est terminé par des pétioles secondaires sur lesquels des folioles sont attachées. Ex. Mimosa purpurca.

DrGitús, adj. et s. m. pl., Digilali. Nom donné par Blumenbach à un ordre de la classe des Mammilères, comprenant ceux qui ont les doigls libres aux quatre pieds.

DIG ITYFonIE, adj. , digitifolius; fingerblaturig (all.); qui a des feuilles digitées. Fx. Valcriana triphyllos.

DIGrTrronve, adj., digitiformis; fingerförmig (all.) (digitus, doight, forma, forme); qui a la forme d'un doigt, comme les épines de certains oursins et les feuilles du Mesembryanthemum digitiforme; ou qui a des feuilles digitées, comme l'Hibiseus digiliformis.

DIGITIGRADES, adj, et s.m.pl., Digitigrades (cligitus, doigt, gradior, marcher). Nom donné par Storr, Cuvier, Desmarest, Duméril, Tie- 
demann, Blainville, Latreille, Ficidus et Carus à une famille ou tribu de Mamaifères, comprenant ecux qui marelient sur le bout des doigts.

DrGITINERví, adj., digitinervis, digitinersius (digitus, doigt, ncrous, nerf). Sa dit d'une feuille dont les nervures partent toutes de la base et se dirigent vers le sommet, sans éprouver de division. Ex. Graninées.

DIGONE, adj., diyones (Diti, deux, javic, angle); qui a deux angles. Ex. Tercliratula digrona.

DIGYNE, adj., digynus; zuciveibig, zweigrifflirh (all.) (fis, diux, guyr, femme). Fipillide douné ì une fleur qui a deux pistils distiucts, ou un style surmonlé de deux stigmates, ou mêne denx stigmattes séssiles. Ex. Rumex digynus, Halorigis digyna.

DIGLNE, s. f. , digynia. Nom donné par Liuné à un ordre de cinit classes du systène sexuel, compremint des plautes qui ont di'ux pistils; par Malaearne, à une elasse de unns. tres, ayant pour caractère la présentee dn sexe féminin donble clı:z un individu.

DIIEPTAPOHES, adj. et s. In. pl. , Diheptapoda (ois, deux, $\dot{\varepsilon} \pi+\dot{\delta}$, $\mathrm{sej}_{\mathrm{j}} \mathrm{t}$, той, pierl ). Satreille propnse de substituer ce nom i celui de T'itradécapodes iutroduit par Blainville.

DHEXAEDHE, idj., dibexaed'\%s

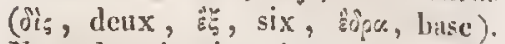
Nom donné, dan; la nomencluture minéralogique de Haiiy, it un cristal ayant douze faces qui, prises six à six, et prolongées jusqu'is se réunir , donneraient deux solides hexiëkires. Ex. Cliaux earbonatíc dilicxaëdre.

DIIYDnIQue, adj. , dihjodrieus. Se dit, dans la nomenelature ehimi-que de Berzelius, d'un composé contenant denx fois autant d'lyylrogèiac qu'un autre du même geure. "Ex. Carbure dilydrique, ou gaz liydrogène deulocarboné.
Dilatabilití, s. f., dilatabilitas; Delinbarlicit (all.). Proprićté qu'ont les corps de elanger de volume par l'influence de la chalenr, de s'agrandir quand on les ehauffe, dese resserrer lorsqu'on les refroidit, et de revenir exaclement aux mêmes dimensions quaud on les ramène prícisément au unème degré de chaud ou de froil.

DLLATATION, s. f., dilatatio;

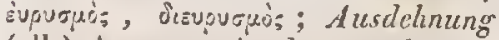
(all.). Augmentaliondans tous les sens qu'éprouvent, sinus changer de constitution, les corps soumis à l'action de la chaleur. Il a été reconnm cqu’à charjue degré de thermotnetre de Réaunur, le fír se dilate denviron $1 / 75,000$ dans clacure de ses dimensions, le cuivre de $1 / 4,3,000$, le platine de $1 / 92,000$, le verre de $1 / 1,000,000$. Quant aux gaz, leur dilitation est de $1 / 213,33 \mathrm{du}$ volume, pour claque degré de chaleur.

DHLAT́́, arli., dilatatus; ausgebrcitet (all.). Se dit : $1^{\circ}$ en minćralogic, d'un dodicaëdre dans lequel les bases des pentagones extrêmes éprouvent une sorte de dilatation, par suite de l'inclinaison des faees latérales (ex. Chraux carbonatée dila$\left(c^{c} e\right)$, ou d'un prisme qui, cn conséquence d'un défaut de parallélisme dans deux de ses pins opposis, semble subir nie dilatation (cx. Arragonite dilatéc); $2^{\circ}$ en botanique, d'unc partie qui s'élargit en lame, de la base vers le sonumet, comme le filet des étamines de l'Ornillogalum pyrenaicum, la grorge de la eorolle du Mrirabilis Jalapa, le stigmate de l'Orobanche minor ; $3^{\circ}$ en zonlogic, du corselet des iasectes, quand ses bords latéraux sont grands et avaneés, comme dans queleques cigales.

Dilaticonxi, adj., dilaticornis (dilalalus, dilitté, cormu, corne); qui a des antennes dilatées dans une portion de leur éleudue, comme le sont 
au milicu de leur longueur eclles du Malachius dilaticornis.

DILATRIDEES, adj. et s. f. pl., Dilatridea. Nom donné par Jussicu. à la famille des Homodoracées, a cause du genré Dilatris qu'elle renferıne.

DILÉPIDE, adject., dilcpidus (ois, deux, גerris, ćeaille); qui a denx ćailles.

DHLÉnLCÉEs, adj. et s. f. pl., Dilleniacea. Famille de plantes, qui a pour type le gene Dillenia.

DILLÉNWÉs, adj. et s. f. pl., Dillenica. Non donné par Candolle à une tribu de la famille des Dilléniacées, gui renferme le grenre Dillenia.

DILOPuE, adj., dilophus ( $\delta \mathrm{i} s$, deux, jópqs,aigrette). Fipithètc donnée à un oiscau qui a la tête conrounce pir une double huppe rerticalc (ex. Columba dilopha), ou par deux touffes de plumes, l'une sur le synciput, l'antre sur l'occiput (cx. Iydrocorax silophins).

Decuvial, adj. , clilewialis. SynoIyme peu usité de diluvien.

DLuvueN, adj., diluvianus. Lrs féognostes appelleut dépót diluvial ou diluvien un dépôt fort irrégulier de sable, d'ar'gile, de gravier à gros desins, dout la formation est dive a des conrans considéraliles produits par des causes qui nous sont inconnues. Brongniart et Onalius donnent cette épithètc à unc classe ou ì un groupc de terrains, comprenant cux qui sont dus, pour lis plus Srinde partie, à la catistrophe désirnce sous le nom de eléluge dans les (Bonumens historiques. Un polypier parce fossile. DILUviuar, s. m., diluvium. Bucrésultats comprend sous ce nom tous les 'Tu'il suppose d'une inondation marine tt it laquelle on ne saurait uémmoins comparer aucune de celles qui sont arrivécs dims les temps historiques, tant sous le rapport de l'étendue, que sous rclui de la variété.

DIMùre, adj., limeruss (ois, deux, unpos, partie). Kirby donne celle épithète aux insectes dont le trone est eomposé de deux grands segmens. Ex. Coléoptc̀res.

Dnúmé, adj., dimerus. Dumćril, Latreille et Eichwald admettent sous ec nom une section de l'ordre des Coléoptères, comprenaut ceux qui u’ont que deux artieles à tous les tarses, ou plutoot qui sembieut n'en avoir que deux, ear llliger et Reichenlach ont reconnu que celte division du tarse en denx articles n'est qu'apparente, relui qui se tronve le plus près de la jambe étant si petit qu'on a de la peine à le distinguer.

DMuirtibis; adj. et s. m. pl., Dimeredes (jiç, denx, unpóe, partie ). Nona donné par Duméril í une famille de Poissons loolobranches, conprenant ceux qui ont plusieurs rayons flexilles distinets aux nagcoires pectorales.

Dnúrné, adj., climerius. Bredsdorfi nomme aiusi les minéraux composés dans lesquels les principes constituans positifs et négatifs sont simples.

DINEROSOMATES, adj. et $\mathrm{s} . \mathrm{m}$. pl. , Dimerosomata (ois, deux, $\mu \cdot n-$ pós, partie, aw̃ux, corps). Non donné par Leach à un ordre de la classe des Arachuides, conprenant ccux qui ont le corps divisé en deux grands segrneus.

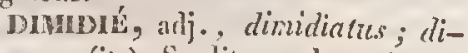
mezsato (it.). Se dit, en botanique, d'un organe qui a perdi la moitié de ec qui le constitue ailleurs, de sorle que le mot renilatéral a la mûme siguification et scrait préférable ; chapeare dimidiué, dans les champignons, celui dont il ne se développe que lia moitié (ex. Agraricus odoram 
tus); couronnc dimidiée, dans les Synanthérées, d'après H. Cassini, celle qui n'occupe qu'un seul côlé de la calathide; involucre dimidić, celui qui n'entoure le pédoncule qu'à moitić (cx. Apium Petroselinum) ; verticille dimidié, celui dans lequel les fleurs n'enlourent qu'à moilić l'axe qui les porte (ex. Humcx acelosa).

DrMonPr: adj., dimorphus; zweiförmign, versehicdengestaltig, zweigestaltig, doppeltgestalige (all.) (Sis, deux, uocen, forme). Se dit. en minćralogie, d’une substance qui pent donner des cristaux appartenaut à deux systemes différens (comune le Spath d'Islande et l'Arragonitc), ou apparlenant à un même système, mais avec de telles différcnces d'angles, qu’on ne saurait les dériver d'unc forme fondamentale conmune (ex. Oxide de lithium). En bolanique, de loute partie qui offre des formes diflérentes dans une nême plante: ainsi Bidel appelle les mous ses dimorplies, pirse qu'elles ont deux modes d'inflorescence, les urnes ct les roselles.

DIMORRHLSU, s. m., dimorphismus. Phénomènc qui caractérise les substances dimorphes.

DHM⿻上丨E, adj. , dimyarius (ďi, deux, uviss, muscle). Epithète donnée par Lamarck aux coquilles bivalves qui ont deux impressions nusculaires sur hague valve. Ex. Tenus.

DIMYAInLS, adj. et s. in. pl., Dimyaria. Noon donné par Lamark à un ordre de la classe des Conchilires, comprenanl ceux qui onldeux museles d'at tache, et dont la coquille ofre distinctement deux impressions nuuseulaires séparées et latćrales.

DHVYES, adj. et s. m. pl., Dimya (Jis, deux, puc̀, musele). Nom donné par Merike à un sous-ordre de l'ordre des Elntobranches Ostracés, comprenant ceux quiont deux impressions musculaires sur leur coquille.
DINEME: adj., dinemus (dis , deux, ขร̄us, fil). Une Mćduse (Occania dincma) est ainsi appelée parce qu'elle a quatro bras, deux de ebaque côté du corjus.

DIOCTAEDRE, adj., dioctaedri-

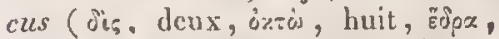
basc). Se dit, dans la nomenclature minćrnlogique de Ifaüy, d'un cristal qui offre, dans l'ensemble de ses faces, la combinaison de deux octaëdres différens. Ex. Prroxine diociaëdre.

DIOCTONAL, adj., dioctonalis. Nom donné, dans la nomenclature minćrnlogique de Haüy, ì un cristal offrant, dans l'ensemble de ses faces, la combinaison d'un oclaëdrc avee un solide qui a pareillement huit faces, mais dout la forme est d'espéec différcnte, telle que celle d'uu prismc. Ex. Cuivrc carbonaté bleu dioctonal.

DIODONCÉPIIALE, adj. et s. m. diodoncephalus ( $\mathrm{Si}_{5}$, deux,

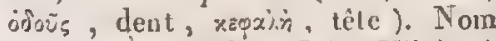
donné par Geoffroy Saint-Hilaire it une classc de Monstres, comprenant ccux qui offent unc double rangéc de dents.

DIOECIİ, s. f., dioecia (dits, deux, oixix, maison). Nom douné par Linné, dans son système sexuel, à une classe et à un ordre de plantes, comprenant celles qui ont des fleurs uniscxuelles, mâles sur un individu et feniclles sur un autrc. La dioécie pent aroir licu de dix-huit manières différentes, dont la rature parait n’avoir réalisé que le plus petit nombre.

MIOIOUE, adj., dioǐcus; zueihäusig, getrenntblumig (all.). Se dit d'une plante dont les sexes sont séparés sur des iudividus différens. Ex. Urtica dioüca, Diosma dioücum.

DIOIQUES, adj. et s. m. pl., Diö̌ca. Nom donné par Latreille ì une section de la classc des Céphalopodes, par Blainville ì unc sousclasse de celle des Paraçéphalophores, 
comprenant ceux de ces animanx qui ont les sexes distinets, porlés par des individos différens.

DIOMÉDÉEs, adj. et s.f. pl., Diomedec. Nom donué par Lessing à unc scction de la sons-tribn des Astéröidécs Ecliptćes, qui a poor type le genre Dioncdea.

Dropinrs, adj. , dioplerys (òis, deux, óppis, sourcil). La Sylvia diophrys est ainsi appelćc paree qo'clle a les ycux placés cntre deux traits noirs.

Drors, adj., ciiops (oits, dcux, wi, ocil); qui a deux yeox. Le Muscicapa diops doit ce nom à une tache blanche qu'il porte au devaut de chaquie ail.

DIORTuQQue, adj., dioptricus;

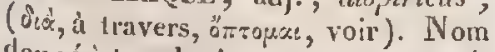
donné à tous les iustrumens composćs de verres gui grossissent ou rapetissent les objets qo'ou regarde a traVers. Gœthe donuc cette épithètc au $\mathrm{x}$ couleurs qui sont produites par la réfraction de la lumière.

Dioptrique, s. f., dioptrica, dioptrice. Partie de la physique qui traitc de la lumière refractée, des phénomenes qu'elle produit en Iritversant des milieux de densité différeute.

DIORITQUE, adj., dioriticus; qui conticnt du diorite. Ex. Porphyre dioritique.

DIoscortís, adj. ct s. f. pl., Dioscorece. Nom donné par R. Brown a une fimille de plantes qui a pour type le genre Dioscorca. Reichenbach a établi sous ce nom un groupe daus celle des Liliacées.

DIOSCOmwies, adj. ct s. f. pl., Dioscorina. Kunth appelle ainsi la famille des Dioscorées. DIOSMćes, adj. et s. f. pl., Dios-
mea. Nom donné par Bartling, Wendland, Candolic, A. Jossien et $\Lambda$. Rifamille des Rutacées, qui a pour type
Ie genre Diosma, et que R. Brown a érigce en famille.

mosmuxe, s.f., diosmina. Brandes désigne ainsi unc substanec amere qui paraît êtrc le principe actif des ferilles du Diosma crenata.

DLOSzynécs, adj. et s. fém. pl., Diospyreas. Nom donné par Callin a la faunille des Ebćnacées, en raison du gente Disspyros qu'clle renferme.

nutmonTH, adj., diperianthus (ois, deux, $\pi$ soi, autour, "̈.0os, fleur). Marquis doune ce rom, déjà comployé par Wachendorf, aux plantes dicotylédones qui sont pourvues de deux enveloppes florales distiucles.

DIPLTALE, adjret., dipctalus;

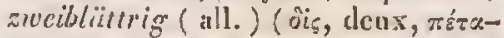
hov, pétale). Se dit de lit corolle, quand elle est formée de deux pétaies (ex. Pelargonium dipetalum), et de la carène, lorsqur les deux pítales qui la forment sont libres dans toute leur longuenr.

IMPYYDUS, adj. it s. nı. pl., $D i$ phyelcs. Nom donnć par Qnoy, Gaimard et Blanville à une famille de Zoophytes, comprenant ceux dont le corps est composé de deux parties transparentes, siluées a la soite l'une de l'aulre, comme dans les Diphyes.

DIPHYDLES, adj. ets. C.pl., $D i$ plyidex. Noun donné par F. Eschenholız ì unc fanille d'Acalèptes, ayant pour type le genre Diphye.

DIPHX LLE, adj., diphyllus; $\approx$ ivej"blïtrig (all.); bifillo (it.) (Jis, deux, yujtiov, feuille); qui est composé de deux fenilles ou picees, comme la spalhe de l'Allium carinatum et le ealice des Papaver, ou qui ne porte que dcox feuilles, commc lis bulbe dn Chiloglottis diphylla, et la tige do Deniaria diphylla. On appelle diphylles les fouilles composées dont le pétiole commun ne porte que deux folioles (ex. Cassia diphylla, Hedjsarum dipleyllum), ou celles 
qui sont profondément divisées au sommet en deux lobes ( ex. Jcffersonia diphylla). Voyez Burouí.

DIPIYLLOBnaNCHES, adj. et s. m. pl., Diphyllobranchia (dis, deux,

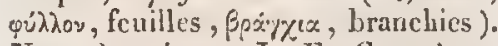
Nom donné par J.-E. Gray à un ordre de la classe des Mollusques saceophores, correspondant aux Biphores de Cuvier.

DIPHISLS. Vorez Dinnytes,

DIPIXTANTHE, adj., diplytanthus ( $\delta i_{5}$, deux, putò, plante, Q⿻, $00_{5}$, "fleur) ; qui porte des flemrs diff rentes sur des pieds divers. Synonyme de dioïque, dont s'est servi Wachendorft?

DIPHYTus, s. f., Diployla ( deux, yutóy, plante). Nom donné par Bory à une section de la fanille des Chaodinécs, comprenant eclles dans lesquelles il semble y avoir deux existences végétales distinctes, des filamens prineipaux el des ramules de formes ties-différentes, dont les prolongemens eiliformes séerètent du muens.

DIPLĆcolobéEs, adj. , dipleco-

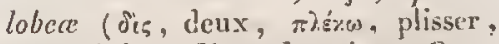
inpiós, lobe). Nom donné par Candolle à un ordre de la clissse des Crucifères, comprenaut celles dont les cotylédons sont pliés deux fois cu travers.

DIPLEUROBRANCHCS, adj, et s. m. pl., Dipleurobranclia (jis, deux,

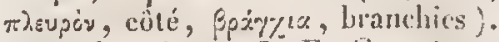
Nom domé par J.-E. Gray à un ordre de la elasse des Gastéropodnphores cryptoliranches, qui correspond aux pleurobranches de Cuvier.

DIPLOCEDILLIE, s. f. , diploce

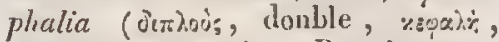
tête ). Nom donné par Bresehet à un genre de déviation orranique qui est caractérisé par la présence de deux têtes sur un mêrne eorps.

DIPLOGASTRLE, s. f. , diplogastria ( $\delta$ itroois, double, yrotip, ven-

\section{DIPL}

tre). Nom donné par Breschet à un. genre de déviations organiques qui est caractérisé par la présence de deux trones implantís sur un même bassiu.

IIPLOGEvi:EN, adj, diplogenezs

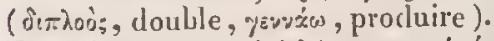
Fries donne eette épithète aux végétaux qui sont produits par des filamens et eonstitués par des cellules régulierenent unies.

DIPLOGÉNE'SE, s. f., diplogene-

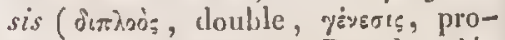
duction). Sous ce nom Bresehet désimne un genre de déviations organiques qui est caractérisć par la réunion de lenx ou plusirurs germes.

DIPLORÉPAILES, adj. et s. m. pl., Diploleparia. Nom donné par Iamarek it unc fanille de l'ordre des Hyménoptères, par Goldfuss à une trilua de la fanille des Tehneumonidles, aysut pour type le genre $\mathrm{Di}^{-}$ plolepis.

Diplodipides, adject. et s. m. pl., Diplolepidre. Lench désigne la fanilie des Diplolépaires sous ectle dénonination.

DIPLONEURES, adj. et s. m. pl., Diploncura ( nerf). Nom donné par Rudolphi á une scclion de la série des animaux planćroncures, comprenant ceux qui ont deux systènes nerveux, l'um ganghliounaire, l'autre cérćbro-rachidien, et eorrespondant aux vertíbris.

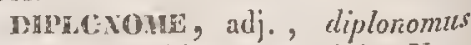
(ótrioje, double, yơos, loi). Nom donné, dans la nomenclature ninéralogique de Haity, it une variété dans laquelle ehacun des angles subit deux déeroissemens, tandis que chaque bord n'en sulit qu'un seul, on réciproquement. Ex. Baryle sulfatéc diplonome.

DIPLOPĹRISTONATES, adject. el s. m. pl., Diploperistomali (óm double, $\pi \varepsilon_{i} i$, autour, $\sigma \approx \dot{q u} x$, bouche). 
Nom sous lequel Bridel désigne une elasse de Mousses, comprenant celies qui ont le péristome doulıle.

DIPLOPÍRSTONús, adj. et s. f. pl., Diploperistomii. Fedwig appelait ainsi les mousses dont l'orifice de l'urne est garni de dents en dehor's el de eils en derlans.

MipLOpogones, adj. ct s. f. pl. ,

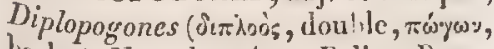
barbe). Nom domné par Palisot-l'euuvois à un ordıe de Mousses, eomprenant cell's qui ont un double péristome.

DIPLOPTL̀n, adj., diplopterus

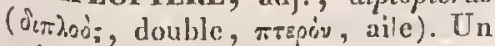
poisson (Callianira diploptera) est घinsi nommé parce que soll corps offre de chaque eôté une aile membraneuse partagée en doux folioles.

DIPLOPTLYIES, adj. et s. m. pl., Diploptera. Nom donné par Cuvier, Jatreille et Eichwald is une famille de l'ordre des Hyménoptìres, renfermant eeux de ces insectes qui ont les ailes supéricures plićes dans le sens de leur longucur, pendant le repos.

DIPLOSANTminies, adj. et s. f.

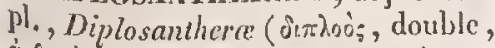
arrpose, fleuri). Nom douné par Rinyen à une elasse de plantes, daus laquelle il range celles qui ont des étamines en nombre double de celui les divisions de la corolle.

DIPLOSTÉnones, adj. et s.f. pl., Diplostemones (jitodon, double, Torusy, filment). Nom donné par Wachendorlf el Uiller nux planies dans lesquelles les étaurines sont en nombre double de celui des divisions de la corolle.

DIPLOSTVManopútALES, adj. et s. f. pl., Diplostemonopetala (ji-

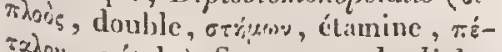
salov, péiale). Synonyme de diploslemones, dont s'est servi Wachen-
dorff.

DIPLoríge, s. m., diplotegis, diplolegia, diplotegium (detrioos,

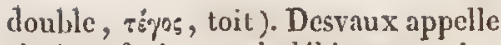
ainsi un fruit sce, indéhiscent et infère ou engagé dans lc caliee. Ex. Campanula.

DiPNBunONLEs, adj. et s. f. pl.,

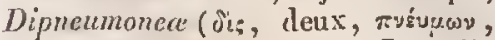
poumon). Nour donué par Latreille et Eichwald à une section ou tribu de la fianille des $\Lambda$ ranéides, comprenant celles qui n'ont que deux sacs pulmonaires.

DrpNoĹs, adject. et s. m. pl., Dipnoa (ồ, deux, тv'́w, respirer). Nom donué par P.-F. Fitzinger à une division de la elasse des reptiles, coinpreuant ceux qui respirent par des branchies et des poumons en mème temps, soit seulement dans l'élat imparfait, chez eeux qui subissent une mélamorphose, soit pendant toute la vie, chez ceux qui n'en subissent pas.

DIPODEs, adj. et s. m. pl., Di-

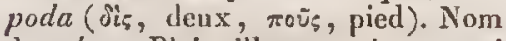
donné par Blainville aux poissons qui n'ont que deux meinhres, par lui et par Latreille à une famille de la elasse des reptiles, comprenant ceux qui n'ont que deux palles sculement.

DIPOLY COTYLÉDONi, adj., dipolycolyledoneus ( $\mathrm{d} \mathrm{i}_{5}$, deux, molus, beaucoup, rotuhziò, eolylédon). Quelques bolanistes ont proposé d'uppeler ainsi les végétaux qui ont deux eotylédons multilides.

DHOPOBRAvCnes, adj. et s.m. pl., Diporobranchia (dis, deux, rópos,

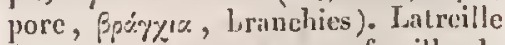
désiunco sous ec nom une famille de l'ordredes Ichthyolieres suecurs, Ficinus et Carus une famille de l'ordre des Cyclostones, comprenant ecux dout les branchies s'onvrent à l'extéricur par deux trcus, un dle chaque côté. mriosores, adj. et s. m. pi, Diprosopa (dis, deux, тровотх́ш, regarder). Nom donné par I atreille ì une famille de l'ordre des Subbram chicus, par Ficiuus et Carus a une 
famille de eelle des Sternoptérygiens: comprenant des poissons qui ont les deux yeux d'un seul côté.

DIPноTOPHLEE, adj. , diprotophyllatıs. Épithète, synonyure de dicotylídon, que Turpin emploie pour désigner les végétaux appendiculés qui ont des embryons pourvus de deux, de trois, de quatre ou d'un plus grand nombre de fenilles opposćes on verticillées, et clont quclyues uns ont leurs cmbryons dépourvus de protophylles.

Dreshálí, adj., dipsaccus. L'Astrea dipsaeca est unc masse hénisphćrique, ofrrant de grandes étoiles hérissées de dents aignuës, cc qui lui doune quelque ressmblatuce avee les têtes de flenrs du Dipsacus.

DIPS IC Dipsacea. Famille de plantes, établie par Candolle, qui a pour type le genre Dip.sacus.

DIPSECTEUR, s. m. Instrument imaginé par Wollaston, en 1817 , et qui sert à mesurer sur mer la dépression de l'horizon.

D[PTÈRE, adj. ct s. m. , diptertes,

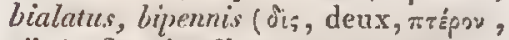
aile). Se dit d'une graine qui est garnic de deux ailes (cx. Halesia diptera), et d'un inseete (zweifliggler, all.) qui n'a que deux ailes. L'Eplecmera diptera est appelée aiusi, paree que ses ailes inférieures sont fort peu apparentes.

InPTELres, adject. et s. m. pl., Diptera. Nom donné par Liuné, Degeer, Cuvier, Lamarck, Duméril, Goldfuss, Leach, Kirhy et Eichwald a un ordre, par Schaeffer, Blainville, Latreille, Ficinus ct Carus ì une sonsclasse de la classe des insectes, eomprenant ceux qui n'ont que deux ailes.

DIPTÉROCARPÉss, adj. et $\mathrm{s}$. $\mathrm{f}$. pl, Dipteroearpece. Famille de plantes, établie par Reinwardt, qui a pour type le genre Dipterocarpus.
nIPTÉRologie, s. f., dipterologia. Traité sur les inseetes diptères.

DIPTÉROLOGIQUE, adj. , dipterologicus; qui a rapport ì la diptérologie.

DIPTEROLOGLE, s. m., dipterologus. Naturaliste qui se livre d'une manic̀re spéciale à l'étude des insectes diptères.

DIPTERYGIENS, adj. et s. m. pl.,

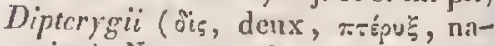
geoire). Nom sous lequel Schneider désigne une famille de poissons, comprenant eeux qui n'ont que deux nagenires.

DEPTRÉnÉ, adjeet. , dipyrenus; zwcikiornig (all.) (òs, deux, тupriv, noyan). Dont la baic contient deux pyrènes. Ex. Ilcx dipyrena.

DIRECTION, s. f., directio ; Richtreng (all.). Tendance ì se porter vers uu point déterminé. La dircetion d'une force est la droite suivant laquelle elle tend à nouvoir les corps qui éprouveut son action.

DHahomisoennove, adj., dirhomboedricts. F. Mohs donne eette épithète aux combinaisons de son système riomboëdrique d'oì résultent denx rhomboëdres pareils unis ensemblc.

DIRIYYQUes, adj. el s. m. pl., Dirhynehi (dis, deux, p่ưvz's, bee $)$. Nom donné par Blainvilje à une tribra de la famille des Subanuélidaires polyrhyucques, comprenant cenx qui ont deux appendices céphaliques garto nis de crochets.

DISCICOLE, adj., discincolus (discus, disque, colo, habiter). Un Champignon (Splearia discineola) est ainsi appelé parce qu'il croît sur' la tranche les troncs de pommiers coupís.

DISCIEhHE, adject., diseiferts (discus, disquc, fero, porter); qui porte un disque, comme les apothécies des lichens gymnocarpes, Ex. Parmelia. 
DISCIFLORE, adject. , disciflorus (discus, disque, flos, flewr). Le Cornus disciflora a les folioles de son involuere réunies en un disque subsirrondi et sublobé.

DISCIFOnME, adj. , disciformis; scheibcnformig (all.) (discus, disque, forma, forme); qui est plat et orbieulaire, en forme de disque, comme les apothécies des Sticta, les liggumes Contournés du Mcdicago disciformis, le ehanjuignon appelé Spheria disciformis.

DISCIGINE, adjeet., discigynus (oicars, disque, yurn, femme). Epithète domée par A gardh anx plantes dont l'ovaire est implanté sur un disque.

DISCOBOLIS, adj. et s. m. pl., Discoboli (jicros, disque, $\beta \dot{\alpha \lambda \lambda \omega}$, linecr). Nom donné par Cuvier et Latreille à une lamille des Subbrachiens, par Tïicinus el Carus à nue fàmille de Sternoptérygicus, par EichWald à une famille de Malacoptérygiens, comprenaul des poissons qui ont les nageoires ventrales réunies sous la goroce en un disque arrondi. Discocrinateris, adj. et.s. m. pl, Discocymatii (òं $\sigma^{2} 0_{3}$ disque, *upzeses, eymation). Nom donné par Wallrolh ì une tribu de la famille des Liehens, compremant ceux qui sont pourvus d'une membrane proligère, el correspondant aux liyméhocarpes de Meyer.

DISCORAr, idject., discoidalis (dizros, disqune, हiong, ressemblance). Kinlyy donne celte épithète anx épipleures, quand ils procident du disque de la surface inférieure des élytres. Ex. Lampyris.

Discorbe, adj. , discoïdcus; ơtRostoris; schcibcnförmig (ill.) (dizros, disque, aidos, ressemblance). Se dit, en botaniquu, de parties qui ont denx éces aplaties parallèles, avee uue epaisseur notable et un bord eirenlaire oblus, comme la baie dn Phy- tolacca, le chapeau de l' Agaricus discoidcus, l'ćtairion du Gratiola, la graine de la Noix vomique, le regmatc du Hura crepitans. Cassini domne celte épithète ì la calathide couronncee, dans les Synanthérées, quana les fleurs de la eouronne ne sout pas plus longnes que celles du disque et suivent lạ même direelion (ex. Jasione discoidea). En zoologie, on l'applique à des aninamx qui offrent un disque eoloré au milieu d'un fond d'une aulre teinte, comme la Nitichla discoidea, on qui sont aplatis et presque orbieulaires, eomnue l'Asterias discoidca et la $V_{\text {cnus }}$ discina. Une coquille univalve est dite diseölde, lorsque ses tours de spire s'enroulent vertiealement sur un mème plau, de manière a former un disque (ex. Cyclostoma planorbula).

DISCOIBÉ, adj., discoidcus. Autrefoison a donné ce nom aux Symanthúrées dout la calithide, ni radiée, ni raliatiforme, est pelite, déprimée ouplaniuseule au sommet, et eom posée de tleurs courtes, droites, parallèles, entassces. Ex. Anthomis Cotula.

DIScOIDLs, adj. et s. m. pl., Discoïdei. Nom donné par Fries à une finuille de la cohorte des Hyménothalames, par Aeharins à un ordre de la elasse des Conothalames, comprenant les Liehens qui ont lcurs ipothéeies en forme de scutelles entourées d'un relord produil par la fronde.

DISCOUO-RAULÉ, adj., discoïdo. radiatus. Cassini appelle ainsi la $c a-$ lathicle des Synanthérées, quand il y a denx couronnes, l'une extérieure radiante, l'antre intérieure irradiante. Ex. Erigeron acre.

DISCOLOn, adj. , discolor ; ungleichfarbig (all.). Se dit de tout ongane plane, surlout des feuilles, dont les deux faees ne sont pas de la même eouleur. Les feuilles du Goodyera discolor sont vertes en dessus et 
pourpres en dessous ; celles da Cianothus discolor, d'un brun foncé en dessus et blauchâtres en dessous; celles du Momogyne discolor luisaulcs en dessus et tomcnteuses en dessous. Lc Gnaphalium discolorum a les écailles extéricures de son involucre rouges et les internes blanches. Voyez Versicolor, Dicunoé, Bicolor.

DISCONTINU, adj., discontinures. Nom donné, daıss la nomenclature minéralogique de Jlaiiy, à une variété dont le signe cal composé d'cxposans formant unc progression it linquelle il manque un terme porr qu'clle soit contimue. Ex. Chaux sulfalée disconlinute.

DISCOPHORE, adj., discophorus ( ji Tetrarliguchus discophorus a un renflement céphalique en forme de disque.

nIsCopHones, adj. et s. m. pl., Discophora.' Nom donné par F. Eschenholtz ì un ordre de la classe des Acalèphes, renfermant cevx qui n'ont qu'un scul organe natatoirc en forme de disque.

DISCORDANT, adj. , discordants. Se dit, en gíognosie, de la stratification, quand deux ou plusicurs systèmes de couches qui se touchent inmédiatement, ont une inclinaison différente.

DISCOSUnt, auject. , discosurus (dickos, disque, ojpò, queuc). L'Agama discosura a la queue déprinéc et orbiculéc à la base.

DisDinClusioue, adj., disdia-

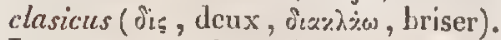
La chaux carbonatéc rhomboïdalc d'Islande a été nomméc spath disdicaclasigue, à cause de la double réfraction dont elle jouit.

DIST'PALE, adj., disepalus. Eipithète donnéc au calice, quand il se compose de deux pic̀ces distinctcs. Ex. Papaver Rhocas.

DIS HOINT, adj., disjunctus. Nom donné, dans la nomenclature minéralogique de Haüy, à une variété dans laquelle les dćcroisscmens font un saut brusque, comme de un it qualre ou à six (ex. Chaux carbo natée disjointc). Lues entomologistes disent qu'un insecte a le corps disjoint, quand la tête, le tronc et l'abdomen sont séparés les uns des autres par des incisures.

DISJONCTIF, adj., disjunctivus. Épitlıcte donnée par A. Richard ì l' ill" sertion pleurodiscale des lćtarnines, quand les pétales sont attachés sous le disque, et non à ce disque, dc même que les étamines. Ex. Simaroubées.

DISJONCTIFLONE, adj., disjunctiflorus; qui a les fleurs ćcartées. Ex. Crolon disjunetiflorum. Voyez DissiTIFLORE.

DISPERVE, adject. , dispermus,

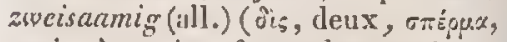
graine ) ; qui renferme deux graines, eomine les baies du Jasminim dispermum et du Ruellia disperma, la careerule de la Circa lutetiana, l'iréme des Labićes, Jes légrumes de l'Indigofera dispcrma et du Dorycnium dispermum, les prxides du Plantago slicla.

DISPERSIF, adj., dispersious. O॥ appelle pouvoir dispersif'd'unc substánce, lc quotient que l'on obtient en divisant sa dispersion par son iıdice moyen dininuć de l'unité, ct l'indicc moyen de réfraction est celuí qui appartieut à la lumière moycnne du spectre.

DISPELSION, s. f. , dispersio ;

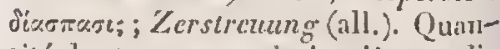
tilé dont un rayon de lumière se dilate par l'effet de la réfraction; effet par lequel les molécules simples, do divcrses coulcn's, dont l'ussenblage produit la lumièrc blanche qui provient du soleil, sont débrouillées et rassemblćes en plusieurs faisccaux distinets. 
DISQUE, s. m., discus; ơø Scheibc (all.). On employe ce mot: $1{ }^{0}$ en astrnnomie, oì il exprime la surface visible da soleil, de la lune, d'une plarì̀te, d'une conrète; $2^{\circ}$ eu botanique. On nomme ainsi toute la partic de la surlace d'une leuille qui est situéc entre les bords, eenx-ei cxceptés; la portion centrale de l'assemblage des flenrs qui eonslituent une ombelle, un copitule, un eorymbe; la surfice élargic d'un pérlonenle de Syuanlhéré, qui supporte les pelites fleurs ; d'apré: Cassini, l'assembiage de fleurs i rovolles masculines, e'est-ì-dire hermaphrodites ou mâles : qui, daus une calathide de synanthérée composée de fleurs différant essentiellement par la corolle. vecupe le milieu de la ealathide, c’està-dire les fleurous du centre; d'après Adanson et L.-G. Rieliard, un corps eharnu, de nature glandnleuse, ordinaircment janrâtre, plus rarement verd, qui, dans heaucoup de plantes, placé sur le réceptacle, tantôi est resserré sous l'ovaire íex. Ruta), lantồ le déborde un peu (cx. Porrogo), tautôt s'étend bien avant sur la partie interne du ealice (ex. Punica), et semble quelquefois repousser l'insertion des étamines vers l'orifice de ec dernier ; enfin, l'alprès Aeliarius, la partie supérieure des apothécions ouverts et marginés; $3^{a}$ en zoologie. Jurine appelle dispue toute la partie de l'aile des insectesqui se trouve enferméc entre les bords ; mais, comme alors le mol devient synonyme de surface, Latreille pense qu'on doit le restreindre à exprimer le suilieu de l'aile. $\mathrm{O}_{\mathrm{n}}$ donne ce nom a la partie convexe d'une coquille bivalve, eelle qui se trouve ati-dessous du ventre, e'està-dire du point le plus saillant; quelquefois aussi au corps d'unc coyuille univalve (ex. Haliotis), mais alors on n'entend par lis que le dernicr tour de la spire.
DISSRMHZABLE, adj, dissimilis; unëhnlich (all.). Sc dit, en botanique, d'un orģane qui, sur le même individu, offreplusienr's varićtes daus si forme, counme les lobes des anthères dn Salpia; les anthieres des étanines du Cassia, dans une mème fleur; les fenilles du Morysia diversifolia et du Ludia heteripleylla (voy. Diversifolié, Jlétéropuýle, VArirvolaté), sul un unème pied. Les cotylédon.r dissemblables sant ceux qui differeul ento'eux d'une manicre queleouque dans le racme cmbryon (ex. Ceralophyllum denersum).

DrsslunNaton, s.f., disscminatio; Aussircuen (all.). Dispersion naturelle des graines sul la surface de la lerro, à l'époque de leur maturité; manière dont les plantes répandent leurs semenees lorsque eclles-ei sont müres.

DISSÉMuñ, adj., disseminalus. I cs géngrnnstes donnent cette épithète aux parlies accessoires d'une roche qui sout réunics cu paquets ou pelotons dans ecrtaines parties de eette roche, comme l'agate daus le porphyre; aux mincraux qui sont engagés, en eristaux, grains on rognons, dans des roches, et répandus assez uniformément dans ees masses pour paraître en faire partie constituante, comme le diamant.

DISSkQUÉ, adj., disseclus; zerschnitten (all.). Se dit d'une plante qui a ses feuilles Ires-déconpécs. Ex. Fiola disscela, Heracleum dissectum, Rananculuts disscetus, Rhus dissceta, Perucedanum dissectum.

DISSMLLARRE, adj., dissimilaris. Se dit, en minéralogie, de la potessicre d'un corps, quand elle differe sensiblement de eelle de la masse, et d'une varićlé dalus laquelle les burds el les anghtes sur lesquels agisseut les décroissemeus en subissent ehacun drux, à l'execption d'un bord ou d'un angle qui ne subit qu'un seul 
décroissement (ex. Chanx carbmatéc dissimilaire). En zoologic, on applique ectte épithcite à l'opercule, quand il n'a pas la forme de l'ouverture de la coquille, ì quelque profondeur qu'il s'y trouve enfonce; ì la eharnière d'une eoquille bivalve, quand elle n'est pas semblable sur les deux valves, et qu'il y a d'un côté des dents qui ne eorrespondent ì rien.

DISSITIFLORE, adj., dissiiflorus (dissitus, éloigné, flos, fleur); dont les fleurs sont ćcarlées, comme les épillets de l'ćpi du Paspalus dissitiflortes.

DISSIVArve, adject., dissivalvis (dissitus, éloiggné, valva, valve). Denys de Montfort a eréé ee noun pour désigner les mollusques munis de plusieurs valves non réunies, et distinctes entr'elles, c'est à dire non assemblées par des ligamens on des chatnières. Ex. Taret.

DISSOLUTION, s. f., dissolutio;

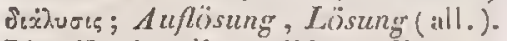
Liquéfaction d'un solide ou d'un gaz par son union avee un liqquide. Union intime de deux liquides différens, qui n'en forment plus alors qu'un seul parfaitement liomogène à l'oeil. Résultat de cette opération. On a proposé de réserver ce terme pour désigner le eas où le corps dissous et le eorps dissolvant changent de nature, et, c'après Proust, les combinaisons en proportions indefinies, qucl que soit l'état des eorps qui les constituent. Ces restrietions n'ont point été adoptées, malgré l'uvantage qu'il y aurait à distinguer la sinple disgrégation d'un corps par un liquide qui labsorbe tel qu'il est, de celle d'un antre corps par un liquide qui $\mathrm{cn}$ change la nature.

DISSOI.VANT, adj. el s. ml., di.s-

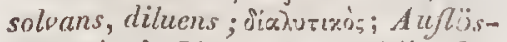
zungsmittel, Lösungsmillel (all.). Liquide qui a la proprieté de dissoudre une substance solide, liquide ou gazense.

DISSONAXCF, s. f., dissonans sonus; ¿̇oupepraia; Misslume(all.). On appelle ainsi tantôtl'intervalle de deux sons yui forment ensemble un accord désag réable, tantôt, et plus suuvent, celui de deux sons qui choque paree qu'il est étranger à l'aecord, et ce nom vient de ee que les sons, quoique siunulanés, sout perças par l'oreille comme s'ils étaient distincts. Suivant Roussean, il n'y a de vraiment dissonans que les intervalles dont les rapports sont irrationncls, parce qu'ils sont les seuls auxquels on ne puisse assigner aueun son fondamcntal commun. Or, an delà du point où les harmoniques (voyez ce inot) nalurels sont encore sensibles, la consonanee des intervalles conmonsurables ne s'adnet plus que par induction, et quoique ces intervalles fassent bien partie diz système harmonique, pusqu'ils sont dans l'ordie de sa génération naturelle et se rapportent au son fondamental commun, ils ne peuvent être admis comme consonans par l'oreille, qui ne les apercoit pas dans l'harmonie naturelle du corps sonore.

DISSOLs, adj. et s. m. pl., dissoluti. Nom donné par Nees d'Esenbeck i) une scetion de la famille des Riro. gastres triehocystes.

DISTACmí, adj. , distachyus;

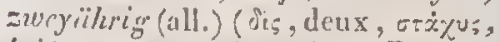
épi); qui porte deux épis. Ex. Cy"perits dislachyos, Eiriocleloa disiachya, Aponogeton distachyon.

DISTAICE, s. f., distantia; Absland, Enlfermung (all.) ; distenza (it.). Espace à pareourir, entre deux licux, pour aller de l'un ì l'autre; temps qui, cntre deux ćpoques, s'est écoule depuis la plos ancienne jusquià la plus récente; cnsemble des oljets intermédiaires ct de méme nature, en nombre plus ou moius 
grand, que nous pourons concevoir entre deux objets considérés eomme séparés.

DISTANT, adj., distans, remolus; cnlfernu (all.). Se dit des camines, quand elles sont plus on moins éloignćes (ex. Lycopus), ct des antennes d'un insecte, lorsqu'elles sont écartécs l'une de l'autre à leur originc.

DISTEGE, adject., distegus (dìs, deux, $\tau \tau \dot{x} \gamma$, toit). Nom donné, dans la nomenclature minćralogique de Hä̈y, à une variélé de chaux carbonalée dans laquelle les arètes horizontales sont remplacécs par des faectics qui forment comme la naissance d'un second sommet au dessus de celui que produisent les faces extrêmes.

DISTŔnONE, adject., distemonis

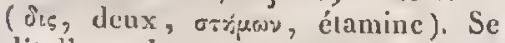
dit d'une plante qui a deux ćtamines.

DISTÉMONOPLÉANTHúlí́:ES, adj. et s. f. pl., Distemonopleanulere (oiv,

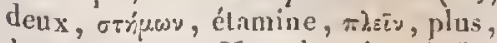
¿.vonpois, flcuri). Nom donné par Wachendorff ì une classe de plantes, eomprenant eelles qui ont les anthères en nombre double de celui des Glamens.

DISTICHOPHYLLE, adj., distichophyllus (dĩrtıos, sur deux rangs, quiोos, feuille); qui a les feuilles disposées sur denx rangs. Ex. Ehrharta dislichoplyzlla, Panieum distichopleyllum.

DISTIGMATE, adj. , distigma (óis, deux, oriqua, stiguate). Se dit d'un pistil qui a deux stigmates. Ex. Tripsacum.

Distigmatin, s.f., disligmalia. Nom donné par A. Richard à une section de la Synanthérie, comprenant les Synanthérćes qui sont nunies de deux stigmales.

DISTILLATION, s. f., distillatio ; Abzielen (all.) (stillo, dégoulter). Opération dont le but est de soumeltre une substance à l'action de la cha- leur, dans des vaisscaux elos, pour la réduire en produits qui diffèrent les uns des autres sous le rapport de la volatilité.

OISTILLATOIRE, adj., distillatorius. Le $N$ cpenthes distillatoria est ainsi appelé parec que sa feuille ascidiée est pleine d'nn liquide sécrétć, à ee qu'ou croit, par les parois mếmes.

DISTINGT, adj., distinens, diseretus, disjunetus; abgesondert, unverbunden, untersehieden (all.). On cmploye ee mot : $1^{\circ}$ en minéralogic, pour désigner une variété de magnésic boratíe dans laquelle les angles solides opposés riont pas de faces semblablement situćes, tandis que, parmi les quatre qui, sur une même variété appclée surabondante, remplacent tel angle solide, il y cn a une située comme eelle qui est solitaire à l'endroit de l'angle solide opposć. $2^{\circ}$ En botanique, il se dit d'un organe qui n'a ni connexions, ni adhérences avec les organes voisins. On dit étamines dislineles, cellesqui ne se tiennent ni par les filets, ni par les anthères; lobes disincts, dans les anthères, quand lcurs contours respectifs sont bien arrêtés ( ex. Tradescenlia virginica); nervules distinetes, dans le placentaire, quand elles forment des eordons séparés (cx. Portulaca) ; stipules distinctes, lorsqu'e!les sont séparécs l'unc de l'autre, dans tontc leur longueur, comme e'est le eas le plus ordinairc ; $l e g-$ men distinct, quand il est séparé de la lorique, de manic̀re à pouvoir $\mathrm{cn}$ ĉtre délaché sans rupture on déchirement (ex. Nympluaea); valves distintes, lor'squ'clles sont renirantes, et qu'elles n'ont pas d'nnion entre elles (ex. Colcliqque). $3^{\circ}$ En zoologie, Kirby donne cettc épithète au seutellum, quand il cst séparé du dorsolum par tine sulure (ex. Hyménopicress. 
DISTIQUE, adj. , distichus; ơं $\sigma \tau \nmid \chi^{0} ; "$ zuveizcilig, zweireihig (all.). Se dit des parties qui sont rangées en deux séries disposées le long d'un axe comnun, et daus le mème plan, mais à des hauteurs différcntes, de manièrequ'il y en ait alternativement une d'un côtć et l'autrc de l'autre; de celles qui sont tris-lapprochécs, et forment deux raugs lien prononcés; de celles qui, partant de deux points opposés, sont altachées sur deux rangs seulcment, comme les fcuilles de l'Eurtachys distichoplylla, du Trisetum distichophyllum, du Didymodon distichus, du Schubertia disticha et du Pachyphyl. lum distichum; les fleurs de l'Hordeun distichum; les poils du T'cucrium Chamadrys; les rameanx de l'Abics canadensis; les spatellules du Briza media.

DISTORT, adj., distortus; qui est de travers, cornme la coquille du Turbo distortus, dont les tours de spire supéricurs sont plissés longitudinalement, et dont la smrface est couverte de sillons tuberulenx.

DISTRACTULE, adj., distractilis (distractus, séparé). Se dit du connectif, quand il ćearte très-sensibleniucut les loges de l'anthìre. Ex. Salvia.

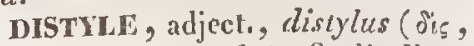
deux, Grýlos, style). Se dit d'une fleur dans laquelle il y a deux styles. Ex. Casuarina distyla.

DITANION, s. m. , dilaxion (dì,

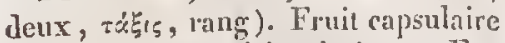
contenant deux séries de loges. Ex. MIarettia.

DITÉTRAEDRE, adj. dictrae-

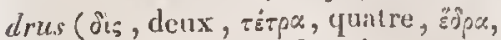
base). Nom donné, dans la nomenclature minéralogrique de Haüy, it une variélé en prisne léträ̈dreà sommets diëdres. Ex. Feldspatl dilétraëdre.

DITHYRE, adj., dithgress (oì, deux, oups, portc). A ristote appelait ainsi une coquille bivalve, ct Turton s'est servide ce mot en place de conchifcre.

DITONE, adjcet., ditomus (dis,

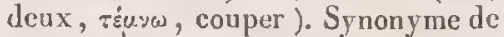
bivalve, dont s'est servi Tournefort.

DITIID $\Lambda$ CTVLES, adj. et s. m.pl., Ditridactyles ( Dis, deux, tois,

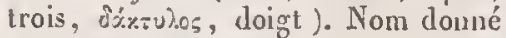
par Vicillut à une tribu d'oiseaux Echassiers, comprenant ccux qui unt dcux ou trois doigts devant, et point derric̀re.

DITRINOHE, adject., ditrinomus (jis, deux, teis, trois, vóuos, loi). Nom donné, dans la nomenclature minéraloğique de Haüy, à une variété qui résulte de décroissemens par une, deux, trois rangées, dont chacun agit sur deux parties de la forme primitive.

DUURNE, adj., diurnus ; riusoriotos, riusotvós, ripépเos ; läglich (all.); diurnal (angl.) ; diurno (it.). Ce qui appartient ou cest rclatif an jour. On employe ce mot : $\mathrm{x}^{\circ} \mathrm{cn}$ astronomie. I'arc diurne est eelui que les corps eélestes déerivent depuis leur lever jusqu'à leur coucher apparent. Le mouvement diurne est la rotation journalière de la terre sur son axe, ou la révolution apparente commune à tous les asires, qui s'accomplit dans l'espace d'un jour et d'une nuit. On nomme variations diurnes les mouvemens que l'aiguille de déclinaison éprouve tons les jours à l'est ou à l'ouest du méridien maguétique, quand ils sout réguliers et périodiques : observées pour la premic̀re fois par Gratram, en I7 I2, elles ont été ensuitcéludiées par Hiorler, Celsius, Wargentin, Canton, Aselepi ct Cassini, $2^{\circ}$ Eu histoire naturelle, On donnc cetle épithète aux animaux dont la vie ne se prolonge pas au delii de vingt-quatre heures (ex. Fiplemera), et aux plantes dont les lleurs 
s'ouvrent et se ferment peudant que le soleil est sur l'horizon (cx. Cestrum diurnum, BIescmbryanilhemum pomcridianum :.

Divines, adjeet., Dizuni. Nom donné par Cuvier, Blainville, Vieillot et Lcsson iो une scetion, famille on tribu de l'ordre des oiseaus accipitres, par Cuvicr, Lamarek, Iatreille et Eichwald à une famille de l'ordre des insectes lépidoptères, comprenant des animaux qui, pour la plupart, ne volent guc̀res que pendant le jour.

DIVAlBLut, adj., disaricaltus ; autsgesperrt, ausgebreitct (all.); allontanato (it.). Sedil, cu botanique, des pidoncules dont les ramifieations s'écartent l's mues des :ntres dans tous les seris, sans former d'angles tres ouverts (ex. Poa divarica!a, Polygonum divnricalum); des rameaux qui s'éeartent beancoup dès leur origine, el se portent lirusquement en diflérens sens (ex. Plarginnthus divaricatus, Mimctes divaricatn, Dysodium disaricalum).

DIVELLENT. adj., divellons (discllo, armeher). Auttefois un disait que deux dissolutions salines milérs ensemble: se décomposent par l'effet d'ine affinitó divellente, e'est-ì-dirc paree que la summe des aflinités de leurs aeides respectifs pour leurs bases respeelives est moindre que ecile des affinités de l'acide de ehacune d'elles pour la luase de l'mutre, en sorte que les aeides semblent s'arracher réeiproquement lemr buse. On donne eette épithìte, daus la nomenclature minéralogique de 1laiiy, à une variété relalive au rhomboide, dans liaquelle des firees maissent sur les angles inférieurs et se rejettent en arricre, eomme pour fuir d'autres faces qui naissent sur les hords dont la réunion forme ces mèmes angles (ex. Chaux cartionatic divellente).

DIVERGENCE, sujst. $\mathrm{f}$ ( di, de, vergo, tourner ). Ėcart d'un centre commun.

DIVERGENT, adject., divergens; aussesperrt, auseinanderfahrend, auscinanderlnufend, auscinanderstchend (all.) (diverto, détourner); qui s'écarte d'un centre commun. Épithete donnée, en minúralogie, dans la nomenelature de Haüy, à une variété prodnite en vertu de deux déeroissemens, l'un simpie, l'autre intermédiaire, en sorte que la loi des décroissemens semble diverger à l'ćgard d'elle-même, en passant du premier au second (ex. Fer oligislc divergent); $2^{\circ}$ cul lonanique : on dit camares divergentes, celles qui s'écartent les unes des antres (ex. Paronia); corylédons divergens, ecux qui s'eloignent l'un de l'autre par leur somnet (ex. A conitum prenaïcum) ; folioles divergentes, dans une leuille trifoliolée, eclles qui, pendant le sommcil, redressérs et rapprochécs par leur bise, s'éeartent l'une de l'autre par leur sonmel (ex. Melilotus) ; follicules divergens (cx. Aselepias nigra); lobes divergens d'une antlière, cenx qui sont rapprochés ou coufluens par l'une de leurs extrémités et ćcarlés par l'autre (ex. Thymus palavinus); neroures divergcules, celles qui se dirigent vers divers points de la périphérie de la fuille; rameaux divergons, ceux qui sollt très-ouverts et verticiliés (ex. Abics); stipules divergentes, celles qui s'écartent l'une de l'autre, ct se plicent daus unc dircetion horizontale par rapport à la base de la feuille (ex. Ranunculus ncris).

DIVERGENTIFLORE, adj. , diporgentifores; qui a des fleurs divergentes, comme celles du Diclicuxia divergentiflora.

IDVERGRESTE, adj., diverginervius. Épithète dunnée par Mirbel aux fcuilles dont les nervures, dirigécs en ligne droitc, se portent en 
divergeant de la base au sommet. Ex. Viburnum Opulus.

DIVERGIVEIvis, adj., divergivenosus. Nom donıć aux feuilles dont les veines se portest en divergeant de la base au sommet. Hx. $S a-$ lisburia asplenifolia.

DIVERSICOLOR, adj., dirersicolor. Il se dit de quelques champiguons dont la coulcur varie suivant les individus. Ex. Peziza diversicolor, Pcriza variccolor.

DIVERSHLOLE, adi. , diversiflorus. Se dit, d'après Cassini, de la calailhide, de la coururne et du disquc des Synanthérées, quant ils sont cornposés de fleurs à cololles variables. Il sc dit aussi de l'ombclle, quand les flcurs du centre sont régulières et celIes de la circonférence irrégulières (ex. Tordylium officinale).

orvenSTFoLn', adj. , diversifolizs (dipersus, divers, folium, feuilles); qui n'a pas les feuilles toutes semblables. Ex. Sabiaea diversifolia, Pelargonium diversifolium. Voyez Dissemblable, Héténophylee, VaRIIFOLIÉ.

DIVERSIF ORME. Voyez HÉTÉRoMORPHE.

DIVERSIFLONS, adject., diecrsifrons. Unc fougèrc (IIymenostachys diversifrons) cst appelée aiusi, parce que ses frondes stériles sont pinnatifides, tandis que les fructifères sont simples et linéaires.

DIVERSisporieEs, adj., Diversisporea (diversus, divers, orropà, semence). Nom douné par Link à une séric de l'ordre des Gastéromycètes, comprenant des champignons dont les conceptacles conticument des sporidies de formes diverses.

orvisî́, adj., divisus; getheilt, zcrtheilt (all.); divided (an.); diviso (it.) (divido, partager). Se dit, cu botanique, de tout organe qui, bien que formé en apparcuce d'unc seule pièce, se partage profondément en plusieurs parties qui vont presque jusqu'à sa basc. On nomme androphore divisć, cclui qui est partagé à son sommet en plusienrs filcts (ex. Jatropha pandurafolia ); ovaire divisé, celui qui, n'ayant qu'un style, est composé de plusieurslogesnon soudées cnscmble, dont chacune a souvent été décrite comme un ovaire particulier (cx. Labiées ).

DIVISnButét, s. f., divisibilitas; Theillarkeit (allem.); divisabelness (angl.).Propriétć qu'ont tcus les corps de pouvoir c̀tre divisés en plısicurs partics, et les partics elles-mèmes en parcelles plus petites, jusqu'à ce qu'elles échappent à nos scus el à nos instrumens. On peut étirer un lingot d'argent de dix-huit grammes, doré arec cinq décagrammes d'or, en un fil plat, également doré partout, long de six mille mètres, ct dont on cstime que la pellicule d'or n'a pas plus de la deux ccnt vingt-denx millième partie d'un millimètre d'ćpaisseur. Haüy a obtenu des lames de mica dont le calcul lui a fait évaluer l'épaisseur à quarantc-trois millionièmes de millimètre. De lì on ne doit pas conclure que les corps sont divisibles à l'infini, du moins physiquement parlan!, puisqu'il ne nous est permis par aucun procédé d'en isoler les particules mèmes, $\mathrm{ct}$ de les atlaquer individuellement.

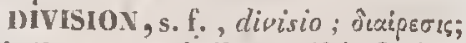
Thcilung, Zcrlicilung (all.). Opération par laquelle on reduit un corps solide en parties plus ou moins ténues. Haüy appelait division mćcanique, la proprićté qu'ont un grand nombre de nunéraux cristallisés de se diviser mécaniquement dans des directions planes.

Docrmsin, s. f., docimasia, ars docimastica; Probirkunst (all.) (do-

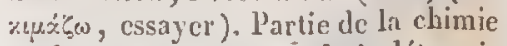
analytique qui apprend à déterminer la nature el les proportions des 


\section{DODE}

métaux utiles contenus dans les mélanges naturels el arlificiels, afin d'évaluer les produits qu'on peut espérer de leur exploitation en grand.

Bocmastiouvi, adj., dorimasticus; qui a rapport à la docimasic. Arl, moycn, opcration, procédé docimastique.

DODÉCAFDRE, adj. , dodecac-

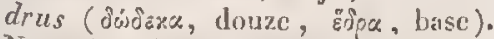
Nonı donué, dans la nomenelature minéralogique de lJaiiy, à un cristal dont la surface est composée de douze facettes triangulaires, quadrangulaires ou peutagones, toutes égalc's et semblaliles, ou seulement de deux mesures d'angles différens (ex. $\mathrm{Fer}$ sulfurć dodćcaèdre). Les utricules du pollen du Geropogon sont à douze facettes.

BODÉGAFTUE, adj., dodccafidus. Se dit, en bolanique, d'unc partic dont le limbe est divisé en douze segments plus ou moius profonds.

DODÉCACONE, adj., dodecago-

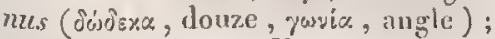
qui a douze angles. Ex. Pegasia dodecagona.

DODLCAGYNE, adj., dodecagy-

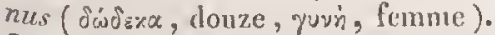
Se dit d'une fleur qui a douze pistils, douze styles, ou douze stigmates sessilcs.

DODKCAGNIE, s.f., dodecagynia. Norn d'un ordre dans l'une des elasses du système sexucl de Iinné, comprenant des plantes qui ont douzc pistils.

DUDECLNDDE, adj.. dorlecandes, dodecandrus; zwel/mümig ( all.) (o'soce\%, douze, axyo, homme). Se dit d'une platule gui a donze ćtamines dans ehique tleur. Ex. Jussicea dodecandra.

DODĹGANDRIE, s.f., dodecandria. Nom donné, dans le système sexuel de linné, a une classe et ì trois ordres, compreninut des plantes qui ont de douzc à dix-neuf étanimes.

DOdÉCANDRiQue, adj., dode. candricus. Synonyme de dodécanárc. DODÉCANOME, adj., dodecano-

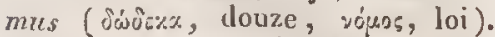
Nom donné, dans la nomenelature minéralogique de Ilaiiy, à une varièté qui résulte de la combinaison de donze lois de décroissement. Ex. Epidote dodécanome.

DOD LCAPATTI, adj., dodecapartilus. Se dit, en botanique, d'une partie dont le limbe est divisé en douze par des incisions aiguës.

DODÉCAPETALE, adj., dodecape talus; qui a douze pélales.

Donovíacées, adj. et s.f. pl. Dodonacacex. Nom donné par Cambessidles et Kunth a une tribu de la famille des Sapindacées, ‘qui a pour type le genre Dodonoa.

DOIGT, s. m. , digitus, dactylus ; Jxxsulo; Finger (all., augl.); dito (it.). On appelle ainsi chaeune des douze parties égales dans lesquelles on divise le diamètre d'un astre ćelipsé ; les cinq prolongemens qui forment l'extrćnitić de la main de l'homme; les prolongemens analognes qui terminent les quatre nembres d'un trèsgrand nombre de mammifères, d'oiseaux et de reptiles; chaeun des deux derniers articles de la pinee des crustacés, dont l'un est mobile, et l'auIre immolsile; enfin, d'après Kirby, l'ensenible des articles de la patte des insectes, hors le premier, qu'il nomme tarse.

DOLABIBF ORME, adj., dolabrauns, dolubriformis; hobelformig (all.); acelliformic (it.) (dolabra, doloire, forma, formo). Se dit d'une feuille charme, presque eylindrique ì la buse, plate au sommet, offrant deux bords, l'un épais et reetiligne, l'autre élargi, circulaire ef tranchant (cx. Peperemice dolabriformis, $M c$ scmbryanthemun dolabriforme). Les phyllodes ont la mêne forme dans I'Acacia subfalcatum, et la coquille dans la Pinna dolabrala. Kirby donne 
cetle épithète au cubitus des insectes, Jorsque son sommet est dilaté et représente en quelque sorte la tête d'une bachetle.

DOLASPISTE, adj.cts. m., dolaspistis (ón).05, perfidie, á.0तis, bouclicr ). Nom que J.-A. Ritgen donne aux serpens à plaques qui ont des croehets iे venin.

DoLÉRITIQUe, adj., dolerilicus; qui eontient de la dolérite. Roche doléritique.

DOLIALRES, adj. et s. m. pl., $D_{0-}$ liaria. Nom donné par Latreille à une fanille de l'ordre des Peetiniliranches, qui a pour type le genre Dolium.

DOLICHochirss, adj. ct s. m. pl., Dolichocera (jexixis, long, eseces, corne). Nom donné par Cuvier et Latrcille à une sous-tribu de la tribu des Museides, comprenaut ceux de ces insectes dont les antenues sont de la longurur de la face de la tête.

DOLICIODiris, adj., dolichodeirus (dodexis, long, jepin, eou ); qui a le col loug. Ex. Plesiosaurus dolichodeirus.

DOLICUOPODES, adj. et s. m.

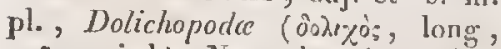

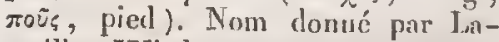
treille, Wiedemann, J. Macquart et Eichwald à une tribu de la famille des Tanystomes ; par Goldluss, Ficinus et Carus à une famille de l'ordre des Diptères, ayint pour type le genre Dolichopurs.

DOLIOLOHE, adjeet., dolioloüles (dolium, tounear, sions, resscnblanee). Lamarck appliquait cette épithete aux chrysalides qui ont le corps ovalaire, un peu dur, en gévéral subeerelé par les restes des anneaux, et sur lesquelles les partirs que duit avoir l'insecte parf it ne forment aucun relief. Ex. la plupart des Diptères.

DOLOMITLQLe, adj., dolomiticles; qui eontient de la dolonie. Ex. Serpentine dolomitiquec.
DOLOPE, adj., dolops ( Bònơ , cspion). Nour que J.-A. Ritgen emploie dans le mème sens que celui de Dolaspiste. Voyez ee mot.

DOIBËYACÉES, sdj. ct s. f. pl., Dombeyacece. Nom douné par Candolle ai une trilun de la famille des Buttnériacées, qui a pour type le genre Dombeja.

DOvils INT, adj. Brochant appelle forme dominanie d'un erislal, le solide gémćtriqne simple auquel on peut le rapporter, en nc considérant que l'ensentile de ses faces les plus élendues et faisant alsstraction moinentanée des facetles qui les modifient. Il admet neuf de ces formes: le tétraëdre, le parillélipipède, l'octac̈dre, lc prisme hexaëdre, le dodéeaüdre rhomboïdal, le dodécaëdre pentagonal, le dodceenèdre triıngulaire, l'icosaëdre triangulaire et Ic trapezoïlc. Il appelle faces dominantes ou principales d'un eristal, celles qui sont le plus étendues, et dont l'cnsemble déturmine la forme générale de ce cristal.

Donć, adj., auralus, aurosus, aureus; goldgell (all.); qui a la couleur jaune de l'or. Ex. Erianlhus aureus, Dillenia aurea, Ribes aurcum, Gobius auratus, Celonia antala, Ampelis aucenla, Conus aurisincus, Trockilus aurulenins, Campaca chrysitis, Da. sypogon aurarius, Hypsonotus aurosus.

Donidés, adject. et s. m. pl., Doridea. Nom donné par Menke à une fanille de l'ordre des Gastéropodes grmnolıranches, qui a pour type le genre Doris.

DORNÉEs, adj. et s. f. pl., Dorinca. Nom donné par RobiteauDesvoidy ì une triluu de la famille des Myodailes muciphorées.

Dononicúes, adject. ct s.f. pl. , Doronicere. Nom donné par H. Cassini à une sectios de la tribu des Sé- 
nécionidées, qui a pour type le genre Doronicum.

DORSAL, adj., dorsalis; riockenstïndig (all.). Sc dit $: 1^{\circ} \mathrm{en} \mathrm{bo-}$ tanique, d'nne partic qui nait surle dos d'un autre organe; arcite dorsale (ex. Agrostis canina); conneclif dorsal, eelui qui n'existe que sur le dos de l'anthère (cx. Lilium); radiculc dorsalc, celle qui se replie sur le dos de l'un des eolylédons (ex. Cruciferes notorhizées); sunure dorsale, d'après Candolle, la nervure moyenue de la feuille carpellaire, quand, celleci étant ployée sur eetie nervurce paur forner la earpelle, il se détermine une rupture le long de la nerrure. On lvi donne même eette épithète dans le cas où elle ne s'ouvie pas, ponrvu que la nerrure soit bien prononcéc. $2^{\circ}$ En zoologie, les plumes dorsales sont eelles qui couvrent le dos, el la nageoire dorsalc, celle qui surmonte le dos. On donne ee nom au crochet d'une valve de eoguille hivalve, quand il répond an dos de l'animal ou au bord supéricur de la coquille. $O_{11}$ l'applique aussi à des animatux dont le dos se fait remarquer par une particularité quelcorinue, commecelui du Zostcrops dorsalis, qui èst cendri', 'u milieu d'un plunagge jaunâtre.

Dorsacées, adjuct, ct s. l. pl., Dorsalea. Nom donné par Tamarek à une famille de l'oralce des Annelides sédculaires, comprenant celles qui ont les branchics sur le dos.

DORsé, adj., dorsatu.s. Se dit d'un animal dont le dos est antrement coloré que le reste du corpi, comme le Noctilio dorsatus, qui a unc bande bauclie lout le long du dos. La $V_{e-}$ nus elorsata est litumehe en dedans, avee une teinte de coulenr de chair lans le disque.

DORSibliancins, adj. et s. $\mathrm{m}$. pi., Dorsibranchiala (dorsum, dos, Bpàylx, branchies). Nom donnć par Cuvier et Straus à nom ordre de la famille des Annelides, comprenant eelles qui ont les branehies saillantes sur la partic moyenne ou sur le côté du corps.

Donsiritiv, adject., dorsiferus (dorsum, dos, fcro, porter). Quelques botanistes ont appelé ainsi les Fongères, pall all usion à lenr fructification, qui uaît en général sur le dos des organes foliatés.

DOISIGERE, idj., dor.sigrcr, dorsigcrus. La Leucopsis dorsigcra a l'abdonen noir, marqué de bandes jaunes. Le Tabanus dorsiger a le dos brun, marqué de raies blanelies. Le Rhinorrarus dorsiger porte sur les élylres une tache qui est commune a ees deux élıis.

DORSH'ARES, adj, ct s. m. pl., Dorsipari (dorsum, dos , paro, produire). Nom donné par Glainville à un sons-ordre de l'ordre des Batraeicns, comprenant ceux dont les petits se développent dans la peau din dos de la mère.

DORSIRLE, adj. , dorsipcs (dorsum, dos, pes, picd); qui a les pieds sur le dos. Un erustacé (Ranina dorsipes) a les pieds de la dernière paire insérés sur le dos.

DOnsondn, s. m., dorsolum. Kirlyy appelle ainsi une pièce située cutre le collier et l'ceusson, a laquelle est entièrementallacló le prophragme, ct qui donne insertion aux organes anlérienrs dis vol.

Donsténacies, Dorsténiées, adj. ct s. I. pl., Dorsicniacea, Dorstenica. Nom donné par A. Richard à un groupe de li famille des Viticées, qui a pour ype le genre Dorsicria.

DOS, s. m., dorstum, fcrgum; ขตัน0ร; Rücken (all.); back (angl.); dorso (it.). On nonme ainsi : I" en hotanique, la partic relevée d'nue stric; celle des faces d'une graine comprimúe qui est tournce du cồté des parois du péricarpe; d'après Candolle, la portion 
de la feuille earpellaire opposée à la suture formée par le rapprochenient des bords, et due elle-mème à la nervure moyenue de la fenille. $2^{\circ} \mathrm{En}$ zoologie, la partie postérieure du trone; la partic supérieure du nez, de la main, du pied et de la verge, ebez l'homme; la région du còté spinal du eorps des mammifères qui est comprise entre le eou et lc bassin, et, dans le cheval eu partienlier, celle qui se trouve entre le garot et la eroupc; dans les oiseanx, la partie la plus élcvée du milicu de la mandibule supérieure, depuis la base da bee jusqu'nu sommet, et le dessus du eorps, depuis le cou jusqu'an croupion; dans les insectes, tantôt, d'a-. près Degecr et Olivier, l'ensemble des partics supérieures des segnicns moyen et postérieur dlu thorax des insectes, qui sont l'arriëre-tergum, on arriëre-dos d'Audouin; lantôt, d'aprés ce dernicr, toute la partie supérieure du eorps entier de l'animal; dans les eoquilles univalves, la face opposce ì l'ouvcrture; dans les eaquilles bivalves, d'après Blainville, le bord supérieur de la eoquille, cclui qui serait en l'air si l'animal marehait devant l'observateur.

DOTHIDINES, adj. et s.m.pl., Dothidini. Nom donné par Fries à un sous-ordre de l'ordre des Pyrénomyectes sphériacés, qui a pour type le genre Dolhidea.

DOUBLANT, adjeet., duplicans. Nom donné, daus la nomenchalure minéralogique de llaiiy, à une varicité dans la signe de laquelle les exposans forment une progressiou qui semil régulière si l'un d'enx n'était double (ex. Péridot). La elinux carbonatée rhomboïdale était appulée autrefois spath doublane, quind elle avait isserz de limpilité pour pernocttre d'obsciver le phénomène de la double réfraction.

DOUBLE, adj., duplex; doppelo (all.); double (angl.); doppio (it.). On se sert de ee mot: $1^{\circ}$ en astronomie; on appelle étoiles doubles, non celles qui semblent se toveher par l'effet optique de la direction sous laquclle nous les royons, mais celles qui, réellement très-rapprochées, forment un système tournant périodiquement autour d'un eentre comnun de gravité. $2^{\circ}$ En physique, on nomme double réfraction un plicnomène qui consiste en ce que chaque rayon lumineux qui traverse eertains cristaux (par exemple ecux du Spatl d'Islande), se partage eur deux rayons émorgens distincts, dont l'ın suit la loi de la réfraction ordinaire, et l'autre suit une loi particulière dont la déeouverte est due à Tllujgens. $3^{\circ}$ En chimie, Berzelius appelle sels doubles ccux qui résultent de la eombinaison de deux sels haloides (ex. Chlorofluorure barylique, Chlorure ferroso-potassique), do deux oxisels ( ex. Oxalate potassico-sodique), de denx sulfosels, d'un sel haloïde et d'un oxisel (ex. Chlorure el carbonate plombiques), d'un sulfosel et a'un oxiscl (ex. Nitrate et sulfomolyblate pnlassique). $4^{\circ}$ En botanique, on uomme calice double cclui qui est muni d'unc espèee, d'involncre simulant un second calice (ex. Erica vulgaris); périanthe double, d'après Mirbel, eclui qui se conrpose d'une corolle et d'un ealice, ou de denx enveloppes florales; $p \dot{c}$ ricline double, d'après Cassini, eelni dont les squames internes et externes sont d'une nature assi'z différente pour qu'on puisse les distinguer en deux rangées ; stigmale double, celui qui est double pour un seul pistil (ex. Convolvulus sepium). La Reur double des botanisıs, pleine des fleuristes (flos multipliralus), résulte de co que les divers organes floratix on l'un d'eux prcunent l'apparence de pétales; une fleur polypétale devient 
double quand le numbre de ses pétales augmente (ex. Ranunculus asiaticus), et une monopétale, quand il $s^{\prime} y$ développe plisieurs eorolles l'une dans l'autre (ex. Hyacinthes orientalis); une synnullérée qui double ne fait que changer de forme, ses demi-flcurons divenant des fleurons, ou ses fleurons des demi-feurons.

DOUBLE-F OLLICULE, subst. m., bifolliculus. Fruit composé de deux follicules. Ex. Asclepias Vinceloxicum.

nouteux, adj. et s. m. pl., Dubia. Nom donné par Blainville à une souz-classe de la elasse des Aetinozoaires, comprenant des aninaux auxquels on ne peut point eneore assigner posilivenent de place, et qu'on laisse là d'une unasière provisoire.

Doux, adj., dulcis; yiuxis; qui agit laiblement sur nos organes, ou $\mathrm{d}_{\text {ia moins sans les offenser (son doux }}$, voix douce); qui a use saveur suerée (fruit donx). Un métal donx est eclui que l'on prut aplatir sous le marleau, sans le liriser (for doux).

DracénAcíes, adj. et s.f. pl., Draccenacea, Dracanca. Nom donné par Reiebenlrach et par Link à un groupe de la famille des Liliacées, qui a pour type le genre $D_{r} a-$ coena.

DIMCINE, s. f., dracina. Melandri appelle ainsi un alcali organique qu'il a découvert dans le sang-dragon.

DRAcious, adj., dracinus. Nom que doivent porter, dans la nomenclatnre ehimique de Berselius, les sels à base dle dracine. DraconiENs, adj. et s. m. pl.,
Draconii. Nom domé pir J.-A. Ritgen à un sous-ordec de i'ordre des heptiles eampsichrotes, gui a pour type le genre Dreco.

Dricovere, s. f., draconina. $V$.
DRACINE.

DRACONITIQUE, adj., diaconi- ticus. Le temps que la Lune met à revenir à l'un de ses nocuds, et qui est de $27 \mathrm{j} .5 \mathrm{~h} .7^{\prime}$, est appelé mois draconitique paree qu'autrelois on nommait le nœud ascendant tête, et le noeud desccudint quene du Dragon.

D) IACONOIDES, adj. et s. m. pl., Draconoidea, Draconoidci. Nom donué par P.-IS. Fizzinger et Eichwald à une fimille de Repliles, qui a pour type le genre Draco.

DhaCoNTúts, adj. et s.f. pl., Dracontier. Salishury appelait ainsi la fanille des $A$ roïdées, à eatise du genre Dracontium qu'elle renferme.

DRAGEON, sulssi. m., stolo, surculus; IV urzelschössling (all.); shoot (angl.). Tonte pousse on tige nouvelle qui s'éleve des racines. Plusieurs botanistes ont donné ce non aux coulans, ou filets traçans, qu'on reneontre chez un assez grand nombre de plantes. On l'applique anssi à d's jets particuliers qui partent de la tige de cerlaines monsses, et qui s'élalent à la surface da sol.

DlRAṔ́, adj., paunacens, pannosus; qui a la forme d'un morccau de drap ou d'un fentre, conme le squelette de la Spongia pannacea, ou la masse des filamens de l'Oscillaria pannosa.

Drap-Marin, s. m. Espèce de pluche ou de laine qui garuit la surfaec extéricure d'une coquille univalve (ex. Turbinella rapa) ou bivalve (ex. Arca pilosa).

Dhiche, sulsst. l'. Orge dont on a arrêté la gormination au moyen de la chalcur, et qui, après avoir été moulue, sert is faire la bicre.

DuLSSE, adj., crectus; auf stchend (all.). Se dit, en bolanigue, d'une parlic qui est perpendiculaire, on à pex près, an plan de sa halse, qui se dirigge de has en haut d'un axe rationnel ou réel. Les anthères dressces sont notablement longues, fixées par l'un de leurs bouts, el elles se tiennent dans tute direction verticale par rap- 
port au plan de la base de la feuille. La camare est dressice daus le Sedum album, et ic chuton dans le Salix triandra. La cupulc du caly bion est dress.céc, quand son orifice est tourné vers le point opposé à la base de son support (ex. Taxus); celle du strobile l'est dans le Cupressus. I'cmbryon dressé est celui dont la radicule se dirige vers la Irase de la graine, e'est-ì-dire vers la cieatrieule. Les étamines dressées se tiennent par leur propre force daus la direction de l'axe de la fleur (ex. Tulipa). Ises fouilles dressées forment un angle très-aigu avec la tige (ex. Iris sermanica). Les fleurs dressécs se dirigent vers le ciel (ex. Gentiana verma). Les folioles d'une feuille composće sont dressces la nuit, pendant le sommeil, lorsqu'elles s'appliquent au dessns du pétiole commun par leur face snpérieure (ex. Colutea). Les follicules du Nerium Olcander sont dressés. La graine dresséc est fixćc su fond du péricalpe, dont elle snit plus ou moins bien la direction (ex. Berbcris); la grappe de l'Accr campestre est drcssee, counne l'ćpi du Reseda litea. Ie limbe d'une corolle monopétale est dit dressé, quand il est parallèle a l'axe de la fleur (ex. Cynoglossum officinale); les pélales prennent cette épitlète dans la mène circoustance (ex. Hatlicteres Isora). Les rancuux drossís montent vers le ciel (ex. Populus fasligiala). Le sligmale dressé a une longueur notable et la même direction que eclle de l'axe de la fleur (ex. Slatice Armeria) . La tigeestdresséc dans l'Orthostcmon crectum.

DROIT, adj., rectus; solvis; aufrcchl (all.); right (angl.); diritlo(it.). Se dit : $1^{\circ}$ en astronomie; l'aseension droite d'un astre est la distinuec comptée rlepuis le point de l'équalenr qui est au commencement du bélier jusqu'au point de l'équatéur qui se lève en mène tempsque lastre. $P$. Desm
CENSION. $2^{\circ}$ En minéralogie; le prisme, soit rectangulaire, soit rhomboidal, est appele droil par Brochant; quand la base qui le termine est perpendiculaire à l'axe et pa $r$ conséquent aux arcites. Le prisme reclangulaire droil peut ètre: A. cubique, quand les plans de clivage paralleles aux faces latérales et aux bases sont tous également nets et distincts, en sorte quic chacune des faces se trouve daus le mème rapport avec le clivağe qui lui correspond, que toutes sont identiques, el qu'on peut les regarder toutes comme ćtant à une égrale distince d'un point central ; B. a base earrće, quand les plans de clivage parallc̀les à quatre fices sont éçalement nets el distincts, et un troisième plus ou moins distinct qu' 'ux, ou mêtne nul, d'oi il snit que ces quatre faees sont scmblables et semblablement ordonnées par rapport ì une ligne joignant les centres des deux autres, que cetle ligne constitue l'axe, et que, pour représenter l'identité de position des faces latérales par rapport à cet axe, on cloit considérer les bases, e'est-àdire les autres faces, comme carrées; C. à hase rectangle, quand les trois sens du clivage sont différemment distircts, cn surte que chaque face peut ètre regardée comme différente des deux anties, ou quand deux sens de clivage patallétes à l'axe ne sont pas parallèles aux faees. Le prisme rhombüulal droit pent être: $\mathrm{A}$. à base isoscèle, quand les deux faces latírales, celles qui ne sont pas perpendieulaires entre elles, présenteut des elivages identiques; B. is loase oblongne, quand e's denx faees présentent des clivages différens. Le prisme pentagonel, soit régulier, soit symétrique, est droit, quand sa hase est perpendictr laire à l'axe. $3^{\circ}$ En zoologie, les dents sont droites, quand leur direction est perpendicnlaire à l'axe des mâchoires. Les ailes des insectes prennent eetto 


\section{DRUP}

épithète toutes les fois qure, daus le repos, elles sont relevées perpendiculairement. à la surface du corps.

DROITS, adj. et s.m. pl., Erecta. Nom donné par flliger à un ordre de la classe dis Mammiferes, gui ne comprend que le genre Hommc.

DromALECTORES, adj. et s.m. pl., Dromalectores (Jobors, eourse,

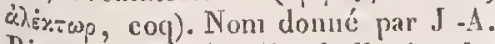
Ritgen à une fanille de l'ordre des Choroptènes, eomprenant les gallinacés coureur's.

DROMOciloroptetres, adj. et s. m. pl. , Dromochoropteni (d'sopos, course, $\chi \vec{\omega}$ opos, champs, $\pi$ Onyos, volatile). Noin donné par J.-A. Ritgen à une famille de l'ordre des Choroptènes, comprenant les gallinaeés qui courent dans les champs.

DROMOnNTILs, adj. et s. m. pl., Dromornilecs (jpócos, course, öpue, oisean). Nom donuć par J.-A. Ritgen it un ordre de la section des Mydalurnithes, eomprenaut les oiseaux qui ne sont aptes qu'ì mareher et courir.

Drosinacírs, adij. et s, f. pl., Droseracece. Fumille de plantes, établie par Candolle, qui a pour type le genre Droscra.

DROSONÈTRE, s. m., drosometrum ; Thaumesser (all.) (Sobosos, ro-

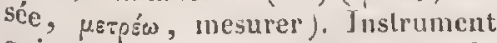
qui a été proposé pour mesurer la rosée.

DRUP ACÉ adj. , drupaceus; stcinfruchtarlig (all.); qui est de la nature du drupe, qui ressemble ì un drupe. Le calybion drupace a l'aspect d'un drupe, parce que sa cupule est formée de denx substances, l'une interne ligueuse, l'autre cxterne suceulente (ex. Cycas). Le légume drupacé a une partic externe succulente ch charnuc, ct une interne ligncusc, imitant un noyau (ex. Geofficea). Un péricarpe drupacé est celui dont l'endocarpe est dar et revèia d'une
DRUS

écorce séparable ou distinele et à pcine charume.

DRupACLES, adj. et s. f. pl., Drupacce. Nom donné par Candolle a une tribu de la famille des Riosacées, comprenant eclles de ees plantes qui ont pour fruit un drupe.

DRUUPE, s. m., drupa; Stcinfrucht (all.). Fruit charnu, indéhiseent, qui renferme daus son intérienr un noyau formé pill l'endocarpe cndurei, auquel s'ist jointe une partic plus ou moins épaisse du salcocirpc (ex. Cerise). Comblo!le définit le slrupe une earpelle iudchiscente où le mésocarpe est dharnu et l'endocarpe osseux.

Drupurare, subst. m., dripeola. Mirbel appelle ainsi les drupes qui sont plus pelits qu'm pois. Ex. Rhus.

idiupiordí, adj., drupeotatus. Ayant l'apparenee d'un petit drupe, par sa strueture suceulente en dehors et ligncuse en dedans, eomme la $c a-$ mare de l'A ctáa, le cénobion du Pra. sium majus, la crpsèle du Cliliadium, la graine de l'Ixia chinensis.

DRUPH'LnE, adj., drupiferus; qui porte des drupes. Ex. Camcllia drupifora.

Dhupulines, adj. et s. f. pl., Drupifera. Nonı domé par Balseh ì une famille de plantes, qui correspond à la triba des Drupacécs.

Dnusy, s. f., drusa (òpúw, cacher). Cavité qu'on rencontre dans certaines roches, et qui est tapisscéc ou comme hérissce de eristaux ordinairement prismatiques.

DRUSIFORME, adj, drusiformis; (drusce, diuse, forma, forme); qui a la forme d'une druse ou d'un rognun, comme la virićté de ehaux sullatéc appelée $S$ path drusiforme.

DRUSILAARE, adj., drusillaris; qui est en masses eoncrétionnées, commc la variété de cuivre oxidulé appelće Spath drusillaire.

Drusiove, adj., drusiczes ; qui a la forme d'un lognon, comme la ya- 
riété de chaux carbonatée appeléc Spatle drusiquc.

DRYADí, adj., dryadeus, dryinus

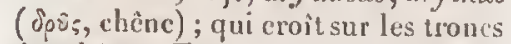
des ehenes. Ex. Polyporzes dryadeus, Agaricus dryinus.

DRYADrins, adject. et s. f. pl., Dryadece. Nom donué par Ventenat et Candolle à une tribu de la fanille des Rosacécs, que Caffin a érigée en famille, el qui a pour type lc genrc Dryas.

DRYRurRuzḱes, adj. ct s. f. pl., Dirmirrlizex. Ventenat appelait ainsi la famille des Amomées.

DRYOPHILE, adj. , dryophilus

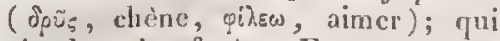
vit dans les forêts. Ex. Agraricus dryophilus, Peziza dryophila.

DRYOPHTHOHDLs, adj. et s. m. pl., Dryoplethorides. Nom douné par Schoenherr it un groupe de l'ordre des Curculionides gonaloccères,

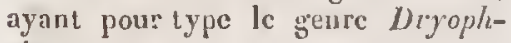
thortus.

Dhroptrate, adj. , dryoptcris

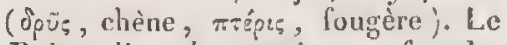
Polypodiun dryopteris a ses frondes ailées.

DUAL.usuie, s. m., dualismus. Système dans lequel on explique tous les phénomènes de la nature au moyen de deux principes, qui sont l'origine et la cause de tout.

DUnlisTe, s.m., dualista. Partisan de la doctrine du dualisme.

DUALISTIQUn, adj. , dualisticus; qui a rapport au dualisme : theorie drualistique.

DUCTILE, adj., ductilis, ducti-

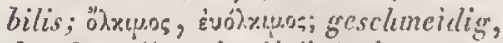
dehnbar (all.); dunile (it.) (duco, conduire); (nipent s'alonger et s'étendre.

DECTILITh́, subst. f., deetilitas; Strechbarkeit, Zidlighcit, Gesehmeidigkeit (all.); ductility (ungl.); duttilitie (it.). Proprićté qu'ont eertains corps de pouvoir s'ćtendre par l'effet de la pression, de la percussion, de
Ia tension, ou de la traction, et de conserver sensibler aent la forme qu'ils ont ainsi recue, quand la force a cessé d'angir snr eux.

DUFourides, adj. et s. f. pl., Dufourida. Nom douné par Robineau-Desvoidy a une section de la famille des AI yodaircs calyptérées, qui a pour type le genre Dufouria.

DUMicoLE, adj. , dumicola (dumus, huisson, colo, habitcr); qui vit dims les taillis, dans les brousstilles. Ex. Sy.lvia dunicola.

DUNE, s. I. , Sandhïgel (all.); down (angl.). Colline de sable mobile, que les rents dominans sur une plagc accuinulent près des bords de la iner, et font avancer peu à peu dans l'intérieur des terres

DUODÉCLMFIOE, adj., dreodccimfidus (duodecim, douze, findo, fendre). Se dit du calice, quand il offre douze divisions égales à la moilić de sa longuenr totale. Ex. Peplis.

DuonḱcivLobí, adj., bisscxlobatus (duodecim, douze, lobus, lobe); qui a douze lobes. La Coronula bisscxlobata est une coquille formée de six pièces litlohées.

DUodéciuponctué, adj., duodecimpunetatus (duodecim, douze, punctum, point); qui cst marqué de donze points. Ex. Coecinella duoelecim-punctuta.

DUODÉCITERVAL, adj., duodecitcrnalis. Noun donné, daus la nomenclature minéralogique de Haiiy, ì une variété de topaze dont le prisme est à douze pans, et dont le sommel supérieur se termine par unc face perpendiculaire à l'axe, cntre deux ohliqques.

nบonÉs ARE, adj., duotenarius. Waclicndorff cmployait ce mot comme synnnyme de dorlécandie.

vUOTRIGÉSLILL, adj. , dıotrigesimalis. Nom donné, daus la nomenclature minéralogique de Haïy, à ut:c varićté dont la surface est 
composíe de trente-deux facettes. Ex. Chaux carbonatée duotrigésimale.

DUPLICATEUR, s.m., duplicator; Elekiricitïtsucrdoppler (all.). Bennet a fait connin̂tre sous ce nom un appareil propre a cnlliger des quantités d'électricité trop faibles pour êlre apprćciables à l'électromètre mòme le plus scusible, jusqu'i ce qu'elles aient acquis assez de tension pour produire des plićnomènes ślectriques bien manifestes. Nicho!son, en $y$ joignant un mécanisme, y a fait uu perfectionnement, que Bolinenberger a depuis modifić aussi.

DUPLICATILE, adj., duplieatilis (duplex, doulule). Epiphète donnée anx ailes des insectes, quand elles se ployent en tinvers. Ex. Colioptéres. DUPLICATO-CRÉNELÉ, alljeet., deplicato-srenatus. Se dil d'une faille dont les erénelures sont ellesmènes crénclées. Ex. Chrysosplerium alternifolium.

DLPLIGATO-DENTELE, adj., duplicalo-serralus. Se dit d'une feuille dont les dentelures sont elles-mèmes dentelées. Ex. Ulmus campestris.

I) UPLICIDENTÉs, adj. et s. m. pl, Duplicidentala (duplex, double, dens, dent). Nom donné par Illiger, Goldfuss, Ficinus et Carns à unc famille de rongeurs, comprenant cenx qui ont quatre ineisives à la mâchoirc supérieure.

DURLICIPENNES, adj. et s. m. pl., Duplicipennes (duplex, double, Penna, aile). Nom sous lequel Duméril désigne une fumille de l'ordre des insectes IIyménoplères, comprenant cux dont les niles supérieures forment un pli longitudinal, lorsque laninal est cen rejos.

DUPLOCONE, adj. , duploconus (duplex, double, coruss, cóne); qui a la forme de deux cônes superposés. Ex. Balanus duplocontes.

Dun, adj., durus; arknoo's; hare (all.); hard (angl.); duro (it.). Se dit, au sens propre, $\mathrm{d}^{\prime} u$ n corps qui résiste ¿t l'action d'un choc tendant à le briser, qui ne cède pats quand on le presse entre les doights, qu'on ne peut evtaner avec l'ongle ou avee un instrument tranchint; et, au sens figurć, de ce qui llesse un organe de sens par son âpreté, soit l'oreille (voix dure, sondur), soit la langue, eonme les caux dures, ou chargées de sels ealcaires, qui sont en outre impropres ì cuire les légunes.

DURAMEN, s. m., duramen. Dntroclict propose d'appeler ainsi le bois parfiait ou le cour du bois.

DunúE, subst. fém. , longinquitas, ecmporis spalium ; otzuovin ; Dauer (all.); duration (angl.); durata (it.). Temps plus ou moins long pendant lequel peut se prolonger l'existence d'un corps ou la manifestation d'un phénomène quelconque.

vunetrí, s. f., duritia, duritias,

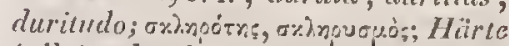
(ill.) ; hardness (angl.); durezad (it.). Génćralement, on appelle ainsi la résistance d'un corps ì tout effort quelennque qui tend à le diviser, d'oir il suit que, quand on parle de cctie propriété, à l'oecasion d'une substance domé, il faut toujours annoncer de quelle inanière ou s'y prend pour l'éprouver. Aussi, en minéralogie, entend-ou par dureté d'un corps la résistance qu'on rencontre lorsqu'on cherehe ì l'entancr avec un instrument, ì le rayer ou à l'user avec un autre corps.

DURIVENTIE, adj., duriventris (durtus, dur, venter, ventre); qui a le ventre dur ou rude. Ex. Mytetes duriventris.

DUVET, s. m., arium molliores pluma; háxwn; Flaumhaare (all.); down (angl.). On donne ee unm à de petites plumes dont la tige est très-faible, et yui sont garnies de harbes alongées, plus ou moins crêpues, uon altachées ensenible par 
leurs barbules. On l'applique nussi (poil follet; lanuga ; isulos; Milchhaare (all.), aux petils poils doux et flexibles qui garnissent le menton des adolescens. Enfin les Intanistes le donnent par extension à des poils mous et peu nombreux qui se développent sur diverses partiıs, dans les végélaux.

DUVEré, adj., flaumiog (all.); downy (augl.). On nomme plantes dupctées celles qui sont couvertes de poils courts, donx et peu scrrés ("x. Circaza luteliana. Voyez Pubescent); plumes duvetées, celles dnnt les barbes et barbules s'alongent en un duvet fin et soyeux (ex. Chouct(es).

DrNauLe, s.f. On appelle ainsi, ou zenite dynamique, eelui des effets dont les forces sont eapables qu'on ehoisit pour terme de comparaison, lorsqu'on veul meanter ces forces̀ ou plutôt leurs effels. On peut nommer dynamie, par cxemple, la force capable d'élever un kilograume à un mètre de hauteur. Diru alors qu'une force vaut cent dynamies, e'est exprimer qu'elle pent élever dans un temps convenu eent kilogrammes à un mètre, ou vingt kilogramnes a cinq mètres, ctc.

DYNAMUQEe, adi. , dyamicus. Monge appelait effet djramique le résultat de l'emploi d'une foree, ou le nombre d'unités dynamiques ́voyez Dxname) qui en mesurent l'eflet. C'est ce que Conlomb nommait quantité d'action, Sulcalion, puissrance mécanique, et Carnot, moment d'activité. Or cette quantité est le produit le la prission du motcur sur le mobile, mullipliéc par l'espace que ce dernier parcourt dans le sens de la pression.

DYNANH@UE, sulsst. f., dynamica (ơvque, foree). Lxpression, introduite par Leiluuiz, pour désigner la partie la plus abstraite de la mécanique, celle dont l'objet sst de se.

\section{DYSC}

livrer à des réchercues sur les forces motriees en général et sur les lois des monvemens qui en résultent.

D INAMISUE, s. m., dynamismus. Système qui établit que la matic̀re n'a point d'existence par elle-mème, qu'elle est le résuliat de la tendance cn scus opposés de deux forees, l'une contractive, l'autre expansive, dont la première, si clle parvcıait á subjuguer l'antre totalemenl, réduirait l.a matière à n'ètre qu'un point mathématique.

DIN.AMISTE, s. m., dynamista. Partisan des doctrines du dynamisme.

DYNAMOLOGIE, s. f., dynamo-

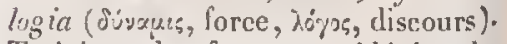
Traité sur les forces considérées abstraclivement.

DYNAWOULTRE, s. m., dynamometmum ; Kraftmesser (all.) ( oj-

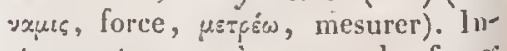
strument propre à mesurer les forces d'un homme, d'un animal, ou do moleur d'une machine, dans certaines circonstances donuées. Graham, Jeroy et Regrnier ont imaginé des instrumens de ec genre. Celui de Riegnicr est le plus eommode et le mcilleur; cependant G.-G. Munke l'a modifié depuis. - On employe gualquefois le mot de dynamomeitr comue synonyme d'auxomètrc. Voy. ee mot.

DIS.ISPISTES, adj. et s. m. pl., Dysaspistes (dis, marque de privar tion, ¿̇sтis, plaque). Nom donlué par J.-A. Ritgen à une division dil groupe des Hémichalinaspistes, con'r prenant les serpens qui n'ont qu'un petit nombre de plaques sur le eorps.

DISCOLOBBATHISTES, adj. at s. m. pl., Dyscolobathristes (d̛́r

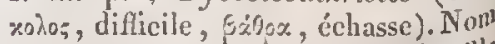
donné par J.-A. Ritgen à unc famille de l'ordre des Limnoptènes, compre" nant des oiseaux qui ont les jambes longues, presque en échasses.

DISCOPIDOPTLives, adj. ets. m. 
pl., Dyscopidlopteni (Jis, à demi,

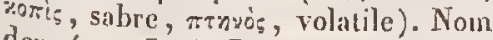
donné par J.-A. Ritgen à une famille de l'ordre des Haliptenes, comprenant des oiseaux qui ont les ailes à demi en forme de salure.

DYsicunes, adj. et s. m. pl.,

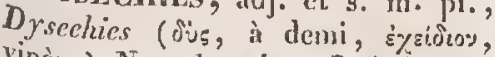
vipère). Nom douné par J.-A. Pitgen it un groupe de l'ordre des Aspistes, renfermant les ophidiens qui ont à la mâchoire supérieure des dents ordimaires et des crochets ì veniu.

DYSEDEtes, adj. et s. m. pl., Dysereta (ờ , à demi, s̊óctns, rameur). Nom donné par J.-A. Kiigen à une famille de l'ordre des Halicolymbes, comprenant des oiseanx qui nagent sur l'eau avec des moignons de bras.

DISG MMNOPIIIES, adj. ct s. $m$. pl., Dysgrmnophides (dus, à demi, 7นpyò, nu, öpes, serpent). Nom donné par J.-A. Ritgen à une section de l'ordre des Sirepsichrotes, contprenant les serpens qui n'ont que tris-pen d'ćcailles sur le corps.

DYSGYRIOPIIDES, adj. et s.m. pl., Dysogriophides (ờ, à demi, Y'pes, circulaire, osots, serpent). $\mathrm{N}_{0 \text { in }}$ donné par J.-A. Ritgen à une section de l'ordre de Strepsichrotes, comprewant des serpens qui ne peuvent rouler lcur corps qu'ineomplètement.

DYSú́rontaxs, adject. et s. $\mathrm{m}$. ll., Dysherorlii (divs, à demi, spódiş, héron). Nom domé par J.-A. Ritgen a une famille de l'ordre des Colobal 3 ropodes, comprenant des deisenux qui se rapprochent beancoup sérons.

DYSHERTYES, adj, et s. m. pl., p(iv). Nom donné par J.-A. Ritgen ì une famille du groupe des Holodontaspistes, comprenant des ophidiens qui, comme l'amphisbènc, rampent difficilenent.

DISMOLGES, adj. et s. m. pl.,

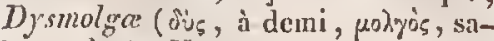
lamandre). Noin donné par J.-A. Ritgen à une section de l'ordre des Uromolges, comprenant des batraciens qui ressemblent beancoup aux salamandres, comme les sirènes.

DrsODLs, adj. et s. m. pl., Dy-

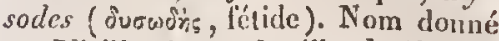
par Vicillot à une famille de l'ordre des Sy!vains, par Latreille, Ficinus et Carus à unc fannille de celui des Passcrigalles, par Lesson à une famille de celui des Grimpeurs, comprewant un seul oiscau, dont la chair exhale l'odeur désagrćable du castoréum.

DYSSODIEEs, adj. et s. f. pl., Dyssodica. Nom douné par H. Cassini à une section de la tribu des Tagélinées, qui a pour type le genre Drssodia.

DISSYMETRIE, s. f., dyssymetria. Défaut de symétrie, comme lorsque les cristaux d'une substance minérale sont groupés en sens inverse.

DYTiCIDEs, adject. et s. m. pl., Dyticida. Nom donné par Leach à unc famille del'ordre des Coléoptères, ayant pour type le genre Dy-tiscts.

Drercites, adject. et s. m. pl., Djticites. Nom donné par Latrcille á un groupe de la triluu des Hydrocanthares, qui a pour type le genre $D_{y}$ tiscus.

DYTIQIES, adject. et s. m. pl. (ourtzios, plongeur). Nom donné pat Ranzani à unc famille de l'ordre des niseaux Plongeurs, comprenant ceux qui out l'uahitude de plonger. 
EAU, s. f., aqua; ürwp; WVasser (all.); wwater (angl.); acqua (it.). Liquide qui résulte de la combinaison de l'oxigène avee l'hydrogène. Les chimistes nomment eau mère le liquide qui reste après la eristallisation d'une ou plusieurs substances qu'il tenait en dissolution, celui qui, ayant déjì donné des eristaux, ne peut plus en fournir dans les mèrnes circonstances où il avait produit les premiers. En minéralogie, le terme d'eau exprime un genre de transparenee et de limpidité que présentent les pierıes gemmes. On appelle cau de eristallisation celle qui se trouve répandue entre les parties intégrantes de ecrtains cristaux, qui est ntême une condition indispensable de l'existence de plusieurs sels, et qui, dans tous les cas, s'y rencontre en quantité déterminéc et telle que l'oxigène qu'elle contient est un inultiple, parfois aussi un sous-multiple, par un nombre entier, de l'oxigène de la loase.

Ĺ3ARBuLÉ, adj., cbarbulalus. Épithète donnéc aux quatre ou cing pennes de l'ai!e du casoar, qui sont lépourvues de barbes et qui ressemblent à des piquans de pore-épic.

EsBucait, adj., inchoatus. Latreille donno ectle épithète à une métamorphose qui aeeroit le nombre des pieds et quelquefois celui des anneaux. di corps (ex. Iule, Scolopendre, Nonoele).

EBRNACEEs, adject. et s.f. pl., Ebenaece. Nom donné par Jussicu à une famille de plantes, dont fuil partie l'arbre qui fouruit le bois d'ébine (Diospyros Ebenum).

GBOULIS, s. m. Omalitis appelle ainsi les dépôts moderues ou postéricurs aux dernières révolutions du globe, qui ont élé produits par éboulement, et qui, ai licu de former des assises superficielles, cont posent souvent des talus de montagnes et quelquefois des fitons ou des amas.

EBRACTÉLt:, adj., cbraeteolatus; qui est dépourvu de braetéoles (vores ee mot), comme le ealice du 'Tephrosia candida.

ÉRRACTÉTE, adj. , ebractealus; deckblaulos (all.); qui n'a point de bractées. Ex. Quisqualis cbractcala, Thesium elracteatum.

EBuLcirrov, subst. f. , cbullitio;

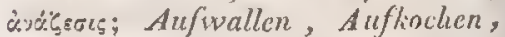
Aufsieden (all.); ebollimento (it.). Mouvement violent d'un liquide soumis àl'action du calorique, que produisent les grosses bulles auxquelles dounent naissance eelles de ses parties inférieures qui, réduites à l'état de vapcursur' les points oì s'applique plus partieulicrementla chaleur, deviennent par cela même plus légères, traversent toutes les eouches supérieures, et viennent ercver à la surface. Tuis les liquides ne bouillent pas à la même temp’rature, sous la pression moyenne de l'atmosphère, et ils exigent une températurc ou plus laate ou plus basse suivant quon augmente ou qu'ou diminn ectle pression. Tant que celle-ci reste la mème, la température d'un liquide qui a commencé à bouillir ve changc plus.

Binurux, adj., eburnerts; elfenbeinarig (all.) (ebur, ivoire). Se dit, cu histoire naturelle, de corp $p^{5}$ qui ont la blanclieur et l'apparence de l'ivoirc. Ex. Larus eburneus, Conus cburneus, Clayaria cburnea, Dentalium cburneum.

BCAILLE, s. f., squanta, 1 egmen* lum; >smis; Scluppe (all.); scalc 
(ang!.); scaglia (it.). On emploie ce mot: $1^{0}$ en botanique. Le mot d'ccaille, qu'on y applique en géuéral a de petits eorps planes et pointus, placés sur divers points de la surface des végćtaux, a par eela inême une signifieation très-vagne. En effet, on donne ce nom à des espèces de disques peliés qui semblent formćs par la soudure habituclle de plusicurs poils rayonnans sur le mème point ( $\mathrm{cx}$. Élaeagnus angustifolius); à des poils élargis, scarieux et dilatés, au moins ¿l la base, qui garnissent les pétioles des fongères; anx indusies de ces plantes, d'après Linné; à des expanle fruit des Synanthérées et de quelques Dipsacées; à des appendices membraneux qui font partic du caliec (ex. Salsola), ou de la gorge de a corolle (cx. Nerium); aux laures, en forme de cuiller ou d'écuille de poisson, qui constituent l'oignon du lis; à la glande neelarifère qui garnit l'onglet de chaeun des pétales des renoneules; il de petits corps planes qui sont des rudimens de feuilles avortées ou d'organes analogues, stiPules, braetées, sépales, on même dautres organes rédnits à de trìspetites dimensions ( ainsi les écailles du calice des œillets sont des bractées; celles des rameaux du Picletia squenmala des stipules; celles des involucres des Composées ct des Dipsacées des feuilles; eelles qu'on trouve entre lesfleurs des Composécs, des brietécs arorlées; celles de cerlaines aigretles de Synanthérées, des pièces du eildes, aussi bien que eelles des cônes et et glumes de plusieurs Graminces les bouracées; celles qui culourent avourgeons, des rudimens ou des avortons, tantót de pétioles (cx. Samriodes ), tantôt de stipules (ex. Lifeuillendron), tantôt dc feuilles). Les cailles prennent l'apparence d'ćcailles dans la portion enfouie en terre des plantes lierbacées et vivaces ; elles l'affectent mème darns la portion aérienne des Orobranches ct de la Clandestine. 20 En zoologie. On appelle icailles les lames minees et aplaties dont la peau de la plupart des poissons est recouverte; les petites plaques cornées ou osseuses qui garnissent le corps dn plus grand nombre des Sauriens et des Oplidiens, la queue de divers Manmifères (Castor, lial), le eorps de quclques uns d'entre eux (ex. Pangolin), les pattes des oiseaux, les ailes des manehots, et les bords des doights de quelques échassiers; les plaques imbriquées qui recouvrent la carapace du Chclonia imbricata, et auxquelles s'applique spécialement le non d'écraille dans le commerce; les petites membranules pellueides et farinacées que produit l'épiderıne des mammifüres ct des oiseaux, en se détachant; les valves de la coquille de l'huittre ct d'autres bivalves; une pelite plaque cornće et verticale qui se remarque sur le pétiolc de l'abdo. men des fourmis.

ECALLETYE, s.f. , squamula, tegrula.Petite éeaille eornée, ayant la forme d'une valve de equille dont Ja coneavité rugarderait en dessus, qu'on voit à la naissance des ailes des gruêpes.

ículitex, adjet. , squamatus, squamosus, squamulosus, frle-

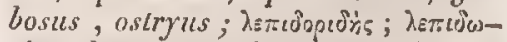
ròs; beschuppt (all.); scaly (ang.); scaglioso, squamoso (it.); qui est aceompagné d'éenilles, ou en forme d'écaille. On emploie ce terme : $1^{\circ} \mathrm{en}$ minéralogrie. On donne eette épithète à une varićté de miea, dont les masses sont composées d'une infinité de parcelles qui se délaehent aisćmcnt par l'action du doigt. $2^{\circ}$ En botanijue, on appelle aigreue ćcailleuse, celle qui résulte d'un assemblage d'ćcailles; bouton ćcailleux, celui qui 
est enveloppé d'écailles; bulbe écailleuse, celle dans laquelle les feuilles extérieures, naissant de la tige snuterraine, sont réduitcs à l'ćlat d'éeailles charnucs, rétrécies à la base (cx. Lis); bulbille écaillcuse, cclle qui est composée d'écailles (ex. Lilium bulbiferum); hampe écailleuse, celle qui porte des rudimens de f'cuilles comparables à des écailles (ex. Tussilago Farfara); péricarpe écailleux, celui qui cst couvert d'écailles imbriquécs, furfurneées (ex. Coronilla squamata); pérule écaillense, cclle qui est composée d'écailles appliquées les unes contrc les autres ( $\mathrm{ex}$. Daphne) ; racinc écailleuse, celle qui est couverte d'écailles (ex. Lathrac Squamaria); lige écaillcuse, celle qui porte des ćcailles (ex. Orobanche major); rameaux écailleux ( ex. Pictetia squamata). Le Carpinus ostrya a élé appelé ainsi, parce que ses fruits sont formés de capsulcs agréegées ct aplatics, qui rcssemblent it de petites écailles; l'Agaricus lepiderts et l'Agaricus pholideus, parce que lenr chapeau est chargé de petites écailles. $3^{\circ}$ En zoologie, on dit les pieds des oiseanx écaillcur., quand ils présentent toutes sortes d'ćcailles, et lcs ailes des insectcs écaillentses, lorsqu'ellcs sont recouvertes d'une poussière dont les grains, vus à la Joupe, ressemblent à des écailles imbriqućes. Une coquille bivalve cst dite ćcaillcusc, quand ses côtćs ou sa surfaec offrent des éminences minces, aplatics ct saillantes, simples et non découpécs sur les bords (ex. Bénitier), ou découpées à leur circonférence cn plusicurs appendices inégaux (cx. Clucme fcuilletéc).

richilLELx, adj. et sulssl. in. pl., squamosa, Squanata. Nom domé par P.-F. Filzinger à the tribu, par Merren ct Iatreille ì une section de lin elnse des Reptiles, compremant ceux dont le corps n'offre que des ćcailles, qui ne constituent pas une véritable cuirasse.

ÉCALYPTREES, adj. el s. f. pl. Ecalyptrati.Hoffmann donnait le nom de Airesci ccalyptrati aux Hépatiques, parce que lenr fructification n'est pas couverte d'une coiffe, comme celle des nousses.

Écalpptrocarpes, adj. et s. f. pl., Ecalyptrocarpa. Luhnemanı appelait ainsi les Hépatiques, par le méme motif que celui qui est cxposé dans l'article précédent.

ÉCARLATE, adject., coccineus, flammcus; qui est d'un rouge vif ct éclatint. Ex. Indomychus coccineus, Quercus coccinea, Zygoply llum coccineum, Emilia flammea.

I:CARTE, adject., distans, divergens; entfornt, zerstrcul, ausgewichen (all.). Les entomologistes donnent celte ćpithète aux pattes des insectcs, quand les paires en sont ćloignćes les uncs des antres à leur base, comıne les pattes intermédiaires des Copris.

ECASTAPIILLE, adj. , ccastaphyllus ( $\tilde{x} \times \sigma \sigma \tau 05$, chacun à part, qừ-

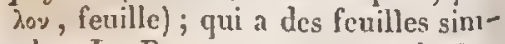
ples. Le Ptcrocarpus ecastaphyllum est ainsi appelé parce qu'il n'a pas les feuilles composćcs, comme les autres espèces du genre.

ECALDÉ, adj, , ecrudatus; unbcschwü̈nzt (all.); qui 11 'a pas de queue (ex. Gallus ccaudatus, Glossoplaga ccaudala); qui cn a unt trics-courte (ex. T'eratlopius ecaut datus).

ECALDÉs, adj.et s.m. pl., Ecat" dala, Ecaudati. Norn donuc par Du" méril à une familic de l'ordre dc\$. Batraciens, comprenant ceux $\mathrm{q}^{1 \mathrm{il}}$ n'ont pas de queue (voyez A rounes), et par Latreille a un ordre de la classe des Gymnogènes, qui renferme ceux chez lesquels on ne roit pas de queuc. 
ĹCMANCRÉ, adj., cmarginatus. Voyez EMarginé.

ÉCHASSIER, adj. , grallarius. Sc dit d'un oiseau qui a ics janbes très-longues, comme des échasses. $\mathrm{E}_{\mathrm{x}}$. Vanellus granarius.

ÉCHASSIEIS, adj. et s. m. pl., Grallas, Grallatores. Nom donné par Linné, Cuvier, Duméril, Vigors, Vieillot, Meyer et Wolf, Illiger, Goldluss, Ficinus et Carus, Blainville, Temminck, Latreille, Ranzani, C. Bonaparte, Eichwald et Lesson à un ordre de la classe des oiseaux, comprenant ccux qui ont les tarses longs et grêles, et qui sembent être niontés sur des échiasses. GCHeLLE, s. f., seale; Tonlciter (all.). On appelle ainsi, en musique, la série des sons successifs que renferme unc octave. Cette manière de pirler des sons, qui donnerait ì eroire Tu’ils sont placćs à différens degrés les uns des autres, est un laogage figuré qu'ont suggèré les apparences, et îuquel les morlernes ont assorti aussi leur système de notation, les notes représentatives des sous étant rangécs en manière d'échelons sur l's Dortées de notre musique. On distinSu. en Europe, trois échelles musicale appelées chromatique, diatonique "l onharmonipue. Voyes ces mots.

ÉCHévorr's, $\mathbf{s}$, adj. et s. m. pl. , Echenö̈dci. Non. Jonné par Eich wald à une famille de Pusuns osscux malacoptérygiens, qui pour type le genre Echeneis.

ĹCuIES, s. m. pl., L.

vipère). Noin donnć par Jos ( ${ }^{*} / \iota_{5}$, gen ả un groupe de reptiles oph hitrenfermant les scrpens armés de ' $₹$, chets à venin.

ÉCIINARACÉES, adj. et s. f.pl., Echinariacea. Noun donné par Linli a unc tribu de la famille des Graminées, qui a pour type le genre Echinaria.
Lamivi, adj., echinalus; stach-

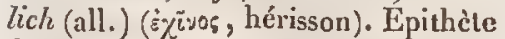
donnéc á tonte partic d'un végétal qui est hérissćc de poils raides, corame le fruit du Bignonia celuinata.

ÉCIIINúENS, adj. et s. m. pl., Echinei (Èyivos, hérisson). Nom donné par Desinarest á une famille de Mammifères, qui a pour type le geure Hérisson.

ĆCIHNELLEES, adj. ct s. f. pl., Echinellev. Nom donné par Fries à une tribu de la famille des Diatomécs, et par Reichenbacl à une tribu de celle des Confcrvacées, ayant pour type lc genre Echinella.

ÉCIINIDES, adj. et s. m. pl., Echinida, Echinides, Echidna. Nom doune par Lamarck à une section de la elasse des Radiaires échinodcrmes, jenfermant ceux de ces animaux qui sont plus ou moins voisins du genre Echinus, et par Blainville à un ordie de la classe des Polycérodermaires, comprenant ceux qui ont le corps soutenu par un test calcaire et hérissé d'épines raides.

ÚCIINIY'DE, adj., celinipes; qui a les pattes hérissées de poils raides ou de piquans. Ex. Caculus echinipes.

ÉCnINITE, adj., echinites ('́xivos, hérisson ); qui est lićrissé d'épines. Ex. Asterias celinitcs.

ÉCHINOCARIE, adj., echinocar-

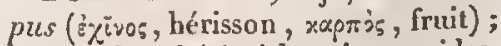
qui a le fruit hérissć de pointes raides. Ex. Randia echinocarpa , Cymbizm echinocarpum.

HCIINODERMIIRES, adj. et s. m. pl., Echinoderma (Exivos, hérisson, déppex, peau). Nom donné par Blainville à unc classe d'Aetinooaires, comprenant ceux dont le éps est cnveloppé d'une peau part, nolic ou sulidifićc par des est inceleaires. Cctte dénomination i tous lesiante, nes'appliquant pas 'atux qu'clle embrasse. 
ACMIVODFRMES, adj. ct s. m. pl., Eclinoderma, Echinodermata (Ėzìo;, hérisson, sépuc, peau). Nom donné par Lamarck à un ordre de la classe des Radiaires, par Cuvicr et Latreille à une classe du règne animal, par Eichwald à un ordrede la elasse des Cyclozoaires, coupes qui toutes renferment des animanx à peau coriace ou crustacće, le plus souvent arınéc de tubercules, de pointes ou d'épincs.

ÉCIINOIDEs, adj. et s. m. pl.,

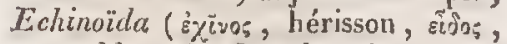
ressemblancc). Nom donné par $\mathrm{La}-$ ireille à un ordre de la classe des Echinodermes, comprenant ceux qui ont de la ressemblance avec un oursin (Echinus).

ECHINOPEES, adj. et s. f. pl., Echinopece. Nonı donné par Caudolle à une section des Cynarocéplates, qui a pour type le genre Echinops.

ECHINorilles, adj. , cchinophi-

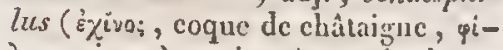
$\lambda_{\varepsilon \omega}$, aimer) ; qui croît sur les involucres des chấtaigues. Ex. Pcaiza. cchinophila.

ECHINOPHORE, adj. , cclinoplen-

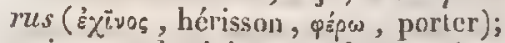
qui porte des épincs nombreuses (cx. Astcrias echinophora), ou des tubercules verruciformes (cx. Cassidaria cclinophora).

LGHINOrODES, adject. et s. f. pl., Echinopodece. Nom donné par II. Cassini à une tribu de la famille des Synanthérées, qui a pour type le genic Echinopus.

\section{DÉEs. \\ EGIInOPSÉls. Voycz Echivopsi-}

ECHinonswotes, adj. ct s.f. pl., Eclinopsirlce. Nom donné par L.-C. Richard ì une section de la family des Synanthérées, par Kunth jug division de celle fimille, parts $\mathrm{Ci}_{\mathrm{i}}$ a nue sous-nibu de la trile genre nircées, ayant pour $\mathrm{t}^{\mathrm{r}}$ Echirops.

\section{ÉCLA}

v́cmnostones, adj. et s. m.pl, Echinostomata (é₹ivos, hérisson, oró$\mu a$, bouche). Nom donné par Latrcille à une famille d'EIminthogames lombricoïdes, compremant ceux qui ont la bouche armée de dents oude crochets.

licunutí, adj., echinulatus; qui est hérissé de pctites épines ou de petits lubercules, comme la partie inférieure de la feuille et les squames du péricline de l'Homoianthus echinulntus, ou le dernier tour de la coquille du Purpura echinulata.

ÉCHINUnE, adj., echinurus ( $\dot{2} \chi^{\mathrm{i}}$ yos, hérisson, sjoc, queuc). La Salia cchinura est ainsi appelée parce que l'anus porte des appendices, dans les mâles.

ÉCHITÉEs, adj, et s. f. pl., Echitca. Nom donné par Bartling à une tribu de la famille des Apocynées, qui a pour type le genrc Echites.

f́cillnE, adj., cchiurus ( $\chi^{i} \vee 05$, hérisson, oùó̀, (queue); qui a la queve hérissée. Le Thalasscma cchiurus est aiusi appclć parce qu'il a l'extrémitć posléricurc du corps hèrissce d'épines raides.

CCHuches, adj. ct s. m. pl.: Echiuri. Nom donné par Savigny a une famille de l'ordre des Araelides lombricines, qui ne compr ad que le genre Thalassema.

Écirvtrides, ar et s. m. pl., Echiuridea. Non dounć par Blainville à une far.lle de Chétopodes homocriciens renfermant lc Thalassema, ilt. rappros, sti.

Nín, s. m., ccho; IVicderhall Giéchi par son ). Répétition da son laquelle ecttc répéps; localité dans tendre.

GChonvirre. $V$. Mítrovome. ECLALR, s. m., fulgur; IV cllerslrahl, Blitz (all.); lightuing (angl.). Lacur subite, plus ou moins vive, 
ou presque instantanée, que répandent, daus l'espace qu' embrasse l'horizon d'un lien, le sillonnemens lumineux tracés par les nuasses d'électricité atmosphérique, quaud elles se transportent, à travers l'air, d'un Mage à un autre, ou d'une partie sur nne autre d'un mêne nuage. On appelle éclairs de chaleur ceux qui, d'après l'explicalion qu'en a donnće Gay-Lnissac, paraissent ì peu près dans l'horizon, et ne sont suivis d'aucun bruit, paree que le nuage ou ils ont licu est trop éloigné pour que le son, qui se propage beaucoup moins que la lumière, se fasse entendre.

ECLAT, sulist. m. , fulgor, splendor ; äiryh ; Glanz ( all. ); Lrightness (augl.); lucentczza (it.). $\mathrm{O}_{11}$ appelic ainsi le phénomène tenant à la vivacité et à l'intensité avec lesquelles la lumière frappe nos yeux, quand la surface naturellement ou artificiellement polie d'un corps la renvoye en très-grande quantité daus une même direction. Il $\mathrm{y} a$, daus l'éelat, denx effets différens, dont l'un tient à la réllexion de la lumière, ct varie suivant le degré de poli du corps, la finesse de son grain, ct sa structure, tandis que l'autre dépend de l'aetion même excrée par lui sur la lumière, qui cn pénètre pour ainsi dire la pelliculc avant d'être renvoyée à l'ocil.

LCLATANT, adj. , fulgidus, fulgens. Dont les couleurs ont beaucoup d'ćclat. Ex. Xeranthemum fulgidum.

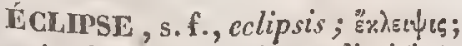
rcstirnfinstcrniss (all.); cclissi (it.). Disparition instantanéc, totalc ou partielle, d'un astre, par l'effet de l'interposition d'un corps opaque entre lui et l'ocil de l'observateur', ou entre lui et celui dout il reçoit la lunière.

ECLIPTíES, adject. et s. f. pl., Ecliptece. Nom donné par Lessing à une sous-tribu de la tribu des Asté- roidées, qui a pour type le genre Eclipta.

ECLIPTIQUE, s. f., eclipticus ; Sonncnbahn (all.); colittico (it.). Orbe que déerit la terre darss son mouvement annuel autour du solcil, yue ce dernier semble pareourir lui-mèrne, et qui traverse la série des douze constellations zodiacales. Grand eercle fixe suivant lequel le plan prolongé de l'orbe terrestre va couper la sphère céleste. Le mot écliptique, qui vient de ec que la lune se trouve toujours dans ce plan ou auprès lorsqn'il y a éclipse, a été introduit par les grammairiens modernes. Les astronones grees se servaient d'une périphrase :

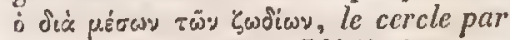
le milien des signes. L'écliptique est inclince de $23^{\circ} 28^{\prime}$ sur le plan de l'éqnateur céleste. Voyez Onfiqurtí.

recosion, s. f., exclusio; Auskriechen (all.). On s'est quelquefois servi de ce mot pour désigner la sortie des petits hors de l'neuf.

ECNÉPIIL, s.f. , concphia ; $\dot{\varepsilon} \times y \varepsilon-$ piaş. Vent violent qui paraît s'élancer d'un muage.

ÉCONOMIE, s. f., aeonomia;

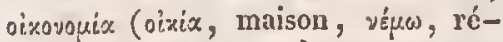
gler). Terine vague dont on se sert pour désigner l'ensemble des lois qui régissent l'organisation des animaux ct des végétaux, l'ordre et l'enchaînement des phénomènes qui s’olsservent dans les rorps organisés.

ECOnCE, s. f., cortex; ploxos; Rinde (all.); rind, bark (angl.); cortcceia, scorza (it.). Partie la plus extérieure de la tige des végétaux. herbacés et ligneux, mais plus particulièrenent des dieotylédions. On appelle, par analogie, écorce de la terre (Erdrinde, all.) lia croûte extérieure et superficielle de la terre, dont ou présume que l'épaisseur moyentue ne dćpasse pas vingt lienes, et qui présente aussi de grandes irrégularités.

CCORGE, adject., excorticalus; 
qui n'a pas d'écoree. Isc Fuchsia excorlicala cst ainsi appelć à eause de son trone très-lisse, qui semble avoir été dépouillé d'écorce.

LCChASÉ, adj., obtritus, depressus. Épithètc donnée à la spire d'unc coquille spirivalve, quand sa marche en sens vertieal est peu rapide en comparaison de celle en sens opposé. Ex. Solarium.

ÉGrix, adj. , scriplus, litlcratus, graphieus, glyphicus, signatus, signiferus; buchstabeniillnlich, schrifiälınlich (all.). Épithète donuéc à des corps qui offrent des taches ayant de la ressemblance avee des caraetères d'éeriture (ex. Cytherea scripta, Cymbidium scriptum, Crenilabrus scriptura, Cerithum littcra. tum, Venus litteruta, Conus litteratus Cylherea graphica, Noctua glyphica, Noctua signata, Noetua signifera, Heilipus calasraphus). On précise quelquefois davantage ce terme, en comparant les taches, soit aux caractères d'une écriture donnée (ex. Conus hebraicus, Cytherea hebraca, Coccinella hicroglyphica, Nocluagothica, Noctua runica), soit aux dessins d'une carte de géographic (cx. Noctun gcographica), soit à une lettre en général (ex. Nocuza litura), soit à quelque lettre ou signe d'éeriture en particulier (ex. Alica s. lintcra, Noclua iola, Leplura exclamationis, Noctua interrogationis, Noctua questionis).

ECroursseueNt', s. m., metalli frigidi excusio; Hürtcn.(all.); hardcring (angl.). Augmentation de dureté et de densité qu'on fivit acquérir à plusicurs métaux duetiles, cn les baitint à froid pendant un laps de temps sufisant, ou cn les fiisant passer ì travers les trous sucessifs de la filicre, ec qui les rend aigres el cassans.

ECTOCAnpés, adj. et s.f. pl., Eclocarpece. Nom dome par Agardh

\section{ECUS}

à une famille de Confervacées, qui a pour type le genre Ectocarpas.

FCTOPULEODE, adjeet. , cclophlocodes (śx-òs, ell dehors, plocós, ceorce). Wallroth appelle morphosis ectophlocodes le développement des lichens qui naissent à la surface extćrieure d'autres plantes.

ECTOPIE, subst. f. , eclopia (z’, hors de, тiтrs, lice). Nom donné par Breschet à un genrc de déviations organiques, comprenant eelles qui sont caractérisées par une anomalic queleonque dans la situation des organes en partieulici.

ECTOpOGONES, adj. et s. m. pl., Eclopogoni, Ectopogones (E்ròs, cu dehors, тìjwy, barbe). Nom donné par Palisot-Beaurois à une tribu de IVousses, comprenant eclles dont l'orifice de l'urne est garni de deuts doubles on fendues, qui composent un péristome externe.

ECU, s. m., scutum. Audouin appelle ainsi la seconde des quatre pièces prineipales qui forment la partie supérienre on le tergum de chaeun des trois segmens du thorux des inscetes hexapodes. Vay. Tironax.

ECUnIL, s. m., scopulus; Klippe (all.); quicksand (angl.); scoglio(it.). Petile pointe de terre ferme qui s'ćlève au milicu de la mer, on qui, sans êtrc tout-à-fiit découverte, s'approche assez de la surface pour gener la naviration.

ECUMEUx, adject., spumosus, spumeus, spumarius; qui porle de l'ćcume. Le Cercopis spumarius est ainsi appelé, parce que sa larve s'cnveloppe d'une liqueur ćcumeuse qui la fait ressembler à un erachat.

DCUSSON, s. m., sculclium, scutum; ürtis. Ce terme est cmployé : $L^{0}$ en botanique. Il y désigne les conceptacles des lichens, et alors il est synonyme de setuclle; le disque circulaire qui entoure le capuchon des Stapelic, et remplace souvent les lan- 
guettcs; enfin, d'après Palisot-Beauvois, la tache basilaire latérale formée, à la grime des graminées, par le blaste et l'hypoblaste non encore développés. $2^{\circ}$ En zoologic, on appelle ainsi des pièces de différentes formes que présente lit peac dont les tarses et les doigts des oiscaux sont recouverts; les plaques i ealcaires qui sont contenues dans l'épaisscur de la peau de eertains poissons (ex. Cofre, Esturgeon); d'a près Brugniçre, Draparnaud et Lamarek, une dépression longue et un peu large qu'on voit assez souvent, en arriére du sommet, ì la partie dorsale de la lice cxterue d'une valve de coquille bivilve; la pièe triangulairc (Sclitdehen, all.) qui, dans la plupart des insectes à étuis, sc trouve sur le dos, an milieu du bord postérieur du corselet, entre les ćlytres, surlout quind elle est saillante on eolorće; les tubercules que le corselet présente entre lcs ailes antérieures des libellules; la partie postérieure di eorsclet des hyménoptères, des diptères et des lépidoplères; enfin, d’après Audonin, qui a rendu plus rigourcuse l'aeeeption de ce mot, la troisiène des quatre pièces formaut la partie snpéricure ou le tergum de chacun des trois segmens du eorps des inseetes hexapodes, pièce qui comprend la saillie aeeidentelle a laquelle seule les entomologistes avaient a vant lui appliqué le nom d'écusson. V.Thonas. LCUSSovvé, adj., scutcllalus, sculcllaris. Les botanistes donnent celte épithète aux poils dont les rameiux sont soudés ensemble de manière à former des espèces d'ćcailles ou d'éenssons. En zoologie, on dit que le corsclet d'une cocpuille livalve est ćcussonné, quand il est séparé cu deux partics par une ligne, on par des strics, ou par un changement de couleur. Certains insectes ont recu cette épithele, parce que leur éeus- son offre quelque particularité de coloration ( ex. Mutilla scutcllaris, Coccinclla sculcllata), ou de formo (ex. Colypluus sculatus). Un crustacé (Albunca sculcllata) est ainsi appelé, parce qu'il a une carapace ovale et en forme de bouclier. Un poisson (Contriscus scutatus) est ì per près dans Ie mème cas.

IDENTÉ, adj., edcntulus, edentatus, anodonta; zalinlos (all.). Épithète donnéc ì la charnicre des eoquilles bivalves, quand elle ne présente pas de dents (ex. Lucina anodonta), el par Kirby aux mandibulcs des inseetes, lorsqu'elles ne sont point armées de dents (ex. Apogonia gemellata). Le Placocharus ctlcntalius est ainsi appelé, parce qu'il n'a de dents ineisives à aucune mâehoire; le Blennius edentulus, parce qu'il u'a pas de dents du tout; la likinomyza cdcnulula, parce que ses antennes n'offrent pas à Icur dernicr article la dent qu'clles présentent dans une autre espice du même genre.

isDENTES, adject. et s. m. pl., Edcntati, Edentala. Nom donné par Linné, Cuvier, Desmarest, Jatreille, Blainville, Ficinus ct Carus, Blumenbaeh et Vieq d'Azyr à un ordre de la elasse des Mammifères, comprenant des animaux dont l'appareil dentaire est plus ou inoins ineomplet; par Latreille á une seetion dé la classe des Crustaećs, ì laquelle appartiennent ceux qui n'ont pas de mandibules proprenent dites, ou qui du unoins les ont transformées en filets faisant partic d'un suçoir.

EDOLIENs, adj. el s. m. pl., Edolianc. Noun donné par G. Swainson à un groupe de la fimillc des Laniades, qui a pour type le genre Edolizs.

HpRenox, $V$. Arguenon.

EuRiophtialves, adj. el s. m. pl., Edrioplelhalma (Ëjpxios, stable, oq̧3xingos, acil). Nom sous lequel 
Leach désigne une légion de la classe des Crustacés malacostracés, comprenant ceux qui ont les yeux sessiles.

EDULE, adj., edullis; geniessbar (all.); qui est susceptible d'ètre mangé, qui peut servir d'aliment. Ex. Lous edulis.

EFT LIRV ESCENCE, s. f., cfferves-

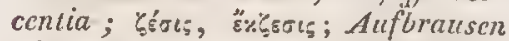
(all.). Phénomène qui a licu quand un fluide ä̈riforme, développé dans le sein d'un liquidc, sc dégage en bouillonnant, pourvu tontefois que l'effet résulte d'un corps mis en contact avec ee liquide à la température ordinaire.

EFFHDEsCENT, adj. , efferpescons; aufbrausend (all.); qui est susceptible de faire effervescence.

EFFEUILLAISON, s. f., cffoliatio. Action par laquelle on dépouille une plante de ses feuilles. Quelques botanistes ont fait à tort ce mot synonyme de defcuillaison. $V$. ce mot.

EFEICE, adj. , virgatus, juneeres, tonuis, vimineus, virgultuosus, $f i-$ latus, extentuatus; rulkenförmig(ail.). Se dit, en botanique, d'une plante dont la tige et ses ramifications, les pétioles ou les pédoncules, $\mathrm{cn}$ un mot les partics alongées, sont très-longues, grèles, droites et amincies de la base au sommet (ex. Paliurus virgatus, Phynizm virgatum, Cuphea virgata, Urena viminea, Buphithalmum junceum, Chondrilla juncea, Chondrosium tenue, Paspalus cxtenuatus); ell zoologie, d'un animal dont le corps est long et grêle ( $\mathrm{ex}$. Mydas filatus), ou partagé en ramifications très-minces (cx. Spongia virguliuosa).

EFLODESCENCT, s. f., epporescentia; Besehlag, Auswittern, Auswuchs, Auswiticrung (all.). Phénomène que présentent diverses substanees, à la surfacc desquelles une maticre pulvérulente se manifeste, par l'effet de la perte ou de l'absorption de l'eau. En minéralogie, on donne ce noın à un enduit pulvérulent, quelquefois cristallin, aciculaire, qui recouvre certaines roches, et qui annonce qu'une substance saline se forme vers la surface de celles-ci, au moyeu des principes qu'elles renferment. Les botanistes appellent quelquefois cflorescence l'aete par lequel la floraison conımence, le premier moment où clle a lieu.

EFFLORESCENS, adj. et s. m. pl., EfMoresccnics. Nom douné par Nees d'Esenbeck à une division de la tribu des Champignons aërogastres sporomestes, comprenant ceux qui ressemblent à une efflorescence étalée à la surface des corps.

EFFLORESCENT, adj., eflorescens. Se dit de sels qui, à l'air, perdent tout ou partie de leur eau de cristallisation, deviennent opaques, et tombent quelquefois $\mathrm{cn}$ poussière.

EFLAGELLE, adj. , cflagellis ( $c$, priv., flagcllum, coulant). Se dit d'une plante qui n'a pas de coulans, par opposition avec d'autres especes du même genre, qui en sont pourvues. Ex. Fragaria eflagellis.

IGAGROPILE, adj., agagropilus

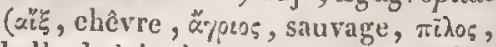
balle de laine); qui a la forme d'un ćgagropilc, e'est-à-dire des concrétions qu'on trouve quelqucfois dans le canal alimentaire des chcvaux. La Conferva agagropila a été appeléc ainsi, parce qu'clle est disposée en touffes vertes, grosses comme des noix.

EGAL, adj., aqualis, rqquans ; glcich (all.); equal (angl.); uguale (it.); qui ne présente aucune aspćrité; qui est identique de forme, de disposition, de hauteur. C'est dans ee durnier sens que les botanistes disent: aigrette égale, celle qui est composée de soies ayant à per près la mêne longueur; étantincs égales, celles qui sont aussi longues les unes 
que les auires (ex. Bucumus umbellatus); ombrclle egale, quand les fleurs du centre sont égales à celles de la circonférence; sépales ćganx (ex. Primula); spathelles égales (ex. Secale Cercalc). La polygamie égale est un ordre, dans le sysieme sexuel de Linné, comprenant celles des Syngénèses dont toutes les fleurs sont liermaphrodites (ex. Tragopogon).

EGaLUnE, sulst. f. En termes de fauconneric, on nomme ainsi les mouchetures du dos d'un oiseau de vol. GGLavburdsux, adj., eglandulosus; drïsenlos (all.); qui est privé de glandes. Ex. Psorculca eglandulosa, Gossypium erlandulosum.

LGrisín, s. f. Poussière du diamant, à l'aide de laquelle on taille cette pierre, en la frollant contre une autre, art dont la découverie a été faite en 1476 par Louis de Berquem.

ÉLABRĹ, adj., elabratus. Se dit d'un insecte qui n'a pas de labre. Ex. Aranćides.

ILEAGNǘs, adject. et s. f. pl., Elaagnea. Famille de plantes, ćlablic par Jussicu, qui a pour type le genre Elaragnus.

flacanoines. $V$. Étengnées. ELALOcanpíes, adj. et s. f. pl., Elcuocarpe. Nom donné par Jussieu it une famille de plantes, par A. Richard à une section de celle de Tiliacécs, ayant pour type lc genre Elaoearpis.

Ét_EOSÉLINÉES, adj. et s.f.pl., Elacoselinece. Nom donné par Candolle à une tribn de la famille des Ombciliféres, qui a pour type le genre Elecoselinum.

ELALATE, s. m. Genre de sels qui résultent de la combinaison de l'acide élä̈dique avec les bases salifialsles.

LuADrra, s. f. F. Bolidet nomme ainsi nue subslance solide qui résulic de l'action de l'acide hyponi- trique sur les huiles d'olive, d'amande douce, de noisette ct de noix d'acajou, et qui a beaucoup derressemblance avee la stéarinc.

ELA IDiQue, adj. Nom donné par F. Boudct à un acide particulier, qui résulte de la saponification de l'élaïdine.

ELAIME, s. f., elnima. Guibourt donne ce nom à l'élaïne.

tLAINR, s. f., claina; Oelfell (all.) ("̈̀xเoy, huile). Noun donné par Chevreul a la portion des huiles grasses qui reste liquide au dessous dela température ordinaire, et qui depuis a été appelé oléine (luuile absolue de Braconuot).

ILANONATE, snbst. m., eloiadas. Genre de sels (elaidsaure Salze, all.) qui sont formés par la combinaison de l'aeide élaïodique avec les bases salifiabies.

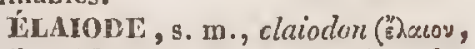
huile). Herberger propose d'appeler ainsi la partie fluide des luuiles volatiles.

LLAIODrove, adjeet., elaiodictıs (ž)xcov, liuile). Epithète donnée par quelques ehimistes à l'acide olco-ricinique (Elaidsaüre, all.). Vojez ce mot.

ILANCÉ, adj. , cxallatus, procerus. Se dit, en botanique, de toute plante ou partie de plante qui cst beaucoup plus longue que ne sembleraient 1c comporter ses autres dimensions (ex. Zapania virgala); en zoologie, d'une spire de coquille spirivalve dont le cône spiral avance beaucoup plus cu hauteur qu'en largeur.

ĹLAPniris, adj. et s. m. pl.,

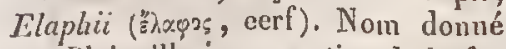
par Blainville a unc section de la famille des Piuminans, qui comprend le gente Cerf.

HLAWHOGRA'HE, s. f., clupho-

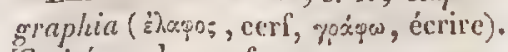
Traité sur les cerfs.

ĹlAPHORNTIES, adj. et s. m. 
pl., Elaphornithes ("zhxps, cerf, öprt5, oiseau). Nom donnć par J.-A. Rilgen à une famille d'oiseaux, qui ne comprend que le genre Casour.

ĹLAPIIRIENs, adj. et s. nı. pl., Elaphrii. Nom donné par Latreille à un groupe de la tribu des Carabiques, ayant pour type le genre Elaphrus.

KiLARGI, adj., dilatatus, extcnsus; augrggebreitet (all.). Se dit, eu botanique, de tout nrgane qui, a sa base ou à son sonmet, est plus large transversalemeul que dans le reste de son étendue, conıme le réccpiacle des Potentilla.

GLASMIE, s. f. , clasmia ( हैhaqux, lame ). Illiger désignait sous ee non. les plaques cornées transversales qui, ehez lcs baleines, tiennent lieu de derits et pendent des partics latérales du palais dans la louehe.

ÉLASTES, s. m. pl., clastes (ל.).\%$\tau \dot{r} \zeta$, qui pousse). Kirhy appelle ainsi les organes élastiques des segmens abdominaux du Machilis polypoda, qui rendent eet inseete apte à sauter.

ĹLASTIGITh́, subst. f., elasticilas, elater; Fclcrkraft, Schncllkraft, Spannkraft, Springkrafi(all.j; clas-

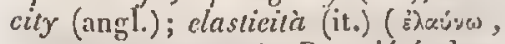
pousser en avant). Propriété dont jouissent eertains eorps de reprendre cxaetement leur état primitif saus se rompre, ni se désagréger, lorsque vient à ecsser la cause mécanique passagère qui ehangenit leur forme ou leur volume.

ELASTique, adj., clnsticus. Se dit de tout corps qui est ì la fois flexible et susecptible de revenir a sa première forme. On dit, en hotanique: arillc ćlastique, eclle qui s'étend jusqu'à un certain point à mesure que la graine qu'elle renferme prend un plus grand volume, mais se déehire cnfin et s: retire sur elle-même par un mouvement subit (cx. Oxalis); filet ćlastique d'étanine, eclui qui est suseeptible de se redresser avee foree, au moment de l'épanouissement, comme ûn ressor't qu'on lâehe tout a eoup (ex. Urtica); pollen élastique, celui qui offrc une masse susceptible de s'alonger quand on la tire, et qui reprend sa forme dès qu'on l'abandonne à lui-même (ex. Orchis) ; valpcs ćlastiques d'un fruit, quand elles s'éeartent brusquement (ex. Cardaminc Impatiens). L'Hymenophyllum elasticum est ainsi nommé à cause de l'élasticité remarquable qu'il conserve, mème après un trèslong temps de dessieeation; l'Hcluclla claslica, paree que, quand on eoupe son stipe, chaque moreeau reprend avee élastieité la forme eylindrique; l'Ecbalium elatcrium, paree que son fruit mùr, quand on le détache-du pédoneule, lausee rapidement les graines au loin.

GLATHEE, s. m., clater; Sporcnschleuder, springfad (all.). Candolle appellc ainsides fitets élastiques, membraneux, tordus, qui, dans quelques hépatiçues, fixent au placenta les graines auxquelles ils adhèrent, et les dispersent à l'époque de la maturité.

ELATÉmEEs, adj. et s. m. pl., Elaterides. Nom donné par Iatreille, Cuvier et Eiehwald à une tribu de la famille des Coléoptères serrieornes, qui a pour type le genre Elalcr.

flatínie, s.f., elatcrium. L.-C. Richard donnait ce nom à uı fruit qui, parvenu au terme de sa maturité, se parlage uaturellement en autant de coques dislinetes qu'il présente deloges. Ex.Euphorbiacées.

IILATERINE, subst. f., elaterina. Matic̀re eristallisable que Hennell a retirće clu sue du Mormordica Elatcrizen, et qui diffère de l'élatine de Pallas.

ILATÉnovìne, s. m., clateromctrum ('kurrip, ressolt, $\mu \varepsilon т \rho \dot{\varepsilon} \omega$, nesurer). Appareil quon adapte aux machines it vapeur, et aux machines à condensation, pour connâtle l'é. 


\section{ÉLEC}

lastieitć avec laquclle l'air raréfié ou condensé dans le récipient, ou la vapeur contenue dans le cylindre de la machine, réagit contre la pression de l'air atmosphérique.

ELATINE, subst. f., clatina. Nom donné par Pallas à une résine molle et verte qui cxiste dans les fruits du Momordica Elaterium.

ilcativies, adject.et s. f. pl., Elatinea. Nom donné par Cambesscdes à une famille de plantes, qui a pour type le geurc Elatine.

ĹLTOHRANCuEs, ndjeet. ct $\mathrm{s}$. m. pl., Elatobranclia ( $\dot{\lambda} \alpha \dot{\tau}$, , ramc, Ppóyxisx, branchies). Nom donné par Menke à une classe de. Mollusques, répondant aux lamclliluranclıcs de Blainville, qui renferme lcs Acćphales ì branchies lamelleuses.

ELATOSTÉmúes, adj. et s. f. pl.; Elatostemece. Nom donné parA. Richard à un groupe de la famille des Urticées, qui a pour type le gente Elatostcma.

ELECTIF, adj., elections (eligo, choisir). Les chimistes appcllent affinité ćlective la force en vertu de laquelle un corps simple opère la décomposition d'un composé hinairc, parce qu'il scmble y avoir choix entre lui et l'élément qu'il culève à ce dernier.

iLectnrairí, s. f., clectricitas; Elcktricität (all.); elcctricity (angl.); electricitì (it.) (ท̆ Nom collectif d'une séric de phénomènes que certains corps préscntent, soit naturcllement, soit par l'actiou de divers excitateurs, et parmi les guels on distinguc lia propriććc d'attirer les corps légers, qui fut découvcrle dius le sucein dès le temps de Thales.

ELECTRIOUE, adj., clectricus; elektrisch (all.); electric (angl.); elettrico (it.); qui a rapport it l'électricité. On dit, en physique, aisrette élertrique, jet de lumic̀re qui s'ćlance d'une pointe placée sur le conductcur d'une machine, quand on tourne le platenu ; atmosplicre électriquc, ou sphèred activité électrique, la plus graude distance à laquelle les cerps électrirques puissent manifester lcur action ; commotion électrique, la seconsse plus on moins violcute que l'électricité iuprime à l'homme; corps électrique, celui qui cst susceptible de devenir ćlectrique, ou qui l'est déjì; étincelle ćlcctrique, unc bleuctte lumincuse qu'on tire d'un conductcurchargé d'électricité, cen lui présentant le doigt; fluidc, force ou matièrc électrique, la cause hypothétique des phémomèues de l'électricité; tcrision ćlectrique, la forcc répulsive avec laquelle les molícules du fluide électrique répandu à la surface d'un corps, tendent à s'écarter les unes des autres. Les naturalistes donncnt cctte épithète à plusieurs animaux qui peuvent développer à volonté des phénomènes d'électricité (ex. Gymnotus clectricus, Scolopendra clectrica).

ÉLECTIISABLE, adj. Se dit de tout corps qui est susceptible d'acquérir d'une manière quelconque les proprićtés électriques.

FLeCTISATION, s. f., elcctrisatio ; Elekirisircn (all, ). Opération de plysiqque qui consiste à mettre en évidence ou à cxcitcr la propriété électrique des corps parle frottement, le contact, la chaleur ou la compression.

HECTRo-CIIVIE, s. f., clcctron chemia. Systime de chimic dans lequel la théoric des phénomènes chimiques repose sur l'application des lois connues de l'électrieité.

HLECTT()-CImMQUE, adj., clcctro-chemicus: qui a rapport ì l'ćlectro-chimic. Théurie électro-chimique.

ELECTHO-CUMISME, subst. m., clectro-chemismus. Théoric dans lacurellc tous les phénomènes chimignues, 
généraux et particuliers, des corps sont expliqués par les lois de la polarilé électrique.

ELECTIO-DYNAMrQ⿻e, adjcct., elcetro-dynamicus. Les physiciens appellent élcetro-dynamique la propriété que les corps solides qui ont scrvi de conductenr à l'électricilé, acquièrent, quand ils sont placés dans des circonstanees favorables, de donner lien à un eourant électrique.

ÉEETI0-DYNAMISME, s. m., elcetro-dynamismus. Terme créé par' Ampère, pour exprimer les cffets de la pile fermée par un fil métallique comminiquant avec ses denx bouts.

ÉLECTLO-GALVANIQUE, adj. , electro-gralvareicus. Epithète dont on se sert quelquelois pour désigner le fluide éleetrique, lorsqu'on parle des effets de la pilc voltaique.

ÉLCTROGive, s. m., elcetrogenizm. Quelques physiciens ont proposć de donner ce nom à la cause inconnuc des phénomèmes de l'électricité.

ELECTROLoGm, s. f., electro-

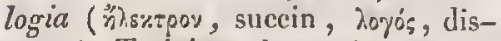
cours). Traité sur le sucein.

ÉLECTROM GNÉTIOUE, adlject., electro-magneticus. On appclle ainsi la force qui procluit les phénomènes de l'électromagnélisme.

ÍLECTROUIAGNÉtisvese, s. m., electro-magnetismus. Eusemble, dicouvert en $18_{20}$ par OErsted, des phénornènes magnćliques qui sont produits par l'électricité ou par l'action mutnelle de corps ćlectrisés et d'simans.

ÉLECTRONÈtre, s. m., clectrometrum ( ท̆ mesurcr). Instrument qui scrt à délerminer d'une nanière approximative la quantité de fluide électrique que renferine un corps.

ÉLECThonetrue, s.f., eleetromciria. Partie de la physique qui a pour objet la messure de l'ćlcctricité.

\section{ÉLEMT}

ELECTROUWTRIQUE, adj. , clectromctricus ; qui a rapportá l'électrométrie. Expćrienee électrométriquc.

ÉLECTROMOTEUR, adj., clcetromotor. On appelle force élcctromotricc celle qui s'exerce entre les substances hétérogènes, aux surfaces de jonetion, produit la décomposition des fluides naturels, dont ehacun se disperse, et empêche lcur recomposition.

ELECTRONÉGATIF, adj., elcctro-ncgativus. Épithdte donnée aux corps qui se portent au pôle positif de la pile voltuïque, comme l'oxigène et les acides.

ÉLECTROPHORE, s. m., clectro-

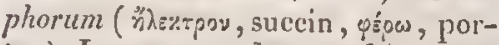
ter). Instrumeut dont on fait usagc pour rendre l'élcctricité sensible it volouté.

ELLCTRopositrF, adj., electropositivus. Eipithète donnée aux corps qui se portent au pôle négatif de la pile voltaïque, comme les corps inflammables et les bases salifiablcs.

ÉLEGTROScOPE, s. m., elcetro-

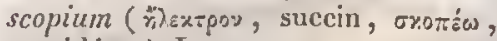
considérer ). Inst rument propre à déterminer l'espèce d'électrieité dont un corps est animé.

ELECTROSCOPE, s. f., clcetroscopia. Branche de la physique qui recherehe de quelle cspèce d'électricité les divers corps sont animés.

ELECTROSTATIQUe, adj., elcetrostaticus. Épithètc donnée par Ampére aux effets de la pile voltaïque ordinaire et de la machine électrique.

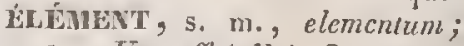
бтохziov; Urstofl (all.). On sc sert de ce mot : $1^{\circ} \mathrm{cn}$ astronomic. On appelle élćmons des orbites des planètcs les donuées nécessaires pour déterminer lis situation de ces corps ả un instant quelconque, et qui sont au nombre de sept: la position de la ligne des nocuds, l'inclinaison sur l'écliptique, le tcmps de la révolution en- 


\section{ELEM}

tière, la moyenne distance au soleil, an le demi-grand axe, l'cxecntricité, la situation d'un des sommets de l'ellipse, cnfin le licu de la planète diurs son orbitc, ì une éporjue clonnéc. $2^{\circ}$ En physique, on nommc élémons des couples de plaques de zinc el de cuivrc, soudces par toute leur surface, dont on se scrt pour construirc les piles voltaïques dites à auge. 3 ' Eu ehimic. Autrefois les chimistes donmaient le uon d'élémens à tous les corps qu'ils regardaient comme sinples. Ce mot avait alors ponr eux une simnification absoluc. Aujourd'hui on ne l'emploie plus que dans un sens rclatif, pour lésigner des corps à l'égard desqucls on n'affirme pas qu'ils sont récllement simples, mais on veut seulenıcnt dire que, jusqn'ì ee jour, la chimic n'a pu les réduirc en plusicurs sortes de matières. On conple maintenant cinquante-trois de ces corps.

HLCMLNTAIRE, adj. , elementaris, clementarius; qui a ou anquel on attribue lc caractère d'élément. Les minéralogistes de l'ćcole de Ilaiiy appellent molécules élémentaires celles qui, par leur comhinaison, proluiscut les molécules intégrantes, ou la nature mème de chaque minéral, comme la chaux et l'acide carJonique dans la chaux carbonalće. In zoologie, et surtout en botanique, on donne le nom de parlies élémentuires à des tissus qu' on retrouve seinblables à cux-mêmes dans toutes les parlies des animaux et des végétaux ' u'on analyse, et qui semblent en etre les élémens. Jjerthollet nomme affrnité élémentaire celle qui s'exerce yuand un corps compo:é agil par ses élémens, écst-à-dire par un de ses élémens plutôt que par l'autre, comme quand on fait passer sur du fer rouge de l'cau, qui se décompose et abandonne son oxigène an métal, taudis que son lyydrogène se dégage.
BLLUMTLRE, adj., clemiferus ; qui donue ou produit de la résine élémi. Ex. Amyris elemifera.

Diconises, adj. et s. f. plur., Elcodere (È)xtwins, onctueux). Nom que Leman propose de donner à une famille de plantes qui serait instituće pour le genre C'hara, parce que les graines de ces végćtaux sont enveloppées d'une matière mucilagincuse.

ELLOPTENE, s. m. , claoptena

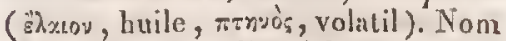
donuć par Berwclius à la partie des huiles volatiles qui reste liquide audessous de la tenipérature ordinaire.

ĹLGPIANTIDES, adj. et s. m. pl., Elephantida. Nom donné par J.-E. Gray à une famille de Mammifères pachydermes, ayant pour type le genre Elephas.

Eilépilan'iv, adj., elcphanlinus; qui a la forme et la légère courbure d'une défcuse d'éléphant. Ex. Conilites clephantinus, Dentalium clephanlinume.

Éciphantivs, adj. et s. m. pl., Elephantini. Nom douné par Vieq d'Azyr à une classe de Maumifòres, ayaut pour type le genre Elephas.

ILLPHANIOGRAPIIE, s. f., clcphantographia ( yox́ọ, écrire ). Traité ou histoire de l'éléphant.

BLEPILNTOIDEs, adj., clephan-

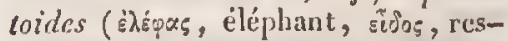
scinblance); qui a de la ressemblance avec l'éléphant; commme le Mastoclon clephantoilles, dont les dents mo. laires se rapprochent, pour la forme, de celles de ec mammifère.

ILERHANTOP'DE, adj., clephantopes; qui a des picds scmblables it ceux de l'ćléphint. L'Hydrocharus elcphantopedes a été ainsi appeić à cause du volume de ses jambes et de l'épaissenr de la pean de ses pieds.

LLEPHANTOPËES, adj. et s. f. pl., Elcphaatopece. Nom donné par H. Cassini à un groupe de Synanthé- 
récs, qui a pour type lc genre Elcphantopus.

ELIEPIINTOROD Ees, adj. et s. f. pl., Elephantopodex. Nom donnć par Lessing à une sous-tribu de la tribu des Vernoniacées, qui a pour type le genre Flephantopus.

ILLEHANTORNITHES, s. m. pl., Elephantornithes (Ėzépos, éléphant, ögues, oiscau ). Nom donné par J.-A. Ritgen à une famille d'oiseaux qui renferme le dronte, remarquable surtout par son corps lourd et massif, comme cclui de l'élćphant.

ELEUTHírantuéné, adj., clez-

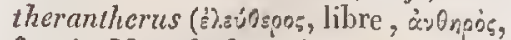
neuri). Mounch domnait cette ćpithète anx plantes dont les anthères ne sont point soudćes ensemble.

ÉLEUTMLRATES, adj. et s. m.

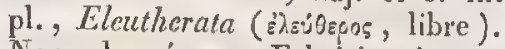
Noin donné par Fabricius à une grande division de la classe des insectes, comprenant ceux qui ont les mâchoires nues et libres, comme les Colćoptères.

ÉLUTUÉRes, adj. ets. f. pl., Eleutherea. Non donté par Robincau-Desvoidy à une tribu de la famille des Mrodaires.

ÉLEUTUÉLOGYNE, adj., elcullerogynus (s่)sú0 epos, libre, quvin, femme). Epithèie imposéc à toute flerer dont l'ovaire n'a point d'adhérence avec le calice.

Íleutuéroginie, s. f., eleutherogynia. Nom douné par A. Richard à une classe, renfermant les plantes monocotylédones et dieotylćdones dont l'ovaire est libre.

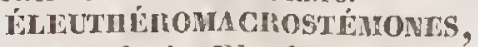
adj. et s. f. pl., Eleutheromacrostc-

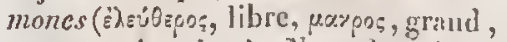

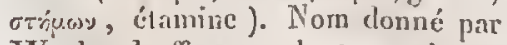
Wachendorff anx planies qui ont leurs étamines libres, ct guaclques unes de ees dernières plus longues que les autres.

ELEUTUÝROPHILINES, adjeet. et s. f. pl. , Eleuterophyllina ( Aepos, libre, qú2.0\%, feuille). Non donné par Reichenbach à une section de la famille des Hćpatiques, renfermant celles qui ont les feuilles libres.

ÉLETHCROPODEs, adj. et s. m.

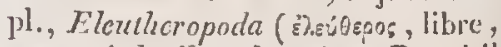
тоบे , pied). Nom donné par Duméril à une famille de poissons, comprenant ceux qui ont les nageoires pectorales séparécs.

ÉLEUTHÉRonomes, adj. et s. m. pl., Eleutheropoma (

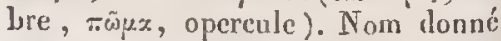
par Duméril à une famille de poissons cartilagineux, comprenant ceux qui ont l'opercule dépourva de membrane.

Éceutriérostínone, adject, elculherostemonus ( -тxipes, élamine). Epithète qu'on applique aux plantes dont les ćtanines sont libres de toute adhérence.

ELECTHLROTHLLE, adj. , eleu-

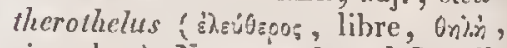
niamelon). Non sous lequel G. Allman désigue les plantes dont l'ovaire est libre.

ELEVÉ, adj., cxcelsus, cxaltatus; qui a une grande taille (ex. Agaricus procerus, Inightia cxcelsa, Fraxinus cxcelsior, Lycoptes exaltatus, Plantago exaltata, Thalictrum cxaltatum). Les conchyliologistes donnent cetie épithète à la spire d'une coquille spirivalve, quand le còne spiral avance plus en hauteur qu'en largeur.

MLIGNITE, s. f. Desvaux propose ce mot pour remplacer celui d'exostose, en parlant des végétaus.

ELINGUt, adj. , elinguzis ; qui n'a point de languc. Lc Naüs elingruis est ainsi appclé parce qu'il a la bouche chtuse, sans tromne.

ELLAGATE, s. m., cllagas. Sel produit par la combinaison de l'acidle ellagique avec une base salifiahle.

ELLAGIOQUE, arlj., ellaggictıs (dı 
mot galle renversé). Nom donné par Braconnot à un acide qui se forme par la décomposition spontanée de l'infusion de noix de galle.

ELLibonine, s. f., ellchorina. Non donné à la résine molle que Vauquelin a trouvće dans la racine de l'Ilelleborus hycnialis, et qui est la partie aetive de cette raeinc.

TLLIPANTIE, adj., cllipanthus

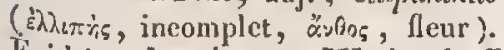
Epithète donnée par Waehendorff aux plantes dont les fleurs sort incomplètes, ne renfermant que des ćtamines ou des pistils. Syronyme de dioique.

EllLPSOIDE, adj. , ellipsoidens

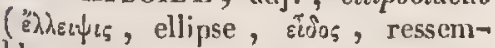
blance ); qui a la forme d'une ellipse; dont le diamètre longitudinal égale environ une fois et demie à deux fois an plus le diametre transversal, et dont la masse s'arrondit également et insensiblement, du sommet aux deux bouts, qui sont obtus, de sortc que la coupe longritudinale offre un plan à peu près clliptique. Lus botanistes donnent cette épithète ì la sraine (ex. Qucrcus Robur), à l'embryon, it la sorose (cx. Artocarpus incisa), au drupe (ex. Olca curopaa), à la carcćrulc (ex. Zostera marina), à la capsule (ex. Silenc Armeria), au crémocarpe (cx Carum Carvi), à l'érème (ex. Salvia bicolor), itu calice (ex. Astragalus ellipsoideus).

ELLIPSOSPERTE, adj. , cllipsospermus ( graine); qui a des graines elliptiques. Le Spharia cllip.sosperma est insi llommé à cause de la forme presque globuleuse de ses périthécions.

ELLipsostome, adj, , cllip.so-

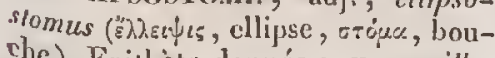
che). Epithete donnée aux coquilles univalves dont l'ouverture est ovale, c'est-i-dire a un diamcitre longituI.
ELMI

dinal plus long que le transversal. Ex. Mrelania.

ELLIIPSOSTOMES, adj. et s. m. pl., Ellipsostomata. Nom donné par Blainville à une famille de l'ordre des Asiphonobranches, comprenant ceux dont la coquille a une ouverture elliptique, et à une famille de $\mathrm{Co}-$ quilles, dans Jaquelle sont rangées celles dont l'ouverture a la mềme forme.

ELLIPTIQUE, adj. , ellipticus ; clliptiseh (all.); ellittico (it.) (हैh$\lambda \varepsilon u_{4} t_{5}$, ellipse); qui a la forme d'une ellipse, c'est-à-dire dont le diamètre longitudinal est une fois et demie plus grand que le transversal, et la eirconférence eireulaire, avee les deux extrémités arrondies également (ex. Mycetophagus ellipticus). Les botanistes donnent cette épithète à la griane (ex. Isatis tinctoria), au hile (ex. Phaseolus communis), à la silicule (ex. Draba verna), ì la eapsule (ex. Veronica multifida), aux pétales (ex. Saxifrasa decipiens), aux feuilles (ex. Lyperanthus ellipticus, Mraba clliptica, Oxylobium ellipticum), aux urnes des mousses (ex. Dryptodon ellipticus). Le Lutujanus ellipticus est ainsi nommé à eanse d'une ellipse de couleur violette qu'il porte à la partie supérieure du corps.

ELMINTUAPROCTES, adj, et $\mathrm{s}$. m. pl., Nlminthaprocta

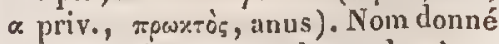
par Latreille à une elasse du règne animal, comprenant les Entozoaires qui sont déponrsus d'anus.

ELMINTHOGAMES, adj. et s. m.

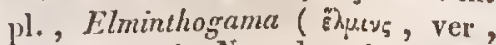
yx́xurs, noees). Nom donné par Latreille à une classe du rìgne animal, comprenant les Vers qui ont des organes' scxuels sépariés et qui s'uccouplent.

Fi.MINTIIOIDEs, adj. et s. m. pl.,

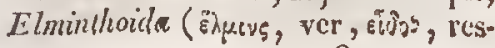
28 
semblanec). Nom donné par Latreillc à nne race d'animaux Céphalidiens, comprenant les Cirripèdes et les Annelides, el qui tire son nom de ee que la plupart des animaux qu'clle comprend ont la forme de vers.

TroculaIRE, adj., clocularis (c, priv., locula, loge). Sc dit, d'après link, du péricarpe, quand on n'y apercoit pas le moindre vestige de eloisons. Ce mot est done synonyme d'zniloculaire.

ÉLOIGNí, adjecl., remotus. On donne eetle épithète, en zoologie, aux ccailles des poissons, quand elles sont éparses à la surface da corps, sans se toucher (ex. Anguille); en botanique, aux fouilles, Jorsqu'elles sont placécs les unes à l'égard des autres à une plus grande distance qu'elles ne le sont dans la plupart des plantes; aux lobes des anthères, quand ils sont temus à une distance notable l'un de l'autre, soit par le filct (ex. Begonia dichotoma), soit par le connectif (ex. Melissa grandiflora).

LLONGANTIW, adj., clonganthus. . L'Jsolepis clongantha est ainsi appelé, parce qu'il a ses fleurs disposées en épi un pen alongé.

HONGATION, s. f. , clongatio ; Ausqueichung (all.). On appelle ainsi, en astronomie, l'éloignement apparent d'une planète du soleil, ou l'angle que font ensemble les lignes tirćes vers eelle planète et vers le centre du soleil.

ELVELLACELS, adj. el s. f. pl, Elucllacci. Nom donné par Fries à un ordrc de ehampignons hyménomycctes, qui a pour type le genre Helselln.

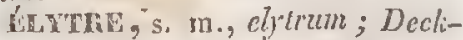
-schild, Flügscldeclic (all.) ("̈huQgov, - gaine ). On appelle ainsi : $1^{0}$ en botanique, d'aprés Mirbel, lcs conceptacles particuliers qui renferment les corps reproducteurs de quelques li- ehens et algues, et qui sont rćunis dans des eoneeptacles communs. $2^{\circ}$ En zoologic, les ailes supérieures des insectes à quatre ailcs, quand ellcs sont coriaces, peu flexibles, el protègent les inférieurcs, comme pourraicnt le faire des gaînes, des fourreaux ou des ćłuis. On donne aussi le nom d'elytres aux écailles qui recouvrent le dos des Annelides.

ELTTROCLE, s. m., clytricultus ( ह̉̀upoy, gaînc). Nom donné par Necker à ehacune des pelites flcurs qui, par leur assemblage, constituent les fleurs composées.

b́LYTnop'tires, adject. et s.m.

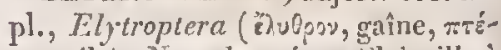
poy, aile). Nom donné par Clairville à une section de la classe des insectes, qui eorrespond à l'ordre des Coléoptères; par Latreille, Ficinus et Carus, à une division des Inscctes ailés, eomprenant ceux qui ont les ailes proprement diles recouvertes par des élytres ou des demi-élytrcs.

EMAL, s. m., indumentum vitrcum, dentium nitor. Substance blanche, lisse, polie, ot d'apparence vitrcuse, qui recouvrc d'une eouche mince le futt ou la couronne des dents.

BusLLL, adj., niten.s; qni est eouvert d'émail, ou qui a l'apparence de l'émail.

Gianation, s. f. , cmanatio ( $c$, hors de, mano, conler). Se dil à la fois et d'un corps qui tire sa source d'un antre corps, conme la lumiere du soleil, suivant le systeme newtonien, ou les odeurs des plantes, $c$ t de l'acte par lequel a licu cette provenance.

ÉMANDHBEะ, adj., cmandibulatus. Epithète donnće par Kirby aux insectes qui sonl dćpourvus de mandibules.

LuAnués, adj. cl s. m. pl., Emanuati, ( $c$, priv., mants, main). Non donné par G.-C.-C. Slorr à une tribu 
de Mammifères, comprenant ccux dont les pattes ne sont pas conformées en manièrc de maius.

ÉMARGINÉ, adj., emarginalns; ausgerändert, ausgezwriekt, eingekerbt (all.); emarginato (it.) ( $c$, pliv., margo, bord). Synonyme d'éehaneré. On emploie ee not: $1^{\circ}$ en minéralogie. L'épithète d'émargince est donnée, dans la nomenclature minéralogique de IIaüy, à une variété qui présente la forme primitive ayant ehreun de ses londs remplaeć par une facette (ex. Chaux phosphalée émarginéc). 2。 En bolanique, clle $s^{\prime}$ applique à toute parlie qui est terminée par un sinus rentrant ou par une entaille arrondie. Ainsi on dit: pétales émarginés (exemp. Berberis emarginata); feuilles émarginées (ex. Loranlhus emarginalus, Glycine emarginata); filet d'élamine émarginé (ex. Allium Porrum); stiginate emarginé (ex. Cireca lutctiana); capsule émarginée (ex. Euphrasia officinalis); lèore supéricurc émarginee, dans une eorolle lahiće (ex. Lycopus europaus ); Cypsèle ćmarginéc (ex. Eneclia); silienle émarginée (ex. Thlaspi campestre); urne émarginée (ex. Tetraphis repanda);
folioles émarginées (ex. Galactia emarginala). $5^{\circ}$ En zonlogie : la Salpa emarginata a l'extrénité postérieure di corps échaoerće.

buarginatirnont, adjeclif , emarginatifrons. Épithète donuće par A.-H. Harvorth anx crustacés dont le l'ront présente une ćebanerure. Ex. liyas.

EMARginatmosturs, adj. ct s. in. pl., Emarginatirostres (emarginattls, échancré, rostrum, bec). Nom donnépar Limué à une section d'oiseaux, renfermant ceux qui ont une petile ćchanerurc de ehaque eôté de la mâchoire supéricure, avant son extrềme pointe.

EMIBLiLLÉES, adj. et s, f.pl, , Eme beliece. Nom donné par Barlling à une tribu de la famille des Ardisiaećes, qui a pour type le genre Embelia.

EMBOLL, s. m., embolus; ITornzapfen (all.) ( $\left(\ddot{p} \mu p_{0} \lambda_{0}\right.$, , piston). Illiger appelait ainsi l'axe osseux des cornes des Ruminans eavicornes.

EMBOUCHULE, s. f., ostium; Dlïndung (all.); mouth (angl.); sboeco(il.). Point où un cours d'eau se jelte dans une mer ou dans un lac.

IMMBRISSANT, adj., amplectans, amplexans. Sc dit, en botanique, des ferilles, quand elles cmbrassent la tige par leur base ćlargie (ex. Silene Armeria). Voyez AmputexiCavus. Kirby doune cette épithète au. collier, daus les insectes, lorsqu'il est courbé en arrière, de manière à former un large sinus qui embrasse le dorsolun (ex. $V$ espa).

MMUBLASSE, adject., amplexzes. Épillète donnéc par Candollc aux feuilles eontenues dans le bourgeon, lorsque leurs eôtés, repliés l'un sur l'autre, sont recouverts par les deux côtés de la feriile précédente, pliés de même ( ex. Iris germaniea).

LMIBR graplia ("sp.ppuos, foetus, zpóxew, éerirc). Description généralc du foctus.

LMBEROLOGIE, s. f., cmbryolo

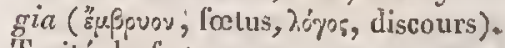
Trailé du foetus.

EMBRYON, s. n.., emliryon; "ै $\mu-$

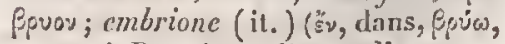
pousser). Premicr rudiment d'un corps organisé, peu de temps après qu’il a ćté formé par l'aele de la génération. Les bolanistes appelicut cmbryon (corculum, d'après Césalpin et Linné, cor seminis), la parlic essentielle d'une graine parfaite, eelle qui constitue le rudiment d'une nouvelle plante semblable au végćtal qui l'a produile. Raspail donne aussi ce nom. il Ia sommité rudimentaire d'un xameau, 
EMBRTONE, adj., embryonalus. Nom donné par L.-C. Riclıard anx végétaux pourvus d'un véritable ennbryon.

EMBRYONELLE, s. m., embrjonellum. $\Lambda$ gardh nomme ainsi les spores des plantes eryptoganes, pour les distinguer des germes des plantes pourvues de vérilables graines, atxquels il réserve la dénomination d'embryon.

FMBRYON-GRAINE, s.m. Turpin désigne ainsi quelquefois les graines des végélaux, et plus souvent les embryons libres. Foyez Libne.

EMBRYONIF⿱R⿴囗十 niferus (embryon, embryon, fero, porter). I. -C. Richardappliquc cette épithèle a la cavité d'une amande qui renferme l'embryon.

EMBRIONTORME, adjeet., embryoniformis; qui a la forme d'un embryon, eonume les petits des mammifères marsupiaux, au moment où ils quiltent la matriee pour entrer dans la poebe ventrale.

EMBRYONNAIRE, adj., embryonnaris; qui a rapport à l'embryon.Sac embryonnaire; vie embryonnaire (Fruchleben , Föusldeben, Embryonenleben, all.).

EMBIRYPARE, adj. , embryoparus (embryon, embryon, paro, engendrer). Nom imposé par Desmoulins à une sous-elasse de la classe des Mammifìres, eompreuant eeux dont les f'emelles aceouchent d'embryons, conme les marsupiaux.

EMBriotige, s. nı., embryotegium ( toit ). Noun douné par Gacrtner à une petite saillie en forme de calotte qui, dans certaines graines, eorrespond ì l'extrémité radiculaire de l'eawisyon, et se détache, au temps de la gerınination, pour livrer passage à ec dernier. Ex. Tradeseantia eristata.

EBBRTOTHUPIE, s. m., embrrotrophe; Fruchisioff (all.). (ëß-
Pfuov, embryon, тpoon, nourriture). Dutrochet nomme ainsi les envelopjes séminales ou leurs annexes, dout le parenchyme est destiné à contenir la substanee qui doil nourrir l'embryon. 11 propose ce mot pour remplaeer eclui de périsperme, qui, suivant lui, ne désigne pas un organe partont identique, et quil pense par conscquent devoir disparaître lorsqu'on aura délerminé quel est, dans eharue famille, l'organc embryotrople qui accompagne l? embryon dans la graine, et qui a pour destination de la nourrir, soit pendant son développement dans l'ovaire, soit pendaut la germination. Burdach employe le même terine pour désigner la substanee de laquelle se forme l'embryon des eorps organisćs, e'est-à-dire l'amnios dans les plantes, le jaune et le blane de l'oul dans les animaux.

ExIÉRAUmrí, adj., smaragdinus; qui a la coulenr verte de l'émeraude, comme l'épiderme du Mrtilus smaragdinus, ou le corps de la Grmnetis smarasdinea et de la Gnathoeera smaragdina.

ÉvLIaGE, adj., emersu.s ( $e$, hors de, mergo, plonger). Se dit, en botanique, d'une plante aquatique $q^{u i}$ élève sa sominité hors de l'cau (ex. Ceralophyllum enersum), et do ferilles que leurs pélioles élèvent at dessus de la surface de l'eau (ex. Alisma Planlago).

ÉMERT:Ci, s. f., emergentid. Iues physieiens appellent point d'emersenee celui par lequel un rayol lumineux sort d'un milieu qu'il a traversé.

iHERGENT, adjeet., emergens; hervorragend, herausstehend (all.). Se dit, en physique, d'un rayon de lumic̀re qui sort du milieu dans lequel il avait pénétré; en minéraloģic, dans la vonnenclature de Haüy, d'une variété d'arragonite composée de six prismęs rhomboides, dont cing tendent 


\section{EMMÉ}

à produire un prisme unique, et le sixième semble sorlir de eet assemblage en faisant des angles reutrans avec les deux prismes adjacens.

CMension, s. f. , emersio; A ustritt (all.). Les istronomes se scrvent de ce terme, lorsqu'ils parlent d'un corps célcsie, pour désignucr l'instant où, après avoir été éclipsé, il paraît de nouvenu, cn se déģageant de l'ombre du corps qui le cachait.

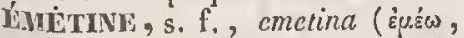
vomir). Alcali végétal qui a élé découvert par Pelletier dans la racinc d'ipéencuanlaa, et qui est niusi appclé parec qu'il possède it un haut degré la faculté d'exciter des vomissemens.

EMÉTroue, adj, , cmeticus. Lipithète donnée, dans la nomenclature chimique de Berzelius, aux sels qui Ont pour base l'émétine.

HMiGMN1, idj., cmigrans, misratorius ( $e$, de, migro, délogere). Se dit des animaux qui, à certaines époques de l'année, quittent un pays pour passer dans un autre. Ex. Corcgonus mirratorius, Columba migratoria, Acrydium migratorium.

GMigrizion, s. f., migratio. Passage d'uu pays dans un autrc. Evirssi", adj., cmissivus ( $c$, hor's de, milto, cuvoyer). En physique, on appcllc pouvoir émissif la faculté qu'out tous les corps ct les eorps lumincux d'ćmettre, les preniers de la chaleur, et les autres de Ja lumic̀re, dans lous les sens.

EMLIAILLOT'SÉ, adject. , inertnabulatus. Latreille appelle aiosi les nymphes dont le corps est couvert d'une pellicule commune, mais qui ont le thorax et l'abdomen distinets, comme celles des Lépidoptères.

EMVÉNoLoGiE, s. f., emmeno-

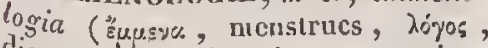
discours). Traité sur la menstruation.

EMIIEsostondes, adj. et s. $m$.

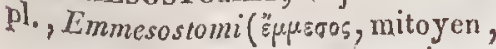

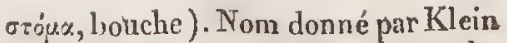
aux Echinodernes qui ont la bouche plaeee exactement au milieu du corpss.

EMVIORPLOSE, s. f. , cmmorphosis (šmpopopos, revêtu d'une forme). Latrcille dome ee nom au mode de métamorphose dans lequel la forme de l'insecle reste à peu près la même, c'est-ì-dire dans lequel les larves' ne diffërent des nymplies que par la taille et les dimeusious des parties, ou par l'absence, le rudiment ou le développement complet des ailes, l'animal conscrvant souss les trois états les mèmes mocurs et la mênıe nature de nourriture ( $\mathrm{ex}$. Orthoptères, Пémip tères et quelques Névroptères).

Émotssế, adj., hebetatus, retu* sus; gestumpft (nll.). Fithìte donnée: $I^{\circ}$ en minéralogie, daus la nomenelature de Haüy, à une variété dans laquellc certaines fitcettes intercepteut et rendent comme émoussúes des parties qui, sans elles, seraient plus saillantes que les autres (ex. Chaux carbonatéc émousssée) ; $2^{\circ}$ en botanique, à des organes qui sont dépourvus de pointe, ou dont le snmmet est si obtus, qu'il semble avoir étć retranché à dessein (ex. Salix retusa).

EMPA t'́, adj. Les minéralogistes disent qu'une roche a une texture empátée, lorsque sa base est une pâte sensiblement homogìne, dans laquelle sont dissćminées les parlies constituntes ou accidentclles (ex. Porphyre). Bonnard appelle roches cmpriteces eclles dont les parties sont enveloppées par uue pâte très-distinete (ex. Mimophyre).

EMPATEMLNT, s. m., pes. Base élargie et épaisse des Hydrophytes, qui sert à les fixer sur les rochers ou sur les corps auxquels ces végélaux sont attachés.

EMPATÉS, adj. et s. m. pl. Nom donné par Lamarck ì une section de la classe des Polypiers, eomprenant 
ceux qui sont composés de nombreuses fibres cornćes et d'une pulpe charnue on gélatincuse, empâlant les fibres el contcriant lcs polypes.

EMPALuitre, s. f. Nom donné à la couronne du bois de cerf, quand elle se divisc en manière dc main.

EHPENví, adjeet., pennatus. Synonyme peu usité de penné. Voyes ce mot.

EMPÉtTaACÉE, adj. et s. f. pl., Empelracea, Empetrece. Non douné par A. Richard ì unc section de la famille des Ericinées, par Nuttall, Don et Kunth à une famille de plantes, ayant pour type le genre Empetrum.

EMPÊTTi, adj., apersus; hintengestellt (all.). Illiger donne cette ćpithète aux pieds des oiseaux (compedes; Afierbeine, all.), lorsqu'ils sont situés à l'arrière du corps et cugagéés vers l'anus, de manière que lc eorps de l'auimal debout cst parfaitement droit. Ex. Manehots.

TMPÉTriḱes, adject. ct s. f. pl., Empetrca. Nom donné par Bartling à ume famille de plantes, qui a pour type le genre Empetrum.

Eupliritis, adj. el s. m. pl., Inyoluti. Nom donnć par Vicq d'Azyr à une classe de Mammifères, comprenant ceux qui ont les membres réduits à l'état rudinıcntaire, comıne les ploques et les lamantins.

EMn'HSÉMATEUx, adj., emphy.

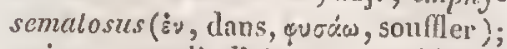
qui est rempli dair, ou gonflé à la manière d'unc vessic, commc les fruits du Colutea arboreseens.

INMPIDES, s. m. pl., Empiles, Empida, Empilia. Nom douné par Wiedeman ct J. Macquart à une famille, par Latrcille et E. Eichwald à une tribu d'inscetcs Diptères, ayant pour type le genre Empis.

TMPLUME, adj., pennatus. Épithètc donnce par les ornithologistes à des oiscaux qui ont les jambes cou- vertes de plumes. Ex. Aquila pennala.

EMPREINTE, s. f. ILes géognostes désignent sous ce nom les impressions que laissent dans les couchcs pierreuses les corps organisés qui s'y sont trouvćs emprisonnés au moment de leur formation.

EMPROOPHYTE, s. m. , emproos

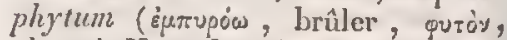
plante). Nom donné par Necker aux plantes dont les sucs âcres exercent une action caustique sur les tissus animaux.

ENPYREUMATIQce, adj. , empy-

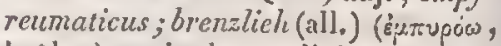
brûler); qui a les qualités ou les caractères de l'empjreume. Odeur, huile, saveur empyreumatique.

EMPIREUWE, subst. m., empy-

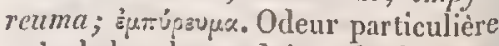
qu'exbalent les produits volatils qqu'on obtient en distillant les matières aninıales ou végétales.

LMCrsive, s. f. , emulsina. Nom douné par Pfaff à la matière qui est plus géućralement conure sous celui d'amygdaline. Voyez ec mot.

ÉMUÉEs, adj. et s. f. pl. , Emy" dea. Nom donnć par J.-E. Gray à une faunille de reptiles Chélonieus, qui a pour type le genre Emys.

HMOIDES, adjeel. et s. nı. pl., Emydida. T. Bell donne ce nom it unc famille de reptiles Chéloniens, ayant pour type le genre Emys.

IMIDDINEs, adject. el s. m. pl., Emydina. Nom donné par T. Bell à une seetion de la famille des Emydides, qui renforme le genre Emys.

EMYDOIDEs, adj. et s. m.pl., Emydoidea. Nom donne par P.-F. Fitzinger à une fanille de reptiles sauriens, qui a pour type le gente Emys.

EMIDO-SAURIENS, adj. et s. m. pl., Emydo-Saurii. Blainville, J.-Es. Gray, Latreille, Ficinus et Carus appellent ainsi un ordre de la classe 
des reptiles, comprenant ceux qui se rapproehent des Chéloniens par leur corps euirassć el des sauriens par leur forme générale, eomme les crocodiles.

GNALLOSTÈGURS" adj. et s. m. p]., Enalloslega (ร̈volios, diflérent, oтśgn, toit ). Nom donuć par Orbigny, Tichwald et Menke à unc famille de Mollusques eéphalopotes, comprenant les Foraminięres aplostègues dont les loges sont assemblées en tout ou en partic par alternance, ou enfilées sur deux ou trois axes distinets, mais sans lormer une spirale carnetérisée.

ÉNANTIOTnLtes, adj. et s. m.

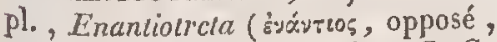
Tpx́s, trouer ). Nom donné par C.-G. Ehrenberg à uue famille de la classe des Polygastriques, coinprenant ceux qui ont la bouche ct l'anus terminaux, opposés.

ENARTHLOCARPLEs, adj. ct s. f. pl., Enarllirocarpece. Nom donné par Meyer el Bunge à unc tribu de la famille des Crueifères, qui a pour type le genre Enarthroearpus.

ENCADlí́, adj. Épillucte donnée, dons la nomenclature minéralogique de Haiiy, à des eristaux offrant des faeellcs qui forment une sorte de eadre autour d'une forme plus simple, déjà existante dans la même espèce. Ex. Idocrase cneadrće.

ENGal YPTíiss, adj. et s. f. pl., Encalyptea. Nom dunné par Furnrohr à un groupe de Mousses, qui a pour type lc genre Enealypta.

ENCÉPIIILI: s. m.', encephatum (iv, dans, wsęhin, tête). Ensemble de toutes les parties qui, ehez les animaux vertébrés, sant contenues dans la envité du erînc.

ENGÉPIALIQUE, adj., encephalicus; qui a rapport ou qui appartient à l'eneéphale. Vaisseaux encéphaliques.

ENGL̈PIALOIDE, adj. , cncepha-

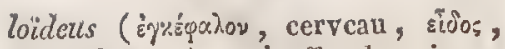
ressemblance); qui offre des sinuosités comparables à celles qu'on apereoit sur la surface du eervean. Ex. Polyportes enccphalum, Conioplores cerebclla.

ENCËPIILOzoames, adj. ct s. m. pl., Enccphalozoa ( है7rzépaìv, cerveau, ร̌wo\%, animal). Sous ce nom; Ficinus et Carus désignent un embranchement du règue animal, eomprenant lcs animaux qui sont pourvus de dcux systèmes nerveux, l’un ganglionnaire, l'autre cérébro-spinal.

ENCIIAINÉ, adj., concalcnaitts; zusammengekettet (all.); qui offre l'apparence d'anneaux disposés à la suilc les uns des antres, et eonstituant une ehaîne, comme les vésieules rẹnflées dont sont garnis de distanee en distance les rameaux du Fucus concatcnatus. $V$. Catúnifìre, Caténulatre, Caténulé.

ENĆmASŠ́, adj. Epithètedonnée par lesbotanistes aux graines, quand elles sont fixées une ì une dans les fossettes d'un plaecntaire alvéolé. Ex. Primulacécs.

ENGHĹLYES, adj. ct s. m. pl.; Enchelya. Nom douné par C.-G. Ehrenberg à une tribu de la classe des Polygastriques, qui a pour type le genre Enchelys.

ENCHLLYOIDEs; adj. et s. m. pl.;

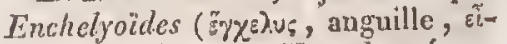
jos, resscmblance). Nom donnć par Goldfuss, Fieinus et Carus à une famille de Poissous, renfermant l'anguille et ccux qui lui ressemblent.

IENCuÉLXSOHE, adj., enchely so-

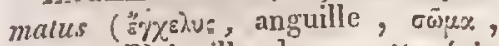
corps). Blainville donne ecttc épithètc aux poissons qui ont le corps long et eylindrique ou peu aplati, conme eelui de l'anguille.

ENCRASICHOLE, adj. ; cncrasi-

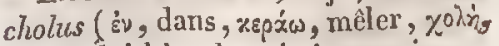
bile). Epithète donnée à un poisson, l'anchois (Engraulis encrasicholus) 
paree qu'il a la tête fort amìre, co qui fait qu'on la lui cnlc̀ve avant de le saler.

ENCRINES, s. m. pl., Encrini. Goldfuss, Ficinus et Carus ont établi sous ee nom une famille de Lillozoaires, qui a pour type le geure Encrinus.

ENGRINITIQUE, adj., encriniticus; qui renferme des enerines : calcaire encrinitique.

ENCRINOIEEES, adj. ct s. m. pl., Encrinoïdci. Blainville cmploye quclquefois ee tcrme, eomine synonyme d'Astérencrinicns (vojez ce mot), parce que les animaux qu'il sert à désigner sont voisins des Encrinus.

ENCROUTANT, adj. , incrustans; qui enveloppeles corps, ct forme au tour d'enx une sorte de croûte plus ou moins épaisse. Ex. Alveolita incrustans, Spongia incrustans.

ENDECAGMNE, adj. , endccagy-

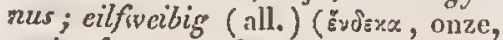
gryn่, femme). Se dit d'une plante qui a onze pistils.

ENDÉCaNdRE, s. f. , endeean-

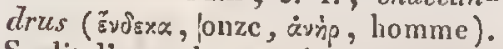
Se dit d'une plante qui a onze étamines dans chaque fleur. Ex. Hondccandra proeumbens.

ENDEGANDRIE, s. f., endecan-

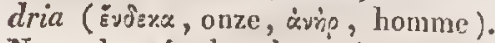
Nom donué, dans le systcme sexuel de Linné, à un ordre renfermant des plantes qui ont onze ćtamines.

ENDECAPIIYLLE, adj. , endecapluyllus; cilfblättrig (all.) ( $\varepsilon^{2} \cdot \delta \varepsilon \times x$, onze, gidiov, feuille); qui a des feuilles ailées, composées de onze folioles, dout l'impaire terminale. Ex. Indirofcra endecaplyylla.

ENDLiMIQue, adj., endemicus ;

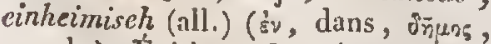
peuple). Epithéte donnée par Candolle aux genres et aux familles de plantes dont tontes les especes eroissent dans un même pays, comme les
Hermannia au cap de Bonne-Espérance, les Cinchona dans l'A mérique du Sud, les Epacridées daus l'Anstralasie.

LNDOBRaNcues, adj. et s. m. pl., Endobranchiala ("̈vơv, dedans,

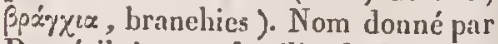
Duméril à une fanuille de la elasse des Annelides, comprenant ceux de ces animaux qui n'offrent pas de branehies à l'extérieur du corps.

ENDOCARPE, s. nı. , endocarpium, membrana intcrna s. cortcx internus peridii; Inncnhaut, Wand-

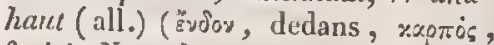
fruit). Non donné par L.-C. Richard à la membrane qui revêt la cavité intérieure du péricarpe, et dont l'épaisscur et la dureté augmentent quelquefois par des eouches additionnelles qu'y dépose successivement la partie parencliymatense, comme dans le noyau de la pêche.

ENDOCARPúEs, adj, ct s. f. pl., Endocarpere, Endocarpice. Non douné par Fries, Reiclienbach ct Zenker à une tribu de Liehens, qui a pour type le genre Endocarpon.

ENDOCÉPIALES, adj. et s. m. pl., Endoecphala (E้ขoำ, dedans,

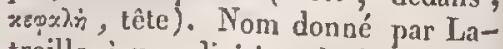
treille à une division de la branehe des Mollusques agames, comprenant ceux qui n'ont pas de tête saillante.

ENDOCIRONE, s. m., endochroma (ร้ขòวv, dedans, xp Gaillou désigne ainsi chacun des artieles ou entrenoeuds tubuloïdes qui composent les algues inarines, parce qu'en gćnéral ils sont colorés intérieurement.

ENDOGÈve, adject., endogenus

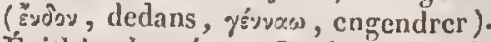
Épithète donnée par Candolle aux végétaux vaseulaires dont les vaisseaux sont comme ćpars dans toute la tige, et disposés de manière que les plus durs, e'est-à-dire les plus anciens, se trouvent à l'extérieur, en sorte 
que l'accroissement prineipal a lien de dedans en deliors.

ENDONIYCHIDES, adj. et s. m. pl. Endomychida. Nom donné par Leach à une famille d'inseetes eoléptères, qui a pour type le genre Endon:ychus.

ENDOPIOnE, s. in., endophora (E้vờy, dedans, épos, porter). Dénomination que divers botanistes ont ssignée à l'endoplevre. Voyez ec mot.

BNDOPIRAGME, s. m., endophragma (ëvos, dedans, ypónua, eloison). Nom donné par Gaillon aux diaphragmes transversaux qui, dans les Thalassiophytes diaphysistées, résultent de l'applicatiou bout à bout des cellules dont la plante est formée.

ENDOplevie E, s. f., endopleura, tegmen, tunica interior s. interna, integumentum interius (Link), nuclecanium (Tittmann), hiloferus (Mirbel); Pergamenthaut, Lederhaut, Kernhaut (all.) ("Evờ, dedaus, $\pi \lambda \lambda_{\varepsilon}$ pò่, côté). C'est le nom que Candolle donne à la pellieule intérieurc de la graine.

LNDOPTLE; adject. , endoptilus

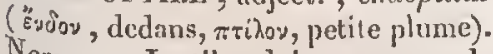
Nom que Inestilondois propose de donner ì l'embryon des plantes monoentylédones, paree que sa gemmule est renferméc entièrement dans $l_{a}$ cavité cotylédonnaire.

ENDOnHI\%, adj., endorhizus

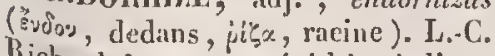
Riehard donne cette épithète à l'embryon végétal dont la radieule, à l'époque de la germination, ne s'alonge presque pas, mais donne naissance, soit latéralement, soit par le sommet, ì quelques radicelles simples, qui joutent le rôle de radicule. Une plante endorlize est eelle qui produit un scmblable embryon.

ENDOSMOMLTRE, s. m., endosmometrum (endosmosis, endosmose,

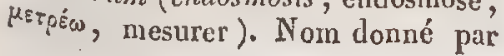

Dutrochet à un instrument au moyen duquel on peut rendre sensibles les phénomènes de l'cudosmose.

ENDOSHOSE, s. f., endosmosis

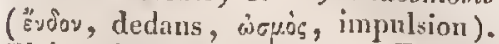
Phénomène, déeouvert par Dutroehet, qui consiste en ee que, quand deux liquides différeus d'aseension eapillaire sont séparés par une eloison mince et perméable, il s'établit, au travers de cette eloison, deux courans dirigés en sens eontraire; un fort , qui est eelui du liquide le plus aseendant, se porte vers le liquide le moins ascendant; un faible, qui est eelui du liquide le moins aseendant, se porte vers le liquide le plus ascendant.

ENDOSPERIE, s. m., endosper-

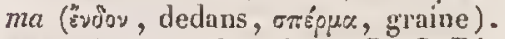
Mauvais nom dormé par L.-C. Richard au corps, distinct de l'embryon végétal, et formant avee lui l'amande de la graine, qu'on appelle plus généralement périsperme, ou mieuxalbumen.

ENDOSPERMIQUe, adj., endosper-

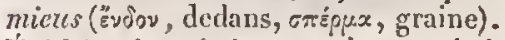
Épithète donnée à un embryon végétal qui est accompagné d'un endosperme ou albumen. Turpin appelle fluide endospermique celni qui remplit le sae ovulaire et dont, après qu'il a servi d'aliment à l'embryon, le résidu se conerète autour de ce dernier, pour prochnire l'endosperme ou albumen.

ENDOS!OLE; ; adjeet. , endosportes

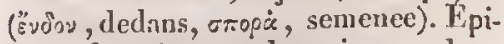
thìte donnée aux champignons dont les spores sont situćes ì l'intérieur. Ex. Lyeoperdon.

LNDOSTONE, s. m., endostoma

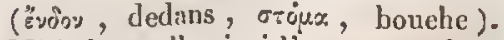
Mirbel appelle ainsi l'ouverture dont est perecéc la partie de l'ovule qu'il appelle sceondine, et par laquelle sort le mucelle, qui est inséré par sa base au fond de ectte dernière. 
FNDOTRICHLES, adj . cts. f. pl.,

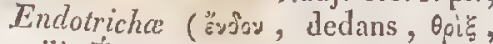
poil). Epithète donnée par Froclich à une seetion du geure Gentiana, en raison des appendiees eapilliformes garnissant l'entrée de la corolle des espèees qu’elle renferme.

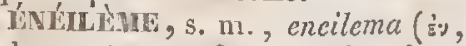
dedans, eì่śs, renfermer). Nom donné par Dutrochet ì la membrane interue de la graine.

ENERVi, adj., encrvis, enervius, apcnius; aderlos, rippcnlos (all.); sncrvato (it.) (c, priv., nervus, nerf). Se dil d'une feuille qui n'a pas de nervures. Ex. Plcurandra encrvia.

ENANGL, s. I., infantia, puer itia, puerilitas; $\pi$ isise; $K$ indheit (all.); infancy (angl.); infunzia (it.) (en, nég., fari, parler). Période de la vie humaine qui s'étend depuis la naissanee jusque vers la septieme aunée.

ENFANT, adj. et s. m., infans, parvulus; rexis; Kind (all.); child (angl.); fanciullo (it.). Individu de l'espèce lumaine qui cst dans l'âge de l'enfance.

ENFA XTEMENT, s. nı., parturitio. On appclle ainsi la parturition (voyez ce mot), dans l'espèce humaine.

ENFERMÉs, adj. et s. m. pl., Clausi, Inclusa. Nom donné par $\mathrm{Cu}-$ vier et Schweigger à une famille d'Acéphalcs Testacés, par Nerıke à un ordre de la classe des Élatobranehes, renfermant ceux qui out l'habitude de s'cufonecr dans le hois, le sable, les pierres, ou de s'envelopper d'un tube.

ENGUE, adj., perforalus. Synonyme peu usité de perfolié. Vorez ce mot.

INFLí, adj., inflalus, turgidus, tunidus, zriculatus. Se dit: $1^{\circ}$ en hotanique, d'une partie membraneuse qui se dilate vers sa partie moyenne ct se resserre à son sommet de mavière à ressembler á une vessie pleíne d'air "̈ comme le calice du Cucubalus bacciforts et du Silcne inflalus, le nube de la corolle de l'Erica inflata, le légume du Colulea arborescens, la silicule de l'Aly ssum utriculatum, le pétiole du Trapa natans, le follicule de l'Asclepias fruticosa, les semmens de la frorde du Fucus inflatus, les ramcrux du Pilotrichum tumidum; $2^{\circ} \mathrm{cn}$ zoologie, d'une coquille qui a l'air d'avoir ćté soufflée (cx. Crassatella tumida, Vcnus turgida).

ENFONCl, adj., recessus, immersus, dcfixus. Epithète donnée par les bolanistes aux feuilles dont les intervalles des nervures sont creux; aux sutures des valves, d'après Mirbel, lorsqu'elles sont placées an fond d'un sillon plus ou moins profond (ex. Thododcndrum); "aux iubcrcules d'un liehen, quand ils sont plongés daus la substanee même de la plante (ex. Lichcn immersus); aux racines fusiformes qui pénètrent profondément en terre (cx. Crinum defixum).

EXFCuE, adj., fumosus, fumigatus, fuscalus; affumicato (it.); qui a la couleur de la fumée; qui est d'un brun noir ou d'un roux brun. Ex. Cypris fuscala, Clavaria fumosa, Spondylocladiun funrosum, Conus fumigalns.

ENGAINANT, adjeet., vaginans; guainante (it.); qui enveloppe, comme ferait une gaîne. Se dit, en botanique, de toute partie qui embrasse la tige; des fuilles (ex. Myricaria vaginata), des pétiolcs (cx. Cistus vaginatus), des stipules (ex. Ononis vaginatis, Hedysarum vaginale, Psychotria vaginans). Le sligmate reegoit eette épitlète, quand il se compose de deux lames, dont l'une cmbrasse l'autre (ex. Sideritis inca$n a)$, et l'androphore, lorsqu'ćtant tubuleux, il forme une gaîne autour du pistil (ex. MIalpa officinalis). En zoologie, on appelle engaínantes les 


\section{ÉNIC}

coquilles uniralves qui sont coniques et sans spire proprement dite (ex. Patella).

ENGAINÉ, adj., vaginatus; grzainato (it.). Epithète donnée à la tige, lorsqu'elle est enveloppée par des laases de feuilles (ex. Graminées, Dicranum vaginatum), ou par des pétioles (ex. Musa paradisiuca) cngaiJans.

ENGAINLE, adj. et s. m. pl, , $V_{a-}$ finati. Nom dounć par llliger à une famille d'oiseaux Échassiers, comprenant ceux dont le bec est garni d'une gaîne cornće à la base de sa partie supćricure.

ENGINITES, adject. et s. m. pl., Engrinites. Nom donné par Cuvier à une tribu de la famille des insectes Colćoptères clavieornes, qui a pour type le genre Engis.

ENGOUFFRaNs, adj.et s. m.pl., Hiantes. Illiger désignait sous ce non une fanille d'Oiseaux, comprcnant ccux qui engouftrent les insectes en volant.

ENIIARMONIQUE, adj., enharmonicus. Épithète donnée di unc échellc musicale comiposéc d'une succession de vingt-et-un sons consécutifs d'une octave à l'autre, échelle qui n'existe que par supposition. Chaque ton, même mineur, contenant plus de deux demi - tons, le complément de la somme de ces deux demitons au ton entier est précisément l'interpalle entharmonigue, appelé communément quart de ton, lequel prend l'épithète de majeur' quand il est le complément de deux demi-tous au ton majeur, et celle de mincur lorsqu'il est le coinplément de deux deuni-tons au ton mincul:

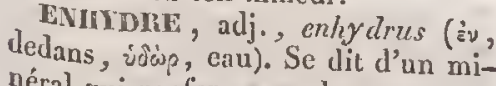
néral qui renferme quelques gouttes d'eau. Ex. Quarz gćodique enhydre. Evicuiez, adj., enicurus (Évıòs,
singulier, oujps, queue); qui a une
ENNÉ

queue singulièrc. Le Trochilus onicurus est ainsi appelé parce qu'on ne connait point d'autre oiseau que lui qui n'ait pas six pennes a la queue: le Caprimulgus enicurus, parec que scs pennes caudales offrent une ćchancrure en carré, la troisième dépassant la première de quatrc lignes, et les quatriène et cinquiène de dix.

ENIVRANT, adj., incbrians, me-

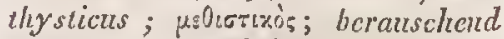
(all.); qui produit l'ivresse. Le Pipcr melhyslicum cst ainsi nommé paree que les insulaires de la mer du Sud s'en servent pour faire des boissons cnjvrantes.

IENNÉACANTIE, adj. , enneacan-

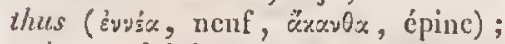
qui a neuf ćpincs, comme le Scarus ernacacanthus, dont la nageoire dorsale offre ncul rayons aiguillonnćs.

ENNÉACONTAEDIE, adj. , cn-

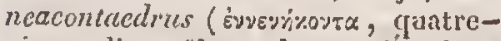
vingt-dix, Ẽ jos, base). Epithète donnée, dans la nomenclature minéralogiquue de Haüy, à un cristal qqui préscnte quatre-vingt-dix faces. Ex. Idocrase ennéacontäedre.

INNŔAGONE, adj., enneagonus

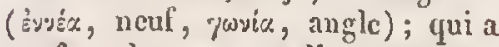
neuf angles, comme l'organe nalatoire antéricur de l'Enneagonum hyalinum.

LNNEAG YNIE, s. f. , entcagynia (')ข้ d'un ordre, dans le système sexuel de Linné, qui comprend des plantes ayant neuf pistils.

Minvigivioue, adj., enneagynicus; qui a neuf pistils.

TNNRHIEANEDE, adject. , enneahexactrus ( Épec, base). Tipithèle donnée, dans la nomenclature minćralogique de Haiiy, ì une varićlé de elsaux fluatéc en cube, dont chaque angle solide cst remplacé par six facettes situćes de biais.

GNNÉANDRE, adject., cnneander 


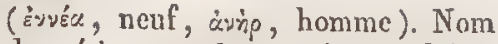
donué à toule plante qui a neuf étamines. Ex. Icica enncandra.

ENNÉANDRLE, s. f., cnncandria. Nom d'une classe et de deux ordres, dans le sysieme sexuel de Linné, comprenant des plautes qui ont neuf étamines.

ENNÉANDIIQUF, adj., cnncandricus. Sc dit d'une plante qui a neuf étamines.

ENvíanTHùre, adj., cnncan-

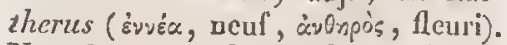
Nom donné par Gleditsch aux plantes qui ont neuf étamines.

ENNíaplTALE, adj., cnncape-

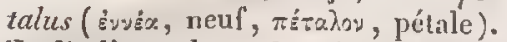
Se dit d'une plante dont la corolle est composée de neuf pétales.

ENVÉAPIIYLLE, adj., enneaplyyllus; neunbläırig (all.) (

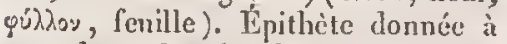
une plante dont les fouilles sont composées de neuf folioles (ex. Oralis cancaplylla), ou peunées et formées de neuf folioles, dont une impaire (ex. Indigof cra cnneaphylla), on triteruées (ex. Sarcocapnos enneaphylla, Deniaria enncaplyllos).

ENNEAPTÉRYGIENS, adj. ct $s$. m. pl., Enneapterygii (ย่vขร์x, ncuf,

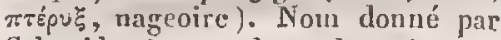
Schmeider ì une classe de poissons, comprenant ceux qui ont neuf nageoires.

ENNÉARRHINE, adj., cnncarrhinus

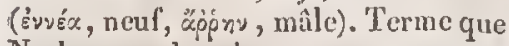
Necker employait comme synonyme d'cnncandre. Voyez ce mot.

ENNÉaSÉPALE; adj. , enncascpalus. Epithèle que Neckcr propose de donner au calice, quand il est composé de neuf folioles.

ENNÉASPERME, adj. , cnneaspermus ('่vvéa, neuf, бте́ppa, graine). Dont le fruit contient neuf graines. Ex. Ionidium cnneaspormum.

TNODE, adj., enodis; knotenlos (all.) (e, priv., nodus, nœud). Ri- chard donne cette épithètc aux tiges qui sont entièrement dépourvues de nouds.

ENROULÉ, adj., revolutus, convolians, convolutus; zusammengerolle (all.). Épithète donnée à une coquille univalve diseoidd, comprimée de droite à gauche, dout l'axc est tout-à-fait transversal, et dont on n'aperçoit pas le sommet, soit que les tours se touchent sans se pénétrer (cx. Argonautc), soit que le dernier envcloppe et cache tous les autres (ex. Nautilc flambé), soit enfin que les tours ne se touchent pas, et que la coquille représente en quelque sorte une crosse (ex. Spirula convolvans).

ENroulés, adj. ct s. m. pl., Rcvoluta. Nom donné par Lamarek à une famille de Mollusques trachélipodes, compremant ceux dont la coquille a ses tours de spire cnroulés de manière que le dernier recouvre presque cntièrement les autres.

ENSANGLANTÉ, adj., cruculus, crucntatus, sanguinolentus; qui est marqué de taches rouges, qui a des parties rouges. Le Crinum crucntum a les filels de ses étamines d'un rouge de sang; le Cineraria crucnlata a ses feuilles agréablement teintes de pourpre en dessous; la Chrysomela sanguinolonta a lc bord externe de ses élytres d'un jaune rougeâtre; le Gobius crucntalus a la bouche, la gorge, les opereules et les nageoires tachetés de rouge; la Natica crucnfala est lllanche et parsemée de taches rouges et rousses; la Columba crucnla a une tache rouge sur la poitrine.

ENSEVELI, adj., sepultus. Épithète donnée par Kirby à l'alitronc des insectes, lorsque sa face supérieure cst totalement couverte par le thorax, les ćlytres ou aurres organes de vol. Ex. Colcoplères, Orthopières.

ENSICAUDE, adj., cnsicaudatzes. (cnsis, épée, cauda, queue); qui a 


\section{ENSI}

la queue plate, amincic sur les bords et pointue. Ex. Asearis ensicaudata.

WNSIFHDE, adj. , ensiferus (ensis, épée, fero, porter'). I'Alcyonum ensifcrum est ainsi appelć parec qu'il a ses rameaux longs, élloits, un peu comprimés et ayqués.

ENSWOLIC, adjest., cnsifolius; schuerdibläurig (all.) (ensis, épéc, folium, feuille); qui a des feuilles ensiformes. Ex. Juneus cnsifolits, Lindsaa cnsifolia, Ornithogalum onsifolium.

ENS1EORuE, adj., ensiformis, gladiatus, cnsatzes; schwertfirmig (all.) (cnsis, sabre, forma, forme). Fithète donnéc par les botanistes aux feuillcs, quand clles sont un peu épaisses au milien, tranchantes aux deux bords et rétrćcies de la base au sommet, qui est nigu (cx. Iris xiphium); au fruit (ex. Dolichos cnsiformis, Dolichos gladianus, Dolichos cultratus), et an seyle, quand ils ont la mèrue forme. Les zoologistes l'appliquent aux coquilles qui ont la forme d'un sabre (ex. Solen cnsis), anx untennes des insectes, quaud elles sont larges ì lia basc, terminécs en pointe et angulcuses (cx, Truxalc); it l'ovipositor de ces animaux, d'aprìs Kirby, quand il est long, comprimé ct tranchanl (cx. Aerydium).

Evsiponies, adj. et s. f. pl., Ensata. Nom donuć par Limué à une famille de plantes qui ont les feuilles ensiformes et les fleurs monopćcrianthées, et par Barting à une classe comprenant les familles des Burmanniacées, des Hypoxidées, des Ilaemodoracées, des Iridées, des Amarylliclćes et des Broméliaeées.

ENSIPENINE, adject., ensipennis (cnsis, épée, penna, plume). I'Ornysmia ensipennis cst ainsi nonmué, parce que les bagnettes des rémiges de ses ailes sont aplaties ct élargies, c qui lcur donne une disposition recoupldée, en faejon rle sabre.
ENSIROSTRE, adject.; ensirostris (ensis, épéc, rostrum, bec); qui a le bee ou le rostre compriné et recourbć en forme de sabre. Ex. Calandra cnsirostris.

EN'ASSE, adj., conferlus. Se dit des fcuilles, lorsqu'elles sont en assez grand nombre ct placécs si près les unes des autres, sur la tigc, qu'elles se dérolicnt presque à lit vuc.

ENTfillonilincins, adj. et s. m. pl., Enterobranchia ("Evspou, intes-

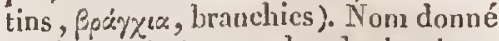
par Latrcille à uı ordre de la classe des Annelides, comprenant eeux dc ces animaux dont les branehies sont intéricures, ou ne font pas de saillie an deliors.

ENTÉRODI:LAS, adj. et s. m. pl.,

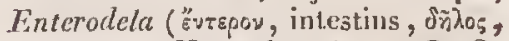
manifeste). Non clouné par C.-G. Ehrenberg à une section de la classe des Polygastriques, comprenant ceux de ecs animaux qui ont un tube intestinal parfait, e'cst-à-dire terminé par une bouche et un anus.

ENTĹROPHLitoDE, adj., cnterophlocodes (sruspor, intestins, plocos, ceorce ). Wallroth nomme morphosis entcrophloxodes le développement des lichens qui naissent sur l'intéricur mis à nu des tiges ligneuses d'antres plantes, sur la moelle, l'aubier, le liber, le bois, ctc.

LNTÉrostís, adj. et s. m. pl.,

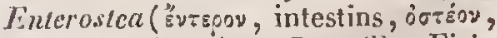
us). Nom donué par Latreille, Ficinus et Carus à une famille de Céplanlopodes, comprenant ceux qui ont dans l'intèrieur du corps une pièce ealeaire en forme de lame et représentaut la coquille.

ENTHELMHNTHES, s. m. pl. , Enthelmintha (घ่rós, dedans, Ë̀uevs, ver). Nom donué par Goldfuss, Ticinus el Carus à une classe du règne animal, qui comprend les vers intestinaux.

INTLER, adj., integer ; фilog; un- 
gctheilt (all.); inticro (it.). Se dit, en botanique, de lout organc qui n'offre surseshords ni incisions, nidentelures, ni découpures, comme les feuilles du Ricinus integrifolius, du Tessaria integrifolia et du Chrysanthemum integrifolium; le calice du Fissilia; la lèvre supérieure de la corolle dú Moluccella lavis, les stipules du $P_{0}$ lygonnm amphibium. Les fouillets des agaries sont dits entiers, quand ils s'ćtendent depuis le pédicule jusqu'à la circonférence du chapeau.

ENTIMIDES, adj. et s. m. pl., Fntimides. Nom douné par Schoenherr à un groupe de la famille des Curculionides gonatocèrcs hrachyrhinques, qui a pour type le genre Enimus.

ENTOCímILAE, s. m., entoce-

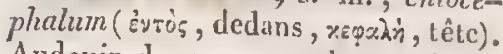
Audouin donne ce nom à une piece, correspondante à l'entothorax, qu'on trouve dans la tête des insectes hexnpodes.

ENTOniscar, adj., cnlodiscalis ('̇vò̀, dedans, disxos, disque). Epithètc donnée par Lestiboudois ì l'insertion des étamines, lorsqu'elle a licu en dedans dn disque.

ENTOGASTRE, s. m., entograstrium ( tre). Sous ce nom, Andouin désigne une pic̀ce, correspondante à l'entothorax, qu'on troure dans le premier anneas de l'abdomen des insectes hexapodes.

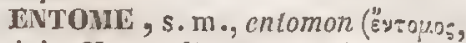
incisé). Nom collectif donné par Latreillc aux animaux articulés qui sont pourvus de pieds également articulés.

ENTOMonies, adj. ct s.f. pl., Entomobice ("voopos, insccte, fiow, vivre). Non donné par RobincauDesvoidy à unc trilua de la famille des Myodaires calyptérées, comprenant celles qui vivent dans le corps des insectes.

ENTONOGLNE, adj., cntomoge-

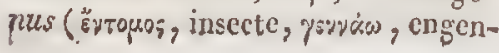

\section{ENTO}

Arer); qui vit sur les insectes morts. Ex. Racodium eniomogena.

NATOMOGRAPIE, s. m. , ento-

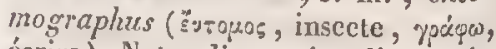
écrirc). Naturaliste qui se livre spécialcment à l'étude des insectes.

ENTOHOGRAPIE, s. f., entomograplia. Histoire des insectes. Synunyme d'entomologie, employé par G. Fiseher.

ENTONOGRAPHIQUE, adj., ento mographicus; qui a rapport à l'entomographie.

ENTOMOIDES, adj. et s. m. pl., Entomoïda (हैंrou.s, insecte, Eiरos, resscmblance). Nom donué par Latreille à un ordre de la classedes Elminthogames, renfermant ceux qui sont généralement munis d'appendices simulant des pieds.

ENTONOLOGIE, s. f. , entomolo-

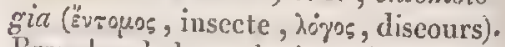
Branche de la zoologie qui traite dc l'histoire des insectes.

ENTOMOLOGISTE, s. m., entomologista. Naturaliste qui s'occupe spécialcment de l'histoirc des insectes.

ENTOHOMÉLINE, s. f., cntomomeilina ( noir). Lassaigne désigne ainsi la substance animale à laquelle Odicr a donné le nom de chitine. Voyez ce mot.

ETTOMOPILAE, adj. , entomo-

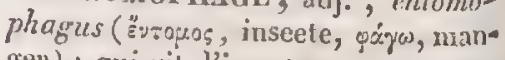
ger) ; qui vit d'insectes.

ENTOMOPHAGES, adj. ct s. m. pl., Entomophagi, Entomophaģa. Nom donné par Latreille, Ficinus et Carus à unc famille de Manmifères marsupiaux, par Goldfuss, Ficinus et Carus à une famille d'insectes coléoptères, renfermant des animaux qui font leur principale nourriturc d'insectes.

ENTOMOPILE, adj., cntomophi-

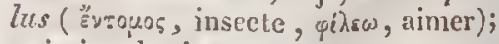
qui aime les insectes.

ENTOMORHEE; adj. , entomo- 


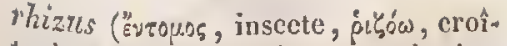
tre); qui naît ou qui croît sur les insecles (cx. Spharia entomorhiza, Isaria splingum ). Il paraît, d'après les observations de Wydler, que beaucoup de prétendues clavaires haissant sur des insectes, ne sont nutre chose que des masses polliniques et pédiculées d'orehidées.

ENTOMOSTivues, adj. et s. m. pl., Entomostcgea ("ขropos, insecte, otérn, toit). Nom donné par Orbigny et Menke à une famille de Céphilopodes fornminifères, dont la co. Tuille est garnic de cellules subdivisées par des cloisons transversales, de minière que sa coupe représente une sorte de treillis.

ENTOMOSTONE, adj., cntomo-

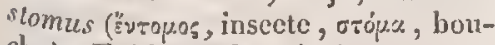
chc). Epithètc donnée à toute coquille univalve dont l'ouverture est plus ou moius profondément ćchantrée en devant.

ENTOnOSTOTites, adj. et s. m. pl., Entomostomata. Nom donnć par Blainville à une fumille de coquilles, comprenant les univalves non symétriques dont l'ouverture est échancrée, et à une famille de l'ordre des Paracépbalophores siphonobranches, comprenant ecux de cesanimaux dont ì coquille est munie d'un caual trèscourt, plus ou moins échancré en avinut.

ENTonostraclis, adj. el s. m. pl., Entomostraca ("̈ขтop.rs, coupé, "grpxzoy, coquille). Nom donné par Dumćril ct Eichwald à un ordre, par $D_{\text {csmarest et Leach à une sous-classe, }}$ par Cuvier a une division de la classe des Crusticés, par Blainville à unc famille de la classe des Irétéropodes normanx, coupes qui toutes reliferment des animaux à lésum:ns cornés très-minces, qui ont le test cn louclicr, composé d'une à deux pieces.

L LNTOMOTHLES, adj, et s. m. pl., Entomotilla. (हैvтous, insecte,

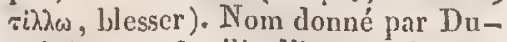
méril à une famille d'insectes hyménoptères, dont la plupart, à l'état: de larve, se développent dans l'intérieur du corps d'autres insectes.

ENTOMOzOAInEs, adj. et s. m.

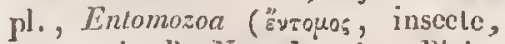

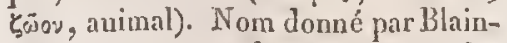
ville à un type du sous-règne des animaux artiomorphes, comprenant ceux dont le corps est articulé extérieurement.

ENTOMOzoOLOGIE, s. f., cntoa mozoologia (

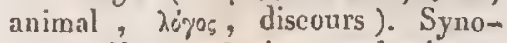
nyme d'cntomologic, employé par blainville.

ENTONoul, s. m., scaphus. On appelic ainsi le pédoncule creux ct cn forme d'entonnoir qui porte la fructifieation de cerlaius lichens.

ENTOPIILLINES, adj. ets. f. pl.,

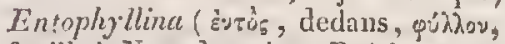
feuille). Nom donné par Reichenbach à une section de la famille des Hépatiques, comprenant celles qui portent ảes bourgcons ou gemnes plongós daus la substance même de la plante.

ENTOPIILLOCARPES, adj. et s.

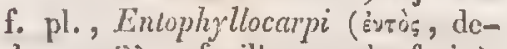

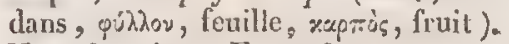
Nom clonné par Furnrohr a un groupe , par Bridel à une classe de Mousses, comprenant eclles dont la fructification naît dans le scin des feuilles, par une duplicature ou une fissure de ces dernières.

ENTOPUXTES, adj. et s. m. pl., Entoplyyte, Eintophyti. Nom donné par firies à un ordre de Champignons couiomyeètes, par Link ì unc séric de l'ordre des Muecedinécs, renfermant des champignons quui croissent sur les plantes vivantes ou mortes, dans leur tissn même.

ENTOPOGONES, adj. et s. ᄃ. pl.;

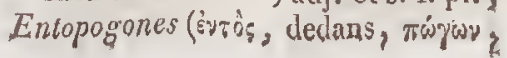


barbe). Nom donné par Palisot-Beautvois à un ordre de Mousses, comprenant celles dont lc péristome simple et interne est formé de cils libres ou réunis en une membrane plissée.

ENTOPRTQUE, adj. , entopticus (Ẻvtòs, dedans, örouxt, voir). Goethe appclle ainsi les couleurs qui se forment dans des prismes ou des curbes de verre refroidi rapidement, lorsqu'un rayon de lumièrc olliquement réfléchi y pénètre et s'y réfracte.

ENTORTLLLE, adj., involutus. Expression que quelques botanisics substituent ì celle de volubile (voyez ec mot), en parlant de la tige.

ENTOTHOLAX, s. m. , entotho-

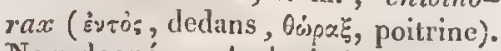
Nom donné par Audouin à unc pièce qui, dans les inscctes hexapodes, existe au-dessus du sternum et à sá face interne, c'est-à-dirc au dedans du corps de l'insecte, sur la ligne mćdiane, et qui naît ordinairement de l'extrćmité postérieure du sternum, ì chacun des segmens du thorax. C'est la piëee en forme d'y gree de Cuvier. Voycz Tuorax.

ENTOUnAN', adj. , eireundans, cireumsepiens, cingens, amplectens ; zumgebend, wmfassend (all.). Epilhète donnée aux feuilles, lorsque, dans le sommeil de la plinte, elles sont roulées en cornet, et enlourent la tige, comme pour protéger les jeunes pousses. Lx. Malva peruviana.

EvTouné, adj., circumdatus, amplextes, cinclus; ungseben, umfasst (all.). Nom douné, dans la nomenclature nuinéralogique de Hä̈y, à ure variété daus largucllc les décroissemens ont lieu sur toutes les arc̀tes ct sur tons les angles solides, autour de la base d'un zoyau prismatique. Ex. Strontiane sulfatie entouréc.

EvTOzonires, arj. et s. m. pl., Entozoa (Evtòs, dedans, Čŏos, animal). Nom donné par Rodolphi et Goldluss à une classe du règne ani- mal, qui comprend les vers intestinaux.

ENTozot́s, adj. et s. m.pl., Entozoa. Latreille appelle ainsi une branche de la race des animaux Acéphalcs gastriques, parce que tous les animaux qu'elle renferme sont parasites.

ENTOZOIQUE, adj., entozö̈eus.Se dit des aninaaux qui vivent dans l'intérieur du eorps d'autres animaux (ex. vers entozoĩques), ct des champignons qui croissent, soit sur le corps des insectes morts ou vivans (cx. Is $a^{\circ}$ ria sphingzom), soit au milien des pièces d'appareil employées au pansement des plaies, eoinme on en a divers excmples. Voyez Enтомов

ENTOZOOLOGIE, s. f., entozoolo gia. Branche de la zoologie qui traite spécialement de l'histoire naturclle des vers intestinaux.

ENTRECOLPÉ, adj., interscelts. Bilderdyk donne le nom de vaisseau. entrecoupés au tissu cellulaire moniliforme deCandolle.

ENTRíE, s. f.Quelques hotanistes substituent ce terme à celui de gorge en parlant des corolles monopétales.

ENTREGRELF'́, adj. , coalitus. tepithète donnée, en botanique, à des organes qui, après la maturité, sont réunis et ne forment plus qu'une scule masse, comme les cotylédoris du Tropecolum majus, et les camares du Rubus Idcous.

ENTRELAĆ́, adj. , implexus, in tertextus, intricatus, eontextus; ver quebt, verflochten(all.). Dans la nomenclature minéralogique de Haiit, eettc épithète est donuée à une varič́t en cristaux aciculaires, lorsque les $\mathrm{il}^{-}$ guilles se croisent dans tous les $\mathrm{se}^{\mathrm{1} 1^{\mathrm{s}}}$ (ex. Manganese oxidé entrelacé). I.es géognnstes diseut qu'une roche'a une strueture cntrclacéc, lorsqu'dle est composce de parties anguleuse's, arrondies ou ovoïlles, qui s'cn grènent les unes dans les autres, et semblent 
liécs par une matière colorée, disposée en veines on en réseaux. Le Bryzum contextum est ainsi appelé parce qu'il forme un gazon épais et serré dans les Alpes.

ENTRENOEUD, subst. m., internodium; Zwischenknoten(all.); internodo (it.) (inter, entre, nodus, noud). Les botanistes appellent ainsil'espace compris entre deux nouds d'nne tige noueuse, et, comme les feuilles partent ordinairenent des ncuds dans ces tiges, on a souvent étendu ce nom à la partie de la tige comprise entre deux paires ou deux rangées de feuilles.

ENTRITIQUE, alject., entriticzts ("E๋น Nom donné par Brongniart à un groupe de terrains abyssiques et is un autre groupe de terrains plutoniens, comprenant des roches dout la pâte est eomme lardéc de cristanx, ou pétrie de nodules et de parties eristallisées eonfusément.

ENVELOPPANT, adj. , convoluti"us, involvens, includens, insolulans; cinhüllend (all.); swiluppantc (it.). Epithète donnce anx feuilles, lorsqu'étant alternes, elles s'ippliquent contre la tige, pendant le sommeil de la plante, comme pour envelopper le bourgeon situé à leur aisselle (ex. Silla Abuliton), et ì l'cstifalion, quand la picee extérieure est conrbéc de manière à convrir on cnvelopper toutes les autres, et que celles qui viennent au dessous enveloppent de mêmes celles qui suivent (ex. Ies pétales de la Giroflée).

ENVELOPIN, s. f., integumentum;

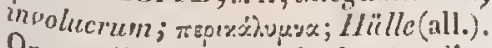
On appelle cnseloppe herlance, d'inpres Mirbel, une couche de tissu ecllulaire qui, dans la tige dies plantes dicutylédones, se trouve placéc immédiatement alt-dessous de l'épiderme, qu'clle nnit aux couches corticales; enveloppes florales, l'eusemble des I. parties qui euvironnent les organes scxuels des plantes; enveloppcs sćminales, celles qui cntourent l'amande de la graine.

ENVELOPPL, adject., involutus; cingehzïlle (all.). Les géognostes disent qu'uue roche fenilletée a vae structure cnvcloppée, lorsque ses partics, étant quelquelois moins grosses, sont enveloppées par les feuillets de la roche, qui se contournent et s'y appliquent dens tous les points. Ex. Siéaschiste notulenx.

INVTELOPPÉs, adj. et s. m. pl., Involuta. Nom donné par Menke ì une fianille de l'ordre des Gastéropodes cténolranches, comprenant ceux dont le dernier tour de la eoquille enveloppe tons les autres.

iNVERGune, subst. f. Etendue qu'embrassent les ailes d'un oiseau étendues pour le vol.

ENVIrONNANT, adject., ambiens. Épithete donnée à la superposition d'une roche, lorsque les couches superposéess entonrent seulement la base de la roche ou montagne fondamentale, dont le somnet semble les pereer.

ENZOIQUE, adject. , cnzoïcus ( $\dot{\mathrm{\varepsilon} v}$,

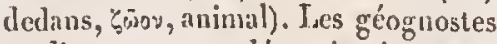
appliquent eelte dénomination aux terrains dans lesquels on reneontre des déluris fossiles d'animaux en grunde quantité.

LPACnIDres, adject. et s. f. pl., Epacrider. Nom donué par R. Brown ì une famille de plantes, qui a pour type lo genre Epacris.

ÝPAYS, adj., crassus; Taxùs; dick (all.); thick angl.); fosco(it.). Se dit, en botanique, de tontes les parties dont l'épaisscui', comparéc à eelle d'organes analognes, est plus grande que ne semblerail le comporter leur étendue. Cette ćpithète s'applique ì l'androphore (ex. Hura crepitans); an chaton (ex. Salix capreca); à l'épi (ex. Typlus latifolia); aux fuilles (ex.Sarcocapnos crassifolia); aux 
spathelles (ex. Trispsacum hormaphroditum).

EPAISSIS, adj. et s. m. pl., Incrassata. Nom douné par Latreille à unc famille de l'ordre des Gymnogènes inappendicés, comprenant ccux de ces animaux dont le corps a une certaine épaissenr.

EPALPÉ, adj., epalpalus. Kirby donne ectte épithète aux animaux qui, comme les Hémiptères, ont la bouche imparfaite et dépourvie de palpes.

MPALPúnné, adj., cpalpebralus (c, priv., palpebra, paupière); qui a'a point de paupières. Epillicte donnéc par A.-H. Harvorth aux reptiles Ophidiens.

CPALTIDÉE, adjeet. ct s.f. pl.; Epalidea. Nom donné par Lessing à une section de la sous-tribu des Astérọ̈dées Tarchonanthées, qui a pour type le genre Epaltes.

GPArOLL, adj., effusus; aufblïhond (all.). On dit qu'unc flcur est épanozie, lorsque ses pélales sont parfaitement dévcloppés.

EPANUULSSEMENT, s. m. effitsio, explicatio; Aufblühen (all.); blowing (angl.); aprimento (it.). Epoque à liqquelle une fleur déploie ses pétales; ouverture de la corolle d'une f)ent.

HBANTre, adj., spanthus ( $\dot{\pi} \pi$, sur, ${ }_{0}, 200$, fleur). Epithete donnce par Linné anx champignons qui croissent sur les flenrs des végétaux.

CPARAPSTALE, adj., cparapetalus. Moench donnc cette épithète aux fleurs qui sont dépourvues de parapétales, e'est-à-dire de nectaires.

íPARPLI, it, adj., sparsus.'Terme quelquefois, niais rarement, imployé par les bolanis'es, comme synonyme d'ćpars. Voyez ce mot.

EPARPLLEHANT, s. m. DupetiiThouar's dounc ece nom au phénomène qui frit que, quelque nombreuses que soicnt les culanines, les antheres sont parfaitement isolées les unes des autres, eclles-ci chcrehant ì s'ćcarter et á laisser entr'elles des distances égalcs, disposilion qui existc aussi dans les feuilles.

f́PARS, adj., sparsus; stéтрqu$\mu$ śvą; zerstreut (all.); scattered (angl.). Se dit, en botanique, de toutes les partics qui naissent sans ordic ou régularité; des rameaux , quand il n'y a aucune régularilé dans les distaneesqui les séparent (ex. Daphne Miczercum) ; des fcuilles, quand elles sont solitaires sur un mème plan horizontal aulour de la tige (ex. Rhynchospora sparsa). Ce lerme est inexact, du moins en parlant des feuilles, puisque, daus le eas supposć, elles obscrvent toujours un ordre régulier.

TPAULE, s. f., scaptzla; अैuos; Schuller (all.); shoulder (angl.); spalla (it.). Nom donné, dans les animaix vertébrés, à la partic du membre thoraeique qui est le plus rapprochée du trone; dans les inseetes hexapodes, par Kirluy, au second artiele des paties antéricures ou bras; parWicdenann, aux coins antéricurs du test de la poitrine.

ÉPAURETTE, s. f. Les entomologistes appellent aiosi une pic̀es yui cnveloppe la base de l'aile antéricurc des inscetes lyménoptères. Voyez Ptérycone.

HeICLICine, s. f. Nom donnć par Siraus à trois picees moliles, placécs en delans de l'apophysc bifurquée de's élytres des insectes coléopieres, atr moyen desineiles celles-ci s'articulent médialement ou inımédiatement avec l'ćeusson et la premiere paire iliaque.

trenon, s. m. , calcar, produc-

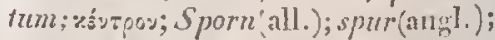
sperone (it.). On appelle ainsi : $1^{\circ}$ en minéralogic, l'extrémité brusque et ćlevéc qu'un ramear de montignc préscnte e'll arrivant dans la plainc, lorsque la ringidicé ar ec laquelle il s'a 


\section{EPHE}

baisse, à une distance plus ou moins considérable du faîte, est si forte qu'il semble eomme coupé à pie et arrèté lins le milieu de son cours. $2^{\circ}$ lin botanique, une sorle de corne ou de prolongement tubuleux qui se dirige du côté du pédiculc, et qui est une forte bossclure, ordinairement erense, de la eorolle (ex. Linaria), du ealice (ex. Balsamina), du périgone ou lablier (ex. Orchis), des anthères (ex. Arthrostemmneralcaratum). $3^{\circ} \mathrm{En}$ Zoologie, l’apopliyse coruée qui se voil à la partie postérieurc du tarse et au dessus da pouce de plusieurs oiseaux, notamnent dans les Gallinacés; une apophyse que présente los du nétacarpe du Jaeama, qui se dirige en arant, et sc termine en Pointc aiguë, lorsque l'aile cst pliće; d'après Kirby, une, deux ou plusieurs épines moliles, ordinairement insćrées à l'extrémité du tibia des insectes, et qui, daris quelques $\mathrm{C}_{\mathrm{a}-}$ rabes, Lépidoptères et Triehopteres, se voyent aussi an milien de eette partie de la patte.

Émonví, adject., calcaratus ; respornt, sporntragend (all!.); spurmuningl.); spronato (it.); qui est de l' d'un épcron, comme les antheres d Arthrostemmacalearatum. Kirby sectese cclte épilhète an tibia des inplasie, lorsqu'il est armé d'unc ou au pienrs épines. On l'appliquc aussi Farni ples oiseaux, quand il est al'ai d'un ou plusieurs éperons, et que le de ces mòmes animaux, lorsexe le mélacarpe offre une ou deux aigroissanees cornćcs, saillantes et rip.

Fiplionaclés, adj. et s. f.pl., the fracea. Now downé par Yulc à d'étabilile de plantes, qu'íl propose genre Ephe qui aturait pour type le ipe Ephedra.

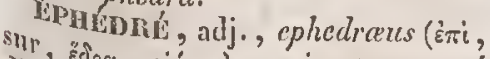
dir, हैo\%, siêge); qui est composé ariculations cupilées les unes ì la

\section{EPI}

suite des autres. Jue Corallina ephedrara cst ainsi appelé à cause de ses articulations longues et grĉles, qui resscmblent à eclles de la prêle.

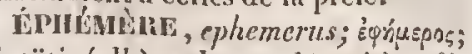
eintiilig (all.); cphemeral (angl.); effi-

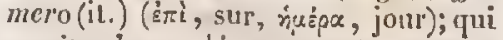
ne vil qu'ur seul jour, on même à peine (ex. Agaricus ephemerus). On appelle flcurs éphémères celles qui ne restent anvertes que quelques lieures, et tombent ensuile, ou se ferment pour ne plus se rouvrir (ex. Cactus srandiflorus).

Jiphímèies, s. f. pl., Ephemerce. Quelques botanistes ont donné ce nom à la fiumille des Commélinées. Vorez ec nol.

EIIILUÉRE, s. m. pl., Ephemera. Lantarek appelle ainsi une famille d'insectes Névroptères, qui a pour type le genre Eplemera.

Erifuinines, adj. et $\mathrm{s}$. m. pl., Ephemerida. Nom donné par Leach a la famille des Ephémérins. Voyez ce mot.

IPIÉvérns, adj. et s. m. pl., Ephemerina. Nom donné par Latreille, Goldfuss, Eiehwald, Fieinus et Carus à unc famille d'inseetes Névroptères, qui a pour type le genre Ephemera.

fipulgiamue, s. m. , ephigram. ma (imi, sur, yocepex, fcuillet). Draparnaud appelait ainsi l'opercule momentané, presque nembrancux, que eertains Mollusques terrestres, â coquille univalve, qui habitent les climats froids, ont la faculté de former en certains temps de l'année, pour boucher l'orifiee de lenr coquille.

ÉPIIPronnvous, adj. , ephip piorhynchus ( Ėं bee); qui a le bee chargé d'un ceroma en forme de selle. Ex. Ciconia cphippiorhyncha.

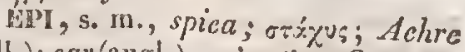
(all.); enr(angl.); spiga(it.). Candolle appelle ainsi un mode d'inflorescence 
452

EPIC

$\mathbf{i}_{\text {ndéfinie, dans lequel les fleurs nais- }}$ sent à l'aisselle des feuilles, soit sessiles, soit portées sur un pédicelle visible (ex. Loranthus spicatus). Trinius donne ce nom, dans les Graminces, a un assemblage de fleurs, consistant en un axe régulièrement articulé, dont chaque artiele porle à sa base un épillet fixé alternativement à droite et a ganche (ex. AEgilops, Tripsacum). Pour Link, il y a épi toutes les fois que le pédoncnle ou le rameau du pédoncule se prolonge jusqu'à la dernière Aleur, et que les fleurs sont sessiles le long de son étendue.

ÉPIBLASTE, s. m. , epiblastanzs ( donné par L.-C. Richard à un appendice unguiforme qui garnit antérieurement le blaste, vers son milieu, dans certaines Graminées, le recouvre quelquefois en entier, et semble n'en être qu'un simple prolongement. Raspail considère cet organe cumme un débri supérieur de la radiculode.

ĹpIBLASTL̀丶, s. f., cpiblastesis. Wallroth désigne sous ce nom l'accroissement des Lichens qui a lieu par le développement des gonidics dans l'intérieur mếnc du système où elles ont pris naissance.

EPIBLASTÉTYQUe, adj., cpiblasteticus. Nom donné par Wallrolh à l'une des quatre eouches qu'il admet dans le talle ou blastème des lichens, celle qui en forme la surfice supérieure, et que Acharius appelle substantia corticalis.

híradrare, s. f., epicalycia

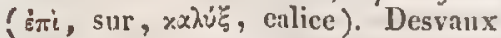
propose de donner ce nom à une elasse de la méthode de Jussicu, quii porte maintenant le nom d'épistaminic.

ÉPRCARIDES, adj. et s. m. pl., Epicarides. Nom donné par Cuvier à unc section, par Latreille à une famille de Crustacés isopodes, paree que les animaux que ce groupe ren-

\section{EPIC}

ferme se tiennent fixćs sur le tronc de quiclques salicoques.

EPICARPANTIKE, adj., cpicar-

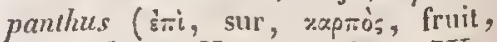
\&̈: Aoc, fleur). Nom donné par Wachendorff aux plantes dont la fleur est supportéc par l'ovaire.

ÉPICARPE, s. m., epicarpium ; Fruchtoberhaut, Fruchtrinde (all.)

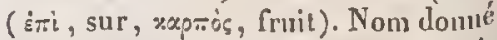
par L.-C. Richard à la portion de l'épiderme général de la plante qu'ou distingne sans nécessité dans le fruit, dont elle revêt la surface extérieure; par Bernhardi, aux organes qui ne couvrent le fruit que d'un seul côté, comme les paillettes dans benueoup de Synanthérées. L'épicarpe de Richard est le cortex pcridii de Link.

EPICARPIE, adject. , cpicarpils

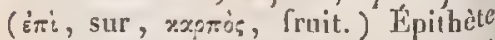
dounce par Gleditseh aux flcurs $\mathrm{c}^{t}$ aux étamincs, quand elles sont stupères, ou portées par le fruit.

IPICARPloue, adj. , cpicarpicus. Se dit d'une flcur ou d'une partie de fleur qui est portée par l'ovaire.

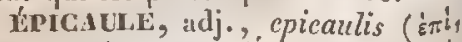
sur, $2 x \cdot 3.0_{;}$, tige). Tipithète donné par Link aux ehampignons qui croissent sur la lige d'aulres végétanx.

FPICERQues, adj. et s. m. pl.s Epicerci (érit, sur, réczoc, queuc). Nom donnć par J.-A. Ritgen à ull groupe de reptiles Ophidiens, renfer mant ceux qui portent des grelots ath bont de la queue.

ERICHLME, s. m. , epichemis

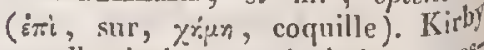
appelle ainsi une articulation ace es $^{g^{\circ}}$ soirc qui se voit à la base du tibia" dans quelques Arachnides, et $q^{13 \mathrm{in}}$ paraît pas exécuter de mouremens part.

ÉPICHILE, s. m., epichilium (arti sur, $\chi^{z} i \lambda_{s} s$, lèrre). L.-C. Richar donnait ce nom à la partic supérierel1" du tablier des Orchidces, quand elle est divisće en deux parties dissenta 
blables, qui ressemblent à des lèvres. ÉPICHLAMÝLES, adj. et s. f.

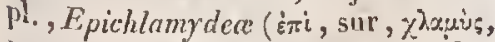
matcau). Nom donnć par Agardh á une elasse de plantes planéroeotylédones inconplites, comprenant les Ulmacées, Limrinées, Eléagnées, Thynélées et Protúacées.

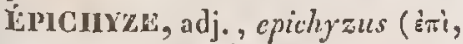
sur, zúate, amals de terres rapportées). L'Agaricus cpiehyzus croît sur les racines des graminées dactylö̈les.

EPICLINE, arlj., cpielinus ( $\dot{\pi} \pi$,

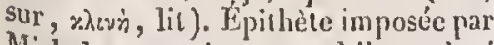
Mirlocl au nectaitce, quand il est placé sur le réceplacle de la fleur. Ex. $L a$ biècs.

ÍPICOROLLÉ, adj., epicorollatus. Nom donné, dans la unéthode de Jussicu, aux plantes dont la corolle est épigync.

EPICOROLLIE, s. f., epicorollia. Nom de deux classes, dans la méthode de Jussicu, yui comprennent des plantes à corolle épigyrne.

EPICRANE, subst. m., cpieranium (втi, sur, zpx:jov, crâne). Straus appelle ainsi une des six pièces du crâne des insectes ; qui comprend la majeure partic de la tête, dont clle occupc principalement la région supéricure.

GPICRMNIEN, adj. Pièce épicrânienne est synonyme d'épicräne. $V$. ce mot.

EPIDÈnE, subst. m., epidema

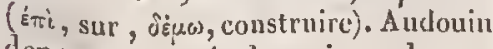
donne ce nom à dc petils prolongemens lamellaires qui existeni dans l'intéricur du thorax des aumaux articulés, uc naissent pas du point de réunion de deux pièces, et sont plus ou moins mulviles. Les uns (épidémes dinsertion) donnent allache a des museles, ut jouissent d'une grande mobilité; les autres (cipidémes d'articulation) servent à l'attache des appendices supéricurs ou des ailes.

HPIDENDRE, adj., epidendrus

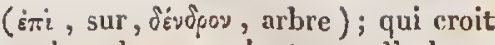
sur les arbres, surles troncs d'arbres. Ex. Lycoperdon epidendrum.

GPIDENDnées, adj. et subst. f. pl., Epidendrea. Nom donné par Lindley et $A$. Richard à une tribu de la lamille des Orchidées, qui a pour type le genre Epidendrun.

(iprivenine, subst. m., epiderma,

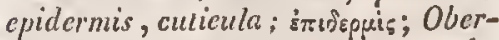
haut(all.); cutiele(angl.); epidermide, cuticola, soprapellc (it.) ( isi, sur, ¿śpece, peau ). On appelle aiusi : $x^{\circ} \mathrm{en}$ botanique, la membrane minee, ordinairement incolore et transparente, qui tapisse la superficie des plantes, et qui se détache plus ou nıoins facilenent du reste du tissu végétal. Gaertner donne ec noin à l'expausion du funicule qui forme unc bourse membraneuse, seehe, mince, bicn appliqućc à la graine, dans cerlaines planles, et qui la recouvre lout enticre (ex. Malvacées). $2^{\circ}$ En zoologic, l'épidernte est la mentbraue seche qui recouvre la peau, el la pellicule plus ou moins ćpaisse, comme cornćc, qui tapisse l'exterieur de cerlaines coquille's univalies et bivalves.

IPIDEnuE, adj., epidermalus. Se dit d'une coquille qui est couverte d'un épiderme.

iPIDERuĹcs, adj . el subst.f.pl., Epidermece. Nom donné par Bouncnaisou à une fimille d'Hydrophytes loculées, comprenaul eclles qui sont munics d'une membrane cxtérieure très-délieate.

HPIDERuQue, adj., epidermicus ; qui it rapport à l'ćpiderne.

EPIDERVOIDE, adj., epidermoüdes; oberhaulartig (all.) (i்t-

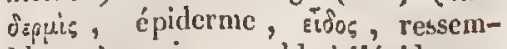
blatace); qui ressemble à l'ćpiderme.

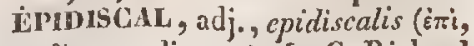
sur, dir:os; ; disque ). L.-C. Richard. donnc cetle épithète à l'insertion des ćtamincs ou de lacorolle staminifère, 
lorsqu'elle se fait immédiatement au pourtour du disque, de manière que la base ou le point d'origine des étamines ou de li corolle est simplement en contact avee eclle dn disque, et que les pétales, s'il y ell a, touchent également celui-ci, ou bien sont contigus aux étamines qui leur correspondent. $\mathrm{E}_{\mathrm{x}}$. Vitis vinifera.

ĹPIDROME, adj. , epidromis, epidromus (èriópopos, ouvert, uni). Le $S$ trombus opidromus est ainsi nommé párce queson bord droit est dilaté et re'evé.

EPIÉ, adj., spicatus; aehrenförmig (all.); spigato (it.). L.-C. Richard a proposé d'appeler ainsi les fleurs qui sont disposées en épi.

ÉPreT, subst. m., spicula. Nom donné par Palisol-Beauvois aux épillets secondidires dont sont formés les épillets de eerlaines Graminées.

ÉPIGASTRE, subst. in. , epigas-

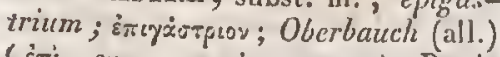

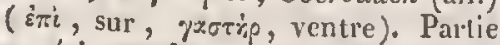
supérieure de la région antéricure du ventre des inammifères, eelle qui se rapproche le plus de la poitrine. Kirby donne ce nom au premier segment ventral tout eutier des insectes hexapodes.

EPIGE, adj. , epigeus; zubcrirdig'

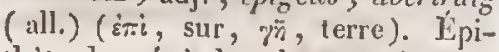
thète donnée à des plantes qui eroissent sur la terrc (ex. Arundo epigcos, Erysiphecpigara). Les cotylédons sont appelés ainsi lorsyue, dans l'acte de la germination, ils s'élèvent au-dessus du sol, a vec le caudex ascendant, ce qui a lieu quand celui-ei se dévcloppe uu dessous d'eux (ex. Phaseolus commutuis).

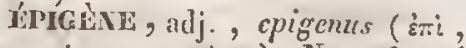
sur, ๆivopas, nâ̂tre). Nom douné par les niućralogistes à tout cristal dans lequel on reconnaît que le plićnomène de l'épigénie a eu licu. Necs d'Esenbeck applique eette épithète aux arbres dont les feuilles durent souvent plusieurs années avant de mourir, et Link aux champignons parasites qui eroissent sur la face supéricure des feuilles.

EPIGtinese, subst. $f$, cpigenc-

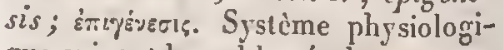
que suivant lequel le résultat ou produit de la génération a été formé dans son entier de toutes pièces, c'est-à-dire par la réunion de moléeules rapprochées subitement, en vertu de l'aete qui a donné lieu à sa naissunce, de sorte qu'il n'existait pas du tout auparavant, et que, quand il a été produit, il a reçu toutes ses parties, avec leur coordination et leurs propriétés.

ÍPIGÉNÉSIQQE, adj., epigencsicus; qui a rapport à l'épigénèse ; thcoric épigénésique.

ÉPIGÉÉSISTE, subst. m. , cpigencsisla. Physiologiste qui est partisan des doetrines de l'épigénèse.

líprgéNIE, subst. f. , epigenia

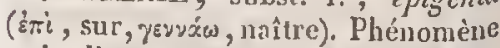
qui a lieu quand un minéral cristallisé a subi, depuis sa cristallisation, ct sans que sa forme ait élé altérée, des changemens de nature ehimique consistant, soit en perte d'un de ses principes, avee admission d'un autre, soit en ee dernier eas seulement.

ÉPIGLOSSE, subst. ᄃ. , cpiglossa

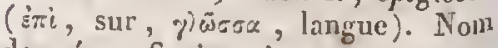
donné par Savigny ì un organe partieulier de la bouelie des inseetes hy" ménoplères, à une sorte d'appendice membraneux, qui est recu cutre les deux branches des mîchoires, et qui recouvre le plarynx, dout il a pour lase le bord supérieur.

EPIGLOTTE, adject., cpiglottis

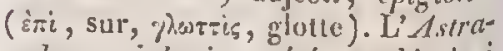
galus cpisclotis a été appelé ainsi paree qu'on a cru trouver quelque ressemblance entre la forme de ses gousses et celle du cartilage laryngien qui ports le nom d'épiglotte.

ÉPIGLOTTE, sulsst. m., cpiglot- 
tis. Straus désigne sous ce nom le diaphragme de l'anneau corné qui forme les lèvres des stigmates chez les insectes.

EligOve, subst. m, , cpigonium

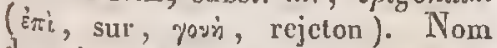
donné par Bernhardi aux parties tćgumentaires et protectrices qui n'entourent les partics sexuclles des plantes que d'un seul côté, counme les éenilles des épis, dans un grand nombre de Cypéracécs.

EPIGYNE, adj., epigynus (ह்i, sur, yuv่, fenme); qui naît sur l'ovaire, ou au dessus de lui. Epithète donnće à la corolle ( ex. Lonicera), aux étamines (ex. Orehidées), au nectaire (ex. Ombelliferes).

EPIGYNLE, subst. f., epigynia. Terme dont on sc sert pour exprimer पqu'une parlie d'une plante est supère, par rapport à l'ovaire.

ÉPIGYNiQue, alj., epigynicus. Epithète dounée par L.-C. Richard à l'insertion des étamines ou de la corolle staminif'ère, lorsqu'elle a lieu tout-à-fait ou seulement en partie au dessus de l'ovaire.

EPIGYNOPIORIQUe, adj. , episynophoricus (ėri, sur, yuy่, femWe, ys̃pw, porter). Épithìte donnée par Mirbel au neetaire, quand il est placé sous l'ovaire, an sommet d'un Synophore. Ex. Cueubalus Belien.

EPILLET, subst. m., spiculus, $l_{0-}$ custa; Aehrchen(all.); spighetta (it.). Les botanistes donneut ec nom, en général, aux petils épis qui en forment un grand par leur réunion; dans un sens plus restreint, aux petits groupes de fleurs qui, ehez les Graminées, sont renfermés originairement dans la glume, et dont se compose l'épi général.

EILININIQue, adj., cpilimnieus

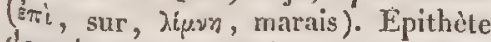
donnée par Brongniart aux terrains lacustres supérieurs. C'est à tort qu'on écrit épilyninique. ĺpuobiacíes, ípilogiées, ÉpLOBIANÉIS, EPHLOBLENES, adj. et subst. f. pl., Epiiobiacea, Epilobiana, Epilobiea. Ces diver's nous out été appliqués ì la fannille de plantes plus généralement counue sous celui d'Onagraires, à canse du genre Epilobium qui en fait partie.

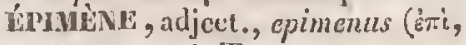
sur, $\mu \varepsilon^{\prime}: \omega$, rester). 'Terme, symonyıne d'épigyne (vajez ce mol), dont Necker s'est servi.

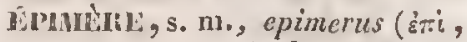
sur, pripos, euisse). Audouin appelle ainsi l'unc des pièces latérales de chaque segment du thorax des insectes hexapodes, qui se soude avec l'épisternum, lui est postérieurc, et a des rapports constans avee les hanches du segment auquel elle appartient. Voy: Thorax.

lípIMćrine, adject., cpincridus. Nom donné, dans la nomenclature minéralogique de Haüy, à une variété dans laqualle les bordssubissent un décroisseinent de plus que les angles, ou réeiproquement. Ex. Chanx carbonatée épiméride.

EPIMETTRAL, adject., epimetralis

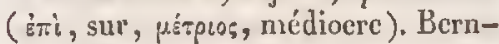
hardi appelle feuilles épiniétrales, phylla cpimetralia, les parties dont la réunion, quand il y en a plusienrs, eonstitue l'épimétre. Voyez cc mot.

EPIMLtTRE, s. m., epimetrium

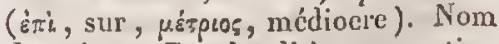
donnć par Bernhardi à une partie, en forme de membranc, quelquefois anssi de poil ou de brosse, qui entoure l'ovaire d'un seul eôté, dans beaucoup de Synanthérécs.

ÉpINE, subst. f., spina, aculeus ; "x. $x$ $v \theta$; Dorn (all.); thorn (angl); spince (it.): Ce not est employé : $\tau^{\circ}$ en botanique. On donnele nom d'épineà toute exeroissanec dure qui naît da eorps ligneux, et qui doil naissance à un organe queleonque (excepté racinc , graine ou poil) transformé en piquant, 
par exemple à un rameau avorté (ex. Prunus), à un lobe de feuille endurei (ex. Datticr), à une stipule endureie (ex. Erythrina), à un pétiole (ex. Astragalus tragacandha), a un coussinet (ex. Acacia hamatomma). $2^{\circ}$ En zoologie. On appelle épincs, dans les poissons, les rayons des nageoires yui se terminent en pointe, les piquans qui garnissent les côtés de la queue ou la totalité de la peau chez quelques uns de ees animaux, et les dentelures de leur opercule, quand elles ont une certaine longueur; daus les inseetes, les piquans de nitture fort diverse gu'offrent un assez grand nombre de cheuilles; dans les chétopodes, les soies qui sont plus longues, plus groeses ct plus résistantes quc les autres; dans les oursins, les bâtons ou appendices calcaires qui s'articulent sur le corps de ees animaux.

GPNEME, s. m., cpinema (iтi,

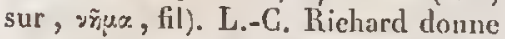
ce nonı à la partie supérieure dissemblable des filets stiminaux des Synanthérées, pour laquelle il rejette la dénonination d'articlc anthérifécre, proposée par H. Cassini, celle-ci supposant une jonction artieulaire avec le filet, qui n'existc pas.

EPIVstu, adj., spinosus, spinescens, pungitius, aeulcalus, muricaus, acanlhias, hispidus, luss-

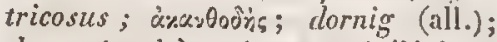
thorny (angl.); qui est muni d'épines. Se dit : $1^{\circ}$ eu botanique, de la tige (ex. Convolvulus armalus, Cactus spinosissimus, Rosa spinosissima) ; des ramcaux (ex. Prunus spinosa, Com. brctum aculeatum); des pćlioles, quand ils devicunent aigus après la clute des feuilles (cx- Cordia spincscens); du bord des fenilles (er. Cardutus lanceolatus, Globularia spinosa); de l'involucre (ex. Contanrca ferox); du calice (ex. Moluccella spinosa). $2^{\circ}$ En zoologie, d'un mammifere dont les poils sont entrcuêlés de productions cornées, raides el piquantes (ex. Echimys spinosus, Echimys hispidus , Echidna hys(rix); d'un oiseau dont les pennes de la queue se terminent chacune par une pointe aiguë (ex. Anas spinosa); d'un poisson qui a des aiguillons ì l'une de ses nageoires (ex. Gastcrosteus pungitius, Squalus acanthias); d'une coquillc bivalve offrant sur toute sa surfacc (ex. Cardium aculeatum), ou seulement sur quelques unes de ses parties (ex. $C y$ therca dione), des cônes alongrés et pointus q qui $y$ sont implantés par la base; d'un insecte dont les côtés du corselet se terminent par des épines plus ou moins longues et pointues (ex. Capricorne); d'un polypier dont les rameaux sont bérissés de mamelons raides (ex. Eunicea muricala).

ÉPINEUx, adj. et s.m. pl., Aculeala, Hystricosa. Nom donné par Illiger el Isatreille à une famille de Mammifires rougeurs, comprenant ceux dont le corps est armè de piquans.

EPIOLITIIOUE, adj., epiolithicus

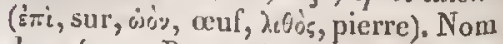
donné par Brongniart à un groupe de terrains, appelés oolithiques supérieurs par Conybeare, qui sont supéricur's à l'oolithique.

IPIPLTALE; adject, epipetalus

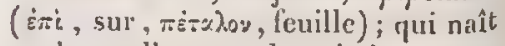
sur la corolle ou sur les pétales, contme les glandes (ex. Berbcris), les étamines (ex. Lalicés).

EPIPETAL i., adj., epipetalatus. Se dit d'une plante dont les étamines naissent sur les pétales.

EPIPLTALIE, s. f., epipctalia. Desvaux a proposé d'appeler niusi la classe du système de Jussieu gui renferme les plantes dicotylédones polypétales à étamines épigynes.

E'PIÉTIOLÉE, adj., cpipctiola- 
neus (в̈ri, sur, peliolus, pétiole). Épithète donnće amx stipules, quand elles adherent it la partie supérieure du nétiole.

ĹPIPAR Nx, s. m., epipharynx

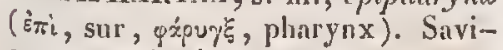
gny a employé ce terme comme synonyme d'épiglotte (voyez ce mot). Kirby s'en sert pour désigner une valvule étroile, situće sous le labre, qui, dans quelques IIyménoptères, ferme le pharynx, et qui est un appendice de son bord supérieur.

IPPIPILÚLODE, adj., epiphloodes

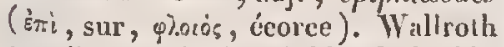
appelle morphosis epiplutrodes le développement des lichens qui naissent à lia surlace de l'épiderme d'autres végétaux.

CPIPILOSE, subst. m., epiphlosis (èmi, sur, yìos, pearu). Noni donné par Lamarck à l'épiderme en forme de poils on d'écailles qui recouvre la surface extérieure de eertaines coquilles. Dupetit-'Thouars a proposé de désigner ainsi l'épiderme des végétaux.

Epiphagmatioue, adj., epiphragmaticus. Bridel appelle quelquetois l'épiphragme des mousses membrane épiphriggmatique.

Epiphragne, s. m. , epiphragma; Zwerelefell(all.); cpiframma(it.)

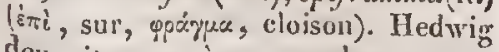
donnait ee nom a une membrane transversale qui, dans quelques mousses (ex. Caharinca), ferme l'orifice de l'urne, et persiste long-temps apres la ehute de l'opereule; Draparnand à une espèce d'operenle, pour ainsi dire momentanc (operculum hybernum), que certains mollusques ì equille univalve fabriquent pour clore leur coquille pendant la saison de l'hibernation, el qui paraît être le résidu caleaire d'une excrétion de la face inférienre du pied.

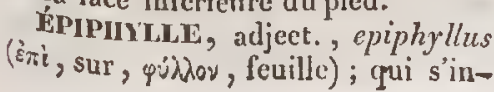

sère sur les feuilles, comme les pédicules du Jungermannia epiphylla; ou qui eroît sur les feuilles, comme l'Agaricus cpiphyllus, le Botrytes epiphylla, le Dematium cpiphyllum.

ElipusLLiNes, adj. et s. f. pl., Epiplyyllina. Yom donné par Riciclienbach à une section de la famille dus Ilépatiques, comprenant celles dont les organes reprodueteurs etoissent ì la surface des feuilles.

EPIPIILLOSPEIRUES, adj. et $\mathrm{s}$.

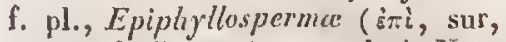

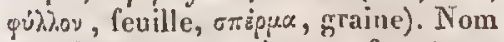
que Haller donnait aux fougires, par allusion it ce que leur fructification naît en général sur le dos des organes foliacés.

ÍPIPIITL, adject., epiplytus, pscudo-parasiticus (iri, sur, ழvंrov, plante). Fithète donnée par Mirbel aux plantes qui croissent sur d'autres végéliaux, ınais sans en tirer leur nourriture, cornme les mousses et les lichens.

IIIIIIYTIS, adject. ct s. m. pl., Epiphyta, Epiphyta. Nom imposé par Persoon, Fries et Link à un groupe de Champignons, comprenant ceux qui vivent eu parasites sur les végélanx morts ou vivans.

ÉPIPODE, 5. m., cpipodium (втr,

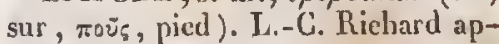
pelait ainsi un ou plusicurs tubercules distincts, n'ayant aucune connexion immédiate soit avec l'ovaire, soit avec le ealice, qui naissent en dedaus de celui-ci, sur le sommet du pédonenle. Ex. Crucciféres.

GPIPODIove, adj., epipodicus. Tithète donnée par L.-C. Riehard à l'insertion des étamines, quand elle a lieu sur l'épijode.

IDTPOGE, adj., epipogius ( $\dot{\varepsilon} \pi \dot{\text { in, }}$ ressemblance, $\pi \omega \bar{\sigma}$ yw, barbe). Le $S a$ tyrium epipogium est ainsi appelé paree que les fibres longues et mcnues de sa raciue imitent en quelque sorte $\mu$ ue barbe. 
EPIPTÉRE, adj., epipteratus (èri, sur, $\pi \tau$ ćpov, aile); qui se prolonge en aile, c'est-à-dire cn lame minec; ou qui porte une ailc à son sommet. Epithète donnée par Mirbcl à la carcérule (ex. Fraxinus exeelsior), a la graine (ex. Bignonin Calalua), au lógume (ex. Securidaca volubilis).

ÉPIPTERIGIEN, adj., cpiptcrigius

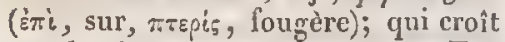
sur les fongeres ou les nousses. Ex. Agaricus cpipterigius.

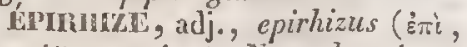
sur, pič, raeine). Nom donné par Nirbcl aux planies parasites qui naisscnt sur les racines des végétaux vivans, et se développent a leurs dépens. Ex. Cytinus hypocistis.

IPIRREOLOGIE, s. f., epirrco-

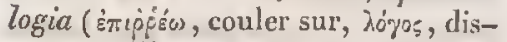
cours). Picconi propose d'appeler ainsi la partie de la botanique qui traite de l'inlluence des agens ou milicux extéricurs sur les ètres organisés.

ĹPISLPPALE, adject., episcpalus. Epithète donuée par Mirbel aux glandes qui naissent sur les sépales du calicc. Ex. Malpighia urcns.

ÉPISLASTIQULS, adj. et s. m. pl.,

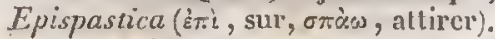
Non douné par Duméril à une famille de Coléoplères, comprenant des insectes qui, pour la plupart, produiscut un cffet vésieant à la peau, quand on les laisse en contact avec elle pendant long-temps.

ÉRISPEIRATIOUL, adj., episper-

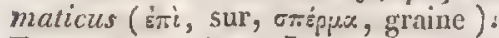
Epithète donnée par L.-C. Richard à l'cmbryon végétal qui, étant dépourvu d'albumen, se trouve immédiatement rccouvert par l'ćpisperme. Ex. Phaseolus communis.

ípisireruz, s. m., episperma. C'est le nom que L.-C. Richard donnait au tégument propre de la graine.

HírsioraNGE, s. m., cpispon rangium (ह่тi, sur, எторx́, graine, àyyeio\%, vase). Noin donné par Bcrnhardi aux indusics des Fougères.

ÉPISTAMINAL; adj., cpistami-

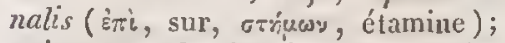
qui naît sur les étamines, commc les glandes du Dictannus albus.

ÉPstanuxÉ, adject., episiamineus. Epithète donnée à toute plante dont les étamines sont ćpigyncs.

EPISTAMINIE, s̀. f., cpistaminia. Nom que Desvaux propose de donner à une classe de la méthorle de Jussieu, qui reuferme les plantes dicotylẹdones apétales à étamines épigynes.

EPISTERVAL, adj., episternalis

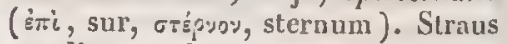
appelle apophyses épisternales unc des deux paires d'apophyses du sternum, du prothorax et du mésotborax, celles qui se portent dans l'intérieur du eorselet et se dirigent obliquement en dessus et en dchors.

EPISTERNUM, s. m., episternum. Audouin donne ce nom a une pièce, située de chaque côté du sternum des insectes liexapodes, qui est soudée d'une part avec lui, de l'autre avec la pièce supćrieure du segment.

TPISTOHE, s. m., cpistoma, epi-

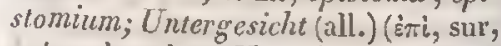
бтóus, bouche). Nom donné par Latreille à l'espace compris entre la cavité buecale et l'origine des antennes intermédiaires, daus les Crustacés maxillaires; par Robineau-Desvoidy au loord antérieur du péristome des Myodaires, qui souvent se développe en bec; par Bernhardi aux parties qui couvrent l'orifice du réservoir des semences, par exemple dans les Mousses.

ÉPSTOMES, adject. et s. f. pl., Epistomi. Bridel donne ce nou à uı ordre de Mousses, comprenant celles qui ont l'orifiee de l'urne fermé par une membrane horizontale. 


\section{ÉPOM}

CPITIEtye, s. m. , cpithema;

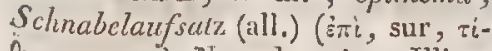
Oru, , poser ). Nom donné par Illiger à un appendice corné qui surmontc le Jee de certains oiseanx.

EPTRIILLITE, adj., cpitriha-

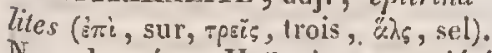
Nom donnć par Haiiy à une variété de chaux anhydrosulfatéc qu'il regarde comme un mélange d'anhydrite avec trois autres sulfates auxquels elle a inprinć sa forme.

EPronioues, adj. ct s. m. pl.,

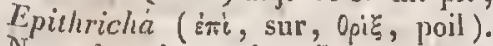
Nom douné jar C. - G. Ehrenbers. à une famille de la elasse des Polygastriques, renfermant ceux de ces animaux qui ont le corps cilié.

IPIXYLE; adj., cpixylon (èmi,

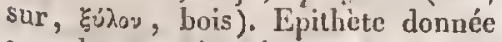
âux plantes qui croissent et végètent sur le bois, sur le tronc des arbres. Ex. Agaricus epixylon.

TEPIZOAInEs, adj. et s. m. pl.,

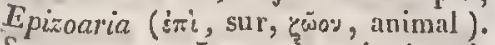
Sous ce nom, Lamarck a réuni quelques animaux dout le rang parmi les autres n'a pas été parfaitement assigné, et qui sont parasites externes. Blainville le donne à unc famille à peu près correspondante de la classe des Hétéropodes.

ÍPIZOIQUE, adi., epizoicus (i்i,

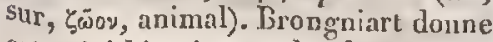
Cettc épithete à un ordre de terrains, comprenont les terrains primordiaux de cristallisation supéricurs à ceux qui renferment des debris de eorps organisés.

ĹPONTÉ, adj. Épithète imposćc, dans la nomenelature ninéralogique de Jaüy, ì des crislaux dans lesquels les angles solides de la forme primitive ont été remplacés clacun par une facette. Ex. Émeraude ćpointée.

EPONoprone, adject., cpomo-

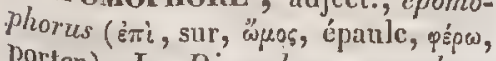
porter). La Diomedea epomophora est ainsi appelée à causc d'une tache noire, en forme d'ćpaulette, qu'on remarque a la base de son aile blanche.

Heonges, s. 1 . pl., Spongia. Nom donné par Blainville à un ordre de la classe des Spongiaires, comprenant ceux de ces animaux qui ont pour hase une substance cornćc.

EPONTES, s. f. pl. On appelle ainsi les parois supérieure et inféricure d'un filon.

IPORSIDES, adj. et s. m. pl.,

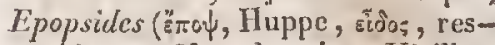
semblance). Nom douné par Vieillot, Ranzani et Lherminier à une famille de Passcreaux, comprenaut la Huppe et les oiseanx qui lui resscmblent.

EPoptrous, adj., cpopticus (imi, sur, "̈тsopat, voir). Nom donné par Goethe aux couleurs qui se produisent entre deux corps durs et transparens, appliqués l'un contre l'autre par leurs laces, dans les minćraux à structure feuilletée, et à la surface des bulles de savon.

LPOQUE; s. f. , epocha; вेтохи; Zeitpunkt (all.); epoch (angl.); cpoca (it.). On appelle ainsi, en astronumic, le point où eommenec le mouvement d'un corps céleste, pour un inslant donné; en clironologie, le point fixe du temps d'où l'on part pour eompter les années précédentes ou suivantes.

ÍPovelí, adj., epollicatzs; zungedaum (all.). Epithète donnée par Illiger an peed d'un oiseau, quand il est déponrvu de pouec.

Jroocclis, adj et s. m.pl., Epollicali. Illiger et Eichwald désignent ainsi une fimille d'oiseaux sarcleurs, comprenant ceux qui n'ont point de doiggts en arrière.

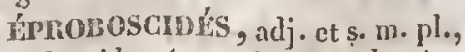
Eproboscidea (c, priv., proboscis, trompe). Nom donné par Goldfuss, Ficinus et Carus à unc fanille d'in- 


\section{0}

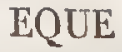

secles diptéres, compreuant ceux qui n'ont point de trompe.

EPTAHEXARDRE, adject., hepta-

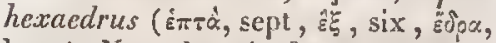
base). Nom douné, dans la nomenelature minéralogique de Haüy, a une variétć dont la surface est composée de sept rangées de facettes situées six a six, au dessus les unes des autres. Ex. Potasse nilratce eptahexaèdre.

EQUALIFLORE, adj. , cequaliforus (aqualis, égal, flos, fleur). Fpithète donnée par H. Cassini, dans les Synanthérées, au disque et i la ealaihide ineouronnée, lorsque toutes les fleurs sont égales en longueur.

EQUATEUR, s. m. , aqualor; isn-

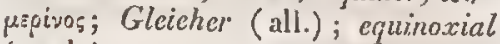
(angl.) ; equacore (il.). Prolongement dans le ciel et à la surface de la terre d'un plan qui est eeusé couper celte plancte en deux moitiés perpendiculaires à son axe, et qui est egalement distant de chacun de ses deux pôles.

ÉuATron, s. f. , aquatio; Gleichung (all.). En astronomic, on donne ce nom au nombre qu'il faut ajouter ou retrancher à des valeurs moyennes pour obtcnir les véritables. L'équation du centre (aquatio centri, prostupharesis ) est la différence entre l'anomalie vraie et l'anomalic moyenne d'une planèle. L'équation du temps est la difírence entre le lemps vrai ou apparent el le temps nioyeu, c'est-ì-dire, cntre le temps inégal mesuré par le mouvement du soleil et le temps égal nesurć par un mouvement uniforme.

EQUATOHIAL, adj., aquatorialis; qui appartient à l'équateur; contrées, régrions équatoriales.

EQUESTRE, adj., equestris(equus, cheval). L'Agaricus equestris est ainsi appelé parce que son chapeau s'ouvre en forme d'étoile, et ressemble un peu à un ordre de ehevalerie; l' $A$.

\section{ÉQUI}

maryllis equestris, parce que l'ensem: ble de sa fleur oflre la même apparence.

EQUIAxE, adj., equiaxis; gleichaxigr (aquus,égal, axis, axe). Epithète donnée, dans la nomenclature minéralogique de Haüy, à une variété dans laquelle les nombres qui désignent les faces du prisme el celles de ses deux soinmels qui, dans ce cas, diffèrent l'unde l'aulre, forment un commencement de suite arithmétique, comme 6, 4, 2. Ex. Amphibole équiaxe.

Éurcosté, adj., cquicostatus (aquzus, égral, cosla, côle ). Se dit, en zoologie, d'une coquille dont la surface offre des côtes ou saillies égales. Ex. Peeten aequicostalus.

ÉQUIDÉs, adj. et s.m. pl., Equidce. Nom donné par J.-E. Gray à une famille de Mammil'ères, qui a pour type le genre Eguus.

ÉLIDILATÉ , adj., aquidilatalus. II. Cassini donne celte épithele aux squames du péricline des Synanthérćes, quand elles sont disposćes sur plusieurs rangs, et toutcs à peu près de la même largreur.

LQUnDSTANT, adj., aquidistans. Epithete donnée par Kirby aux trois paires de pattes des inseetes hexapodes, lorsqu'un intervalle égal les sépare l'une de l'autre à leur base. Ex. Cassida.

EQULLARGE, adject., aquilatus; qui a la mème largeur dans toule son étcndue. Se dit surtont, mais rarement, du tube d'une corolle monopétale.

EQULATEIRA, adj., cequilateralis ; glcichseilig (all.) (aquus, égal, lauss, côté). On apjellc ainsi une coquille bivalve qui, lorsqu'on la partige par une ligne médiane dirigée des erochets vers le milieu du bord inférieur, présente deux moitiés semblables. Ex. Pecten.

ÉQULIBRE, s. m. aquilibrium; Gleichgewich (all.) (cquus, égal, 


\section{ÉQQUI}

lilro, peser ). Repos qui a lien lorsque plusieurs forces appliquées à un même corps se détruisent mutuelicment.

EQQULImLÉ, adj., aquilibratzs, requilibris. Epilhète donnéc, dans In nomenclature minéralogique de Haüy, à une variétć de chaux earbonatce, composéc de deux dodécaëdres et de quatrerr rhomboïles, en sorte que, les nombres de finces relatives aux deux espèces de formes étant de part et d'autre de vingt-quatre, ils offrent unc sorte d'équilibre. 1lliger aprelait ainsi, dans les oiseaux, les picds posés au milieu de l'abdomen, en soric que le corps de l'animal debont est presque horizontal et en équilibre.

LQUINOXE, s. m., aquinoctium; ionużox ; Nachtagleiche (all.) (aquiss, égal, nox, nuit). On donnc ce nom alux deux points on l'écliptique coupe l'éteur céleste, parce que les nuits sont ćgales aux jours én duréc lorsque la Terre y passe dans sa révolution annuclle, ce qui arrive le 20 ou 2 I mars, et le 22 ou 23 septembre.

EQUINoxIAL, adj., a quinoxialis; ionuṡprvos; nachtgleichigy (all.); equinoctial (angl.); qui a rapport aux équinoxes. On appelle points cquinoxiaux, les deux intersections de l'équatcur el de l'éeliptique; ligne équinoxiale, la trace de l'équateur sur la terre; fleurs équinoxiales, celles qui, plusicurs jours de suite, s'ouvrent et se ferment ì des heures fixes, commel'Ornithogalum nmbellatum à onze heures du matin.

ÉQUIPİUES, adj, et s. m. pl., Aqquipedes (aquus, ćgal, pes, pied). Nom donuć par Latreille ì une famille de la classe des Myriapodes, paree quc les animaux qui la composent ont les pattes ì peu près égales.

EQupétalí, adj., aqquipetalatus (exquus, égal, pelalum, pétale). Se dit, en bolanique, d'une plante
ÉQUI

dont less pétales sont égaux, ou à peu près. Ex. Cuphea aquipetala.

WQUIPOLLENT, adj., aquipollens; iondüvques; gleichargchend (all.). Epithèc donnce, dans la nomenclature minéralogique de IIaiiy, ม̀ une variété produite par des décroissenens en nombre égal sur deux angles ou sur deux bords. Ex. Fer oligiste équipollent.

ĹQuisúracées, adj. et s.f. pl., Equiselaceo. Nom donné par Candolle, Kunth et Bartling ì une famille de plantes, qui a pour type le genre

\section{Equisetnon.}

ÍQuislitate, s. m., equisetas. Sel formé par la combinaison de l'acide ćquisétique avce une base saLifiable.

ÉQusítrQue, adj. , equiscticus. Nom douné par Braconnot a un acide qu'il a découvert dans l'Equisctum fluviatile.

Ḱ(UVTANT, adj., equilans, obrolutus; reitend (all.); cavalcante (it.). Les botanisles donnent cette épithètc aux colylédons, quand la moitić de l'un, plićc dans sa longmeur, reçoit dans son pli la moitié de l'autre, pliée de la mème munière ( $\mathrm{ex}$. Coldenia procumbens); anx pétales, dans les corolles irrégulières, lorsque, avant l'épanonisscment, ils cmbrassent, tous les autres (cx. Lígumincuses); aux feuilles, dans le bourgeon, lorsqu'une feuille entière (ex. Hcmerocallis fava), ou une moitié de feuille (cx. Saponaria officinalis), pliée en long, recoit dans son pli une autre feuille ou demi-feuille pliée de la nềne masière.

SQuITATIF, adject., equitativus. Candolle donne ce nom aux fcuilles incore renfermées dans le bourgeon, lorsque les deux côtés, séparés par le moyen de la nervnre longitudinale, s'appliquent ou teudent à s'appliquer face contre face, et plus particulièrement, dans ee eas, lorsyue ćtant op- 
posées, clles sont légèrement plićes sur leur nervure longitudinale, de manière que leurs bords se touchent. Ex. Ligustrum vulgare.

ÉQUivaleNT, ádj. ct s. m., cequivalens (requus, egal, valco, valoir). Epithète donnée, dans la nomenclitture minéralogique deIlaiiy, s̀ un cristal dins le signe représentatif duquel l'exposant qui indique un décroissement est égal a la somme des exposans qui iudiquent les autres (cx. Chaux sulfaté iquivalente). I es chinistes donneut quelque $\int_{0}$ is le nom d'équivalens chimiques aux nombres proportionnels. Voycz ee mot.

EOUIVAINE, adjert. , aquivalvis; gleichlilappig, gleich.schalig (all.) (aquus, égal, valua, valve). Epithète qui sert à caractériser une coquille bivalve, lorsque les deux valves sont égales en grandeur et cn profondeur, ou de forme seinblable. Ex. $V$ enus.

Éuivarves, adj. , Equivalvia. Nom donné par Latrcille í une famille de Brachiopodes, comprenant ceux dont la coquille est composée de deux valves égales.

IQUORÉES, adject. ct s. f. pl., Equorea. Nom donné par Ficinus et Carus à une famille de la classe des Acalèphes et par Goldfuss à une farmille de l'ordre des Nédusaires, ayant pour type le genre Equorea.

iovonméles, adject. et s. f. pl., Equoridea. Nom douné par Eschenholtz à une famille d'Acalèphes, qui a pour type le geure Equorea.

Grabizes; s. m. pl. Nom donné par quelques botanistes à la famille des Accracées. Voyez ee mot.

EDE, s $f$, cra, ara. Point fixe, pris dans l'hictoire ou arbitraircment choisi, i partir cluquel on conple les annces qui ont précédé et celles qui ont suivi. On peat diviscr les ćres en trois entégories. $1^{\circ}$ Eres qui commoncent à l'cepoyze arbitraire de la creca-

\section{ERE}

tion du monde Śvéncment qui cut lieu le 7 mars 5984 selon Pelau, en 563 d'après les Septante, en 6000 sclon Suidas, en 3949 selon Scaliger); ère de Constantinople, en usage chez les chrétiens grees, et snivie par les Russes jusqu'à Pierre-le-Grand, qui fixe la críation an zer septembre 5508 avant J.-C.; c̀re des anciens Juifs, qui la fixe au Io avril $4179 ;$ cre des Juifs modernes, qui la place au 26 mars 5762, ire uncicnne d'Alexandrie, imagincée par Julius Africanus, et eneore suivic par les Coptes, qui la fixe à l'an 5502; cre moderne d'Alexandric, ou ére d'Antioche, réformée par Panodorus, qui la fixe en $549^{3}$; ire d'Eusube, qui la place au 2 mai $5200 \cdot 2^{\circ}$ Eres antérioures as la naissance de Jésus-Christ, mais dont on rapporte l'origine a cette époque; irrc des Olympiades, dont le conmencement tombedans le mois de juillet del'an 776 avant J.-C.; íre de la fondation de Rome, qui répond, d'après Varron, à l'an -55 avant J.-C.; ère de la réforme julicnne ducalondricr, qui tombe en l'an 45 avant J.-C. ; cre des empereur's romains, qui commence avee l'un 27 avant J.-C.; ire actiaque, le serlmai de l'an 3 I avant J.-C. ; cre de César ou de Pharsale, l'an 48 avant J.-C.; cre d' Espagne, l'an 38 a vant J.-C.; ère d'Alexandrie ou des Séleneidles,

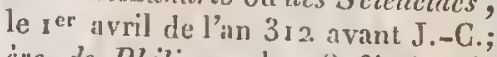
ire de Plilippe, le Is février de l'an 324 avant J.-C. ; ére de Nabonassar, te 5 wovembre de l'an 747 avant J.-C. ; la période julienue, établie par Scaliger, l'an 4713 avant J.-C. $3^{\circ}$ Eres postérieures à la naissance de Jésus-Christ; íre de Dioelćtien, ou ire des martyrs, qui commenee le $g$ août 284; íre del'Higyre, le 16 juillet 622 ; ére d' $1 c \approx d l e r c r d e$, le 16 juin 650 ; cre de Dsehelaleddin, le 12 mars 1077 . Par décret du 5 octubre $179^{3}$, la Convention nationale 


\section{ERET}

fixa le commencement de l'ère réptzblicaine au 22 septenubre r792, à minuit, jour de la fondation de la République française. Cette ère fut abolie par un sénalus-consulte du 22 fructidor an $\mathrm{x}$, après treize ans de duréc (.9 septembre i 805 ), et le calendrier grégorien remis en vigneur à compter du $\mathrm{I}^{\mathrm{er}}$ janvier 1806 . Dans toules ees ères les années sont évaluées à $565 \frac{1}{4}$ jour's, à l'exception de cing : celles de Nabonassar et d'Iezdegerde, où elles sont de 565 jours ; celle de l'Hégyre, de $354 \frac{11}{30}$ : celle de Dschelaleddin de $365 \frac{8}{\frac{8}{3}}$, et celle des Juifs modernes de $365^{3} \frac{2+31 r}{894,50}$.

HRECTO-PATENT, adj, crectopalens. Epithète par laquelic Kirby désigne les ailes des insectes lépidoptères, lorsque, dans l'úlat de repos, les premières sont droitcs et $l_{\text {es }}$ autres horizontales.

ERÉDOPIYTE, s. m., eredopliytrem (èpriow, appuyer, ơtós, plante). Nom douné par Necker aux plantes dont les étamines et le pistil som élevés et soutenus par un disque propre.

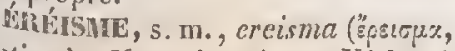
souticı). Nom domné par Kirby à un organe glutineux, biparti, rétraclile, qui fait saillie entre les pattes du $S$ minthurus, et que l'animal emploie ponr se soutenir. Ćrive, s. m., cremtes ("̈pnus, solilaire). Mirbel désigne ainsi une loile péviearpienne sans valves ni sutures, provenant d'un ovaire qui ne porte pas de style. Ex. Labiées.

Etultes, s. un. pl., Ereta (épátns, ramear). Nom donné par J.-A. Ritgen à une famille d'oiseaux aqualiques qui, coinme les Manchots, sont orginisés presque uniquement pour nager.

ERETHOchícones, s. m. pl., Erclnochelones (Ép'stros, nageur, $\chi^{\prime}-$ Ry, tortuc). Nom donné par J.-A. Rigen à une famille de septiles ebé-
ERIC

loniens, comprenant les tortues marines.

ÉRETHORNiTHES, subsl.m.pl.,

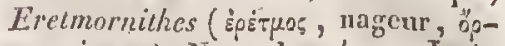
ขe६, oisenu ). Nom douné par J.-A. Ritgen à une section de la elasse des oiscaux, comprenant ceux de ces animaux qui sont aquatiques, ct qqui se scrvent de leurs picàs en guise de rames.

LideTnosures, adj. et s.m.pl., Erelmosura ( queue). Non donné par J.-A. Ritgen à une famille de reptiles sauriens, renfermant ceux de ces animaux dont: on we eonnaît plus que des débris fossiles, et qui se servaient de leur queue cn guise de rame, pour nager dans les eaux de la mer.

ERGOT, s. m., calear. On donne plus particulièrement ec nom à l'éperon (voyez ee mot) des oiseaux. Cependant on l'applique aussi aux doigts rudimentaires des eochons et des ruminans, à une petite excroissance cornée qui se voit souvent, dans le eheval, à la partie postéricure et inférieure de chaque boulet, et en génćral à tout ongle imparfaitement développé, surtout lorsque le doigt auquel il appartient est placé en arrière des autres.

IBIANTHL, adject., erianthus, crianthos (šocov, coton, $\ddot{a}, 2005$, fleur); qui a des fleurs couvertes de poils laineux ou lanuginenx, comme les calices de l'Astragalus crianthus, les involucres de l'Hydrocoty le eriantha, les glumes du Deycuxia eriantha, Ís corolles du Bombax erianthos et de l'Iresine crianthos, les grappes du Paspalus crianthus.

firscacíns, adj. et s. f. pl., Ericacce. Voyez Eniciníes.

ERICiEs, adj. ct s. f. pl., Ericca. Voyez Erieinées.

ERICETIN, adj., cricetinzts (eri$c a$, bruyère). Epithèle donnéc aux 
plantes qui eroissent dans les laudes on les bruyères.

ÉRICINíEs, adj. et s. f.pl., Ericincce. Nom donl:ć par Jussien à une famille de plantes, qui a pour type le genre Erica.

ERICOPHILE, adj. , ericnphilus; qui croît sur les tiges des Erica. Ex. Antennaria cricophila.

ÉniGúrítes, adj.els.f. pl., Erigerea. Nonı donné par H. Cassini à un groupe de la seetion des $\Lambda$ stérées prototypes, ayant pour type le genre Erigcron.

EnNACRes, adj. ct s. f. pl., Erinacer. Nom donnć par Duvau à une famille deplantes, qu'il propose d'établir, en lui donnant pour type le genre Erinus.

ÉnIOCALICF, adjeet. , criocalyx ( le calice velu. Ex. Myrcia eryocalyx.

ÉRIOCARPE, adj., criocarpus ( le fruit velu. Ex. Astragalus eriocarpiss, Farsetia criocarpa, Acer criocarpum.

ÉrIOCALE:; adject. , criocaulis, eriocaulos ("̈pเov, coton, xaú).s૬, tige); qui a la lige velue. Ex. Astragalus eriocaulos, Trelianlhemum eriocanlon.

Éruocaulées, adj. et s. f. pl., Eriocaulca. Nom douné par L.-C. Richard, d'après eelui du genre Eriocaulon, qui lui servait de type, à une famille que R. Brown a depuis appelée Restiacces. Kunth l'applique à une tribu de celle derniere famille.

GRIOCEPHALE, adj, , erincephalus ("splo\%, coton, xeqzinin, têtc); qui a la tète velue. Iu Lachnca eriocephala est ainsi appelé parce que ses fleurs sont ramassées en une tête trè̀tomenteuse.

Énocipiarées, adj. ct s. f. pl., Eriocephalca. Nom donné par Lessing à une seetion de la tribu des

\section{ERIO}

Sćuéeionidées artémisićes, ayant pour type le grenre Eriocephalus.

ERIOCLADE, adjeet. , eriocladus ( a les rameaux velus. Ex. Spermacoce erioclada.

Éniodonte, adjeet. , criodontu.s (हैpเo\%, coton, a่doûs, dent); qui a les dents du calice velnes. Ex. Miconia eriodonta.

ínIoLONE, adj., criolomus ("̈pı\%, coton, 2.̄jux, bordure); qui est velu sur le bord, conme les cupules du Peziza crioloma.

f́RIOULTRE, s. m., criometrum ("̈pov', coton, $\mu \varepsilon \tau \rho \dot{\varepsilon} \omega$, nesurer ): Instrument que Young a imaginé pour mesurer les épaisseurs des fibres déliées, ou les diamètres des globules très-petits.

ÉRIOpétaLe, adi. , criopetalus.

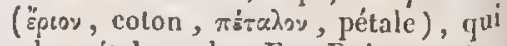
a les pétales velus. Ex. Poivrea eriopetala.

Errophone, adj., criophorus ; wolltragend (a!l.) (Ëpเay, coton, ę́pw, porter ); qui est chargé de poils cotonncux, comme les silicules du Clypeola criophora, l'involuere du Sarcolana eriophora, le calice du Carduus criophorus avant l'épanouissement de la fleur, les cellules du Flus" tra erinpliora; ou qui a ses rameaux aussi déliés que des brins de laine, comme le. Nescea erioplora.

ínopnLLE, adj., erioplyllus. ("̌pen\%, coton, qu' $\lambda_{20 \%}$, fcuille); qui a les feuilles velues. Ex. Pelargonitzm crioplyyllum.

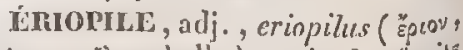
colon, rìos, balle); qui a les fruits velus. Ex. Duroia criopila.

ÉnIOPODE, adjeet., eriopodus (हp pédicules velus. Ex. Caldesia eriopoda, Lcontodon criopodum.

traOstachyé, adj., eriosta-

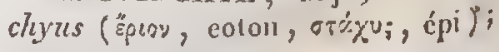


qui a les épis velus ou laineux Ex. Plantago eriostachya.

GRIOSPERME, adj. , criospermus

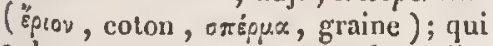
a les semences couvertes de poils. Ex. Convolvulits criospermus.

ERIOSTEMONE, adj., eriostemus

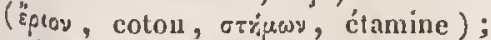
qui a les étanines velues. Ex. Aconitum eriostcmum.

EMIRHINIDEs, adj. et s.m. pl., Erirhinides. Norn donné par Sehoenherr à un groupe de Cureulionides gonatoeéres brachyrhynques, qui a pour type le genie Erirhinus.

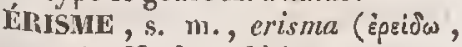
appuyer). Necker désigne sous ee nom le rachis des Graminées.

ERODÉ, adj., erosus. Jixpression dont L.-C. Richard se servait pour désigner toute partie d'nn végétal dont les bords sont dentelés d'une manière légire et fort inégale, comme si une chenille les avait rongés.

GROTYLENES, adj. ct s. m. pl., Erotylence. Noin donné par Lamarek, Goldfuss, Fieinus et Carus à une famille d'insectes colćoptères, qui a pour type le genre Erotylns.

EROTYLIDEs, adj. et s. m. pl., Erotylida. Lcach désignesous ee nom la famille des Erotylines. Voyez ee snot.

ERPÉtologie, s. f. , erpetolo-

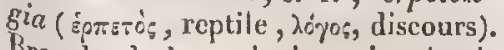
Branche de la zoologie qui traite de l'histoirc naturelle des reptiles.

ERṕtTolociloue, adj., erpetologicus ; qui a rapport ì l'erpétoloSie; classification erpetologique.

ERPétologiste, s. m., erpetologista. Naturaliste qui se livre d'une dnanière spéciale ia l'étude des reptiles.

LHRANTES, adj. ct s. f. pl. , $V a-$ gantes. Nom donué par RobineauDesvoidy à une section de la famille Ues Muscides, conı prenant les espèces qui n'ont pas de séjour déterminé.

Lrian'incE, adject., erraticus (erro, aller ca et là). Mauduyt donne cette épithete aux oiseaux qui, commc les hérons et les pétrels, n'aloplent pas de patrie, et ne s'arrêtent dans chaque endroit qu'autant qu'ils y trouvent de la nourriture, ous pour élever leurs petits. D'autres la réservent pour les oisenux émigrans. Voycz cc mot.

Énvcames, adj. et s. m. pl., Erucaria (eruca, ehenille). Nom. donné par Lanıarck ì une famille d'inseetes hyménoptères, comprenant ecux dont les larves offrent une sorte de ressemblance avec les ehenilles ou larves des Lépidoptères.

Énucanrúes, adj. et s. f. pl., Errecarice. Nom donné par Candolle à une tribu de la famille des Crueifères, qui a pour type le genre $E_{r}$ 'bcaria.

ÉncCrFonure, adj. , cruciformis (eruca, chenille, forma, forme) ; quia la forme d'une chenille, comme le Cyphella eruciformis, qui ressemble à unc cupulc oblongue, velue et blanche, peadante aux branches des arbres.

ERUPTION, s. f., cruptio; Expovts; Ansbrruch (all.) (crumpo, sortir avec impétuosité). Opération par laquelle les voleans brûluns émellent les produits d'un embrasement intérieur, des fumées, des eendres, des seories, des torrens d'eau ou de boue, des matières à l'état de f'usion ignée. On donne quelquefois ee nom, par abus, an $x$ matic̀res liquides que les voleans rejettent ì la surface de la terre.

fúnycivrs, adj. ets. f. pl., Erycince (eruca, chenille). Nom donné par Robineau-Desvoidy à une section de la famille des Myodaires calyptérées, eomprenant des espèces dont Jes larves vivent dans les chenilles.

ínxwGIíes, adject. et s.f. pl., Fryngica. Nom donné par K. Sprengel à une tribu de la fimille des 30 
Ombellifères, qui a pour type le genre Eryngium.

ÉRYTHRLEN, adj., erythrceoncnsis (épuopxios, rouge); qui habitc la mer Rouge. Ex. Cerithinm erythraonense.

GRITHRN, adject, erythrinus (èpvepós, rouge ); qui est rouge en totalité ou en grande partic. Ex. Sparus erythrinus, Aranea erythrina.

ERYTHRINE; subst. f., eryllirina. Nom donné par Hecren à une substance contenue dans le Lichen Roccella, qui donne naissance à la matiere colorante rouge qu'on retire de cette plante.

EnYTurIQUE; adj., erythricus. Nom donnć par Brugnatelli, parce que, de jaune qu'il est, il devient d'un rose rouge sous l'action des rayons solaires, à un acide (acido ossieritrico, it.) qu'on obtient en traitant l'acide urique par l'acide nitrique, et qui paraît êtrc un mélangc on unc combinaison d'acides nitrique et purpurique,

ÉRTHinoGarPE, adj., erythrocarpus (èpulpòs, rouge, xupròs, fruit): qui a des fruits rouges (cx. Eugenia erythrocarpa, Trillizem crythrocar$p n m$ ), ou des urnes rouges (ex. Brytum eryilhocarpunz).

ÉRYTInOCEPHALE, adj. , erythrocephalus (épuppos, rouge, xzepring, (têtc); qui a la tốte rougc ou d'un roux ardent (cx. Carabus erytlerocephalus, Musca eryltrocephala, Loxia rubrieeps, Tanagra flummiccps, Dicaum rubricapilla, Sylvia ignicapilla, Columba roscicapilla) ; qui a scs fleurs disposces cn capitules garnis de poils rouges (cx. Coecccypsclum crythrocephalum). Se dit aussi d'un clsampignon ayant la formc de capitules qui sont d'unc couleur rougc (ex. Hclolium erythrocephalum).

น́nXTInock̇ne, adj, , crythroee-

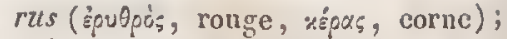
qui a les antennes rouges. Ex. Ceromya erythrocera.

ERYTHROCNìne, adj., erythro. cnemis (écutpòs, rouge, rvrun, janıb); qui a Ics jambes rousses. Ex. Allecula erythrocucmis.

EnYTInoctk̀Ne, adj., erythroclenus (èpuppòs, rougc, жrsi६, pcigne); qui a les antennes pectinées et ferrugineuses. Ex. Ceropria crylhroctena.

inTtIRODACTYLE, adj., cry"

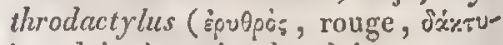
$\lambda_{\text {ac }}$, doigt); qui a les doigts rouges. Ex. Portunus erythrodactylus.

ERXTHRODANE, s, m., erythro"

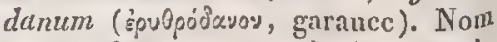
que Fechner propose de donner à la substance colorante rouge de la garance, généralement appelée aliza rine.

ERYTUmOGASTRE, adj., erythro"

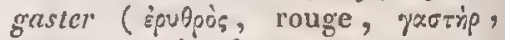
ventre); qui a le ventre rouge ou. marron. Ex. Hypterus erythrogaster, Sylvia erythrogastra, Dicaum rubriventer.

ERYTinoGiese; s. m. , erythror

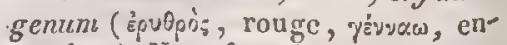
gendrer). Nom donné par Bizio à une substance particulière, qu'il a trouvć dans la bile d'un sujet mort d'hépatite, arcc jaunisse, et qui, vertc froid, donne par l'action du feu des vapeurs d'un bean rougc.

ínYTIIROGRAMMe, adj., ery'

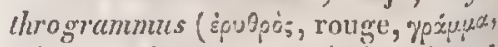
raie); qui est marqué de rities ot de traits rouges. Ex. Coluber crythir gramma.

EnYTIUOLEEQU, adject. , ery throlencus, erythrolencos (épupoòs,

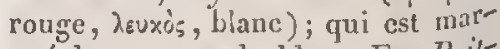
qué de rouge et de hlanc. Ex. Psittacns erythrolcucns, Trochies crythrolencos.

İRTHROLOPHE, adj., eryllhror lophus (špupoì;, rouge, dóeps, ai- 


\section{ERYT}

grette); qui a une huppe rouge. $\mathrm{Ex}$. Opalhus crythrolophus.

ERYTIROAELAS, adj., crythro-

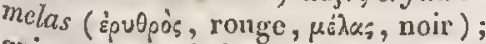
qui est marqué de rouge et de noir. Ex. Ardea erythrometas.

GrYTIRONIUM, s. m., crytturonium. Nom donné par Del Rio à un métal partieulier, dont il apercut l'existenee en 180 , que Collet Descotils erut être du chrome impur, et que Woehler a reconnu être le vanadium.

ERYTHRONOTE, adj., eryihronotos, crythronoltes ( ̇̀vipòs, ronge,

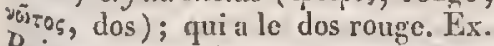
Psiltacts crythronotus, Fringilla eryihronota.

IIRYTHIOPE, adjeet., erythropus (èvopos, rouge, roūs, pied). Se dit d'un champignon (ex. 'Typhula erythropus) qui a le stipe, ou d'un insecte (ex. Nitidula eryihropa) qui a es pattes rouges.

IRYTHROPITHALME, adj., erythrophihalmus (épupoos, ronge, oqQa)uos, oil ); qui a le tour des yeux rouge. Ex. Piaya erythrophthalma.

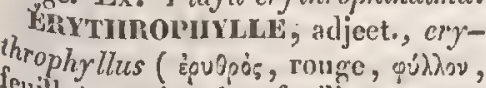
feuille); qui a les feuilles rouges. x. Terminalia crythroply lla.

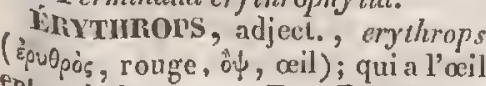
enlouré de rouge. Ex. Picus erythrops.

HRYTIROvThre, adject, erythropterus (épulous, rouge, тrв́por, aile). Épithète donnéc à un poisson qui a les nageoires ronges (ex. Creni(ex.s eryihropterus), à un oiscau. un Psitacus erythropterus), ou à pterusecte (ex. Truxalis erylliroa les, Leptura crythroptera) qui tiles rouges.

ERYTIROl'IGE, adj., crythroPygius (épuppos, rouge, ruyri, derdiere); qui a le tour de l'anus, le derrière, le eroupion rouge, $\mathrm{Ex}$. $\mathrm{Co}=$

\section{ÉRTT}

lius crythropygius, Simia erythropyga, Dicaum erythropygium, C'crcupithecus prgeryihreus.

ERYTIROIMAMPIE, adj. , erythroramphos, erythroramphus (sंouOpos, rouge, px́sesos, bee); qui a le bee rougre. Ex. Coracia erythroram phos.

ERXTILORHYNQUE, adj., crythrorhynchus, crythrorhynchos (covOpós, rouge, púyxos, luee). Se dit d'un oiseau (ex. Cinnyris crythror/hylchus, Pclecanus erythrorlyynchos, Anas erythrorhyncha), ou d'un inseete ( ex. Pissodes erythrorhynchus), qui a le bec rouge.

ERYTHIOSONF, adj., crythrosonuzus (s̀pu0pos, rouge, бwipe, eorps); qui a le corps rouge. Ex, Locusta eryithrosonia.

EnTYIInOSIERvítes, ndj. et s. f. pl., Erythrospermea. Nom donné par Candolle à une tribu de la famille des Flacourtiances, qui a pour type le genre Erythrospermum.

ERYTHLiOSTONE, s. m., crythrostomum (épupoós, rouge, crépec, bouche). Nom donué par Desvaux de un fruit hétéroearpien ayant un placenta. conique, qui supporte un grand numbre d'ovaires distincts, baceiformes, provenant d'une sculc fleur. Ex. Rubus Idcus.

LRYTHROSTONE, adjeet., crythrostomas; qui a la bouche ou l'ouverture rouge. Ex. Olise erythrostome, Gymnostomum erythrosiomum.

GHTHRO'TE, adject., eryilirotis (E่ovopos, rouge, ờ่, oreille). Le Philemon erythrotis est ainsi appelé paree qu'il a les oreilles grarnies d'un long faiscean de plumes rouges.

ERVTimotiorax, adjeet., crythrothorax (Ẻpuppós, rouge, Cápxz, poitrine); qui a la poitrine rouge, Ex. Coluniba crythrothorax.

ERYTIIHONILE, adj., erythroxy-

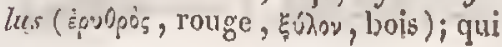


a le bois rouge on rougeâtre. Ex. Rhamnus eryihroxylum.

ÉRTTHRoxyLES, adj. et s. f. pl., Erythroxylea. Nom douné par Kuntls à une famille de plantes, qui a pour type le genre Erythroxylon.

Érinunuke, adj., cryihrurus (èpuopos, rougc, ovjox, qucuc); qui a la queue rouge. Ex. Psittacus erythrurus, Cichla crythrura.

ESGALLONI:US, adject. et s. f. pl., Escalloniea. Nom clonné par R. Browu à une fasuille de plantes, par Candolle à une tribu de la fanvillc des Saxifragúes, qui ont pour type le genre Escallonia.

ESCARPENENT, s. m., abruptum; Abdachung (all.); declivity (angl.). On dorne le nom d'escarpement d'une montagne à son versant le plus abrupte, celui qui se rapproche le plus de la perpendiculaire.

ESCHALí́s, adjcet. et s. f. pl. , Escharea. Nom douné par Lantouroux à une famille de Polypiers, ayant pour type le genre Eschara.

ESCHONILLIE, s. f., eschomelia ( ${ }^{\prime \prime} \sigma \chi^{\alpha \tau o \xi}$, dernicr, $\mu \dot{\varepsilon} \lambda \varepsilon \circ \xi$, inutile). Malacarne désigne ainsi une classe de monstres caractérisée par la djfformité monstruense de quelgue membre, qui le rend impropre à remplir ses fonctions.

ÉSENBLCKINE, subst. f., esenbeckina. Alcali organique que Buchner a découvert dans l'écorce de l'Esenbeckia febrifuga.

ÉSExte: , adject. , esexualis ( $c$, priv., sexus, sexe). Quclques botanistes ont employé ec mot, conune synonymc d'agame, pour désigner les végétaux qui u'ont point de sexes.

Esoces, s. m. pl., Fisoces. Nom douné par Cuvier à une fimille de poissons Malacopterygiens abdom:naux, qui a pour type lc genre Esox.

ÉsocIexs, adject. et s. m. pl., Esocii, Esocini. Nom donné par Latxcille, Eichwald, Ficinus et Carus à une famille de poissons Abdominaux, dont le genre Esox est le type.

ISODELVE, subst. m., esoderma ( Kirly donne ce nom à une espèce de cuticule fibreuse qui rcvêt en dedans l'enveloppe extérieure du corps des insectes.

ESPACE, s. m., spatium ; Raun (all.); space (angh.); spazio (it.). Idée qui restc après avoir fait abstrac* tion par la pensée de tous les corps ou d'une partie seulement des corps de l'univers; idée que nous nous formons de la contiguité des corps et de leurs parties. Indéfini pour notre conception, l'espace est par conséquent infini dans la réalité.

ESPÈCE, s.f., species; Art. (all.) On eruplaye ce mot: $1^{\circ}$ En climie. Il $y$ a une signification diflérente sui* vant les corps auxquels on l'applique. Lorsqu'on parle d'un corps simple, il exprime l'idée d'une collection de propriétés qui n'appartiennent qu'i ce corps, et quand il s'agit de composés, on cnlend par là une substance forméc: des mêmes élémens, unis dans lc nême ordre et dans la même proportion, unc collection d'ètres idcritiques par la nature, la proportion el l'arrangement de leurs molécules. $2^{\circ} \mathrm{En}$ niuéral ogie, Linné, Wallerius, Bcrgmann et Werner ont employé le mot espéce pour désigner les premières divisions de leurs $\mathrm{sy}^{5}$ tèmes, sans cliercher à le définir d'üle manière rigoureuse, et sans poser le 5 principes qui doivent guider daus le détermiuations scientifiques. Il est défini par Haüy, unc collection de corps dont les inolícules intégrantes sont semblables par leur noubre $e^{t}$ composées des mèmes principes, unis entre cux dass le uène rapport; par Dolomicu, Beudant, Brongniart, unc réunion d'individus contr posés des mèmes principes combinés daus les mênes proportions dẹfinies; 
par Mohs et Breithaupt, une collection de corps qui, dans chacun de leurs caractères extérieurs, sont identịues on peuvent être considérés comme les termes voisins d'une même séric; par Fuchs, une eollcction de minéraux qui ont une même cristallisation et une même composition chimique, ou bien, quand il y a des élémens qui se remplacent mutuellement, une combinaison analogue sous le rapport stœchiométrique. Ainsi, suceessivcment, l'idće d'cspèce, en minéralogie, d'abord vague et indéterminéc, a été appliquée à l'aceord cutre la composition chimique et la forme cristalline, a l'idenbilé ou a la continuilé des caraetères extéricurs, enfin à l'identité ou à l'isomorphisme des élémens. $3^{\circ}$ En bolanique et en zoologie, l'idée qui se rattache an mot espece, quoique mieux déterminće en apparenec, n’est guère moins vague daus la réalité. Ce mol exprime, d'après Linné, toutes les formes diverses qui ont élé produites au commenecment du monde; suivant Adanson, tous les individus qui se ressemblent par une Sueeession eunstante; selon Jussicu, tout individu quelconque qui offre la véritable image de toute l'espèce passée, présente et finture; d'aprìs Buffon, une ressemblance parlaite entre les individus, et des différences trop légères pour être distinguées; d'après Cnvier, une rónuion des individus descendus l'un de l'autre ou de parens communs, et de ccux qui leur ressemblent autant qu'ils se ressemblent cutr'eux; une réunion de corps dont la russemblance est telie qu'ils peuvent ĉtre eonsidérés comme originaires d'un seul et même individin, dont ils ont conservé les traits caractéristiques ; selon Lamarek, toute eollcction d'individus semblables, que la génération perpétue dans le même étal, tant que les circon- stances de leur situation ne changent pas assez pour faire varier leurs balitudes, leur caractère et leur forme ; suivant Mirbel, la suecession des individus qui naissent les uns des autres par génération directe et constantc, soit qu'elle s'opère par œuls ou graines, soit qu'elle ait lieu par simple séparation de parties; sclon Candolle, la collection des individus qui se resscmblent plus eutr'eux qu'ils ne resscmblent à d'autres, qui peuvent, par une féeondation réciproque, produire des individus fertiles, et qui se reproduisent par la généra tion, de telle sortc qu'on peut, par analogic, les supposer tous issus originairement d'un scul individu; d'après Blainville, une collection plus ou moins nombreuse de variétés plus on moins fixes, conslituce par un nombre variable d'individus qui, scmblables dans l'cnsemble de l'organisation, et surtout dans tontes les parties de l'organe reproducteur, peuvent se continuer dans le temps et dans l'espace par la génération. Il est évident qu'on ne peut, dans les corps organisés, considérer comme espèee gu'une collection d'êtres quelconques qui se ressemblent plus entr'cux qu'ils ne ressemblent à d'antres, el que, d'un accord plus ou moins unanime, on cst convenu de désigner par un nom cormunun; ear une cspecc n'est qu'une simple abstraction de notre esprit, et non un groupe exactement déterminé par la nalure elle-mème, aussi ancicn qu'elle, et dont elle ait tracé irrévocablement les limites. C'est dans les définitions de l'cspèce qu'on reconnaît combien l'influence d'idées adoptées sans examen dans la jeunesse est puissante pour obscurcir les rsolions les plus simples de la physique générale.

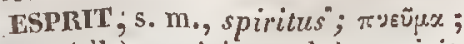
Geist (all.); spirit (angl.); spirito 
(it. ). Ensemble des facultés cérébrales, vivacité d'imagination, faculté de créer des idées, ou de les combiner licurcusement, talent de dire ee qui convient, d'assaisonner la raison par la délicatesse du sentiment, par la justesse et la promptitude des pensécs. - Autrefois les chimistes donnaient ee nom à tous lcs liquides qu'on obtient en soumetlant les corps à la distillation.

ESQUAMÉ, adj., esquamaulus ( $e$, priv., squama, ćeaille); qui est privé d'écailles. Synonyme inusité d'alépidole. Voyez ce mot.

ESQUiLLEUX, adj., squidillatus; splitterig (all.). Les géognostes disent d'une rocle qu'elle a la cassure esquillcuse, quand la surface de cette dernière présente une multitude de petites écailles ou esquilles, qui se détachent avec plus ou moins de facilité.

ESSAI, s. m., Probe (all.) ; cssay (angl.); assaggio (it. ). Opération analytique qu'on exécute cu pelit, dans la vue de déterminer la proportion suivant laquelle un ou deux corps précieux ou utiles se trouvent eontenus dans une masse inorganique, en négligeant généralement de rcchereher la nature des corps qui acconpagnent ceux-ci.

ESSAIM, s. m., aptom examen; Schwarm(all.); swarm(angl.); essame (it.). Colonie d'abeilles qui, à l'époque du printemps, où la population angmente bcaucoup daus les ruehes, abandonncrit celles-ci pour aller cliereher gîte ailleurs. Pour qu'un essain puisse prospérer, il faut qu'il contieme vingl-cinq mille abeilles, et sous le climat de Paris, une ruche fournit ordinairement deux, quclquefois quatrc essaims par année, e'est-à-dire dans l'espice de quinze à dix-hnit jours.

Essarmentent, s. -m. Partage qui, ì une certaine époque de l'an- née, se fait de la population d'une ruche, dont une portion abandonne l'ancienne demeure pour aller en construire une autre ailleurs. $O_{11}$ dit alors que les abeilles essaiment.

ESSENTIEL, adj., essentialis; wesentlich (all.); (esse, être). On appelles caractères essenticls, en histoire naturelle, ceux qui expriment les particularités les plus remarquables des espèces, des genres et de toutes les coupes systématiques. En minéralogie, on nomme parties cons. tituantes essentielles d'une roche, eelles dont la présence est nécessaire pour la eonstituer, comme le quarz, le feldspath et le mica dans le granite.

ESSORILLÍS, adj. et s. m. pl. Sorices. Noun donné par Desmarest à unc famille de Mammifères rongeurs, qui a pour type le genre Sorcx.

EST, s. m., oriens; Ost (all.); cast (angl.); oricnle (it.). L'un des quatre points cardinaux du monde, celui où le Soleil paraît se lever aux équi: noxes.

ESTHÉostones, adj. et s. m.

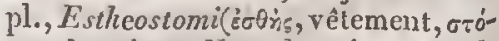
$\mu \approx$, bouche). Nom donné par Hedwig aux mousses qui n'ont qu'une garniture simple à l'orifiee de leur urne.

ESTIVAL; adj., restivalis, astivus. Epithèe appliquée, par les botanistes, aux plantes qui fleurissent dans le eours de l'été, depuis le mois de juin jusqu'ì la fin d'août (ex. Adonis ostisalis, Barbula (estiva); par lcs entomologistes, à des insecte's qu'on trouve en été (ex. Platymya astivalis ).

ESTIVATION; s. f., estivatio. Liuné et $\mathrm{R}$. Brown appellent ainsi la disposition respcetive des tíguncns floraux des plantes, avant l'époque de leur épanouissement complet, ee que L.-C. Richard nomınait préfleuraison.

ESTOMAC, s, m, stomachus, ven* 


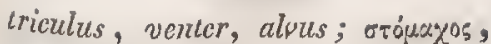
Vkurip; Magren (all.); stomach (angl.); stomaco (it.). Portion du eanal alimentaire dans laquelle les substances ingérées, à titre de nourriture, s'accumulent, séjournent pendant quelque temps, et subissent un commuencenıent d'élaboration.

ESTROPĹ, adj. Tpithète donnée par Geoffroy aux papillons de jour qui, dans l'élat de repos, tiennent lrurs ailes inféricures horizontales, et les supéricures relevćes, de sorte qu'ils out l'apparenee d'inseetes à ailes luxées.

ÉTAGÉ, adj., gradatim ordinatus. Se dit des organes qui sont placés les uns au dessus des autres par rangées distinctes et régulières. On employe ce terme en parlant de la queue des oiseaux, des bractées, des feuilles et des graines dans les végétaux.

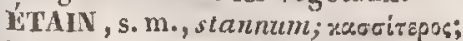
Zinn (all.); lin (angl.); stagno (it.). Métal solide, et de eoulcur argentine, qui est eomu de toute autiquité.

ETainion, subst. m. , cairizm (Érouozia, socićté). Mirbel donne ce nom à un fruit eomposć de plusieurs camares disposées autour de l'axe rationnel du fruit. Il faudrait éerire létairion.

ÉTAIRIONNAIIE, adj. , elairionarius, elairionaris, etairioncus. Epithète dounce par Mirbel aux fruits composés qui proviennent d'ovaires portant le style, et aux capsules polycéphales qui sont divisées presque complètement en plusieurs lobes représentant autant de eaunares. Ex. $I l$ licium anisulum.

GTALÉ, adj., patulus, patens, expansus, effusus, diffusus; weitscluweifig, abstchend (all.). Se dit, en général, dans la langue botanique, de parties ouvertes ou étalées, sans ordre rćgulier, formant un angle presque droit avec eelles d'où elles tirent leur origine, en s'éloignant beaucoup de la perpendienlaire à l'horizon, eomme les ramcaux (ex. Oxybapluss expansus, Tagetcs paula, Talinum patens, Leplocaulis diffusus), les fenilles (ex. Milium effusum), la panicule (ex. Prenanihes muralis), les pétales (ex. Geum urbanum), les sépales (ex. Borrago offeinalis), le limbe d'une eorolle monopélale (ex. Anchusa italiea), les ćlamincs (ex. Pyrola minor).

ETAMiNe, subst. f., stamen;

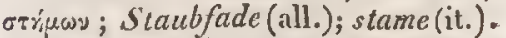
Organe mâle des plantes phanérogames.

ÍTANG, s. m., stagnum; Tcig (all.); pond (angl.); stagno (it.). Pièce d'ean plus ou moins étendue, plus souvent artificielle que naturelle, et qui résulte d'un obstacle mis au cours d'un ruisseau dans une vallée.

ETĹ, s.f., astas; Gźoos; Sommer (all.); summer (angl.); stale (it.): L'une des quatre saisons de l'année, celle dans laquelle règnent en général les plus grandes chaleurs. Daus notre liénisphère, l'été commence au passage apparent du Soleil par le premier point du signe de l'Eerevisse, et finità son passage par l'équinoxe d'automne, vers le 2 I septembre. Pendant sa duréc, la Terre pareourt réellement les signes du Caprieorne, du Verscau et des Poissons.

ĹTENDAIID, subst. n., vexillum; Fahne (all.). Ies botanistes appellent ainsi le pétale supérieur des corolles papilionacées, qui est ordinairement plus grand que les autres, et redressé en manièrc d'étendard. Illiger donnait le même nom au rachis des plumes pris eolleetivement avce les barbes.

IETENDU, adj., expansus, extensus. En ehimie, Berzelius appelle acide ćtendu, un simple mélange qucleonque d'un aeide et d'eau. Les rninéralogistes disent que les parties d'une roche feuilletée sont étendues, 
lorsqu'elles sont parallèles aux feuillets, comme le quarz dans le gneiss. En botanique, Mirbel dounc l'épithète d'étendu au neclaire qui forme comme un enduit sur le sommet de l'ovaire (ex. Saxifraga hypnoïles). Les cntomologistes discnt les ailes élendues, lorsque, dans l'élat de repos de l'insecte, elles ne se rabatlcnt point sur le corps et laissent l'abdomen à découvert (ex. Libellules).

ÉTENDUE, subst. f., extensio; Ausdelnung (all.); extension (angl.); estenzione (it.). Portion finie ou limitée de l'espace.

ETrAL, s. m., athalium. Chevreul donnc ce nom à un corps gras particulier qu'il a découvert, et qui est produit par la saponifieation de la cétine. Ethal est formé des premières syllabes des deux mots éther et alcool, par allusion à la composition de ce corps.

ETrEen, subst. m., ather; ailni ; Himmelsluff (all.) ( $a i \theta \omega$, brûler). Originairement on appelait ainsi le eiel Iui-mème : puis les physiciens grees ont employé le mot pour désignet un esprit hypothétique qui, suivant cux, animait le moude entier. Les physiciens modernes entendent par lì un quide éminemmentsubtil et élastique, qu'ils admettent dans la uaturc, pour expliquer les phénomènes du caloriqnc, de la lunic̀re, de la pesantcur, et qu'ils supposen tremplir tous lcs corps, ainsi que les espaces intermédiaires. Le mot éther a été introduit dans lc langage chimique par Frobenius, cu I 730 , pour désigner un liquide, déjà connu auparavant, qu'on oltient en distillant parties égales d'alcool et d'acide sulfurique, et qu'il appela ainsi probablement par allusion à sa légèretć et à sa volatilité. Aujonırd'hui on donne ce nom, devenu collectif, à des composés dont plusieurs, n'étant pas distillables, rnanquent par conséquent de la proprićté en raison de laquelle on l'avait appliqué au corps qui l'a porté le premicr. Le mot éther u'exprime donc plus aucune relation aux propriélés, et ne s'employe qu'eu ćgard à la composition des sulstances auxquelles on l'applique, lesquelles né:inmoins ont eela de comnıun que toules elles résultent d'une nıodification apportée à la composition de l'alcool par l'action d'un corps électro-négatif, halogène, oxacide, hydraeide, ou mème sel, soit que le corps dont on s'est servi reste cul conbinaison avec le produit, soit que celui-ci n'ell contienne aucune trace. Les ehimistes allemands réservent nieême le nom d'éther pour ce dernier cas exclusivement, et dans l'autre ils employent celui de naphthe. Berzclius n'applique le mot éther qu'aux composés du premier genre, et quant i ceux du second, il les désigne par le méme ternıc, auquel il joint pour épithète le nom de l'acide dont les élémenssesont combinés avcc l'ćther.

ÉTnÉRATE, sulst.m., atheras. Genrc de sels (athersaure Salze, all.) qui sont produits par la combinaison de l'acide éthérique avec Ics bases salifi:bles.

ÉTnéné, adj. , athereus; wheriseh (all.); qui a les qualités ou les propriétés de l'éther; liquetrer éthérée, odeur éthérée. Bory établit, sous le nom de règne éthèré, une grande classe de corps naturels, dans laquelle il comprend tous les fluides impondérables. Le Phacton cethereus est ainsi appelé paree qu'il ne s'éloignc pas des régions que le soleil n'alıandonne jamais.

KTHÉRME, subst. m. Non générique dont Guibourt se sert pour désigner les ćlhers.

ÉTIĹnIQQUE, adj., athericus. Le nom d'acide échérique (Aethersäure, all. ) a ćté donné à l'acide Jampique, 
paree qu'il est le produit de la combustion de l'aleool.

ÉTHÉRISATION, subst.f. Conversion en éther.

ÉTMÉRISÉ, adj.; qui a été converti en éther.

ÉTIIRIOSCOPE, s. m., aillorio-

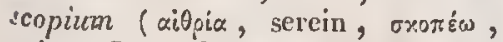
voir ). Sorte de lisernoscope, imaginé par Lceslie, qui sert à faire eonmaitre la foree du rayonnement de lia chaleur vers le cicl exempt de nuages.

ÉTHULIĹES, adj. et subst. f. pl., Ethuliea. Nom donné par H. Cassini à un groupe de la trilua des Vernoniées prototypes, qui a pour type le genre Ethulia.

ETIOLÉ, adj. Se dit d'une plante qui, ayant eru dans un endroit obseur ou peu échairé, n'a fourni que des pousses grêles, alongées, flexibles, d'un blane soyeux, munies de feuilles petites, écartćes et d'un blane jaunàtre.

CETIOLEMENT, subst. m., chlorosis; seloramento (it.). Phénornène offert par les plantes ćliolées, qui, déjà connu d'Áristote, a été observé pour la première fois dans les temps modernes par Ray, puis étudié par Bonnet, Meese et Scuebier, dontles recherehes en ont fait eonnaître la cause, due à la privation de la lumière.

ÉTOILE, s. f., slella; *ैrтрон;Stern. (all.); star (angl.); stella (it.). Nom donné aux astres qu'on voit briller la nuit d'une lumière très-vive, dont nos plus forts télescopes n'augmentent pas la grosseur apprarente, qui paraissent conserver toujours entre eux les mêmes situations respectives, qu'on suppose lumineux par euxmêmes, et qu'on regarde comme autant de soleils plus ou moins gros, placés hors des limiles de la sphère du nôtre, à une distance plus ou moins considérable. Le nombre des étoiles que de bons yeux peu- vent distinguer sur les deux hémisphères du eiel s'élève à environ sept mille; mais les instrumens d'optique le multiplient prodigieusement. Les botanistes appellent quelquefois éto $i-$ $l e s$, les roseltes des mousses. $V$. ce mol.

FTOLË, adj., stellatus, stellulatus, stelliformis, radiatus, asterizans, stellaris, sidereus; gestirnt (all.) ; starry (auchl.); stellato (it.); qui a la forme d'une étoile. On employe ec mot: $1^{\circ}$ en botanique : ealice étoilé, quand il s'ouvre eu forme d'étoile, après que la fleur est passée (cx. Lampsana stellala); péricline éloilé, lorsqu'avant sou épanouissement ses picees sont muuies de longues épiues disposées en étoiles (ex. Calcilrapa stellata); corolle ćloilce, quand elle est monopétale, régulière, à tube très-court, à limbe ouvert et plane, mais que les divisions de eelui-ei ont de petites dimensions et sont pointues (ex. Valantia cruciala); stigmate ćtoilé, quand il est déeoupé en lobes imitant une étoile par leur disposition (ex. Nymphaca radiala); poils éloilés, quand ils produisent des rameaux simples; qui partent d'un centre eommun cn divergeant (ex. Cistus polifolius); fcuilles étoilées, lorsqu'elles sont petites, verticillées et fort élalées au sommet des rameaux (ex. Callitriche verna ) ; fruit ćtoilc, lorsqu'il est divisé en lobes aigns, yui divergent comme des rayons (ex. Damasonium stellatun), ou qu'il se compose de plnsieurs gousses disposées en ćtoile sur un même pédlicule (cx. Astragalus stella). $2^{\circ}$ En zoologic, ee mot est souvent employé comme épithète indiquant soit la disposition des couleurs du corps, qui forment une ou plusieurs taches ou mouchetures ćtoilées (ex. Mustelus asterias, Balista stellatus, Cyclops asterizans, Muscicapa siellata, Ardea stellaris, Naïa 
asterias), soit la présenec, sur diverses parties du corps, de petits appendices disposćsde manière à imitcr plus ou moins hicn une étoile (cx. Acipenser stollatus, Bodianusstellatus, Astrea siderea, Astrea stcllulata).

t́tondists, adj. et s. f. pl., Stellatce. Noun douné par Linné à une famille de plantes, qui correspond aux Rubiacées des moderncs, et par Candollc à une iribu de cette dernière famille, ì cause de la disposition des fcuilles autour de la tige.

Eroiclis, adj. et s. m. pl., Stellata. Nom donné par Lichwald à une faunille de la classe des Cyclozoaires, renfcrinant ceux qui, eomme les astéries, ont le corps étoilé.

ÉTOUPE, s. f., stupa; W $\operatorname{erg}($ all.); lown (angl.); stoppa (it.). Matic̀rc filamenteuse qu'on trouve soit au eollet, soit dans l'intéricur du fruit de eestaines plantes.

ÉTOLPEUX, adj., stuposus; weroartig (all.). Les entomologistes appellent palpes ctoupcux eeux qui sont couverts de poils fins, serrés et mous au toucher. Ex. Papillon.

ÉTUI, s. m. vagina. On donne ce nom, chez les inseetes, a la tige cornée qui fait partie de l'aiguillon des Iymćnoplères, et qui est un fourreau destiné à loger le dard. Parfois aussi on l'applique aux élytres des coléoptères.

Euchilonive, s. m. ( $\varepsilon^{\tilde{j}}$, bien,

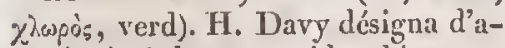
bord ainsi le gaz oxide chloreux, découvert par lui en 181 , parce que ce gaz a une coulcur plus foncée que celle du chlore.

EUCHONDRITES, adj. et s. m. pl. , Euchondrites (sं , bien, $\chi^{\dot{0} y \delta p o s,}$ grain). Nom donné par J.-A. Ritgen à une famillc de Reptiles ophidiens, renfcrnant ecux qui ont la peau grenue ct ne sont pas vénéncux.

EUCHrour, adject. , euehromus

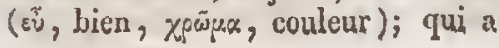

unc belle couleur. Ex. Equorea euchroma.

EUCIIYVE, s. m., cuehymus ( $\varepsilon \tilde{\text {, }}$ bien, zưòs, chymc). Nom donné par Hayne au cambium des végétaux.

EUCLANIDOTES, adj. ct 5 , in. pl., Euclanidota. Nom donné par C.-G. Ehrenberg à une tribu de la classc des Rotiféres, qui a pour type le genre Euclanis.

IVCLIDIÉES, adj . et s.f.'pl., $E u$ clidiece. Nom donné par Candolle à une tribu dc la famille des Cruciferes, qui a pour type le genre Euclidizum.

IUDIOVITRE; s. m., eudiometrum; Lufigütemesser (all.) (๕v̋dios, serein, $\mu \varepsilon \tau \rho \dot{s} \omega$, mesurer). Instrument dont on se sert pour mesurer le degré de pureté de l'air atmosphćrique, la quantitć d'oxigène qu'il conticnt.

NUDIONÉTRE, s. f., eudiometria. Art de reconnaître, par des procédés chimiques, la proportion d'oxigène qui existe dans l'air atmosphérique.

EUdIOMÉTRYQUe, adj., eudiometricas; qui a rapport à l'eudiométrie; experience ou instrument eudiométrique.

EUIILDDSARÉES, adj. et s. f. pl., Euhedysarce. Nom donné par Candolle : une section de la tribu des Hédysarées, comprenant celles qui appartiennent par excellence at ce groupe.

EULEPTOSPERIÉES, adj. et s. f. pl., Euleptospermece. Nom donné par Candolle ù uu groupe de la tribu des Leptospermées, qui a pour type le genre Euleptosperinum.

Euaŕínones, adj. et s. m. pl., Eunterodes ( $\varepsilon^{\bar{\nu}}$, bien, $\mu$ śpos, membre). Nom donné par Duméril à une famille de l'ordre des Sauriens, renfermant ceux de ces reptiles qui ont les membres bien conformés.

EUNICÉES, adj. et s. f. pl., Eu nicea. Nom donné par Latreille à une 
famille d'Annelides, qui a pour type le genre Eunice.

EUNIClS, adj. et s. m. pl., Eunices. Nom sous lequel Savigny et Lamarek désignent une farnille d'Annelides, ayant le genre Eunice pour type.

EUNICIISN, adj. et s. m. pl., Eunicici. Nom donné par Audonin et M. Edwards à une fanille de l'ordre des Annelides errantes, qui a pour type le genre Eunicc.

EUPATOHACÉLS, adj. els. f. pl.; Eupatoriaceex. Nom donné par Lessing à une tribu de la famille des Synanthérées, qui a pour type le genre Eupatorium.

EUPatomúEs, adj. et s. f. pl., Eupatoriea. Nom donné par H. Cassini à une tribu de la famille des Synanthérées, par Lessing à une soustribu de la tribu des Lupatoriacées, ayant le genre Eupatorium pour type.

EUPATORNE, s. f., cupatorina. Alcali organique que Riphini a découvert dans l'Eupatorium cannabinum.

EUPHORBLACÉE, adj. et s. $f$. pl., Euphorbiacea. Nom donné par Jussicu à une famille de plantes, qui a pour type le genre Euphorbia.

EUPHOLHน́ES, adj. et s. f. pl., Euphorbiex. Nom donné par A. Jussieu et Kunth ì une tribu de la famille des Euplıorbiaeées, qui reaferme le genre Euphorbia.

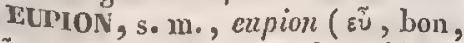

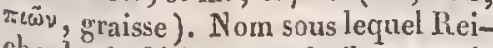
chenbaeh désigne une huile pyrogénée liquide qui se produit pendant la distillation sèehe des substauces organiques.

EUPLOTLS, adj. et s.m.pl., Enplota. Nom donné G.-G. Ehrenberg à une tribu de la classe des Infusoires Polygastriques, qui a pour type le Senre Euplcea.

EUPODEs, adj, ct s. m. pl. , Eu= poda ( $\varepsilon \tilde{u}$, bien, $\pi$ uั donné par Latreille et Eiehwald à une fanille d'Insectes coléoptères, dont la plupart ont les cuisses postérieures très-reullées ou fort grandcs.

EUPTERIDE, adjeet. , eupterideus (' $\varepsilon \dot{*}$, bien, $\pi \tau$ scis, fougère). L'Antipathes cupteridea est ainsi appelée à cause de la forme de ses pinnules, qui ressemblent ì une belle plume de paon décolorée.

EURYCOP'IDOPTÈNEs, idj, et s.

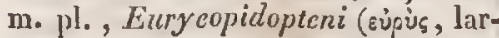

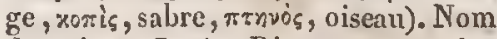
donné par J.-A. Ritgen à une famille d'oiseaux marins ou plongeurs, qui, eomme les Pélieans, se font remarquer par la forme et la grandeur de leur bee.

EURYLABE, adjeet. , eurylabis

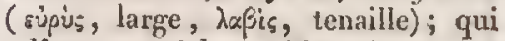
a l'auus gnarni de tenailles très-larges. Ex. Asilus curylabis.

EunYLA muics, subst. m. pl. Nom donné par Lesson à une fanille de l'ordre des Passereaux, ayant pour type le genre Eurylaimus.

EURTSTONES, adj. et s.m. pl. ; Eurysloma (evipus, large, бторнs, bouehe). Nom sous lequel Ranzani désigne une famille de Passereaux, dang laquelle il range des oiscaux qui ont le bee largeneut fendu.

ELSPERULCOCLES, adj. et 's. f. pl., Euspermacocea. Nom donné par Candolle à une seetion de la famille des Rubiacées, eomprenant eelles qui se rapprochent le plus du gente Spernacoce.

sUTHÉTIQUE, adject., eutheticus ( $\varepsilon$, bien, rion $\mu r$, disposer). Épithète donnce, dans la nomenelature minćrilogique de Ilaüy, à une variété dont les faees présentent un assortiment d'où résultent des earactères remarquables de symétrie. Fx. Chaux carbonatéc euthétique.

EUXíniées, adject. et s. f. pl. ? Euxenice. Nom donné par Lessing 
à une section de la sous-tribu des Astéroïdées mélampodiées, qui a pour type le genre Euxenia.

ÉVAGINULiES, adj., Evaginulati (e, priv., vaginula, petite gîine). Bridel donne ce nom à une classe de Mousses, comprenant cclles dont le pédicule cst privé de périchèze.

ÉVALVE, adj, , evaluis ( $e$, priv., valva, valve). Epithète donnce par Mirbel an drupe, quand il est déponrvu de valves (ex. Olea europa:a), et par quelques autres botanistes aux périearpes qui ne s'ouvrent pas, eas dans lequel clle devient synonyme de indélriseent. $V$. ce mot..

EVANESCENT, adj., evaneseens; verschwindend (all.). Mirbel appelle neetaire évanescent, celui qui s'amoindrit à mesure que lc fruit se développc, et qui finit par disparaître entièrement (ex. Saxifraga hypnoides). Un prothorax évanescent est, suivant Kirby, celui qui n'est point distinct, ou qui est seulement représenté par une nuembrane (ex. benucoup d'hyménoptires et de diptères).

ÉVANIaDES, adj. et s. m. pl., Evaniada. Nom donné par Leach à la famille des Evaniales. $V$. ce mot.

Civaniales, adj. et s. m. pl., Evanialia. Non donné par Lamarek, Cuvier, Latreille, Groldfuss et Eichwald à une famille ou tribu des insectes hyménoplères pupivores, qui a pour type le genrc Evania.

ÉVANInNERvé, adj., evanidinervus (evanidus, effacé, nervus, nerf). Se dit d'une plante dont lcs nervures des feuilles sont presque effacées. Ex. Gymnostomum graeillimum.

EVAPORABLE, adj., vaporabilis;

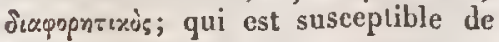
s'évaporer.

ívaponation, s.f., vaporisalio, evaporatio, vaporalio ; diạdipnoıs ; Ausdünstung, Verdünstung (all.).
Ascension lente et graduelle, dans l'air, d'un liquide qui s'y répand sous la forme de Quide aériforme; réduction d'un liquide en vapeur à une température qui serait insulisisnute pour lui donner une teusion ćgale á eelle de l'atmosphère; formation d'une vapcur à la surface libre d'un liquidc ou même d'un corps solide; disparition graduelle d'un eorps liquide ou solide à l'air ; opération qui consiste à réduirc cn vapeur un liquide contenant en dissolution une substance fixc ou susceplible de se volatiliser avee lui.

ÍVAPORONLTRE, s. m. , cvaporalorum. Synonyme peu usité d'atmomètre. Voyez ee mot.

EVection, s. f., evectio. La plus considérable des inégalités périodiques auxquelles est assujéti le mourcment de la Lune. Elle a été déeouverte par Ptolémée. Son effet constant et général est de diminuer l'équation du centre dans les syzygies, et de l'augmenter dans les quadratures. Sa valeur absolue varie avec la distance angulaire de la Lune au Soleil, et celle cle la Lunc au périgée de son orbite. Sa période est de 3 ij. 8 × 939 , intervalle après lequel elle rcprend suceessivement la mème valeur.

EVENT, s. m., apertura. On appelle ainsi les narines des cétacés, paree qu'elles leur servent à rejeter l'eau qui reste dans leur bouche ela. que fuis qu'ils la ferment pour saisir leur nourriture. Au moyen d'un mécanisme particulier, eette eau est rejetée par les narines, et laneée avcc force en un jet souvcnt fort èlevé.

EVoLUTÉ, adj., evolutus. Épithète que Férussac donne aux eoquilles univalves, lorsqu'elles sont enroulécs dans le plan vertical, et que leur spire est plus ou moins alongée.

fvolution, s. f., evolutio (evolvo, dérouler). Développement, ac- 


\section{EXAN}

tion de se développer, de se dérouler. On appelle ainsi un sytème physiologique (Einschachtclungslehre, all.), dont les partisans supposent que le nouvel çtre qui résulte de l'acte de la génération, préexistait à cet acte, lequel ne fait que le tirer de la torpeur où il ćlail plongé , lui donner uue vie plus active, lui imprimer assez d'énergic pour qu'il puisse croitre rapidement et parcourir les phases de sa nouvelle existence.

EVOMPHALE, adj., evomphalus ( $\varepsilon^{\top}$, bien, oupextos, nombril). Le Planorbus evomphalus est ainsi nommé parce qu'il est tout-à-fait plat en dessus et concave en dcssous.

Evonymúcs, adj. et s. f. pl., Eyonymca. Nom sous lequel Candolle désigne unc tribu de la famille des Célasirinées, érigéc en famille par Caffin, qui a pour type le genre Eyonymus.

EXaLbUMini, adjeet., exalbuminosus (ex, sans, albumen, périsperme). Gaertucr donnait celte épithète à l'embryon, lorsque, après la f́ceondation, il absorbe ct fait disparâitre l'armuios, sans laisser de résidu, en sorte qu'il ne se produit pas d'albumen ou de périsperme.

EXAMPUigastruk, adj., examphigastriatus. Nom donné par J.-B.-G. Lindenberg aux Jnngernannies dont les feuilles sont dépourvues de stipules ou amphigastres.

EXANTLNiví, adj., exantcnnatus ( $e x$, sans, anterna, antenne). Epithèle que Lamarck appliquait aux Arachnides qui n'ont point d'antennes.

EXANTENNTLES-IBANCHIALES, adj. et s. f. pl., Exantennala-branchiales. Sous ce nom, Lamarck désigue un ordre de la classe des Arachnides, comprenant ceux de ces animaux qui n'ont pas d'anteme's el respirent par des poches branchiales.

EXANTENNLES-TUACHELNNES, adj, et s.f. pl., Exantennata-trachea- lcs. Dénomination imposée par Lamarck ì un ordre de la elasse des Arachuides, comprenant ceux de ces aninaux qui sont privés d'antennes ct respireut par des trachées.

ExANTHEMatigue, adj., cxanthematicus, exanthematosus ( $\xi_{\nu} \sigma_{\nu} \theta_{s} \omega$, fleurir); qui est muni de tubercules semblablesà une éruption cutanée. Ex. Varanus cxanthematicus.

EXINTUĹMUUL:, adj., cxanthemoüdeus; qui ressemble à une éruption de boutons ou de pustules, comme certains ehampignons. Ex. Variolaria.

EXAPOPIIYSí, adj., exapophysatus. Épithète donnéc à une mousse qui csı dépourvue d'apophyse. Ex. Coscinodon nudum.

ExARTICULE, adj., exarticulatus. Epithète donnée par les entomologisles à des antennes qui n'ont point d'irtieulations visibles.

EXATMOSCOPE, s. m., exatmoscopium ("'̌), de, $\dot{\alpha}=\mu \dot{o}^{\circ}$, vapeur, oxa$\pi \dot{\varepsilon} \omega$, voir). Synonyme inusité d'atmometre. Voyez ce mol.

ExGENTHiCIT: , s. f., excentricitas; Ekccntricitiit (all.); eccontricity (an.) (ex, en dehors, centrum, centre). Les astromomes donnent ce noin a la distance du solcil au point central de l'ellipse que décriveut les planètes et les comc̀tes, dans leur révolution autour de lui. En botanique, on appelle cxcentricité des couchcs ligneuses, la disposition ordinaire des tiges des arbres qui fail que la moelle occupe rarement le contre du bois, dont les eouches conentriques sont en grénéral plus larges d'un côté que de lautrc.

EXCAVE, adj., excavalus; qui offre un crcux, une exeavation. Les filets des étamines du Clauscna excafata sont élargis et creusés à leur partie inférieure, qui enveloppe l'ovaire.

IXCENTRIQUE, adj., cxcentricus. Op donne cette épithète, cn botanị 
que, à l'owaire, quand il n'oeeupe pas le eentre de la fleur, mais se trouve placé sur le côté du placenta, et ì l'embryan, lorsqu'il s'éloigne seusiblement du eentre du périsperme, dans lequel.il est tout-à-fait renfermé (ex. Cyclamen curopaum). Les physiejens disent qu'il $y$ a choe exeentrique quand les corps ne se meuvent pas sur une même ligne qui joigne leur eentre d'inertie.

EXCENTnOSTOMEs, adj. et s.m. pl., Execntrostomata (हैं , hors de, xévтрo\%, eentre, cróvex, bouche). Nom donné par Blainville à une famille de l'ordre des Echinodermaires éehinides, comprenant ceux de ees animaux dont la bouehe, au lien d'être au centre du corps, se rapproche plus ou moins de son extrémité an. térieure.

EXCIPIENT, adj. et s. m., excipiens (excipio, reeevoir). Autrefois ce mot était, en chimie, synonyme de dissolvant.

EXCIPULE, s. f. , excipula. On appelle ainsi de petites verrnes qui, dans eertains liehens, sont formées par le thalle, et pereées d'une étroite ouverture. Ex. Trypethelium.

EXCHULITOHuE, adj., cxcipuliformis (excipula, vase, forma, forme); qui a la forme d'une coupe (ex. Lyeopcrdon excipuliforme). Synonyme peu usité de cyatiformc.

ExGTABLITR, s. f., cxcitabilitas; Reizbarkeil (all.). Taeulté dont. les corps organisés vivans sont doués d'entrer en aetion lorsqu'ils viennent à recevoir l'impression d'une eause stimulante.

ExCITATELin, adj. et s. m., cxcitator; Auslader (all.). Instrument de physique à l'aide duquel on parvient à décharger un appareil électrique, sans craindre de reevoir ancune cominotion.

Excontî́, adj., cxeoriatus. (ex, sans, corium, peau); qui n'a pas de penu. Lc Coccoloba excoriata est ainsi appelé paree que son écoree est tellenent fine qu'il paraît ne point en avoir; l'Agaricus excoriatus, paree que l'épiderme de son ehapeau est si adhérent, qu'il semble en être dépourvn.

EXGRibuENT, s. m., exerementum, excretum; Ausleerungen (all.) (cxeerno, séparer). Ce not exprime, dans un sens général, tout ee qu'un corps organisé rejette au dehors, et, dans une acception plus restreinte, les rćsidus de la digestion, ehez les animaux pourvis d'un eanal alimentaire.

Exchítion, s.f., excrctio; Ausfültring, Auslcerung, Arussonderung (all.) (excerno, séparer). Aetion par laquelle un organe ereux se débarrasse des matieres qu'il contenait et qui s'y étaient aceumulćes; produit de cetle aclion.

ExchítomE, adj., excretorius; ausführend (all.). Épithète donnéc aux organes qui préparent eertains liquides destinés à sortir des corps organisés vivans, et à ceux qui eondnisent ees liquides au dehors.

EXFOLLTION, s. f., exfoliatio ( $c x$, de, folium, feuille). On employe ce terme quand il s'agit d'exprimer qu'une partie se détache de la surface d'une autre par feuillets desséchús.

Exhucssé, adj., sublatus. Épithčte dounée par Mirlsel à l'ovaire, quand il s'anincit en une cspèce de support (ex. Colutca arborescens), ou lorsqu'il est porté sur un véritable support (ex. Silene Armeria).

EXOCHNATES, adj. et s. m. pl., Exochnata ( ${ }^{*} \xi_{\xi} \omega$, hors de, qudं $\theta 0 \varsigma$, nuâhoire). Nom donné par Fabricius à un ordre d'inseetes, comprenant eeux qui ont plusieurs mâchoircs en dehors de la lìvre.

EXODERVE, subst. m., exaderna

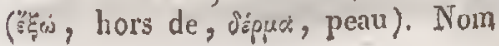


donné par Kirby à la croûte extérieure du corps des insectes.

EXOEME, s. m. , exocmum (है hors de, oiuxis, sortir). Sous ce nom, L.-C. Rielrard désignait denx petits firsceaux de poils qui semblent quelquefois former un vertieille, ou deux petites éminenees rarement prolongées comme de trìs-petiles paillettes, au sommet du support de la glume, dans plusieurs graminces.

EXOGENE, adj. , exogenus ("̈̌s, hors de, ๆ:́vycw, engendrer ). Nour donné par Candolle aux végétaux dont les vaisseaux sont comme épars dans la tige, et disposés de manière que les plus anciens, c'est-ì-dire les plus durs, occupent la cireonférence, et que l'aceroissement principal a lieu par le centre.

EXOGYNE, adj. , cxogynus (ह̌ॅॅ, dehors, gurr, femme); qui a le style saillant hors de la lleur. Ex. Bouvardia exogyna.

Exovní, adj. , exundalus. On s'cst servi de ee mol pour désigner les parties du grlobe terrestre qui font saillie au-dessus de la surface des eanx.

ExOvGutaulí, adj., cxunguiculatus, muticus; ungenagclt (all.) (cx, priv, tenguis, ongle). Epilhète donnée par liltiger aux doigls des mannmiléres, quand ils ne sont point garnis d'ongles.

EXOPTILE, adj., exoptilus ("žs, hor's de, $\pi \tau i$ iov, aile). Lestiboudois donne cette ćpithètc aux végétanx et aux embryous dont la geenmule est libre, c'est-it-dire n'est point renferMiéc dans la cavité cotylédonnaire.

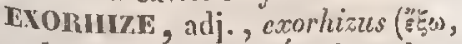
bors de, pičx, racine). Fipithète donnée par L.-C. Richard aux plantes dont, à l'époque de la germination, la radicules alonge parson extrémité, comme le font les racines pendant le cours de la vie, ct ne pousse qu'assez. tard des radicules latérales. Richard. exprimait par lì que ces végétaux out une radieule pour ainsi dire saillante et développéc.

EXOSUIOSE, s. f. , cxosmosis (हूँ hors de, Giruris, impulsion). Impulsion du dedaus au dehors. $V_{0 y} \circ z$ EnDosmos:.

ExOSPories, adj. cl s. m. pl., Exosporii ( $"$ हैँ menec). Nom donué par P(rsoon à une classe de elımpigunons, comprenant ceux dont les spores sont contenues dans un réeeptacle qui s'ouvre à l'époque de la malurité.

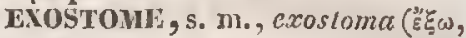
hors de, orópe, bouche). Nonı donné par Mirbel á l'ouverture dont est pereée la partie de l'ovule qu'il appelle primine.

CXOSTYLE, adi., exostylus (

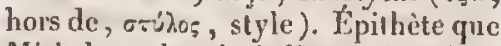
Mirbel employait jadis, mais qu'il a rejetée depuis, pour désigner les périearpes qui se divisent en plusiezrs parties sur lesquelics il ne reste aucune trace de style. Ex. Labices.

EXOTILALASSIBIE, adj., exothalassibius ( mer, Pios', vie). Lipithète donnée par Gualtieri aux coquilles qui ne sont pas marines.

FXOTIQuL, adj., cxotictes, ex-

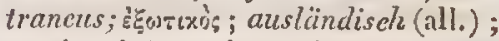
esolico (it.); qui est étranger, qui vient des pays étrangers. Ex. Cardium cxoficum.

ExoTn cube, s. f., exotrachea

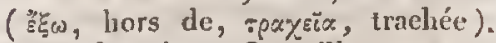
Nom donné par Latreille aux trachécs qui, dans quelques larves aquatiques (ex. Cyrinus), parcourent, en forme de veines anastomosées, l'intérieur de divers appendices, ou nageoires latérales, ๆu'on appelle fausses branehies.

EXPARSIBHITt, s. f., expansibilitas; Ausdehnsamkeit (all.). Faculté de se distendre par l'effet d'une cause quelconque. On employe sur- 
tout ce thot lorsqu'il est question de gaz.

EXPANSIBLF, adj. , expansibilis ; ausdehnsam (all.) (expando, étendre); qui est doué d'expansibilité.

EXPANSIF, adj. , cxpansious; qui est susceptiblc de s'éteridre.

expaNsion, s, f., expansio; Ausdehnung (all.); espanzione (it.). Etat de dilatation d'un corps doué d'expansibilité.

EXPIRATION, s. f. , expiratio; Ėхтуй; Ausalhmon (all.) (ex, hors de, spiro, souffler). Expulsion de l'air qui a été introduit dans l'organe respiratoire.

EXPLOSIF, adj., explosivus (explodo, chasser en poussant). Les physiciens nomment distance explosive le plus grand intervalle qui, dans un milieu quelconque non conducteur, puisse se trouver entre deux corps dont l'un sonlise le fluide électrique de l'antrc par une étincelle, laquelle n'a plus lieu au delà de cette distanee.

EXPLOSION, s. f., eruptio. Mouvement impétucux, et aecompagué de bruit, qui a lieu quand un corps, s'enflammant tout à coup, produit un dégagement considérable de gaz qui déplacent violenment lous les corps gazeux, liquides et solides euvironnans.

EXPRESSION, s. f., expressio; Auspressen (all.) (ex, hors de, premo, presser). Opération par laquelle on sépare, au moyen de la pression, un liquide interposé cnlre les particules d'un corps solide; manière dont les impressions que nous reccvons du dehors se peignent dans tout notre extérieur, et notamment daus les traits du visage.

EXSCUTELLE, adj. , exscutellatus. Epithc̀te donnćc par Kirtsy i tout. insecle dout on n'aperçoit pas le seutellum, qui est couvert par le prothorax. Ex. Copris.
EXSERT, adj., exserius ; herausgeschoben (all.). I.-C. Richard cmployait ce terme pour désigner, dans les plantes, toute partie qui fait saillie an dehors de celle par laquelle cllc est contenue, ou qui dépasse les parties environnantes en longuenr ou en hauteur; il s'applique surtout aux éramines. Ex. Morinda exserta, Vouapa staminea, Ribes stamineum.

EXSERTION, s. f., cxsertio. Candolle propose, avec raison, de substituer ce mot à celui d'insertion, dans la langue botanique, parce qu'il s'agrit loujours d'organes qui se séparent ou qui saillent d'une lıase commune, et non d'organes qui s'implantent sur d'autres ou s'ajoutent à eux.

ExSTIPULAÉ, adj., exstipulaecus; afterblatılos (all.) (ex, priv., stipula, stipule). Se ditd'unc feuille qui u’a pas de stipules.

EXSTIPULAIRE, adj. , exstipularis; qui n'a point de stipules. Ex. Sida exstipularis.

ExSTIPuLl, adj., exstipulatus; afierblattlos, nebenblattos, nacktwinklig (all.); qui n'a pas de stipules. Ex. Calythrix exstipulatus, Pelargonium exstipulat $m$.

EXTENSIBILITÉ, s. f. , extensibilitas; Ausdehnbarkeit (all.); cxtensiveness (angl.) ; stendibilità (it.). Propriété dont jouissent eertains eorps de s'élendre lorsqu'on les souniet it l'action simultanéc de denx forecs agissant sur cux en sens contraire.

EXTEXSIBLE, adj., extensibilis ; ausdchnbar ( all.); siendibile (it.); qui est susceptible de s'étendre, de s'alonger.

EXTENSILINGLE, adj., extensilinguis (extensus, étendu, lingua, lancrue ). Eppithète donnée par A.-F. Harvorth aux reptiles sauriens qui, ayant des palles de longueur ordinaire, ont aussi la faculté de tirer la languc hors de la ljouche, commele lézards. 
ExTínIEUR, adject., exterior; iusserlich (all.) ; external (angl.); esterno(it.). Épithète donnéc à l'conlryon végétal, quand il cst siluć, dans la griaine, à la surfacc du périsperme. Ex. Graminces.

EXTERIEURs, adj. el s. m. pl., Extera. Nou donné par E. Eiehwald à un ordrc de la elasse des Grammazoaires, qui compreud les vers exterites.

EXTERNA; adject. , cxlernus. Ises botanistes appellent houton externe relui qui fint suillic au dehors dès quil eommenec à se foruncr. Ex. Syringa vulgaris.

ExTERvo-MídaL, adj., cxterno-medialis. Épithète donnéc par Kirby à la troisième priucipale nervure de l'aile des insectes.

EXTHA-AXILIAInE, adj. , extraaxillaris; estrascellare (it.) (crtra, en dehors, axilla, aisselle). Se dit d'un bourgreon ou d'unc fleur, quand, au licu de maître de l'aisselle des feuilles, il preud naissanee au dessus ou hors de ce point. Ex. Vitis vinifera.

EXTIRACRESCENT, adj., cxtracrescens; qui croît ou se développe en dehors.

ExTraCTIF, adj. ct s. m. (cxtraho, rclirer). Nom donné pal Vauquelin à unc substance qu'on suppose cxister dans toules les plantes, êlre commune a tnutes, ct posséder la propriélé de s’épaissir pendanl l’évaporalion de sa dissolutiou.

ExTRACTHOLME, adj., cxtractiformis; qui a la forme ou l'apparence d'un extrait; masse cxtractiforme.

ExTRADILATE, adj. , cxtradilatatus. Épithète donuće par H. Cassini aux squames du périeline des Syunnthérées, lorsquelles sont disposées sur plusieurs rangées, et que les exléricures sont plus larges que les intérieures.
RXTRAFOLraci, adj. extrafoliaceus; estrafogliaceo (it.). Epithète donnéc aux stipules, lorsqu'au lien d'ètı placées sur les feuilles ou sur les pétioles, elles naissent sur les liges ou Irs rameaux. Ex. Jegrumineuses.

LXTMA FOLI', adject. extrafoliatus. Épithète donnéc par Mirbel a lit hampe, lorsqu'elle nait, sur la racine, d'un puint autre que colui qui donne maissance aux feuilles. Ex. Limodorum purpureum.

ExTRAIRL, adjeet., cxirarius. I,-C. Richard donne ectle épithète ì l'cmbryon végétal, quand il est silué au dehor's du périsperme (ex. Dianlhées). Suivant Raspail, ccltc nudité de l'cubryon n'est qu'unc illusion provenant de ec qu'ume portion du sac perispermalique, phos eomprimé d'un côlé que de l'autı'c, s'est plus infiltréc du eôté de la noindro pression, et que l'autre côté, rédnit it l'ćlat d'une simple pellicule, ad hìre quelquelois en entier contre la paroi col'respondante du test.

EXTRAOCURAIRE, adj ., cxtraoctlaris. Se dit des antennes des insectes, quand elles s'insèrent cu dehors des yeux. Ex. Noloncete.

ExTRAVERTíbr:, adj., ex/ravertebratus. Synonyme d'invertébré, dans lc système de Gcoffroy SaintHilaire, qui admet que, chez les imimaux articulés, le squelctce est cxlćricur, au lieu de nc point exister, conme le pensent la plupart des natura!istes.

EXTRAXILI. AIRE. Voyez ExrmaaxilzaiRE.

EXTIROLSE, adject. , cxirorsus; auswärtsgehend (all.). Eppithìte donnée par Richard aux antheres, lorsqu'elles se dirigent en dehors (cx. Iris). R. Brown l'cmplace celte épithete par calle de posticus.

EXUVIABLE, adject, , cxuviabilis (cxuo, dépouiller). Sc dit, en zoolo31 
gie, de tout animal qui mue, e'csta-dire qui change de peau sans prend re une autre forme, comme les serpens et les araignécs.

EXUVIabiLIT:, s. f., exuviabilitas. Faculté dont certains animaux jouissent de changer de peau, sans changer de forme.

EYY,AIDES, adj. ct s. m. pl., Eylaides. Nom donné par Leach à une famille de la classe des Arachnides, ¡ui a pour type le genre Eylais.

\section{F.}

FACE, subst. f. On appelle ainsi : $1^{\circ}$ en bolanique (pagina; Flïche, all.), les deux surfaces d'une feuille plane; en zoologie (facies, vuluzus,

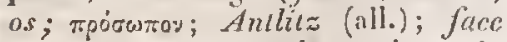
(angl.); faccia (it.), lat partic antérieure de la tètc des mammifères, celle ou s'ouvrent les organes des sens. Dans les oiseaux, on donne ce nom à l'cnsemble des régions ophthalniques, des joues et des lempes, en y comprenant souvent le front, le vertex et les tempes. Kirby applique celte dénomination, dans les inscctes, à toutes les parties situécs enlre le labre ct sa jonetion avec le prothorax; Robincau-Desvoidy à la région qui s'étend plus ou noins verticalement de la base des antennes à l'épistome, et transversalcment d'un oeil à l'autre, ce que les auties entomologistes nppellent heppostome.

racícibies, adj. et s. f. pl., Facclidea. Nom donné par Lessing á une sous-tribu de la tribu des Mutisiacées, qui a pour type le genre Facelis.

FACETTE, s. f., latusculum. On appelle sinsi, en minéralogic, les plus petites faces des cristanx, cclles dont la présence ou l'alsenec n'altère pas sensiblement la forme générale; ent zoologic, les lentilles diverses et nombreuses qui sont scmécs à la surface de l'ocil des insectes, et. à chilenue desquelles correspond un filet du nerf optique. Tes yenx de ces animaux sont dits a facelles ( Nolzaugen, all.).
FACIAL, adject. et s. m., facialis (facies, face); qui appartient ou qui a rapport à la face. L'angle facial est un angle plus ou moins aigu que forment ensemble deux lignes idéales, dont l'une passe par le méat auditif et vient toucher à l'cxtrémité antérienre du bord alvéolaire de la mâchoire supéricure, tandis que l'autre, partic de ce dernier point, serait tangente à la partie la plus saillante du frout. Robincau-Desvoidy nomme faciaus deux pièces de la face des Myodaires, qui partent de la base des anteunes, longent le bord de la firee, et portent différens cils.

MaCrEs, s. f. Mot latin, que Linné adopta pour cxprinicr l'ensemble des fornies et des caractères extérjeurs dont on cst frappé au premier coup d'ocil jelć sur un corps naturel, et que l'usage a consaeré dans notre langue. Ce mot est synonyme, ou à peu près, de port en botanique, et de physionomie en zoologie.

FaCule, s. f. , facula. Les astronomes appellent aiusi des points plus lumineux ou plus brillans que les autres qu'on remarque sur le disque du Solcil.

FACULTh, s. f., facullas; dúse-

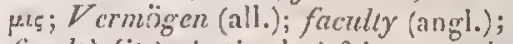
facollà (it.). Aptitude is faire ou opérer quelque chose, qui est inhérente à un corps, el qui sulssiste cu lui tant que la disposition des parties qui $y$ donne lien se maintient. Faculıales, dit Cicéron, sunt aut quibus facilius 
$f t$, aut sine quibus aliquid confici non polest.

FAGICOLE, adj. fagicolus f fagus, hêtre, colo, habiter); qui vit cu eroît sur le hêtre, eomme le Spharia $f a$ gicola sur les feuilles sèehes de cet arbre.

FAGOPYMINÉEs, adj. ct s. f. pl., Fagopyrince. Nom donné par Bartling a une classe de plantes, qui a pour type le genre Fagopyrum, et qui renferme les familles des Polygonées et des Nyclaginées.

FAILLE, s. f. (de l'allemand fal$l_{c n}$, tomber). Fissure de séparation, perpendiculaire ou très-fortement inelinée ì eelles de stralification, gुu'on désigne sous ce nom parce qu'ellc détermine une chute on un dérangement brusque dans la marehe des eouches minérales.

FAM, s. f., fames, csuritio, csu-

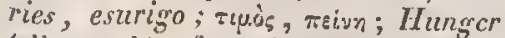
(all., angl.); fame (it.). Besoin d'introduire des alimens solides dans l'estomác.

FAISCEAU, s. m., fasciculus, fascis, fascllus. Les botanistes appellent ainsi un assemblage de fleurs serrées les unes contre les autres, dont les pédienles, courts ct droits, partent du méme point et s'ćlc̀vent à peu près à la même liauteur ( ex. Diantlus bar-

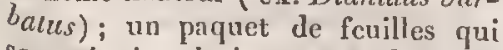
sont réunies plusieurs ensemble dans une même gaîne (ex. Larix); chaque paquet d'étamines soudées par leurs filets, dans les plantes polyadelphes.

Farte, s. m. , juga, fastigium; Gipfel (all.); summil (angl.); fustigio (it.). Ligne droite, eourbe ou brisće, que l'on imaginerait à la jonction des points les plus élevés des deux vorSans d'une chaîne dc montagnes, et Yu'on suppose ordinairement traverser eelle-ei dans lc sens de sa longueur.

FALAISE, s. f. Escarpement des eôtes; eontrc lequel la mer vient battre avec violencc.

FALCIFines, adj. ct s. f. pl., Falciferce (falx, faux, fera, porter). Nom donné par Debuch à une tribu de la famille des Ainmonées, comprezant celles dont les côtés sont garuis de plis eontournés en forme de faux.

TALCIFOLIÉ, adject., falcatus; sichelblïttrig (all.); qui a des feuilles faleiformes. Ex. Phyllanthus falcata.

FAICIFOR.ME, adj. , faleiformis, falcalus, falcarius, falcatorius ; sichclförmig (all.); falcato (it.) (falx, faux, forma, forme); qui a la forme d'une laux ou d'une faueille. Se dit: $I^{0}$ en bolanique, des feuilles (ex. Oncopleorus falcalus, Mesembryanthomum falciforme); des fruits, quand ils sont prolongés au sommet en unc longue corne eomprimée, courbće ct comme traneliante (ex. Ccralocephalies falcritus ; d des lćgumes (ex. Astragalus falciformis); des phyllodes (ex. Acacia falcata). $2^{\circ}$ En zoologie, d'un poisson qui a les nageoires en forme de faueille (ex. Monodactylus falciformis); d'un oiscau dout les ailes sont dans le même cas (ex. Anas falcaria); des ailes de eritains papillons (ex. Platrpterix falcataria); de l'abdomen de quelques ichneumons.

FALCIVELLES, adj. et s. m. pl., Falcati. Nom donné par Illiger à unc famille de l'ordre des oiseanx échassiers, eomprenant eeux qui ont le bec en faux.

FALGIROSTHE, adj. , falcirostris (falx, faux, rostrum, bec); qui a le bee (cx. Pyrrlula falcirostris), ou l'ume des mâtuloires (ex. Hydrocyon falcirostris) en forme de faueille.

FALCROOSTRES, adjeet. ct s. m. pl., Falcirosires. Nom donné par Schacffer, Vieillot, Panzani et C. Bonapartcà une famille d'oiseaux éehassiers, dans laquelle ils rangent ccux 
qui ont le hee en forme de fatucille.

FALCONIDEs, adj. el s.m. pl., Falconida. Non donné par Vigors et Lesson à une famille de l'ordre des Aceipitres, qui eorrespond à l'ancien genre Falco de Linné.

Falcoxiss, adj. et s. m. pl., Falconina. Sous ee uon Vigors désigne une tribu de la famille des Falconides, qui renferme le gense Falco.

FALCULAInE, alject. , falcularis (falcula, faueille). Illiger donnait cette épithète anx ongles qui sont alongćs, comprinés on un peu arrondis, atténués, et implantés sur le côté supérieur de la phalange onguéale.

FALCULE, adj., falculatus; krallcnfürmigr. Sc dit d'un doigt qui est garni d'un ongle faleulaire.

FaLcuLís, adj. et s. in. pl., Falculata. Nom donnć par Illiger ì un ordre de la famille des Mammifères, coniprenant eeux qui ont les patteả arnées de griffes, ou la plupart des Car'nassiers des autres autenrs.

paloú, adj., falcalus ífal.x, faux). Mirbel applique cette épithète aux cotylédons, lorsquu'its sont alongés et courbés conune le fer d'unc faux ou d'une serpette (ex. Fygiceras majus), et à la lcure supéricurc d'une corolle labiec, quand elle est dans le même cas (cx. Salvia pratensis).

FALSINERVE; adj. , falsincrvis (falsus, faux, nersuls, nerf). Épithète donnée par Candolle aux feuilles dont les nervures n'ont pas de vaisseaux, et sont composées de simple tissu eellulaire, eomme dans les Fucus.

ralun, s.m., Muscluclerde (all.). Terrain meuble et sablonneux, principalement eomposé de coquilles et autres corps marins, brisés cull grande partie, et ayant peu d'adhérence entr'eux.

Favon, s. m., palearia laxa; mammen (all.) ; dewlap (angl.); paglinlaja (it.). Pli de la peau du bouf qui pend à la partie anlérieure du col et de la poitrine; touffe de poils lougs et forts, qui naissent à la partie postérieure et inférieure du boulet, dans le cheval; assemblage de lames cornées qui garnissent trunsversalement le palais des baleines, et qu'on a regardées à tort comme ses dents, parce qu'elles en tiennent lieu, car Geoffroy Saiut-1Iilaire a trouvé de vérilables dents dans les máchoires; paire de earoncules situées sur les côtés ou à la base de la mâchoire inférieure, dans quelques oiseaux; repli cutané, en forme de goître, qui pend sous la gorge de quelques reptiles sauriens.

FARINACÉ, adj., farinaceus; qui est d'une substance friable et suseeptible de se réduire en farine par la trituration, comme le périsperme des Graminées. On donne cette épithète à des plantes qui sont, ou couvertes d'une poudre blanche (ex. Pcziza. farinacea), ou parsemées de tubereulesfarincux (ex. Pliyscia farinacea ), ou entièrement pulvérulentes (ex. Polyportus farinellus).

FAnIVAL, adj ., farinalis (farina, farine); qui se nourrit de farine, comme la larve de la Phalcena farinalis.

FARrveux, adj., farinosies; mehligg (all.). Ce mot, qui a la même signifieation que le précédent, est eimployé conune épithète pour désigner des plantes qui offrent une poussière blanchâtre, semblable à de la farine, sur leurs rameaux (ex. Loranthus farinosus), lenrs feuilles (ex. Cadaba farinosa, Combretum farinosum), ou leurs graines (ex. Phaseolus farinosus). En zoologic, il désigne quelquefois des aninaax qui se nourrissent de farine, conme la chenille du Crambus farinalis, mais plus soureut des animaux lont le corps est couvert d'une poussicre fa- 
rinaece, eomme le corps de la femelle du Coccus farinoszes, ou les élytres du Melolontha farinosa. En minćralogie, la haryte sulfatce terreuse a été appclée spath farincux, parce qu'elle ressemble à de la farine.

FASCIATION, s. f., fasciatio ; Breitwerden (ali.) (fascia, bande). Conformation vieieuse des branches, pécloneules et pélioles, lorsqu'ils prennent l'aspeet d'expansions fascices. Voyez ce mot.

FAsciculaIDE, adj., fascicularis (fasciculus, faisecau). Ce ierme est quelquefois employé comme synonyme de fasciculd. On nomme réscrvoirs fascicnlaircs, des faisceanx de petites cellules tubulées, parallèles, ct pleines de sues propres, tels que cenx qui se trouvent dans l'écorce des $\Lambda$ pneynées.

FASCICULE, s. m., fasciculles; Bïschel (all.); fascicole (it.). A quelques léggìes différcur'es près, Linné, Willdenow, Candolle, Hayne et Link définissent ce terme un assemblage de fleurs serties les unes contrc les autres, et arrivant presque au même uivean, dont les pédoneules courts partent du mème point, ou ì peu près (ex. Dianthus Larbatus). Pioeper définit le fascicule un mode d'inflorescencc eonsistant en une cyme génćralc dont la fleur centrale a avorté, et qui se divise en plusieurs branches latérales, les unes dichotomes à la base, les autres simples, et à flcurs toutes latérales par l'avortement des pétioles seeondair's, mais où ees deruières sont très-courtes, de sorte que les flenrs se trouvent agglomérécs ensemble.

FAScrCuLí, adj. , fasciculatus, fascicularis; büschelartis, biuschelförmig (all.); affustcllato (it.); qui est réuni en liviscentu. Candolle appelle fouilles fasciculées, celles yu: paraissent naître en faisceatix, so.t qu'étint conposées elles aicut leur pétiole eommun si court qu'elles semfllent provenir d'une mème base (ex. Aspalathus), soit que la véritable feuille avorte en tout ou cir partic, et que le rameau qni se développe í son aisselle, reste très-court et chargé de petites fenilles (ex. Bcrbcris). D'autres botunistes appellent fcuilles fasciculics eclles qui partent ensemble d'un même point (ex. Larix), ou celles qui forment des touffes épaisses (ex. Dicranum fasciatum, Leskin fasciculosa, Darrsina fascicularis). On nomule fleurs fasciculies celles qui viennent en grappes serrées (ex. Mahonia fascicularis, Canthium fasciculatum); ćpines fasciculces, celles qui proviennent d'un mème point (ex. Cactus cylindricus) ; ramcaux fuscicrelćs, eeux qui sont trèsserrés les uns contre les autres ( $\mathrm{ex}$. Racomitrinm fascicular', Leskia congcsitu); racincs fasciculces, celles qui sont divisćes jusqn's̀ la hase en plusicurs parties alongcese, qui, par leur rapprochement, forment une espèce de filiseean (ex. Raninculus fascicularis). Les zoologistes disent le corselet fasciculé, dans les insectes, quand il cst garni de poils ramassés en forme de houppe (ex. quelyue Buprestes). L'Hystrix fasciculata est ainsi appelé paree qu'il a la queue termince par un faiseeau de lanières cornées aplaties.

vASClÉ, adj., fasciatus, fascialis, fusciurins, fasciolaris, fasciolatus; bandförmig (all.) (fascia, hande). On emploie cc mot: $1^{\circ}$ en botunique, où il signifie aplati cn forme de bandelelle. Candolle appelle expansions fasciécs, des branches, des pédoncules, des pétioles dont les fibres ou nervures, au lieu de former un corps cylindrique, ou environ, restcut presque parallèles, convergentes on divergentes vers le sommet, mais a peu près simples, de maniçre a produire unc surface plane, disposi- 
tion naturelle dans le $X$ ylophylla, et accidentelle dans beaucoup de plantes, entr'autres dans les Asparagus. $2^{\circ}$ En zoologie, où il signifie chargé d'une bande ou ligne large et colorée (ex. Blennius faseialus, Mactra fasciala, Ccrilhium fascialum, Plcuroloma fascialis, Putrpura fasciolaris, Zuphium fasciolalum, Coryphana fasciolala, Campaca fasciaria).

FASCIPENIE, adj., fascipennis (faseia, bande, penna, aile); qui a des ailes faseiées, comme cel'es du Limenobia fascipennis, sur lesquelles on voit quatre bandes d'une teinte plus foncée.

FASTIGIÉ, adject., fastigialus ; gleichhoch, gegipfelt (all.); fastigated (angl.). Se dit d'une plantc dont toutes les liranehes se rapprochent de la tige, en sorte que les rameaux pointent vers le eiel. Ex. Powlus fastigiata.

FAUNE, s. f. , fauna. Tableau des animaux qui vivent dans une contrée. Ce titre, donné à plusieurs ouvrages, est tronipeur ou abusif, en ce qu'on n'y traite sourent que d'une partie de la zoologic, ou mêne d'un seul ordre d'animaux. Ainsi la Faune de Sucde, par Paykull, n'a pour objet que les colćoptèrcs, et celle de 'Toscane, par Mossi, ne traite que des insectes.

FAUMIDES, adj. et s. f. pl., Fannidoe. Nom douné par RobineauDesvoidy it une section de la famille des Myodaires calyptérées, comprenant des especes dont les latrves vivent presque toules rlans les chenilles.

FAUSSES_HĹPATIQUES, sulst. f. pl., Hepaticas spurice. Nom donné par Fce ì une scetion de la famille des Lichens, qui ne renferme que le genre IEndocarpon.

FALSTULi:Ls, adj. et s. f. pl., Faustulcee. Non donné par H. Cassini à un groupe de la section des Inulées gnaphaliées, qui a pour type le genre Faustule.
FAUVE, adj. , fulous; roltgelb; röthlichgelb (all.); fallow (angl.); fulvo (it.). En tcrme de vénerie, béles fauves est une dénomination collective qui embrasse les eerfs, les daims et les ehevreuils. Fauve se dit d'un corps dont la couleur est rousse ou roussâtre (ex. Misus fulvas, Silvia fulva, Ozonium fulvum, Eurybia fulvida, Mactra helvacea, Cytherca chione).

FAUX, adj., falsus, spurius; falseh (all.); false (angl.); falso (it.). On employe ce terme : $1^{\circ}$ en chimie. C. Pauquy appelle faux oxides tous les composés qui, jonant le rôle de liaseà l'égard des acides, remplissent quclquefois eelui d'acide faible et très-imparfait envers quelques oxides. $2^{0}$ En bolauique ; fausses cloisons, celles qui sont formćes par un simple amas de tissu cellulaire ( $\mathrm{ex}$. Chelidonium glaucium); fausses lo. ges, d'après Candolle, certaius vides qui se trouvent dans quelques fruits, et qui ne renferment pas de graines, non par avortement, mais par leur nature propre. Candolle range dans cette ca tégorieles cinq vides extérieurs du Nigclla damascena, dus à ee que l'épicarpe se gonfle pendant la maturité, de manière à rompre la mésoearpe et à s'en écarter : le eas où les earpellcs, au lieu d'attcindre à l'axe, laissent un vide au centre; celui où il s'en forme un entrc les loges, quand les faces rentrantes des carpelles ne sont pas soudćes intimement ensemble; ceux qui se forment sur les côtés des valves, quand celles -ci sont renflces (ex. M1 yagrum); ceux qu'on obscrve au sommet du pedicelle, ou dlins l'axe, lorsque eclui-ci est fistulcux; cenx gu'on voit is la base du style, quand cettc base est elle-mêne fistulcuse. Fausses nervures, d'après Candolle, celles des feuilles qui n'ont pas de vaisseaux, et dont les nervures appa- 
rentes sont produites par un simple tissu cellnlaire alongé (ex. Fucus); fausse ombelle, on eorymbe (voyez ce mot); faux ovaires, d'après II. Cassini, l'ovaire demi-avorté et inovulé qu'on trouve très-souvent dans les flcurs mâles et le's fleurs neutres des Synanthérées; fausses parasites, d'après Candolle, les plantes qui végètent sur d'autres plan. tes vivantes on mortes, mais sans vivre à leurs dépens, comme les lichens, les mousses, les Epidendrum; fausse silique, d'après Monch, celle qui a des graines altachées aux bords de ses valres; fausses trachées, d'après Mirbel, les vaisseanx anuulaires, on rayés; faux verlicille, un mode d'inflorescence dans lequel les pédoneules partent sculement de deux côtés opposés, mais on les fleurs, plus ou moins nombreuses, se portent à droite et à gauche, et forment uu anneat autour de la tige ou de la branche (ex. Phlomis tuberosa). $3^{\circ}$ En zoologie, fausse aile, ou aileron (voyez ce not); fausse chenille (suberuca), nom sous lequel on désigne les larves a luit, dix-luait et vingt-deux paltes, ì eause de lcur ressemblance avee les elonilles (ex. Tenthredo): fausses coquilles, celles qui n'appartiennent pas à des mollusques, et qui sont composées d'un grand nomlire de petits polygones appliqués les uns à côté des autres, dont l'enscinble forme une enveloppe caleairc dure el eassanic (ex. Oursius ) ; faux écusson, ou arrièreécusson, uu pelit espace carré que présentc, daus quelques diptères, le milieu du inćtathorax ou segment portant les ailes inférieures; fuusses nagcoires, appendices cutanés, remplis de graisse, et non supportés par des rayons osseux, qu'on voit sur le dos de certains poissons (ex. Saumon); parfois ausci des rayons détachés d'une nagcoire, comme les derniers de la seconde dorsale ct les correspondans de l'anale, dans les seombres; fausses ncroures, d'après Kirlby, celles, fort peu dislinetes, qu'on observe quelquefois en outre de culles qui existent ordinairenent (ex. Syrphtes) ; fansse nymplec ( pseudonymphu), d'après Lamarek, une nymple inactive, ne prenant pas de nourriture, nue, médiocrement resserrće on rnccourcic, et en général enfermíc dans un fourreau que le larve a faluriqué (ex. Plurygane); fausses pattes, d'apris Lamarck, de très petits appendices mamelonnés on peu saillaus, qui servent moins d'organes loconoteurs que de poinls d'ippai, dinns les Anuelides. On donue aussi parfois ee nom aux pattes antéricures de quelques lépidoptères diurnes, qui sont très-courtes, coudées, replićes, sans ongles, ct inutiles pour la marche. Dans les erustacćs, on l'applique à quatre ou cinq paires de petits appendices Icrminés chacun par deux lanes ou deux filets, et qui sont aunexés aux premiers anneaux de la quene, en dessous.

IACX-BONiBr, s. m. pl.,Pseudobombyces, Noetuo-bombycites. Nom donné par Latreille à une tribu de la famille des Lépidoptères nocturnes, renfermant ceux qui ressemblent aux bombyees sous ecrtains rapports et en diffèrent sons plusieurs autres.

paux-Cuantignons, s. m. pl: Nom donné par Fee à une scetion de la fanille des Liehens, dans laquelle il range ceux qui ont des apothécies arrondies cl clarnues.

FAUX-IIYPOXYLONS, s. m. pl: Nom sous lequel Fee désigne une section de lia fauille des Iichens, comprenaut ceux qui ont des aprothéeies linéaires.

FACx-SCORPIONS, s. m. pl., Pseudo-scorpiones. Nom donné par Lamarck, Cuvier et Iatreille ì unc familie de l'ordre des Arachnides 
trachéennes, renfermant ceux de ces animaux qui ressemblent aux scorpions pour la forme genérale du corps.

FA VÉOLÉ, adj. , favcolatus, fa. wosus; wabig, wabenartig, bicnenzcllig (all.) (favtes, alvéole); qui est garni de petites cellules à parois minces et adosscies les unes contre les autres.

FAVULEUX, adj., favulosus; zellig (all. ) ( favus, alvéole); qui est marqué de petiles cellules à la surfacc. Ex. Glyphis faulosa.

FÉCONDATION, s. I'., facuendatio; $B c$ fruchtung (all.); Secondazione (it.). Acte par lequel, dans les corps organisćs pourvus de sexes, le mälc innprime au germe les modilications ıćeessaires pour gue la vie puisse se développer en lini.

Fícondité, s. f., frocundilas ; feeonditì (it.). Faculté de se reprodnire; reproduction abondante.

FECurr, s.f., frecula, fcenla; $\tau p i \xi$ ( fax , lie). Synony me d'amidon, qu'on employe surtout en parlant de celui des poinmes de terre.

FECULOIDE, adj. , faculoüdens; qui ressemble à la fécule sous ccrtains rapporls, comme la substadce des lichens, laquelle, suivant Raspail, renferme la partie soluble de la fécule dans les tégumens qui refusent de $s$ 'isoler les uns des autres et restent emprisonnés, avant comme après l'ébullition, dans le tissu qui les engendre.

FÉDIACÉES, adj. ct s. f. pl., Fediacece. Nom donné par Caffin à la famille des Valérianćes, ì cause du genre Fedia, qu'elle renferme.

FELDSPATHIVonME, adj., feld. spathifornis. Epithètc donnée à une variété de stćtaitc, qui présente la forme d'emprunt du feldspath qunadriliexagonal.

FELDSPA THIQUE, adj. , jeldspathicus.' Se dit d'une roche dont le fcldspath fait la base (ex. Euphotide feldspathique), ou qui en contienl (ex. Alicaschiste feldspathique). Bonnard et Omalius donnent celte ćpithète à un genre de roches dont le feldspath est la partie constituante essentielle ou dominante.

FĹLIDES, adj. et s.m. pl., Felida. Nom donné par J.-E. Gray à une famille de Nammitères, qui a pour type le genre Felis.

FÉLivs, adj. et s. m. pl., Felir.x. Nom donné par Desmarest ì une famille de Mammiferes carnissiers, par J.-E. Gray i une tribu de la fafinmille des Fèlides, ayant le genie Felis pour type.

FEneLLE, adj. et s. f., famincus. Les bolanisies appedlent feur fomelle, eclle qui ne porte que des pistils. En zoologie, on appelle femelle I'individu d'une espèce ì deux sexes qui conçoit ct porle les petits.

Fumivifore, adj. , fominiRorus. Se dit, dans les Synanthérées, de la calathide et du disque, quand ils sont composés de fleurs femelles.

FÉnININ, adj., famininus; wcib. lich (all. ); feminino (it.); qui a rapport à la femne (sexc féminin). H. Cassini donne cette épilhète anx corolles de Synanthérées qui ne circonserivent que des organes femclles.

FÉuorat, adj. , femoralis ( $f c$ mur, cuisse); qui a rapport ou qui apparticnt à la cuisse ( plumes fómorales); qui a les cuisses remarquables par leur dilatalion, leur volume (ex. Ceratopogon femoratus, Cincliophora femoraia, Nymphon fcmoratum, Hyla fenoralis), ou par une goutticre dont elles sont ereusées (ex. Pcllinus femoralis).

FEMUIR, s. m. , femur. I.es entomologistes appellent ainsi la prenière partic des pattes des insecles, celle qui suit immédiatement la hanclic et porte la jambe. 
FENDILLE, adject., fissuratus; rimulosus; qui est muni d'une ou plusicurs petiles fentes longitudinales, Ex. Galerites fissuratus,

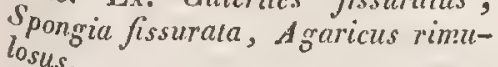

FENDU, adj., fissus, magradiolus; gespalten (all.); clefi (angl.); $f_{o_{s o}}$, spaccato, intagliato (it.). On enploye ce rool : $1^{\circ}$ en bolaniquc, pour désigner toute partie offrant une scissure médiane, plus ou moins profonde, dont les bords sont rapprochés; androphore fendu, colui qui est tubuleux et fendu dans sa longueur (cx. Polggala heisteria); calice fondu, celui dont chaque rayou, creusé en gouttière, représente une fente ou gercure (ex. Lampsana rhamadiolus); corolle fondue, d'après I1. Cassini, celle d'unc fleur de Symanthérée dont "incisure antéricure pénètre jusqu'ì la base du limbe, taurlis que les quatre autres sont extrêmement coultes (ex Lactuea); feuille fonduce, celle qui est incisée, mais a lnhes "L'oits; gaîne fendue, eelle qui ollre une solution de continuilé dans toute sa longueur (ex. Graminces) ; levere fendue, dans une cnrolle labice, quand elle est partagée en deux jus'u's moitié ( cx. Salvia bicolor); pórianlhe fendu, lorsqu'il offre des découpures étroites, qui égalent au moins sa moitic en longueur (ex. Tyacinthus) ; tissu collulaire fendu, apris Mirbel, celui dont les parnis présentent des raies trausversales, qui sont peut-çtredes fissures; tubc fondu the corolle mnuopétale irrégulic̀re, quand il est fendu longitudinalement "ne thanière qu'ou peut l'étendre en (ex. lame plane, sans le déchirer lex. Goodenia). $2^{\circ}$ Lin zuologie; on dit elles des insectes fendues, quand des présentent dis divisions profonpieds leurs bords. Illiger appelait dont fendlus, dins les oiscaux, eeux ćtroitement joints, ni réunis par une membrane.

TENESTRAI, adj., fenestralis ( $f c$. nestra, fenètre); qu'on trouve habiluellcment sur les carreaux de vitres. Ex. Latridius fenestralis, Sporotrieluum fencstrile.

FWNisTmí, adject., fencestratus, peritusus,; fenestcrartig (all.); qui est peré de trous d'un eertain diamètre, conmme les eolylédons du Menispernum fenestratum, les dents du péristome du Grimmia pertusa et du Dryptodon cribrosus, les fouilles du Dracontium pertusum, la silicule du Cochlearia fenestrata, dont la eloison oflre Je plus sonvent uue fente longitudinale; la surfaee de la Spongra fencstrata, qui cst irrégulièrentent erevassée, et les ailes de l'Allacrs allas, du Dasypogon fenestratus et de l'Anthrax fonesirella, qui offrent, uon des trous, inais des tachcs transparentes, simulint des trous.

FEMÈTE, subst. f., fonesira; Fenster (all.). Quclques botanistes ont donué ce nom an hile externe, à l'ombilic externe.

FENTT, s. f. , rima; Spalle (all.); slit (angl.); fessura. En géoguosie, on appelie ainsi des vides longitudinaux, plus ou moins larges, qui existent daus l'intéricur d'une roche ou d'un terrain, qui ont été ćvidemment produits, après la formation des masses minćrales, par l'écartement des parlies qu'on trouve disjointes, et qui ne peuvent être atttribués à nulle autre enusc.

FENT', adj., rimatus; qui s'onve jar wae fente.

INR, s. Ill. , forrum, Mars; oiónpos; Fisen (all.) ; iron (angl.) ; ferro (it.). Métal solide et d'un hlane pen éclatant, qui est connu de tozte antiquilé.

FERHATE, s. m., ferras. Ou pourrait appeler ferrate ferrique la 
combinaison des oxides ferrique et ferreux, dans laquelle le premier joue le rôle d'acide.

FERmiux, adj., ferrosus. Dans la nomenclature chinique de Berzelius, cctte épithète est donnéc à un oxide (protoxide de fer; Eiscnoxydul, all.), yui est le premier degré d'oxidation du fer; à un sous-sulfure (Achtelschwefeleisen, all.), qui cst ic premier degré de sulfuration de ce métal; à un sulfure (Einfachschwe(clcisen; all.), qui est le troisic̀me; aux composés résultant de la combinaison d'une certaine quantité de fer a vee unl corps halogène (ex. C'hlorurc ferreux), et aux sels (Eisenoxydulsalzcn, all.) produits par la com'binaison de l'oxide ferreux ou du sulfure ferreux avec les acides ou les sulfides.

FERMENT, s. m., fermentum ; ל̌̉un; Gährungsstoff, Gälırungsmittel (all.). Prćcipité insoluble, qui se produit dans le sue des fruits suerés, après qu'ils ont subi la fermentation, et qui jouit de la propriété d'exciter la fermentation dans les dissolutions de sucre pur.

FERMENTATION, s. f., fermen-

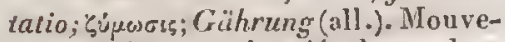
ment intérieur qui se dćveloppe dans un mixte, et dont les produits sont des corps jusqu'alors non cxistans. Les eonditions de ba formentation sont du sucre, de l'eau, une certaine températurc et une matière nitrogénéc, d'origine animale ou végćtale, le gluten de préférenee à toute autre.

FERMENTESCIBLE, adj. , fermentationi obnoxius; sührungsfähig (all.); qui réunit les conditions nécessaires pour culter en fermentation.

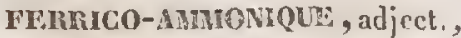
ferrico-ammonicus. Nou donné, daus la nomenclature chimique de Berzclius, à des scls doubles qui résultent de la eombjinaison d'un sel ferrique avec un sel ammonique. Ex. Chlorure fe:rico-ammonique (hydrochlorate de fer et d'anmoniaque).

FERRIC:O-ARGENTIQUE, adject., ferrico-argenticus. Nom donné, dans la nomenclature chinique de Berzelius, à des sels doubles qui résultent de la combinaison d'un sel ferrique avec un sel argentique. Ex. Cyanure ferrico - argentique (hydrocyanale de fer et d argent).

FERRICO-1BARTTIQUE, adjeet., ferrico-baryticus. Nom donné, dalls la nomenelature chimique de Berzelius, à des sels douliles yui sont procluits par la combinaison d'un sel ferrique avec un sel barytique. Ex.Cya nure fervico-barylique (hydrocyanate de fer et de baryte).

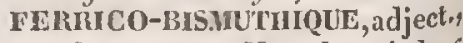
Serrico-bismuthicus. Nom donné, dans la nomenclature chimique de Berzelius, à des scls doubles qui sont te résultat de la combinaison d'un ${ }^{\mathrm{c}} \mathrm{l}$ ferrique avec un sel bismuthique. Ex. Cyanurc ferrico-bismuthique ( hy" drocyanaic de fer et de bismuth).

FERRICO-CALCIQUE, adj., fer" rico-calcicus. Nom donné, dans ta nomeuclature chimiqque de Berzelius" à des sels doubles qui résultent de ${ }^{\text {la }}$ combinaisou d'un sel ferrique aver un sel ealcique, Ex. Cyanure ferr co-calcique ( his drocyanate de fer de chau $x$ ).

FERRICO-COB.ALTIQUe, adject." ferrico-cobalticus. Non donné, dill ln nomenclature climique de $\mathrm{Bcr}^{2} e^{-}$ lius, à des sels doubles qui sont to produit de la combinaison d'un se ferrique avee un scl cobaltique. Ex. Cyanure ferrico-cobaltique (ly $d^{\prime r^{-}}$ cyanate de fer et de cobalt).

FERTCO-CEIVROUE, adject.! ferrico-cupricus. Nom donné, dan la nomenelature chinique de $\mathrm{Ber}^{2}$ lius, à des sels doubles qui résul(êl de la combinaison d'un sel ferriq ${ }^{10}$ avee un sel cuivrique. Ex. Cyanlt 
ferrico-cuiorique (hydrocyanate de fer et de cuivre).

FERrico-mYinioue, adj., $\mathrm{fer}$ rico-hydricus. Nom donné, dans la nomenelature ehrinique de Berzelius, à un surscl produit par la combinaisoll d'un scl halöde avec l'hyclracide du corps halogene. Ex. Cyanure forrico-hydrique (hydrocyanate acide de $f e r)$.

FERrico-nanganioure, adj. , ferrico-manganicus. Nom donné, dans la nonenclature chimique de Berzelius, à des sels doubles produits par la combinaison d'un sel ferrique avec un sel manganique. Ex. Cyanure ferrico-manganique (hydrocanate de fer el de manganese).

Feririco-nericuraloue, adj. , ferrico-mercuricus. Nom donné, dans ta nomenclaturc chimique de Berzelius, à des scls doubles qui doivent naissance à la combinaison d'un sel ferrique avec nn sel mercurique. Ex. Cyanure ferrico-mercurique (hydrograrate de fer et de mercure).

FerRrico-niccocroue, adject. ferrico-niccolicus. Nom donné, dans la nomenclature chimique de Berzelius, a des sels doubles quir résultent de la combinaison d'un sel ferrique avec un sel niceolique. Ex. Cyanure ferrico-niccolique (hydrocyarate de for et de nickel).

FERrico-rloxwioue, adject. , ferrico-plumbicus. Nom dunné, dans la nomenclature climique de Berzeins, à des sels doubles qui sont pro. duits par la combinaison d'un sel ferrique avec nin sel plomlique. Ex. -janue ferrico-plombique (hy drocyanale de for ot de plomb).

Ferarico-romsistem, alject. Ja nico-potassicrs. Nom domé, dins lius nomelature climique de herzeprod is des sels doubles qui sont produits par la combinaison d'un sel
ferrigue avec un sel polissique. Ex.
Tartrate ferrico-potassique (tartrate de potasse et de fer).

FERrico-sodrout, adj., forrico-sodicus. Nom douné, dams la no. menclature chimique de Berzelins, à des scls doubles qui résultent dé lit combinaison d'un sel ferrique avec un sel sodique. Ex. Cyanure ferrico-sodique (hydrocyanate de fer et de soude).

Ferrico-stanvioue, ndj., ferrico-stannicus. Nom donné, dans la nomenelisture chimique de Berzelius, a des sels doubles qui rćsultent de la combinaison d'un sel ferriqgue avce un sel stannique. Ex. Cranure ferrico-stannique (hydrocyanale de fer et d'élain).

FEnRiCo-TITANIQUF, adj., ferrico-titanicus. Nom donué, dans la nomenclature chimique de Berzelius, ì des sels doubles qui sont produits par la combinaison d'un sel ferrique avec un sel titanique. Ex. Cyanurc ferrico-titanique (hydrocyanate de fer et de titane).

FERrico-unanique, adj., ferrico-uranicus. Nom donné, dans la nomenclature chimique de Berzclius, à des sels donbles qui résultent de la combinaisun d'un sel ferrique avee un sel uranique. Ex. Cyannrc forricouranique (hydrocyanate de fer et d'urane).

FERAICO-VANADIQUE, adj., /errico-vanadicus. Nom donné, dans la nomenclature chimique dc Berzelins, à cles sels doublics qui sont produils par la combinaison d'un sel ferrique avec un sel vanadique. Ex. Cyamere forrico-vanadique (hydroejante de for et de vanadium ).

WTIMCO-zancrove, adj. , forrico-zincicas. Nom douné, dans la nomenclature climique de Berzelius, à des sels doubles qui résultent de la combinaison d'an sel ferrique avee un sel zincique. Ex. Cyanure forrico. 
zincique (hydrocyanale de for et de zinc).

FERRUDEs, subst. m. pl. C. Pauquy désigne sous ce nom une famille de eorps pondérables, qui a le fer pour type.

WGRnLÈnE, adj. , ferrifcrus ; eisenhaltend (all.); (forrum, fer, foro, porter). Se dit, en minćralogie, d'une substance qui contient accidentellement du fer, à l'état d'oxide ou de carbonate. Ex. Magnésic sulfatce ferrifere.

FEnRiove, adj., ferricus. Berzelius appelle oxide ferrique, lc second degré d'oxidation du fer (tritoxide de fer; Eiscnoyd, all.); sous-sulfure ferrique (Halbschwefeleisen, all.), le second, et sulfure ferrique (Anderthalbscluve folcisen, all.), le quatrieme degré de sulfuration de ce nétal; sels ferriques (Eisenoxydsalaen, all.), les combinaisons de l'oxide ferrique avec les oxacides, ou du fer avec une certaine proportion des corps halogènes.

FELho-ARSENIFthe, adj., forroarscniferus. Sc dit, en minćrnlogic, d'une substanec qui eonticnt accidentellement du fer et de l'arsenic. Ex. Argent antimonial ferro-arsénifère.

FERHO-CIMAZICUE, adj., forrochyazieus. On a appelé acide ferroehyazique l'aeide ehyazique ferruré, ou aeide ferro-cyanique, ou cyanure ferroso-ferrique.

FERRO-CYANATE, s. m. , forrocyanas. Scl produit par la combinaison de l'acide ferromeyanique avee une base.

FERRO-CYANIQUE, adj. , forrocyanicus, sidero-cyanicus. On a appelé acide forro-cyanique le cyanure ferroso-ferrique de. Berzelius.

FERRO-FUR.MINIOUE, adj. , forro-fulminictes. Licbiy croit it l'existenee d'un acidle ferro-fulminique, composé de fer nétallique et d'acide fuluinique.
FERR0-MavganESICN. $\mathscr{V}$. FenR-MAYGANÉSIFÉRE.

FERIO-MANGANESWFIn, adj., ferro-manganesiferus. Se dit, en minéralogie, d'une substanee qui eontient aceidentellement du fer et du manganèse. Ex. Chaux carbonatéc ferro-manganésiferc.

FEIRTO-PRUSSICUE, adj. , ferroprussiacus. Synonyme de ferro-cyanique. Voyez ce mot.

PERnoso-ALUMLNiQue, adj. , ferroso-aheminicus. Nom donné, dans Li nomenelature chimique de Berze lius, à des sels doubles qui résultent de la combinaison d'un sel ferreux ávee un sel aluminique. Ex. Cyantre ferroso-aluminique (lydrocyanalc do fer et d'alumine).

FERROSO-1MMONIQUE, adj. , ferroso-ammonicus. Non donné, dans la nomenelature climique de Burzclius, i des scls doubles qui ré sultent de la eombinaison d'un sel ferreux avec un sel ammonique. Ex. Sulfate forroso-anmoniqae (sulfale de fer et d'antmoniaque).

FERROSO_AhGLNTIQUE, adj.' frrroso-argenticus. Nom donuć, daus la nomenclature ehinique de Berzclius, à cles sels doubles qui sont produits par la combinaison d'un scl ferreux ivee un sel argentique. Es. Cyanure ferroso-argentique (hydro cyanate $d c$ fer etd argent).

FERLOSO-B.RTTLQUE, adj., fol" roso-barylicus. Nou donué, dans la nomenclature chimique de Berzelius, i. des sels doubles qui sont produits par la combinaison d'un sel ferrear avee un sel barylique. Ex. Cyanuth ferroso-barytique (hydrocyanale do fer et de baryte).

FERLOSO-BISHUTHLUE, adj;" ferroso-bismulicus. Nom donné, dans la nomenclature climicquc de Berzelins, a des sels doubles qui ré sultent de lia combinaison d'nu sc $^{\circ}$ ferreux avec un sel bismuthique. Exi 
FERR

Cyanue ferroso-bismuthique (hydrocyanate de fer ct dc bismutth).

Perroso-car ciove; adj. , forroso-calcicns. Nom douné, dans la nomenclature chimique de Berzclins, i des sels doubles qui résultent de la combinaison d'un sel ferreux avec un sel ealcique. Ex. Cyanure ferrosocalcique (hydrocyanate de for et de chan $x)$.

FERroso-ch́rour, adj. , forroso-ccrieus. Nom donné, dans la nomenclature ehimique de Berzelius, à des sels doubles qui résultent de la combinaison d'un sel ferreux avce un sel ećrique. Ex. Cyannre ferrosocérique (hydrocyanate de fer et de cérium).

FEnoso-Cunomioue, adject., forroso-chliromicns. Nom donné, dans la nomenclature chimique de Berzelins, à des sels doubles qui résultent de la eombinaisou d'un sel ferrellx avec un sel chromicque. Lx. Cyanute ferroso-chromique (hydrocyanate de fer st de chrome).

FERROSO-COBALTIQUe, adj. , Serroso-coballicus. Nom douné, dans la nomenclature elimique de Berzelius, à des sels doubles qui sont produits par la combinaison d'uu sel ferreux avee un sel cobaltique. Ex. Cyanure ferroso-cobaltique (hydrocyahatc de for et de cohale).

FELRoso-Guivriqui, adj., $\int \mathrm{cr}^{-}$ roso-cupricus. Nom donné, dans la nomenclature chimique ch Berzelius, à des sels doubles qui résultent de la combinaison d'un sel ferreux avec un sel cuivrique. Ex. Cyanure ferroso'uivique (hydrocyanate de fer el de cuive).

FEnRoso-FERLIQUE, adj., ferroso-ferricns. Nom donné par Berzelius à un oxide (Eiscnoxydoxyclul, all.), qui résulte de la combinaison des deux oxides de fer, et ì des sels doubles (Eiseroxydoxydulsalzen, all.)

résultant de la conilinaison d'un sel ferreux avec un sel ferrique, comme le cyanue forroso-ferrique, ou bleu de Prusse, découvert en i zro par Dicsbach.

FEImoso-GLUGIQUE, adj., ferroso-ghlnciens. Nom donné , dans la nomenclature chinnique de Berzelius, à des sels doubles produits par la combinaison d'un sel ferreux avec un sel glncique. Ex. Cyanure ferrosoglucique (hydrocyanate de fer et de glucine).

FERROSO-ITYDIIQUE; adj., $/ \mathrm{cr}$ roso-hydricus. Nom donné, daus la nomenclature chimique de Berzelius, à un sur-sel rúsultant de la combinaison d'un sel haloide ferrcux avce l'hydracide du corps halogène. Ex. cyanue forroso-hydrique, ou acide cyanique ferruré , on cyanure ferreux acide, ou acide hydroferrocyanique.

FERIROSO-IIYEREANADIQUE, adj., ferroso-kypervanadieus. Nom? donué, dans la nomenclature chimique de Berzelius, à des sels donlules qui résultent de la combinaison d'un sel ferreux nvec un sel hypervanadique. Ex. Cyanure forroso.hypervanadique (lividrocyanate de fer et de vanadium).

FFRROSO-MAGNésIQUE, adj. , ferroso-magnesicus. Nom donnc', dans la nomenclature ehimique dé Berzelius, ì des sels doubles résultant de la combinaison d'on scl ferreux avec un sel magnésique. Ex. Cyanurc forroso-magnésique (hydro. cyanatc do fer et de magnésic).

FERTOSO-MANGANEUX, adj. , fcroso-manganosus. Nom donné, dans la nomenclature chimique de Berzelius, à des sels dloubles qui sont produits par la eombinaison d'un sel ferreux avee un sel manganeux. Ex. Phosphatc ferroso-mangineux ( hydrocyanate de for et de manganćsc).

TERROSO-HANGANiQUE, adj., ferroso-manganicus. Nom donné, 
dans la nomenelature chimique de Berzelius, à des sels doubles qui rćsultent de la combinaison d'un sel ferreux avecun scl manganique. Ex. Cyanurc forroso-manganiquc ( $\mathrm{hy}$ drocyanate de fer el de manganésc).

FerRoso-Mercerique, adj. , ferroso-mercuricus. Nom donnc, daus la nomcuclature chimique de Berzelius, à des sels doubles qui sont produits par la combinaison d'un scl fer. reux avec un scl mercurique. Ex. Cyanure ferroso-mercurique (hydrocyanate de fer el de mcrcure).

FERROS0-MOLYBDECX, adjeet., ferroso-molybalosu.s. Nom donné, dans la nomenclature chimique de Berzelius, à des sels doubles qui résultent de lia combinaison d'un sel fcrreux avee un sel molybdeux. Ex. Cyanure forroso-molybdcux (hydrocyanate de for et de molybdìne).

FEruroso-morybireue, adj., ferroso-molybdicus. Nom donné, dans la nomenelature chimique de Berzclius, it des sels doubles qui son $t$ produits par lit combinaison d'un scl ferreux avec un sel molybdique. Ex. Cyanure ferroso-molybdique ( hydrocyanate de fer et de molybiène).

FERROSO-NICCOLIQUE, adj., ferroso-niccolicus. Nom douné, dans la nomenclature chimique de Berzelius, à des sels doubles qui résultent de la combinaison d'un sel ferreux avec un sel niccolique. Ex. Cyanure fcrrosoniccolique (lydrocyanale de fer el de nickel).

FERIOSO-PLOMIBIQUE, adject. fcroso-plumbicus. Nom donné, dans la nomenelature chimique de Berzclius, à des sels doubles qui doivent naissance à la combinaison d'un sel ferreux avec un sel plumbique. Ex. Cyanure Jerroso-plombique ( hydrocranale de fer et dc plomb).

FrRROSU-pOTASSIQUE, adjeet., ferroso-potassicus. Nom donné, dans la nomenclature chimique de Berze- lius, à des sels doubles qui résultent de la combinaison d'un sel ferreux avec un sel potassique. Ex. Cyanure ferroso-potassique ( hydrocyanale de fer et de potasse).

FERROSO-SODIQUE, adj., ferroso-sodieus. Nom donné, lans la nomen elature chinaique de Berzelius, ì des sels doubles produits par la conbinaison d'uu sel ferreux avec un sel sodique. Ex. Cyanure ferroso-sodique (hydrocyanale de $\int \mathrm{cr}$ el de soudc).

FERroso-sTANIQUE, adj., ferroso-sinnnicus. Nom domnć, Jans la nomenclature chimique de Berzclius , ji des sels doubles qui résultent de la combinaison d'un sel ferrcux avee un sel stannique. Ex. Cyankre ferrosostannique ( hydrocyanate de fer ot d'é(ain).

FERROSO-STRONTIQUE, adject., ferroso-stronticus. Nom donné, dans la nouncnclature chimique de Berzelius, iो des sels doubles produits par la combinaison d'un sel ferreux avec un sel strontique. Ex. Cyanurc ferroso-strontique ( hydrocyanate de fer el de strontiane).

FERROSO-TANTALQUE, adject., ferroso-tantalicus. Nom donné, dans la nomenclature chimique de Berzelius, à des scls doubles qui résultent de la combinaison d'un sel ferreus avec un sel tantalique. Ex. Cyanure ferroso-tantalique ( hydrocyanate de fer et de tantalc).

FLRROSO-THORIQUE, adj. , ferroso-lkoricus, Nom donné, daus la nomenelature ehimique de Berzelius, à des sels doublés qui résultent de la combinaison d'un sel ferrenx avec un sel thorique. Ex. Cranure ferrosothorique (hydrocyunale de fer el de thorine).

FERROSO-TITAXIQtE, adj. , $\int \mathrm{er}$ roso-tilanicus. Nom donné, dans la nomenclature chimique de Berzclius, à des sels doubles qui résultent de la 
combinaison d'un sel ferreux avec th sel tilanique. Ex. Cyanure ferrosolilanique (lyydrocyanate de fer et de lilane).

PERmoso-uraniQ̨e, adj. , ferrosomuranicus. Nom donné, dans la nomenelature ehimique de Berzelius, ì dessels doubles produits par la combinaison d'un sel ferreux avec un sel uranique. Ex. Cyanure ferroso-uranique ('hydrocyanate de fer et l'urane).

I'ERroso-VANADIQUE; adject. , ferroso-vanadicus. Nom donué, dans a nomenelature elinique de Berzelins, à des sels doubles qui résultcut de la combinaison d'un sel ferreux avee un sel vanadique. Ex. Cyanure ferroso-vanadique (hydrocyanate de fer et de vanatium).

FERROSO-YTTRIQUE, adj. , $f(r-$ roso-yttricus. Nom donné, dans la Momenelature chimique de Berzelius, a des scl doubles qui résultent de la combinaison d'un sel ferreux avec un sel yttrique. Ex. Cyanure ferrosortrique (hydrocyanate de fer el d'yttrin).

FRrinoso-zINCIouE, adj., ferroso-zincieus. Nou donné, daus la noMenelature chimique de Berzelius, a des scls doubles qui résultent de la combinaison d'un sel f'erreux avee un sel zineique. Ex. Cyanure ferrosozincique (hydrocyanate de fer et de $\left.2 i i_{c}\right)$.

"rarugiverux adj., ferruginosus, ferrens, forrugineus, ferruginaus ; rostjarb, rostbratun, rostSärbig (all.); qui contient du for (eau Serrusincuse); qui a la coulcur de la rouille de fer (ex. Polyportus forreus, Carabus forrugineus, Virgilia ferruginea, Lasiopsctalum ferrugineum, Varrusia ferruginosa, $\$ i$ mia ferruginatus, Tabanus ferrusalus).

Far FrLE, adj., fortilis ; fruchtbar (all.). Fćcond, qui produit beaucoup (feur, plante jertile). On ap- pelle etamines fortiles; celles dont les anthères sont pleines de pollen.

HERTIIITÉ, subst. f., fertilitas; Fruchıbarlicit (all.). Qualité de ce qui est fertile.

IESTONNE, adj., repandus. Se dit des feuilles, quand elles sont munies de découpures peu profondes et marginales.

FESTuCACEEs, adj. et s. f.pl., Festucaeca. Nom donné par Link, Nices d'Esenbeck et Kunth a unc tribu de la famille des Graninées, qui a pour typele gen re Festuca.

FEsTucies, adj.et s. f. pl., liestueca. Nom donné par Nees d'Escnbeckì une scetion de la tribu des Fcstucées, qui renferme lc genre Festuca.

FETTDE, adj. , factidus, sravenlens, teter; ơvo'ions; stinkend (all.); stinking (angl.); qui exhale une odeur désagréable, soit par le frottement ou l'action du feu (ex. $B a$ ryte sulfatée fétide), soit spontanément (ex. Agarieus folens, Hellebortus fortidus, Passifora fortida, Iris frotidissima, Hieracium fatidum, Inula graveolens, Anthenis Cotula). Qucl(quefois on exprime la fétidité en la comparant à une autre odcur bien conme (ex. Orchis hircina, Hyperioum hircinum, Chenopodium vuluaria, Glycine bituminosa, Pelargonium terebinthinaceum).

FETIDITÉ, s. f., forlidilas ; juowớiz. Qualité de ce qui est fétide.

FEU, s. m. , ignis ; $\pi$ ip ; Feuer (all.); fire (angl.); fuoco (it.). Phénomène qui a lieu lorsque de la clialeur et de la lumière se manifestent simultanément à nos sens. On applique aussi quelquefois ce nom ì la causc mème du phénomène, à la matière de la chisleur, ou ealorique.

FEU FOLLET, s. m., vapor ardens, ignis fatuus, ambulo; Irrlicht, Irrwisch (all.); wile with tho wisp (angl.). 
Flamme erratique produite par des émanations gazeuses qui sortent des eudroits marćcageux, des lieux où des matières animales et végćtales sc décomposent, et qui s'enflamment ì unc petite distance du point d'où elles se dégngent.

FEU S.IN'T-ILLNE, s. m. Aigrette électrique qui brille souvent à l'extrémité des corps pointus, bouts de mâts, croix de clochers, pendant les temups d'orage.

FEUILLLDE, s. f., frons. Riehard 'désigne sous ce nom chaque feuille de fougère, parce qu'elle ressemble plus à une tige foliacéc qu'à une véritable feuille.

FEUILLAGE, s. m., frondes, folia. Ensemble des fenilles d'une plante; terme plus popnlaire que seientifique.

Feuillaison, s. f. , foliatio ; fogliazione, frondescenza (it.). Action de sc couvrir de leuilles; époque ì Jaquelle les bourgcons s'épanouissent.

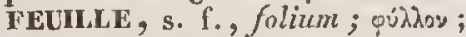
Blalt (all.) ; blade, leaf (angl.) ; foglia (it.). Turpin définit la feuille tout organe appendieulaire, et le plus souvent articulé, quelles qu'en soient les dimensions, la furme, la consistanee et la coulcur, qui borde extérieurgment mn nocud vital, est souvent réduit à la ncrvure médiaue, maiss"élargit ordinairement, des deux côtés de cette nervure, en une lame xćgulière our iłrćgnlière, simple, découpéc ou lobée. Après avoir lu cette longuc phrase, ainsi que celles de Jung, de Ludwrig, de Mceneh, de Bernlardi, de Voigt, de Candolle, de Smith, de Nees d'Esenbeek et de Willbrand, on aequiert la convietion, avee Linné, Iink et Schulz, que la feuille ne peut point être définic, ou avec Agardh, qu'il faut s'en tenir sur son compte aux idées populaires, comme représentant en effet l'ćtat de choses qui a lieu le plus communément. Nuts dirons seulement que ce qu'on appelle ordinairement feuille, même daus le sens vulgaire, est tautôt une feuille entière, composéc du pétiole et du limbe (cas le plus ordinaire), tantôt un limbe sans pétiole (cas des fcuilles sessiles), parfois aussi un pétiole foliaeé sans limbe (ex. phyllode, voyez ec mot), ou une simple foliole d'une feuille composéc, ou mènc cufin une tiğc aplatic et en forme de fcuilles (ex. Cactus Opuntia).

FEUILLE, adj. , foliatrus; beblit tert (all.). Se dit d'une plante quil est munie de feuilles, ou d'une tige $q^{\mathrm{ut}}$ porte des feuilles. Plumule feuillée, lorsque le bouton qui la termine dans la graine est assez développé pour qu'on $y$ distingue de petitus feuilles (ex. Coratopliyllum); panicule feuillée, quand les ramifications sont entremèlées de feuilles (ex. Ru mcx oppositifolius) ; ćpi feuillé (ex, Pedicularis foliosa) et verticille feullt (ex. Erica cinerea), ceux qui se trouvent dans le nème eas.

FEurLLET, s. m., lamina ; Blit terchen, Blätllein (all.). On doune ce nom, en géognosic, aux parties min ces dans lesquelles se subdivise une couche, une assise, un lit; on botauique, à la membrane, ployée sous forme de lames, qui garnit lin partie inféricure du chapenu des agaries, et qui porte les spores.

FEchLLE', adj., blütrig (all.); foglictlato (it.). Se dit : $1^{\circ} \mathrm{en} \mathrm{minéra-}$ logic, de la cassure, quand elle pré sente des lames exeessivement mil ces, scmblables anx feuillets d'un livre (ex. Mica), et de la strueturc, solit d'un minćral qui se clivise avec facilité en feuillets extrèmement mince $e^{s}$ et flexibles (ex. Mica), soit d'un roche qui paraît formée de feuillels (ex. Pliyllade micacé); $2^{\circ} \mathrm{cn}$ zoologie, d'une coquillc bivalre qui a son $1 \mathrm{~s}^{\mathrm{s}}$ formé de nombreux feuillets réunis, dont les extréruitćs font souvent saillie 
au dehors (cx. Ostrea), ct des antemes d'ui iusecte, Jorsque chaque arlicle est garni, sur un côté, d'une lame mince et plus ou moins alongéc (ex. Lampyris pennatr).

FEULLU, inlj., foliosus; blattreich (all.). Sc dit d'une plante qui est elargéc d'un grand nombre de feuilles, soit partout (ex. Cytistus foliosus, Buxbaumia foliosa), soit at somnet seulement (ex. Flyeraria frondosa); on dont les fenilles sont disposées d'unc manière insolite, cornme celles du Gymnopogron foltiosit.s, qui sont roulées; ou eufin dout Ii forme générale inite celle d'une feuille onduléc (ex. Trumella foliacea). On cmploye anssi cette épithèco pour désigner des polypiers á expansions planes (cx. Diastopora foliacen), ou des insectes qui onl quelque partic du corps en forme de feuille, comme le corselet du MIembracis foliata, qui sc prolonge en une sorle de erête.

FEUTiE, s. m. On nomme ainsi, chez les mammil'ies, des poils doux et plus ou moins ćpais, qui garnissent immédiatcment la pean, ct que I raversent d'autres longs poils plus ou moins cylindriques; on reneontre principalement le feutre chezcenx qui labitent les pays reculés vers le nord ou trèsélevés au dessus du nivean de la mer.

VÈVE, subst. f. Nom vulgaite des elirysalides.

IIBRE, s. f. , fibra, villus; "६; Faser (all.). Corps long et grrèle, dont la disposition ci les connexions produiscnt la trame de tous les êtres orGanisés, et dont ort aperçoit aussi des traces dans quelques minéraux.

MIBREUx, adj., fibrosts; faserig (all.); fibroso (it.); composé de fibres. Se dit: ${ }^{\circ}$ cn minćralogic, d'un mélal qui présente des fibres dans sa cassure (fer fibrenx); d'un mineral dont les partics sout déliées et sem1) lables il des fibres (cx. Mésotyje); de masses qui résulient d'un assenu- blage de pelites aiguilles ou de filets déliés, cristallisés on accidentels, droits ou contournés, accollés sur lenr longuenr, disposés cu rayous divergens, et entrelacés de différentes manières; $2^{\circ}$ en botanique, d'une racine qui se compose de filets d'une épaissenr notahle, alongés, distincts et peu ou point ramenx (ex. Allium (сра); $3^{\circ}$ en zoologic, d'aprés Illiger, des dents de manmifères qui sont composées de fibres ou de lubes longiludinanx (cx. Olyctérope).

FHBituame, adj., fibrillaris; qui est disposé en filannens très-déliés, comme les Himantia.

TrimuLLE, s. f., fibrille; Faserchen (all.). On dome ee nom anx ramifieations capillaires d'une racine très-divisće, ainsi qu'aux filcts déJiés yui naissent dn thíalle des licliens, et servent à fixer ees derniers sur l'cerce des arbres, la terre ou les pierres.

MHbLxit, adj., fibrillatus; fudig (all.). Se dit de lil racine, quand elie est composíc de fibrilles ou de filures délićes.

Finfilluwu, adj. , fibrillosis. Epithète donnée au stipe de certains champiguons. Lx. Agaricus fibrillostis.

ribnuLdrins, adject. , fibrilliferzes. Le clinanthe du Gymnanthemuen fibrilliferum est muni de quelques fimbriltes piliformes éparses.

FIBMINe, s. f., fibrina; Fasersloff (all.). Substance particnlière qui fait lis hase des muscle's et du caillot du sang des animans it sing ronge.

FusminTex, alj: ,fibrinosus; qui cst composé de librine, qui en contient, qui co présenle les círactères.

FIBR(0-GBSWULIRE, adj., fibro. grauularis. Fithète donnce, en minéralogic, it un corpss, lorsqu'il présente un tissu granulenx entrentèle de fibres. Lx. Pyroxine.

FIBRO-ZAWKAMRE, adj. , fibro32 
laminaris. Épithète dnnnće à un minéral, lorsqu'il est fibreux dans un sens et laminaire dans l'uutre. Ex. Diallag'e.

FIBRo-scinstreux, adjeet. , $f-$ bro-seluistostes. Les géognostes disent qu'une roche a la structure fibroschistcuse, lorsqn'cllc est fissile en plaques, par l'uffet de petites aiguilles cristalliues qui sont rangées parallèlement les unes aux autres ct bout a bout, croisées ct entremèlées sur le même plan de différentes manières, ou jetcées en tous sens d'un plau is l'autre; e'cst le cas de certaine's roches anphilioliques.

FIBru-SOswux, adj. , fibro-scriceus. Se dit d'un minéral yui cst en filamens réunis par firisceau $x$ et ayant le luisant de la soie. Ex. Alumine sulfatée fibro-soyentse.

FICÉ lis, adj. et s. r. pl., Ficece. Nom donné par A. Richard à un groupe de la famille des Urticées, qui " pour type le genre Ficus.

PrchontuE, adject., ficiformis (ficus, figue, forma, forme); qui a la forme d'unc figue, eomme la $S$ pongia ficiformis, laquellc est turbince, avec une perforation an sommet.

FICOnis, adj., ficoidens. Epithète donnee aux flcurs conjointes, lorsqu'clles sont eutièrement enveloppćes par un :éceptacle charna et succulent. Dix. Ficts Carica.

FICOIDELS, adj. et s. f. pl., Ficoidce. Manvais uom donné à une famille de plantes, que K. Sprengel a proposé d'appeler Aizoidécs.

IGUE, s. f., cartca, ficus; бisəv; Feige (all.); fig (angl.); fico (it.). Candolle désigne sous ec nom un fruit aggrégé, composé d'um graud nombre de cariopses réunies dans un involucre charnu ct sueculent. Ex. Ficus Carica.

VIGULIN, adj..figutimus, figularis, figlinus (figulus, potier de terre). On appelle argile figuline, celle qui se laisse pétrir et appliquer à la fubrication des poterics.

FIGLRE, adj. , figuratus. On appelle pierros figurées eclles qui offrent fortuitcment, dims leur forme, quclque ressemblance avee des corps organisés, végétaux ou animaux, mais qui, dans leur structure, n'ont aucune trace de l'organisation des corps qu'elles semblent représenter plus ou moins grnssièrement.

FIL, s. m., filum; Faden (all.). $\mathrm{Cc}$ nom est donné par Kirby à deux organes filiformes et non articulés qui garnissent l'anus de's Machilis. l'crsoon appelle fila scminifera les parlies capillaires qui fixent et reticnnent les sporidics des champignons, Les paraphyses (voyez ce mot) sont nommées fila succulenta, Safifaden (all.), par quelques botanistes.

FLAGINÉES, adj. et s. f. pl., Filasginece. Nom donné par H. Cassini à un groupe de la section des Inulées gnaphaliées prolotypes, qui a pour type le gonre Filago.

FILAGNOIDES, adj. ct s. f. pl., Filaginoidece. Noun don né par Schrauk i) une section de la tribu des Gnaphinliées, qui a pour type le genre Filago.

FuAUENTAIRE, alj. , filamentaris; qui est produit par des filamens, comme le tube dû à la soudure des lilets des étamines dans certaincs plantes.

WH AMEVTLU, adj. , filamentosus; fadenfürmig (all.). Se dit: $1^{\circ} \mathrm{ell}$ minéralogic, d'un corps qui semble êtré un asscunblagge de lilimens plus ou moins déliés (ex. Asbeste) $; 2^{\circ}$ en lotanique, de plantes qui sont alongées sous la forme de filets grếles (ex. Conferva), ou qui portent des filamens, comme ceux qu'our roit sur le bord des feuilles di Yucca filamentosa; $3^{\circ}$ en zoologie, d'un animal qui a la forme d'un fil (cx. Tania 
flamentosa), ou dont une partie du corps est garnic de filamens, comme le Cantharts filamentosus, dont le bord supérieur de la nageoire caudale se prolonge en rayons filiformes.

FHandirins, adj. et s. f. pl., Textoria. Nom donné par Degcer et Lamarck à unc trilıu d'Aranéides, renfermant ceux de tes animaux qui font des roiles à réseau irrégulicr', dont les fils sc croisent en tous sens et sur plusicurs points.

FILANDREux, adj. Se dit d'un drupe dont la pamnexterue est divisible en filamens. Ex. Cocos nucifera.

FILET, s. m., filamentum, capillancntum, pcliculus;'Trägcr(all.); filanento (it.). On appellc aiusi, $1^{\circ} \mathrm{cn}$ géognosie, un filon qui n’a pas les dimensions ct la suite requises pour être exploitable; ; $2^{\circ}$ en hotarique, le support d'une seule anthc̀re, qucile que soit sa forme.

FILEUSEs, adj. et s. f. pl. Nom douné par Degeer, Clerk et Lamarck à une tribu d'Aranéides, comprcnant celies qui tendent des filets, tissent des toiles ou filent des cordages pour se transporter et se soutenir, ou pour se procurcr, dans ces sortes de piéges, les insectes dont clles vivent.

FILICAULE, aulj., filicanlis (filum, fil, caulis, tige); qui a la tige filiforme. Ex. Oxalis filicanlis.

FILICIFÈR, adject. , filiciferus (filix, fongère, fero, porter). Se dit d'une roche qui renferme des fougìres fossiles. Ex. Oolithe filicifere.

FILICIFOnve, adj., filiciformis (filix, fougère, forma, forme). Se dit, en ninéralogie, d'un corps partagé en rameanx, lorsque ceux-ci, étant sur le rac̀me plan, imitent par leur disposition les folioles qui s'insèrent des deux côtés de la tige d'une fougère. Ex. Argent natif ramuleux filiciforme.

FILIcrN, adj., filicinus (filix, ougìre); qui a la forıne d'une fou- gère. Ite Palmaria filicina est ainsi nounmé à cause de sa frondc, une ou dcux fois ailée, comme celle d'une fougère.

FIlicines, adj. ct s. f. pl., Filicince, Filicina. Nom douné par Batsch et par Wibel à la famille des Fougères.

TruICOIDEs, adj. et s. f. pl, Filicoides. Non donné par Bridel à une farmille de Mousses, et par Lindley aux cryptogames vaseulaires collectivement.

FILICONNE, adj. , filicornis ( $f i-$ lum, fil, cornu, cornc). L'Agaricus filicornis est aiusi appclé à cause de la mineeur ale son stipe; la Nereis filicornis, parce que ses tentacules céphialiques sout longs et capillaires.

FiLicornis, adj. et s. m. pl., Filicornes. Nom donné par Lamarck à une famille de Coléoptères, par La treille ct Eichwald à unc fomille de Névroptc̀res, par Dumćril à une famille de Lépidoptères, comprenant ceux de ces insectes qui ont les antenues en fil, ou ì peu près.

FILIṫie, s. f., fusus. On désigne sous ee nom des pores par lesquels les araignées et les clienilles font sortir la maticre soyeuse dont se servent les preniceres pour tisser leurs toiles, les anties pour construire la coque dans lequelle elles se changent en chry. salides.

FHLiFillie, adj., fliforts (filum, fil, (ero, porter). Un polypier ( $\mathrm{Ccl}-$ laria filifera) est ainsi appelé parce que ses rameanx sont cliargés de filamens snr les ròtés.

FILFOLIF, adj. , filifulius; fa. denbliutrig (filum, fil, folium, feuille). Se dit d'une plinte dont les fenilles on leurs divisions sont fil:formes. Ex. Asier filifolius, Albuca filifolia, Leptalcum filifolium.

FII.FORME, adject. , filiformis; fadcnförmig, fïdlich (all.) (Jilum, fil, forma, forme ); qui a la forme 
de fil. On emploie ee terme: $1^{\circ}$ en minéralogie, pour désigner un corps qui ressemble a un fil plus on moins contourné (ex. Argent nalif filifor$m e) ; 2^{\circ} \mathrm{cn}$ botanique, pour désigner les parties qui sont longues, grêles et cylindriques on aplaties, comme les anthères du Ternstrocmia filiformis, l'axe du Phleum pratense, l'ensemble du champignon appelé Clavaria flata, l'embryon du Damasonizm stellatum, l'ćpi du Verbena triphylla, les feuilles de l'Hymenatherum filifolium, le funicule du Magnolia grandiflora, les pédoneules des Fuchsia coccinea, le placencaire du Velezia, la racinc du Lsemina, les rameaux du Dolichos filiformis et de l'IIelichrysum filiforme, le stigmate du 'Zec Mays, le style del'Halesia teiraptera, la lige du Tlymus filiformis et du Ple. rigynandrum filiforne; $3^{\circ} \mathrm{en}$ zoologie, pour distinguer des animanx dont le eorps ressemble à un fil (ex.Stenosoma filiforme), ou des parties du corps qui sont minees, alongées et de grosseur à peu près égale partout, eomme l'abdomen de l'A silus filiformis, les anlennes du Midas filala, les palpes des abeilles.

FIMIFOnNes, aủj.et s.m. pl.,Filiformia. Nom donné par Cuvier, Latreille et Eichwald à une famille de l'ordre des Iscmodipodes, eomprenant ecux qui ont le corps très-gréle ou linéaire; par Latreille, à une famille d'Annelides entérobranehes, clans laquelle il range eeux de ces animaux dont lc corps eșt de fignure eapillaire.

FLIGLinE, adj., filigerus; fadentragend (all.) (filum, fil, gero, purter). Ia Mrereis filigera est ainsi appelée, parce que sa rame supérieure se compose d'un pinceau de soies et d'in très-long eirre filiforme.

FILIPLDE, adj., filipes (filun, fil, per, pied); qui a des pattes tris-longues el grếlts. Colles de la

\section{FINB}

Tipula filipes sont trois fois plus longues que le eorps.

FIrIPENDUL í, adj. , filipendnlatus; angereihet (all.). Se dit de la racine, quand elle est forméc de tilberenles attaehés à des ramifications très-menues. Ex. Spiraza Filipendula.

FILIROSTRES, adj. et s. m. pl., Filirosires (filum, fil, rosirum, bee). Nom donné par J.-G. Schaeffer ì un ordre de la elasse des oiseaux, qui, avec les doigts fendus, ont le bee filiforme.

FUITARSE, adj., filitarsis; qui a des tarses alongés et grèles. Ex. Melolontha filitarsis.

FILITLLLS, adj. ets. f. pl., Filitela. Eipithète donnce aux araignces qui filent des toiles composées de fils lîehes et écartés. Ex. Aranca phalanginides.

lilLon, s. m., Gang (all.) ; flone (it.). Les géognostes donnent ee nom it des masses minérales, pierreuses ou métalliques, très-peu larges eomiparativement à leur hauteur et a leur longueur, qui traversent, an moins dans une partie de son étendue, un terrain ou une masse de roehes queleonque.

FILOPÈDE, adj., filopes; qui a le pied ou le stipe filiforme. Ex. Agarieus filopes.

FILTRATIoN, s. f. , filtratio, colatio; Seihung, Durcliscihnng (all.). Opération qui consiste à séparer une matière solide mêlée avee un liquide, en faisant passer celui-ei à travers unc substanee, papier non collé, étoffe, colonne de sable ou de verre pilé, dans les pores ou ì la surface de laquelle reste celle qui troublait sa pureté el sa transparenee.

FILTRE, s. wn., filtrum. Intermède queleonque dont on se sert pour exéeuter la filtration.

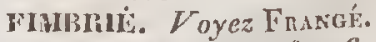

FIMbRiLIs, subst. f', , fimbrilla; 
Spreufaden (all.). H. Cassini appelle ainsi des appendices du clinantlie des Synanthérées qui nnt la forme de filets membrancux, laninés, linćaires ou subulés, inćgaux, irréguliers, souvent cntregreflés inféricurcment, loujours beacicoup plus nombrenx que les fleurs, et qui sont de simples saillies du rćseau.

FLMBRILLIY ÈrE, adj. , fimbrilliferus (fimbrilla, fiubrille, fero, porter). Se dit da clinanthe des Synanthérées, lorsqu'il est cliargé de fimbrilles. Ex. Carduinćcs.

FrMérame, adj., fimetaritus; qui vit dans le funicr, dauns les matières excrémentitielles. Ex. Aphodius fimelarius, Aplundius merdarius, Ap dius serballarius.

FIMUCOLE, adj., fimicolus; qui vit ou eroît dans le fumier. Ex. $A g a-$ ricus fimicola.

HimuLENT, s. m. , firmamentum; Himmelsgewö̈lbe (all. ); Heaven (angl.) ; firmamento (it.). On ippelle ainsi le eicl, pare qu'il se unontre à nous sous l'apparence d'u॥ hémisphère solide ou d'une voûte reposint par sa base sur l'horizon.

FISSLDACTrLes, adj. ct s. m. pl., Fissidactyles (fissus, fendu, dx́xtu$\lambda_{05}$, doigl). Non donné par Lesson a une division du sous-ordre des Passereaux marcheurs, comprenant ceux qui ont Irois doigts antéricurs libres et isolés.

FISSIF LORE, adject., , fissiforus (fissus, fendu, flos, fleur). H. Cassini donnc cel te épithètc ì la calathide, quand elle cst composce de corolles fissiformes.

Fissifontú, fissifolius (fissus, fendu, folium, feuille); qui a des feuilles linéaircs el fcndues au sommat (ex. Puspalus fissifolius), ou des feuilles pinnatifides à segmens incisés au sommet (cx. Pelargonium (issifolium ).

FISSIFORJE, adject, , fissiformis (fissus, fendu, forma, forme). Epithètc donnće par H. Cassini it un geure indétcrminé de corolles de Synanthérées.

VISSTLABRES, adj. et s. m. pl., Fissilabra. Nom sous lequel Cuvier, Latreills et Eichwald désignent une tribu de la famille des Coléoptìres brachálytres, comprenant ceux dicz lesquals le libie est profoudérnent éehancré ou bilobé.

FISSLLE, adj. , fissilis; spaltbar (all.). Sc dit, cn minéralogie, d'un corps, lorsqu'il a unc tendance enchéc à sc diviser par feuillcts (ex. Talc glaphique), ct de la structure d'unc roche, quand celle-ci paraît formée de lits minces (ex. Greciss). Un chanpixnon (Auricularia fissilis) a été appclé ainsi, parce qu'il finit par se fendre en particules cohérentes à la base.

FISSIEIrís, adj. cts. f. pl., Fissilien. Caflin désigne sous ce nnm la famille des Olacinćes, à cause du genre Fissilia qu'elle renferme.

FISSINERVE, adj., fissincrvius (fissus, findu, nervus, nerf). Le Lasiandra fissinervia a des folioles munies de trois nervures, dont les deux latérales sont bilides.

FISSIPALIE, adj., fissipalmalus (fissus, feudu, palmatus, palmé). Illiger appelle doigts fissipalmés ccux qui présentent une large bordure étcndue de la basc d'un doigt à l'autre, les ongles étant en forme de lane sur les bords. Ex. Gribe.

IISSIPARE, fissiparus (fissus, fendu, paro, cngendrer). Se dit d'un corps organisé qui se reproduit par la scission de son propre corps, comsne il arrive à un graud nombre de polypes et à bcateoup de plantes.

FISSIPAIIL, s. C., generalio fissipara; Spaltzeugung (all.). Nom donné par Burdach au mode de génóratiọn qui consiște dans la scission 
d'un eorps organisé, dont chaquè scgment devicnt un tout semblable à celui dont il provient.

FISSHetedes, adj. ets. m. plur. , Fissipedes (fissus, iendu, pes, pied). Nom» donué par Blumcubacl à un ordre de Mammiferes, comprenant cenx qui ont deux à quatre saljols ; par Latreille, Ficinus ct Carus à une famille de l'ordre des Pachydermes ; comprenant ccux qui ont des doigts distincts à tous les pieds; par J.-C. Schaffer a trois ordres d'oiscaux, dans lesquels sont rangés ceux qui ont denx, trois ct quatre doigts fendus; par Lamarek à une fimille de Crustacés homobranche: macroures, dans laquelle il comprend ccux qui ont les pattes bifides.

TISSIPENNES, adj. ct s. m. pl., Fissipcnnes (fisstes, lendu, penna, aile). Nom donné par Cuvier à ure tribu de la fannille des Lépidoplères diurnes, comprenant ccux qui ont les quatre ailes, ou dcux an moins, fendues dans leur longueur en brauches orl digitations.

FISSHROSThes, adj. et s. m. pl., Fissirosires (jissus, fiendu, rosirum, bec). Vigors et Cuvier désigneut sous cc nom une famille de l'ordre des Passereaux on des Percheurs, conprenaut ceux de ces oisenux qui ont le bec fendu trìs-profondément.

FISSURATION, s. f., fissuratio (fissura, fente). Elat de ce qui est fendu, de ce qui offre des fissures: fissuration al'une roche.

FISSLIti, s. f., fissura; Spalte (all.). Les géognostcs appellent fissures de stratification celles qui séparent les assises d'une mème couche, ou des conclies de mème nature, et fissures de superposition, celles qui séparcut des conches de diverse naturc. Généralement, en minéralogie, Ic mot fissure exprime des séparations dans une masse qui ue sont pour ainsi dire qu’indiquécs, les parois ne laissant pas d'écartement entr'elles. On ne le dit guères que des minéraux et des roches considérés en petit. Dacosta donne le nom de fissure à une dépression longue et peu large qu'on voit assez sourent, en arrière dn sommet, à la partie dorsale de la facc extcrne d'une valve de coquille bivalve.

FISTULAIRE, adj., fistularis (fistula, flûtc). Se dit, en minéralogie, d'un corps concrétionné qui est traversć dans toute sa longueur par une cavité scmblable à cclle d'un tube. Ex. Chaux carbonatée fistulaire.

- FISTulís, adj. et s. m. pl., Fistulata. Eichwald donne ce no in à une famille de la classe des Cyclozoaires, comprenant ceux de ces animaux qui, comne les Holothurics et les Fistulaires, ont le eorps fistnleux.

FISTULELX, adject. , fistulosus; hohl, röhrig (all.). Se dit, en botanique, de tout organe alongé et cylindrique qui offre unc cavité longitudinale à son centre, comme les ferilles de l'Allium fistulosum, la hampe du Pissenlit, le spadix de l'Arum Dracunculus, la lige de l' $O E$. nantle fistulosa.

FISTULELX, adj. et s. m. pl., Fistulosa. Noun donné par E. Eichwald à unc famille de Phytozoaires lithophytes, par Schweigger à une famille de Zoophytes, comprenant les polypiers dont le centre vide est ocenpé par les polypes, qui, quoique distincts les uns des auires, conmmniquent réellement entr'eux, chacun ayant une issue particulière pour faire saillir nu dehors sa bouche et ses tentacules.

FISTLLiDEs, adj. et s. m. pl., Fisiulides. Nom donné par Lamarck à une section de l'ordre des Radiaires ćchiuodermes, comprenant ceux de ces animaux qui ont le corps alongó et cylindrique. 


\section{FIXE}

FISTULIVALVE, adj. cts. f., fistulivalya. Tourncfort désignait sons 'e nom les coquilles fistuleuses, e'està-dire les fourreaux tubulaires improprement appelés coruilles.

FIXATION, s. f. , fixalio ; $\pi$ r̆ğı. Opération par larquelle on donne en quel que sorte de la stabilité à un corps gazeux, en le combinant avec un corps solide.

FIXE, adj., fixtss; fest (all.). Ce nıt cst reçu dans plusieurs acceptions différentes. $I^{\circ}$ En astronomic. Lesétoiles sont appelées fixes, parec qu'au enntranic des antres astres lumineux, elles paraissent conserver tonjours les mêmes distance's les unes à l'éğard des autres. $2^{\circ}$ En physique. Fixe se dit d'une couleur qui reste la mềne, quel que soit l'aspect sous lequel on contemple le corps qui la présente. $3^{\circ}$ En chimic. On appelle fixes (fenerbeständig, feucrfest, all.) les corps qui ne sont point volatilisables, ì moinsqu'on ne les expose à un fur violent, ou même qui ne se volatilisent point anx plus hants degrés de chaleur que nous puissions prodluire (alcali fixe, huile fixe, mótalfixe). $\mathrm{O}_{\mathrm{n}}$ donne aussi celte épithète aux roz qui ne penvent ĉlre rannenés à l'état liquide or solide, ni par le refroidissement, ni par la compression, ni par ees denx moyens réunis, comme l'oxigène, l'azote et l'hydrogène. Le mot permanent est plus souvent usité daus ce dernicr eas. $4^{\circ} \mathrm{En}$ histoive naturelle. Mirbel appelle cloisons fixes celles qui, à la maturité du fruit, restent immobiles "t conservent leur allache, ec qui n'a lieu communćmeut que dans les périenpes indélinseens on déhiseens seulement, soit par des pores, soit pardes fentes (cx. Campanula). Dupelit - Thouars nomine embryons fixes des corps reproducteurs non fécondés, nus ou ćcaillenx, naissant successivement les uns des autres, formant par répétition l'aggrégation d'êtres qui composc la masse géuérale d'un grand arbre, ne se délaelant jamais naturellement de l'iggrégation à laquelle ilsapparticunent, inais pouvant, quand par accident ils en sont isolés, aller au loin en former nne nouvelle. Ce terme est done. pour lni synonyme de bourgeon.

FIxITí, s. f., fixilas. Faeulté dont jouit un eorps de ne pas se vola. tiliser par l'action de la ehaleur, de ne eluanger son mode d'aggrégation par l'effet d'aucune influenec quelconque.

Fixiva LVRS, adj. et s. m. pl., Fixipalpia (fixus, fixe, valva, valve). Nom donné par Latreille à une famille de la classe des Brachiopodes, comprenant ceux de ces animaux qui sont sessiles, c'est-a-dire fixés par la valve inférieure de leur coquille.

WLABELLE, adj., fabellatus, ventilatorius (flabollum, éventail); qui inite plus ou moins un éventail, qui s'élale de la ba:e au sommet en unanière d'éventail, comme les feuilles élégamment décomposćes de l'Adianium flagellatum, les fouilles réniformes à lobes très.ouverts du Caltha flabellifolia, les épis du Scleria fabillum, les faisceaux de l'Echinella ventilatoria, les rameaus de l'A mipathes flabellum et de l'Omalia fabellata, les antennes de la Mruilla flabcllata, la coquille de l'Ostrea flabellum et de l'Osirea flabelloides, les antennes de l'Eulophiss flabollatus. On dit anssi expansion fabellée.

F A IBELLICOHNE, adj., flabellicornis ( Rabellum, éventail, cornu, corne) ; qui is les antemues (labellées. Ex. Lampyris flabellicornis.

FLABELL1WERT, adj., fabelliferus (Rabellum, éventail, fero, porter); qui porte un éventail. Le Coccothraustesfabellifera a la quenc en éventail. 
ILABELLIF OLIE, adj. , flabellifolius ; fücherblätrig (all.) (flabellum, iventail, folium, feuille); qui a les feuilles disposées en manière d'éventail. Ex. Oxalis flabellifolia, Asplenium fabellifolium.

FLABELLFOnine, adj. , flabellifornis ; füelerförmig, wedelformigr (all.) (Rabellun, éventail, forma, forme). Mlirbel donne celte épithète aux feuilles cunćaires qui sont arrondies an sommet (ex. Salishuria asplenifolia, Euryops fabelliformis). Le Spongodium plabcliforme a unc fronde plane, disposée en forme d'eventail. L'Urlotea fabcliformis et la Spongia Rabclliformis ont leurs raneaux nabellés. Ise Cuculus fabelliformis a la queue très-élagéc, en éventail.

FLABELLIPEDE, adj., frabellipes (fabellum, ćventail, pes, pied). Sc dit d'un oiseau qui a les quatre doigts diriggés en avaut et rénnis par unc mème membranc, de manière à figurer un éventibl. Ex. Pélican.

JuACOURTYANivs, adj. et s. f. pl., Flaeourianea. Famille de plantes, proposée par L.-C. Rieliard ct ćtablic par Candolle, qui a pour type ld genre Flacourtia.

FLACOURTILES, adj. et s. f. pl., Flacourliere. Nom donné par Candolle à une tribu de lis famille des Flacourtiances, qui renferme le genre Flacourlia.

FLAGEILAIRE, adj. , pagcllaris (flaycllum, fouct); qui est long, délié et souple, en maniçre de fouct, conme les coulaus filiformes du Saxifraga flagellaris.

FLAGELI, adject. , Raggellatus; qui porte des inćgaliués semblables à celles quanratient pu produirc des coups de fouet. Ex. Copris flagellatus.

FLAGELIFIRE, adj. , fagellifurus (flagellum, coulint, foro, porter). Se dit d'une plaute qui est unu- nie de coulans. Ex. Splachnum flagellare, Pilotrichum flagelliferum, Saxifraga flagellaris.

FrateLLLIF ORuE, adj., flagelliformis ; peitschcnförmig (all.) ( flagcllum, fouct, forma, forme ); qui a la forme d'un foutet. On employe ce terme : $1^{\circ} \mathrm{cn}$ botanique; une $r a-$ eine flagclliforme est longue, souple et grêle (ex. Arenaria maritima); une tige flagelliforme est souple et déliéc comme un fouet (ex. Clematis $V$ italba), ou très-longne et cylindrique (ex. Cactus fragelliformis). Le $S_{\text {em }}$ pervivum flagetliforme est ainsiappelé it cause de ses coulans alongés; le Gigartina flagelliformis, parce qu'il a des rameaux longs et épars; le Spermacoceflagelliformis, paree que ses licuilles oblongues, lancéolées, aiguës et roulćes sur les bords à lat base, ressemblent presque à des pétioles. 2 ' En zoologie. Fabricius nomme palpe flagelliforme, dans Ies Crustaeés décapodes, une pièce antcnniforme, semblable ì une sorte de fouet garni de son massche, terminéc par une tige sélaccée, et produite par un grand nombre d'articlcs, qui sur-monte les deux paires inféricures de pieds - mâchoires ou de mâchoires auxiliaires.

FLAGRUM, s. m. , flágrum. Savigny donne ce nom à une sorte de long pilpe, ayant la forme d'un fouet arméde sa courroie, qu'on olserve it la base extérieure de chacune des six mâchoires extérienres des crabes.

FLAMBÉ, adj. , flammeus, flammeolus, fiamniculatus, flanmulatus. ; qui offre des dessins représentant des flammes par leur disposition ondoyante (ex. Contes frammeus, Cassis flammea, Troehus flammulatus, Oliv'a framnulata, Vemus flam. miculata). Le mot flammeus est quelquefois employé pour signifier écarlale (ex. Gorgonia flammca).

rLAJiue, s. f., flanma; yido . 
फloyiov, proquòs ; Flamme (all.); flame (angl.) ; fiamma (it.). Légìre auréole ardente, lumineuse et diversement colorée, qui s'élève à la surface des corps qu'on lurûle, et qui résulte de l'ignition des gaz combustibles produits par la décomposition de ces corps.

FLAHUICERS, adj. , flammiceps (Nammeus, rouge, capul, tète), qui a la tête rouge. Ex. Motacilla fanmiceps.

FLANC, s. m. On nomme ainsi, en géognosic (latus), la partic d'une montagne qui est comprise entre la eime et le pied; en zoologie, che'z l'homme et les manmilères? (ilia), la partic de la région littérale du corps qui s'ćlend depuis le bassin jusqu'aux fausses côtes; dans les trilobites, les lobes latéraux de l'abdomen et du postabdonten ; dans le thorax des insectes hexapodes (plcura), d'apròs Audouin, la réunion de l'épisternum, du paraptcire et de l'épimère.

TLASOQuE, adj. , flaccidus, lantsuidus; qui est mou, sans consistance, comne, le chapeau de l'Agaricus flaccidus, les feuilles du Brynm flaccidum et du Lestia fiaccida.

FLAVbrices, adj. et s. f. pl., flaveriece. Non domé par Lessing iो une sous-tribu de la tribu des Sénécionidées, qui a pour type le gente Flaveria.

FLAVICAUDE, adj., flavicaudarus (flasus, janne, cauda, queue). Le Sientor flavicandatus a la queue brune, avec deux bandes jaunes sur les côlés.

FLAVICOLLE, adj., flavicollis (favis, jaune, collum, col); qui a le col (ex. Motacilla flavicollis) ou le corselet (cx. Laphria flavicollis)
jaune.

FLAviconNE, adj., flavicornis (Naples, jaune, cornu, corne); qui a les antennes jaunes. Ex. Colaspis flavicornis.

MLAVIG ASTnE, adj. , flavigastcr (flaws, janne, gastcr, ventre); qui a le ventre ou la partie inféricure du corps jaune. Lix. Corvus flavisaster, sylvin fasošastia.

IuAvigudine, adj. , flavigularis (/lavus, jaumc, gula, gorge); qui a la gorge jaune. Ex. Agama flavigularis.

FLA VILABRE, adject., favilabris (fasus, jaune, labrum, labre); qui a le labre jaune. Ex. Cantharis flapilabris.

FLAVIPALPE, adj. , :llavipalpis (/lavus, jaune, palpres, palpe); qui a des palpes jaunes, Ex. Pleryxe flavipalpis.

ILAVIPLDE, adj., favipes ( /asas, jauue, pes, pied); qui al les pieds ou les pattes (ex. Coccinclla flasipcs), ou les pédoneules (cx. Racomilrium flasipes) jaunes.

MLAVI'LNNE, adj. , flavipennis (flas'zs, jaue, penna, aile); qui a les ailes (ex. Sphex Jlaripennis), ou les d́lyires (cx. Trichius fluvipennis) jaunes.

FrAVirostrel, adj. , flavirostris (flayns, jaune, rostrum, bee); qui a le bec jaune. Ex. Plibalura flavirostris.

MLAVTSQURME, adj., , flavisquamis (flaw'us, janne, squama, cueilleron ); qui a l's cneillerons jaunes. Ex. Filophoria Ylarisquamis.

FunVTARSE, adject., flavitarsis (flaus, janse, larsus, tarse); qui a les tarses jaunes. Ex. Panops Jlavilarsis.

TLAVIVENTRE, adj., flavipentris (Jlarus, jutine, venler, veutre); qui a le ventre jaune. Ex. Tanagra flavisentris.

FLAvopTine, adj. , flawoptcrus (flaws, janne, $\pi \tau$ spoy, aile); qui a les ailes jaumes. Ex. Fringilla flavoptera. 
506 FLEU

FLÉCIII, adj., Jlexus, inflexus. Les géognostes dounent cctic épithète aux couches, lorsqu'elles offrent des plis angulcux plus ou moins multipliés.

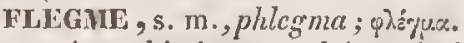
Les aneiens chimistes appelaient ainsi l'eau qu'ou retire des eorps soumis à la distillation, soit qu'ils la contiennent toute formce, soit qu'ils en renferment seulement les élénens.

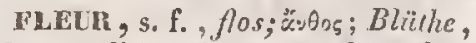
Blume (all); floster (angl.); fiore (it.). On cmploye ce mot: $1^{\circ}$ en ehimie. Les ancicns chimistes donnaient le nom de fleur's anx substanees rédnitcs en poudre, soit que la nature les offrc dans cet élat, soit qu'clles y aient élé amenées par quelque opération de l'art, mais surtout aux sublimés qui se eomposent de parlicules très-divisées ou d'aiguilles fortdéliées; fleurs d'antimoine, acide antimonieux préparć par sulblimation; flcurs d'arscnic, aeide arsénieux sublimé; flcurs rlc benjoin, aeide beuzoïgue obtenı par sublimation ; fleurs de bisnuulh, cffloreseenee d'nxide de bismuth qu'on trouve à la surface des minéraux qui renfernent en mème temps ce métal à l'état nalif; flours cle cobalt, arsénite de colsalt pulvérulent; fleurs de cuivre, oxide de cuivre rouge eapillaire; fleurs de nickel, oxide de niekel; ffeurs de sel ammoniac, chlorure anınonique sullimé; fleur's de soufre, soufre sublinic en très-petits eristaux aciculaires; fleurs de zine, oxide de zine produit par la eombustion du mélal. $2^{\circ}$ Ln botanique. $\Lambda$ vant Linné , on u'appelait flcur, dans les plantes, que les corolles ou calices colorés, et c'est encorc ainsi qu'ou entend le mot daus le langange vulgairc. Lirnné le prenier y attacha l'jdéc de générition, en disant que l'essence de la fleur consistc dans l'anthère et le stigmate, opinion que Ludwig embrassa sur-le-champ, et

\section{FLEU}

qui depuis a ćté adoptéc par la plupart des botanistes. Cepcndant, comme le fait observer Agardh, il est non-seulement siugulier qu'on range parmi les parties de la Aleur l'ovairc, qu'on $n^{\prime} y$ eomprend plus lorsqu'il s'est développé en fruit, mais encore ćvident que la fleur et le pistil sont deux organcs bien différens, puisqu'ils sont souvent séparés, que leur position relative varie beaueoup, et qu'il n'y a presque jamais coincidence d'époque entre l'épanouissement de l'ovaire et celui des étamines. Ainsi que Goethe l'a vait pressenti, gue Roeper l'n admis, ct que R. Brown paraít le penser, la fleur est une espècc de bourgeon terminal, dont les feuilles, vertieillées el modifiées par leur position, produisent toutes les parties qui la constituent. C'e'st, d'après Cindolle, un assemblage de plusieurs vertieilles de feuilles (ordinairement au nombre de quatre), diversement transformées, et situées cn forme de bourgeon à l'cxtrémité d'un rameiu. C'est, d'après DupelitThouars, un dévelopement de la feuille ct du bourgeon axillaire réunis. Turpin admet celte définition, cn exeeptant toutefois le pistil, qu'il regarde eomme formé par le prolongement de l'axe végétal, ou eomme produit par la tige. Ainsi envisagćc, la flcur s'èloigne beaucoup de l'idéc qu'on attache vulgairement au mot, unais rentre dans les conditions géuérales de la végétation, auxquelles on n'avait pu jusqu'alors la rapporter. Le uom de flcur est donnć aussi ì une sorte de vernis ou de poussièrc glauque, de uature eéraeéc, qui recouvre ecrtains fruits (ex. Prune).

FLEURAISON, s. f., florescentia, anthesis; $\dot{x}, 0 \dot{\mathrm{r}} \sigma \mathrm{t} ;$ B Blumenentfaltung, Blulhezcil (all.); fiorilura(it.). Action de flenrir; ćpoque à laquelle, ou temps durant lequel unc plante épanouit ses lleurs. 
TLEURETTE, subst. f., flosculus; Blümchen (all.). Petite fleur.

ILLURI, adj., floridus ; ג̇onpòs; blülend (all.). Epithète donnée, par les minćralogistes, au jaspe panachć, quand le verd y domiue. Le Liclen floridns est aiusi appeléà cause de ses grandes cupules, bordées de flets, qui ressemblent assez bien à une fleur radiéc. Cetle épithète est donnce aussi à des plantes qui produisent uue grande quantité de fleurs (ex. Cornus forida, Plysocalymna forida).

TLEURON, s. m., flosculus; Blïmchen (all.) ; fiorellino, fiorelto, flosculo (it.). Petite fleur. On appelle génćralement ainsi chacune des pctites fleurs dont l'aggrégation produit les capitules des Synanthérées, et mĉmc plus particulièrement celles Tui ont une forme tubuleuse et qui sont régulières. $\Lambda$ gardh prend ce mot dans un autre sens, el l'applique à chaque pétale d'une corollc polypétale, ou à ehaque lobe d'une corolle monopétale.

FLLURONNÉ, adj., flosculosus. H. Cassini doune cetle ćpithète à la calathide des Symanthérées, lorsqu'elle ne contient, au centre eomme à la circonfércuce, que des flenrons, c'est-á-dire des fleurs régulières et tubulenses. Hx. Centaurca.

FLEUVE, s. m., flumen; Fluss (all.); rioer (ungl.); fiumc (it.). Cours d'can, alimenté par' unc ou plusicurs rivières navigables, qui se jelte daus une mer.

HLEXIBnLtTE, s. f., fexibilitas; Biegsamkeit, Bcrigsanticit (all.) ; Mexibility (angl.); Alessibilita (it.) (Recto, ployer). Propriété qu'ont certains corps de se laisser courber plus ou moins faeilement jusqu'à un certain point, sans se briscr.

PLExibue, adj. , flexibilis, flexilis; $x \propto \mu \pi т \dot{s}$; biegsam, bcugsam (all.); flessibilc (it.); qui est susceptible de se ployer sans sc rompre, eomme la tige dil Juncus cffusus, qui est droite ct souple, et eelle de l'Isotlaccium flexile.

FIEXIBI.ES, adj. et s. m. pl., Flexibilia. Nom donné par Lámouroux à un ordre de la classe des Polypiers, comprenant ceux dont la substance est souple, et qui peuvent être pliés.

FLEXICAULE, adj., flexicaulis (flexus, eourbé, caulis, tigc); qui a une tige flexueuse. Ex. Solidagro Mcxicaulis.

FIEXIFOLn', adjeet. , Rexifolius (Mcxus, eourbé, folium, feuille); qui a des feuilles flexneuses. Ex. MIescnibryanthemum flexifolium, Barbula flexifolia.

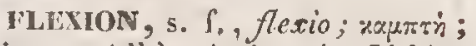
Bicgung (all.). Action de fléchir; état de ce qui est fléchi.

FLEXIPEDDE, adjectif, fexipes (Aexrs, fléchi, pes, pied); qui a des pédoncules flexueux. Ex. MYP = num Rexipcs.

FLIXUSUX, adj., flexuosus; zichzaclig, geliniet (all.); Ressuoso (it.); qui décril des flexuosités, des angles mousses plus ou moins ouverts; qui est conrbé en zigr-zag avee une eertaine régularité, comme la lige de l'Aristolochia serpcntaria, du Lotus Mcxuosus et du Delphinium flexuosum, ou les pédoncules du Campylopus flexuosus; qui esi replić sur soiméme, conmel'cmbro'onelel'Anguillaria bahamensis, le fruit du Cucumis flexuosus, les spadices du Muuritiaflexuosa, les fcuilles du Phascum flexuosum, les jeunes rameaux: du Spiraca flexuosa.

FUOCON, 5, m., תoccus; rooxis. Nom douné par les ehimistes aux touffes légères que eertains précipités forment en se rassemblant; par les zoologistes, aux touffes de poils qui garnissent le bout de la queue de 
certains mammifères (cx. Lion, Ane et quelques Singes).

Floconneux, adj., Rloccosus; flockig (all.); fioccoso (it.); qui a la forme de llocons. Se dil: $1^{\circ} \mathrm{cn}$ minćralogic, d'un corps qui ressembleà un flocon dc laine. (ex. Mesolype) $2^{\circ}$ En botanique, des poils, quand ils sont réunis en pelits loeons, qui se détachent sous la forme de touffes légères (ex. Astrotricha floccosa, Verbascumfloccosum), et dc plantes qui se composent de filamens groupés en touffes(ex. Colophermum fluccosum), ou dont les ramifications sont couvertes de petites aspérités qui les rendent comme villeuses (cx. Corallina floc$\cos a)$.

FLOCONNEUx, alj. et s. m. pl., Floccosi. Nom donné par Link à une section de l'ordre des Gastćrony cètes, comprenant ceux dout les sporules sont situées sur une bise floconneuse.

TLOCOPE, adj. , floccopus (floccus, floccon, pes, picd). Le Boletus floccopus al son slipe couvert d'écailles floconneuses.

FLOculeux, adj., floccuiosus, flocculatus. Une conferve (Diatoma flocculosum) est ainsi appelée parcc qu'elle rcssemble à un duvel verdâtre. Kirby donne cette épithète aux cuisses des insectes, quand elles portent une touffe de poils (ex. Andrena).

floraison. Voyez Fleuraison.

FLonaL, adj., floralis; fioralc (it.) (flos, fleur); qui apparticut à la flcur, qui naît sur ou dans la flcur. On appelle bulbilles floralcs, celles qui remplacent les fleurs dans certaines cspèces d'ail ( ex. Allium carinatum); cnveloppes florales, celles qui cntourent immédiatenent les organes sexucls; fouilles florales, celles qui sont placécs immédiatement à la base ou dans le voisinage des fleurs, et qui ne diffèrent pas des autres pour la forme (ex. Lonicera Caprifolium); glandes florales, eclles qui uaisseut sur les fleurs. Cette épitlette est donnćc aussi à divcrs insectes qu'on troure habitucllement sur les fleurs (ex. Anticus floralis, Fausta florea).

FLORALEs, adj.et s.f. pl., Floralcs. Nom donué par Latreille à une tribu de la famille des Tipalaires, comprenant celles dont les larves se trouveut dans les fleurs.

FLole, s. f., flora. Tableau des plantes d'une contréc : ouvrage destiné à présenter l'ćnumération des végćtaux d'un pays; recueil périodique consacré spécialement à la botanique, comme celui que public la société de Ratisbonne.

FLOnmoxD, adj. , floribundzes; blumenreich (all.). Se dil d'une plante qui est chargée de fleurs nombreuses (cx. Loranthus floribundus, Dillwinia floribunda, Hypericum florilusendum), et de quelyues a nimanx, par exemple de la Spongia floribunda, dout les rameaux sont couverts de paillettes imitant des fleurs.

FlOHICOLE, adject., foricolns (flos, fleur, colo, habitcr); (pui vit sur les fleurs. Ex. Tomisus floricolus, Mrclolontlea floricola.

TLOHCOLES, adj. et s. f. pl., Floricola. Nom donné par RobincauDesvoidy à une scetion de la famillc des Muscides, comprenant celles qu'on tronve sur les tleurs.

FLORIDÉ, adj. , floridcus ( Ros, flcur, E⿱乛ீ)่s, ressemblance). Épithète domnée à quelques plantes qui sont couvertes de fleurs nombreuses. Ex. Sabinea ploridca.

HLORIDELS, adj.et s. f. pl., Floridece. Nom donné par Agardh à un ardre et par Reichenbach à une famille d'Hlydrophyles, par Fries à unc tribu d'Hydrophyces, par Greville ì un ordre de Thalassiophy tessymphysistées, parce que les végćlaux compris dans ees diver's groujes ont une belle conleur pourpic ou rougeâtre 
qu'on a comparće a eelle des fleurs pour l'éclat.

FLORIDULEES, adjeet. et s. f. pl. , Floridulea. Nom donné par Robineau-Desvoidy à unc tribu de l'ordie des Myodaires Mieronydes.

Flomídration, s. f., florife 4 ratio. Synonyme peu usité de fleuraison. Voyez ec mat.

FLORIF Ella, adject. floriferus; bliitkentragend (all.) ; fiorifero (it.) (flos, fleur, fero, porter); qui porte des fleurs, comme les bructées du Populus, les feuilles dn Xylophylla faleata. On donne eette épitlictc aux bourgeons qui ne contiennent que des fleurs.

FLORIHORME, adj., floriformis (flos, fleur, forma, forme); qui a li forme d'une fleur. L'Aleyoniun Roriformis est ainsi nommé parce qu'il ressemble à une fleur à douze pétales; le Diderma floriforme, paree que son péridion globuleux s'ouvre en six ou sept lanières rayonnautes. $\mathrm{O}_{\mathrm{n}}$ donne aussi ectte épithète an corps de eertains animanx, comme les Actinies, qui onl élć eomparées de lout temps à des fleurs.

FLonmkges, adj. et s. m. pl. , Florilega (flos, fleur, lego, eueillir). Nom dounć par Duméril à une famille d'Inscetes hyménoptères , qui, à l'état parfait, vivent sur leş fleurs. $V$ oyez Antrophiles.

FLORIPARE, adjeet., Roriparus (fos, fleur, paro, engendrer). I.-C. Richard propose d'appliquer cette épithète au bouton qui ne donne que des fleurs, eonme étant plus cxaete que eelle de Joriférc.

Flonule, s. f. , fornla. Petite fleur; fleur isolée d'une ealathide, d'un céphalanthe, d'un épi.

Flosculdaís, adj. et s. m. pl., Floscularia. Nom doune par G.-G. Elurenberg à une tribu de la classe des Rotiferes, qui a pour type le genrc Floscularia.
FLOSGULE, s. m., floseulus (flos, fleur). Synony me de florule (voj. ce mot). Kirby appelle ainsi un organe tubulaire, étroit, lunulé et garni d'un style eentral, qu'on voit a l'anus de ln Fulgora candelaria.

ILOSCULEUSES, adj. et s. f. pl.; Flosculose. Nom d'une classe, dans le systime de Tournefort et dans eelui de Guiart, comprenant les plantes composíes dout les eorolles sont fleuronnées.

PuOscincux, adj. , floseulostus. Épilhìte donnée à lit cillathide des Synan thérées, lorsqu'elle ne renferme que des flemons. Ex. Centaurea.

FLOT'TANS, adj. et s. m. pl., $N a$ tantes. Nom donné par Lamarek à un ordre de la classe des Polypes, conprenant ceux qui sont réunis à un eorps eommun libre, Jequel, ehur. la plupart, flotle et semble nager dans les enux.

FLOTINNT, adj. , fuilans; fliessend, sehwimmend, flüthend (all.). Se dit, en botanique, des plantes qui, fixées au fond de l'enu par des racines, ont leurs tiges, leurs raneaux et leurs feuilles abandonnés au grédu eourant (ex. Potamogeton licens, Poa fuitans); en zoologie, de quelques infusoires qui semblent flotter dans les caux (ex. Crelidium fluitans), et des plumes des oiseaux, lorsqu'elles ont des barlues très-grandes, mais si flexibles qu'elles me s'accrochent pas, comme celles des ailes et de la queuc de l'autruche.

HLUA's, s. m., fuas. Aneienne dénomination des liydrofluates ou fluorures.

FLUATí, adj. Se dit en minéralogic d'une luse convertie a l'état de fluate ou de fluorure (ex. Chaux fuatée). Omalius donne le nom de roches fuatécs à un genre de roches pierreuses, eomprenant celles dans lesquelles le fluor entre conume principe constituant. 
FLULDE, adj. et s. m. , fuidus; flissig (all.); fluid (angl.). Ce mot, employé souveut pour désigner col. lectivement les gaz et les liquides, et quelquefois aussi res!reint à celte dernièıe signification, est unc épithète qu'on donne à tout corps dont les molécules sont assez pen colıćrentes cutre clles pour pouvoir glisser aisément les uncs sur lcs autres.

FLUIDIHICATION, s. f. Réduction d'un corps à l'état de fluide.

Fudidrú, s. f., fluidilas; Flüssigkeit (all.); fuidity (angl.). Ltat d'aggrégation dans leyuel se trouvent les corps liquides.

FLU0-BORATE, s. m. , fuo-boras. Genre de sels (flussboraxsaure Salze, all.) qui sont produits par la eombinaison de l'acide fluo-bnrique avec les bases salifiables.

FLLO-BORE. $V$. Fluo-bortQue.

FLUO-BOnIgUL, adj. , fuo-boricus. On a donné le vonn d'acide fluoboriquc (Flussboraxsïure, all.) ì nue combinaison de fluor et de hore, découverte en i 608 par Gay-Lussae ct Thénard.

FLUO-BORLRE, s. m. , fluo-boruretum; Fluorboronfuormetall'all.). Bcrzelius donuc ce nom à des sels doubles, qui résultent de la combinaison d'un fhorure avec le fluoride borique.

FLUO-COLOHBATE, s. m. , fltocolımbas. O11 a appelé ainsi des combinaisons du fuorure de colombium avec d'antres fluorures.

FLUO-MOINBDATE, s. m. , fluomolybdas. Nom dounć à des combinaisons du fluorure de nolyludène avec d'autres fluorures.

FLUOL, adj. el s. m. , fuor, fuo. rum ; Iluorine (all.). On employe ce mot pour désigner tautôl l'état Jiquide de certaius corps (aiusi l'alcalivolatil fuor est de l'ammoniaque dissonte dansl'eau), tantôt diverses substances minérales qui sont incombustibles, mais fusibles (ainsi le fluorure de ealcium a été appelé spath fuor). Fluor cst aussi lc nom d'un corps simple, dont on admet l'existence par pure analogie, car on n'est pas encore parvenu à l'isoler. Ce corpsa été appelé philiore par Ámpère.

HLUOR 1 CIDE, adjec:. et s. m., furacidum. Acidc dans lequel le fluor joueou est ccnsé jouer le rôle de principe acidifiant.

FLUORÉ, adj., fuoratus; qui conticut du lluor. On a appclé hydrogène fluoré l'acide liydrofluorique.

FLCOHIDE, s. m. , fluoridum. Bcrzelius donne ce nom aux combinaisons du fluor avec des corps moins électro-négatifs que lui, dans lesquclles les rapports atomiques sont les nic̀mes que dans les acides.

FLloriQue, adj., fluoricus. On appelait acide fluorique (Flusssäure, Flussspathsïure, all. ) l'acide hydrofluorique, lorsqu'on supposait que de l'oxigèc en rait dans sa composition.

Fldorisel, s. m. P. Boullay propose de nonmer aiusj les conbiuaisons des flunırures des métaux élcctro-négatifs arec ceux des métaux ćlectrn-positifs.

rLUORITIQUE, adj, fuoriticus. Omalius appelle roches fuoritique. no genre de roches pierreuscs daus lesquelles le fugr entre comme principc collstituant.

CluokuRE, s.m., fltoruretum, fluorctum. Combinaison du fluor avee un autre corps simple. Berzclius réserve ee nom pour lcs combinaisons du fluor aree les unétaux électro-positifs dans lesquelles les rapports atomiques sont les mêmes que dans les bases.

FLEOSHICATE, s. m. , fluosilicas. Combinaison du fluorure de silicium avec d'autres fluorurcs.

FLUOSILICIÉ, adj. La combinaison gazeuse de fluor et de silicium, ou le tuoride silieique, a été appelée 
quelquefois gaz pluosilicic on fluosiliciquc.

FLUOSILICROUE, adj. , fluosilici'zus. On appele acide fluosilicique tme combinaison de silieium et de Auor, dont la découverte est due à Seheele, et que Berzelius nomme fluoride silieique.

TLUOSILICIUnE , s. m., fuosiliciuretum. Une combinaison de fluoride silicique et d'ammoniaque est appelée fluosiliciure ammoniacal.

FLLOTANTALTE, s. nı., ftuotantalas. Combinaison du fluorure de tantale avec un autre fuorure.

FLUOTITANATE, s. m., Rmotitana.s. Combinnison du flnorure de titane avee un autre fluorure.

FLCOTUNGSTATE, s. m., fltotungstas. Combinaison du fluorure de tungstenc avec un autre fuorure.

FLUSTRÉEs, adj. et s. f. pl., Flicstrece. Nom donné par Lamouroux à une famille de l'ordre des Polypiers llexibles, qui a pour type le genre Filustra.

FLUURE, s.m. Synonyme peu usité de fuovure. $Y$. ce mot.

Feuvial, $V$. Fluviatile.

pleviales, adj. el s.f. pl., $P_{0}$ tame, Polamophite, Nä̈ades, Ily. drogetones. Nom donné par Ventenat et Kunth à une famille de plantes, qui est plus généralement connue sous celui de Naïades.

FLUVIATILE, adj. , fluvialis, fuviatilis, fluminalis, flumincus. Se dit de plantes qui eroissent dans les eaux courantes (ex. Ranunculus /lu"ialilis, Equisctum Rturatile), et d'animaux qui rivent dans ees enux (ex. Perca Ruviatilis, Cyclas Ruminalis, Cyrcna funinea).

Wruviatules, adj, et s. m. pl., Elusiatilcs. Nom douné par Lamarck Ine scetion de la classe des Polypes, Comprenant ecux qui n'labitent que les taux donees, principalement vives, et qui y sont libres on fixés sur les eorps aquatiques.

PLUVIO-MARIN, adject., fupiomarinzes. C. Prevost donne cette épithète a des formations mixtes, composées de súdimens qui ont été apportés par les caux douees eouranies, et déposés par clles sous la mer, soit avant, soit après le mélange de ees eaux, et à une dislinee plus ou moins grande de leur embouchure.

FLLX, s. m., maris eestus. En géégraphie, ce mot désigne eelle des deux oseillations journalieres qui fait monter l'eau de la mer et la porte vers la terre, dans les parties de l'Océan sujetles aux marées. En chimie, flux est synonyme de fondant. $V_{\text {aycz }}$ ce minol.

FOETAL, adj., fectalis (foutus, embryon ); qui a rapport au foctus. Vie foctale.

FOETrPARE, adjeet. , foctipartes. ( foetus, embryon, paro, produire). Desmonlins donne ce nom à une sousclasse de la elasse des Mammifères, comprenant ceux qui acconchent de foctus it non de pelits à terme.

rore, s. m., hepar. Les anciens chimistes donnaient ee now à diverses substanees dans la eomposition desquelles il entre du soufre, et dont ils comparaient la couleur lirunâtre à eclle du parencliyme du foie. Le foie d'antinoine est de l'hyposulfantimonite potassique; le foic d'arsenic, de l'arsenite potassiune ; le joic de soufre, un mélange de plusieurs sulfures alcalins. En anatomie, on appelle foie (jecur, lecpar; भ̆สхр; Leber (all.); liver (angl.); fegato (it.) la glande qui sćcrète la bile, chez les animaux.

Fon, s. m., fenum. On donne rulgairement ce nom à la masse des tubes qui garnissent en dessous les bolets, et qu'ou enlive pour manger ees ehampignons. On l'applique aussi a la masse de poils et de fleurs qui oceupent le eentre de la ealathide de 


\section{2} FOLI

l'artichaut, avant son épanouissement. roLIIGĹ, alj., foliaceus; blattartig (all.); fogliaco (it.); qui est de la nature des feuilles, qui en a la minceur lıabituelle ou la consistance. Se dit $: x^{\circ}$ en minéralogie, d'une substance qui, eomme le mica, se divise en grandesfeuilles ou lames. $2^{\circ} \mathrm{En}$ lotanique, des bourgeons, d'après Candolle, quand leurs enveloppes sout des feuilles sessiles, dont le limbe bui-même se trouve réduit ì la forme d'une écaille (ex. Daphnc Mezercum); des cotylédons, lorsqu'ils sont minees et souvent relevés de nervures à la manière des feuilles (ex. Tilia creropra); des involucres, lorsque les bractéesqui les composent sont larges,minees et vertes, il la miniere de la plupart des feuilles (ex. Lagrasca mollis); des pétioles, quand ils ont la forme de feuilles (voyez Phrllode); des spalhes, quaud leur substance est analogue à eelle des fuilles (ex. Gladiolus communis); des stipules, lorsqu'elles ont la coulenr et la consistance des \{ fenilles (ex. Agrimonia Eupatoria). $3^{\circ}$ En zoologie, du corselet des insectes, quand ses bords latéraux sont très-grands, membraneux et en forme de feuilles (ex. Mantis gongylodes); du tiliza de ces animaux, d'après Kirby, lor'squ'il se dilate latćralement en une plaque minee (ex. Euglossa cordata). L'Hippocampus foliatus est ainsi appelé a cause des appendices folincés qui garnissent diverses parties de son corps; l'Adeona foliacea, paree que sa tige est eouverte d'expansions folliaeées.

Fun ICís, adj. s. m. pl., Foliacea. Nom donné par Selıweigger et Eichwald à une famille de la elasse des zoophyles, eomprenant ceux de ees aninaux qui ressemblent à des expansions foliacées.

FOLIMInE, adj., foliaris ; blattstïndig (all.) (folium, feuille); qui appartient aux feuilles, qui naît sur les feuilles, comme les épines du Carduus murianus, les glandcs du Drosera, les flcurs du Xylophylla falcata. Candolle appelle vrilles foliaircs eelles qui sont produites par la feuille elle-neème prolongée en un appendice tortillé (ex. Methonica superba).

nOLLATION, s. f., foliatio ( folium, feuille). Moment out les bourgeons commencent à développer leurs feuilles. Linné entendait par ee mot l'arrangement des feuilles dans le boureon.

FOLICOLE, adj. , foliicolus ( folizm, feuille, colo, habiter); qui vit ou eroît sur les feuilles. Ex. Spharia foliicola, Hysterium foliicolun.

roLnEÈrE, adj., foliiforus; bliittertragend (all.); foglifcro (it.) (folium, feuille, fero, porter). Mirbel donne eetle épithète aux bourgreons qui ne contiennent que des feuilles. Un polypier (Adeona foliifera) est ainsi appelć, paree qu'il ressemble à un arbuste ehargé de feuilles alternes dćconpées.

FOIIIFERO-FLORIFURE, adj. , foliifero-florifertus. Se dit d'un bourgeon qui contient à la fois des feuilles et des fleurs. Ex. Syringa vulgaris.

FOLIIFLORt, adj., foliiflorus (fo. lium, feuille, flos, fleur); qui a les fleurs insérées sur le pétiole de la fcuille. Ex. Peperomia foliifora.

ror.IITOnviE, adj., foliiformis (folium, feuille, forma, forme); qui il la forme de feuilles, comme les expansions de quelques polypiers et les ramuscules de certaines 1) yetiotées.

FOLIIPARE, adj., foliparus ( folium, feuille, paro, produire). Synonyme de foliifére. $V$. ce mot.

FOLIOLdire, arlj., foliolaris. Epithète domée par Canclolle anx stipules, quand elles sont placées sur le pétiole conmmun, à la base des folioles. Ex. Phascoliss.

FOLIOLE, s. f., foliolum, foliolus; Blätcken (all.); forclietta, fogliolina 


\section{FOLI;}

(it.) (folium, feuille). Petite feuille: $\mathrm{O}_{\mathrm{n}}$ appelleainsi les pièces articulćes et séparables sans déchirement à la fin de leur vic, qui, par leur réunion sur un pétiole comınun, forment les feuilles dites composées. On donne le unême nom aux sépales du calice et aux pic̀ces de l'involucre. Kiby l'applique aux organes raides, non articulés et dilatés, qui garnissent l'anus des lilicllules.

FOLIOLE, adj., foliolatus. On donuc celtc épilliète aux fouilles qui sont formées de lenilles partielles on de folioles, atlachées sur un pétiole commnn. Ex. Phascolus.

NOLIOLEEN, adj., folioleanus. Mirbel appelle épincs foliolécnnes celles qui doivent lenr origine à des folioles transformécs. Fix. Chameerops humilis.

FOLIOLILLE, s. f., foliolollum. Nom donuc par Bernbardiax folioles d'une fentille bipinnéc.

- Moldorezurares, adj., foliolellularis. Berulardi donne celte épithìte aux pétioles des foliolellıles.

VOtronduldie, s. f., foliolcllulun; Bläuleinclicn (al!.). Noin donné par Beruhardi aux folioles d'une feuille tripinnéc.

Forrounex, adj.., foliolosus. Sc dit d'une plante qui a des feuilles trèsaljondantes el très-serrées (ex. Adenocarptes foliolosus), ou des feuilles romposées ì folioles très petites (ex. Rubus foliolosus, Thatictrum folinlosum).

IOLIOUWLis, adj., folioliferts. (foliolum, foliole, fero, porter); qui porte des foliolis. Ex. Liriospermum folioliferum.

NoLIOrluw, adj., foliopes (folinon, leuille, pes, pied \}. Se dil d'un insecte qui a les pattes accompangnées d'expansions membranenses plus ou moins grandes. Ex. MTantis filiopeda.

FOrricure, s. m. , folliculus, J. concepiaculum; Balgliapscl (all.); follicolo, bozzolo, guscio (it.). Sorte de fiuit formé par une scule feuille carpellaire pliéc longitudinalement sur ellemême, de manicre qu'il ne se présente qu'une seule sutire, résultant du rapprochement des lords de cetle feuille, et qu'a la maturité les bords se séparent an point de leur soudure, soit dans toute leur longucur (cx. Asclepias), suit vers le sommet seulement (ex. Trollius). Ics entomologistes domnent quelquefois le nom de foliicule au cocon des lépidoptères.

londescuné, adj., folliculatus. Ita Nercis folliculata al été ainsi nounInéc à cause dela forme aplatie de ses languettes vaginales.

POLLICulyorwe, adj., folliculiformis. Mirhel donne celte épilhète aux capsulcs qui sont formées d'nne seule valve soudíc sur ies bords, comme dans le foliicule. Ex. Avicennia.

FouldCunone, s. m., folliumodium; Balsliapsclliranz (all.). Nom donné par Agardh à un lruit composé de plusicurs follicules adassés (ex. Apocynécs, Colchicum, Hellcborus.

Foncine, adj. On appelle avalanclics foncières, celles qui, étant formée's d'une neige tres-compacte, ct ayant une grande pesauteur, détruisent complètement tout ee que, dans leur ehute, elles rencoutrent sur leur passage.

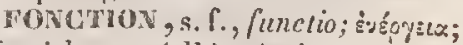
Ferrichneng (all.). Action que les partics d'un corps organisé exerecnt en vertu de leur texture spécialc, et dont le résultat cat de mettre cn évidence un ou plusicurs phénomènes de la vie.

IONDAMUENTAL, adj. , fundamentalis. Brochant appelle forme fondamcntalc celle, parmi toutes les formes dominaules qu'on a observéc-s 


\section{$5 \times 4$}

FONG

dans un minéral, dont la structure est la plus simple, dont on peut faire dériver toutes les autres par les modifieations les plus naturelles, et qu'on considere ecmine le type prineipal du système cristallin. W erner avait déjà admis sept formes fondamentales, dont il eroyait pouvoir faire dépendre toutes celles que présentent les cristaux de diverses espicees.

FONDANT, adj. et s. m., Fluss (all.); fucx (angl.); fondente (it.). On appelle ainsi, en ebinie, tout corps qui fond aisément, et qui, mêlé avec un autre corps, infusible par lui-mème, mais ayant de l'aflinité pour lui, détermine ee dernier. à entrer en fusion, par l'action combinéc de l'attraction que ses molécules exereent sur les siennes et de l'effort que le ealorique fait pour séparer ees dernières.

vovgate, s. m., fungas. Genre de sels (pilzsaurc Salze, all.), qui sont formés par la combinaison de l'acide fongique avee les bases salifiables.

Fongicoles, adj. et s. m. et f. pl., Fungicolat (fungus, eliampignon, colo, habiter). Nom donné par Cuvier, Latreille et Eichwald à unc fanille de l'ordre des Coléoptères, eomprenant cenx qui, pour la plupart, se trourent sur ou dans des champignons, dont il dérorent la sulsstance, et par Macquart à un groupe de la fanille des 'lipulaires, auquel il rapporte ecux de ces Diptères qui se développent dans les ehampinnons.

rovgluolkm, ndj. , fungiformis (fungzes, chanupignon, forma, forme). Se dit : $1^{\circ}$ en géognosie, d'une coulée de lave qui, partant d'une ouverture, el s'épanchaut sur ini terrain horizontal, bombé ou conique, s'y répand d'une manière à peu près cireulaire et égale, à partir de son point de départ. $2^{0}$ En botanique, d'apress Mirbel, d'un embryon

\section{FONG}

qui a la forme d'un champignon de couche (ex. MIusa coccinea). $3^{\circ}$ En zoologie, d'un poly pier qui ressemble à un ehampignon (ex. Chenendopora fungiformis).

FoNGixe, s. f., fungina (fungus, ehampignon). Nom donné par Braconnot au squelette des ehanpignons, à ee qui reste quand, après aroir exprimé ees corps, ou les a épuisés par l'action de l'alcool et des alealis élendus.

Fongrves, adj. ct s.f. pl., Frungina. Nom sous lequel Agardh désigne un groupe de la tribu des Confervoïles.

FONGIQUE, adj. , fungicus. Nom d'un acide particulier (Fungussä̈ure, Pilssïture, all.), que Braconnot a déeouvert dans plusieurs espèces de ehampignons.

FONGWone, adj., fungivorus (fungus, ehampignon, voro, dévorer); qui vil dans les champignons. Ex. MIuscina fungivora.

Foxgrvones, adj. et s. m.pl., Frengivora. Nom donnć par Duméril à une famille de l'ordre des Coléoplères, comprenant ceux qui virent dans l'intérienr des champignons $(V$. Mrycélobics), et par Jatreille à une sons-tribn de la trilon des Tipulaires, à laquelle il rapporte ceux de ecs Diptires dont les Iarves vivent dans lcs ehampignons.

FovGorne, adject., fungoildes (fungus, ehampignon, Eidos, ressemblance); qui a la forme d'un champignon. Ex. Hippalimus fungoïdes.

rovgueur, adjeet., fungosus; schrormmichl(all.). Se dit, en bolatnique, d'une plante (ex. Boletrs.s igniarins), on d'une partic de plante (comme la lorique de la tulipe ), qui est d'une substanec épaisse, coriaec el ćlastique. Le Coryclalis fungosa il une corolle persistante, qui se renfle uu peu après la tloraison, et parât 
alors forméc d'un tissu cellulaire trislâche et comme fongueux.

FONTALE, s. f. , fons; Quelle (all.); fountain (angl.); fonte (it.). Point où l'on voit une certaine masse d'eau sourdre de l'ćcorce solide du globe.

FoNTrGève, adj. , fonligents; qui croît sur les conduits ou sur les robinets des fontaincs. Ex. 1Rhizomorpha fontigena.

FonTival, adj., fontanus, fon. linalis; qui a rapport aux fontaines. Sc dit des plantes qui croissent a uprès des fontaiucs (ex. Montia fontana), ou des animaux qui virent dedans (ex. Cyclas fontinalis). C. Prevost appclait formations foninales, eelles qui sont dues à des sources d'eaux chindes ou froides, qui ont déposé les substances qu'elles tenaient en dissolution, soit sons $I_{a}$ seule influence atmosphérique, soit sous des caux donecs, ou mème sous des enux salćes, pen ou très-profondes.

TONTINALOIDIES, adj. ct s. f. pl., Fontinaloüdec. Nom donuć par Furnolir à un groupe de la famille des Mousses, qui a pour type le genre Fontinalis.

roravinú, adj. , foraminatus (foramen, trou); qui est pereć de petits trons.

FORAMINís, adj. et s.m. pl., Foraminosa. Nom donné par Lamarck, Lamouroux et Latreille ì une sectiou de la classe des Polypiers, comprenant ceux qui ont de petites cellules semblables à des pores presque tinbulcux, sans aucunc apparenee de lames.

ronamineux, adj., foraminosus ; qui est percé de petils trous.

Foriaminivires, adj. ct s. m. pl., Foraminifera (foramen, trou, S'ro, porter). Nom donné par Orbigny à un ordrc de Céphalopodes, comprenant ceux qui n'ont pas de siphon, mais seulenent une ou plu- sieurs ouvertures établissant communieation d'une loge à l'autre du test polythalame intéricur.

IORAMINULE, adj., foraminulatus; durchbohrt (all.); qui est percé de très-petits trous. Ex. Tubulipora foraminulala.

FoliCL, subst. f., vis, potentia,

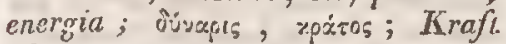
(all.); power (angl.); forza (it.). Expression, difficile à définir, que tout le monde comprend eependant, et à laquelle on atlache plusieurs sens. En général, on entend par force toute cause d'un effet quelconque, mesurable ou non d'après l'effet produit. C'est tout ce qui produit, empêche, change ou modific le mouvement: c'cst la raison suffisante de tout phénomène queleonque. " $\mathrm{La}$ foree, a dit Voltaire, n'est pas un être, un principe interne, unc substance qui anime les corps, et qui soit distinct d'eux : c'est unc propriété ou plutôt un mode de ces corps, c'est l'iction des corps en mouvement."

HORCEPS, s. m., forceps. Nom donnć par Kirby à une paire d'organes, transversalement mobiles et pointus all sonmet, qui garnissent l'extrémitć anale du corps des Forficules.

roncipule, s.f. , forcipula. On appelle ainsi chacune des deux mandibules succédanées constituécs, dans les Arachinides, par les deux premiers appendices manducateurs qui s'insèrent en avant du labre.

FOnfEx, s. m. , forfex. Nom donnć par Kirhy à une paire d'organes mobiles, suseeptibles de joucr transversalement l'un sur l'autre et de se eroisel, qui garnissent l'inns des mâles, dans les genres Raphidlia cl Phiopsis.

WOBWCUMAIIE, adj. , forfictllarizs; qui ressemble à une forticule. Ex. Anceuss forficularius.

NOPHICLALR:s, adj, et f. pl., 
Forficularia. Nom domnć par Latreille, Duméril , Goldfuss, Eichwald, Fieinus et Carus à une fanille d'insecte's orthoptères, qui a pour type le genre Forficula.

Foniatiox, s. f. Les géognostes employent ec mot daus des acceptions différcules, dont la plus simple est celle qui, se londant sur lc mode de production des masses minérales, lui fait désigner des roches ou des terrains qui se sont produits sous l'influence des mênes circonstances. Werner, détournant le mot formation de ce sens naturel, exprima par lá des assemblages de masses minćJales telle rnent liées en tre cllesqu'clies semblent avoir été produites à la tnême époque. On a réuni aussi les deux considérations ensemble, ct l'on a dit qu'une formation ćtait un assemhlage de masics minérales liées cnscuible de manière à ne faire qu'un tout ou systçme, sans interruption notable, tant sous le rapport du mode que sous celui de l'époque de la production. Ainsi formation s'entend, ou de l'origine d'une roche, ou d'une famille de roches prises cnscinble, ou d'une réunion de inasses minéralcs, ou d'une ríunion de dépôts qui sc sont faits à peu près à la uème ípoque dans différens pays.

FORMIATE, sulst. m. , formias. Genre de sels (anteisensatere $S a l z c$, all.), qui sont prodnils par la combimaison de l'acide formique avec les bases salifiables.

FORIMICADÉEs, adj. ct s. f. pl. , Formicadea. Nom donné par Leach is la famille des Formicuires.

Fonarcaire, adj. , formicarius (formica, fourmi). Se dit d'inscctes qui ressemblent i des fourmis, pur la formc générale de leur eorps (ex. Aranea formicaria), on qui font leur principale nourriture de fonrmis (cx. Myrmcleon formicarium).

rorilicallues, adj. et s. f. pl.,
Formicaria. Nom donné par Duméril, Latreille, Eichwald, Ficinus et Carus, à une tribu de la famille des Hyménoptères porte-aiguillons, qui a pour type le genre Formica.

FORMICIVORE, adj. , formicivorus (formica, fourmi, voro, dévorer); qui vit de fourmis. Ex. Myothera formicivora.

FORuIQUE, adj. , formicus. Nom donnć à un acide (Anteisensïure, all.), existant dans les fourmis rouges, qui fut découvert par. Noelse el Fischer en ${ }_{1} 6_{7}$ I, regardé en I So $_{2}$ par Fourcroy et Vauquelin comme un mélange d'acides acétique et malique, et réintégré en 1805 par Suersen et 1812 par Gchlen. L'éther formique (Ameiscnäther, all.) a été découvert en 1277 par Afzelius.

Fonuule, s.f., formula. Forme preseritc et consacrée. Depuis l'introduction de la théorie atomistique cn chimie, la nomenclature présente taut de difficultés pour être mise en harmonie avce les résultats de l'analyse et du calcul, qu'on a cherché des moyens d'y suppléer. Ites formules ou syniboles chimiqucs de Berzelius expriment très-bien la composition des corps, tant sous lc rapport de leurs ćlémens, que sous celui du nombre de leurs atomes constituans. D'abord chaque corps simple est désigné par un signe particnlier, représentant le poids relatif de son atome. Ces signes sont: $\mathrm{Ag}$. argent; $\mathrm{Al}$. aluminium; As. arsenic; $\mathrm{Au}$. or; B. bore; Ba. barium; Bi. bismuth; Br. brome; C. carbone; Ca. ealcuum ; Cd. cadmium ; Ce. cérium; Cl. chlore; Co. cobalt; Cr. chrone; Cu. cuivre; F. fluor ; Fe.fer ; G. glucinium ; H. hydrogene; Hg. mercure; I. iode; J. iridiun; $\mathrm{K}$. potassium; L. lithium; M. mansanese; MIg. magncsium; Mo. molybdenc; $\mathrm{N}$. nitrogene; Na. sodium; $\mathrm{Ni}$. nicliel; $\mathrm{O}$. oxigène; $\mathrm{Os}$. osmium; P. phosphore; $\mathrm{l} \mathbf{b}$. plomb; 
Pd. palladium; Pt. piatine; R. rhodium ; $\mathrm{S}$. soufre; $\mathrm{Sb}$. antimoine; $\mathrm{Sc}$. sélénium; Si. silicium; Sn. stain; Sr. strontium; Ta. tantale; Te. tellure; Th. thorium; Ti. titane; U. urane; $\mathrm{V}$. vanadium; W. tungsstene; $\mathrm{Y}$. yurium; $\mathrm{Zn}$. zinc; $\mathrm{Zr}$. zirconium. Chacun de ees signes indique un alome simple et pur du eorps qu'il désigne. $U_{n}$ alome double se rend par le même signe, dont l'initiale est traversée par une ligne droite (ex. $\mathrm{s}, \mathrm{p}$, $\hbar_{\text {s }}$, etc.). Deux sigues, placés ì eôté l'un de l'autre, indiquent un composć d'un sesul alome de chaeun des deux corps correspnndans (ex. SO, soufre et oxigène). Si le nombre des alomes de l'uu des denx eomposans est supérieur à l'unité, on l'exprime par uu pelit chiffre placé en haut de la leltre, il clroite, et qui ne multiplie que le poids alomique situé immédiatement is sa gatuehe (ex. $\mathrm{SO}^{2}$, in atome de soul'e et deux d'oxifine, acide sulfureux; $\mathrm{SO}^{3}$, un atome de soufre et trois d'oxigìne, acide sulfurique). Veut-on indiquer deux atomes du composé tout entier, on place ì la gauche du symbole un chiffre yui mulijplie tous les atomes de droite (ex. 2SO, deux atomes d'une combinatisou rle soufre et d'oxigène). Afus d'abréger, les corps basigènes s'expriment aussi par d'autres signes partieuljers qu'on place audessus des juitiales, savoir : un

paint (.) pour l'oxigène (ex. $\ddot{\mathrm{S}}$, au lieu de $\mathrm{SO}^{2} ; \dddot{\mathrm{S}}$, an lieu de $\left.\mathrm{SO}^{3}\right)$, une virgule (,) pour le soufre (ex. K, pour $\mathrm{KS}$, un atome de potassium et un de soufre), un trai ( - ) pour le sélénium (ex. Mo; in atome de molybdine et trois de sélénium ), et une eroix $(t)$ pour le tellure (ex. Mo, un atome de molyludène et trois de tellure). Par la combinaison de ces divers signes, on parvient à exprimer tous les composés chimiques, en séparant par le signe + les atomes composés dont la réuniou les produit. Ainsi $\mathrm{Cu} \mathrm{O}+\mathrm{SO}^{3}$ veut dire sulfate cuivique, et le $\mathrm{O}^{3}+3 \mathrm{SO}^{3}$, sulfate forrique, ce qu'il est plus court et plus coonmode d'écrire $\dot{C} u \stackrel{S}{S}$ pour le premier, et $\dddot{F}$ e $\dddot{S}^{3}$ pour le second. De mème $\dot{K}$ M̆o est un sulfomolybdate polassique; $\dot{\mathrm{K}} \ddot{\mathrm{M}}$ o, un sélénimolybdale potassique; $\hat{K} \stackrel{+* *}{\mathrm{~N} o \text {, }}$ un tellurimolyludate polassique. Ces formules out le grand avanlage de mettre ì la fois soas les yeux un grand nombrede données différentes. Ainsi,

par exemple, celle de l'alun, $\dot{\mathrm{K}} \mathrm{S}+$ $\dddot{\mathrm{f}} \mathrm{IS}^{3}+24 \dot{\mathrm{I}}$, fait voir de suite que ce sel conlicnt 1 atome de potassiun, 2 d'aluminium, 4 de soufre, 48 d'hy* drogìne th 10 d'oxigène; que 1 atome de potasse y est conbiné avee 1 atome d'alumine, \& d'acide sulfi1rique et 2.4 d'eau, ou I atome de sulfate potassique avec un de sulfate aluninique; que les deux sels sont neutres, c'est-ì-dire au degré de saturation où l'acide contient trois fois aulaut d'oxigine que la base; que l'oxigène de l'alunine rst triple de cehni de la potasse; que l'oxigune de l'acide sulfurique est 12 fois celni de la potasse, et 4 fois celui de l'alumine; que l'oxignene de l'eau est 24 fois celui de la potasse, 8 fuis celui de l'alumine et 2 fois celui cle l'aeide sulfuriqque. Voulant simplifiec encore cette mél bode graphique, dans ses applicatious à la minéralogie, Berzelius at imaginé de lui faire suhir des modificatious qu'il serait trop long de faire connaittre ici, et qua d'autres minéralogistes ont également changées depuis. Lc mênı morí nous fait passer sous silence les notantions cristallographiçues, qui ont 
singulièrement varié depuis Haüy, les formules géognostiques qu'a proposées Humboldt, et tous les cssais, parfois ingénicux, mais la plupart du temps bizarres, qu'on a tentés dans l'espoir de simplificr la nomenclature botanique introduitc par Linné.

VORNICIFE'RE, adj., fornicifcrus (fornix, voûte, fero, porter). La Spongia fornicifera cst ainsi appelée parce que ses rameaux forment des espèces de voûtes en se réunissant ensemble.

FOnSKIILLÉes, adj. et s.f.pl., Forskhaliere. Nom donné par A. Iichard à un groupe de la famille des Urticées, qui a pour type lc genre Forskhalea.

FORTIROSTiE, adj., fortirostris (fortis, fort, rostrum, bec); qui a le bee fort. Ex. Dendrocolaptes fortirostris.

DOSSETTE, s.f. , fossula, scrobiculus; Pröproy; Gruluc (all.). Cavité d'une charnière de coquille bivalve.

rOSSILE, adj. et s. m., fossilis. Ce mot qui, autrefois, exprimait tout ce qu'on trouve dans le sein de la terre, ne désigne plus anjourd'hui que les débris de eorps organisés, enveloppés dans des masses menbles ou pierreuses, qui ont vécu soit sur la terre, soit dans les eaux, et pour la plupart ì des époques tellement éloignées que nous n'avons aucuue donnée pour en apprécier l'ancienneté. Quelques géognostes en ont encorc restreint davantage la signification, et l'ont employé conme synonymc d'antédiluvien. Deshayes définit les fossiles des corps organisés qui ont été enfouis dans la terre à une époque indéterminéc, et qui y ont conservé ou qui y out laissé des traces non équiroques de lcur existence. Celle détinition est plus générale, mais peut être moins logique, que l'ancienne, d'après laquelle un fossile est un corps organisé dont les parties solides déposées dans lc sein de la terre ont eonscrvé intacte leur struclure organique. Un poisson (Mrisgurnus fossilis) a été appelé ainsi parce qu'il a la faculté de vivre long-temps dans la vasc, après l'épuisement des eaux; l'Hyana fossilis , paree qu'on ne la connaît qu'à l'état fossilc.

FOSSILISE, adj.; qui a été eonverti en fossilc. Se dit du bois, des os, des cequilles.

FOSSIREDES, adj. et s. m. pl., Fossipedes (fodio, fouller, pes, pied). Nom donné par Blainville à une famille de l'ordre des Mammifères carnassiers, comprenant ceux qui ont les extrémités des membres dissemblalıles et les mains exclusivement destinćes à fouir.

FOUDnE, s. f. , fulmen, fulgur ; Wettcrschlag, eirssehlagender Bliz (all.); thunderbolt (angl.); folgore (it.). Écoulement subit, à travers l'air, sous la forme d'un grand sillon lumineux, de la matière électrique dont était elıargé un nunge. Tout danger est passé quand on a entcndu le bruit que fait la foudre et vu l'ćclair qui l'accompagne, ear celui qui doit être foudroyé nc voit ni n'cutend le coup prèt ì le frapper.

FOUET, s. m., flagellum, flagrum. Appendice en forme de petite anteune portée sur un long pédoneulc, qui naît extérieurement de la pic̀ce serrant de base aux pieds-mîchoires des Crustacés décapodes. Foutet de l'aile. Voyez A ileron.

roughines, s. f.pl., Filiccs. Nom d'un ordre dans les systèmes de 'Tournefort et de Lisné, d'une fanille de plautes dans celui de Jussieu.

FOUISSELR, adj., fodiens, cunicularius; qui se creuse en terre des retraites ou des espèces de terriers. (ex. Mygale fodicns, Mygale cunicularia). Kirby appelle picds fouis- 
seur's, dans les insectes, ceux dont les tibias sont palmés on digités (ex. Scaritcs).

FOuQuirnacles, adj. et s. f. pl., Fouquicracere. Nom donné par Candolle et par Kunth i une famille de plantes, qui a pour type lc genre Fouquiera.

noverie, subst. f. , furca. Nom domé par Illiger aux deux branches de Ia mandibule inféricure des $\mathrm{O}_{-}$ seaux, prises ensemble, depuisle bout du bee jusqu'ì leur insertion; par Kirby, à un organe élastique, infléchi el tcrminé en fourche, qui garrnit l'anus des Pordurus, el permicl it l'animill de satuter.

FourcneT'te, s. f., fuscina. Filévation en forme de $V$, qui, daus le pied du cheval, se trouve au milicu de la sole ct à la partie postérieure.

rourciv, adj., furcalus, bifurcatus, forficalus, fiurcellalus, lituatus, forcipatus, furcifer; sabolformig, gabelig, segabeh, zangenfurmin, zinkig, ziveizinkig (all.); forlicd(angl.); forculo (it.); qui se divise en deux parties ou brauches plus ou moins écartíes, comme les poils de plusicurs Arabis. Le Nauclerts furcatus, le Caprimulgus forficalus et le Caprimulgus furcifer ont la queuc très-fourchue; l'Ornismya furcata l'a un peu fourchue; le Fucus furcellatus in sa frondescence fourchuc à l'extrémité.

FOURWLI:LE, s.f., formicarum cubile. Socićté ou famille nombrcuse forméc par des lournis; habitation de cette société.

pourutucioss, s. m. pl., Myrmeleonides. Nom donné par Latreille ì unc tribu de la famille des Nérroplères planipennes, qui a pour type le genre Fourmilion.

counnure, s. f., villosa pellis. Peau de mammifère revêtue des poils de l'animal.

NOVEOLAIRE, adj, , fopeolarius (fovea, fosse). Se dit d'un corps dont la superficie est ereusće de petites fossettes inégales. Ex. Spongia foveolaria.

vovíoté, adj, forcolants, favulosus, scrobiculatus; foingrabis (all.); qui est marqué de fossettes ou de petiles dépressions. H. Cassini dit le clinanthe fovcolć, quand les aréoles paraisscut enfoncées par l'effet de la saillie du réseau, que les fossclles sont arrondies, el que le réseau est épais, peu élevé. L'Andropogor fovcolatum présente, au dessus du sommet de la valve extéricure du calice de ses fleurons fertiles, une lossctie qui resscmble à l'impression qu'on pourrait prodnire avec une tête d'épingle. Le Glyplis favulosa a ses apothécies crensées de profondes impressions qui simulent les alvéoles d'un guêpier. Le Cucrellanus foveolatus a unc fossetle en dessous de la tête. La Spongia scrobiculata est couverte de fosseltes arrondies.

Fovilla, s. r., Befrucletungsstoff (all.). Martyn a désigne sous ce nom Ia liqueur fécondante contenue dans les grains du pollen, et où Gleichen a le premicr observé des corpuseules auxquels Amici et Brougniart ont attribué une sorte de mouvement animal, opinion que $\mathrm{R}$. Brown et Raspail ont combaltue.

Foren, s. m., focus; Éctix. Licu plus au moins circouscrit ax l'on a produit une tempérnture plus ou moins élevéc (Fcuerherd, all. ; heart, augl.); point où se réunissent les rayons luminenx réféchis par un miroir oil réfractés par unc lentille (Brennpunlut, all.; focus, angl.).

Fricticolle, adj., fraciicollis (fractus, rompu, collunt, col). Le Pachymerus fracticollis a le thorax. profoudément lobé sur les côtés, ce grui le fait parấtre comme brisé.

FRACTCORNE, adj. , fracticornis (fractus, rompu, cormle, corne). 
Le Copris fracticornis porte sur l'occiput unc lame terminéc par une épine qui se recourbe en avant.

Fracticonves, adj. et s. n. pl., Fracticorncs (fracins, rompu', cornu, corne). Nom donné par Latreille ì use section de la famille des Rhynchophores, compreuant ceux de ces coléuptères qui ont les anteunes coudées.

FRACTIPÈDE, adject. , fractipcs (fractus, roupu, pcs, pied ). I'O. robitis fractipes a les euisses resserrées et comne ćtranglées un fcu audessus de lcur extrémitć.

ERAGARI cieses, adj. ct s.f. pl., Fragariacea. Nom donné par Candolle à un groupc de la fanille dés Rosacées, qui a pour type le genre Fragaria.

FRAGAnLÉES, adj. et s. f. pl. , Fragarice. Voycz Fragaricétes.

FRAGIVthe, adject, , fragiforus (fraga, fraise, fcro, porter). Le Trifoliun fragiferum est ainsi appelé parce que ses fleurs, aggrégées en tètes arrondies et à calices renflćs, ont quelques ressemblance avec unc fraisc.

Flacimonue, adj., fragiformis ( $f r a g \alpha$, fraise, forma, formc). Sc dit d'une plante qui a le port du fraisier (cx. Duchesnca frayiformis), on qui ressemble a une fraise, soit parec qu'clle a unc forme ronde (ex. Tremella frasiformis, Dacrymyces fragiformis), soit parec qu'ellc est ronde et ronge dins sa jeunesse (cx. Tubulina fragiformis).

FRAGILAlues, adject. et s. f. pl., Fragilaria. Nom donué par Bory à une tribu de la famille des Arthrodićes, ayant le genre Fragilaria pour type.

FRAGILARINÉES, adj. ets. f. pl., Fragilarina. Nom donné par Fries à une tribu de la cohorte des Diatornées, qui a pour type le genre Fragilaria.

FRAGLLE, adj. , fragilis ; «pa:joss; zerbrechlich, brïchion (all.) ; britlle (angl.); fragile (it.); qui est susecptible de se briser en morceaux au moindre effort de flexion, comme la tise du Sonclus olcraceus, ou au moindic con tact, comme la quenc de l'Anguis fiagilis, la coquille de la Ianthina fragilis, les rameaux du Corallina fracrilissima.

FMGIITÉ, s. f. , fragilifas;

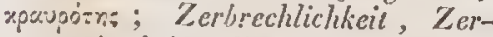
sprengbarkcit (allem.); brittlcness angl.). Fuculté qu'ont ccrtains corps de se briser plus ou moias facilement par l'effet de la pereussion.

FRAGNENTAliLE, adject. Se dit d'une substance qui est susceptible de se briser, de se réduire en fraguneus, on qui peut acquérir cctte propriété après avoir subi l'action du leu, ou avoir été traitée d'unc autre mavière.

PRAGMENTAME, arlj . fragmentarius (fragmentum, fragment). On dit qu'une roche a unc structure fragmentaire, quand ellc est composée de fragmens d'autres roches préexistantes, qui, après avoir été clariés dans les licux oi on les voit, y ont été agglutiućs par un ciment ordinairement d'une autre nature (ex. Briches, Poudingucs); ou quand sa massc est divisce par une multitude de joints, qui suivent tontes sortes de directions, et qui permettent de la partager en fragmens anguleux, i angles ct arćtes indéterninables (ex. Porphyre).

FRAGMEvTELx, adj. Brongniart désigne sous ce nom un groupe de terrains hémilysiens, qui sout abondans en débris ou en roches composées de débris.

FRAI, s. m., piscium sobolcs; Lcichon, Lcich (all.); spawn, fry (angl.). O11 appelle ainsi les œurfs des reptiles batraciens et des poissons.

FRANGE, s. f., fimbria, annulus; Franze, Ringr, Saum, Bräme (all.). 
Willdenow appelait ainsi une membrane ćlastique et dentée qui est situce sous l'opercule de ecrtaines mousses.

FRATGÉ, adj., fimbriatus; gefranzt, gebrämt (all.); fimbrialo, frangiato (it.); qui offie une bordure quelconque, découpée en manière de franges, comme le tlicalle du $S_{\text {cyphophorus fimbriatus, les pétales }}$ du Dianthus fimbrialus et du $\mathrm{Ce}-$ raslium fimbriatum, les lobes de la corolle dn Pracela fimbriala, la coiffe de l'Encaly pla fimb́riala, les funes et la queuce du Gecko fambrialus, les liveres du Labco fimbrialus, les plis transversiux di la Chama fimbriala. Ou dit que les ailes des insectes sont frangées, quand clles présentent une bordure de dents alongées, pointues et très-serrées, qui figurent une cspèce de frange.

NRAvGés, adj. ot s. m. pl., F'im. briala. Nom donné par Lamarek it une famille de l'ordre des Crustacés branchiopodes, comprenant eeux qui ont les pattes sćtifëres pour la plupart.

Frangueacíes, adj. et s. f.pl., Frangrularece. Lamarck désigne sous 'e nom la fanille des Rhamućes, at cause du Rhamnus Frangrula qu'ellc renferme.

FRANGULINE, s. f. , frangulina. Principe amer de l'écolec du Rhannus Frangula, que Gerber est parvenu à isoler.

Fhank Exiacérs, adj. et s.f. pl., Franlieniacea. Nom donné par A. Saint-Hilaire à une famille de plontes, qui a pour type le genre
Frankenia.

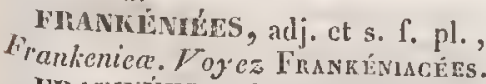
FRaxivies, adject. et s. f. pl., Fraxinea. Nom donné par Barting à une trilua de la famille des Oléinécs, qui a pour type le genre frra-
xinuls,
FRAXINELlEes, adj. ets. f. pl. , Fraxinella. Nom donné par Nees d'Esenbcek el Martius à ure famille de plantes, ayant pour type le genre Fraxinelle.

THAXnvCOLF, adj., fraxinicolus (fraxinus, frène, colo, babiter); qui vit sur le frène. Ex. Melolontha fraxinicola.

FREIN, s. m., frenum, frenulum. liepli menbranenx qui retient un organc; frein de la languc, frein du prépuce. Latreille donne ce nom au crochet alaire des Lépidoptères. KirJy l'applique à nne picee siluce au dessous du bord latéral dn scutellum et du dorsolum, et qui, dans beaucoup de cas, a cles connexions avec la base des ailes supéricures, ì la dislocation lesquelles elle s'oppose.

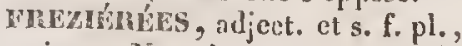
Frezieree. Nom douné par Candolle a uuc tribu de la famille des Ternstroemiacécs, qui a pour type le genre Frezicra.

Gnußruné, s. f., friabilicas; qaOupónn:; Zerreiblichlieit(all.). Proprićté qu'ont eertains corps de se réduire en menus fragmens ou en poudrc grossière sous l'influence d'un choc même léger.

PHIABLE, all. , friabilis ; ఛैoupò;; zerreiblich (all.); lacile ì rérluire cu poudre. Se dit d'une roche, quand ses parlics se désaggrégent aisément (cx. beaucoup de granizes), et du périsperme, lorsque étent de nature sèche, il s'émictie par l'effet de la moindre trituration (cx. Piper nigrum).

fricandes. Vojez PhrygaNIDES.

FuGnH!1Que, adjcct, , frigorificus, frigcfaciens, refrigerans; $4 \dot{y}$ $\mu x=0$ (frignzs, froid, fio, êtrc fait); qui produit du froid. Ūn mélange frigorifique est celui qui abaisse la température des corps qu'on y plonge, parce qu’il se liquéfie aux dć- 
pens du calorique qu'il leur enlève. Rumford donnait lc nom de rayons frigorifiques aux mouvemens rectilignes de propagation des ondulations du Aluide éthéré qui excitent une action retardatriec.

FuIMas, s. m., pruina (/remo, frissonner). Nom collectif du givre et du grésil, parce qu'ils sont dus à un Lrouillard épais, qui se congèle avant de tomber. On emploie quelquefois ee not pour désigner tous les météores de l'hiver, en partieulicr la neige.

TRIVillivies, adj. ct s. m. pl., Fringillide. Nom donné par Viggors ì une tivibu de la famille des Conirostres, qui at pour type le genre Frinsilla.

FHIPIER, adj.et s. m. Nom rulgaire donné à plusieurs eoquilles, ì cuuse du grand nombre de petites pierres ou autres corps dont elles se courrent, cn les fixant à leur surface d'une manic̈rc assez solide. Les larves des phryganes agglutinent aussi des corps étrangers autour de lcur fourreau. Foyez Agglutinant.

FLITTAGE, s. m. Opération ayant pour objet de brûler les eorps orginisés ou combustibles qui peuvent se trouver dans uu mélange minéral, et de produire un commenecment de combinaison.

ForTte, s.f. Mélange des matic̀res employées à la fabrieation du vcrre, qui a été exposé à uue teinpćrature insuffisante pour opérer la vitrification, mais sufisante pour déterminer un commenecment d'action chimique entre les eorps constituant le mélang’e.

FROIi), s. m. , firgus; ఫ่úyos, p̈yos; Källe (all.); coid (angl.); freddo (it.). Scusation que nons ćprouvons lorsque notre corps abandonne du ealorique à des corps dont la température est moiudre que lit nôtre. Ainsi, tunte température in- féricure à une autre est du froid par rapport à celle-ei, et le mot froid n'exprime qu'une idée relative. Cependant quelques physiciens ont cherelié à déterminer le froid alısolu, que Clémeut et. Desormes fixent a $266^{\circ} 66 \mathrm{c}$. an dessous du terme de la congélation de l'eau, el que Benzenberg place bien plus bas, $77^{\circ}$. Les calculs de Fourier ont ćtabli qu'il ne peut y avoir de froid absolu.

Fllow, adj., frigidlus; kalt (all.); freddo (it.); qui n'est pas chatud. Le Dodecatheon frigidum est ainsi appelé parce qu'ou le trouve dins les parties les plus froides di grolfe SaintLaurent. Les canx miućrales qui onl Ia température moyeune di lieu d'où elles sourdent, sont appelćes froidcs, par opposition avee celles dorit la température est supéricure à celle de l'atmosphère, cl qu'on nomme thermales.

FFONDE, s. f., frons; Laul, IVedel (all.); fronda (it.). Les ancicis désignaient l'ensemble des feuilles ou le feuillage des arbres sous ee nom, que Liuué appliqua au trone des palmiers et des fougtres, mais dont il se servit cependant aussi pour exprimer les cxpansions foliacécs des hépatiques et des fucus. Peu de botanistes ont appelé le feuillage despalmiers fronde, comme l'a fait Jussieu ; mais beaucoup ont donné ectte ćpithète aux feuilles des fonģèt cs. Quelques modernes proposent, arce Link, de la réserver pour les expansions des lépatiques, qui ue sont propreunent ni tige, ni feuille, ou pluıôt qui sont l'un et l'autre it la fois: Lamouroux nomme fronde, dans les alguc:s, toute la partie de la plante qui ne sert point a la reproduction.

FHONDLSCENCE, s. f., frondes". centia. Ce mot est ensployé quelqué fois, inais rarcment, comme synonyme de vernation. On dit sourent li froudesecnee d'uu poly pier, pouts 


\section{FRON}

exprimer que ses rameaux s'étalent en expansions foliacées.

FRONDESCENT, adj. , frondescens; qui a la forme d'une feuille; cxpansion frondesecnte.

FRONDICULE, adj. , frondicolus (frons, feuille, colo, habiter); qui vit sur les feuilles. Wx. Spheria frondicola.

FIRONDICULÉ, adj. , frondiculatus. Synonyme peu usité de dendroidc, quion employe pour désigner quelques polypicis rameux. Ex. Hornera frondiculala.

FRONDIF (frons, feuille, fero, porter); qui a des lobes foliacés. Ex. Spongia frondifcra.

Frondure , s. f. , frondula. Division d'une fronde.

FRONT, s. m., frons ; $\mu \dot{\varepsilon} \tau \omega \pi \circ$; Stirn (all.); forchcad (angl.). On appelle ainsi, daus l'homne et les manmifères, In portionde la faee eomprise, d'une tompe à l'autre, entre le rebord orbitaire, la base du nez et le sommet de la tête; dans les oiscaux, la partie de la tète quis'étend depuis le hee jusqu'au vertex ; dans les crustacés, l'iutervalle qui sépare les ycux, quand le bord antérieur de la tèle ne se prolonge point en rostre; dans les tribolites, la partie moyenne du bonelier; dans les insectes, la partie antérieure et supéricure do la tète, comprise entre la bouche, les antemur's, l's yeux et l'occiput, et plus spécialement eelle qui s'élend d'une antenue à l'autre ct de la région stemmatique à la base des antennes.

FRONTAI, adj. et s. u., frontalis; qui tient on qui a rapport, au front, comme les plumes qui le garnissent dans les oiscaux. Robineau-Desvoidy noune frontaux, dans les Myodaires, deux pièees assez régulières, ordinairement adossées et colorćes, qu’on voit sur lo milicu du front de ces insectes. Blainville appelle segment frontal, dans les vers, l'une des pièces qui conyosent leur segment céphalique. Cette épithète est donncé à quelques animaux qui ont le front d'une autre eouleur' que le eorps, ou remirquable par son mode de colomation (ex. Coccinclla frontalis, Fal. cunculus frontatus, Psittacaria frontala).

Frontales, adj. et s. f. pl., Frontales. Nom donné par Lamarck à une section de l'ordre des Hémiptìrcs, comprenant ceux de ces insectes dont le bee, naissant de la partie antérieure et supérieure de la tête, semble sortir du front.

PRONTICORNE, adj. , fronticornis (frons, front, cornu, corne); qui porte, sur la partie an téricure de la tête, une véritable corne (ex. $L a-$ mia fronticornis), ou une protubérance cu forme de corne (ex. Naseus fronticornis).

Hiontmostiles, adj. et s. m. pl., Frontirostres (frons, front, rostrum, bec). Nom donné par Duméril i une fanille de l'ordre des Hémiptères, eomprenant des insectes munis d'un bee qui paraît uầtre du front. Voycz lininostomes.

MOTTEMENT, s. f., fricatio, fricus, affrictus; Reiben (all.); rubbing (anglo). Résistance au monvement qui tient ì ce que, quand deux corps sont appliqués l'un eontre l'autre et se pressent mutuellement, il y a toujours quelques aspérités de l'uu qui s'cugagent daus les cavités de l'autre.

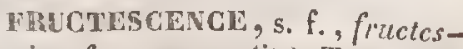
centia; fruilescenza (it.). Torme peu usilé qui désigne l'époque de l'année à laquelle la plupart dos semences mûrissent.

FHUGTIFkE, adj. , fructifcrus; fruchuragend (all.) (fruelus, fruit, fero, porter) ; qui porte des fruils: membrane, organe, surface, tubcr- 
culc fructifère, tous termes usités en parlant des partics qui, dans les cryptogames, portent les corps reproducteurs.

FRUCTIEICATION, s. f. , fruclificatio; Befruchung (all.); fruttificazione (it.). Collection des phéno. mènes qui acconipagnent la Cormation du finit, depuis le premiermoincut de son apparition jusqu'à sa matnrité. Se dit alussi de la disposition des partics dont la réunion forme le fruit, et de l'ensenible des fruits eux-mèmes que porte un végétal quelconque.

FRUCTIFLORE, adj, , fruclifor'us (fructus, fruit, flos, fleur). Lamarck dounait cette épithète aux fleurs dontl'ovaire est infère.

NRUCTKLORES, adj. et s. f. pl, Fructiforce. Nom donné par Royen ì une classe de plantes, comprenant celles qui ont les étamines sur le pistil.

FRuCTrionwe, adj. , fructiformis (fructus, fruit, forma, lorme); qui a l'apparence ou la forme d'ua fruit.

FRUC'TIGÈE, adj. , fructigenus (fructus, fruit, gcno vaittre); qui croît sur les fruits. Ex. Pcziza frucligena, Acrosporium fructigenunu.

Fnveriste, adj., fructista. Nom donné par Liuné aux holanistes qui, comme Cósalpiu, Morison, Rai, Kuaut, Boerhaave, Hermann ct Gaertner, ont établi lcurs méthodes sur la considćratious du péricarpe, de la graiue ou du réceptacle.

TRUCTUAme, adj., fruchiarius (fructus, fruit). Terme que L.-C. Richard a proposé pour désigner ec qui appartient on est relatif au fruit.

Frucrulk, s. m., fructulus. Se dit de chacun des fruits particuliers qui concourent à la formation d'un fruit composć.

Frugibles: adject. , frugillgus S(rux, production de lia terre, lego, eueillir). Le Corvus frucilegus vit de grains, qu'il va chercher en terre.

FRugivone, adject., frugivorus (frux, production de la terre, voro, dévorer) ; qui vil de grains ensemencés. Ex. Mlus frugivorus.

risugivones, adj. et s. m. pl., Frngivori. Nom donné par Vieillot et C. Bonaparte à unc famille de l'ordre des Sylvains ou Passereaux, comprenant des oiscaux qui se nour. rissent de fruits.

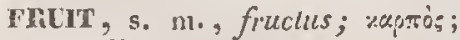
Frucht (all.); frutlo (it.). Dous le Jangage vulgaire, on a l'labitude de ne donner ee nom qu'aux fruits charnus el susecptibles d'ctre mangés. Les botanistes lui ont donné zum sens beaucoup plus étendı, car ils le définissent, aree Cardolle, le corps résultant des orules transformćs cu graines par la fécondation, des carpelles qui entourent ces ovules, les contieunent et les vourrissent, et de toutes les parties de la fleur qui, par leur adhérence aree les carpelles, semblent plas ou moins former partie intigrante de l'appareil entier. D'où l'on voit quu'ils rattachent à l'idée du fruit, clans les plantes, plusicurs organes qui sont origiuairement étrangrers à son essence.

FrumeNacis, adj., frumentaccrss (frumcntum, cérćalc). Épithète donnéc ì toutes les Graminées que l'on cultive a cause de la grande quantité de farine que fourmissent leurs graines.

FnustruxE், adj. , frustraneus (frustra, en vain). Limné donnait ee $110 \mathrm{~m}$ à nu ordre d'une des classes de son sysiène, paree qu'il renferme des Synanthérées dont les flcurs du disque sont hermaphrodites ct fécondes, et celles de la circonférence neutres ou femelles et stériles, c'està-dire inutiles. Ex, Gicorgina frustranea.

IRUSTUL: adjcct, frustulat;s 
(frustulum, petit moreenu). La Retepora frustulata a été appelée ainsi parce qu'on ne la trouve qu'en petits moreeaux à l'ćtat fossile.

FIRUTESCENT, adj., frutescens, fruticans, fruticcsccus. ; strauchartig (all.) (frutcx, arbrisscau). Les géognostes donnent cette épithète ì la surface d'une coulée volcanique, quand elle est eouverte de végétaux ligneux. En botanique, clle s'applique ì des plantes qui sont de la nature des arbrisseaux, on qui $\mathrm{cn}$ ont le port (cx. Bocconia frutcsccns, Jasminum fruticans, Bupleurun frulicescens).

FnUticuleux, adj. , fiuticulosus; straucharlig (all.) (ficulc $x$, arbrisseau). Dont la taille est au-dcssous de colle d'un arbrisseau. Ex. Aster fruliculosus, Ruta fruticulosa, Dracocephalum fruticulosum.

FRUTIQUEUx, adj., fruticosus ; fruticoso (it.) (frutex, arbrisseau); qui a la taille d'un arbrisscau. Ex. Prismalocarpus fruicosus, Achyrauthes fruticosa, Dccaspermum fruticosum.

FUCACEES, adi. et s. f. pl., Fucacca. Nom douné par Fries à une tribu de l'ordre des Hydrophyees, pnr Agardh à un groupe de la famille des Fucö̈dées, par Lamouroux à un ordre de Thalassiophytes non arlicuculées, par Leman à une seetion de la famille des Algues, par Bory ì une famille d'Hydrophytes, coupes qui toutes ont pour type le genre fiucus.

FUcEes, adj. et s.f. pl., Fucca. Nom sous lequel L.-C. Richara désignait les Algues en général, ou la famille des Hydrophytes, et que Reichenbach donne à une tribu de la section des lucoïdécs, contenant le Senre Fucus.

FucIISICEs, adj, et s. f. pl., Fuchsiece. Nom donné par Candolle à une tribu de la famille des Onogra- riées; qui a pour type le genre Fuclesia.

FUCICOLE, adj., fucicolus ( $f u-$ cus, fucus, colo, habiter); qui vit parmi les Fueus ou les Algues. Ex. Pherusa fucicola.

FUCrFonwe, adjeet., fuciformis (fucus, fucus, forma, forme). Le Roccclla fuciformis est ainsi appelé paree que la longueur de ses expansions en lanières lui domne quelque ressemblance avec un fuets.

vucondies, adj. et s. f. pl., Filcoïdce. Nom donnó par Agardh et Greville à unc trilsu ou à un ordre de la famille des Algues, par lieichenbach à une seetious de l'ordre des Algues aseophyces, ayant pour type le genre Fucus.

Fucordes, adj. et s. $\int$. pl., Fucoïdce. Nom douné par Blainville à une fanille de la elasse des Calciphytes, renfcrmant eelles dont la tige et les rancaux sont eneroûlús d'une sulsstance très-gélatineusc, non articulée, ce qui les rapproclse des véritables fucus.

FUGACE, adj. , fugax; ijparos ; verchwindcad (all.); fusacc (it.); qui dure peu, comme les Trcmclles, lesquelles ne vivent que quelques loeures. Les botimistes employent quelquefois ee inot, eomme synonyme de caduc, pour désigner des parties qui tombent peu de timps apres leur apparition; calice furtace, celui qui tombe des que la fleur commenec ì s'épanouir (ex. Papaser) ; corolle fugrnce, celle qui tom he aun noment de l'cntier épanouis. sement de la fleur, ou mêne avant (ex. Thalictrum); foutlles furgaccs, eclles qui ue restent en place que trèspeu de tesups (ex. Cactus Opuntia); spatlic fugrace, eelle qui sc délache jeu apres s'ctre ouverte (ex. Allium Porrum); stipules fugaccs, celles qui tonhent avant les feuilles (ex. Ceratonia siliqua).

FụccaAce, adject. , fulcraceus. 
Candolle donne éelte épithète anx bourgcons dont les éeailles sont formées par l'avorlement de pétioles bordés de stipules. Ex. Prunus.

FULCRE, adj., fulcratus; $\mathrm{gC-}$ siülzl (all.). Willdenow appelle aiusi les tiges d'où partent de longues raeines qui vont gagner la terre, et se transforment bientüt elles mûmes en tiges, ou en especees de soutiens de la plante. Ex. Rhizophora.

wurchur, subst. m. , fulcrum; Slïlzc (all.). Linné eomprenait sous ec nom, sans le définir, les pétioles, les pédoneules, les stipules, les brac: tées, les armes, les eirres, les glindes et les poils. Willdenow a encore donné plus d'extension à cette elasse ineohérente d'organes, dont la majeure partie ne servent en rien ả soutenir les plantes qui les portent. Bernhardi réserve le rom de fulcrum aux parties qui aident le vígétal à se soutenir, comme les pédoneules, les pétioles, les filets des étmnines, les gynophores, ele. Sprengul n'appelle ainsi que les cirres et les suçoirs. Candolle a eneore restreint davantage (voycz Crampor ) la signification de ce terme, dont on se sert rarement aujourd'hui.

Fungontules, adj. et s. f. pl., Fulgorellce. Nom donné par Latreille et Eichwald à une trilsu de la famille des Cieadaires, qui a pour type le genre Fulgora.

Fulguistiox, s.f., fulguratio (fulgur, foudre). Phénumène électrique de lumic̀re, qui a lieu dans l'atmosphère, qui n'est point aecompagné de tonnerre, et qu'on doit Lien distinguer de l'éclair.

Fégurionitre, s. m., fulgurometrum (fulgur, foudre, p.eteśso, mesurer). Appareil que Leroy a décrit pour constater l'existence et mesurer l'intensité de l'électricité atmosphériquie, dins les temps d'orage.

TUXIGINIIS, adj. et s. f. ple,
Fuliginece. Nom donné par A. Brongniart à une tribu de la famille de Ly. coperdaećes, qui a pour type le genre Fuligo.

FULIGINELX, adj., fuliginosts, fuligineus; russfirbig (all.) (fuligo, suic; qui a la couleur et l'aspect de la suie, qui semble eouvert de suie. Se dit, en minéralogie, d'un corps, quand il ressemble à de la suic dont les grains auraient été agglutinés, et qu'il taebe les doigts comtne cetle matière (ex. Fer oxidé fuligincux ). On doune eette épithète ì des corps de teinte roussâtre ou noirâtre (ex. Polyporus fuliginezes, Clavaria fuliginea, Dendrocolaptes fuliginosus, Tournefortia fuliginosa, Lamia fuliginaior).

IUtMMAnE, adj. , fulminaris (fulmen, fondre). On appelle tubes fulminuires (Blilasinter, Kiesselsinter, Blitzrohr, Fulgurit, all.; vitreous tzcbes, angl.) des tubes plus ou noins longs, vitrifiés à l'intérieur, rugueux et granuleux à l'extérieur, qui sont produits par le passage de la foudre à travers un terrain sablonneux. Découverts en 171 I par Hermann, en Silésie, ils ont été retrouvés en 1805 , dans la lande de Paderborn, par Hentzen, qui en a le premier indiqué l'origine.

FLlWIVANT, adj. , fulminans, tonitruans, tonans; knallend (all.) (fulmon, foudre). Epithète donnće à tout mélange, à tout composé qui, soumis a la chaleur, ì la eompression, à la trituration on à la pereussion, produit une détoustion plus ou inoins bruyante.

FuLMiNAT'i, s. m., fulminas. Ginre de sels (linallsaure Salae, all.), qui sont prodnits par la combinaison de l'acide fulminique avec les Jnses salifiables.

FULMINTION, s. f. , fulminatio; néparvesers (fulmen, foudre). Détovation bruyante qui résulle de la dé- 
composition instantanéc de ccrtains corps.

Fulurvi, adj., fulminatus ( rulmen, foudre). Se dit l'un corps qui présente des raics colorées en zigg"arr. Ex. Voluta fulminata, Achatina fitminea, Oliva fulminans, Colombella fulgurans.

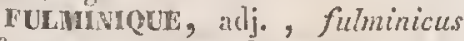
(fulmen, loudre). On appelle acide Jiclminique ( $K$ nallsäarc, all.) un icide qui a la propriété, mème étant uni aux plus fortes bases, de sc décomposer avee une violente explosion, par l'cffet de la percussion ou de l'élévation de la icmpérature. Comme, toutes les fois yuton eherclie a le séparer des basts, scs élcmens se combinent daus d'autres proportions, on u'a pas cneorc pu l'isoler, et l'on ignore quelle est sa composition, qu'on croit cepcndant être la. même que celle de l'acide cyancux.

FULVIBALBE, adj., fielvibarbis (fulvus, fauve, barba, barbe); qui i la barbe roussc. Ex. Calliphora fulvibarbis.

Futrour.: adj, fulicollis (Sulvus, roux, collum, col); qui a le corsclet roux. Ex. Lebia fulvicollis.

fuLvrcorse, adj., fulvieornis ( (ull'us, roux, eornu, corne); qui a les auteunes rous:cs. Ex. Allica fulvicornis.

Fudvicudne, adj. , fulvicrurts (fulous, lisuve, erus, cuisse); qui a les euisses f'auves. Ex. ('hrysom) a fulvicrura.

HULVTPlDE, adj., fulvipes ( fulols, fauve, pes, picd); qui a lcs Pitles lauves. Ex. Ceranllia fulvipes.

IULVIPLNNE, adj., fulvipennis (filvus, roux, penna, iile); qui a les ailes on les élylues rousses. Ex. "ederus fulvipennis, Bruchus fulvipennis.

FUCVIMRST, adj. , fulvitarsis (Sulpus, roux, larsus, tarse); qui a les tarses roux. Ex. Anthribus falvitarsis.

FULVITITORAx, adj., fulvithorax; qui a la poitrine on le thornx brun. Ex. Pangonia fulvilhorax.

FULVIVEXTILE, adj., fulviventer, fulviventris (fulpus, roux, venter, ventre); qui a le ventre roux ou roussâtre. Ex. Falco fulviventer, Osmia fulviventris.

MUMurackis, adj. et s. f. pl., Fumariaces, Fumariece. Famille de plantes, établie par Candollc, qui a pour lype le genre Funaria.

FUHIIILis. Voyez Fumariacíles.

Fumarive, s. f., fumarina. Alcali, cncorc problématique, que Pesehice dit avoir déconvert dans le Fumaria offieinalis.

FUMWhODE, adject., famarioiders. Necs d'Esembeck donne cetle ćpithètc aux corolies dont les ailes se fendent en un palais bifulc, el dont lc fond dn tube est tuberculcux ct éperonné. Ex. Fumaria.

FUMB์ Rauch (all.); reck (angl.); fumo (it.). Mlelange de cendres, cle charbon trèsdivisé et de partics non brulées des produits de la distillation des matic̀res eombustibles, qui, nc pouvant s'oxider au nulicu de la flamme, fante d'oxigène, ni au sortir de celte Inume, parce que l'air cst trop corrompu, se refroidissent, se coudensent, et sont lancées dans l'atmosplière, sous la forme de nunges, par le coumant d'air que la chalcur du foyer a ćlabli.

FUn:HOLLE. On donne ee nom à des erevasses qui se voyent dans certains cratcres de volcans en activilé, ou à la surfiace de laves nouveilcment ćcoulées, et d'oil s'échappent des masses de vilpours ct. de fuméc.

FUMIENXW, adject, fumiponnis (fumus, fumćc, penna, aile); qui a les ailes d'une couleur obscure el 
eomme enfumées. Ex. Culex fumipennis.

FUNARIOIDES, adj. et s.f. pl., Funarioidea. Nom donné par Fu'nrohr à un groupe de la famille des Mousses, qui a pour type le genre Funaria.

FUNibne, adj. , funcbralis, funercus. Epithète donnée à divers animaux qui ont des conlcurs sombres. Ex. Oliva finebralis, Psittacus funcrens, Strix funcrea.

FUNiCULE, subst.m. , finniczlus, chorda umbilicalis; Nabelschnur, Nabelstrang, Keimgang (all.). Les hotanistes appellent ausi un cordon, de longueur et de forme variables, par le moyen durguel la graine tient au. placenta; il se eompose, au moment de la floraison, d'un filet venant du eordon pistillaire et d'un autre venant du cordon nourrieier; ces denx filets, dont le premier ne farde ordiuatremenal pas à disparaître après la féeondation, sont le pluss sonvent unis ensemble, mais yquelquefois aussi séparés et distinets (ex. Statice). $V_{\text {ojez }}$ Podosperme.

FUnicule, adj., funiculatus. Se dit, en botanique, d'une graine qui est munie d'un funienle bien appitrent (ex. Plombaginécs); en \%oologie, d'une coquille qui est garnic de eòtes longitudinales strices en travers (ex. Fusus funiculosus). Voyez ConDELÉ.

FUNIFlne, adj., funifcrns ( $/ u$ nis, eorde, fcro, porter). Une plante sarmenteuse (Luclorin funifora) est ainsi appeléc parce 'qu'cle émet de sa tige cles racines longues et semblables à des cordes, qui descendent perjendiculatement vers la terre.

FUNivorue, adj. , funiformis; strangförmig (all.) (funis, corde, forma, forme). Se dit, en minéralogie, d'un corps eomposé de eristaux rangés à la suite les uns des autres, et formant des espèces de petits cordons. Ex. Plomb sulfuré antimonifëre finiforme.

FUVILIF OnME, adj, , funiliformis, funalis. Se dit d'une racine qui est forniée de grosses fibres semblables à des cordes plus ou moins déliées (ex. Clusia rosca). Le Grimmia funalis est ainsi nommé ì cause de ses longues tiges, qu'on a comparćes à des cordeleltes.

Purcellarúkes, adj. et s.f. pl., Furcellariea. Nom donné par R.-K. Greville à un ordre de la famille des Algues, qui a pour type le genre Furcellaria.

PURCIFEI:, adj., furcifer (fur$\mathrm{ca}$, fourehe, fero, porter). Le $\mathrm{Ca}$ primulgus furcifer a la queue fourchue. L'Antilucapra furcifor présente, vers les deux tiers de la hauteur de ses cornes, un andouiller dirigé en avant, qui rend ces dernières fourcliues. Le Sargus furcifer a l'ceus. son garui d'un long appendice fourelsu a l'extrćmité.

FuxcIc:B3!z, adj., furcilabris (fierce, fourche, labremn, lahire); qui a le libre fourehu. Ex. Passalus furrilabris.

Furdirre, adj., furcipilis (furca, fourche, pilns, poil); qui a des poils fourchus. Un poisson (Chironectus furcipilis) cot aiusi appclé, paree qu'il porle de véritables poils sortaut fourchus d'in petit tubercule.

Fundhesi, adi. , furfuraceus;

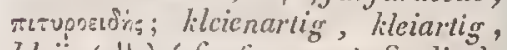
klciig (all.) ( furfur, son). Se dit de corps qui sont eonverts d'une poussiere blanchâtre analogue ì de la favine on ì du son. Ex. Ascobolus firrfuraceus, Phy'sciafurfuracea.

FUSCICOLEE, adj., fuscicollis (fuscus, brun, collun, col); qui a le eol brun. Ex. Ardea fuscicollis.

rUSCICORNE, adj., fuscicornis ( filscus, brun, cornu, corne); qui 
a lcs antennes bruncs. Ex. Sirex fuscicornis.

EUSCINT, s. f. , fuscina (fuscus, brun ). Nom donuć par Unverilorben, en raison de sa couleur brune, à une sulstance particulière qu'il est parvenu is extraire de l'huile animale de Dippel non purifiće.

FUSCIPLDE, adj. , fuscipes (fuscus, brun, pes, pied); qui a les pattes brunes. Ex. Altica fuscipes.

IUSCIPENNE, adj., fuscipennis (Juscus, brun, penna, nile); qui a les ailes bruncs. Ex. Pangronia fuscipennis.

FUSCIVENTRE, adj., fusciventer, fusciventris ( fuscus, brun, venter, ventre); qui a le ventre brun. Ex. Molossus fusciventer, Baccha fusci"entris.

FUSCOMANE, adj., fuscomanus (fieseus, brun, manus, main); qui a les mains on les extrémités des pilites brmes. Ex. Tarsius fuseomanus.

FUSIBILITÉ, s. f. , fusibilitas; Schmelabarkcit (all.). Proprićté dont jouissent certains eorps solides de passer à l'ćtat liguide en sc combinant d'ure manière intine avec lc calorique.

TUSIBLE, adj., fusilitis; schmelabar (all.) (fundo, fondre). Se dit de tout corps qui est susceptible d'entree en fusion, arec on sans addition d'un fondant. Ex. Spath fusible.

rusiconnes, adjcet. et s. m. pl., Fusicornes ( $\int u s u s$, fiuse:tu, cormu, corne). Non dounć par Duméril ì une famille de l'ordre des Jeépidoplères, comprenant ceux de ces insce-
Ics qui ont les antennes en fuseau, renflées à la partie moyenne. (Voyez Crostérocíres). Latreille propose de le sulbstituer à celui de Lépidoptères crépusculaires.

rusinicirs, adj. ct s.f. pl., Fusidiece. Nom donuć par A. Brongniart ì uuc tribu de la famille des Urédinécs, qui a pour type le genre Fusiditum.

IUSEYORWE, adj., fasiformis; spindelförmig, spindelig (all.) ; $\int u-$ siforme, alfizsaio (it.) (fusus, fuseau, forma, forme); qui a la forme d'un fuseall, e'est-à-dire qui est alougé, renflé au milieu et aminei aux deux cxtrémités, eomme les antennes de l'A tractocerus abreviatus, la baic du Billardicra fusiformis, la coquille du Bulimus fusiformis, l'cmbryon dn Thesium alpinum, le follienle du Nerium Olcander, le pépon du Curcumis Chate, la racine du Trieluinium fusiforme, le corps de la Chodiuc fusiformis.

rusiforiues, adj. et s. m. pl.; Fusiformia. Nom donnć par Latreillé à une famille de Gastéropodes gymnococlulides, comprenant eeux qui ont la coquillc fusilorme, et ayant pour type le genic Fustus.

Fusion, subst. f., fusio; quois; Sclunclzung (all.); melling (angl.). Opération par laquelle on fait passer un eorps de l'état solide à l'état liquide, en l'exposant à l'action du calorique. Ia glace fond à zéro, et le zinc à $370^{\circ}$.

TLSIPlOE , fusipcs ( fusus, fuseau, pes, pied ). L'Agaricus fusipes a le stipe renflí ì sa partic moyenne. 
GADITES, adj. ets.m. pl., Gadites. Nom donné par Latreille à une famille de l'ordre des poissons Subbrachiens, par Fieinus et Carus à une farnille de l'ordre des Sternoptérygiens Orthosomes, ayant pour type le geure Gadus.

GADOIDES, adject. et s. m. pl., Gadoüles, Gadoullei. Sous ee nom Cuvier désigne une famille de Malacoptérygieus subbrachicns, Blainville et Eichwald une famille de l'ordre des Poissons jugulaires, ayant le genre Gradus pour type.

GAGATELS, adject. et s. f. pl., Gagatee (gagales, jayet). Nom donuć par Robineau-Desvoidy à une section de la famille des Myodaires calyptérées, comprenant eelles dont les teintes sont d'un noir luisant, conume celui du jayet.

GaIvE, sulst. f., vagina; हैخuтpor; Scheidc (all.); sheath (angl.); guaina (it.). On nomme ainsi : $1^{\circ}$ en botanique, une partie de certaines levilles qui entoure la tige dans une portion de sa Iongueur, sit semble remplacer lo pétiole (ex. Graminces). $2^{\circ}$ En zooJogie. Falıricius donne ee nom, dans les insecles suceurs, principalement chez les hémiptères et chez les diptères, à sucoir eorné ou tryau dans lequel sont renfermées les soies aigrüs qui font oflice delaneette et de pom pe pour ancuer jusqu'ì l'oesophage les liquides de la plaie faite ì l'êrre organisé par l'insecte qui l'a piquué atin de s'en nourrir. Blainville l'applique an tuberenle plus ou moins saillant daus l'iutéricur duquel sont portés les pinceaux de soies des Cilućtnpndes.

GAIXULE, s. f., vaginula. On appelle ainsi la partie inférienre de l'écoree superliciclle del'urne des mous- ses, lorsque, peu de temps après la matnrité des corps reproducteurs, clle a cessé d'adlićrer aux parties intéricures, et s'est divisée en deux par une fente transversalc.

GiLACINEES, adject. ct s. \{. pl., Galacinece. Nom donné par D. Dnn et Kunth à une famille de plantes, qui a pour iype le genre Galax.

Gahictate. Voycz Lactate.

GALACTIQUE. Vogcz LACNiQUE.

GALACTONHTRE, s. m. , galac-

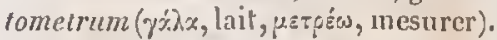
Instrument qu’on a proposé pour niesurer la bonté du lait ou la quantité de beurre qu’il eontient.

GATACTOPHORE, adj., galac-

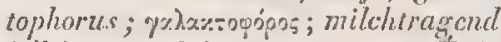

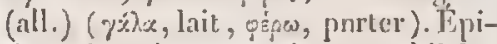
thète donnée aux vaisscaux chilifires, à cause de la couleur généralement blanche du ehyle, et aux eonduits exeréteurs du hait, qui portent ce liquide de la glande mammaire au manuclon.

GA1.1CTOSE, 5. I., gुalactosis, galaclopoicsis; Milchabsonderung (all.) ( $y^{x} x_{x}$, lait). Sécrútion du lait.

G.ALARDIÉES, adj. et s. f. pl., Galardica. Nom donné par Nuttall it une tribu de la famille des Synauthérées, par Lessing i une seetiou de la sous-tribu des Sénćcionidées Hélénićes, ayant pour type le genre $\dot{G} a-$ lardia.

GALATHÉADÉES, adj., Galatlecadece. Non donné par İeneh à un section de lin famille des Crustacés déeapodes maeroures, qui a pour type le genre Galathea.

GALATIILTES, adj. et s. f. pl., Galallinca. Nom sous lequel Latreille et Eicliwald désignent une tribu de la famille des Crustacés décapodes 
maeroures, ayant le genre Calathca pour typc.

GALBANIFtre, adj. , galbaniferus; qui produit du galbanum. Ex. Bubon galbaniferum.

GALbULE, s. m., galbulus; ZapScubcerc, (all.). Gaertner, d'après Varron, et Sprengel, d'après Gxrlner, désignent sous ec nom une espéce de cône dont les bractées sont très-ćlargics ì leur sommet, peltćes, strićes en forme de rayous, mucronćes au centre, ct s'ouvrent à peine à l'époquc de la maturité. Ex. Cupressus.

GALBULÉE, adj. et s. f. pl., Galbulece. Nom donné par Lesson à anc famille du sous-ordre des Passcreaux grimpeurs, qui a pour type le genre Galbula.

GALEES, adj. et s.f. pl. , Galca. Nom donné par Kunth à une tribu de la famille des Rubiacées, qui a pour type le genre Galium.

GLizicíns, adj. el s. f. p!. , $G a-$ legece. Nom donné par C.-G. Ebermaier a une tribu de la famille des Papilionacées, par Candolle à une solrs-tribu de la tribu des Lotées, ayant pour type le genre Galega.

GALEIFOIME, adj, , galciformis; helmförmig (all.) (galca, casque, forma, forme). Les botanistes donmeut cettc épithète aux pélales, quand ils sont ereux, voûtés et ouverts antéricurement en forme de casque. Ex. Aconitum.

GALEOPITHÉCIDES, adj. et s. m. pl., Galcopithecida. Nom sous Jequel Gray désigne une famille de Mammifères, de l'ordre des Primates, qui a pour type le genre Galcopithecus.s.

Garéoprtméchess, adj. el s. m. pl., Galeopithecii. Nom donné par Desmarest, Blainville et Goldfliss ì une famille de Mammilères, ayant pour type le genre Galcopithecus.

GaLG̉ingrtes, adj. et s. m, pl, ,
Galerucita. Cuvier, Latreille et Eichwald désignent sous ee nom une tribu de la famille des Colćoptères cyeliques, ayant le genre Galcruca pour type.

GALET, s. m., lapillus; Geroll, Gerull, Rollstein(all.); pebble (angl.). Les gćognostes appellent ainsi des morceaux de silex, de quarz, de granite, de schiste, de éalcaire, ou de toute autre roche, dont le volume varic depuis cel ui d'une noix ou d'une amande justu'à cclui de la tête, et nu-delà, qu'on trouve, roulćs, arrondis et rémis en grand nombre, soit sur les bords de la mer, sur les rives des grands fleuves, dans le lit des torrens, soit dans l'intérieur des terres, formant alor's des amas immenses, qui ont dounć naissance à des collines, ontrempli des bas-fonds, et les ont changés en de vastes plaines.

GALÈTE, s. f. , galca; Helm, Kinnladenhelm (all.). Fabricius et Olivier ont appelé ainsi une grande pičee voûtće el mobile, de consistance membrancuse, qui recouvre les mảchoires, dans les orthoptères et quelques névroptères, qu'on a cru propre exclusivement à ces insectes, mais qui, d'apris Straus et Blainville, se retrouve également chez la plupart des Goléoptères.

GALIXSOGÉES, adj. et s.f. pl.; Galinsogrere. Nom donné par II. Cas a sini ì un groupe de la section des Hélianthées Héléniées, par Lessing à une section de la sous-tribu des Sénécionidées Mélénićes, ayant pour type le genre Galinsoga.

GALLATE, s. m. gallas. Genre de sels (gallussaure Salze, all.), qui sont produils par la combinaison de l'acide. gallique avec les bases salifiables.

GARLE, s. l., galla; xmxis; Gallïpfel, Gallnuss (all.); gall (angl.); galla (it.). On donne ce nom à des excroissances produites, sur diverses 
parties des végétaux, par les piqûres d'insectes qui déposent leurs ouls daus la blessure. Les cynips et les diplolipes sont les insectes qui produisent le plus de galles; cependant des saperdes, des charansours, des criocìres, des tonthrèdes, des acanthies, des psylles, des purerons, des thrips, des scalopses, des cosmies, destipules, cu font naître ćgalement.

Gallicores, adj. et s. m. pl., Gallicole (galla, galle, colo, habiter). Noun donné par Cuvier, Isatreille et Eichwald à unc tribu de la famille des Hyınénoptères pupipares, par Latreille ct Eich swald à me soustribu de la tribu des Tipulaires, comprenant des insectes dont les larves habitent dans des galles.

Garliforues, adj. et s. m. pl., Galliformes (gallus, eoy, forma, forme). Noun donné par Latreille, Ficinus ct Carus à une famille de l'ordre des Grimpeurs, comprenant des oisenux qui se rapproehent des Gallinacés.

GALIINACs, adj. et s. m. pl., Gallinaceœ, Gallinacci, Gallina, Rasores. Nom donné par tous les ornithologistes à un ordre de la classe des Oiseaux, reufermant le genre Gallus et ceux qui s'on rapprochent Ic plus.

GALLINIVOR;, adj., gallinivorus (gallina, poule, voro, dévorer); qui dévorc les poules. Ex. Buico gallinivorus.

GALIINOGRALIES, alj. et s. m. pl., Gallinogralle. Non donné par Blainville à une famille de l'ordre des Échassiers, par Lesson à une famille du sous-ordre des Himantogralles, comprenant des oiscaux qui sont intermédiaires entre les Gallinacés et les Échassiers.

GALLINSECTES, s. m. pl., Gallinsecta. Nom donné par Cuvier, Iamarck, Goldfuss, Latreille, li- einus et Carus à uue famille de l'ordre des Hémiptères, comprenant des insectes dont les femelles, vers l'époque de la ponte, prennent la formed'une boule, analogue aux petites galles des allures, qui recouvre et garantit les ouls.

GaLdivlles, s. f. pl., Gallinulce. Non donné par Goldfuss et Iesson ì une famille de l'ordre des Echassiers, qui a pour type le genre Gallinula.

GALIIOQLE, subst. $f$, , gallioca; Hüllzapfcr (all.). On a proposé d'appeler aiusi la cupule, au moment ou le fruit cst développé, et de rapporter ì ec même genre de fruits celui dı noyer, qu'ou pent également considérer comme le résultat de la soudure de plusieurs ćeailles d'un chaton.

GALIIOUE, adj., gallicus (galla, galle). Épithète donnéc à un acide (Gallussäure, Gallïpfolsüurc, all.), qu'on trouve prineipalement dans la noix de gralle, et que Schecle a le premier obtenu à l'état de purcté.

GALONVE, adject., lemniscatus, marginatus. Épishète donnće à des animaux qui ont, sur quelque partie du corps, soit des éeailles (ex. Elaps (cmniscatus), soit des lignes colorees (ex. Rana marginata), disposées de manière á représenter une sorte de galon.

GALOPL, adj., gralopus (gź) $\lambda \alpha$, lait,

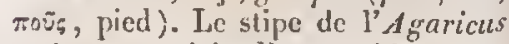
galopus est plein d'un sue blane.

GALVANioue, adj., galsanicus; qui a rapport au galvanisme. Synonyme parfait d'elcctrique.

GALVANISME, subst. m., galvanismus, clcctricitas galvanica. Nom donıć aux pliénomènes ćlectriques manifestés par le con tact de sulsstanecs hétérogènes, mćtalliques surtout, paree qu'ils out étè découverts par Galvani.

GALVATOMAGNiTISUE, s. m., galsanomagnetismis. Quelques ply= 
siciens out employé ce mot, qui est synonyme d'électromagnétisme.

GaivaNometre. Voyez ÉlecTROMETRE.

GaLVANOSCOPE. Voyez ÉreTROSCOPE.

Gammaridés, adj. ct s. m. pl., Gammarida. Non donné par Leach à une famille de l'ordre des Crustacés amphipodes, qui a pour type le genrc Grammarus.

GAMMAYiENS, adj. et s. m. pl., Gammarince. Norn donné par Latreille et Eichwald à une famille de l'ordre des Ctustacés amphipodes, par Blainville à une famille de la classe des'T'ćlralćcapodes, ayant pour type le genre Gammarus.

GAMUAROLOGIE, s. f., grammarologia (rx́pexapor, homard, hóyac, discours). Traité sur les erustacés. P.-J. Sachs a publié un ouvrage sous ce titre, cn 1665 .

GAMASIDÉES, auljcet. ct s. f. pl., Gamaside. Nom donné par Lcach à une faumille de l'ordre des Arachnides trachćennes, ayaut pour type le genre Gamasus.

GAMOGASTrie, adj., gamograster

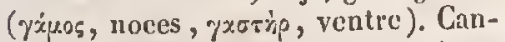
dolle appelle ainsi les plantes qui ont Jes ovaircs soudés, e'est-à-dire dont l'ovaire sc compose de plusieurs ovaires parliels déterninant autant de loges qu'il $y$ avait primitivement de carpelles.

GAMOPÉTALE, adj. , gamopelalus; vereintblïltrig (all.) ( vंxuss,

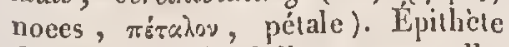
donnée par Candolle aux corolles monopétales, qu'il regarde comme produites par la soudure d'un plus ou moins grand nombre de pétales.

GAMOPHYLE, s. m., gamophyl-

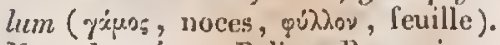
Nom donné par Palisot-Beauvois et Lestibondois à l'enveloppe ou écuillc propre de ehangue fleur, dans les $\mathrm{Cy}_{\mathrm{y}}$ pérucées.
GAMOPIYYLE, adj. , gamoply llus. Candolle donne cette épithète a l'involuere (ex. Othonna) et is la collerctie (ex. Seseli hippomarat/ritum), quand les pic̀ees ou bractées composaut cs sont soudćes ensemble, par leurs bords, de manicre ì ne former qu'une seule enveloppe autour des fleurs.

GaMOSLPALE, adj., gamosepalus. Épithète donnce par Candolle au ealice, quand il est composé de plusieurs pièces plus on moins soudćes euscmble.

GAUIOSTYLE, adj., gramostylus

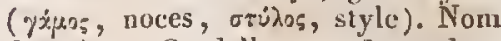
donné par Cindolle aux fleurs dans lesquclles ies styles partiels sont soudés entr'eux, de sorle que, de leur cohérence, résulte un style en apparence unique, mais formé réellcment d'autant de styles particls yqu'il y a de carpelles.

Gavacie, s. f. Région de la tête du cheval qui est situéc au contour de l'os maxillairc. Autrefois on donnait aussi ce nom à l'uue des pièces de la lèrve des inscetes, qui aujourd'bui esl plus généralement appelée menton.

GANGLIYOHY, adj. , ganglifor-

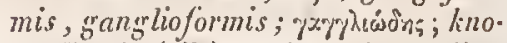
tenformiog (all.) ; qui al lil forme d'un ganglion, comme ecrtains plexus nerveux.

GANGLION, subst. 1n. , ganglion; 7xyyhios; Knote (all.). Miasse de tilets nerveux ou de vaisseunx entrelacés, unis ensemble par dn tissu cellulaire, et envcloppés dins une membrane eomuunc.

GaxGLIONeLties, adj. ct s. In. pl., Ganglioneura ( yxpphiov, ganglion, szüpov, nerf). Now donné par Rudolphi à un groupe du règne animal, comprenaut les animaux qui, eonme les mollusques ct les radinires, n'ont qu'uu systeme nerveux ganglionnaire, analogue à eclui des auimaux vertébrés.

GANGLIONNAIRE, adject., gan- 
glionaris, ganglionosus. Se dit particulic̀rement d'un nerf qui présente des gauglions dans son trajet. Le nert' grand sympathique est trc̀s-souveut désigné sous le nom de systeme ranslionnaire, cn tantqu'on le considire comme un ensenıble de ganglions qui ne font qu'un tout par le moycn de leurs filets de jonetion ou de communication.

GANGLIONvË, adi. , gangliosus, sanglioncus ( yxyrioy, ganglion). Boué appelle filons ganglionnés les mamelons et Jongues bandes que la diabase forme au milicu des schistes et des calcaircs, dans certaines localités des Pyrénécs. - On donne celle épithète, dans les plantes, aux poils qui sont garnis de noends pilíleres (ex. Verbascum lychnites).

GANGUE, s. f., ganga (it.). Par unc fausse application du mot allcmand Gangr, qui signifie filon, on donne ce nom à une substance dlans laquelle un minéral eristallisé, rure ou précieux, se trouve engagé. En langage de mincurs, c'est une substance sans valcur, qui contient la ma. tière métallique utile faisant le but de l'exploitation ou des travaux métallurgiques.

GARCINIÉES, adj. et s. f. pl., Garcinica. Nom donné par Choisy et Candolle à une tribu de la famille des Guttifères, par Callin à une fumille de plantes, ayant pour type le genle Garcinia.

GARDĹNHacées, adj. et s. f. pl., Gardcniacce. Nom donné par Candolle à une tribu de la famille des Rubiacées, qui a pour type le ressre Gardcnia.

Gardúnées, adj. et s. f. pl., Garelcniece. Nom donné par Clamisso, Schlceliteudal et Kunth à unc tribu de lat famille des Rubiacées, par Candolle à une sous-tribu de lat tribu des Gardéniacées, qui contient le genre Gardenia.
GARDNERIẺES, adj. ct s. f. pl.; Gardnerica. Nom dounć par Wallich à une famille de plantes, ayant pour type le genre Gardncria, que R. Brown a depuis appelée Loganićcs.

GARROT, s. m., armus; Widcrist (all.); withers (angl.). Partie élevée et plus ou moins tranchante de la région supéricure du corps du eheval, qui est situce au bas de la crinière, et dont la saillic est produite par les apophyses épineuses des cinq ou six premières vertèbres dorsales.

GASTÉrODìLE, adj., gastcro-

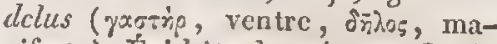
nifeste). Épithìte dounée par G.-G. Ehrenberg aux Infusoires rotifères qui ont des organes de mastication, un osoplnage très-court et un intestin divisé par un rétrécissement en deux portions, dont la première figure un cstomac. Ex. Euchlaris.

GASTÉROMYCES, subst. m. pl. , Gasteromyci, Gastcromycctes ( $\gamma \alpha \sigma-$ trip, ventre, $\mu$ úks, champignon). Nom donné par Willdenow, Liık, Fries, Nees d'Escenbeck et Spr'engel à un ordre de la famille des champignous, comprenant ceux qui sont mlobuleux ou sphériques ct composés d'une membrane dans laquelle sc trouvent contenues des sporidics nues.

Gastíropodes, ad. els. in. pl.,

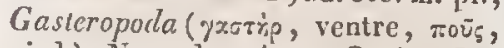
pied). Nom donné par Cuvier, Latreille, Ficimus et Carus à uuc classe d'auimaux mollusques, par Lamarck, Duméril, Schweigger, Goldfuss et Eichwald à un ordre de la classe des Mollusques, comprenant ecux de ces aninaux chez lesqucls un cmpâtenent plus ou moins grand du disfuc ventral forme une sorte de pied qui oceupe toute la face inféricure de l'abdomen et qui leur permet de glisser en rampant sur le plan de position.

GASTÉROPODORILLLE, adj, ct 


\section{GAST}

s. m. pl., Gastcropodophora (

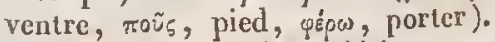
Nom soris lequel Gray désigne une classe de Mollusques, qui eorrespond exactement à la coupe précédente.

GASTLROPTĹLOP'LORES, adj. et s. in. pl., Gastcropterophora (yxa-

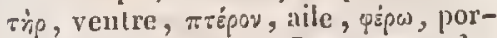
ter). Nom donuć par Gray à un ordee de la elasse des Gissićropodophores, qui répond aux Nucléobranches (voy. ce mot) de Blauville.

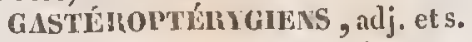
m. pl., Gastcroptery.gii (ga.rzinp, ventre, $\pi \tau \dot{\varepsilon}$ puร̆, nageoire). Non donné par Goldfuss, Ficinus et Carus à un ordre ou sous-ordre de Poissons, eomprenant ecux qui ont les eatopes sitnées derrrière les nageoires pectorales.

GASTŔROSPORES, adj. et s. m. pl., Gasicrospora: ( gaбin $\rho$, ventre, бторѐ, graine). Nom donné par Reiehenbach à une seetion de l'ordre des lichens ascophores, eomprenant ceux qui sont munis d'un nucleus.

gastíliotrisLAvis, adj. et s. II. pl., Gastcrothalami ( $y \times a \tau$ i.p, ventre, oxilap.os, lit). Nom donnć par Fries à un ordre de la elasse des Liehens, comprenant ceux dont les corpuscules reproclueteurs sont entourés d'un réeeptacle elos, qui ne procède pas du thalle, mais qui y est plongé.

GASTĹnOZOAIRES, adj. et s. m.

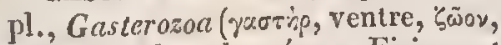
animal). Nom donné par Ficinus et Carus à une division du règue aninol, comprenaut les animaux chez lescuels le système digestif a aequis une prédominanee de développement.

GASTILUUM, s. m., gastraum;

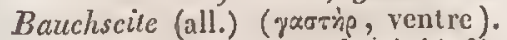
Illiger appellc ainsi tout le côté inférieur du corps des mammiferes, depuis le larynx jusqu'à l'anus.

GASTLICOLE, adj. , gastricola (gaster, ventre, colo, habiter). Cilerk donne eette épithète aux oestres dont les larves vivent dans l'estomac des animaux.

GASTIIQUES, adj. et s. m. pl.; Gastrica. Latrcille désigne sous ce nom une race du règne animal, coinprenant les animaux acéplaales qui ont un canal alimentaire, soit formé pal un sae distinct, soit creusé dans le parenchyme intérieur du corps.

Gastrocarilíles, adj. et s.f. pl., Gastrocarpece (yxornip, ventie, rapsós, fruit). Nom donné par Greville a un ordre de la famille des Algues, renfermant eelles qui, eomnic l'Iridea edulis, ont pour fruits des agglomérations de séminules arrondies, eomplètement plongées dans la substance intéricure de la fronde.

Gastroníes, adj. et s. f. pl., Gastrodca. Nom donné par Robineau-Desvoidy à une seetion de la famille des Myodaires Calyptérćes, comprenant eelles qui ont l'abdomen aplati et hémisplérique.

GASTRODIEES, adj. et s. f. pl.; Gastrodice. Nom donné par Lindley à une tribudela famille desOrchidćes, qui a pour type le genre Gastrodia. GASThoNECTES, adj. ets.m. pl., Gastronectcs ( yactip, ventre, ขn\%тri, nageur). Rolineau-Desvoidy donne ee mom aux Crustacés décapodes maeroures, parce que leurs vertubbres abdominales trìs-développées fornent un organe propre à la natation.

GASTLOPLATYPODES, adj, et s. m. pl., Gastroplatypoda (gzбтrip, ventre, $\pi \lambda_{\alpha} \tau_{\mathrm{v}}$, large, $\pi \mathrm{\omega}_{s}$, pied). Nom douné par J.-A. Ritgen à unc famille d'oiseaux aquatiques, comprenant ceux qui ont le corps en équilibre sur leurs pattes largement palmées.

GASTROTIL̀UE, s. f., gastro-

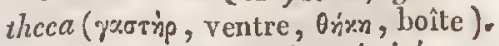
Kirby appelle ainsi l'extrémité postérieure de la clirysalide, celle qui 
convre et protége l'abdomen de l'in. secte.

GATEAU, s. m. Assemblage des cellules que les abeilles et les guêpes construisent pour conscrver leur mic: et loger leur progéuiture.

GAUFIĹ, adj., clatluralus; qui présente des enfoncemens produits par des lignessaillantes entrceroisées. Ex. Murex clathratus, Pyrula elathruta, Triton clathratum. $V$. T REIrLLsÉ.

GAZ, s. m., gaz. Ce nom, dont Vanhelmont s'est le premier servi pour désigner toute substance quelconque dégagée des corps, à l'état de vapeur, par l'action du calorique, et dont Macquer a introduit l'usage dans la langue de la chimic modcrnc, sert aujourd'hui à désigner des eorps qui, sous l'influence de la température et de la pression atunospliérique ordinaires, et même bien au dessous, restent à l'état de fluides aériformes. Cependant Davy et Faraday ont reconnu que les gaz sout seulement des vapenrs plus ou moins éloignécs de leur maximum de tension, ct l'on est parvenu ì en liquéfier plusieurs.

GAZÉRIABLE, alj. ; qui est susceptible de se convertir en gaz.

Gazḱficatron, s. f. Réduction à l'état de gaz.

GAZEIFIÉ, adj.; qui a été réduit en gaz.

GAZELFORME, adj., gazeiformi.s. Se dit d'un corps qui est à l'élat de gaz.

Gazḱité, s. m. Propriété qu'out certaines substances d'exister à l'ćtat de gaz.

GAZEUX; adj. ; qui a les qualilés d'un gaz, qui cst à l'état de gaz.

Gazochrme, s. f. Partje de la chinic qui traite spćcialement des gaz.

GAzoryres, adj. et s.m. pl., gazolytes ( $i \dot{\omega}$, dissoudre). Nom donné par Ampère à une classe de corps simples, comprenant ccux qui, par leur mutuelle eombinaison, forment des gaz permanens, capables de subsister en contaet avec l'air, et par Beudint à une classe d'especes minériles, dans laquelle il range les corps susceptibles de former des combinaisons gazeuses permanentes avec l'oxigène, l'hydrogène ou lc fluor.

G.1zoulirili, s. m., gazometrum (us-péw, nesurer). Appareil propre à contcuir et mesurcr des volinnes plus ou moins eonsidérnbles de gaz.

GAZONNANT, adj., caspitosus; rasicht, grashü̈zclicht (all.); ccspuglioso (it.). Se dit de planles berhacées grèles et courles, qui, par lcur rapprochement, forment une sort: dc tapis ou de gazon sur le sol. Ex. Dianthus caspitosus, Catananec cospitosa, Trifolium caspitosum, Dryptodon cospiticius, Schistidium easpiticium, Dryplodon pulvinatus.

GAZOCHA EMENT, s.m., garritus; Zwitschern (all.); chirping (angl.); garrilo (it.). Ramage des oiscaux. Se dit principalement de celui des petits oiseaux de l'ordre des Passcreaux.

GEANs, adj. et s. m. pl., Proceri. Nou donné par Illiger á unc famille de l'ordre des Oiscaux coureurs, par Lamarck à une famille de l'ordre des Crustacés branchiopodes, couprenant ceux de ces animaux qui sont les plus grands de leur section.

GlisiT, adj. et s. mn., grigas, giganteus, colosseus, procerus ; yirye; Riesc (all.); igiant (angl.); grigante (it.). Se dit de tout corps orgauisé dont la staturedépasse les proportions com. munes des iudividus de son espèce, on des espèees voisines de la sicnne. Fx. Tapirns ginanteus, $V_{\text {crbsina gigan- }}$ tea, Xylostronu giganteum, Fusus colosiscus.

GLANTURACL, s. m., geanthrax

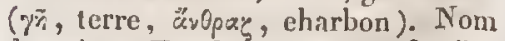
donné par Tondi au eharbon fossile, à l'antluracite métalloïde.

GLANTISHL, s, in. Geofroy Sl- 
Hilaire fils désigne sous ce nom le genre d'aunmalic qui earactérise les géans.

Gliate, s. m., geas. Sel produit par la combinaisou de l'acide géique ayec une base salifiable.

GÉGLADES, adj. et s. m. pl., Gcbiada. Nom donné par A.-H. Ilarvorth à une famille de Crustacés décapodes macroures, qui a ponr type le genre Gebia.

GECKOIDES, adj. et s. m. pl., $G_{\text {eckoüdes. Nom sous lequel Blain- }}$ ville désigne une famille du sons-ordre des Reptiles bispéniens, qui a pour type le genre Gecko.

GECKO'TUDE, adj. et s. m. pl., Geckolida. Nom donné par Gray à une famille de Reptiles sauriens, dont le geure Gecko est le type.

GECKOTIENS, adj. et s. m. pl., Geckotii. Nom donné par Cuvier, I,atreille, Ficinus et Carus ì unc famille de Sauricns, ayant pour type le genre Gecko.

GLHYDROPHLES, adj. et s. m. pl., Gchydrophiles ( $\eta \tilde{n}$, terre, üjwp, eau, yilsai, aimer). Nom douné par Férussac à une section de l'ordre de Gastéropodes pulmonés, comprenant cenx qui vivent à la fois sur terre te dans l'eau.

GÉINE, s. f., geina ( $\gamma \tilde{r}$, terre). Berzelius désigne sous ce nom l'ulmine de Braconuot, paree qu'clle constitue la masse principale du terreau.

GriloLOGIE, s. f., geiologia ( $\gamma \tilde{n}$, terre, hóyos, discours). Burdach nomıe ainsi la counaissance générale des choses terrestres, ou de ee qui se passe tant à la surfaec que dans l'intćrieur de la Terre.

GEIQUE, adj., geicus. La géine cst appelée acide géique quand on a égard à la propriétć dont clle jonit de former des combinaisons solubles ivec les alealis. C'est l'acide ulmique ou humique des aulcurs (Humus- sïure, Humus-Oxyd, oxydirte Humus, all.; körte, mylla, suéd.).

GELATINe, s.f., gclatina; Gallerte, thicrischer Leim, Thiorleim (all.). Substance que l'on oblient en traitant par l'eau bonillante la peau et autres parties animales formées de tissu celluliare, s:t que Berzelius considere comme un prodnit direct de l'ébullition. On l'appelle vulgaircment colle animale ou colle forte.

GiLATINEUSES, adj. et s. f. pl. , Gclatinose. Nom donné par Bonncmaison à une trihu de la famille des Alyucs, comprenant celles de ces plantes qui n'ont que la consistanee d'une geléc.

GELatrinex, adj., gelatinosus; gallertartig (all.); qui contient de la gélatine. Mirbel clonue ect te épithète aux plantcs qui ressemblent a une gelé pour la consistanee (cx. Tremella). Un poisson (Cyclogasterus gelatinosus) est ainsi appelé à cause de sa peau gluante; un polypier (Alcyonidium gelatinosum), paree qu'il forme une masse presque gélatincuse.

GĹLATINIFORME, adj. , gelatiniformis (gelatina, gélatine, forma, forme); qui resscmble à de la gúlatine, qui on a l'aspect.

GELEE, s. f., gelu ; Frost (all. et angl.) ; gelo (it.). Grand froid qui glace; température de l'eau qui se solidific; solidification d'un liquide par le froid. On donne le même nom à un état que des substances diverses, la siliec, l'alumine, la colle, etc., prennent lorsque, ayant été dissoutes dans un liquide, clles s'en séparcut à l'état solide, cu retenant entre lcurs molécules tout ou partie du dissolvant, qui leur donne l'aspect d'un morceau de glace.

GLLW, adject. Ou appelle picre gelive ou gelisse celle dont l'agrégation n'est point assez forte pour résister à l'action expansive ale la gelće. 
Gélif se dit aussi des arbres dont les pousses sont sujettes à être gelées au printemps, et des trones d'arbres que les fortes gelcies d'hiver ont fendus longitudinalement, ce qui en rend le bois impropre à la charpente et à la menuiscrie.

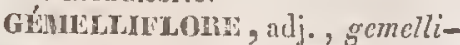
florus (gemellus, jumeau, flos, fleur); qui a les fleurs disposées denx ì deux. Ex. Quereus gemolliffora.

GEMInvE, adj., binus, binatus, geminatus; sepuart, zuillinspaarig, gezweyl (all.). Sc dit, en botanique, de parties qui sont disposécs deux à deux, ou qui naissent par paires du même point, corume les ferilles du Pinus syluestris, les fleurs du Passiflora geminifora, les slipules, dans la plupart des cas où il y en a. Candolle fuit observer qu'à l'égard des feuilles, cette disposition est toujours le résultat de quclqu'autre arrangement primordial, qu'elle est diue, tantôt à ce que des fcuilles alternes naissent trc̀s-rapprochées, tanlồt à ce que, dans desi fcuilles verticillées par trois, il $\mathrm{cn}$ cst une qui manque accidentellemcnt, tantôt enfin à ce qu'on prend des: fcuillcs composées ponr des feuilles entières. Un insecte (Leptis geminata) est ainsi appelé a cause des taches gemirées, ou disposées deux à deux, dont son abdumen est marqué.

GLVIN IFLORE, adj. , geminiflorns (geminus, double, flos, fleur); qui a des fleurs disposées deux par dcux. Ex. Astragalns geminiflorus, Sanvagesia geminif!ora, Egopogon geminiflor um.

GEMUAACĹ, adject., gemmaceus (gemna, bouton). On donne cette épithète aux plumes, lorsque les petites barkes sont coupées en demicercle à leur extrémité, comme dans plusieurs Colibris.L'Explanaria gemmaeea est appelée ainsi, parce que ce polynier porte une multitude de eel lules saillantes, qui sont renflées comme des boutons.

GEMMALE, adject., gcmmaris. Dutrochet appelle élongation gemmaire, dans les régétaux, ecllc qui résulie de la production des parties nouvelles sortant de l'intérieur des auciennes.

GLHIVLL, adj., gemmalis (gemma, bouton). Ifithete par laquelle L.-G. Richard désignait les écailles qui courrent et protègent le bourgeon.

GEnMATION, s. f. , gemmatio; Knospern, Knospentreiben(all.); gemmasione (it.) (gemma, bouton). Ensemble des bourgeons d'unc plante; disposition générale des Jourgeons; ćpoque de l'épanouissement des bourgeons.

GLMNIE, s. f., gemma. Les ancicns désignaient sous ce nom toutes les pierres (Edelsteine, all.) qui se font rechercher par leur rareté, l'éclat et la vivacité de leurs couleurs, lcur transparence complète, la pcr* fection avec laquelle clles se laissent polir, réfléchissent et réfractent la lumière, en un mot cclles qui semblent réunir le plus de perfections sous le plus petit volume possible. En botanique, le mot gemme (Krospe, Auge, all.), très-peu usité aujourd'hui, a été emplojé pour désigner toutes les parties, autres que les graines proprement dites, qui peuvent reproduire les vćgétaux, soit en se détaclant de la plante mère, soit en $y$ restant fixées. On a aussi donné ce nom aux rosettes des mousses.

GENLUFڤ̀nE, adj., gemmiferns; (gemma, gemme, fro, porter). On appelle ainsi le gravier au milieu duquel se trouvent les diamans.

GEMnIFICATION, s. f. , gemmifeatio; Knospung (all.). Link désigne sous ce nom la manière dont les bourgeons se dévcloppent, etil emploic le mot comme synonyme de ramif- 
eation, paree que ordinairement les bourgeons se prolongent en branehes.

GEMHILOIE, adj. , gemmiflorus (gemma, bouton, flos, fleur). Dont les fleurs ont l'air d'être renfermées dans des bourgeons, comme celles du Cephaclis gemmiflora, qui sont en eapitules, involuerés. Le Loranthus gemmifortes a des fleurs uaissant dans des involueres imbriqués, axillaires, solitaires et sessiles, qui ressemblent à des bourcreons.

GEMMHF ORME, adj., gemmiformis ; knospenförmig (all.). Willdenow donne eette épilliète aux fleurs qui sont entourćes de feuilles, et qui ressemblent à uu gros bourgeon. Voyes Gemairlone.

GEULU1'ARE, adj., gemmiparte; knospentragend (all.) (gemma, bouton, paro, produire); (qni produit des bourgeons. Ce terme s'cmploye surtout en parlant des zooplyytes.

GEMMULATION, s. f., gemmulatio. L.-G. Richard appelle ainsi le développenient de la geumule.

GEMMULE, gemmula; Knöspehen (all.). Ce nom est donné par Link au rudiment d'une nouvclle branche, qui est situé dans l'aissclle d'une feuille, el qui consiste en feuilles bien distinetes, qnoique fort petites; par L.-C. Riehard, au premier bourgeon de la plante, à celui de l'embryon, à la partie de l'enbryon qui termine la tigelle, est contenue entre les bases des eotylédons, ou incluse dans le eotylédon, et croît, par la gernination, en sens eontraire de la radicule ; par quelques botanistes aux rosettes des mousses. Meyer appelle gcmmules les corpuscules reproducteurs des algues, que Fries nomme cellules vérgétalcs, et Wallroth gonidics.

GENCIVE, s. f., gingiva; ZahnAcisch (all.); gum (angl.); gengiva (it.). Tissu rougeâtre et lerme; qui eouvre les areades dentaires et enveloppe le collet des dents, ehez beaucoup de mammifères.

GLVÉ ANTHROPIE, s. f. , genean-

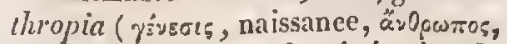
homme). Traité sur la génćration de l'homme. B. Sinibaldi a publié un ouvrage sous ec titre, en 1642 .

GENERAI, adject., generalis. On emplaye ce not: $1^{\circ}$ en botanirjuc. Les cloisons grinerales sont, d'apres Mirbel, celles dont les lords aboutissent de toutes parts à la paroi interne de la cavilé púricarpienne, en sorte que ehircune d'elles suffit pour diviser complètemeul eelle cavilé en deux loges (ex. Cassia fistula). L'involucre général enloure la base d'uno ombelle composéc (ex. Daucus $\mathrm{Ca}$ rotta). L'ombille genéralc est l'ensemble des rayons prinaires d'une ombelle composée, de ceux qui portent les onbellules. La spathe générale est cello qui renferme plusieurs fleurs munies de spathes particulic̀res. $2^{\circ}$ En zoologie. Lamurck appelle métamorphose généralc celle de l'jusecte qui, pendant le cours de sa vie, subit des nutations dans sa forme générale e dans toutes ses parties, les extéricures surtout, de sorte que la forme sous laquelle il naît diffère totalement de eclle qu'il doit avoir par la suite, et qu'aueune des parties qu'il possède dans son premier état, ne se eonserve la mêne daus le deruier.

GLNiRALISATION, s. f. Faculté au moyen de laquelle l'esprit rattache plusieurs jdćes semblables ou analogues a une généralíté commune.

GÉvirateUr, adj. ; qui engendre; faculté sénérutrice.

GureTATION, s. 1., generatio; ซร́vธฮเร; Zeugung (all.); gencrazione (it.). Nom eolleetif qui comprend toutes les opérations vitales ayant pour but de produire un nouvel ctre vivant.

GLNIGULÉ, adj., geniculatus; 
gcnuflexus; schnict, gelenkig, knieförmig (all.); ginocchiato (it.) (genu, genou ); qui est ployé ou coudć. Se dit: $I^{\circ}$ en minćralogic, d'un cristal composé de deux autres qui, en se réunissant par leurs extrémités, forment une espc̀ce de genou (ex. Titane oxidé géniculé); $2^{\circ}$ en botanique, des parties qui sont plićes brusquement sur leur longucur, de manicre à former un angle plus ou moins aigu, conime l'arète de l'Avena, le filct des étamines du Mahernia pinnata, les filamens du Conferva genuflexa, les pćdoneules du Pelargonium, ccux du Grimmia geniculaia, la racine du Gratiola, le style du Geum urbanum, la lige du Jasminum geniculature; $5^{\circ}$ en zoologie, des genoux ou de la partic correspondante aux genoux, quand la couleur n'en cst pis la mc̀me que ecllo du reste de la patte (cx. Laphria geniculata).

GENICULIFLORE, adj. , geniculiflorus (grnu, genou, flos, lleur). Le Mesconbryanthemum geniculiflorum est ainsi nommé parce qu'il a ses fleurs sessiles dans la dichotonic des rameaux.

GÉNIE, s. m. genizs. Activité très-énergique d'une faeulté quclconque, intellectuclle surtout ; supériorité d'esprit, force d'imagination, faculté créatrice; disposition naturelle pour une science, pour un art. "A près le génic, dit madame de Staël, ec qu'il y de plus semblable à lui, e'est la puissance de lc connaitre et de l'admircr."

GENISTLES, adj. el s. f. pl., Genistea. Nom douné par C.-H. Ebermaier à une tribu de la famille des Papilionacécs, par Candolle à unc sous-tribu de la tribu des Isotécs, ayant pour type le genre Genista.

GĺNTHL, adj., genitalis ; qui a rapport à la génération ou ì ses organcs. On appellc organes génitaux ou parties gínilales (Zugungstheile,

\section{GEOC}

Geschlechtstheilc, all.; genitale, iı.) les organes dont l'aetion et le concour's sont néecssaires pour la production d'un nouvel individu, et apparcil génital l'ensemble de tous les organes qui servent à la génćration.

GENOU；s. m., genu ; 7óvn ; Knic (all.); knec (angl.); ginocchio (it.). Articulation de la cuisse a vec la jambe, considérće dans sa partie antéricuro sculement.

GFNOUILL: $V$. GÉNICULE.

GENTiANÉEs, adj. et s.f. pl. , Gentianea. Famille de plantes qui a pour type le genre Gentiana.

GENTIANINE, s.f., gentianina. Nom donnć par Henry et Caventou á unc substance eristalline qu'ils ont trouvéc dans la raciıte du Gentiana lutea.

Géobatr.iciens, adj. et s. m. pl., Geobatrachi ( $\bar{n}$, terre, $\beta \dot{x} \tau \alpha-$ $\chi^{a \zeta}$, grenouille). Non donné par J.A. Ritgen à une famille de Batraeiens, eomprenant ceux de ces animaux qui sont privés de queue et qui vivent sur terie.

GÉOBLASTE, s. In. , gcoblastus, Erdkcins (all.) ( $\gamma_{\bar{n}}$, terrc, $\beta \lambda_{x \sigma}-$ $\tau \dot{x} v \omega$, germer). Nom donnć par Willdenow aux cmbryons dont les cotylćdons resicnt sous terre pendant la germinalion. Ex. Vicia.

GEOCENTRIQUE, adj., geocentricus ( $\tilde{y}$, terre, xદ́vтรo\%, centre). Lies astronoines appellent latitude géo. centrique d'une planètc la distance à laquelie cllc nous parait être de l'écliptique, l'angle que la ligne qui joint la planc̀te à la Terre forme avec nne ligne qui aboutirait à la perpendiculaire abaissée de la planète sur lc plan de l'écliptique. La longitude géocentriquc d'une planète est le lieu de l'écliptique auquel on rapporte eette dernière vue de la Terre.

GÉOCILÉLIDONES, adj. et s. m. pl., Geochelidones $\left(\gamma^{n}\right.$, terre, $\chi^{s-}$ 
hiè̃u, hirondelle). Nom donné par J. $-\Lambda$. Rilgen à une lamille de l'ordre des Hyloptènes, qui renferme les hirondelles de ierre.

Gl'ocochrides , adj. et s.m.pl.,

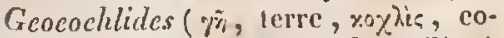
quille). Nom donuć par Latreille it une fanille de l'ordre des Gastéropocles puluonés, comprenant ccux qui vivent sur terre et qui ont des coquilles.

GĹocorises, adj. et s. f. pl., Geocorisa. Nom donne par Cuvier, Isitreille et Liebwald it une famille de l'ordre des Hémiptères, comprenant les punaises qui vivent sur terre.

GhONE, s. f., gcodes; \%scoins

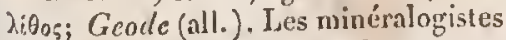
désignent sous ec nom des masses sphéroïdales, qui off'rentà leureentre un vide hérissć de eristaux.

Gb́odrous, adj., geodicus. Se dit en minéralogie d'un corps conerétionné qui s'est moulé, sous la lorme d'unc croûtc, dans une eavité arrondie.

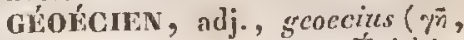
terre, oixos, habitation). Epithète donnée par Wallroth aux licheus qui croissent sur la terrc.

GĹfOFFícs, adject. et s. f. pl., Geoffrece. Nom doriné par Candolie à une tribu de la famille des Légumineuses, qui a pour type le genre Gcoffrea.

GÉGASTRES, adj. et s. m. pl., Gcogastri ( $\gamma^{n}$, terre, yxarip, ventre). Nom donné par Nees d'Esenbeck à une irihu de l'ordre des Gastéronyyces, comprenant ccux qui vivent dans la terre.

GLOGLNE, adj., geoments.s ( $\bar{n}$, tcre, fávyow, produire). L. Schweinitz donne cette épithète aux champignons non parasites qui croissent iminćdiatement sur le sol.

GÉOGÉNIE, s. f., geogenia, gcosonia. Branche de l'histoire naturelle qui examine la manicre dont les ma- tériaux constituans de la Terre ont été formés et disposés dans lcur position actuelle, et qui se livre à des considérations eosmogouiques ayant pour but de remonter à un état de clioses plus ancicn que celni dont la nature nous offre les dernières traces.

GLOCǴviQue, adj. , gengenicus ; qui a rapport à la géngénie ; conséquenec, hypothèse, idée, théorie géogénique.

GLOGNOSIE, s. f., geognosia ;

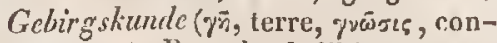
naissanec). Branche de l'histoire naturelle dont le but est de faire connaître la composition minéralogique, la structure, la forme et l'étendue des divers groupes ou systèmes de masses minérales dont l'ensemble eonstitue la partie solide du globe, lcur disposition réciproque, les circonstances de leur superposition les uns aux antres, leurs différens rapports entr'eux, et tout ee qui est relatif, soit à lenr unode de formation, soit aux changemens qu'ils out éprouvés.

GLOGNOSTE; s.m., geognosia. Naturaliste qui s'occupe spécialement de la géognosie.

\section{glognostico - botanieue,} adj., geomnostico-botanicus. Sternberg a publice un essni, portanl ec titre, sur la flore du monde primitif, en 1820 .

GíogNostroue, arlj., geognostictis. On appelle périodes géognosniqucs, tout le temps pendant lequel les mêmes phénomènes géognostiques ont cu licu à la surface de la Terre. Ia suceession des temps n'est rien pour ces périodes, qui se fondent sur l'apprarition des grands phénoménes our des grandes eatastrophes.

GĹogoxmiQur, adj., scogonimicns ( $\% \bar{n}$, terre, yoy่, procréation). Epithète dounée par Wallroth aux lichens qui eroissent sur la terre.

GEOGRAPHIE, s. f., geographia; Erdbeschrcibumg (all.). Deseription 
de la forme extérieure de la Terre, dourt elle esquisse à grands traits lá figure, sans nul égard aux divisions artificielles et arbitraires de la politique.

GÉOGRAPIIQUE, adj. , gcographicus. Épithète donnée à des corps qui sont marqués de lignes colorées irrégulières, représertant en quelque sorte un dessin de carte géographique. Ex. Rhizocarpon geographicus, $V_{c-}$ nus gcographica, Conus gcographicus. Voy. Ecrur.

GÉoLOGIE; ;. f., gcologia ( $\gamma \tilde{n}$, terre, dóyos, diseours ). Partie de l'histoire naturclle qui traite de la forme cxtérieurc de la Terre, de la nalure des matériaux qui la composcrit, de la manière dont ces matćriaux ont été formés et placés dans leur situation actuelle.

GÉOLOGIQUe, geulogictu; qui a rapport à la géulogie. Haüy nonıme relations gćologiques d'un minéral, Jes différeutes manières d'ètre qui déterninent ses rapports avee la strueture dı globe.

GĹOLOGISTE, s. m. Naturaliste qui sc livre spécialement à l'ćtudc de la géologie.

Grologue, s. m. Synonyme de géologiste.

GÉonúTIaLES, adj. et s.f. pl., Geometrales. Nom donmé par Lamarek à une famille de Ićpidoptères diurnes, renfermant ceux de ees insectes dont les chenilles marchent en arpentant le terrain.

GÉmetre. Voye Anpeyteun.

GÉomérRoue, adj., gcometricus ; qui est marqué de lignes angnleuses et irrégulic̀res simulant des figures géométriques. Ex. Holacanthus geometricus, Chersine geometrica. Voy. Ecnit.

GLOMOLGES, s.m. pl. ( $\gamma \bar{n}$, terre,

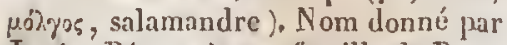
J.-A. Ritgen à une finille de Rep- tiles batraciens, qui compreud les salamandres terrestres.

GíouvzLDEs, adj. et s. f. pl., Geomyzides. Nom donné, par Fallen, à une famille d'issectes Diplères, qui a pour type le geure Geomyza.

GÉoNoNIE, s. f., geonomia ( terre, yricos, loi ). Partie de la playsique générale qui traite des lois auxquelles sont soumis les ehangemens qu'on observe à la surface de la terre dans l'atmosphìre.

GÉoPULE, adj., geoplitus ( $/ \tilde{n}$, terre, pilizes, aimer); qui habile ou croit sur la terre. Ex. Agarieus geophilus, Cenocaccum gcophilum.

GÉOPHLLS', adj. ct s. m. pl. , Gcophila. Nom donné par Hartmann, Férussac el MIenke á une division de l'ordre des Gastéropodes pulmonés, comprenant ceux qui vivent sur terre.

GÉPHLIDEs, adj. et s. m. pl., Grophilida. Nom sous lequel Leach ảćsigne une famille de l'ordre des Myriapodes chilopodes, qui a pour type le genre Geophilus.

GLOMIULLE, adject., gcopliyllus

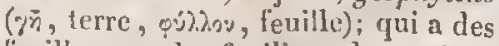
feuilles ou des feuillets de couleur terreuse, comme les feuillets du chapenu de l'Agaricus geophyllus.

GLOPIITE, s. m., gcophyton ( terre, ýves, eroitre). Lamouroux appelal d'abord ainsi les végétaux terrestres, que depuis il a nommés aćro. phyles.

Gŕontuáciens, adj. et s. m.

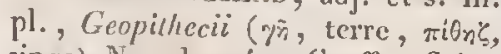
sinnce). Norn douné par Geoflioy SaiutHilaire à un groupe de la famille des quadrunsaues Platyrhiniens.

Gíconcrivies, adj. et s. f. pl., Gcorginece. Nom sous lequel Lessing désigne une seetion de la sons-tribu des Astéroüdées Éeliptées, qui a pour type le genre Georgina.

Grosiuriens, adj. ct s. m. pl., Gcosaurce ( Nom douné par J,-A. Ritgen à une 
scetion de l'ordre des reptiles saturiens, comprenant ceux qui virent sur terre.

GLotnumides, adj.et s. m. pl., Gcotrupide. Nom donnć par Leaeh ì une famille de Coléoptères, qui a pour type le genre Geotrupes.

Géothupins, adj. et s. m. pl., Gcotrupini. Latreille et Goldfuss désignent sous ee nom une triba de la fannille des Colćoplères lamellieornes, qui a pour type le genre Gcolrupes.

Géraniciés, alj. et s. f. pl., Geraniacea, Geranicer, Geranioidea. Famille de plantes, qui a pour lype le genre Goranium.

Ghinimes. VoyezGriraniacées. Cóns.

Gúmavomóns. Vojez Gérania-

GLRASCANTIE, adj. , gerasean-

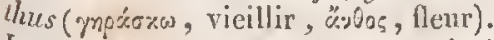
Ic Cordia gerascanthus est ainsi appelé à cause de la longue durée de sa corolle.

GErblnées, adj. et s. f. plar., Gerberice. Nom donné par II. Cassini isue scetion de la tribu des Mratisices, qui a pour type le genre Gerberia.

GERBWORUE, adj, gerbiformis. Se dit, en minéraloggie, des crislaux neiculaircs, lorsque les aiguilles, adhérentes el parallèles par le lias, divergent par lear partie supérieare. L.x. Stillite.

METhombís, adj. et s. m. plur., Cerboildce. Nom douné par Gray à une famille de l'ordre des Marnmifires gliriens, comprenant les Gerhoises.

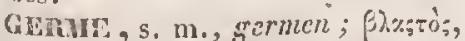

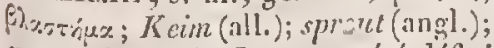
sermogolio (it.). Ce mot a élé défni Par Bonnet, une espẻee de préformatlion originelle dont un toat organique pcul résulter eomme de son prineipe immédiat; par Sencbier, une Machine organisćc, parfaile à tous éards, qui ne peut etre modifice que par développement, mais qui ne saurait l'être par changement ou par addition d'organes essenticls, à moins qu'il ne survienne des eirconstanees particulieres capables de produire des monstruosités; par Chaussier, une partie organisée qui contient l'ćlément de la forme et du mouvement ; par Cindolle, un corps, imperecplible pour nos sens, qu'on suppose exister dans les corps organisćs, et être ou renfermer en minjature le corps ou la partie du corps qui doit en provenir. Il es t plus simple de clire qu'un germe est le rudiment d'un nouvel être ou orgune cqui vient d'cttre produit on engendré. On donne vulgairement ee nom à la cicatricule de l'ocuf ; Limé l'a, par abus, appliqné ì l'ovaire des plantes, du moins quand il est supère.

Grunuti, adj. , germinutus; sclicimu (all.). Se dit d'une graine qui eommence à montrer sa radicule.

GRHMINAr, adject., germinalis. Nom donné par Eysenhardt anx feuilles qui sc déreloppent en plaee de la graine.

GERurnstw , adj., germinativas ; licimfähig (all.). On appelle faculté germinutue (Kcimfähigleit, Entusvickelungsfïhigkcit, all.) la fineulté qu'ont. les graines de germer, et plus géućralement celle qu'ont les corpuscules reprodueteurs des êtres organisés, après aroir joui pendant plus on moins long-temps d'une vie en quelque sorte litente, de se développer lorsqu'ils viennent à être plaeés dans des cireonstanees lavoriables.

GLRVINATION, s. f., germinatio; Keimen (all.) ; germinazione, germoglinzione, germogliumento (it.). Développenent du germe des végétaux, pour produire une nonvelle plante; ensemble des phénomènes que ee germe présente el des changemens qu’il subit lorsqu'après son isolement 


\section{4}

du végétal qui l'a produit, il se trouve placé dans des cireoustanees eapables de réaliser sa tendanee a devenir lui-raême une plante. On n'applique commusément ee inot qu'aux graines; miris il doit évidemment s'ćtendre aussi aux eorpuseules reprodueteurs des plantes agames.

GEIminipane, s. f., germiniparia (germen, germe, paro, produire). Burdaeh appelle ainsi (generatio monogenea productiva; $K$ cimzeugrung, all.) le mode de génération qui consiste en ee qu'un eorps organisé pousse de nouveaux produits (germes), dont le développement donnc lieu a de nouveaux individus.

Gkrivovines, adj. et s. m. pl., Geryonidex. Nom douné par Eschenholtz à une famille de l'ordre des Aealèphes libres, qui a pour type le gemre Geryonia.

GESIER, subst. m., ventricules; Fleisclemagen, Kropf (all.) ; gizzard (angl.). Estomac proprenent dit des oiseaux.

GESNkRIEES, adj. et s. f. pl., Gesnerica, Gesnerior. Famille de plante, proposéc par Jussieu et L. - C. Richard, et admise depuis par Nees d'Esenbeck, qui a pour type le genre Gesneria.

GESTATION, s. f., gestatio ; Tragezeit (all.) (gero, porter). Temps durant lequel un être organisé femelle qui a eonçu eonserve le nonvel êtrc daus son eorps, et le nourrit it ses propres dépens jusqu'à ec qu'il soit eu élat de venir au monde.

GIBmEdx, adj., gibbosus, giblus; höckerigr (all.) (gibbus, bosse). Les botanistes donnent celte úpithète anx parties des végétaux qui sont relcvées en bosses plus ou moins apparentes, comme le tube de la eorolle de l'Antirrhinum majus, le nectaire des Salvia, le calice du Tezecrizm Loirys, la paléle du Bromus pinna-
GIGA

tus, les fouilles du Crássula Colyledon, ou qui sont garnies de boutons renflés, et semblables à de petites hosses, comme los noeuds de la tige du Pelargonium gibbosum. En znologie, nn appelle gibbeux des animaux gui ont plusicurs bosses sur le dos (ex. Balcena gibbosa), ou le dos très-arqué (ex. Holoecntrus giblosus, Coccinclla gibbosa).

GHBBIFERE, adj. , sibbifer, sibbiferus (gibbus, bosse, fero, poiter); qui porte une bosse. Mirbcl donıe eette épilhète à la gorge de la corolle, quand on $y$ voit des dilatations cu forme de bosses. Ex. Borrago.

GHBBIFLORE, adj., gibbiflorns (gibbus, bosse, flos, fleur); qui a des pélales gibbeux. Ex. Echeveria gibbiflora.

GIBBIPENNE, adj., gibbipennis (gibbus, bossu, penna, aile). Iue Ceutorhynchus gibbippennis a les élytres bombées, ovales et globuleuses.

GHBBIROSTRE, adj., gibbirostris (gibbus, bossu, rostrum, bee); qui a le bee ou le rostre hossu. Ex. Bnris gibbirostris, Apion gibbirostre.

GmbOnYDES, adj. et s. f. plur., Gibbomydes. Nom donné par Robineau-Desvoidy à une tribu de la famille des Myodaires mueiphorées.

GIBBOSIFOLIÉ, adj. , gibbosifolius (o ibboszu, bossu, folium, f'cuille); qui a desfeuilles bosselées. Ex. Phaseolus gibbosifolius.

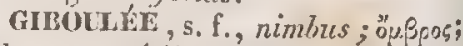
Platzregen (all.); shower (angl.); aquazzonc (it.). Espèec d'orage qui se réduit ì des eaups de vents médioeres et passagers, avee de petites averses, des ondées passagìres ou do petiles grồles.

GIGANTESQLE, adj., migantens; riescnllaft (all.); gisantic (angl.) (jíras, géant). Se dit d'un corps dont les dimensions dépasşent Juate. 


\section{GITO}

coup les limites ordinaires. $V_{o y} c z$ Colossal, Géant.

GiganTOLOGIE, s. f., giganto-

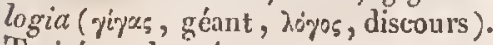
Traité sur les géans.

GIGAItTIN, adj., gigartinus ( rirxotar, pepin de raisin). Épithète donnée par Lamouroux à la fiructification des hydrophytes, quand elle il la demi-transparence nébuleuse des grains de raisin, et qu'au centre existe un corps opaque, formé par la réunion des capsules, qui ressemble à la massc des pepins. Ex. Gigarlina.

GrLLIEsiEes, adj. ct s. f. pl., Cillicsicr. Famille de plantes, établic par Lindley, qui a pour type le genre Gillicsia.

GILVICÉPILALE, adj., gilviccphalus (gilvus, gris cendré, $x \varepsilon p x \lambda \dot{y}$, tête); qui a la tête grise. Ex. Mtelilircpens gilvicapillus.

GILVICOLLE, adj., gilvieollis (gilvus, gris cendré, collum, eol); qui a la gorge cendréc. Ex. Sparvius gilvicollis.

GINIKOIQUE, adject, ginhoücus. Nom donné par Peschier à un acide, encorc problématique, qu'il dit avoir trouvé dans le Gingrio biloba.

GISEMENT, s. m. 'Terme dont les géognostes se servent pour exprimer en général la manière d'etre d'un minéral dans le sein de la tcrre ou à sa surface.

GITE, s. m., Lager (all.). Les gúognostes donnent ec nom aux masses minérnles, considćrées relativement à certaines substanecs qu'clles renferment et qu'on se propose d'en extraire. Les gîtes généraux $x$ sont les terrnins, et les grites particulicrs sont des masses particlles, intercalées dans des terrains, dont elles diffìrent sous le ripport de leur nature, comme les lilous, les amas.

GITONOH:HTE, s. m., gitono-

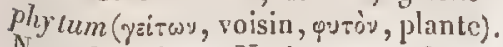
Nom donné par Neeker aux plautes qui, par la disposition de leur fructification, se rapprochent de celles qu'il appelle Scadiophytes ou Ombcllifères.

GIVHe, s. m., pruina; $\pi \dot{x} y$ w; Riaule. reif (all.); hoarfruse (angl.); brine (it.). Glace en floeons dout les corps se eouvrent en hiver, lorsquela tempér ture est au dessous de zéro, et qui paraît. être due en partic à la congélation de la rosće, en partie à un dépôt d'atomes glacés qui se précipitent de l'atmosplıère.

GLABRE, adject. , slabcr ; vnbchaart, kahl, abgeliaart, geschoren (all.). Se dit d'une surface qui est totalement dépourvue de poils (ex. Crypticus glaber, Cncstis glabra, Chrysophyllum glabrum, Panicum calvescens, Dauecus glaberrimus, Clarionia glabcrima). Illiger donne cette épithète aux pieds des oiseanx, quand ils sont couverts d'nn épiderme lisse. Le Leptograsterglabratus a le corselet glabre.

GLAmiste, s. r., glabrcitics; Kahlhcic (all.). Terme dont Candolle se sert pour indiguer l'état d'une surface qui ne porte pas de poils.

GLABRLSCENT, adj., slabrescens; lahl werdend (all.). Se dit d'une plante qui perd ses poils avee le tcmps.

GLABHEOLuL, adj., glabrifolirs (glaber, glabre, foliuin, fenille); qui a les feuilles glabres. Ex. Oxy ba phus glabrifolizes, Polycarpca glabrifolia.

GIAABRIUSCUıE, adj., glabriusculns, glabrcllus, glabraius; fost kahl (ali.); qui n'est pas tout-i-fait glabre, mais n'offre qu'une villosité à peine sensible. Ex. Frallicria slabrinscula, Amplaidesma grabrclla, Mimulus glabratus, Michauxia slubrala, liuccinum glabratum.

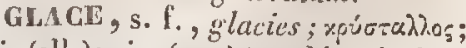
Eis (all.); ice (angl.); ghiaccio (it.). Enu devenue solide parl'abaissement 
de sa température jusqu’à zćro. - GLACIAL, adj., glacialis; ciskalt (all.); icy (angl.). On appelle zónes rlaciales celles qui s'étendent depuis les pôles jusqu'aux eercles polaires, à cause des froids rigoureux qui $y$ règnent pendant la plus grande partie de l'année. Cette épithète est donnće aussi à des plantes qui végètent au milieu des glaciers t des nejges, dans les haules montagnes ( ex. Arıemisia glacialis!, Lichcn gelidus, Liclen frigidus), et à des animaux qui habitent dans les régions du nord (ex. Balana glacialis, Buccinum glacialc, Procellaria gclida).

GrACIER, subst. m., Glctscher, Eisberg (all.). Amas énorme de neige eudurcie et de glaee, qui remplit les vallécs et couvre la eroupe et les plateaux des hautes montagnes.

GLACHiRE, s. f.; Eisgrube (all.); iccuell (angl.). Exeavation naturclle dans le sol, ou grotte dans laquelle la glace sc conserve pendant toute l'anuée.

GLAnIÉ, adj., gladialus, anccps; schwerdlformig, (all.) (gladium, épéé). Se dit, en botanique, d'une partic qui est eomprimće, el qui offic des arètes vives, une sorte de trainchaut, comme les articulations supcricurcs do la Corallina anceps, les épincs de l'Echinocactus gladiatus, les feuilles de l'Ornithocephalus gladiatus et du Lcpidospcrma gladiata, les filcts des ćtamines du Canna indica, les légumes du Trigonclla gladiata, la nagcoirc dorsale du Delphinus gladiator.

GLADIWIRE, adject., gladifer, gladiferus (sladium, épće, fero, porter). I'Tstiophorus gladifcr est ainsi appelé, parce que sa mî̀choirc supérienre sc prolonge en forme de lame d'épéc.

GLADIOLKES, adj. et s. f. pl., Gladiolece. Nom donné par Salisbury à une famille de plantes; qui a pour type le genre Gladiolus.

GLAirine, s. f. , glairina. Anglada appelle ainsi une matičre mucilagineuse ou glaireuse particulicre, qu'il a trouvée dans les eaux sulfureuses des Pyrénées.

GLAND, s. m., glans, balanus; Bंiגavos; Eichel (all.); acorn, mast (angl.); ghianda (it.). Appliqué d'abord uniquement an fruit du chêne, ee nom a été étendu ensuite anx autres fruits qui ressemblent plus ou moins à celui-là, et les botanistes définissent le gland un fruit uviloenlaire, indćhiscent, monosperme par avorteinent, provenant constamnient d'un ovaire infère - pluriloculaire et polysperme, dont le péricarpe, uni intimenent à la graine, présente toujours à son sommet les dents fort petites du limbedu ealiec, et ost renfermé en partie (cх. Quercus), ou en tolalité (ex. Corylus), dans une sorte d'involuerc écailleux (cx. Qucrcus ) ou foliacé (ex. Corylus). On a proposé de réserver le nom de gland pour la noix contenue dans la eupule. Quclquefois on appelle gland la partic supérieure des Phallus et des Clathrus, parce que sa lorme et l'euduit muqueux qui la reeouvrc lui donnent quelque ressemblanee avec le gland de la verge.

GLANDAIRE, adj. , glandarius; qui vit de glands. Ex. Corvus glandarius.

GLANDE, s. ^., glandula; à่ว̀y ; Driusc (all.); kcrnel (angl.); glandold (it.) (glans, gland). Organe, quel qu'il soit, qui aecomplit la séerétion d'un liquide parliculier. Ce terme a une signifieation bien vague déjà cn zoologie, muis beaneoup plus indéterminće encore en lıotunique, où il sert abusivenreut à désigner, nonseuleunent des organes sćcrélcires, mais encore des tubercules de toutc espèce, de petites écailles, et mène 
de simples taches, sans qu'on sache trop ce qui a motivé celte appellation.

GCANDIFL̀RE, adj., glandiferus (glans, gland, fero, portcr); qui porte des tubereules en forme de glands, comme on en voit sur le disque de la Porpita glandifcra.

GLANDIFOHW:, adj. , glandiformis; eichenförmig (all.) (glans, slaud, forma, forme); qui a lá forme d'un gland, comme les capsules du Chorda, ou les fraits de l'Areca glandiformis.

GLANDULEUx, adj., glandulostus; ainvwirn's ; drüsig (all.) (slandula, glande). Se dit d'une plaute qui a des glandes, soit dans l'ćpaisseur de son tissu, comme celles qu'on voit dans le parcnchyme des feuilles de l'Arctotis glandulosa et du Thymus glandulosies, soil sur sn surface toute entière (ex. le Psoralea slandulosa), soit sur quclques unes de ses partics seulement, comme sur les dents de ses folioles (cx. Pscudopetalum glandulosum), à la circonférence de ses feuilles (cx. Loureira glandulosa), sur ses bractécs et ses calices (ex. Lavradia glandulosa). Glandulenx se dit également de toute partic qui porte des glandes, eomne les anthères du Lconurus Cardiaca, les filets des étamines du Dictamnus allus, les pétales du Borbcris, les pćtioles du Viburnum Opulus, les poils du Rosa maxima.

GLANDULIFlen: adject. , glandulifer, glanduliforus; drüsentragend (all.) (glandula, glandc, fcro, porter). Sc dit d'une plante qui est entièrement couverte de glandes éex. Parmelia glandulifera, Dolichlasium. glanduliferum), ou qui en porte sur quelqu'une sc ses plarties, sur ses feuilles (ex. Cinchona glandulifera), ses légumes (ex. Glycyrrhiza glandulifera), ses pédonenles (ex. Lampsana glandulifcra).

Granpulfolime; adj. , glandu. liformis (glandula, glande, forma, forme); qui a la forme d'une glande. Épithète donnce par II. Cassini aux collccteurs, dans les Adénostylées.

GLANES, s. m. pl., Glani. Nom donné par Latreille à une tribu de la famille des Siluroïdes, renfermant lc Silurus Glanis el les poissons qui lui ressemiblent le plus.

GLAPIIQUN, adject., glaphictss ( yix́w, seulpter ). Haüy donnait cette épithète à une varićté de tale, parce que les seulpteurs clinois s'en servent beaucoup pour faire des magots.

GLAPISSEAIENT, s. m., gannitus; xขuלnsนòs; Klï/fcn, Bolfern, Gälfern (all.); yelping, barking, squeaking (angl.); ghialtimento (it.). Cri du renard et des petits chiens. Sc dit aussi d'une roix aigre et perçante.

GLAUCES, subst. m. pl., Glaues (jiaǐ, chouette). Nom donné par J.- $\Lambda$. Ritgen ì une famille de l'ordre des Hypsoptènes, comprenant les chourties.

GLAUCÉs, adj. et s.m.pl., Glau$c e a$. Nom donué par Menke à une famillc de l'ordre des Gastéropodes gymnobranches, qui a pour type le genre Glaucuss.

GIAUCESCENCE, s. f., glaucescentia ( ${ }_{1} \alpha u x$ s̀, verd de mer). État d'une surface glauque.

GLAUCESCENT, adject., grlaucescons ( $\gamma \lambda x$ wsxó, verd de mer); qui tire sur le verd grisâtre. Fx. Panicum glauccscens.

GLAUCiQue, adjcct.; glaucicus: Runge donne celle épithète à un acide qu'il a trouvé dans les Dipsacées, paree qu'avec l'ammoniaque cet aeide forme une combinaison jaune, qui devient d'un bleu verdâtre au contact de l'air.

GLAUCO-TERRUGINEUx, adj. , glauco-Jerruginosus. Êpithète donnée par Dclabâche au sable verd.

GLAUCOPE, arject., glaucopus 


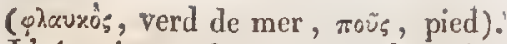
L'Agaricus glaucopus a le stipe bleuâtre.

GLAUCOPĹs, adj. et s. m. pl., Glaueopa. Nom donné par Lesson à unc famille de l'ordre des Passereaux, qui a pour type le genre Claueopis.

GLAUCOPITYLLE, adj. , glaucophyllus ( ghavrós, verd de mer, vij)sov, feuille); qui a les fenilles glauques. Ex. Cristaria slaucoplyylla, Nasturtium glaucoplyyllum.

GIaAUCOPTERE, adj. , glancom

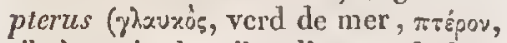
aile); qui a les ailes d'un verd glanque. Ex. Musca grlaucoptera.

GLAUCURE, adjcet., glaucurus

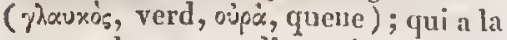
queue glanque ou d'un gris verdattre. Ex. Chironomus glaucurus.

GLAUQUE, adj., grlanecus, glaueius;

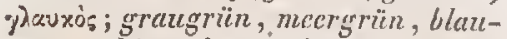
grün, schimmelgrün(all.); rlauco, appannato (it.).Se dit, cn bolanique, de plantes ou parties de plantes dont la surface est d'un verd ou d'un bleu blanchâtrc et comme pulvérulente, ce qui, d'après Candolle, tient à une multitudo de petits poils extrêmement eourts (ex. la face inférieure des feuilles du Rubus), à l'écartement d'une lame très-mince de tissu cellulaire sous laquelle se glisse une eonché d'air qui l'empêche de toucher an reste de la feuille (ex. la faee inférieure des feuilles du Buxus), ou à une couche pulvérulente due à une multitude de petits globulcs cirenx, ce qui est le plus ordinaire ( ex. Cocculus glaucus, Gleichcnia glauca, Didymodon glaueescens, Mrsentbryanthemum glaueum, Chelidonium glaucium). Un poisson (Carcharias ólaucus) a élé appolé aiusi parce qu'il est bleu.

GLEICHúvées, adj. et s. f. pl., Gleielenea. Noun donné par R. Browı à une tribus de la famille des Fougè- res, qui a pour type le genre Gleiehenia.

GLEICIĹXIACĹES, adj. et s. f. pl., Gleicheniaecer. Kaulfuss et Gaudichaud désignent sous ce nom une tribu de la famille des Fougères, ayant lc genre Glcichonia pour type. GLIDDINE, s.f., gliadina, gloiodina; Pfanzcnlcim (all.) ( $/$ hix, gुlu). Nom donné par Taddei à un mélange de gluten, de gomme et de mueilage, qu'il considérait comme principe constituant des végélaux, et rqu'il supposait produire le gluten du froment par sa combinaison avec une autre substance appelée zimome.

GLINíEs, adj. et s.f. pl. , Glinea. Caffin appclle ainsi une famille de plantes, qui a pour type le genre Glinus.

GLIPIIENS, adj. et s. m. pl., Glires, Rosores, Prensiculantia. Nom donné par Pallas, Desmarest et quelques antres zoologistes, à la famille des Mammifères rongeurs, en raison du Myoxus glis qu'elle renforme.

GLOBAIRE, adj., globaris. Sc dit, en minéralogie, d'une substanee qui se compose d'un assemblage de masses globuleuses (ex. Diorite globairc). et de la structure d'une roche, quand ses parties constituantes sont disposées sous la forme de sphéroïdes, comme dans les Variolites.

GLOBICEPS, adj., ğlobiceps ( $\mathrm{g} l 0$ bus, globe, eaput, tête); qui at la tête ronde. Ex. Delplinuts globiceps.

GLOBICÊRE, adj., globicertes (globus, globe, ecra, cire). Le Crax globiccra est ainsi appelé à cause d'une prolubérance jaune, ct grossc eonme une eerise, qu'il porte cntre les ouvertures des narines.

GLOBICORNE, adj., globicornis (globus, globe, cornu, cornc). Le Tabanus grlobicornis a le second article de ses antennes globuleux.

GLOBFW LRE, adj., sioliferus (g/o bus, globule, fero, porter); qui portc 
des corps globuleux, renflés en tête ou en boule, comme les pédicules du Pedicellaria globifera, et le perithécion des Spluceronoma. Les urnes du Pleuridium globiferm sont globuleuses.

GLOBHELORE, adj., globiforns (slobus, globe, fros, fleur). Se dit d'une plaste qui a des corolles globulenses (cx. Sida globiflora), dont les fleur's sont sessiles et riunies on tête (ex. Adina globiflora), au dont les ombelles sont sessiles et.globuleuses (cx. Hydrocotyle globifera).

GLOBHORwE, adj., globiformis (globus, globe, fornua, lorme). Se dit, cn minćralogic, d'un corps qui a la forme d'un globe plus ou moins volumineux (cx. Fer sulfuré globiforme). L'Erhinus globiformis est ininsi nomné a canse de sa forme gुlobuleuse.

GLOBHOFE, adject., gloiniporus (slobus, glolic, portes, porc); qui a des pores orbiculaires. Ex. Disioma slobiportum.

GLOBULALE, adj., globularis (globus, glohe). On appelle glandes glabulaires celles qui sont tout-àliit sphériques et n'althèrent ì l'épiderme que par un point de leur périphérie, comme eclles qui forment unce poussic̀re brillante sur le ealice, ta corolle et les anthires de beaucoup de Labiées.

GLOBLLARIES, adj.et s. f. pl., Globularien, Globularine. Fanille de plantes, que Lamarck avait proposée d'ćtablir', que Candolle et Kunth ont adoptéc, et qui a pour type le genre Globularia.

GLOBUEE, s. m., globulus; Knöpfcluen, Kügelehen (all.); globeulo (it.). En bolanique, ce nom a été donné par Bernhardi aux pelites parlies rondes, situces la plupart dia temps sur latige et les pétioles, qu'on ringe habitucllement parmi les glandes ( comme eclles des pétioles du
Vilurnum Opuluss, quoiqu'elles paraissent ne rien sécréter ; par Acharius et Willdenow à des conceptacles globuleux, qui maissent à l'extrémité d'un podétiou dans la substance duquel ils sont euchâssés à moitié, se délachent au bout d'nn certain temps, ct laissent voir par leur chute la fosselte qu'ils remplissaicnt ( $\mathrm{ex}$. Isidium); par Necker, aux eapsules globuleuses de's Jungermannies.

GLODULEUX, adj., globosus, globulosus; бọatposton's; geballe, liugclrund, kugclig (all.); globoso (it.); rqui a une forme arrondic ou sphérique, comme les antheres du Mereurialis, la Laic de l'Asparagus, la carcérule du Lagetia, le córion du Panicum italicum, le chaton du Platane, la corolle du Ternstroumia gelobifera, l'érème du Collinsonia canadensis, les glumes de l'Airopsis globosa, l'invaluere de l'Achillea sambueina, le noyan du Cerasus.s, le pépon du Cueurbita Pepo, la pyxide de l'Anagallis arvensis, la silicule du Crambe, le stigmate du Mirabilis Jalapa, les utricules du pollen du Phleum nodosim. En zoologic, on donue cette épithète à quel. yues animaux yui ont une forme exactement sphérique (cx, Aphodius globosus, Volvox globator, Bursaria globina, Agrathidiun scmilunum); ì des coquilles bivalves dont les valves, très-bombées, présentent chacume exactement la forme d'un hémisphère (cx. Cyclas globus), ou univalves dont tous les diamètres sout sensiblement égaux, à cause du grand développement du dernier tour de spire, qui dépasse de beancoup le précédent (ex. Turbinclla globulus); au eorselet des iusectes, quand. il est arrondi (ex. quelques Callidies); à des polypiers de forme ronde (ex. Aleyonium globulosunt).

GLOHULCORNES, adj. et s. m. pl., Globulicornes (globullus, globule, cormu, corne). Nom donné par 
Duméril à une famille de l'ordre des Lépidoptères, comprenant ceux de ces insectes qui ont les antennes en masse, renflées au bout. Voyez RoPALOCÉRES.

GLOBULIFLIRE; adj., globuliferus (globulus, globule, fero, porter). Se dit, en botanique, d'une plante qui a quelqu'une de ses parties globuleuse. La coupe du Peziza glolulifera est bordée de longs cils globuliféres; les fruits de l'Areca globulifera sont globuleux; Ic Scevola globulifera a Porifice du tube de sa corolle garni de glandes capitées; le caliec du $P_{i-}$ cris globulifera devient gloluleux après la floraison; les involucres du Pilularia globulifera sont arrondis ct naissent presque sessiles au bas de la tige; le Saxifraga globulifera a ses rameaux couverts de bourgeons laineux et oblongs, qui ne sont pas épanouis.

GLOBULIFOLIË, adj., slobulifolius (globulus, globule, folium, feuille); qui a des feuilles globuleuses ou à peu près. Ex. Crassula globulifolia.

GLOBULTFORME, adj., globuliformis (globrelus, globule, forma, fornic). Se dit, en minéralogic, d'un corps disposé en globules dont l'iutérieur cst continu, sans couches concentriques. Ex. Chazex carbonatée slobuliforme.

GLOBULINE, s. f., globulina. Turpin propose de donner ee nom aux vésicules distinetes, diversement soudées, et quelquefois entièrement libres, qui, suivant lui, composent le tissu régétal tout entier. L'hypothèse dans laquelle les corps organisés en général sont le résultat d'une agrégation d'organismes inférieurs, et les plantes en particulier celui d'unc association de végétaux d'une excessive simplicité, appartenant à la classe des Algues, est due à Agardh, et diffère beaucoup du système des molécules organiques de Buffon; malgré quelques rapports apparens. La globuline de Turpin u'est autre chose que ce qu'Agardh avait décrit avant lui sous le nom de Protococcus.

GLOCIIDE, s. m., glochis; Angel, Widerhake (all.); lappola (it.) ( $\gamma$ hiw $i_{i}$, pointe). On a désigné ainsi des poils minces et raides, qui portent à leur extrémité plusieurs branches pointucs et reeourbées en arrièrc. Ex. Myosolis Lappula.

GLOCHDL, adj, glochideus, glochidiatzes; wviderbakig (all.); qui a des poils disposés en glochides, comme ceux qui garnissent les scmences du Polvgala gioclidala.

GLOIOCÉpiriL: E, adj., glö̈ocecephalus ( L'Agaricus gloiocephalus alc chapeau glabre et visqueux.

GLOMÉRÉ. $V$. AgGLoméné.

GLONERIDES, adj. et s. m. pl., Glomeridce. Nom donné par Leach à une famille de l'ordre des Myriapodes chilognathes, ayant pour type le genre Glomeris.

GLOMÉRYLORE, adj., slomcriflorus; knuulblüthigo (ali.) (glomerulies, glomérule, flos, fleur) ; qui a des fleurs agglomérées en capitules. Ex. Cantua glomeriflora.

GLovitrocantes, adj. et s.m. pl., Glomerocarpe (glomus, agglo-

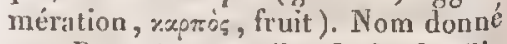
par Bory à une tribu de la famille des Céramiaires, comprenant celles dont la fructification est composée de glomérnles externes et nus.

GLOUÉRULE, s. m., slonecrulus; Knaul, Knaüel (all.). Conımunément on appelle ainsi une :tgrégation de fleurs formant par leir réunion une sorte de tête irrégulière (cx. Chcnopodizm). Berrarilhi donne ec nom a un mode d'inflorescence qui consiste en ce que des fleur's sessiles sont insérées il l'extrémité et dans les angles 


\section{GLOS}

que forment les branches d'un pédoneule commun. Roeper l'applique à une cyme (voy, ee mot) tellement contractée (voy. ce mot), que sa ramification est peu apparente, et qu'elle semble an premier coup d'ouil un véritable capitulc, dout elle diffère toutefois en ee que la flornison commence par le eentre et non par les bords (ex. Corymbintm). Acliarius a d'abord appelé grlomérules les coneeptacles demi-sphérirques et pulvérulens des Variolaria et Parmelia, auxquels il a donné depuis le nom de sorédion.

GLOMénul.É , adj, ghlomerulatus; geknault (all.); qui cst réuni en paquets, comme les fleurs de l'Hedera slomerulata.

GLOMULIF inE, adj., glomuliferus (glomus, boule, fero, porter); qui porte de petites têles globuleuses, comme eelles que forment, par leur réunion, les fleurs du $M e-$ trosidcros glomulifera.

GLONuS, s. m. Martyn donnait ee nom aux eapitules de fleurs qui ont une forme parfaitement ronde. Ex. Gomphrena globosa.

GLOSSAIRE, s. m., slossarium ( $\gamma \hat{\operatorname{\omega } \omega \sigma \sigma \alpha}$, langue). Latreille appelle ainsi l'ensemble de la langue et de la languette ou lèvre des inscetes.

GLOSSARIPIIYTE, s. In., glossa-

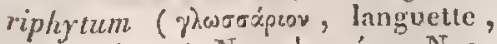
guròs, plante). Num donné par Necker aux plantes synanthérćes dont tous les fleurons sont ligulés.

GLOSSATES, adj. et s. m. pl.,

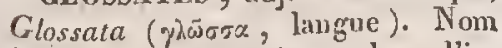
donné par Fabrieius à une elásse d'illseetes, correspondant aux Lépidoptères, dont la bouche sc compose d'une langue spirale plus on moins longue, située entre deux palpes.

GLOSSE, s. f., glossu ( langue). Savigny nomme ainsi In langue des jnscetes liymúuoptères ct diptères.
GLOSSODONTw, adj., 5 lossodon-

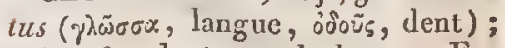
qui a des dents sur la langue. Ex. Argentina glossodonta.

GLOSSOIDE, adj., glossoideus

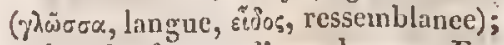
qui a la forme d'zuc langue. Ex. Ammonoceras glossoidea.

GLOSSOIDE, s. m., glossoüdea. Latreille a nommé ainsi l'organe des Arachnides appelé live par Fabricius et langue par Savigny, paree que, ne portant pas de palpes, il peut ctrc assimilé â une sorte de lèvre faisant anssi l'office de languette.

GLOSSO-PHAmXGIEN, adjeetif. Strats donne ce nom à deux longues apophyses qui portent les quatre lolos de la langue des insectes, se prolongent en arrière, et sont contenues dans la partic inféricure du pharynx.

GLOSSOTHL̀QUe, s. f., glossotheca ( Nom donné jar Kirby à la partic de la chrysalide qui loge la langue de l'inseetc.

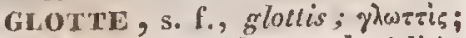
Stimmritze, Luftröhrenspalle (all.). Ouverture supérieure du larynx.

GLOTTIDES, adj. et s. m. pl., Glotides. Forster a établi sous ce nom une famille d'oiseaux, dans laquelle il réunit ceux qui, comme les pies, ont la langue trés-longue.

GLOUSSANT, adj., glocitans. L' $\mathcal{A}$ nas glocituns est ainsi appelé parce que son eri inite le gloussement de la poule.

GLOUSSEMENT, s. m., glocitatio, singultus; \%hwquòs; Gluehzen (all.); clucling (angl.); chioecare (it.). Cri par lequel la poule appelle ses petits aupris d'elle dans les momens de danger, ou quand elle a trouvé de la nourriture à leur distribuer.

GLouroxs, adj. ets.m. pl., Glulones. Nom donné par Merrem à une famille ou race d'Ophidiens, comprenaul ceux qui ont une grapde 
gueule, et avalent des proies d'un volume énorme eu egard au leur.

GLU, s. f., glu, viscum; ghica. Sorte de résine visqueuse, gluante et incapable de se dessécher, qu'on cxtrait de l'éeorce et des parties vertes du Viscum album.

GLUCiCO-HYDRiQ̨e, adj., glucico-hydricus. Nom donné, dans la nomenclature chimique de Berzelius, à des sursels qui résultent de la combinaison d'un sel haloïde avec l'hydracide du corps laalogène. Ex. Chlorurc slucico-hydrique (hydrochloratc acide de glucine).

GLUCico-potassique, adject. , glucico-potassicus. Nom donné, dans la nomenclature chimique de Berzelius, à des șcls doubles qui résultent de la combinaison d'un sel glucique avee un sel potassique. Ex. Fluorure slucico-potassique (fluate dc potasse ct de glucinc).

GLUGIDES, s. m. pl., glucides ( yhuxis, sucré). Guilourt nomme ainsi une famille de composés ternaires organiques, dans laquclle il range des substances de saveur sucrée ou douce, la glycyrrhile, l'olivile et l'oléile.

GLUGIove, adject. , glucicus L'oxide glucique est la combinaison du glucium avce l'oxigc̀ne, ou la glutcine. Le sulfure glucique, seul degré de sulfuration du métal, eonstitue une sulfobnse forte. Les sels grluciques sont des combinaisons du glucium avec des corps lualogènes (ex. Chlorure glucique), ou d'oxide glucide avec un oxacide (cx. Silicate glucique) ou de sulfure glucique avec un sulfide.

GLUCIUM, s. m., glucium, glycium, bcryllium. Nom donné à un métal que Woehler a le premicr réduit, et dont l'oxide (glucine) l'avait reçu paree qu'il produit des scls sucrés en se combinant avec les acides, proprićté qu'il partage eependant avec d'autres bases.

GLLXIACÉ, adj., ghluntaceus; spclförmig (all.). Se dit, en botanique, du périanthe lorsqu'il cst d'un tissu sec et dur, comme la glume des Juncus. Nices d'Esenbeck appelle calice glumacć la glume calicinale de Limné, ct corolle glumacéc sa glume corolline. (V $y^{\circ}$ cz Gleme.) Le Mahonia sluniacca doit cette épithète aux bractées ovales et concaves dont ses grappes sont munies.

GLUUACÉLS, adject. et s. f. pl., Glumacer. Nom donnć par Guiart et Bartling à une classe de plantes, comprenant celles qui ont des fleurs glumacées.

GLUNE, subst. f., sluma; Balg, Spelz (all.); gluma, leppa, lolla, pula (it.). Ce nom, dont la signifieation est très-vague, a été donné par Linné à l'espèce d'involucre situé au bas de l'épillet, dans les Graminées, et ensuite étendu par lui à toutes les enveloppes des fleurs de ces plantes, dont alorz il désignait l'externe sous le nom de glume calicinale ( $K$ clchspclae, fílchbalg, all.), et l'interne sous celui de glume corolline (Blitmenspclic, Blumenbalg, all.), appliquant la dénomination de valpes (Spelz, Klappe, all.) aux pičces constituantes de l'une et de l'autre. Depuis, la glume calicinale de Linné a été appelée tegrmen par Palisot-Beauvois, glume par Jussieu, Desvaux et Candolle, lépicienc par L.-C. Richard, peristachyum par Panzer, calicc glumacć par Niees d'Esenbeck, et ses parties ou valves, spalhelles par Mirbel, glunes par Palisol-Beauvois, bractécs par Turpin, enfin par Trinius sylumes dans les épillets uniflores, ct ćcailles basilaires ou coetonium dans les épillets multillores : la glume corolline de Linné est devenue stragale pour Palisot-Beauvois, glume pour L.-C. Richard, slumclle pour Des- 
vanx, corolle glumacéc pour Nees d'Esenbeck, calice pour Panzer et $\Delta$ gardh, et ses parties, pailleltes ( $p a-$ lece) pour Palisot-Beauvois, spathellules pour Mirbel, spathelles pour Turpin ; enfur les écailles les plus intérieures, appelées nectaires par Linné et Sehreber, sont les éeailles hyposynes de Robert Brown, la glumelle de L.-C. Richard, la glumellule de Desvaux, la lodicule de PalisotBeauvois, le paraphylle ou parapétale de Link, la corolle de Panzer, Micheli ct $A$ gardh, et ses pièces ou valves, des palioles pour les uns, des phycosiémes pour les autres. Link veut que, pour la commodité, on conserve les expressions linuéeunes de glume calicinale et de glume corolliue, ct que, quand la distiuction est diffieile à établir, on dise glume externe, intermédiaire et interne. Toutes ces parties sont regardées par Turpin et Link comme des bractées ou des fcuilles atrophićes. Pour augmenter encore la confusion, Ehrhart et quelques autres bolanistes ont appliqué la dénomination de glume aux écailles qui, dans diverses plantes, telles que les Dianthus et les Juneus, sont situées au dessous du véritable ealice, parce qu'elles ressemblent aux glumes des Graminces.

GLUMÉ, adjcet., glumatus; glu'noso (it.). Mirbel donuc celte épithite aux fleurs dont les organes sexuels sont entourés de glumes, eomme celles des Graminées.

GLUMELLE, s. f., glumella. Nom donné par Desvanx à la glume corolline de Linné, par L.-C. Richard i la lodieule de Palisot-Beauvois. toyez GLume.

GLUMELLEEN, adject., glumelleanus. Épithètc donnée par Mirbel à l'indusie, quand ellc provient des glumelles. Ex. Oryza sativa.

GLUMLLLULE, s. f., glumellula. Ce nom est donné par Desvalux à la lodieule de Palisot-Beauvois. $V_{\text {oyez }}$ GLUME.

GLUMUrLORES, adj. et s. f. pl., Gluniflore. Nom donné par Agardh à uue classe de plantes Cryptocolylédones, comprenant celles qui ont des fleurs glumacces, comme les Typhacées, Cypéracées, Graminées, Juncacées et $\mathrm{X}$ yridées.

GLUTEN, subst. m., , sluten; Kleber (all.); glutine (it.). Substanec qui reste après qu'on a ćpuisé la farine dc froment de tout l'amidon qu'elle contenait, ct qui est ainsi nommée, parce qu'elle a la propriété de se coller aux corps avee lesquels on la met en contact.

GLUTĹNOIDE, s. f. Nom donné par Brandes à la gliadine ou mueilage des graines du Datura Stramonium.

GLUTINE, s. f., glutina. Sous ce nom, Soubeiran désigne, d'apris Rouelle, l’allsumine végćtale, que les travanx d'linhof ont appris à bien distinguer du gluten.

GLUTINEUX, adj., glutinosus ;

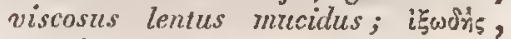
roìnodñs; klebriro (all.); glutinous (angl.) ; slutinoso (it.). Se dit, cu minćralogie, d'un corps qui aequiert de la viseosité à une certaine température (ex. Bilume) ; en botanique, de plantes qui sont recouvertes d'une substanec collante, plus ou moins tenace (ex. Mimulus glutinosus, Nicotiana glitinosa). Un poisson (Myxine glutinosa) est ainsi appelć à cause de la prodimieuse abondance de mucus que sécrète la surface de són corps. L'Agaricus unguinosils et l'Agarious mucidus out le ehapenu gluant. Le Siaavia grlutinosa a ses fleurs réunies par un sue glutineux.

GLYCERINE, s. f., glycerina;

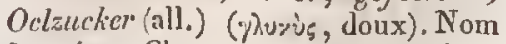
donné par Chevreul au principe doux des huiles, substance dont la découverte est due à Sehecle, qui est un 


\section{4}

GNAP

produit. général de la saponification des corps gras, et qui a une saveur sucrée.

GLYCÉnINLES, adj. et s. f. pl., Glycerina. Link désigne sous ce nom une tribu de la famille des Graminées, qui a pour type le genre $G l y$ ceria.

GLYCYCARPE, adj., glycycarpa ( des fruits doux et agréables. Ex. Leonia glycycarpa.

GLYCXnuile: s. f., slycyrhila. Guibourt appelle ainsi la glyeyrrhizine.

GLYCXRnIIIE, s. f., glycyrrhiza. Ce nom a été donnć à la glycyrrhizine par Clsevreul.

GLYCYRHUIIINE, subst. f., glycyrrhizina, slycion; Süssholzzuckcr (all.). Nom donné par Robiquet à une substance sucréc qui existe dans le Glycyrrtiza glabra et l'Abrus precatorius.

GLYPIIDÉEs, adj. et s. f. pl., Glyplidea. Nom donné par Fries à une tribu de Lichens idiothalames, et par Fee à un groupe dc la tribu des Verrucarices, ayant pour type le genre Glyphis.

GLYPIIQUE, adject., glyplicus

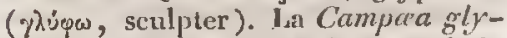
phica est ainsi appelée à cause de la disposition des eouleurs de ses ailes, qui les font parâtlre coinme sculptées.

GLYPHORaMphes, adj. et s. m. pl., Glrplorampha ( $\mathrm{g} \lambda \dot{\varphi} ф \omega$, sculpter, éxuyos, lice). Nom donné par Duméril à une famille de l'ordre des Passereaux, renfermant ccux de cesoiseaux qui ont une on deux échancrures au moins sur la pointedu bec.

GLIPTOSPERMES, adj. et s. f. pl., Glyplosperma ( $\gamma \lambda u \pi \div o ̀$, sculpté,

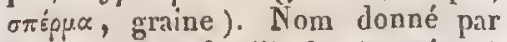
Veutenat a la famille des Anonćes, à causc des rides que présente l'endosperme de ces plantes.

GNAPHALLEES, adj. et s. f. pl.,
Gnaphaliece. Nom donné par II. Cassini à une section de la tribu des Inulécs, par Lessing à une soustribu de la tribu des Sénécionidées, ayant pour type le genre Gnaphalium.

GNAPIHLOIDÉES, adj. et s. f. pl., Gnaplualoidece. R. Brown désigne sous ce nom une section de la tribu des Corymbilères, ayant pour type le genre Gnaphalium.

GNATIIAPTERES, adj. et s. m. pl., Gnathaptera ( yyíloọ, mâchoire,

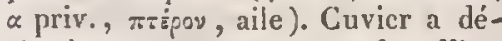
signé sous ce nom un ordre d'insectes, comprenant ceux qui sont pourvus de måchoires ct privés d'ailes.

GNATIIDIE, s. f., gnathidium (qu'́0o૬, mùchoire). Illiger appelle ainsi chacune des branches de la mandibule inféricurc des oiseaux.

GXATIOCÉPIILE, adj. et s. im.,

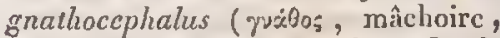

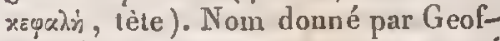
froy Saint-Hilaire aux monstres qui sont dépourvus de tête, mais qui ont dcs mâchoires issez volumineuses.

GNA THODONTES, adj. et s. m. pl., Gnathodontes ( yućoss, mîchoire, òjoūs, dent ). Nom donné par Blainville à une sous-classe de la classe des Poissons, comprenant ceux de ces animaux qui ont les dents implantćes dans les os des mâchoires.

G.VATIOPODEs, adj. ets. in. pl.,

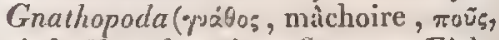
pied). Nom donné par Straus ct Eichwald à un ordre de la classe des Crustacés, comprenant ceux chcz Icsquels, la tète ayant disparu complc̀tement, les substances dont ces animaux se nourrissent sont mâchées pardes pattes transformées.

GNATIOTILQUE, s. f., gnathothera; Ladenschcide (all.) ( quátos, mâchoirc, Orizn, étui). llliger appclle aiusi le tégument corné ou cutané de la mâchoire inférieure des oiseaux.

GNEISSIQUE, adj. , qui a la structure du gneiss, comme le Leptynite 
sncissique, qui est très-fissile, et contient un peu de mica. Brongniart donne ee nom à un groupe de terrains agalysiens hypozoiques, comprenant ceux dont le greiss fait la base.

GOBIOIDES, adjeet. ets. m. pl., Gobioides. Nom donné par Cuvicr, Blainville, Latreille, Eichwald, Ficinus ct Carus à unc famille de poissons, qui a pour type le genre Gobius.

GOITRE, s: m., struma; $K$ ropf (all.). On appelle ainsi une expansion cutanćc plus ou unoins considerable, ct susceptible de se gonfler par l'entríe de l'air dans la pochc membrancuse qu'clle rcvêt, qui se voit sous le cou des Igouanes et de plusieurs $\Lambda$ gamcs, parmi les reptiles sauricns. Candolle applique aussi ce nom aux saillies latérales que présenten tecrtaines parties des végétaux.

GOITREUX, adject., strumarius, strumosus, cerviculosus, gutturosus; kropfig (all.); qui a la partie antéricure du cou ou du corps dilatée. L'Antilope gutturosa est ainsi appelé à cause de l'énorme volume du larynx dans les mâles; la Colamba gutturosa, parce qu'elie enfle prodigieuscment son jabot en aspirant et retcnant l'air; le Pipra gntturosa parce qu'il a les plumes de la gorgc longues, clijées et representaut une sorte de goître quand l'oiscuu les relève: l'Ornismya strumaria, parre qu'elle a une collerette blandhe ; l'Echynorhynchus strumosus, parce que la partie anićrieure de son corps est subglobulcusc ; la Mantis strumaria, parce que sou thorax offre de toutes parts des dilatations menibraneuses; quelques mousses (ex. Oncophorus ccrviculatus, Oncophorus strumifer), parce que leur urne est munie d'une apophyse quila rend bosscléc.

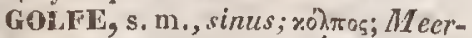
buscu (all.); gulf (angl.). J'́chancrure plus ou moins profonde que la mer forme en s'avançant dans les terres.

GOMME, s. m. guzmmi; xóuнe; gtımmi (all.); gunı (angl.); gomma (it.). On confond vulgairement sous ce nom une multitude de substances qui ont ccla de commun seulement qu'elles ćpaississent l'eau, en la rendant mucilagineuse, et qu'clles sont ensuite précipitées parl'alcool.Berzelius le réscrve pour celles qui, comme la gomme arabique, se dissolvent dans l'eau froide et daus l'cau chaude.

GOMML', adj., gummatus. Se dit du teginen, lorsqu'il est rccouvert d'une substince mucilagineusc. Ex. Pyrus Cydonia.

GOMnIDLS, s.f. pl. Sous ce nom Guibourt désigue une fanille de composés ternaires organiques, ayant la gomme pour type.

GoMMITE, s. f.Guibourt appelle ainsi la gomme proprement dite.

GOMPIOLITIQUE, adject. Omalius nomme calcaire gompholitique le gompholite monogénique de Brongniart, ou nagelflue calcaire des Allemands.

GONaTOCLrREs, adj.et s. m. pl., (yóvy, gewou, xépxe, corne). Nom donné par Latreille à une section de la famille des Rhynchophores, par Sehocuherr à un ordre de la famille des Curculionides, comprenant ceux de ces insectes qui ont les antennes brisécs ou coudées.

GOVATOPIORE, adj., gonato-

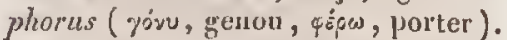
Uu mollusque (Dermatobranchus gonalophorus ) est ainsi appelé parce qu'il offre sur son dos une ligne médiane a laquelle aboutissent, par des angles droits, des sillons obliques, transverses ct parallèles, de chaque côté du corps.

GONGYI.ANGE, s. m., gongylangium; Brubchälter (all.) ( yoyryuinss, rond, a'yraios, vase). Nom donné par Bernhardi à la partie des plantes imparfailement cryploganıes qui 
renferme les corps reproducteurs. P. GONGYLE, s. m., gongrlus; Kno. tcn, Brut, Bruttorn, Fruchticim ( yoygúlyes, rond). Nom donuć par Gaertner à des corpuseules reproducteurs simples, aphylles, presque globuleux et pleins, qui sont plongés dans l'écorce de la plante mere, et qui s'en détaclicnt par les progrès de l'àge, comme dans les Ulves et les Fucus. Acharius l'applique à des cor pss globuleux et opaques, qui sont épars dans les différentes parties du thalle des lichens, surtout dans la partie cortiealc et la lame proligère. Willdenow le réserve peur désigner les corps reprodueteurs des algues. Bernhardi le donne aux parties destinées it la reproduction, dont on ne peut dire si elles sont des graines ou non. Enfin, Caudolle appelle gongyles les globules reproducteurs des plantes dans lesquelles la fécondation n'est point démoutréc. Gongyle est synoayme de spore, sporidic, speireme.

GONGYLODE, adj., gongylodes

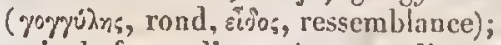
qui a la forme d'une tête arrondie.

GONGVLOPUYCles, adj. ct s. m. pl., Gongryloplyece (royruilins, rond, фũzo5, fucus). Nom donné par Reiehenbach à une seetion de la famille des Hydropbytes, comprenant selles qui se multiplicut par des gongyles sculement.

Goniatités adj. ct s. m. pl, Goniatitea. Nom donné par Haan ì une famille de Mollusques eéphalopodes, qui a pour type le genre Goniatites.

GONiDES, adj. et s.f. pl. , Gonidcc. Noun douné par Robincau-Desvoidy à une section de la tribu des Myodaires calyptérées entomobıcs, comprenant ceux de ces insectes dont on a fait le genre Conia.

4: GONIDIE, s.f., gonidium ; Brut-

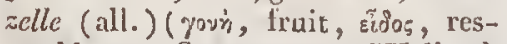
semblance). Sous ce nom, Wallroth désigne des organes composés d'une petite vésiculc membraneuse pleine d'un mueus organisable, et verte ou d'un jaune doré, qui servent de eorps reprodueteurs aux algues, et que Meyer avait désignés sous le nom de gemmules.

GOMIIQUE, adjeet., goninicus. Wallroth appelle couche gonimique (stratum gonimon; Brutzellensehicht, all. ), dins les lichens, taute expansion qui résulte d'un assemblage de gonidies apposées les unes contre ou sur les autres.

GONIOGLNE, adject., goniogenus

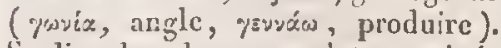
Se dit, dans la uomenelature minéralogique de Ilaiiy, d'une varićtć dans laquelle les décroissemens n'ont lieu que sur les angles, et celin d'une manière inégalc. Lx. Baryte sulfatće goniogène.

Govioutetne, s. m., goniometrum; Winkelmesser (yovi\%, angle,

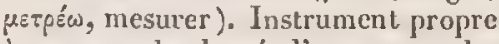
à niesurer le degré d'ouverture des angles. On connaît un goniomètre par applieation, dunt l'invention est due à Carangeau, et un autre à réflexion, imaginé par Wollaston, et modifić depuis par Muncke, Rudberg. et Riese.

Goxionyces, s. m. pl., Gonio-

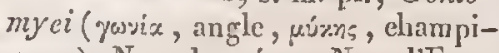
gnon). Nom donné par Nees d'EsenLeek a une famille de l'ordre des Prolomyces, comprenant ccux qui ont une fornse ungulcuse.

GONIOSTONE, adj., goniostomus (jarix, angle, oxips, bouehe). Se dit d'une coquille univalve dont l'ouverture offre un angle plus ou moins marqué dans un certain point de sa eirconférenee. Ex. Bulimus goniostomus, Ilelix goniostoma.

GOviostonies, adj. ct s. m. pl. , Goniostomata. Nom donné par Blainville à une famille de l'ordre des $\mathrm{Pa}$ racéplaalophores asiphonobranches, 


\section{GONY}

comprenant ceux de ces animaux dont l'onvertare de la coquille est anguleuse.

GONOCÉPIIALES, adj. et s.m pl.,

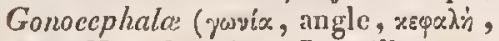
tête ). Nom donné par Latreille à une sous-tribu de la tribu des Muscides, comprenant eeux de ees inseetes dont la tête, vue en dessus, est presque triangulaire.

GONOOPIITE, s. m., gonoophy-

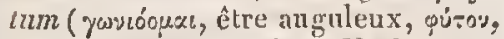
plante). Nom donné par Necker aux plantes qui ont le fruit anguleux.

GONOPHOHE, s. m., gonophortum; Befruchtungsträger, Gesehlechtstheih träger (all.) (yòvos, génération, $\varphi$ śpw, porter). Candolle appelle ainsi un prolongement du réecptacle qui pari du fond du calice et porte les étamines et le pistil. Ex. Anonacícs.

GONOPTiRE, adj. , gonoptcrus

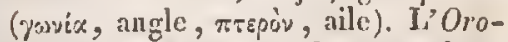
bitis gonopterns a ses élytres prolongćes en angles aux bords latéraux de leur base.

GONOSPERHE, adj., gonospermus ( yavix, angle, oт:́puo, graine); qui a des semenees angulcuses, Ex. Phascolus gonospermuts.

Govyoptínides, adj. et s.f. ph, Gonyopterides ( fougère). Bartling appelle ainsi, d'aprèsWilldenow, une classe de plantes, comprenant les familles des Characécs et des Equisetacées, qui se rapprochent des fougères et qui ont la tige artieulée.

Govis, s. m., gonys; Dillenkante (angl.) ( you, genou). llliger appelle ainsi la partie moyenne du bord inférieur de l'espice de masse produite par la réunion des deux hranches de la maudibule inférieure des oiseaux, celle qui s'étend depuis l'angle mental jusqu'art sommet de celte masse, qu'il nomene myxa.

GONYTHEे(UE, s. f. , gonytheca

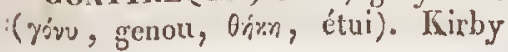

désigne sous ee nom une coneavité située à l'extrémité de la euisse des insectes, et qui est destinée à recevoir la base du tibia.

GOODENaCÉLS. Voyez Goodéroviérs.

Goodénacées. Voyez GoodíNoVIÉEs.

GOODENOVIÉES, adj. et s. f. pl,, Goodenovica, Goodenacea, Goodeniacece. Nom donné par Candolle it une tribu de la famille des Campanulaeées, par R. Brown et Kunth à une famille rle plantes, ayant pour typc le genre Goodenia.

GOHDOVIliEs, adject. et s.f. pl., Gordonica. Nom sous lequel Candolle désigne une tribu de la famille des Ternstroemiacées, qui a pour type le genre Gordonia.

GORGE, s.f. Se dit, en géographie, d'unc vallée conrte, inclinée et ordinairement évasće, quelquefois cependant profonde (monturem fauces; Schlucht, Engpass, all.). Les botanistes appellent ainsi (fan $x$; Sclulund, all.; fauce, it.) l'entrée du tube de la corolle, du calice ou du périgone, que ce tube soit réel, on qu'on le suppose formé par la réunion dles onglets non sondés. En zoologie, la gorge (guttur, jugulum, gula;

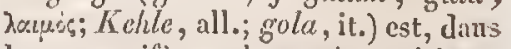
les mammifères, la partie antéricure du cou; chez les oiseaux, la partie du dessous du cou qui tient à la tête; dans les coquilles univalves ( faux), d'après Linné, tout ce qu'on pent voir de leur intéricur, en regardant par l'ouverture, c'est-à-dire à pen près le dernier demi-tour.

GORGoní́s, adj. et s. f. pl., Gorgoniece. Nom donné par Iamonroux à une famille de l'ordre des Polypiers flexibles, qui a pour type le genre Gorgonia.

GOLTWulliss, adj. et s. f. pl., Gorteriece. Nom donné par H. Cassinj à une section de la tribu des Arc- 
totidées, qui a pour type le genre Gortcria.

GOSIER, s. m., gula. On donne vulgairement ce noun à l'arrière-gorge. Chez les insectes, on l'applique à l'espace du dessous de la tète qui est compris entre lc trou occipital et la naissance de la lèvre inférieurc.

GOSSYPIN, adj., gossypinus (gos sypum, coton). Le Lycoperclon gossypinum est ainsi appelé à cause de sa surface cotonncuse et un peu laincuse.

GOSSYPINE, subst. f., gossypina. Thompson appelle ainsi le coton.

GOSSTPIHOIE, adj. , gossypiphorus (gossprium, coton, بépes, porter). Le Saussurca gossypiphora a ses fleurs cachées par unc laıne trèslongue.

GOUFFRE, gurges, vorago, ba-

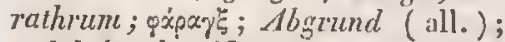
gulph (angl.). Nom donué, en géognosie, ì des cavités naturelles, presque perpendiculaires, d'une profoudeur ou capacité snpposće incommensurable, et qui reçoivent ou laissent ćchapper quclque liquide ou fluide élastique.

GOURMAND, adj. Les branclics gourmandes sont celles de l'année, qui ne doivent pas donncr de fruit, et qui absorbent la nourriture des branches voisines.

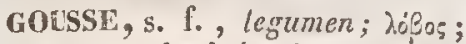
Hülsc (all.); huski (angl.); legume, bacccllo (it.). Fruit sec, bivalve, ordinairement uniloculaire, quelquefois biloculaire (ex. Astragalus) ou multiloculaire (ex. Cassia), dont les graines sont attachées à un scul trophospermé, qui suit la direetion de l'une des sutures. Ce fruit résulte d'une fuille pliée en long, et qui a par conséquent deux sutures, produites l'une par l'aglutination des bords, l'autre par la saillie plus ou moins prononcéc de la nervure médiane. A la maturité, la déhisccnce se fait paî le décollement des bords et la rupture de la nervure (ex. la plupart des Lćgumineuscs), ou bien par deux ruptures longitudinales sur le inilieu de chaque surfacc, lcs deux sutures restant cohérentes (ex. Hrzmatoxytum). Une coquille (Solcn legumen) est ainsi appelée à cause de sa ressemblance arec une gousse de pois.

GOUSSETTE, s. f. Nom donnć par Barbeu-Dubourg à de petites gousses monospermes, telles que celles du tréfle.

GOUT, s. m., gustus, gustatio,

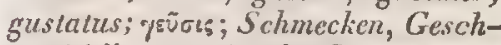
mack(all.); laste(angl.). Sens qui nons fait apercevoir la saveur des corps. On employe aussi ce mot all moral, pour exprimer le sentiment des beautés et des défauts dans les arts ( $j u-$ dicium ; velorxilia). "De tous les dons niturels, dit Rousseau, le goût cst celui qui se sent le micux et s'explique le moins; il ne serait pas ce qu'il est si l'on pouvait le définir, car il jugc des objets sur lesquels le jugement n'a plus de prise, et sert, si j'ose parler ainsi, de lunette ì la raison."

GoutTILIE, s. f., collicia. On appelle ainsi les sillons qui séparent les élévations du mcrrain et des andouillers, ainsi que ceux qu'on voit à l'unc des extrémités de l'ouverture de ccrtaines coquilles univalves.

GRACILICOSTE, adj., gracilicostatus (gracilis, grêle, costa, côte); qui est garui de côtes très-fines. Ex. Clausilia gracilicosta.

GRAChirLONL, adj., graciliflorus (gracilis, grêle, flos, fleur); qui a des fleurs grc̀les, comme les corolles du Loranchus graciliflorus.

GRACILIFOLIÉ, adi., gracilifolius (gracitis, grêle, folium, fcuille); qui a des feuilles lougues et presque linéaires. Ex. Habranthus gracitifolius.

GRACILI:DE, adj. , gracilipes 
(gracilis, grêle, pes, pied). Se dit d'un oiseau qui a les pieds menus, on d'un champignon dont le stipe est filiforme (cx. Meteorina gracilipes).

GRACILHOOSTRE, adj., gracilirosiris (gracilis, grêle, rostrum, bee); qui a le bec grêle.

GRADAIRE, adj., gressorius (gradior, marcher). Epithète donnce par Illiger aux pieds des oiseaux, quand ils sont emplumés jusqu'au talon, et au nombre de trois cn avant, dont les deux extcrnes sont réunis depuis la base jusqu'au dela du milieu, sans aucune membrane intermédiaire. Ex. Calao.

GilAIN , s. m., gramum;Korn (all.); corn (angl.); grano (it.). On appelle ainsi les parties de substances minérales, ordinairement de forme arrondie, dont le volume ne dépasse pas de beaucoup celui d'un pois. Hedwig donnait ce nom à la membranc interne de l'urne des mousses. A gardh propose de le eonsacrer à l'usage qu'on en fait déjà dans le langage vulgaire, c'est-a-dire á désigner la graine des monocotylédones, qui diffère assez de celle des autres plantes, sous le rapport de la structure, pour mériter une dénomination particulière.

GHA1NL, subst. f., semen; Saame (all.); seed (angl.); scme, grano(it.). $\mathrm{O}_{\text {vulc fécondé; cavité close de toules }}$ parts, qui renferme le rudiment d'une plaute, c'esl-ì-dire un petit corps organisé réunissant en lui toutes les conditions nécessaires pour produire un Yégétal scmblahlc à celui dont il est issu, dès que les eirconstances extérieures favorisent son accroissement.

Ganissw, s.f., adepss, pinguedo,

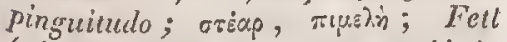
(all.); fat (ancl.); grasso (it.). Composé de sulbstances diverses, principalement destéarine et d'élaïnc, qu'on Ironve dans les aréoles du tissu cellulaire des animunx.

GRALLAIILE, adject., grallarius (gralla, échasses); qui a de longucs jarnbes. Ex. Noctua grallaria.

GralLES. Voyez Échassiers.

GRALLIPìEs, adj. ct s. m. pl., Grallipcdes'grallue, ćchasses, pcs, pied). Van der Stegen donne ce nom aux oiseaux échassiers.

Graminíes, adj. et s. f. pl., Graminea (ypús, manger). Famillc de plantes, ainsi appelée parce que celles qui forment le gazon (gramen) cn font partic.

GRAMINICOLE, adj., graminicolus (gramen, gramiuce, colo, babiter); qui vit sur les ehaumes arides (ex. Agraricus gramimicola), on dans les chimps de ećréales (cx. Melolontha graminicola).

GRAMINIFOLIÉ; adj., graminifolius; grasblättrig (all.) (gramen, graminée, folium, feuille); qui a des feuilles semblables on analogues à eelles des Graminćes. Ex. Oetomeria sraninifolia, Stylidium graminifolium.

GraMTVIFORME, adj., graminous; grasiihnlich (all.); gramigneo (it.) (gramen, graminée, forma, forme); qui resscunble à une graminée. Ex. Sagillaria graminea, $M c$ lanthium gramincum.

GRAVINOLOGIE, s. f., graminologia (gramen, graminće, גígs;, discours). H. Cassini s'est servi de ce mot hybride, qui est synonyme d'agrostologic.

GianMuArrecx, adject. Se dit d'une roche qui renferme des aiguilles disséminées de grammatite. Ex. Ophiolile grammaliteux.

GRMMMOPÉTML, adj., grammo.

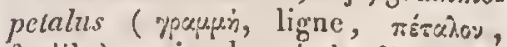
feuille); qui a des pétales linéaires. Ex. Polentilla grammopetala.

Gramnozonimes, adj. et s. m. pl., Grammozoa (yosuur, ligne, خั)os, animal). Lichwald désigne sous ce nom un type d'organisation animale, comprenant les vers internes et ex- 
ternes, animaux chez lesquels prédomine la dimension en longueur du corps.

GRAVMURE, adject., grammuzurus

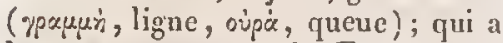
la queue courte et grêle. Ex. Sciurus grammurus.

GRANAIRE, adj., granarius (gram num, grain ); qui vit dans les grains, qui ravage les greniers. Ex. Bruehues granarizs, Calandra granaria.

GRANATÉES, adj. et s. f. pl., Granata. Famille de plantes, établic par D. Don, et adoplée par Candolle, qui a pour type le Punica Granalum.

Granatioue, adj. Se dit, en minéralogie, d'une roche qui contient des grenats disséminés. Ex. Leptinite granatique.

GRANDIDENTÉ, adj., srandidentalus (grandis, grand, dens, dent); qui a de larges dents, conmme les feuilles du Populus grandidentala.

GRANDTELORE, adj., grandiflorus, floridus; grossblühend, grossblumig (all.) (grandis, grand, flos, fleur); qui a de grandes fleurs. Ex. Aster grandiflorts, Hamelia grandiflora, Dracorephalum grandiflorum, Gardenia forida.

GRANDIFOL.1C, adj., grandifolius (grandis, grand, folum, feuille); qui a de grandes fenilles. Ex. Ranuneulus grandifolius, Frankenia grandifolia, Caladium grandifolium.

GRANDIPAEPES, adj. et s. m. pl., Grandipalpi (grandis, grand, palpus, palpe). Nom donné par $\mathrm{Cu}$ vier à une section de la tribu des Caralsiques, compreuant ceux de ces insectes qui ont le dernier article de leurs palpes ordinairement plus grand que les autres.

GRANDKROSTRES, adj. et s. m. pl., Grandirostres (grandis, grand, rostrum, bee). Nom donné par Latreille, Fieinus et Carus à une fimille de l'ordre des Oiseaux grimpeurs, comprenant ceux qui ont le bec d'unc grandeur démesurće.

GRANGÉINÉES, adj. ct s.f. pl., Grangeinea. Nom donné par H. Cassini à un groupe de la section des Inulées buplithalmécs, qui a pour type le genre Grangea.

GRUNIFLE, adject., graniferus (granum, grain, fero, porter). Non donné par Aggardh, et adopté par Fries, aux végétaux qui ont des graines unilobées, arec un albumen adnć à l'embryon, tenant lieu de cotylédon, sorte de graine que le premier de ces botanistes veut qu'on appelle grain. Granifère est synonyme de monocotylédone. Il se dit aussi d'un corps qui est chargé de petits grains, comme les ecllules des Flustra, l'extrémité des pinnules du Corallina granifera, et la coquille de la $\mathrm{Me}$ lania granifera, de la Mitra granatina.

GRANIFORME, adj., graniformis (granum, grain, forma, forme); qui a la forme ou le volume d'un grain de blé. Ex. Mitra graniformis.

GRINITELLE, adj., granitellus. Se dit d'un corps dont les coulcurs sont disposécs par taches variées, de manière à imiter le granit, commc la coquille de l'Oliva gratinella.

GRANITELLIN, adj. On donne cette épithète à une variété de ealseliste, qui offre une structure entrelacéc, avec des grains on nodules cnveloppćs, de manière à ressembler un peu au granite.

GHAMTIOQUE, adject., granitieus (granum, grain). On dit que la texture d'une roche est granitique, quand celle-ci résulte d'une agrégation de matériaux différens, intimement aceolés les uns aux autres, ct tenant ensemble, soit par l'aflinité de cohésion, soit par l'en trelacement de leurs partics. On nomme roekes granitiques, dont Qmalius fait un groupe 
de terrains, non senlement le gra* nite, mais cncore plusieurs autres qui Jni ressemblent pour la strueture et en partic aussi pour la composition, conme la diorite.

GRANITOUE, adj., granitoïdcus. Se dit d'une roche nuélangée et cris talline qui a quelques rapports avec le granite, on qui dı moins a une texturc grenue, de mème que lui (cx. Arkose granitoüle, Syénile granitoüde). Brongniart a établi sous ec nom un groupe de terrains plutoniens.

GRANITO-POHPIYROIDE, adj., granilo-porplyreus; qui se rapproche à la fois da granite et du porphyre. Ex. Minzosite granilo-porphy. roïde.

GRATrVores, adj. et s. m. pl., Granivori (gramunl, grain, voro, (lévorer). Noun donné par Temminck à une famille ou à un ordre d'oiseanx sylvains on Passerenux, comprenant ceux qui vivent de grains.

GRANO-LAMELLAIRE, adject, grano-lancllaris. Se dit, en minér:logic, d'un corps compose de grains qui offrent des indiees sensibles de joints naturels. Ex. Chanex carbonatée grano-lamcllaire.

GRANULAIRE, adj, , granularis ; granulirt, kristallinisch-körnig (all.) (granum, grain). Sc dit, en minéralogie, d'un corps qui est composé de Srains distinets (cx. Epidole granulairc), et de la structurc d'une masse minérale, quand ses parties composantes se détachent les unes des autres, par l'effet du choe, sans se briser, comme si e'étaient autant de petils graius réunis.

GRaxuex, s. nı., granuliem; Körnchen, all. (grantm, gruin). On donne quelquefois ee nom aux corps reproducteurs des plantes eryptogames. Guillemin l'applique a de petits graiıs que lui et Gleichen ont vu être renfernićs daus le fovilla, c'est-ì- dirc dans la liqueur que contient chaque grain du pollen des végétaux. On appelle aussi granules les petites verrues arıondies qui garnissent le calice des Rumcx.

Gravutí, Granuleux, adj., granulosus, granulatus, granosus; gekïrnt, gekörnele (all.); granclloso (it.) (granum, grain ); qui porte des tubercules en forme de petits grains, comme lo stigmate du Convaluulues inflatus, la racine du Cardamine granulosa, la coquille de l'Unio granosa, du Trochus granulatus, du Solarizum granulatum et du Cardium granulosim. Voy. Grumeletx.

GRANULICAULE, adj., granulicaulis (granum, grain, caulis, tige); qui a la tige et les ramenux chargés de petits grains ou de tuberenles. Ex. Mrsembryanthemuna granulicaule.

GR sNuLIFlir:, adj., granuliferus (granum, grain, fero, porter); qui est chargé de graunlations, comine la coquille de la Mirra granulifera.

GHANULHOHRE, adj., granuliformis (granum, grain, forma, forme). Se dit, en minéralogic, d'un corps qui est en grains irréguliers. Ex. Pyroxine granuliforme.

GMANUkOSITÉ, s.f. , sranulositas. Amas de petits tubereules imitant de pelits grains.

GrAOSOMES, adj. et s. f. plur.;

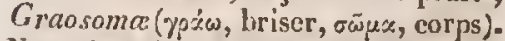
Nom donné par Robineau-Desvoidy it une section de la famille des Myodaires calyptérées, comprenant ceux de ces insectes dont le corps se brisc et se détériore aisément.

GRAPHIDÉS, adj. ct s. f. pl. , Graphide. Nom donné par Fries et liseliweiler à une cohorte, par Fee, Reichenlach et 'Zenker à une tribú de Lichens, ayant pour type le genre Graphis.

GHAPUITÉnIDEs, adj. ct s. m. pl., Graphipterides. Non donné jadis parr Latreilld à une section de la tribu 36 
des Carabiques, ayant pour type le genre Graphipterus.

GRAPHIQUE, adject., graphicus (yox́ow, écrire). Se dit, en minéralogie, d'un corps dont les cristaux se réunissent deux à deux par une de Jeurs extréinités, sous un angle droit, et se rangent souvent de celte manière plusieurs à la file les uns des autres, ec qui les a fail comparer à des lettres hébraiques ou persanes (ex. T'cllure natif). On applique aussi cette épithète à des roches composées dont la coupe offre, sur la substance qui sert de fond ou de base, des!ignes brisées, en forme d'écriture, dues à la section des cristaux d'une des parties composantes (ex. Pegmalite graphique). L'Ampélite graphique doit cette dénomination à ee que ses feuilles sont ascez serrées pour lui donner un peu de consistance, san; cependant qu'elle cesse d'ètre tendre, ce qui permet de la tailler en forme de crayons pour dessiner.

GRAPHITEUX, ndj., graplitosus; qui contient du graphile; comme le gneiss graphitcux, dans lequel lo graphite remplace en partie le mica.

GRAPPE, s. f., raccmus; propu:; Traube(all.); bunch(angl.); rrappolo, racemo (it.). Assemblage de fleurs portécs sur des pédieclles à peu près de même longueur el disposís à quelque distance les uns des autres le long d'un pétiole commun. Ex. $V_{c-}$ ronica Beccabunga.

GRAS, adi., pinguis, succulentus, adiposus; riw ; fetl, fottig (all.); fat (angl.) ; grasso (it.). Se dit, en minéralogie, ile l'éclat, quandle corps qui l'offre semble avoir ćtć frotté avce une matière grasse (ex. Quar gras). Les plantes grasses sont eclles qui ont beatcoup de tissu cellnaire et pen de tissu ligneux, ec qui les rend épaisses et suceulentes.

Gnave, adj. el s. m. Se dit, au sens propre, de ce qui est pesant (gravis; ßácus; schwer, all.; heavy, angl.: corps grave, chutc des graves), ou bas, profond (son grave); nu liguré, de ce qui est séricux ou imporlant(caractere grave, air grave). Les sons graves ue le sont, comme les sons aigus, que par comparaison avec d'autres qui n'offrent pas ce caractìre; ou, ponr parłer d'une maniëre plus précise, la ggravité des sons dépend de la lenteur des vibrations du corps sonore. Le son le plus grave que nous puissions entendre a une longueur d'onde de trente deux pieds.

GLIVELE, adj., gravelatus, clapellatus. Un mélange de sous-carbonate polassique, avec du sulfate potassique, du sel commun, du fer et du manganese, de la silice, de l'alumine et du charbon, qui reste après la combustion des lies de vin, porte le nom de ecndres gravelées, parce que plusicurs de ses parties sont réduites, par l'action du fcu, cn grains fondus ayant quelque ressem blance avec du gravier.

GraviEn, s. m., glarca; Grics (all.) ; grit (nogl.). Dépôt arénacé, dont les grains, anguleux ou arrondis, varient depuis la grosscur d'un pois jusqu'is celle d'une noix, et quil lait le prissige du sable au galet.

GRAVIGRIDES, odj. el s. m. pl., Gravigradia (gravis, lourd, gradior, mareher). Nom douné par Blainville à un ordre de la classe des Nammitères, comprenant des animaux dont la démarche est lourde, counme l'éléphant.

GRAVLULTRE, s. m., gravime-

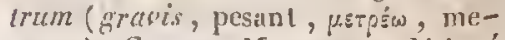
surer). Guylon-Morveau a désigné sous ce nom l'arćumètre de Nicholson.

GRAVTATION, s. f., gravitatio. Force en vertu de liquelle un eorps, abantonné ì luj nsême, se précipite vers la terre, comme si le centre de cette planète était doué d'une vertu 
attractive qui fit tendre vers lui tous les corps environnans.

GRAVIVOLE, adject., gravivolus (gravis, lourà, volo, voler). Se dit d'un oiseau dout le vol est pesant.

Gróbifouloules, s. f. pl. , Grebifulica. Nom domé par Lesson a une famille de l'ordie des Echassiers, comprenant les grèbes et oiscaux vo:sins, qui se rapprnchent des foulques par lcurs doigts lobés.

GRELE, s.İ., grando; $\chi^{x} \lambda \alpha \xi \alpha ; I I a-$ gel (all.); hail (angl.); grandine (it.). Phénomènemétcorologique qui a lieu quand l'eau atmospliérique, au licu de tomber à l'état liquide et sous forme de gouttes, se précipite congelée el en grains ou en masses d'un volume plus ou moins considérable, qu'on appelle grétons.

GRELE, adj., gracilis, tenuis ; iøхvö; ; dïnn, schlank, sehnächtig (all.); qui est long, élıoit et unince; comme le chaton du Salix alba, l'ipi del'Ophrys ovata, les feuilles du Sarcanthus ierchifolius, lin radicule du Cheiranthus cheiri, la tige clu Plrchosperma gracilis, la tige el les rameaux du Fesluea misera, du Dicranum gracilescens, dı Grmnosiomxm graeillimum et del'Allium subtilissimum, le corps du Loris gracilis, du liorynchus gracilis, et des Mantis Phalisica, pauperata et atrophica.

GRELES, adj. et s. m. pl., Gracilia. Noun donné par llliger à une famille de l'ordre des Mammiferes carnassiers, comprenant cux qui ont le corps mince el alongé.

Grelot, s. m. , urceola. On appelle ainsi des especes de clochettes pergamenteuses, ou productions épiderniques, enchîssíes les unes dans les autres, qui gramisseut l'extrémité de lil queure des Crotales, et dout le follement mutuel, quand l'animal remue la queue, produit un cortain bruit.

GRevatirkère, adject. Épithète donnée à une roche qui eontient des grenats dissćminés. Ex. Sehiste grenalifere.

Grivnatiour, adj. Sous le nom le roches grcnatiques, $\mathrm{O}_{\text {nalius éta- }}$ blit un genre de roches pierreuses, ui comprend le grenat.

GIENU, adj., granulatus, granosus; kïrnig (all.). Se dit, en minćralogie, de la texture d'une roche, quand elle est composée de grains anguleux ou arrondis, bien distinets, et réunis sims pâte sensible. Candolle désigue sous le nom de racines grenues celles qui sont formées de petits tubercules propres à reproduire la plante, sans fécule qui entoure les germes non développés (ex. Saxifiara granulata). On donve aussi ectte épithèle à des corps dont la surface est lıérisséc de petites granulations (ex. Trochus granosts). Voyez Graxulé.

GrístForiue, adj.; qui a l'apparenee du grès. Ex. Arlose grésiforme.

GIRSIL, s.m., minutissima grando ; Craupenlagrel (all.). Très-petite grêle.

GHiTSSORIPLDE, adj. , gressoripes (gradior, mareher, pes, pied). Se ditd'un oiscau dont les trois doigts antéricurs, en partie réunis ensemble, semblent former une sorle de plante de pied.

GHEve, s. f., arenosum litus; dxiтท; Strand (all.). Lieu plat, uni et convert de sable, sir le bord d'un fleuve, d'une rivière ou de la mer.

GRIF $\mathbf{F}$, s. f. On appelle ainsi des especes de crochets très-courts et durs, au moyen desquels eerlaines plautes se eramponnent le loug des corps qui leur servent de soutien. Ce non est aussi donué, ehez les mammiféres, aux ongles aplatis latéralement en ure lame plus ou moins trancliante, et termirtés par nue pointe recourbée (ex. Chat, Tigre; on dit cependant 
Jes ongles du Lion). Latreillel'applique ćgalementaux chélicères des arachnides el de certains crustacés, quand il n'y a qu'un scul doigt ou crochet.

Grillid. Voyez Cancellé.

GRIMA C.ANT, adj., ringens. Se dit d'un corps qui olire des plis irréguliers, et ressemble is une bouche faisant la grimace, comme l'Explanaria ringchs, dont les cellules sont irrégulières et garnies de nombreuses lames deutées, ou le Donax ringens, dout la coquille est baillantc à l'angle supérieur du corselet. En botanique, on ensploie plus souvent Ic mot de personé. Foycz ce mot.

GRIMnIOUEERs, adj. et s. f. pl., Grimmioidea. Nom donné par Bridel, Arnott ce Furnolir à une tribu de la famille des Mousses, qui a pour type le genre Grimmia.

GRIIRANT, adj., scandens, reptabundus; klctlernd, klimnend (all.); rampicante (it.). Se dit, en botanique, d'une tige trop faible pour se soutenir elle-même, yui s'élève le long des corps voisins, soit en sc roulant autour d'enx (ex. Cuscuta), soit an moyen de vrilles (ex. Vilis), ou de crampons, de griffes (ex. Bignonia radicans), soit eu tortillant ses pétioles (ex. Clcmatis).

GRMPeneaux. $V$. Grimpens.

GRIMPEURS, adj. , Scansores, Anerpontes. Nom donné par Scopoli, Lacépède, Cuvier, Duméril, Illiger , Blainville, Ranzani, Latreille, Ficinus et Carns à un ordice, par Lessou et C. Bonaparte à un sons-ordre, par Vigors et Vieillot à une faniile de la classe rles Oiseaux, coinprenant cenx à qui la disposition de Icurs paltes permet de grimper avec facilité; par Blainville it une fimille de l'ordic des Mannuiferes rongeurs, dans Inquelle il range eeux qui, eomme les Ecureuils, grimpent avec facilité sur lcs arbres; et par lc même à unc section de la famille des Repliles ophi- diens apodes, comprenant ceux qui, comme les Boa, out la faculté de grimper sur les arbres.

GRINDíliées, adj. et s. f. pl., Grindclice. Nom donné par H. Cassini à un groupe de la scetion des Astćrées solidaginées, qui a pour type le genre Grindelia.

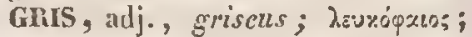
grau (all.); grey (angl.); grigio (it.). Blane plus ou moins mècéde noir (ex. Notidanus griseus, Plurygania grisea, Fusidium griseum). On distingue quelquefois les nuances du gris, en les comparant à la couleur d'un objet bicn connu. Ainsi on dit gris cendré (voyez Cendrí); gris de lin (ex. Noctua linogrisea); sris de souris; mäusegrau (all.) (cx. Staphylinus murinas, Unthilicaria murina, Agaricts myochrons); gris de for (ex. Hirundo chalylica); voyez (Hhasmbé; gris de plomb; bleigrau (all.) (ex. Toelus plunibeus, Mitra plunibea, Homalura plumbella, Sepedon plum. bellus). On distingue nussi un gris roux (cx. Kangrurus rufogriseus).

GRISATRE, adj. , grisescens, griseolus, griseatus, grisolns; graulich (all.); greyish (angl.) ; qui tire sur lc gris. Ex. Noctua grisescens, Agaricus griseolus, Strix griseala, MIuscicapa grisola.

GRISÉICOLLE, adj., griscicollis (griseus, gris, collune, col); qui a le eol gris. Ex. Sylvia griscicollis.

GrisovvaNe, adj., canescens, aniculosatus. La Phalcena aniculosata est'ainsi appeléc parce qu'elle a la partie antéricure du corps el le vertex blanchâtres. La Thereva senilis a aussi le haut de la tète blanc.

GROGNANT, adj., grunniens. Un poisson (Cottus gruminicns) est ainsi appelé parce que, dans certaincs circonslanees, il fuit entendre un sol qu'on a comparé su grognement du cochon, el qui tient a la sortic do l'air que contenait l'intérieur de son 


\section{GROS}

eorps. Le Bos grumniens a une voix analogue à celle du cochon.

GROGNEMNNT, s. m., grunnitus;

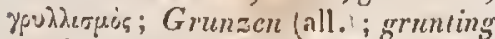
(angl.). Cri du coehon. On dit grogner ou grouiner (grrennire, grundirc), en parlant du cochon, et grrumeler en parlaut du sanglier.

GROIN, s. m., rostrum; ṕryzo; ; Russel (all.); shout of a hog (ingl.). On appelle ainsi le nez mobile et prolongé du cochon.

GROSSESSE, s. f., graviditas, pragnatio ; xن̉nots; Schwangerschaft (all.); pregnaney (angl.); gravidanza (it.). État d'une femelie dans le sein de laquelle se développent un ou plusieurs germes, depuis le moment de la fécondation jusqu'à celui del'accouchement. On n'emploie guère ce mot qu'en parlant de la femme.

GROSsiER, adj. Se dit, en minéralogie, d'un corps, quand il a un air de rudesse, joint à l'opacité. Ex. Quarz agate.

GROSSIFICATION, s. f., gro.ssificatio; Fruchtansctzen (all.). Phénomène qui a lieu lorsquapres la floraison, le fruit commence à grossir.

GROSSIMLINE, adj., grossimanus (grossus, gros, manus, inain); qui a de grosses mains. Ex. Gammarns grossimanus.

GROSSIPLDE, adject., grossipes (grossus, gros, pes, pied); qui a des pattes grosses ou renflées. Ex. Nymphum grossipes.

GROSSULARIÉS, adj. et s. f. pl., Grossularica. Nom donué par Candolle à une fanille de planles, ayant pour type le genre Ribcs.

GrossulaninF, s. f., grossularina. Guibourt dome ce nom à la šclicc végétale, e’est-à-dire à une matière qu'on trouve dans les fruits acides, qu'il considere comme une substance spéciale, et que 'Thomson soupconne ĉtre de la gormme combinée avec l'aeide pectique.
GRYL

565

GROSSULARINíes, adj. et s. $f$. pl., Grossularinc. R. Brown appelle ainsi la famille des Grossularićes ou Ribćsićes.

grossuline. Vojez GrossulaRINE.

GR OTTE, s. f., specus, spelunca; वैvтроч; Höhlc (all.). Ce mot est quelquefois cmployé comme synony me de caverne; mais on s'en sert plus communément pour désigner les petites cavernes qui ne se composent que d'une seule salle.

GROTTITEIE, adj., arcellarius. On donne celle épilhète aux araignées vagabondes qui tendent des fils propres à ployer les feuilles et à les faconner en groltes.

GROUPL, s. n., sorks; Hïufchen (all.). Agrégation des petites capsules qui constituent la fruetifieation des fougères. Foyez Sore.

GRUIDLs, alject. et s. m. pl., Grzeida. Nom donné par Vigors à une famille de l'ordrc des Échassiers, qui a pour type le genre Grus.

GruINALES, adject. et s. f. pl., Gruinalcs (grus, grue). Sous ce nom, Linné désignait une famille de plantes, comprenant celles qui, conune les Geranium, ont des capsules alongées en pointe et semblables a uu bec de grue.

Gruveri, adj., grumosus, gra-

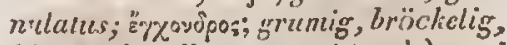
klumperig (all.); rusged (angl.); qui est divisé en petites masses arrondies, conme le Dematium grumosum. On. donne celte épithète au pollen, quand il est composé de corpuseules nom. lreux, attachés sur un axe commun, et pressés les uns contre les autrcs (ex. Orchis); et à la racine, quand elle se compose de petits grains agglo-

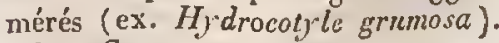
Fojez Granuleux.

GTUMELEUX. Vorcz Grumelt. GRYLLIDES, adj. et s. m. pl., Gryllida. Nom donné par Latreillo, 
Goldfuss, Eichwald, Ficinus ot Carus à unc famille de l'ordre des Orthoptères, qui a pour type le genre Gryllus.

GRYLLIFORMES, adj. et s. m. pl., Grylliformes. Nom domú par Duméril à uuc fiunille d'insectes orthoptères, ayant pour type le genre Gryllus.

GRYLLOIDES, adj. et s. m. pl., Grylloides. Nom donné par Lamarck à une famille de l'ordre des Orlloptères, ayant pour type le genre Gryllis.

GRYLionisns. Vorez Grylidoes. GRXPAví́, adject. , grypanius; krummfirstig (all.) (ypuraivw, courber). Epithète douné par Illiger an bec des oiseaux, quand l'extrémité de la mandibule stipérieure s'arque et se reeourbe, comme dans l'Aigle. Synonyme d'aquilin.

GUAJACANúES, adj. et s. f. pl., Guajacaneae. Quelques botanistes ont appelé ainsi la famille des Ebcinacées, à cause du genre Guajacum, qu'elle renferme.

GUARANINE, s. f., guaranina. Aleali organique, encore problématique, que Martius a découvert dans le Guarana, pâte préparée avee les fruits pétris du Panllinia sorbilis.

GUL̂PIAIRES, adjee!. et s.f. pl., Vesparice. Nom donné par Cuvier, Latreille et Lamarck à une tribu, par Goldfuss, Ficinus el Carus ì une famille de l'ordec des Hyméno plères, qui a pour type le genre Gucipe, Vespa.

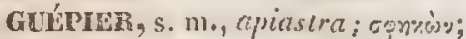
Wespennest (all.); avasphise (inglo). Nid composi de inatieres diverses, et dont l'enveloppe exlérietre semble papyracéc ou cartomeuse, que se construisent les guêpes sociales.

GUETTARDACEES, adj, et s. f. pl., Guettardacece. Nom donuć par Candolle s une tribu de la famille des Rubiacées, qui a pour lype le genre Guellarda.

GUETTARDSES, adj. el s. f. pl., Guctlardece. Nom donné par Kunth à une trilu de la famille des Rubiacées, par Candolle à une seetion de la tribu des Gueltardacées, ayant pour type le genre Gnetlarda.

GUELLE, s. C., gula; Maul (all.); mouth (angl.); gola (it.). Se dit de la bonche, dans la plupart des animanx. Voy. Botcue.

GULAIRE, adj., gularis (aula, gorge). Epithètc donnée à quelques oiseaux dout la couleur du cou trinche sur celle du reste du corps. Ex. Loxia guluris.

GUninflise, adj., gummifer, gummiforus (gummi, gomme, fero, porter); qui produit de la gomme. Ex. Dauclls gummifer, Gardenia gummifera, Ceratopelalum gunmifervem.

GurnhLLCÉEs, adj. et. s. f. pl., Gundeliacece. Nom donné par Candolle a un groupe de la famille des Gynarocéphales, qui a pour type le genre Gundclia.

GUTTIFL̀ns, adject., gutuiferus; qui produit de la gomme gुulte. Lx. $V$ ismea gullifera.

GUTTIFEIES, adjeet, et s. f. pl., Gnuiferce. Famille de plantes, ainsi appelée paree que presque tous les végétaux qui la constituent renfernent un sue grommo-résineux de couleur janne, comme la gorme gutle.

GUTTWORME, alj., gutliformis (gutta, goutte, furma, forme). Epilhite donnce à quelques poly piets qui sont très-petits, comme le I'ulytrema minincea.

GUTTULAIRL, adject., gutlularis (guthula, peitite gontle). Se dit d'un minéral qu'on trouve sous la forme de petits grains, sembliables à des gouttes d'eau, comme la variété de chaux phosphatée appelće Moroxite.

GUTrURAL, adj., gutturalis (gut- 
tur, gosier); qui appartient au gosier : plumes gutturales.

GUTTIPENNE, adj., guttipennis (gutta, goutte, penna, aile); qui a les ailes ehargées de laches blanches, dissćminées sur un fond brun, ce qui les fait resscmbler à des gouttes d'eau. Ex. Tabanus guttipennis.

GYMNAMIIIOHE, adj., gymnamphorus. Le Nepenthes grmnamplora cst appelé ainsi, parce qu'au licu de feuilles radieales, on n'aperceit dans celte plante que les seuls godets, implantés sur les pétioles.

GYMNANDRE, adj. , symnander,

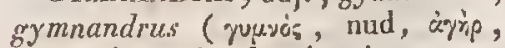
homme); qui a des ćtamines nues. Ex. Bartsia gymnandra.

GYMNANOL ENES, adj. et s. m. pl. , Gyminamolena ( yuuvos, nud, $\alpha$

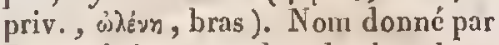
Ranzani à un ordre de la elasse des Acéphales, comprenant ecux de ecs animaux qui n'ont ni bras ni test.

GYMNiouES, adj. et s. m. pl., Gymnica ( yueròs, nud). Nom donné par C.-G. Ehrenberg à une famille de la elasse des infusoires Polygastriques, comprenant ceux de ces animaux qui ont le corps dépourvu de cils.

GMMNOBrastes, adj. et s. f. pl., Gymnoblasta ( rejeton). Barlling désigne sous ce nom un groupe de l'ordre des plantes dicolylédonées, comprenant eclles dont l'embryon u'est point renfermé dans un sac propre.

GYMNOBRANCHEs, adj.et s. m., pl., Gymnobranchiata ( rup yos, nud, Bod́yxia, brauchics ). Nom donné par Schweigger et Fischer à une famille, par Grey à une sous-classc, par Menke à un ordre de la classe des Mollusques gastéropodes, comprenant. ceix qui ont les branchies nues.

GYMNOCARPE, adj. , gymnocar-

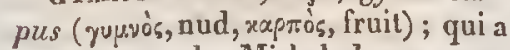
les fruits nuds. Mirbel donne cette épithète aux fruits quine sont soudés avce aucun organe aceessoire. Lé Tauschcria gymnocarpa est ainsi nommé paree que ses silieules sont glabres; le Panicum gymnocarpon. parce que ses glumes écartécs liaissent apercevoir les graines.

GMMocanPEs, adj. et s. m.pl., G) rmnocarpi. Nom donné par Persoon ct Marquis à un ordre de la classe des Champignons, comprenant ceux dont les corpuseules reproducteurs sont situćs ì la surface extérieure.

GYMNOGARPIEN, adj., grmnocarpeus. Epithictc donnèe par Mirbel aux végélaux qui ont le fruit découvert.

GYMNOCAUILE, adj. , gymnocau-

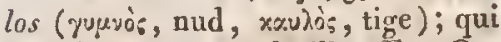
a la tige nue, sans feuilles. Ex. Geranium gymnocaulon.

GTHNOCLPHALE, adj. , 5ymno-

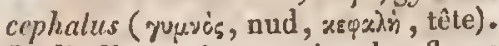
Se dit d'une plante qui a les fleurs nues, comme le Borreria g.ymnocephala, à cause de l'avortement des feuilles florales. Se dit aussi d'un oiseau qui a la tête dégarnie de plumes, conme la Coracina symnoccphala, dans l'ầge adulte.

(i) ViNOCOCHLIDES, adj. et s.m. pl., Gymnocochlides ('vuvis, nud, *oxiो;, coquille). Nom donné par Latrcille à une division de l'ordre des Gastéropodes pectinibranches, comprenant ceux de ces mollusques qui ont la coquille à l'extérieur du corps.

GMMNODELE, adj., gymnoderus

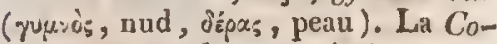
racina g) mnodera est ainsi appelée parce qu'cile a lc col nud sur ses parties la tćrales.

GYMNODERures, adj. et s.m. pl.,

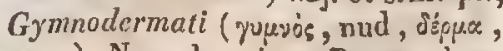
peau). Nom donné par Persoon à un groupc de champignons, renfermant ecux dont la surface fruetifère est nue ou couverte de papilles.

GYMNODERMES, adj. et s.m.pl., 
Gymnodermala. Nom donné par. Intreille à une famille de l'ordre des Cirripèdes polybranelics, comprenant ceux qui ont la majeure partic du corps it nud et sans pièces testncécs ; par Goldfuss, Ficinus ct Carus à une famille des Annelides, conıprenant ceux de ecs animaux qui ont le corps entièrement nud.

GYMNODĺs, adj. ct s. m. pl., Gymnodea, Gymnodaca (rup.jos, nud, sidos, forme). Nom donné par Boly à un ordre de la classe des Microseopiques, comprenant ceux dc ees animaux dont le corps cst dépoursu de test, de cils et de cirres vibratiles.

GYMNODISPERUES, adj. et s. f. pl., Gymnodispermee (yuevò, nud, Jis, deux, $6 \pi \dot{e} p u x$, gratine). Nom donné par Boerhanve à une famille de plantes, comprenant celles qui ont deux graines, en apparence unes, comme les 0 mbellifères et les Rubiacées.

GYMNODONTES, adj, et s.m. pl., Gymnodontes (rupers, nud, dobũ , dent). Non donné par Cuvier, Látreille et Eichwald à une famille de l'ordre des poissons Plectognathes, comprenant ceux qui ont lcs mâchoires garnies d'une sulsstance éburnéc, produitc par la réunion dés dents.

GYMNOGÈNES, adj. ct 5. m. pl., Gymnogena ( produire). Sous ce nom, Lnircille, Ficinus et Carus désignent unc classe du règne animal, comprcuant les animaux qui, comme les inlusoires microseopiques, maissent à nud dans des infusions végétales ou animales.

GYMNOGOMPUL, adj., gyminogomphus (yupvö, nud, qnupiō, dent). Epithète donnée par C.-G. Elrenber. aux Infusoircs rotifères dont les dents ne ticnnent à la mâchoire que par leur base, et n'y sont point atlachées en avant. Ex. Diglena catellina.

GYMNOGINE, adj., gymnogy'nuts (quuvos, nud, yuvi, femme). Rafinesque propose de donner cette épithìte aux plantes dont l'ovaire est nud. Unc Synanthérée (Hohenwartha agmnogyna) est ainsi nomnic parce que les fleurs femelles de la eirconférence de ses "calatlides sout privées de corolles.

GIMNOMONOSPERMES, adj, ct s. f. pl., Gymnomonospcrma (yuy.s,

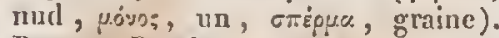
Ray et Boerhaave appeiaient ainsi les plantcs qui n'ont qu'unc seulc graine, en apparence nue.

GYMNOMYCES, s. m. pl., Gymnomyceles ( pignon). Nom donné par Link à un ordre de champignons, couprenant ceux dont les corpuseules reproducteurs sont à uud.

GIMNONIZIDES, adject. et s.f. pl. , Gymnomyaides. Nom donné par Cuvier a une sous-tribu de la tribu des Museides, qui a pour type le genre Gymnomyza.

GMHNONECTES, adj. et s.m. pl., Gymenonectes ( nirgeur). Nom donné par Duméril à une fanille de l'ordre des Entomostracis, comprenant ceux qui ont Je corjs tout-i-fait uud.

GYMNOp'́RISTOMATES, adj. ct s. f. pl., Gymnoperistomati ('pusies,

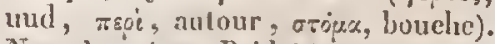
Nom douné par Bridel à un ordre de Mousses, comprenant eelles qui ont lc péristome entier, nud et sans dents.

GXanonirubes, adj. ct s. m. pl., Gymnophides ( qupros;, nud, öres, serpent). Noru donne par Latreille, Ficinus et Carus à une famille dé Reptiles oplidiens, comprenant ceux qui ont la pentn nuc, lisse et visqueuse.

GWHNOPHONES, adject. et s.m.

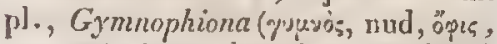
serpent). Nom douné par Muller à une famille de Reptiles nuds, ou Batreeicns, comprenant les Cécilies, ou serpens ṡ peau une. 
GYMN

GMMNOPITHALYOOIDES, adj. et s. m. pl., Gymnophlhalmoidea. Fitzinger désiguc sous ec nom une famille de heptiles sanriens, qui a pour type le geure Gymnophthalmus.

GrMNOPODES, adj. el. m. pl.,

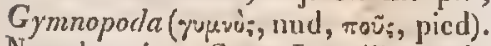
Nom donné par Gray, Lalreille, Ëichwald, Ficinus et Carus ì unc farnille de Reptiles chélonicus, comprenant ccux dont les pieds ne peuvent pas rentrer, du moins entièrement, dans la boîte qui renferme le corps.

GYMNOPOLYSPERMES, adj. et s. f. pl., Gymnopolysperma (yusvo's,

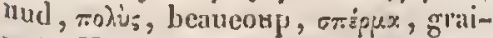
ne). Nom donné par Ilermanu ct Bocrhaave a une classc de plantes, renfermant celles qui ont plus de deux semences, en apparence nues.

GTMNOPOMIS, adj. et s. m. pl.,

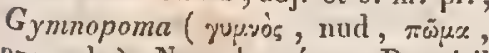
opercule). Nom dounć par Dunéril à une famille de Poissons osscux holobranches, dins larpelle il range ceux qui ont les opercules lisses ct sans ćcailles.

GYMNOPtènes, adj., Gymnoptera (yuuròs, nud, $\pi \tau$ s.oo\%, aile ). Nom donné par Degeer, Schafler el Scupoli ì unc classe ou section d'Insectes, comprenant ccux qui ont les ailes nues, saus élytres ni écailles farinacécs.

GMuxodnuE, adj., g)mnorhizils (qupys, nud, pege, racine); qui a des raciues nues. Le Brúguicra Eymnorhiza est aiusi appelé paree que, de ses branches, partent de longs jels qui vont prendre racine en terre. GrMNoRIINQUES, adj. et $s$. in.

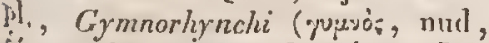
Pisyos, bec). Nom donué par Latreille it une famille de l'ordre des $\mathrm{P}_{0 i s s o n s}$ sturioniens, comprenant ceax qui ont le museau courl et déपué d'appendiecs.

GYunosones, adj, et s. m. pl.,

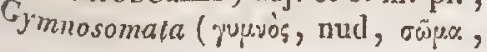

corps). Nom sous lequel Blainville désigne une famille de l'ordrc des Paracćphalophores aporoloranches , ct Eichwald une fauille de la tribu des Micrognathes, comprenant cenx qui ont le corps entierement. nud.

GYMXOSPERME, adj., grmno-

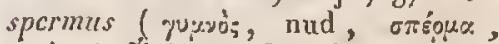
graine). Epithìte donnce anx plantes qui ont les graines nues, du moins en apparence.

GYMNOSPERMES, adj. ct s. m. pl., Gymnospermi, Gymnosperma. Nom ilunuć par Herinann, Knaut et Wachendor ff́ à une fimille de plautes, qui renferme celles dont les graines paraisscnt ètre nues; par Marquis à une tribu de la fanille des Dermatocarpieus, comprenant ceux de ces chumpignons qui renferment des séminules pulvérulentes, sans filamens réticulés.

GYMNOSPERMIE, s. f., symnospermia. Linné donnait ce nom à un ordre de la didynamie, dans lequel il ranggcait les plantes didynames qui ont les graines nues en apparence.

GYMNOSPERMIQUN, adj., gymnospermicus. Se dit d'une planle dont les graines paraissent être nues.

GXMNOSPORE, adj. , gymnosporus ('yuvò;, und, oropz, semence). Se dit d'une eryptogame, ct principalement d'un clampiguon, dont les spores sont à nud.

GruNoSponés, adj. et s. m. pl.,

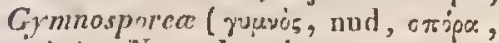
grain). Nom donné par Reichenbach ì un ordre de la classe des Lichens, compremant ceux qui ont leurs corpuseules reproducteurs ì nud.

GYMNOSTOMÉEs, adj. et s.f. pl.,

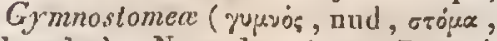
buuche). Non donné par Bory à une fanille de l'ordre des Microscopiques Vorticellaires, comprenant cen $x$ de ces animanx dont l'o rifice buccial est dépourvu de cirres vibratiles. 
GYMNOSTOMES, adj. ets.m.pl.,

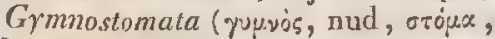
bouche ). Latrcille forme sous ce nom un groupe comprenant les insectes dont les partics de la bouche sout á nud, ct quatre d'entr"clles maxilliformes.

GMMvostoves, adj. ct s.m. pl., Grmnost mi. Nom donué par Bridel à plusieurs ordies de Mousses, qui comprenuent celles dont l'urifice de l'urne est nud.

GYMNOSTOMOIDES, adj. et $s$. f. pl., G) mnostomoidea. Noun donné par Arnott à une tribu de la famille des Monsses, qui a pour type le genrc G.rmrosiomum.

Gruvotes, adjeet. et s. m. pl., Gymnota (yupvós, nud). Nom donné par Latreille, Goldfuss, Ficinus et Carus à une fumille d'Entomostracés, comprenant ceux de ces aniInaux qui ont le corps nud.

GYMNOTÉTRASPERME, adjeet., gymnotetraspermus ( yuevòs, lued,

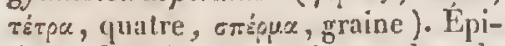
thète donnée à des plantes dont lo fruit parait être formé de quatre graines nues. Ex. Heliotropium.

GYUNOTITRASPERnIE, adject. ets.f. pl., Gymnotetrasperma. Sous ce nom Boerhaave désignait trois classes de plantes, renfermant eelles qui ont quatre semences nues, du moins en apparence.

Grunotines, adj. et s. m. pl., Gymnotides. Nom donné par Blainville et Lalreille à une famille de Poissons, qui a pour type le genre Gymnotus.

GMMNURE, adj. , gynnumus (qupvòs, nud, oupgè, quene); qui a la queuc nuc. Ex. Dasypus grmnurus.

Grinures, adject. et s. m. pl., Gymnuri. Nom sous lequel Spix désigne une section de la famille des Singes, comprenant les Sapajous à queue uuc et' calleuse.
GYNANDRE, $;$ adj . , gynander, gy-

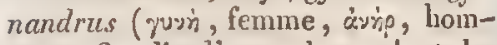
me). Se dit d'une plante dont les étamines sont altachécs au pistil. Ex. Craleva grnandra.

GYvANDres, adj. et s. f. pl., Gynandre. Nom donné par Agardh à une classe de plantes cryptocotylédones, renfermant celles dont les étamines et le pistil font corps cnsemble, et comprenant les Musacíes, Cannées, Scitaminées et Orchidées.

GYNinDnIe, s. f., gynandria. Nom d'une classe et de deux ordres, dans le systême de Linné, fondés sur la réunion des étanines au pistil.

GINANDRiQuis, adj., grnandricus. Se dit d'une plante dont les étamines sont iusérées sur le pistil (ex. Orchis). C.-C. Sprengel appelle dichoganie gynandrique le cas oir l'organe femelle, dans les plantes, se développe avant l'organe mâle (ex. Euphorbia).

GYNÉCEE, s. f., grnocium ( fenme, oixix, maison ). Rocper propose d'appeler ainsi l'appareil femelle ou ovarien, dans les plamtes.

GYNIZE, s. m., gynisus. I.-C. Richard nomme ainsi l'aire humido et visqueuse du stigmate des orehidées.

GrNobASE, s. m. , grnobasis

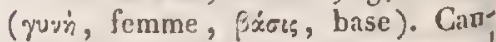
dolle donne ce nom à la base, quand elle est très-renflée, du style unique qui surmonte les loges d'un ovaire divisé (ex: 'Ochna).

GTNOBASḱies, adject. et s. f. pl.t Gynobasea. Nom donné par Agardl à unc classe de plantes phaoérocoly, lédones complètes diseigynes polypé tales, comprenaut celles ehez lesque les oo observe un gynobase, tclles qu les Ochnacécs, Rutacées, Zygophyllées et Géraniacées.

GYNOBASIQUE, adj., gynobast culs. Candolle donne cette épithéle aux fruits dont les loges sont teller 
ment écarlécs les uncs des autres, qu'elles semblent a utant de fruits sćparés, mais sont toutes articulécs sur un gynobasc plus on moins dilatí, qui est la base d'un frnit unique (ex. Labiées). On dit le nectaire gynobasique, quand il naît sous l'ovaire, et ne s'étend pis benucoup au delá (ex. Cncorum tricoccum).

GYNOCHION, s. un., gynoeidium. Necker et Hoffmann nomment ainsi un petit reuflement situé à la hase dn pédoncule de l'urne, dans certaincs mousses.

GYNODYNAME, adj., grnodyna-

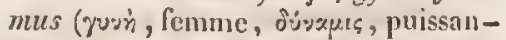
ce). Fries donne cette épithète aux plantes nonocotylédones, parce que lorganc fcinelle prédomine dans toutes, et que c'cst cette classe qui renferme toules les plantes gynaridies.

GYNOPHORE, s. m., grnophorum, Stampcltrigev (all.) ( үuv่, femme, qéfea, porter). Nom donné. par Mirhel à un support né du réceplacle, ct qui soutient le pistil seul. C'est le carpophore de Link, qui lui-même a adopté depuis le nom de Mirbel. Quand le, gynophorc ne souticnt qu'un pistil, il est appclé par Mirbel grnophore monogyne, par Ehuhart Thecaphore, par Richard Basigrne. S'il cen souticut plusieurs, Mirliel le nomme gynophore polyeyne, et Richard Polyphore. Quand il supporte en même tcun ș les étamines, Mirbel l'appellc gynophore staminifère, et Candolie Gonophore; s'il porte en mèune temps des pétales et des étamilles, Mirbel le nommc synophore corollifere, et Nces d'Esenbeck, d'apres Mirbel, Anthophore.

GYYOPuOni, adj. , grnophoratus. Se dit, d'après Mirbel, du réeeptacle, quand il forme nue sujllie sur laquelle sont fixés les ovaires. Hx. Reseda.

GYNOPionIEN, adj., gynophorianus, Epithc̀tc donnée par Mirbel au style, lorsqu'il prend naissance sur un receptacle saillant, e'est-à-dire. sur un gynophore. Ex. Scutellaria.

GYNorunrotDE, adj., grnophoroidcus. Mirluel nomine ainsi lc neclaire, quand il exhausse l'ovaire, comme ferait un gyuophore Ex. $Z y$ grophyllum morgsana.

G) MOSTÈE, s. I., synostegium; Geschicchtshülle (all.) ( үuvi, femme,

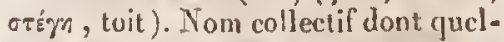
ques botanistes se sont servis pour désiguer les cnveloppes des organes génilaux dles plantes, calice, corolle, nechairc, ete.

GYMOSTHMe, s.m., gyzostemium

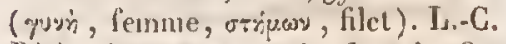
Richard appelait ainsi, dans les $\mathrm{Or}$ cluidées, la basc de la coloune de fruetification, c'est-à-dire toute la portion de la colounc charmue, partant lu centre de la flemr, qui s'ćtend jusqu’à l'insertion du stigmate, et qui scrt de moyen d'union en tre l'organe mâle et f'organc fenclle.

GYLALTLS, s. nı. pl., Gypati. Nom donné par Vieillol à une famille de l'ordre des oisenux Accipitrins, qui a pour type le genre Gypoetus.

GYPOGRRANES, s. m. pl. , Gypogerani. Nom donné par Goldfuss à une famille de l'ordre des oiseaux ravisscurs, qui a pour type le genre Gypogeranus.

GYPOGLiRANUIES, adj. et s. m. pl., Grpogeranida. Vigors désigne sous ce nom la famille des Gypogćrancs.

Giv'SLUX, adj., gypsosus, grpseus; gựings; gypsartig (all.); chalky (แagl.) ; gessoso (il.) ( $\gamma$, terre,

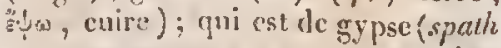
sypseux, massc gypseuse), on qui en conticnt (cau gypseuse). Onalius, sous le nom de roches gypseuses, établit un genue de roches pierieuses, qui comprend le gypse.

GYPSHFE?E, adject., gypsiferus (gypsum, gypse, fero, porter); qui 
contienl du gypse. Ex. Marne sypsifirc.

GYPSOPHILE, adj., grpsoplilus (yưyos, gypse, piìsw, aimer); qui aime les terrains gypscux. Ex. Silene sypsophila.

GYRINIDES, adj. et s. m. pl., Gyrinida. Nom donné par Leaeh à une famille d'insectes coléoptères, qui a pour type le genre Gyrinus.

GYRINITES, adj. et s. m. pl., Grrinites. Sous ee noin Latreille, Eichwald, Ficinus et Carus désignent une famille de Coléoptères, ayant le genre Gyrimus pour type.

GYRIOPIIDES, adj. et s. m. pl., Gyriophides ( rüpos, cercle, öors, serpent). J.-A. Ritgen appelle ainsi un groupe de reptiles ophidiens, comprenant ceux qui ont le corps garni de plaques et susceptible de se rouler en cerele sur lui-même.

GLRONE, s. m., gyroma ; Kreis -

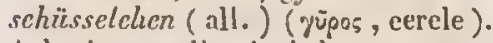
Acharius appelle ainsi des conecptacles formant sur le thalle des lichens une protubćrance orbiculaire, nıarquée de plis saillans, qui sont contour. nés en spirale, se fendent dans leur longueur, et laissent échapper des élytres (ex. Gyrophora). Link donne ce nom i l'anneau élastique et circulaire qui entonre lc plus souvent la fructification des fougères.

GTRopionées, adj. et s. f. pl., Gyrophorca.Nom donné parZenker et Reichenbach à une tribu de la famille des Lichens, qui a pour type le genre Gjrophora.
IABITABLE, adj. , habitabilis; wohnbar, bewohnbar (all.) ( habito, habiter ); qui pent ctre habilé : climat, pays, terre habilable.

HABITANT, adj. et s. in., habitans, habitator; wohnhafi, wohnend (all.); qui réside habituellement dans un lieu.

IIABITATION, s. f. , habitatio; öknats; Vorkommen (all.); abitazione (it.) Pays où croît spontanément une plante, où vit un animal; climat que chaque être vivant préfère.

IIBBITE, adj. , habitatus; bewolunt (all.). Se dit d'un lieu oùl'on habile, où il y a des habitaus.

IIABITUDE, s.f., habiludo, as-

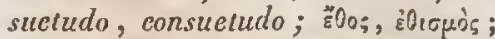
Gewohnlueit (all.). Pratique ordinaire, répétition fréljuente ct souteune d'un acte quelconque; disposition organique qui résulte de cette répétition , qui la rend facile ou même nécessaire. En physiologie, on entend par habitusde du corps (liabitus; हैלs; habit (angl.; abito, it.) l'ensemble de toutes ses parties extérieures, considérécs en masse et sans cntrer dans aueun détail.

IADITUEL, adj., consuctudinarius; qui est tourné en habitude. Les naluralistes prennent souvent ce mot dans un autre sens; ils entendeut par caractòre habiluel, l'ensemble des particularités relatives au port ou a l'extérieur, aux habitudes, au séjour des corps naturels.

IIEHODORACÉES, adj. et s. f. pl. Hamodoracca. Nom donué par P. Brown is une familie de plantes, qui a pour type le genre Hamodorum.

IALCYONIDÉs, adj. et s. m. pl., Halcyonidece. Nom donné par Vigors à une tribu de la famille des oiseaux fissirostres, qui a pour type le genre Alcyon. On ćerit ordinairement alcyonides (voyez ce mot), orthographe

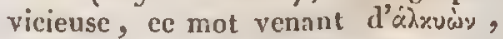
aleyon, lequel dérive lui-même de 


\section{HALI}

dìs, mer, et «ن่es, être plcin, paree que les Aleyons font leur nid sur le bord de la mer.

IIALE, 5. m. , halitus ; Schwiehllhitze (all.); surburning (angl.) (halito, cxhaler). Air sce et chaud, qui dessc̀che, fanc et llétrit.

ILALÉ, adj. ; qui est dessćchć, jauni, lrûlé par le hâlc ; teint hálé.

H.NLEINE, s. C. , lualitus, anlueli-

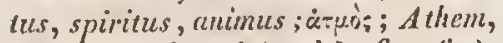
Oden (all.); breath (angl.); fiato (it.). Mélange d'azote, de gaz acide carbonique ct de vapeur aqueuse tenant une matière anima!e en dissolution, qui sort des poumons pendant l'expiration.

HALÉSIACÉES, adj. et s. f. pl., Halesiacea. Non donné par D. Don à une famille de planies, ayant pour type le genre Halesia.

HALICHÉLIDONIS, adj. et s.m.

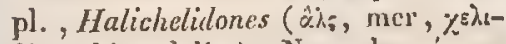
jं่, hirondelle). Nom donné par J. -A. Ritgen à une famille d'oiscaux, qui comprend les hirondelles de mer ct les allatros.

HALICHĹLONES, adj. et 5. m. pl., Halichelones $\left(\hat{\alpha} \lambda_{5}, \operatorname{mcr}, \chi^{\dot{s} \lambda_{2} u_{5}}\right.$, tortne ). Noin donné parJ.-A. Ritgen à unc famille de reptiles chéloniens, qui renferme les tortues de mer.

IIALICOTYMBES, adj. et s. m. pl., Halicolymbi (àl, mer, rolup $\beta \dot{\alpha} \omega$, plonger). Nom donné par J.-A. Ritgen à nn sous-ordre de la classe des oiscaux, comprentant ceux qui vivent dans les eaux salées, et qui ont l'liabitude d'y plonger.

HaLiconicis, adj. ets. m. pl., Halicoraces ( $\hat{\alpha}_{5}$, mel, róo hean). Nom donuc par J.-A. litgen à une famille d'oisenux, qui comprend les corlocanx de mer, c'est-ì-dire les pélicans, frégates et autres voisins.

IIAciconinas, adj. et s. I11. pl., Halicoridce. Non donné par Gray à une fannille de Manmifères cétacés, qui a pour type le genre Halicorus.
HALG

HALIGRAPHIE, s. f., haligra-

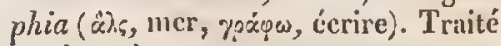
sur les sels.

maLiotinés, adj. et s. m. pl., Haliotidea. Nom donné par Mcnke à une famille de l'ordre des mollusques gastéropodes aspidobrnnches, qui a pour type le genre Haliotis.

IIALIPTÈvis, adj. et s. m. pl.,

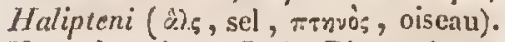
Nom donuć par J.-A. Ritgen à un sous-ordre de la classe des oiseaux, comprenant ceux qui virent sur les bords ou à la surface de la ner.

IIALISAURIENS, adj. et s. m. pl., Halisaura ( $d \lambda_{i}$, mer, oxĩpos, lézard ). Nom donné par J.-A. lititgen a une section de Repiles sauriens, comprenant ceux de ces animaux, anjourd'lui perdus, qui, suivant toules les apparences, vivaient dans le sein des caux de la mer.

HALrTULUx, adject., halituosus; àtpwờ̆: (lealitus, vapeur); qui est chargé de vapeurs, qui s'élève en vaprur, comne l'halcine pendant le froid. On dit la peau halitueuse, lorsqu'elle est recouverte d'une douce moitcur.

IHLLÉIIACÉES, adj. et s. f. pl., Halleriacea. Nom donné par link à une tribu de la famille des Personées, qui a pour type le genre Halleria.

mat.uatunes, adj, et s. m. pl., Halmaturini (ảjux, sant, oùpé, quenc). Nom donné par Goldfuss à unc fauille de Mamnifères, comprenant eeux qui, conme lés Kangurons, sc servent de leur quene pour sauter.

IHLLO, s. m., Halo; żhos; Hof (all.); crown (angl.). On appelle ainsi des ccrcles brillans, ordinairement colorés, qui se forment autour su disque du Soleil, de la Lune et des planctez, et qui sont dus aux réfractions que les rayons lumineux subis- 
sent quand ils traversent du brovillard.

HALOCHIMEE, s. f. , halochemia

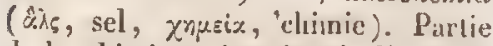
de la ehimie qui traite de l'histoire des scls.

ILALODENDEF, adj. , hatodendron (aks, sel, ofsofos, arlse). Se dit d'un arbre qui croît darss des terres inpréznées de sel. Ex. Robinia halodendron.

HALOGENE, adj.ets. m., halogc.

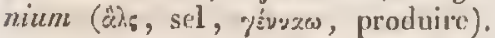
Schweigger avait dëja proposé ee noin pour remplacer eelui de chlore. Berzelius, qui l'adopte, désigne ainsi une classe entière de corps électro-négatifs, comprenant ceux qui, comme le chlore, l'iode; le brounc et le fluor, donnent maissance à des sels cn se combinant aree les mélaux électroposilif's et les neutralisint.

HALOGW.IPHE, s. f., halographia; Salzbeschreibung (all.) (âh, sel, ypros, ćcrirc). Description, aité des sels.

HALONDE, adj., haloüleus; sals-

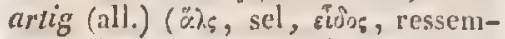
blance). Epithète donnéc par Berzelius aux sel.s qui résultent de la combimaison d'un corps halö̈de nvec un métal électru-positif.

HALOLOGIE, s. f., halologia (às, sel, lí́gos, discours). Truité des sels.

HALOBHIIE, adject., halophilu.s

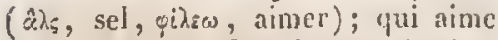
le sel, qui croît dinıs les terraiuss imprégnés de sel. Ex. Ranunculus halophilus, Iris halophila, Sisymbrium hatophilum.

INALOPHYR, s. m., halophilinm. Nom que Berzelius serait tenté de donner à la matière extractiforme solulile dans l'alcool anliydre, que eontient l'urine de l'homme, s'il ne soupconnait composic de plusieurs substanecs cette malière qui est sur. tout remarquable par la grande faci- lité avec laruelle clle s'unit à tous les sels.

IIAEOPHITE; s. f, haloplyton, planta sulsa s. salsuginosa (ầ, $\lambda_{5}$, sel, y'vor, plaute). Plante qui croit dans un terrain imprérné de sel inarin.

HaLorigkes, adj. et s.f. pl., Haloragece. Norn donné par R. Brown ì une fiamille de plantes, qui a pour type le genre Haloragis.

ILALOTECHNIE, s. f., halotechnia; Salsbercitungsshunst (all.) ( $\mathrm{Ad}_{5}$, sel, tóxyn, art). Parlie de la chimie qui traile de la préparation des sels.

IMLTÉRE, adj., haleraius (hat ter, balancier, qui vient de ENopuxt, santer). Epithète donncé à un insecte qui est nutuni de balanciers. En ce sens, le mot est synonyme de diptère; mais on s'cu sert quelquefois aussi ponr exprimer la forme des ailes, comme chez cerlains Névroptères qui ont les ailes inférieures très-longucs et dilalćes au bout.

IMALTLRes, adj. ct s. m. pl., Halicrata. Nom dunné par Degeer à un sons-ordre de la classe des insectes, comprenant ceux de ees animanx qui ont des balanciers, ou les Diplères.

IsALTÉRIPTLERE, adj. ct $\mathrm{s} . \mathrm{m}$. pl., Hatteriptera (a)ing, balancicr, rezéoy, aile). Nom donué par Glairville à un ordre de la classe des Insectes, comprenant ceux qui ont des lalanciers, c'est-à-dire les Diptìres.

HALURGIE, s. f., halurgia (d.ts, sel, äqyoy, travail). Art d'extraire ou de filiriquer les se's.

Halgr: MHe. $V$. Haltgaphe, HaLOgRaPIIE.

VAE MMENIACRES, adj. et s. f. pl., Hal.meniacere. Nom donnè par Reichenbach à une tribu de la fautille des Floridées, qui a pour type lc genre Halimenia.

IIALYOSOME, adj., halyosoma

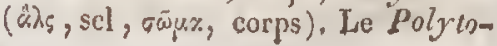




\section{HAMI}

mus halyosoma est ainsi appelé parce que son corps se compose de pic̀ees juxta-posćes, taillées à faceltes et translucides, comme des morceaux de eristal.

maMaMÉLÉs, adj. et s. f. pl., Hamamelex. Nom donné par Candollc a une tribu de la famille des Hamamélidées, qui renferme le genre Hamamclis.

maMavútunÉs, adj. et s. f. pl., Hamamelidere. Nom donué par R. Brown à nue famille de plantes, ayant pour type le genre Hamamelis.

THMECON, s. m., hamus, hamulits, zencus, rostellum; äyreatpov, Halicn (all.) (üunx, altache). Pointe croehue el un peu épaisse.

HAMECONNE, adject., hamosus, hamatus, lappaceus, lappulacezts, uncosus; hakenfïmig (all.); qui se prolonge ou se courlse au sommet ell forme de lanecon, romme le calice dn Falerianella hamata, l'insolucre de l'Arclium Lappa, Ies aiguillons du Schrankia hamata, les pédoncules de l'Unona hamata, le fruil du Turretia lappacea, du l'hanus lappulaceus et du Ramex hamalus, le ligu$m c$ de l'Anilyyllis hamosu et de l'Astragalus uncanes, les poils du Galizun rotundifolium. Le Cervus hamatless est ainsi appelé parce que son bois se termine supérienrement par une pointe rceourbće en arrière; le Salino hamalus, parce que le bout de sa mâchoire inférienre se relève en forme de eroehet.

mamíuches, adj. el s. f. pl., Hamcliacece. Non doné par Candolle et $A$. Richard is une tribu de la famille des Rubiacées, qui a pour type le genre Hamclia.

IIAMLiLIEEs, adj. et s. f. pl., Hamelica. Nom donné par Kunth à une tribu de la farnille des Rubiacées, ayant le genre Hamclia pour type.

IMMIGÈRE, adject., hamigerus; hakentragend (all.); hamus, hanıe-
HAPL,

con, gero, porter); qui porte des hameegons, comme le Trigonella hamigera, dont les légumes sont liameconnés.

IAMPE, s. f., scapus; Schaft (all.); sta// (angl.); scapo (it.). Ce mot, introduit pir Linné, désigne un rameau nud, terminal on le plus souvent ixillaire, qui se développe sur les plantes dont la tige prineipale est déprimée et pour ainsi dire enchée sous terre; il se fait surtont remarquer par la longueur de son premier entrenoud, qui explique l'absenec desfeuilles, celles-ci ne pouvint en effet se développer qu'antour des fleurs terminales, lesquelles représentent autnat de rameaux (ex. Diplotaxis scaposa).

IARULIUX, adject, hamulosis; hakerig, kurzhakigg (all.); qui est garni de petits poils erochus, eomme Ja tige dn Galizem Aparine.

HANCIE, s. f., coxa, coxcndix,

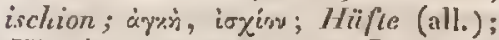
Hip (angl.); anca (il.). Parlie du corps qui, dans certains mammifères, est formée par l'évasement de l'os iliaque et les parties molles environnantes. On donne aussi ce noin it ln première des pièces dont se compose la patte des animanx articulćs, celle qui l'attache au corps.

IMPLOGENÉEN, adj., haploge-

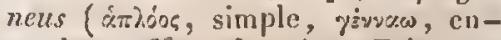
gendrer). Nom donné par Fries anx végćtanx qui sont formés de eellules anomales subfilamenteuses. Syuonyme de hétéronéméen.

HAPLOPÉRISTOUATE, arlj. , haploperistomatus (órióos, simple, $\pi$ spi, iutonr, wojoze, bouche). Epithète donnée pir Nees d'Esenbeck aux Mousses qui sont munies d'un púristome simple.

IHAPLOPETALE, adj. , haplope-

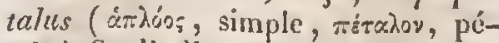
tale). Se dit d'me plante dont la corolle n'est fopmée que d'un seul 
pétale. Ex. Amorpha haplopetala.

IAPLOPOGONE, adj., haplopogonus ( $\dot{\alpha} \pi \lambda \dot{\omega} \dot{\omega} \xi$, simple, $\pi \bar{\omega} \gamma \omega v$, barbe). Nees d'Esenleck cmploie ce terme comme synonyme de haplopéristomate. Vorcz ce mint.

MAPLOSTEMONOPLTALES, adj. et s. f. pl., Haplostemonopelala

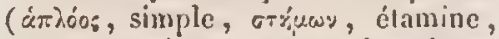

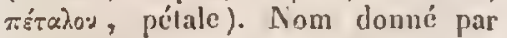
W achendorffì unc faınillede plantes, comprenant celles qui ont les élamines siniples, c'est-à-dire en mèmc nombre que eelui des divisions de la corolle.

IIAPPAxT, adj. Se dit d'un minéral qui happe fortement ì la langue. Ex. Argile happante.

HAPPEMENT, s. m., Anliëngen an die Zunge (all.); l'appiccarsi alla lingua (it.) ("xлторхе, s'atlaclier ì). Adhérence quue certaius minćraux contractent avec la langue, quand on les pose sur cet organe. On dit qu'un corps happe à la langue, lorsqu'étant placé sur l'extrémitć de cet organe, il contracle adhérence avec lui, de sorte qu'on éprouve ensuite un peu de résistance quand on veut l'en détacher.

HAPTOPODES, adj. el s. m. pl., Haptopode: (äersopast, s'attucher à, $\pi$ пǘ, pied). Nom donné par J.-A. Ritgeu à un sous-oldrc de la classe des oiseanx, comprenant ceux qui, cornme les perroquets, saisissent les alimens avec leur's pattes.

nAIDÉ, adject., accluphus. Ou donne celte épilhète anx oufs sans coquille que pondent quelquefois les oiscaux, soit parce que la matière dont se forme la coquille manque chez ces animaux, soit paree que les ocufs sont chassés de l'oviduclc avant l'époque de la maturité parlaite.

HaRrone, s. f., harmonia; $\dot{\alpha} \beta-$

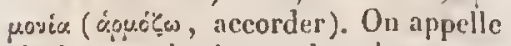
ainsi, eu physique, la résonnance simultanée de plusicurs sons dont l'en. scmble flatte l'oreille, et en musique, une suceession d'accords ou une coexistence de plusieurs sons, sclon les lois de la modulation. Un son qui nous parait simple n'élant en réalité qu'un assemblage d'harmoniques dont la réunion seule le constitue son, et ces harmoniques ne s'entendiut pas à moins quele son ne soit extrémennent fort, il s'ensuit, non seuleınent que la proportion naturelle est altérée dès qu'ou distingue les consonnauces, et qu'alors l'harmonie véritable ou naturelle a perdu sa pureté primitive, pnisque se trouve changé le rapport de foree qui doit régner untre tous Ies harmoniques pour produite la sensation d'un son unique, mais cncore que chacune des consonnances qu'il f'ait sentir, a clle-mème d'autres harmoniques qui ne le sont pas dụ son fondimental, et que, quand on introduit une disnonnance, les liarmoniques du son qui la donne et ce son lui-même n'entrent point dans le système harmonicux du son fondnmental.

InAmoniecx, adj. Tout ce qui fait de l'cffet dans l'harmonie, et même quelquefois tout ce qui est sonore et remplit l'oreiile, soit dans la voix, soit dans les iustrumens ou la simple mélodie.

HiMuoviQue, adj., harmonicus. On appelle sons harmoniques tous eeux qui suirent la série des nonbres naturels $1,2,3,4,5$, ctc., parce qu'ainsi ils ne forment jamais de dissomances. On donne aussi ec nom à tous les sons concomitans oa accessoires qui accompagnent un son quelconque et le rendent appréciable.

IARMONOMETRE, s. m., harmonometrum (águnicu, harmonie, $\mu \varepsilon-$ zośs, mesurer). Instruınent propre it incsurer les rapports harmoniques. C'est la mème chose que sonometre.

HARMOPLANE, adj., harmophanus (ápusis, cmboîtenicnt, ழxirw, 
montrer). Épithète donnćc, dans la no. menclature minéralogique de Haüy, à un minéral qui offre des indiees de joints naturels, sullout quand on désigne sa structure laminairc par opposition à celle qui, dans d'autres corps de mème naturc, présente des modifientions différenies. Ex. Feldspall harmopleane.

IIAPACES, adj. et s. m. pl., Harpaces (র்prážc, ravir). Nom donné par J.-A. lkitgen à un sous-ordre de l'ordre des Oiseaux terrestres, comprenant eeux qui vivent de proic.

IARPALIDES, adj. et s. m. pl., Harpalida. Nom donné par Macleay à une famille d'insectes Coléoptères, qui a pour type le genre Harpalus.

IIARPYES, s. f. pl., Harpyica. Nom donné par Goldfuss, Fieinus et Carus à une famille de Chéiroptères, ayant pour type le genre Harpyia.

IIASTÉ, adj., liastatus, liastilis (hasta, haelse); spicssförmig (all.); astato, alabardato (it.); qui is la forne d'un fer de lance. On appelle àinsi les fcuilles dont la base se prolonge cn deux lolies aigus, rejetés en dehors et ćeartés des pétioles (ex. Cocculus hastalus, Amneannia hastala, Karpaton hastatum, Hulchinsia hastulata, Leontodon leastile). On donne aussi cette épithète à la feuille nasale de certains Chćiroptères, quand elle a la forme d'un fer de fliche (ex. Phyllostoma hastatumj. La Belemnites hastata est ainsi appclée parce qu'elle est droite, élargie et compriméc vers l'extrémité.

IASTIROLIĹ, adj., hastifolius; spiessbläurig, spontonblautrig (all.) (hasta, lache, folium, feuille). Se dit d'une plante qui a les feuilles hastées. Ex. Scutellaria lastifolia.

inAUSTEr.dis, adj. et s. m. pl., Haustellata (haustellunı, suçoir). Nom donné par Duméril à une famille d'insecles Diptères, dans lit- quellc il range ceux qui ont un sucoir saillant; par Clairville à une division. des inseetes ailés et à une autre division des insectes aplères, comprenant ceux qui ont la bonehe en suçoir; par Macleay à une division des Insectes vrais, embrassant tous ecux qui, à l'ćlat parfait et après leur transformation, ont uı organe queleonque de suecion.

Ma USTELLum. Voyez Sucorr.

IISUT, adj., alues; leoch (all.). Epithètc dounée par Mirbel à la radicule, lorsqu'elle est tournée vers le sommet du fruit (cx. Borrago offe. cinalis). La haute mer est le moment ou finit le flux, et où les eaux paraissent rester pendant quelque temps stationnaires.

IHATEEUR, subst. f. , altitudo ; Höhe (all.); height (angl.); alıczza (it.). Grandeur, élévation, orgucil, fermeté. Ita hauleur d'zen astre au dessus de l'horizon est l'angle que forme avee ee dernier le rayou visuel dirigé à sou centre, ou l'are du cercle vertical qui se trouve entre ec corps et l'horizon. La hauteur relative d'un lien est la longueur de la perpendieulaire de ee licu ì celui qu'on ehoisit pour point de départ. Sa lauteur absoluce est la longucur de sa perpendieulaire à une surface eirculairc dont le centre coïncide avec cclui de la terre et la circonférence a vee la surface de la mer, qu'on considère ainsi comme un splićroïde régulier prolongé jusuqu'à l'endroit désigné. La haulcur du baronictre est la longucur de la colonne de mercure, qui varie suivant leslieux et les temps. IÉBíANTIE, adj., helscanthus.

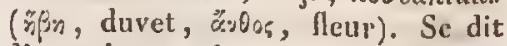
d'une plante qui a ses corolles tomenteuses. Ex. Palieourca hebeanilia.

IÚBÉCAnUE, adj. , licbecarpres ( d'unc plante qui a ses fruits pubescens. Ex. Delima licbecarja. 
HÉBÉCLADE, adj.; hebecladus ( $\bar{\beta} \beta n$, duvet, $* \lambda x^{\prime} \hat{\delta}_{5} 5$, branche). So dit d'une plante qui a ses rameaux pubescens. Ex. Cantlium hebecladum.

ILẺBÉGYse, adjeet. , hobegynuss ( $n \hat{\beta} n$, duvet, $\gamma w \dot{n}$, fomme). Se dit d'une plante qui a ses ovaires pubeseens. Fx. Aconitum hebegynum.

IIĹBÉPÉTALE, adj., hebcpetalus

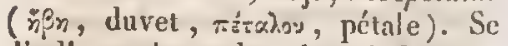
dit d'une plante dont les pétales sont pubescens. Ex. Myrcia hebcpetula.

HÉCATOPIYLLE, adj., hecato-

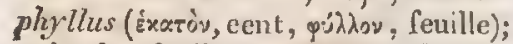
qui a des fenilles composées de einquante paires de folioles. Ex. Cassia hecatophylla.

HECTIQUE, adj., hecticus (s: xòs, desséché). Ise Stenostoma hecticum et l'Idolea hectica ont ćté ainsi appelés à cause de leur corps long, mince et étroit.

IÍ́dĹácíEs, adj. et s.f. pl., Hederaeece. Nom donné par A. Richard à une famille de plantes, yui a pour type le genre Hedera. Linné appelait ainsi une famille dans laquelle il rangeait des plantes ì lige grimpante. l'hililicrt nvait appliqué la même dénomination à la famille des Ampélidées.

IńmYoties, adj. et s. f. pl.; Hedyotece. Nom domic par Candolie à une section de la tribu des Hédyotidées, qui renferme le genre $H_{e-}$ dyotis.

IIÉDYotmíes, adj. et s. f.pl., Hedyotidece. Nom donné par Candolle à une tribu de la famille des Rubiacées, qui a pour type le genre Hedyotis.

núnisanúrs, adj. et s. f. pl., II edysarea. Nom donné par Candollé à une tribu de la famille des Léguminenses, qui a pour type le genie Medysarum.

nêDSAROmb́es, adj. ct s. f. pl., Hedysaroidce. Nom donne par

\section{IIÉLT}

Candolle ì une seclion du genre Oxalis, comprenant les espèces qui ont du rapport avee les Hledysarum.

IELEviniss, adj. et s. f. pl., Hcleniece. Nom donuć par H. Cassini à une section de la tribu des Hélianthées, et par Lessing à une sous-tribu de la tribu des Sénéeionidées, ayant pour type le genre Helenium.

HÉLEVTVE , subst.f. , helenina. Quclques chimistes ont appelé ainsi l'inuline (voy. ee mot), parce qu'on l'a trouvée d'aboid dans l'Inula $M e-$ lenium. On donne le mêtme nom à une substance végćtale, ayant dc l'analogie arcelesstéaroptèues, quis'obtient quand on distille la racine de cette même plante.

IĹLLANTHẺES, adj, et s. f. pl., Hclianthea. Nom donné par II. Cassini ct par Kunth à une tribu de la famille des Synanthérées, par Lessing à une sous-tribu de la tribu des Sénćcionidées, ayant pour type le genre Hclianthus.

IIÉIANTHOHES, adj. et s. m. pl., Helianthoida (भìıs, soleil,

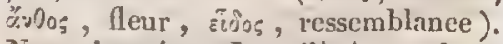
Non clonné par Jatreille à une classe d'animaux, comprenant ceux yui ont la bouche couronnéc de tentacules non rétractiles.

IISLIAQUE, adj., heluectus; riduazis. Lu lever héliaque d'un astre a licu quand l'appacition de celui-ci sur l'horizon préeède assez eclle du Soleil pour qu'on puisse l'apercevoir le matin; et son coucher héliaquc, quand il cesse de paraître après le coucher du Soleil, dans les rayons duquel it semble se plonger.

nELIC thìte donnce quelquuefois, par les bolanistes, aux pédonculcs qui sont ronlés en spirale. Ex. Vallisneria spiralis.

IÚLICẺs, ađj.ct s.m.pl., IIelicea. Nom donné par Menke à une famille de l'ordre des moliusques 
Gastéropodes colopnés, qui a pour type le genre Hclix.

IEELICURTSES, adj. et s.f. pl., Helichrysea. Nom donnć par H. Cassini à un grompe de la section des Inulées gnaphaliées, et par Isessing it une section de la sous-tribu des Sénécionidées gnaplaaliées, ayant pour type le genre Helichrysum.

HéLICIFOnME, adj., leelicifor'mis (helix, limacon, forma, forme); qui a la forme d'une coquille de limaçon, comme le test du Magilus antiques.

IIELICINIDES, adj. et s. m. pl. , Helicinides. Nom donné par Latreille à une famille de mollusques Gastéropodes, qui a pour type le genre $H$ clicina.

núLICINés, adj. et s. m..pl., Helicinaa. Nom donné par Menke à une famille de mollusques Gastéropodes colopnés, qui a pour type le genre Hclicina.

ińLICoNéiss, adj. ct s. f. pl., Heliconea. Nom donné par Salisbury à la famille des Musacées, en raison du genre IIcliconia, qu'elle renferme.

IúLICONIENS, adj."et s.m. pl., Heliconii. Nom donné par Latreille à une section, par Swainson à une famille de Isépidoptères diurues, ayant pour type le genre $\boldsymbol{H}$ cliconia.

IIÉLICOSTÈGUTS, adj. et s. m. pl., Helicostcga (छ̈. $\xi$, circuit ,

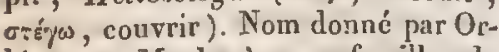
bigny et Menke à une famille de Céphalopodes, comprenant ccux dont la coquille se compose de loges as'semblées sur' un ou deux axes distincts, mais fornant une spirale régulière.

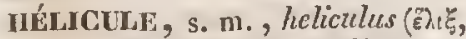
circuit). H. Cassini propose d'appeler ainsi les vaisseaux en spirale des plantes.

MELIGMA, s. m. Illiger nomme ainsi l'éminence hélix de l'oreillc.
IúLrOCENTRIQUE, adj., helio-

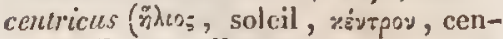
tre). On appelle lieze ou longitude laćlioecntriquc d'une planètc le point de l'ćcliptique où nons rapporterions l'astre si nous étions au centre du Soleil, et latituede héliocentrique la distance de la planète à l'écliptique, telle qu'on la verrait si l'on était dans le Soleil, l'angle que la ligne inenée du centre du Soleil à celui de l'astre fait avee le plan de l'ćcliptique.

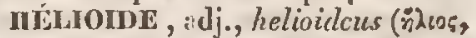
solcil, Eiơos, resemblance). Se dit d'un corps qui cst arrondi et garni à sa circonférence de cils rayonnans, eomme le Trichnoda solaris.

IÚcIOUiTRE , s. m., heliome-

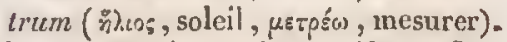
Instrument inventé en 1743 par Servington' Severy, perfectionné ensuite par Dollond, puis par Frauenhofer, qui sert à mesurer le diamètre apparent du solcil.

Iúcrophuses, adj. et s. f. pl., Holiophiluer. Nom donné par Cinndolle à une tribu de la famille des Crucifères, qui a pour type le genre Helioplilita.

IÉ́LIOPSIníEs, adj. et s. f.pl., Heliopsidece. Nom donné par H. Cassini a un groupe de la section des Hélianthées Rudbeckiées, par Lessing ì une section de la sous-tribu des Sénécionidées hélianthées, ayant pour type le genre ITeliopsis.

IILLL1OSCOPIE, adj., leclioscopius

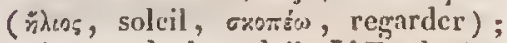
qui regarde le soleil. L'Ertphorbia helioscopia a été appulée ainsi parce que, sur l'autorité dc Dioseoride, on lui a attribué la propriété do tourner toujours son fcuillage vers le soleil, ce que font tontes les plantes librenıent abantionníes ì elles-mèmes.

mílIOSCOPH, s. m. , leclioscopium. Schneiner appelait ainsi un instrument de son invention, qui sert à observer le soleil. 
míncrostat, s. in., beliostata

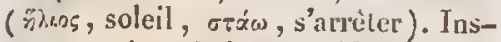
trument imaginé par s'Gravesande pour projeter invariablement l'imase du soleil sur un poiut. Fahrenhcit $\mathrm{crt}$ a construit un aussi, bien plus simple que celui de Ganbey, pour fixer i volonté le rayon solaire dans telle direction qu'on choisit.

HELIOTROPE, adj. , heliotropius; sonnenwendig (all.); eliotropo (it.) (ทั่ Épithète donnéc par les botanistes aux plantes dont les fleurs se tournent constanment vers le soleil, qu'clles semblent suive dans son cours apparent.

ITLIOTUG'E, s. m. heliotropium. Instrument imaginé par Gauss pour renvoyer le rayon solaire à un observateur ćloigné, et remplacer, dans les yrandes opératiens géodísiques, les signaux ordinaires, qui sont d'un cmploi si peu conmmode quand il s'agit de stations éloignées. Selıeiner avait déjà ılonné ce nom ì un instrument semblable à la machine parallactique, parce qu'on peut aisćment le tourner vers le soleil pour observer eet astre.

HELIOTHOPLÉs, adj. cts. f. pl, Heliotropica. Nom domé par Selira. der à une famille de plantes, ayant pour type le geure Heliotropium.

HELIOTROPISWE, s. in. Faculté dont ecrtaiues plantes jouissent de tourner constamineut leurs fleurs vers lesoleil. Ex. Mclianthus annuus, Hoya carnosa.

IİulsoxTeS, adj. ct s. m. pl., Helisontes. Nou donué par Goldfuss a une famille de reptiles ophidiens, qui a pour type le genre $H_{c}$ clison.

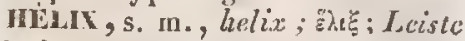

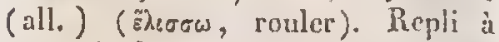
peu près demi-circulaire qui entoure le pavillon de l'oreille, ehez l'homme.

MELLEBORACENS, adj. et s. f. pl. Helleboracea. Nom donné pa!
Caftin et Marquis à une famille de plantes, qui a pour type le geure Hellebortes.

HELLEBBORLES, adj. et s. f. pl., Helleborca. Nom donné par Candolle à une tribu de la famille des Pienonculacées, ayant le genre Helleborus. pour type.

HELLLBORINEs, adj. et s. f. pl., Helleborina. Nom donné par DupetitThouars à une section de la famille des Orchidées.

IHEIMINTIES; adj. et s. m. pl.,

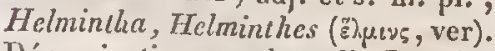
Dénomination sous laquelle Duméril désigne la classe des Entozonires ou vers intestinaux.

HELMMTHQUES, adj. et s.m. pl., IIelminthica (छ)uเvs, ver). Nom donné par O.-F. Muller à un ordre de la classe des vers, comprenant tous ceux qui ressemblent plus ou moins au ver de terre.

IIENIINTIOGLS, adj. et s.m.pl.,

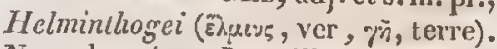
Nom donné par Latreille à unc classe d'animaux sins vertèbres, comprenant les Hirudinées et les Lombricinées de Savigny.

IIELMINTIOIDES, adj. et s.m.

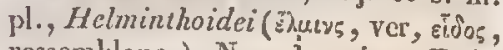
ressemblanec). Nom donné par Eichwald à un ordre de la clisse des poissons, comprenant ceux qui se rapprochent des vers d'apres leur mode de respiration, l'eau n'arrivant pas aux branchies par la bouche, mais par des ouvertures latérales, ct d'après leur mode de génération.

IELMINTIIOLOGIE, s. f. , hel-

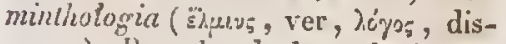
cours). Branclie de la zoologie qui traite spćcialement des vers et surtout des vers intestinaux.

IEIAINTHOLOGISTE, s. m. , helminthologista. Naturaliste qui se livre spécialement à l'étude des vers.

IELMIV'THOTIEQUE, adj., hel-

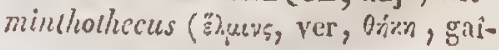


ne ); qui a des graincs cylindriques, vermiformes. Ex. Porocarpus helminthothcea.

nílobuéss, adj. et s. f. plur.,

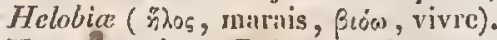
Nom donné par leichenbach à une section des plantes R hizo-Acroblastes, comprenant les trois familles des $\mathbf{T} \mathbf{y}$ phacées, des Alisnracées et des $\mathrm{Hy}_{\mathrm{y}}$ drocharidées, dont toutes les espececs sont aquatiques.

IILLOChriles, adj. et s. in. ph,

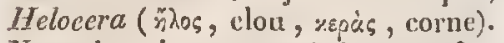
Nom donné par Duméril à une famille de l'orilre des Coléoptères, comprenaut ecux dont les antennes représentent une masse oblonguc, composée de feuilles qui semblent ctre perforées par un axc central. Voyez Claviconnes.

IIÉLONIÉES, adj. et s. f. pl., Hclonice. Nom donue par Reichenbach à une section de la famille des Joneacées, qui a pour type le genrc Hclonias.

MĹLONONES, adj. et s. m. pl.,

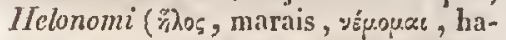
liter ). Nom donné par Vicillot à une famille d'oiscaux échassiers, comprenañt celx qui se tiennent habituellement dans les marécages.

HÉLOPHORIDES, adj. et $\mathrm{s}$. $\mathrm{m}$. pl. , Helophorida. Nom donné par Iseach à une famille de l'ordre des Coléoptères, qui a pour type le genre Helophorus.

IIÉLOPIENS, adj. et s. m. plur., Hclopii. Nom donné par Cuvier, Latreille, Goldfuss, Eischwald, Ficinus et Carus à unc tribu d'insectes eoléoptères, de la famille des Sténélytres, qui a pour type le genre $H_{c-}$ lops.

nécoprTux̀ours, adj. ct $\mathrm{s}$. m. pl., Helopitheci. Norn donné par Geoffroy Saint-Hilaire à un groupe de la farnille des Quadrumanes, renfermantccux qui ont la queue prenante. HELVLLLACíEs, adj. et s. f. pl.,
Helvellacece. Nom donné par A. Brongniart à une section de la famille des champignons, qui a pour type le genre Helvella. Poyez ElveluaGÉFs.

IUEVELIAIRES, adj. et s. m. pl., Hcĺvellarii. Nom douné par Reichenbach à une fimille de champiguons, dont le geure Helvella est le type.

IIBLVELLGis, adj. et s.f. pl. , Helvellew. Nom douné par $\Lambda$. Brongruiact à un groupe de la section des Ifelvellacées, conprenant le genre Helsellact ceux qui s'en rapprochent le plins.

IIEL VELLAS, s. f. pl., Helpelle. - Marqunis désigne aiusi un groupe de la fumille des champignons Ilyménnthéciens, qui a pour type le genre Helvella.

HELVELLOIDES, adj. et s. m. pl., Helvelloidei. Nom donué par Persoon at une famille de champignous charmus, ayant le genre II type.

MEMA CRIMEs, adj. et s. m. pl., IIamacryma (aip.x, sang, хрито̀, froid). Latrcille désigne sous ce nom unc race d'animanx, comprenaut ccux qui ont le sang froid.

MÉMASTATIQUE, adj., hama-

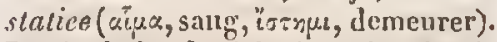
Partie de la plyysiologie qui traite de - lil forec inhérente aux vaisscanx sanguins.

IIĹmASTONE, adj. , hamastomus (aiux, sang, esópse, bouclic). Epithète donnéc à unc plante (Encalyptus hecmastoma) dont l'orifice du fruit est bordé de rouge, et à des coquilles dout le labre et la columelle sont de couleur rouge (cx. Bulimus hemastomus, Helix homastoma).

néva THERHES, adj. cl s.m. pl., Hamathcrma (vitux, saug , Oäpun, chalcur). Nom donné pur Latreille à une race d'animaux, comprenant ceux qui ont le sang chaud.

HÉLITL, s. m., hamalintes. 
Non donné par Guibourt à l'hématine. Voyez ce mot.

IIÉMATINE, s. f., homatina (aíH.x, sang). Chevreul a imposć ce nom au principe colorant du bois de Campêche (Hocmatoxylum campechianum):

IIINARTOCARPE, adj. , hamalocarpus (ailus, sang, xaprios, fruit); qui a des fruils tachetés de rouge. Ex. Pliascolus hamatocarpies.

HLALTOCÉPIILE, s. m., he-

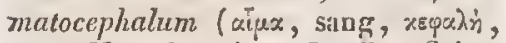
tête). Nom donné par Geoffroy SaintHilairc aux monstres chez lesquels un épanchement de sang dans les hémisphères cérébraux a causé d'étranges déformations.

IIĹMATODE, adj., hamatodes; qui est marqué de taches rouges, comparables à des gouttes de sang (ex. Salvia hamatodes). La Xylosa hematodes a l'abdomen rougc.

Húuatognapine, s. f., hamatographia (cipea, sang, yojow, écrire). Descriptiou du sang.

IÉnATOIDE, adj., hømatoidleus; cmatoide (it.) (aiuz, sang, हỉos, ressemblanec). Tom donné par Haüy à une varićté de quarz d'un rouge sombre, dû à un mélange de fer analogue à celui dont est composée l'hématinc.

IIÉMATOLOGIF, s. f., hecmatologia (oijux, sang, hóyos, discours). Traité du sang.

IÍMATOLIAGE, adj. , hamatophagus (aiju, sang, qxio (w), manger). Épithètc Jonnée aux insectes qui sucent le sang des animaux pour s'en nourrir, comme la puce el la punaise.

HÉMATORYLLIE, adj., hemato-

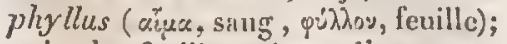
qui a les feuilles teintes d'un rouge de sang, conmecelles de l'Iris hecma. tophylla le sont à la base.

HÉUATOSE, s. f., hrematosis,

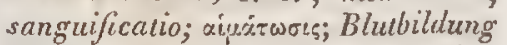
(all.) (aiux, sang). Transformation du chyle en sang ; formation du sang tant artéricl que veineux.

IEMATOXINE, s. f., hematoxina. John appelle ainsi l'hímatoxyline, par abréviation.

nkMaToXYLINE, s. f. , hematoxylina. L'hématine (voyez ce mot) a étć ainsi appelée, parce qu'on la retire de l'Hamaloxylum.

IUEvÉLVTrE, s. nı., henelytrum;

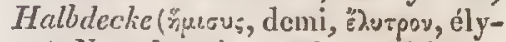
tre). Nom donnć aux ailes supérieures des insectes tétraptères, lorsqu'elles sont cornées ou coriaces à la base, membraneuses et scmblables aux ailes inférieures vers l'extrémité. Ex. Hémiptères hétćroptères.

Iİ⿴囗十́nonLanés, adject. et s. m. pl., Hemerobiadce. Nom donné par Leach à la famille des Hómćrobiens.

IÉMÉrionieNs, adj. et s. m.pl., Hemerobini. Nom donné par Cuvier, Latreillc et Eichwald à une tribu, par Lamarck et Goldfuss ì une famille d'iusectes névroptères, ayant pour type le gemre Henterobus.

IÍ́MĹRoGaLLIDÉEs, adj. et s. f. pl., Hemerocallidee. Nom donné par R. Brown et Salisbury à une famille de plantes, qui a pour type le genre Hemerocallis.

IÚ́uĹRYPSOPtères, adj. et s. m. pl., Hemerypsopteni (r.jeśps, jour,

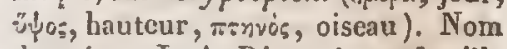
donné par J.-A. Ritgcu ả une famille d'oiscnux, comprenaut les oiseaux de proie diurnes.

HEMULNCALOPTENES, adj. et $\mathrm{s}$. m. pl., Hentiancalopteni (inuscus,

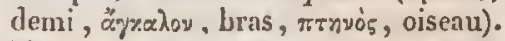
Nom donné par J.A. Ritgen à uue fauille d'oiseaux, comprenant ceux qui uagent à la surface de l'eau avec des moignons de bras.

HÉVICARPE, s. m. , hemicarpus

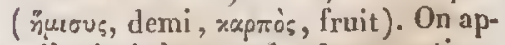
pclle ainsi chacune des deux portions d'un fruit quise partage naturellemient 
en deux moitiés, comme cclui des Ombellifères.

MÉMICHAMINASPISTES, adj. et

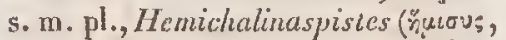

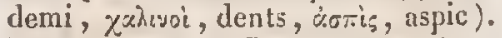
Nom donné par J.-A. Ritgen à un groupe de reptiles ophidiens, comprenant ceux qui ont it la mâchoire supélieure des dents percées et d'autres qui ne le sont point.

HÉMrCHALnOHULES, adj. ct s.

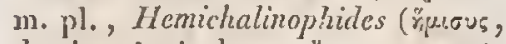

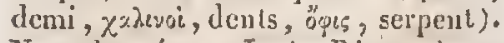
Nom donné par J.-A. Rilgen ì un groupe de repliles ophidiens, eomprenant ceux qui ont des dents percées, et d'autres qui ne le sont pas, ì la mâchoire supéricure.

MÉMrunis:, adj., hemichrysus

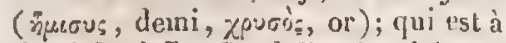
demi dorć. Le Cordy lina hemichrysa est ainsi appelé parce guc ses fcuilles sont couvertes en dessous d'un du. vet comme doré.

nüNuCrCLOSTOM:, adj., hemi-

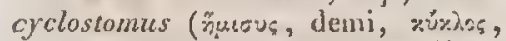
eercle, orópe, bouche). Se dit d'unc coguille univalve dont l'ouverture, à demi ronde, représente une sorte de guenle de four. Ex. Natica canrena.

IÉMCYCLOSTOMES, adj. et s. m. pl., Hemicy ulostomata. Nom donné par Blainville à une famille de coquilles, comprenant les univalves à ouverture demi-ronde, et ì une fímille de l'ordre des Paracéphalophores asiphonobranches, qui embrusse ccux dont la coquille a la nème forme.

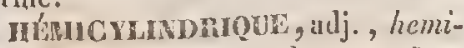
cylindricus, henicylindraceus (jutous, demi, xủh thète donnée aux hampes qui sont plates d'un côté et convexes de l'antre (cx. Allium tricoccum), ct aux fcuilles qui sont alongées, avec une face plane et l'artrc convexe (cx. Tjpha angustifolia).
MÓMDACTYLE, adj. , hemidac-

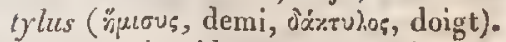
Le Falco hemidactylus est ainsi appelé parce qu'it al le doigt extérieur trìs-court; l'Eriodes hemidacty'lus, parce qu'il a aux mains antérieures un ponce tris-court, atleignant à peine l'origine du secoud doigt.

númbinomomirours, adj., hemidirhombicus (nuruos, demi, dis, deux, póp.jos, losange). Nom donné pur Mols à une combinaison de son système rhomboëdrique dans laquelle a disparu la moitić des faces des deux rlonloödres unis cusemble, soit celles qui sont parallèlcs aux autres, soit celles qui sont inclinécs sur elles.

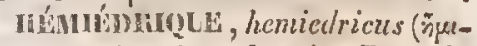
ous, deuri, Ẽpos, base). Daus la nomenclature cristallographique de Niumann, une forme lémicilrigue est la moilié du nombre total des faces d'une forme holoidrique (voyez ce inot) symétriquement partagéc.

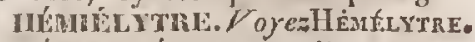

nÉMrExcúpHALL, adj. et s.m., homiencephalus ( dans, mę̧xiǹ, têtec). Nom donné par Gcoflroy Saint-Hilaire à un genre de inonstres, comprenant eeux qui, sans aucune trace d'organes de seus, ont un cervean à peu près normal.

nimbane, s. f. , hemigamia ( huu.cus, demi, yxuss, noces). Nom donnué par Tyinins an eas dans lequel uu calice de Graminée renferme it la fois des lleurs mî́les, des feinelles et des neiztres.

ILRAGONante, adj., hemigo-

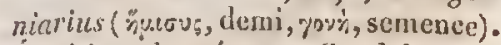
Epitlète donnée par Candolle aux fleurs doubles dans lesquelles une parties des organes des deax sexes se trouve changée en pétales.

ú́vuruxte, subst. m., hemigyrus ( צur vaux appelle ainsi le fruit des Protéacces, qui est souvent ligneux, déhiscent d'un sent côtć, non sytnétri- 
que, et à une ou deux loges monospermes ou dispermes.

IUEMULÉPIDOTE, adj., hemilepidotus (äjuovs, demi, $\lambda \varepsilon \pi i_{5}$, ćcaille). Lc Colus hemilepidotus cst aiusi appelé parce que son corps offre des bandes longitudinales l'écailles, sćparécs par d'autres bandes nues.

HÉNIL SSIEN, adj., hemilysianus

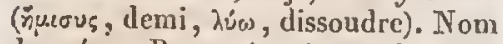
donné par Brongniart à une classe, et par Omalius i un ordre de terrains, comprenant ceux qui se sont formés en parlie par voie de sédiment, et en partie par voie de dissolution chinique. Ex. Traumales.

IIEMLLÉROPTKHes, adj. et s. m. pl., Hemincroptera (ñusous, demi, $\mu$ épos, partic, $\pi$ Épov, aile). Noun donné par Clairville à un ordre de la classe des inseeles, eomprenant ccux qui, avec un suçoir à la bouche, ont des demi-élytres.

IÉMIPOMATOSTONES, adj . et s.

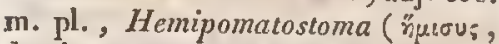

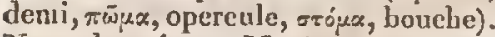
Nom donné par Menke à un sousordre de l'ordre des Gastéropodes eténobranches, correspondant aux Hémipomastomes de Férussac, aux Entomnstomcs de Blainville, et aux Buccinoïdes de Cuvier.

IÚMINOPTL̀nes, adject. et s. m.

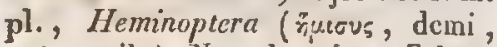
mrépoy, aile). Norn donné par Schæffer:à une classe d'insectes, comprenant ceux qui ont des élytres membraneuses à l'extrémité libre, eomme les Hémiptères.

HÉMIOLOGaMIE, s. f., hemiolo-

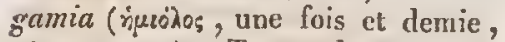
زrxus, noce). Terme dont Trinius se sert pour exprimer le cas des Graminées dans lesquelles un ealice renferme une fleur natle, une femelle et une hermaphrodite.

IIǴMIONITIDĹES, adj. et s. f.pl., IIemionitidece. Nom donuć par Gan- dichaud a une sections de la fanille des Fongères, qui a pour type le genre Hemionitis.

IĹLMLPALMLis, adj. et s. m. pl., Ilemipalmati. Sous ce nom, Lesson désigne un sous-ordre de l'ordrc des Eehassiers, comprenant ceux dont les doigts antérieurs sont courts et en grande partic réunis par une membrane natatoire.

HIEMIIPRISUATIQUE, adj. , hemi-

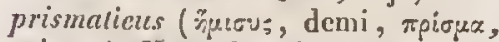
prisiuc). Nom donuć par Mohs aux combinaisons de son système pristnatique dans lesquelles il ne paraît que la moitié des faces.

IÉMIPTL̀RE, adject., hemipterus

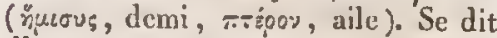
d'une plante ou d'un animal dont les ailes sont courtes, ou dont quelque partie du corps est chargéc d'une ailc courte. Lc Plerocarpus homiptera a le sommet de son fruit élargi en une aile membrancuse. Lc Trichius hemipterns et la Nitiduli hemiptera ont des élytres très-courtes. I La Coryphcena hemiptera a la nageoire dorsale courte.

HÉNPTLiRES, adj. et s. m. pl. , Homiptera. Nom donné, depuis Linné, par lous les entomologistes, Fabricius exeeplé, à un ordre de la classe des Inscetes, eomprenant ceux qui ont la bouche en suçoir et les ailes couvertes par des hémélytres, c'estì-dire par des élytres dures à leur base et membraneuses à leur sommel.

IÚWHPTH́ROLOGE, s. f., hemiptcrologia. Traité sur les insectes hémiptères.

HEMIPTÉROLOGIQUE, adj . , hemipterologicas; qui a rapport à l'hémiptérologic.

HĹMPTEROKOGUE, s. m. , $h c-$ mipterologns. Naturaliste quis'occupe spéeialement de l'histoirc des insectes hémiptères.

ILÉMIRHONDOENRIQUE, adject. , hemirhomboedrieus. Épithète par litquelle Mohs désigne les combinaisons 


\section{HÉMI}

de son système rhomboëdrique dans lesquclles a disparu la moitié des faces, soit cclles qui sont parallèles aux autres, soit celles qui sont inclinéces sur elles.

HEMISALAMANDRES, s. f. pl., Hemisalamandra. Sous ce nom, Goldfuss désigne unc tribu de l'ordre des Reptiles batraciens, comprenant la sirc̀ne et le protée, qui se rapprochent à beaucoup d'égards des salamandrcs.

IÚMISPIÚRAL, adj., hemispha-

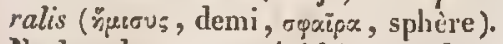
Necker donnc cettc épithètc aux deux valves demi-sphériques qui embrassent les corpuscules reproducteurs du Targionia.

HÉMispIÉneUe, adj., hemispharicus; halblugglign (all.); qui a la forme d'unc deni-sphère, e'est -idire de la moitié d'un globe par le centre duquel passerait nn plan, conme la cupule du Quercus Robur, l'involuere de l'Anthenis tinctoria, l'ombelle du Scandix infesta, le stigmate du Hyoscyamus aureus.

IÉMISPIÉROEDIQUUE, adject., hemisphacroedricus. Nom donnć par Wciss ausystème de cristallisation \&́ trois axes égaux cntr'cux daus lcquel il n'existc que la noitić des faces exigées par la synnetrie.

IIEMISYNGYNIQUE, adj., hemi-

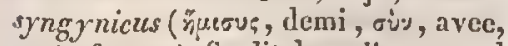

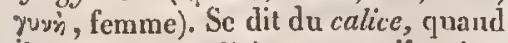
il est à demi adhérent avee l'ovaire.

nÉMTt́rie, s. f., homiteria (n̈pt-

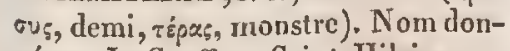
né par 1. Geoffroy Saint-Hilaire áux déviations ou anomalies organiques simples et pcu graves sous le rapport anatomique, soit qu'il n'cn résultc aticune difformité, et alor's clles produisent les variétés, soit qu'elles cn oecasionent umc, et alor's clles constituent les vices de conformation.

HúMTOME, adject., hemitomus

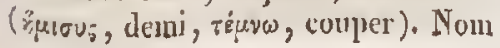

donné, dans la nomenclature minéralogique de Haüy, à unc variété de chau x earbonatćc, composée du dodécaëdre métastatique et d'un rhomboïle dont les faces rencontrent la partie de l'axc de ce dodécaëdre quì excède l'axe du noyau, à moitié de sa hauteur.

IULMTRrotene, adj., hemitri-

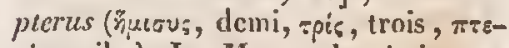
pò, ailc ). Le Murex hemitripterus est ainsi appelé parec que sa coquille se prolonge d'un eôté en trois ailes.

IIÉMITROPN, adj., hemitropus

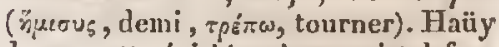
donne ectte épithète à un cristal formé de dcux noitiés réunies ensemblc régulièrement, maisen sensinverse de leur position naturelle, comme si la supćricurc avait subi une demi-révolution sur l'inféricure.

IĹMTROPIE, s. f., hemitropia. Résultat de cristallisation qui produit les cristaux appelés hémitropes.

HÉMOPTÉRE, adj., hemopterus

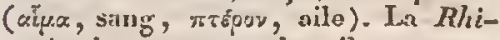
notia hamoptcra a les élytres couverles de poils d'un fauve doré.

HÉvORRHOLDL, adj., hamom rhoidalis, homorrhaus (aije, sang, ṕós, eours). Plusieurs animaux ont recu ectle épithète, indiquant qu'ils ont la partie postérieurc de l'abdomen d'un roux fauve ou rouge, comme si elle ćtait salie par un écoulcment de sang (cx. Apis hemorrheca, astrus hamor. rhoidalis, Mruscicapa hamorrhousa). Une plante (Serratula arvensis) est nommée chardonihémorrhoidal, parce que la piqure d'un insecte (Cynips Scrratula ) fait naître sur ses liges des renflemens rouges qu'on a comparés à des hémorrhoïdes.

IIENDÉGAGNE. Voyez ENDÉCAGYNE.

IIENDÉCANDRE, VOY. ENDÉCANDRE.

IIENDŔ, GAPHLLE, Voycz ENDÉCAPUYLLE, 
IIENNISSEMENT, s. m., hinnitus; Wiehern (all.); neighing (angl.); nitrito (it.). Gri ordinaire du cheval.

IIÉPATIQUE, adject. , hepaticus ; leberbraun (all.); qui a la coulcur du parenchyme du foic, comme le $\mathrm{Cu}$ culus hepalicus, qui est roux, l'Oliva hepatica, quiest d'un roux brunâtre, la Cytherea hepatica, qui est blanchâtre, avec des taches roussâtres, la Linaria hepatica, qui a des corolles rousses ou d'un rouge sale. Hipatique signifie aussi, qui a rapport au foie : c'est dans ce sens qu'oa dit Fasciola hepatica, parec que eet animal habite la vésieule dı fiel.

IIÉPATIQUES, adj. et s. f. pl., IIepatice, Muscilicpatici, Musciecalyptrait, Eealyptrocarpa, Jungermannia ; Lelscrmoose (all.). Rangécs par les anciens bolanistes, Limé compris, en partie parmi les mousses et en partie parmi les algues, les Hépatiques unt été érigées pour la premic̀re fois en famille dislinete par Adanson, que suivirent à peu près Jussieu et Schreber. Depuis, Willdenow et Sprengel ont coupé en deux cette famille, dont les limites ont beaucoup varié ensuitc, Les principaux botanistes qui s'en sont occupés sontDickson, Ehrhart, Hedwig, Hooker, Libert, Martius, Nees d'Esenbeek, Palisot - Beauvois, Radui, Sehmiedel, Schwagrichen, Swallz, Schrader, Weber, Weiss et surtont Reichenbach.

HEPLALIDES. Voyez Hiplalites.

HúpLLITws, adject. ct s.m. pl., Hepialites. Nom donné par Cuvier et Latreille à une famillc de Lépidoptères nocturnes, qui a pour type le genre Hepialus.

HEPIACANTIE: adj.; heptaean-

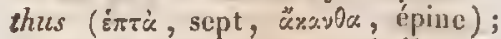
qui a sept épines. Le Clecilodipterus heptacanthus offre scpt rayons aiguillonnés à sa première nageoire dorsale.
HEPTADACTYLE, adj. ; hepta-

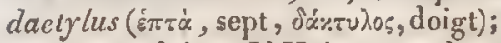
qui a sept doigts. L'Holocentrus heptadactylus a sept rayous aux catopes.

HEPTAGONE, adj., heplagonus

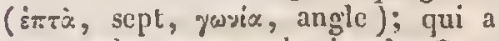
sept angles, conme la tige du Cactus heptagonzs et la spire de la coquille du Fusus heptagonus.

HEPTAGINE, s.f., heptarynin

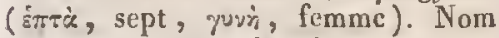
d'un ordre d'une des classes du système de Linnć, comprenant des plantes qui ont sept pistils.

HEPTANDRE, adj. , heptander,

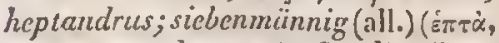
scpt, ¿xrip, honme). Se dit d'une plaute qui a sept ćlamines. Ex. $E s$ culus Hippoeastanum.

IIEPTANDRIE, s. f., heptandria. Nom d'uue classe et d'un ordre, dans le système de Linné, renfermant des plantes qui ont sept ćtamines.

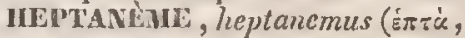
sept, угіна, fil); qui a sept tentacules. Ex. Cyanca heptanema.

HEPTANTIERĹ, adj., heptanthe-

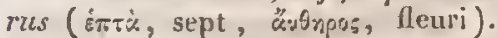
Nom donné par Gleditsch aux plautes qui ont sept étamines.

HEPTAPETALE, adj., heptapcta-

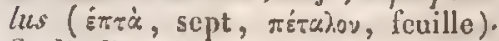
Se dit d'une planie dont la corolle cst composée de sept pétales. Ex. Sedum leptapetalum.

IIEPTAPUYLLE, adj., heptaphyl

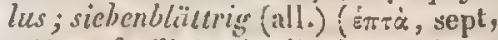
yìnov, feuille). Se dit d'une plante dont le périgone est composé de sept folioles (ex. Lonchocarpus heptaphyllus ), ou dont les feuilles pennées sont lormées de sept folioles (ex. Sophora heptaplyzlla, Bombax hcptaphyllumi).

nEPTARINE, adject., heptarints

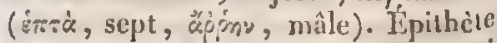
donnée par Necker aux planies qui ont sept élamines.

HEPTASEPALE, adj., heptasc- 
palus. Se dit du calice, quand il est formé de sept pièces distinctes.

HEPTASTLMONE, adj. , heptaste-

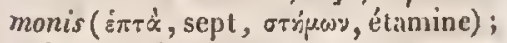
qui a sept ćtomines.

IIELBACE, adjeet., herbaeerts; krautartig (all.); erbaceo (it.). On appelle plantes herbacíes celles dont la tige et les branches, qui ne produisent pas de bois et qui périssent après quelques mois de végétation, sont revêtues d'une écorce ordinairement vertc, ayant la consistanec des feuilles, un tissu peu serré, mou, tendre ct incapable de résister à la gelée (ex. Tetragonia luerbaeea, Dorycnium herbaceuin). On donne cctte épithète aux parties des végétaux qui sont d'un tissu verd, comparable à celui des feuilles, comme lo périanthe du Daphne Laureola ct les spathelles du Milium effusum.

UEMBE, s. f., herba; Kraut (all.); erba (it.). l'lante dont latige, molle et analogue aux feuilles pour la consistance, périt après avoir végété pen. dant quelques mois. Tschudy a employé le mot de herbe comme synonyme de tissu cellulaire végétal.

HERBELLIDÉES, adj. et s.f.pl., Herbellidece. Nom donné par Robinenu-Desvoidy à unc tribu de l'ordre des Myodaircs micromydes.

IIERBICOLE, adject., herbicolus (herba, herbe, colo, habiter). La Sylvia herbicola habite les campagnes couvertes de grandes herbes, au Paraguay. La Delia herbicola vit dans les prés.

IERBICOLES, adj, et s. f. pl., Herbicolce. Nom don né par RobineauDesvoidy a une section de la tribu des Myodaires mćsomydes anthomydes, compienant les espèces qu'on trouve dans les herbes des prés et des bois.

IIERBIER, s. n., herbarium, hortus siceus; Kräuterbueh (all.); herbal (angl.); erbolario, crburio, crba- rolo (it.). Collection de plantes desséchées au moment de leur fleuraison et de leur fructification, ct avec assez de soin pour qu'elles conscrvent autant que possible leur forme et leurs caraetères.

IERHICICATION, s. f, , herbificatio. L.-C. Kichard se servait de ce terme pour désigner tout ce qui a rapport aux organes de la conservation des végélaux.

HELHU:ORnE, adj., herbiformis (herba, herbe, forma, forme). On a donné cette épithètc aux poils du Paresseux didactyle, parce qu'ils resscmblent à de l'herbe sc̀che.

IIERBIVORL, adj., herbivorus ; тonpónos (herba, herbe, voro, manger); qui se nourrit de végétaux.

HEnBIVoltes, adj. et s. nı. pl., Herbivora. Nom donné par Cuvier, Eichwald et Latreille à une famille de Mammiféres célacés, et par Duméril à une famille d'inscctes Coléoptères, comprenant des animaux qui font leur nourriture principalc ou exclusive de végćtaux.

INEBORISATION, s. f. , herbarum inquisitio; erborizzazione (it,), Promenade ou voyage dont le but est de recueillir des plantes et de les observer sur place. On employo aussi ce terme comme synonyme d'arborisation. Voyes ce mot.

IÍ́nssé, adj., hirtus, hispidus, hirtellus, hispidulus, liystrix, strigosus, echidneus, echinalus, echinulatus, ericialus, erinaeeus, asperellus; borstig, hackerig, stachlich (all.). Terme très-vague, qu'on emploie : $1^{\circ}$ en Lolavique. Il désigne des plantes ou des parties de plantes qui sont couvertes, snit de poils raides, longs et droits, comme la lige du Dancus hispidns, de l'Onosmodium hispidam et du Potentilla lirka, la tige ct les feuilles du Chondrosium hirtum, les feuilles du Pisonia hirlclla et de l'Ischomum hispidum, l'in- 
volucre du Fimbristylis hirtella; soit d'aiguillons grêles et nombreux ou rapprochés, comme les folioles calicinales du Paronychia echinata, les feuilles de l'Arctopus echinatus, les fruits du Bignonia echinala et de l'Oncidium echinatum, les épis du Chrysurus cchinalus, la face infórieure de l'Hericium crinaeeum; soit enfin de verrues, comme la tige du Columnea hispida, on de granules comme la surface du Conoplea hispidula. L'Elymus hystrix est ainsi appelé a eause de sa rudesse générale, I'Aspalathus hystrix, l'Oncophorus strigosus et le Grimmia strigosa, paree que leurs feuilles ressemblent a des épingles; le Chara hispida et le Poa hispida, parce qu'ils sont entièrement couverts d'aiguillons dúliés. $2^{\circ}$ En zoologic. Hispidc exprine la même idée qu'en botanique, et désigne une surface couverte ou de poils assez longs, serrés, un peu raides et durs an toucher, comme ceux qui hérissent le corps du Staphylinus hirlus, de la Phalana hirlaria, du Pilumnus hirlellus, de la Dromia hirsutissima, et les divisions de la Flustra hirle; ou de petits piquans, d'épines courtes, comme le tesi du Sicnopus hispidus et de l'Arcania erinaceus, les tubcs de la Clavagella echinata, la eoquille du Murex erinaceus, de la Fistulana echinata et du Cerithium echinatum, les étoiles de l'Oculina echidnca. La Spongia cchidnea est ainsi appelée à cause de ses rameaux droits, raides et épineux; la Chama echinulala et la Chama asperella, paree que leurs coquilles sont garnies de petites écailles relevées; l'Oliva hispidula, paree que sa spire est pointue.

IIÉRISSONNÉ, adj. , erinaeens, hystrioosus; couvert d'épines ou d'aiguillons grêles, flexibles, nombreux vu rapprochés. Voyez Hínissé.

IIERMADEES, adj. et s. fi. pl.,
Hermadea. Nom donné par Reichenbach à une tribu de la famille des Araliacées, qui a pour tye le genre Hermas.

HERMANVIACÉES, adject. et s. f. pl., Hermaniniaece. Non donné par Kunth à une tribu de la famille des Buttnériacées, ayant pour type le genre Hermannia.

HERuANvífes, adj. et s. f. pl. , IIermanniece. Nom donné par Auguste Sain t-Hilaire à une tribu de la famille des Malvacées, par Candolle à une tribu de cellc des Butlnériacées, ayant pour type le genre Hermannia, et que Jussieu, d'après Veutcnat, a érigée en famille.

neriapirode. Voyez Herma. PHRODISME.

IIERUAPHRODISUE, s. m., hermaphrodismus, hermaphrodisia, fabrica androgyna (Epur.,5, Mercure, À iproditn, Vénus). Réunion complète des deux sexes chez le mème individu. Cet état de choses est naturel dans beaucoup de plantes et d'animaux; mais parfois aussi, ehez ces dernicrs, il résulte d'une anomalie qui fail que les conditions organiques des deux sexes se trouvent réunies d'une manière plus on moins complète chez un mème individu appartenant à unc espèce où elles sont naturellement dévolues à des individus séparés.

IERMAPHRODITE, adject. et 's. m., hermaphroditus, bisexuinus, gynandrus, androgynus; gouxupóds-os; Zwitter (all.); crmafrodilo (it.). Se dit d'une planie qui réunit les deux sexes dans une même fleur, et d'un animal qui possède les deux sexes, surtout quand il est en ćtat de se féconder liii-même.

IERMAPIRODITES, adject. et s. m. pl. , Hermaphrodila. Nom donné par Latreille à une sous-classe de la elasse des Gastéropodes, comprenant les espèces hermaphrodites avee aecouplement réciproque; par Blinin- 
ville, à une section de la elasse des Céphalophores, embrassant ceux qui ont les sexes distiuets, réunis sur un même individu; et par le même, à une section de la classe des Paracéphalophores, où il range ceux qui se suffisent à cux-mêmes dans l'acle de la reproduction.

HERMOGRAPUE, s. f., hermo-

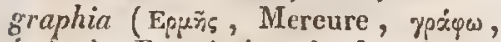
éerile). Deseription de la planète Mercure.

IIERMOGRAPHIQUE, adj. , hermograplicus ; qui a rapport i la deseription de Mereure. Sehroter a publić des fragmens hermographiques.

inernavia ches. Ýgez HerNANDIÉES.

IERNANDIÉES, adjeet. et s. f. pl., Hcrnandica. Famille de plantes, proposée par Blume, et ayant pour type te genre Hernandia.

HÉlionLECTORES, adj. et s.m. pl., Heroalectores (xipúdtos, héron,

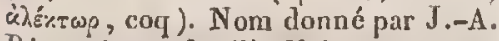
Ritgen à une famille d'oiseaux, comprenant ecux qui, comme le Psophia et le Palamedea, se rapprochent des Hérons et des Gallinacés.

IILRODIENS, adj. et s. m. pl., Herodii, Herodiones (ripúsios, hér'on). Nom donné par Illiger, Vieillot, Goldfuss, Lherminier, Ranzani, Eichwald, C. Bonaparte et J.-A. Ritgen, à une famille de la elasse des oiseaux, qui eomprend les hérons et les genres voisins.

IIEPPLECTORIDES, adj. et s. m. pl., Horpalcctorides ( $"$ p $\pi \omega$, ram-

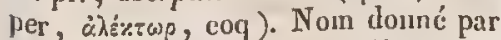
J.-A. Ritgen is une famille d'oiscaux, qui comprend les pigeons.

IERPOGHOROPTEvis, adj. et

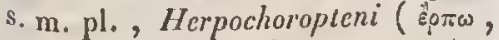

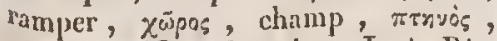
volatile \}. Noon donné par J.-A. Ritgen ì une famille d'oiscaux vivant dans les champs, qui renferme les pigeons.
HERPYLES, adject. et s. m. pl., Herpyla ( $"$ sp $\pi \omega$, ramper ). Nom sous lequel J.-A. Ritgen désigne une famille de Reptiles ophidiens, renfermant eerx qui rampent sculcment, comme les orvets.

IIERSECR, adj. , craticrss. Épithète donnée ì une araignée (Mygale craticns) qui a le bout des tarses garnis en dessous d'une brosse épaisse et serrée, en forme de herse.

IIESPÉRIDĹES, adj. et s.f. pl.,

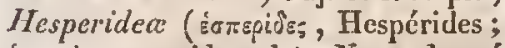

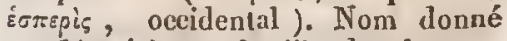
par Linné à une fumille de plantes, que Jussicu a adoptće, et qui renferme les orangers, dont on suppose qu'était rempli łe jardin my thologique des Hespérides. Reichenbach eomprend sous ee nom les trois familles des Léeacées, des Mćliées et des Aurantiacées.

IIESPÉUIDES, adj. et s. m. pl., Hcsperida, Hcsperides. Noun sous lequel Latreille et Eichwald désignent une tribu, Leach et Swaiuson une famille d'insectes lépidoptères diurnes, ayant pour type le genre Hesperia.

IIESPERIDIE, s. f., hesperidium. Desvaux appelle ainsi, parce qu'il apparticnt aux plantes de la famille des Hespéridées, un fruit charnu, à enveloppe consistante et munie de grlandes vésiculaires, qui est divisé intéricurement en plusieurs loges membrancuses, suseeptibles de se séparer sans mul déchirement.

IIES1'ÉRIJINE, s. f., hesperidina. Lebreton donne ce nom it une nıatière parliculière et eristallisable ${ }^{\circ}$, qu'il a retirée des oranges non à maturité.

IIESPÉRILS-SPIITX, s. m. pl. , IIcsperi-Sphinges. Noun donné par Latreille à une tribu de la famille des Lépidoptères nocturnes, comprenant ecux qui tiennent à la fois des Hespéries et des Sphinx. 
iéteracantie, adj., hetcra-

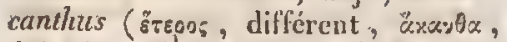
épine ); qui a des épines différentes. Le Capparis heteracantha a des stipules epineuses, dout l'nne est droite et l'autre uncinéc; l'Echinospermum hcteracanthum a ses caryopses garnies de glochides disposćes sur deux rangées et dissemblables.

MÉTHRANDRE, adj. , heterandrus ("̈твро , différent, ùvip, homme). Se dit d'une plante dont les étamines ou les anthères sont de forme différente. Ex. Solantum hetcrandrum.

HÉTÉRANTIU, alj., hctcranthus

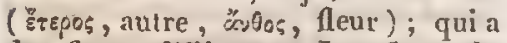
des flcurs différentes. Les fleurs du Viscum heteranthum sont disposées de manicre qu'il $y$ en a unc centrale, et que les autres sont verticillées autour d'elle.

HÉTÉROBAPUIE, s. f. , heterobaphia; Vielfärbightcit (all.) ("̈rвpos, différent, $\beta$ axp̀n, couleur). État d'un corps dont la surface est de deux ou plusieurs conleurs.

mETt́́nobmaxGnes, adj. et s. m. pl., Hctcrobranchiata (ह๊ंรрos, différent, Bpiryesx, branchies). Nom donné par Latreille à une tribu de la famille des Siluroïdes, comprenant des poissons dont les branchies sont accompagnées d'appendices ramifiés; par Lamarek à un ordire de la classe des Crustacés, dans lequel il range ceux qui ont les branchies très-diversiffées sous le rapport de la forme et de la situation; par Blainville à un ordre de la classe des Acéphalophores, cmbrassant des animaux dont les branchies varient quant à la forme.

nĹTĹmocanPE, adj. , hctcrocar.

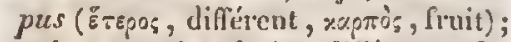
qui porte des fruits différens. On donne cettc épithète à la calathide des Synanthérées, quand elle offre des ovaires ou des fruits dissembla-

\section{HÉTÉ}

bles, soit par eux-mèrnes, soit par leurs aigrettes (ex. Heterospcrmuin pinnalum); le Dcsinodium hetcrocarpum est ainsi appelé paree que ses épis portent en bas des gousses rondes et monospermes, en haut des légumes ì six ou sept articulations, dont ehicune renferme une scmence.

HÉtúmocarpiEv, adj., hetcrocarpinus ( fruit). Desvaux donne cette épithète aux fruits provenant d'un ovaire développé conjointement avce quelque partic qui, sans le cacher entièrement, modifie sa forme primitive. Ex. Quercus.

HÉtÉROCEILDES, adj. et s.m. pl., Heterocerida. Nom donné par Macleay à une famille d'insectes coléoptères, qui a pour type le genre Hctcroccrus.

HÉCÉROCHL̀E, adj. , heterochclus ( dit d'un erustacé qui a un bras plus grand que l'autre. Ex. Alciope heterochcliss.

IIÉTŔROCHÈLES, adj. et s. m. pl. , Heterochela ( pinee). Nom donné par Latreille à une section de la famille des Crustacés Décapodes Brachiures, comprenant ceux chez lesquels les serres des matles sont notablentent plus longue que celles des femelles.

HE்TÉROCLITE, adj., hcterocli-

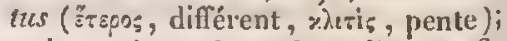
qui ne suit pas la règle ordinaire. Se dit des plantes qui ont les sexes séparćs, qu'elles soient monoïques or dioïques.

HÉTÉRocures, adj. et s. m.pl., Hctcrocliti. Noun donné par Lesson à une fainille de l'ordre des Gallinacés, renfermant un scul oisean (Sirrhaptcs helcroclitus), qui est d'un type bizarre et anomal.

IIEThnocniciens, adj. et s.m. pl. , Heterocricii ( $\varepsilon z$ zpos, différent, rọizos, anneau). Nom donné par 
Blaninville à $m$ ordre de la châsse des Chétopodes, comprenant eenx de ces animaux dont les annenux da corps sont très-différcns les uns deś autres.

WĹTĹnODACTYLE, adj. et. s. m. pl., Heterodactyli (ëtzpos, différent, Sáxtuhos, doigt). Nom donné par Blainville à une fimille del'ordie des Grimpeurs, cumprenant des oiscaux dont le doigt externe est versatilc.

HÉTẺrodERMES, adj. et s.m. pl., Hetcrodermala (žrępos, différent, déprex, peau). Nom donné par Blainville à une division de la sousclnssc des poissons gnathodontes, comprenant ceux dout la peau est de structure variable; par Duméril ì une famille de reptiles ophidicns, renfermant ccux qui ont des ćcailles sur le dos el des plaques sous la queue et le ventic.

IÉTERODONTES, adj.et s. m.pl.,

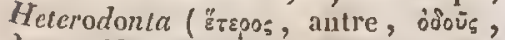
dent). Nom donué par MIuller à une famille de reptiles ophidiens, comprenant ccux qui ont quelques unes de leurs dents maxillaires plus grandes que les autres.

mítínODOXE, adject., heteredoxus. Eipithćlc donnće par Iinné aux botanistes qui ont fondé leurs méthodes de elassification sur la considćration de toute autre partic que celles de la fructification.

métínogame, adj. , helorogamres (z̈rzpos, différeul, yźuss, nonces). Otl donne celte épithcitc, d'après Candollc, aux plantes qui ont des flcurs monoöques, dioïques ou Polygames; d'après Trinius, anx ealircsides Graminćes polygames; d'aprè̀s I sessing, aux capitules des Synanliérćes, lorsqu'ils renferment des lleurs de sexes différens. Le Geranium helerogamum n'a que six élamines fertiles, au licu de sept.

HétŔROGAHE, s. f., heterogamia. Trinius désigne ainsi le cas des Graminées dans lesquelles un calice renferme des fleurs liermaphrodites et un autre des femelles ou des mâles seulement. Ex. Rottboellia.

InÉTÉnOGÈNE, adj. , heterogenus; غ̇vop.osopsin่s; ungleichartig

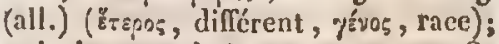
qui n'est pas de la même nature. Se dit, en minéralogie, de la texture d'unc roche, quand les parties qui la constitucnt diffèrent de nature ou. d'aspect.

MétrínogúNúrté, s. f., helcrogeneitas; Ungleichartigkeit (all.). Qualité de ec qui est hétérogéne.

IÉTÉROGiNes, adj.ets.m.ctf. pl., Helerogenci. C. Prevost ct Brongniart désignent sous le $110 \mathrm{~m}$ de roches hétérogènes une classe de mélanges natmrels, fréquens, constans et en masscs étendues, de minnéraux apparlenaut soit à des especes rigoureusemen! déterminées, soit à des espèces imparfaites, qui ne peuvent étre rapportèes ì :ncune des premičrcs. Ce nom est donné aussi par Aeharius à un ordre de la elasse des Lichens idiolhalames, coniprenaut ceux dont les conceptac!cs contionnent un noyau renfermé dans un perithćcion; par Bory à un ordre de Phytoz.onires, dans lequel il comprend ceux qui se composent d'unc couche animalc et d'une couclie calcaire, et dont l'animalité est répandue dans tout l'ensemble de l'ètre, mais qui ue sont ni polypes, nizoocarpes.

IÉtrínogúvìse, s. f., hctero-

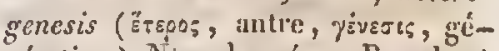
uération ). Nom donné par Bresche! à une classe de déviations organiques, comprenaut celles dans lesquelles il existe une anomalic relative soit à la silualion on à la couleur des organes, soit au nombre ou à la situntion des fotus apparlenaut à une même gestation, soil ì la situation ou au nombre des organes en particulier. 
Héténoglivie, s. f., heterogenia

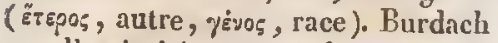
appelle ainsi (generatio heterogenea, aquivoca, primiliva, originaria, primigena, spontantea; ungleicharlige Zcugung, all.) la production d'un être vivant, uon par des individus de même espèce que lui, inais par des corps d'une autre espèce, soumis à l'influence de certaines eircoustances. C'est ce qu'on nomme communément génération spontanée.

HÉTÉROGONE, adj., heterogonits (ërzрos, autre, ywyia, angle). La Spongia helerosiona est eontournée en tubes imparfaits.

IIÉTh́ROG lNEs, adj. et s. m. pl., Heterogyna ("̈твро;, antre, 'yư⿱ femme). Nom donné par Latrcille et Eichwald à une famille de l'ordie des Hymćnoptères, eomprenant des insectes parmi lesquels on trouve des individus de plusieurs sortes, des mîles, des femelles et des neutres.

IÉTÉROHYLES, adj. et s. m. pl.,

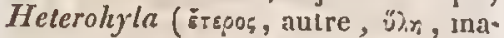
tière). Nour donnc par Schweigger à une section de la classe des Zooplaytes, par Eichwald à un ordre de celle des Phytozoaires, comprenant ceux de ces animaux dout le corps cst formé d'une substance non homogèue.

HÉTÉROLE , heteroideus ; andersgestalten (ह̈repos, autre, हi்os, forme). L.-G. Richard s'est servi de ce mot pour désigner les organes qui varicnt pour la forme sur un même individu, conme les feuilles di Broussonetia papyrifera.

ПĹTÉROLOBE, adj., heterolobus

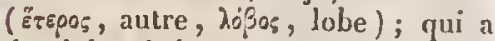
des lobes inégaux, comme ceux des feuilles du Pelargonium heterolobum.

IĹtÉRorYTiRes, adj. et s. m.

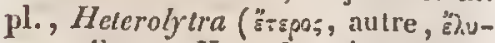
tpo\%, élytre). Nom donné par Goldfuss, Ficinus et Carus à unte famille de l'ordre des Colćoptères, compremant ceux de ces inscctes dont les tar- ses n'ont pas le même nombre d'articles à tous les pieds.

mÉTÉROMALLE, adj. , heteromallus; allseitswendig, vielwendig

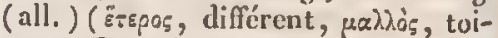
son). Dont les eôtés sont différens par le poil. Se dit d'une plante qui a les feuilles tournécs de tous les eôtés. Ex. I eissia heteromalla, Dicranum heteromallum.

MÉTÉROML̀RE, adj. , heterome-

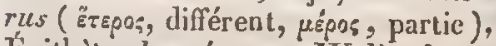
Épicliète donnée par Wallroth au thalle ou blastème des lichens, quand il est composć de plusieurs couches différentes.

HúTÉRONkRES, ad. ct s. m.pl., Heteromera, Heteromeri ("̌sรos, dif-

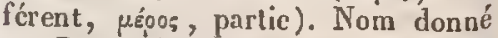
par Lamarck, Cuvier, Duméril, Latreille et Eichwald à une section de l'ordre des Coléoptères, comprenant ceux de ces insectes qui ont cing ar ticles aux tarses des pattes de devant, cing à ceux des pattes intermédiaires, et quatre seulement à ceux des pattes de derrièrc.

IÉTÉROWORPHE, adj., hetero* morphus; verschiedengreslaltet (all.)

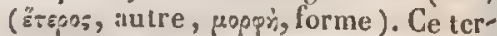
me peut être employé , en opposition à cclui d'isomorphe, pour désigner des corps qui contiennent un même nombre d'atômes des mêmes élémens, mais autrement arrangés, d'où résultent des différences dans leurs propriétés chimiques et leurs formes cristallines. 'Tel est entr'autres le eas des acides phosphorique et paraphosphorique. Les entomologistes disent les palpes hétéromorphes, lorsque les deux articles intermédiaire ${ }^{\xi}$ sont beaucoup plus longs que le pre unicr et le dernier (ex. Cerocoma).

HE்TÉRONORPuEs; adj. et s. m. pl. , Ileteromorpha. Nom donné pat Lamarck à une section de la classe des Vers, comprenant ceux dont le corps est souvent difforme; par Blain: 
ville à un sous-règne du règne animal, daus lequel il range des animaux qui ont une forme irrégulière.

ILTínomyzines, adj. et s.f. pl., Heteromyzides. Nom donné par Fallen à unc famille de l'ordre des insectes diptires, qui a pour type le genre Hetromyza.

Hútwín oviue, adj. , heteronemus (Ërsoos, autre, vingece, filct); qui a des filatnens inćgaux, comme les filets des étamines de l'Epacris heteronema, el les tentacules de l'Oecania lecteronema.

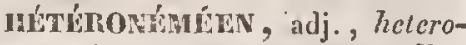

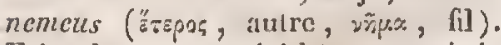
Fries donue cette ćpilhète aux végétaux néméens (voyez ce mol) dont les sporidies s'alongent, par la germination, en des filameus qui se réunissent pour produire un corys lićti:rogène, comune il arrive daus les fougères et les mousses. Cc not est synonyme de diplogéne, de cryplandre et de sporifere, ou du moinss'applique aux mèmes végétanx.

MeTrionoxie, adj., lecterono-

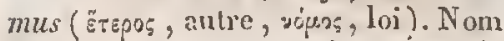
Couné, dans la nomenclature minéralogique de Haiìy, à une varićté de topaze dont le signe indique des lois de déeroissement qui ne se retrouvent dans aucune autre espèce connue.

IIĹtÉROPEs, adject. el s. m. pi.,

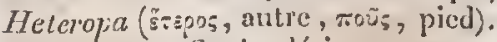
Sous ec nom, Cuvier désigne unc section, ct Latreille une fimuille de l'ordre des crustacés branchiopodes, eomprenanl ceux de ces animaux dont les quatre derniers pieds au moins sont mutiques et propres à la nalation.

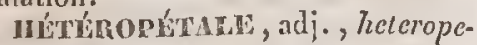

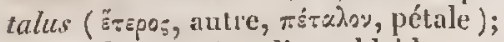
qui a des pétales dissemblabl s ou inégaux. Se dit de la ealathide des Synanthércies, quand clle offre des corolles dissemblables, comme lors- qu'elle est couronnée, soit radice, soit discoide. Le Mesembryanthemum heteropetalum a des pétales inégaux. IĹ rÉnOPIN LLE, adj, , heterophy llus; verschiedenblittrig (all.) (šepos, différent, ơं $\lambda_{0 \%}$, fcuille); qui porte des feuilles dissemblabics. Se dit d'une plante qui a toules ses fenilles de forme et de grandeur diverses (ex. Juglans heieroplyrlla, l'zucus discors), ou dont la forme des feuilles différe dans le bas et le hame de la tige (L'Actinea letcrophylla a les inféricures lisćatres et les supéricurcs lincéolées; le Celsia heicroplylla, les inférien"es ailées et les supérienres entic̀res; Ic Ionidium heterophyllum, les inféricures orales et les supérieures linéaires). Il se dit aussi des planles dont le fenillage variesuivant l'ige, soit prour la forme (ex. Lredia leterophy/la), soit pour la pubescence ( ex. Populus heteropleyllus, dont les feuilles, chargées d'un duvet blane des deux cớlós, dians la jeunesse, ne sont plus ciurctées qu'il leur face inféricure dans l'ânge avancé de la plantc). 11 se dit cufin d'une plaute ì feuilles verticillćes dont ehaque verticille en offre une pétiolée, ovale et incisće, tandis que les autres sont sessiles, linéaires et entieres (ex. Malernia leterophylla), ou d'une autre parmi les folioles de laquelle on en trouve d'orales, d'orbiculaires, el quelques unes qui sont presque linćaircs (ex. Clituria heteropleylla). Voyes DIversifoliz, Varurolić. L'Asgaricus heterophyllics est aiusi appclé parce que les ferillets de son chapeau sont bifurqués et raccourcis de moitié.

HÉTER phyllia. Etat d'une plante dout les feuilles diffèrent les unes des autres, sous un rapport quelconque.

nĹtícropones, adj. ct s. m. pl.,

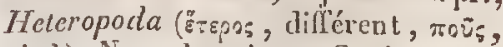
pied). Nom donué par Cuvicr à un ordre de la fauille des Gastéropodes, 38 


\section{4}

comprenant ceux qui ont le pied comprimé, ou nne nageoire mince et verticale; par Lamarck à unc famille dc Crustacés, à làquelle apprartiennent ceux dont les pattes de derric̀re servent i nager; par Blainville à une classe du regnc animal, dans laquelle il range les animaux articulés qui ont des appendices articulés en nombre variablc ; par le mêne à une division artificiclle de la classe des Microzoaires, comprenant ceux qui ont le corps pourvu d'appendiccs latéraux, tres-diversifiés pour la forme, qui servent à la locomotion on à quelque autre usage.

métúropons, adj., hetcroporus ( qui a des pores dissemblables, comme la Plexaura lecicropora, polypier dont les ouvertures des cellules sont dirigées dans tous les seus.

METÉROPSDE, adj., lecteropsi-

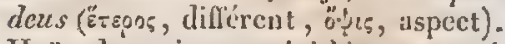
Hariy dounait celte épithète aux métaux quc la nature nous offre dans des états où ils sont privés de leurs proprićtés spéciales, notamınent de leur éclat.

nÉTÉRopride, adj., hctoropte-

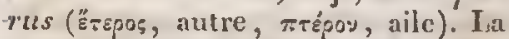
Callianira hoteroptera a de chaque côté dı corps une grande ailc ct six ntermédinires plus petites. L'Avicula heteroplesa a une aile très-obliqne. Lc Bibio heteroptera a l'ivaut-ilernière nervure de ses ailes reeourbéc ì l'extrénilć . et ne joignant pas la dernière. I'Amictus heteroptertes a les ailes extrèmement longues.

méturoptsins, adj. et s, m.

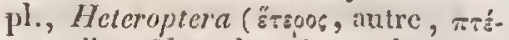
poy, aile). Nom donné par Blanville à unc famille de Gnathodontes liétérodctmes, comprennut des poissons qui ont des nagreoiles très-viriubles et sonvent nulles; par Cuvicr, Ia treille, Eiclswald, Ficinus et Carus it une section de l'ordre des insectes

\section{HETE}

hémiplères, comprenant ceux dont les élytres se terminent brusquement par un appendice membraneux.

IEThinOPYGL, adj., heccropy-

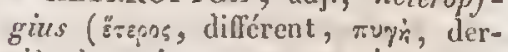
ric̀re); qui a une qnene singulic̀re. L'Ornismya heteropy'sia n'a que six rectrices ì la qucue.

HÉTÉRORUYNQUES, adj. et. s. m. pl., Heterorhynchi ( púfyos, bec). Nom donné par Lherminicr à unc famille comprevant des oiseaux qui diffèrent tous les uns des autres, mais se ressemblent d'ailleurs.

HÉTEROnOSTREs, adj. et $\mathrm{s} . \mathrm{m}$. pl., Hetcrorostres (Eัธะс05, différent, rostrum, bec). Nom donné par Lesson à une famille du sous-ordrc des Jćmipalnés, comprenant des oiseanx qui ont le bee anomal ou de forme bizarre.

núténoscres, adj. et s. m., heleroseius ( ombre). Epithète que l'on donne aux habitans des zônes tempérćes, parce qu'à midi ils ont lcur ombre différemment tournée dans les deux hénisphères.

mítúnosones, adj. et s.m. pl.,

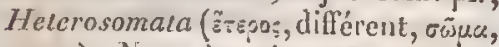
corps). Nom donné par Duméril ct par Blainville à une famille de poissons, comprenant ccux dont le côté droit et le côté gauche du eorps ne se resscmblent point.

núth́nostúmoNe, adj., hete-

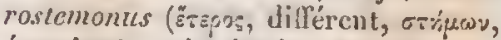
étamine); qui a des étamines dissemblables. Ex. Trembleya hetcrostemon.

WdeTrROSTIQUE, adj., hetcrosti-

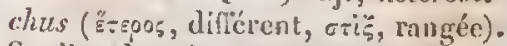
Se dit, dans la nomenclature minéralogique de Haiij, d'unc variété dans laquelle le nombre des rangées de facettes qui se succèdent sur unc partie surpasse de beaucoup celui des rangées situées sur les autres par- 
tics (ex. Baryle sulfatée hétérostique). Le Raeomitrium heterostichum est ainsi appelé paree qu'il a ses feuilles presque unilatérales.

HÉtELROSTOvE, adj., heterosto-

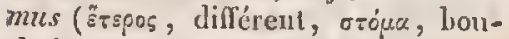
che); qui a une lrouche extraordinaire. Le Distoma helerostomzm offre un troisiène orifice an milieu de la longueur de sou ventre.

IUETLIOOSTHOHEL, adj., hete-

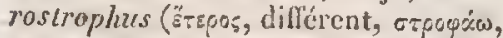
tourner). Se dit d'une eoquille spirivalve dout le bord terminal est ì gauehe de l'animal. Ex. Ploysa heierostropha.

"LTUROTAXE, s. f., heterolaxia

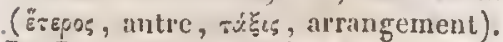
I. Geoffroy Saint-Hilaire appelle ainsi les anomalies complexes, qui, bien que graves sous le rapport anatomique, ne metient cependant obstaele à l'aceoruplissement d'aueune fonction, et ne sont point apparentes à l'extérieur.

IIETELIRTOME, adj., heicrotomus ( per). I.-C. Richard donne ce nom au périgone, lorsque ses divisions n'ont pas la mème forme.

HETEROTHIpUe, adj., heterom

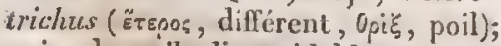
qui a des poils dissemblables. Le $G y$. nandropsis heterolricha et ic Ribes heterotrichum ont des poils dont les uns sont alongés et les autres glandulcux.

HithinothopE, adj., heterotro-

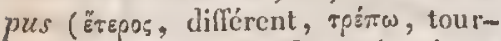
ner). I.-C. Richard employait ce terme pour désigner l'embryon dont la direction eoupe obliquement ou transversalement l'axe de la graine, aucun de ses deux bouls n'étant dirigé exactement vers le hile.

IrútẃnovaLve, adj, heterovalvatus ("zвpos, différent, valva, valve). Peyre appelle ainsi les fruits dont les valves sont dissemblablites.
IIEXA

míthozosures, adj. et s. m.

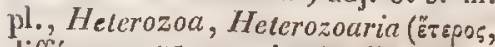

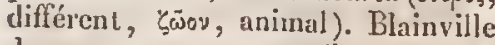
donne ee nom aux reptiles, à eause des différences nombreuses et essenticlles que présentent entr'cux les animaux compris dans eetle elasse. Eiehwald l'applique à une série du règne animal, eomprenant des animanx qui diffèrent beaucoup entre cux et de cenx des autres séries.

WÉRBinLE, adj., heterylus, he-

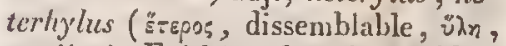
matière). Epithète donnéc par Moquin-Taudon aux oufs qui contiennent des sulistanees étrangères.

IHECHĆń́Es, adj. et s. f. pl., Heucherea. Nom donué pir Bartling à une tribu de la famiille des Saxifragées, qui a pour type le genre Heuchera.

ILURE, s. f., hora; ẅpx; Stunde (all.); lour (angl.); ora (it.). Vingtquatriène partic du jour. Ileure se prend aussi très-souvent pour temps.

IEXAGANTIE, adj., hexacan-

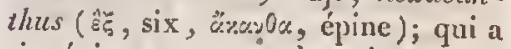
six épines, comne les six rayons aigus de la premic̀re nagcoire dorsale du Dipterodon hexaeanileus.

IEXACIRCWE, adj., hexacircinus (हैं, six, rigros, anncau). Lc Macropteronolus hexacircinus a six borlillons.

MEXACOQUe, adj., hexacoectes

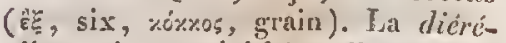
sile reeoit cette épithète, d'après Mirbel, quand elle est composće de six eoques. Ex. Triglochin maritima.

IrExACTE, adj, , hexactus ( $\hat{\xi} \xi$, six, axtiv, rayon ); qui a trois rayons ou trois stries longitudinales, comme le Pecten hexactes.

HEXADACTYLT, adj., hexadae-

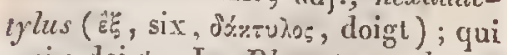
a six doigts. Le Platystacus hexadaetyius a six rayous aux nageoires pectorales. L'Orneades hexadactyla 


\section{HEXA}

a ses ailes divisées en six lanières ou doigts.

IIEXAGONAL, adj., hexagonalis ( $\hat{\varepsilon} \xi, \operatorname{six}, \gamma \omega v i x$, angle). Epithète clounée à un prisme qui a pour base un hexagone, c'est-à-dire six laees latérales. C'est un des neuf genres que Brochant adinet parmi les formes dominantes des cristaux. Lx. Talc hexagonal.

IIEXAGONs, adject., hexagonus;

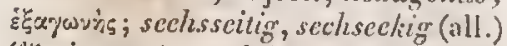
( $\xi \xi$, six, \%wvia, anglc); qui a six angles, comme la eapsule du Iritillaria impe. rialis, le corps du Lutjanus hexagonus, la lige du Cachus hexagonus, la coquille du Cerithium hexayonum.

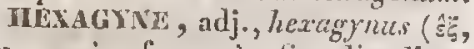
six, quvis, femme). Se dit d'une plante qui a six pistils.

IEXAGXNI, s. f., hexagjnia. Nom de deux ordres, daus te système de Linné, eomprenaut des plantes qui ont six pistils.

ILXAIrnnIQUE, adj., hexahydricus. Se dit d'un composé qui eontient six fois autaul d'bydrogerne qu'une autre combinaison de ee dervier corps avee la mème substance simple. Ex. Phosphurc hexalyydrique.

HEXALTPDE, adj., hexalcpidas

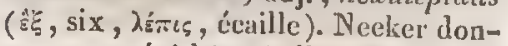
ne eette épithète ì l'involucre des Synanthérées, lorsqu'il est formé de six éeailles.

IIEXANDRE, adject., hexander, hexandrus; scchsmiinnisy (all.) ( $\mathrm{E \xi}$, six, ¿่visp, lomme). Se dit d'une planle ou d'une fleur qui a six étámines. Ex. Diplosodon hexander, Mimusops hexandra, Epimedium hexandrum.

ILXINDRIE, s. f., hexandria. Nom d'une elasse et de trois ordies, daus le système de Linué, comprenaut des plantes qui ont six étamines.

IFXANDRIOUE, adj., hexandricres; qui a sis étumiues.

HEXANEME, adjeet., hexanemus

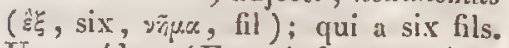
Une méduse (Faronia luexanenta) est ainsi appelée paree qu'elle a six bras.

HEXINGULALE, adj., hexanglllaris ( $\dot{\xi} \xi$, six, angulus, angle); qui a six angles, comme la tige du Spermacoce hexangularis.

IEXANTIERE, adj., hexantherus, hexanthereus ( हैं six, sinonpòs, fleuri). Nom donué par Gleditseh et Allioni aux plantes qui ont six étamines. Il conviendrait mieux à quelques espèees de Cascaria qui n'ont que six étamines pour douze an thères.

HEXAPE, adj., licxapres ( то\%; , pied ) ; qui a six pieds seulement, conme le Sepia hexapus, dont les deux dernières paires de pattes sont très-pelites. Seopoli appelait ainsi les papillons que d'autres entomologistes appellent hexapodes, e'est-à-dire ceux qui ont six pattes semblables, à peu près égales, et toutes propres à la marelie.

HEXALE'TALE, adj. , hexapetalus ( $\varepsilon_{\xi}$, six, ть́́ eorolle est lormće de six pétales. Ex. Perigala hexapeiala, Phebalium hexapetalum.

IEXAPÉTALÉE, adj. et s. f. pl., Hexapetalce, Hexapelali. Noin donné par Rivin à une famille de plantes, coinpicnant celles dont la fleur a six pétales.

HEXAPITLLE, adj., hexaphyllus ( périgone, d'un involucre, qui est composé de six folioles, et de plantes qui ont les feuilles pennées et eomposées de six folioles (ex. Rajania hcxaply.lla), ou verticillées six par six (ex. A sperula hexaphylla).

IIXXPODE, adjeet., hexapodus; qui a six pieds. Foyez Hexape.

IIEXAPODES, adj. et s. m. plur., Hexapoda. Nom donné par Latreille a une race d'animaux céphalidiens eondylopes, et par Blainville à une 
classe d'animaux articulés, comprenant ceux qui ont six pattes ; par Latrcille a une sous-tribu de la tribu des Papilionides, dans laquelle il rauge cenx de ces inseetes qui ont six pieds ambulatoires presque semblables; par Kirby à un sous-ordre de l'ordre des insectes aptères, renferJant ceux qui n'ont que six palles.

IIEXAPTEIEE, adj., hexapterus ( de six ailes, comme la capsule du Fritillaria imperialis. La Phaloenr hexaplera est ainsi nomméc parec que le muile semble avoir une troisième paire de petites ailes, les inférieures ayant auprès de leur naissance une espéce d'appendice couehé sur le dessus de ces ailes.

IIEXARIVE, adj. , hexarinus (埆, six, äpip̀, mâle). Epithète donnç par Necker aux plantes qui ont six ćtamines.

IIEXASÉPALE, adj., hexasepalus.s. Se dit d'un calice qui est composé de six pièces. Ex. Clemalis hexusepaia.

IIEXASPERYE, adj., hcxaspcrmus ( $\hat{\varepsilon} \xi$, six, orésps, graine) ; qui a des fruits renfermant six semences, comme les drupes du Pyrostria hexasperma, les pomunes du Trichosperma hexasperma.

IIEXASTh́丶HONE, adj., hexastenio-

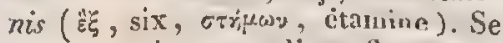
dit d'unc plante ou d'nne fleur qui a six étamines.

IIEXASTIOUE, adj. , hexastichtss; scchsscilig (all.) ( ${ }^{\hat{\varepsilon} \xi}, \operatorname{six}, \sigma \tau i \xi$, rangéc); qui a six rangées de graines, comme l'ćpi de l'Hordcun hexastichum, ou dont les feuilles sont disposćes sur six rangs, comme celles de l'Isothecium hexastichum.

IEXA TÉTIRAÈDIS, adj., hexa-

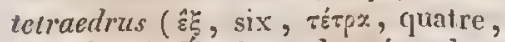
Ẻopx, base). Epithèle domnćc, dans la nonenelaturc minéralogique de Haïy, à unc variélé de chaux carbonatée ayant pour forme un cube dont chaque face porte une pyramidc tétrac̈dre.

HIANTICONouEs, adj. et s. f. pl., Ilianticoncha (hio, bitiller, concha, coquille). Nom donué par Latreille à une section de l'ordre des Concliifères tubulipalles, comprenant ccux de ces animaux dont la coquille est très-lnillante, du moins à l'uuc de ses extrémitc̉s.

InBBertianíles, adj. et s. f.pl., Mibbcrtianere. Nom donné par Candolle à une scetion du genre Plaztrandra, comprenant les espèces qui ont de l'affinité avee les Hiblicrlia.

mibmTrises, adj. el s. f. pl., Hibbertica. Nom donné par Reichenbaeh à une section de la famille des Dilléniacées, qui a pour type le gente Hiblertia.

nHBENNACT. culum; Wincrhaus (all.) (hy-bernus, d'hiver). Jinné désignait sous ce nom toutes les parties des plautes qui servent ì envelopper les jeunes jousses et a les garantir du froid pendant l'hiver, comne les bourgeons et les luulbes.

IIBLERNAI, adj. , hybcrnus; icmalc(it.). Ce cui a lien pendantl'hiver (température hivernale). Le $\mathrm{Ga}$ lanthus nivalis et l'Hellcborus hy'emalis fleurissent en hiver. C'est pendant ectle saison que le Larzs lybernus sp montre en Angleterre.

HIBEIRNNT, ndj., hibernans. On donne cctte épithete aux animaux qui passent unc partie de l'antomne ct l'hiver dans un état d'engourdissement et de léthargie, d'où ils ne sortent qu'à l'entrće du printemps.

HIBEIBNATION, s. f., Winicrschlaf (all.). Engourdissentent ou sommeil d'hiver des animaux chez lesquels a lieu ec phénomène plysiologique.

nIBISCLES, adj. et s. f. pl., $H_{i-}$ biscece. Reiehenbach désigne ainsi une tribu de la famille des Malvacées, 
qui a pour type le genre Hibiscus. IIńRACÉEs, adj. cts. f. pl., Hicracca. Nom donné par $\mathrm{D}$. Don à unc tribu de la famille des Chicoraeées, par H. Cassini à une section de la tribú des Laetucées, et par ILessing à une sous-tribu de la tribudes Chicoracćes, ayant pour type le genre Hieracium:

HíkOGLYHIQUE, adj., fieroglyphicus. Se dit d'un corps qui est marqué de lignes colorées sinueuses, qu'on a comparécs ì rles hiérogly phes: Ex. Python hieroslyplicus, Coccinclla hicroglyphica. V оycs Eсriт.

MLAmE, adj. , hiluris (hilum, hile): Ou appelle cicatricc hilaire, cellc qui est produite par l'abouchement des vaisscaux nourriciers au moyen desquels a eu lieu le développement des tuniques de l'embryon.

HILE, s. m. , hilum, hilus, fenestra, cicatricula; Nabel, Samcnnarbe, Samongrube, Keingrubc (all.); ilo (it.). L'usage général est de donner ce nom, avee liuelle, au point par lequel la graine tenait à la plantcmère, et auquel aboutissait par conséquent le funieule; cependant on ne l'applique souvent qu'a l'ombilic externe, e'est-à-dirc à celui de la première cnvcloppe de la graine, et ce eas a toujours licu quand on parlc du hile en général. Link prend le not dans un autre sens; pour lui ce qu'on désigne eommunémént par là estl'ombilic, et son hile est l'aurćole, souvent colorée, dépriméc ou verruqueuse, qui l'entoure. C'est ì tort qu'on appelle litle la cieatrice indiquant le point d'attache des aelaincs, des caryopses et des noix, ear il n'y a de hilc que pour les graines, et ee sont lì des fruits.

IILLIFÈRE, adj., hiliferus (hilum, hile, fero, porter). I a radicule est dite hilifere, d'après Mirbel, quand l'amande est nuc, et que la radiculc reçnit directement les vaissenux du funicule (ex. Apicennia); le pórisper- me prend la même épithètc quand il portc immédiatement le bile(ex. $C_{0-}$ nifircs).

IILOFÈnE, s. m. , hilofer (hilum, hile, fero, porter). Nom donué par Mirbel à la tunique interne de la graine, endoplèvre ou endosperine.

HILOSPELMĹEs, adj. et s. f. pl., Hilosperma (hilum, hilc, бтврpe, graine). Ventenat donnait ce nonı à la famille des Sapotées, parce que les plantes qu'clle renferme ont ordimairement l'ontbilic très-grand.

IIMIANTOCirrs, adj., himanto-

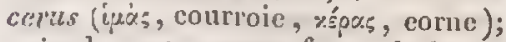
qui a les antenncs cn forme de fouet, comme celles de l'Asilus himantoccrus, dont lc troisieme article aplati se termine lout a coup par une petite épine très-courte.

HMANTOGALLES, adj. et s. m: pl., Hinantogralli (i $\dot{\mu} \dot{\alpha} s$, courroic, gallets, eoq). Non sous lequel Lesson désigne un sous-ordrc de l'ordre des Echassiers, comprenant ceux de ces oiseaux qui ont de l'analngie avec les Gallinacés.

IIMANTOPODE, adj., himantopodtus (iucs, courroie, r.oũ , pied). Se dit d'un oiseau qui a les jambes trèslongues.

IIIPPÉASTRIF ORMES, adject. et s. f. pl., Hippcastriformes. Nom donné par G. Herbert à une section de lá fauille des Amaryllidées, comprenaut le genre Hippcastrum.

IIIPPIUES, adj. et s. f. pl., Hippides. Nom sous lequal Latreille et Eichwald désignent une tribu de la faruille des Crustacés décapodes maeroures, qui a pour type le genre Hippa.

HIPPIĹES, adj. ct s. f. pl., Hip. pica. Nom donné par Lessing à une section de la sous-tribu des Sénéeionidées anthémidées, qui a pour type le genre Hippia.

IIIPPOCASTANÉES, adj. et s. f. pl., Hippocastanca. Famille de plan. 
tes, établic par Candolle, qui a pour type l'Asscultus Hippocastanum.

IIIPPOCRATÉACĹES ; adj. ct s.f. pl., Hippocrateacece. Famille de plantes, ćlablic par Jussicu, qui a pour type le genre Hippocratca.

HPPOCIRTtíls, adj. ets.f.pl., Hippocratce. Section, élablic par Rcichenbach dans la fauille des Théacées, qui a le geure IIippocralca pour type.

HippochaticÉes. Voyez IHrPOCRATÉACÉES.

IIPPOMANĖes, adj. et s. f. pl., Hippomance. Ricichenbach désigne sous ce nom une section de la famille des Euphorbes, qui a pour type legenre Hippomanc.

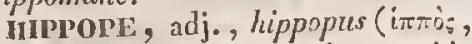

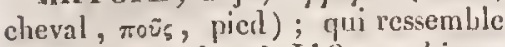
à un pied de cheval. L'Ostrca hippopus est ainsi appelée en raison de sa largenr et de sa forme.

IDPPOPODIF Orme, adj, , hippo-

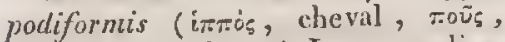
pied, forma, forme). Les appendices gélatincux et natatoires qui garnissent supérieurement le corps du Protoncdea lutca ont recu celtc épithète, à cause de leur ressemblance arec un sabot de cheval.

IIPPOPOTAMENS, adj. et s.m. pl., Hippopotamii. Vieq d'Azyr avait établi sous ce nom uue classc de Manmifères, ayant pour type l'Hippopotame.

IIPPURATE. $V$. UROBENZOATE.

HIPIURIDÉES, adj. el s.f. pl., Hippuridce. Famille de plantes, établie par Link, que Caudolle regarde comme une simple tribu de celle des Haloragécs, et qui a pour type le genre Hippuris.

Hippuneuri, adj., hippuricus ( $i \pi \pi 0_{5}$, cheval). Lichig donne ce nom à un acide particulier, qui cxiste dans l'urine des animanx herbivores en général, et que, par cela mème qu'il u'apparticut pas exclusivement au cheval, Berzelius désigne sons une autre dénomination, celle d'acide urobcnzö̈que. $V$. cc inot.

mPMGGílis, adj. et s. f. pl., Hip. tagece. Nom donné par Candolle à uue tribu de la fanille des Malpighiacées, qui in pour type le genre Hiplage.

mildati, s. in., hircas ( hircus, bone). Genre de scls (hircinsaure $S a / z c$, all.), qui sont prodnits par la combinaison de l'acide hircique avec les hases salifiables.

IntraIv, arlj., hircinus; bocks$\operatorname{artig}$ (all.). Se dit d'une odcur analogue a celle din bone, qu'on observe dans plusieurs planteș. Ex. Lo-. roglossum hircinum.

MrRCINr, s. f., himcina; Hircinfetl (all.). Substance grasse pirliculière, que Chevreul admet dans la graisen de houc, et a laquelle il attrilune l'odeur de celte graisse.

Hucrours, alj., hircicus. Nom donné par Chevreul à un acide particulier (Hircinsä̈urc, all.), que produit las siponilication de l'hircine.

Inzcisvas, s. m., hircismus, fa*. tor alarum s. ascellarum. Odeur forte et particulière qui s'exhale des aisselles chez. beancourp d'honmes.

nunsuTí, adj. , hirsutus; rauh, struppig (all.). Garni de poils longs et nombrenx. Voyez Ilénussé.

Inissurwex, adj., hirlns; borstion (all.). Garni de poils raides et piquans. Vayez Hérisst́.

HBRTCAUNE, alj., hirticaudis, (lirlus, velu, caudn, queuc); qui a la qrenc velue. Le Lixus hirlicaudis a l'extrémité des élytres garnie de poils.

HInTrCOLEF, adj., hirlicollis (hirtus, vclu, collum, col); qni a le col ou le corsclct couvert d'un épais duvet. Ex. Melolontha hirticollis, Gibbium hirticolle.

IHRTCORE, adj., hirticornis (hirtus, hérissć, cornu, corne); qui a les antenines velucs (ex. Poly- 
mera hirticornis, Sarrotrium hirticorne), hérissées d'épines (ex. Coreus hirticornis), ou termincées par une masse de poils en forme de petit balai (cx. Orthocerus hivticornis).

IIIRTIELORE, adj., hirtiflorus (hirtus, velu, flos, fleur) ; qui a les fleurs velues. Le Myrcia hirtiflora a ses braclées et ses caliees très-velus; le Galium hirtiflorum, ses corolles velues en delıors; le Schizachyrium hivtiflorum, ses épis velus.

HIRTIMANE, adject, , hirtimants (hirtus, hérissé, manus, main); qui a les mains hérissées d'épines. Ex. $P a-$ lamon hirtimanus.

HIRTIPEDE, adj., hirtipes (hirtus, hérissé, pes, pied); qui a les pattes garnies de poils. Ex. Dasypoda hirtipes.

IIIUDIFORuEs, adj., Hirzediformia (hirudo, sangsue). Nom donné par Latreille à un ordre de la classe des EIminthaproctes, comprenant ceux de ces animaux dont le corps cst plus ou moins semblable à celui d'unc sangsuc.

IIRUDINÉis, adj. et s. f. pl., Hirudinea, Hirudinei, Hirudines. Nom donné par Savigny, Lamarek et Latreille il une famille de la classe des Annelides, par Eichwald à une famille de celle des Grammazonires, ayant pour type le genre Hirudo.

HURUNDINACE, adj. , hirundinaceus (hirundo, hirondelle); qui tient del'hirondelle, comme la queue du Merops hirundinacea.

IIRUNDINIJES, adj. cl s. m. pl., Hirundinida. Nom donné par Vigors à une famille d'oiseaux percheurs, qui a pour type le genre Hirundo. HISPIDE, adj., hispidus, hispi-
dosus, strigosus; hackerig (all.); qui est garni de poils rudes el épars, comme la totalité de la plante dans le Silphium laeiniatum, les anthères du Lamium garganieum, les utricules du pollen du Malva miniata, la tige de l'Epilobinm hirsutum, les fcuillcs du Leontadon hispidum. Foyez Hérisst́.

IIISPIDIr:, subst. f., hispiditas. État d'une partic qui cst couverte de poils raides et piquans.

IISPMDULE, adj., hispidulalıs; qui est un peu hispide.

IISPPDDULEU, adj. , hispidulosus; qui est garni de poils raides, très-écartés.

FISTÉLIDES, adj. et s.m.pl., Histerida. Nom donnć par Leach à une famille d'insectes coléoptères, qui a pour type le genre IIister.

IIISTÉrónes, adj.el s.m. pl., Histeroüda, Histcrö̈des. Nom donné par Paykull à une famille, par Latreille, Cuvier et Eichwald à une tribu de la famille des Colcopteres clavicornes, qui a pour type le genre Hister.

IISTOHE NATUTELLE, subst. f., historia naturalis; Naturgeschichte (all.). Science quí étudic les formes et les direrses parties de chacun des corps existans a la surface ou dans l'inlćrieur de la terre, examine la strueture de ceux dans lesquels on ne trouve ancune trace de l'organisation nécessaire à l'excrciee des fonctions vitales, rceherche l'organisation et les fonctions des ètres vivans, s'oceupe des diverses classifications propres à facilitur l'étude des eorps naturels, et s'allache surlout à les disposer. dans un ordre méthodique qui soit aussi conforme que possible à leurs annlogies.

IIVER, s. m., hicms, hilscrnum; $\chi \varepsilon \varepsilon$ isv ; Vinter (all., angl.); inverno (it.). L'une des quatre saisons de l'année, qui s'éteud depuis l'arrivée du Soleil à l'un des tropiques jusqu'ì sou retour à l'équateur, ct pendant laquelle règnent les plus grands froids, dans les régions tempérées et glaciales. Chez nous l'hiver dure depuis le 21 ou 22 décembre, époque du passage du So- 
leil au premicr point du Capricorne, et terme de son plus grand abaissement au dessous de l'équateur, jusqu'au 19 ou 2 I mars, retour de l'astreàl'équinoxeduprintemps. La'Terre parcourt pendant ee temps les signes du Cancer, du Lion et de la Vierge.

iIVernal. Voyez Hingrasa.

mivernant. Voyez Hinernant. IIVERNATION. Voyez HIBER NATron.

HODONÈTRE, s. m. hodometrum, pcolomcter, perambulator, viatorum (óòs, chemiu, p.s-pís, înesurer). Iustrument ou appareil servant á mesurer la longueur d'un chemin parcouru, à déternsiner la distance qui sépare deux points l'un de l'aulre. Le plus connu de ces appareils csl eclui de Ilohlfeld, qui n'est qu'un perfeclionnement d'autres plus anciens, et avec lequei on peut, sans s'en occuper, mesurer nn million de révolutions d'uue zone, ce qui, en supposant celle-ci à quinze picds de circonférence, fait quinze inillions de pieds, ou près de onzecents liencs.

HOLACANTHE, adj, , holacanthzıs

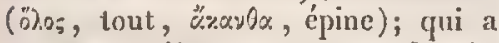
e corps entièrement couvert de piquans très-rapprochés. Ex. Diodon holacanthus. lotte.

IHOLTMENT, s, m. Cri de la hu-

hou f́rackés. Voycz Oúracées. HOLÈTRES, adject. el s. m. pl.,

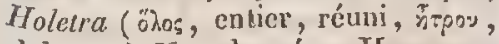
abdomen). Nom donné par Hermau, Cuvier, Latreille et Eichwald ì une famille de l'ordre des Araclinides trachéalcs, comprenant ceux de ces animaux qui ont l'abdomen réuni au thorax.

HoLonRavciIEs, adj. cts. m.pl., Holobranchii, Holobranchia, Holo-

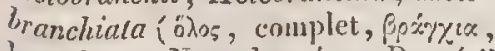
branchies ). Noun donné par Duméril a unc famille de Poissons osscux, dans laquelle il range ceux qui ont des branchics completes, c'est-à-dire pourvues d'un opercule et d'une membrane hranchinstège.

HOLOCHALINEs, alj. et s. m. pl.,

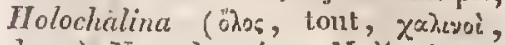
dents). Nom donné par Aruller à une fimille de repliles ophidiens, eomprenant ccux qui ont toutes les dents maxillaires venimenses.

HOLODONTASPISTES, adj. et s. m. pl., Holodontaspistes (öhos, com-

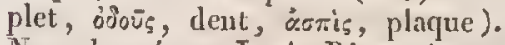
Nom donné par J.-A. Ritgen à une tribu de Reptiles ophidiens, compreuant ceux qui ont des plaques sur le corps et tontes les deuts entières, non percées.

IHOLODONTES, adj. ct s.m. pl., Holodonta (òdos, tout, oovors, dent). Nom donné par Muller à une famille de Rieptiles opbidiens, comprenant ecux qui ont toutes les dents pleines ct entières, ou des dents partout oix I'on en trouve dans ect ordre.

MoronovionILDEs, adj. et s. m. pl., Holodonenphides ("̈hos, complet, ôsov̄s, dent, öpes, serpent). Nom donné par J.-A. Ritgen à une tribu de Reptiles ophidiens, dans laquelle il range ceux qui out des placues sur le corps et les dents pleines.

HOLOEDh(UUL, adj, , holocdricus (ònos, enticr, हैंpo, base). Naumann donne celle épithètc aux fornes cristallines réunissant toutes les faces qui peuvent se coordonner autour d'un système d'axes déterminés pour un certnin rapport, ćgaleınent déterminé, entre les paramètres.

HOLOGONIDE, s. f., hologonidium; Vollbrutzelle (all.). Wallroth nomme aiusi les gonidies des lichens considérées isolćment, lorsqu'elles sont dans les couditions néeessaires pour se dévclopper, et au moment de le faire.

IrOLOGONIVIRQUe, adj., hologonimiczs. Wallroth appelle morphosis hologonimica celle qui résulte du dé- 
veloppememt des corpuscules reproducteurs des liehens auxquelsil donne le nom de hologonidies.

HOLOLÉPIOTE, adj., hololepi-

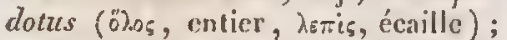
qui est entierement couvert d'écailles. Ex. Cichla hololcpidota.

HOLOLEvQur, adj., loololeucus

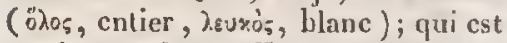
totalement blanc. Lx. Agaricus hololeucus.

HOLOpÉTALE, adj. , holopclalus

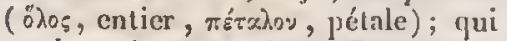
a des pétales entiers. Ex. Silene holopetala.

HOLOPIANERE, adj., holophanerus (ölos, complet, yxrzoos, manifeste). Latreille donnc cette ćpithèle aux métamorplanses des insectes, quand elles sont complètes ou totales.

HOLOPORE, adject., holoporus (òos, complet, $\pi \dot{0} \mathrm{pos}_{5}$, porc). Lc $P_{0-}$ lyporus looloporus est presque uniquement composé de tubes parallèles.

HOLOPTL̀nE, adj. , holoptcrus (òos, complet, $\pi \tau$ s'pn, aile). L'Ascaris loolopterus doit uc nom it ce qu'une membranc latćrale mince règne sur toute la longueur de son corps.

HoLOnAGÉEs, adj. et s.f. pl., Holoragea. Famille de plantcs, établie par R. Brown, qui a pour type le genre Holoragis.

HOLOT HURIDES, adj. ct s. f. pl., Holothurida, Holothuridea. Nom donnć par Latreille à unc classe dn règne animal, par Blainville à un ordre de la classe des Polycérodermaires, ayant le genre Holothuria pour type.

IOLOTIUnIES, s. f. pl., Holothuria. Nom dounć par Goldluss, Ficinus et Carus à un ordrc ou à une famille de Radiaires, ayant pour type le genre Holothuria.

HOMLLINÉEs, adj, el s. f. pl.,
Homalinece. Famillc de plantes, établie par R. Brown, qui a pour type le genre Homalium.

HOMALOCÉPIIALE, adj., homa-

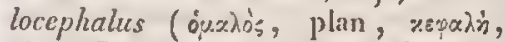
tête ). Le Laccrta homaloceplucta est ainsi appclé, parce qu'il a les côtés de la tête et du corps garnis d'une large membrane, qui les fait paraître aplatis.

hovilogonées, adj. et s. f. pl., Homalogonata (ómàb; , plan, ซóv, genou). Nom donné par Lyngbyc it une section de la classe des Hydropleytes, comprenant cclles dont la fronde est articuléc et planc.

HOMLOPHYLEES, adj. et s. f. pl., Homalophylice (ouados, plan, pijliov, feuille). Nom donné par Willdenow à un ordre de plantes eryptogames, comprenant celles qui ont une fronde aplatic sur terre; par Sprengel à uue famillc, démembréc des Hépatiques, dans laquelle il range celles de ces plantes dont la fronde forme unc expansion foliacée.

HOMARDiENs, adj. et s. m. pl.. Astacini. Nom donné par Cuvier et Latreille à une tribu ou scetion de la famille des Crustacés décapodes Macroures, qui a pour type le genre Homard.

HOMÉOMk'RE, adj. , homceomerus (ơzess, semblable, prosos, partie). Wallroth donne ectte épithète au tballe ou blastème des lichens, quand il est formćd'une substance unique, homogène ou gélatineuse.

IIOMINIDES, adj. et s. m. pl., Hominide. Gray désigne sous ee nom une famille de l'ordrc des Mammifères primates, qui renferme le genre Homo.

HOMOBRANCHES, adj. et s. m. pl., Homobranchiata (ouos, sembla-

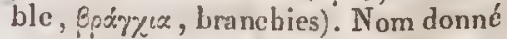
par laaniarck à un ordre de la classe des Crustacés, comprenant ceux qui ont les branchics en pyramide et com- 


\section{$110 \mathrm{MO}$}

posćes de lames empilées les unes sur les autres.

Hovocarie, adj. , homocarpus (oucs, scinblable, гарлós, f'ruit). H. Cassini donne cette ćpithète à la calathide des Synanthérées, quand tous les ovaires qu'elle renferme sont semblables.

HoMocheres, adj. et s. m. pl., Homocheles (juó, senblable, $\chi_{n} \lambda \dot{y}_{i}$, pince). Nom donné par Latrcille à une section de la famille des Crustacés décapodes brachiures, comprennnt ceux dont les serres sont de grandeur identique ou peu différente dans les deux scxes.

nOMOCRICIENS, adj. ct s.m. pl., Homocricii (juis, scmblable, xoiros, anncau). Nom donnć par Blainville à un ordre de la classe des Chétopodes, dans lequel il range ceux de ces animaux dont le corps est composć d'articulations presque similaires.

IONODERMES, adject. et s. m. pl., Homoderma:, Homodermata (ojess, semblable, dófpus, peau). Nom donné par Duméril à une famille de l'ordre des Reptiles ophidiens, comprenant ceux qui ont la peau couverte d'ćcailles partout.

HOMOGANE, alj. , homogamus

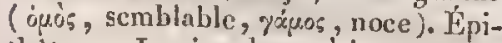
thète que Lessing donnea la calathide des Synanthérées, quand toutes les fleurs qu'elle renferme sout du même sexe.

Homogame, s. f., homogamia. C.-C. Sprengel désigne ainsi le cas dans lequel les organes mâles et les organes femelles d'une plante arrivent cnsemble à maturité.

IONOGEve, adj. , homogenus; glcichartig (all.) (ouós, semblable, yéros, race). Se dit de la texture d'une roche, quand les parties qui la constituent sont de mème nature ct ont le même aspect.

IIOMOGĹNËIté, s. f., homogenei-
IIOMO

tas; Gleichartigkeit (all.). Qualité de ce qui est homogène.

IIOMOGLNEOCARPES, adj. ct s. f. pl., Homogeneocarpi (ópoyevis, homoginc, raorsis, fruit). Nom donuć par tiony à une tribu de la fanille des Céramiaires, comprenant eelles qui produisent de véritables capsules lomogenes.

MOMOGENEs, adj. et s. m. ctf.pl., Ilomogenei, Homogenea. Nom donné par Brongniart et C. Prevost à une classe de roches, comprenant les masses minérales dans lesquelles on ne distingue à l'oeil qu'une seulc matière composante; par Acluarius, à un ordre de la classe des lichens idiothalames, aupuel il rapporle ceux dont la substanee est homogène; par Cuvier, à un ordre de la classe des Infusoires, comprenant ceux de ces animaux dont le corps est sans viscères.

HOMOG ÉNIE, sulst. f, homogenia (óvòs, semblable, yśsos, race). Burdach appelle ainsi (gencratio homogenea s. propagatio; glciehartige Zeugung, Fortpllanzung, all. ) le mode de génération qui consiste en ce que le nouvel être vivant est produit par un ou par deux corps organisés de la même espece que lini.

HOMOMn:, adject.", homoideus; gleichgestallet (óvòs, semblable, sióo;, ressemblance). I.-C. Richard donne ccttc épitbète anx parties qui ont la même forme que leur tégument ou enveloppe.

HONoIODIPÉRIANTIn:Es, adj. et subst. f. pl., Homoiodiperianthe ("ipolos, semblable, o"ts, deux, твpi , autour, "艹: $\theta_{0}$, fleur). Wachendorff noonme ainsi une classe de plantes, comprenant celles qui ont un même nombre d'étamines et de divisions de chlarun de leurs denx périanthes.

HOMONAE: E, homomallits, sccun. dus; cinseitswendig ( all.) ( ojos , semblable, $\mu x) \lambda \dot{d}_{5}$, toison). Se dit 
d'un corps dont les parties se dirigent d'un seul côtć, comme les phyllodes de l'Aeacia homomalla, les feuilles du Didymodon hontomallus, et les rameaux du polypier appelć Plexaura homomalla.

IIOMOMÉnÉs, adj. ct s. m. pl. ; Homomeres (ò.ò̀ ; scmblable, $\mu$ śpos, partie). Nom donnć par Blainville à un ordre de li classe des Chétopodes, comprenant ceux dont les anneaux du corps sont semblables les uıs aux autres.

IrOMOMORPIE, adj., homomorphus, uniformis; einformig (all.); (ouòs, semblable, uopen, forme). Sc dit de parties ou de corps qui ont la même formc.

Hononḱnérs, adj. ets. m.pl., Homoncmea (ờis, semblable, ขñux, fil). Fries donue ce nom aux végétaux produits par des filamens qui, dans la germination, sc séparcut clia. cun de lcur adliérenec à un corps homogène, commc dans les algues et les champignons. Homonémé on Homonemécn est synonyme de haplogine, anandre et sporidiifère.

HOMONOuE, adject., homonomus (ơos, semblable, vómos, loi). Nom donné, dans la nomenclature minćralogique de IIaiiy, 丸 une variété dans laquclle tous les déeroisscmens naissent sur les augles ou sur les hords. Ex. Baryle sulfarée homonome.

IOMOPĹtALE, adj., homopelalus

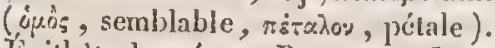
Epithètc donnée par. Peyre aux Reur's dont les pétales se ressemblent tous; par H. Cassini, aux calathicles, quand les fleurs qui les conposent ont toutes des corolles senublables.

IOMOPIYRLE, adj., homophy-llus (ónós, semblable, gúlinoy, feuille). Se dit d'une plante dont les feuilles ou les folioles sont toutes semblables. Ex. Cassia homopliylla.

ILOMOPTÈHES, adj. et s. nt. pl., Momoptera (ọpòs, semblable, $\pi$ śspoy, aile). Nom donné par Cuvier, Latreille, Eichwald, Ficinus et Carus à une section de l'ordre des Hémiptères, comprenant ceux de ces insectes dont les ćtuis ont la même consistance et sout demi-membranenx dans toute leur étendue.

IONOSPIÉROÉDIOUE, adject., homosphceroedricus. Nom donné par Weiss au système de eristallisation dans lequel le eristal offre tontes les faces que détermine l'cnsemble de trois axes inćgaux entr'cux, systc̀me qui a pour type l'octaëdre régulier.

HOMOTLVE, adj. et s. m., homo-

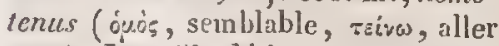
vers). Latreille désigne sons ce nom les aninuau articulés qui conservent toute leur vie la forme qu'ils avaient en naissant, qui ne font que eroitre ct changer de peau.

HOMOTHARAMES, adj. et s. m. pl., Homolhalami (évó;, senblable, Osinu.0s, lit). Nom douné par Acharius à une classe de Lichens, comprenant ceux dont les conceptacles sont de mème couleur et de neème nature que le thalle.

HOMOTROPE, adj., homotropus

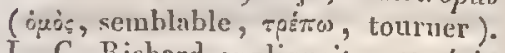
I.-C. Richard appliquait cette épithète à l'cmbryon qui, sans être droit, a la mème direetion que ln grainc.

nOMOVALVE, adj., homoralpes (ópris, scrublable, valpa, valve). Peyre indique par ce nom les frrits dont les valves sont semblables.

IOPLOPODES, adj. et s. m.pl., Hoplopode ("o $\pi \lambda_{0.5}$, arme, $\pi 0 \tilde{\nu} 5$, pied). Nom donné par Goldfuss à un ordre de la classe des Mammifères, comprenant ceux qui ont les pieds armés dc sahots.

mORAIRE, adj., horarius; qui a rapport anx heures, qui les marque ou les mesure, qui se fait par heures. On appelle plans horaires, les plans visuels dont les ares gu'ils intereeptent sur le ecrele diurne d'un 
astre répondent aux heures on fraetions d'heure dans lesquelles on divise la durée de la révolution entiere ou du jour sidéral. Les cereles horaires sont ceux qu'on vertu du monvement diurne de la terre, ehaque étoilc semble tracer en décrivant soit l'équatcur mème, soit uu cerele plus petit, mais parallèle à celui-là. On les noinme parallìles. S'angle horaire est l'angle diëtle forıné par le plan du méridien avec le plan horaire d'un astre. On donne l'épithète de horaires anx végétaux qui ne vivent guère plus d'une licure.

IIOrDb́lch́, adject., hordeaceus (hordeum, orge); qui resscmble à un grain d'orge, eomme la coquille du Bulimus hordeaceus; ou qui a lit forme d'uu épi d'orge, comme l'ćpi floral du Chamarophis hordeaceus.

monbiaClitis, adj. et s. f. pl., Mordeacea. Nom donné par Kunth et Nees d'Esenbeek à une tribu de la fanille des Graminces, qui a pour type le genre Hordcum.

HORUEIT ORME, adj., hordeiformis ; gerstenartig (all.); qui ressemble à l'orge. Ex. T'riticum hordciforme.

Hordétue, s. f., hordcila. Guibourt appelle ainsi l'hordéinc.

IrORDLiNE, subst. f., hordcina. Proust nomme ainsi une substance qu'il a relirce de l'orge, et qu'il regarde comme un principe immédiat des végétaux, mais qui, d'aprè̀ Zenneck et Guibourt, cst un mélange de son et des tégumens de l'ainidon irsolubles dans l'eau, el, d'après Raspail, de son pur très-divisć. Ifcrbmstacdt donne le même nom ì une sulstance fort différente, le gluten de l'orge. HORDlinizis, adj. ct s. f. pl., Hordcince. Non donné par Link à une tribu de la famille des Graminées, qui a le genre Irordcum pour type.

IronInLes, adj. et s. m. pl., Horialcs. Nom donné par Guvięr et Lat- treille à une famille des Coléoptères trachćlides, ayant pour type le genre Horia.

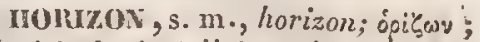
Gesiehtskrcis (all.); orizonte (it.) (opiç, terminer). Plan qui, passant par l'œil de l'observatcur, perpendieulaire à la verticale, et rasant la surfaec de la terre, sépare la partie visible du ciel de celle que nous cache la courburc du globe; on le nomue ainsi parec qu'il borne la vue. L'horizon sensible est la limuc qui sćpare la partie visible du eiel de eelle qu'ou ne peut apereevoir. L'horizon rationnel est un ecrcle parallèle an préeédent, mais plus griand, qui passe par le centre de la terre, et dont le plan divisc en deux parties égales le globe terrestre et l'cspace dans lequel il cst situé. Ces deux cereles changent pour chaque licude la terre.

HORLYNTAL, adj., horizontalis;

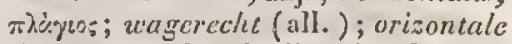
(it.); qqui est dans la direction du plan de l'horizon. Les géologues appellent stratification horizoniale eelle des massifs dont les conches sont gènéralement peu inelinées. En botanique, on nomme horizontales, les antherres qui. sont placées en travers sur le filet (cx. Lilium); les racines qui couzent entre denx terres, parallelement au plan de l'horizon (ex. Anemone nemorosa) ; les graines qui sont atlachées par leur bord ou par l'un de leurs bouts, et qui se tiennent dans un plan parallele à la base du fruit (ex. Lilium). Les entomologistes nomment ailes horizontalcs eelles qui, étant étendues, forment un angle droit avec le corps (cx. Libellula).

HOIUZONTALTí, s. f, , horizontalitas. État de ce qui est horizontal.

InOLWOTL, adjeet., hornotinus; dicssjährig (all.) (hornus, de cette année). Se dit d'un eorps organisé dont la paissance date de l'année, par 
exemple, d'un oisean qui est sorti de l'oenf pendant le cours de l'aunće.

IORTICOLE, adject., horticolus (hortss, jardill, colo, habiter); qui fréquente les jardins. Ex. Melolontha horticola.

HOULLER, adj. On appelle terrains houillcr's ceux qui renferment des couches de houille. On dit aussi bassin, dépót houiller. Onalius et Brongniart ont établi un groupe de terrains houillers, caractérisés principalement par la ricliesse des conches de houille quiils reuferment.

HOURLEUX, adj.; qui contient de la houille. Fiche houilleuse.

IrOULE, s. l., fuctuum agitatio; xथिps; pot (angl.). On nomne ainsi les vagues dont la mer cst couverte après la cessalion d'une tempête, ou avant que celle-ci u'ait licu.

IIOLLEUx, adj., aestustos ; ropuswins; wogig (all.); swollen (angl.). Se dit d'une mer agitée par des vagues.

HOUPPE, subst. f., пpex, barba, coma; doфos; Troddel (a!l.); cop (ang.). Petite touffe étalée de poils à l'extrémité d'une graine ou de quelque partie du corps d'un animal.

moch's', adj. Se dit des poils, quand ils sont disposćs en forme de houppe.

IIOUpPrinta, adj., scoposus. $\mathrm{O}_{\mathrm{II}}$ donne cette épithète à certains oiseaux, tcls que les coqs, lorsque leur tète, au lien d'une eréte, porle des plumes susceptibles de se redresser et de former ume aigrette analogue ì celle du paon. Le Brachyeerus scoposus a le élytres chargées de tubercules qui portent des poils fasciculés.

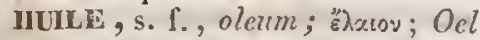
(all.) ; oil (angl.); olio (it.). Anjourd'hui on appelle ainsi tous les corps gras qui couservent l'élat liquide à la température de 15 a 20 degrés, $\mathrm{ct}$ à plus forte raison au dessous. Autrefois on donnait aussi ce nom à des liquides dow's d'une certaine eonsi- stance, par cxemple eelui d'haile de vitriol à l'acide sulfurique aqueux, celui d'huile d'arsenie au chlorure d'arsenic distil!é. L'huile douec du vin, lị̣uide oléagineux qui se produit par l'action des acides sur l'aleool, n'est hien conmue que depuis Ilennel, qui en a étudié la composition, et qui a fait voir qu'elle rentre dans lin-classe des cthers.

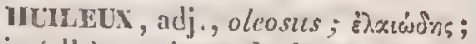
vilig (all.); qui est de la nuture de l'huile, ou inbibé d'huile.

HUM.1TE, s. m. , humas. Sel formé par la combinaison de l'aeide bumique avec une base. Voyez GÉAtE.

InUMECTANT, adj., humeetans, humifieus, humifer; beferchtend, aufeuchend (all.); qui huniecte.

IICMECTATION, s.f., madefaetio, fumectatio; ṽyoxere; Anfeuchtung, Befeuchten (all.). Ĺtat d'un corps à la surface duquel est restéc uno eertaine quantité d'eau, qui ne se dissipe qu’à une température plus ou moins élevéc, parec que l'adhésion lui fait perdre une grande partic de sa tension.

GIUMLC'T, adject, humeclatus, humectus, humejactus, lumigatus? angefeuch (all.); qui relient de l'can à sa surlace. On dit, par abus, qre certaius corps s'hurnectent dans le mereure, lorsqu'ils cu retiennent un peu quand on les y a plongés, car alors il n'y a pas seulement adliésion, mais combinaison.

nutúraL, adject. , humeralis ; qui a rapport i l'humcirus. Les plumes humérales sont celles qui garmissent l'hunérus. Kiby appelle angle haméral des élytres, dans les inseetes, l'angle externe de leur base. I es erllules humérales de l'aile d'un insecte sont, pour Jurime, eclles que les ncrvures brachiales et leurs ramifications forment en s'anastomosant entr'elles et avec le cubitus. On donne cette épithète a des animaux clont la région 
humćrale, ou eelle qui y eorrespond, présente quelque particularité de eoloration ou autre. Le Psittacus humecralis a les scapulaires vertes. Le Bufo humeralis a de grosses parotides, qui font paraître ses épaules comme reuflées. Le Melolontha humcralis a une taehe sur la base externe des élytres.

Huméraiffire, adj. , humeralifcrus (humeralc, cape, fcro, porter). Te Jacchus humeralifer a ses parties antéricures d'une conleur blanehe disposée de manic̀re à former une sorte de eanail, le reste du corps ćtant d'un brun clıâtain.

IUUMérus, sulst. m., tumerus. Kirby appelle ainsi le troisiène article des pattes antérieures ou bras, dans les insecteshexapodes.

IIUNIESCENT, adjeet., humescens (humesco, humeeter); qui devient humide.

IIUMIDE, adj., humidus, humons, usidus, zudus, uliginosus; íypos; fcucht (all.); moist (angl.). Se dit d'un air qui est imprégné d'eau à l'état de vapeur, d'un corps à la surface duquel il y a de l'cau, mais non encore rassemblée en gouttes.

IUмпот's, s.f., huntidilas, humor, mador; úyporins; Fcuchtigkeit (all.). État d'un corps qui est imbibé d'ean, et qui a de la disposition à en communiquer une partic aux corps environuans

IIUMIYUSE, adj., humifusns (humus, terre, fusus, conché). Se dit de la tigc des végélanx, quand elle est eouclée et ćtalée sur le sol, mais sans y jeter de raeines. Ex. Exocarpos humifusa, Hypcricum humifusum.

IFUnLUE, adj., humieus. Sprengel dome it l'ulmine le nom d'acide humique, parce qu'on la trouve dans le terreau, et qu'clle se combine avee les luases. Foy cz Gúrede.

IIUnman ć́ces, adj. et s. f, pl.,
Humiriacea. Famille de plantes, établie par A. Jussicu, qui a pour type le genre Humiria.

HUIPW, s. f., crista, apex. On appelle ainsi, dans les oiseaux, un faiseeau de plumes plus longues que les autres, qui sont constamment droites sur la tête, ou pendantes en arrière, ou couchées, mais susceptibles de se redresser à la volonté de l'animal.

InPPE; adj. , cristatus, cristatcllus, cirratus, cirrhatus, cuculla-

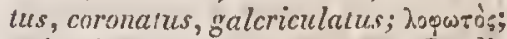
gehaube (all.); copped (angl.). Se dit d'un oisean qui a la tête garnie on ombragée d'une touffe de plumes droites, pendautes on suseeptibles de se dresser. Ex. Morplnus crislalus, Pernis cristala, Acridolheres crislatellus, Phateris cristatclla, Ilydrocorax cirralus, Thamnophilius cirrhatus, Loxics cucullata, Spizatus coronatus, Loxia coronata, Anas galcriculala.

HuRE, s. f. Tète du sanglier, du lion, du satmon, du brochet, du thon, après qu'elle a élé séparée du corps.

HURLEHENT, s. m., ululantes; öhohiquos; Heulen (all.); howling (ang.); urlo (it.). Cri du loup, du elien dans quelques eirconstances, comme lorsqu'il exprime la douleur on l'inquiétude, et de quelques singes, les Alouates, appelés hurlcurs, paree qu'ils font retentir les forêts de leur voix forte et ciclatante.

IYACINTIL, adj., hyacinthus, hyacinthints: váxivoss. D'un blen tirant sur le violet. Ex. Psitlacus h) $a$ : cinthinus, Motacilla hyacinthina.

irvacivinnwes, adj. et s. f. pl., Hyarinthina. Nom donné par Link à une section de la famille des tiliaećes, qui a pour type le genre IJjacinchus.

IIYANiNs, adject. et s. m. pl., IIyanina. Nom donné parGray à unc 
trilun de la famille des Félides, qui a pour type le genre Hyana.

IYYALÉACES, adject. et s. nı. pl., IIyalceacea. Nom donné par Menke ì une famille de la classe des Ptéropodes, qui a pour type le genre $H_{y}$ aleca.

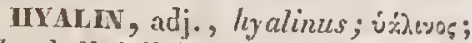
slasslucll (all.) (üzios, verre); qui ressemble á du verre, qui cn a l'apparence (ex. Quarz hralin), ou la diaphaućilć, comme la sulsstance du champignon appelé Monilia lyalina, la fleur du Gladiolus hyalinzes, l'une des pièces de la glume du Paspalus hyalinus, le champignon appelé $P^{2} c-$ ziza hyalina, le corps du Limax liyalinus et du Physidium hycalinum, les ailes du Perilampus liyalinus et de l'Anthrax hralina, l'abdomen de la Musca lycalinata.

IIYALINonurize, adject, , hyali-

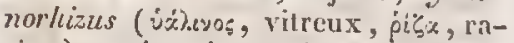
cine); qui a des racines lilauches, transparentes. Ex. Valoriana $h_{y}$-alinorhiza.

ITYALIPENvE, adj., ligalipennis (üz.os, verre, ponna, aile); qui a les ailes :musparentes. Ex. Dioctria tyaliponnis.

IIYALOPTELE, adj , , hyaloptertes (ㅊìos, verre, $\pi$ - spoy, aile); qui a les ailes transparentes, comme du verre. Ex. Leplis hyaloptera.

IIYALOSPLIRE, adj. , lyalosper-

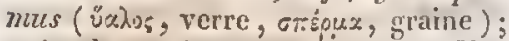
qui a les graines transparentes. Ex. Namaspora lyalosperina.

IYALURGie, s. f., hyalurgia; Glassehemic (all.) (vंexhos, verre, špyov, travail). Fabrication du verre.

IIIBERNACLE. Voycz HiberNACLE.

IMBotines, adject. et s. m. pl., Hybolidec. Nom donné par J. Macquart à nne tribu de la famille des Diptères tanystomes, qui a pour type le genre Hylos.

InbOTiss, adj., Hibotii, Hi- botini, Hibotincr. Nom donné par Latreille à une tribu de la famille des Diptères tanystomes, ayant pour type le genre Hybos, que Meigen, Wicdemann ct antres entomologistes ont érigée en famille.

IIIREDE, adj. et s. m., hybridus; bastardarlig (all.) ; ilrido (it.) (íßpis, métis). Les bolanistes donnent ce nom, synonyme de bálard ou de métis, à des plantes dont la grainc provient d'un végétal qui, au lieu d'être fécondé par sa propre espèce, l'a été par un autre; ainsi, par exenple, le Ranunculus laccrus est le résultat du Rinunculus pyrenceus fécondé par le Ranunculus aconitifo. lizs. Cependant, à l'excmple de Limné, et par abus, ils l'ont appliqué aussi à des plantes qui ont seulemeut de l'nnalogie avec deux autres, sans qu'il soit démontré, ni toujours prohałıle, ni même quelquefois possible, qu'clles en proviennent, d'où il suit qu'en botanique, le nom spécifique d'hybride n'a guère d'autre seus que celui d'intermédiaire. Ex. Veronica bylrida, Saponaria hylurila, Delphinium hybridum, Chcnopodium hybridum.

IMBNiDIT , s. f., leybridizas; Bastardzustand(all.). Condition d'un végétal qui est le produit de deux espèces différentes.

IIYDITIFORIE, adj., hydalifor. mis (iouris, vessic, forma, forme); qui a la forme d'une poche ou d'une vessie. Corps hydatiforme.

IIYDATIS, adj. et s. m. pl., $H_{y}$ datina. Nom donné par C.-G. Ehrenberg ì une tribu de la elasse des Rolifères, qui a pour type le genre IIydatina.

IIDATISONES, adj. et s. m. pl.,

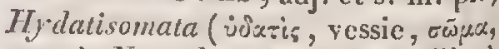
corps). Nom donné par Blainville it une tribu de la elasse des subannclidaires, comprenant des animaux qui ont le corps en forme de ressic. 
IIYDATOLOGLE. VOJCz HYDROIOGIE.

IIYDvés, adj. et s. nı. pl., IIrdnea?, Hydnei. Nom donné par Tries, Reichenbach et Mar'quis ì une tribu de champignons, qui a ponr type le genre II ydnum.

IIYDNOMLS, adject. et s. m. pl., Hydnoidei. Nom sons lequel Persoon désigne une iribu de la famille des Champignons, ayant le genre $\mathrm{Hy}$ rdnum pour type.

IIYDNORINÉEs, adj. et s. f. pl., Hy dnorinex. Nom donué par A gardh à un groupe de la famille des Champignons, qui a pour type le genre Hydnora.

IIXIPACINADLES, adj. cl s. f. pl., Hydraclinade. Nom donné par Leach à une famille de l'ordre des Arachnides trachéales, qui a pour type le genre Hydrachina.

IIYDRACINELLES, adj. el s. f. pl., Hrdrachnella. Nom sous lequel Latreille désigne unc famille de l'ordre des Araclinides trachéales, ayant le genre Hydraelina pour type.

IIYDRACIIE, adj. et s. m., hydracidus, hrdracidum; Wasserstoffsüurc (all.). Acide résultant de la combinaison d'un corps simple ou composé avec l'hydrogènc. Duloug considère tous les oxaciles aqueux comme des hyllacides, c'est-it-dire qu'il attribuc à l'acide lá quatulíé d'oxiggene contenue dims l'un, et admet qu'elle forne, tant avec l'oxigène qu'avec le radical combustible de l'aeide, le radical combustible d'un. hydracide, e'est-à-dire un corps halofene. Quand ect liydracide se combine avecun métal, l'lyydrogènescul cst mis en liberté, et le métal s'unit an corps hitlogène composé, pour produire une combinaison, non de l'oxacide anhyWre ct de l'oxide, unis da métal ct du radical de l'hydracide. Quand cet acide est mis en contact avec un oxide, cclui-ei est réduit ì l'ćtat métallique par l'hydrogène de l'acide, ct il se forme de l'can. Cette hypothèse ingénieuse, mais que les chimistes n'ont point admise, rétablit l'harmonie cntre les oxacides et les hydracides.

UYDRALEGTORES, adj. ets. m.

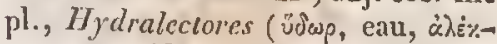
zwo, coq). Nom donné par J.-A. Ritgen à une famille d'oiseaux aquatiques, comprenant eeux qui, à certains úgards, sc rapproehent des $\mathrm{Gall}$ nacés, comme les Foulques.

III DraLGUes, s. f. pl., Hydralga. Roth désigne sous ce nom les Hydrophyles.

IYMHANGúA Gées, adj. et s. f. pl., Iy ydrangeaeea. Nom donné par Kuntli à unc famille de plantes, qui a pour type le genre Hydrangea.

IIVDrixgLies, adj. et s. f. pl.; Hydrangce. Sous ce nom, Candolle désigue nue tribu de la famille des Saxifragées, ayant le genre Itydrangea pour type.

IYOHARGVHDES, s. m. pl., Hydrar syrida (idox́pgupos, mercure)' Nom douné par Bonnsdorf aux amalgames, par Bcudant et Pauquy à une lamille de corps pondérables ou de minéraux, qui a pour type lc mercurc.

IYYDARGYROCYANIQUE, adj., hydrargyrocyanicus. Quelques chimistes admeltent un acide bydrargrrocjanique (Quecksilberblausäure (ill.), dans lequel le cyanure de nsercure jonerait le rôle de radieal d'un bydracide.

HYDRARGVROFULMINATE, s. nı., hydrargyrofulminas. On appelle ainsi les sels (quectisilberknallsanre Salve, all.) produits par la combinaison de l'aeide lydrargyrofulmique aree les bases salifiables.

INYDIAIRGYTOFULMINIQUE, adj., hydrar'gyrofulminicus. Quelques chimistes ont admis sous ce nom un acide (Quccksilbcrknallsïure, all.), 
composé de mercure ct d'acide fulminique ou de ses ćlémens, qui n'a point encore élé examiné.

HYDLARGVRURE, s. m., lydrarsyretum. Nordenskiocld et Beudaut appellent ainsi les amalgames.

MYURARSENIATE, s. ni., $h y$ drarsenias. En minéralogie, on dome ce nom aux arséniates qui coutiennent de l'eau à l'état de combinaison chimique.

HVDRATABLE, adj. Se dit, en chimie, d'unc substance qui est suseeptible de se convertir en hydrate, de se combiner avec de l'eau en proportions définies.

IIYORATE, s. m., hydras; $\mathrm{Hy}$ drat (all.). Combinaison d'un oxide métallique et d'eau, dans laquelle cette dernière jonc le rôle d'acide. C'est Bcrzelius qui donne cette acecption précise au mot hydrate, anquel on eir attache une beaucoup plus vague dans les écrits des antres chimistes et des minćralogistes.

ITDRATÉ, adj., gewässert (all.); idrato (it.). Épithète donnée par Berzelius aux acides, quand ils contiennent de l'cau combinćc avec eux et jouant le rôle de basc. Daus les éerits des autres chimistes, cc mot exprime simplement un acide qui conticnt de l'eau.

IFVDATIQUE, adj., lyrdraticus. Chevreul a proposé de donner à l' $l^{\prime} c-$ ther produit par les acides sulfurique, phosphorique et arsénique, cette épithùle indiquant que le corps qu'il désigne est à l'hydrogène percarboné ce qu'un hydrate est à son oxide. Sa coruposition peut effectivemient ètre représentéc par les élémens de l'cau et par ceux de l'hydrogène percarbonć.

IIYDRAULES, s. m. pl., $H_{y}-$ draula. Nom donné par Ficius ct Carus à une famille de l'ordre des Cétacés, comprenant ccux qui sont carnas icrs,

\section{HYDR}

ITPRAULIQUe, s. f., hydraulica; W asscrlcitungskunst (all.). Partic de la physique qui traite de tous les phénomènes ayant rapport aux mouvemens des corps liquides. Cette expression est réservéc ordinairement pour désigner les applications techniques qu'on fait dn inouvenent des eaux.

ITORALIQUE, adj., hydraulicus. On appelle chaux hydraulique une chaux produite par la calcination ménagée d'un calcaire contenant une certaine quantité de silice très-diviséc. C'est un silicate de chaux, susecptible de former unc pâte qui se durcit sous l'cau et $s^{\prime} y$ convertit à la longue en une sorte de pierre tendre.

ITORÉchiovis, adj. et s. m.

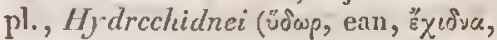
vipère). Nom donné par J.-A. Ritgen à une famille de Reptiles ophidiens, comprenant ccux qui ont des crochets à venin, et qui vivent dans l'cau.

HYDRELLǴDÉs, adj. et s. f. pl., Hydrcllcdece. Nom donné par Robineau-Desvoidy à une tribu de la famille des Myodaires napcellées, ayant pour type le genre Hydrella.

IIYDIRICO-NITRIQUE, adj., hydrico-nitricus. On appelle sulfate bydrico-nitrique une sorte de sel double ou d'acide double, qui résulte de la combinaison de l'acide sulfurique aquenx arec l'acide nitrique.

IIDDICO-pOTASSIQUE, adject, bydrico-potassicus. Le nom de nitrure hydrico-potassiquc conviendrait au corps appelé azoture ammoniacal de polassium, si cecorps élait, comme le pense Gay-Lussac, une combinaison de nitrure de potassium et de nitrure trihydrique ou ammoniaque.

IIYDRICO-SOHIOE, adject., lirdrico-sodicus. Les réllexions de l'article précédent sont applicahles à l'azoture ammoniacal de sodium. 
HXDRIDES, adject.ct s. m. pl., Hydrida ("üope, hydre, siojos, resscmblance). Nom donuć par Gray à une famille de l'ordre des Reptiles sauriens, comprenant ceux de ces animaux gui vivent habituellement daus l'eau.

IIYDIRFORME, adj. , hydriformis (hydra, hydre, forma, forme); qui resscmble à unc hydre. L'Holothuria hydrifornis est ainsi appclée parce qu'ellc a la bouche cnlourée de donze tentacules.

IINDinUnwes, adject. ct s.m. pl., Hydriformia. Nom donné par Schweigger et Eich wald à unc famille de la classedes Zoophytes ou Phytozoaires, qui a pour type le genre $\mathrm{Hy}$ dra.

IYYDLuNES, adj. el s. m. pl., $H_{y}$ drina. Nom donné par Bory à un ordre de la classe des Ichnozoaires, comprenant les polypes qui vivent sans être enracinés, comme les $I_{Y}$ dres.

IIYDrins, adj. et s. m. pl. , $H y-$ drini. Nom sous lequel Spix désignc une fanille de l'ordre des Opliuliens, qui comprend les serpens aqualiques.

HYDRIODATE, s. m. , liydriodas. On donne ce nom ì un genre de sels (kydriodsaure Salze, all.), qui sont formés par la combinaison de l'acide hydriodique avec les bases salifiables.

IYDHIODLux, adj., hyclriorlosus. L. Guclin nomme acide hydriodeux (hydriodige Saïre, all. ) l'acide bydriodique ioduré.

IIYURIODIQUE, adj. , hydriodieus. Nom d'un acide $H_{y}$ driodsïure, Iodwassersiof(sidure, all.), produit par la combinaisou de l'hydrogène avec l'iode. L'éther ligdriodique est un corps peu connu, sous le rapport de sa composition, el donton doit la découverte à Gay-Lussac.

IIYDHIODITE, s.m. , hrdriodis. On appelle ainsi un genre de sels (hydriodigsaure Salze, iodhallende hydriodsaure Salze, all.), qui sont produits par la combinaison dc l'acide hydriodeux avec les bases salifiables.

iry Driodene, s. m. , lyydrioduretum. Combinnison d'iode ct d'hydrogène avec un autre corps. L'liydriodure de carbone (Kohlenhy-driod, Iodkohlenwasserstom, all.), admis par quclques chimistes, d’aprìs Sérullas, est regardé par d'autres comme un hydrnealbure d'iode.

MDEIQUe, adj., hydricus. Dans la nomenclature chimique de Berzelius, on donne cette épithite aux composés d'uu corps simple ou d'un eorps halogène avec de l'hydrogène. Ex. acide ou oxide hydrique, eau; suroxide hydrique, eau oxigénce; telluride hydrique, gaz liydrogène telluré; sulfocyanide hydrique, acide hydrosulfocyanique.

IIDDOAKÉE, adj. , hydroaeratues. Sons ce nom, Rotassel a ćtabli une classe de Cryplogames, ou il range des plantes dont les unes vivent dans l'can et les antres dans l'ail.

HDDRO MLUMEATE, s. m., ly dro-aluminas. liendant nomme ainsi un aluminate qui contient de l'eau combince chimiquement.

ITDHO-ALUMTNEUx, adj. , $7 y-$ Aromaluminosus. Se dit d'un minéral qui contient de l'cau et de l'alumine. Ex. Plombly Gedro-alumineux.

IIYDMO-AR(VIENTO-GYANIQUE, adj. , hydro-argento-cyanieus. Synonyme de hydro-artyro-cyanique. Vorez ce mol.

IIIDRO-ARGIrEux, adj., hydroarçilosus. $\mathrm{O}_{1}$ a donné le nom de volcans Iydro-argitenx aux salses, parce qu'elles rejettent de l'argile délayée dans de l'eat.

HUDRO - STGTRO- CYANTQUE, atj., hycdro-areyro-eyanicus. Ittner admet un acide hydro-argyro.eyanique (Silberblausänure, all.), dans lequel le cyanure d'argent jonerait le róle de radiend d'un hydracide. 
IIYDRO-AURO-CYANOUE, adj. , bydro-auro-cyanictes. Ittneradinet uu acide hy dro-auro-cranique (Gold'lausäure, all.), dans lequel le cyanure d'or jouerait le rôle de radical d'un hydraeide.

HYDROBATHACLES, adjeet. et s. m. pl., Mydrobatrachi ( vijwo,

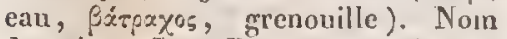
donné par J.-A. Ritgen à une famille de Reptiles batraciens, comprenant eeux qui vivent habituellement dans l'eau ou dans des lieux humides.

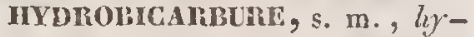
drobicarburclum. Composé d'hydrogène biearboné ct d'un corps simple. Ex. Hydrobicarbure de chlore.

MVDROBIEs, adj. et s. f. pl., $H_{y}$ drobie (v้นus, eau, fiow, vivie). Noin donné par Reiehenbach à une tribu de la famille des Haloragées, eomprenant celles qui vivent dans l'eau.

IIYDROBISULFATE, s. m. , hydrobisulphas. Nom donné anx hydrosulfates dans lesquels la proportion du sonfre est double de celle de l'hydrogène.

IYYOROBORIQUE, adj. , tyrdroboricus. Berzelius nonme l'acide hydrofluoborique fluoride lyctroborique.

IYYDROBRANCIIES, adj. et s. m. pl., Hydrobranchiata (üjoso, eau, $\beta p \dot{x} \gamma \chi(x)$, branchís). Nom donné par Lamarck à une section de l'ordre des Mollusques gastéropodes, comprenant ceux qui ont des branehies propres à respirer l'eau.

IIYDRQBRONATE, s. m., $h y d r o-$ bromas. On donne ee nom à un genre de sels (hydrobromsaure Salze, all.), qui sont produits par la combinaison de l'acide hydrobromique avec les bases salifiables.

HYOROBROMIQUE, adj. , Tydrobromicus. Nom d'un aeidc (Bromwas. serstoffsäure, all.), qui résulte de la compinaison du brome ayec l'hy- drogène, et qui a été déeouvert par Balard.

HYDrocanTHARES, adj. et s. m. pl., Hrdrocanthari (údwo, eau, *xंขexpos, searabée). Nom donné par Cuvier, Latreille, Goldfuss, Ficinus ct Carus à une tribu de la fimille des Coléoptères earnassiers, comprenant ceux de ees insectes qui vivent dans l'eau.

HVDROCANTHARIDES. Voycz Hydrocanthares.

IVDROCAREONATE, s. m. , hydrcearbonas. Nom donné, dans la nomenclature chimique de Berzelius, à des sels doubles résultant de la comhinaison d'un earlonate avec un hydrate (ex. Hydrocarbonate magnésique, ou magnésie blanche). Ce terme a été adopté par Bcudant, qui désigne ainsi des combinaisons d'un carbonate et d'eau.

IHYDROCARBoné, adj., hydrocarbonatus. Caudolle désigne sous ce nom ceux des malćrianx immédials des végétaux que quelques chimistes appellent neutres, et qu'on peut, d'après les expériences de Proust, considérer comine représeutés par une molécule d'cau et une de carbone.

IYYDROGARBURE, s. m., lyydracarburetum. Combinaison d'hydrogène et de carbone avec un autre corps. Ex. Hydrocarbure de chlorc.

HYDROCARYES, adj. et s. f. pl., IIydrocaryes ("̈r)wo, eau, rapus, noix). Nom donné pas Candolle à une tribu de la famille des Onagrarićes, qui a pour type le genre Trapa (noix ou châtaigne d'eau), et que Link eonsidère comme une famille distinete.

HYDROCALLE, s. f., hydrocau-

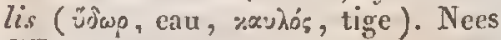
d'Esenbeck désigne sous ce nom les tiges noueuses, garnies de feuilles engaînantes, qui nagent dans l'eau. Il ne cile aucun exemple.

uYorocíréEs, adj. et s, f. pl., 
Hydrocerex. Nom donné par Blum ì une famille de plantes, qui a pour type le genre Ilydrocera.

IIYDRochaneEs, adj. ct s. f. pl., Hydrocharece. Nom donné par Reichenbach ì uuc tribu de lá famille des Hydrocharidées, qui renferme le genre Hrdrocharis.

iYTonocharinéEs, adj. ct s. f. pl., Hydrocharidece. Famille de plantes, établie par Jussieu, qui a pour type le genre Hydrocharis.

uYonociétudoois, adj. et s. m. pl., Hydrochelidoncs ( v้วิup, eau,

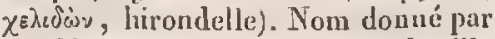
Goldfuss et Lesson à unc famille d'oiseaux nageurs ou Palmipèdes, ayant pour type le genre Sterna ou Hirondelle de ner.

IIYDROCHLME, s. f. , hydrochemia. Partie de la chimic qui traite spécialement de l'eau.

IYYDROCHLORATE, s. m., hydrochloras. $\mathrm{On}$ appelle ainsi un genre de scls (salzsaure Salze, all.), qui sont produits par la combinaison de l'acide hydrochlorique avec les bases salifiables.

HYDROCHLORIQUe, adj., $h y$ drochloricus. On nomme acide hydrochlorique (Salssäure, Clelorwasserstoffsïure, all.) un acide qui résulte de lin eombinatison du chlore avec l'hydrogène; ciller hydrochlorique, un composé découvert par Courtanvaux en 1759 .

IIXDROGILOHOCYANIQUE, adj., hydrochlorocyanicus. Gay-Lussac et Liebig admettent un aridchydrochlorocyanique (Chlorcyansiiurc, all.), e'est-à-dire composé de chlore, de cyanogène et d'hydrogène, qui sc produit quand on décompose l'argent fulminant par l'acide liydrochlorique.

IIXDROCHLORONITRIQUE, adj., hydrochloronitricus. On a donné le nom d'acide hydrochloronitrique à l'eau régale jaqua regis ; Königgs(passer, Goldscheidewasser, all.), qui est un mélange ou une combinaison d'acide hydrochlorique et d'acide nitriquc.

IIDDROGOBALTOCYANIOUE, adj. hydrocoballocyanicus. Quelques chimistes ont admis un acide hydracobaltocyanique (Kobaltblausäure , ali.), dans lequel le cyanure de cobalt jouerait le rôle de radical d'un hydracide.

IIYDroconÉis, adj. ct s.f. pl., Hydrocorea ( Jowap, cau, ropis, punaise). Nom donué par Duunéril à une famille dc l'ordre des Hémiptères, compreuant les punaises qui vivent daus l'eau. Voycz Rémitarises.

IIVDROCORIDES, adj. et s. f. pl., Hydrocoridar. Nom donné par Fallen à une famille d'Hémiptères, qui rculfcrne les punaises aquatiques.

WYmioconsses, adj. et s. f. pl., Hydrocorisce. Non donné par Cuvier, Latrcille, Goldfuss, Eichwald, Ficinus et Carrus à une famille de l'ordre des Hémiptères, dans laquelle ils rangent les punaises aqnatiques.

IIUROCORMUS, s. m., lycdrocormus; Schsvimmlialm (all.) (üowp, eau, xорu. $\sigma_{5}$, tige). Nees d'Esenbeck appelle ainsi la tige des Naias, Lem$n a$, etc., qui cst horizontale, et nage dins l'eau, ou à sa surface.

ivDHocoticlís, adj. et s. f. pl., Hydrocotylea. Nom douné par Candolle à une tribu de la fomille des Onlvellifèrcs, par Reichenlsach à une section de eelle des Araliacées, ayant pour type le genre Hyilrocotyle.

II DHOCOTYLINLES, adj. ct $\mathrm{s}$. f. pl., Mydrocotylincex. Nom donné par Hoffmann, Sprengel et Koch à une tribu de la famille des Ombellifères, qui a pour type le genre Hydrocotyle.

IIIDROCUPROCVANIQUE, adj., hydrocuprocyanicus. Quclques chimistes ont adunis un acide hydrocuprocyanique (Kupferblatsäurure, all.), danslequel le cyanure de cuivre jouerait le rồle de radical d'un hydracide. 
IIYDROCYANATE, s. m., lyydrocyanas. On nomme ainsi un genre de sels (blausaure Salze, all.), qui sout produits par la combinaison de l'acide hydroeyanique avec les bases salifiables.

IIIDROCVANIOUE, adj., hydrocyanieus. On appelle acille liydrocyanique (Hydrocyansäure, Blausüure, Cyanwasserstof]süure, preussisch blausüure, literische Siiure, all.) une combinaison de cyanogène et d'hydrogène. Lacide liy drosulfoeyanique sulfuré est nomnié sulfide lyydrocyanique par Berzelius.

IIY DROCYANONERREU, adject., hydrocyanoferrosus. Queiques chimistes donnent le nom d'acide lydrecyanoferreux (Eisenblausioure, all. ) au eyanure ferreux.

IYYDLOCYANOFERRIQUE, adj., hydrocyanoferricus. Le cyanure lerrique est désigné par quelques clumistes sous le nom d'acide lirdroferroeyanique (Eisenperoxyilblausüzre, all.).

IYY DRODOLOPES, adj. ct s. m.

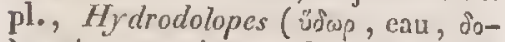

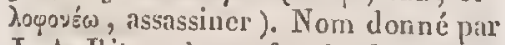
J. - . Ritgen à une famille de reptìles ophidiens, comprenant les serpens venimeux aquatiques.

IYDRODXNAMUUE, s.f., hydrodynamiea ; Wasserkrafllelure (all.) (ưdwp, cau, dúvaps, force). Partie de la physique qui iraite du mouvement des liquides, des lois d'équilibre et de pression auxquelles ils obéissent.

IIURO-PLECTRIOCE, adj., $l y$ dro-eleetricus. Epithète donnéc aux plénomènes que produit la pile voltaïque, parce que la présence de l'eau est une condition de leur plein développement.

IIVIIOFERIOCTAMOUE, adj., hydroferrocyanicus. Synonyme de hydrocyanoferrique. Poyez ce mot.

HYDLOPLUATE, s. m. , hydro-
Ruas. Sel qui résulte de la combinaison de l'acide hydrofluorique avee une base salifiable; symonyme de fluorure.

IIYUROFLCOBORYUE, adj., hydrofuoboricus. Nom donné à un acide (Flussboruxsiüre, Borfluorvasserstoff siiure, all.) composé de fluor, de bore et d'hydrogène, on de fluoride hydrique et de fluoride borique.

II) DIROFLUORIQUE, adj., $/$ ydro. fuoriczis. On donne ee nom à un aeide (Flussspathsïure, Spathsäure, Fluorwasserstoffsiiture, all.) produit par la combinatson du fluor avec l'hydrogène.

II X DIOF LUOSILICIQUE, adjeet., byclrofluosilicieus. Nom donné à un aciule (Kieselfusssïure, Kicselfluorwassersto(fsünre, all.) composé de fluor, de silieium et d'hydrogène; ou de fluoride hydrique et de fluoride silieique.

IIDROFLUOTANTALIQUE, adj., lyydrofluotantaliers. Nom domné à un aciele (Taulfluorwasserstoff säure, all.) composé de fluor, de tantale et d'hydiogène, ou de fluoride bydrique ct de flnorure tantalique.

IIDTOFLLOTITANIQUL, adj. , h) elrofluotitanieus. Nom donnć ò un acide (Titanfuorwassersloff siisure, all.) compose de fluor, de titane et d'hydrogène, ou de fluoride hydrique el de fluorure titanique.

In DHOGENe, s. m. , hrdrogenium; Trassersioff (all.); idrogeno (it.) (üjos, cau, yivขsis, produire). Corps simp)!e, qu'on ne connaît encore qu'à l'état gazcux, qui a été découvert par Cavendish en $r \mathrm{~S}_{\mathrm{I}}$, et qui est appelé ainsi paree qu'en se combinant avee l'oxigène il produit de l'enu.

INDROGËxE, adj., hydrogenatus; qui contient de l'hydrogine à l'état de combinaison. Ex. Soufre lyydrogéné.

HIDROGÉNIDES, adj. ct s. m: 
pl., Hydrogenida. Nom donné par Beudant à une famille de minéraux, comprenant des corps gazeux qui donnent de l'ammoniaque par la combustion, ou des corpssolides qui donnent de l'eau par l'action d'un alliage de potassium.

InDROG kNIFline, adj., by drogeniferus; wassersto:fhualtig (all.) (hydrogenium, hydrogine, foro, porter); qui conticnt de l'hydrogènc. Êpithète donnće par Tondi au soufre subliné des s'anx thermales.

IIYDHOG ÉNOSUCCINIOUE, adj., hydrogenosuceinieus. Tondi ippeile Ie suecin earbone hydrogéno-suecinique.

IIDDROGÉologie, s. f., hydro-

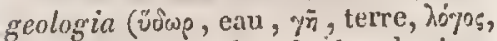
discours). Branche de la physique générale qui traitc des eaux répandues ì la surface du globe.

IIVDROGìne, adj., hydrogerus (v้owe, eau, gero , porter). Hedwig appelait vaisscaux hydrogères les tubes roulés en spirale et pleius de sue qu'il admcttait ì la surlaee du tube central, droit el aérifire suivant lui, dans les trachées des végétaux.

IYDROGE'TONLS, adj. ets.f. pl.,

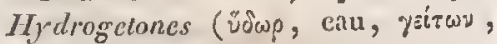
voisin). Link désigne sous ee nom uue fanille comprenant des plantes qui toutes vivent dans l'eari.

m'Dllogiosir, s. I., hydrogno-

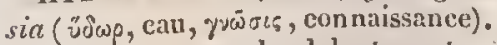
Histoire des eaux du globe terrestre.

monogirapille, s. f., lydro-

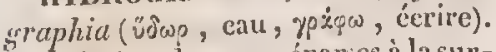
Deserjption des eaux éparses à la surface du globe.

MDHOGRAPHIUUe, adj., hydrosraphicus ; qui a rapport à l'lyydrographic.

MYDROGuRE, s. m., hydroguretum. Quelques chimistes ont employé ee terme, qui est synonyme de hydrure.

IIXROIIPERSULFOGANIQUE, adj., hydrohypersulphocyanicus; geschwefelte Schwefolblausäure (allo). Berzelius donne ee nom à un aeide produit par la combinaison de l'hypersullocyanogène avee l'hydrogène, et que Wochler considere conme une combinaison d'aeide hydroeyanique avee peut-être deux fois autant de soufre qu'il y en a dans l'aeide liydrosulfocyanique.

HODROJOBOLLS, adj. et s. m.pl., Hydrojaboli (vojop, cau, iopoìas, venimeux). Nom donué par J.-A. Ritgen à une famille de Reptiles ophidiens, comprenant les serpens venimeux et aquatiçues.

UYDROLÉACÉES, adj. et s. f. pl.; Hydroleacce. Nom donné par Kunth à une famille de plantes, qui a pour type le genre Hydrolea.

INDROLLES, adj. et s. f. pl., $\mathrm{Hy}^{\circ}$ drolea. Nom dorné par R. Brown a a une fimille de plantes, ayant pour type le genre Hydrolea.

HY'DhOLOGIE; s. f., hydrologice (volwp, eau, dóyos, diseours). Histoire de l'eau cn général, de ses propriétés et de ses diverses manières d'être dasis la nature.

IIYTROLOGIQUE, adj., hyelrologicus; qui a rapport à l'hydrologie.

InDDrOLYTES, adj. et s. m. pl., Hydrolyles (vodwp, eau, húes, dissoudre). Nom donné par C.-F. Naumann à une classc de minéraux, comprenant ceux qui sont solubles dans l'eau.

HO ROVANG ANOCYAXXUE, adj., hyrdromanganocyaniczs. Quelques chimistes admettent un acide hydromanganocyanique (Manganblausärt$r e$, all.), dans lecruel le cyanure de mangauèse jonerait le rôle de radieal d'un hydraeide.

UVDRONÉTÉORE, s. m., hydrometeorus. Métćore aqueux, ou produit par l'eau ì l'état de vapeur, de liquide ou de glaec.

IYYDROMÉTRIDES, adj. et $s$. f: 
pl. , Hydrometridce. Nom donné par Leach à une famille de l'ordre des insectes Hémiptères, qui a pour type le genre IIydromctra.

IIYDihomolGES, adj. et s. f. pl., Hydromolga (üowo, eau, podyos, salamandre). Nom donué par J.-A. Ritgen à une fanille de Reptiles, comprenant les salamandres aquatiques.

HYDROMVE, adjeet. et s. f. pl.,

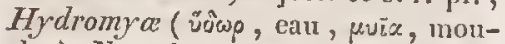
che ). Nom donué par Duméril à une famille de l'ordrc des Inseetes diptères, comprenant ceux dont les larves vivent daus l'eau.

ITYDROMYzides, adj. ct s.f. pl., Hydromyzides. Non donuć par Cuvier, Falicn et Latreille ì une soustribu de la tribu des Muscides, comprenant ceux de ces diptìres dont les larves sont aquatiques.

IIYDHONEMATÉES, adj. et s.f. pl., Hycironematea, Hydronematei. Nom donné par Wiegmann et Nces à un groupe de végétiux eryptogamcs, intermédiaire cntre les mucors et les conferves; par Meycrà uue famille de Champignons aquatiques; par Reichenbach : uıc section de la famille des Mucédinées : coupes qui toutes ont pour type le genre 15ydronema.

IIYDRONICKÉLOCYANIQUE, idj., hydronickelocyanicus. Woehler admet un acide hjdronicliclocyanique (Nickelblausïure, all.), dans lequel le cyanure de niekel joucrait le rôle de radical d'un bydracicle.

HYDROPALLADOCYANIQUE , adj., hydropalladocyanicus. Quelques chimistes admettent un acidc hyodropalladocyanique ( Palladiumblausäure, all.), dans lequel le eyauure de palladium jouerait fe rôle de radical d'un hydracide.

IYDROPELTELES, adj. ct s.f. pl., Iydropellidea. Nom donné pal Candolle à une tribu de la famille des Podophyllées, qui a pour type le genre Hyclropcltis; par Bartling a une classc renfermant les familles des Cabombces, des Nymplıæacées ct des Nélumbonces.

ITDROPERIONE, s. m., hydro-

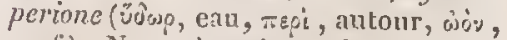
oeni"). Nom donné par Breschet au liquide qui distend le kyste formé par la membrane caduque.

IIIDROPEISULAFATE, s. m., lydropersulpluas. Hydrosulfate dans lequel lia proportion da soufre est quintuple de celle de l'hydrogène.

HDROPH.LE, adj., hydropha-

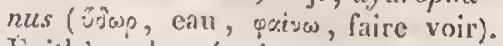
Lipithète doméc ì unc rarićté de quarz, parec que lorsqu'on la plonge dans l'eau elle acquicrt de la transparence, en s'iubibant de ce liquide.

Hyolophos, adj. ct s. m. pl., Hydrophides ( vंjo), eau, öocs, serpent). Nom domé par Blainville à un groupe de Reptiles ophidiens, qui comprend les serpens aqualiques.

HYDROpHuLes, adj. et s.ni. pl.,

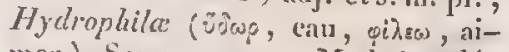
mer). Sous ce nour, Moéluring désignait une famille d'oiseax, qui correspond at celle qu'llligher a établic sous le nom de IIygrobales.

HiDhORHLines, adject. et s. $\mathrm{m}$. pl., Hydroplitiela. Yom donnć par Leuch is une famille de l'ordec des Coléoptères, qui a pour type le genre Mrdrophiliss.

nyonopnLmen, adjact.ets. m. pl., IIydropliliie. Nom domé par Lamarck, Cuvicr, Latreille, Goldfuss, lichwald, Ficinus et Carus à une tribı de la fanille des Colćoptéres palpicarncs, ayant pour type le geure Hydrophilus.

II YDROVIOLnOPInDE, adj. ct s. m. pl., H) dropholiduphides ("Oowp, eau, ọiì, écuillc, öpre, serpent). Tou donné par J.-A. Ritgen à une famille de licptiles ophidicns, comprenant les serpens qui sont cou- 
verts d'écailles et qui vivent daus l'enu.

IIDRopuone, adj. , hydropho-

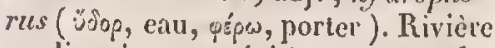
appliquait cette épithète aux substances qui attirent ct eonservent fortement l'humidité de l'air.

IITDROPIORES, adj. ct s. m. pl., Hydrophori. Nom donné par Battara à une classe de Champignons, comprenant ccux qui se résolvent facilement ct promptement en liquide.

IIVROPIIOSPIATE, 5. m. hydrophosphas. Combinaison d'un phosphatc et d'eau.

IIDROPHospinté, adj. Se dit d'un minéral qui consistc en une base combinée avee de l'acide phosphorique, plus de l'eau. Ex. Alumine lydrophosphaté, on Wavellite.

IIYUROPIY GES, s. ‘. pl. , Hydro. pleyca (üowp, eau, püros, fucus). Nom donnć par Frics à unc cohorte de la famille des Algues, comprenant les algues aquatiques.

WVIOPIYLLÉes, adj. et $s$. $f$. pl., Hydroplyllece. Nom donné par Brown à une lamille de plantes, par Link it une section de eclle des Cordiacées, ayant pour type le genre $H_{y}$ drophyllum; par Schrader à̀ unc tribu de celle des Borraginćes.

IIIDNOpHYTis, s.f. pl., II.ydrophyta (vँowp, cau, ตvтòv, plante). Nom donné par Iatamourousx aux Algues aquatiques de Linué, qu'il avait auparavant uppelées Thalassiophytes. Parmi les botanistes unodernes qui ont plus particulièrement ćtudié cette classe de Cryptoganmes, on distingue Agardh, Bertoloni, Jommemaison, Bory, Dillwyn, Draparnaud, Frics, Gaillon , Girod-Chautrans, Grateloup, Greville, Link, Lynghye, Mertens, Mohr, Nees d'Esenlueck, Stackbouse, Trentepohl, Turuer, Vaucher et Weber.

IYUROPIYTOGRAPIIE, s. fćm., hydrophylographia ("vंwp, eau, py- тòv, plante, ypó $\varphi \omega$, ćcrire). Descrip tion des Hydrophytes.

IYYNOPIITOLOGIE, s. f., hydropleytologin (v้๊wo, eau, ovròy, plante, גivo; discours). Partic de la botanique qui traite spécialement de l'histoire des liydrophytes.

IMnRopitycis, adj. et s. f. pl., Hydropityea. Nom donné par Reichenbacls a une tribn de la famille des Lythrariées, qui a pour type le genre Hydropityon.

ITYDiOPLATTINOCYANIQUE, adj., hydroplatinocyaniezs. Quelques chimistes admeltent un acide hydroplalinocyanique (Platinblausiuure, all.), dans lequel le eyanure de platine jouerait le rôle de ridieal d'un bydraeide.

IVIDIOPTÉnIDEs, subst. f. pl.,

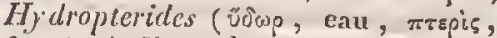
fougère). Nom domné par Willdenow à un ordre de plantes Cryptogrames, comprenant ce qu’il appelle les fougcres aquatiques, e'est-ìddire la famillc des Marsiléacées.

IIYDROQUAUHSULATE, subst. m., bidroquadrisuiphas. Ifydrosulfate clans lequuel la proportion du soufre est quadruple de eelle de l'hydrogène.

indROSLLLNATE, s. m., hydroselenias. $\mathrm{On}_{\mathrm{n}}$ appelle aitsi un gente de sels (hydroselensaure Salze, all.), qui sont produits par la combinaison de l'acide hydrosélénique avec les bases salifialoles.

IIV DLOSELENIQUE, adj , hydrosclenicus. L'acide hydrosélénique $\left(H_{y-}\right.$ droselensïure, ali.) résulte de la combinaison du sćlćnium avee l'luydrogence.

IIY DrosmidRuM, s. m., hydrosidcrum, siderum; Wasscreisen (all.). Bergoman et Meyer ont donné ce nom au phosphure ile fer, considérć par eux comme un tnétal distinct, erreur qui a ćté rectifiée depuis par Meyer, Kliproth et Schecle. 
HYDROSHICATE, s. m., hydrosilicas. Combinaison d'un silicate et d'eau.

IYVDROSILICILX, adj., hydrosiliciosus. Terme usité en minéralogie pour désigner un corps qui contient de la silice et de l'eau. Ex. Cuivre hydrosiliecux.

nYDROSTATIQUE, s.f., hydrostatica; Trasscrstandlehre (all.) (üdwp, eau, "irrua, se tenir). Partie de la physiñue qui a pour objet de déterminer lcs conditions d'équilibre des liquides et les pressions exercées par cux sur les parois des vascs qui les contiennent.

IIDDROSTATIQUES, adj. ct s. m. pl., Hydrostatica. Nom donné par Cuvier et Latreille à un ordre ou à unc fauville de la classe des Acalìphes, par Eichwald à une famille de colle des Cyclozoaires, rcnfermant ceux de ces animaux dont le corps offre plusieurs vessies, ordimairement pleines d'air, qui servent a les suspendre et soutenir dans l'cau.

IYDHOSULFATE, s. m. , hydrosulphas. On appclle ainsi, en minclalogie, des combinaisons de sulfates et d'eau; en chimie, un genre de sels (lyclriothionsaure Salze, all.), qui sont produits par la combinaison de l'acide lydrosulfnrique avec les bases salifiables. Berzelius róserve ce nom pour ceux de ces sels dans lesquels l'hydrogène et lc soufre sont en proportion égale. Thénard nomme hydrosulfates sulfurés les composés contenant plus de soufre qu'il u'eu cntre dans l'hydrogine sulfurć, mais dont on ne connaît ni l'ćtat de saturation, ni celui de sulfuration.

IHYDOSULF OCARBONIQUE, adj., lydrosulphocarbonicus. On donne ce nom ì un acide (Kohlenschwefelwassersto/fsïure, Rotlisiure, all.), qui contient de l'hydrogène, du soufre ct du carbone, et que Berzelius appelle sulfide carbohydrique.
IrVDROSUL FOCYANTQUE, adj: , hydrosulphocyanicus. L'acide hydrosulfocyanique (Schwefelblausïurc, Seluve felcyanwassersto/fsüure, all.), qui résulte de la combinaison de l'hydrogène avec le sulfocyanogène, a èté découvert par Rink.

IXDROSULFURE, s. m., hydrosulphuretum ; Sehwefelwasserstoffuerbindung (all.). Combinaison d'hydrog’́ne sulfuré avec un autre corps. Berzelius préfère ce mot à celui $d^{\prime h y-}$ drosulfate, cette dcrnière terminaison annonçant communément la présence d'un oxacide.

MDRosULEURi, adj. , hydrosulphurosus. Berzclius nomme cyanogène hydrosulfuré un composé pcu connu, découvert par Woeliler, qui paraît résulter d'unc combinaison d'hydrogène avec du cyanogène et du soutre cn d'autres proportions que celles qui existent dans le sulfocyanogène et l'hypersulfocyanogène.

IIDROSULFLREU, adj., hydrosulphurosus. Nom donnć par Thomson à un acide qu'il a obtenu cn mêlant ensemble des volumes égaux de gaz hydrogène sulfurć et de gaz acide sulfurcux, et dont l'existence avait été annoncée, en I 86, par Kirwan.

IIYDROSULFUILUUE, adj., hydrosulphurieus. On nomnc acide hydrosulfurique (II)drothionsïure, Schwcfelwasserstofsäure, all.) une combinaison de soufre et d'hydrogène. C'est le sulfide hydrique de Berzelius.

HYDROTELLURIQUF, adj. , hydrotelluricus. On a proposé d'appeler acide hydrotellurique (Hydrotellursüure, Tellurwasserstoff süure, all.) le gaz hydrogène telluré, qui a la propriétć de s'unir aux bases salifiables et de les saturer jusqu'a' un certain point.

IIYDROTELLUROGYANIQUE, adj., hydrotellurocyanicus. Quelques chimistes admettent un acide lydrolcl- 


\section{IIYDR}

lurocyanique (Tellurcyansïure, all.), dans lcquel le cyanure de tellure joncrait le rốle de radical d'un hydracide.

IIYDROTHOCARBONIOUE, adj., hydroltiocarbonicus. Nom donné à un acide (Hydrothiocarbonsüurc, all.), qui est composé de earbone, de soufre et d'oxigène.

IXDROTHIOCAREONATE, $5 . \mathrm{m}$., liy drothiocarbonas. On nomme aiusi un genre de sels (hydrothiocarbonsaure Salse, all.), qui sont produits par la combinaison de l'aeide hydrothiocarbonique avee les bases salifiables.

IINDROTIIONATE, s.m., hydrothionas. Nom d'un geure de scls (hydrothionsaure Salze, all.), qui résultent de la combinaison de l'acide $h_{y}$ drothionique avee les bases salifiables.

IIYDROTHIONEUx, adj., hydrothionosus. L. Gmelin apprile acide hy drothioneux (hydrothionige Süurc, all.) l'hydrure de soufre ou soufre hydrogéné.

IIYDROTHONIQUE, adj. , hydrothioniczes. Quelques chinistes donnent ee nom ì l'aeide $(\boldsymbol{H})$ drollionsïure, all.) plns généralement eonnu sous celui d'acide hydrosulfurique.

HVIROTHIONIA, s. m. , herdrothionis. Nom donné par (inuelin à un genre de sels (hyclrothionigsaure Salze, all.), qui correspondent aux sulfures hydrogénés on liydrosulfures sulfurés, et qui résultent. de la combinaison de l'aeide hydrothioneux avee les bascs.

InYDRothÉMELLivess, adj. et s. f. pl., Hydrotremellina. Meyan propose de former sous ee nom un groupe particulier de Cryptogames aquatiqucs, eomprenant tous les rhampignons qui se développent daus l'cau, sur les substanees animales en décomposition.

IIXDROTRISULFATE, s. m. , hydrotrisulphas. Trisulfate qui contient
HYGR

de l'eau à l'ćtat de combinaison. Ex. Hydrotrisulfate d'alumine.

IIX'DROTRLSULFURE, subst. m., iydrotrisulphurelum. Hydrosulfure dans lequel la proportion du soufre est tripple de celle de l'hydrogène.

IIYDROXANTIQUE, adj. , hydroxanthicus. Nom domné par Zeise à uss acide (Xanthogenwasserstoffsäure, Hydroxanthsïure, all.), qu'il regarda d'abord comme une eombinaison de xamthogène el d'hydrogène, mais que depuis il a eonsidéré comme un oxacide, et appelé en conséqquenee acide xinsthique.

IIDLOXIDE, s. m., hydroxydrum. Combinaison d'un oxide métallique et d'eau.

IINDroxinE, adj., lydroxydatus. Se dit d'un métal oxidé et combiné avee de l'eau. Ex. Urene hrdroxide.

II'DROzINGOCMANrQue, adj., hydrozincocyanicus. Quelqnes chiinistes admeltent un acide hydrozinco. cyanique (Zinkblausizure, all.), dans lequel le cyanure de zine jouerait le ròle de radical d'un hydraeide.

IVInozoés, adj. ct s. m. pl.,

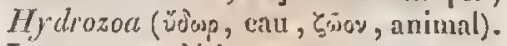
Lanouroux clésigne sous ee nom un embramchement du règne animal, comprenant les animaux, tels que les Mollusques et les Zoophytes, auxqucls l'eau est indispensable à tous les âges ct dans tous leurs ćtats.

II) DRURE, s. m., hydrurctum, hydretum. Combinaison solide d'un métal ćlectro-positif avee l'lyddrogुc̀e.

IIYDRUih, adj.; qui contient de l'hydrogène.

IITHML, adj., hremalis (hrems, liver); qui vit ou végète cn hiver. Eix. Equiscum hycmale, Panorpa hyentalis.

IIYGROBATES, adj.et s. m. pl., Hygrobala, Hy grobate (viyodo , eau, Bairw, marehcr). Nom donné par IIliger, Goldfuss, Ranzani, C. Bona- 
parte et Eichwald à une famille de l'ordre des Eehassiers, comprenant des oiseaux auxquels leurs longues jambes permettent de marcher dans l'eau.

IIYGROBIÉES, adj. et s. f. pl. , Hygrobice (irgoiv, cau, piow, vivre). Nom donné par L. $-C$. Richard à une fantille de plan tes aquatiques, queCandolle considère comme une simple tribu de celle des Haloragées.

HYGROGÉOPIHLS, adj. et s.m.

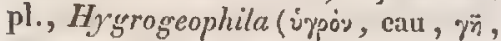

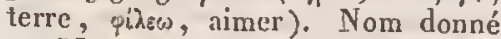
par Menke à un sous-ordre de l'ordre des Gastéropodes Cølopnés, conıprenant ceux qui vivent à la fois sur terre et dans l'eau.

IIYGROLOGIE, s. f. , hy'grologia (irpò, cau, lógos, discours). Histoire de l'eau, traitć sur l'eau.

IIYGROMETRE, s. m., hygrome-

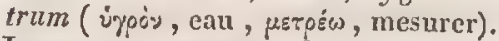
Instrument propre à fairc connaître la quantité d'humidité que contient l'air atmosphérique ou tout autre gaz.

HYGROMÉTRIE, s. f. , hygrometria. Partie de la physique qui traite des moyens d'apprécier les variations de l'humidité de l'air, la quantité d'eau en vapeur contenue dans l'air ou dans un gaz quelconque.

IIYGRONLTRIQUE, adj., hygrometricus ; igrometrieo (it.); qui a rapport à l'hygroniétric. On appelle état hygrométrique d'un corps, la quantité plus ou moins eonsidérable de vapeur aqucuse qu'il contient, et $f a-$ cultć hysrométrique, le pouvoir quil a d'absorber plus ou moins de celle vapeur. Hygrométrique se dit aussi d'un corps ou d'une substance qui est suseeplible d'éprouver quelque changement de la part de l'humidité atmosphérique. Le Porlicra hysrometrica rapproche, dit-on, ses folioles dès que le temps sc dispose à la pluie. Les appendices du péricline du
Lepteranthus hygrometrietts, forlement arqués en dehors pendant la sćcheresse, se redressent quand l'almospbère devient humide. Les lanières de la collerette du Geastrum hygrometricum, roulées sur clles-mêmes par un temps sec, se déroulent ct prennent une position horizontale par l'effet de l'humidité. Les pćdicules du Funaria hygrometrica se tordent sur eux-mêmes par la sćcheresse, et se déroulent avec rapidité lorsqu'on les mouille.

HYGROPHILE; adj., hygrophilus (úyoìs, eau, oithew, aimer); qui aime l'humidité, les lieux humides. Ex. Agaricus bygrophilus, Lasiandra hygrophila.

HIGRORITHES, s. m. pl. , Hygrarniches ( บंypiry, can, öpres, oiseau ). Nom donné par J.-A. Rilgen ì un ordre de la classe des Oiseaux, eomprenant ceux qui vivent dans l'cau.

HYGROSCOPE, s. m. , hygroscopium (íypiry, cau, $\sigma \times 0 \pi \tilde{c} \omega$, ('onsidérer). Instrument propre i faire connaître l'existence de la vapeur aqueuse dans l'air ou dans un gaz.

IXGRoscopicité, s. f., hygrascopicitas. Proprićté dont jouissent un grand nombre de corps inorganiques, et tous les corps organisés vivans ou morts, d'altirer ou d'abandonner de l'humidité, selon les cireonstanecs, de manière à se trouver sous ce lapport, avec le milicu ambiant, dans un état d'équilibre dont la proportion est donnéc par la nature mêne de leur tissu.

HYGROSCOPIE, s. f., lygroscopia. Synonyme de hy grométric.

IIYGRoscorloue, adject., $h y$ groscopicus. Synonyme de hygrométrique.

IIGRUSINE; s. f. , hygrusina (íyós, liquide, ovirix, essenee). Nom donné par Bixio à la partie des huiles esseptielles qui reste liquide à 
zéro. Synonyme d'Eléoptène. Voyez ec mot.

IIYL APYRIIYNQUES, adj. et s.m. pl., Hylapyrlynchi ( $\lambda_{n}$, taillis, airsis, haut, púrzos, bec). Nom donné par J.-A. Rilgen à use famille d'oisenux sylvains, comprenant ceux qui ont le bec élevć.

IVLidBates, adj, el s. m. pl., Hylebates (" $\lambda_{n}$, taillis, faivw, marcher). Nom donné par Vieillot à une famille d'oiscaux sylvains, comprenant ceux à qui la disposition de lcurs paltes permet de marcher aisćment dans les taillis.

IIYLÉLUYXES, adj. ct s. f. pl., Hylcmides ( $\mathrm{J}_{n}$, taillis, $\mu$ vĩ $\alpha$, monche). Nom donné par Robincau-Desvoidy à une section de la tribu des Myodaires Mćsomydes Anthomydes, comprenant ceux de ces insectes qui vivent dans les taillis et les haies.

IIYLINs, adj. et s. III. pl., $H_{y}$ lina. Sous ce nom Gray désigne une tribu de la famille des Ranades, qui a pour type le genre IIyla.

MULOBATRACIENS, adj. ct s.m. pl., Hylobatrachi ( Üin, taillis , Px́rpayos, grenouille). Nom donné par J.-A. Ritgen à une tribu de la classe des Reptiles, qui a pour type le genre Hyla.

HILOCMASMOPTÈres, adj. cts. m. pl., Hylochasmopteni ( $\mathrm{YZn}$, tail-

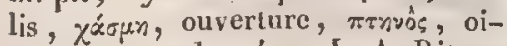
seau ). Nom donnć par $J_{\text {. }}-\Lambda$. Ritgen à unc famille d'oiseaux sylvains, comprenant ceux qui ouvient le bec pour saisir leur proic au vol.

IIIOCLASMOP'TìNES, adj. ets. m. pl. , Hrloclasmopteni ( Uंगn, taillis,

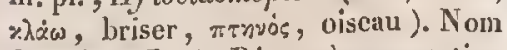
donné par J.-A. Ritgen à unc section de la classe des oiscaux sylvains, comprenant ceux qui se servent de leur bec pour écraser ou briser les objcts qu'ils serrent.

IIYLORLATYRIYYQUes, adj. ct s. m. pl., Hyloplatyrleynchi ( Vìn,

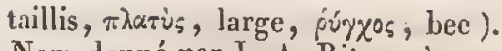
Nom donnć par J.-A. Ritgen à une famille d'oiscaux, comprenant ceux qui vivent dans les bois et qui ont le bec large.

IIYLOPTh̀丶

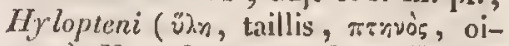
seau ). Nom donné par J. $-\Lambda$. Ritgen à un sous-ordre de la classe des oiseaux, comprenant ceux qui vivent dans les furêts.

IIYORTIORIIYNQUES, adj. et s. m. pl., Hylorthorhynchi ( taillis, opo ós, droit, pưv $\chi^{05}$, bec). Nom donnć par J.-A. Ritgen à une section de la classe des oiseaux sylvains, comprenant ceux qui ont le bee droil.

IYLOTRYPANOPTÈNES, adj. et s. m. pl., Hylotrypanopteni (

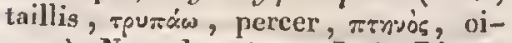
seau). Nom donné par J.-A. Ritgen à une section de la classe des oiseaux. sylvains, dans laquclle il range ceux qui se servent de leur bec pour percer.

HULOzOISME, s. m. , hylozoismus ( ${ }^{\prime \prime \lambda \eta, ~ m a t i e ̀ r e, ~ \zeta ̧ ่ \omega, ~ v i v r e) . ~}$ Système dans lequel on attribuc à la matic̀re unc existence primitive, et où l'on considère la vie comme n'étant qu'une de ses proprićlés. Ce terme a étć créé par Kant.

IYYLYPSOPTL̀NES, adj. et s. m. pl., Hylypsopteni (

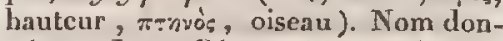
né par J.-A. Ritgen à une famille d'oiscaux sylvaius, comprenant ceux qui aiment à se percher au haut des arbres.

MVMĽ́nLLYTRES, adj. ct s. m. pl.,

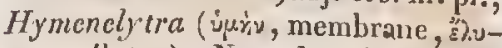
tpov, élytre). Nom donné par Latreille et Eichwald à une famille de l'ordre des Hémiplères, renfermant ceux de cesinsecles qui ont les élytres meinbraneuses.

IYMÉNION, s. m., hymenium, lymeneum, membrana thecigera; 
Schurz, Bruthaut, Keimhaut, Schlauchschicht (all.)'; imcnio (it.) (ú $\mu x_{i} y$, membranc). Persoon a désigné sous ce nonı une expansion menturaneuse qui, dans les champignons, porle les corpuscules reproducteurs, et qui alfecte des formes trìs-varićes, celle de lames dans les Agarieus, eclle d'épines dans les Hrdnum, eclle de papilles dans les Telephora.

IIVMÉXOCARPES, adj. et s. m. pl., Hymenocarpi (نेx's, nembrane, s.хpтìs, fruit). Nom donné par Meyer à un ordre de la classe des Lichens, comprenant ceux qui sont munis d'une mernbrane proliggère.

IIYMéNODEs, adj. et s. f. pl., Hymenodes ( $\dot{\mu} \mu \dot{\gamma}$, membrane, ơvoù, dent). Nom donné par Palisot-Beauvois à une tribı de la famille des Mousses, comprenant celles dans lesqueltes il naît de la columelle une membrane qui s'élend horizoulalement sur l'ouverture de l'urne, et qui porte des dents.

IYMÉNOGASTHRQUE, adj., lymenogastricus ( yiǹ, inembrane, frotrip, estomac). Daudin donne celte épithète aux oiscaux qui ont l'estomac membraneux.

IIYMĹXOLÉPIOOPTLIIES, adject. et s. m. pl., IIyrmenolepidoptera

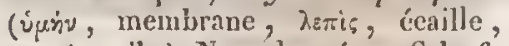

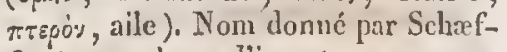
fer à une classe d'insectes, comprenant ceux qui ont quatre ailes membrancuses couvertes d'une poussière éeailleuse.

IIMÉNOUYCES, s. m. pl. , $I I J_{j}-$ menomyci, IIymenomyectes ( บุy.r. membrane, $\mu$ ins, champignon). Nom sons lequel frries désigne une cohorte de la classe des champinnons, comprenant eeux qui ont à l'extérieur une membrane fructifire dans laquelle sont placés les eorpuseules reproducteurs.

IIYMĹNoPAPPÉ:Es, adj. et s.f. pl., Hymenopappece. Nom donné par H. Cassini à un groupe de la section des Hélianthées héléniées, qui a pour type le genre Hynenopappus.

HYMísopiryuacées, adje et $s$. f. pl., Hymenophyllacece. Nom donné par Gaudichaud à une tribu de la famille des lougères, qui a pour type le genre Hymenopliyllum.

WMUĹXOPHLLEES, adj. et s. f. pl., Hymenophyllea. Nom donnć par Bory et Reichenbach à une triba de la famille des fougères, ayant le genre Hymenophyllum pour type.

IIUMENOpOnEs, adj. ets. m. pl., Hymenopodes ( ưniv, membrane, noūs, pied). Sous ce nom, Mohring désignait une famille d'oiseaux, comprenant ceux qui ont les doigts réunis jusqu'à la moitié par une membrane.

IIYMúxoptìnes, adj. et s. m. pl., Hymenoptcra (ưuris, membrane, тre epir, aile). Tous les entomologistes modernes, Fubricius excepté, admettent sous ce nom un ordre de la classe des iosectes, comprenant ceux qui ont quatre ailes peu veinées ou sans nervules.

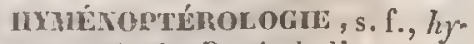
menopteralogicia. Partic de l'entomologie qui iraile des hyménoptères.

iTMévopTĹlioLOGIQUe, adj. , hymenopterologieus; qui a rapport à l'hyménoptérologic.

IIYMÉNOPTELOLOGUE, s. m., hymenoptcrologus. Eutomologisle qui s'occupe spécialement des hyménoptères.

IIxMÉvoniIzE, adj., hymeno-

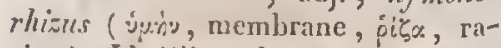
cine). L'Allium ligmenorlizüum est ainsi appelé à cause de ses bulbes, qui soni complasces de membranes fumes et trís-serrées.

nMminospoubs, adj. et s. m.

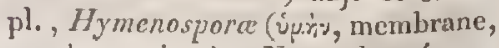
бтора́, graine). Nonı donnć par Reichenbach à une section de l'ordre des Lichens aseoplares, comprenant 


\section{IIYPA}

eeux qui ont une membrane proligère.

IMMLNOTHAi.AMES, adj. et s. m. pl., Hymenothalami ( $\dot{\mu} \mu \dot{r} v$, membrane, 0 x́tu.s, lit). Nom donné par Fries à un ordre de la famille des Lieheus.

IVMLENoTHỉciens, adj . et s. m. pl., Hymenothecii (íury, membranc, Onxn், boite). Nom donné par Per'soon et Marquis à un ordre de ehampiguons, dans lequel ils rungent ecux qui sont pourvus d'un hyménion, ou d'une membrane eontenant les eorpuscules reproducteurs.

IIYMĹNULES, adj. et s. m. pl., Hymonuli. Nom douné par Fries à une triba de l'ordre des Tremelles, qui a pour type le genre $H_{y}$ menula.

IYYOSCYMMINE, s. f. hyoseyamina. Brandes avail donné ee nom à un aleali organique trouvé par lui dans l'H yoseyamusniger, mais que Lindlerggson a reeoniuu être du pliosphate ammoniaco-magnésien.

IrYoskininies, adj. et s. f. pl., Hyoseridece. Nom donné par H. Cassini à un groupe de la seetion des Lactueées seorzonérées, par Lessing it une sous-tribu de la tribu des Chieoracécs, ayant pour type le genre Hyoscris.

IXPANTIE; ; s. m., hypanthium ( $\dot{u} \pi \dot{c}$, sous, ${ }^{\circ}: 005$, lleur ). Link appelle ainsi la partic inférieure du ealiec des plantes, qui a fort souvent unc toute autre manièrc d'être que la supérieure, qui, par exemple, dans le Rosa, prend la forme d'une baie (t se resserre à son orilice, tandis que la parlie supéricure se flétril.

MYPANTIEYs, adj. et s.f. pl.,

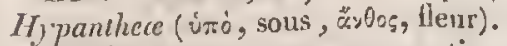
Link désigne sous ce nom uue section des plantes exogines, comprenant eelles qui ont un ealice nonophylle, ou divisé jusqu'à la base, et une eorolle monopétale insérée au réceptacle.
IIYPE

623

MYPANTHODION, subst. m., hypanthodium. Link donne ec nom à l'extrémité eharnue d'un pédoncule qui se détache de la plante en neême temps que le fruit, soit qu'elle eonserve la forme ordinaire des pédoneules (ex. Artocarpus), soit qu'elle s"élargisse (ex. Dorstenia), soit enfin qu'elle sedilate en une sorte de bourse ou de poche qui enveloppe et renferme les fleurs et les fruits (cx. Ficus).

IIYISNTIMONIEUX, adj., hypantimaniosus. Berzelius nomme sulfide lypantimonieux (Anderthalbschusfelantimon, all.) le premier degré de sulfuration de l'antimoine, qui joue quelquefois le rôle de base, mais plus souvent celui d'acide.

IYYPANTIMONITE, adj. et s. m., bypantimonis. Sel produit par la combinaison de l'oxide antimonieux avee une base. Ex. Iypantimonise ammonique.

IIYPAHGMLÉ, adj., lypargrrezts (نт:ò, sous, äprupos, argent); qui est argenté en dessous, comme les feuilles du Tephrosia hyparsyrea.

IIYPAIISÍNIEUx, adj., hyparseniosus. Berzelius appelle sulfide hyparseinicux (Einfachschwefelarscnik, all.) le second degré de sulfuration de l'arsenic, ou le réalgar.

visuThíes, adj. et s.f. pl, Hypelyirece. Nom donné par Presl à une tribu de la famille des Cypéracées, qui a pour type le geure $\mathrm{H}$ pelyirum.

HYPELAURIQUE, adj. , lyperauricus ( (umżo, au dessus, aurum, or). Le Telluride hrperaurique est ainsi nommé parce que le tellure s'y tronve eombiné invec une proporlion d'or doulle de eelle qui existe duns le iclluride aurique.

IYPERBatrous, adj. , hyperbaticus (imepGarís, qui prédonine ). Épithète donnée, dans la nomenclature minćralogique de Haïy, à une rariété qui résulte de la combinaison 
de plusicurs formes, dont l'une est la primitive, et les autres, étant dues à des lois très-simples de déeroissement, sont eelles que l'on reneontre le plus communément parmi les cristaux de l'espèce. Ex. Chaux earbonatéc hrperbatique.

IIYPERBBORE, adj., hyperborezts (ن่rs̀ , nu delì, Bopíxৎ, Borée). Sc dit des plantes et des animaux qui habitent dans le nord, vers les contrées voisines du cercle polaire. Ex. Phalaropus hyperboreus, Dicranum hyperboreum.

UYPERGÉNÈSE, s. f., hyperge-

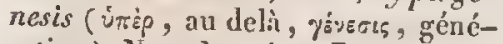
ration ). Nom donné par Breselset aux déviations organiqucs qui sont déterminćes par une augmentation ou un excès de la force formatrice.

II PERHEXAPES, adj. et s. m. pl., Hyperhexapi, IIyperhexapoda ( Latreille désigne sous ce nom une branehe d'animaux articulés, conlprenant ceux dont le nombre des pattes, à pcu d'exceptions près, est de huit au moins, dans l'état parfait.

IYPERHEXAPODES. Voyez HyPERHEXAPES.

IUPPÉLCEES, adj. et s.f. plur., Hypericea. Nom donné par Choisy à une section de la famille des $\mathrm{Ily}_{\mathrm{y}}$ périeiuées, qui renferme le genre Hyperiezs.

ITPÉLICINÉES, adj. et s. f. pl., Hypericinea. Famille de plautes, établic par Jussieu, qui a pour type le genre Hypericus.

IIYPERICOIDES. Vojez HypertCINÉEs.

IIYPĹRINEs, adj. et s.f. pl., $H_{\text {r }}$ perince. Nom donné par Latreille à une famille de l'ordre des Crustacés amphipodes, qui a pour type le genre Hyperia.

ITPERHOL YBDICO - POTASSI QUE, adj. , hypermolybdico-potassicus. Nom donné, dans la nomencla- ture chimique de Berzclius, à des sels doubles qui résultent de la combinaison d'un sel hypermolybdique avec un sel potassique. Ex. Oxalate hypermolybulieo-potassique.

ITPERMOL YBDIQUE, adj. , hypermolybdicus. Berzelius appelle sulfide hypermolybdique (Vierfachschuef elmolybdïn, all.) le troisième degré de sulfuration du molybdène, et sels lyperntoly bdiques ceux qui ont l'acide molybdique pour base (ex. Sulfate hypermolybdique).

IIPÉrioGÈNes, adj. et s, m. pl.,

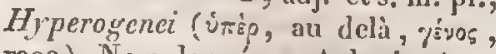
race). Nom donné par Acharius à un ordre de la classe de Lichens, comprenant ceux qui ont des ennceptaeles composés, e'est-ì-dire réunis plusieurs ensemble dans un tubercule ou unc verrue de substance homogène.

ITPEROXIDE, s. m., hyperoxy-

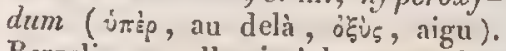
Berzelius appelle ainsi les suroxides.

IIYPEROXIDE, adj., hyperoxydus. Nom donné, dans la nomenclature minéralogique de Haüy, à une varićté de chaux carbonatée offrant la combinaison de deux rhomboiddes, l'un aigu, qui est l'inverse, et l'autrc incoup parablement plus aigu.

HYPERSTANELX, adject. , $h y$ perstannosus. Nom donné par Berzelius à l'un des sulfures d'étain.

IIPERSTÉNIQUE, adj., hyperstenicus. Les minéralogistes appellent Syćnitehy persténique une espèce dans laquelle l'amplibole est remplacéc en tout ou en partic par de l'hyperstìue.

IMPERSTONIQUE, adj., lerperstomieus (insio, sur, бrópa, bonehe). C. Richard donne celle épithìte a l'inserfion des étamines, quand elle a lieu au dessus de l'orifice du tube du calice, ct par conséquent au linbe de ce dernier organe (ex. Eléa snées). 
IIYPERSTYLYQUE, adj., lyper-

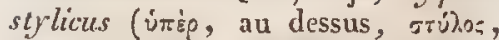
style). A. Richard donne cette épithètc à l'insertion des élamiues, q̣ıand elle a licu sur le contour d'nn ovaire complètenucut iufère (cx. Jussiere), ou loin de la base du stylc, sur in prolongement ou evascment du caliee (ex. OEnothera biennis).

IIPERSULFOCYANIDE, s. m., Berzelius appelle ainsi un liypersulfoeyanure jouant lc rôle d'acide ou de eorps électro-négatif, dans une combinaison.

IIYPERSULFOGYANOGÉNE, $s$, in. Berzelius doune ce nom à unc combinaison de soufre et de cyanogène que l'on n'est point encore parvenu á isoler.

IYPERSULFOCYANURE, s. $m$. Nom donné par Berzelius aux combinaisons de l'hypersulfocyanogèneavee les corps simples, principalement avec les métaux.

H Y PERSUL F OMOLBYD.ATE, s. m., hypersulphomolybdas (molybdïnüberschwefligesatze, Vierfachschwefelmolybdïnsehwefelmetallcn, all.). Berzelius appelle ainsi un genre de sursels, qui sont produits par la combinaison de l'hypersulfide niolybdique avec les sulfolases.

HYPERSULWURE; s. m., hypersulphuretum. Sulfure au maximum de soufre, comme le lypersulfure d'lydrogine, dont on ue connaît pas encore la composilion.

IIYPERVANAIICO-POTASSIQUE, adj., hypervanadico-potassicus. Epithète donnéc par Berzelius à des sels donbles qui résultent de la combimaison d'un scl d'acide vanadique avec uu sel potassique. Ex. Sulfate hypervanadico-potassique.

NYPERVANADICO-STLICIQUE, adj., hypervanadico-silicicus. Berzelius donne ce nom à des sels doubles qui sont produits par la combinaison d'un sel d'acide vanadique avee un sel d'acide silicique. Ex. Phosphate hypcrvanadico-silicique.

IIYPERVANADICO - SODIQUE adj., lypervanadico-sodicus. Non donni par Berrelius à des sels douliles qui doivent unissance a la combinaison d'un sel d'aeide vanadique avec un sel sodique. Ex. Phosphate byporranadico-sodique.

IIXTII, s. f., hypha; Saite (all.) (ขึ๗, tissu). Willdenow désignait sous ce nom les expansions filamentcuses, un peu charnues, déliquescenles on filreuses, des Moisissures.

IIYPILLTES, adj. ct s, m. pl.,

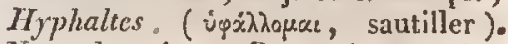
Nom donué par Ranzani à une famille de l'ordre des Passereaux, comprenant des oisenux qui ne font que sautiller.

IIYPIANTES, adj. et s. m. pl.; Hyphantes (น Noul donné par Ranzani ì une famille de l'ordre des Passereaux, coinprenant des oiscaux qui mettent beaucoup d'art dans la confection de leurs nids.

IYPIASME, s. n., hyphasme

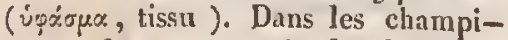
guons dont une partie du thalle floconncux est couchée, tandis que $l^{3} \mathrm{au}$ tre, qui est dressée, porte les corpuscules reproducteurs, Link donne le nom d'hyphasme à la portion étalée.

IVPHONTCES, s. m. pl., II/

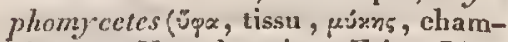
pignon ). Non donné par Fries, Link et Sprengel à une classe ou a un ordre de Chanpignons, renfermant ceux de ecs végélaux qui ont le thalle floconneux, coune les Moisissures.

nypliosponks, arlj. et s. m. pl.,

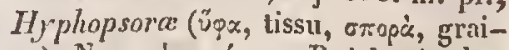
ne). Noin donné par Reichenbach à une section de l'ordre des Lichens gymnosporés, comprenant ecux qui ont la forme de filamens.

HYPNÉEs, adj. et s. f. pl., Hrpnea. Nom donné par Reichenluach à 
une tribu de la famille des Mousses, qui a pour type le genre Hypnum.

IIVPNOTDES, adj. et s. f. pl., Hypnoidei, Mypnoider. Nom donné par Arnott, Greville, Furnrohr et Bridel à une tribu de la famille des Mousses, ayant pour type le genre Hypnum.

IIYPNOPHLE, adj., hyponophi-

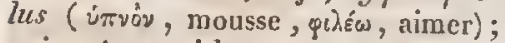
qui croît parmi les mousses (cx. $A g a$. ricus hypnoplitus). Le Plysarum hy pnoplitum croît sur l'Hypnum $\mathrm{cu-}$ pressiforme.

INYPOBLASTE, s. m., hypoblas-

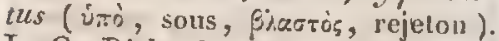
L.-C. Richard et Nees d'Esenbeck appellent ainsi un corps charnu, épais, généralement discoïde, qui est appliqué contre le fond de la fossctte du périsperme, claus la graine des Graminces. C'est l'organc que Grertner appelait vitcllus, que Kunth, Brown, Poiteau, Turpin, Fischer et Treviranus nomment cotylćdon, et auquel d'autres encore donnent le nom de scutcltum.

IVPOBI A STETrede, adj, , hypoblasteticus. Nom donné par Wall roth à la couche inféricure du thalle ou blustème des lichens ì expinsions larges et étalées.

IHYPOBRAvGMES, adj. et s. m. pl., Hypobranchiata, Hypobranclia (نтro, sous, fox́y\%єx, branchies). Nom donné par Scliweigger, Fischer, Menke et Eichwald a une famille de Mollusques gastéropodes, comprenant ceux qui ont les branchies plaećes au dessous du corps.

ITYPOCALICIE, s. f., hypocalycia ( donné par Desvaux à une classe de plantes, renfermant les dicotylédones apétales ì ćtamines liypogynes.

HYPOGARPE, s. in., hypocarpium, Fruchtunterlag (all.) ( نло, sous, kugtis;, fruit). Beruhardi appelle

\section{HYPO}

ainsi les parties sur lesquelles le fruit repose.

IYPOCAPPOGE, adj. , hypocarpogaus ( $\dot{\pi} \pi \dot{0}$, sous, $x_{x p} \pi \dot{s}$, fruit, $\gamma \tilde{y}$, terre). Bodard appelle ainsi les plantes qui mûrissent leurs fruits et leurs graines sous terre. Voyez Hypogḱ.

IYPOCHERIDÉs, adj. ct s. f. pl. , Mrpocharidea. Nom donué par H. Casnini à un groupe de la section des Lactuećes scorzonérées, par Lessing à une sous-tribu de la Iribu des Chicoracées, ayant pour type le genre Hypocharis.

HYPOCHLE, s. m., hypochilc

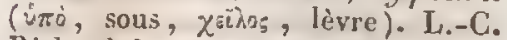
Richard donne ce nom à la partie inférieure du tablier des Orehidées.

HYPOCnLonique, adj., hypochloriezes. Nom que desrait porter l'acide oxichlorique, afin de correspondre à la nomenclature adoptée pour les acides du soufre.

ITPOCINES, s. m. pl., IIypoclıni. Nom donné par Fries à une section de la famille des Mucédinées, qui a pour type le genre Hypochnus.

HYPOCONDIE, s. m., Jypochondrium; ن́ro \%o dpeo\%; Weiche (all.). On appelle ainsi, chez les minumifères et les oiseaux, la parije latérale de l'alıdomen, au dessous du rebord des fausses cótes. Kirby donne le mêne nom, cluez les insectes, à deux portions de segmens, une de chaque côté, qui, dans quelquues genres (ex. Carabus), interviennent cntre lc premier segment ventral et la partie postćrieure de l'arrière-poitrine.

IYPOCONDRML, adject., hypochondrialis; qui appartient, à l'hypocondre (plumes ly) pocondriales.). Se dit aussi d'un animal dont les côtés du corps offirent quelque particularité de coloration (ex. Calamita lypochondrinlis).

MPOCOnOLL', adj., hrpororollatus ( $\dot{\pi} \dot{0}$, sous, corolla, corolle). 
HYPO

Se dit d'une plante dont la corolle est hypogyne.

IIYPOCOROLIIE, s. f. hypocorollia. Nom donné par Destaux ì une classe de plantes, eomprenant les dicotylédones monopétales à corolle hypogyne.

IYPOCATÉRFORME, adj., $h y$ pocrateriformis : prüscntirvellerförmig, tellcrförmig, untertassenförmig (all.); ipocrateriforme (it.). Se dit de la corolle, lorsqu'étaut monopétale et régulière, elle a son tube court etson limbe plane ou peu eoueave, comine une soueoupe très-évitsée (ex. Vinca); des stipules, quand elles forment un tube terminé par un limbe élargi et plane í ex. Polygonzem orientalc).

IIPODACTMU, s. m., hrpodactylum; Zchensohle (all.) (ن́no, sous, dixzulas, doigt). Dessous de chaque doigt de lin patte d'un oiseau.

HXPODERUE, s. m., hypoderma ( pelle ainsi la peau, agréablement coloréc dans quelques espèces, qui couvre les élytres des Coléoptères.

IIYPODERUE, adj., hypodermius; qui eroît sous l'épiderme des végétaux, comme le ehampiguon appelé Conoplea hypodermia.

HYPODERUIENs, adjeet. et s. m. pl. , Iy podermia, Iypodermii. Nom donné par Frieset Pieichenbach is un groupe de champignons, qui a pour type le genre IIrpoderma.

InXPDigariens, adjeet, et s. f. pl., Hypodicarpre (úrì, sous, dits,

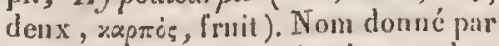
Agardh à une classe de plantes phitnérocot ylédones complètes pórigy nes, comprenant edlles qui ont deux pistils it deux ovaires réunis, conme les Caprifoliaećes, Rubiacées, etc.

HYPOGASTRE, s. m., hypogastrizm; Unter auch (all.) (ن்tio, sous, 7zarip, ventre ). Parlic inféricure du ventre. Sprengel donne ce nom aux stipules des Jungermannia,
IMPOGE, adj., hrpogaus; unterirdig (all.); ipogeo (it.) (imó, sons, yñ terre). On appelle cotylédon lypoogé, eelui qui reste sous terre lors de la germination. Celte épithète est donnée anssi i des plantes qui, après avoir fleuri à l'air , enfoncent lenrs pédonenles en terre, pour que les fruits y mûrissent (ex. Trifolium subterrancum), ou dont il n'y a que les fleurs enterrées daus le sol qui parviennent it mùrir, leurs graines (ex. Arachis hypogrea, Voandzeia subtcranea).

IMPOGLOSSE, adj., hypoglossus

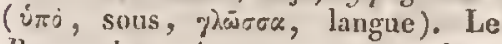
Ruescus ly po goglossum porte une languette sur ses feuilles, dans le milieu. Le Delesseria hypoglossa a la: forme d'une languc.

HYPOGONE, s. m., hypogonium ;

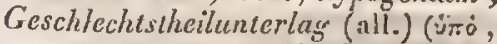
sous, yovn', semenec) Nom donné par Bernhardi à des parties membraneuses situées an dessous des organes génitaux, dans les plantes.

HYPOGYNE, adj-, hypogynus (نंrí, sous, quỷ, fenme). Se dit de la corolle, quand elle prend naissancesous l'ovaire (ex, Cheiran thuts); des étamines, lorsqu'elles sont fixées sur' le réceptacle, soit plas bas que l'ovaire, soil an niveau de sa base; des pítales, quand ils naissent d'un torus réduit à unc zone ćlroite sitnée sous l'ovaire.

IIPOGVNIT, s. f., hypogynia. Iftat d'une partie de la fleur qui s'insère an dessous de l'ovaire.

WYPOG VNIQU: adj., hypogrnicus. Se dit de l'insertion des élamines, des pétiles ou de la corolle staminifère, quand le point d'attache est en contzet, soit asee la base de l'ovaire libre, si celni-ei est fixé par celte base, el sans podoggne, au foud de la fleur (ex. Tiliacées), soit avee un polvphore (vorez ee mot), soit 
avec la eirconl'érenee de l'ovaire même (voyez Pledrogrniouer).

IYYPOLAMPRE, adject., hypolam-

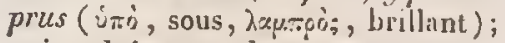
qui est luisunt en dessous, comme les feuilles du Pultenaa hypolampra.

IIYPOLEUQUE, adj., hypolencus,

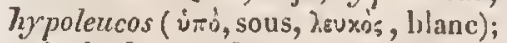
qui a le dessous du corps blane. Ex. Cebus hypoleucus, Phthiria hypoleuca, Tamnus lypoleucos.

HYPONTREux, adj., hyponitrosus. On a proposé d'appeler acide hyponitreux, untersalpetrige Süure (all.), le protoxide d'azote, qui jone le rôle d'aeide dans quelques circonstances.

HYPONITRITE, s. m., hyponitris. Genre de sels (untersalpetrigesaure Salze, all.), qui sont produits par la combinaison de l'acide hypouitreux avee les bases salifiables.

IYPOPĹTALE, adj. , hypopeta-

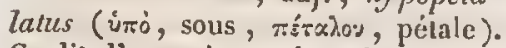
Se dit d'une plante dont les pétales sont insérés sous l'ovaire.

IYPOPLTAYIE, s. f. hypopetalia. Nom donné par Desvaux à une classe de plantes, comprenant les dicotylédones polypétales à étamines hypogynes.

HYPOI'HARYNx, s. m, hypopha-

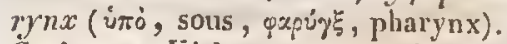
Savigny et Kirby nomment ainsi un appendice solide qui, dans quelques insectes hyménoptères, les Eizcera surtout, nait du bord inlérieur du pharynx, et s'emboîte avec lui.

IIYPOPHLÉODE, adject., hypo-

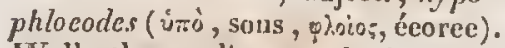
Wallroth appelle morphosis hrpophloeodes le dévcloppement des lichens qui naissent et vivent sous l'ćpiderme d'autres végétaux.

IIYPOPIOSPHITE, s. m., hypophosphis. On doune ec nom it un genre de sels (unterphosphorigsaure Salie, all.), qui résultent de la com- binaison de l'acide hypophosphoreux avec les base's salifiables.

IIPORHOSPIOREUX, adj. , hypophosphorosus. Nom d'un acide (un. terphosphorige Süure, all.), qui a été découvert par Dulong, ct qui est le premier des trois anxquels le phosphore donne naissance.

IITPOPIOSPHORIQUE, adj. On a appelé acide hypophosphorique, ou phosphatique, un acide qui n'est, d'après les reeherebes de Dulong, qu'une combinaison d'acides phosphorique et phosphoreux, ou un phosphate plosphoreux.

IYPOPHTHALMES, adj. et s. m. pl., Hypophthalma (i்ô, sous, ò Qẋjus, œil). Nom donné par Latreille à une famille de Crustacés décapodes maeroures, comprenant ceux qui ont les yeux très-rapprochés à leur insertion, laquelle se trouve sous le museau.

IMPOPIYLLE, adj., hypophylhis ( des champignons qui ne se plaisent qu'à la surface inférieure des fcuilles. Le Ruscus hypophyllum a ses flcurs au milieu de la surface inférieure des feuilles. Ie Protea hypophylla a ses fruits eachés sous les feuilles.

IITPOPHYLLE, s. m. , hypophy/lum, hypophyllium; Unterblat (all.) ( Nees d'Esenbeck appellent ainsi une petite gaine, représentant la véritable feuille, à l'angle de laquelle naissent des rameaux dont l'apparenecest la même que celle des feuilles. Ex. Asparagus.

HTPOPIILLINES, adject. et s. f. pl., Hypophy-llina. Non donné par Reichenbach à une seetion de la famille des Hépatiques.

IMPOPHYLLCARPES, adj. et s. f. pl., Hrpophy-locarpi (ía', sous,

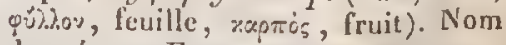
donné par Furnrohr à un groupc, par Bridel à une elasse de Mlousses, 


\section{HYPO}

renfermant eelles dont le fruit naît au dessous de la feuille aceessoire.

IIYPOPTLRE, s. m. , hrpopterum (ن่⿰ò, sous, $\pi \tau \varepsilon \dot{c o s}$, aile). Audouin désigna d'abord sous ce nom l'organc des insectes que depuis il a appelé paraptère. Vorez ce mot.

IYPOPTĹlié, adj., hypoptcratus. Épithète donnée par Mirbel à la cupule, quand elle est ailée in lérieurement. Ex. Cédre.

IIMPOPYGE, s. In., hypoprgium

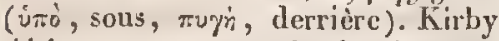
désigne sous ee nom le dernier segment ventral de l'abdomen des inseetes.

IUPOPYRRE, adj., lypopyrrus

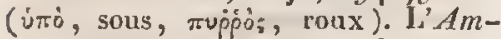
pelis hypopyrra a les flancs d'un roux orangé.

HYPOSPERMATOGYSTIDE, s. m., Mypospermaloeystidium ; Pollenunterlag (all.) ( $\dot{v} \pi \dot{0}$, sous, $\sigma \pi \dot{s} q u \alpha$,

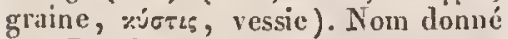
par. Bernhardi à de petites partics membrancuses qui, dans ccrtaines fouggères, paraissent servir de support aux masses polliniformes.

HYPOSPORANGE, s. m., Iyposporangium. Beruhardi appelle ainsi les indusies des fongères qui portent les sporanges mêmes. Ex. Adiantum.

IIVPOSTAMrNé, adj., hypostamineus ( Se dit d'une plante qui a les ćlamines hypogynes.

IIYPOSTAWINE, s. f., lypostaminia. Non donné par Desvauxà une classe de plantes, comprenant les dieotylédones monopétales à élamincs hypogynes.

iIYPOSTATE, s. m., hrpostala (iтi, sous, iraquzl, se tenir). Dutrochet appelle ainsi les corps parenchymateux et souvent transparens qui sont situćs sous l'emlıryon végétal, à l'institnt où il conmmenee à se développer après lia fécondation. Ces corps, ordinairement au nombre. de deux on trois, disparaissen 1 à mesure que l'embryon grandit, soit en totalité, soit en partie seulement, et, dans ce dernier cas, lenr résidu produit l'albumen.

IIPOSTIBLEux, adj., hypostibiosus. Synonyme de hypantimonicux.

IIYPOSTIßIITE, s. m., hypostibiis. Synonyme de hypantimonite.

IIVPOSTONE, s. m., hypostona

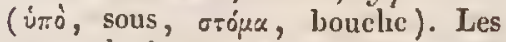
entomologistes allemands nomment ainsi a tort la faec des inseetes, ou la région qui s'étcud, entre les ycux, de la base des antennes à l'épistome.

IYYOSTONIDEs, adj. et s. m. pl., Mypostomides (i்rì, sous, orópre, bouehe). Nom donné par Latreille á une famille de poissons, eomprenant. ceux qui ont la bonche situce inférieurement, à la base du muscau.

IYPOSTRONE, s. m., hypostroma. Martius désigne sous ee nom un organe qui est ì peu près le même que celui auquel Link donne la dénomination d'hyphasme, e'est-à-dire la base sur laquelle, dans les Calieium, reposent les pédoneules qui supportent les corpuseules reproducteurs.

HYPOSULF ANTTHONTTE, s. m. , hjposulphantimonis. Berzelius appelle airisi un genre de sulfosels (unterantimoniehtschweflige Salee, all.), qui sont produits par la combinaison du sulfide bypantimonicux avec les sulfolases.

IIYPOSUTFARSÉNTTE, s. m., hy posulpharsenis; unterarseaichtschweflige Salze (all.). Nom donné par Berzelius à un genre de sull'osels, qui résultent de la combinaison du sulfide lyyparsénicux avee les sulfobises.

IIVPOSULFATE, s. m., hyposulphas. Nom d'un genre de sels (unterscluse folsaure Salze, all.), qui résultent de la eombinaison de l'aeide hyposulfurique avee les bases salifiables. 
IYPOSULFINDIGOTATE, s. m., hyposulpluindigolas. Nom donné à un genre de sels, qui résultent de la coinbinaison de l'aeide hy posulfindigotale avee les bases salifiables.

HYPOSUL FINDIGOTIQUE, adj. , hyposulphindigoticus. Berzelius désigue sous le nom d'acide hyposulfindigotique une combinaison qu'jl regarde eomme forme de bleu d'indigo soluble et d'acide hyposulfurique, quoique jusqu'à présent on ue soit point cneore parvenu à en extraire ce dernicr.

IIYPOSULFTTE, s. in., hyposulphis. Nom donné à un genre de sels (unterschwefligsaure Salze, all.), qui résultent dé la combinaison de l'acide hyposulfurcux avec les bases salifiables, et qu’on a appelés :ussi sulfites sulfurés.

IIYPOSULFOSTIBITE, s. m., $h y-$ posulphostibis. Synonyme de hyposulfantimonite.

ITYPOSULFUREUX, adj. , hyposulphurosus. Nom d'un acide (unterselwweflige Sï̈rre, all.), qui cst le premier des quatre auxquels le souf 'c donne naissance, et dont on doit la déeonverte a Vauquelin.

IYPOSULFURIQUE, adj., hyposulphuricus. Nom d'un acide (Unierschwefelsäure, all.), qui cst le troisième des quatre auxquels le soufre donne naissance, et dont on doit la découverte à Welter et Gay-Lussae.

IYPOTHWE, s. m., hipotema; Flechtenunterlage (all.) (ن்̀, sous, ¿отирь, se tevir). Wallroth désigne sous ee nom la face inférieure des expansion's des lichens.

IISOTIILLE, s. in., hrpothallus (i்ò, sous, $\theta x \lambda \lambda 0^{\circ}$, thalle). Nom donné par Fıies à la couche interne ou inférieure des lichens, parce qu'el!e sert en quelque sorle de base ou de soutien au thalle, c'est-il-dire il la couche externe, supćricure, ou corticale.
HYPOTHALLIN, adj. , hypothallinus. Fries donne cette épilhète à l'état élémentaire des Iichens dans lequel leurs deux couches constituintes sont eneore eonfondur's ensenible.

IIXPOTILCION, s. m., hypothe-

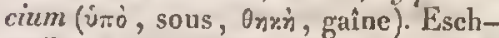
weiler désigue sons ce nom la base du thalame des Jichens, qui est ordinairement formée de eellules rondes et stérilus.

HYPOTIĹNAR, sulsst. m., hypo-

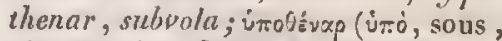
ósup, main). Saillic qui se remarque à la face palmaire de la main, sous le petit doigt et dans sa direction.

IIPOVANADATE, s. m., hypovanadas. Nom donné nux combinaisons de l'oxide verd dı vanadium ou duvanadale vanadienue avec une base, en les considérant comme résultat de l'union d'une base avee un acide hypovanadique, intermédiaire entre l'oxide et l'acide vanadiques, hypotlı̀se qui $d u$ reste ne parnît point fondée.

IITPOVANADTQUE, adj. , hyporenadicus. On pourrait considérer dans certains cas l'oxide verd de vanadium enmme un acide hrpovanadique. Foyez Hypovanadate.

HУPOXANTIE, adj., lypoxan-

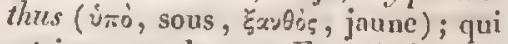
est jaune en dessous. Ex. Aicles hypoxanthus.

IYPOXIDE, s.m., hypoxydum. Daus la nomenelature chinique de Berzelius, ce mot est synouyme de sons-oxide. Guibourt nomme l'acide hyposulfurique hpoxile sulfurique.

IIYPOXIDÉES, adj. et s. f. pl., Hypoxidra. Norn donné par R. Brown à une famille de plantes, qui a pour type le genre Hrpoxis.

MVPOXYLELS, adj. et s. f. pl. , Hypoxylee, Hypoxyla. Nom douné par A. Bronghiart à une fumille de la 
classe des champignons, qui a pour type le genre Hypoxylon.

IYYPOZOIQUE, adj., hypozoïctus

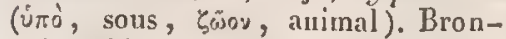
gniart désigne sous ec nom un ordre de terrains, eomprenaut les terrains primordiaux de crislallisation inférieurs à tous ceux dans lesquels on rencontre des débris de corps organisés.

IIYPSIPILE, adjeet., hypsipilns

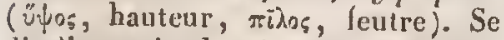
dit d'un animal qui a des épincs sur le dos, comme la chenille du Thais hypsipile.

IIIPSOMÉTRIE, s. f., hypsometria; Illöhenmessang (all.) (ừns, hau-

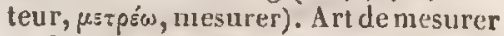
la haulcur relative ou alsolue d'un licu ou d'une portion quelconque du sol terrestre, par des nivellemens, des observations barométriques, ou des opérations trigonométriques.

HYPSOMÉTRIQUE, adj. , hypsometricus; qui a rapport à l'hypsométrice. J. Oltmans a publić des tables hypsomćtriques.

IIYPSOPTL̀NES, adj. et s.m. pl.,

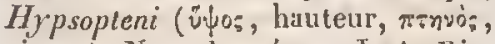
oiseau). Nom donné par J.-A. litgen à un sous-ardre de la classe des Oiseaux, comprenant ceux qui recherchent de préférence les lieux élevés.

IIYPSORTIORIYNQUES, adj. et s. m. pl., Hypsorthorhyncki. Nom donné par J.-A. Ritgen à une famille d'oiseaux, comprenanl ceux qui ont un vol élevé et le bec drrit.

IIPSSOPINE, s. f., hyssopina. Herberger appelle ainsi une base salifiable qu'il dit avoir découverte dans l'Hyssope.
MYSTÉRANDRIE; s. f., hysteran-

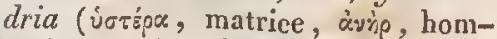
me). Nom donné par L.-G. Richard à unc classe de son systìne sexuel modifié, qui eomprend les plantes ayant plus de dix étamines insérées sur un ovaire tout-à-lait infère.

IIYSTLRANTIE, adj., hysteran-

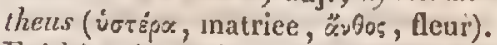
Epithète imposée par Viviani aux plantes dont les fleurs apparaissent avant les feuilles (ex. Tussilago).

II'sThínOPHONE, adj., hysterophorus ( ter). Le Parthenium hysterophoris a été ainsi nommé parce que l'enveloppe de l'ovaire représente deux lèvres sćparées par une seissure, ee qui lui dlonne l'aspeet d'une vulve.

UYSTÉnOPIYTES, s. f. pl., hysterophyla ( planle). Fries désigne sous ee noin les champignons, parce que, suivant lui, ils ne pcuveut naître qu'aux dépens de corps organisés mouraus ou morts, qui leur servent en quclque sorte de inatrice.

IIYSTRELIE, s. f, , hystrella (iv$\tau \dot{z} p x$, matrice). Mirbel appelle ainsi les pistils simples, qu'ils soient formés d'une seule pièce eoneave, ou de deux pièees réunies par les bords. C'est la même chose que carpelle.

IYSTRICIDES, adj. et s.m. pi.,

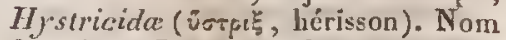
donné par Gray à une famille de l'ol." dre des Mammifères Rongeurs, qui a pour type le genre Hystrix.

IISTRICIENS, adj. et s.m. pl., Hystricii. Nom sous lequel Desma. rest désigne une famille de Mammifères Rongeurs, ayant le genre Hystrix pour type. 
IANTIIIN, adj., ianthinus ("ay 0 \%, violet); qui est d'un violet plus ou moins brillant, comme le Coluber ianthinus, chez lequel cette coulenr paraît être due ì une altération produite par l'immersion dans l'alcool.

IANTHINES, s. f. pl., Ianthina. Nom donné par Lamarek à une famille de l'ordre des Mollusques traehélipodes phytiphages, par Blainville à une famille de l'ordre des $\mathrm{Pa}-$ raećphalophores asiphonobranches, ayant pour type le genre Ianthina.

IBLADES, adj. et s. m. pl., Iblades. Nom donné par Jueach à une fâmille de l'ordre des Cirripèdes eampylosomes, qui a pour type le genre Ibla.

ICINANTIE, , adject., ichnanthus

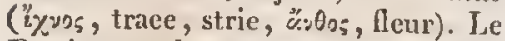
Panicum ichnanthum a ses épillets striés.

ICIINECMONIDES, adj. et s. m. pl., Ichneumonida, Ichncumonides. Nom donné par Isamarck, Iatreille, Leach, Cuvier, Eichwald, Ficinus et Carus à une famille de l'ordre des insectes hyménoptères, qui a pour type le genre Ichneumon.

ICIINEUMONIFOLIE, adj., ichneumoniformis; qui a de la ressemblance avee un ichneumon. Ex. Larra ichncumoniformis.

ICIINEUNONOLOGIE, s. f., $i c h-$

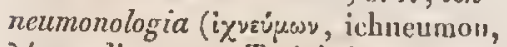
hóyas, discours). Traité des icluncumons. Gravenhorst a pulslić en 1829 , sous ee titre, une lisstoire des iehneumons d'Europe.

ICHNIOGRAPHE, adj., ichniogra. phus ("yjov, trace, ypג̌pes, éerire). Épithète donnéc par Linné amx bolanistes dont les ouvrages consistent prineipalement ou uniquement en fi- gures de plantes, comme Rheede, Plumier, Brunsfeld, ete.

ICIINOROAURES, adj. et s. m.

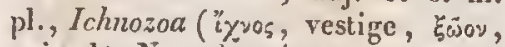
animal). Nom donné par Bory à une classe de Psyehodiaires, comprenant ceux de ees êtres qu'on peut regarder comme les ébauehes de l'aninalité, élant privés d'organes spéciaux, et égalemient doués de con tractilité dans toutes leurs parties.

ICHTIYYDINS, adj. et s. m. pl., Ichelyclina. Noru donné par C.-G. Elirenberg à une tribu de la classe des Rotiferes, ayant pour type le genre Ichthy-dium.

ICITIYODÈRES, adj. et s. m. pl., Ichthyodcro (ixgis, poisson, dépzs, peau). Nom sous lequel Latreille désigne une classe d'animaux à sang froid, comprenant ceux qui ont la forme et les tégumens des poissons, mais respirent par des branchies dont une des extrúmités se tronve fixéc à la peau.

ICHTHYODES, adj. et s. m, pl.,

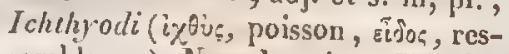
scmblanee). Nom donné par Wagler à un ordre de la classe des Reptiles, eorrespondant aux Protéides, qui on quelques rapports avee les poissons.

ICUTUYOGRA PUIE, s. to, ichllyorraphia; Fischbeschrcibung (all.)

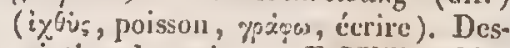
cription des poissons. F. Willoughby a publić en 1685 un ouvrage sons ec titre.

ICITIYYoInEs, adj. et s. m. pl., Ichihyoielcs, Ichllyoida, Ichlhroidei (i $\mathrm{O}^{3} \mathrm{i}$; poisson, हidos, ressemblance). Nom donné par Latreille à une famille de l'ordre des Amphibies pérennibranches, par Eichwald à une famille de Batraciens, comprenant 


\section{ICHT}

ceux qui ressemblent aux poissons par la forme, de leur corps et surtout la persistance de leurs branchies.

ICHTIIYOLOGIE, s. f., ichthyologia; Fischluunde (all.) (iYois, poisson, hóros, discours)! Branche de la zoologie qui traite de l'histoire des poissons.

ICIITHY OLOGleve, adject., $i c h$ thyologicus; qui a rapport à l'ichthyologie, aux poissons, ou à lcur histoirc.

ICIITIYYOL.OGISTE, s. m., ichthyologista. Naturalistc qui se livre spécialement à l'ćtude des poissons.

ICIITHYOPIIAGL, adj. et s. m., ichthyophagus; Fischesscr (all.) (i义$\theta \dot{u}_{\xi}$, poisson, $\dot{q}^{\alpha} \gamma(\omega)$ manger ); qui fait sa principale nourriture de poissons.

ICIITIYYPIIAGIE, s. f., ichthyophasia. Habitude de se nourrir principalcment ou habituellement de poissons.

ICIITIIYOSAURIENS, adj. et s. m. pl., Ichthyosaurii. Nom donné par Gray, Fieinus et Carus à une famille de reptiles, par Blainville à un ordre de la classe des Squamifères, ayant pour type le genre Ichthyosauris.

ICHTYYYOSALnomes, adj. et s. m. pl., Ichthrosauroidea, Ichlyyosauroidei. Noin douné par Fitzinger et Eichwald is une famille de reptiles, ayant le genre Ichlhyosaurus pour type.

ICITTIYQUE, adj., icheleycus (iðOis, poisson). On a appelé poison ich. thyoque un poison qui se développerail, dil-on, chez cerlains poissons, duus certaines circoustances. Tout ec qu'on a dit à eet ígard est sinon fiabulcux, au moins surcliargé d'cxagération. Il paraît cependant que la chair de certains poissons pcut altérer la santé de ccux qui cn mangent; mais c'est un phénomène qui denıande à êtrc constaté, ct dont surlout il faut étudier les circoustances.
ICMADOPIILE, adj., icmadophi-

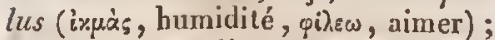
qui aime les lieux humides. Ex. A garicus icmadophilus, Biatora icmadophila.

ICOSAEDRE, adject., icosaedrus

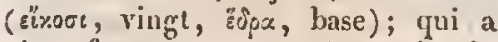
vingt facctes, comınıc les grains de pollen du Tragopogon. On donnc ce nom, dans la nomenclature minéralogique de Haïy, à une varićlé donit la surface sc compose dc douze triangles isocèles et de buit ćquilatéraux (ex. Fcr sulfurć icosac̈dre).

ICOSANDire, adject., icosander, icosandrus ( houme). Se dit d'une planle qui a vingt étamines ou plus, insérées sur le calice. Ex. Cleome icosandra, Melastoma icosundrum.

ICOSANDIRES, adj. et s. f. pl., Icosandice. Nom donné par Agardle à unc classe de plantes phanérocotylédones complètes et périgynes, comprenant celles dont les flcurs sont icosandres.

ICOSANDRE, adj. , icosandria. Non donué, dans le système sexuel de Linné, à unc classe et ì deux ordres de plantes, dans lesquelles se rangent celles qui ont vingt étamincs ou plus atlachées sur la paroi interne du calice.

ICOSANDRIQUE, adj., icosandricus. Synonyme d'icosandre.

IGOSIGONE, adject. , icosigonus (sixoos, vingt, qwrise, ingle); qui présente vingt angles, comme la tige du Cereus icosigonus.

ICTÉRIN, adj., iclcrinas ("หxєeos, jaunisse); qui a unc teinte jaune ou jaunâtre. Ex. Cypraca ictcrina, Tachina ictcrica. Voyez JaUne.

ICTULOCGEPIILLE, adj., ictero-

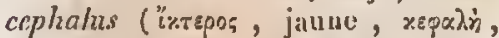
tĉte ); qui a la tète de couleur juunc. Ex. Pendulinus ictcroccphalus, Sylsia icteroccphala.

ICTÉrROMLLE, adj., icleromelas 


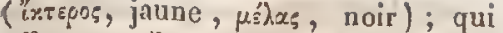
offre un mélange de jaune et de noir, comme le plumage du Pyranga ictcromelas.

ICTÉROPE, adject., icteropus

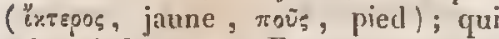
a les pieds jaunes. Ex. Pjranga icteropus.

ICTÉROPIRYS, adj., ictcrophrys

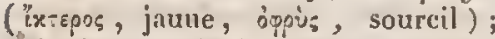
qui a les sourcils jaunes, ou qni offre au-dcssus des yeux une bande jaunc en forme de sourcil. Ex. Mrtscicapa icterophrys.

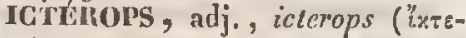

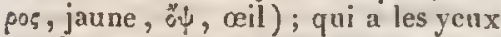
ou l'entourage des yeux jaunes. Ex. Philemon iolerops.

ICTÉROPTERE, adjcct. , ictero-

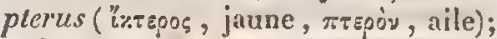
qui a les ailes jaunes, ou tachetées de jaune. Ex. Caprimulgus ictcropterus.

ICTÉnote, adj. , icterotis ("ixน६pos, jaune, oús, oreille). Le Psittactes icterotis a une tache jaune de chaque côté, depuis la mandibule jusqu'à la région temporale.

IDÉ ALISME, s. m. , idcalismıs. Système dans lequel on n'sccorde l'existence réelle qu'à la pensée, tout ce qui est étranger à l'cntendement étant regardé comme un simple produit de son action. Descartes, Malebranche, Berkeley et Fichte ont été, parmi les inodernes, les principaux défenseurs de ce système.

IDÉALISTE, subst.m., idealista. Partisan des docirines de i'idéalisme. IDÉN, s. f., iden, idnlum; iơz์ ,

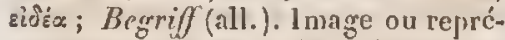
scutation d'un objet dans l'entend'ment. "Les idées sont le résultat des objets qui les excitent, des comparaisons qui lcs rassemblent, et du langage qui en facilite la eoneeption." (Mme de Stael.)

IDENTIQUE, adj. , identicus. On donne ec nom, dans la nomenelature minéralogique de Haïy, à une rariété de chaux carbonatćc dans laquelle les lois de décroissentent qui agissent sur le véritable noyau sont les mêmes que celles qui se rapportent au noyau hypothétique. Les minéralogistes disent que les angles d'un crisial sont idcntiques, lorsque, ayant leurs côtés égaux respectiveınent, ils sont du mêne nombre de degrés et font partie d'angles solides ćgaux. On donne aussi cette épithète aux bords d'un cristal, quand ils ont la même longueur, ou que les faees à la jonction desquelles ils sont situés, sont également inclinées entre elles.

IDENTITÉ, s. f. , identitas ; $U_{c-}$ bercinstimmung (all.). Conformité absolue entre denx choses. On appelle systeme de l'identité (Identitätssystem, all.) une doctrine, soutenue par Schclling, dans laquelle tous les objets cxistans ou concevables par la pensée sont envisagćs sous le point de vuc de leur identité, c'est-à-dire de leur unitć d'existence.

IDḱOLOGIE, subst.f., idcologia

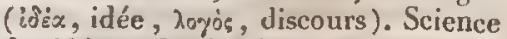
des idées, des fitcultés intelleetuelles de l'homme.

IDIO-ÉLECTRIQUE, adj. , idio-

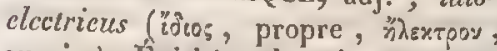
succin). Épithète donnće cn physique a tous les corps qui sont suscep. tibles d'acquérir les proprićtés électriques par le frottement.

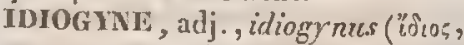
propre, qurn, fomme). Quelques botanistes ont donné cette épilbc̀te anx étamines, lorsqu'elles ne se trouvent pas placées dans la même fleur que le pistil.

IDIOGYNLE, subst. f. , idiogynia. Etat d'une plante dont les élamines sont idiogyncs.

IDIOvétatcroue, adj. , idiometallicus. Salvator del Negro appelle le galvanisme électricilć idiométal- 
lique, parce qu'il se unanifeste de lui-même, au contact de deux métaux.

IDIOPASSALE, adj. , idiopassalus ("ioios, propre, $\pi \dot{x} \sigma \sigma \alpha)_{0 s}$, passale ). G. Allman donne cette épithète aux plantes gui ont des passales distinets, ou qui en ont unseul oblique.

IDLOPIInEs, adj. ct s. m. pl., Idiophides ("idos, propre, öes, serpeni). Nom donnć par Latreille, Ficinus ct Carus à une section ou famille de l'ordre des Reptiles ophidiens, coniprenant les serpens proprement dils.

IDIOTHALAMLS, adj. et s. m. pl., Idivthalami. Nom donné par Acharius à une classe de Lichens, comprcnant ceux dout les eneeplacles different du thalle par lcur nature et leur coulcur.

IDIOTIQUE, adj., idioticus (ijonstxòs, particulicr). G.-G. Ehrenberg désigne sous le noun de Fungi idiorici Ics champignons dans lesquels, du rhizopode, s'ćlèvent des filamens libres et distinets, dont chacun porte soit des sporules éparses à sa surface, soit des vésicules remplics de spornies.

IDIOTROPIOSPERME, adject. , idiotrophospermizs. Nom donné par G. Allinan aux plantes qui ont soit un trophosperme latéral nonosperme, soit plusieurs trophospermes pariétaux, dispusés sans ordre, ou divergens au somnict.

IDOTÉAD lís , adj. et s.m. pl., Idotcada. Leach désigne aiusi une famille de Cruslacés, ayant pour type le genre Idotea.

IDOTĹIDES, adj. ct s. in. pl., Idoteides. Nom donné par Latreille, Cnvier et Eicliwald à unc famille de l'ordre des Crustacés Isopodes, qui a pour type le genre Idotea.

IDOTKLORME, adj. , idoleiformis. Kirby désigue par eelte épithète une larve hexapode du Brésil, dont on ne connât pas l'insecte parfait, et dont le corps très -déprinié ofire un dernier segurent alongé, terminć par plusieurs prointes, et ayant quelque rapport avee la partie postérieure du corps des idotéides.

lGASURATE, s. m., igasturas. Nom d'un genre de sels (igasursaure Salze, all.), qui résultent de la combinaison de l'acide igasurique avec les bases salifialiles.

IGASUnouE, adj. , igasurieus. Pelletier ct Caventou ont donné ce nom, d'après celui de la fève saint Innace en langue malaise, à un acide (I gasursïure, all. ), qu'ils ont découvert dans plusieurs espèces de Siryehnos, et que depuis ils ont appelé strychnique, dénonination que Berzelius rejette, pour conserver l'ancienne.

IGNR, adj., igneus; тupcxòs; feurig (all.); igncous (angl.) (ignis, feu); qui tient de la nature du feu (matière ignée, ou ealorique); qui est produit par le feu (roche ignee, origine igncee d'unc roche $)$. On nomme fusion ignée celle qu'un sel éprouve quand, après qu'il a perdu son eau de cristallisation, on conlioue de le chauffer, pourvu que la température devienne suffisanment élevée, ct qu'à cedegré de chaleur il ne puisse pas se décomposer.

IGNIAIRE, adj., igniarius; qui sert a fiaire de l'amadou, comnte la substance du Boletus igniarius, et le duvet qui couvrc toutes les parties, les jeuncs pousses surtout, de l' $A n-$ dromeda iyniaria.

IGNLCOULE, adject. , ignieollis (ignis, liu, collam, cou); qui a le con ou Ic corselet conleur de feu. Ex. Celonia ignicollis.

IGNICOLOH, adj., ignicolor, ignitus, igneus (ignis, feu, color, cou. leur); qui a la coulcur du feu, un ronge mêlé de jaune. Ex. Fusus 
ignicolor, Phasianus ignitis, Chrysis ignita, Solanum igneum.

IGNIQUE, adject. , ignicus. Oken donne cette épithète à unc classe de minćraux, comprenant ecux gui sont influcneés par le feu, dans lesquels les caraetères du feu se répètent par l'éclat, la fusibilité et la grande pesanteur.

IGNITION, s. [., ignitio, cande-

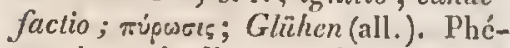
nomène qui a lieu quand il se dégage simultanément une grande quantité de calorique et de lumière, soit qu'il dépende de ce que le eorps dans lequel on l'observe a précédemment été soumis à une forte chaleur, qui l'abandonne sans causer en lui aucun changement, soit qu'il tienne à une combinaison de deux corps, ou à la désunion de deux corps combinés ensenble. Ce dernier cas est le plus rare; toutes les substanees qui s'y trouvent, comme entr'autres le ehlorure d'azote, ont cela de commun que les corps dont la séparation produit le phénomène de l'ignition sont unis par une affinité très-faible, qui n'agit qu'à de basses températures, et qui cesse quand la chaleur augmente, les corps se désunissant alors, ou sc combinant cnsemble d'une autre manière, qui est plus fixe.

IGNOBLE, adj. On appelle filons ignobles ceux qui renferment trop peu de minerai métallique pour que l'exploitation en soit avautageusc. Cette même épithètc était donnéc aux oiseaux de proic qui refusent de se laisser dresser aux exereices de la faueonnerie; le roides oiscaux, l'aigle, était par conséquent regardé comme un oiseau ignoble.

IGUANIDES, adject. et s. m. pl., Iguanides. Nom donné par Gray à une fanille de l'ordre des reptiles sanriens, qui a pour typele genre 1 guana.

IGUANILNs, adject. et s. m. pl., Iguanii, Igruanoidei. Nom sous lequel
Cuvier, Eiehwald, I atreille, Ficinus et Carus désignent une famille de Sauriens; ayant le genre Iguana pour type.

IGUANOIDES, adj. et s. nı. plur., Iguanoides. Nom que Blainville donne à une famille du sous-ordre des reptiles bispéniens, qui a pour type le genre Isuana.

ILE, s. f., insula; (all.); island(angl.); isola (it.). Purtion de terre plus ou inoins considérable qui est en tourée d'eau de toutes parts.

ILEADELPIE, s. m., ilcadelphus. Nom donné par Geoffroy Saint-Hilaire à des monstres qui sont doubles infërieurement, depuis et compris le bassin.

LES, s. f. pl., itia. On appellc ainsi, chez l'homme, les parties latérales et inféricures de l'abdomen. Straus donue le même nom, dans les insectes, à une plaque quadrilatère, située des deux côtés du protlıorax, et composée de deux pic̀ces, parce qu'elle est placée à l'origine des pattes, ct qu'on peut la considérer comme l'analogue du pubis dans le corselet.

ILICICOLE, adj. , ilicincolus (ilex, houx, colo, habiter); qui vit ou croît sur les houx, comme le R/yrtisma ilieincola sur les feuilles de l'Ilex Prinos.

ILICINÉES, adj. et s. f. pl. , Ilicinec. Famille de plantes, établic par A. Brongniart, qui a pour type le genre Ilc.x.

HLODEEs, adj. et s. f. pl. , Iliodece (iגúóns, limoneux). PalisotBeauvois appelle ainsi une section de la fanille des Algues, comprenant celles qui eonsistent en une matiòre gélatinense parseméc de grobules ou de filamens.

ULĹCĹBnÉES, adj. et s. f. pl. , Illecelrece. Nom donnć par Candolle à une tribu de la famille des Paronychićes, qui a pour type le genre Illeeebrum. 
ILIICnES, adj. ct s. f. pl. , İliciece. Nom donné par Candolle à une tribu de la fanille des Magnoliacées, qui a pour type le geure Illicium.

ILIOCLLi:, adject. , illoculatus. Pronnemaison appelle Hydrophyess illoculces eelles qui n'offrent pas de locules. Voyezce mot.

ILLUMINANT, adj. , illuminans; erleuchtend (all.). Ou appelle pouvoir illuminane des corps lumineux, la faculté qu'a clacun d'eux d'éclairer plus ou moins les objels vers lesquels il envoye de la lumière, le degré de clarté qui lui est propre, et qui varic suivant l'intensité de sa lumière.

ILLUMINATION, s. f., illuminatio;

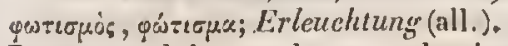
Lucur produite par les corps lumineux; clarté qu'ils communiquent aux objets cnvironnans.

ILLUMIN fi, adj., illuminatus; erleuchet (all.). Se dit d'nn eorps qui n'est point lumineux par lui-même, mais qui le devient cn refléchissant la lumière qu'un autre corps lui envoye.

ILYSIOIDES, adj. et s. n. plur., Ilysioidea. Nom donné par Filzinger ì une famille de reptiles ophidieus, qui a pour type le genre I bsium.

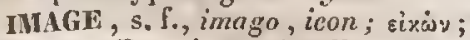
Bild (all.). Représentation d'un objet, réunion des faiscéaux lumineux émanés d'un corps, rélléchis on réfractés par un corps. Fabricius et autres cntomologistes donnent le nom d'image (eorpus declaratum) à un insecte parfait et complélement organisc, qui a subi toules ses inćlamorphoses.

IMAGINATION, s. f. , imaginatio,

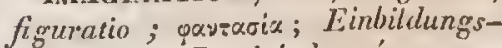
krafi (all.). Faculté de erécr, avec des idées aequises, des idées d'un ordie différent de eclles qui doivent naissance aux jugemens et aux misonnemens ordinuires, fondés sur l'expérience el l'observation.

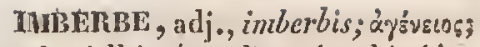
bartlos (all.); beardless (angl.) (in, priv. , barba, barbe); qui n'a point de barbe. Se clit aussi d'un poisson qui n' $x$ pas de barbillons (cx. Uphidium imberbe), et d'une plante dont les tètes de fleurs (cx. Abolboda imberbis), les fenilles (ex. Sehistidium imberbe), ou les divisions de la corolle (ex. Viola imberbis, Hypecoum imberbe) sont dípourvues de poils.

IMBERBES, adj. et s. m. pl., Inberbes. Nom donné par Vieillot à une tribu de l'ordre des Sylvains anisodactyles, comprenant des oiseaux dont le bec est glabre à la basc.

IMBRICATIF, adj., imbricativzs. Candolle donne cette épithète aux feuilles encore renfermées dans le bourgeon, lorsque leurs rudimens sont appliqués en recouvrement les uns sur les autres, et forment plus de deux sćries (cx. Larix); à l'estisation, quand les parties d'un tégument floral sont verticillées sur deux ou plusieurs rangs, que l'ordre de ces rangs n'est pas bien détermiué, et que les pièces se recouvrent les unes les autres à peu près comme les tuiles d'un. toit, ec qu'on voit dans les involucres de la plupart des Synanthérées et dans les pétales du plus grand nombre des fleurs doubles. Beaucoup de botanistes appellent estivation inibricative celle que Caudolle nomme irrésulière. Vorez ce mot.

IMBзHQUANT, adj., imbricans; cmbriciantc(it.). Cetteé pithè te est appliquéc par Mirbel aux folioles d'une feuille composćc lorsque, pendant le sommeil de la planle, elles s'appliquent le long du péliole, qu'elles cachent tout crier, en se recouvrant les unes les autres comme les tuiles d'un toit, et se dirigeant de la base vers le sommet. Ex. Mimosa pudica.

IMBRIQUÉ, adject. , imbricatus; dachzicgelförnig, dachziegelig, ziegeldacharlig , schindeldacharig , 
dachziegelartig (all.); embricialo , tegrolato (it.). Se dit d'un corps qui est composé de parties placées en reconvrement les unes sur les autres. $\mathrm{O}_{\text {In }}$ enploye ee mot: $1^{\circ}$ en holanique. Thes camares dn Magnolia sont imbriquées, de mème que le's sipales du calice des Convolyulus, les graines du Cobea scandens, les involucres du Laetuea perennis, les spallicllules du Bromus secalinus. On dit les étamines imbriquées, quand elles sont disposées eu gradins, et qu'elles se recouvrent en partic les unes les autres (ex. Liriodendron tulipifera); fouilles imbriquées, lorsqu'elles sont $r$ approchées, redressées, et q i'clles se reeouvrent en partie les unes les antres (ex. Sorocephalus imbricalus, Gnidia imbrieala, Leskia imbricatula); pétales imbriqués, quand, avant l'épanouissement, ils se reeouvrent particllement les uns les autres (ex. Rosa); squames imbriquées du périeline, d'après H. Cassini, quand, étant sur plusieurs rangs, eelles des rangs intérieurs sont progressivement plus longues que celles des rangsi extéricurs. L'Agaricus ostreatus est ainsi appelé parce qu'il est presque dépourvu de stipe, et que, vivant en société, les individus réunis ressemblent, par leur agglonúcration, à des éeailles réunies et inlıriquées. 20 En zoologie. On appelle cicailles unbriquées, dans les poissons, celles qui s'appliquent en partie les unes sur Jes autres, de manicire que l'extrémité de la première caehe la base de la seecnde, et ainsi de suitc (ex. Carpe); antennes imbriquées, dans les insectes, eelles dont les articles, enfilés par le milieu, sont concaves ì leur sommet, de manicre qu'ils recouvreat la base de eelui qui suit, comne les tuiles d'un toit. La Turritella imbricataria a ses tours de spire semblables à des entonnoirs empilés les uns sur les autres, La Purpura imbricala csl entourée de petites eôtes transver'sales que relèvent des écailles peu saillantes. Le Planorbis inbricallus a ses tours formés de lanelies transversales imbriquées les unes sur les autres.

MTTABLE, adj. , imilabilis. ĺpithète donnce, dans la nomenelature minéralogique de Haüy, à une variété de chaux earbonatée qui présente naturellement le dodécaëdre à plans pentagones qu'on obticut par la division mécanique da prisme haxaëdre régulier de la mêne substance.

IVITATIF, adj., imilativus. Se dit, dans la nomenelalure minéralogique de Haiiy, d'une variété dans laquelle une nonvelle loi de déeroissement détermine une forme semblable ì celle d'une autre variété plus simple. Ex. Feldspath imilatif.

IMUACuLl, adj., immaenlatus, emaculatus, illibalus; unbeflecke (all.); spolless (angl.)' (in , priv., maeula, tache); qui n'a point de taches sur le eorps. Ex. Hemerobius immaculatus, Unibranchiapertura immaculata, Scapleidium immaculautum, Sonerila cmaculata, Noctua illitata, Nylabris impunctata.

maLincret, adj. , immargina tus (in, priv., margo, bord); qui n'a point de rohord, ou dont le bord ne diffère eı rien du reste. H. Cassini doune celte épithète aux squames du péricline, quand leurs bords sont de la mème nature que la partic moyenne, ou yuand la difírenee est legere, ou enfin quand lo ehangement s'opère par degrrís insensibles.

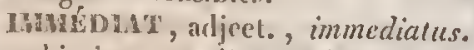
Ises ehimistes apjelten! principes immédicus des végélaux ut des animaux, les substances compocées quils en obticaucut par des manipulations diverses, sans exercer sur eux d'action décomposante. Les bolanistes disent l'insertion immédiate lorsque l's étaunes sont atlachécs sans in- 
termédiaire sous l'ovaire (ex. Cruciféres), sur le calice (ex. Rosacées), ou sur lc pistil (ex. Onbellifires).

MMMELGE, adj., immer'sus; intmerso (it.) (in, dans, mergo, plonger); qui est plongé dans l'eau, eomme ecrlaines plimtes acjuatiques, ou dans toute autre substance, comme les eonceplaeles de divers lichensdans Ja thalle.

IMVERSION, s. m., immersio ; Eintauchen (all.). Commencement d'unc éclipse; instant où la lumière du corps éelairé commence à être interceptće par le eorps opaque qui passe dévant ce dernier. On employe aussi ee terme en parlant d'une éloile ou d'une planète qui est assez proche du soleil pour que la clarté ćblouissante de l'astre empêche de l'apereevoir. En physique, on nomme point d'immersion eelui par lequel un rayon lumineux se plonge daus un milicu quelconque.

MMMOBHLE, adj., inmobilis; unbeweglich (all.); immoveable (angl.) (in, priv., moveo, nouvoir). On appellc anthères immobiles eelles qui sont attachées solidement an filet, de manière à ne pouvoir exécuter aueun mouvement, soit qu'il y ait artieulation (ex. Synanthérées), soit qu'il n'y en ait pas (ex. Laurus Persea).

IMMOTIF, adj., immotivus (in, priv., moveo, mouvoir). L.-C. Richard donnait eette épithìte à la germination, quand elle a lieu sans que l'épisperme se déplaee.

IMPAIR, adj., imparus; \&̈voos; ungoleich (al!.). Nom douné, dans la yomenelatureminéralogique de Hariy, ì une varićté de tourmaline dans laiquelle les nombres qui désignent les pans du prisme et les faces des deux sommets, censés différens l'un de l'autre, sont tous les trois impairs, sans être d'ailleurs en progression. En botanique, on appelle foliole im- paire celle qui termine le pétiole d'une feuille ailée avic impaire.

IMPALPABLE, adj., impalpabilis; unfiuhlbar (all.). Qu'on ne peut toncher ou palper, à eause de sa ténuité, eomme les flamens de l'Anabaina impalpabilis.

IMPARDA CTYLE, adj. , impardactylus. Se dit des oisenux qui ont trois doights devant et un derrière.

IMPURFAIT, adj., imperfeetus; unvollstïndig (all). Le nom de nue imparfaite est donné à eelle qui ne consiste que dans le renouvellement. périodique des appendices de la priar, comme chez les mammifères et les oiseaux.

IMPARI-NERVE, adj. , imparinoryatus. Épithète donnée par Raspail à la pailletlc supérieure des Graminécs, quand elle possède une nervure médiane, avee (ex. Asprella) ou saus (ex. Crypsis) nervures latérales.

IMPALL-PENNÉ, adj. , imparipennatus; unpaargefiedert (all.). Se dit d'unc feuille penuće dont le pétiole est terminé par une foliolesolitaire. Ex. Fraxinus excelsior.

IMPARTIBLE, adj. , impartibitis (in, priv., pars, partic). Mirbel appelle ainsi le crémocarpe qui ne se partage point en deux. Ex. Sanieula marrlandiea.

IMPATIEN' , adjeet. , impatiens; ungeduldig (all.). Le Balsamina impalicns doit cette dénomination à ce que, quand ses eapsules ont atteint leur mat urité, elless'ouvrent avee élastieité au moindre eontact, propriété que partagent également les autres espicees du genre.

IMPENETRABHTTE, s. f., impenetrabilitas; Undureledringlichheic (all.). P'ropriété dont jouissent les eor'ps d'exclure tons les autres du lien qu'ils oceupent, e'est-à-dire, non de l'espnce qu'ils remplissent réellement, mais de celui qu'ils circonscrivent par 
la continuité apparente de leur surface.

MMPENNÉ, adj.; impennis (in, priv., penna, aile). Se dit d'un oi-seau qui n'a point dc plumes ì ses ailes (ex. Pingonin), ou qui n'cn a que de lâches, dont il ne peut se servir pour volcr (ex. Autruclic).

IMPENNÉs, adject. et s.m. pl., Impennes. Nom douné par llliger, C. Bonaparte et Eichwald à une famille de l'ordre des oiseaux nageurs, comprenant ceux dont les ailes sont courtes et couvertes seulcment de petites plumes semblables à des écailles. $V$. Aptenodytes et Manchots.

IMPÉRATRINE, s. f., imperatrina. Snbstanee cristallisable particulière que Osann a déeouverte dans la racine de l'Imperatoria Ostruthium, et dont les propriétés ont été étudiées par Wackenroder.

IMPERFOLIĹ, adj. , imperfoliatus. Se dit d'une plante qui n'a pas les feuilles perfoliées. Ex, Chlora imperfoliata.

IMPLTIOLAIRY, adj. , impetiolaris. Épithète donnée à une plante dont les fenilles sont sessiles. Ex. Mikonia impctiolaris.

IMPLANTÉ, adject. , implantatus. Se dit, cn minéralogie, des cristaux qui sont attachés par un de leurs bouts aux parois d'une excavation creusce dans une roche. Ex. Stilbite.

IMPLUMĹ, adj. , implumis, deplumalus. Illliger donne eette épithèle à toute partie du corps des oiseaux qui est dégarnie de plumes.

IMPONDERABILITÉ, s. f. , intponderabilitas ; Unwügybarlicit (all.). Qualité d'un corps impondérable.

IMPONDÉRALLE, adj. , imponderabilis; unwaigbar (all.) (in, priv., pondus, poids). On donne le nom de fuides impondérables aux causes qui produisent les phćnomènes de la chaleur, de l'électricité et du magnétisme, parce qu'elles diffèrent des substanees eonnues en ce qu'on ne peut point les peser, de sorte que leur cxistence matérielle est douteuse, quoiqu'on en parle toujonrs comme si elles éłaient des corps réels, parce que cettc liy pothèse cst plus commode pour concevoir, exposer et cxpliquer les faits.

IMPONDÉRÉ, adj. Terme préférable à celui d'impondérable, parce qu'il répugne de déclarer qu'une capacitć est absolue, quand on ignore si elle l'est rćcllement. Aussi beaucoup de physicienz disent-ils fluide impondéré, au licu de fluide impondérable.

TMPREGNATION, s. f. , impra-

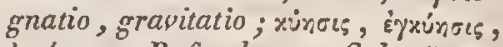

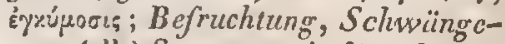
rung (all.).Synonyme de fécondation.

IMPRESSION, s. f., impressio;

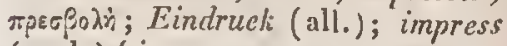
(angl.) (in, sur, premo, presser). Action d'un corps sur un autre, à la suite de laquelle eelui-ci conserve la forme de l'autre. Empreinle, trace plus ou moins profonde, quelcs objets extćrieurs font sur les organes des sens et toutes Jes partics sensibles. Les zoologistes nomment impressions ou empreintes musculaircs (impressiones musculares; Mruskclcindrïick, all.) des enfoneemens qu'on apercoit, dans les coquilles bivalves, a la face interne des valves, au milieu ou sur les côtés, et qui sont la trace de l'attache des fibres museulaires at moyen desquelles l'animal parvient ì fermer sa coquille.

INPRESSIONVÉ, adj., inupressus. Épilliète donné par Raspail anx ćcailles des Graninces, quand elles sont marqućes à leur sommet de dépressions qu'il consillère comme la trace des lobes inférieurs des anthèrcs.

IMIDnive, adj., impressus. Tcrme que H. Cassini employc, en parlant du clinanthe des Synanthérées, pour exprimer quc les arćoles orari- 
fères et le réseau sont à peut prìs au même niveau.

IMPUBATRE, adj . , impuber , impu-

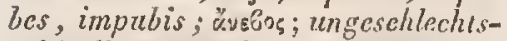
reif (all.); qui u'a point eneore atteint l’âge de la puberté.Quel quefois, mais rarement, on employe ce terme pour désigner l'anthère (unaufgebliilut, all.), jusqu'au moment oǹ elle s'ouvre pour laisser échapper le pollen.

IMPUDIQUE, adj., impudicus. T.c Phallus impudieus est ainsi appelé paree que sa forme, sa eouleur et son odeur rappellent l'idée d'un pénis en ćrection; la Cytherea impudica et la Cytherea meretrix, parce qu'elles ont leur vulve d'ume eouleur livide, olivâtre ou bleuâtre.

IMPCSTULĹ, adj., imprestulatus; qui n'est point marqué de taehes rouges ou de pustules. Ex, Coccinella impustulata.

INADHURENT, adj. , incelharens. Sc dit, en botanique, de tout organe qui est libre, qui ne tient à aneun autre; du calice, quand il est parfaitement détaché de l'ovaire (ex. Labices) ; de l'ovaire, quand il n'a aneune adhérenee avee le périanthe simple ou le caliee, et n'est allaché à la leur que par sa base (ex. Crutciferes); de la baie (ex. Vitis), de la capsule (ex. Silene), de la rarcé. rule (ex. Rumex), de la dicrésila (ex. Lavatcra arborea), du drupe (ex. Prunute), dn regmate (ex. Eutplorbia), quand ees organes sont dans le mème cas.

INAIGRETTÉ, adj. ; qui n'a point d'aigrette.

INAILLS, adj. ets. m. pl., Impennes. Nom donné par Blainville à nue scetion de l'ordre des Oiseaux nageur's, comprenant eeux qui n'ont pas d'ailcs proprement dites, mais seulement de courts moignons, ne pouvant servir qu’á la natation.

INALRUMENí, adj., inalbumina- tus. Se dit d'un embryon qui est dépourvu d'albumen. Ex. Faba.

INATCIABLE, adj. , incoibilis, insociabilis. Se dit d'un métal qui ne peut s'allier ou se eombiner avee aucan antre.

INANULR, adject., inangulatus (in, priv., angulus, angle); qui n'a point d'angles.

IVANIME, adj., inanimus, inanimalus; cuvuos; leblos (all.); inanimale (angl.). Se dit d'un corps qui n'est joint doué de la vie.

INANTMÉnÉ, adj., inantheratus (in, priv., antlucra, anthère). Se dit des filets des étamines, quand ils ne portent pas d'anthères, comme beaucoup de eeux du Sparmannia africana.

IN ANTHĹRTÈ丶 , adj. , inantheriforus (in, priv., anthera, anthère, fero, porter). Épithète donnće à un filet d'ćtamine qui ne porte point d'anthìre.

INAPPENDICŕs, ndj. ct s.m. pl., Simplicissima. Non donné par Latreille à un ordre de la elasse des Gymnogènes, comprenant eeux de ees animaux qui u'out aueun appendice extérieur.

INAPPENDICULE, adj., inappendiculatus (in, priv., appendix, appendice). Privé d'appendices, comme le elinanthe du Bellis, les squamellules de l'aigrette du Grindelia. Les squames du péricline des Symanthérées reçoivent cette épithcite de H. Cassini, quand elles sont de la même nalunre et suivent la inême direction d'un lout it l'autre, ou lorsqu'elles ve elangent de direetion et de nature de laaut en bas que par des degrés insensilles.

IN.APPIIQUí, adj. , inapplicatus. Jisilhète donnée par II. Cassini aux bractéoles des Synanthérées, quand elles ne s'appliquent pas contrele eliuanthe.

ivartrauti, adj. , inarticulatus 41 
(in, priv., articulo, artienler). Se dit de tout organe qui u'offre pas d'articulation dans sa longueur, et qui n'est point non plus articulć à sa base. On donne quelquefois celte épithc̀te aux coquilles bivalves acardes, - paree qu'elles n'out pas de dents à Jeur eharuic̀re.

INSURICLLÍ, adj., inauriculatus (in, priv., auricula, aurieule); qui est dćpourvu d'aurieule. On employe principalement ee terme en conchyliologic.

MCALICE, adj., incalycalus (in, priv., calyx, calice). Se dit d'une fleur qui mançue de calice.

INCANDISCWNCE, s. f., cxcandescentia, incandesccntia; Glühc (ali.).Etat d'un corps qui a été chauffé jusqu'au point de devenir lumineux. $\mathrm{O}_{\mathrm{n}} \mathrm{n}$ 'applique cependant ee terme qu'aux cas dans lesquels le eorps devenu lumincux cst en mème temps fort chaud.

INCANDESCENT, adj., incandescens; glïhend (all.). Se dit d'un corps qui a été ehauffé jusqu'à ee que sa surface devienne blanehe et triséclataute.

INCARNAT, adj., incarnatus, carnalus, carnarius; fleischfirbig (all.); qui est d'unc teinte intermédiaire entre li coulcur de chair et le rouge vif. Ex. Psiltacus incarnatus, Passiflora incarnata, Erodium incarnalum, Dalea carnata, Lucina carnaria.

INGINÉRATIUN, s. f., incincralio; répparts; Einüscherung (all.) (cinis, cendre). Opération par laquelle ou brüle une malière organique contemant des parties minérales fixes, atin d'obtenir ces demières séparées.

RCISk, adj., incisus; cingeschnitten (all. ). Se dit géuéralcueut, en botanique, d'une partic, et surtout d'une feuillc (ex. Pclargonium incisum), qui a des découpures plus profondes que celles auxquelles on lonne le nom de dents ou de crénelu- res, lorsqu'on ne peut ou ne veut pas déterminer d'nne manière rigoureuse la forme des lobes et la profondeur des incismes.

INCISIF, adj., incisivus ; qui coupe. Lesdcnts incisives (Schneideziilene, all.), au nombre de quatre ì la partie antérieure de claqque mêchoire, ehez l’homme, ont étć appelées ainsi parce qu'elles sont iranchantes. Kirby donne cette épithète aux dents des mandibules de quelques insectes (ex. Giyllolalpa), quaud elles sont convexes en dehors et coneaves en dedans. Le Phacocharus incisivits et le R/inoceros incisiurs sont nomwés aimsi parce qu'ils ont des incisives.

IVCLINAISON, s. f. L'incliuaison de l'orbe d'un plinète est l'angle que son plau forme aree celui de l'écliptique ou de l'orbe de la Terre. On appelle inclinaison de l'aiguille aimantće l'angle que fuit avec l'hurizon une aiguille qui pent se mouvoir librement autour de son centre de gravité, dans le plan vertical du méridien magroélique, phénomène dont la découvcrte a été faite par R. Norman en 1576.

IXCLINí, adj., inclinans, inclinatus, deflexus; geneigt (all.). Se dit de la tigge des végétaux, quand elle s'élève en décrivant nne eourbe bien prononece, dont la convexité regail le le cicl; de l'urnc des mousses, quand clle se penche vers la terre par l'elfet de la flexion du pídicule (ex. Cynodon inclinalıs, Lcplospermum inciinans); de l'aile des insectes, lorsque le sommet en est comme pendant, c'est-ì-dire sur un plan moins élevé que la base. Les géologonos appellent.rlratification inclinće celle des massifs dont les couches sont on forteuent obliques, on presque vertieales.

IYCLLS, adj. , inclusus ; cingcschlosscn (all.). Épithète donnce aux organes sexuels des plantes, aux 


\section{INCO}

ésamines (ex. Jasminun) el au style (ex. Narcissus), quand ces paries ne font passaillie au dessus de l'orifice du périanthe.

INCOERGIBLTES, s. f., incoercibilitas; Unspervbarlicil (all.). Qunlité ou état des corps intocreibles.

INCOERCTBLE, adj., incoereibilis; unsperbar (all.). On nomme fuides incoercibles les causes de lit chalcur, de l'électricité et da magnétisme, en les supposant de nature matériclle, parce que leur subtilité est telle qu'on ne suurait les renfermer dans aucun des vaisseaux dont nous pouvons faire usage.

INCOLOHATIOx, s. f., incoloratio. Défaut de couleur.

INCOLORE, incolorus; ungefärbl (all.). Se dit d'un corps qui se laisse pénétrer par des rayons lumineux assez abondans pour permettre de distinguer nettement les objets à travers son épatisseur, et qui en même temps les transmet snuts les décomposcr, de sortc que l'oeil les reçoit dans l'état où ils étaient en arrivant à la surface de ce eorps.

INCOMBLNT, adj., incumbans; aufliegend, anf cinanderliegend \{all.); bilicato (it.); qui se couche dessus. Se dit des anthères, quand elles sout atlachées par le milicu, et dressées de nanicre que leur moitié inférieure se trouve appliquée contre le filet (ex. Monolropa hypopillyss); des pétales, quand its se recouvrent les uns les aulres par les côtés (cx. Oxalis versieolor); de la radicule, lorsqu'elle est appliquée sur Ic milieu da dos d'un des colylédons (cx. Crucifires); des ailes des insectes, quand elles ont leurs bords internes les uns au dessis des autres (ex. Noclica geometra).

ivCONPLIT, adj., incompletus; ḋtèins; urvollstïndig (all.) (in, priv., completus, complet). On appelle $t^{\circ}$ en botanique; arille incomplet, celui qui ne recouvre la graine qu'cn. partic (ex. Bocconia frutescens); cloisons ineompleces, celles qui ne sćpareut qu'iuzparfaitement la cavité da péricarpe (ex. Papaver); feuillets incomplets, daus les $\Lambda$ garies, ceux qui ue: s'ítendent pas depuis le stipe jusqu"i la circonférence du chapeatu; Reur incompléte, suivant les uns cellc qui manque de alice, de corolle, d'ćtamines ou de pistil, suivant d'autres colle seulement qui cst dépourvne d'une caveloppe florale ou des deux, qu'elle soit d'silleurs unisexuéc ou hermaphrodite. C'est dans ee dernicr sens que le terme était employé par les anciens botanistes surtout, et que Thoyen s'en est servi pour désigner une classe de son systènc. $2^{\circ}$ En zoologie; nymphe incomplèce, d'après Linné, celle qui est pourvue d'ailes et de pattes, mais imnobile (ex. dpis); aréoles incomplètes, d'après Kirlyy, celles qui se terminent au bord de l'aile (cx. Apis); tútc incomplète, dans les Chétopodes, d'après Blainville, celle qui n'est pas composće de cinq sermens, un, deux, trois ou quatre de ceux-ci étaut rentrés dans le corps du tronc proprement dit.

INCOMPRESSIBUITT: , s. f., in-

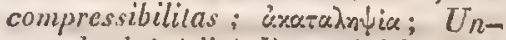
pressbarkeic (all.). Propriétéde résis. ter ì toute compression, de ne point diminuer de volume sons son in. fluence.

INCOMPRESSIBLF, adjectif , incompressibilis; ärisaros; unpressbar (ali.). Se dit d'uu corpsqui ne donne aucune marque sensible de diminution dc volume, quand on le comprime: İCONDTrPLìE, adj., inconditipes (in, priv, conditus, caché, pes, pied). Epithète donnéc par Harvorth aux erustacés brachyures dont les pieds ne peuvent point se cacher sous le rebord du test, ce qui est le cas du plus grand nombre. 
INCOURONNE, adj. , incoronatus (in, priv., corona, couronne). 11 . Cassini donne eette épithète à la calathidc des Synanthérées, quand toutes les fleurs qui la constituent se ressemblent pour la forme de la corolle.

INCRISTALLISABUITt, s. fém. Qualité d'un eorps qui ne peut cristalliser.

INCIRISTALLISABLE, adj. Se dit d'une sulsstanec qui ne peut eristalliser, qui n'est pas susceptible de prendre une forme régulière.

INCRUSTANT, adj., incrustans ; überzieltend (all.); incrostante (it.). Se dit, en ninéralogic, d'un eorys concrétionné dont les molécules se sont déposécs à la surface d'un corps qui laisse apereevoir sa forme a Iravers celtc enveloppe étrangère. Ex. Chaux carbonatée incrustaute.

INGRUSTATTON, s. f., , incrusta-

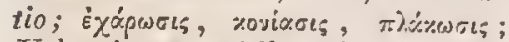
Ucbersinterung (all.); incrostazionc (it.).Dépot de molécules pierreuses qui se rassembleut à la surface des corps plongés dans une eaus chargéc de sels calcaires, ou habituellement baignés par celte eau.

INCnUSTE, adj., incrustatus. Se dit, en botanique, de ln graine et du pericarpe, quand ils adhèrent l'un à l'autre avee tant de force qu'ils seınblent faire corps ensemble.

INGUBateur. Voyez Lithogéne.

INGUBATION, s. f. , incubatio; Brütcn, Bebrïtcn (all.). Aetion par laquelle la plupart des oiscaux couvent leurs oufs, c'est-à-dire les échauflent, en leur comınuniquant In chaleur de leur propre corps, afin de faire développer les embryons qui s'y trouvent eontenus.

INGURVG, adj., incurvatus, incurvas; getrïmmet (all.) (in, en dedans, curvus, courbé); qui est courbé de delıors en dedans. S'enplnye particulierement en parlant des feuilles (ex. Spatalia incurva)
INDE

et des filcts des étamines (ex. Atropa).

INCCnVTF OLTÉ, adj., incurvifolints (incurvus, reeourbé en dedans, folium, feuille); qui a les fcuilles (ex. Ieiotheca incurvifolia, Orthotrichum incurvifolium), on les lobes des feuilles (ex. Saxifraga incur'ifolia) recourbés en dedans, infléchis dans toute leur louguenr ou ì l'extrémité seuleınent.

INDEFIN, adj., indefinitus, indcterminatus, unbestimmt (all.). Les chimistes appellent combinaisons indéfinies celles qui se font en des proportions illimitées. En bolanique, le mot indéfini exprime que le nombre des parties auxquelles on l'applique n'a ricn de constant, ou que, bien qu'il soit eonslaut, on ule veut pas ehereber à le déterniser. Ainsi, lorsqu'il y a plus de douzc étamines, nn ne les eompte plus, et ou dit qua'clles sont indéfinies. Candolle nonme inflorcseenec indcfinic eelle dans laquelle la tige ou le rameau, terminé par un bourgeon dont le développemont peut l'allonger, pol'te des fleurs aux aisselles de ses feuilles, ou diss bractées qui en tiennent lien et les représentent.

INUÉTHISCENCR, s. f. , indchiscentia. Propriété qu'ont certains péricarpes de rester constamment elos.

INDínSCENT, adj., indehiscens. Se dit d'un péricarpe qui ne s'onve pas spontanément à l'époque de Ja maturité, eomme le calj-bion du Taxus baccata, les camares du Liriodcndrum tulipifora, les coques de la dićrćsile du Tropaolum, le légume du Cassia fistula.

INDENTÉ, adj., indcntatus (in, priv., dens, deut); qui n’a ui dents , ni dentelures, comute les feuilles du Dionedea indentala.

INDÉPENDANT, alj., unabhüngigr (ali.). Ln cóognosie, on dit d'une fornation, que elle est indépendinte, 
pour indiquer qu'elle a été retrouvće la nième daus des contrées éloiguées les unes des autres, et que, parmi celles 'qui partent cette épithète, chacune a été vue superposée indifféremment sur l'nue de celles qui sont plus anciennes.

INDICATEUR, adj. et s. m., indi. calor. Le premier do igrt du membre antérieur, après le pouce, clicz l'homme, porte cc nom, paree qu'il sert ì montrer los objels. Le Cuculus indicator' est ainsi appelé parce qu'il se tient dans le voisinage des uids d'abeilles sauvages, dont, par son eli, il facilite la recherche et la découverte.

INDIFI'LENCE, s. f., indifferentia; úvtapopis; Glcichgültigkeit (all.). On nomme indifférence électrochimique un état de ehoses, janais atbsolu, toujours relatif, qui se présente sous deux nuanees différeutes. Tantôt uil si grand nombre de corps se sont combinés ensemble qu'il en est résulté une parfaite neutralisation, et qu'aucun autre ne peut plus entrer dans la combinaison; alors toute réaction électrique cesse à l'égard des corps qui tendraient ì se combiner avec le composć, mais les ćlémens de cclui-ci conservent encore leurs ríactions spécifiques sur les corps qui tendent à les décomposer. 'Tantôt, Jorsque cerlains eomposés sont exposćs ì une certaine température élevéc, il y éclate subitcinent da feu, comme s'il s'y opérait une combinaison chimique, sans que, du moins daus la plupart des eas, leur poids augmente ou diminue. Cependant leurs propriélés et le plus souvent lcur couleur ont changé. Ils sont alors dans un étal d'indifférenee élcetrochimique gni ne permet plus de les combincr avee les corps pour lesquels ils avaient auparavant une grande aflinité, et d'ou ils ne sortent qu'après avoir été exposés, sous l'influenec d'une haute température, à l'action de corps doués d'une trèsforte affinité chimique.

INDIFFLRENT, adj. , indifferens; àșxioopos; gleichgültior (all.). Cette épitlicte est donnée aux corps composés qui n'exercent plus de réactions chectro-chimiques, et qui ne se combinent point avec d'autres corp's.

INDIG kVE, alj., indigenus; ह่тाXúpros; cingeborne, cinheimisch (all.) (indè, de lì, geno, naitre). Mirbel appelle ainsi les plantes qui eroisscut naturcllement ou spontanément dans le pays sur le sol duquel elles végètent.

INDIGOCA RUINE, s. f., indigocarmina. Ce nom a été donné par quelques chimistes au pourpre d'indigo, modification du bleu soluble, dont la découverte est due à Crum, qui l'appelle phénicine.

INDIGOG ENE, s. m., indigogenum. Sous ce nom, Brugnatelli et Doebereiner ont désigné l'indigo, regardé par cux comne un métal végétal, qu'ils prétendaient avoir amalgamé à ehaud avec le mercure.

INDIGONùtre, s. m., indigometrum. Nom donné quelquefois au chlorométrc. Voyez ce inot.

INnIGOTATL, s. m., indigotas. Genre de sels (indigsaurc Salze, all.), qui résultent de la eombinaison de l'ncide indigotique avec les bases salifiables, et que Berzelius nomme nilranilates.

INDIGOTIQUE, adj. , indigoticus. Noin donné à un acide (Indigsäure, all.), conıu déjà de Foureroy et Vauquelin, puis étudié par Chevreul, nıis surtout par Buff, qui résulte de l'action de l'acide nitrique sur l'indigo, el que Berzelius appelle nitranilique.

INDIRECT, adj., inclirectus. Se dit, dans la nomenclature minéralogique de Haüy, d'une variété dont le sigue est eomposé d'un exposant fractionnaire et de plusieurs exposans simples, en sorte que la sommue des 


\section{INDI}

deux termes de la fraction est égale à celle des autres termes, ce qui offre d'une manière indirccte l'analogue de la variété équivalente. Ex. Chanx carbonatée indirecte.

INDIVIDU, s. m., individurm, ens singulare; Einzelwesen (all.); indisiduo (it.) (in, priv., divido, diviser). Rigourcusement parlant, un individu est un être qu'on ne peut diviser sans que, dans son entier on au moins dans la partie qui a été séparéc, il périsse, e'est-à-dire passe sous l'em. pire d'autres conditions, qui suscitent un nouveau mode d'existence. C'est en ce scns qu'on a défni l'individu, tout ètre organisé, complet dans ses parties, distinct et séparé des autres êtres (Mirbel), tout être vivant ou mort, indépendant, adulte ou non, que nous avons actuellement sousles yeux, el que nous caractérisons en le rapportant à une varićté fixe ou non, et par suite à une espèce détcrminée. Mais il y a des êtres organisćs, parmi les animaux et surtout parmi les végétaux, qu'on peut diviser, sans que nile tronc ni les partics qu' on en sépare périssent. 11 en est même à l'érard desrquels on ne comnaît pas d'autre mode de propagation, comme le Saule pleureur, dont nous no possédons qu'un des sexes, et qui ne se reproduit que de bouture. Cenx-là ne sont donc pas des individussuivant l'aception grammaticalc du mot, quoiqu'on leur en donne le nom dans le lingage vulgaire. Pour ćcartcr ectie difficulté, Darwin, Lanarek et autres ont imaginéde distinguer les individus en simples et composés. Un arlıre, dit Turpin, est un individu composé par l'agglomération d'un plus ou moius grand nombre d'individus particuliers qui, bicn que concourant à la commune existence du végétal, n'en ont pas moins leurs centres vitaux particuliers de végétation et de propagation. Aussi a-t-on été eonduit à n'admettre pour individus distinets que les végétaux provenus d'une grainc, et, avec Agardh, à considérer, par excmple, comme un seul individu tous les individus de Saule pleurcur qui se sont répandus en Europe depuis l'introduction de cet arbre, vers la tin du dix-septième siècle. Ce n'est là évidemment qu'une vaine dispute le mots, dans laquelle on ne s'est point aperçu qu'on poussait les choses jusqu'au point de ne pouvoir plus considérer que comme des demi-individus ce qu'on nomme comnunément des individus; car, dans la dernic̀re hypothèse, l'individu humain se composerait réellement de l'homme ct de la femme, tandis qu'une huittre ou une moulc seruit un individu complet. Nous avons là un exemple des subtilités dans lesquelles on toinbe quand on veut accorder le langage vulgaire, presque toujours fondé sur des aperçus superficiels et incomplets, avec les notions dont les seiences s'enrichissent progressivement. L'idée de l'individu est inapplicable aux minéraux, puisqu'on peut les diviser en autant de parties qu'on veut sans que ces parlies cessent d'êtrc senıblables les nnes aux autres el à la masse d'où clles proviennent. Cependant on a vonlu l'introduire aussi en minćralogic, où l'on a donné le nom d'individu, soit, comme Lconhard, aux cristaux, soit, conume les minéralogristes frangriis, à la nıolécule intégrante, parce que, telle qu'oul la conecoit, elle ne saurait être divisée sans être en mênc temps déeomposće. Reste à savoir quelle peut étre l'utilité d'une scinblable abstraction.

INDIVIDUALITE, , s. f. , individualitas, individuilas, heeceitas; Einzelsvesenheit (all.). Qualité de ce qui constitue un individu.

INDIVIS, adj., indivisus; ungetheilt (all.); qui n'est point divisé. 


\section{INDU}

Se dit de la tige et des feuilles. On employe plus souvent le mot entier eu simiple.

INDUMENT, s. m., indumentum; Ueberaug (all.) (induo, couvrir). Beruhardi dounc ce nom à l'épiderme des végélaux el à cclui delcurs graines, y compris les partics qui $\mathrm{y}$ adhèrent.

INDUPLICATrE, adj., indruplicalivus. Candolle dit l'estivation induplicative, quand, les prities d'un tégument floral étant rigourcusenent verticillées en un scul rang, elles sont disposées d'unc manière circulaire, ayant chacune leurs bords reutrans et comme reppliés en dedans. Ex. Clemalis.

NDDUSIE, s. f. , indusium; $\chi(\tau \omega)-$ vicusc; Schleier, Schleverchen, Deekc (all.); indusio, eamicia (it.) (induo, couvrir). La plupart des botanistes donnent ce nom à une membrane qui, dans les fougères dont la frućification est placée à la face inférieure des feuilles, recouvre l's sores, c'cstà-dire les petits amas dc conceptacles dans lesquels sont contenus les corpuscules reproductears. Cet organe est appelé écailles (squamw), et quiclquefois calice, par Linné, membranule par Nceker, glandes squameuses par Guettard, insolucre par Smith, tégument ou tegmen par divers botanistes, périsporange, épisporange et hyposporange par Bernhardi, suivant qu'il enveloppe les spores de toutes parts, ou qu'il les couvre sculcment cn dessus ou en dessous. On appelle aussi indusie une membraoc partieulière qui voile le stigmatcides Lobelia, avaut la pubertć. Quelquefois on donne ce nom au volva des champignons.

INDUSıÉ, adj., indusiatus. Se dit d'une mousse dont les urnes sont enveloppées d'une membrane qui finit par se rompre (ex. Buxbaumia indusiata), et d'un champignon dont le

volva est très-grand (ex. Hymenophallus indusiatus).

INDUVISL, adj. , indusialis. Epithète donné par Mirbel an calice, quand il persiste et reconve le fruit. Ex. Phrsalis Alkekengi.

INDUVIE, s. f., induvicr; Kelchchen (all.) (induo, convrir). Mirbel appelle ainsi tout périanthe ou toute partie accessoire de la fleur qui persiste et recouvre le fruit, apris la malurité de l'ovaire, sans faire corps avec lui.

INDuvrú, adj. , induviatus. Se dit d'un fruit qui est recouvert d'une induvic provenant de la persistance soit du périanthe simple (ex. Salsola Tragus), soit du caliec (ex. Trifoliume repens), ou des glumelles (ex. Oryza).

IVEGAL, adj. , inaqualis, impar,

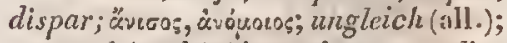
zinequal (angl.) (in, priv., cequalis, égal). Se dit de parties qui n'ont pas les mêmes dimeinsions, comme les poils ou soies de l'aigrette du Pirris hieracioides, les élamines des Crucifères, les deux côtés de la fcuille de l'Ulmus compestris, les pétales de l'Iberis, les sépales du Salvia, les spathelles de l'Avena elarior.

INEMBRYONVE, adject. , incmbryonnatus (in, priv., embryo, embryon). L.-C. Pichard donnait cette épichète anx plantes dont le mode de germination est inconnu, qui n'ont pas de graine proprement dite, ni par eonséquent de véritable embryon.

INEP'CES, adj, et s. m. pl., Inepti. Nom donné par llliger et Eichwald à unc famille de l'ordre des Gallinacés, comprenant lc genre Didus, dont l'existence réelle est au moins donteuse.

INÉQUALIF OLIÉ, adj. , inaqualifolius (inaqualis, inégal, folium, feuille); qui a des feuilles inégales ou dissemblables. Ex. Peperomia inaqualifolia. 
rvéqurcostí, adj. , inaquicostatus; qui est marqué de côtcs, ou saillies longitudinales, de dimensions différentes, comme la coquille du Peeten inaquicostalis.

INÉQULATÉRAL, adj. , incequilateralis; ungleichseitig (all.) (in, priv., aquus, égal, latus, côtú). Epithète donnée à une coquille bivalve dont le somnet céphalique ou dorsal est situé en avant ou cn arrière de la partie moyenue du côté où il se trouve, de sorte qu'une ligne droitc tirée de ce point an côté opposé partagerait la coquille en denx parties inégales.

INÉ QUULA'TÉrRE, adj , incequilaterres; qui n'a pas les côtćs égaux, eomme une feuille que sa nervure médiane ne partage point en deux moitiés égales. Ex. 'Tilia.

INEQUILOBÉ, adj., inaquilolsatus (in, priv., aquus, égal, lobus, lobe).. Ce mot est employé comme synonyme d'inéquilaićral. Les valves du Birostrites incequiloba sont inégales, l'une d'elles cnveloppaut l'autre par sa base.

INÉQUIPÈDES, adj. et s. m. pl., Inaquipedes (in, priv., aquus, égal, pes, pied). Nom donné par Latreille à une famille de l'ordre des Myriapodes chilopodes, comprenaut ceux qui ont des pattes inégialcs, les dernières ćlant plus longues que les autres.

INĹQuTrulLLS, adj, ct s. f. plur., Inaquilcle (in , priv. , cequus, égal, tcla, toile). Nom donué par Littreille à une tribu de la famille des Aranćides, dans laquellc il range ceux de ces animaux qui filent des toiles irrégulièrcs, dont les fils se eroiseut en tous sens et sur plusicurs points.

INÉQUIVALVE, adj., incequipalvis ; ungleichklapping, unglcichschalig (all.) (in, priv., cequtus, ćgal, valpa, valve); qui est composé de deux valves inégales, comme la glume du Paspalus inaquivalvis. Se dit surtout d'une coquille bivalve entre les deux valses de laquelle il y ane grande différence pour la grandeur ou pour la forme (ex. Plagiostoma incequivalvis).

INéQUTraLves, adj. et s. m. pl., Incquipalvia. Noun donné par Latreille à une farnille de l'ordre des Brachiopodes pédonculés, comprcnant ccux dont les valves de la coquille sont d'inégale grandeur.

INERUE, adject. , inermis ; unbewehre, nvehrlos, waffenlos, unbewaffnet (all.) (in, priv., arma, axme) ; qui est dépourvu d'armes, de piquans, d'aiguillons (ex. Labrus inermis, Prosopis inermis, Berleris inermis). Richard donue cette épithète au tablier des Orchidćes qui n'ont pas d'éperon.

INERMES, adj. et s. m. pl., Iner. mia. Nom donné par Latreille, Ficinus et Carus it une famille de l'ordre des Ruminans, comprenant ceux de ces mammifères dunt la tête ne porte point de cornes.

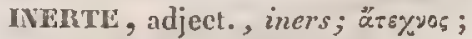
trïgre (all.) Sans ressort, sans aclivité. Les minéraux sont appclés corps inertes, parce qu'ils paraissent dépourvus de toute espèce d'aetivité.

INERTES, adj. et s. m. pl., Inertes. Nom donné par Temminck à un ordre de la classe des oiseaux, renfermant des animaux qui, comme l'Apteryx el le Didus, ne peuvent pas voler.

INER'TE, sof., inertia, ignavia ; cotryvin; Trägheit (all.); dulncss (angl.). Inaction, défaul d'aptitude à changer spontanément d'état. On appelle force d'ineric la propriété qu'ont les corps de persister dans l'état où ils se trouvent tant qu'une cause ćtıangire n'agit pas sur eux. L'incrtie n'est en réalité qu'unc résistance active à tout changenient, de quelque nature 
qu'il soit, une foree agissant en sens inverse d'nne autre foree qui tend à chauger l'état d'un eorps. L'incrtie absolue ne pent se eoneevoir.

INEXTENSILINGUE, adj. , ine $x$ tensilinguis (in, priv., extendo, étendre, lingua, langue). Se dit d'un animal qui ne peut alonger sa lamgue liors de li houche, par opposition à un autre qui jouit de cette faeulté.

INEXUVLABLE, adj., inexupiabilis (in, priv., exuo, dépouiller); qui ne mue jamais, qui n'est point sujet à la muc.

IXrĹCOOND, adj. , infacundus, sterilis ; "̈yovos; unfruchlbar (all.); qui produit peu ou point. Synonyme peu usité de sterile.

INFLIRAXILLAIRE, adj. , inferrxillaris (infra, au dessous, axilla, aisselle); qui est fixé au dessous de l'ais. selle. Epine infercaxillaire, placéc au dessonsdu point d'attache de la fenille ou du rameau (ex. Ribes grossularia); feuille inferaxillaire, insérée sous la branehe ou le rameau (ex. Tilia curopaca); stipules inforaxillaires, attaehées sur la tige au dessous des feuilles (ex. Ribes).

INTËRE, adj. , inferts, niedrigstehend (all.). Se dit, en botanique, l'un organe qui est placé au dessous d'un aulre; du calice, quand il s'insère au dessous de l'ovaire, avec lequel il n'a aucune adhérence (ex. Lilium); de l'ovaire, lorsqu'il adhère au tube du périanthe, dout le limbe le conronne, ec qui le fait paraître inf'éricur à toutes les autres parties de la fleur (ex. Pyrus); de la rudicule, quand elle se dirige vers la lase de la graine, e’est-il-dire vers la eicatricule.

INFÉRIEUR, adj., inferus. Les astronomes appellent planètes inféruxes eelles qui, comme Mereure et V $\mathfrak{c}_{\text {aus, }}$ ont un rayon vectetur phis petit que celui de la Terie. Geoffroy noinme les enimaux articulés verté-. brés inféricurs, paree qu'en les considérant eomme organisés sur le même plau que les vertélırés propre. ment dits, ils offrent néanmoins une sorte d'infériorité dans le mode de développement de ce plan.

INTLRTEDES, adj. et s. m. pl., Inferipedes (inforus, inférieur, pes, pied ). Nom donné par Latreille à une famille de l'ordre des Holothurides polypodes, comprenant ceux de ees animaux qui ont les pieds inférieurs.

INFÉnTÉ, s.f. Richard appelait ainsi l'état des ovaires qui sont infères.

INFǴROBRANCIIES, adj. et s. m. pl., Inferobranchii, Inferobranclia, Inferobranchiata (inferus, inféricur, Bpá $\gamma \chi \varkappa$, branehie). Nom donné par Cuvier et Latreille à un ordre de la elasse des Gastéropodes, par Blainville à un ordie de celle des Paraećphalophores, comprenant ceux de ees animanx qui ont les branchies placées sons le rebord saillant du manteau.

INFÉItovanié, adject. Epithète donnée par Marquis aux plantes dont l'ovaire est infèrc.

INFEULLE, adj. , infoliatus (in, priv., folizm, feuille); qui n'a point de feuilles. Synonyme inusité d'aploylle.

INFINI, adj. et s. m., infinitus; ärevoos; unendlich (all.); qui n'a pas de fir. "Ce n'est qu'en ajoutant les ehoses matérielles les unes aux autres qu'on est parvemu à counaître qu'on ne verra jamais la fin de son compte, et cette irpuissanee, on l'a appelće infini, ee qui est biell plutôt un aveu de l'igoorance humaine, qu'une idée au dessis de nos sens. " (Voltaire.)

INFLNITOVISTE, adj. et s. m. pl. Physiologiste partisan de la doctrine suivant laqueile tous les eorps organisés sont le résultat du développement de germes emboîtés à l'infini les uns dans les autres. 
INTLAMMABILITE" , s. f., inflammabilitas; Entzündbarkeit (all.). Qualité ou caractére des corps qui sont inflammables.

INFLAMMABLE, adj., inflamma-

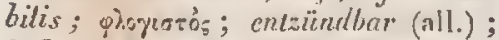
infiammabile (it.); qui est suseeptible d'entrer en combustion. On donne ectte épithèteà tous les eorps composés qui peuvent hrûler, et alors le mot est synonymede combustible, on anx substances simples, non nétalliques surtout, qui brîlent facilement. C'est en ee dernier sens que l'hydrogène a été appelé air inflanıniablc.

INFLAMMALLES, adj, et s. m. pl., Inflammabilia. Nom donné par Werner el Hausmanı à une elasse de minéraux, comprenant ceux qui sont susceptibles d'alimenter le feu; par Brongniart a une formation comprenant les corps combustibles qui se déposeut ou se dégagent encore actuellement, dans les couches du globe, ou à sa surface, parl'effel des voleans.

INFLAMMATION, s. f. , inflam-

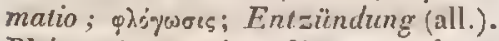
Phénomène qui a lieu quand un corps produit de la flamme en brûlant, soit parce qu'il est lui-même volatil, soit parce que les combinaisons qu'il produit sous l'intluence de la chaleur jouissent de cette propriété.

INTLECII, adj., inflexus, ineurvus, introflexus, reclinatus, introcurvus; rxpr.ülos; cingebogen, umgeschlagen (all.); inflesso, incurvato (it.) (in, en dedans, flccto, fléehir); qui ést eotilué en dedius. On employe ce terme : $1^{\circ}$ en minéralogic; l'épithete d'infléchie est donnćc, dans la nomenclature minéralogique de Haüiy, à une variété dans laquelle les faces des différens ordres se suecèdent, depuis un sommet jusqu'à l'auIre, sur des intersections parallèles entr'elles, en sorte qu'elles présentent l'aspect d'un seul plan qui au- rait subi plusieurs inflexions conséeulives (cx. Chaux carbonatie inflechic). $2^{\circ} \mathrm{En}$ botanique. Aiguillons infléchis, ceux qui sout courbés, et qui dirigent leur pointe vers la partie supérieure de la tige ou de la branche (ex. Mimosa cineraria); étamincs infléchies, celles dont le sommet s'ineliuse vers le centre de la fleur (ex. Salvia); feuillcs infléchics, celles qui sont courbées en dedans (ex. Araucaria cxcelsa), ou qui, dans le bouton, sont plićcs de haut eu bas (ex. Anemone Hepatica); licure supéricure infléchie, dans une corolle labiée, celle qui se renverse sur l'inférieure (ex. Brunclla); licore inféricurc infléchie, celle qui se recourbe vers l'orifice du tube (ex. Plcctranthus punctatus); pctales infléchis, ceux qui se réfléchissent vers le centre de la fleur (ex. Astrantia major !; rameaux inflechis, ceux qui se recourbent vers la tige (ex. Anastalica hicrocuntica); style inflèchi, celui qui se courbe en dedaus (ex. Eroum tctraspermum).

INFLEXIOSCOPE, s. m., in plexioscopium (inflexio, inflexion, бхстта丿, considérer). On a proposé d'appeler ainsi l'instrument nommé chromadote par Hoffmann, parce qu'il montre les phénomènes de l'inllexion de ln lumiere.

INFLEIYPEDE, adj., inflexipes (in/cxus, infléchi, pes, pied). La Mantis inflexipes a été appolće ainsi parce ru'elle a les euisses des pattes de devant très-courbées en dedans.

INHLORESCENCE, s. f., inflorescentia; Blülhenstand (all.); infiorescenza (il.). Linné désignait sous ee nom la manière dont les fleurs sont disposées sur la plante qui les porte. Candolle définit l'inflorescence, l'enscmble ou la disposition des $u r-$ ganes et des opérations qui proparent ou effeetuent la floraison.

INFORML, adj., in ormis; form- 
los (all.). Qui n'a pas de forme déterminable. Ex. Salpa informis.

INFORMes, adj. et s. m. pll., Obesa. Nom cionné par Illiger à une famille de l'ordre des Mammifères multongulés, comprenant ceux qui, comme les cochons, ont le tissu cellulaire sous-eutané tellement chargé de graisse, que leurs formes en sont pour ainsi dire effacćes.

INFRAJURASsioue, adject. Épithc̀te donnée par Brongniart à un groupe de terrains sédimentenx péligiques, cornprenant ceux qui sont situés au dessous des teirains jurassiques.

INFUNDIBULE. Foy. INFENDIBULIFORME.

INFUNDIBULIF L̀RE, adj., infundibuliferus (infundibulum, entonnoir, fero, porter). On donne cette épithèle à la languc, lorsque son extrémité se tcrmine par un disque en forme de ventouse (ex. Glossophaga soricina). L'Oculina infundilulifcra cst ainsi appelée, parce que les articulations de ce polypier portent des étoiles en forme d'eutonnoir.

INFUNDIBLLIFOrME, adj, , infundibuliformis; richterfirmis, trichterig (all.); imbuliforme (it.) (infundibulum, entonnoir, forma, forme); qui a la forme d'un cutonnoir, c'esta-dirc qui offre un limbe évasé faisant suite à un tube semblable à un cône renversć, comme la corolle du Campanula infundibuliformis, te style du Huta crepitans, Ic stigmate du Kampferia longa, le chapeau de quelqnes champignons (ex. Agaricus infundibuliformis), le corps de la Salpa infundibuliformis.

INFUNDUBULTFORviES, adj. et s. f. pl., Infundibuliformes. Nom donné parTourncfort à une classe de plantes, renfermant celles qui ont la corolle en forme d'entounoir.

INFUSIBILITÉ , s. f., infusilititas;
Unschunelzbarkcit (all.); qualité de ce qui est infusiblc.

INFCSIBLE, adj., infusibilis ; unschmelzbar(all.); unfusible(angl.); qui n'est pas susectible de se fondre.

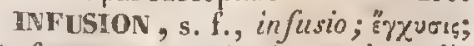
Anfouss (all.). Općration par laquelle on met une substance organ ique composéc de plasieurs principes imnédiats dans un liquide chand ou froid, afin d'cu séparer les principes soluhes de ecux qui ne le sont pas. Produit de cetle opération.

INTCSOrRes, adj. et s. m. pl., Infusoria; Infusionsthicrchen (all.). Nom donné par Muller à un ordre qu'il a créć dims la classe des Vers de Linné, poury ranger les animalcules qui se développent dans les iufusions végétales ct animales. Cet ordre, conservé parSchweigger et Goldfuss, érigé en classc par Lamarck et $\mathrm{Cu}-$ vier, n'est point admis par Blainville, qui regarde les anmaux qu'on $y$ comprend comme apparlenant a diverses classes, opinion à l'appui de laquelle vit nnent les recherches faites depuis peu par C.-G. Ehrenberg.

MGLUVES, s. m., inglinvies. Illiger nomme ainsi, daus les Mamnifères, la régiou de la partic inférieure du corps qui est comprisc entre les branches de la mâchoire inférienre et le sommet du larynx.

EVGULNAL, adj. , inguinalis ( inguina, aine ); qui appartient à l'aine. Région inguinale, celle de l'aine mêne. Mamelles inguinales, celles qui sont situées près de l'aine, comme dins le cheval et le tapir.

INwit, adj., innatus, ingenitus; हैupuros; angelioren (all.); innate (angt.); qui n'a point ćté acquis (idćcs innécs, pcnchant inné). "Rien n'est ce qu' ou appelle inné, c'est-àdire né développć.n(Voltaire.)

INNERVÉ, adj., inncrvis, cnervis, enervizs; qui n'a pas de nervures. Mirbel employe ce terme pour dési- 
gner les colylédons (ex. Faba) et les feuilles (ex. Sempervivum tectorum), lorsqueles nervures, enveloppées par le parenchyme, ue paraissent point au dehors, et sont eensées xe point exister.

INNovation, s. f., innoyatio. Hedwig appelait ainsi les drageons que pousse lia tige de certaines mousses (ex. Polytrichum undulatum), qu'ils servent à multiplier.

INOCARPE, adj., inocarpus ("is, fibre, жхртоь, fruit); qui a le (ruit fibreux. Ex. Eugenia inocarpa.

INOCUlaInE, adj., inocularis. Epithète donnée aux antennes des inseetes, quaud elles s'insèrent dans l'angle des yeux. Ex. Crrambyx.

INODONE, adj., inodorus; gcruechlos (all.) (in, priv., odor, odeur); qui n'exhale auenne odeur. Ex. Philadelphus inodorus, Artemisia inodora.

INOMYCrs, s. m. pl., Inomycetes (is, fibre, púven, champignon). Nom donné par Fries à un ordre de la elasse des Hyphomyees, comprenant les champignons filamenteux.

INONDÉ, adj., inundatus; ueberschwommt (all.). Se dit des plantes qui, suivant la saison, vivent couvertes d'eau ou à sec. Linné avait ćtabli sous ce nom une famille entièrement artifieielle, dans laquelle il réunissait des plantes qui n'ont entr'elles que ce simple rapport, auquel rien ne correspond dans leur organisation.

INONGUTCULÉ, adj., inungzuis (in, priv., unguis, ongle); qui n'a point d'ongles. Le Gccko inunguis n'a pas d'ongles du tout. La Lutra inunguis n'en a que deux rudimentaires aux deux grands doigts de ses pattes de derrière.

INOPIYLLE, adject. , inophyllus

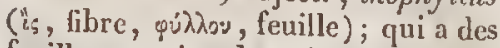
feuilles garnies de veines réticulées

\section{INSE}

bien apparentes. Ex. Syzygium inoplyllum.

INORGANIQQUE, adj., inorganicus (in, priv., organum, ormane); qui n'il point d'organes ou d'instrumens particuliers d'aetion. Bory définit les eorps inorganiques, eeux dont ehaque molécule représente un eorps complet, et chez lesquels la forme, entièrement aecessoire, ne saurait être qu'une agglomération inerte, soumise à des lois mécaniques, d'où il ne peut rien résulter qui ressemble à la vie et qui établisse un individu.

rNovULÉ, adj., inovulatus. Se dit d'un ovaire qui ne eontient point d'ovules, comme eelui des fleurs mâles et des fleurs neutres dans les Synauthérées.

INRADIANT, adject., inradians. Épithète donnée par H. Cassini à la couronne de la ealathide des Synanthérées, lorsque les fleurs qui la eonstituent ne sont pas plus longues que celles du disque, el n'ont point leur partie supérieure dirigée en dehor's.

rNSALIFIABE, adj. On appelle ainsi les oxides qui ne sont ni acides, ni eapables de neutraliser les aeides et de donner naissanee à des sels.

INSECTES, adj. ct s. m. pl., Insecta (in, à travers, seco, eouper). Nom d'une elasse du règne animal, dans laquelle on range les animaux artieulés munis seulement de six pattes. Cette délimitation est toute réeente, ear la elasse des insectes a subi de grandes variations sous le rapport de son étendue, ayant long-temps embrassé tous les animaux articulés dont le corps offre des divisions à l'extérieur, et n'étant arrivée que par des réductions sueeessives à l'état où nous la voyons aujourd'lui.

INSECTIFERE, adj. , insectiferus (inscctum, insecte, fero, porter). Se dit du succin, quand il contient des insectes emprisonnés.

INSEGTIRODES, adj. et s.m. pl., 
Insectirodes (insectum, insecte, rodo; ronger). Nom donné par Duméril à une famille de l'ordre des Inscetes Hyménoptères, eomprenant ecux dont les larres se développent daus l'intéricur dn corps d'autles inscctes, aux dépens desquels elles virent. Voycz Entonotrlles.

INSEGTIVORES, adj. ct s. m. pl., Inscetivora, Insectivori (insertum, insecte, voro, dévorer). Nom donné par Cuvier, Desinatesı, Blaiuville, Latreille, Ficinus ct Carns ì une fit mille de l'ordre des Manmifires carnassicrs, par Tcmminek à un ordre de la classe des oiscaux, comprenant des animaux qui viveut principalement ou exelusivenent d'insectes.

INSECTOLOGIE, s.f., insectolo-

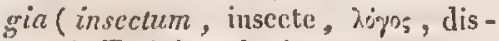
cours). 'Traitć sur les iusectes, comme eelui que C. Bönnet a publié en 1745 .

INSECTOLOGUE, s. m. Synonyme iususité d'crtoriolog giste.

INSERE, adj., insertus; cingcfügl (all.); qui est fixé sur.

INSERTION, s. f., inserlio; gúp-

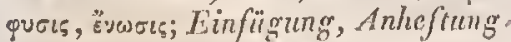
(all.); inscrzione (it.) (insero, meltre dedans). Attaclie d'une partic sur une autre. On cmploye ectte expression parce qu'on suppose que les parties sont enchâssées les unes dans les autres par lcur base, ee qui est précisément le contraire du véritable état des choses.

IXSExh, adj. , insexus, insexifcr; geschlecheslos (all.) (in, négal., scxus, sexe); qui u'a point de sexe. On sc scrt plus communément du wot Neutre.

INSIPIDE, adjectif, insipidus ;

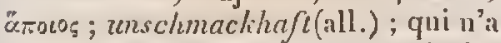
point de saveur. Ex. Tasmannia insipida.

INSISTANT, adj. , insistans (in, priv., sisto, appuyer). Épithètc donnée au poucc des oiseaux, quand il ne porte at terre que par le bout.

Ex. Gallinacés.

INSOLATION, s. f., insolatio, apricalio. Exposition d'une matière quelconque aux rayons du soleil, soit pour séparer un principe fixe d'un liquide évaporable qu'clle eonticnt, soil pour lui faire éprouver quelque changement dans sa composition ou dans l'élat d'aggrégration de ses molécnles.

INSOLUBILITÉ, s. f. , itsolubilitas ; Unauflösbarkci, Unauföslichkeit (all.). Qualicé d'un corps solide', liquide ou gazcux, qui ne pcut se dissoudre dans un liquide.

INSOLUne, adject., insolubilis ; ״̀vros; unauflïslich (all.); qui n'est point soluble.

INSTABLE, adject. , instabilis ;

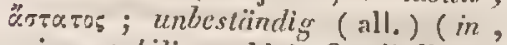
priv., stabilis, stable). On ditl'ćquilibre instable, quand le centre de gravité d'un corps, ou la résultante des actions de la pesanteur, cesse de tomber entre les appuis de ce corps, qui dis lors ne peut plus conserver lá position qu'il avait.

INSPIIATLON, s. f., inspiratio;

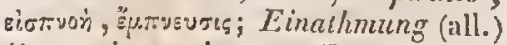
(in, priv., spiro, sonffer). Action par laçuclle l'air sc précipite dans les ponmons, pour servira la respiration.

INSTAMivÉ, s. f., instaminatus (in, priv., stamen, étamine). II. Cassini donne cette épithète à la corolle, dans les Synauthérées, lorsqu'elle n'est point accompagnéc d'organcs mûles parfaits.

INSTUNCT, s. m., instinctus; yutis; Naturtricb (all.). Penchant intéricur qui porte à cxécuter un acte sans a voir notion de son importance linale, à employer des moyens toujours les mêmes, sans jamais ehercher à en créer d'autres, ni à connaitre lc rapport entr'eux el le but, et qui, pour ctlre altribué à l'intelligence, supposerait des prévisions et des connais- 
sances infiniment supérieures à eelles qu'ou peut admettre dans les êtres qui le manilestent. C'est, dit Voltaire, l'arrangement des organes, dont le jeu se déploye par le temps. Chaque animal nait ivec des organes qui, à mesure qu'ils croissent, lui font sen. tir tout ce qu'il a besoin d'éprouvec pour sa conservalion.

INSTIR Lú; ; adject. , instipulatus (in , priv., stipula, stipule); (qui n'a point de stipules.

INSLLÉ, adj., insulatus (insula, íle). Kirby donne cettc épithète à eelles des aréoles discoïdales de l'aile des iusectes qui sont absolument sans connexion, soit avec les autres, soit avee la base de l'aile. Ex. Dynastes alocts.

INTEGRANT, adjeet., integrans; rexipes; crgünzend, wesentlich (all.); integral (allo). Haüy appelait molécules intégrantes les plus petites parcelles dans lesquellés on eonçoit qu'un minćral puisse être divisé sans que sa nature éprouve aucune altération. $\mathrm{O}_{u}$ donne aussi eette épithète aux atomes des corps simples.

INTUGCIFOLIE, adj., inlegrifolizs; ganzblïtrigg (all.) (intcger, cntier, folium, feuille); qui a des fenilles enticres. Ex. Nabalus integrifolius, Alodecca integrifotia, $D_{0}$. decatheon integrifolium.

INTEGRIFOrHE, adj. , integriformis (integer, entier, forma, forme). Épithete donnée, dans la nomenclature minćralogique de Haïy, à une variété d'Arragonite composéc de qualre octaédres primitils réunis sans aucune pénétration, de sorle que la forme primitive s'y montre dans toute son intégrité.

INTÉGROSTONE , adj., integrostomus (inleger, entier, crojx, bouehe). Se dit d'une eoquille univalve dont l'ouverture est cutière en devant.

INTELLIGENCE , s,f. , intellectus; yoü;; Ferstand (all.); understanding. (angl.) ; intelligenza (it.). Faculté d'appricier l'importance d'un ou plu. sienrs faits d'après les eirconslances dans lesquéles ils ont licı, d'en déduire les rapports, de se déterminer suivant les conséqunences, alin de prendre une volon té d'agir, et de créer les moyens d'exécuter cctte denic̀re pour arriver an résultat défiuilif auquel on veut parvenir. Tous les hommes u'ont pas l'intelligence développée all mène degré. "L'infériorité de eelle des individus qui forment la trèsgrande majorité d'une population, dit Lamarek, rend ces individus iuincapahles de reconnaître leurs intérêts gćnéraux, leurs droits naturels, et les met constamment à la merci de ceux qui sont plus adroits, ainsi que des intérêts personnels des puissins. On les mène et on les satisfait aisćment avec des mots, des prestiges et des préventious adroitcment entretenues. Daus toute assemblée délibćrante, comme ceux qui la composent présentent entl'eux néeessaircment une portion de l'échelle sous le rapport du déreloppement de leur inlelligrunce, e'ust presque toujours dans une minorité de eclte réunion que se irouvent le plus de sagesse, les vues les plus profondes, les pensées les plus justes, les jugemens les plus solides."

INTELLIGLNS, arlj. et s. m. pl., Intelligentia. Lamarck donne ee nom anx animaux eompris dans l'une de ses Irois divisious primaires du règne animal, $\vdots$ eeux qui sentent, acquic̀rent des iilécs, qu'ils couscrvent, exéeutent entre ces idées des opérations qui lcur ell fournissent d'autres, el sont intelligens à différens degrés.

INTENSITÉ, sulst. f., inicnsitas. Taut degré de forec, de puissance, d'activité. L'intensilé d'une force est l'effet qu'elle exeree sur le corps mis en mosnement par elle. L'intensité 
du son dépend de l'étendue des exeursions des particules aëriennes suecessivement agitées, de l'énergie des eondensations et dilatations passangìres que ehaque onde sonore produit en elles, du nombre plus ou moins grand de partieules qui éprouvent ees effets et les transmellent simultamciment à l'organe auditif. L'intensité de la chaleur, de la lumiere et de l'élcciricicé tient ou ì la mème eause que celle du sou, ou ì l'abondance du fluide producteur, suivant celle des deux hypothèses qu'on admet pour expliquer les phénoınèues.

INTEUANTENVAIRE, adj. et s. m. , interantennarius. No:n donué par Roluneau-Desvoidy ì deux petites crètes ou squamules qui font quelquefois sa illir, au côté interne du premier article des antenutes des insectes Myodaires, les pièees appelées par lui antemnaires.

INTERCALATION, s. f., interculatio ; Tapepepoln ; Einschaltung (all,). Opéralion qui consiste à fairc entrer en ligne de compte, dans le ealeul du temps, les heures, minutes et secoudes dont l'année tropique est plus longue que l'annice civile. Lossque ce surplus s'est accumulé assez pour qu'il en résulte un nombre entier quelcouque, par exemple un jour, on doune le uon d'intercalaire ù ec jour, et ou l'ajoute à l'année, qui prend la mème dénonnination. Ainsi l'annćc eivile est évaluée à 565 jours, "t tous les quatre ans on y ajonte un jour produit par l'accumulation de l'excédant de l'année tropique sur elle. Ies années qui ont ámsi 366 jours sont nommées intercalaires, pour les distingुner des autres, qu'on appelle anníes eommznes. La unème chose a lieu pour l'année lunaire, elsez les peuples qui professent l'lslamisme.

INTERGELEUEAIRE, adj., intercellaloris. Treviranus et Link nom- ment canaux intercellulaires (meatus s. ductus intereellulares, vasa revehentia, Iledwig) des vaisseaux qu'ils admettent entre les eellules du tissu végétal, et dont l'existence n'est pis bien prouvée.

IVTEIDILATE, adj., interdilatatus. Se dit, d'après H. Cassini, des squames du péricline, quand elles sont disposécs sur p’nsieurs rangs, ct que les intermédiaires sont les plus larges.

INTERPÉRENGE, s. f. , inter $f c$ rentia (de l'angiais to interfcre, se reneontrer). Nom donné par Y Young à des phénomènes que la lu mière présente en s'infcéelissinnt vers les extrémités des corps, paree qu'ils s'expliquent aisément par la reneonire des rayous lumincux dont, par le résultat mème de leur councidence, les effets se détruisent mutucllement.

IXTERHOLIACÉ, adj. , interfoliacets (inter, entre, folium, feuille). Se dit des fleurs qui naissent alterwativenent entre chaque eouple de feuilles opposées.

INTENRLONTAL, adj. et s. m., intcrfrontalis. Robineau - Desvoidy nomme interfrontaux, dans les Myodaires, deux pièces plus ou moins développées, qu'on remarque à la partie antérieure du front, et qui parviennent quelquefois à s'interposer entre les froutaux dans toute leur longueur.

nNTHGTERoN, s. m., intergerium. Germar appelle ainsi la eloison en manic̀re d'arète ou de earène, et quelqucfois saillante supéricurement, que la languctte paraît former derrière le meutou, dans les Piméliaires et dans beaucoup de Coléoptères lamellieornes.

INTEIMÉDIAHE, adj. , intermedius; swischentiegend (all.) (inter, entre, medius, milieu). Werner donnait eette épithète à des terrains qui ressemblent aux primordiaux 
zant par la nature que par la structure des roches qui les composent, mais eontiennent des débris on des empreintes de corps organisés. Ce sont en quelque sorte les restes de la formation primitive, avec les premiers dépôts des formations sulsćquentes. Poslérieurs aux catastrophes qui ont dégradé les premicrs, ils ne se sont formés qu'après l'apparition de certains êtres organisés sur la terre. En botanique, on nomme sti. pules intermédiaires, celles qui naissent sur la tige, cntre des feuilles opposées, mais à la mène hanteur qu'elles (ex. Cofen arabica). Kirby appellc arcole intermédiaire la partie de l'ailc située entre l'aréole costale et la nervure interno-médiale, dans les insectes diptères.

IVTEIRITTENT, adj., intermil -

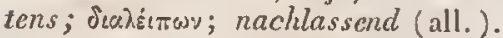
Les sources intermittentes sont celles qui, de temps en temps, et à des intervalles variables suivant les localités, ne fournissent plus d'eau et s'arrêtenl tout court. Ce phénomène, qui souvent est astreint à des périodes réguliëres, leur a valı le nom populaire de fontaines miraculeuses. On voit de ces sonrces à Belestay, à Boulaigne, à Colmars, à Come, à Tronzanches, ctc.

INTELINE, adj., internus; po.; imnerlich (all.); internal (angl.); üntcsno (it.); qui est placé en dedans. Ies boutons internes sont ceux qui res. tent cachés dans le corps de la tige, de la branche ou du rameau, jusqu'ál l'époque du bourgeonnement (cx. Rob:nia pseudo-acacia). L'endoplèrre est appeléc aussi tunique interne, et la chalaze ombilic interne. Interne se dit souvent, comme synonyme d'intrairc, en parlant de l'cmbryon cnveloppé par le périsperme.

INTERVO-MuÉDIAL, adj. , internomedialis. Kirlyy donne cette épithete a la quatricme nervure principale de l'aile des insectes.

INTEROCULAIRE, adj., interoczelaris (inter, entre, ocnluts, ,eil). Se dit des antennes des insectes, quand elles sont insérées toutes les deux entre les yeux. Ex. Leptura.

IVTERPOSIT⿱ tivus, interfoliaceus (inter, entre, pono, placcr); qui est silué eutre. On dil: ćlamines interpositives, celles qui sont situécs cutre les divisions d'un périantlıe simple (ex. Alangium), on d'une corolle (ex. Borrago officinalis); cloisons interpositives, d'après Mirbel, celles qui, partant en divergeant de l'axe central d'un péricarpe multivalve, vont chacume s'unir à l'une des sutures, en sorte qu'elles alternent avec les valves (ex. Convolvulus); pleurs interpositives, celles qui naissent entre des paires de feuilles opposées, et alternent arec elles (ex. Asclcpias syriaca); pétales intcrpositifs, ceux qui alternest avec les divisions du calice (ex. Crueiferes).

INTERHANÉ, adj. , interranežs (inter, dedans, terra, terre). Mirbel appelle ainsi les plantes qui croissent et végètent dans le scin mème de la terre. Ex. Tuber cibarium.

INTERLONirU, adj., interruptus ; unterbrochen (all.); interrotto (it.) (inter, entre, rumpo, rompre). Sc dit, en minéralogie, dans la nomenclature de Haiity, d'une variété dans laquelle un décroissement mixte s'intercale entre des décroissemens sinples qui tendent à former une progression (ex. Baryte sulfatce interrompue). En bolauique, de l'épi, quand les fleurs dont il se compose sont disposées sur l'axe en groupes ou verticilles distans los uns des autres (cx. Lavandula spica); de la feuille, d'après Richard, lorsqu'elle a un disque formé par une expansion des deux côtés de la nervurc médiaue, 
mais interrompu, surtout inféricurement, par des incisions latérales qui s'étendcnt jusqu'à celte nervure, d'ou résultent des lanières tonjours moindres que la portion terminale du disque, ct tellement adnces i la nervure par lcur portion foliacéc gise les bords de celle-ci sont confluens avee cenx de celle-là.

INTERIRUPTE-PENNÉ, adj., interrupte-pinnatus. Se dit d'uve fcuille peunćc dont les folioles sont alternativement grandes et petites. Ex. Marlinezia interrupta.

INTERSCAPULIUM, s. m. , interscapuliun; Vorderrükken (all.) (inter, entre, scapula, épaule). Illiger appclait ainsi la x'égion du dos, celle qui est placée cntre les omoplates chez les mammifères, entre les ailes chez les oiseaux.

INTERTROPIGAL; adj, , intertropicalis; qui esl situć entre les deux tropiques. La zone torride est quelquefois nomméc zone intertropicale.

IVTERVALLE. s. m. En physique, c'est le rapport d'un son à uu antre, ou plutôt le rapport entre les nombres des vilurations qui produisent ees sons. L'organc auditif, n'ayant pas la subtilité de l'intelligence, ne peut, à l'instar de celle-ci, admellre, cntre les nuances des sons, la même variété infinie qu'entrc les nombres des vibrations qui les produisent: il ne distingue ces nuances qu'autant que la distance eutre elles cst assez considérable pour lui permettre de l'apprécier. Sous ce rapport, les musiciens, outre l'acception génćrale ou abstraite du mot, suivant laquelle il exprime pour eux la distance quelconque de deux sons donnés, lui cn appliquent deux uutres qui, rattachées au mode actuel de notation, expriment la première, tonte distance susceptible d'ètre notée, la secondc, toute distance qui, bien qu'égale à une autre, se marque sur un degré différent.

INTERVALVAIRE, adj. , intervalvaris; qui est cntre les valves. Une cloison intervalvaire est relle qui, par son interposition, produit la commissure des valves d'ın péricarpe, de sorte qu'elle devient libre par lá débiscence de ce dernier.

INTERVALVE, adj., intervalvis. Mlirbel donne cette épithète aux nerrules du placenta qui sont placées dans la suturc, entre les bords des valves. Ex. Crucifcres.

INTESTINAUx, adj. el s. m. pl., Intestinalia. Non donnć par Linné à u u ordre de la classe des Vers, par Eichwald à un ordre de celle des Grammazoaircs, par Cuvier à une classe du règne animal, comprenant des ansmaux qui vivent dans l'intérieur du corps d'autres animaux. Voyez Entozolires.

INTIGí, acanlis; qui n'a point de tige. Synonyme inusité d'Acaule.

INTOnSION, s. f., intorsio, torsio. Linné appelait ainsi le phénomèue offert par certaines plantes qui, pour s'ćlever, serrent étroitement les végélaux placés daus leur voisinagc, en roulant autour d'enx leurs tiges flexibles, soit de droite à gauche (ex. Phaseolus), soit de gauche ì droite (cx. Humulues).

INTRACRESCENT, adject, intracrescens (intrà, dedans, eresco, croître). Épilhète donnée par H. Cassini aux corolles dont la force d'accroissement est plus grande sur la facc interne que sur l'externe, coinne dans les fleurs qui constituent la couronne dn Zoegea lcplaurca.

INTRADLATÉ, adject. , intradilatatus. H. Cassini appelle ainsi les squames du péricline des Synanthérées, quand ellcs se trouvent disposćes sur plusieurs rangs, et que la largeur des internes surpasse cclle des externes. 
INTRAFOLIR, adj. , intrafoliacctss (intrà, en dedans, folitum, feuille). Sedit de la hampe, lorsqu'elle naît entre les feuilles radicales (ex. Bellis perennis); des stipules, quand elles sont soudées par leur base seulcment à la partie antérieure des pétioles, et que, libres dans leur partie supéricure, elles forment ainsi une lame placée entre la tige et le pétiole (ex. Arenaria rubra).

INTRAIRE, ndj., intrarius (intrà, dedans). L.-C. Richard donne cette épithète à l'embryon, quand il est renfermé dans l'albumen.

INTRA-MARGINAL, adj. , intramarginalis (intrà, en dedans, nuargo, bord). Se dit des nervures des feuilles et des fleurs qui sont placées en dedans des bords.

INTRA NSUUTABLE, adject. , intransmutabilis. Epithète que WilIughby et liay donuaient à ceux des animaux articulés qui ue subissent pas de métamorphoses.

INTRAVEITEBBRÉ, adj. , intravertelratus. Dans le système de Geoffroy Saint-Hilaire, qui ramène à un mérne type d'organisation les animaux articulés et les vertébrés, ceux-ci prennent le nom d'intravertébrés, parce yu'ils ont leur apparcil osscux à l'intérieur du corps, tandis que, cliez les autres, il est extérieur.

IRTuORSE, adj., introrsus; cinwïrsgehend (all.); qui est toumé en dedans, comne les anthères, lorsqu'elles s'ouvreut du côté du pistil, ce qui est le cas le plus ordinaire. R. Brown remplace cette épithète peu harmonieuse par celle d'anticus.

INTSIÉES, adj. ets. f.pl., Intsiea. Nom donué par C.-H. Ebermaier ì une tribu de la famille des Papilionacées, qui a pour type le genre Intsia.

INTUSSUSCEPTION, subst. f. , intussusccptio, introsusceptio (intus, dedans, suscipio, recevoir). Acte
INVE

par lequel les matières qui doivent ĉtre assimilées sont introduites dans l'intérieur des corps organisés, pour y être absorbées el servir à la nutrition.

INULÉES, adj. et s. f. pl., Inulea. Nom donné par H. Cassini à une tribu de la famille des Synanthérées, par Lessing à une sous-tribu de la tribu des Astéroildées, ayant pour type le genre Inala.

INULINE, s. f., inulina. Espèce d'amidon que Rose a découvert dans la racine de l'Inula Helenium, et qui a été appelé aussi hélénine, alantine, ményanthine, élécampe, dihline ct datiseine.

INULITL, subst. f. , inulita. Nom donné par Guibourt à l'inuline.

INVEINÉ, adj., avenis, invenosus; qui n'a point de veines ou de nervures, comme les feuilles du Clusia rosea.

INVERSE, adj., inversus, posticus, aversus; umgckelert (all.); qui est renversé en dedans. Se dit, en minćralogie, d'un rhomboïle dont les angles saillans sont égaux aux angles plans du noyau, ce qui est l'inversc de la forme primitive (ex. Chanx carbonatée inverse); en botanique, des anthères, d'après Mirbel, quand la suture des valves est tournee vers la eireonférence de la fleur (ex. Cucumis); de l'cmbryon, quand, l'ombilic interne ne correspondant point à l'externe, la radicule, qui se porte toujours vers ee dernier, est latérale (ex. Cofca), ou dirigée en haut (ex.Palmicr Doum); de la radicule, lorsqu'elle est tournée du côté diamétralement opposé au bile (ex. Polygonum seandens); du stigmate, lorsqu'il y en a plusicurs dans une fleur, et que chacun d'eux regarde le centre de celle-ci (ex. Renonculacées).

INVERSO-BINOANNULAIRE, adj., inverso-binoannularis. Eipithète don- 


\section{INVO}

née, dans la nomenclature minéralogique de Haüy, à une variété en prisme liexac̈dre régulier, dont la base est entourée d'un rang de facettes disposées en anneau, qui rósulte d'un décroissement par deux rangées en hauteur sur les bords de la même base, ce qui donne l'inverse du cas où le décroissement a lieu par deux rangées en largeur. Ex. Chaux phosphatée inverso-binoannulaire.

INVERSO-hMARGINí, adject. , inverso-emarginatus. Se dit, dans la nomenclature minéralogique de Jaüy, d'une variété de chaux carbonatée qui présente la forıne de l'inverse, émarginée aux bords supérieurs par des faces primitives, et aux bords inférieurs par celles d'un prisinc hexaëdre.

INVERTúBR $\hat{L}^{\circ}$ adject. et s. m., invertebratus, inspiralis; wirbenlos (all.) (in, priv., vcrlebra, vertèbre); qui n'a point de vertèbres ou de squelette intérieur. Les animaux invertébrés forment un des groupes les plus considérables du règne animal, et on les divise communément aujourd'hui en trois séries ou types, les Mollusques, les Articulés et les Radiaires.

INVISIBLE, adj., invisibilis, inconspicutus; unsichtbar (all.). Se dit de la plumule, quand clle n'cst pas assez développée, avant la germination, pour qu'on puissc l'apercevoir, de quelque manière que ce soit (ex. Allium Copa); de la radicule et de la tigelle, lorsqu'elles sont daus le même ens (ex. Commelina).

INvOLUCELLL, s. m., involucellum ; Hüllehen (all.); involucretto (it.). On appelle ainsi, quand il y a plusieurs rangées de bractées autour des fleurs, celles qui forment la rangée la plus voisine de ecs dernières, ct plus généralcment les bractécs qui, dans les Omhellifères, naissent à la base des ombellules ou ombelles partielles.

INVOLUGELLÉ, adj., involucella tus; qui est muni d'un involueelle.

INVOLUGRAI, adj., involurralis. On dounc cetle épithète aux épines qui naissent sur l'involucre (ex. Cen-. taurca bencdicta). On nomme aussi enveloppe involucrale eclle qui cst produite par un involucre.

INVOLUCRE, s. m., involucrum; Hülle (all.); involncro, invoglio (it.) (involvo, envelopper). Assemblage de bractées ou de feuilles rudimentaircs, lilıres ou soudées cnsemble, que le rapprochement de l'origine des pédicelles forec ì naître en verticilles plus ou moins réguliers, et qui forme une enveloppe extćrieure à une ou plusieurs đeurs. H. Cassini donne ee nom au verticille des bractées qui entourent ln base du péricline, dans cerlaines Synauthérées, et qui ressemblent plus aux feuilles de la plante qu'aux squames de ce péricline (ex. Cnicus benedictus). Il a aussi ćlé appliqué par Malpighi aux conches du bois, qu'il appelait involucra lignea, par Gaertner aux écailles des bourgeons (involucrn gemme) , par Scopoli à la membrane qui recouvre le péricarpe, par Swartz à la membrane qui prolége les amas de séminules de certaiues fougères, par d'autres encore au collier ou a la cortine des champignons, e’est-à-dire au rolva, quand il persiste après s'ètre déchiré, enfin à l'enveloppe génćrale et indéliscente qui entoure les graines des Marsilćacées. Quelquefois on trouve insolucrum genitalium au licu de périgone.

INvoLucué, adj. , involucratus; gehüllt, hüllblättrig (all.); qui est muni d'un iuvolncre, comme les capitules du Gomphrcna globosa, l'épi du Branella vulgaris, la glume du Cynosurus cristatus, l'ombelle $\mathrm{du}$ Daucus Carolta. Le Fritillaria involucrata est ainsi appelé parce que ses trois feuilles supérieures sont rapprochées de manière à former une sorte 


\section{0} INVO

d'involuere autour de la fleur; l'Heliarthenum involucratum, parce que ses fleurs, munies de pédoncules trèscourts, sont entourées de près par les feuilles; le Navarctia involucrata, paree qu'il a ses fleurs rćunies en tète dans un involuere commun; le $P$ cntachondra verticillata, parce que ses calices sont entourés de dix-huit bractées; le Symphorcma involucratum, parce que ses flenr's sont renfermées, au nombre de six i ucut, dans des involneres formés de six à huit feuilles.

INVOLUCHIFOR.1E, alj., involucrifornis. Eppithète que H.' Cisssini donne au péricline des Synanthérées, quand il ressenible à l'involuere.

INVOLUTĹ, adj., involulus; um. gerolle, eingerolle (all.); avvolto, accarlocciato, incollo (it.); qui est roulé en dedans, comne les sépales du Faleriana rudra, les píales de l'Anethum gravenlens et de l'Brypericum involutum, dont la lame se roule de haut en bas vers le ecnire de la fleur, ou comme les fcuilles du Clcistastoma involutum, qui sont roulées sur les bords de delor's en dedans.

INVOLUTIF, adject., insolutives. Candolle appelle estivation involutive celle dans laquelle les organes florauxsont roulés en dedans d'une manière sensible, ce qui a lieu entı'autres pour le caliec des $V$ alérianes; et préfoliation involutive, le cas où les deux bords de la feuille eontenue dans le hourgeon se roulent de dehors eı dedans, comme dans le Lonicera Caprifolium.

INVOLUTIFOLIÉ, adi , involutifolius (involutus, roulé, folium, feuille); qui a des feuilles ronlées du sommet à la base. Ex. Lciotheca involutifolia, Orthotrichum involutifolium.

INVOLVANT, adj., involvens. On donne cette épithète aux folioles d'une feuille trifoliolée, lorsque, pendlant le sommeil de la plante, elles se redres. sent, se réunissent vers le sommet,

\section{IÓDİ}

et s'écartent par le milieú, de mänière à former une espèce de pavillon ou de bercean qui cache et abrite les feuilles. Ex. Lotzes ornithopodoüles.

INTOrve; adj., involvatus. Se dit d'une coquillc univalve, lorsque l'cnroulement du cône spiral se fait transversalement, ou de gauehe it droite, en suivant sa marehe sur l'animal. Ex. Cypraca.

IOnATE, subst. nı., iodas. Nom d'un genre de sels (iodsaure Salze, all.), qui résultent de la combinaison de l'aeide iodique ave les bases salifiables.

IOUE, s. m., iodunu, iodina; $V_{a-}$ rechstoff, Iod (all.) (icusins, violet). Corps simple, qui a été déeouvert en 18.5, par Courlois, ct nomné ainsi ú eause de la belle eouleur violette qu'affectc sa vapeur.

IODE, adj., iodatus; qui contient de l'iode. L'éther iodé, découvert par Faraday, est une combinaison solide d'iode avee le gaz oléfiant.

IODEUX, adj., iodcus. Un acide iocleux (Iodigsäure, all.), premier degré d'oxidation de l'iode, avait été admis par Sementini; mais Wochler a reconnu que c'élait du ehlorure d'iode. Ce dernier a cependaut cru le trouver par un autre procédé, et en effet, il parait exister, quoiqu'on ne l'ait pas encore démontré.

IODIDL, s. m. Nom donné par Berzelius aux combinaisons de l'iode avec des eorps moins ćlectro-négatifs que lui, dans lesqquelles les rapports atomiques sont les mèmes que dans les acides.

IODINE, s. f. , iodina. H. Davy donnait ce nom à l'iode.

IODIQUE, adj. , iodicus. L'acide iodique (Iodsüure, Iodincsïure, Oxiodinsäurc, all.) sera le second degré d'oxidation de l'iode, si l'existenee de l'acide iodeux se confirme. Berzulius donne eette épithète à des sels dans lesquels l'acide iodique joue 
lc rôle de basc, et que d'autres regardent comme des acides doubles. Ex. Borate, Nitrate, Phosphate, Sulfate iodique.

IODOAIGENTATE, s. m. , iodoargentas. Nom donné par P. Boullay à un genre desels, qui résultent de la combinaison de l'iodide d'argent avec les iodures des métaux électro-positifs.

IONOBORIQUE, adj., iodoloricus. Nom d'un acide doublc (iodsaure Boraxäure, all.), résultant de la combinaison des acides iodique et borique.

IODOCIIIORURE, s. m., iodochloruretum. Composé qui résulte de la combinaison d'un chlorure avec un iodure, par exemple, du chlorurc potassique avec l'iodure mercu rique.

IODOCYANuRE, s. m., iodocya. nuretum. Composé qui résultc de la combinaison d'un eyanure arec un jodure, par exemple, du cyanure mercurique avec l'iodure potassique.

IODOHYDRARGYRATE, s. m. , iodohydrargyras. Bonnsdorff appell. ainsi un genre de sels, qui résultent de la combinaison de l'iodure de mercure avec les iodnres des métaux électropositifs.

IODONITRIQUE, adject., iodonitricus. Nom d'un acide double (iodsantre Salpetersiumre, all.), résultant de la combinaison des acides iodique et nitrique.

IODOPLOSPITURE, s. m., iodophosphuretum. Combinaison d'vode et de phosphore avec un autre corps simplc. Er. Iodoplosphurc hydrique, produit par la combinaison de l'iodideliydriçue avec $I_{c}$ phosphurc, soit bihydrique, soit trihydrique.

IODOPIOSPHORIQUE, adject., iodophosphoricus. Nom d'un acide double (iodsaure Phosphorsäure, ill.), qui résulte de la combinaison des acides iodique et phosphorique. IODOPLONBATE, s. m., iodoplumbas. Nom douné par P. Boullay à un genre de scls, qui résultent de la combinaison de l'iodide de plomb avec les iodures des métaux électropositifs.

IODOSEL, s. m. P. Boullay appelle ainsi les combinaisons des iodures de métaux électro-nćgatifs avec ccux des mćtaux élcctro-positifs, et il les considère comme une classe particulière descls.

IODOSULFUnE, s. m. , iodosulphuretum. Combinaison d'un iodure avec un sulfurc. Ex. Iodosulfure antimonique.

IODOSULFUTIQUE, adj., iodosulphuricus. Nom d'un acide double (iodsaure Schnefelsiure, all.), qui résulte de la combinaison des acides iodique et stulfurique.

IOUURE, s. m., ioduretum, iodetum. Combinaison de l'iode avec un corps simple. Berzelius réserve ce nom pour les combinaisons de l'iode avec les corps ćlectro-positifs dans lesqueilcs les rapports atomiques sont les mêtnes que dans Ics bases.

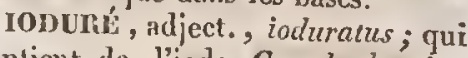
contient de l'iode $G a z$ hydrogéne ioduré, ou acide hydriodique. Acide hydrivalique ioduré ou acide hydriodeux (hydriodige Süure, iorllualtende Hydriodsäure, all.). Hydriodrates iodurés ou lyydrioditos (hydriodigsaure, iodhaliende hydriodsaure Salze, all.).

IOLITHE, adject., iolithzes ("ov, violette, $\lambda_{i} \theta_{0}$, pierre). Le Bissus iolithus est aiusi appelé, parce qu'il communique une odeur de violettc aux pierres sur lesquelles il croît.

IONELLIS, adj. ct s. m. pl., Ionella. Nom donné par Lamarck à une famille de l'ordre des Crustacés isopodes, qui a pour type le genre Ione. IOPTÈE, adject., iopecrus ("oy,

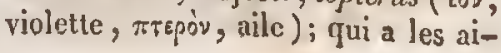




\section{2} IRID

les violâtres ou violettes. Ex. Midlas iopterus, Anehrax ioptcra.

IOSTOME, adj., iostomus (iòs, rouille, orópe, bouche); qui a la bouche couleur de rouille. Ex. Bulimus iostomius.

IOTÈRE, s. In., iotcrium (iós, venin). Kirby appelle ainsi l'organe qui sćerète le poison darss les insectes venimeux.

IPSIDES, adj. et s. m. pl., Ipsides. Nom donné par Latreille à une tribu de la famille des Coléoptères clavicornes, qui a pour type le genre Ips.

IRIDATION, s. f. On a donné ce nom a la propriété dont certains minéraux jonissent de produire sur l'organe de la vue l'impression de la série des couleurs de l'iris, soit a cause d'une substance légere èt incolore qui se trouve appliquée à leur surface, soit en raison. d'une altération survenue dans leur structure par l'éffet ou de fissures, on d'un écartement de leurs lames.

IRIDEES, adj. et's. f. pl. , Iridea, Irides. Famille de plantes, établie par Jussieu, qui a pour type le genre Iris.

MTIDESCENT, adj. , iridescens, iricolor; qui réfléchit les conleurs de l'iris.

IRIDEux, adj. Berzelius appelle oxide irideux (Iridiumoxy dul, all.) le prenier degré d'oxidation de l'iridium; sulfure iridcux, le premier degré de sulfuration de ee mélal; scls iridefix, les oxisels produits par la combinaison de l'oxide irideux avec les oxides, les sulfosels qui résultent de la combinaison du sulfure irideux avee les sulfides, et les sels haloïdes correspondans \& l'oxide irtdeux pour la conposition.

IRIDICO-ARHONIQQUE, ddj., ividico-ammonicus:s: Nom donné, dans la nomenclature chimique de Berzelinis, aux sels doubles qui résultent

\section{IRID}

de la combinaisons d'un 'sel iridique avec un sel ammonique. 'Ex. Chlorure iridico-anmonique (hydrochloralc d'iridizm et d'anmoniaquie).

IRIDICO-POTASSIQUE, adject. , iridico-polassicus. Nom donné, däns la nomenclature chimique de Berzelius, aux sels doubles qui doivent maissanee a la combinaisou d'un sel iridique avec un sel polassique. Ex. Chlorure iridica-polassique ( hydrochlorate d'iridium el de polasse).

IRIDICO-SODIQUE, adj. , iridico-sodicus. Nom donné, dans la nomenclature chimique de Berzelins, à des sels youbles qui résultent de la combinaison d'un sel iridique arec ù sel sodique. Ex. Chlorure iridico-sodique (hydrochlorate d'iridium ct de soude).

IRIDIQUE, adj., iridicus. L'oxide iridique (Iridiumoxyd, all.) est le troisième degré d'oxidatión de l'iridiurn, qui parait joticr le rôled d'acide ; le sulfure iridique est le troisic̀me degré de sulfuration de ce métal, ét le sulfide iridique est le cinquième. Les 'scls iridiques sont les sels haloïdes correspondans à l'oxide pout la composition, les oxiscls et les sulfoscls produits par la combinaison de cet oxide et du sulfide aree les oxacides et les sulfides.

IliDIUW, s. m. , iridium. Métal

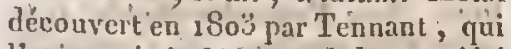
l'a riomnić ainsi à cause de la propriété doint il jouit de donner des dissolutions ayant toutes les couleürs de l'are-en-ciel.

mIDOSO-AMnrovieue, adject. , iriloso-amunonieus. Nom donné, dan's la nomenelature chimique de Berzelius, à des scls doỉbles qui rćsultent de la combinaison l'un sel irideux avec un sel ammonique. Ex. Chlorure iridoso-ammonique.

inmoso-sonique, adj. , iridososodicus. Nom donné, dans la nomenclature chimique de B̉erzelius, ả des 


\section{IRRÉ}

sels doubles, qui sont produits par la combinaison d'un sel irideux avee un sel sodique. Ex. Chelorure iridososodique.

IIISÉ, adject., irintus. On donne cctie épithète à des eouleurs de diverses tcintes qui se manifestent sur la surfaec de eerlains eorps, soit par l'effet d'un eommencement d'altération (ex. eerlains min erais de cuit'rc), ou d'une légère pellicule de matière étrangère (ex. Fer oligiste de l'île d'Elbe), soit à eause de la disposition partieulière des molécules à la surfaee (ex. Ficr olisiste) ou dans l'intérieur de la masse (ex. Opale), mais qui dans aucun eas ne tiennent à la nature même des corps ou à eelle des matières qu'on y trouve aceidentellement mêlées, et dépendent des fissures dans lesquelles la lumière éprouve une dééomposition, de manière qu'il se forme dans l'intérieur ou à la surface des anneaux eoneentriques plus ou moins réguliers, d'où partent des jets rouges, bleus, jaunes, ete., dont l'effet est semblable à eelui de l'iris ou de l'are-en-cicl. Le phénomène de l'irisation s'observe dans diverses eoquilles ( ex. Trochus iris, Oliva irisans) et plusieurs insectes (ex. $H e$. merobius iridcus, Myrmelcon irinum). La Coccinclla iridea est ainsi appelée, non parce qu'elle reflète des couleurs irisées, mais parce que son corps est rouge et marqué de points noirs auxquels un entourage jaune dome quelque ressenblanee avec l'iris de l'ocil.

ImRaniation, s. f., irradiatio; Ausstrahlung (all.). Mouvement du centre à la eireonférenee. I Les physieiens nomnent ainsi le grossissement apparent d'un objet ćclairé, qui est produit par, l'intensité de la lumière.

IRRĹDUCTIBLE, adj., unherstellbar(all.); qui n'est pas suseeptible de réduction. Se dit d'un oxide mé- tallique qu'on ne peut ramener à l'état métallique.

IRREGULIER, adj., irregularis ;

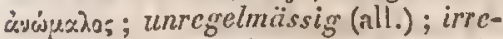
golare (it.) (in, priv., rcgula, règle). On appelle calice irrégulice, celui dont les parties constituantes ne sont pas symétriques, e'cst-à-dire diffèrent pour la grandeur, la position ou la forme dans divers points de leur ćtendue (ex. Delphinium) ; corolle irrégulicre, eelle dont les pétales (ex. Viola tricolor) ou les lobes (ex. An. tirrhinum majus) sont sensiblement inégaux ou dissemblables; corymbe irrégulicr, celui dans lequel les pédoneules s'alougent sans garder de propurtion entreux, de sorte que Jes lleurs arrivent ì des hauteurs inégales (ex. beaueoutp de Radiées); déhisconce irréguliere, celle qui a lieu quand les earpelles sont tellement soudées entre elles que, par aueune partie de leur surface, elles ne peuvent se désunir ni se fendre réguliè rement, el sorte qu'il se détermine, ordinairement vers le haut de ehaque carpelle, des especes de pores ou de ruptures irrégulières, qui donnent passage aux graines (ex. Linaria); estivation irrégulière, eelle qui a lieu quand les parties de la corolle ou du ealiec ne sont pas exactement situées de la nême manière relativement à l'axe, cas dans lequel une ou plusieurs d'entr'elles tendent à reeourrir les autres pendant la préfleuraison; flcur irréguliçre, celle dont les divisions ou les segmens du périanthe diffèrent entr'eux sous le rapport de la grandeur, de la forme ou de la position; antennes irrégulieres, eelles dans lesquelles les arlieles ehangent de forme sans que le changement se fasse d'une manière graduée; coquille irrégulière, celle qui élant inéquivalve présente des différenees dans les divers individus de la même espèee ( $\mathrm{ex}$. Osirea). 
IRRLGULIERs, adj. et s. m. pl.; Irregularia. Nom donné par Latrcille à une famille de l'ordre des Echinodermes Echinoides, comprenant eeux qui ont l'anus et quelquefois la bouehc en dehors de l'axe du eorps.

IRRTTABILITE, s. f. , irrizabili-

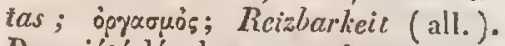
Propriélé dévolue aux seuls corps organisés vivans, qui fait que certaines parties de ces eorps cxéeutent, sans que l'être enticr y participe, et souvent mème sans qu'il s'en apcrcoivc, des mouvemens subits ct plus ou moins remarquables, sous ${ }_{1}^{1}$ influence d'une eause exeilante interne on cxterne. Ces mouvemens, qui earactérisent la vie, n'exigent aucun organe particulier; mais, à mesure que l'organisation se eomplique, surtout dans la série animale, ils se particularisent, de généraux qu'ils sont dans les eorps vivans les plus simples, e'cst-à-dire qu'ils deviennent plus remarquables ct plus puissans dans certaines parties que dans d'autres. C'est ainsi qu'ils finissent par produire la contractilité musculairc, ou.la myotilité, à laquelle seule Haller et son éeole attachaient le nom d'irritabilité, mot qui doit exprimer, comme l'avait bien senti Glisson, un phénounène beaucoup plus général.

URITTABLE, adject, , irritabilis ; rcizbar (all.) ; qui est doué d'irritabilité, comme toutes les parties d'un corps organisé vivant. On prend quel. quefois cc mot dans un sens plus restreint. Ainsi on appelle irritables les étamines dont les filets sont suseeptibles de se monvoir au temps de la fécondation, sans qu'on puisse altribuer leurs mouvemens à aucune force mécanique connue (ex. Berberis).

ISABELLE, adj., isabellus, isabellinus. Se dit d'un eorps dont la eoulcur est le jaune elair. Lix. Lepus isabellinus, Cyprea isabella, Astro. thelium isabellinum.
ISADELPIE, adject. , isadclphus

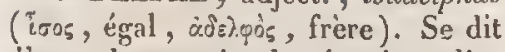
d'une plante qui a les étamincs diadelphes, et formant denx paquets égaux, comme les dix étamines du Drepanocarpus isadelphus.

ISANTHE, adj. , isanthus (ioos, égal, äv0s, fleur). Épithète donnéc par G. Allman aux plantes qui ont les périgoues ou tégumens de toutes leurs fleurs semblables.

ISANTHÈE, adjeet. isantherus (iros, égal, d̀Ansós, fleuri). Se dit d'une plante qui a les anthères égales ou semblables.

ISARIĹES, adj. et s.f. pl. , Isariea. Nom donné par A. Brongniart à une seetion de la tribu des Mucédinées, qui a pour type le genre Isaria.

ISATIDÉES, adj. et s. f. pl. , $I_{s a-}$ tidea. Nom donné par Candolle à une tribu de la famille des Crueifères, qui a pour type le genre Isatis.

ISATIQUE, adj. , isaticus. Dobcreiner appelle l'iudigo réduit acide isatique, paree qu'il a la proprićté de se eombincr avec les bases salifiables.

ISCHIADELPHE, adjeet. ct s. m. , Ischiadelphess (ioryioy, ischion,

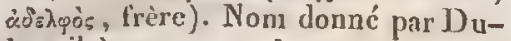
breuil à un genre de monstres doubles, dont les eorps, opposés l'un à l'autre, sont accouplés et soudés par les bassins.

ISCIIION, s. m., ischion. Straus désigne sous ce nom deux pièces situées de chaquc côté du mètathorax des insectes, qu'il considère eomme les analognues des pubis et des iléons.

ISCHNOCuLLE, adject., isehno-

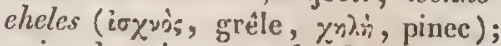
qui a des pinees ou des bras minees et longs. Ex. Obisium ischnocheles.

ISERTIEL, adj. ets. f. pl., Isertiea. Nom donné par Candolle à unc tribu de la famille des Rubiacées, qui a pour type le genre Isertia. 
ISIDĹES, adj. et s. f. pl., Isidece; Isides. Nom donné par Lamouroux, Ficinus ct Carus à une famille de l'ordre des Polypicrs corticifères, ayant pour type le geure Isis.

ISOBAPHiE, s. f. , isobaphia ;

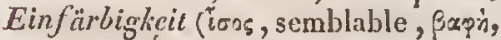
conlcur). État d'un corps qui ne réfléchit qu'une seule couleur.

ISOBRIE, alj. , isobriatus (ĩos,

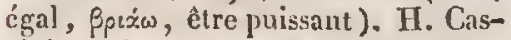
sini employe, ponr désigner les $\mathrm{cm}-$ bryons dicotylédones, ce terme exprimant que les forces d'accroissement sout ćgales des deux côlćs.

ISOCHInE, adj., isochirzes (ĩos,

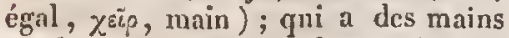
ou des appendiees en forme de bras tous scmblables les uns aux autres. Ex. Polypus isochirus.

ISOGIIRE, adj. , isochrozes ( égal, $\chi \gamma^{\circ} z$, coulcur); qui est d'unc couleur uniforme. Lc Pcziza isochroa est tout blanc.

ISOCIIRONE; adj., isochronus; iøóxpovos (ĩos, égal, xpirvos, iemps); qui se fait dans le incine temps.

ISOCIIRONISML, s. m., isochronismus (iros, égal, ypciros, temps). Qualité de ee qui est isochrone.

ISODACTYLIS, adj. et s. m. pl., Isodactyli ( iøos, égal , d’xxtulos, doigt ). Norn donné par J. - G. Schieffer à un ordre de la classe des oiseaux, comprenant ceux qui ont quatre doigts bien fendus, deux en avant et deux en arrière.

ISODONTES, adj. et s. m. plur., Isodonta (iَos, égal, òdov̄, dent). Nom donné par Muller à une famille de reptiles ophidiens, comprenant ceux qui ont toutes les dents maxillaires simples et égales.

ISODYNAME, adj. , isodynamus (ítos, égal, ớroupes, puissance). Épithète donnée par H. Cassini aux entbryons dicotylédonés, et qui exprime que les forces d'accroissement sont égales des deux côtés.
ISOEDRIQUE, adj., isoedricus (ivos, égal, ع́dpox, base). Nom donné, dans la nomenclature minéralogique de Ilaiiy, à une variété dans laquelle le roonbre des bords senublablement situés, qui sont remplacés chacun par une facelte, est ćgal à cclui des angles semblablement situés, dont chaeun est parcillement renaplacé par unc facelte. Ex. Cltaux ear'bonatéa isoëdrigre.

ISOEtées, adj. ct s. f.pl., Isoetea. Nom donné par Reichenbach à unc famille de plantes, qui a poux type le genre Isoetc.s.

ISOÉTINÉES. V̆

ISOGEOTHERME, adj., isogeo-

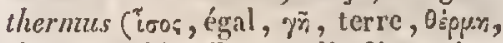
chaleur). Kupffer appelle lignes isogéolhermes celles qui uniraient les points oir la température constantra du sol est uniforme. Ces lignes s'ćcartent eneore plus des degrés de latitude que les lignes isothermes.

ISOGONE, adj., isogonus; iøoyẃyes (ios, égal, qwsix, angle). Nom donué, dans la nomenclature minéralogique de Ṭaiiy, ì un eristal ayant, sur des parties différemment situées, des faces qui forment entrolles des angles égaux ou à peu près. Ex. $C_{y}-$ mophane isogone.

IsOLANT, adj. Les physiciens donnent cette épitlète aux corps qui ne transmettent pas librement l'électricité, parce que, quaud on les employe comme supports, ils isolent les autres de toute communication ávec des conducteurs qui pour raicnt leur eulever l'ćlectricité.

ISOLATEUR, subst. m., isolator; Nichlleiter (all.). Apparcil dont on se sert, dans les expériences ćlectriques, pour isoler les corps auxquels on veut communiquer de l'électricité et dans lesquels on se propose d'accumuler cette dernière.

ISOLÉ, adject. Se dit d'un corps qu'on a entouré d'autres corps non 
conducteurs de l'électricitć, afin de le mettre hors decommunication conductrice avec le sol.

ISOLEMENT, s. m. État d'un corps élcctrisé dont on a éloigné tous les objets conducteurs, afin qu'il puisse conserver l'électricité.

ISOLUSINE, $\mathrm{s}$. $\mathrm{f}$., isolusina. Peschier désigne sous ec nom une substance particulière, qu'il dit avoir découvcrte dans la racine de Sénéga.

ISOuthe, adj., isomerus (igos, égal, pépos, partie). Bonnard donne cette épithète à un ordre de rochos, comprenant celles à parties anguleuses, qui sont liées ensemble par une aggrégation cristalline, sans base de cinıent homogène sensible.

- isomínDE, adject. , isomeridus

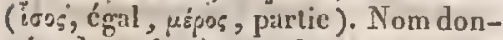
né, daus la nomenclature ninéralogique de Haüy, à une varićtć produite par des décroissemens dont ceux qui agissent sur les bords sont en nombre égal à ceux qui ont lieu sur les angles. Ex. Baryté sulfatée isoméride.

ISONúRtQUe, adj., isomerictus (iøos, égal, $\mu \varepsilon p_{p o s}$, partic). Martius donne celle ćpithète aux feurs régulières. Berzelius proposc de l'appliquer aux corps qui, identiques sous 1c rapport de la composition, e'est-adire sous celui du nombre et de lä nature de leurs atomes constituans, jouijssent cepcndaint de proprićtés chimiques différentes, comme l'acidé cyanique et l'acide paracyanique.

ISOMĹTEIQUE, adj, , isometricus

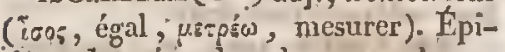
thicte donnce, dans la nomenclature minéralogique de Haüy, à un cristal composé du rhomboïde équiaxe et 'd'un dodécaéưre à triangles sealèncs, daus lequel la somme des deux parties qui cxeèdent l'axe dn noyau est égale a cet axe (ex. Chaux carbonatée isométrique) ; par Hausmann et Naumánn a un système de cristal- lisation comprenant les formes cristallines dans lesquelles les plans coordonnés sont perpendiculaires entr'eux, ef qu'on peut rapporter à un système d'axes, au nombre de trois, qui sont ćgaux.

ISOMIORPIE, adj., isomorphus

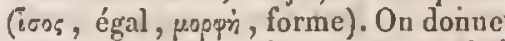
cetle ćpithèle aux substances simples ou composées, lorsqu'clles affectent la méue forme cristalliue dans leurs combinaisons avec d'autres substances, d'après les mèmes proportions atomiques. Ainsi A est isomorphe avec $\mathrm{B}$, quand $x$ atomes $\mathrm{A}+\boldsymbol{y}$ atonies Cmontrent la même formeque $x$ atomes $\mathrm{B}+y$ atomes $\mathrm{G}$, ou quand $x$ atomes $\mathrm{A}+y$ atomes $\mathrm{C}+z$ atomes $\mathrm{D}$ ont la mème forme que $x$ atomes $\mathrm{B}+y$ atomes $\mathrm{C}+z$ atomes $\mathrm{D}$. Le soufre, le sélćnium et le chrome sont isomorphes; un atome de chacun de ees trois corps forme avec trois atomes d'oxigcene des acides isomorphes; savoir les acides sulfurique, sélénique ct chromique, qui, en se combinant avec un même nombre d'atom mes d'unc mème base, produisent des sels ayant la mêrne forme. Il y a également isomorphismc entre le phosphore ot l'arsenic ; la soude et loxide d'argent; le calcium, le magnesium, le manganèse, le zinc, le fer ' le cobalt, le nickel, le cuivre , lé barium, le stronitium et le plomb; l'alumine, l'oxide ferrique, l'oxide manganique et l'oxide chromcux' l'oxide stannique et l'oxide titanique; lc platine, le palladium, l'iridium et l'osmiúm.

ISomorpurisure, s. m. Phénomène; découvert par Mitscherlich ; qui consiste en ee que dies corps composés d'élémens différens, mais d'atomes en nombre égal et combinés de la même manière, affectent la mêine forme cristalline.

ISOPARAMÉTTIQUE, adj. , iso-

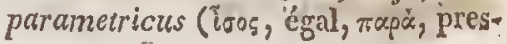




\section{ISOT}

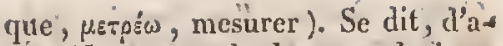
près Nanmann, de deux ou plusicurs faces d'un même systène d'axes', quand leurs paramètres correspondans sont de mènie grandcur, et ne diffèrent que par la direction.

ISOUl'TALE, adj., isopetalus (irot, égal, $\pi \dot{\varepsilon} \tau \alpha \lambda 0 \%^{\circ}$, pctale); qui a des pétalcs égaux. Les ailes, l'ćtendard et la carène de l'Erythrina isopetala sont presque de li méme longueir.

ISOPUYLIE:, adject. , isophrl/hes

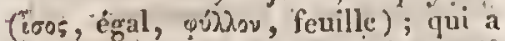
des feuilles pareilles. Ex. Microlicia isophiylla.

ISOrones, adj. et s. m. pl., Iso-

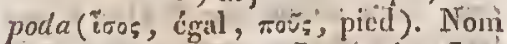
donné poir Cuvier, Lanırak, Latreille, Goldfuss, Straus, Eichwald, Ficinus et Carus, du un ordre de la elasse des Crustacés', comprenant ceux de ces animaux qui ont les paittés toutes semblables, uniquencut proprès à lạ locomotion on a li préhension.

ISOPODHFORME; adj. ; isopodiformis. Kirby donue cetie épithête àt des larves liexapodes, ántenílères ct saprophages, qui on tuo eorps oblong, un bouclier thoracique distinet, et un anus garni de filets ou de lanes. Ex. Blatta sylplac.

ISOPOGONE, adjeet., Isupogon: gleiehbartig (all.) ("iøos, égal, $\pi \dot{\gamma} \gamma \omega s$, barlue). Se dit d'une plume dont les deux côtés de la barbe sont d'une largeur égale.

isos'ÉmoNes, adj, et s. f. pl.,

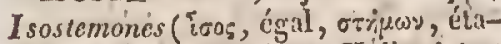
minc). Nom donné par Haller ì üue classe de plartes, comprenant celles qui ont autant d'ćtamines que de pétales ou de divisions ì liı corolle.

ISOSTEMONOPITALE, adj., isostemonopetalus (i ćtaminc, $\pi \dot{\varepsilon} \tau \times \lambda$ ', pétale). Warhendórff donnait cettc épithete aux plantes dont les étamines sont en noubre égal aux diyisions de lí corolle.

ISOTLERME, adj., isothermus (ioos, égal, Aq́pön, chaleur). On nomme, d'après Húribuldt, lignes isothermes, edles qui passent pą tous les points de la surface de la terre pourlesquels la température moyenne est la mèmc, et bandes ou zoones isothermes, les espaces compris cntre deux de ees lignes. Les lignes isothermes ne suivent pas les parallèles à l'équateur ; elles ont des sommets convexes et des sonumets eoncaves qui sont distribués trís-régulièremeit sur le globe, et lórment différen's systènies le long des côtes orientale ct oceidentale des Deux-11ondes; au centre des continens et à proximité des grands bassins de iners.

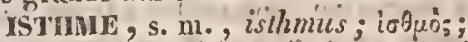
Verengerung (all:); neel of land (angl.). Langue de terre, hordée d'eau de chaque eôté, qui uniténsembledeux continens, ou qui lie une prosqu'île ä d'autres terres. Rétréeissement qui sépare les lobes de certaines feuilles (ex. Zostera), ou les articulations des früis artieulés (ex.' Hippocrepis).

ISTHuIs, adj., isl/hnialus. Epithète donnce par Kirby au tronc des insectes, quand il existe un isthrme ou un rétrćeissement cntré le prothorix et les élytrés (ex. Passalus).

ISTIMOCAIIPE, adj., isthmoear-

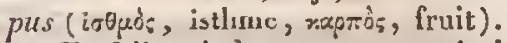
Le Trifolium isthmocarptem est ainsi appelé, parce que son légume offre un rétrécissement à la partie moyenne. ISTIOPIIOLES, adj. et s. m. jl., Isiiurophori (iorioy, voile, páp̧ porter). Nom donné par Gray à une famille de Vespertilionides, eomprenant ecux de ees manmiferes qui ont une membrame en forme de feuille sur le nez.

ITÉRATIF, adj., iterafivits, (iterum, dè nouveau). Spithète donnce, dans la nomenclature minéralogique de Haïy, à une variété dont le signe ést composé d'exposans relatifs à des lois simples, et d'autres exposans 
qui entrent dans l'expression d'un décroissement intermédiaire, et offrent la répétition des premiers. Ex. Fer oligistc itératif.

ITHYCÉRIDES, adj. et s. m. pl., Ithycerides. Nom donné par Schoenherr à un groupe de l'ordre des Curculionides orthocères, qui a pour typc le genre Ithyccrus.

ITIYPIYLLE, adj., ithyphyllus (iQis, droit, $\varphi v \lambda_{\lambda} \lambda_{2}$, feuillc); qui a des feuilles droites. Les feuilles du Bartramia ithyphylla sont linćaires , subulées, droites, raides, longues et capillacées.

IULACE, adj., iulaccus; kïtzcluenförmig (all.); qui a la forme d'uu chaton, comme les jets du Jungermannia iulacea et du Gymnoslomum iulaccum, ou qui croit sur les chatons, comme le $P_{c z i z a}$ iulacca sur ceux pourris de l'aulne.

IULACEES, adj. et s. f. pl. , Iulaccce. Nom donné par Lamarck à une scetion de la famille des Arachnides myriopodes, qui a pour type le genre Tulus.

IULIDES, adj. ct s. m.pl., Iulides. Nom donné par Lcaclı et Blainville a une famille de la classe des Myriapodes, qui a pour type le genrc Tulus.

IULHLORE, adject., inliflorus (izalus, chaton, fos, fleur); qui a les fleurs en épis scmblables à des chatons. Ex. Prosopis iuliflora.

ILLIFORME, adj., iuliformis. Un mollusque (Peripatus iuliformis) cst ainsi nommé à callsc de son corps ridé, annelé de jaunâtre sur un fond brun, ec qui lui donne quclque ressemblanec avec un iule.

IVOIRE, s. m., cbur; ह̇ंéęas; $\mathrm{El}$ fenbcin (all.); ipory (angl.); avorio (it). Substance osscuse des défenses d'éléphant et d'hippopotame; substance qui forme la partie interne du fût et la racine entière de la dent.

IXIA CÉES, adj. et s. f. pl., Ixiacece. Nom donné par Ecklon à unc famille de plantes, qui a pour type le genrc Ixia.

IXIÉLS, adj. et s. f. pl., Ixica. Nom sous lequel Reichenbarh désigne une section de la famille des Iridćes, ayant lc genre Ixia pour type.

IYoDIadís, adj. ct s. m. pl., Ixodiadce. Nom donné par Leach à une tribu de la fanille des Acarides, qui a pour type le genre Ixodcs.

IzÉIINN, adj., , izemianus (içnex, sédiment). Brougniart donne cette épithète aux terrains sédimenteux, à ceux qui so ant formés par voic de sćdiment.
JABOT, s. m., ingluvies; rpólo. Bos; Kropf (all.); crop (angl.). .Dilatation quel'oesophage présente chcz les oiseaux, principalement chez les Granivores, ct dans laquellc les alimens séjournent pendant quelque tcmps, avant de passer dans l'cstomac proprement dit.

JACKINEES, adj. et s. f. pl., Jaceinca. Nom donné par II. Cassini a un groupe de la section des Cicntauriées prolotypes, qui a pour type le genre Jacea.
JACOBLES ; adj. et s. f. pl., Jacobace. Nom donné par Adanson et par Kunth à ture section de la famille des Synanthérées, ayaut pour type lc genre Jacobaa.

JACULATER, adj., jaculator (jaculo, laneer). Le Labrzes jaculator lance sur les insectes qui s'approchent du rivage des grouttes d'eau, au moyen desquelles il les fait tomber dans la mer et s'en saisit.

JACULIFLEE, adj., jaculiferus (jaculum, jayclot, fero, porter); 
qui a des piquans en forme de javidlot, comine ceux qu'on voit sur les flatics du Diodon jaculifcrus.

JADIEN, adject., qui contient du jade. L'Euphotide jadicnne est à base de jadc verdâtı.c.

JALLLISS.INT, adj , , saliens. On donne cette épithète anx sources, quand l'eau s'élève au dessus du sol eu jets ou en gerbes, dont la lauteur varie beaucoup. Les plus remarquables de ees sources sont les geyser d'Islande, dont lc jet, ayant une chaleur de 64 a 80 degrés $\mathbf{R}$., et un diamétre de près de six pieds, s'élance à cent trente pieds de hauleur. Les puits artésiens sont des sourees jaillissan tes créécs par la main de l'homme. Il ya aussi des sources jaillissantes de fen, qui sont produites par des jels embrasés de gaz hydrogene.

JALAPIINE, s.f., jalappina: Substance que Hume a extraite de la racine de jalap, qu'il regarde comme une base salifiable, mais que Schweinsberg croit ètre un mélange de phosphale amoniaco-magnésicn, de chaux et d'une matière organique.

JANAICINE, s. f., jamaicina. Base salifiable, déconverte en 1824 , par Huttenschinidt, dans l'ćcorce du Genfroya jumniccnsis.

JAMA ICIQUE, adj., jamaicictrs. Nom des sels dont la jamaïcine frit la base.

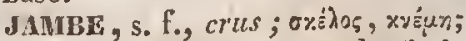
Bcin (all.); leg (angl.); gamba (it.). Portion du membre pelvien des animaux vertébrés qui s'étend depuis le genon jusqu'au pied. Cependant on appelle jambe, dans les ruminans et les solipèdes, la région comprise entre le jarret ct le sabot, c'est-ì-dire le mélatarse et unc portion des phalanges. Jambc se dit aussi, dans le langage commun, de la totalité dit menibre postéricur et mème du membre antérieur des quadrupèdes, ce qui le rend synonyme de patte. On nom : me jambe dans les crustacés, la quatriène pic̀ce des pattes simples, et dans les insectes, le troisième article principal.

MarnE, s. f. C'est le nom qu'or donue ì des poils longs, gros, durs, luisáus et droits, qui percent à travers la fourrure de certains quadrupèdes, et notamment de la laine des brebis de races inférieures. On l'appelle aussi poil mort on poil de chien.

JARIRET, s.m., poples, garotum,

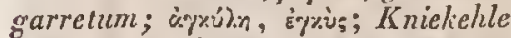
(all.); ham, hough (augl.); garrcllo (ii.). Partie postéricure de l'articulalion da genou dans l'homme. Synonyme de région poplicée.

JARrEuX, adj., struppig (all.). Se dit de la laine, quand elle contient de la jarre.

JASIONLES, adj. et s. f. pl., Jesionece. Famille que Link propose d'établir, et qui aurait pour type le genre Jasione.

JisurníES, adj. et s. f. pl., Jasminece. Famille de plantes, élablie par Jussieu, qui a pour type le genre Jasminum.

JASPÉ, adj., jaspideus. Les minéralogistes nornment agatc jaspée, celle dont la pâte, se trouvant melée d'oxide de fer et de molécules argileuses, perd plus ou moins sa transparence. L'Anas jaspidea est ainsi appclé, parce qu'il a la tête et le haut dus cou lachetés de noir sur un fond jaspé de brun, de blanchàtre et de roussâtre.

JASPIQQUE, adj., jaspicus. Les poudingues jaspiques sont composés de noyaux d'agate ou de silex engagés dans une pâte de jaspe.

JASPOIDL, adj., jaspoidcus. Se dit, cn minéralogic, d'un corps, lorsque sil surface est terne et mate, comme cellu du jaspe. Ex. Feldspati jaspoïde.

JATROPIITE, s. m. , jatrophas. Genre de sels (jatrophasaure Salze? 
all.), qui résultent de la combinaison de l'acide jatrophique avec les bases salifiables. Voy. CRoronatr.

JATROPIIQUE', adj ., jatroplicus. Nom donné par Pelleticr et Caventou à un acide (Jatrophasïure, all.) qu'ils 'ont déeouvert en 1818 dans la' graine du Jatropha curcas, et qu'ils ont appelé depuis crotonique.

JAUNATHE, adj., flaveolus; gelblich (all.)'; yellowish (angl.) ; griallastro (it.); qui est d'un jaune pâle, tirant sur le'blond, ou d'un jaune tirant sur le roussaitie; qui tend à devenir jaune. Ex. Picus exalbiilus, Ichnéumion flavator, Ctenophora flaveolata, Cypraa flaveola, Cocrulus flavescens, Dermosporium flavicans, Cypricia flavicula, T'ecten flavidulús, I'leuróloma flavidula, Conus flavidus, Columbella flavida, Solanum 'flavidium, Cyclosionuaflavula, Griaphaliun luteo-albuem, Cocculns lutescens, Digitalis ochrolcuca, Sylvia subflava, Pcziza xanthosia.

JAUNE, adj. et s.m., flavus; goll (all.); jellow (angl.); giallo (it.). T'une des sept couleurs du prisme. On la rend en latin, elle el ses nomloreuses nuances, par une foule d'expressions, la plupart comparatives; jaune pur, luleus, flavus, xanthns; gelb (all.) (ex. Dolichos lutens, Passiflora lutea, Cymbidiumi luterm, Noctua luteago, Cuculus flavus, Alisma Rava, Fusidium flavim, Iris flavissima, Noctua flavago, Polyporus xanthus, Agaricus icterinus, Agaricus armeniacus); jaune de brique, testaecus; ' lateritius (ex. Hispa testacea, Ozonium lateriliant); voyez Brigueté, 'Testacé; jaune de cire, ceraceus, cerinus (ex. Agaricus ceraecus, Peziza cerina); janne citrin ( ex. Embcriza citrinellà, Noctua citrago, Agaricus cetratus); voycz Citrin ; jaune isabelle, voyez IsabelLe; jazne.jon-

\section{JONC}

quille, jonquillaccus, narcissus (ex. Psittacus jonquillaeeus, Psittacus narcissus); jaune d'cunf, vitellinus (ex. Crocus vitellinus, Clavaria vitcllina, Polyangiune vitellinum, $A g a$ ricus viltellicolor); jaune de miel, mellinus (ex. Polyporus mellinus, Peziza nellina, Tachina mellea); jaune de paille, stramineus (ex. My. cetes stranineus, Nardosmia straminea) ; jaune de safran, croceus (cx. Saxifraga crocea, Lapliria safrana, Nocilea croceago); vojez Safrané; jaune sale, luridus, squalens (ex. Aphodius luridus, Iris squalens); jaunc de soufre, sulphureus (ex. Lanius sulphuraceus, Noctua sulphurago, Peziza theivchlora); vojez Sourré; jaune dé sueein, succineuls (ex. Tremella succinea, Dacus suecinatus) ; jaune labac d' Espagne (ex. Gymnocephalus capucinus).

JET, s. n., flagellum, vilicula, stolo. Branche particulière, dépourvue de feuilles dans une portion notable de sa longucur, que eertaines plintes poussent de l'aisselle de leurs feuilles inférieures, et dont l'extrémité, après avoir jeté des racines en terre, produit soit de suite un bourgeon ì feuille (ex. Fragaria), snit l'année suivante seulement des tiges et des feuilles (ex. Lysimaehia). JOBOLIES, adj. et s. m. pl, , Joboli (io;, venin, (ja) $\lambda \omega$, lancer). Nom donné par J.-A. Ritgen a une tribu de reptiles Ophidiens, qui com. prend les serpens venimeux.

JONCacies, adj. et s. f. pl., Juncacec. Agardh et Bartling appellent ainsi la famille des Joncées. Voyez ce mot.

joxcaGivírs, adj. et s. f. pl., Juncaginea. Famille, établie par L..C. nichard, qui a pour type le genre Trigloehin, appelé Juncago par Tournefort.

JONCúEs, adj. et s. f. pl., Juncece. Famille de plantes, établic par. 


\section{JOUE}

Jussieu, qui a pour type le genre Juneus, et que Richard, Candolle et R. Brown ont bcaucoup restrcinte, en fondant à ses dépens les familles des Alismacées, des Butomécs, des Cabombécs, des Colchicacées, des Commélinées, des Joneagivées et des Restiaccés.

JONCICOLE, adject., juncicolus (juncus, jone, colo, habiter); qui croit sur les jones, eomme l'A garicus juncicola sur les feuilles pourries du Juncus articulatus.

JONGIFORME, adj., junciformis (juneus, jonc, forma, forme); qui a la forme d'un jonc, c'est-à-dirc qui est alongé et grĉle. Ex. Asraricus junceus, Chondrilla juneea, Alcyonium junceum.

JovCINiES, adj. et s. f. pl., Juneinea. Nom donné par Bartling à une classe de plantes, qui comprend les familles des Restiacées, des Joncacées, des Xyridées et des Commélinacées, et qui a pour type le genre Juncus.

JONGERMANNIACÉES, adj. et s. f. pl., Jungermanniaeea. Nom donné par Corda à une fanille de planies, ayant pour type le genre Jungermannia.

JONGERMLNNTíRs, adj. et s. f. pl., Jungermannice. Quelques botanistes donnent ì la famille des Hépatiques ee nom dérivć de cclui d'entre ses genres qui comprend le plus d'espèces.

JONGLRMaNNiograpHIT, s. f., jungermanniographia. Traité sur les Jongermannies. Raddi a écrit un livre sous ce titre.

JONGLRUANNIONDS, adject. et s. f. pl., Jungcrmannioidci. Nom donné par Bridel à une famille de Mousses, ayant pour type le genre Jungermannia.

JUUl', s. f., gena; jírus; Bakke (all.); eheek (angl.); guancia (it.)

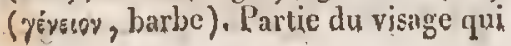

JOVI

formcles parois latćrales de la bouche, et sur laquclle la barbe croit chcz llomme; région de la face comprise entre le nez, la bouche et l'oreille, ehez les manımifères; entre la base du bec, le front et l'oxil, ehez les oiseaux; partic latćrale du bouclier des trilobites; portion de la tête des insectes située de chaque eôté, entre les yeux et les mandibules.

JOUES-CULRASSEES, adject, et s. m. pl. Nom donné par Cuvier à une famille de poissons, comprenant ccux qui ont la tête diversement hérissée et cuirassée.

JoUR, s. m., dies; ijpśso; Tag (all.); day (angl.); giorno (it.). On dorıne ce nom, dans la vie ordinaire, au teinps qui s'écoule depuis lc lever jusqu'au coucher du soleil, et, en astronomic, à la durće d'unc révolution eutic̀re de la terre, e'est-à-dire atu temps compris entre deux retours du soleil au méridien supérieur ou inférieur. On appelle la première période jour naturel, parce, qu'elle est déterininéc par le plus manifeste de tous les ćvénemens naturels, l'altcrnative de la lumière et de l'obseurité; et la seconde jour civil, quand on la commence au passage invisible $d u$ soleil por le méridien inférieur, e'csta à-dire à minuit, ou joutr astronomique, lorsqu'à l'exemple de Ptoléméc, on la fait commenccr au passage du soleil par le méridien supéricur, c'est-à-dire à midi. Le jour civil se partage en vingt-quatre heures, divisćes clles-niêmes en deux portions de douze heures, qu'on ne comple chacunc que jusqu'à douze. Le jour astronomique est également composé de vingt-qualre heures, mais on compte celles-ci de suitc, de sorle que treizc heures et demie, par excmple, correspondent à unc heure et demie du matin.

JOVIEN, adject. , jopiantes. Nom que, par allusion nux récits mytho- 
logiques, Brongniart donne à la période comprenant tous les phénomènes géologiques contempornins des temps bistoriques, et qui a le même sens que celuide postdiluvien, dont on se sert communément.

JUBE, s. f., juba; Mahne (all.). Ce mot qui, dans Pline, signifie la couronne des arbres, était employé par les anciens botanistes pour désigner une panicule lîche, surtout dans les Graminées. Trinius s'en est servi de nouveau, et il entend par là une disposition telle de l'épi des Graminées, que des branches plus ou moins lougues, éparses tt la plupart isolées, naissent sans articulation de l'axe bifurqué, de manière à représenter en quelque sorte des faisceaux vaseulaires qui n'auraient fait que s'ouvrir, eomme dans la panicule que forment les fleurs mâles du Z ea May's. On a aussi donné le nom de juba à un assemblage d'arêtes, comme dins l'Hordeum jubatum.

JUCHEUR, adj., insidens. Illiger sppelait pieds jucheurs (Slitzfïsse, all.), dans les oiscaux, des jambes couvertes de plumes jusqu'aux talons, tétradactyles, et ayant les trois doigts antérieurs réunis à leur base par une membrane qui ne s'étend que jusqu'à la première artieulation.

JUGEUENT, s. In., judicium ; Urtheil (all.); judgment (angl.). Résultat d'une opération intellectuelle, d'une aetion cérébrale, qui consisle en ce que plusieurs idées étant rendues simulianémeut présentes à l'esprit, les divers traits de ehacune d'elles se réunissent pour produire une ou plusieurs idcées nouvelles. On désigne encore sous ee nom l'ensemble des rapports, des différences, des partieularités que présente l'idée qnon a ainsi formée avec celles qui lui ont servi de base, et la fículté elle-même de juger, c'est-à-dire de procéder à cellc opéralion. "In gé- néral les hommes juggent rarement par eux-mêmes; ils suivent le torrent." (Voltaire.)

JUGLANDÉES, adj. et s. f. pl., Juglandece. Famille de plantes, élablie par Candolle, qui a pour type le genre Juglans.

JUGLANDICOLE, adj. , juglandicolus (juglans, noyer, colo, habiter). Qui vit ou croît sur les noyers, comme le Spheria juglandicola sur les rameaux du Juglans alba.

JUGULAIRE, adj. .jugrularis (jugulum, gorge); qui a rapport á la gorge. Les plumes jugulaires sout celles qui garnissent le devant du cou. Straus nomine pièces jugulaires deux petites chaines composées ehacune de deux plaques conséeutives, contenues inférieurement dans la peau du cou des insectes, et unissant la tête au eorselet.

JUGULA IRES, adj. et s. m. pl., Jugulares. Nom douné par Linné, Gouan, Lacépède et Blainville à un ou plusieurs ordres de la classe des Poissons, comprenant ceux de ces animaux qui ont les men bres pelviens en avant des pectoraux.

JUGCLIBRANCIIES; adj. et s. m. pl., Jugulibranchia (jugzulum, gorge, $\beta p \alpha^{\circ} \gamma \chi \chi^{2} \alpha$, branchies ). Nom donné par Latreille a une famille de Poissons normaux apodes, dont les ouies s'ouvrent par un ou deux petits trous sous la gorgrc.

JUGULUi, s. m., jugulum. Ce nom est donné par Illiger, dans les mammifères et les oiseaux (Gurgel, all.), à la partic de la région antérieure du cou comprise entre le larynx et la poitrine; par Kirlyy, dans les insectes, à la partie de la surface inférieure du corps qui est situće entre les tempes.

JUNGníES, adj. et s. f. pl., Jungiece. Notn donné par D. Don à une tribu de la fanille des Lubiatiflores, qui a pour type le genre Jungia. 
JUNIPÉRA GÉES, adj. et s. f. pl., Juniperaeex. Famille de plantes, établie par Caffin, qni a pour type lc genre Juniperus.

JUNON, s. f., Juno. Petite planètc, découverte en 1804 par llarding, qui apparaît comınc une étoile de huitiènc grandcur, et qui n'a pas d'atmosphère épaisse, eonme Cérès et Pallas. Elle tourne autour du Soleil en $15 g^{2}, 1$ jours, en décrivant une orbite dont le demi-graud axe est de 2,668676 ,l'exeentrieité de 0,259875 , et l'incliuaison sur le plan de l'écliptique de $13^{\circ} 3^{\prime} 28^{\prime \prime}$. On la désigue par le signe $\hat{\text {. }}$.

JUPITER, s. nı., Jupiter. La plus grosse des planètes, et la plus brillante après V'́nus. Jupiter accomplit sa révolution en $4332 \mathrm{j} .5848212$, dans un orbe incliné à l'écliptique de $x^{\circ}, 8^{\prime} 44^{\prime \prime}, 5$, et dont l'exeentricité est de 0,04821522 . La Terre étant prise pour unite. sa distance moyenne est $5,20277^{6}$, son volume
1280,9 , son diamètre 10,860 , sa masse 331,5609 , sa densité 0,2589 , son poids 2,716 . Il tourne sur luiniĉme en 9 h. $55^{\prime} 51^{\prime \prime}$. Quatre satellites l'aceompagnent. Le signe par lequel on le désigne est $\psi$.

JURAssiQue, adj., jurassicus. Épithète donnée par Brongniart et Onalius à un groupe de terrains pélagiques ou neptuniens (calcaire oolithique; Jurakalk, Bouć, lower oolitic system, Conybeare, oolite formation, de la Bceche), conprenant ceux qui sont composés de difečrentcs roches se trouvant dans une position géognostique analogue à celle de la chaîne du Jura.

JUSANT, adject, , refluum mare, recedens astus. Noin donné par les marins au reflux de la marée.

JUSSivis, adj. et s. f. pl., Jussiea. Nouı douné par Candolle à une tribu de la famille des Onagraires, qui a pour type le genre Jussica.

\section{K.}

KALIUM, s. m., kalizm. Les Allemands et les Anglais donnent ec nont au potassium.

KARABIQUE, adj. , karabicus. Quelques ehimistes ont donné ee nom à l'acide suceinique, paree que le sueciu ćtait appelć aneiennemient karabé.

KEUPıIQue, adj. Omalius désigne par cette épithète un groupe de terrains neptuniens ammonéens, comprenant plusicurs systemes de roches qui ont été désignées sous le nom de Keuper, terme teebnique des mineurs alleniands ( marnes irisées, Charbaut ).

KIGGÉLARIEES, adj. et s. f. pl. , Kiggelariece. Nom donné par Candollc à une tribu de la famille des I.
Flacourtianées, qui a pour type le genre Kigggelaria.

KINATE, s. m., kinas. Genre de sels (Kinasaure Salze, all.), qui sont produits par la eombinaison de l'acide kinique avee les bases salifiables.

KINIQUE, adj., kinieus. Nom d'un acide (Chinasäure, Cinchonasüure, Fieberrindensüure, all.), qui a été découvert par Vauquelin dans un sel que Deschamps avait retiré de l'ćeorce de quinquiua. L'Ether kinique a ćté déeouvert par Henry et Plisson, qui l'ont obtenu sous forme solide.

HINOVATE, s. m., hinovas. Genre de sels (kinovasaure Salze, all.), qui résultent de la combinaison de 


\section{4}

KOLP

l'acide kinovique avec les bases salifiables.

KINOVIQUE, adj., kinoviczs. Nom d'un acide (Chinoyasäurc, all.), que Pelleticr et Caventou ont découvert dans le ehina nosa, écorce d'un arbre encore inconnu.

KIOSQUIFORME, adj. , kiosquiformis. Une jolie coquille ( Purpura kiosquiformis) porte ce nom parce qu'elle est saulariforme et ornéc de nombreux détails.

KLEISTAGNATHES, adj. et s. m. pl., Kleistagnatha (xistoròs, clos, yya $\theta_{\text {os }}$, mâchoire). Nom donné par Fabricius à un ordre de la classe des insectes, comprenant ceux qui ont la bouche fermée par plusieurs mâchoircs hors de la lèvrc, et répondant assez bien aux crustacés décapodes brachyures.

KonRéstúes, adj. et s. f. pl., Kobresia. Nom donné par Lestiboudois à une tribu de la famille des Cypérö̈des, qui a pour type le genre Kouresia.

\section{KRAM}

KOLPODÉS, adj. et s. m. pl., Kolpodea. Nom donné par G.-G. Ehrenberg à unc tribu d'Infusoircs polygastriques, ayant pour type le genre Kolpoda.

KoLponintés, adj. et s. f. pl., Kolpodinea. Nom donné par Bory à une famille de la classe des Microsco. piques, qui a le genre $K$ olpoda pour type.

KRAMÉRATE, s. m. , krameras. Genre de sels (kramersaure Salze, all.), qui résultent de la combinaison de l'acide kramérique avec les bases salifiables.

KRAMERIACÉES, adj. et s. f. pl., Krameriacea. Nom donné par Kunth à une famille de plantes, qui a pour type le genre Krameria.

KRAMÉriQUE, adj., liramericus. Nom d'un acide (Kramersäure, all.), qui a été découvert par Pesehier dans la racine du Krameria triandra. 


\section{ERRATA \\ DU PREMIER VOLUME.}

Pag. $3-2^{\mathrm{e}}$ col. ligne 15 regarda, lisez : regarde.

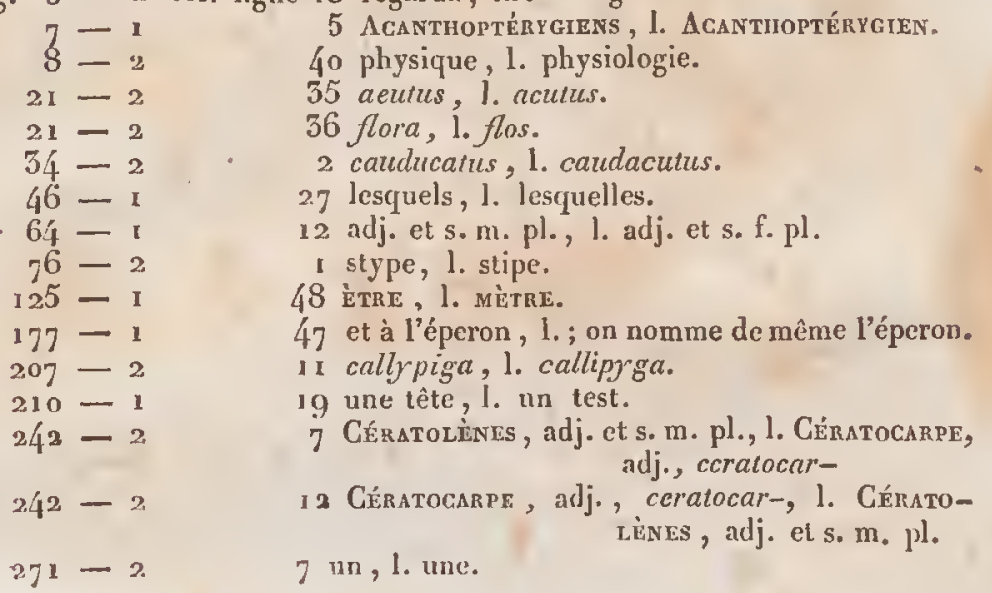








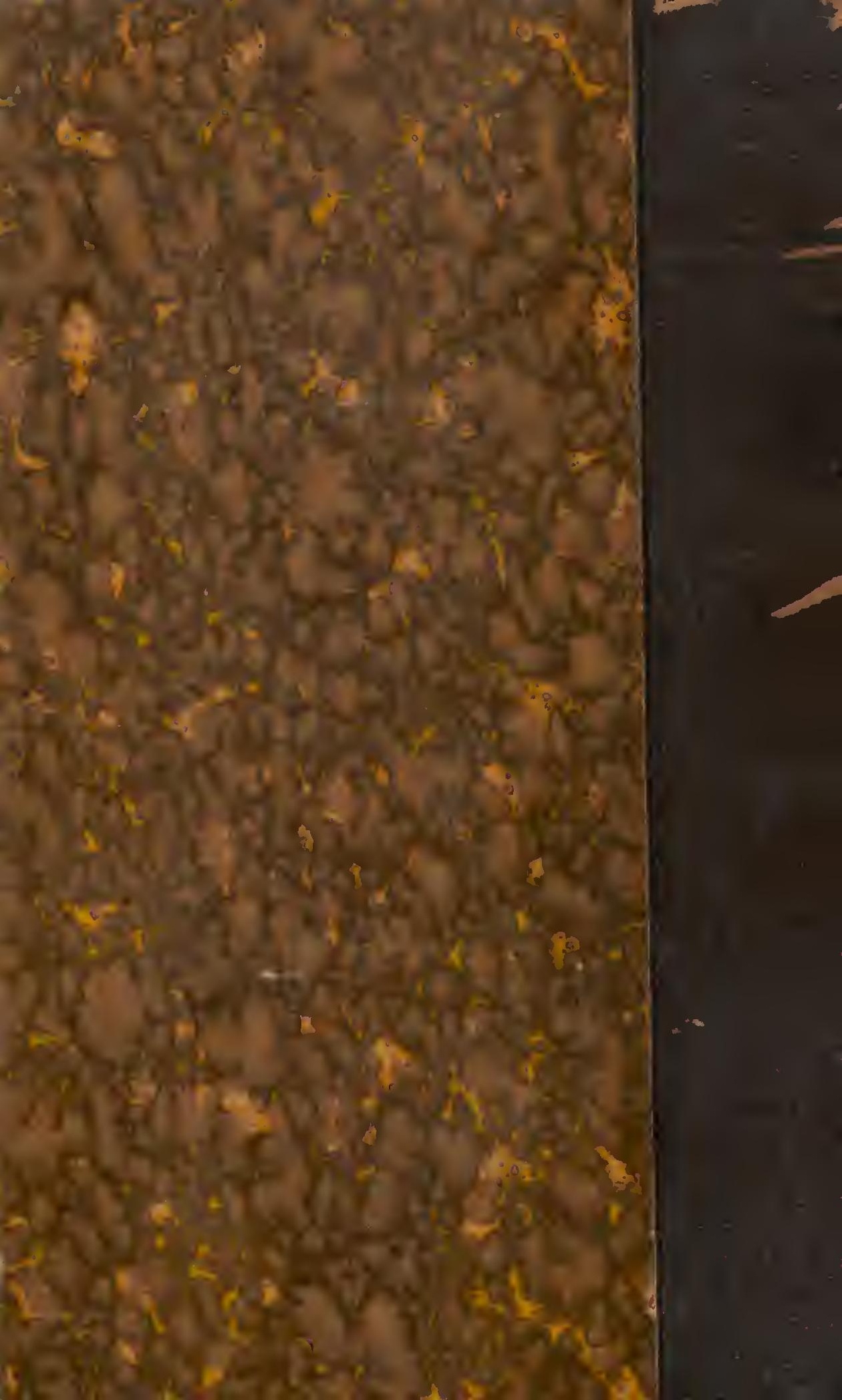

